\title{
STATE OF THE CLIMATE IN 2016
}

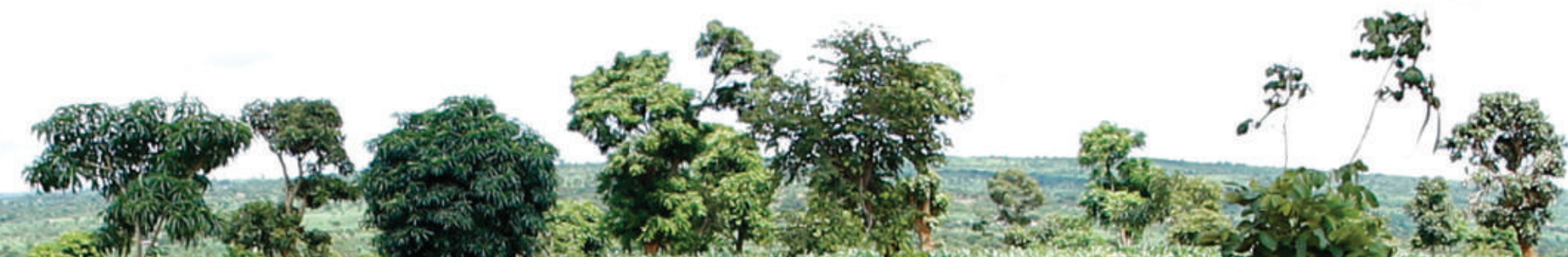

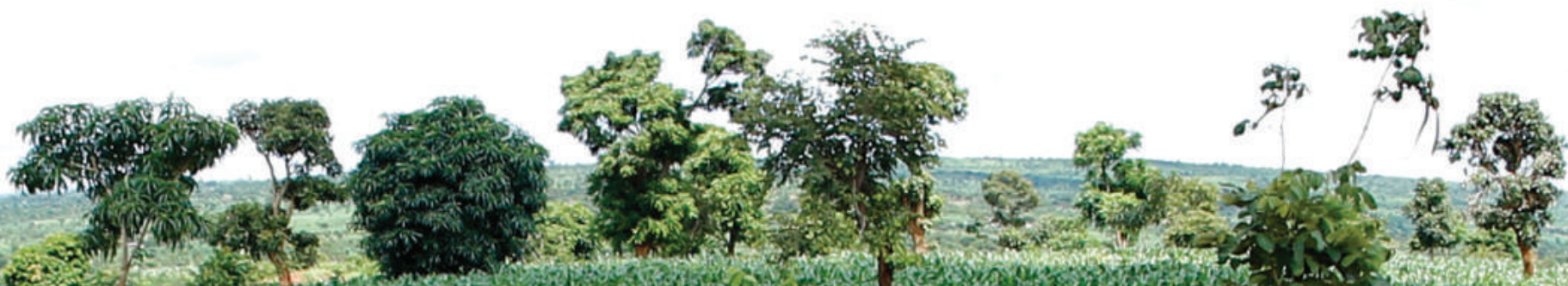

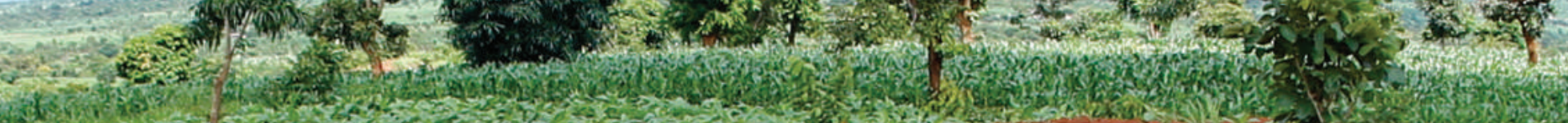

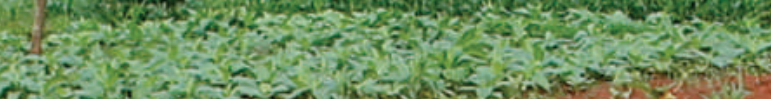

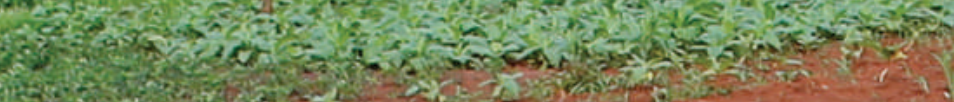

5. 5,5

20

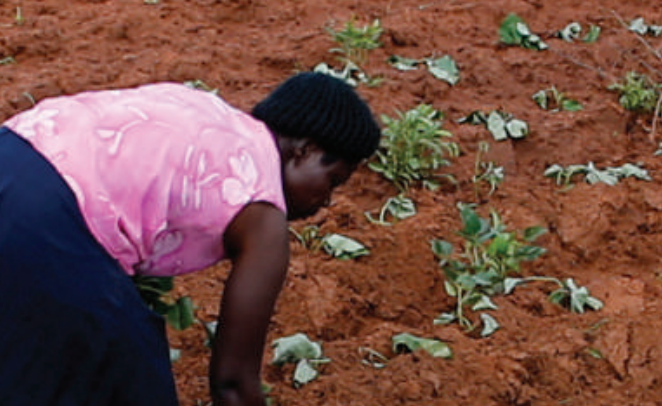
dre

(2)
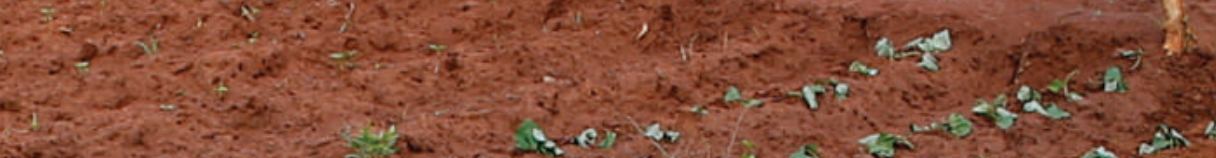

Special Supplement to the Bulletin of the American Meteorological Society Vol. 98, No. 8, August 2017 


\section{STATE OF THE CLIMATE IN 2016}

Editors

Jessica Blunden

Derek S. Arndt

\section{Chapter Editors}

Howard J. Diamond

Robert J. H. Dunn

Nadine Gobron

Dale F. Hurst

Gregory C. Johnson
Jeremy T. Mathis

Ademe Mekonnen James A. Renwick

Jacqueline A. Richter-Menge

\author{
Ahira Sánchez-Lugo \\ Ted A. Scambos \\ Carl J. Schreck III \\ Sharon Stammerjohn \\ Kate M. Willett
}

\section{Technical Editor}

Mara Sprain 
COVER CREDITS:

FRONT/BACK: Courtesy of Reuters/Mike Hutchings

Malawian subsistence farmer Rozaria Hamiton plants sweet potatoes near the capital Lilongwe, Malawi, I February 2016. Late rains in Malawi threaten the staple maize crop and have pushed prices to record highs. About 14 million people face hunger in Southern Africa because of a drought that has been exacerbated by an El Niño weather pattern, according to the United Nations World Food Programme.

A supplement to this report is available online (I0.II75/20I7BAMSStateoftheClimate.2)

How to cite this document:

Citing the complete report:

Blunden, J., and D. S. Arndt, Eds., 2017: State of the Climate in 2016. Bull. Amer. Meteor. Soc., 98 (8), Si-S277, doi:I0.II75/2017BAMSStateoftheClimate.I.

Citing a chapter (example):

Diamond, H. J., and C. J. Schreck III, Eds., 2017: The Tropics [in "State of the Climate in 2016"].

Bull. Amer. Meteor. Soc., 98 (8), S93-SI28, doi:I0.II75/20I7BAMSStateoftheClimate.I.

Citing a section (example):

Bell, G., M. L'Heureux, and M. S. Halpert, 20I7: ENSO and the tropical Pacific [in "State of the Climate in 2016”']. Bull. Amer. Meteor. Soc., 98 (8), S93-S98, doi:I0.II75/2017BAMSStateoftheClimate.I. 
Aaron-Morrison, Arlene P., Trinidad \& Tobago Meteorological Service, Piarco, Trinidad

Abdallah, A., Agence Nationale de l'Aviation Civile et de la Météorologie, Union des Comores

Ackerman, Steven A., CIMSS, University of Wisconsin-Madison, Madison, Wisconsin

Adler, Robert, University of Maryland, College Park, Maryland

Alfaro, Eric J., Center for Geophysical Research and School of Physics, University of Costa Rica, San José, Costa Rica

Allan, Richard P., University of Reading, Reading, United Kingdom

Allan, Rob, Met Office Hadley Centre, Exeter, United Kingdom

Álvarez, Luis A. , Instituto de Hidrología de Meteorología y Estudios Ambientales de Colombia, Bogotá, Colombia

Alves, Lincoln M., Centro de Ciencias do Sistema Terrestre, Instituto Nacional de Pesquisas Espaciais, Cachoeira Paulista, Sao Paulo, Brazil

Amador, Jorge A., Center for Geophysical Research and School of Physics, University of Costa Rica, San José, Costa Rica

Andreassen, L. M., Section for Glaciers, Ice and Snow, Norwegian Water Resources and Energy Directorate, Oslo, Norway

Arce, Dayana, Center for Geophysical Research and School of Physics, University of Costa Rica, San José, Costa Rica

Argüez, Anthony, NOAA/NESDIS National Centers for Environmental Information, Asheville, North Carolina

Arndt, Derek S., NOAA/NESDIS National Centers for Environmental Information, Asheville, North Carolina

Arzhanova, N. M., Russian Institute for Hydrometeorological Information, Obninsk, Russia

Augustine, John, NOAA/OAR Earth System Research Laboratory, Boulder, Colorado

Awatif, E.M., Department of Seasonal Forecast and Climate Research, Cairo Numerical Weather Prediction, Egyptian Meteorological Authority, Cairo, Egypt

Azorin-Molina, Cesar, Regional Climate Group, Department of Earth Sciences, University of Gothenburg, Gothenburg, Sweden

Báez, Julián, Dirección de Meteorología e Hidrología de la DINAC and Universidad Católica Ntra. Sra. de la Asunción, Asunción, Paraguay

Bardin, M. U., Islamic Republic of Iranian Meteorological Organization, Iran

Barichivich, Jonathan, Instituto de Conservación, Biodiversidad y Territorio, Universidad Austral de Chile, Valdivia, Chile; Center for Climate and Resilience Research, Chile; and Instituto de Geografía, Pontificia Universidad Católica de Valparaíso, Valparaíso, Chile
Baringer, Molly O., NOAA/OAR Atlantic

Oceanographic and Meteorological Laboratory, Miami, Florida

Barreira, Sandra, Argentine Naval Hydrographic Service, Buenos Aires, Argentina

Baxter, Stephen, NOAA/NWS Climate Prediction Center, College Park, Maryland

Beck, H. E., Department of Civil and Environmental Engineering, Princeton University, Princeton, New Jersey

Becker, Andreas, Global Precipitation Climatology Centre, Deutscher Wetterdienst, Offenbach, Germany

Bedka, Kristopher M., NASA Langley Research Center, Hampton, Virginia

Behrenfeld, Michael J., Oregon State University, Corvallis, Oregon

Bell, Gerald D., NOAA/NWS Climate Prediction Center, College Park, Maryland

Belmont, M., Seychelles National Meteorological Services, Pointe Larue, Mahé, Seychelles

Benedetti, Angela, European Centre for Medium-Range Weather Forecasts, Reading, United Kingdom

Bernhard, G. H., Biospherical Instruments, San Diego, California

Berrisford, Paul, European Centre for Medium-Range Weather Forecasts, Reading, United Kingdom

Berry, David I., National Oceanography Centre, Southampton, United Kingdom

Bettolli, María L., Departamento Ciencias de la Atmósfera y los Océanos, Facultad de Ciencias Exactas y Naturales, Universidad de Buenos Aires, Argentina

Bhatt, U. S., Geophysical Institute, University of Alaska Fairbanks, Fairbanks, Alaska

Bidegain, Mario, Instituto Uruguayo de Meteorologia, Montevideo, Uruguay

Biskaborn, B., Alfred Wegener Institute Helmholtz Centre for Polar and Marine Research, Potsdam, Germany

Bissolli, Peter, Deutscher Wetterdienst, WMO RA VI Regional Climate Centre Network, Offenbach, Germany

Bjerke, J., Norwegian Institute for Nature Research, Tromsø, Norway

Blake, Eric S., NOAA/NWS National Hurricane Center, Miami, Florida

Blunden, Jessica, NOAA/NESDIS National Centers for Environmental Information, Asheville, North Carolina

Bosilovich, Michael G., Global Modelling and Assimilation Office, NASA Goddard Space Flight Center, Greenbelt, Maryland

Boucher, Olivier, Institut Pierre-Simon Laplace, CNRS / UPMC, Paris, France

Boudet, Dagne, Climate Center, Institute of Meteorology of Cuba, Cuba

Box, J. E., Geological Survey of Denmark and Greenland, Copenhagen, Denmark 
Boyer, Tim, NOAA/NESDIS National Centers for Environmental Information, Silver Spring, Maryland

Braathen, Geir O., WMO Atmospheric Environment Research Division, Geneva, Switzerland

Brimelow, Julian, Environment and Climate Change Canada, Edmonton, Alberta, Canada

Bromwich, David H., Byrd Polar and Climate Research Center, The Ohio State University, Columbus, Ohio

Brown, R., Climate Research Division, Environment and Climate Change Canada, Montreal, Quebec, Canada

Buehler, S., Universitaet Hamburg, Hamburg, Germany

Bulygina, Olga N., Russian Institute for Hydrometeorological Information, Obninsk, Russia

Burgess, D., Geological Survey of Canada, Ottawa, Ontario, Canada

Calderón, Blanca, Center for Geophysical Research, University of Costa Rica, San José, Costa Rica

Camargo, Suzana J., Lamont-Doherty Earth Observatory, Columbia University, Palisades, New York

Campbell, Jayaka D., Department of Physics, The University of the West Indies, Jamaica

Cappelen, J., Danish Meteorological Institute, Copenhagen, Denmark

Caroff, P., Météo-France, RSMC La Réunion

Carrea, Laura, Department of Meteorology, University of Reading, Reading, United Kingdom

Carter, Brendan R., Joint Institute for the Study of the Atmosphere and Ocean, University of Washington, and NOAA/OAR Pacific Marine Environmental Laboratory, Seattle, Washington

Chambers, Don P., College of Marine Science, University of South Florida, St. Petersburg, Florida

Chandler, Elise, Bureau of Meteorology, Melbourne, Victoria, Australia

Cheng, Ming-Dean, National Taiwan University, and Central Weather Bureau, Taipei, Taiwan

Christiansen, Hanne H., Geology Department, University Centre in Svalbard, Longyearbyen, Norway

Christy, John R., University of Alabama in Huntsville, Huntsville, Alabama

Chung, Daniel, Department of Geodesy and Geoinformation, Vienna University of Technology, Vienna, Austria

Chung, E.-S., Rosenstiel School of Marine and Atmospheric Science, University of Miami, Key Biscane, Miami, Florida

Clem, Kyle R., School of Geography, Environment, and Earth Sciences, Victoria University of Wellington, Wellington, New Zealand

Coelho, Caio A.S., CPTEC/INPE Center for Weather Forecasts and Climate Studies, Cachoeira Paulista, Brazil

Coldewey-Egbers, Melanie, German Aerospace Center (DLR) Oberpfaffenhofen, Wessling, Germany
Colwell, Steve, British Antarctic Survey, Cambridge, United Kingdom

Cooper, Owen R., Cooperative Institute for Research in Environmental Sciences, University of Colorado Boulder, and NOAA/OAR Earth System Research Laboratory, Boulder, Colorado

Copland, L., Department of Geography, University of Ottawa, Ottawa, Ontario, Canada

Cross, J. N., NOAA/OAR Pacific Marine Environmental Laboratory, Seattle, Washington

Crouch, Jake, NOAA/NESDIS National Centers for Environmental Information, Asheville, North Carolina

Cutié, Virgen, Climate Center, Institute of Meteorology of Cuba, Cuba

Davis, Sean M., Cooperative Institute for Research in Environmental Sciences, University of Colorado Boulder, and NOAA/OAR Earth System Research Laboratory, Boulder, Colorado

de Eyto, Elvira, Marine Institute, Newport, Ireland

de Jeu, Richard A. M., VanderSat B.V., Haarlem, Netherlands

de Laat, Jos, Royal Netherlands Meteorological Institute (KNMI), DeBilt, Netherlands

DeGasperi, Curtis L., King County Water and Land Resources Division, Seattle, Washington

Degenstein, Doug, University of Saskatchewan, Saskatoon, Saskatchewan, Canada

Demircan, M., Turkish State Meteorological Service, Ankara, Turkey

Derksen, C., Climate Research Division, Environment and Climate Change Canada, Toronto, Ontario, Canada

Di Girolamo, Larry, University of Illinois at UrbanaChampaign, Urbana, Illinois

Diamond, Howard J., NOAA/OAR Air Resources Laboratory, Silver Spring, Maryland

Dindyal, S., Mauritius Meteorological Services, Mauritius

Dlugokencky, Ed J., NOAA/OAR Earth System Research Laboratory, Boulder, Colorado

Dohan, Kathleen, Earth and Space Research, Seattle, Washington

Dokulil, Martin T., Research Institute for Limnology, University of Innsbruck, Mondsee, Austria

Dolman, A. Johannes, Department of Earth Sciences, Earth and Climate Cluster, VU University Amsterdam, Amsterdam, Netherlands

Domingues, Catia M., Institute for Marine and Antarctic Studies, University of Tasmania, and Antarctic Climate and Ecosystems Cooperative Research Centre, Hobart, Tasmania, Australia

Donat, Markus G., Climate Change Research Centre, University of New South Wales, Sydney, New South Wales, Australia

Dong, Shenfu, NOAA/OAR Atlantic Oceanographic and Meteorological Laboratory, and Cooperative Institute for Marine and Atmospheric Science, Miami, Florida 
Dorigo, Wouter A., Department of Geodesy and Geoinformation, Vienna University of Technology, Vienna, Austria

Drozdov, D. S., Earth Cryosphere Institute, and Tyumen State Oil and Gas University, Tyumen, Russia

Dunn, Robert J. H., Met Office Hadley Centre, Exeter, United Kingdom

Durán-Quesada, Ana M., Center for Geophysical Research and School of Physics, University of Costa Rica, San José, Costa Rica

Dutton, Geoff S., Cooperative Institute for Research in Environmental Sciences, University of Colorado Boulder, and NOAA/OAR Earth System Research Laboratory, Boulder, Colorado

EIKharrim, M., Direction de la Météorologie Nationale Maroc, Rabat, Morocco

Elkins, James W., NOAA/OAR Earth System Research Laboratory, Boulder, Colorado

Epstein, H. E., Department of Environmental Sciences, University of Virginia, Charlottesville, Virginia

Espinoza, Jhan C., Instituto Geofisico del Perú, Lima, Perú

Etienne-LeBlanc, Sheryl, Meteorological Department of St. Maarten, St. Maarten, Netherlands

Famiglietti, James S., Jet Propulsion Laboratory, California Institute of Technology, Pasadena, California

Farrell, S., Earth System Science Interdisciplinary Center, University of Maryland, College Park, College Park, Maryland

Fateh, S., Islamic Republic of Iranian Meteorological Organization, Iran

Fausto, R. S., Geological Survey of Denmark and Greenland, Copenhagen, Denmark

Feely, Richard A., NOAA/OAR Pacific Marine Environmental Laboratory, Seattle, Washington

Feng, Z., FCSD/ASGC Pacific Northwest National Laboratory, Richland, Washington

Fenimore, Chris, NOAA/NESDIS National Centers for Environmental Information, Asheville, North Carolina

Fettweis, X., University of Liège, Liège, Belgium

Fioletov, Vitali E., Environment and Climate Change Canada, Toronto, Ontario, Canada

Flannigan, Mike, Department of Renewable Resources, University of Alberta, Alberta, Canada

Flemming, Johannes, European Centre for MediumRange Weather Forecasts, Reading, United Kingdom

Fogt, Ryan L., Department of Geography, Ohio University, Athens, Ohio

Folland, Chris, Met Office Hadley Centre, Exeter, and School of Environmental Sciences, University of East Anglia, Norwich, United Kingdom, and Department of Earth Sciences, University of Gothenburg, Gothenburg, Sweden, and International Centre for Applied Climate Sciences, University of Southern Queensland,

Toowoomba, Queensland, Australia
Fonseca, C., Climate Center, Institute of Meteorology of Cuba, Cuba

Forbes, B. C., Arctic Centre, University of Lapland, Rovaniemi, Finland

Foster, Michael J., Cooperative Institute for Meteorological Satellite Studies, University of Wisconsin-Madison, Madison, Wisconsin

Francis, S. D., National Weather Forecasting and Climate Research Centre, Nigerian Meteorological Agency, Abuja, Nigeria

Franz, Bryan A., NASA Goddard Space Flight Center, Greenbelt, Maryland

Frey, Richard A., Cooperative Institute for Meteorological Satellite Studies, University of Wisconsin-Madison, Madison, Wisconsin

Frith, Stacey M., Science Systems and Applications, Inc. and NASA Goddard Space Flight Center, Greenbelt, Maryland

Froidevaux, Lucien, Jet Propulsion Laboratory, California Institute of Technology, Pasadena, California

Ganter, Catherine, Bureau of Meteorology, Melbourne, Victoria, Australia

Gerland, S., Norwegian Polar Institute, Fram Centre, Tromsø, Norway

Gilson, John, Scripps Institution of Oceanography, University of California San Diego, La Jolla, California

Gobron, Nadine, Joint Research Centre, European Commission, Ispra, Italy

Goldenberg, Stanley B., NOAA/OAR Atlantic Oceanographic and Meteorological Laboratory, Miami, Florida

Goni, Gustavo, NOAA/OAR Atlantic Oceanographic and Meteorological Laboratory, Miami, Florida

Gonzalez, Idelmis T., Climate Center, Institute of Meteorology of Cuba, Cuba

Goto, A., Japan Meteorological Agency, Tokyo, Japan

Greenhough, Marianna D., Environment and Climate Change Canada, Edmonton, Alberta, Canada

Grooß, J.-U., Forschungszentrum Jülich, Jülich, Germany

Gruber, Alexander, Department of Geodesy and Geoinformation, Vienna University of Technology, Vienna, Austria

Guard, Charles “Chip”, NOAA/NWS Weather Forecast Office, Guam

Gupta, S. K., Science Systems and Applications, Inc., Hampton, Virginia

Gutiérrez, J. M., Instituto de Física de Cantabria, CSICUniversity of Cantabria, Santander, Spain

Haas, C., Alfred Wegener Institute, Bremerhaven, Germany, and Earth \& Space Science \& Engineering, York University, Toronto, Canada

Hagos, S., FCSD/ASGC Climate Physics Group, Pacific Northwest National Laboratory, Richland, Washington 
Hahn, Sebastian, Department of Geodesy and Geoinformation, Vienna University of Technology, Vienna, Austria

Haimberger, Leo, Department of Meteorology and Geophysics, University of Vienna, Vienna, Austria

Hall, Brad D., NOAA/OAR Earth System Research Laboratory, Boulder, Colorado

Halpert, Michael S., NOAA/NWS Climate Prediction Center, College Park, Maryland

Hamlington, Benjamin D., Center for Coastal Physical Oceanography, Old Dominion University, Norfolk, Virginia

Hanna, E., Department of Geography, University of Sheffield, Sheffield, United Kingdom

Hanssen-Bauer, I., Norwegian Meteorological Institute, Blindern, Oslo, Norway

Hare, Jon, NOAA/NMFS Northeast Fisheries Science Center, Woods Hole, Massachusetts

Harris, lan, National Centre for Atmospheric Science, University of East Anglia, Norwich, and Climatic Research Unit, School of Environmental Sciences, University of East Anglia, Norwich, United Kingdom

Heidinger, Andrew K., NOAA/NESDIS/STAR University of Wisconsin-Madison, Madison, Wisconsin

Heim, Richard R., Jr.,NOAA/NESDIS National Centers for Environmental Information, Asheville, North Carolina

Hendricks, S., Alfred Wegener Institute, Bremerhaven, Germany

Hernández, Marieta, Climate Center, Institute of Meteorology of Cuba, Cuba

Hernández, Rafael, Instituto Nacional de Meteorología e Hidrología de Venezuela, Caracas, Venezuela

Hidalgo, Hugo G., Center for Geophysical Research and School of Physics, University of Costa Rica, San José, Costa Rica

Ho, Shu-peng (Ben), COSMIC Project Office, University Corporation for Atmospheric Research, Boulder, Colorado

Hobbs, William R., Antarctic Climate and Ecosystems Cooperative Research Centre, University of Tasmania, Tasmania, Australia

Huang, Boyin, NOAA/NESDIS National Centers for Environmental Information, Asheville, North Carolina

Huelsing, Hannah K., State University of New York, Albany, New York

Hurst, Dale F., Cooperative Institute for Research in Environmental Sciences, University of Colorado Boulder, and NOAA/OAR Earth System Research Laboratory, Boulder, Colorado

Ialongo, I., Finnish Meteorological Institute, Helsinki, Finland

Ijampy, J. A., Nigerian Meteorological Agency, Abuja, Nigeria

Inness, Antje, European Centre for Medium-Range Weather Forecasts, Reading, United Kingdom
Isaksen, K., Norwegian Meteorological Institute, Blindern, Oslo, Norway

Ishii, Masayoshi, Climate Research Department, Meteorological Research Institute, Japan Meteorological Agency, Tsukuba, Japan

Jevrejeva, Svetlana, National Oceanography Centre, Liverpool, United Kingdom

Jiménez, C., Estellus, and LERMA, Observatoire de Paris, PSL Research University, Paris, France

Jin, Xiangze, Woods Hole Oceanographic Institution, Woods Hole, Massachusetts

John, Viju, EUMETSAT, Darmstadt, Germany, and Met Office Hadley Centre, Exeter, United Kingdom

Johns, William E., Rosenstiel School of Marine and Atmospheric Science, Miami, Florida

Johnsen, B., Norwegian Radiation Protection Authority, Østerås, Norway

Johnson, Bryan, NOAA/OAR Earth System Research Laboratory, Global Monitoring Division, and University of Colorado Boulder, Boulder, Colorado

Johnson, Gregory C., NOAA/OAR Pacific Marine Environmental Laboratory, Seattle, Washington

Johnson, Kenneth S., Monterey Bay Aquarium Research Institute, Moss Landing, California

Jones, Philip D., Climatic Research Unit, School of Environmental Sciences, University of East Anglia, Norwich, United Kingdom

Jumaux, Guillaume, Météo France, Direction Interrégionale pour l'Océan Indien, Réunion

Kabidi, Khadija, Direction de la Météorologie Nationale Maroc, Rabat, Morocco

Kaiser, J. W., Max Planck Institute for Chemistry, Mainz, Germany

Kass, David, Jet Propulsion Laboratory, California Institute of Technology, Pasadena, California

Kato, Seiji, NASA Langley Research Center, Hampton, Virginia

Kazemi, A., Islamic Republic of Iranian Meteorological Organization, Iran

Kelem, G., Ethiopian Meteorological Agency, Addis Ababa, Ethiopia

Keller, Linda M., Department of Atmospheric and Oceanic Sciences, University of Wisconsin-Madison, Madison, Wisconsin

Kelly, B. P., Study of Environmental Arctic Change (SEARCH), and International Arctic Research Center, University of Alaska Fairbanks, Fairbanks, Alaska, and Center for Blue Economy, Middlebury Institute International Studies, Monterey, California

Kendon, Mike, Met Office Hadley Centre, Exeter, United Kingdom

Kennedy, John, Met Office Hadley Centre, Exeter, United Kingdom 
Kerr, Kenneth, Trinidad \& Tobago Meteorological Service, Piarco, Trinidad

Kholodov, A. L., Geophysical Institute, University of Alaska Fairbanks, Fairbanks, Alaska

Khoshkam, Mahbobeh, Islamic Republic of Iranian Meteorological Organization, Iran

Killick, Rachel, Met Office Hadley Centre, Exeter, United Kingdom

Kim, Hyungjun, Institute of Industrial Science, University of Tokyo, Japan

Kim, S.-J., Korea Polar Research Institute, Incheon, Republic of Korea

Kimberlain, Todd B., NOAA/NWS National Hurricane Center, Miami, Florida

Klotzbach, Philip J., Department of Atmospheric Science, Colorado State University, Fort Collins, Colorado

Knaff, John A., NOAA/NESDIS Center for Satellite Applications and Research, Fort Collins, Colorado

Kochtubajda, Bob, Environment and Climate Change Canada, Edmonton, Alberta, Canada

Kohler, J., Norwegian Polar Institute, Tromsø, Norway

Korhonen, Johanna, Freshwater Centre, Finnish Environment Institute (SYKE), Helsinki, Finland

Korshunova, Natalia N., All-Russian Research Institute of Hydrometeorological Information - World Data Center, Obninsk, Russia

Kramarova, Natalya, Science Systems and Applications, Inc., NASA Goddard Space Flight Center, Greenbelt, Maryland

Kratz, D. P., NASA Langley Research Center, Hampton, Virginia

Kruger, Andries, South African Weather Service, Pretoria, South Africa

Kruk, Michael C., ERT, Inc., NOAA/NESDIS National Centers for Environmental Information, Asheville, North Carolina

Krumpen, T., Alfred Wegener Institute, Bremerhaven, Germany

Lakatos, M., Climatology Division, Hungarian Meteorological Service, Budapest, Hungary

Lakkala, K., Finnish Meteorological Institute, Arctic Research Centre, Sodankylä, Finland

Lanckmann, J.-P., Arctic Portal, Akureyri, Iceland

Lander, Mark A., University of Guam, Mangilao, Guam

Landschützer, Peter, Max Planck Institute for Meteorology, Hamburg, Germany

Landsea, Chris W., NOAA/NWS National Hurricane Center, Miami, Florida

Lankhorst, Matthias, Scripps Institution of Oceanography, University of California, San Diego, La Jolla, California
Lantz, Kathleen, Cooperative Institute for Research in Environmental Sciences, University of Colorado Boulder, and NOAA/OAR Earth System Research Laboratory, Boulder, Colorado

Lazzara, Matthew A., Department of Physical Sciences, School of Arts and Sciences, Madison Area Technical College, and Space Science and Engineering Center, University of Wisconsin-Madison, Madison, Wisconsin

Leuliette, Eric, NOAA/NWS NCWCP Laboratory for Satellite Altimetry, College Park, Maryland

Lewis, Stephen R., School of Physical Sciences, Faculty of Science, Technology, Engineering and Mathematics, The Open University, United Kingdom

L'Heureux, Michelle, NOAA/NWS Climate Prediction Center, College Park, Maryland

Lieser, Jan L., Antarctic Climate and Ecosystems Cooperative Research Centre, University of Tasmania, Hobart, Tasmania, Australia

Lin, I-I, National Taiwan University, Taipei, Taiwan

Liu, Hongxing, Department of Geography, University of Cincinnati, Cincinnati, Ohio

Liu, Yinghui, Cooperative Institute for Meteorological Satellite Studies, University of Wisconsin-Madison, Madison, Wisconsin

Locarnini, Ricardo, NOAA/NESDIS National Centers for Environmental Information, Silver Spring, Maryland

Loeb, Norman G., NASA Langley Research Center, Hampton, Virginia

Long, Craig S., NOAA/NWS National Centers for Environmental Prediction, College Park, Maryland

Loranty, M., Department of Geography, Colgate University, Hamilton, New York

Lorrey, Andrew M., National Institute of Water and Atmospheric Research, Ltd., Auckland, New Zealand

Loyola, Diego, German Aerospace Center (DLR) Oberpfaffenhofen, Wessling, Germany

Lu, Mong-Ming, National Taiwan University, and Central Weather Bureau, Taipei, Taiwan

Lumpkin, Rick, NOAA/OAR Atlantic Oceanographic and Meteorological Laboratory, Miami, Florida

Luo, Jing-Jia, Australian Bureau of Meteorology, Melbourne, Victoria, Australia

Luojus, K., Finnish Meteorological Institute, Helsinki, Finland

Lyman, John M., NOAA/OAR Pacific Marine Environmental Laboratory, Seattle, Washington, and Joint Institute for Marine and Atmospheric Research, University of Hawaii, Honolulu, Hawaii

Macara, Gregor, National Institute of Water and Atmospheric Research, Wellington, New Zealand

Macdonald, Alison M., Woods Hole Oceanographic Institiution, Woods Hole, Massachusetts 
Macias-Fauria, M., School of Geography and the Environment, Oxford University, Oxford, United Kingdom

Malkova, G. V., Earth Cryosphere Institute, and Tyumen State Oil and Gas University, Tyumen, Russia

Manney, G., NorthWest Research Associates, and New Mexico Institute of Mining and Technology, Socorro, New Mexico

Marchenko, S. S., Geophysical Institute, University of Alaska Fairbanks, Fairbanks, Alaska

Marengo, José A., Centro Nacional de Monitoramento e Alertas aos Desastres Naturais, Cachoeira Paulista, Sao Paulo, Brazil

Marra, John J., NOAA/NESDIS National Centers for Environmental Information, Honolulu, Hawaii

Marszelewski, Wlodzimierz, Department of Hydrology and Water Management, Nicolaus Copernicus University, Toruń, Poland

Martens, B., Laboratory of Hydrology and Water Management, Ghent University, Ghent, Belgium

Martínez-Güingla, Rodney, Centro Internacional para la Investigación del Fenómeno de El Niño, Guayaquil, Ecuador

Massom, Robert A., Australian Antarctic Division, and Antarctic Climate and Ecosystems Cooperative Research Centre, University of Tasmania, Hobart, Tasmania, Australia

Mathis, Jeremy T., NOAA/OAR Arctic Research Program, Silver Spring, Maryland

May, Linda, Centre for Ecology and Hydrology, Edinburgh, United Kingdom

Mayer, Michael, Department of Meteorology and Geophysics, University of Vienna, Vienna, Austria

Mazloff, Matthew, Scripps Institution of Oceanography, University of California, San Diego, La Jolla, California

McBride, Charlotte, South African Weather Service, Pretoria, South Africa

McCabe, M. F., Water Desalination and Reuse Center, Division of Biological and Environmental Sciences and Engineering, King Abdullah University of Science and Technology, Thuwal, Saudi Arabia

McCarthy, Gerard, National Oceanography Centre, Southampton, United Kingdom

McCarthy, M., Met Office Hadley Centre, Exeter, United Kingdom

McDonagh, Elaine L., National Oceanography Centre, Southampton, United Kingdom

McGree, Simon, Bureau of Meteorology, Melbourne, Victoria, Australia

McVicar, Tim R., CSIRO Land and Water Flagship, Canberra, Australian Capital Territory, and Australian Research Council Centre of Excellence for Climate System Science, Sydney, New South Wales, Australia

Mears, Carl A., Remote Sensing Systems, Santa Rosa, California
Meier, W., NASA Goddard Space Flight Center, Greenbelt, Maryland

Mekonnen, A., Department of Energy and Environmental Systems, North Carolina A \& T State University, Greensboro, North Carolina

Menezes, V. V., Woods Hole Oceanographic Institution, Woods Hole, Massachusetts

Mengistu Tsidu, G., Department of Earth and Environmental Sciences, Botswana International University of Science and Technology, Palapye, Botswana, and Department of Physics, Addis Ababa University, Addis Ababa, Ethiopia

Menzel, W. Paul, Space Science and Engineering Center, University of Wisconsin-Madison, Madison, Wisconsin

Merchant, Christopher J., Department of Meteorology and National Centre for Earth Observation, University of Reading, Reading, United Kingdom

Meredith, Michael P., British Antarctic Survey, Cambridge, United Kingdom

Merrifield, Mark A., Joint Institute for Marine and Atmospheric Research, University of Hawaii, Honolulu, Hawaii

Minnis, Patrick, NASA Langley Research Center, Hampton, Virginia

Miralles, Diego G., Laboratory of Hydrology and Water Management, Ghent University, Ghent, Belgium

Mistelbauer, T., Earth Observing Data Centre GmbH, Vienna, Austria

Mitchum, Gary T., College of Marine Science, University of South Florida, St. Petersburg, Florida

Mitro, Srkani, Meteorological Service Suriname, Paramaribo, Suriname

Monselesan, Didier, CSIRO Oceans and Atmosphere, Hobart, Tasmania, Australia

Montzka, Stephen A., NOAA/OAR Earth System Research Laboratory, Boulder, Colorado

Mora, Natalie, Center for Geophysical Research and School of Physics, University of Costa Rica, San José, Costa Rica

Morice, Colin, Met Office Hadley Centre, Exeter, United Kingdom

Morrow, Blair, Environment and Climate Change Canada, Edmonton, Alberta, Canada

Mote, T., Department of Geography, The University of Georgia, Athens, Georgia

Mudryk, L., Climate Research Division, Environment and Climate Change Canada, Toronto, Ontario, Canada

Mühle, Jens, Scripps Institution of Oceanography, University of California, San Diego, La Jolla, California

Mullan, A. Brett, National Institute of Water and Atmospheric Research, Ltd., Wellington, New Zealand

Müller, R., Forschungszentrum Jülich, Jülich, Germany 
Nash, Eric R., Science Systems and Applications, Inc., NASA Goddard Space Flight Center, Greenbelt, Maryland

Nerem, R. Steven, Colorado Center for Astrodynamics Research, Cooperative Institute for Research in Environmental Sciences, University of Colorado Boulder, Boulder, Colorado

Newman, Louise, SOOS International Project Office, Institute for Marine and Antarctic Studies, University of Tasmania, Hobart, Australia

Newman, Paul A., NASA Goddard Space Flight Center, Greenbelt, Maryland

Nieto, Juan José, Centro Internacional para la Investigación del Fenómeno de El Niño, Guayaquil, Ecuador

Noetzli, Jeannette, WSL Institute for Snow and Avalanche Research, Davos, Switzerland

O'Neel, S., USGS, Alaska Science Center, Anchorage, Alaska

Osborn, Tim J., Climatic Research Unit, School of Environmental Sciences, University of East Anglia, Norwich, United Kingdom

Overland, J., NOAA/OAR Pacific Marine Environmental Laboratory, Seattle, Washington

Oyunjargal, Lamjav, Hydrology and Environmental Monitoring, Institute of Meteorology and Hydrology, National Agency for Meteorology, Ulaanbaatar, Mongolia

Parinussa, Robert M., VanderSat B.V., Haarlem, Netherlands

Park, E-hyung, Korea Meteorological Administration, South Korea

Pasch, Richard J., NOAA/NWS National Hurricane Center, Miami, Florida

Pascual-Ramírez, Reynaldo, National Meteorological Service of Mexico, Mexico

Paterson, Andrew M., Dorset Environmental Science Centre, Ontario Ministry of the Environment and Climate Change, Dorset, Ontario, Canada

Pearce, Petra R., National Institute of Water and Atmospheric Research, Ltd., Auckland, New Zealand

Pellichero, V., Sorbonne Universités, LOCEAN-IPSL, CNRS-IRD-MNHN, Paris, France

Pelto, Mauri S., Nichols College, Dudley, Massachusetts

Peng, Liang, COSMIC Project Office, University Corporation for Atmospheric Research, Boulder, Colorado

Perkins-Kirkpatrick, Sarah E., Climate Change Research Centre, University of New South Wales, Sydney, New South Wales, Australia

Perovich, D., USACE, ERDC, Cold Regions Research and Engineering Laboratory, and Thayer School of Engineering, Dartmouth College, Hanover, New Hampshire
Petropavlovskikh, Irina, NOAA/OAR Earth System Research Laboratory, Global Monitoring Division, and University of Colorado Boulder, Boulder, Colorado

Pezza, Alexandre B., Greater Wellington Regional Council, Wellington, New Zealand

Phillips, C., Department of Atmospheric and Oceanic Sciences, University of Wisconsin-Madison, Madison, Wisconsin, USA

Phillips, David, Environment and Climate Change Canada, Toronto, Ontario, Canada

Phoenix, G., Department of Animal and Plant Sciences, University of Sheffield, Sheffield, United Kingdom

Pinty, Bernard, European Commission Joint Research Centre, Ispra, Italy

Pitts, Michael C., NASA Langley Research Center, Hampton, Virginia

Pons, M. R., Agencia Estatal de Meteorología, Santander, Spain

Porter, Avalon O., Cayman Islands National Weather Service, Grand Cayman, Cayman Islands

Quintana, Juan, Dirección Meteorológica de Chile, Chile

Rahimzadeh, Fatemeh, Atmospheric Science and Meteorological Research Center, Tehran, Iran

Rajeevan, Madhavan, Earth System Science Organization, Ministry of Earth Sciences, New Delhi, India

Rayner, Darren, National Oceanography Centre, Southampton, United Kingdom

Raynolds, M. K., Institute of Arctic Biology, University of Alaska Fairbanks, Fairbanks, Alaska

Razuvaev, Vyacheslav N., All-Russian Research Institute of Hydrometeorological Information, Obninsk, Russia

Read, Peter, Department of Physics, University of Oxford, Oxford, United Kingdom

Reagan, James, NOAA/NESDIS National Centers for Environmental Information, Silver Spring, Maryland, and Earth System Science Interdisciplinary Center/ Cooperative Institute for Climate and SatellitesMaryland, University of Maryland, College Park, Maryland

Reid, Phillip, Australian Bureau of Meteorology and CAWRC, Hobart, Tasmania, Australia

Reimer, Christoph, Department of Geodesy and Geoinformation, Vienna University of Technology, and EODC, Vienna, Austria

Rémy, Samuel, Institut Pierre-Simon Laplace, CNRS / UPMC, Paris, France

Renwick, James A., Victoria University of Wellington, Wellington, New Zealand

Revadekar, Jayashree V., Indian Institute of Tropical Meteorology, Pune, India

Richter-Menge, J., University of Alaska Fairbanks, Fairbanks, Alaska 
Rimmer, Alon, Yigal Allon Kinneret Limnological Laboratory, Israel Oceanographic and Limnological Research, Migdal, Israel

Robinson, David A., Department of Geography, Rutgers University, Piscataway, New Jersey

Rodell, Matthew, Hydrological Sciences Laboratory, NASA Goddard Space Flight Center, Greenbelt, Maryland

Rollenbeck, Ruetger, Laboratory for Climatology and Remote Sensing, Faculty of Geography, University of Marburg, Marburg, Germany

Romanovsky, Vladimir E., Geophysical Institute, University of Alaska Fairbanks, Fairbanks, Alaska, and Tyumen State University, Tyumen, Russia

Ronchail, Josyane, Université Paris Diderot/Laboratoire L'OCEAN-IPSL, Paris, France

Roquet, F., Department of Meteorology at Stockholm University (MISU), Stockholm, Sweden

Rosenlof, Karen H., NOAA/OAR Earth System Research Laboratory, Boulder, Colorado

Roth, Chris, University of Saskatchewan, Saskatoon, Saskatchewan, Canada

Rusak, James A., Dorset Environmental Science Centre, Ontario Ministry of the Environment and Climate Change, Dorset, Ontario, Canada

Sallée, Jean-Bapiste, Sorbonne Universités, L'OCEANIPSL, Paris, France, and British Antarctic Survey, Cambridge, United Kingdom

Sánchez-Lugo, Ahira, NOAA/NESDIS National Centers for Environmental Information, Asheville, North Carolina

Santee, Michelle L., NASA Jet Propulsion Laboratory, Pasadena, California

Sarmiento, Jorge L., Atmospheric and Oceanic Sciences Program, Princeton University, Princeton, New Jersey

Sawaengphokhai, P., Science Systems and Applications, Inc., Hampton, Virginia

Sayouri, Amal, Direction de la Météorologie Nationale Maroc, Rabat, Morocco

Scambos, Ted A., National Snow and Ice Data Center, University of Colorado Boulder, Boulder, Colorado

Schemm, Jae, NOAA/NWS Climate Prediction Center, College Park, Maryland

Schladow, S. Geoffrey, Tahoe Environmental Research Center, University of California at Davis, Davis, California

Schmid, Claudia, NOAA/OAR Atlantic Oceanographic and Meteorological Laboratory, Miami, Florida

Schmid, Martin, Eawag, Swiss Federal Institute of Aquatic Science and Technology, Kastanienbaum, Switzerland

Schoeneich, P., Institut de Géographie Alpine, University Grenoble Alpes, Grenoble, France
Schreck III, Carl J., Cooperative Institute for Climate and Satellites, North Carolina State University, Asheville, North Carolina

Schuur, Ted, Center for Ecosystem Science and Society, Northern Arizona University, Flagstaff, Arizona

Selkirk, H. B., Universities Space Research Association, NASA Goddard Space Flight Center, Greenbelt, Maryland

Send, Uwe, Scripps Institution of Oceanography, University of California, San Diego, La Jolla, California

Sensoy, Serhat, Turkish State Meteorological Service, Kalaba, Ankara, Turkey

Sharp, M., Department of Earth and Atmospheric Sciences, University of Alberta, Edmonton, Alberta, Canada

Shi, Lei, NOAA/NESDIS National Centers for Environmental Information, Asheville, North Carolina

Shiklomanov, Nikolai I., Department of Geography, George Washington University, Washington, D.C.

Shimaraeva, Svetlana V., Institute of Biology, Irkutsk State University, Russia

Siegel, David A., University of California-Santa Barbara, Santa Barbara, California

Signorini, Sergio R., Science Application International Corporation, Beltsville, Maryland

Silov, Eugene, Institute of Biology, Irkutsk State University, Russia

Sima, Fatou, Division of Meteorology, Department of Water Resources, Banjul, The Gambia

Simmons, Adrian J., European Centre for MediumRange Weather Forecasts, Reading, United Kingdom

Smeed, David A., National Oceanography Centre, Southampton, United Kingdom

Smeets, C. J. P. P., Institute for Marine and Atmospheric Research Utrecht, Utrecht University, Utrecht, Netherlands

Smith, Adam, NOAA/NESDIS National Centers for Environmental Information, Asheville, North Carolina

Smith, Sharon L., Geological Survey of Canada, Natural Resources Canada, Ottawa, Ontario, Canada

Soden, B., Rosenstiel School of Marine and Atmospheric Science, University of Miami, Key Biscane, Miami, Florida

Spence, Jaqueline M., Meteorological Service, Jamaica, Kingston, Jamaica

Srivastava, A. K., India Meteorological Department, Jaipur, India

Stackhouse, Paul W., Jr., NASA Langley Research Center, Hampton, Virginia

Stammerjohn, Sharon, Institute of Arctic and Alpine Research, University of Colorado Boulder, Boulder, Colorado

Steinbrecht, Wolfgang, German Weather Service (DWD), Hohenpeissenberg, Germany

Stella, José L., Servicio Meteorológico Nacional, Buenos Aires, Argentina 
Stennett-Brown, Roxann, Department of Physics, The University of the West Indies, Jamaica

Stephenson, Tannecia S., Department of Physics, The University of the West Indies, Jamaica

Strahan, Susan, Universities Space Research Association, NASA Goddard Space Flight Center, Greenbelt, Maryland

Streletskiy, Dimitri A., Department of Geography, George Washington University, Washington, D.C.

Sun-Mack, Sunny, Science Systems and Applications, Inc., Hampton, Virginia

Swart, Sebastiaan, CSIR Southern Ocean Carbon and Climate Observatory, Stellenbosch, South Africa

Sweet, William, NOAA/NOS Center for Operational Oceanographic Products and Services, Silver Spring, Maryland

Tamar, Gerard, Grenada Airports Authority, St. George's, Grenada

Taylor, Michael A., Department of Physics, The University of the West Indies, Jamaica

Tedesco, M., Lamont-Doherty Earth Observatory, Columbia University, Palisades, New York, and NASA Goddard Institute of Space Studies, New York, New York

Thoman, R. L., NOAA/National Weather Service, Alaska Region, Fairbanks, Alaska

Thompson, L., Department of Earth Sciences, Simon Fraser University, Burnaby, British Columbia, Canada

Thompson, Philip R., Joint Institute for Marine and Atmospheric Research, University of Hawaii, Honolulu, Hawaii

Timmermans, M.-L., Yale University, New Haven, Connecticut

Timofeev, Maxim A., Institute of Biology, Irkutsk State University, Russia

Tirñanes, Joaquin A., Laboratory of Systems, Technological Research Institute, Universidad de Santiago de Compostela, Santiago de Compostela, Spain

Tobin, Skie, Bureau of Meteorology, Melbourne, Victoria, Australia

Trachte, Katja, Laboratory for Climatology and Remote Sensing, Philipps-Universität, Marburg, Germany

Trewin, Blair C., Australian Bureau of Meteorology, Melbourne, Victoria, Australia

Trotman, Adrian R., Caribbean Institute for Meteorology and Hydrology, Bridgetown, Barbados

Tschudi, M., Aerospace Engineering Sciences, University of Colorado Boulder, Boulder, Colorado

Tweedy, Olga, Johns Hopkins University, Baltimore, Maryland

van As, D., Geological Survey of Denmark and Greenland, Copenhagen, Denmark

van de Wal, R. S. W., Institute for Marine and Atmospheric Research Utrecht, Utrecht University, Utrecht, Netherlands van der Schalie, Robin, VanderSat B.V., Haarlem, Netherlands

van der Schrier, Gerard, Royal Netherlands Meteorological Institute (KNMI), De Bilt, Netherlands

van der Werf, Guido R., Faculty of Earth and Life Sciences, VU University Amsterdam, Netherlands

Van Meerbeeck, Cedric J., Caribbean Institute for Meteorology and Hydrology, Bridgetown, Barbados

Velicogna, I., University of California, Irvine, California

Verburg, Piet, National Institute of Water and Atmospheric Research, Hamilton, New Zealand

Vieira, G., Instituto de Geografia e Ordenamento do Território, Universidade de Lisboa, Lisbon, Portugal

Vincent, Lucie A., Environment and Climate Change Canada, Toronto, Ontario, Canada

Vömel, Holger, Earth Observing Laboratory, National Center for Atmospheric Research, Boulder, Colorado

Vose, Russell S., NOAA/NESDIS National Centers for Environmental Information, Asheville, North Carolina

Wagner, Wolfgang, Department of Geodesy and Geoinformation, Vienna University of Technology, Vienna, Austria

Wåhlin, Anna, Department of Earth Sciences, University of Gothenburg, Göteborg, Sweden

Walker, D. A., Institute of Arctic Biology, University of Alaska Fairbanks, Fairbanks, Alaska

Walsh, J., International Arctic Research Center, University of Alaska Fairbanks, Fairbanks, Alaska

Wang, Bin, SOEST, Department of Meteorology, University of Hawaii, and IPRC, Honolulu, Hawaii

Wang, Chunzai, State Key Laboratory of Tropical Oceanography, South China Sea Institute of Oceanology, Guangzhou, China

Wang, Junhong, State University of New York, Albany, New York

Wang, Lei, Department of Geography and Anthropology, Louisiana State University, Baton Rouge, Louisiana

Wang, M., Joint Institute for the Study of the Atmosphere and Ocean, University of Washington, Seattle, Washington

Wang, Sheng-Hung, Byrd Polar and Climate Research Center, The Ohio State University, Columbus, Ohio

Wanninkhof, Rik, NOAA/OAR Atlantic Oceanographic and Meteorological Laboratory, Miami, Florida

Watanabe, Shohei, Tahoe Environmental Research Center, University of California at Davis, Davis, California

Weber, Mark, University of Bremen, Bremen, Germany

Weller, Robert A., Woods Hole Oceanographic Institution, Woods Hole, Massachusetts

Weyhenmeyer, Gesa A., Department of Ecology and Genetics/Limnology, Uppsala University, Uppsala, Sweden 
Whitewood, Robert, Environment and Climate Change Canada, Toronto, Ontario, Canada

Wiese, David N., Jet Propulsion Laboratory, California Institute of Technology, Pasadena, California

Wijffels, Susan E., CSIRO Oceans and Atmosphere, Hobart, Tasmania, Australia

Wilber, Anne C., Science Systems and Applications, Inc., Hampton, Virginia

Wild, Jeanette D., INNOVIM, NOAA Climate Prediction Center, College Park, Maryland

Willett, Kate M., Met Office Hadley Centre, Exeter, United Kingdom

Willie, Shem, St. Lucia Meteorological Service, St. Lucia

Willis, Josh K., Jet Propulsion Laboratory, California Institute of Technology, Pasadena, California

Wolken, G., Alaska Division of Geological and Geophysical Surveys, and International Arctic Research Center, University of Alaska Fairbanks, Fairbanks, Alaska

Wong, Takmeng, NASA Langley Research Center, Hampton, Virginia

Wood, E. F., Department of Civil and Environmental Engineering, Princeton University, Princeton, New Jersey

Woolway, R. lestyn, Department of Meteorology, University of Reading, Reading, United Kingdom

Wouters, B., School of Geographical Sciences, University of Bristol, Bristol, United Kingdom
Xue, Yan, NOAA/NWS National Centers for Environmental Prediction, Climate Prediction Center, College Park, Maryland

Yim, So-Young, Korea Meteorological Administration, South Korea

Yin, Xungang, ERT Inc., NOAA/NESDIS National Centers for Environmental Information, Asheville, North Carolina

Yu, Lisan, Woods Hole Oceanographic Institution, Woods Hole, Massachusetts

Zambrano, Eduardo, Centro Internacional para la Investigación del Fenómeno El Niño, Guayaquil, Ecuador

Zhang, Huai-Min, NOAA/NESDIS National Centers for Environmental Information, Asheville, North Carolina

Zhang, Peiqun, Beijing Climate Center, Beijing, China

Zhao, Guanguo, University of Illinois at UrbanaChampaign, Urbana, Illinois

Zhao, Lin, Cold and Arid Regions Environmental and Engineering Research Institute, Lanzhou, China

Ziemke, Jerry R., Goddard Earth Sciences Technology and Research, Morgan State University, Baltimore, Maryland, and NASA Goddard Space Flight Center, Greenbelt, Maryland

Zilberman, Nathalie, Scripps Institution of Oceanography, University of California San Diego, La Jolla, California

\section{EDITORIAL AND PRODUCTION TEAM}

Love-Brotak, S. Elizabeth, Lead Graphics Production, NOAA/NESDIS National Centers for Environmental Information, Asheville, North Carolina

Sprain, Mara, Technical Editor, LAC Group, NOAA/ NESDIS National Centers for Environmental Information, Asheville, North Carolina

Veasey, Sara W., Visual Communications Team Lead, NOAA/NESDIS National Centers for Environmental Information, Asheville, North Carolina

Griffin, Jessicca, Graphics Support, Cooperative Institute for Climate and Satellites-NC, North Carolina State University, Asheville, North Carolina
Misch, Deborah J., Graphics Support, TeleSolv Consulting, NOAA/NESDIS National Centers for Environmental Information, Asheville, North Carolina

Riddle, Deborah B., Graphics Support, NOAA/NESDIS National Centers for Environmental Information, Asheville, North Carolina

Young, Teresa, Graphics Support, TeleSolv Consulting, NOAA/NESDIS National Centers for Environmental Information, Asheville, North Carolina 


\section{TABLE OF CONTENTS}

List of authors and affiliations. $\ldots . . \mathrm{i}$

Abstract $\mathrm{xvi}$

\section{INTRODUCTION}

SIDEBAR I.I: ESSENTIAL CLIMATE VARIABLES...................................................................................................

2. GLOBAL CLIMATE

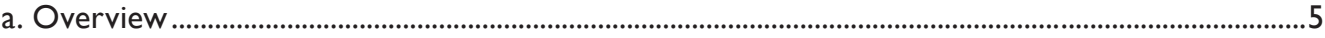

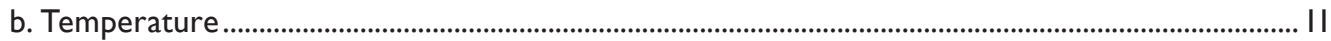

I. Global surface temperature ...................................................................................................... II

2. Lake surface temperature............................................................................................................. 13

3. Land surface temperature extremes …………………........................................................... 14

4. Lower and mid-tropospheric temperature .................................................................................... 16

5. Lower stratospheric temperature....................................................................................................... 17

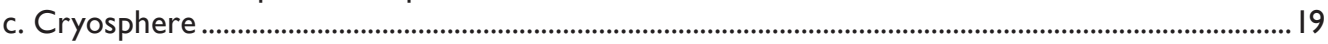

I. Permafrost thermal state .................................................................................................................. 19

2. Northern Hemisphere continental snow cover extent..............................................................2I

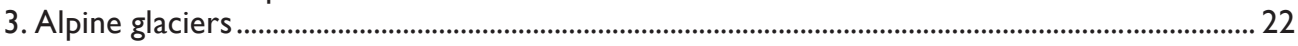

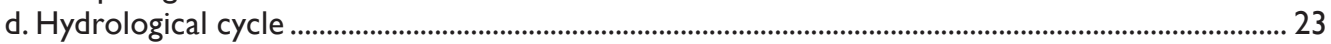

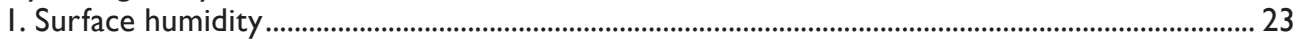

2. Total column water vapor ................................................................................................................24

3. Upper tropospheric humidity ..................................................................................................... 25

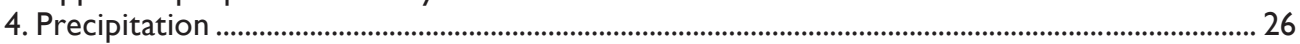

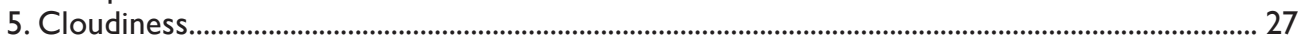

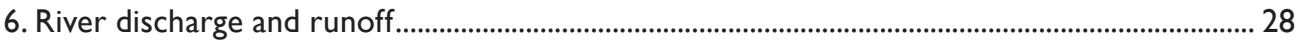

7. Groundwater and terrestrial water storage.................................................................................. 30

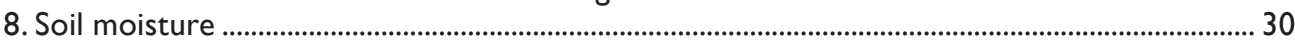

9. Monitoring global drought using the self-calibrating Palmer drought severity index ............... 32

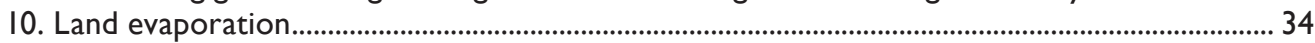

e. Atmospheric circulation ........................................................................................................................ 35

I. Mean sea level pressure and related modes of variability ................................................................. 35

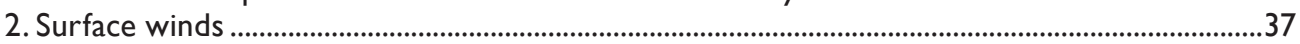

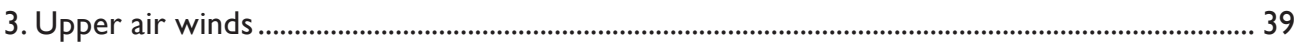

f. Earth radiation budget ..........................................................................................................................

I. Earth radiation budget at top-of-atmosphere ................................................................................

2. Mauna Loa clear-sky "apparent" solar transmission .................................................................. 42

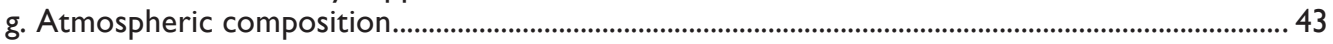

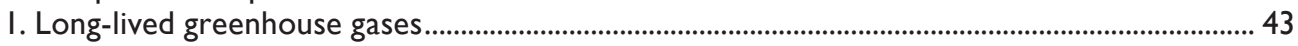

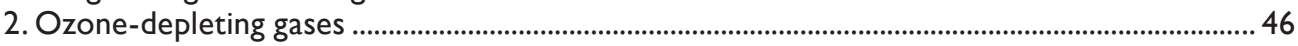

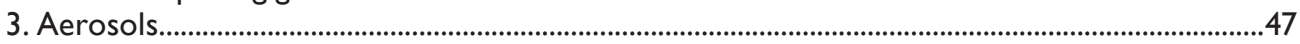

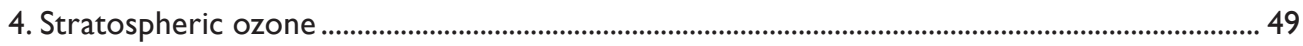

5. Stratospheric water vapor....................................................................................................

6. Tropospheric ozone …………………………………………………………………………...52

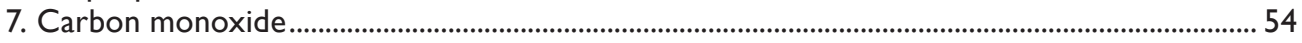

h. Land surface properties............................................................................................................................ 55

I. Land surface albedo dynamics .......................................................................................................... 55

2. Terrestrial vegetation dynamics ........................................................................................................5

3. Biomass burning .......................................................................................................................... 58

Sidebar 2.I: The STATE Of THE MartIAN Climate ........................................................................................ 60

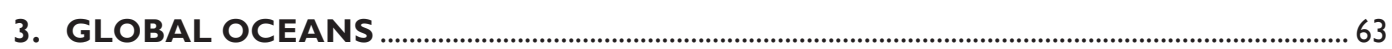

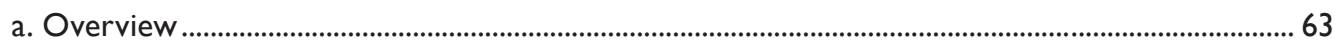

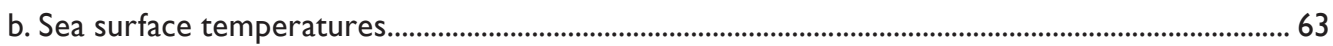

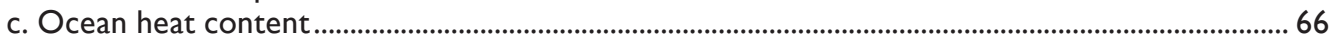

SidebAR 3.I: ChANGES IN THE NORTHEAST U.S. SHELF ECOSYSTEM AND FISHERIES ..........................................69

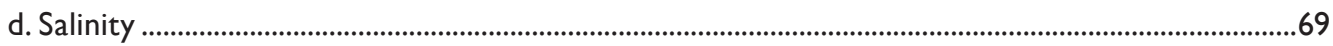

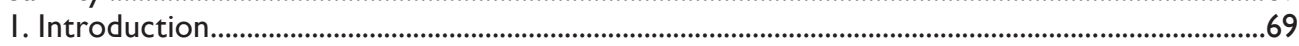

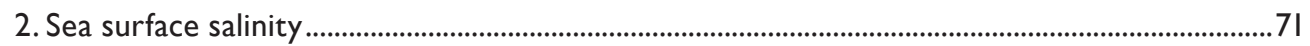

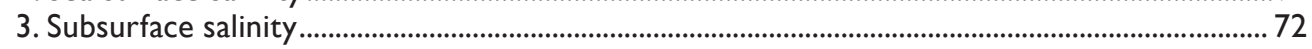


Sidebar 3.2: DeEP ARgo: SAMPLING THE total OCEAN Volume .................................................................. 73

e. Global ocean heat, freshwater, and momentum fluxes................................................................ 75

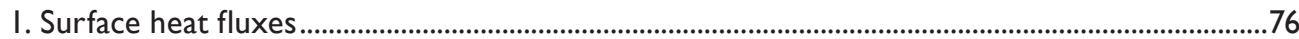

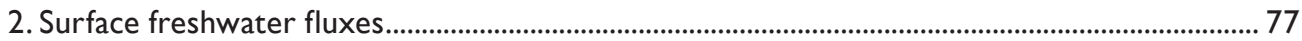

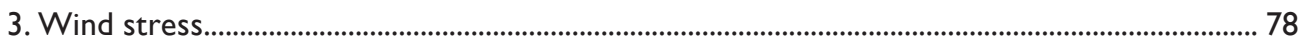

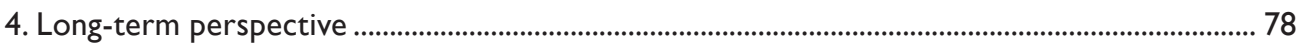

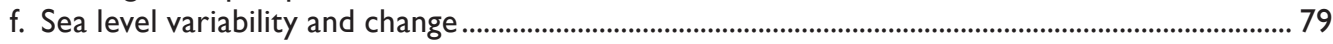

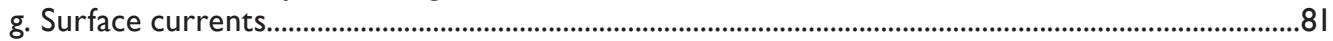

h. Meridional overturning and oceanic heat transport circulation observations in the

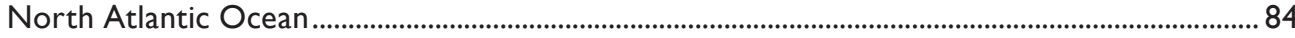

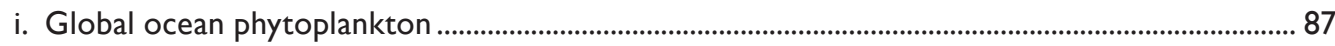

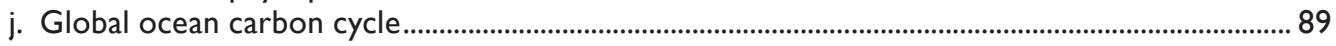

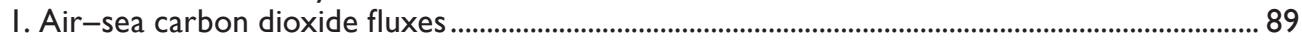

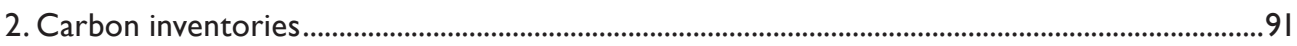

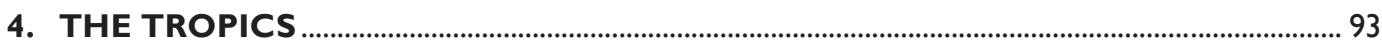

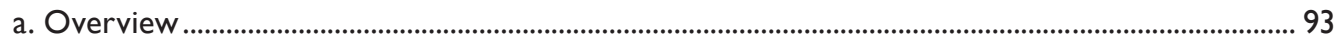

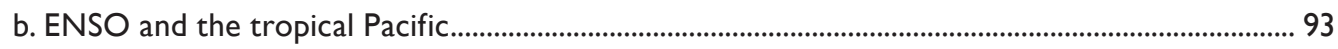

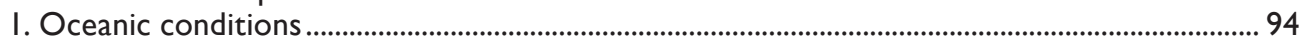

2. Atmospheric circulation: Tropics and subtropics ........................................................................... 96

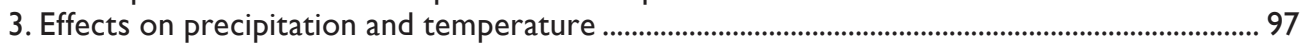

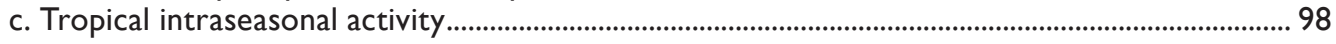

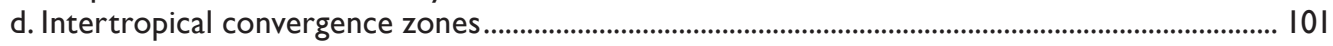

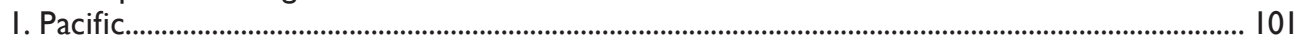

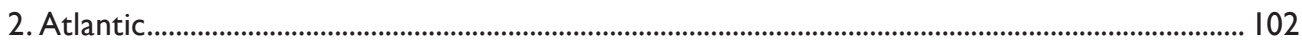

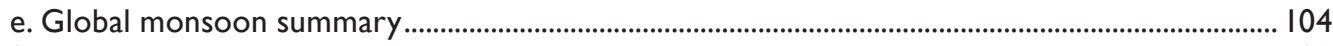

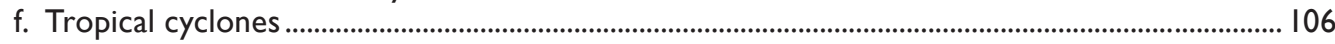

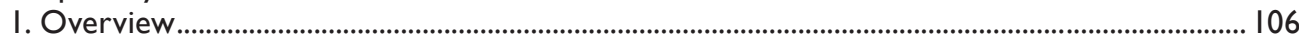

Sidebar 4.I: The record-setting North Atlantic Hurricane Matthew ............................................. 106

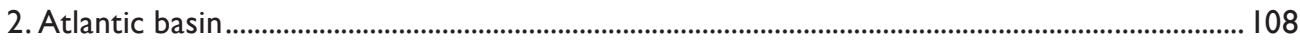

3. Eastern North Pacific and Central North Pacific basins ......................................................... 112

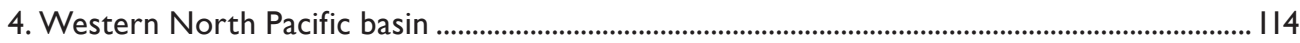

5. North Indian Ocean basin ......................................................................................................

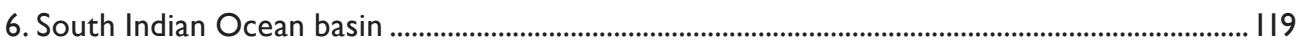

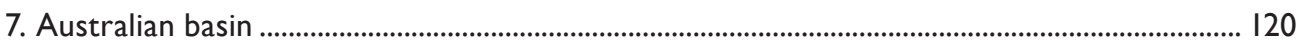

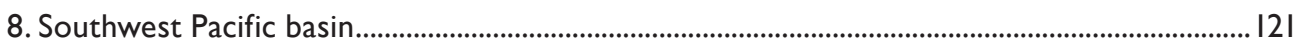

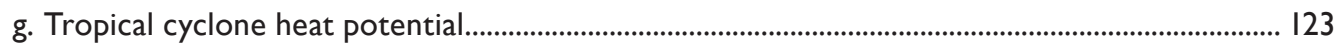

Sidebar 4.2: TAIWAN IN THE BULLSEYE OF SEVERAL MAJOR TYPHOONS......................................................... I 24

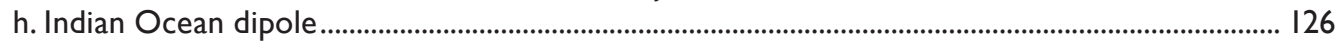

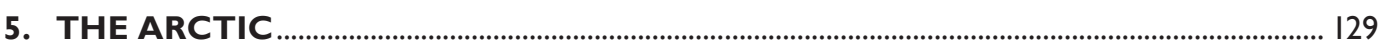

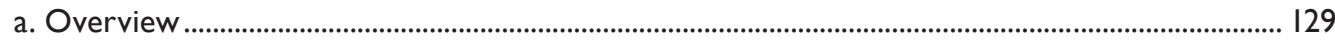

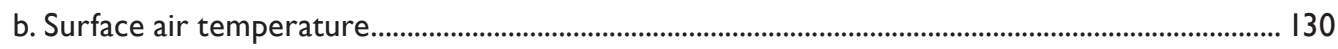

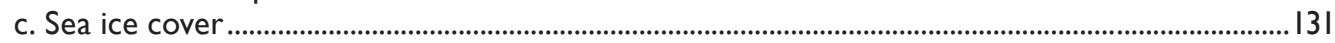

Sidebar 5.I: The StUdy Of ENVIRONMENTAL ARCtic Change:

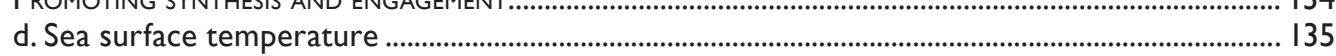

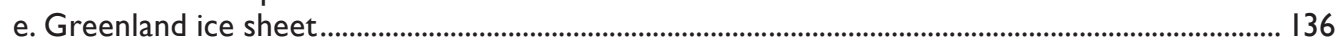

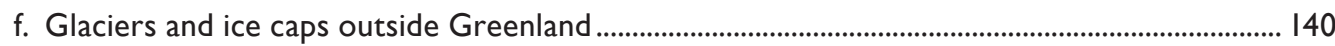

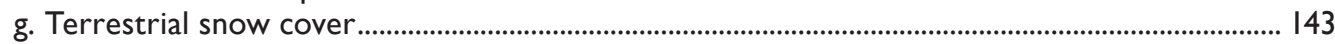

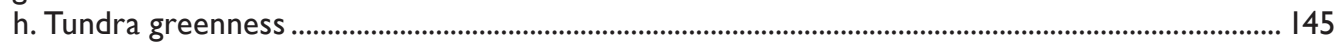

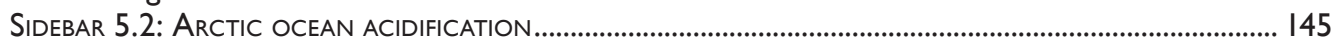

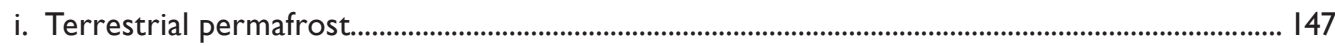

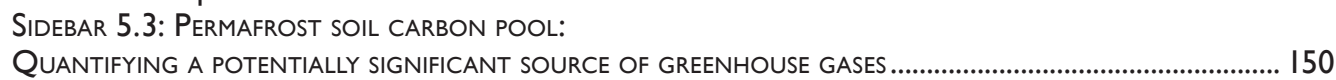

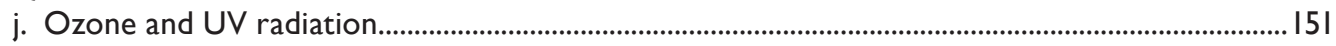

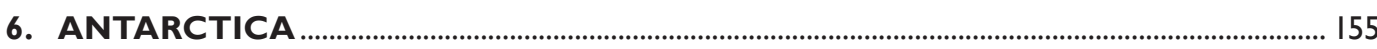

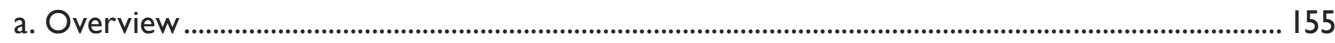

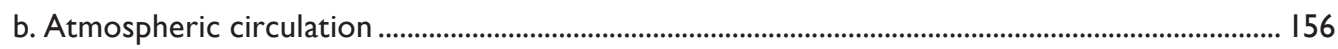

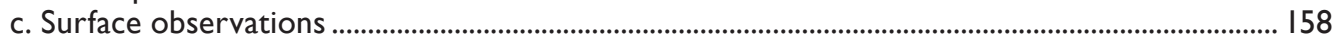




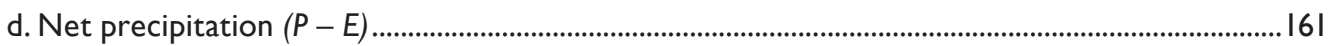

e. Seasonal melt extent and duration ................................................................................................... 162

f. Sea ice extent, concentration, and seasonality …………………………………………………..... 163

g. Southern Ocean .................................................................................................................................. 166

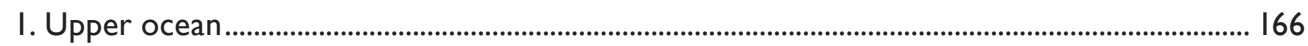

2. The Maud Rise polynya................................................................................................................... 167

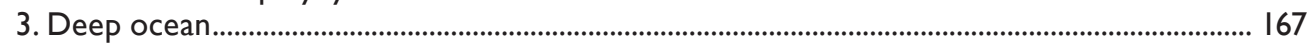

4. Observational gaps and future outlook ....................................................................................... 167

Sidebar 6.I: AdVANCES IN UNDERSTANDING THE SOUTHERN OCEAN'S ROLE IN GLOBAL CLIMATE:

THE ORCHESTRA AND SOCCOM PROGRAMS ....................................................................................... 168

h. 2016 Antarctic ozone hole................................................................................................................. 169

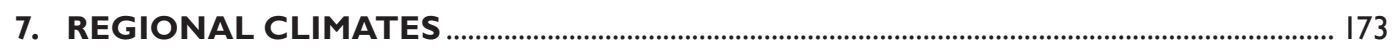

a. Overview ......................................................................................................................................... 173

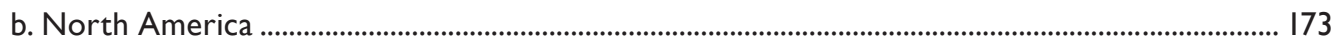

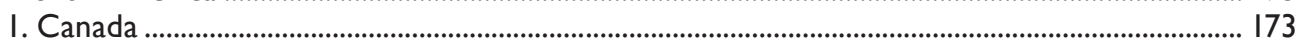

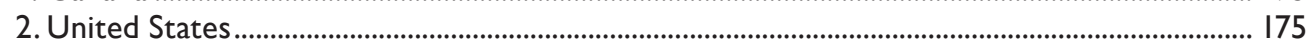

Sidebar 7.I: The extreme 2016 Wild fire in Fort McMurray, Alberta, Canada ........................................ 176

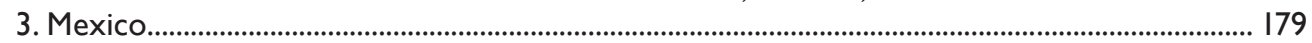

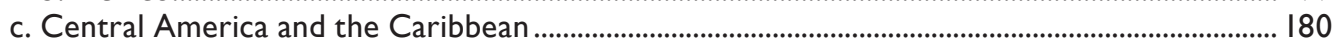

I. Central America.................................................................................................................. 180

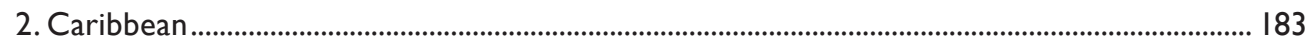

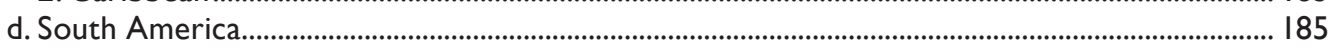

I. Northern South America ............................................................................................................ 186

2. Central South America..................................................................................................................... 187

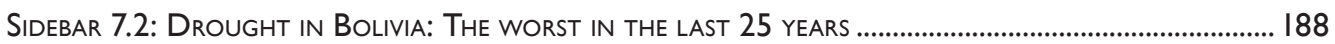

3. Southern South America............................................................................................................ 190

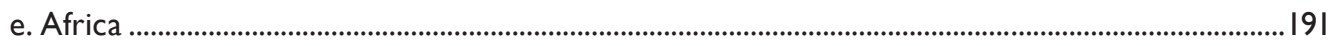

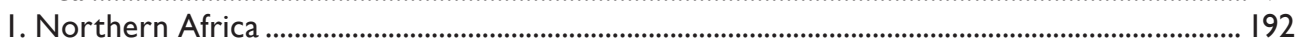

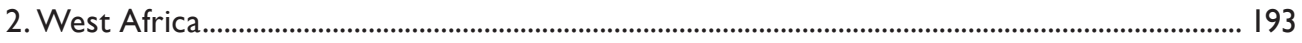

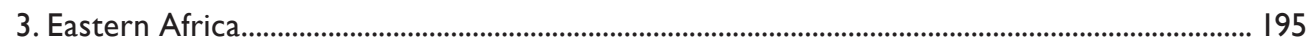

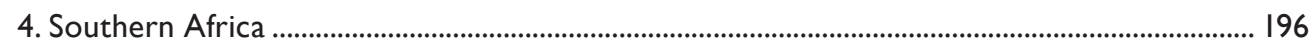

5. Western Indian Ocean island countries................................................................................... 198

f. Europe and the Middle East............................................................................................................ 20

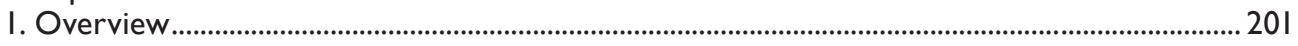

2. Central and western Europe................................................................................................................ 203

3. The Nordic and the Baltic countries ........................................................................................... 204

Sidebar 7.3: THE NAKED SHEEP—RAINSTORMS, FLOODS, AND COLD WEATHER CAUSED BY

EXTRAORDINARY CYCLONIC ACTIVITY IN MAY/JUNE 2016 IN CENTRAL EUROPE................................................2. 205

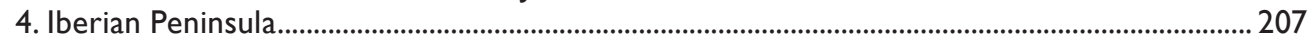

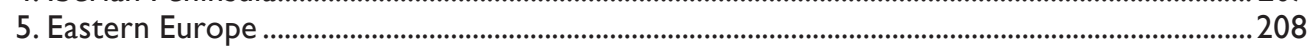

6. Mediterranean and Balkan countries .............................................................................................. 209

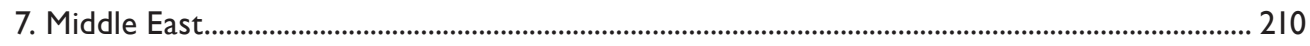

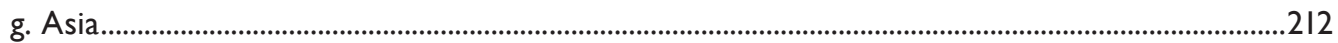

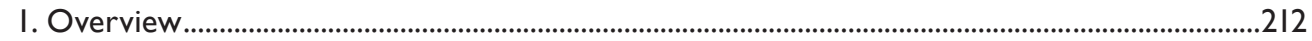

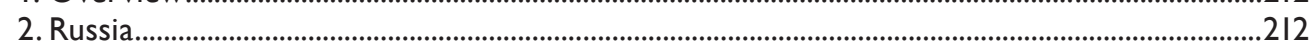

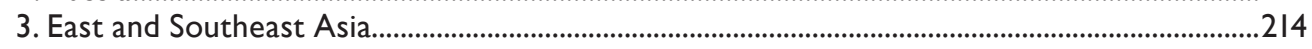

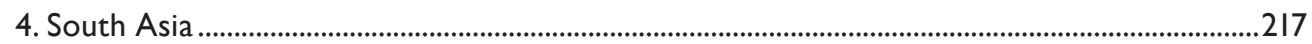

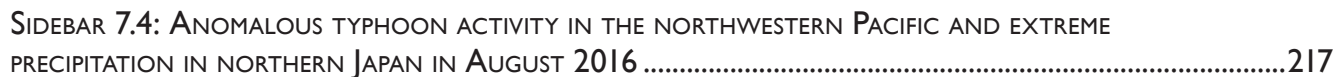

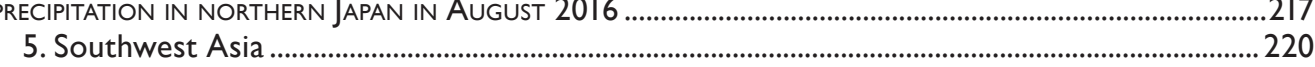

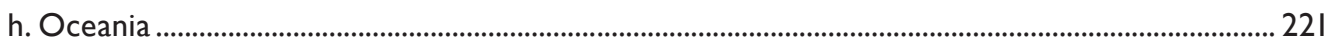

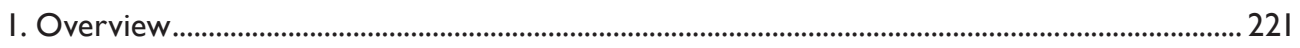

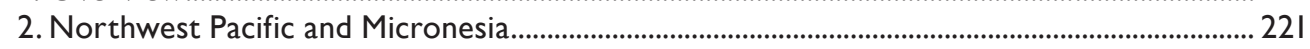

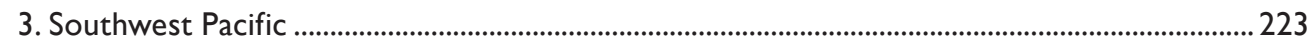

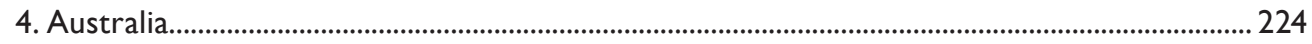

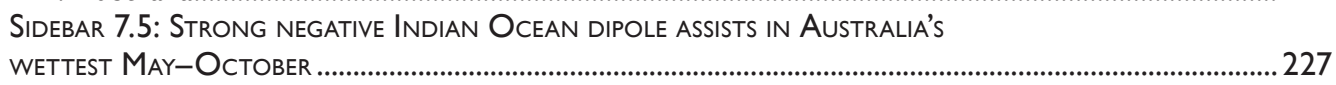

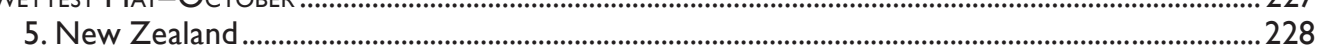


APPENDIX I: Relevant Datasets and Sources. 


\section{ABSTRACT—J. BLUNDEN AND D. S. ARNDT}

In 2016, the dominant greenhouse gases released into Earth's atmosphere-carbon dioxide, methane, and nitrous oxidecontinued to increase and reach new record highs. The $3.5 \pm$ $0.1 \mathrm{ppm}$ rise in global annual mean carbon dioxide from 2015 to 2016 was the largest annual increase observed in the 58 year measurement record. The annual global average carbon dioxide concentration at Earth's surface surpassed 400 ppm $(402.9 \pm 0.1 \mathrm{ppm})$ for the first time in the modern atmospheric measurement record and in ice core records dating back as far as 800000 years.

One of the strongest El Niño events since at least 1950 dissipated in spring, and a weak La Niña evolved later in the year. Owing at least in part to the combination of El Niño conditions early in the year and a long-term upward trend, Earth's surface observed record warmth for a third consecutive year, albeit by a much slimmer margin than by which that record was set in 2015. Above Earth's surface, the annual lower troposphere temperature was record high according to all datasets analyzed, while the lower stratospheric temperature was record low according to most of the in situ and satellite datasets.

Several countries, including Mexico and India, reported record high annual temperatures while many others observed near-record highs. A week-long heat wave at the end of April over the northern and eastern Indian peninsula, with temperatures surpassing $44^{\circ} \mathrm{C}$, contributed to a water crisis for 330 million people and to 300 fatalities.

In the Arctic the 2016 land surface temperature was $2.0^{\circ} \mathrm{C}$ above the $1981-2010$ average, breaking the previous record of 2007,2011 , and 2015 by $0.8^{\circ} \mathrm{C}$, representing a $3.5^{\circ} \mathrm{C}$ increase since the record began in 1900. The increasing temperatures have led to decreasing Arctic sea ice extent and thickness. On 24 March, the sea ice extent at the end of the growth season saw its lowest maximum in the 37 -year satellite record, tying with 2015 at $7.2 \%$ below the 198I-2010 average. The September 2016 Arctic sea ice minimum extent tied with 2007 for the second lowest value on record, 33\% lower than the $1981-2010$ average. Arctic sea ice cover remains relatively young and thin, making it vulnerable to continued extensive melt. The mass of the Greenland Ice Sheet, which has the capacity to contribute $\sim 7 \mathrm{~m}$ to sea level rise, reached a record low value. The onset of its surface melt was the second earliest, after 2012, in the 37-year satellite record.

Sea surface temperature was record high at the global scale, surpassing the previous record of 2015 by about $0.01{ }^{\circ} \mathrm{C}$. The global sea surface temperature trend for the 21 st centuryto-date of $+0.162^{\circ} \mathrm{C}$ decade $^{-1}$ is much higher than the longer term $1950-2016$ trend of $+0.100^{\circ} \mathrm{C}$ decade $^{-1}$. Global annual mean sea level also reached a new record high, marking the sixth consecutive year of increase. Global annual ocean heat content saw a slight drop compared to the record high in 2015 .
Alpine glacier retreat continued around the globe, and preliminary data indicate that 2016 is the 37 th consecutive year of negative annual mass balance. Across the Northern Hemisphere, snow cover for each month from February to June was among its four least extensive in the 47-year satellite record. Continuing a pattern below the surface, record high temperatures at $20-\mathrm{m}$ depth were measured at all permafrost observatories on the North Slope of Alaska and at the Canadian observatory on northernmost Ellesmere Island.

In the Antarctic, record low monthly surface pressures were broken at many stations, with the southern annular mode setting record high index values in March and June. Monthly high surface pressure records for August and November were set at several stations. During this period, record low daily and monthly sea ice extents were observed, with the November mean sea ice extent more than 5 standard deviations below the 1981-2010 average. These record low sea ice values contrast sharply with the record high values observed during 2012-14. Over the region, springtime Antarctic stratospheric ozone depletion was less severe relative to the 1991-2006 average, but ozone levels were still low compared to pre-1990 levels.

Closer to the equator, 93 named tropical storms were observed during 2016, above the $1981-2010$ average of 82 , but fewer than the I0I storms recorded in 20I5. Three basins-the North Atlantic, and eastern and western North Pacific-experienced above-normal activity in 2016. The Australian basin recorded its least active season since the beginning of the satellite era in 1970. Overall, four tropical cyclones reached the Saffir-Simpson category 5 intensity level.

The strong El Niño at the beginning of the year that transitioned to a weak La Niña contributed to enhanced precipitation variability around the world. Wet conditions were observed throughout the year across southern South America, causing repeated heavy flooding in Argentina, Paraguay, and Uruguay. Wetter-than-usual conditions were also observed for eastern Europe and central Asia, alleviating the drought conditions of 2014 and 2015 in southern Russia. In the United States, California had its first wetter-than-average year since 2012, after being plagued by drought for several years. Even so, the area covered by drought in 2016 at the global scale was among the largest in the post- 1950 record. For each month, at least $12 \%$ of land surfaces experienced severe drought conditions or worse, the longest such stretch in the record. In northeastern Brazil, drought conditions were observed for the fifth consecutive year, making this the longest drought on record in the region. Dry conditions were also observed in western Bolivia and Peru; it was Bolivia's worst drought in the past 25 years. In May, with abnormally warm and dry conditions already prevailing over western Canada for about a year, the human-induced Fort McMurray wildfire burned nearly 590000 hectares and became the costliest disaster in Canadian history, with $\$ 3$ billion (U.S. dollars) in insured losses. 
I. INTRODUCTION-D. S. Arndt, J. Blunden, and R. J. H. Dunn

This is the twenty-seventh issuance of the annual assessment first known as Climate Assessment and now known as State of the Climate, published in the Bulletin since 1996. It documents the status and trajectory of the many components of the climate system. By doing so, this report also documents the status and trajectory of our capacity and commitment to observe it.

Surface temperature and carbon dioxide concentration, two of the more publicly recognized indicators of global-scale climate change, set new highs during 2016, as did several surface and near-surface indicators and essential climate variables. Notably, the increase in $\mathrm{CO}_{2}$ concentration was the largest in the nearly six-decade observational record.

The relaxation of ENSO from strong El Niño conditions early in the year to neutral and weak La Niña conditions late in the year is a pervasive thread throughout the volume. It is worth repeating in this year's Introduction that different communities observe ENSO through different lenses and define ENSO by different metrics. Thus, the descriptions and values related to the magnitude and timing of ENSO conditions may vary slightly from chapter to chapter.

Although the State of the Climate's findings are driven by data, its content is built by a community. As always, we express our deep appreciation to its nearly 500 authors for their volunteer and expert contributions. Relative to more traditional journal articles, authors work on compressed schedules with considerably less schedule flexibility. That such a comprehensive assessment can be assembled annually is a testament to their dedication and generosity.

The State of the Climate chapter and technical editors dedicate weeks, even months, to the effort. Their leadership continues to evolve this series, even as some portions of the text draw heavily from that in earlier years. Returning readers may note the following changes arising from their ongoing drive to address a broader swath of the climate system, and the reality that some data and authors simply aren't available every year. Evaporation over land surfaces is now addressed in its own section within Global Climate (Chapter 2d). The global monsoon, a defining feature of seasonality and a major mode of variability of Earth's climate system, is also addressed in a new section within The Tropics (Chapter 4e). Tundra greenness replaces river discharge this year in Chapter 5, The Arctic. Chapter 7, Regional Climates, introduces minor geographical reorganizations. Most notably, Southeast Asia is addressed more directly than in previous editions, and several previous sections have been consolidated into a comprehensive southern Africa section.

Fourteen sidebars are included in this edition. Collectively and individually, they remind us of the many connections inherent in the study and analysis of the climate system. These connections reach as far as our sibling planet, Mars, and what we can - and can't-learn from its climate. These connections reach far into the ocean, by depth in the case of Deep Argo, and by latitude in the case of the Southern Ocean. These connections also reach into our own humanity, exploring how the language of those who are native to areas dependent upon sea ice can inform the science familiar to readers of this document. Our cover image of a Malawian woman sowing drought-resistant sweet potatoes reflects the dry conditions that prevailed over southern Africa during the year. It also serves as a reminder that, beyond the calculations and analyses within this document, climate and climate variability are sown into the human experience.

An overview of findings is presented in the Abstract, Fig. 1.1, and Plate 1.1. Chapter 2 features global-scale climate variables; Chapter 3 highlights the global oceans; and Chapter 4 includes tropical climate phenomena including tropical cyclones. The Arctic and Antarctic respond differently through time and are reported in separate chapters (5 and 6, respectively). Chapter 7 provides a regional perspective authored largely by local government climate specialists. A list of relevant datasets and their sources for all chapters is provided as an Appendix. 


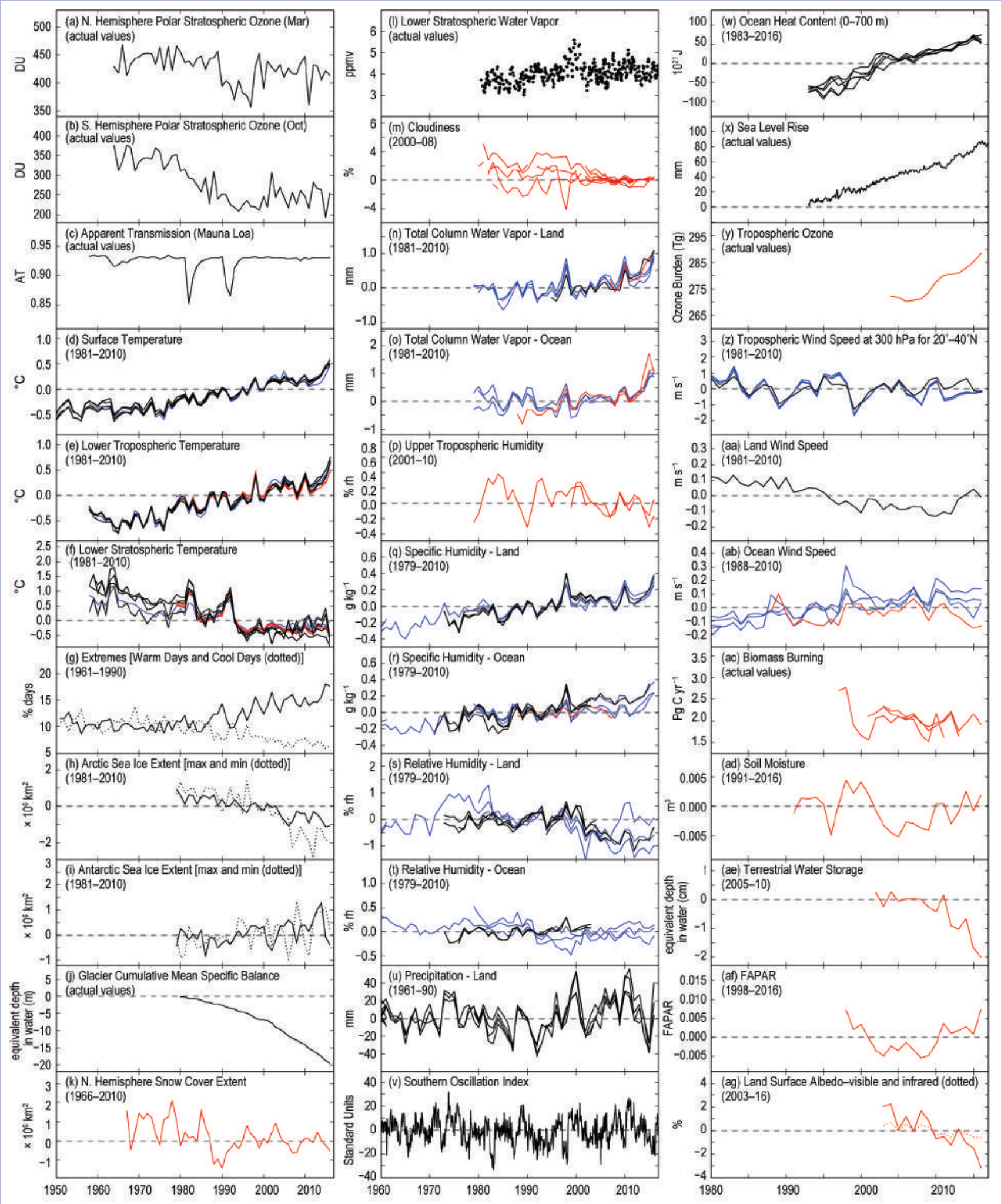


Time series of major climate indicators are again presented in this introductory chapter. Many of these indicators are essential climate variables (ECVs), originally defined in GCOS 2003 and updated again by GCOS in 2010 .

The following ECVs, included in this edition, are considered "fully monitored," in that they are observed and analyzed across much of the world, with a sufficiently long-term dataset that has peerreviewed documentation:

- Atmospheric Surface: air temperature, precipitation, air pressure, water vapor, wind speed and direction.

- Atmospheric Upper Air: earth radiation budget, temperature, water vapor, wind speed and direction.

- Atmospheric Composition: carbon dioxide, methane, other long-lived gases, ozone.

- Ocean Surface: temperature, salinity, sea level, sea ice, current, ocean color, phytoplankton.

- Ocean Subsurface: temperature, salinity.

- Terrestrial: snow cover, albedo.
ECVs in this edition that are considered "partially monitored," meeting some but not all of the above requirements, include:

- Atmospheric Upper Air: cloud properties.

- Atmospheric Composition: aerosols and their precursors.

- Ocean Surface: carbon dioxide, ocean acidity.

- Ocean Subsurface: current, carbon.

Terrestrial: soil moisture, permafrost, glaciers and ice caps, river discharge, groundwater, ice sheets, fraction of absorbed photosynthetically active radiation, biomass, fire disturbance.

Remaining ECVs that are desired for the future include:

- Atmospheric Surface: surface radiation budget.

- Ocean Surface: sea state.

- Ocean Subsurface: nutrients, ocean tracers, ocean acidity, oxygen.

- Terrestrial: water use, land cover, lakes, leaf area index, soil carbon.

PLATE I.I. Global (or representative) average time series for essential climate variables through 2016. Anomalies are shown relative to the base period in parentheses although base periods used in other sections of the report may differ. The numbers in the square brackets that follow in this caption indicate how many reanalysis (blue), satellite (red), and in situ (black) datasets are used to create each time series in that order. (a) N. Hemisphere lower stratospheric ozone (March) [0,0,I]; (b) S. Hemisphere lower stratospheric ozone (October) [0,0, I]; (c) Apparent transmission (Mauna Loa) [0,0,I]; (d) Surface temperature [0,0,4]; (e) Lower tropospheric temperature [3,2,4]; (f) Lower stratospheric temperature [3,3,4]; (g) Extremes [warm days (solid) and cool nights (dotted)] [0,0,I]; (h) Arctic sea ice extent [max (solid) and min (dashed)] [0,0,I]; (i) Antarctic sea ice extent [max (solid) and min (dashed)] [0,0,I]; (j) Glacier cumulative mean specific balance $[0,0,1]$; (k) N. Hemisphere snow cover extent $[0,1,0]$; (I) Lower stratospheric water vapor $[0,0,1] ;(m)$ Cloudiness $[0,8,0] ;(n)$ Total column water vapor - land $[3,1,1]$; (o) Total column water vapor - ocean $[3,2,0]$; (p) Upper tropospheric humidity $[0,2,0]$; (q) Specific humidity - Iand [3,0,4]; (r) Specific humidity - ocean [3,I,3]; (s) Relative humidity - land [3,0,4]; (t) Relative humidity - ocean [3,0,2]; (u) Precipitation - land [0,0,4]; (v) Southern oscillation index [0,0, I]; (w) Ocean heat content $(0-700 \mathrm{~m})[0,0,5]$; (x) Sea level rise [0,0,I]; (y) Tropospheric ozone [0, I,0]; (z) Tropospheric wind speed at $300 \mathrm{hPa}$ for $20^{\circ}-40^{\circ} \mathrm{N}$ [4,0,1]; (aa) Land wind speed [0,0,1]; (ab) Ocean wind speed [3, I,0]; (ac) Biomass burning [0,3,0]; (ad) Soil moisture [0,I,0]; (ae) Terrestrial groundwater storage [0,I,0]; (af) Fraction of absorbed photosynthetically active radiation (FAPAR) [0, I,0]; (ag) Land surface albedo - visible (solid) and infrared (dashed) $[0,1,0]$. 


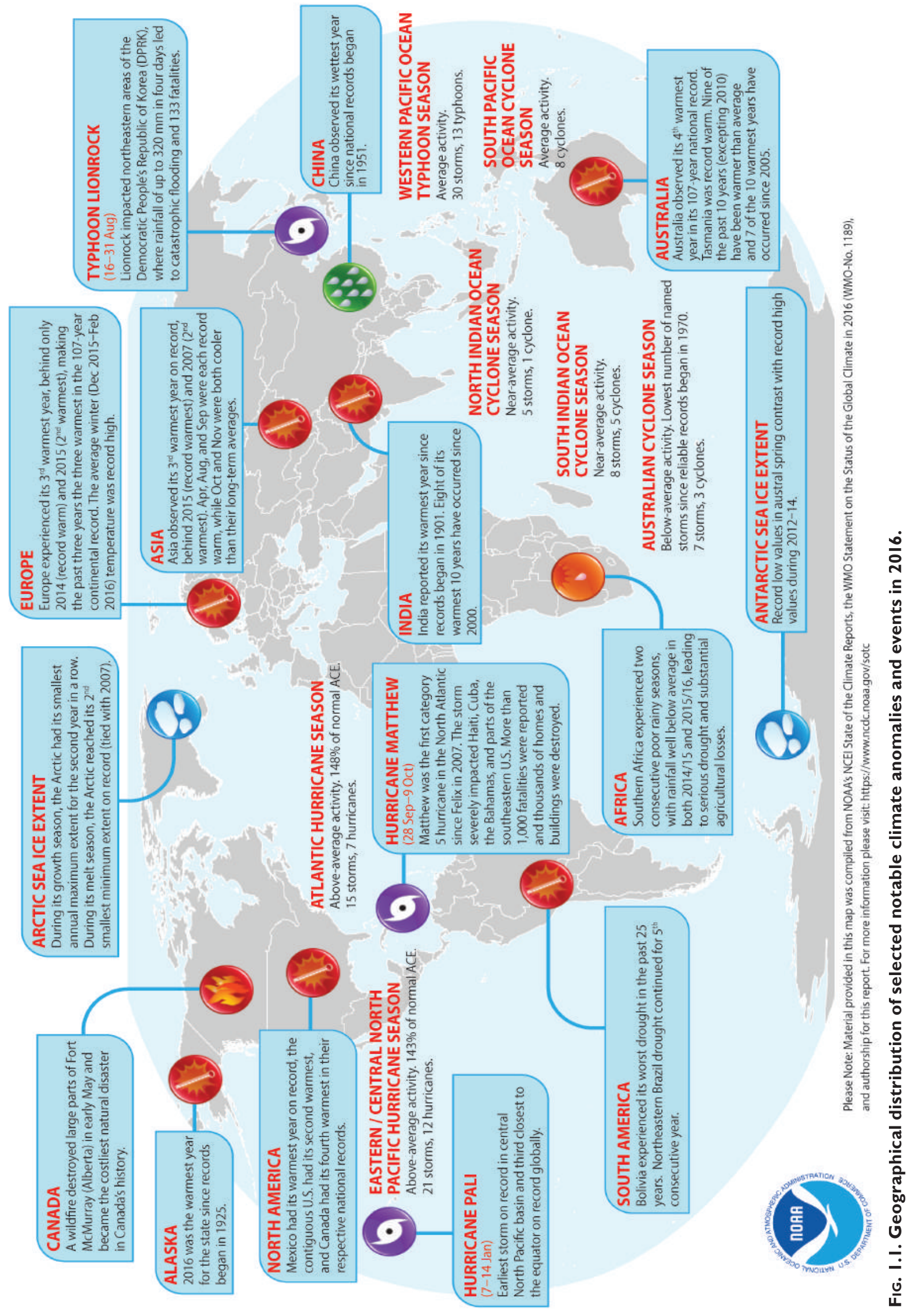


2. GLOBAL CLIMATE-R. J. H. Dunn, D. F. Hurst, N. Gobron, and K. M. Willett, Eds.

a. Overview-R. J. H. Dunn, D. F. Hurst, N. Gobron, and K. M. Willett

For yet another year in succession, 2016 was the warmest at the surface in the 150-year instrumental record with global annual anomalies between $0.45^{\circ}-$ $0.56^{\circ} \mathrm{C}$ above the $1981-2010$ average but by a lesser margin than the previous two. The strong El Niño continued to dominate global conditions during the early part of the year, but the El Niño-Southern Oscillation (ENSO) transitioned to a weak La Niña as the year progressed. Also of note is the largest annual increase of global atmospheric $\mathrm{CO}_{2}$ ever observed in the 58-year measurement record, with an increase of $3.5 \pm 0.1 \mathrm{ppm}$ since 2015 to $402.9 \pm 0.1 \mathrm{ppm}$.

Many other essential climate variables (ECVs), especially those closely linked to surface temperature, responded to these exceptionally warm conditions. Upper atmospheric, lake, and extreme surface temperatures all exhibited exceptional if not record warmth. In the cryosphere, glaciers continued to have a negative mass balance, now for the 37 th successive year. And although the winter season Northern Hemisphere snow cover extent was near average, the rapid increase in snow cover during autumn and decrease during spring is consistent with warmer-than-average conditions.

The global warmth was associated with extensive drought. The global drought extent surpassed most years in the post-1950 record and was strongly influenced by the El Niño, with every month of 2016 having at least $12 \%$ of global land experiencing severe drought conditions. Despite this, strong decreases in fire-related emissions were measured in 2016 for Australia and North America. Tropical Asia also saw decreases in fire-related emissions from the 2015 record high levels to near-record low levels in 2016, but increases occurred for northern and Southeast Asia. Also, atmospheric moisture at the surface and in the upper troposphere was high, and at record levels for surface specific humidity over land, but with little change in global levels of cloudiness. These high levels of moisture were also apparent in the water vapor column, which peaked in line with the El Niño in early 2016 and reached record levels over the oceans. The global average fraction of photosynthetically available radiation (FAPAR) was also above average. Levels of precipitation globally were above average, although by how much depended on the dataset analyzed.

Global atmospheric burdens of the three dominant greenhouse gases $\left(\mathrm{CO}_{2}, \mathrm{CH}_{4}\right.$, and $\left.\mathrm{N}_{2} \mathrm{O}\right)$ continued their long-term upward trends in 2016. Increases in the global annual mean mole fractions of $\mathrm{CH}_{4}$ and $\mathrm{N}_{2} \mathrm{O}$ from 2015 to 2016 were fairly consistent with decadal trends, but the $3.5 \pm 0.1 \mathrm{ppm}(0.88 \% \pm 0.03 \%)$ rise in global annual mean $\mathrm{CO}_{2}$ from 2015 to 2016 was the largest annual increase ever observed in the 58-year atmospheric measurement record. This strong growth pushed the 2016 global average $\mathrm{CO}_{2}$ mole fraction at Earth's surface above $400 \mathrm{ppm}(402.9 \pm 0.1 \mathrm{ppm})$ for the first time in the modern atmospheric measurement record and in ice core records dating back as far as 800000 years. In mid-2016 the global burden of carbon monoxide (CO) returned to near its long-term average after spiking in mid-2015 due to extreme biomass fires in Indonesia.

The burdens of many ozone-depleting substances continued to decline, lowering their associated radiative forcing and reducing stratospheric halogen loading. Ozone measurements in the upper stratosphere $(\sim 40 \mathrm{~km})$ indicate a $2 \%-4 \%$ decade $^{-1}$ increase since the late 1990s that may signal the start of ozone layer recovery. Water vapor anomalies in the tropical lower stratosphere $(\sim 17 \mathrm{~km})$ decreased from $0.9 \mathrm{ppm}$ in December 2015 to near $-1.0 \mathrm{ppm}$ in November 2016. This $1.9 \mathrm{ppm}$ drop is equal to $40 \%$ of the 13 -year average abundance of tropical lower stratospheric water vapor in November. The atypical evolution of the quasi-biennial oscillation during 2016 was undoubtedly a strong contributor to this abrupt and severe drying of the tropical lower stratosphere. The 2016 global averages of total aerosol optical depth and tropospheric ozone again exceeded the previous year's global averages, continuing their upward trends since 2003 and 2004.

In the Southern Hemisphere, the Antarctic Oscillation remained positive until late 2016, which combined with the fading of the El Niño, led to a retreat of the West Antarctic Peninsula sea ice margin. The North Atlantic Oscillation was on the whole positive in both the 2015/16 and 2016/17 winters. Globally, land surface wind speed showed only an insignificant decrease, maintaining the overall recovery since around 2013 of the multidecadal decline since 1973.

This year an other-worldly topic is included in the single sidebar, discussing what is known about the weather and climate on a different planet, Mars. Sidebar 2.1 explores how the meteorological state of Mars is observed and the information that a satellite reanalysis product gives on this dry and cold world, along with the events of the 2015-17 Martian year.

Time series and anomaly maps for many variables described in this chapter are shown in Plates 1.1 and 2.1, respectively. Many sections refer to online figures that can be found here: http://dx.doi.org/10.1175 /2017BAMSStateoftheClimate.2. 
(a) Surface Temperature

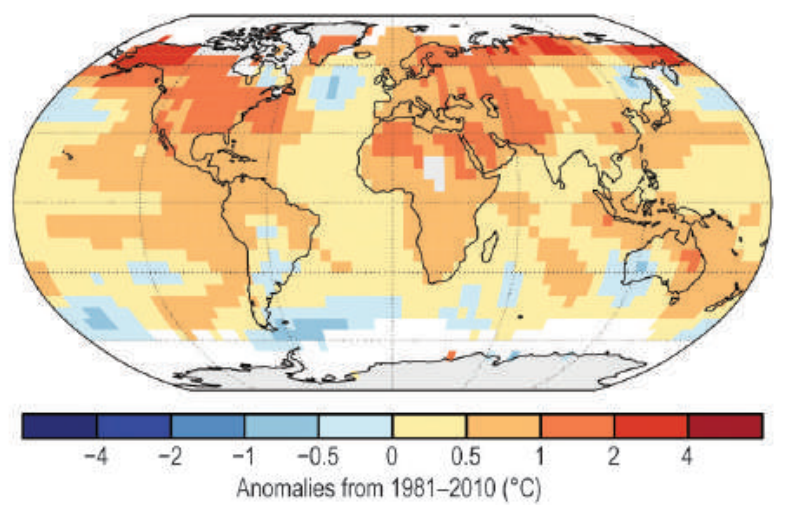

(c) Warm Days

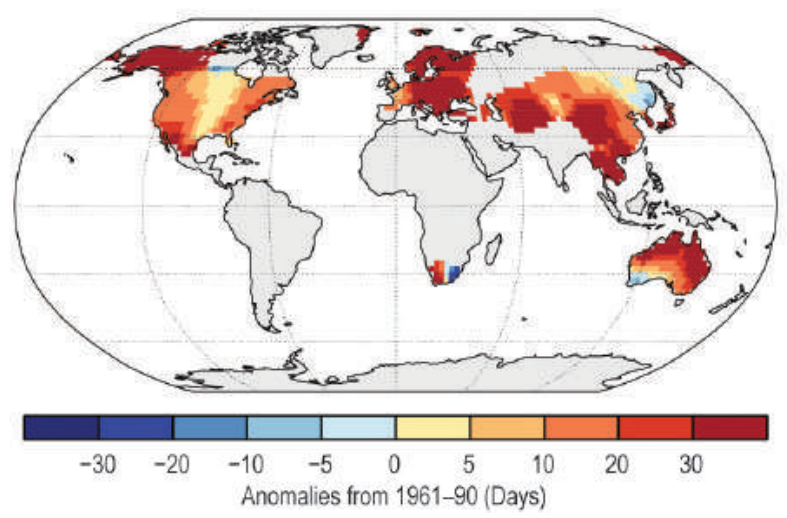

(e) Lower Tropospheric Temperature

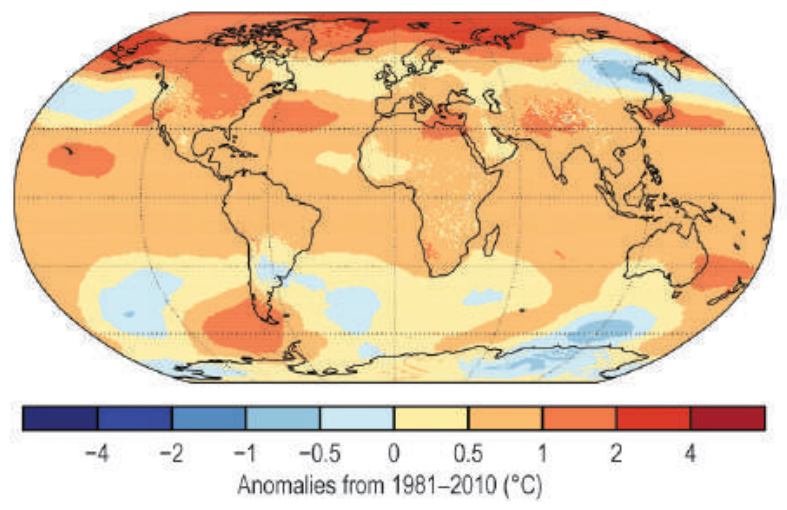

(g) Soil Moisture

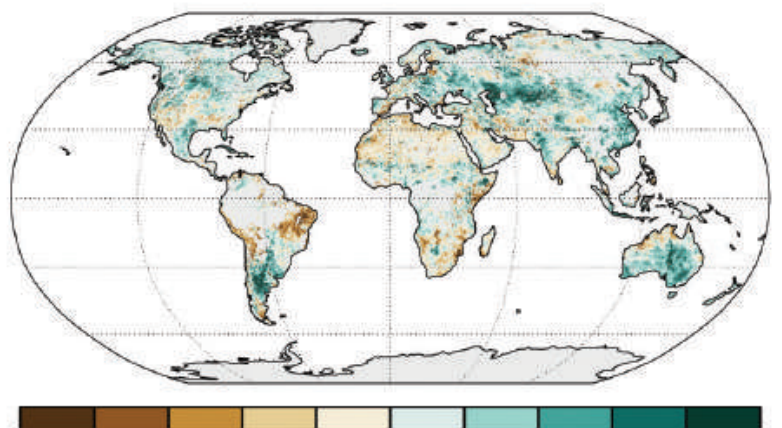

$\begin{array}{lllllllll}-0.04 & -0.03 & -0.02 & -0.01 & 0 & 0.01 & 0.02 & 0.03 & 0.04\end{array}$

Anomalies from $1991-2014\left(\mathrm{~m}^{3} \mathrm{~m}^{-3}\right)$ (b) Lake Temperatures

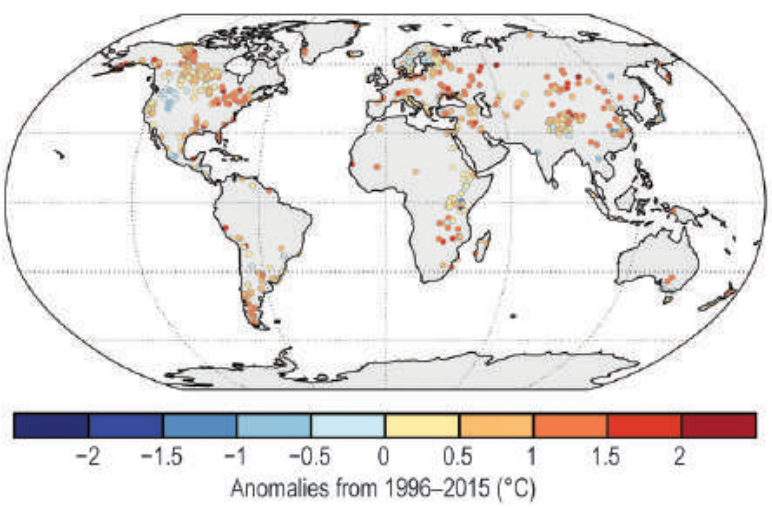

(d) Cool Days

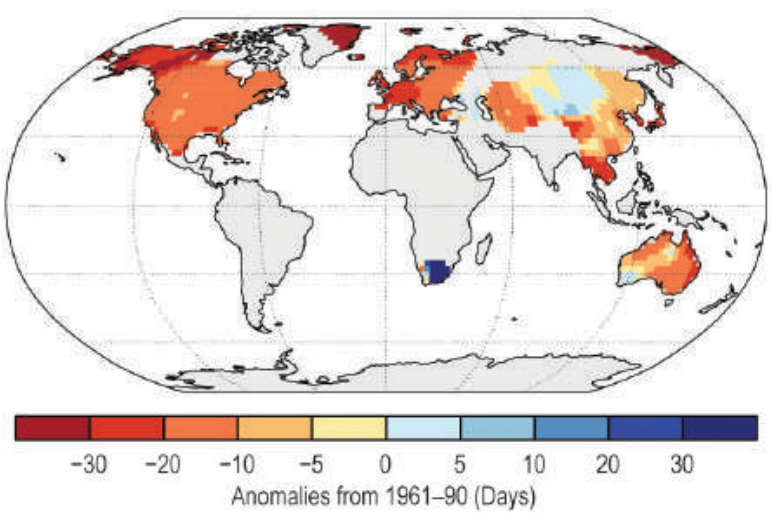

(f) Lower Stratospheric Temperature

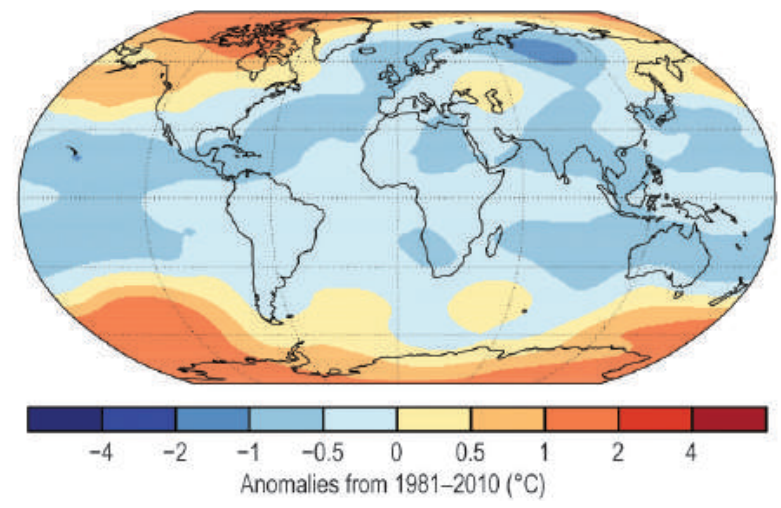

Plate 2.I. (a) NOAA/NCEI surface temperature; (b) Satellite-derived LSWT anomalies in 2016. Annual LSWTs are calculated for the warm season (Jul-Sep in NH; Jan-Mar in SH); (c) GHCNDEX warm day threshold exceedence (TX90p); (d) GHCNDEX cool day threshold exceedence (TXIOp); (e) ERA-Interim lower tropospheric temperature; (f) ERA-Interim lower stratospheric temperature; (g) ESA CCI soil moisture; 
(h) Terrestrial Water Storage

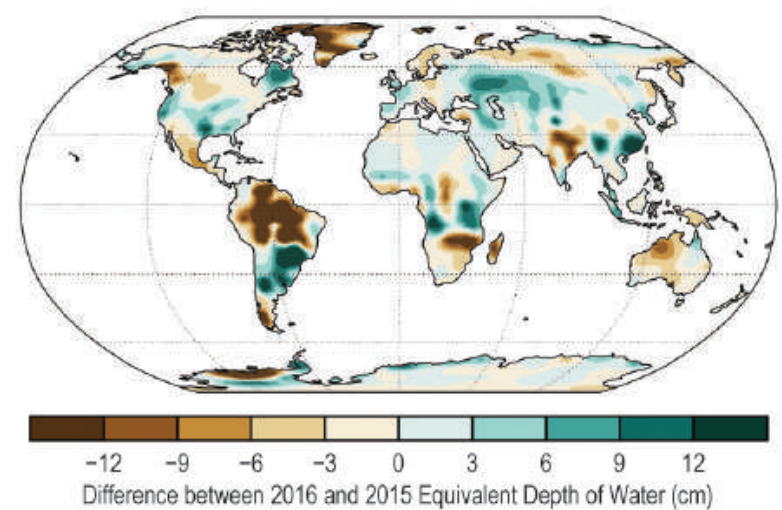

(j) Runoff

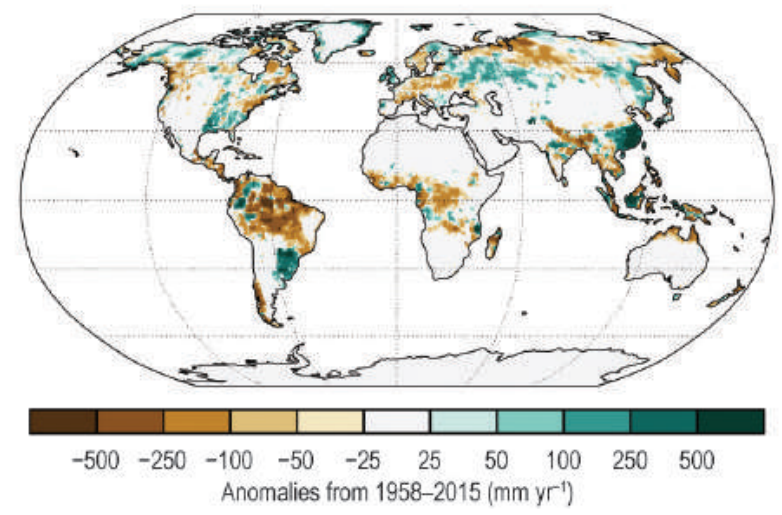

(l) Surface Specific Humidity

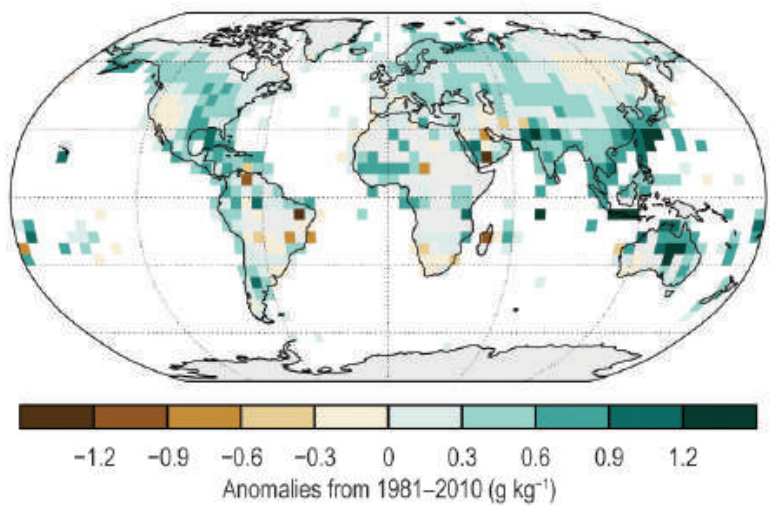

(n) Cloudiness

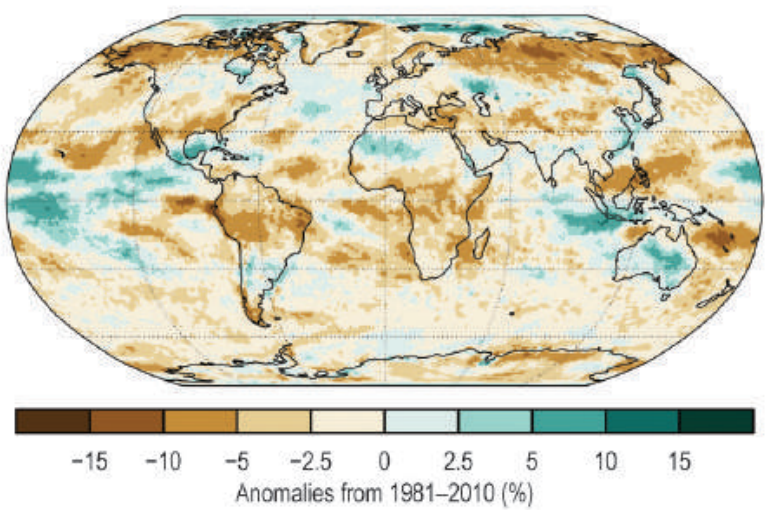

(i) Precipitation

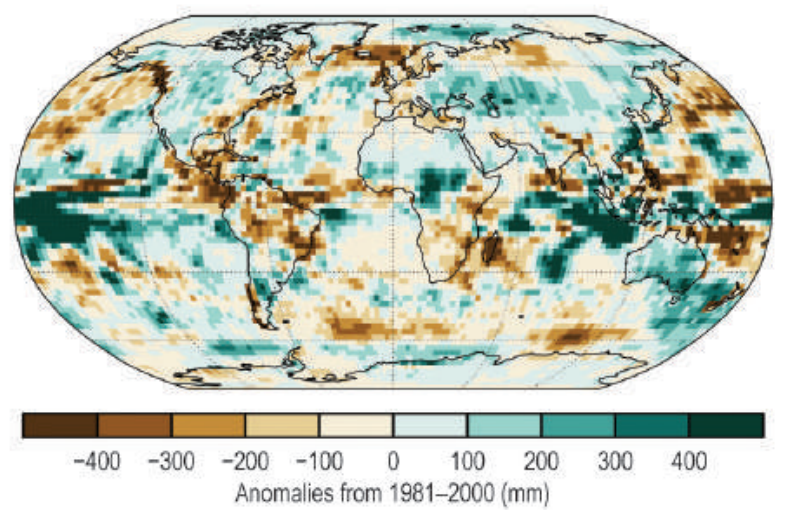

(k) River Discharge

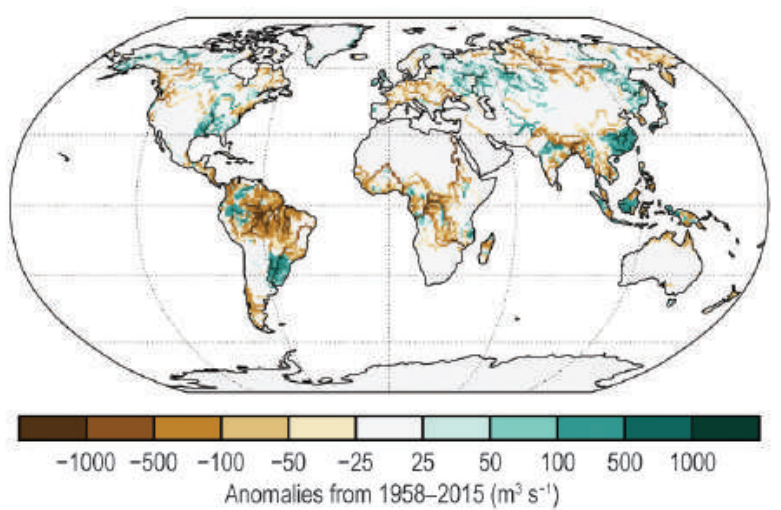

(m) Surface Relative Humidity

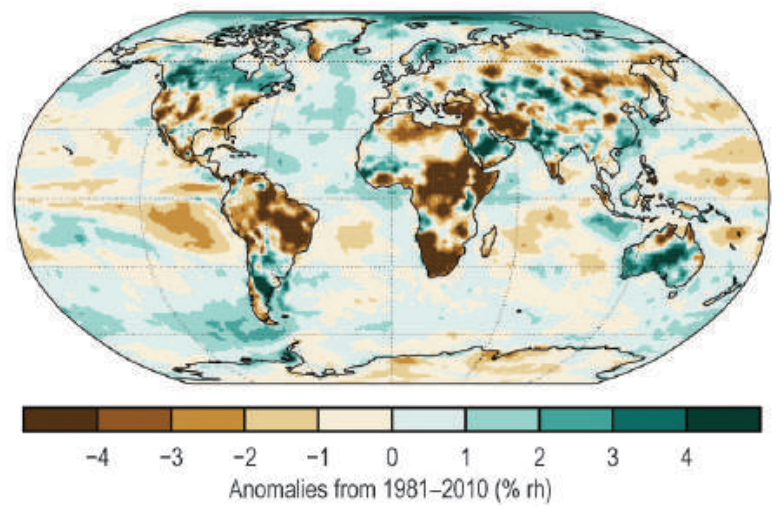

Plate 2.I. (CONT.) (h) GRACE 2016 difference from 2015 water storage; (i) GPCP precipitation; (j) ELSE system runoff; (k) ELSE system river discharge; (I) HadISDH land surface specific humidity; (m) ERA-Interim surface relative humidity; (n) PATMOS-x/AVHRR cloudiness; 
(o) Upper Tropospheric Humidity

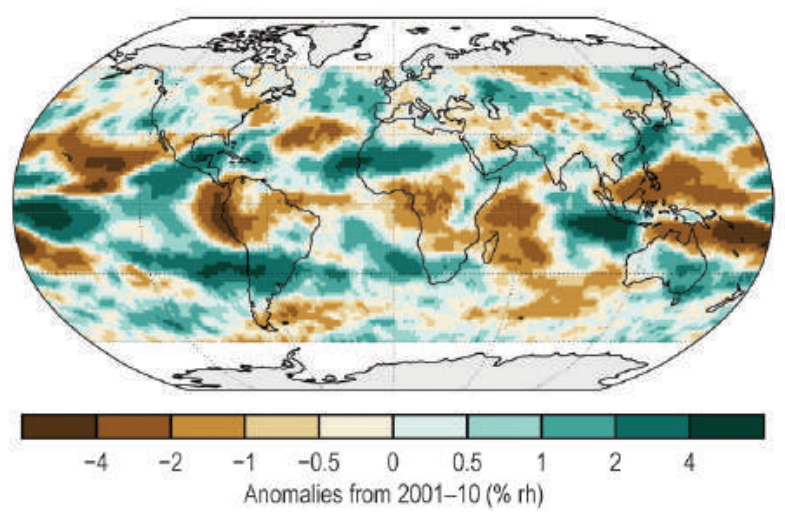

(q) Drought

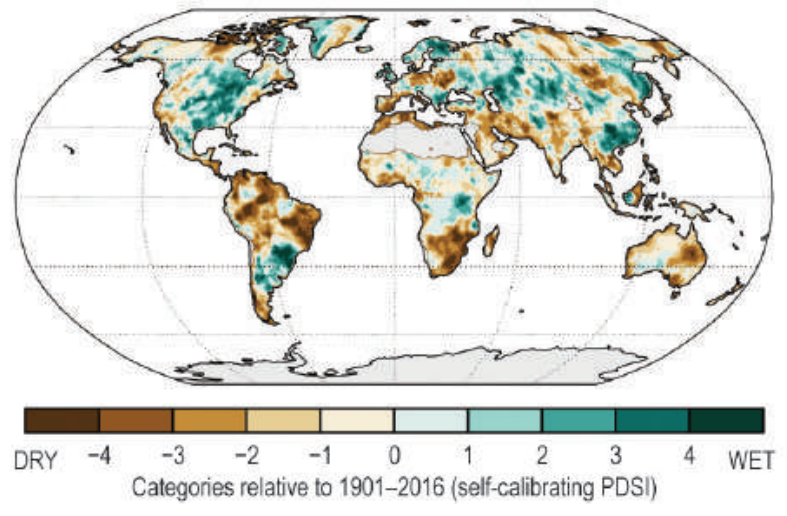

(s) Stratospheric (Total Column) Ozone

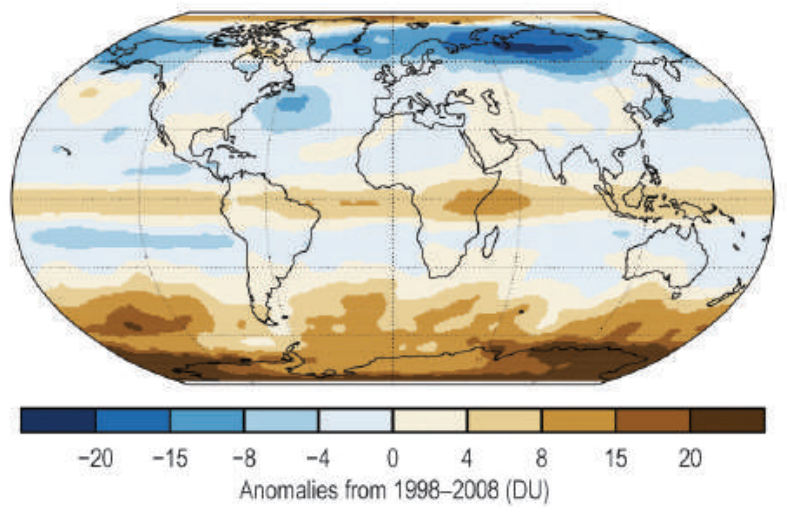

(u) Surface Winds

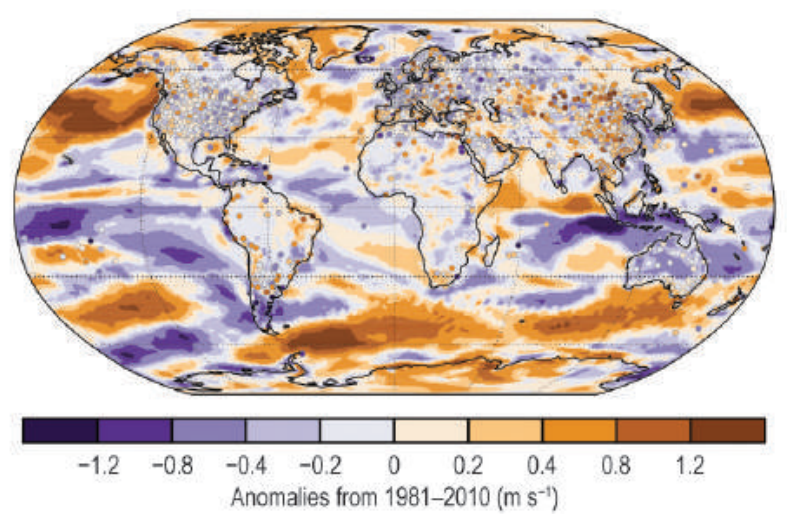

(p) Total Column Water Vapor

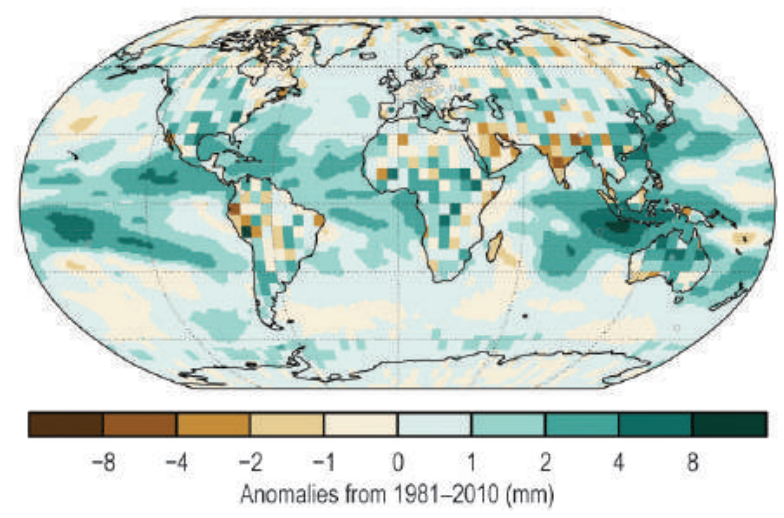

(r) Global Land Evaporation

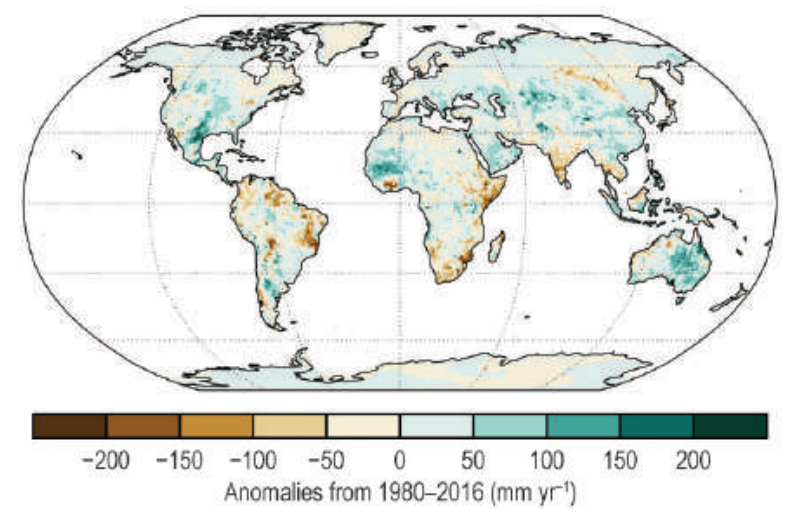

(t) Upper Air (850-hPa) Winds

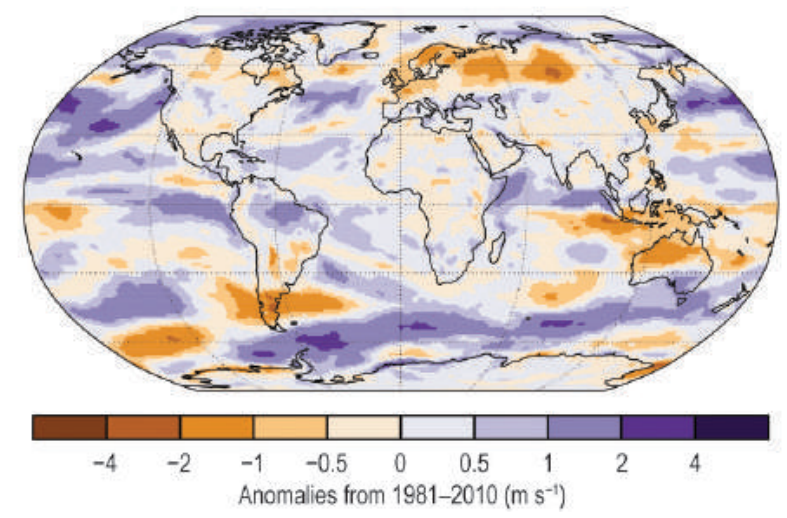

Plate 2.I. (cont.) (o) Microwave radiometer upper tropospheric humidity; (p) Microwave radiometer retrievals (ocean), COSMIC GPS-RO data (land), and GNSS (circles, land) total column water vapor; (q) scPDSI drought annual average 2016 anomaly; (r) GLEAM Land evaporation anomalies for 2016; (s) GOME-2 [using GOME, SCIAMACHY, and GOME-2 (GSG) for the climatology] stratospheric (total column) ozone; (t) ERA-Interim 850-hPa wind speed; (u) MERRA-2 (worldwide grids), HadISD (points, except Australia), CSIRO (points, Australia) surface wind speed; 
(v) Sea Level Pressure

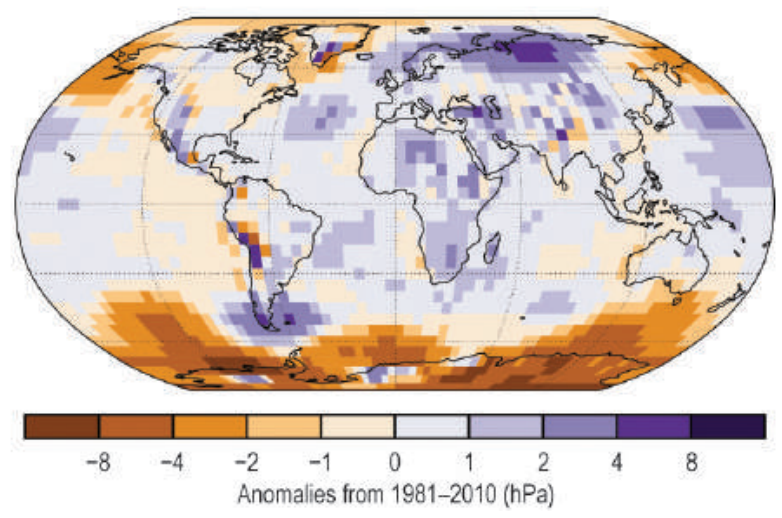

(x) Total Aerosol

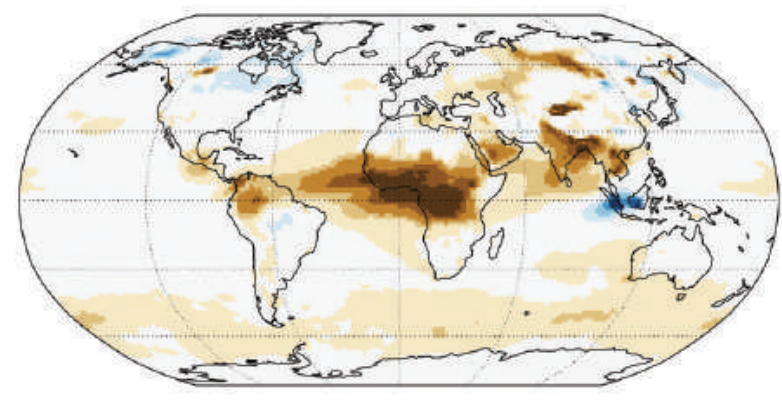

$\begin{array}{llllllllll}-0.14 & -0.1 & -0.06 & -0.04 & -0.02 & 0.02 & 0.04 & 0.06 & 0.1 & 0.14\end{array}$ Anomalies from 2003-14 (AOD)

(z) Biomass Burning Aerosol

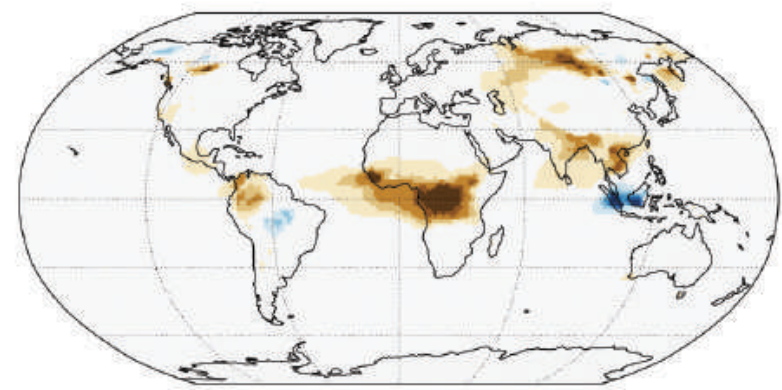

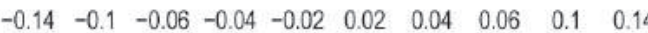
Anomalies from 2003-14 (AOD)

(ab) Land Surface Albedo in the Visible

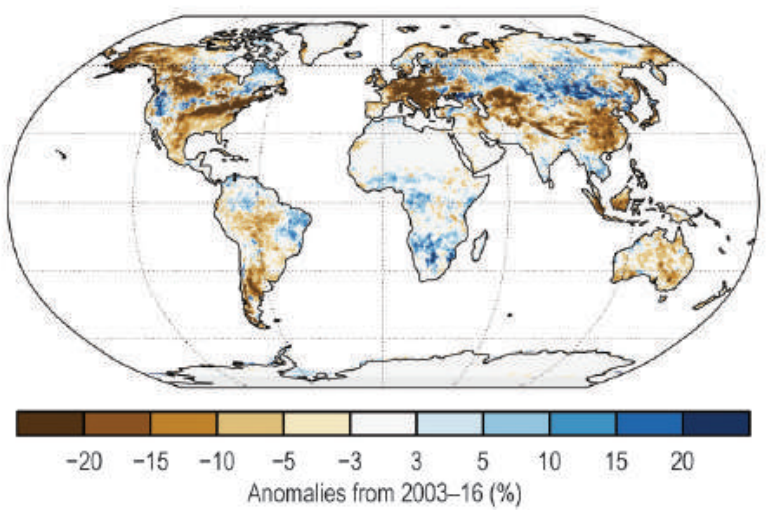

(w) OMI/MLS Tropospheric Column Ozone

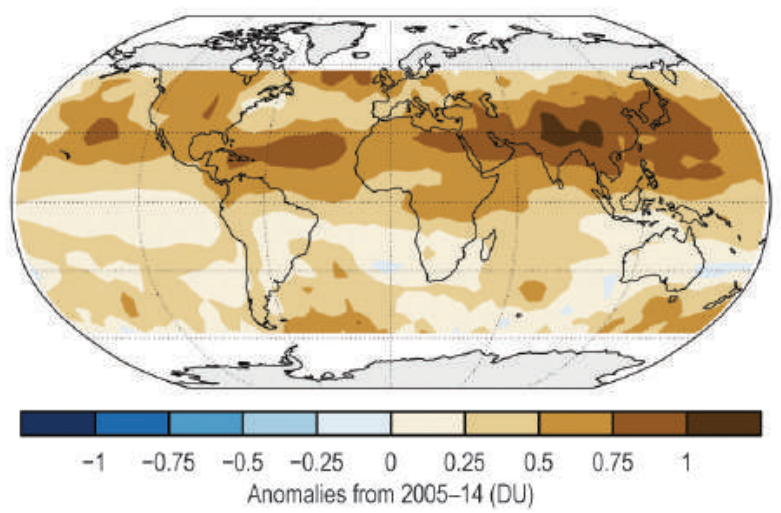

(y) Dust Aerosol

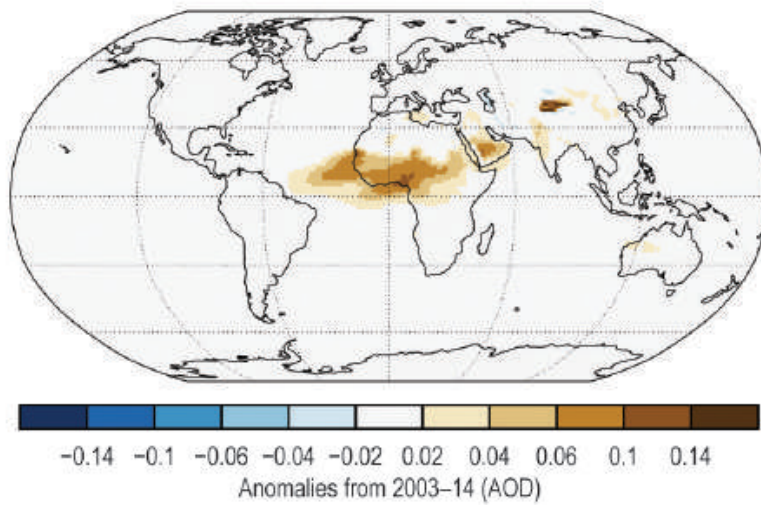

(aa) Fraction of Absorbed Photosynthetically Active Radiation

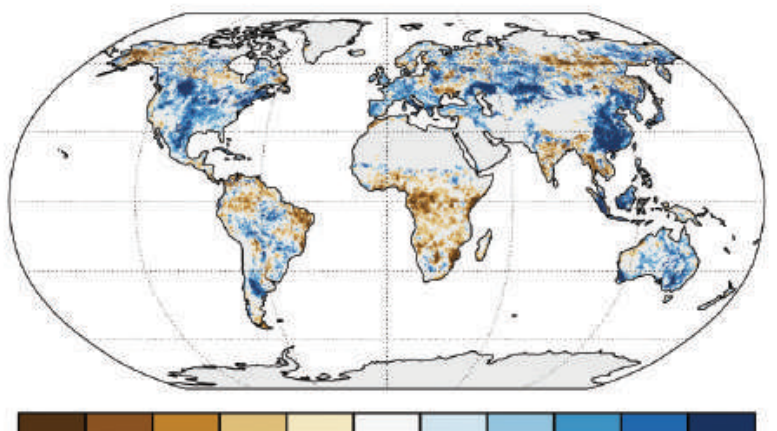

$\begin{array}{llllllllll}-0.04 & -0.03 & -0.02 & -0.01 & -0.005 & 0.005 & 0.01 & 0.02 & 0.03 & 0.04\end{array}$ Anomalies from 1998-2016 (FAPAR)

Plate 2.I. (CONT.) (v) HadSLP2r sea level pressure; (w) Tropospheric ozone; (x) CAMS total aerosol optical depth; (y) CAMS aerosol optical depth from dust; (z) CAMS aerosol optical depth from biomass burning; (aa) SeaWiFS/MERIS/MODIS fraction of absorbed photosynthetically active radiation (FAPAR); (ab) Surface visible albedo from MODIS white sky broadband; 
(ac) Land Surface Albedo in the Near-Infrared

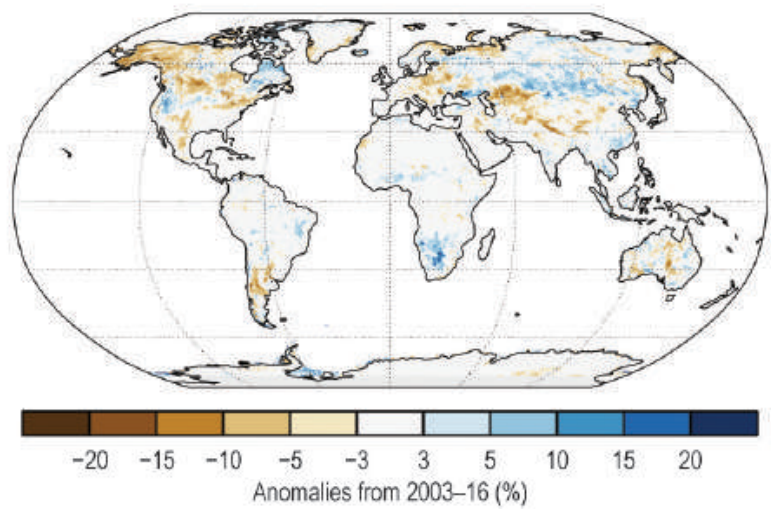

(ae) Carbon Monoxide

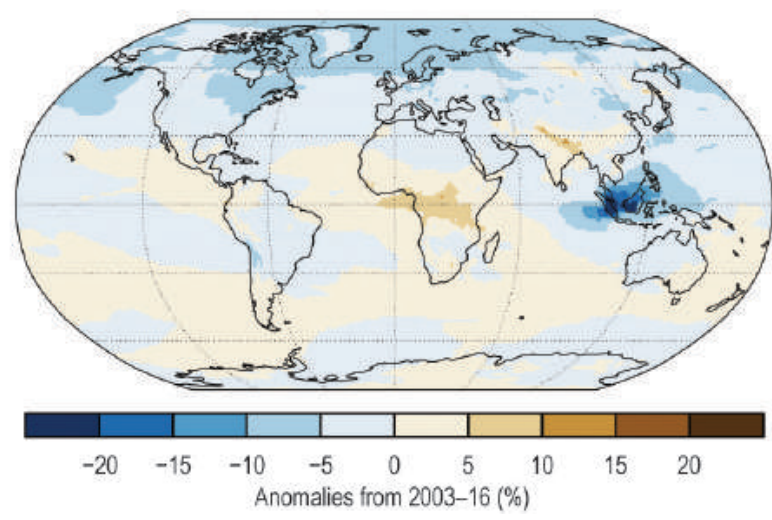

(ad) Carbon Emissions from Biomass Burning

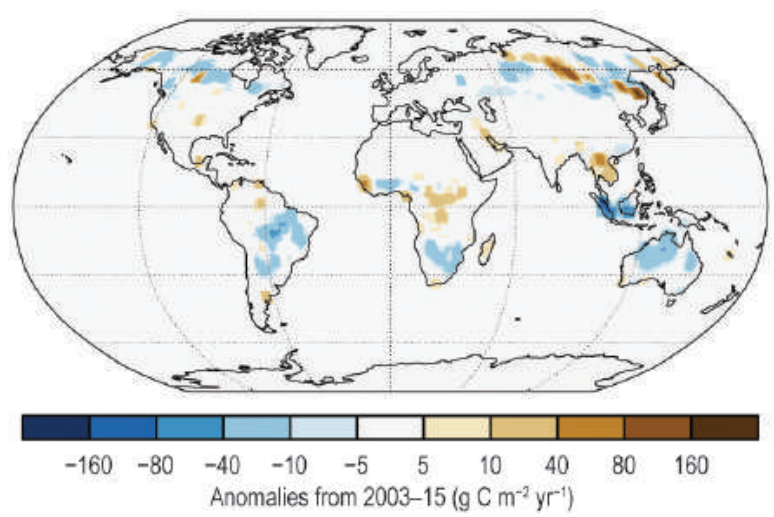

Plate 2. I. (cont.) (ac) Surface near-infrared albedo from MODIS white sky broadband; (ad) GFASvI.3 carbonaceous emissions from biomass burning; (ae) CAMS total column CO anomalies. 


\section{b. Temperature}

I) Global surface temperatures-A. Sánchez-Lugo, C. Morice, P. Berrisford, and A. Argüez

For the third consecutive year, a new global surface temperature record was set. The 2016 global land and ocean surface temperature was $0.45^{\circ}-0.56^{\circ} \mathrm{C}$ (Table 2.1) above the 1981-2010 average. This surpasses the previous record set in 2015 by $0.01^{\circ}-0.12^{\circ} \mathrm{C}$ and the now third warmest year (2014) by $0.18^{\circ}-0.25^{\circ} \mathrm{C}$, according to four global independent in situ analyses (NASA-GISS, Hansen et al. 2010; HadCRUT4, Morice et al. 2012; NOAAGlobalTemp, Smith et al. 2008; JMA, Ishihara 2006). This was also the second consecutive year in which the annual global land and ocean temperature was more than $1^{\circ} \mathrm{C}$ above the mid-to-late nineteenth century average (a period in which temperatures are commonly taken to be representative of pre-industrial conditions) at $1.06^{\circ}-1.21^{\circ} \mathrm{C}$ above average.

The global surface temperature analyses assessed here are derived from air temperatures observed at weather stations over land and sea surface temperatures (SST) observed from ships and buoys. While each analysis differs in methodology, leading to minor differences in temperature anomalies, all four analyses are in close agreement (Fig. 2.1). Differences between analyses are mainly due to how each methodology treats areas with little to no data and how each analysis accounts for changes in measurement methods [for more details see Kennedy et al. (2010); Hansen et al. (2010); and Huang et al. (2015)]. Conditions in higher latitudes are typically a major factor contributing to differences in the global average temperature estimates, with analyses that reconstruct anomalies in sparsely observed regions indicating either warmer or cooler anomalies than those analyses that do not. The ranges of temperature anomalies provided in this summary are ranges of best estimates for the assessed in situ analyses. These ranges do not include additional uncertainty information from each in situ analysis, which can be found in Table 2.1.

The presence of a mature strong warm phase El Niño at the start of 2016 combined with the ongoing long-term warming trend of the global climate system resulted in the highest global temperature departure from average since records began in mid-to late 1800s. Fifteen of the 16 warmest years on record have occurred since the beginning of the 21st century, with 1998 the only year from the 20th century among the top 16 years. The average rate of increase in the annual global surface temperature since 1901 is $0.78^{\circ}-0.90^{\circ} \mathrm{C}$ century ${ }^{-1}$. However, the rate of increase is nearly twice as great in the period since 1980

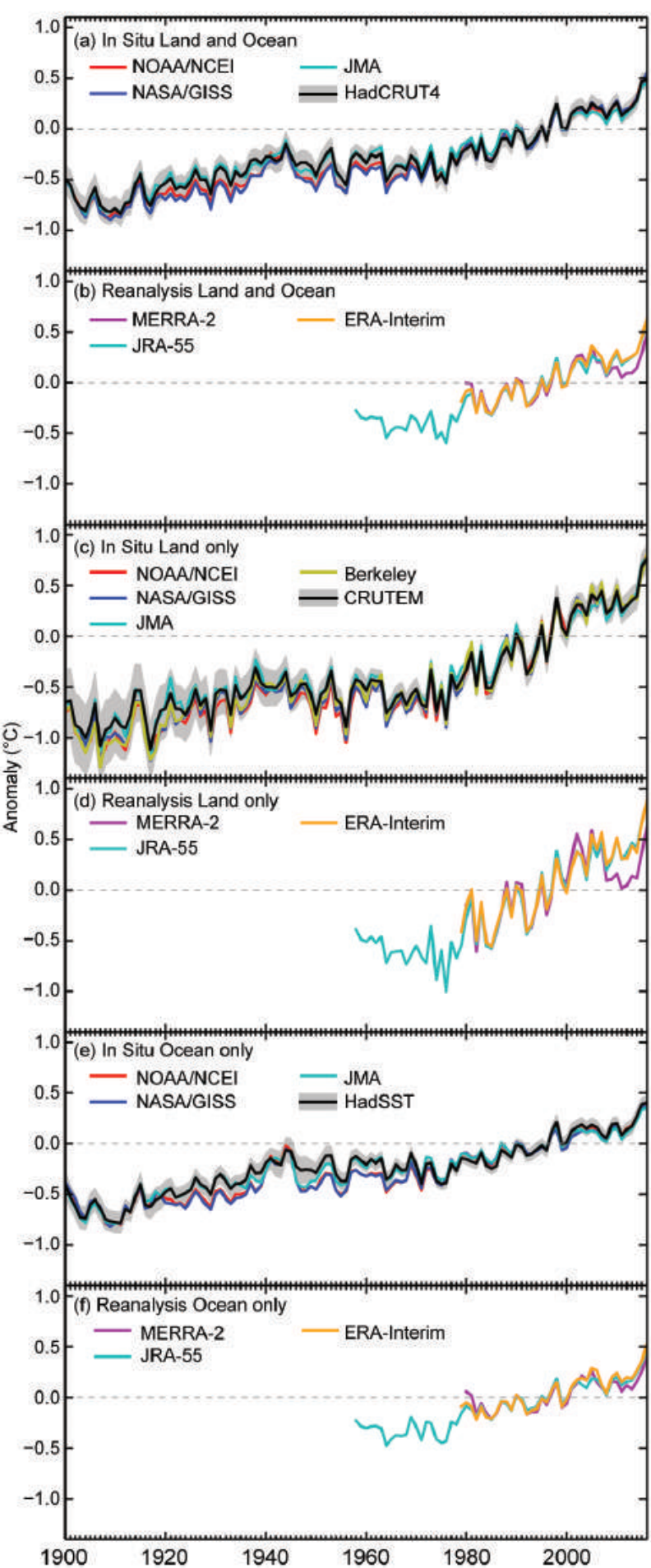

Fig. 2.I. Global average surface air temperature anomalies ( ${ }^{\circ} \mathrm{C} ; 198 \mathrm{I}-2010$ base period). In situ estimates are shown from NOAA/NCEI (Smith et al. 2008), NASA-GISS (Hansen et al. 2010), HadCRUT4 (Morice et al. 20I2), CRUTEM4 (Jones et al. 20I2), HadSST3 (Kennedy et al. 20 I la,b), JMA (Isihara 2006), and Berkeley Earth (Rohde et al. 2013). Reanalyses estimates are shown from ERA-Interim (Dee et al. 20II), MERRA-2 (Bosilovich et al. 2015; Gelaro et al. 2017) and JRA-55 (Ebita et al. 20II; Kobayashi et al. 2015). 
TABLE 2.I. Temperature anomalies $\left({ }^{\circ} \mathrm{C}\right)$ and uncertainties (where available) for 2016 w.r.t. the $1981-$ 2010 base period. Temperature anomalies provided in the table are the central values of a range of possible estimates. Uncertainty ranges are represented in terms of a $95 \%$ confidence interval. For ERA-Interim, the values shown are the adjusted 2-m temperature anomalies. Note that the land values computed for HadCRUT4 used the CRUTEM.4.5.0.0 dataset (Jones et al. 20I2), the ocean values were computed using the HadSST.3.I.I.0 data set (Kennedy et al. 20 I la,b), and the global land and ocean values used the HadCRUT4.5.0.0 data set.

\begin{tabular}{|c|c|c|c|c|c|c|}
\hline Global & NASA-GISS & HadCRUT4 & $\begin{array}{c}\text { NOAA- } \\
\text { Global Temp }\end{array}$ & JMA & Berkeley & ERA-Int \\
\hline Land & +0.81 & $+0.77 \pm 0.13$ & $+0.81 \pm 0.15$ & +0.80 & +0.82 & +0.86 \\
\hline Ocean & +0.37 & $+0.41 \pm 0.07$ & $+0.39 \pm 0.16$ & +0.36 & - & +0.53 \\
\hline Land and Ocean & $+0.56 \pm 0.05$ & $+0.48 \pm 0.08$ & $+0.50 \pm 0.15$ & +0.45 & - & +0.62 \\
\hline
\end{tabular}

$\left(1.3^{\circ}-1.7^{\circ} \mathrm{C}\right.$ century $\left.{ }^{-1}\right)$. From 1891 to 1980 a new temperature record was set on average every $8-11$ years, depending on the assessed in situ dataset. Since 1981, a new temperature record has been set every three to four years on average. However, having three consecutive years $(2014,2015$, and 2016) set a new global surface temperature record is unusual. The question is, how unusual is it?

To estimate the probability of the most recent three years consecutively setting records, a large number (10000) of plausible time series of globally averaged temperatures was generated by Monte Carlo simulation, whereby scenarios are created that exhibit similar statistical properties to the observed record. The probability is calculated as the percentage of the scenarios that show the last three years each setting a warm record. In accordance with Argüez et al. (2013), only the years since 1975 are simulated, as there is virtual certainty that all earlier years in the assessed in situ datasets were cooler than the most recent warm years. Statistical modeling suggests that randomized simulations of natural variability since 1975 is appropriate, and these random scenarios are superimposed on the trend since 1975. This approach results in a probability of $0.8 \%-1.5 \%$. While the warming trend over the last few decades makes such a feat substantially more likely than if the global surface temperature were stationary, it is still quite remarkable for the most recent three years to set consecutive records.

Spatially, the year 2016 was characterized by muchwarmer-than-average conditions across much of the world's surface, with the most notable warm anomalies across parts of the higher northern latitudes (Plate 2.1a; Online Figs. S2.1-S2.3). The only land areas with temperatures below their 1981-2010 averages were parts of eastern Canada, southern South America, western Australia, and parts of Antarctica and eastern Asia. Several locations across the south- ern oceans and the northwestern Pacific Ocean had below-average temperatures, along with persistent cooler-than-average conditions across the northern Atlantic Ocean south of Greenland.

Across the land areas, the globally averaged annual temperature was $0.77^{\circ}-0.82^{\circ} \mathrm{C}$ above the $1981-2010$ average. All six assessed datasets [including Berkeley Earth (Rohde et al. 2013)] rank the 2016 global land-only surface temperature as the highest on record, surpassing the previous record of 2015 by $0.08^{\circ}-0.21^{\circ} \mathrm{C}$. The globally averaged annual temperature over the ocean was the highest on record at $0.36^{\circ}-0.41^{\circ} \mathrm{C}$ above the $1981-2010$ average, surpassing the previous record set in 2015 by $0.01^{\circ}-0.03^{\circ} \mathrm{C}$ (see Chapter $3 \mathrm{~b}$ for a more detailed analysis). The ocean's temperature departure from average tends to be smaller than the land's temperature departure because it requires a larger amount of energy to raise the ocean's temperatures; subsequently the ocean heats up at a slower rate.

Global average surface air temperatures are also estimated using reanalyses, which blend information from a numerical weather prediction model with observations. Reanalysis produces datasets with uniform spatial and temporal coverage of the whole globe. According to ERA-Interim (Dee et al. 2011), the 2016 globally averaged, adjusted (see Simmons et al. 2017 and Simmons and Poli 2015 for details) 2-m temperature was the highest since records began in 1979 . The temperature was $0.62^{\circ} \mathrm{C}$ above the $1981-2010$ average (Table 2.1) and $0.19^{\circ}$ and $0.27^{\circ} \mathrm{C}$ above the previous records set in 2015 and 2005, respectively.

ERA-Interim in 2016 also shows warmer-thanaverage conditions over many regions of the world (Online Fig. S2.3), particularly over the higher northern latitudes. According to ERA-Interim, 2016 was the warmest year on record over both land and ocean. The 2-m temperature over land was $0.86^{\circ} \mathrm{C}$ above average $\left(0.21^{\circ}\right.$ and $0.3^{\circ} \mathrm{C}$ above the previous records 
set in 2015 and 2007, respectively) and over the oceans it was $0.53^{\circ} \mathrm{C}$ above average $\left(0.18^{\circ}\right.$ and $0.25^{\circ} \mathrm{C}$ above the previous records set in 2015 and 2005).

2) LAKE SURface temperature-R. I. Woolway, L. Carrea, C. J. Merchant, M. T. Dokulil, E. de Eyto, C. L. DeGasperi, J. Korhonen, W. Marszelewski, L. May, A. M. Paterson, A. Rimmer, J. A. Rusak, S. G. Schladow, M. Schmid, S. V. Shimaraeva, E. Silow, M. A. Timofeev, P. Verburg, S. Watanabe, and G. A. Weyhenmeyer

Observed lake surface water temperature (LSWT) thermal anomalies in 2016 are placed in the context of the recent warming observed in global surface air temperature (Section 2bl) by collating long-term in situ LSWT observations from some of the world's best-studied lakes and a satellite-derived global LSWT dataset. The period 1996-2015, 20 years for which satellite-derived LSWTs are available, is used as the base period for all LSWT anomaly calculations. Warm-season averages (July-September in the Northern Hemisphere and January-March in the Southern Hemisphere) are analyzed to avoid ice cover, in line with previous LSWT analyses (Schneider and Hook 2010; Hook et al. 2012; O'Reilly et al. 2015; Torbick et al. 2016; Woolway et al. 2016).

In situ observations from 48 lakes show an average warm-season LSWT anomaly of $1.0^{\circ} \mathrm{C}$ in 2016 (Fig. 2.2). The LSWT anomaly in Lake Baikal (Russia), the largest (by volume) and deepest of the world's freshwater lakes, was more than $2.3^{\circ} \mathrm{C}$ warmer than average in 2016. Comparable anomalies were observed in the North American Great Lakes, with an average anomaly of $+2^{\circ} \mathrm{C}$ in 2016 . Warming is not restricted to the largest lakes. For example, Harp Lake in Dorset, Ontario (Canada; surface area $\sim 1 \mathrm{~km}^{2}$ ) was $1.1^{\circ} \mathrm{C}$ warmer in 2016 , compared to its 20 -year average. High LSWT anomalies were also observed in central Europe, with LSWT anomalies $>+0.5^{\circ} \mathrm{C}$, and in Scandinavia, with the second largest lake in Sweden, Lake Vättern, having a LSWT anomaly of $+1.3^{\circ} \mathrm{C}$. Higher-than-average LSWTs were also evident in the Southern Hemisphere, with Lakes Rotorua and Taupo (New Zealand) showing an average LSWT anomaly exceeding $+1^{\circ} \mathrm{C}$, and the smaller lakes in the Bay of Plenty region (New Zealand) experiencing an average anomaly of $+1^{\circ} \mathrm{C}$ in 2016 .

Satellite-derived warm-season LSWTs generated within the Globolakes project (www.globolakes .ac.uk) for 681 lakes are used in this analysis to investigate global variations in LSWT. LSWTs were retrieved during the day using the retrieval methods of MacCallum and Merchant (2012) on image pixels filled with water according to both the inland water

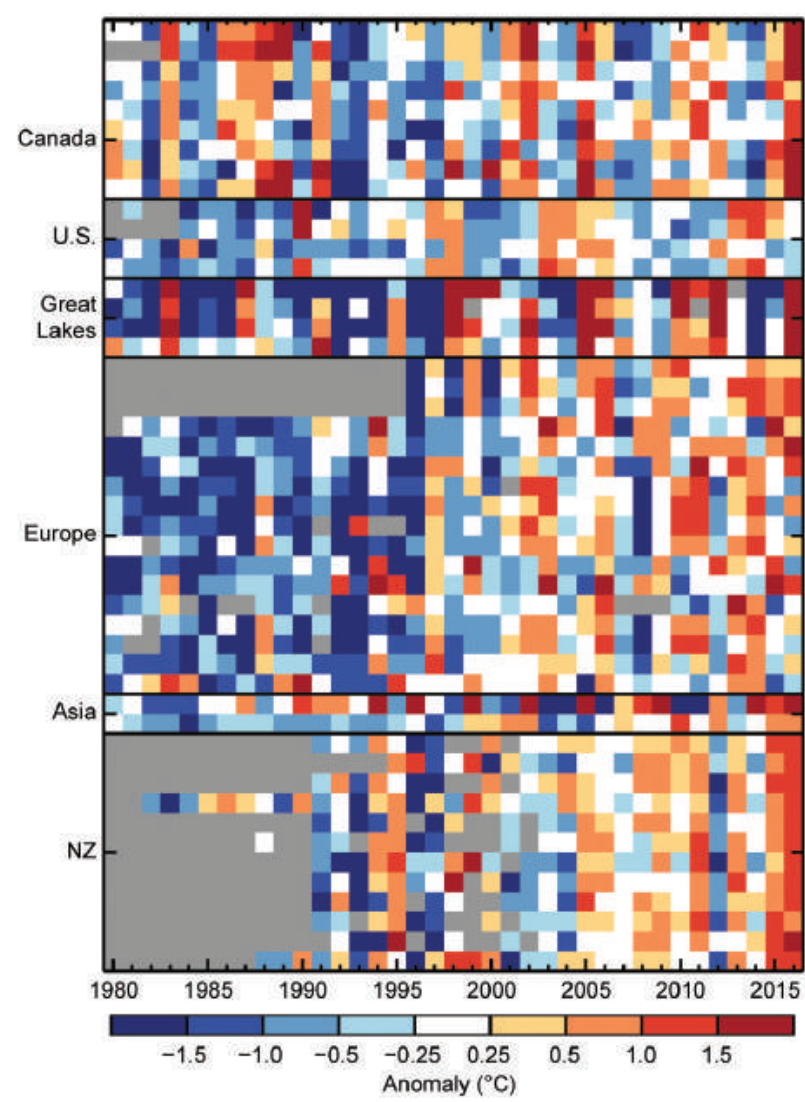

FIG. 2.2. In situ LSWT observations from 48 globally distributed lakes, showing the annually averaged warm season (Jul-Sep in NH; Jan-Mar in $\mathrm{SH}$ ) anomalies $\left({ }^{\circ} \mathrm{C}\right.$; relative to 1996-2015).

dataset of Carrea et al. (2015) and a reflectance-based water detection scheme (Xu 2006). The satellite temperatures represent mid-morning observations throughout the record. The observations were generated using data from the ATSR (Along Track Scanning Radiometer) series including ATSR-2 (19952003) and the Advanced ATSR (AATSR) (2002-12), extended with MetOp-A AVHRR (Advanced Very High Resolution Radiometer) (2007-16).

Globally and regionally averaged warming rates calculated from the satellite data show widespread warming tendencies in recent years (Fig. 2.3), being most evident in the extratropical Northern Hemisphere $\left(>30^{\circ} \mathrm{N}\right)$, with a hemispheric average LSWT trend of $+0.31^{\circ} \mathrm{C}$ decade $^{-1}(p=0.06)$. Warming $\left(+0.21^{\circ} \mathrm{C}\right.$ decade $\left.^{-1}, p=0.07\right)$ is also found for the Southern Hemisphere $\left(<30^{\circ} \mathrm{S}\right)$, but not in the tropics $\left(30^{\circ} \mathrm{N}-30^{\circ} \mathrm{S} ; p=0.4\right)$. Using all available data, and weighting equally the northern, southern, and tropical regions, we obtain a global LSWT trend of $+0.24^{\circ} \mathrm{C}$ decade $^{-1}(p=0.01)$ is obtained. Europe is the region showing the largest and most consistent LSWT warming trend (Fig. 2.3b), inline with previous studies (Hook et al. 2012), with a regional average LSWT 

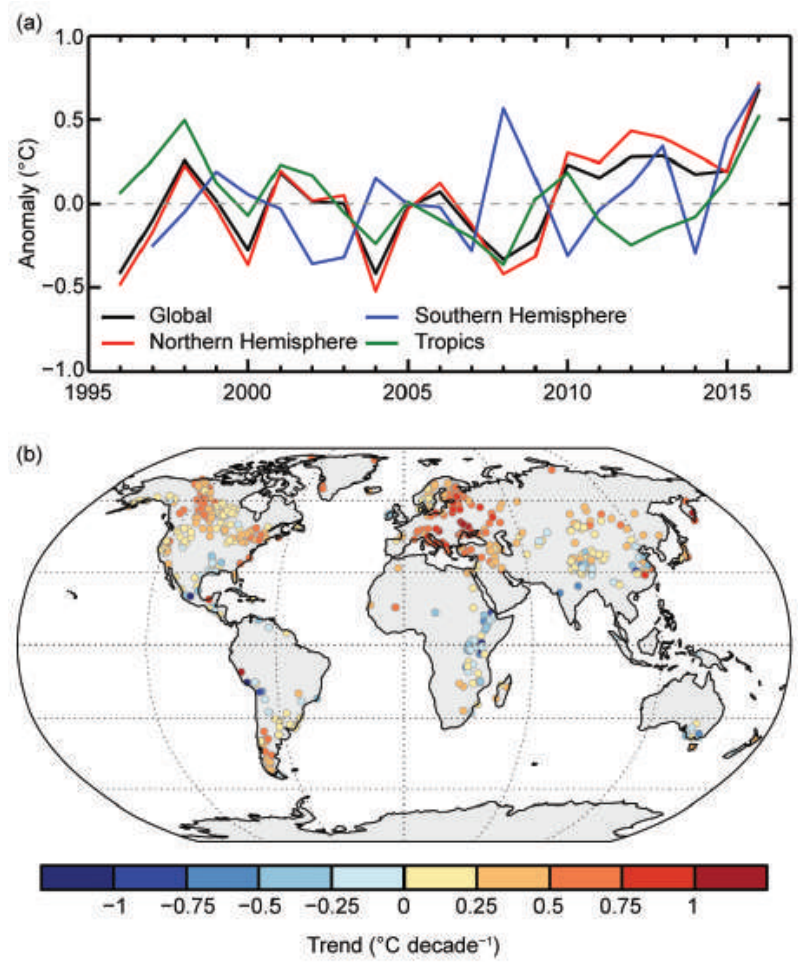

FIG. 2.3. Satellite-derived LSWT measurements from 68I lakes showing (a) global and regional annual average anomalies $\left({ }^{\circ} \mathrm{C}\right.$ ) and (b) 1996-2016 LSWT trend $\left({ }^{\circ} \mathrm{C}\right.$ decade $\left.^{-1}\right)$. Annual LSWTs are calculated for the warm season (Jul-Sep in NH; Jan-Mar in SH) and LSWT trends are calculated on these anomalies.

trend of $+0.55^{\circ} \mathrm{C}$ decade $^{-1}$. Other regions such as northeastern North America $\left(+0.43^{\circ} \mathrm{C}\right.$ decade $\left.^{-1}\right)$ and southern South America (notably those in southern Chile and Argentina; $+0.3^{\circ} \mathrm{C}$ decade $\left.{ }^{-1}\right)$ also experience significant regionally averaged warming.

In 2016, lakes were particularly warm with a global and equally weighted LSWT anomaly of $+0.65^{\circ} \mathrm{C}$. LSWT anomalies in the Northern Hemisphere $\left(+0.72^{\circ} \mathrm{C}\right)$, Southern Hemisphere $\left(+0.70^{\circ} \mathrm{C}\right)$, and the tropics $\left(+0.52^{\circ} \mathrm{C}\right)$ were all anomalously high (Fig. 2.3a; Plate $2.1 b$ ) in 2016 . About $83 \%$ of satellite-observed LSWT anomalies in 2016 were warmer than their 20-year average.

Global in situ and satellite measurements both point to LSWTs in 2016 being anomalously high, the warmest year in the 21-year record, reflecting the observed warming in global surface air temperature. Rising LSWTs have major implications for lake ecosystems (O'Reilly et al. 2003; Smol et al. 2005; Smol and Douglas 2007) and can, among other things, increase the occurrence of toxic cyanobacterial blooms (Kosten et al. 2012) and subsequently threaten water quality (Huisman et al. 2005). Warming of LSWT has been observed since 1996 and was particularly striking in 2016. If this trend continues, local economies dependent on lakes for drinking water, agricultural irrigation, recreation, and tourism are likely to be increasingly affected.

3) LAND surface TeMPerature eXtremes-R. J. H. Dunn, S. E. Perkins-Kirkpatrick, and M. G. Donat

As in the previous year, 2016 set the highest global annual mean temperature on record, and again, it experienced various anomalously high temperature events, especially with respect to minimum temperatures (Plates 2.1c,d). During 2016, Australia and western North America experienced the highest number of warm days and nights (defined below, using the 90th percentiles of the maximum and minimum daily temperatures) in the observational records dating back to 1951. Other than this, only a few regions exhibited record extreme temperatures throughout the year, but the globally averaged temperature for 2016 was the highest on record (see Section 2b1).

As in previous reports, the GHCNDEX dataset (Donat et al. 2013) is used to monitor global temperature extremes. GHCNDEX is a quasi-global gridded dataset of land-based observed temperature and precipitation extremes. A suite of temperature and precipitation extremes indices (Zhang et al. 2011) is first calculated for daily station time series from the GHCN-Daily archive (Menne et al. 2012), before interpolating the indices on global grids. As in previous reports (e.g., Donat et al. 2016), some of the indices fields have limited spatial coverage for 2016, especially those derived from minimum temperatures across central and eastern Asia, compared to those calculated from maximum temperatures.

Results are presented here for a number of the temperature indices in GHCNDEX: TX90p (frequency of warm days, defined as number of days above the seasonal 90th percentile of daily maximum temperatures; all percentiles in GHCNDEX were calculated over the 1961-90 base period), TX10p (frequency of cool days, defined as number of days with maximum temperatures below the seasonal 10th percentile), TN90p and TN10p (analogous definitions using the minimum temperature yielding the frequency of warm nights and cool nights, respectively). Some of the extreme temperature indices showed globally large anomalies during 2016, calculated relative to the 1961-90 average. For example, 2016 had the second largest number of warm days (TX90p; 1.76 times more than the 1961-90 climatology), behind 2015, and the fifth smallest number of cool days (TX10p; only about 0.65 times the climatology; Fig. 2.4) in the GHCNDEX record. The number of warm and cool nights showed record anomalies with 1.96 and 


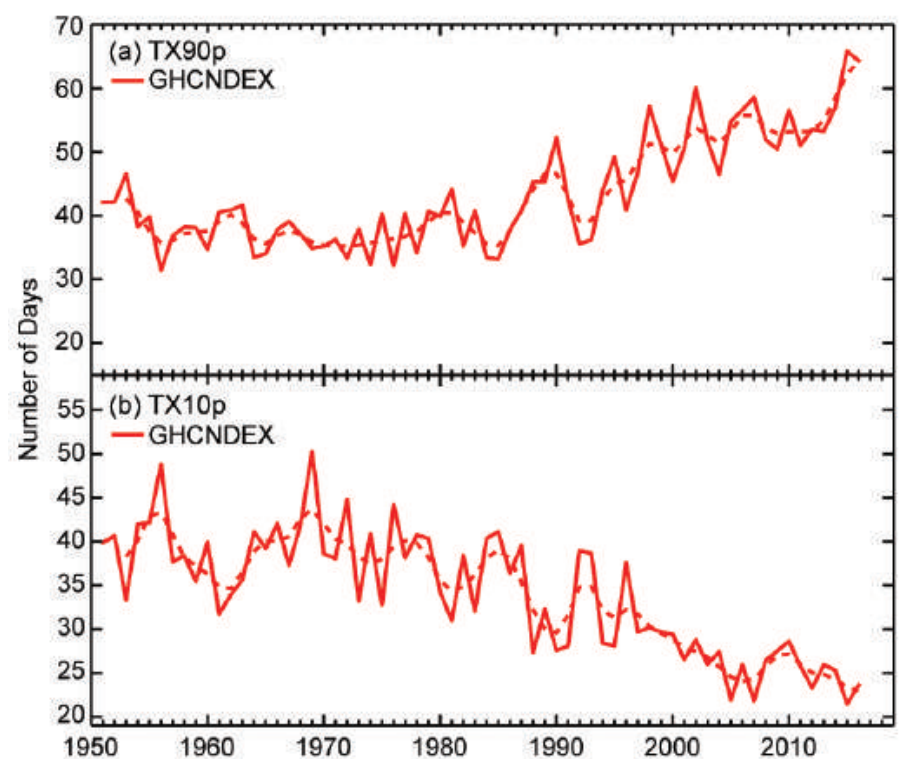

FIG. 2.4. Global average time series of annual local anomalies for (a) TX90p and (b) TXI0p. Units: days.

0.40 times the climatology for TN90p and TN10p, respectively (see Online Fig. S2.5).

Several regions, including western North America, Europe, and large parts of Asia and Australia, experienced warm anomalies in TX90p, TX10p, TN90p, and TX10p in each season of 2016 consistent with above-average temperatures (Online Fig. S2.6). The ERA-Interim reanalysis product (Dee et al. 2011; Online Fig. S2.7) also shows, on an annual basis, warm anomalies in these indices in Africa and large parts of South America, where GHCNDEX lacks coverage, indicating that virtually all land areas have seen warm anomalies in these indices. The seasonal lowest minimum temperatures were the highest on record for all but the Northern Hemisphere summer (JJA). In contrast, a region that showed an excess of cool days and nights was through midlatitude Asia in autumn (SON; Online Fig. S2.6). The indices derived from maximum temperature are consistent with general warm anomalies, but, as in previous years, are more geographically variable, although with predominantly warm anomalies apart from midlatitude Asia in autumn.

The regions that experienced annual records are identified in Fig. 2.5. Record high numbers of warm nights were experienced in Australia, Alaska, and northwestern Canada. These regions also had record numbers of warm days, as did parts of central Asia. There were a number of notable regional anomalously high temperature events during 2016. In North America, Alaska experienced record numbers of warm and cool days (Plates 2.1c,d; Fig. 2.5), while extreme heat contributed to disastrous wildfire conditions in Fort
McMurray in Canada (see Sidebar 7.1 for more details). The contiguous United States experienced extreme heatwaves in June and October, particularly over the Midwest, characterized by high minimum temperatures at the seasonal scale (see JJA and SON TN90p in Online Fig. S2.6). Europe sweltered through heatwaves during August and September, which, combined with a warm winter, contributed to its warm year (see DJF, TX90p and TN90p in Online Fig. S2.6, of which December 2015 has no effect on the 2016 value). During April and May, dry but intense heatwaves set in just before the monsoon, with a new national Indian high temperature record of $51.0^{\circ} \mathrm{C}$ set in Phalodi, Rajasthan. Countries in the Middle East also experienced extreme conditions during July, with temperatures well above $50^{\circ} \mathrm{C}$ recorded in Iran, Iraq, and Kuwait. These regions also experienced large annual exceedances of warm maximum and minimum temperatures (see ERA-Interim TN90p and TX90p in Online Fig. S2.7). South America experienced record warm months in January, February, and April, which contributed to the continent's second warmest year on record (see ERA-Interim TN90p and TX90p in Online Fig. S2.7). Australia experienced its warmest autumn on record where the national average temperature was $1.86^{\circ} \mathrm{C}$ above the seasonal average (TX90p and TN90p in Online Fig. S2.6).
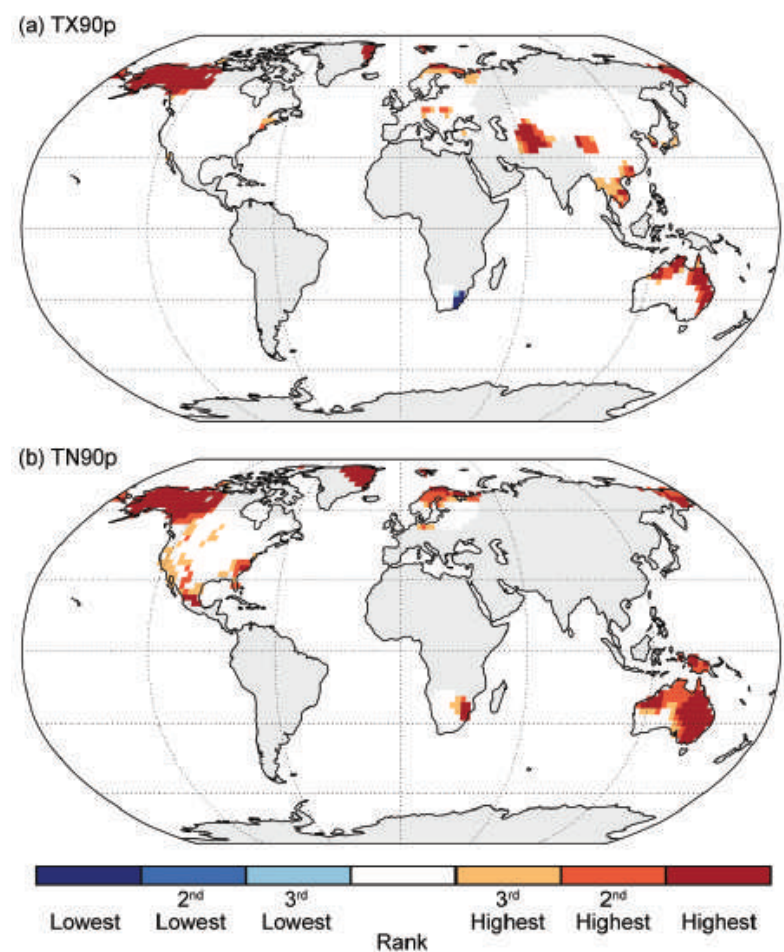

FIG. 2.5. Rank plot over the period 195I-2016 of TX90p and TN90p. 
4) LOWER AND MID-TROPOSPHERIC TEMPERATUREJ. R. Christy

The bulk atmospheric response to the warm phase ENSO of 2015/16 dominated the global and tropical temperature values this year. The 2016 annual globally averaged temperature of the lower troposphere (LT: the bulk atmosphere below $10-\mathrm{km}$ altitude or roughly the lower $70 \%$ by mass) was $0.45^{\circ}$ to $0.75^{\circ} \mathrm{C}$ above the 1981-2010 mean, depending on the dataset. The year 2016 proved to be the warmest of the past 59 years in all datasets, exceeding the previous major warm phase ENSO (1998) by $+0.02^{\circ}$ to $+0.38^{\circ} \mathrm{C}$ (Fig. 2.6). In general, the radiosonde-based datasets displayed greater warming relative to 1998 , likely due to their more limited geographic coverage.

Direct measurements of the LT bulk temperature utilize radiosonde (balloon) datasets beginning in 1958 which are complemented by satellites since late 1978, described in Christy (2016). In addition to radiosonde and satellite estimates, three reanalysis products [ERA-I, MERRA-2, and JRA-55; see Christy

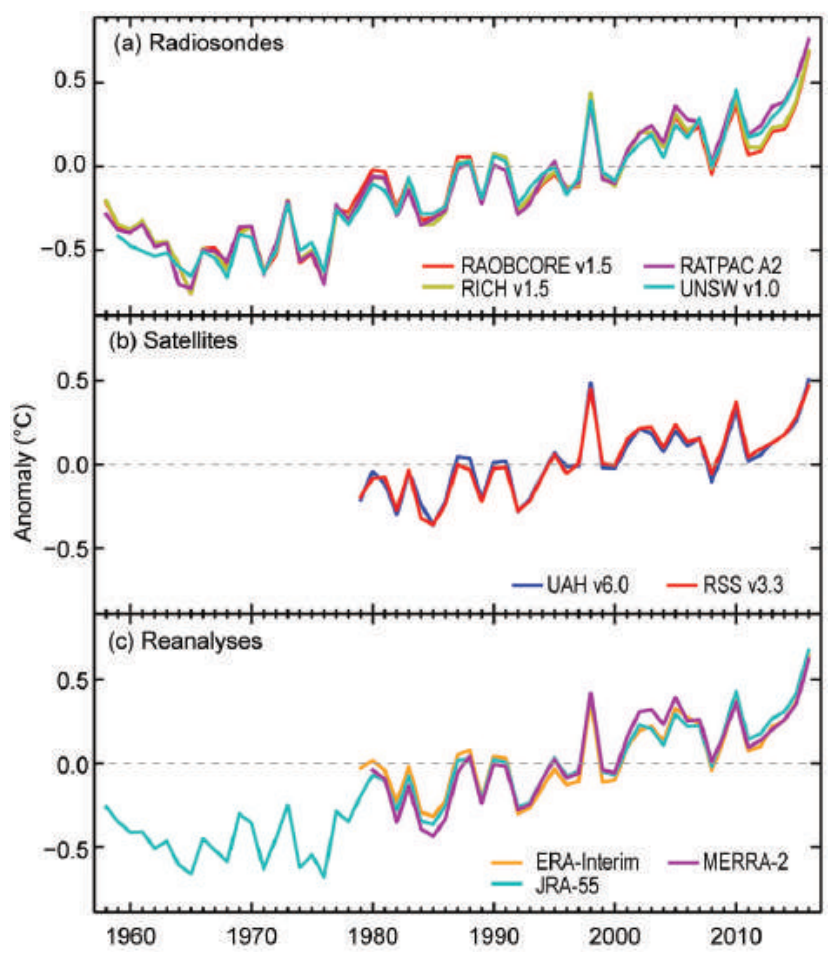

FIG. 2.6. Global average lower tropospheric temperature annual anomalies $\left({ }^{\circ} \mathrm{C}\right.$; $198 \mathrm{I}-2010$ base period for the MSU LT equivalent layer. (a) Radiosonde: RATPAC (Free et al. 2005), RAOBCORE and RICH (Haimberger et al. 20I2) and UNSW (Sherwood and Nishant 2015). (b) Satellites: UAHv6.0 (Spencer et al. 2017) and RSSv3.3 (Mears and Wentz 2009). (c) Reanalyses: ERAInterim (Dee et al. 20II), MERRA-2 (Bosilovich et al. 2015; Gelaro et al. 2017), and JRA-55 (Ebita et al. 20II; Kobayashi et al. 2015).
(2016) for details] are examined with ERA-I used to provide spatial depictions of the temperature anomalies (Plate 2.1e; Fig. 2.7). The peak tropospheric warming in 2016 occurred in February with a rapid decline to June, and from then on was fairly stationary. This lag of a few months of peak warming relative to the surface, which peaked in late 2015, is typical (Christy and McNider 1994).

Regionally, warm anomalies occurred throughout the Arctic (north of $60^{\circ} \mathrm{N}$ ). The midlatitude belts in both hemispheres featured both above- and belowaverage areas. The band from $30^{\circ} \mathrm{N}-30^{\circ} \mathrm{S}$ (half of the global area) was ubiquitously warmer than average (Plate 2.1e). The latitude-time depiction of the LT temperatures beginning in 1979 indicates major responses to the 2016 and prior warm phase ENSOs $(1983,1987,1998,2010$, and 2016) with a protracted ENSO-like period 2002-06 (Fig. 2.7).

The global LT trend based on radiosondes (starting in 1958) is $+0.16 \pm 0.02^{\circ} \mathrm{C}$ decade $^{-1}$ and based on both radiosondes and satellites (starting in 1979) is $+0.16 \pm 0.04^{\circ} \mathrm{C}$ decade $^{-1}$, where the range represents the variation among the datasets and thus serves as an estimate of structural uncertainty in Fig. 2.6. Major volcanic events in 1963, 1982, and 1991 contributed to cooler temperatures at those times that affected the early part of the LT record, especially in the satellite era, thus increasing the upward trend to some extent.

The layer centered on the midtroposphere (MT) is used for tropical atmospheric temperature monitoring and is able to utilize more independently constructed datasets. The top of the effective MT layer reaches higher into the stratosphere than LT, but in the tropics where the tropopause is approximately $16 \mathrm{~km}$ in altitude, there is only a slight influence

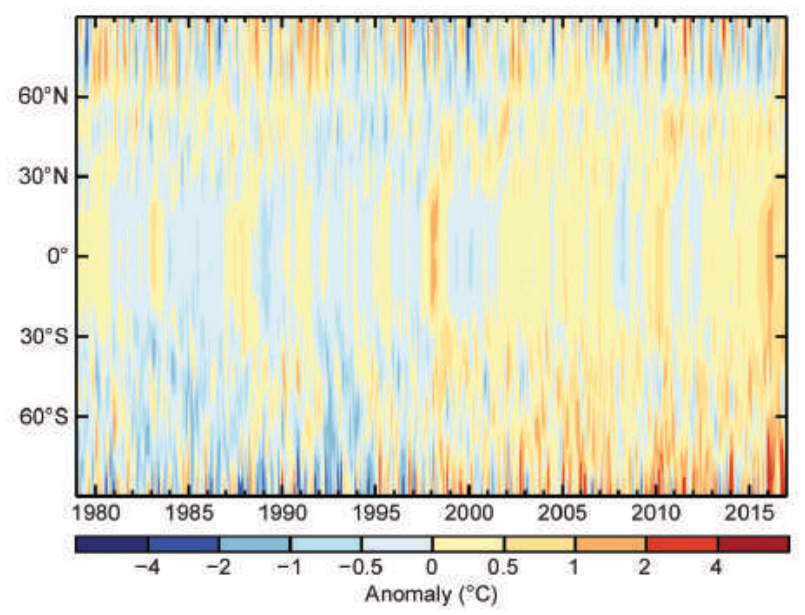

FIG. 2.7. Latitude-time cross-section of lower tropospheric temperature anomalies $\left({ }^{\circ} \mathrm{C}\right)$ relative to I98I-20I0 from ERA-Interim (Dee et al. 20II). 


\begin{tabular}{|c|c|c|c|c|c|c|}
\hline \multirow[b]{2}{*}{ Start Year: } & \multicolumn{2}{|c|}{ Global LT } & \multicolumn{2}{|c|}{ Tropics LT } & \multicolumn{2}{|c|}{ Tropics MT } \\
\hline & 1958 & 1979 & 1958 & 1979 & 1958 & 1979 \\
\hline \multicolumn{7}{|c|}{ Radiosondes } \\
\hline RAOBCORE & +0.15 & +0.14 & +0.16 & +0.14 & +0.14 & +0.10 \\
\hline $\mathrm{RICH}$ & +0.16 & +0.16 & +0.15 & +0.16 & +0.11 & +0.12 \\
\hline RATPAC & +0.17 & +0.20 & +0.15 & +0.15 & +0.10 & +0.09 \\
\hline UNSW & +0.17 & +0.16 & +0.15 & +0.11 & +0.10 & +0.07 \\
\hline \multicolumn{7}{|c|}{ Satellites } \\
\hline UAHv6.0 & - & +0.12 & - & +0.12 & - & +0.08 \\
\hline RSSv3.3 & - & +0.14 & - & +0.13 & - & - \\
\hline RSSv4.0 & - & - & - & - & - & +0.15 \\
\hline NOAAv4.0 & - & - & - & - & - & +0.17 \\
\hline UWvl.o & - & - & - & - & - & +0.13 \\
\hline \multicolumn{7}{|c|}{ Reanalyses } \\
\hline ERA-I & - & +0.14 & - & +0.11 & - & +0.10 \\
\hline JRA-55 & - & +0.16 & - & +0.13 & - & +0.10 \\
\hline MERRA-2 & - & +0.16 & - & +0.14 & - & +0.11 \\
\hline
\end{tabular}

from the stratosphere on MT. Satellite monitoring of this layer is most sensitive to the mid- to upper troposphere, which in the tropics is the layer that typically responds most strongly to thermal forcing of any kind, for example, ENSO, enhanced greenhouse gases, etc. [See Christy (2016) for more details.]

Examining the various datasets of tropical MT trends (1979-2015 in Online Fig. S2.9), it is noted that the 2016 spike in tropical temperature due to the warm phase ENSO has increased trend values relative to those presented last year. Radiosonde values cluster closely around $+0.11^{\circ} \mathrm{C}$ decade $^{-1}$ while satellite results vary considerably from $+0.08^{\circ}$ (UAH) to $+0.17^{\circ} \mathrm{C}$ (NOAA) decade ${ }^{-1}$. The notable difference between $\mathrm{UAH}$ and the other satellite datasets is most evident over the lower latitude oceans (Online Fig. S2.9). This suggests the discrepancy is not due to corrections for diurnal (east-west) drift of the spacecraft, because these are negligible over the oceans, but to differing assumptions regarding basic calibration issues, primarily between 1990 and 2005. Understanding this discrepancy is an active area of research.

Tropical temperature trends are displayed in online Fig. S2.10 to demonstrate their vertical structure, as well as the MT bulk layer values at the top and in Table 2.2. Included are trends from the output of 102 CMIP-5 RCP4.5 model simulations (Flato et al. 2013), demonstrating the theoretical expectation of basic lapse-rate theory in which trends are magnified with altitude into the upper troposphere (National Research Council 2003; Christy 2014). The results (Online Fig. S2.10; Table 2.2) through 2016 continue to show that the observed MT trends tend to be below estimates anticipated from theory. The tropical surface trend (from NOAA/NCEI) is $+0.13^{\circ} \mathrm{C}$ decade $^{-1}$. The median MT trend of all datasets examined here, including reanalyses, is $+0.11^{\circ} \mathrm{C}$ decade $^{-1}$, less than that predicted by lapse-rate theory which indicates MT's trend would be a factor of about 1.4 greater than the surface, or $+0.19^{\circ} \mathrm{C}$ decade ${ }^{-1}$. The CMIP-5 Model mean surface trend is $+0.19^{\circ} \mathrm{C}$ decade $^{-1}$ and the mean MT trend is $+0.27^{\circ} \mathrm{C}$ decade $^{-1}$, in agreement with lapse-rate theory.

5) LOWER Stratospheric temperature-C. Long and J. Christy

Radiosonde data, satellite data, and reanalyses agree that the global annual average temperature of the lower stratosphere layer (TLS) in 2016 was cooler than the previous three years (Fig. 2.8). This behavior is linked to lower stratospheric cooling associated with the strong El Niño and to the unusually persistent westerly phase of the quasi-biennial oscillation (QBO) winds in the tropics from 2015 through 2016 (Newman et al. 2016; Section 2e3). Enhanced upwelling and cooling in the tropical lower stratosphere 


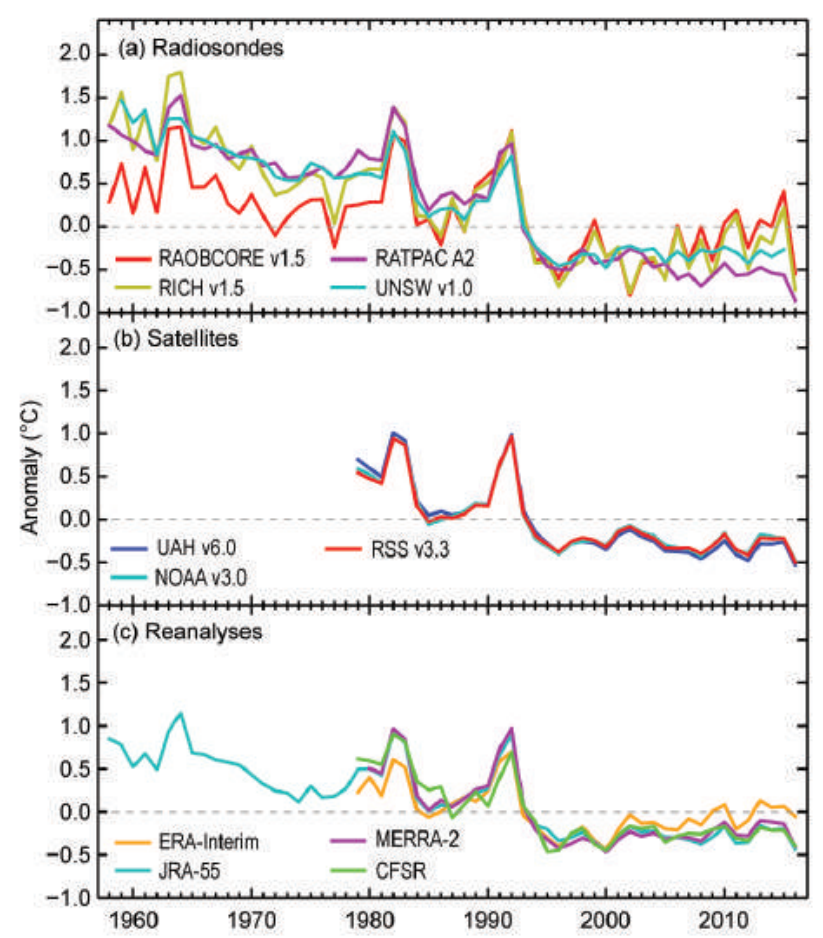

FIg. 2.8. Annual global TLS weighted temperature anomalies $\left({ }^{\circ} \mathrm{C}\right)$ from the $198 \mathrm{I}-2010$ climatology for radiosonde (RAOBCORE, RICH, RATPAC, and UNSW), satellite (UAH, RSS, NOAA/STAR), and reanalyses (CFSR, MERRA-2, ERA-I, and JRA-55). All show a cooler 2016 value.

are associated with El Niño conditions (Calvo et al. 2010; Randel et al. 2009). The QBO westerly phase is associated with a cooler middle and lower stratosphere in the tropics. The shear of westerlies over easterlies results in negative temperature anomalies from the thermal wind relationship. The TLS layer (MSU channel 4 and AMSU channel 9) retrieval is most sensitive to the lower stratosphere but with some influence from the upper troposphere as well as the middle and upper stratosphere. Positive temperature anomalies throughout the troposphere associated with the strong El Niño added complexity to this layer's temperature anomalies. To disentangle the influences of the QBO and ENSO on the TLS retrieval, Figs. 2.9a,b present monthly global temperature anomalies since 1980 at individual pressure levels in the upper troposphere and lower stratosphere, respectively, using the MERRA-2 reanalysis. The upper troposphere (400-200 hPa) contributes $20 \%$ and the lower stratosphere $(70-20 \mathrm{hPa})$ contributes $\sim 42 \%$ towards the TLS weighted layer value. The remaining $\sim 38 \%$ comes from the near-tropopause layer (150-100 hPa). Beginning in mid-2015, the lower stratospheric temperature record shows the negative temperature anomalies associated with the stratospheric influences of El Niño and the persistent QBO westerly phase.

Annual mean TLS layer anomalies for 2016 were positive in both polar regions and strongly negative in the tropics (Plate 2.1f; Online Fig. S2.11). The positive $\mathrm{NH}$ polar TLS anomalies are attributed to large positive anomalies in March due to a strong final stratospheric warming and to positive anomalies in November and December. In the $\mathrm{SH}$, positive anomalies are associated with a warmer-than-average polar region during austral winter and spring. These higher temperatures also resulted in a smaller-than-normal ozone hole in 2016 (also see Chapter 6h). In the tropics, negative anomalies started in March and persisted throughout the rest of 2016, due to the temperature signal of the westerly phase of the QBO.

Figure 2.8 shows that the lower stratospheric temperature is highly impacted by the volcanic eruptions of El Chichón (1982) and Mt. Pinatubo (1991) but shows little trend since 1994. Offsetting impacts of increasing ozone (positive temperature anomalies) and increasing $\mathrm{CO}_{2}$ (negative temperature anomalies) in the lower stratosphere may have led to this flat trend (Ferraro et al. 2015; Aquila et al. 2016). The various observation systems differ slightly from each other during this period since 1994. The four radiosonde datasets (RAOBCORE, Haimberger et al. 2012; RICH, Haimberger et al. 2012; RATPAC, Free et al. 2005; and

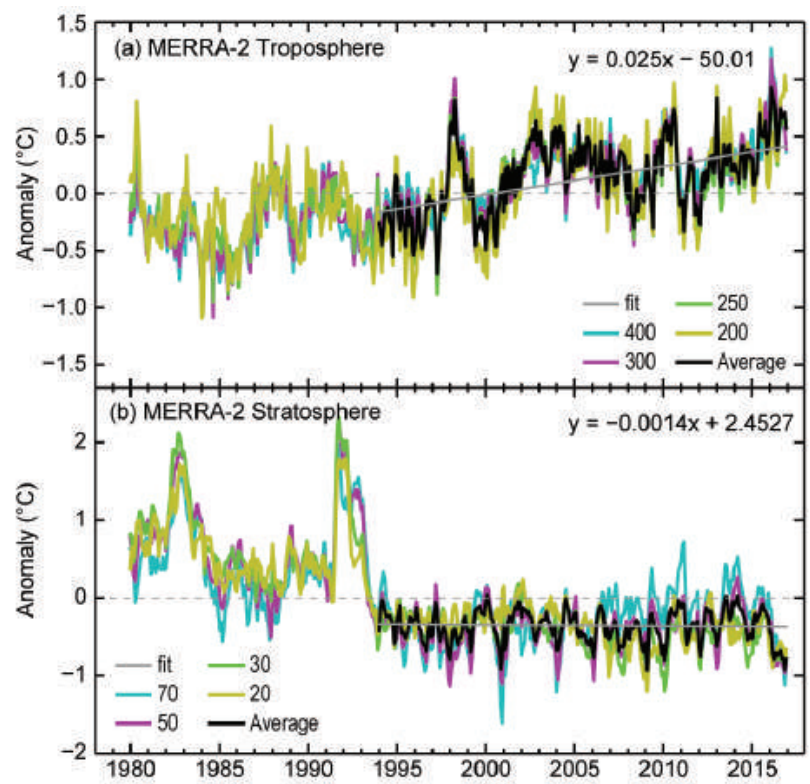

Fig. 2.9. MERRA-2 global temperature anomaly $\left({ }^{\circ} \mathrm{C}\right)$ time series relative to $198 \mathrm{I}-2010$ climatology at various (a) tropospheric and (b) stratospheric levels. The troposphere average anomaly is the unweighted average of (400-, 300-, 250-, and 200-hPa) values. The stratosphere average anomaly is the unweighted average of (70-, 50-, 30-, and 20-hPa) values. 
UNSW, Sherwood and Nishant 2015) show different global trends and variability (Fig. 2.8): RAOBCORE and RICH are similar and highly variable during this period, but RATPAC and UNSW behave more like the satellite and reanalyses. However UNSW (for which 2016 data are still awaited) has a relatively flat trend, while RATPAC has a cooling trend. The three satellite records (RSS, Mears and Wentz 2009; STAR, Zou and Wang 2010; and UAH, Christy et al. 2011) have very minor differences in the global anomalies and show a relatively flat trend from 1994 to present. The four reanalyses (ERA-Interim, Dee et al. 2011; JRA-55, Kobayashi et al. 2015; MERRA-2, Bosilovich et al. 2017; and CFSR, Saha et al. 2010) show varying global trends since 1994. ERA-I and MERRA-2 have positive trends, while the CFSR and JRA-55 are near neutral. Reanalyses assimilate observations beyond the radiosondes and MSU and AMSU radiances, and the positive trends of ERA-I and MERRA- 2 may be due to the usage of GPSRO data beginning in 2006.

Finally, trend variability with latitude is examined. Figs. S2.12a,b show the latitudinal annual trends $\left({ }^{\circ} \mathrm{C}\right.$ decade $\left.^{-1}\right)$ for the four reanalyses and the three satellite TLS datasets. There is a large range of trends in the tropics among the four reanalyses from a negative trend in JRA- 55 to equally positive trends in ERA-I and MERRA-2, to the CFSR neutral trend. The satellite trends in the tropics are all slightly negative. All reanalyses and satellites are in agreement that at more southerly latitudes the trends becomes more positive. The four reanalyses differ from the satellites in the Northern Hemisphere mid- and high latitudes. The satellites all agree upon a negative trend in the midlatitudes while the reanalyses range from near-neutral to positive trends. The reanalyses all show a stronger positive trend in the northern high latitudes while the satellites have neutral or positive trends. Both the reanalyses and satellite data have smaller trend error in the tropics and large error in the mid- and high latitudes.

\section{c. Cryosphere}

I) Permafrost thermal state-D. A. Streletskiy, B. Biskaborn, J. Noetzli, J-P. Lanckman, V. E. Romanovsky, P. Schoeneich, N. I. Shiklomanov, S. L. Smith, G. Vieira, and L. Zhao

The Global Terrestrial Network for Permafrost (GTN-P) provides systematic long-term measurements of permafrost temperature and active layer thickness (ALT) worldwide, and it is part of the Global Climate Observing System under the umbrella of the World Meteorological Organization (WMO). The GTN-P recently launched a sophisticated data management system (http://gtnpdatabase.org), which includes 1350 temperature boreholes and 250 active layer measurement sites worldwide (Biskaborn et al. 2015) in order to assess the thermal state of the permafrost at the global scale.

Permafrost temperature in the Arctic increases along a north-south bioclimatic gradient from $<-14^{\circ} \mathrm{C}$ in High Canadian Arctic to just below $0^{\circ} \mathrm{C}$ (a)
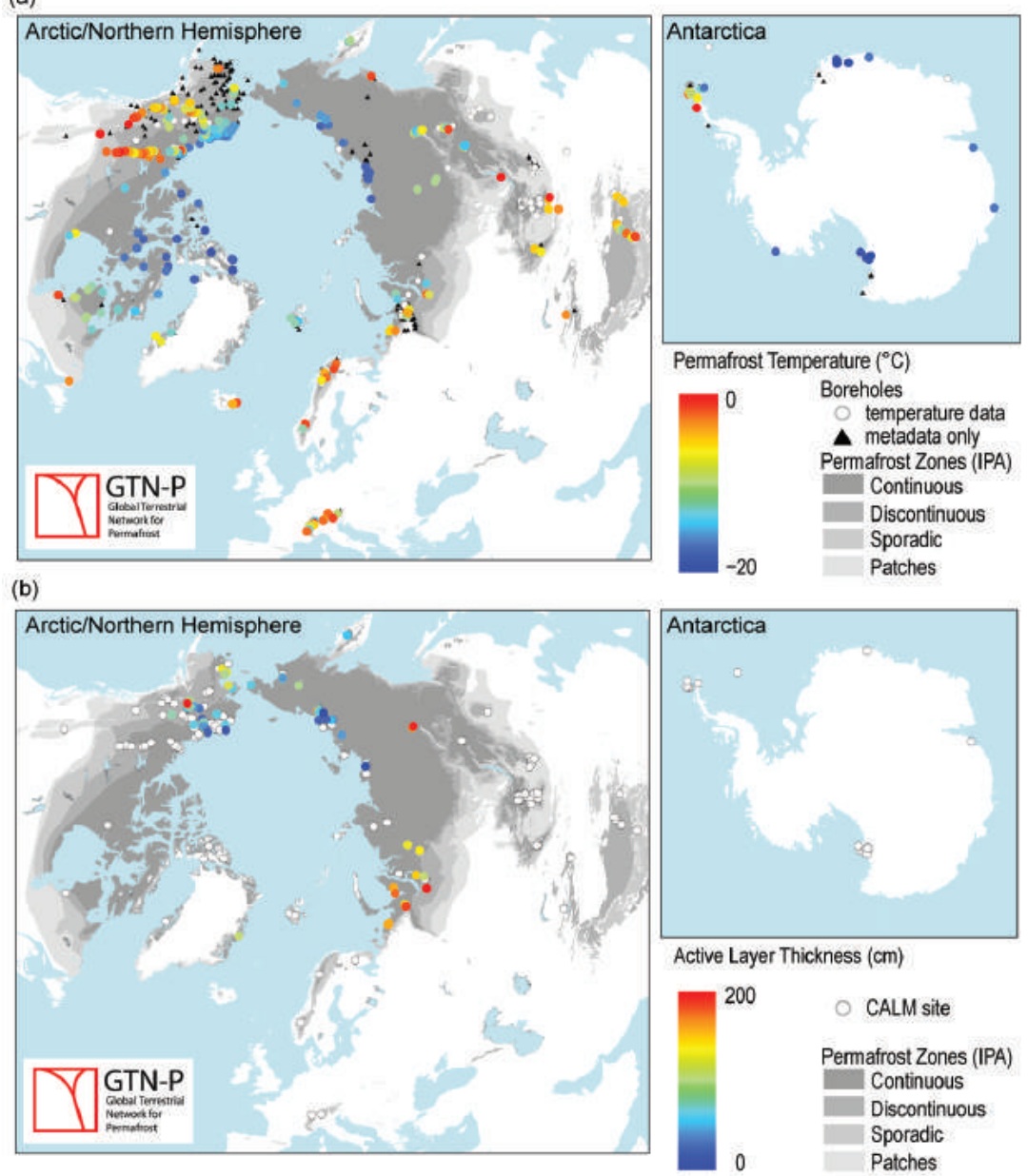

FIG. 2.10. (a) Permafrost monitoring boreholes showing permafrost temperature $\left({ }^{\circ} \mathrm{C}\right.$ ) at zero annual amplitude depth in 2010-16 as reported by 314 sites. (b) Active layer thickness $(\mathrm{cm})$ with data from 2016 as reported by 83 sites. (Source: Global Terrestrial Network for Permafrost.) 
near the limits of permafrost distribution, but differences in site-specific conditions, such as snow depth, vegetation, and soil properties, complicate this general geographic trend (Fig. 2.10a). The permafrost temperature at $20-\mathrm{m}$ depth in the European Alps is generally above $-3^{\circ} \mathrm{C}$ and is above $-1.5^{\circ} \mathrm{C}$ on the Tibetan Plateau. Continental Antarctica is characterized by permafrost temperature below $-15^{\circ} \mathrm{C}$, with the exception of Antarctic Peninsula where permafrost temperature is generally higher than $-3^{\circ} \mathrm{C}$.

Permafrost temperatures over the last decade have generally increased across the entire permafrost domain which is consistent with air temperature trends; however, there is considerable spatial and temporal variability. The highest increases in permafrost temperature are found in the High Arctic of Canada, North Slope of Alaska, and western Siberia and are pronounced in the regions with cold continuous permafrost in Russia and North America. In the subArctic, where permafrost temperatures are relatively high and within $2^{\circ} \mathrm{C}$ of the freezing point, there has generally been little change in permafrost temperature over the last several years. More detailed description of the latest changes in permafrost temperature in the Arctic and sub-Arctic is provided in Chapter 5.

In Alpine permafrost areas most measurement sites show significant warming since 2009. Permafrost temperature in central Europe continued to increase over the last 15-30 years, and 2016 saw the highest temperature on record for 20-m depth, even though the air temperature was not a record there for the year (PERMOS 2016; PermaFRANCE: http:// permafrance.osug.fr; Fig. 2.11a). Permafrost temperatures also continued to increase in central Asia. All observation sites in the Qinghai-Tibetan Plateau showed positive trends from 2005 to 2015; however, there is strong spatial variability. Ground temperature at $10-\mathrm{m}$ depth has increased by $0.04^{\circ}-0.49^{\circ} \mathrm{C}$ decade $^{-1}$, and at $20-\mathrm{m}$ depth by $0.01^{\circ}-0.28^{\circ} \mathrm{C}$ decade $^{-1}$ (Fig. 2.11b).

In continental Antarctica, along the latitudinal transect in Victoria Land from Wright Valley to Terra Nova Bay, permafrost warming of about $0.5^{\circ} \mathrm{C}$ since 2008 has been found in the southern coastal site (Guglielmin et al. 2016). Farther north in Rothera, no apparent trend has been found. In the Western Antarctic Peninsula, ground cooling is significantly controlled by the longer lasting snow cover and warming events seem to be related to strong El Niño events (Oliva et al. 2017), which have resulted in fast warming pulses in the time series. In Antarctic Peninsula permafrost stabilized or even aggraded since 1999 , primarily due to regional atmospheric cooling in the northern Ant-
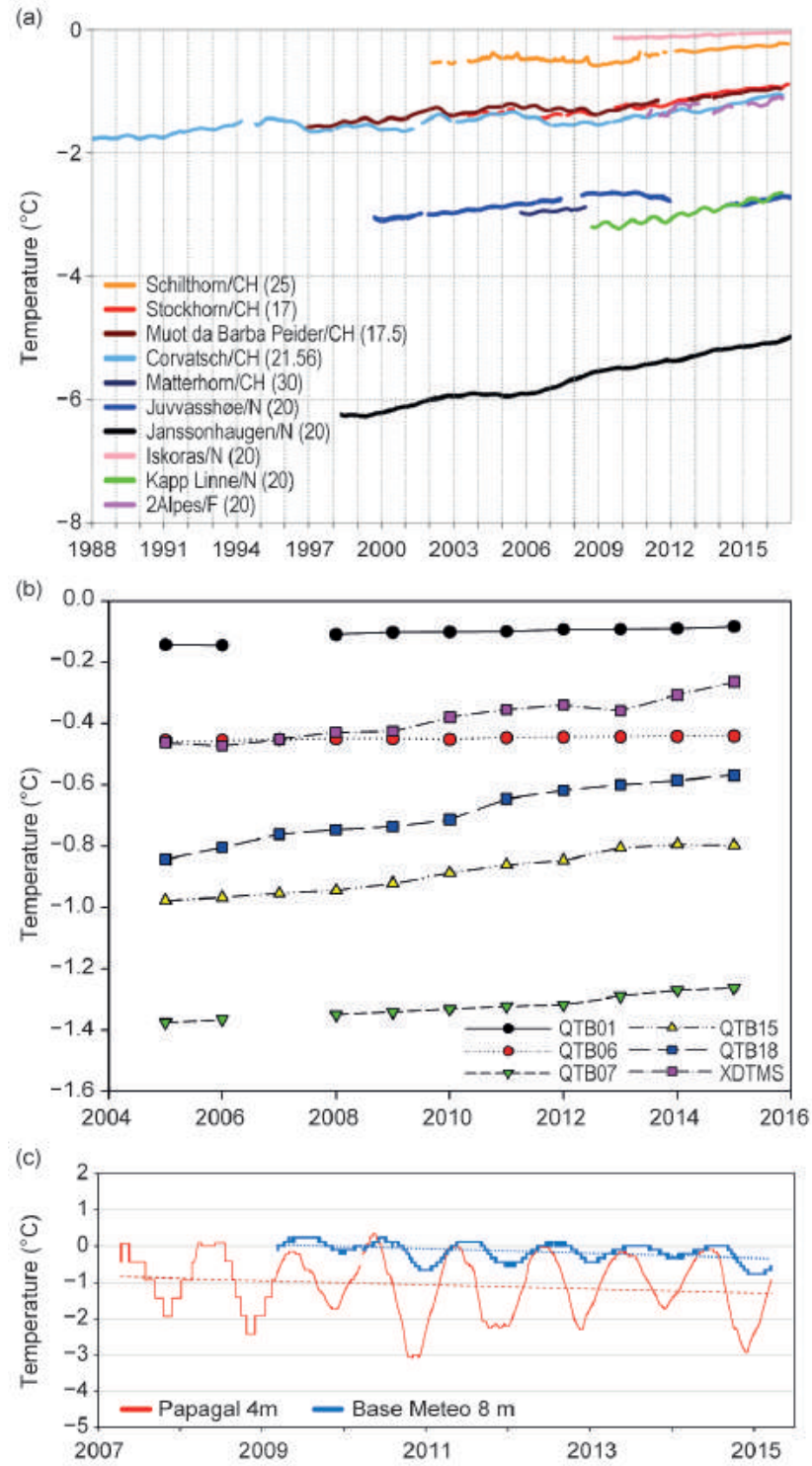

Fig. 2.II. Temperature $\left({ }^{\circ} \mathrm{C}\right)$ measured in permafrost boreholes: (a) monthly mean values in central and northern Europe at approximately 20-m depth; (b) values along the Qinghai-Xizang Highway on the Tibetan Plateau at 20-m depth; and (c) in Levingston Island, Antarctica, at 4- and 8-m depth. (a) and (b) demonstrate permafrost warming with higher rate for colder permafrost, (c) demonstrates permafrost aggradation. (Sources: Swiss Permafrost Monitoring Network PERMOS; French Permafrost Monitoring Network CRYOBSCLIM/PermaFRANCE; Norwegian Meteorological Institute and the Norwegian Permafrost Database, NORPERM; Cryosphere Research Station on Qinghai-Xizang Plateau, CAS.)

arctic Peninsula at a rate of $-0.47^{\circ} \mathrm{C}$ decade ${ }^{-1}$, which followed significant warming that has been estimated at $+0.32^{\circ} \mathrm{C}$ decade $^{-1}$ for $1979-99$ (Turner et al. 2016; Oliva et al. 2017). As a result, the active layer thickness in Deception Island and Byers Peninsula in the 
South Shetlands off the northern tip of the Antarctic Peninsula, as well as in James Ross Island, has decreased (Ramos et al. 2017; de Pablo et al. 2017; Hrbáček et al. 2016). In some locations, such as Papagal, Hurd Peninsula (Livingston Island), ground cooling resulted in permafrost aggradation at sites where permafrost was previously unknown (Vieira et al. 2016; Fig. 2.11c).

The ALT is characterized by large spatial and temporal variability, so only sites that measure ALT at the spatially distributed grids and reported data in 2016 are presented on the global map (Fig. 2.10b). The ALT ranges from $0.3 \mathrm{~m}$ in the High Arctic regions to $2 \mathrm{~m}$ near the southern boundary of permafrost zone. However, ALT can be substantially higher in mountainous regions, where measurements are only possible by using interpolation from temperature boreholes. With the exception of a few sites, ALT experienced positive trends since the mid-1990s. The extremely warm summer of 2016 reinforced this trend; it has resulted in the highest recorded ALT at a majority of the sites located in interior Alaska and northwest Siberia. Close to maximum values of ALT were also observed at the North Slope of Alaska, Greenland, European Arctic, European North of Russia, and Russian Far East, and European Alps, where maximum values of ALT were reached in 2015. However, at several sites of the northwest Antarctic Peninsula, ALT has been stable or even decreased.

2) NORTHERN HEMISPHERE CONTINENTAL SNOW COVER EXTENT-D. A. Robinson

Annual snow cover extent (SCE) over Northern Hemisphere $(\mathrm{NH})$ lands averaged 24.6 million $\mathrm{km}^{2}$ in 2016. This is 0.5 million $\mathrm{km}^{2}$ less than the 47 -year average (1967, 1970, 1972-2016) and ranks 2016 as having the 12th least extensive (or 36th most exten-
TABLE 2.3. Monthly and annual climatological information on NH and consnow extent between Nov1966 and Dec 2016. Included are the the annual calculations. North America includes Greenland. Ranks are from most extensive ( 1 ) to least (ranges from 47 to $5 \mathrm{I}$ depending on the month).

\begin{tabular}{|c|c|c|c|c|c|c|c|}
\hline & Years & $\begin{array}{c}\text { Mean } \\
\text { SCE }\end{array}$ & $\begin{array}{c}\text { Std. } \\
\text { Dev. }\end{array}$ & 2016 & $\begin{array}{c}\text { Nol6 } \\
\text { Rank }\end{array}$ & $\begin{array}{c}\text { Eurasia } \\
\text { Rank }\end{array}$ & $\begin{array}{c}\text { N. } \\
\text { Amer. } \\
\text { Rank }\end{array}$ \\
\hline Jan & 50 & 47.1 & 1.6 & 48.8 & 9 & 13 & 6 \\
\hline Feb & 50 & 46.0 & 1.8 & 43.5 & 48 & 47 & 38 \\
\hline Mar & 50 & 40.5 & 1.9 & 37.2 & 49 & 46 & 48 \\
\hline Apr & 50 & 30.5 & 1.7 & 27.9 & 50 & 46 & 40 \\
\hline May & 50 & 19.2 & 2.0 & 16.3 & 47 & 42 & 49 \\
\hline Jun & 49 & 9.6 & 2.4 & 5.6 & 47 & 48 & 47 \\
\hline Jul & 47 & 4.0 & 1.2 & 2.6 & 42 & 41 & 42 \\
\hline Aug & 48 & 3.0 & 0.7 & 2.6 & 29 & 37 & 23 \\
\hline Sep & 48 & 5.4 & 0.9 & 5.7 & 18 & 20 & 13 \\
\hline Oct & 49 & 18.3 & 2.7 & 23.0 & 3 & 3 & 2 \\
\hline Nov & 51 & 34.1 & 2.1 & 36.9 & 5 & 2 & 40 \\
\hline Dec & 51 & 43.7 & 1.9 & 45.4 & 8 & 12 & 11 \\
\hline Annual & 47 & 25.1 & 0.8 & 24.6 & 36 & 30 & 37 \\
\hline
\end{tabular}

sive) cover on record (Table 2.3; Fig. 2.12). It is almost identical to the 2015 mean extent. This evaluation considers snow over $\mathrm{NH}$ continents, including the Greenland ice sheet. SCE in 2016 ranged from 48.8 million $\mathrm{km}^{2}$ in January to 2.6 million $\mathrm{km}^{2}$ in July and August. Monthly SCE is calculated at the Rutgers Global Snow Lab from daily SCE maps produced by meteorologists at the National Ice Center (a US joint NOAA, Navy, and Coast Guard facility), who rely primarily on visible satellite imagery to construct the maps.

SCE across the Northern Hemisphere started 2016 off on the high side, ranking ninth in January for Eurasia (EU) and North America (NA) combined. This changed quickly, with February Northern Hemisphere extent ranking third lowest of the past 50 years. The dearth of snow cover continued throughout the late winter and spring, with rankings of first through fourth least extensive continuing throughout. Monthly NH anomalies of SCE were between 2.5 million $\mathrm{km}^{2}$ and 4.0 million $\mathrm{km}^{2}$ below average from February through June. During this period, SCE over the individual continents ranked 38th or 


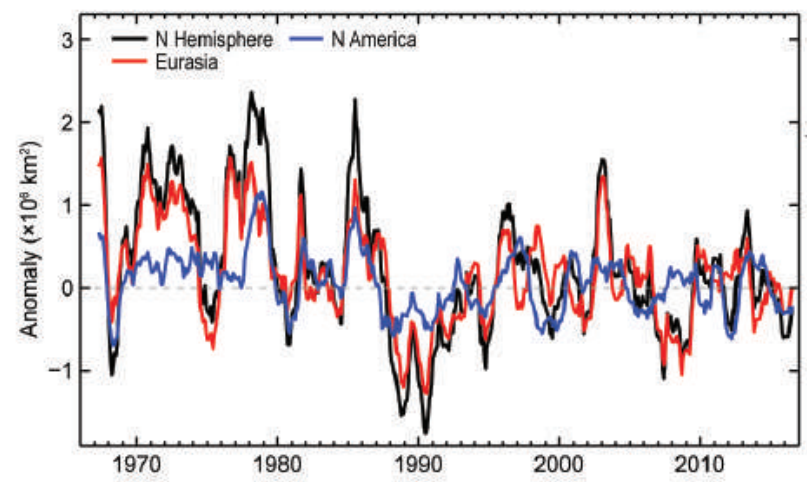

FIG. 2.12. Twelve-month running anomalies of monthly snow cover extent $\left(\times 10^{6} \mathrm{~km}^{2}\right)$ over $\mathrm{NH}$ lands as a whole, and Eurasia and North America separately, plotted on the 7th month using values from Nov 1966 to Dec 2016. Anomalies are calculated from NOAA snow maps relative to 198I-2010. Mean hemispheric snow extent is $\mathbf{2 5}$. I million $\mathbf{~ k m}^{2}$ for the full period of record. Monthly means for the period of record are used for 9 missing months between 1968 and 197I to create a continuous series. Missing months fall between Jun and Oct; no winter months are missing.

lower. This continued the lower spring extents that have occurred in the second half of the satellite record compared to the first.

Much snow, as in the previous three years, arrived early over Northern Hemisphere continents during autumn 2016. October SCE was 4.7 million $\mathrm{km}^{2}$ above average, ranking third most extensive. November came in as fifth most extensive and December eighth. Throughout these months, EU coverage was well above average, while over NA there was pronounced back and forth anomalies, with October second greatest, November 12th lowest, and December 11th most extensive.

SCE over the contiguous United States in January 2016 was seventh most extensive of the past half century but declined precipitously to only 38 th largest in February and a meek 49th (of 50) in March. The extensive October 2016 SCE across NA were due almost entirely to record large extent in Canada. Meanwhile farther south, U.S. October cover ranked just 33rd largest. SCE remained at a 33rd largest ranking over the United States in November, before jumping to 13th most extensive in December.

Maps depicting daily, weekly, and monthly conditions, daily and monthly anomalies, and monthly climatologies for the entire period of record may be viewed at the Rutgers Global Snow Lab website (http:// snowcover.org). Monthly SCE for the NH, EU, NA, contiguous US, Alaska, and Canada are also posted, along with information on how to acquire weekly areas and the weekly and monthly gridded products.

\section{3) Alpine glaciers-M. Pelto}

The World Glacier Monitoring Service (WGMS) record of mass balance and terminus behavior (WGMS 2015) provides a global index for alpine glacier behavior since 1894. Globally in 2015 mass balance was $-1177 \mathrm{~mm}$ for the 40 long-term reference glaciers and $-1130 \mathrm{~mm}$ for all 133 monitored glaciers. Preliminary data reported to the WGMS from Austria, Canada, Chile, China, France, Italy, Kazakhstan, Kyrgyzstan, Norway, Russia, Switzerland, and the United States indicate that 2016 is the 37th consecutive year without positive annual balances, with a mean of $-852 \mathrm{~mm}$ for reporting reference glaciers.

Alpine glacier mass balance is the most accurate indicator of glacier response to climate and along with the worldwide retreat of alpine glaciers is one of the clearest signals of ongoing climate change (Haeberli et al. 2000). The ongoing global glacier retreat is currently affecting human society by raising sea level, changing seasonal stream runoff, and increasing geohazards (Bliss et al. 2014; Marzeion et al. 2014). Glacier mass balance is the difference between accumulation and ablation. The retreat is a reflection of strongly negative mass balances over the last 30 years (Zemp et al. 2015). Glaciological and geodetic observations, 5200 since 1850, show that the rates of early 21 st century mass loss are without precedent on a global scale, at least for the time period observed and probably also for recorded history (Zemp et al. 2015). Marzeion et al. (2014) indicate that most of the recent mass loss (1991-2010) is due to anthropogenic forcing.

The cumulative mass balance loss from 1980-2015 is $-18.8 \mathrm{~m}$ water equivalent (w.e.), the equivalent of cutting a 21-m thick slice off the top of the average glacier (Fig. 2.13). The trend is remarkably consistent from region to region (WGMS 2015). WGMS mass balance based on 40 reference glaciers with a

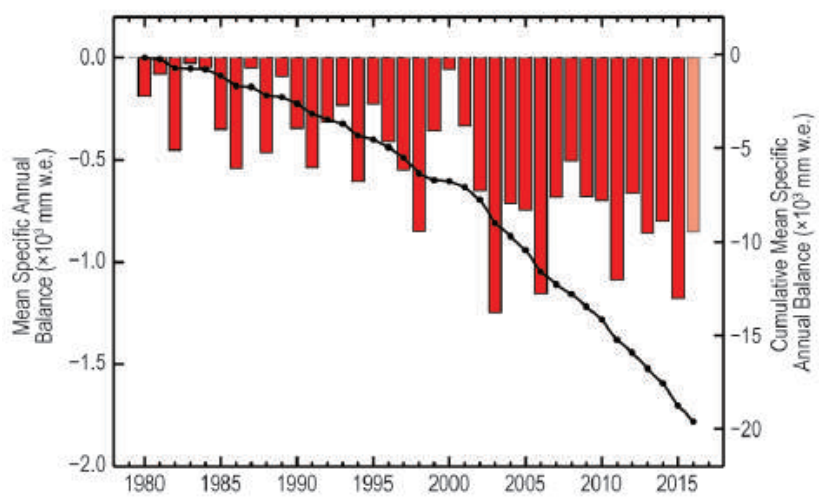

FIG. 2.13. Mean annual (red bars) and cumulative (black line) annual balance reported for the $4 \mathrm{I}$ reference glaciers to the WGMS (1980-2016). The data for 2016 are prelimimary only including $\mathbf{2 7}$ reference glaciers at the time of publication. 
minimum of 30 years of record is not appreciably different from that of all glaciers at $-18.3 \mathrm{~m}$ w.e.. The decadal mean annual mass balance was $-228 \mathrm{~mm}$ in the $1980 \mathrm{~s},-443 \mathrm{~mm}$ in the $1990 \mathrm{~s},-676 \mathrm{~mm}$ for $2000 \mathrm{~s}$ and $-876 \mathrm{~mm}$ for $2010-16$. The declining mass balance trend during a period of retreat indicates alpine glaciers are not approaching equilibrium, and retreat will continue to be the dominant terminus response. The recent rapid retreat and prolonged negative balances has led to some glaciers disappearing and others fragmenting (Fig. 2.14; Pelto 2010; Lynch et al. 2016).

Much of Europe experienced record or near-record warmth in 2016, thus contributing to the negative mass balance of glaciers on this continent. In the European Alps, annual mass balance has been reported for 12 glaciers from Austria, France, Italy, and Switzerland. All had negative annual balances with a mean of $-1050 \mathrm{~mm}$ w.e. This continues the pattern of substantial negative balances in the Alps that drives continued terminus retreat. In 2015 in Switzerland, 99 glaciers were observed: 92 retreated, 3 were stable, and 4 advanced. In 2015 Austria observed 93 glaciers: 89 retreated, 2 were stable, and 2 advanced; the average retreat rate was $22 \mathrm{~m}$.

In Norway, terminus fluctuation data from 28 glaciers with ongoing assessment indicate that from 2011-15 26 retreated, 1 advanced, and 1 was stable. The average terminus change was $-12.5 \mathrm{~m}$ (Kjøllmoen et al. 2016). Mass balance surveys with completed results are available for seven glaciers; six of the seven had negative mass balances with an average loss of $-380 \mathrm{~mm}$ w.e.

In western North America data have been submitted from 14 glaciers in Alaska and Washington in the United States, and British Columbia in Canada. All 14 glaciers reported negative mass balances with a mean loss of $-1075 \mathrm{~mm}$ w.e. The winter and spring of 2016 were exceptionally warm across the region, while ablation conditions were close to average.

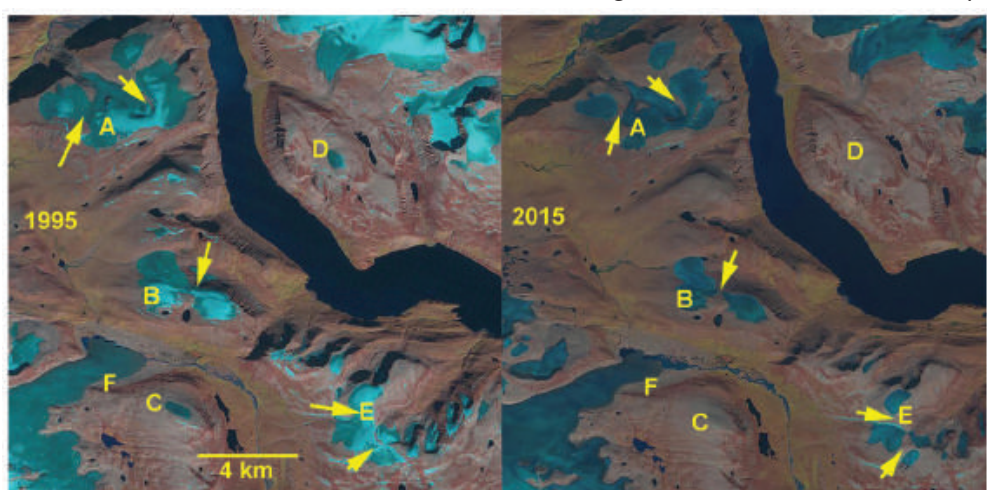

FIG. 2.14. Landsat images from 1995 and 2015 of glaciers in the Clephane Bay Region, Baffin Island (Canada). The yellow arrows indicate fragmentation. Glaciers at points $C$ and $D$ have dissappeared.
In the high mountains of central Asia five glaciers reported data from Kazakhstan, Kyrgyzstan, and Russia. Four of five were negative with a mean of $-360 \mathrm{~mm}$ w.e. Maurer et al. (2016) noted that mean mass balance was significantly negative for all types of glaciers in the Eastern Himalaya from 1974 to 2006.

\section{d. Hydrological cycle}

I) SuRfaCe HUMidity-K. Willett, D. I. Berry, M. Bosilovich, and A. Simmons

Given the record warmth of the surface atmosphere and a strong El Niño at the beginning of the year (ongoing since 2014 in sea level pressure-based indices), concurrent high levels of surface moisture were expected in 2016. Over land and ocean all data products, including both in situ only and reanalyses, show 2016 as a record or near-record moist year in terms of specific humidity (q; Figs. 2.15a-d), well above the long-term average. As El Niño subsided to neutral/sporadic La Niña conditions the specific humidity also dropped substantially, albeit not sufficiently to lower annual averages appreciably.

Drivers of global land and ocean relative humidity are complex as reflected in the greater degree of differences between data products and between land and ocean estimates (Figs. 2.15e-h). Generally over land, relative humidity annual averages remained below the long-term average while ocean averages were close to average according to the reanalyses. Note that reanalyses currently provide the only upto-date estimate of marine relative humidity. Over ocean, the reanalyses also show reasonable agreement with each other. Interestingly, the reanalyses show similar year-to-year variability to each other over land, remaining reasonably steady from around 2009 onwards, albeit at different average levels. The in situonly HadISDH land product (Willett et al. 2013, 2014) differs somewhat with much more recovery from the recent drying period ( 2000 to $\sim 2012$ ). It is too early to say whether the drying or the steadying/ potential recovery is part of a long-term trend or something more transient.

Spatially, the pattern of specific humidity is far less El Niño-like than in 2015 (Plate 2.11; Online Fig. S2.13), and relative humidity shows a general drier-than-average fingerprint over the tropical Pacific (Plate 2.1m; Online Fig. S2.14). Of note is the switch to strongly moister-than-average anomalies in specific humidity around northern Australia, South East Asia, southern China, and the western tropical Pacific 


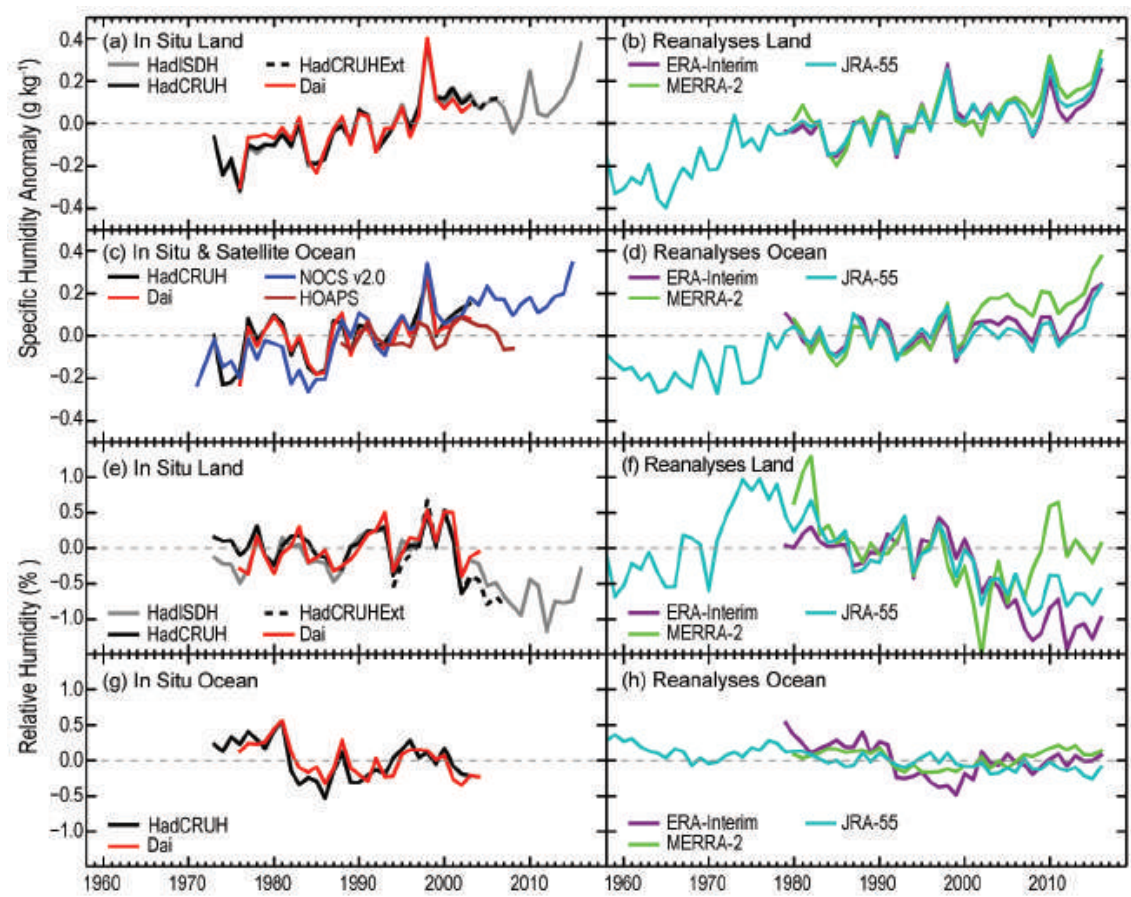

FIG. 2.15. Global average surface humidity annual anomalies (1979-2003 base period). For the in situ datasets $2-\mathrm{m}$ surface humidity is used over land and $\sim 10-\mathrm{m}$ over the oceans. For the reanalysis $2-\mathrm{m}$ humidity is used over the whole globe. For ERA-Interim ocean series only points over open sea are selected and background forecast values are used as opposed to analysis values because of unreliable use of ship data in producing the analysis. All data have been adjusted to have a mean of zero over the common period 1979-2003 to allow direct comparison, with HOAPS given a zero mean over the 1988-2003 period. ERA-Interim values over land have been spatially matched to the presence of HadISDH. [Sources: HadISDH (Willett et al. 2013, 2014); HadCRUH (Willett et al. 2008); Dai (Dai 2006); HadCRUHext (Simmons et al. 2010); NOCSv2.0 (Berry and Kent 2009, 20II); HOAPS (Fennig et al. 20I2) and reanalyses as described in Fig. 2.I. Data provided by authors, A. Dai and S. Kobayashi.]

generally. The drier-than-average anomalies of 2015 over the North Atlantic have persisted but weakened, whereas the tropical Atlantic shows moisterthan-average anomalies in 2016 as opposed to drier. There is reasonable agreement in the spatial patterns presented for specific humidity from ERA-Interim (Dee et al. 2011) and HadISDH (Willett et al. 2013, 2014) over land.

Estimates of surface humidity generally come from in situ observations from weather stations over land and ships and buoys over the oceans. Satellites and radiosondes also provide an estimate of specific humidity at the surface. All of these data require pre-processing to remove random errors and account for systematic biases. Additionally, in situ data suffer from large data gaps in space and time. The reanalysis products combine these observations with a weather forecasting model to provide a physically consistent and globally complete estimate. The model provides considerable skill in dealing with poorer quality observations although such observations and changes to observation streams can still affect the quality and homogeneity of the model output (e.g., Kent et al. 2014). In the case of ERA-Interim note that the background forecast dominates over ocean due to issues with the assimilation of ship data. Clearly, each product has various strengths and weaknesses and it is not straight forward to present a "best" estimate.

The availability of multiple independent (or methodologically independent at least) products provides valuable information about the likely uncertainty in estimates of surface humidity. Note that spatial coverage between the in situ estimates and the reanalyses is drastically different-with little in situ information available outside the Northern Hemisphere. Over land, ERA-Interim has been masked to match the coverage of HadISDH when creating the series plotted in Fig. 2.15. The NOCSv2.0 (Berry and Kent 2009, 2011) dataset has not been updated for 2016 due to the increasing sparseness of the marine observations and decrease in the quality of the observing system (e.g., Berry and Kent 2017). NOCSv2.0 has been included along with the other static products for historical comparison across the various estimates (Fig. 2.15).

2) Total column water vapor-C. Mears, S. P. Ho, J. Wang, H. Huelsing, and L. Peng

Total column water vapor (TCWV) rapidly peaked dramatically in early 2016 in response to the 2015/16 El Niño event (Fig. 2.16). Estimates are available from satellite-borne microwave radiometers over ocean (Wentz 1997; Wentz et al. 2007), COSMIC GPS-RO (Global Positioning System-Radio Occultation) over land and ocean (Ho et al. 2010a,b; Teng et al. 2013; Huang et al. 2013), and ground-based GNSS (Global Navigation Satellite System) stations (Wang et al. 


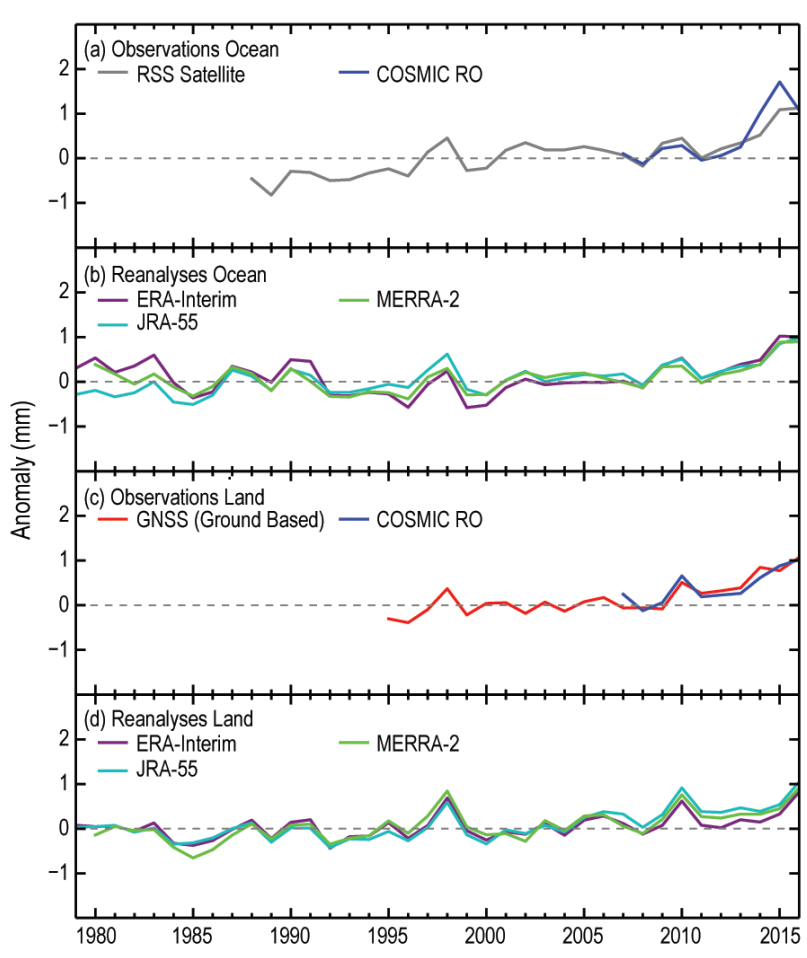

FIG. 2.16. Global mean TCWV annual anomalies ( $\mathrm{mm}$; relative to $198|-20| 0$ ) for (a),(b) ocean only and (c),(d) land only for observations and reanalyses averaged over $60^{\circ} \mathrm{N}-60^{\circ} \mathrm{S}$. Shorter time series are adjusted so that there is zero mean difference relative to the mean of the three reanalyses over the 2006-14 period.

2007; J. Wang et al. 2016) over land. An anomaly map for 2016 (Plate 2.1p) was made by combining data from these sources. Much of the globe showed small moist anomalies, except for small dry anomalies over regions of the Pacific Ocean (most notably off the Peruvian coast), the Southern Ocean, and some land areas. A large moist anomaly was present over the eastern tropical Indian Ocean, a region that also experienced a low wind speed anomaly in 2016 (see Plate 2.1u). The patterns in TCWV over the ocean is confirmed by COSMIC ocean measurements and by output from the MERRA-2, ERA-Interim, and JRA55 reanalyses (not shown). Over land, the patterns from COSMIC are in agreement with the reanalysis output.

Over the ocean, the TCWV anomaly time series (Figs. 2.16a,b) from reanalysis and microwave radiometers show maxima in 1983, 1987/88, 1997/98, $2009 / 10$, and 2015/16 associated with El Niño events. The 2015/16 anomaly is the largest recorded, particularly in the satellite radiometer data and the COSMIC data. This was caused by the large moist anomaly in the tropical Pacific Ocean, coupled with the preponderance of smaller moist anomalies in the rest of the world. The radiometer data show a discern-

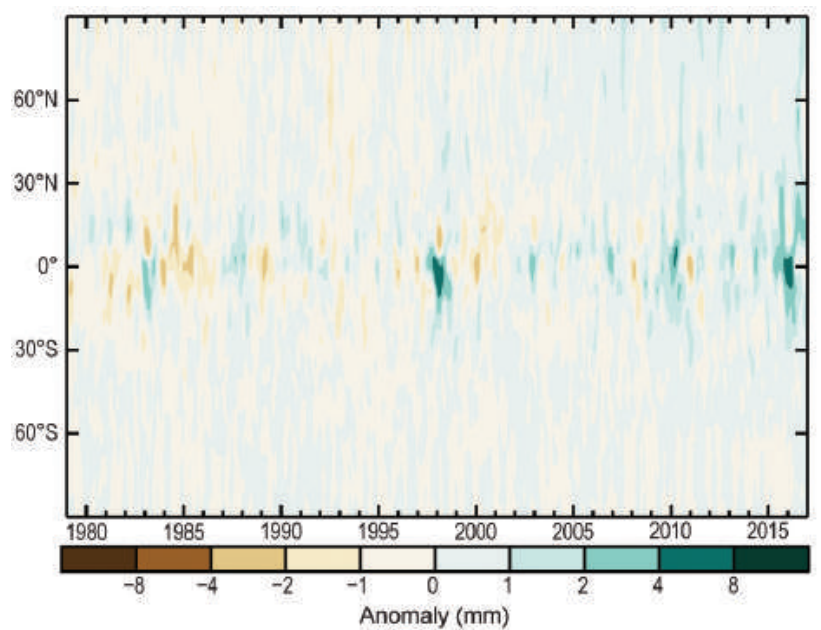

FIG. 2.I7. Hovmöller plot of TCWV anomalies $(\mathrm{mm}$; base period $1981-2010$ ) including both land and ocean derived from the JRA-55 reanalysis.

ible increasing trend while the different reanalysis products show a wide range of long-term trends. Minima are apparent in Northern Hemisphere winters during the La Nina events of 1984/85, 1988/89, 1999/2000, 2007/08, and late 2010 to mid-2012. Global water vapor has increased substantially since this last minimum at most latitudes (Fig. 2.17). The oceanonly COSMIC data are in general agreement with the reanalysis and radiometer data but show a larger peak for 2015 than the other data.

Over land average anomalies from the groundbased GNSS stations are used in place of the satellite radiometer measurements (Figs. 2.16c,d). The various reanalysis products, COSMIC, and GNSS are in good agreement, although as was the case for the oceans, the products more directly based on measurement show a larger increasing trend than the reanalyses over the past two decades. A land-and-ocean Hovmöller plot derived from JRA-55 (Fig. 2.17) indicates that the long-term increase in TCWV is occurring at all latitudes, with less variability outside the tropics. Previous strong El Niño events (1982/83 and 1997/98) showed pronounced drying events in the northern tropics that accompanied the moistening events on the equator and the southern subtropics. For the current El Niño this feature is much weaker, and the moist anomalies extend across most of the Northern Hemisphere.

3) UPPER TROPOSPHERIC HUMIDITY-V. 0. John, L. Shi, E.-S. Chung, R. P. Allan, S. A. Buehler, and B. J. Soden

Water vapor is the principal greenhouse gas in the atmosphere and its changes contribute significantly to feedbacks in the climate system (Held and Soden 2000). Water vapor in the upper troposphere, while 
insignificant by total mass when compared to the total column, constitutes a major part of the feedback because it is responsible for most of the tropospheric radiative cooling (Manabe and Möller 1961), and its radiative effect is proportional to relative changes in water vapor (John and Soden 2007).

Similar to last year's report (John et al. 2016), global scale monitoring of upper tropospheric humidity (UTH) is achieved using two independent satellite UTH datasets: (1) the infrared-based HIRS dataset (Shi and Bates 2011), and (2) the microwavebased UTH dataset (Chung et al. 2013). These datasets were constructed through careful bias corrections and intersatellite calibration. In these datasets, UTH represents a Jacobian weighted average of relative humidity in a broad layer which is roughly between 500- and 200-hPa but varies depending upon atmospheric humidity profile.

The area-weighted mean deseasonalized anomaly time series of UTH for $60^{\circ} \mathrm{N}-60^{\circ} \mathrm{S}$ is shown in Fig. 2.18. The anomalies are computed relative to the 2001-10 base period because the UTH dataset only begins in 1999. Positive relative humidity anomalies are observed in the second half of 2016, in contrast to the 2015 anomalies which were negative, indicating the shift from El Niño to La Niña conditions. A near-zero decadal trend in the upper tropospheric relative humidity time series indicates an increase in absolute (specific) humidity in step with the warming upper troposphere, and hence is consistent with a positive water vapor feedback (Chung et al. 2016). It is encouraging to see good agreement between the two independent datasets despite their differences in sampling: microwave data have an almost all-sky sampling whereas HIRS data sample mainly clear-sky scenes (John et al. 2011). Extreme anomalies for the HIRS time series arise from the sampling issues as

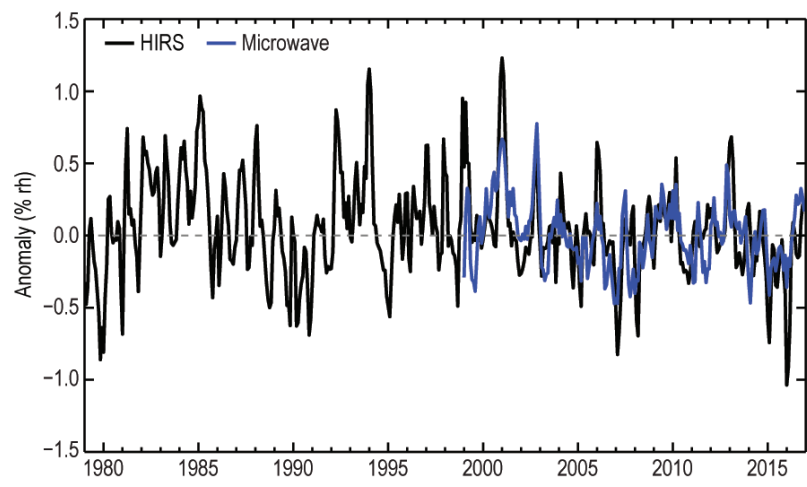

FIG. 2.18. Upper tropospheric humidity anomalies (\%; 200I-10 base period) using HIRS (black) and microwave (blue) datasets. Time series are smoothed to remove variability on time scales shorter than 3 months.

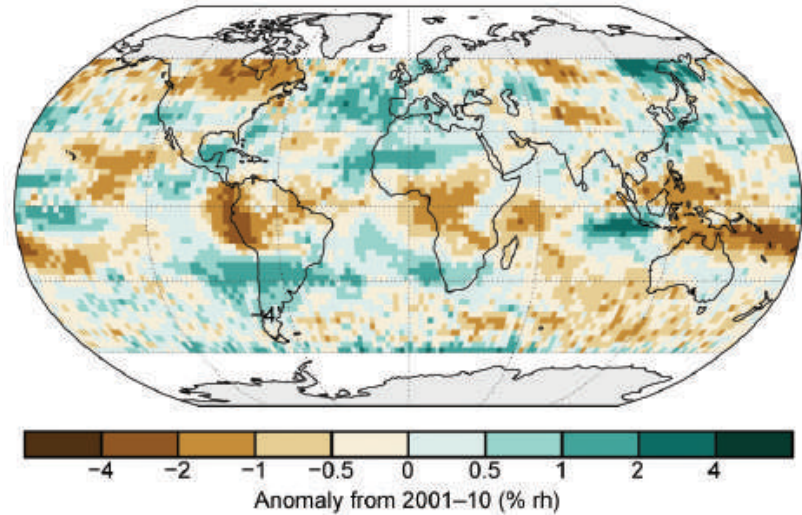

FIG. 2.19. Annual average UTH anomaly (\%; 200I-I0 base period) for 2016 based on the "clear-sky" HIRS UTH dataset.

demonstrated by John et al. (2011). The annual average UTH anomalies for 2016 relative to the 2001-10 base period (Plate 2.10 for microwave data; Fig. 2.19 for HIRS data) show moist anomalies over the central and eastern tropical Pacific and dry anomalies over the maritime continent which result from the still-strong El Niño during the first half of the year. Sampling of only clear-sky scenes by the HIRS dataset reduces the range of UTH between moist and dry regions, explaining the smaller magnitude of anomalies $(\sim \pm 2 \%)$ compared with the microwave dataset $(\sim \pm 5 \%)$.

4) Precipitation - R. S. Vose, R. Adler, A. Becker, and X. Yin

Precipitation over global land areas was above the 1961-90 average in 2016 (Fig. 2.20). However, there were two distinct "above-normal" story lines for the year depending upon the analyses considered. The first story line-one of slightly wetter-than-normal conditions-is supported by the Global Precipitation Climatology Centre (GPCC) dataset (Becker et al. 2013) and by the Global Historical Climatology Network (GHCN) dataset version 2 (Peterson and

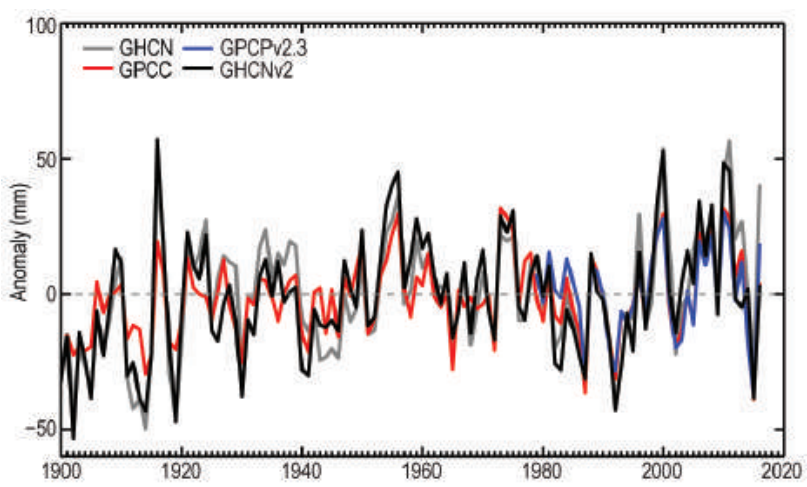

FIG. 2.20. Annual globally averaged precipitation anomalies $(\mathrm{mm})$ over land areas relative to the 1961-90 base period (except GPCPv2.3, which is 198I-2000). 
Vose 1997), both of which are based on surface stations. The 1961-90 base period is used here because it maximizes the number of stations available for a global analysis. The second story line-one of much-above-normal conditions-is supported by a new (experimental) version of GHCN that contains about five times as many stations as its operational counterpart (version 2), as well as by the Global Precipitation Climatology Project (GPCP) version 2.3 (Adler et al. 2003), which is based on both satellite data and surface stations and uses a different base period (1981-2010). (According to GPCP, precipitation over the global ocean surface in 2016 was much above the long-term average, as is typical of El Niño years.)

The annual anomaly map for 2016 (Plate 2.1i) shows a number of features at least partially related to the rapid evolution from an El Niño in the first few months of the year to La Niña conditions later on, with a near-neutral ENSO situation at the end of 2016. The central Pacific positive anomaly from the early months of the El Niño still dominated in the tropics, with a second strong positive feature in the eastern Indian Ocean. Over South America a negative anomaly covered the tropics (typical of El Niño), with a positive anomaly at higher latitudes. Much of North America, central Asia, northern Africa, and Australia experienced above-normal precipitation whereas Central America, western Europe, and southern Africa were below normal. Over the western United States the annual anomaly pattern shows some relief for the West Coast drought whereas the eastern U.S. generally had below-normal rainfall. The western Gulf of Mexico and the associated coastal areas also show a positive annual anomaly where significant floods occurred in Texas and Louisiana during the spring and early summer. Consistent with fading El Niño conditions, the strong positive anomalies over the tropical Pacific were less extreme than in 2015, as were the strong negative anomalies over the Maritime Continent. Broadly similar patterns are found for 2016 by the other precipitation datasets.

5) Cloudiness-M. J. Foster, S. A. Ackerman, K. Bedka, L. Di Girolamo, R. A. Frey, A. K. Heidinger, S. Sun-Mack, C. Phillips, W. P. Menzel, P. Minnis, and G. Zhao

Cloudiness measurements in the satellite era are dependent on the spectral sensitivity of the observing sensor. That said, year-to-year changes in global cloudiness among different sensors are generally in good agreement. Globally, cloudiness experienced only an incremental change $(<0.2 \%)$ from that of 2015. This conclusion is based on several satellite cloud climatologies including PATMOS-x/AVHRR

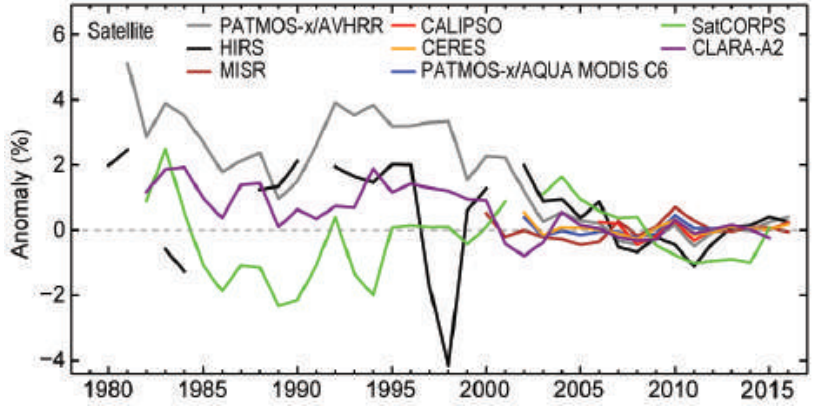

FIG. 2.2I. Annual global cloudiness anomalies (\%) for 1981-2016 (base period 2003-15, common to the satellite records excluding CALIPSO, where the entire record was used instead). Datasets include PATMOSx/AVHRR, HIRS, MISR, Aqua MODIS C6, CALIPSO, CERES Aqua MODIS, SatCORPS, CLARA-A2, and PATMOS-x/Aqua MODIS.

(Pathfinder Atmospheres Extended/Advanced Very High Resolution Radiometer; Heidinger et al. 2014), Aqua MODIS C6 (Moderate Resolution Imaging Spectroradiometer Collection 6; Ackerman et al. 2008), CALIPSO (Cloud-Aerosol Lidar and Infrared Pathfinder Satellite Observation; Winker et al. 2007), CERES (Clouds and the Earth's Radiant Energy System) Aqua MODIS (Minnis et al. 2008; Trepte et al. 2010), MISR (Multi-angle Imaging SpectroRadiometer; Di Girolamo et al. 2010), HIRS (High Resolution Infrared Sounder; Wylie et al. 2005; Menzel et al. 2014), and PATMOS-x/Aqua MODIS. Several of these records-Aqua MODIS C6, CALIPSO, CERES Aqua MODIS, MISR and PATMOS-x/Aqua MODIS-are derived from polar-orbiting satellites flown as part of NASA's Earth Observing System. These records are shorter, the earliest starting in 2000, and do not yet suffer from issues such as satellite drift or intersatellite calibration. Figure 2.21 shows that since 2000 global cloudiness has been relatively stable. The average interannual change in cloudiness among all records represented was $0.3 \%$ after 2000 and $0.8 \%$ before 2000 .

Currently it is not clear how much of this change is attributable to the influx of records taken from more modern satellites versus actual variability in cloudiness in the 1980s and 1990s. Strong El Niño events and the eruptions of El Chichón (1982) and Mount Pinatubo (1991) could explain positive cloudiness anomalies during this early period (a shift to more negative anomalies post-2000 can be seen in Figure 2.22), although it does not explain greater variability among the records. Of the records that extend back before 2000, three: PATMOS-x/AVHRR, CLARA-A2 (cloud, albedo and radiation dataset; Karlsson et al. 2017), and SatCORPS (satellite cloud and radiative property retrieval system; Minnis et al. 2016) are 


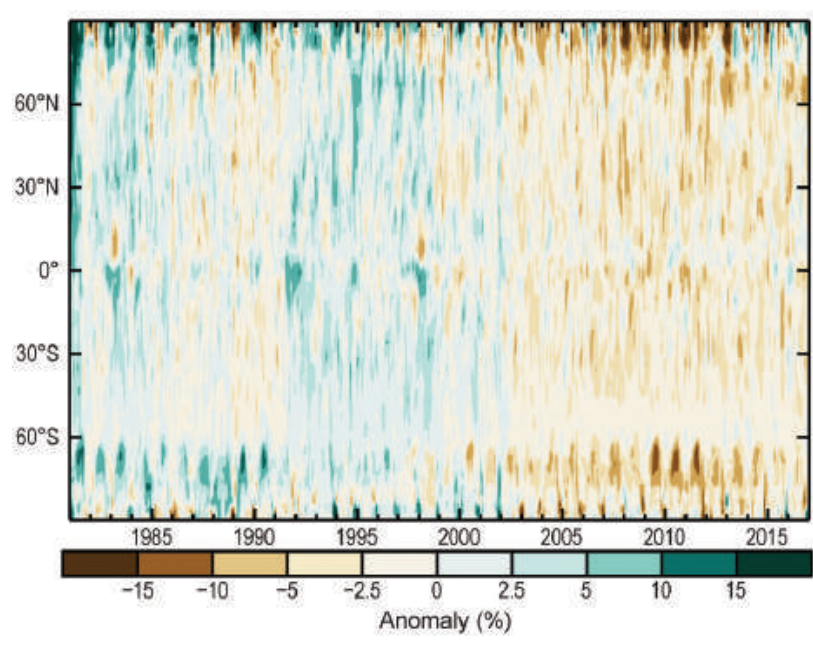

Fig. 2.22. Annual global cloudiness anomalies (\%; 198I-2010 baseline) from the PATMOS-x/AVHRR record calculated using the same method as Plate 2.In but zonally for each degree latitude.

derived from AVHRR instruments flown on NOAA POES and more recently the EUMETSAT MetOP series. Differences among these records can be attributed, in part, to which satellites were chosen for inclusion in the dataset and how the issue of diurnal drift was addressed (Foster and Heidinger 2013), as well as the auxiliary data used in the analyses. The fourth dataset to extend back before 2000, HIRS, has several gaps in coverage during this period and is more sensitive to the presence of thin cirrus clouds.

The emergence of several new global satellite cloud datasets in recent years has provided an opportunity to improve understanding of cloud feedbacks and their microphysical composition, and subsequently how they might be efficiently parameterized in numerical models. This is important as the role of clouds in the climate system is multifaceted. Clouds help modulate the global energy budget through cooling (reflection of incoming solar radiation) and warming (trapping outgoing terrestrial radiation) processes. Clouds affect the hydrological cycle through the storage and precipitation of atmospheric water. The structure of smaller clouds has historically been difficult to simulate on the spatial scales available to most general circulation models and, as such, have been a consistent source of uncertainty for climate prediction.

The global distribution of clouds is driven in part by large-scale circulation patterns such as ENSO. This can be seen in Fig. 2.22, as several of the stronger positive and negative anomalies correspond with phases of ENSO. The El Niño conditions in early 2016 resulted in enhanced large-scale convection in the central Pacific driven by higher-than-normal SSTs and convergence of low-level winds. This created positive maritime cloudiness anomalies in the central and eastern Pacific and corresponding negative anomalies over the western equatorial Pacific and Maritime Continent. This pattern can be seen clearly in online Fig. S2.15, although the El Niño pattern is apparent in the annual average as well, as seen in Plate 2.1n.

There were also several continental cloudiness anomalies significant at the $5 \%$ level relative to the 36 year PATMOS-x/AVHRR dataset, which frequently coincide with drought (negative anomalies) or flooding (positive anomalies) conditions. The significant anomalies in 2016 were almost all of the negative type. Alaska and portions of northern Canada experienced reduced cloudiness for much of the year, which coincided with unusually warm and dry conditions. For Alaska the largest negative cloudiness anomalies also corresponded with negative phases of the Arctic Oscillation. Portions of South America, encompassing Ecuador, Peru, parts of Bolivia, and the southern tip of Chile, also experienced significantly reduced cloudiness. The significant anomalies that covered the largest geographic area occurred in Siberia, which experienced reduced cloudiness for most of the year. Finally, southern Africa experienced reduced cloudiness during the boreal summer and autumn months.

6) River discharge AND RUNOFF-H. Kim

River discharge integrates the residual of precipitation (after evapotranspiration and reservoir storage) from headwaters to river outlets. It is important not only scientifically but also for human society because it is the most easily accessible renewable freshwater resource. It has, therefore, been monitored relatively long-term compared to other atmospheric and hydrologic variables. Still lacking, however, is a proper in situ gauge station network dense enough to provide a global monitoring service. Therefore, offline terrestrial simulation forced by atmospheric observations has been used to estimate global long-term variations. This is one of the most practical alternatives, at least until the Surface Water and Ocean Topography (SWOT) satellite begins to provide global river discharge observations in 2020.

A long-term (1958-2016) global offline land surface simulation has been performed by the ensemble land surface estimator (ELSE; Kim et al. 2009). The atmospheric boundary condition has been updated using the Japanese global atmospheric reanalysis (JRA-55; Kobayashi et al. 2015). To remove model precipitation bias in the JRA-55, the monthly observational Monitoring Product version 5 (Schneider et al. 


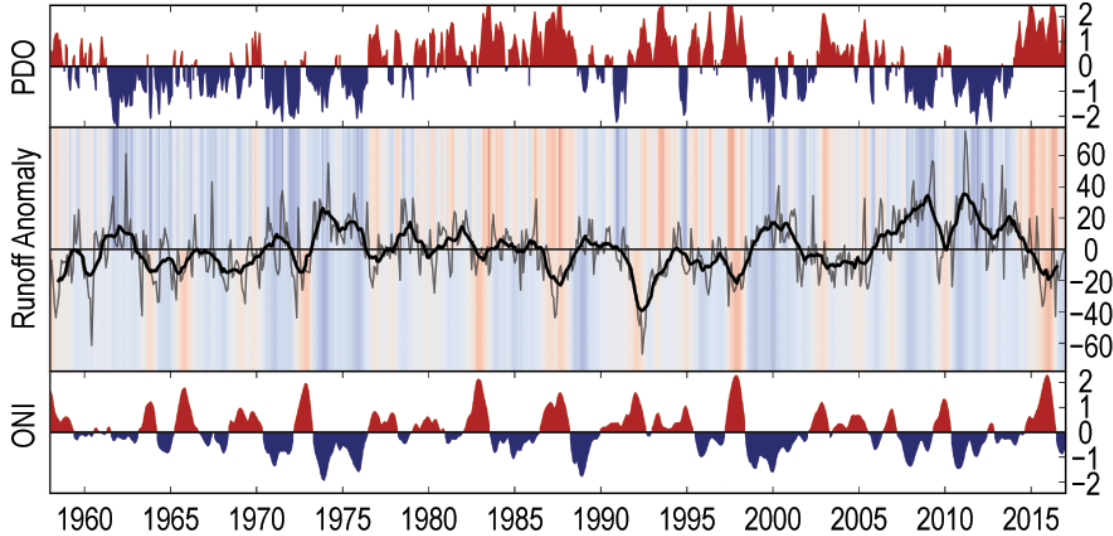

FIG. 2.23. Interannual variability of ONI (lower), PDO (upper), and global runoff (middle; $\mathrm{mm}$; thick line is 12 -month moving average). ONI and PDO are shaded red (positive phase) or blue (negative phase). Shading above and below the zero-line of global runoff is proportional to PDO and ONI, respectively.

Zhang et al. 1997) index. Both indices smoothed by a 12-month running mean are significantly anti-correlated $\left(\mathrm{R}_{\mathrm{ONI}}=-0.65, \mathrm{R}_{\mathrm{PDO}}=-0.55\right)$ with similarly smoothed variations of monthly mean runoff. Dai et al. (2009) showed that the correlations between the global freshwater discharge and ENSO are significant for the rivers draining to the Atlantic $(\mathrm{R}=-0.5$ with Niño3.4), Pacific ( $\mathrm{R}=$ $-0.61)$, and Indian $(R=-0.52)$ Oceans (Dai et al. 2009). PDO is a pattern of Pacific climate

2015) of the Global Precipitation Climatology Centre (GPCC) is used as the reference. The other parts of the simulation framework remain as the configuration from Kim (2016).

The global distributions of runoff (Plate 2.1j) and river discharge (Plate 2.1k) anomalies in 2016 show that large areas of South America, Africa, Europe, and Siberia were under significantly dry conditions. In particular, a number of global river basins, such as Amazon, Brahmaputra, Congo, Danube, Nile, Yenisei, and Zambezi have transported considerably lower amounts of freshwater than their climate normal to the oceans, while some basins including La Plata, Lena, Mississippi, and Yangtze were under wetter conditions than the long-term mean. The 59-year series of total terrestrial runoff anomalies is shown in Fig. 2.23 along with the oceanic Niño index (ONI) and Pacific decadal oscillation (PDO; variability similar to ENSO in character but which varies over a much longer timescale. Approximately $50 \%$ of the global discharge variability $(\mathrm{R}=-0.69)$ is reproducible when those two indices are used as the predictors in a multivariate linear regression. Therefore, reaching the lowest level of global mean runoff in more than a decade (Fig. 2.23) is likely associated with the strong 2015/16 El Niño. As shown in Fig. 2.24, the diminished global runoff, which had been evident since mid-2015, was alleviated from the boreal fall to the end of the year. However, South America and Africa had persistently deficient runoff, close to $-2 \sigma$, through the entire year which may be a major cause of the low level of global runoff because the Amazon River, where the hydrologic cycle is largely controlled by ENSO (e.g., Zeng 1999), solely contributes to more than $15 \%$ and $70 \%$ of the global and South American freshwater discharge, respectively. Europe and North

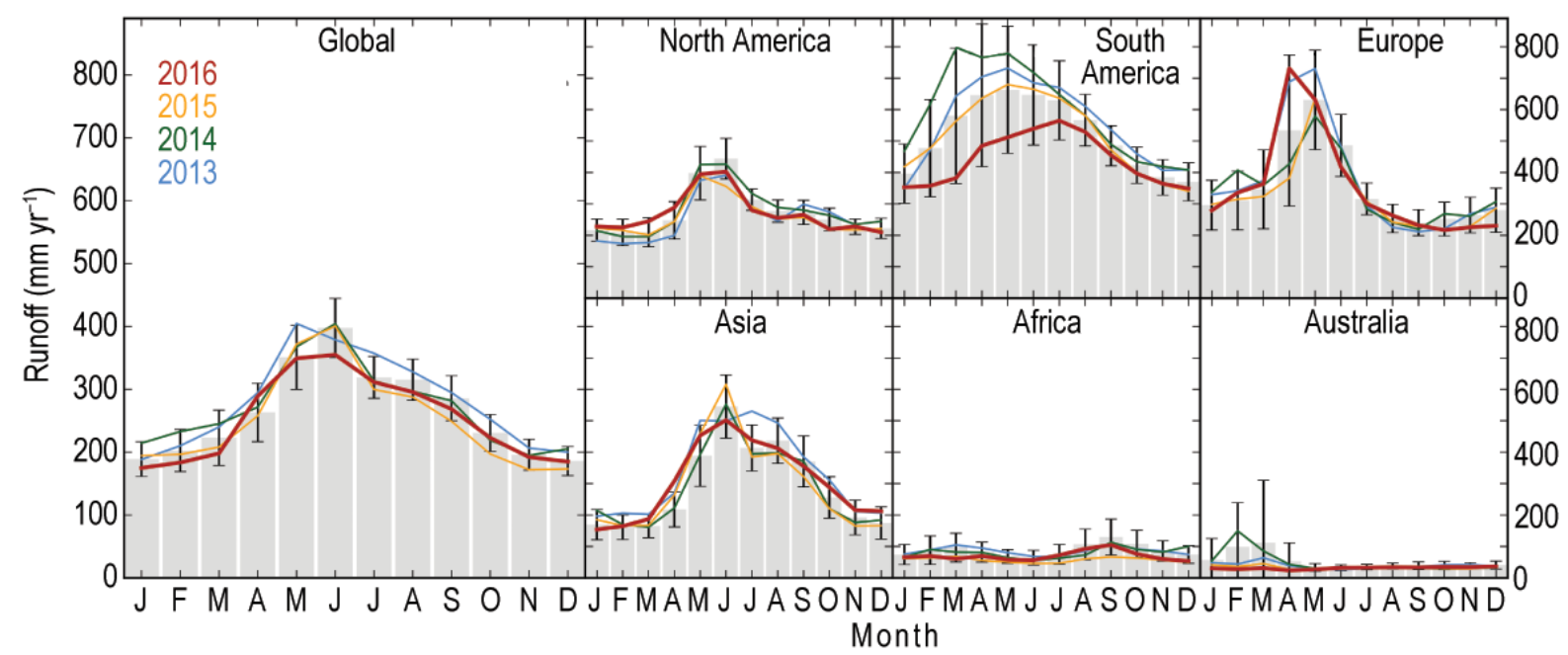

FIG. 2.24. Seasonal variations of global and continental runoff ( $\mathrm{mm}$ ) for 20I3- 16 (gray bar for 59-year climatology; error bars for $2 \sigma$; colored lines for most recent 4 years). 
America had excess runoff in early 2016 but then strong deficits from boreal summer onward. Asia and Australia ended 2016 with excess runoff. During the last four years, there has been large interannual variability, in both amplitude and phase, in South America, Europe, and Australia in boreal spring.

\section{7) Groundwater and terrestrial Water Storage-} M. Rodell, D. N. Wiese, and J. S. Famiglietti

Groundwater, soil moisture, surface water, snow, and ice compose terrestrial water storage (TWS). Groundwater varies more slowly than the surficial TWS components, but it commonly exhibits a larger range on multiannual timescales (Li et al. 2015). In situ groundwater data are only archived and shared by a few countries. Since 2002, however, the Gravity Recovery and Climate Experiment (GRACE; Tapley et al. 2004) satellite mission has been providing observations of TWS variations that approximate unconfined groundwater variations on seasonal and longer scales.

Changes in January-August mean TWS from 2015 to 2016 are plotted in Plate $2.1 \mathrm{~h}$ as equivalent heights of water in cm. Beginning in 2011, certain GRACE instruments have been powered down during part of the orbital cycle in order to conserve battery life, including the last four months of 2016. TWS changes reflect the integrated effects of other hydroclimatic variables (see Plates 2.1g-r). The Amazon basin, which has the largest TWS fluctuations of any river basin, lost a huge amount of water in 2016 as a result of low precipitation (Sections $2 \mathrm{~d} 4,2 \mathrm{~d} 8,2 \mathrm{~d} 9$ ). Somewhat balancing that, heavy rains greatly increased TWS in the southern half of South America, causing flooding and landslides near Sao Paolo in March. In general the rest of the world was more wet than dry. California

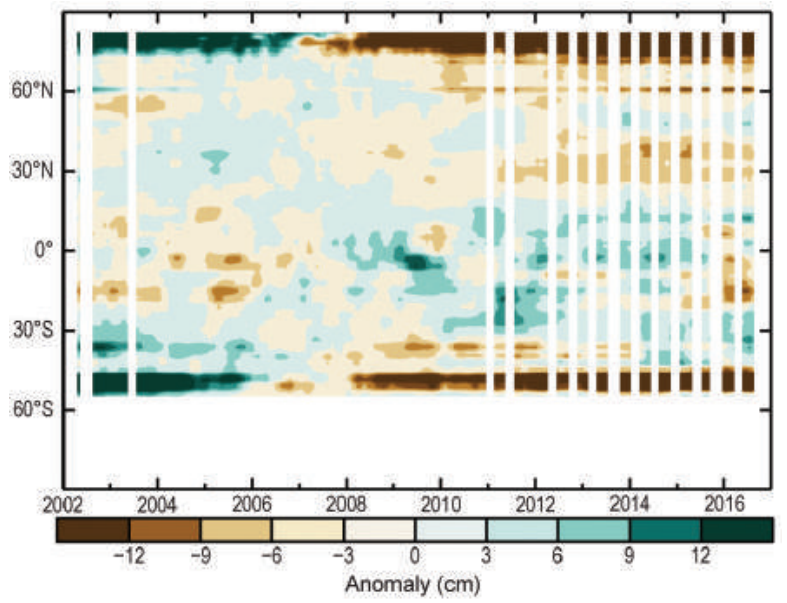

FIG. 2.25. GRACE zonal mean terrestrial water storage anomalies $(\mathrm{cm}$, equivalent height of water; relative to 2005-10). White areas indicate months when data were unavailable. enjoyed some relief from an historic drought, and the central and southern United States gained large amounts of TWS. A large area of western Russia also experienced TWS increases. Massive increases in TWS were associated with flooding in Angola (January-April), Myanmar (June-August), and southern China (June-July). Rains in east central Africa also increased TWS and the water level of Lake Victoria during the first half of the year (based on satellite altimetry; Birkett et al. 2011). Severe drought reduced TWS and caused food shortages in Madagascar, Mozambique, Zimbabwe, and neighboring countries. A region centered on Nepal was similarly afflicted, although continuing groundwater withdrawals for irrigation in northern India (Rodell et al. 2009; Panda and Wahr 2016) contributed to the observed signal. TWS also decreased in Mexico and northwest Australia. Significant reductions in TWS in Greenland, western Antarctica, southern coastal Alaska, and Patagonia represent ongoing ice sheet and glacier ablation, not groundwater depletion.

Figures 2.25 and 2.26 show time series of zonal mean and global deseasonalized monthly TWS anomalies from GRACE, excluding Greenland and Antarctica. The effects of droughts in Brazil, southern Africa, and Australia are clear in Fig. 2.25, as is the wetness in southern South America. Despite the massive Brazilian drought, by August global TWS had recovered substantially to $-0.8 \mathrm{~cm}$ from a GRACEperiod low of $-2.8 \mathrm{~cm}$ in January 2016. That $2-\mathrm{cm}$ increase in TWS (temporarily) offset about $7 \mathrm{~mm}$ of mean sea level rise.

8) Soll moisture-W. A. Dorigo, D. Chung, A. Gruber, S. Hahn, T. Mistelbauer, R. M. Parinussa, C. Reimer, R. van der Schalie, R. A. M. de Jeu, and W. Wagner

Satellite-based microwave radiometers and scatterometers can measure the moisture content of the

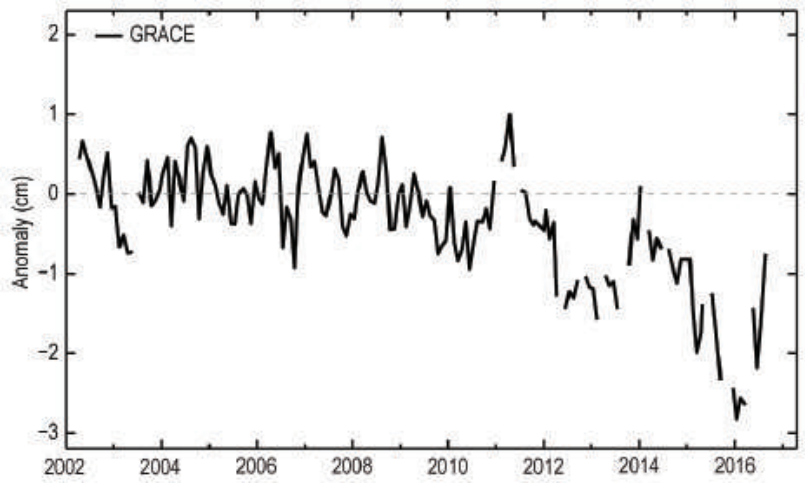

FIG. 2.26. GRACE global average terrestrial water storage anomalies in (cm, equivalent height of water; relative to $2005-10)$. 
upper few centimeters of the soil. While dedicated soil moisture missions, such as NASA's Soil Moisture Active Passive (SMAP), are able to provide nearly contiguous global spatial coverage at daily time scales, as stand-alone missions they are too short for assessing soil moisture variability and change in a climatic context. The ESA Climate Change Initiative (CCI) bridges this gap by combining observations from a large number of historical and present-day passive and active microwave instruments (Liu et al. 2012; Wagner et al. 2012). The latest dataset combines 11 different sensors between late 1978 and December 2016 and now also includes data from the Soil Moisture Ocean Salinity (SMOS) mission (Dorigo et al. manuscript submitted to Remote Sens. Environ.). The dataset has been used for a wide range of applications (see Dorigo and de Jeu 2016; Dorigo et al. submitted, ) and has been benchmarked against a large number of land surface models and in situ datasets (Albergel et al. 2013; Dorigo et al. 2015b; Fang et al. 2016; Loew et al. 2013). Based on the ESA CCI Soil Moisture (SM) dataset the yearly and monthly anomalies are computed here with respect to a 1991-2015 climatology.

For 2016, spatial anomaly patterns (Plate 2.1g) are markedly different from 2015, which was characterized by El Niño conditions throughout the year (Dorigo et al. 2016). Strong El Niño conditions continued into 2016, and aggravated drought conditions in the first months of the year in southern Africa (Online Fig. S2.16). Even though soil moisture conditions in this region returned to normal in the second half of the year, mean conditions for 2016 remained below average, thus increasing the risk of crop failure and food shortage in early 2017. (WMO 2017) For northeastern Brazil strong anomalous negative soil moisture conditions were observed for the fifth consecutive year (see previous State of the Climate reports, e.g., Dorigo et al. 2016) making it the longest drought recorded in this region. Anomalous dry conditions were also observed in western Bolivia and Peru, causing severe wildfires and shortages in water supply(see Chapter 7d2). At the subannual timescale, strong anomalous dry conditions were observed in Iran (January, February, December), Inner Mongolia (July, August), the southeastern United States (October, November), southern India (October-December), Turkey (November), and southeastern Europe (December) (Online Fig. S2.16).

Strong anomalous wet conditions were observed throughout the year for the southern part of South America, causing repeated heavy flooding in Argentina, Paraguay, and Uruguay. Wetter-than-usual conditions were also observed for eastern Europe and central Asia, alleviating the drought conditions that were reported for 2014 and 2015 in southern Russia (Dorigo et al. 2015a; Dorigo et al. 2016). Soil moisture conditions were also above average in central Europe, especially in February (Online Fig. S2.16). Anomalous wet soil moisture conditions throughout the year in Southeast Asia were associated with reported frequent severe flooding in this region. While the dry soil conditions observed in northern and eastern Australia (associated with El Niño) persisted into the first months of 2016 (Online Fig. S2.16), these were broadly compensated by above-average rainfall for the rest of the year, leading to wetter-than-usual soil moisture conditions for 2016 overall.

The year 2016 was marked by transition from strong El Niño conditions in the beginning of the year to weak La Niña/neutral ENSO conditions during the second half of the year. ENSO anomalies are known to potentially cause continental deviations in terrestrial water storages (Bauer-Marschallinger et al. 2013; Boening et al. 2012; Miralles et al. 2014a). ENSO-driven global negative soil moisture anomalies are clearly visible during the 1997/98 El Niño, while positive anomalies were observable for the strong $\mathrm{La}$ Niña episode of 2010/11, especially for the Southern Hemisphere (Fig. 2.27). Even though 2016 started with strong El Niño conditions, its negative impact on the global and, particularly, Southern Hemisphere soil moisture, was not as strong as for other recent $\mathrm{El}$ Niño events (e.g., 2004/05). This limited impact of El Niño on global soil moisture was already observed for 2015 and may be because other climate oscillations may have partly counterbalanced the negative effects

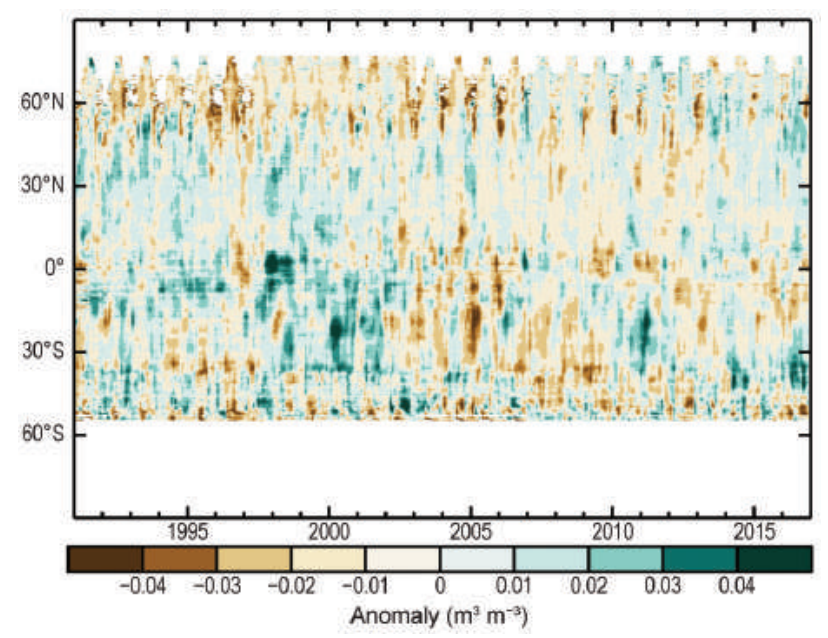

FIG. 2.27. Time-latitude diagram of surface soil moisture anomalies $\left(\mathrm{m}^{3} \mathrm{~m}^{-3}\right.$; base period: 1991-2015). Data were masked as missing where retrievals are either not possible or of low quality (dense forests, frozen soil, snow, ice, etc.). (Source: ESA CCI Soil Moisture.) 


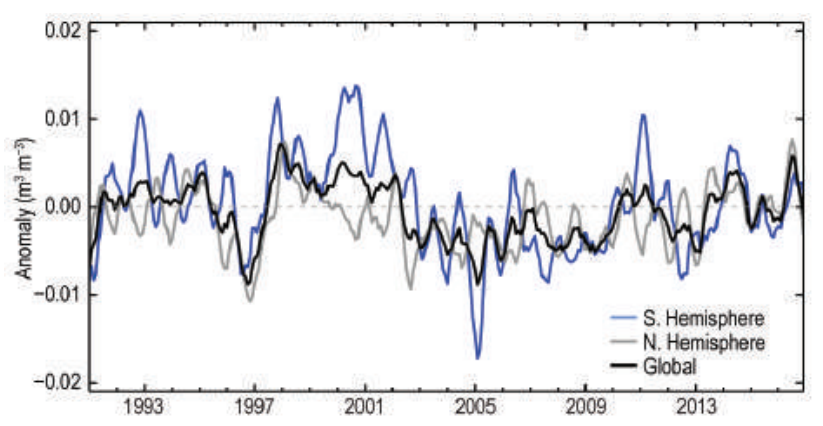

FIG. 2.28. Time series of 1991-2016 average global and hemispheric surface soil moisture anomalies $\left(\mathrm{m}^{3} \mathrm{~m}^{-3}\right.$; base period: 1991-2015). Data were masked as missing where retrievals were either not possible or of very low quality (dense forests, frozen soil, snow, ice, etc.). (Source: ESA CCI Soil Moisture.)

of El Niño (Dorigo et al. 2016). Instead, globally and for both hemispheres, average soil moisture was slightly above normal in 2016 (Fig. 2.28).

No evident large-scale long-term global soil moisture trends can be observed (Fig. 2.28). This does not exclude, however, the existence of long-term trends at regional or local scales (Dorigo et al. 2012; Rahmani et al. 2016; S. Wang et al. 2016). Trends in average global soil moisture should be treated with caution owing to dataset properties changing over time and the inability to observe beneath dense vegetation or in mountain areas and frozen soils (cf. gray regions in Plate 2.1g and Online Fig. S2.16). Although the trends are based on surface soil moisture observations, they are generally also representative for the root zone because of the strong coupling between these layers.

9) Monitoring global drought using the selfCalibrating Palmer drought severity IndeXT. J. Osborn, J. Barichivich, I. Harris, G. van der Schrier, and P. D. Jones

Hydrological drought results from a period of abnormally low precipitation, sometimes exacerbated by additional evapotranspiration (ET); its occurrence can be apparent in reduced river discharge, soil moisture, and/or groundwater storage, depending on season and duration of the event. Here, an estimate of drought called the self-calibrating Palmer drought severity index (scPDSI; Wells et al. 2004; van der Schrier et al. 2013a) is presented, using precipitation and Penman-Monteith potential ET from an early update of the CRU TS 3.25 dataset (Harris et al. 2014). Moisture categories are calibrated over the complete 1901-2016 period to ensure that "extreme" droughts and pluvials relate to events that do not occur more frequently than in approximately $2 \%$ of the months. This choice affects direct comparison with other hy- drological cycle variables in Plates 2.1g-r which use a different baseline period. Other drought indices may give varied results (see van der Schrier et al. 2015).

Following the rapid expansion in the overall area of drought across the globe during 2015 (Osborn et al. 2016), drought area for 2016 was among the largest in the post-1950 record (Fig. 2.29). Every month of 2016 had at least $12 \%$ of global land experiencing severe drought conditions (scPDSI $<-3$ ), matched only by 1984 and 1985 (although 1983, 1986, and 1992 came close). Extreme drought conditions (scPDSI <-4) affected at least $4 \%$ of global land area in every month of 2016; a run of this length has not been matched by any other year in the post-1950 period, although extreme drought area peaked above $5 \%$ briefly in 1983 and above $6 \%$ briefly in 1984 . The area where scPDSI indicates moderate drought (scPSDI $<-2$ ) peaked above $28 \%$ in early 2016 and declined to $26 \%$ by the end of the year. The current run (19 months as of December 2016) with at least $25 \%$ of global land area being affected by moderate drought is comparable with earlier periods such as 1965/66, 1970/71, $1991 / 92$ and 2002/03, but it is currently dwarfed by the extended 69-month dry period of 1982-88. The 2016 peak should be interpreted cautiously, given that more observations for the final months of 2016 will become available in due course.

Although the area in drought during 2016 is no greater than at the end of 2015, the annual average extreme drought area in 2016 is around double the annual average for 2015 because 2015 began with a relatively small area in drought. This is evident in the more extensive regions of severe and extreme drought in 2016 (Plate 2.1q) compared with 2015 (Fig. 2.30). For example, drought intensified over southern and Mediterranean Africa, and it became more extensive across large parts of Brazil (except for the south) and

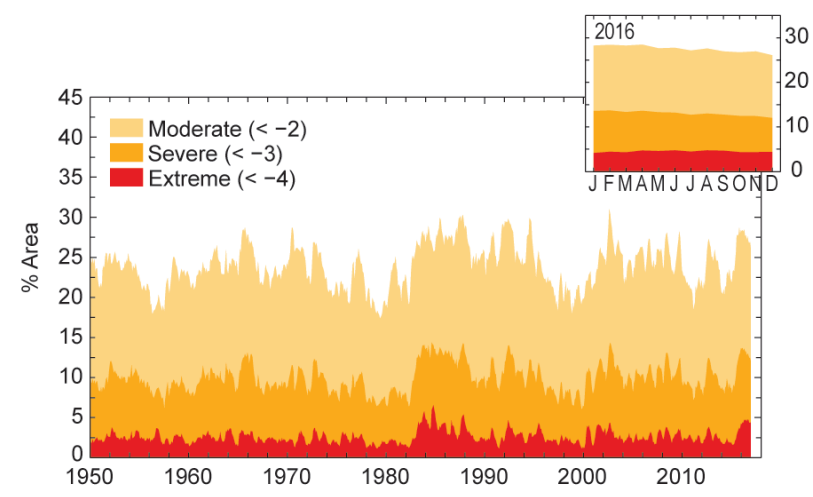

Fig. 2.29. Percentage of global land area (excluding ice sheets and deserts) with scPDSI indicating moderate (<-2), severe (<-3) and extreme (<-4) drought for each month of 1950-2016. Inset: 2016 monthly values. 


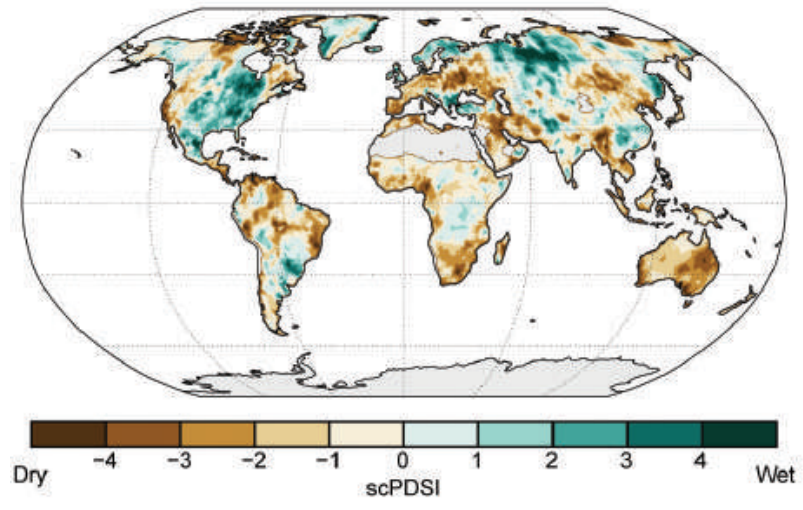

FIG. 2.30. Mean scPDSI for 20I5. Droughts are indicated by negative values (brown), wet episodes by positive values (green). No calculation is made where a drought index is meaningless (gray areas: ice sheets or deserts with approximately zero mean precipitation).

other tropical countries in the northern half of South America (Jimenez-Muñoz et al. 2016). Moderate to severe drought is apparent in south-central Chile, a region undergoing a seven-year drought (Garreaud et al. 2017). Farther north, scPDSI values for 2016 were below -2 (indicating moderate to severe drought) in Columbia, Nicaragua, Honduras, and El Salvador, contributing to food insecurity in the region. The Californian drought was still present in 2016 (Plate 2.1q), although markedly less severe than in 2015 (Fig. 2.30).

The pattern of drought across sub-Saharan Africa is typical of that following an El Niño event, with dry conditions over southern Africa, particularly concentrated over Botswana, Zimbabwe, eastern regions of South Africa, and southern Mozambique, and wetter conditions farther north over Tanzania. Moderate to severe drought conditions are indicated by scPDSI $<-2$ around the Persian Gulf and through Iran to Pakistan (Plate 2.1q). Conditions in parts of India were drier during 2016 than in 2015, whereas much

wetter conditions occurred across all of southern China. Farther north, negative (dry) values of scPDSI occurred over some regions of central Russia, but the remainder of extratropical Asia tended to be wetter than average. Dry conditions in Europe persisted or increased in the circum-Mediterranean, while much of Europe became wetter with the notable exception of eastern Europe. Droughts occurred in 2016 over the eastern half of Australia, parts of Indonesia, and Southeast Asia, as expected due to the strong El Niño event.

Similar to 2015, more than half of the land area south of $20^{\circ} \mathrm{N}$ was subject to some degree of drought in 2016. The area experiencing anomalously wet conditions, however, grew from $12 \%$ in 2015 to $17 \%$ in 2016 , with a corresponding reduction in areas close to normal scPDSI and intense wet conditions in a region spanning southern Brazil, Uruguay, northeastern Argentina, and in areas around Lake Victoria.

Drought in 2016 was among the most extensive in the post-1950 record, including for the severe and extreme drought categories of the scPDSI. The strong El Niño of 2015/16 influenced the pattern of drought across the world's continents, although regional weather patterns modified or even overcame this influence in some parts of the world. The expansion in drought-affected areas during 2015 and 2016 is similar to the earlier expansion during the 1982/83 strong El Niño event (Fig. 2.31), consistent with a reduction in the atmospheric transport of moisture from oceans to land during El Niño events (Dai 2013), although the increased drought area persisted for about four years beyond the dissipation of that $\mathrm{El}$ Niño event (Fig. 2.29). A similar expansion did not occur, however, during the other major El Niño of the last 35 years (1997/98; Fig. 2.31), highlighting the complexity of the link between El Niño events and global drought area and the diversity of event types (G. Xu et al. 2016).
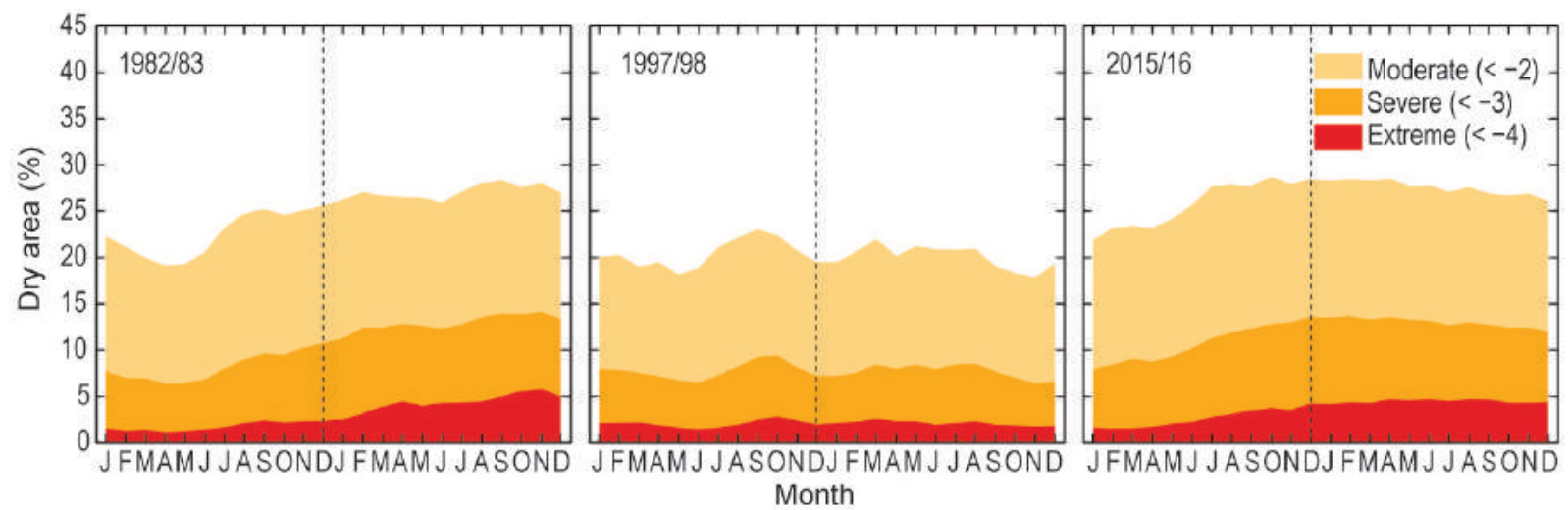

FiG. 2.3I. Comparison of global drought-affected areas (\%) for three strong El Niño events: 1982/83, 1997/98, and 2015/16. 
I0) Land evaporation-D. G. Miralles, B. Martens, H. E. Beck, A. J. Dolman, C. Jiménez, M. F. McCabe, and E. F. Wood

Terrestrial evaporation is an elusive variable: despite its pivotal role in linking water, energy, and biochemical cycles over land, global in situ measurements are scarce and satellites can only sense it indirectly. Nonetheless, pioneering efforts to infer evaporation from its satellite-observed environmental and climatic drivers (e.g., Price 1982; Nemani and Running 1989; Su 2002) have culminated in a range of datasets that can be used to monitor land evaporation dynamics at the global scale (e.g., Fisher et al. 2008; Miralles et al. 2011; Vinukollu et al. 2011; Yo. Zhang et al. 2016). While several international efforts remain focused on characterizing their uncertainties (McCabe et al. 2016; Miralles et al. 2016), these evaporation products are also being used to study a range of process behaviors, including: (1) trends in response to global warming (Jung et al. 2010; Yo. Zhang et al. 2016), (2) effects of internal climate variability on hydrology (Miralles et al. 2014b), (3) irrigation requirements in agricultural regions (Anderson et al. 2015), (4) evolution of drought conditions (Mu et al. 2013), and (5) role of land-atmospheric feedbacks during meteorological extremes (Miralles et al. 2014a).

Analyzing trends in continental evaporation facilitates the scrutiny of anticipated impacts of climate change on hydrology, such as the acceleration of the global water cycle or the dry gets drier, wet gets wetter hypothesis. Despite contrasting numbers found in the literature, the vast majority of studies report a mildly positive multidecadal trend during the satellite era (Miralles et al. 2014b; Yo. Zhang et al. 2016), although the reported trends are often not significant. Figure 2.32 shows the multidecadal terrestrial evaporation

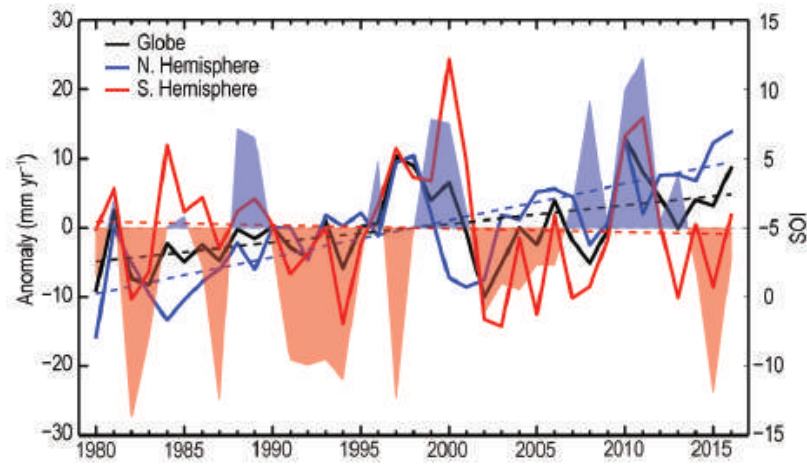

FIG. 2.32. Land evaporation anomaly $\left(\mathrm{mm} \mathrm{yr}^{-1}\right.$; $1980-$ 2016 base period) for the $\mathrm{NH}, \mathrm{SH}$, and the entire globe (solid lines). Linear trends are illustrated (dashed lines) and the values of the SOI (right axis, shaded area) are also shown. (Source: GLEAM.) response based on GLEAM v3 (Miralles et al. 2011; Martens et al. 2017). An indicative linear trend of approximately $0.3 \mathrm{~mm} \mathrm{yr}^{-1}(p=0.002)$ for the entire globe can be determined from this figure, and it is due to the increase in evaporation in the Northern Hemisphere with this value being qualitatively in agreement with Clausius-Clapeyron expectations in a warming atmosphere (Miralles et al. 2014b; Brutsaert 2016; Trenberth et al. 2003). At monthly and annual timescales, the variability in mean continental evaporation is strongly affected by ocean-atmosphere oscillations, particularly due to the imprint of ENSO in Southern Hemisphere water-limited ecosystems (Miralles et al. 2014b).

In 2016, the global average terrestrial evaporation was higher than the 1980-2016 mean (Fig. 2.32), mainly due to a positive anomaly in the Northern Hemisphere during spring and summer (Fig. 2.33). This anomalous behavior is attributed to the high atmospheric temperatures during those two seasons (not shown). As the atmosphere returned to normal from the strong 2015 El Niño event, the negative anomalies in precipitation-and subsequently land evaporation-dissipated in the Southern Hemisphere (Fig. 2.32). Regionally, 2016 experienced anomalously low evaporation in eastern South America, northern Amazonia, southern Africa, the Horn of Africa, India, and Southeast Asia (Plate 2.1r) - in most of these regions, the reduced evaporation was associated with anomalously low precipitation and drought conditions (Section 2d9). Areas of positive anomalies include western Sahel, central and eastern Asia, eastern Australia, and central North America. In the latter region, the high summer temperatures contributed to a positive evaporation anomaly during the early

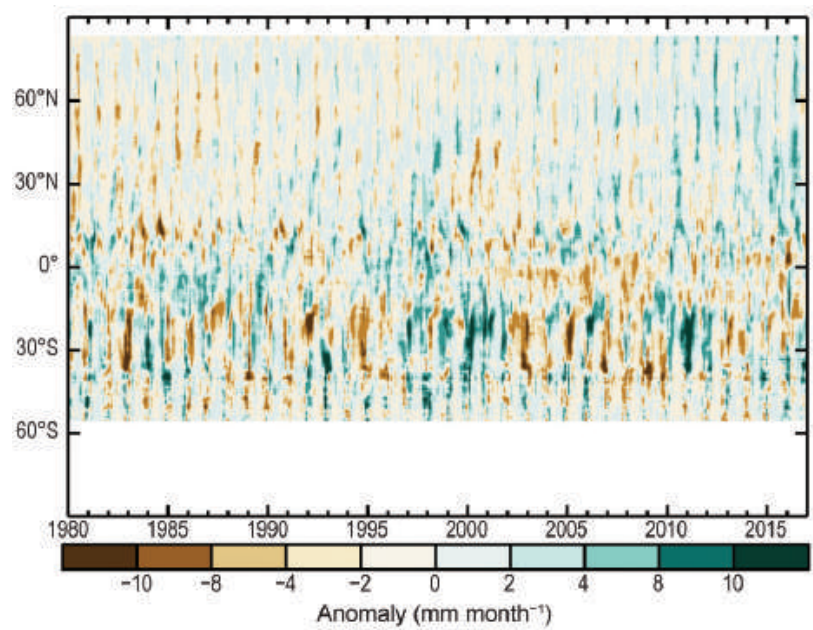

Fig. 2.33. Zonal mean terrestrial evaporation anomalies (mm month ${ }^{-1}$; relative to 1980-2016). (Source: GLEAM.) 
summer that exacerbated drying out the soils during early summer (NOAA 2017).

As a note of caution, anomalies and trends in satellite-based evaporation should be interpreted with considerable care, due to accuracy issues in the satellite and meteorological forcing, parameterization uncertainties, and choice of retrieval algorithms (Ershadi et al. 2014; Martens et al. 2017). Thus, the weighted use of multiple retrieval approaches is usually advised (Miralles et al. 2016; McCabe et al. 2016). While the operational monitoring of continental evaporation is becoming a realistic proposition (Ghilain et al. 2011; Anderson et al. 2011), current algorithms dedicated to estimating evaporation from satellite observations at global scales are mostly intended for research applications and are not currently updated in near-real time.

\section{e. Atmospheric circulation}

I) Mean sea level pressure and related modes of VARIABILITY-R. Allan and C. K. Folland

Mean sea level pressure (MSLP) data reveal the major modes of variability that drive significant weather and climate events (Kaplan 2011). Arguably, the most globally impactful mode is the El NiñoSouthern Oscillation (ENSO), for which the sea level pressure-derived Southern Oscillation index (SOI; Allan et al. 1996; Kaplan 2011) is an indicator. For 2015 through mid-2016, the SOI was negative, indicating the presence of an El Niño that was the strongest since that of $1997 / 98$ (see Chapter 4b).

The SOI since 2009 showed a shift from El Niño to strong La Niña conditions around mid-2010, which persisted until its demise in early 2012, followed by near-normal conditions until early 2013. A swing to negative (El Niño-type) conditions occurred in early 2014 (Fig. 2.34b). The SOI was negative from February 2014 until April 2016 (except April-May 2014 and February 2015; see Fig. 2.34b). Hence, the Niño-3 and -4 regions of sea surface temperature (SST) anomalies

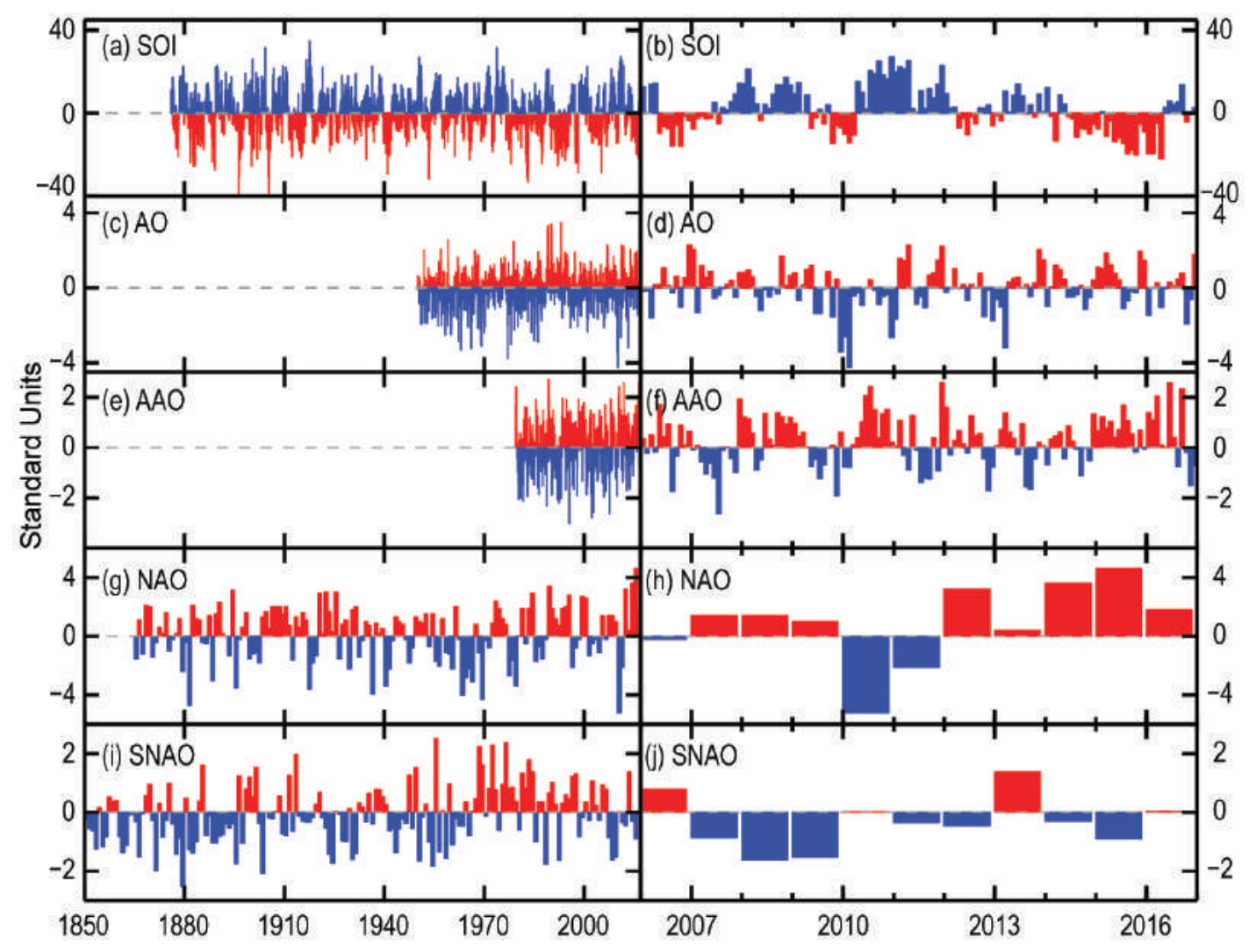

FIG. 2.34. Time series for modes of variability described using sea level pressure for the (left) complete period of record and (right) 2006-16. (a),(b) SOI (provided by the Australian Bureau of Meteorology); (c),(d) AO (NCEP Climate Prediction Center); (e),(f) AAO (NCEP Climate Prediction Center); (g),(h) winter (Dec-Feb) NAO average (NCAR; presented for winter at the beginning of each year so winter 2016/17 is not shown); (i),(j) summer (Jul-Aug) SNAO average (Folland et al. 2009). 
were positive from April and February 2014 until June and August 2016, respectively (see Chapter 4b). Following the definition in Allan and D'Arrigo (1999), this constitutes a protracted El Niño episode. Figures $2.34 \mathrm{a}, \mathrm{b}$ show the presence of these protracted El Niño and La Niña episodes in the SOI record since 1876 , demonstrating that they can last up to six years (e.g., the 1990-95 protracted El Niño; see Gergis and Fowler 2009).

Owing to ocean-atmosphere interactions across the Indo-Pacific region, major El Niño and La Niña events can be near-global in their influence on world weather patterns via teleconnections to higher latitudes. Protracted El Niño and La Niña episodes tend to be more regional in their impacts (Allan and D’Arrigo 1999; Allan et al. 2003). As an example from Australia: in Queensland, the main impact appears to be periods of persistent drought (widespread flooding), which often occur during protracted El Niño (La Niña) episodes (Murphy and Ribbe 2004). The dry 2014 through mid-2016 period across much of Queensland reflects this latest protracted El Niño episode. Since May 2016, the SOI has been around neutral conditions.

More regionally, the Arctic Oscillation (AO), North Atlantic Oscillation (NAO), and the Antarctic Oscillation (AAO) indices can also be derived from MSLP (Figs. 2.34c-h). In the Northern Hemisphere, the last six winters have displayed broadly positive NAO conditions but a diverse range of circulation patterns. During the 2014/15 boreal winter the NAO was mainly positive, the North Pacific anticyclone was weak, and the Aleutian low was prominent (Figs. $2.34 \mathrm{~g}, \mathrm{~h}, 2.35 \mathrm{a}$ ). By contrast, during the early winter of 2015/16 the NAO oscillated between phases, with a deep trough over the North Atlantic leading to an enhanced jet stream that directed a series of extratropical cyclones towards northern Ireland and Scotland-northern England (Figs. 2.34g,h, 2.35b,e). By the mid-to-latter part of the 2015/16 winter the pattern had changed, with the NAO swinging from slightly negative in January to positive in February. The Aleutian low was enhanced, favoring downstream troughs over the North Atlantic-northern Europe sector and a northerly displacement of midlatitude storm tracks. Overall, it was the second wettest winter on record for the United Kingdom with $159 \%$ of normal rainfall, behind 2013/14 which saw $167 \%$, and the wettest on record for Ireland. The 2016/17 boreal winter was marked by an increasingly positive NAO through mid-December 2016, temporarily negative NAO values around the start of 2017, and then a fluctuation between phases for the rest of January (Figs. 2.34g,h, (a)

(a) $2014 / 15$

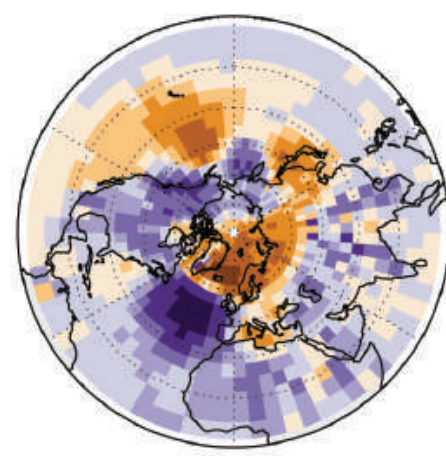

(b) $2015 / 16$

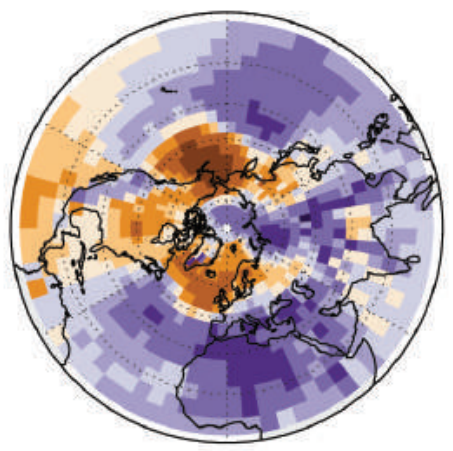

(c) $2016 / 17$
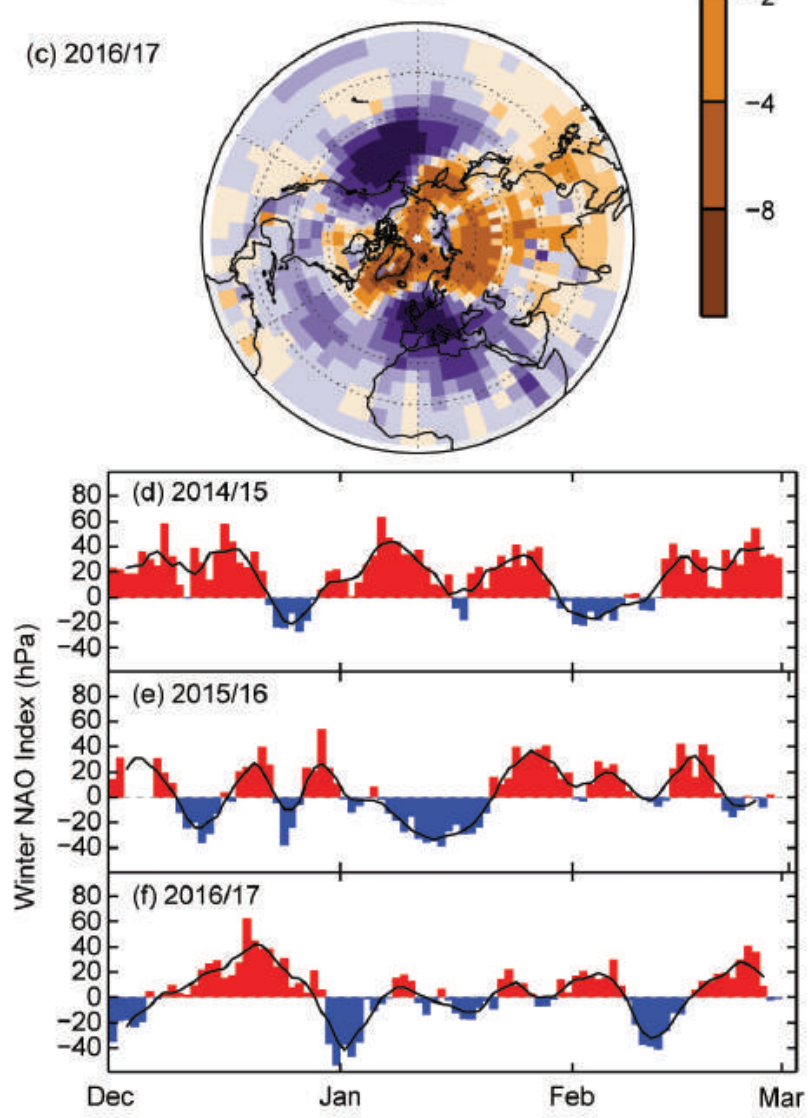

Fig. 2.35. (a) Boreal winter sea level pressure anomalies (hPa; 198I-2010 base period) averaged over Dec-Feb for (a) $2014 / 15$, (b) $2015 / 16$, and (c) 2016/17. (d) NAO daily time series $(\mathrm{hPa})$ for winter (d) 2014/15, (e) 2015/16, and $(f) 2016 / 17$. The 5 -day running mean is shown by the solid black line. The data are from HadSLP2r (AIlan and Ansell 2006). 
$2.35 \mathrm{c}, \mathrm{f})$. The Aleutian low was markedly weakened, and winter storminess over the United Kingdom to western European region was reduced. Values of various UK precipitation series for October 2016 through January 2017 were drier than their counterparts a year earlier.

In 2016, the phase of the summer NAO (SNAO), defined over July and August as in Folland et al. (2009), was on average near neutral (Fig. 2.36a,b). There was a persistent region of anticyclonic anomalies over Greenland, normally associated with a negative SNAO, offset by further anticyclonic anomalies in the Atlantic west of western Europe extending toward Scandinavia with weak negative anomalies in between. Overall, July 2016 showed a weak negative SNAO and August a positive SNAO. Intraseasonal variability was quite large (Fig. 2.36c) compared to the July-August mean SNAO which shows a generally negative level but no trend in recent years. There is

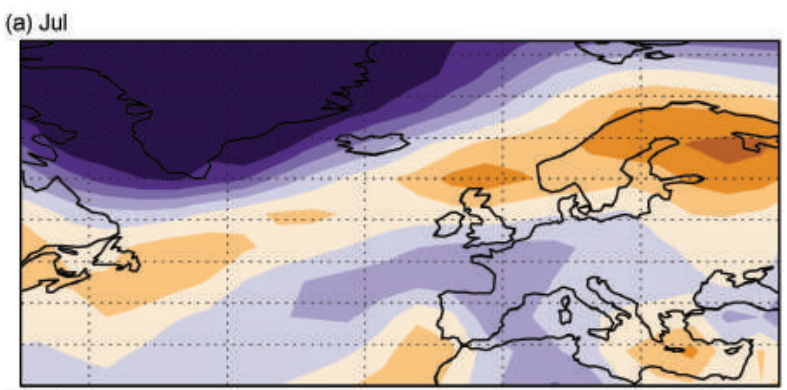

(b) Aug

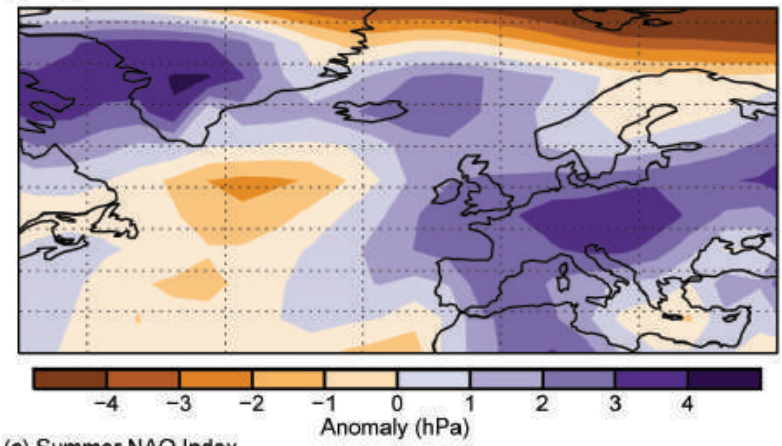

(c) Summer NAO Index

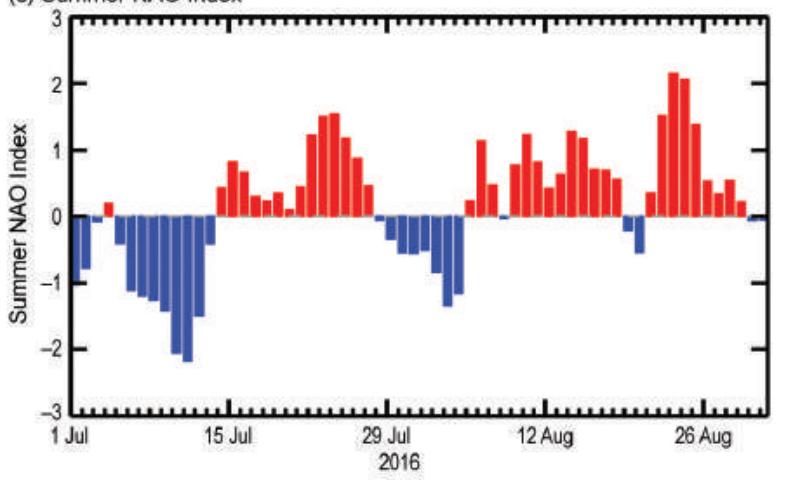

Fig. 2.36. MSLP (hPa) in (a) Jul and (b) Aug 2016 using HadSLP2r; (c) daily SNAO in Jul and Aug 2016. a continuing tendency toward a more negative JulyAugust SNAO on decadal timescales since 1970 (Figs. $2.34 \mathrm{i}, \mathrm{j})$. The current decadally averaged SNAO is at a similar level to its long-term average over 1850-1960. The decline in recent decades, however, has been from exceptionally positive levels in the 1970s.

In the Southern Hemisphere, the AAO was in its positive phase during 2015/16 (Figs. 2.34e,f), which favors reduced sea ice extent in the West Antarctic Peninsula (WAP) region, owing to enhanced westerly wind conditions (Stammerjohn et al. 2008). During 2015, however, the WAP sea ice margins were extended (http://nsidc.org/data/seaice_index) but had retreated to near-normal extent in 2016. In the interplay between the protracted El Niño, which favors a weaker polar jet stream, and a positive AAO mode, with stronger westerly winds, the former appeared to have dominated. Related positive wind speed anomalies were noted at $850 \mathrm{hPa}$ (Section 2e3) over the midlatitude Southern Ocean. However, with the cessation of the protracted El Niño episode in mid2016 and the AAO becoming negative (Fig. 2.34f), there has been a major reduction in the WAP sea ice margin since November 2016 (http://nsidc.org/data /seaice_index).

2) Surface Winds - C. Azorin-Molina, R. J. H. Dunn, C. A. Mears, P. Berrisford, and T. R. McVicar

Surface wind speed slightly declined over land in 2016 (relative to 2015 and the climatology; Plate 2.1u; Fig. 2.37a), with an observed global (excluding Australia) average anomaly from the 1981-2010 climatology of $-0.006 \mathrm{~m} \mathrm{~s}^{-1}$ (Table 2.4). After a continuous slowdown of wind speed (termed "stilling"; Roderick et al. 2007) from the beginning of records in 1973, this negative but nearly zero anomaly confirms indications of a "recovery" of wind speed since 2013 (Kim and Paik 2015; Dunn et al. 2016a). Although negative anomalies were reported for the North America $\left(-0.083 \mathrm{~m} \mathrm{~s}^{-1}\right)$, Europe $\left(-0.073 \mathrm{~m} \mathrm{~s}^{-1}\right)$, and Australia $\left(-0.008 \mathrm{~m} \mathrm{~s}^{-1}\right)$ in 2016, all of them are less negative than the lowest values reached (in around 2013). This recent strengthening in terrestrial wind speed is more evident in central $\left(+0.108 \mathrm{~m} \mathrm{~s}^{-1}\right)$ and East $(+0.084 \mathrm{~m}$ $\left.\mathrm{s}^{-1}\right)$ Asia, both showing positive anomalies in 2016 . The occurrence of moderate $\left(>3 \mathrm{~m} \mathrm{~s}^{-1}\right)$ and strong $(>10$ $\mathrm{m} \mathrm{s}^{-1}$ ) winds (Figs. 2.37b,c) exhibited a different longterm behavior: moderate winds displayed no trend at all or a weakly increasing trend in agreement with the recent recovery mentioned above. Strong winds showed the opposite pattern, reaching the second lowest percentage of occurrence (2.04\%) globally in 2016. 


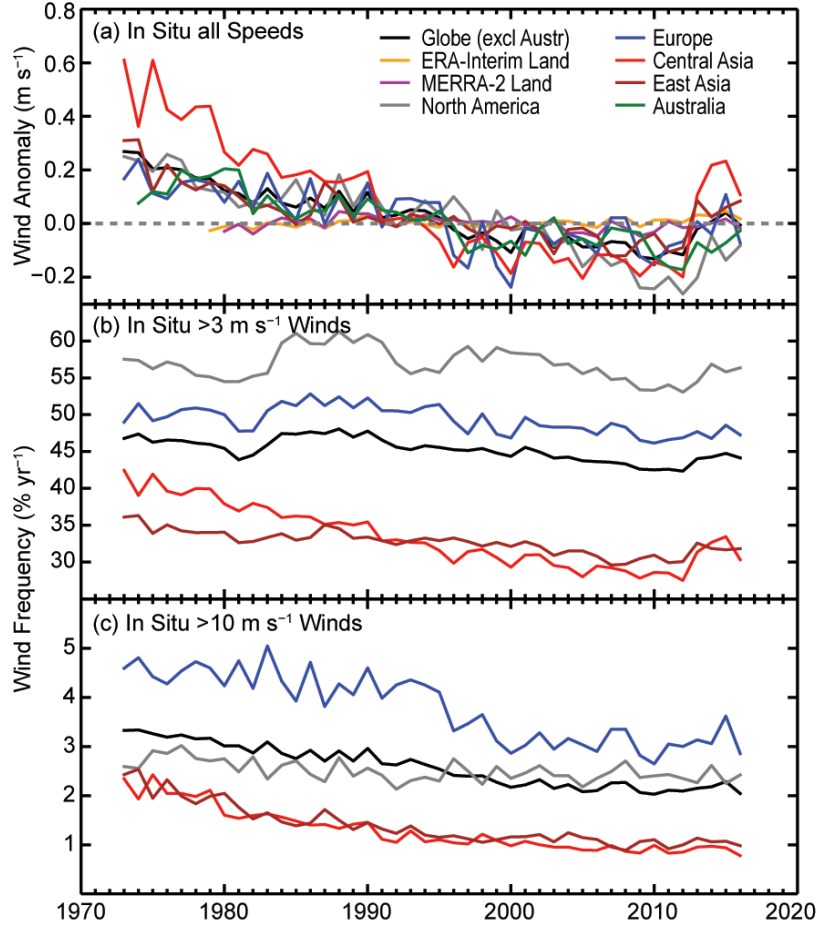

FIG. 2.37. (a) Land surface wind speed anomalies $\left(\mathrm{m} \mathrm{s}^{-1}\right)$ for 1973-2016, relative to 1981-2010: HadISD2 for the globe (excluding Australia) and 4 regions; Australia (1974-2016) is based on an Australian dataset. ERA-interim (1979-2016) and MERRA-2 (1980-2016) anomalies, also shown, cover all land areas. Occurrence frequencies (in \%) for wind speeds (b) $>3 \mathrm{~m} \mathrm{~s}^{-1}$ and (c) $>10 \mathrm{~m} \mathrm{~s}^{-1}$ do not include Australia.
The assessment of the spatial and temporal variability of surface wind speed in 2016 is based on two quality-controlled datasets from anemometer observation records: (1) the global HadISD2 (19732016; Dunn et al. 2012, 2016b) and (2) an Australian database (1974-2016; McVicar et al. 2008). As the spatial representativeness of these site-specific wind speed observations is limited (2625 stations in total), with low-density in, for example, South America and Africa, 10-m wind speed fields from the MERRA-2 (1980-2016; Gelaro et al. 2017) and the ERA-Interim reanalysis (1979-2016; Dee et al. 2011) are used to cover contiguous global scales (including ocean surfaces). Reanalysis products have the ability to provide global wind speed data, although investigations have detected shortcomings in the simulation of near-surface layer processes (e.g., McVicar et al. 2008; Pryor et al. 2009; Vautard et al. 2010).

Over land, during 1979-2016, observed longterm trends of wind speed were slightly negative for all regions, with a global declining change of $-0.070 \mathrm{~m} \mathrm{~s}^{-1}$ decade $^{-1}$, being more negative in Australia $\left(-0.068 \mathrm{~m} \mathrm{~s}^{-1}\right.$ decade $\left.^{-1}\right)$ and less negative in East Asia $\left(-0.043 \mathrm{~m} \mathrm{~s}^{-1}\right.$ decade $\left.^{-1}\right)$ (Table 2.4). In comparison to 1979-2015 trends reported in Dunn et al. (2016a), inclusion of 2016 means linear trends are less negative due to the recent "recovery". This means that the sign and in particular the magnitude of trends are strongly sensitive to the period considered (Azorin-Molina et al. 2014). Despite the slight slowdown of terrestrial 1979-2016 wind speed, Fig. 2.38 displays a clear dominance of stations showing

\begin{tabular}{|c|c|c|c|c|}
\hline \multicolumn{5}{|c|}{$\begin{array}{c}\text { TABLE 2.4. Global and regional statistics for land-surface wind speed } \\
\text { using observational HadISD2 and Australian (McVicar et al. 2008) da- } \\
\text { tasets for } 1979-2016 \text {. Trend column includes 5\%-95\% confidence range. }\end{array}$} \\
\hline Region & $\begin{array}{c}\text { Mean } \\
198 I-2010 \\
\left(\mathbf{m ~ s}^{-1}\right)\end{array}$ & $\begin{array}{c}\text { Anomaly } \\
\mathbf{2 0 1 6} \\
\left(\mathbf{m ~ s}^{-1}\right)\end{array}$ & $\begin{array}{c}\text { Trend 1979-2016 } \\
\left(\mathbf{m ~ s}^{-1} \text { decade }\right.\end{array}$ & $\begin{array}{c}\text { Number of } \\
\text { Stations }\end{array}$ \\
\hline $\begin{array}{c}\text { Globe } \\
\text { (excluding } \\
\text { Australia) }\end{array}$ & 3.327 & -0.006 & $\begin{array}{c}-0.070 \\
(-0.077 \rightarrow-0.062)\end{array}$ & 2584 \\
\hline $\begin{array}{c}\text { North } \\
\text { America }\end{array}$ & 3.715 & -0.083 & $\begin{array}{c}-0.093 \\
(-0.105 \rightarrow-0.081)\end{array}$ & 588 \\
\hline $\begin{array}{c}\text { Europe } \\
\text { Central }\end{array}$ & 3.663 & -0.073 & $\begin{array}{c}-0.057 \\
(-0.069 \rightarrow-0.045)\end{array}$ & 777 \\
\hline Asia & 2.875 & +0.108 & $\begin{array}{c}-0.132 \\
(-0.148 \rightarrow-0.105)\end{array}$ & 258 \\
\hline East Asia & 2.739 & +0.084 & $\begin{array}{c}-0.043 \\
(-0.052 \rightarrow-0.035)\end{array}$ & 460 \\
\hline Australia & 2.066 & -0.008 & -0.068 & 41 \\
\hline
\end{tabular}
negative trends from the observed HadISD2 and the Australian dataset (65.6\%) over those reporting positive trends (34.4\%), especially for Northern Hemisphere midlatitudes. This agrees with the worldwide slowdown of terrestrial wind speed reviewed by McVicar et al. (2012). The wind speed anomalies and trends over land from ERAInterim and MERRA-2 underestimate the magnitude of changes seen in the station-based datasets, as discussed in previous studies (McVicar et al. 2008; Pryor et al. 2009; Vautard et al. 2010). 


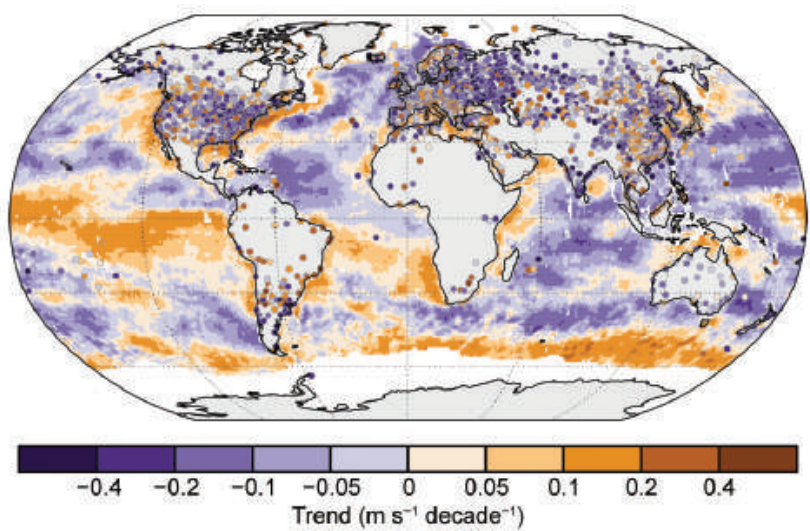

FIG. 2.38. Wind speed trends $\left(\mathrm{m} \mathrm{s}^{-1}\right.$ decade $\left.^{-1}\right)$ for the observational HadISD2 and Australian datasets (points) over land for 1979-2016, and the observational RSS radiometer over ocean for 1988-2016.

The attribution of long-term terrestrial wind speed trends, including the recent "recovery", is uncertain as different possible causes are occurring simultaneously and the mechanisms behind them likely vary spatio-temporally. The declining trend over the last 35 years has been attributed to, for example, changes in large-scale atmospheric circulation (Azorin-Molina et al. 2014, 2016); an increase of surface roughness (Vautard et al. 2010; Bichet et al. 2012; Wever 2012; Wu et al. 2016); instrumentation changes (Wan et al. 2010) and different measurement time intervals (Azorin-Molina et al. 2017); and air pollution (Xu et

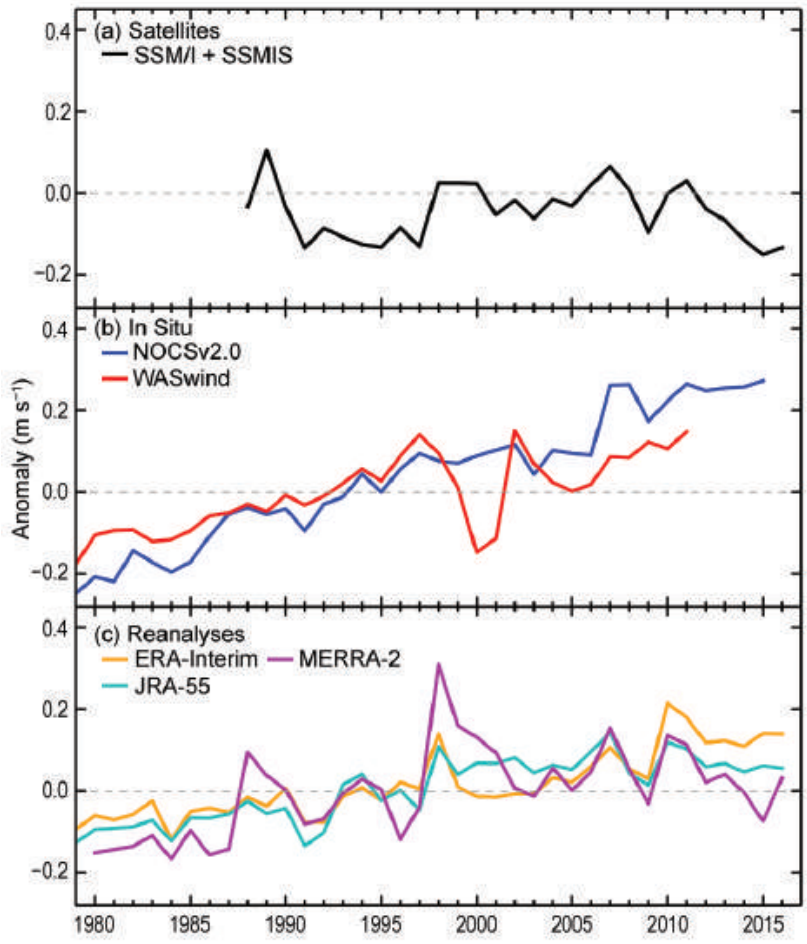

Fıg. 2.39. Global average surface wind anomaly $\left(\mathrm{m} \mathrm{s}^{-1}\right)$ over ocean relative to the $1981-2010$ base period from (a) satellite radiometers, (b) in situ, and (c) reanalyses. al. 2006). In contrast, the recent wind speed recovery has, to date, been poorly analyzed. Kim and Paik (2015) attributed this recovery to an increase of the spatial variance in near-surface air temperature.

Over oceans, estimates of globally averaged wind speed obtained from satellite-borne microwave radiometers continued to be lower than average in 2016 (Wentz 1997; Wentz et al. 2007). Reanalysis winds over oceans, which are in relatively good agreement with both the satellite data and with each other from 1990 to 2009, diverge after 2010 (Fig. 2.39). All products show an increasing trend from 1990 to 2007 , followed by a decline in 2008/09, and a recovery in 2010/11. Since then the wind speeds have fallen substantially in the satellite and MERRA-2 products but remained roughly constant for ERA-Interim and JRA-55. During 2016, winds showed large negative anomalies across the tropical Pacific and Indian Oceans (Plate 2.1u). Other ocean regions with negative anomalies include much of the southern Pacific and regions in the North Atlantic. The North Pacific showed large positive anomalies, with smaller positive anomalies present in the western North Atlantic and the southern Indian and Atlantic Oceans.

3) UPPER AIR WINDS-L. Haimberger and M. Mayer

Upper air winds and their related potential and stream functions are essential climate variables that can indicate changes in planetary scale circulation patterns. During 2016, one of the strongest El Niños in recent decades decayed. As discussed in last year's report, the impact of the 2015/16 El Niño on upperlevel divergent winds was weaker than that of the $1997 / 98$ event. During the second half of 2016, weak La Niña conditions developed in the tropical Pacific. Anomalies of velocity potential and divergent winds at $200 \mathrm{hPa}$ from ERA-Interim in November 2016 (Fig. 2.40b) are compared to those of November 1998 (Fig. 2.40a), when La Niña conditions prevailed. In both years, there is a distinct quadrupole pattern of anomalous upper-level divergence over the IndoPacific warm pool and the tropical Atlantic and anomalous upper-level convergence over the central to eastern Pacific as well as the Indian Ocean. This pattern is consistent with Mayer et al. $(2013,2014)$, who found a similar quadrupole anomaly pattern in the divergence of atmospheric energy transports and ocean heat content changes associated with La Niña.

Over the Pacific, anomalies of upper-level divergent winds seem to be weaker in 2016 compared to 1998, consistent with comparatively weak negative SST anomalies in the eastern equatorial Pacific. In contrast, the anomalous convergence over the Indian 
(a)

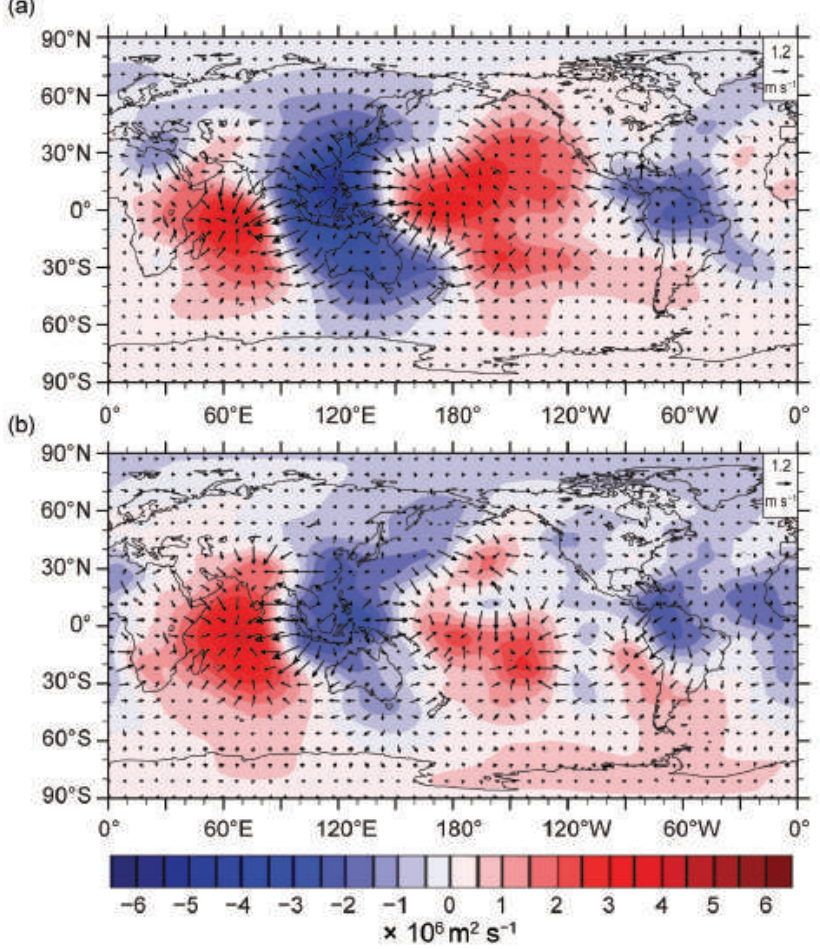

FIG. 2.40. Three-month averages of velocity potential $\left(\times 10^{6} \mathrm{~m}^{2} \mathrm{~s}^{-1}\right)$ and divergent wind at $200 \mathrm{hPa}$ compared to the 1979-2014 average. Anomalies centered around (a) Nov 1998 and (b) Nov 2016.

Ocean was strong, in agreement with severe drought conditions in eastern Africa. Consistent with the shift in the divergence patterns, the number of central $\mathrm{Pa}$ cific hurricanes (2) and Indian Ocean cyclones (1) was much lower than in 2015, while storm counts were high in the eastern Pacific (13) and western Pacific (13; where the storm season started late due to El Niño conditions in boreal spring but became very active in boreal autumn), as well as in the Atlantic (7).

The quasi-biennial oscillation $(\mathrm{QBO})$, perhaps the most prominent stratospheric global oscillation phenomenon, is interesting because it reveals the limitations of our ability to reconstruct the stratospheric circulation with data from the mid-20th century observing system. This year it also deserves special attention because tropical stratospheric winds exhibited a strongly anomalous behavior in the first half of 2016. Figure 2.41 shows series of tropical and northern subtropical upper-air winds from observations and reanalyses since the mid-20th century. Radiosonde and pilot balloon are the best sources for station-based upper air wind climatologies, with data back to the early 1940s in the northern extratropics. Reanalyses need upper air information to capture the QBO, as can be seen from the increasingly better depiction with the ERA-preSAT (Hersbach et al. 2017) experimental assimilation run. Surface data-only reanalyses, which extend further back, currently do not capture the QBO. As suggested by the QBO reconstruction of Brönnimann et al. (2007) in Fig. 2.41c there is, however, enough information back to 1908 to reconstruct the state of the QBO. In the most recent years the agreement between reanalyses in terms of zonal mean winds is excellent.

As noted by Newman et al. (2016) and Dunkerton (2016) the strong 2015/16 El Niño may have also impacted the QBO, which exhibited a highly unusual and strong upward propagation of equatorial wind regimes, particularly between $10 \mathrm{hPa}$ and $40 \mathrm{hPa}$.
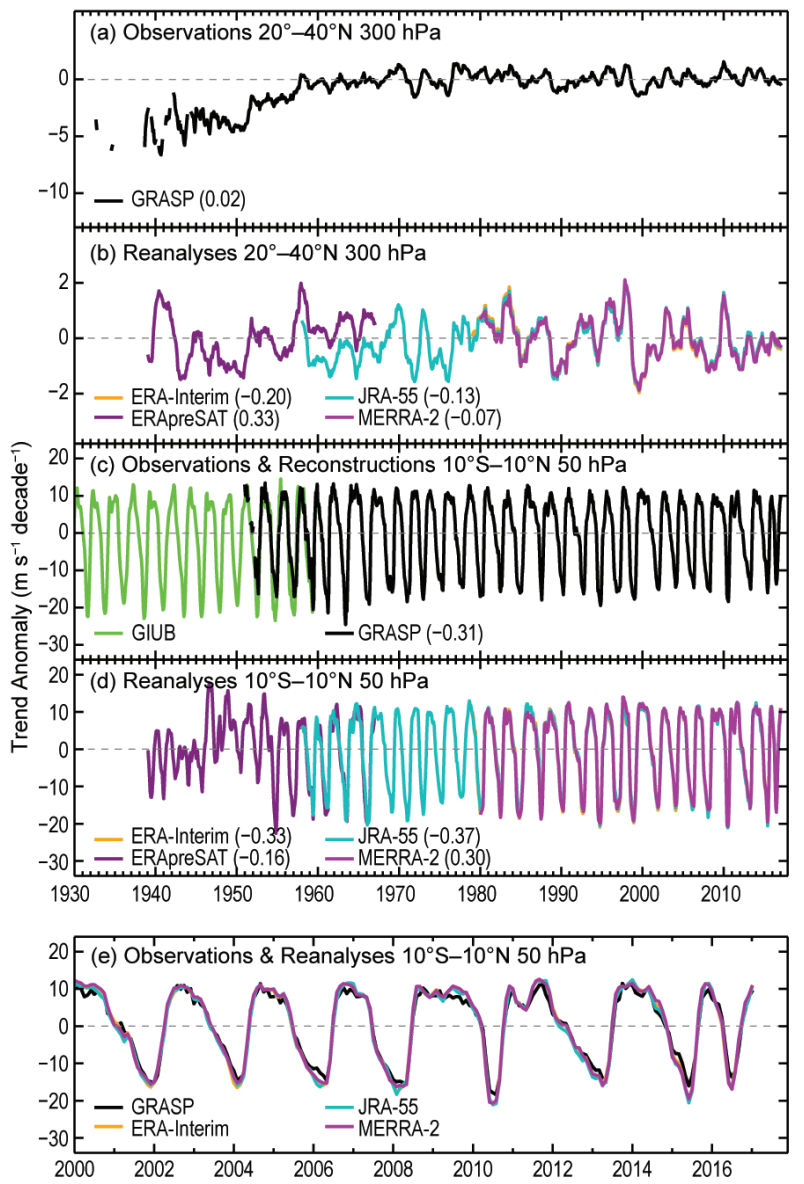

Fig. 2.4I. Time series of zonal mean $\mathrm{U}$-wind component in the $20^{\circ}-40^{\circ} \mathrm{N}$ belt at $300 \mathrm{hPa}$ from (a) radisondes and tracked balloons and (b) reanalyses; smoothed using a 12-point boxcar filter. Time series in the tropical belt $10^{\circ} \mathrm{N}-10^{\circ} \mathrm{S}$ at $50 \mathrm{hPa}$, calculated from (c) pilot balloon/radiosonde winds (GRASP; Ramella-Pralungo et al. 2014) and statistical reconstructions from (GIUB; Brönnimann et al. 2007). (d) ERA-Interim, MERRA-2, JRA-55 and ERA-preSAT reanalyses. (e) Same as (d) but for 2000-17 period only. Values in the legend are linear trends between $198 \mathrm{I}$ and $2010\left(\mathrm{~m} \mathrm{~s}^{-1}\right.$ decade $\left.{ }^{-1}\right)$. Trends for ERApreSAT and GIUB are for 1940-60. Note that positive (negative) changes in the zonal wind speed imply an increase in westerlies (easterlies). 
This upward propagation, which cannot be explained by the QBO standard model, is unique since observations began in 1953 and was observed during the whole boreal spring of 2016. It is visible also in Figs. 2.41d,e as the very last westward wind maximum occurring only one year after the "regular" westward wind maximum in 2015. Osprey et al. (2016) attribute the QBO disruption more to influences from Northern Hemisphere midlatitudes. It will be interesting to follow the QBO after this disruption.

\section{f. Earth radiation budget}

I) EARTH RADIATION BUDGET AT TOP-OF-ATMOSPHERED. P. Kratz, P. W. Stackhouse Jr., T. Wong, P. Sawaengphokhai, A. C. Wilber, S. K. Gupta, and N. G. Loeb

Earth's radiation budget (ERB) at the top-of-atmosphere (TOA) represents the balance of the incoming total solar irradiance (TSI), the reflected shortwave (RSW), and the outgoing longwave radiation (OLR). This balance defines the energetic state of the Earthatmosphere system, which drives weather processes, climate forcing, and climate feedbacks.

The years 2015 and 2016 were remarkable for the rise and fall of the most intense El Niño event to occur since the exceptionally strong 1997/98 El Niño event (see Chapter $4 \mathrm{~b}$ ). Having fully developed by May 2015, the 2015/16 El Niño remained strong through early 2016, as enumerated by the multivariate ENSO index (MEI; Wolter and Timlin 1993, 1998; www .esrl.noaa.gov/psd/enso/mei). After April 2016, however, the MEI index began a rapid decline, falling to roughly neutral levels by August, thereafter remaining relatively neutral through December. This latest El Niño event provided a stark contrast to the overall neutral conditions observed in 2013, the last relatively ENSO neutral year. The global-annual mean OLR in 2016 was $\sim 0.70 \mathrm{~W} \mathrm{~m}^{-2}$ higher and the global-annual mean RSW was $\sim 0.90 \mathrm{~W} \mathrm{~m}^{-2}$ lower when compared to 2013 (Table 2.5). The combination of the individual components amounted to an increase of $\sim 0.15 \mathrm{~W} \mathrm{~m}^{-2}$ in the total net radiation into Earth's climate system relative to 2013, indicating net heating for 2016. The magnitude of the global-annual mean changes appears to be increasing relative to the ENSO neutral year of 2013, perhaps indicative of the atmospheric response due to the circulation anomalies over the past few years. Relative to the long-term average (2001-15), the global-annual mean flux anomalies (Table 2.5) for 2016 are, respectively, $+0.65,-0.05,-0.70$, and 0.00

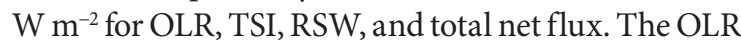
and RSW anomalies were outside the corresponding 2 -sigma interannual variability for this period and, thus, are significant. The positive 2016 OLR anomaly is most likely due to the strong El Niño. The negative 2016 global-annual mean RSW flux anomaly exceeds typical interannual variability, implying a darkening of Earth's TOA albedo. Interestingly enough, however, the large OLR and RSW anomalies in 2016 nearly canceled each other to produce an essentially zero global mean total net flux.

The monthly mean anomaly in the TOA flux time series (Fig. 2.42) for 2016 reveals that the OLR anomaly fluctuated between a maximum of $+1.7 \mathrm{~W} \mathrm{~m}^{-2}$ and a minimum of $0 \mathrm{~W} \mathrm{~m}^{-2}$. Indeed, the amplitude of the anomalies for the first five to six months was often greater than $0.8 \mathrm{~W} \mathrm{~m}^{-2}$. The rapid decrease in the strength of the El Niño thereafter corresponded well with the MEI values. Overall, this led to a large posi-
TABLE 2.5. Global annual mean TOA radiative flux changes between 2016 and 2013 (the last non-EI Nino year), and between 2016 and 2015 for the outgoing longwave radiation (OLR), total solar irradiance (TSI), reflected shortwave (RSW) and total net fluxes. The global annual mean radiative flux anomalies relative to their corresponding 200I-I5 mean climatological values, and the 2 -sigma interannual variabilities of the 200I-I5 global annual mean fluxes are also shown. All units are in $\mathrm{W} \mathrm{m}^{-2}$ and all flux values have been rounded to the nearest 0.05 $\mathrm{W} \mathrm{m}^{-2}$ (round off errors account for components not adding to Net).

\begin{tabular}{|c|c|c|c|c|}
\hline & \multicolumn{2}{|c|}{ Global Annual Mean Difference } & \multirow{2}{*}{$\begin{array}{l}2016 \text { Anomaly } \\
\left(\mathrm{W} \mathrm{m}^{-2}\right)\end{array}$} & \multirow{2}{*}{$\begin{array}{c}\text { Interannua } \\
\text { variability } \\
\left(\mathrm{W} \mathrm{m}^{-2}\right)\end{array}$} \\
\hline & $\begin{array}{c}2016 \text { minus } 2013 \\
\left(\mathrm{~W} \mathrm{~m}^{-2}\right)\end{array}$ & $\begin{array}{c}2016 \text { minus } 2015 \\
\left(\mathrm{~W} \mathrm{~m}^{-2}\right)\end{array}$ & & \\
\hline OLR & +0.70 & +0.40 & +0.65 & \pm 0.60 \\
\hline TSI & -0.05 & -0.10 & -0.05 & \pm 0.15 \\
\hline RSW & -0.90 & -0.15 & -0.70 & \pm 0.55 \\
\hline Net & +0.15 & -0.35 & +0.00 & \pm 0.65 \\
\hline
\end{tabular}

tive annual OLR anomaly (see Table 2.5) with generally higher values near the equinoxes. This observed OLR variability is generally consistent with the NOAA-HIRS OLR (Lee et al. 2011). Meanwhile, the absorbed shortwave (TSI minus RSW) anomaly began the year at +0.5 $\mathrm{W} \mathrm{m} \mathrm{m}^{-2}$, followed by a general oscillating increase to a value around $+0.8 \mathrm{~W} \mathrm{~m}^{-2}$ at year's end. The overall positive values for 2016 led to a large absorbed shortwave anomaly for the year. The total net anomaly, representing the combined OLR and absorbed shortwave anomalies, began 2016 with a value 


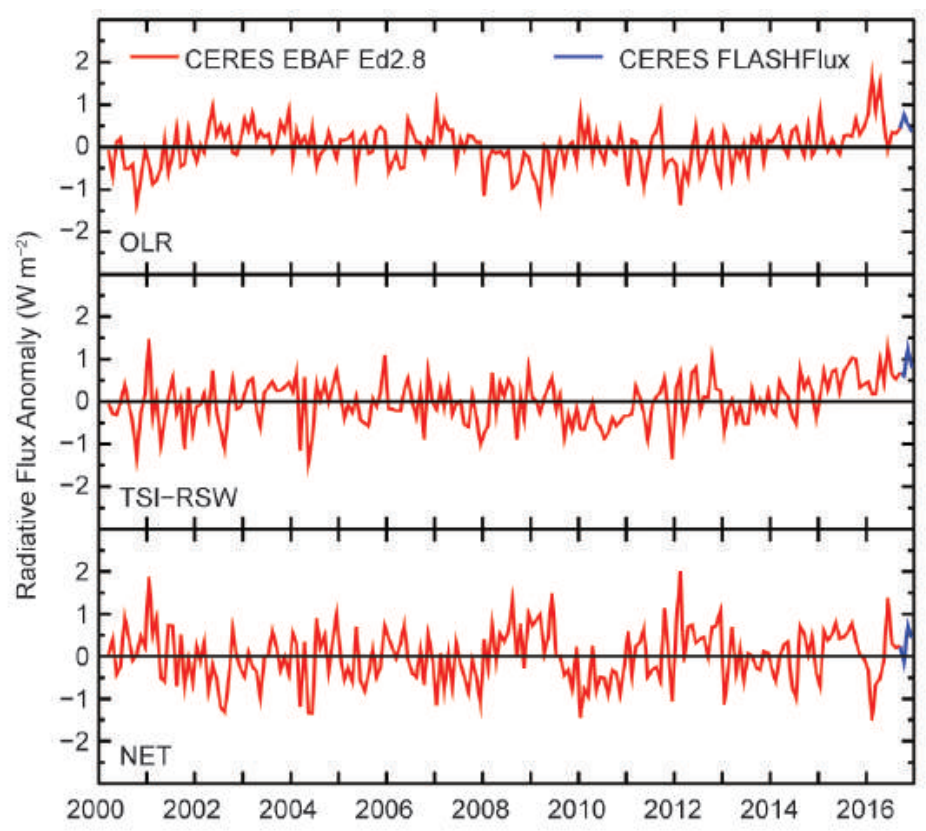

FIG. 2.42. Time series of global monthly mean deseasonalized anomalies ( $\mathrm{W} \mathrm{m}^{-2}$ ) of TOA Earth radiation budget for OLR (upper), absorbed shortwave (TSI-RSW; middle), and total net (TSI-RSW-OLR; lower) from Mar 2000 to Dec 2016. Anomalies are relative to their calendar month climatology (200I-I5). The time series shows the CERES EBAF Ed2.8 IDeg data (Mar 2000-Sep 2016) in red and the CERES FLASHFlux version 3B data (Oct-Dec 20l6) in blue; see text for merging procedure (Sources: https://ceres.larc.nasa.gov/compare_products.php and https://eosweb.larc.nasa.gov/project/ceres/ceres_table.)

of $-0.3 \mathrm{~W} \mathrm{~m}^{-2}$, fell to $-1.5 \mathrm{~W} \mathrm{~m}^{-2}$, then recovered to positive values peaking in June at $+1.4 \mathrm{~W} \mathrm{~m}^{-2}$ before remaining mostly positive, oscillating between -0.15 and $+0.74 \mathrm{~W} \mathrm{~m}^{-2}$ for the remainder of the year. The periods of negative net anomalies occurred during the El Niño, and the positive net anomalies occurred after the El Niño had decayed. These offsetting positive and negative values tended to cancel, thereby producing essentially no annual total anomaly in the net flux.

The TSI data used in this study are provided by the Total Irradiance Monitor aboard the Solar Radiation and Climate Experiment (SORCE) spacecraft (Kopp and Lean 2011) and by the Royal Meteorological Institute of Belgium composite dataset (Dewitte et al. 2004), both renormalized to the SORCE Version 15. The RSW and OLR data were obtained from the Clouds and the Earth's Radiant Energy System (CERES) mission (Wielicki et al. 1996; 1998) aboard Terra and Aqua.

The time series (Fig. 2.42) was constructed from the CERES EBAF (Energy Balanced And Filled) Ed2.8 product (Loeb et al. 2009; 2012) for March 2000 to September 2016 and from the CERES Fast Longwave and Shortwave Radiative Fluxes (FLASHFlux) products (Kratz et al. 2014) for October to December 2016.
The normalization of the FLASHFlux data (Stackhouse et al. 2016) results in a 2-sigma monthly uncertainty of $\pm 0.23, \pm 0.08, \pm 0.19$ and $\pm 0.26 \mathrm{~W} \mathrm{~m}^{-2}$ for the OLR, TSI, RSW, and total net radiation, respectively. Note that FLASHFlux data are not intended for analyses longer than six months.

2) Mauna Loa Observatory clear-sky “apparENT" SOLAR TRANSMISSION-K. Lantz and J. Augustine

Radiation from the sun is the fundamental energy that drives Earth's weather and climate. At the top of the atmosphere (TOA), the difference between the incoming and outgoing solar radiation represents the net radiation (energy) that is available within the Earth-atmosphere system. Incoming radiation is scattered and absorbed by the intervening atmosphere of clouds, aerosols, and gases before being transmitted to the surface. Across Earth the absorbed solar radiation is unevenly distributed both spatially and temporally; these differences are intricately reflected in our weather and climate. Atmospheric solar transmission has been measured at the Mauna Loa Observatory (MLO) in Hawaii by NOAA's Global Monitoring Division (GMD) since 1958 and is one of the longest, continuous records of that quantity. Because of its remote Pacific location and high elevation $(3.4 \mathrm{~km})$, the solar transmission at MLO represents the free tropospheric transmission with limited contamination from local influences. This record is often used to show the influence of large explosive volcanic eruptions, but it can also detect small volcanic eruptions into the upper troposphere and lower-most stratosphere (UT/LMS). Small volcanic eruptions have been shown to contribute aerosols up to $15 \mathrm{~km}$ in mid- to high latitudes (Ridley et al. 2014).

Daily and monthly clear-sky "apparent" solar transmission (AT) is calculated using ratios of directbeam broadband solar irradiance pyrheliometer measurements for various pairs of fixed atmospheric paths (airmass $=2$, 3, 4, 5; Ellis and Pueschel 1971). This technique is advantageous because ratios of direct solar irradiance remove influences due to instrument calibration and the variability of extraterrestrial irradiance. This analysis is also limited to clear-sky periods to remove cloud effects and to highlight the influence of aerosols or other trace gases in the atmospheric column. Past studies of changes in clear-sky AT at MLO have investigated the influences of volca- 


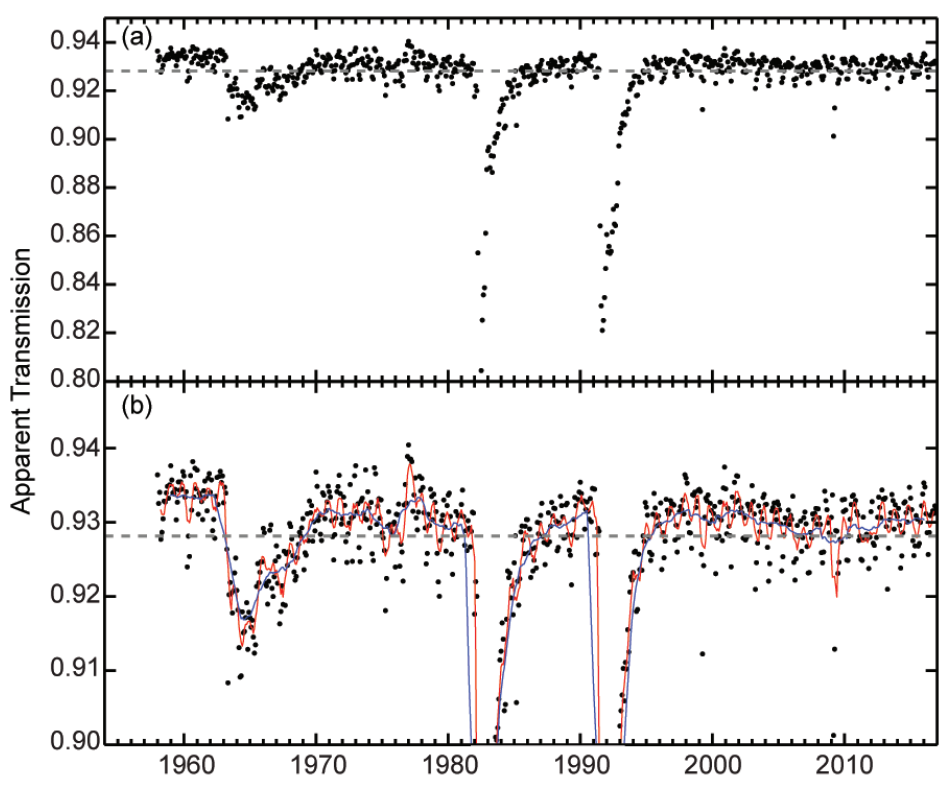

FIG. 2.43. (a) Monthly mean of the clear-sky AT at MLO. Means are determined from the morning values to reduce local influences. Gray dashed line is the 1958-62 background level. (b) Enlarged plot to highlight the seasonal (red line) and longer term changes (blue line) in the clear-sky AT record. The red line is the 6-month running smoothed fit, and the blue line is the 24-month smoothed fit.

nic aerosol, aerosol transport from Asia, ozone, water vapor, and the quasi-biennial oscillation (Bodhaine et al. 1981; Dutton 1992; Dutton and Bodhaine 2001; Dutton et al. 1985). However, effects due to aerosols are the most prominent.

The monthly record of clear-sky AT has been updated through December 2016 (Figs. 2.43a,b). Monthly averages are calculated using morning values during prevailing downslope wind to avoid local boundary layer influences that occur in the afternoon when the wind shifts to upslope conditions. Major volcanic eruptions from Agung, El Chichón, and Mt. Pinatubo are clearly visible in 1964, 1982, and 1991 (Fig. 2.43a). The gray dashed line reflects the cleanest background observed from1958 to 1962 and a brief period in 1978. Seasonal trends are highlighted by a 6-month running smoothed fit to the monthly values (Fig. 2.43b, red line) and have been attributed primarily to Asian aerosol transport in the spring (Bodhaine et al. 1981). Longer-term changes are highlighted by a 24-month running smoothed fit (Fig. 2.43b, blue line). Following the eruption of Mt. Pinatubo in 1991, the monthly clear-sky AT eventually returned to near-background conditions in mid-1998. The 24-month fit shows a slow decrease in clear-sky AT in the following decade (Fig. 2.43b). This slow decrease in clear-sky AT has been attributed to increased background aerosol due to several small volcanic eruptions (Solomon et al. 2011; Vernier et al. 2011). For example, several smaller dips in the 24-month smoothed fit coincide with the eruptions of Sarychev (Russia) and Redoubt (Alaska) in the spring of 2009 and Nabro (Eritrea) in June 2011 (Global Volcanism Program, www.volcano. si.edu; Andersson et al. 2015). This trend in AT does not continue after 2011 and is consistent with evidence from the NASA CALIPSO satellite record of $30^{\circ}-60^{\circ} \mathrm{N}$ that shows a period of quiescence in the effects of these smaller volcanic eruptions on the UT/LMS (Andersson et al. 2015). Interestingly, this pattern of increasing aerosol optical depth (AOD) in the mid-1990s, then a slowing around 2011 can be seen in the long-term NOAA SURFRAD AOD record across rural regions of the contiguous United States, when limiting annual means to the five cleanest days of the year to limit influences from regional pollution (J. Augustine 2016, personal communication). There is a negligible change in the mean of the monthly clear-sky AT in 2016 with an increase of 0.00138 with respect to 2015 , and the amplitude of the seasonal changes in clear-sky AT in 2016 is 0.006 consistent with the observed amplitude in 2015.

\section{g. Atmospheric composition}

I) LONG-LIVED GREENHOUSE GASES-E. J. Dlugokencky, B. D. Hall, S. A. Montzka, G. Dutton, J. Mühle, and J. W. Elkins

The three most dominant long-lived greenhouse gases (LLGHG) contributing to climate forcing are, in decreasing order: carbon dioxide $\left(\mathrm{CO}_{2}\right)$, methane $\left(\mathrm{CH}_{4}\right)$, and nitrous oxide $\left(\mathrm{N}_{2} \mathrm{O}\right)$. In 1958 systematic measurements of $\mathrm{CO}_{2}$ began at Mauna Loa, Hawaii (MLO), and the atmospheric $\mathrm{CO}_{2}$ abundance was $\sim 315$ ppm (parts per million in dry air). In 2016, MLO annual average $\mathrm{CO}_{2}$ reached $404.2 \pm 0.1 \mathrm{ppm}$ (www.esrl.noaa.gov/gmd/ccgg/trends) while global average $\mathrm{CO}_{2}$ at Earth's surface was $402.9 \pm 0.1 \mathrm{ppm}$ (Fig. 2.44a).

Fourfold increases in anthropogenic emissions of $\mathrm{CO}_{2}$ from both fossil fuel combustion and cement production are largely responsible for its atmospheric growth since 1958 (Boden et al. 2015). About half of this anthropogenic $\mathrm{CO}_{2}$ remains in the atmosphere while the other half is taken up by the terrestrial biosphere and oceans where it acidifies seawater (see Chapter $3 \mathrm{j}$ ). The global growth rate of atmospheric $\mathrm{CO}_{2}$ has risen from $0.6 \pm 0.1 \mathrm{ppm} \mathrm{yr}^{-1}$ in the early 

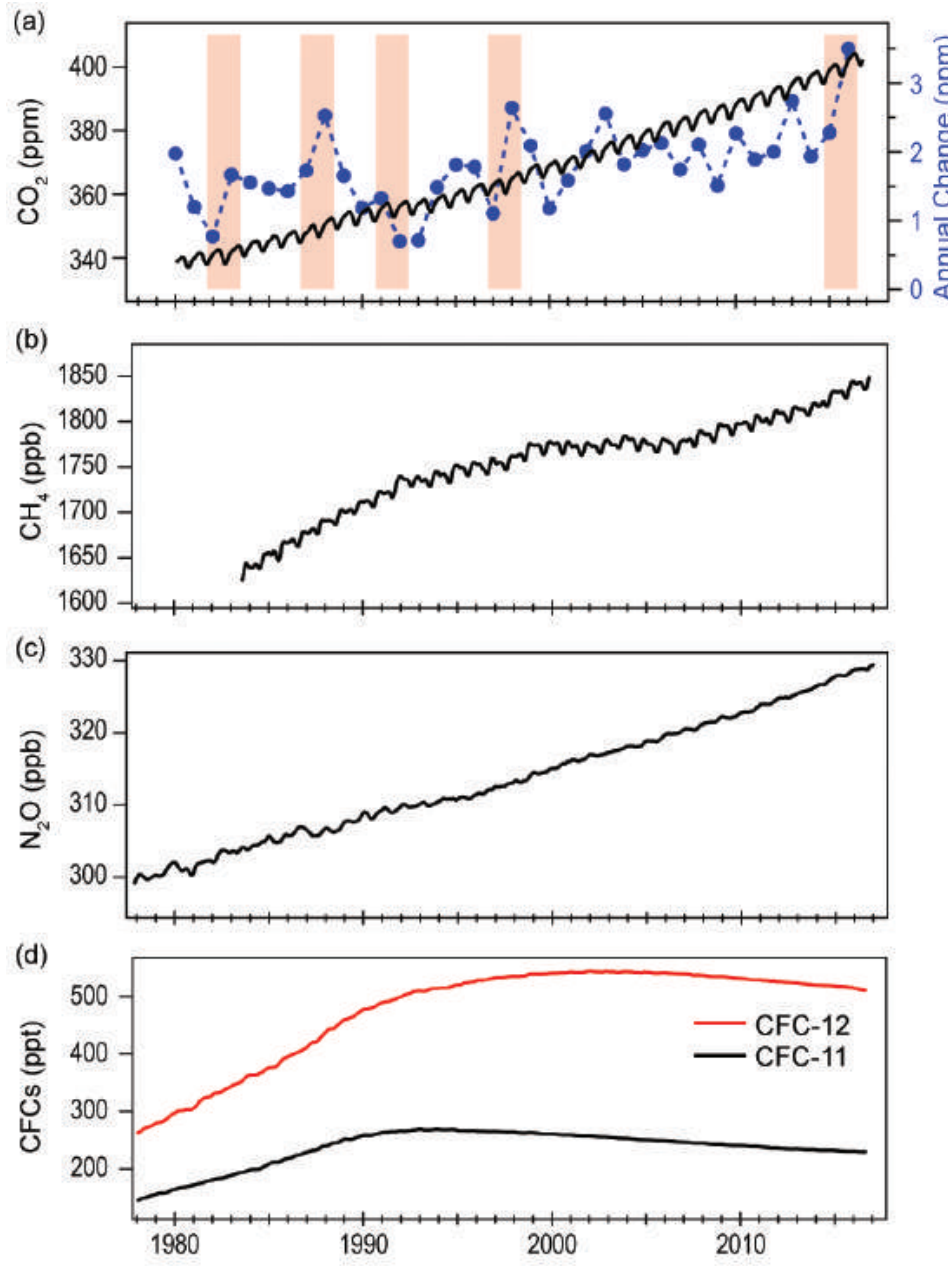

FIG. 2.44. Global mean surface mole fractions (in dry air) of (a) $\mathrm{CO}_{2}$ (black curve, ppm), (b) $\mathrm{CH}_{4}$ (ppb), (c) $\mathrm{N}_{2} \mathrm{O}$ (ppb), and (d) CFC-I2 and CFC-II (ppt) derived from the NOAA sampling network. (a) Also shown in (a) are changes in annual global means of $\mathrm{CO}_{2}$ (blue markers), and periods of moderate or stronger EI Niño periods (shaded bands) based on Oceanic Niño Index values >I.5. (Source: www.cpc.noaa.gov/products lanalysis_monitoring/ensostuff/ensoyears.shtml.)

1960s to an average of $2.3 \pm 0.6 \mathrm{ppm} \mathrm{yr}^{-1}$ during the past ten years. However, the increase in global annual mean $\mathrm{CO}_{2}$ from 2015 to 2016 was $3.5 \pm 0.1 \mathrm{ppm}$ $(0.88 \% \pm 0.03 \%)$, the largest annual increase observed in the 58-year atmospheric measurement record. The previous largest increase ( $2.7 \mathrm{ppm})$ occurred between 2012 and 2013. ENSO can play a role in the interannual variability of the $\mathrm{CO}_{2}$ growth rate through its influence on terrestrial carbon fluxes (Bastos et al. 2013). The strong El Niño that peaked in late 2015 (indicated by shaded area in Fig. 2.44a) undoubtedly contributed to the record $\mathrm{CO}_{2}$ increase from 2015 to 2016 (Betts et al. 2016).

Methane is emitted from both anthropogenic ( $60 \%)$ and natural ( 40\%) sources (Fung et al. 1991). Anthropogenic sources include agriculture (e.g., ru- minants and rice), fossil fuel extraction and use, biomass burning, landfills, and waste. Natural sources include wetlands, geological sources, oceans, and termites (Dlugokencky et al. 2011). A recent study has shown that fossil fuel exploitation (coal, oil, and natural gas) contributes more emissions than previously believed, $\sim 30 \%$ of total global $\mathrm{CH}_{4}$ emissions, but the magnitude of these emissions is likely not increasing (Schwietzke et al. 2016). The atmospheric $\mathrm{CH}_{4}$ burden has increased $250 \%$ since pre-industrial time and currently contributes $\sim 0.5 \mathrm{~W} \mathrm{~m}^{-2}$ direct radiative forcing, with an additional $\sim 0.3 \mathrm{~W}$ $\mathrm{m}^{-2}$ indirect radiative forcing from the $\mathrm{CH}_{4}^{-}$ related production of tropospheric ozone and stratospheric $\mathrm{H}_{2} \mathrm{O}$ (Myhre et al. 2013). Based on observations of globally averaged $\mathrm{CH}_{4}$, its rate of increase, and an estimate of its lifetime $(\sim 9.1 \mathrm{yr})$, total global $\mathrm{CH}_{4}$ emissions are estimated at $\sim 540 \mathrm{Tg} \mathrm{CH}_{4} \mathrm{yr}^{-1}$ $\left(1 \mathrm{Tg}=10^{12} \mathrm{~g}\right)$ with a relatively small uncertainty of $\sim \pm 10 \%$. Bottom-up estimates of $\mathrm{CH}_{4}$ emissions by country and source are challenging because the complex atmospheric $\mathrm{CH}_{4}$ budget is composed of many sources that are difficult to quantify.

The rate of $\mathrm{CH}_{4}$ increase slowed from more than $10 \mathrm{ppb} \mathrm{yr}^{-1}$ in the 1980 s to nearly zero in the early 2000 s, then increased to an average of $\sim 7 \mathrm{ppb} \mathrm{yr}^{-1}$ since 2007 (Fig. 2.44b). Surface observations, including the spatial distribution and rate of increase, provide strong top-down constraints on $\mathrm{CH}_{4}$ source and sink budgets. The 2016 globally averaged $\mathrm{CH}_{4}$ mole fraction at Earth's surface was $1843.0 \pm 0.8 \mathrm{ppb}$ based on NOAA background air sampling sites. The increase in annual means from 2015 to 2016 of $9.0 \pm 0.9$ ppb was slightly less than for 2014 to 2015.

Nitrous oxide is both a greenhouse gas and an ozone-depleting substance (Ravishankara et al. 2009). The observed $\sim 60 \mathrm{ppb}(22 \%)$ increase in atmospheric $\mathrm{N}_{2} \mathrm{O}$ over preindustrial levels (270 ppb) is largely the result of nitrogen-based fertilizer use (Park et al. 2012). The mean global atmospheric $\mathrm{N}_{2} \mathrm{O}$ mole fraction in 2016 was $328.9 \pm 0.1 \mathrm{ppb}$, an increase of $0.8 \mathrm{ppb}$ from the 2015 mean (Fig. 2.44c). The $0.8 \mathrm{ppb}$ annual change is similar to the average increase in global annual means over the last decade.

Halogenated gases, such as chlorofluorocarbons (CFCs), hydrochlorofluorocarbons (HCFCs), hydrofluorocarbons (HFCs), and carbon tetrachloride $\left(\mathrm{CCl}_{4}\right)$ 
TABLE 2.6. Summary table of long-lived greenhouse gases for $2016\left(\mathrm{CO}_{2}\right.$ mixing ratios are in ppm, $\mathrm{N}_{2} \mathrm{O}$ and $\mathrm{CH}_{4}$ in $\mathrm{ppb}$, and all others in $\mathrm{ppt}$ ).

\begin{tabular}{|c|c|c|c|c|c|c|}
\hline $\begin{array}{l}\text { Industrial Designation } \\
\text { or Common Name }\end{array}$ & $\begin{array}{l}\text { Chemical } \\
\text { Formula }\end{array}$ & AGGI & ODGI & $\begin{array}{c}\text { Radiative } \\
\text { Efficiency } \\
\left(\mathbf{W ~ m}^{-2} \mathbf{p p b}^{-1}\right)^{\mathbf{a}}\end{array}$ & $\begin{array}{c}\text { Mean Surface Mole } \\
\text { Fraction, 2016 } \\
\text { (change from prior } \\
\text { year) }^{\mathbf{b}}\end{array}$ & $\begin{array}{l}\text { Lifetime } \\
\text { (years) }\end{array}$ \\
\hline Carbon Dioxide & $\mathrm{CO}_{2}$ & $\bar{Y}$ & $\mathrm{~N}$ & $1.37 \times 10^{-5}$ & $402.9(3.5)^{c}$ & \\
\hline Methane & $\mathrm{CH}_{4}$ & $\bar{Y}$ & $\mathrm{~N}$ & $3.63 \times 10^{-4}$ & $1843.0(9.0)^{c}$ & 9.1 \\
\hline Nitrous Oxide & $\mathrm{N}_{2} \mathrm{O}$ & $Y$ & $\mathrm{~N}$ & $3.00 \times 10^{-3}$ & $328.9(0.8)^{c, d}$ & 123 \\
\hline \multicolumn{7}{|c|}{ Chlorofluorocarbons } \\
\hline CFC-II & $\mathrm{CCl}_{3} \mathrm{~F}$ & $\mathrm{Y}$ & $\mathrm{Y}$ & 0.26 & $230.1(-1.4)^{c, d}$ & 52 \\
\hline CFC-12 & $\mathrm{CCl}_{2} \mathrm{~F}_{2}$ & $Y$ & $Y$ & 0.32 & $512.5(-3.6)^{c, d}$ & 102 \\
\hline CFC-II3 & $\mathrm{CCl}_{2} \mathrm{FCClF}_{2}$ & $\mathrm{Y}$ & $\mathrm{Y}$ & 0.30 & $71.6(-0.3)^{c}$ & 93 \\
\hline \multicolumn{7}{|c|}{ Hydrochlorofluorocarbons } \\
\hline HCFC-22 & $\mathrm{CHClF}_{2}$ & $Y$ & $\mathrm{Y}$ & 0.21 & $237.2(4.2)^{c}$ & 11.9 \\
\hline HCFC-I4Ib & $\mathrm{CH}_{3} \mathrm{CCl}_{2} \mathrm{~F}$ & $\bar{Y}$ & $\bar{Y}$ & 0.16 & $24.5(0.3)^{c}$ & 9.4 \\
\hline HCFC-142b & $\mathrm{CH}_{3} \mathrm{CClF}_{2}$ & $\mathrm{Y}$ & $\mathrm{Y}$ & 0.19 & $22.0(0.2)^{c}$ & 18 \\
\hline \multicolumn{7}{|c|}{ Hydrofluorocarbons } \\
\hline HFC-134a & $\mathrm{CH}_{2} \mathrm{FCF}_{3}$ & $Y$ & $\mathrm{~N}$ & 0.16 & $89.1(5.6)^{c}$ & 14 \\
\hline HFC-I52a & $\mathrm{CH}_{3} \mathrm{CHF}_{2}$ & $Y$ & $\mathrm{~N}$ & 0.10 & $6.6(0)^{c}$ & 1.6 \\
\hline HFC-I43a & $\mathrm{CH}_{3} \mathrm{CF}_{3}$ & $\bar{Y}$ & $\mathrm{~N}$ & 0.16 & $17.5(1.4)^{\mathrm{c}}$ & 51 \\
\hline HFC- 125 & $\mathrm{CHF}_{2} \mathrm{CF}_{3}$ & $\bar{Y}$ & $\mathrm{~N}$ & 0.23 & $18.9(1.9)^{c}$ & 31 \\
\hline HFC-32 & $\mathrm{CH}_{2} \mathrm{~F}_{2}$ & $\mathrm{~N}$ & $\mathrm{~N}$ & 0.11 & $11.5(1.6)^{c}$ & 5.4 \\
\hline HFC-23 & $\mathrm{CHF}_{3}$ & $\bar{Y}$ & $\mathrm{~N}$ & 0.18 & $28.9(0.8)^{c}$ & 228 \\
\hline HFC-365mfc & $\mathrm{CH}_{3} \mathrm{CF}_{2} \mathrm{CH}_{2} \mathrm{CF}_{3}$ & $\mathrm{~N}$ & $\mathrm{~N}$ & 0.22 & $0.89(0.02)^{\mathrm{c}}$ & 8.7 \\
\hline HFC-227ea & $\mathrm{CF}_{3} \mathrm{CHFCF}_{3}$ & $\mathrm{~N}$ & $\mathrm{~N}$ & 0.26 & $1.20(0.02)^{c}$ & 36 \\
\hline \multicolumn{7}{|c|}{ Chlorocarbons } \\
\hline Methyl Chloroform & $\mathrm{CH}_{3} \mathrm{CCl}_{3}$ & $Y$ & $\mathrm{Y}$ & 0.07 & $2.6(-0.5)^{\mathrm{c}}$ & 5.0 \\
\hline Carbon Tetrachloride & $\mathrm{CCl}_{4}$ & $\bar{Y}$ & $\bar{Y}$ & 0.17 & $81.3(-0.9)^{c, d}$ & 33 \\
\hline Methyl Chloride & $\mathrm{CH}_{3} \mathrm{Cl}$ & $\mathrm{N}$ & $\mathrm{Y}$ & 0.01 & $563(13)^{c}$ & 0.9 \\
\hline \multicolumn{7}{|c|}{ Bromocarbons } \\
\hline Methyl Bromide & $\mathrm{CH}_{3} \mathrm{Br}$ & $\mathrm{N}$ & $\mathrm{Y}$ & 0.004 & $6.9(0.3)^{c}$ & 0.8 \\
\hline Halon I2II & $\mathrm{CBrClF}_{2}$ & $Y$ & $Y$ & 0.29 & $3.5(-0.1)^{c}$ & 16 \\
\hline Halon I30I & $\mathrm{CBrF}_{3}$ & $Y$ & $Y$ & 0.30 & $3.3(0)^{c}$ & 72 \\
\hline Halon 2402 & $\mathrm{CBrF}_{2} \mathrm{CBrF}_{2}$ & $\mathrm{Y}$ & $\mathrm{Y}$ & 0.31 & $0.4(0)^{c}$ & 28 \\
\hline \multicolumn{7}{|c|}{ Fully fluorinated species } \\
\hline Sulfur Hexafluoride & $\mathrm{SF}_{6}$ & $\mathrm{Y}$ & $\mathrm{N}$ & 0.57 & $8.88(0.29)^{c}$ & $>600$ \\
\hline PFC-14 & $\mathrm{CF}_{4}$ & $\mathrm{~N}$ & $\mathrm{~N}$ & 0.09 & $82.7(0.8)^{c}$ & $\sim 50000$ \\
\hline PFC-116 & $\mathrm{C}_{2} \mathrm{~F}_{6}$ & $\mathrm{~N}$ & $\mathrm{~N}$ & 0.25 & $4.56(0.07)^{c}$ & $\sim 10000$ \\
\hline
\end{tabular}

${ }^{a}$ Radiative efficiencies were taken from IPCC AR5 (Myhre et al. 2013). Steady-state lifetimes were taken from Myhre et al. (2013) $\left(\mathrm{CH}_{4}\right)$, Ravishankara et al. (1993) $\left(\mathrm{SF}_{6}\right)$, Ko et al. (2013), SPARC (2016) $\left(\mathrm{CCl}_{4}\right)$, and Carpenter et al. (2014). For $\mathrm{CO}_{2}$, numerous removal processes complicate the derivation of a global lifetime.

${ }^{\mathrm{b}}$ Mole fractions are global, annual surface means for the indicated calendar year determined from the NOAA global cooperative air sampling network (Hofmann et al. 2006), except for PFC-14, PFC-116, and HFC-23 which were measured by AGAGE (Mühle et al. 2010; Miller et al. 2010). Changes indicated in parentheses are the differences between the 2016 and 2015 global surface mean mole fractions.

c Preliminary estimate.

dGlobal mean estimates derived from multiple NOAA measurement programs ("Combined Dataset"). 


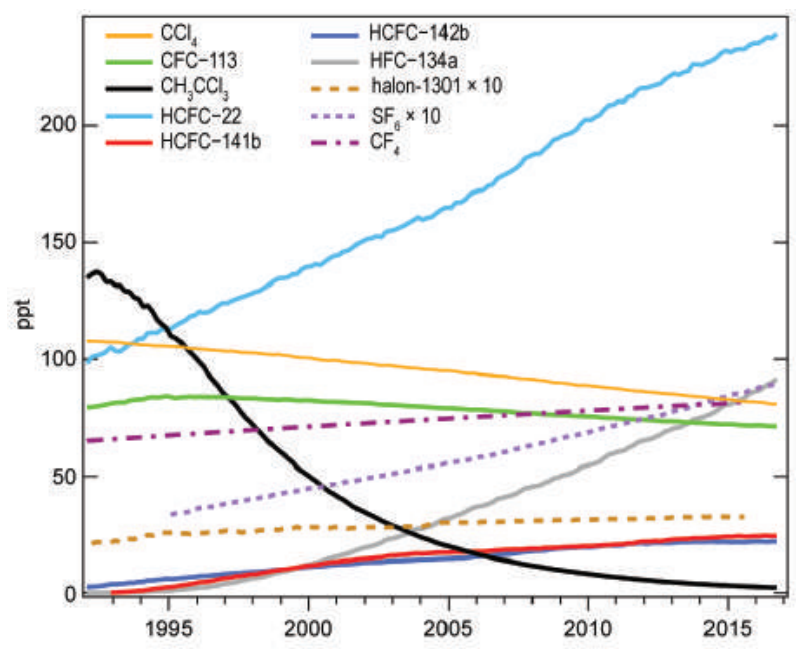

Fig. 2.45. Global mean mole fractions at Earth's surface (ppt, dry air) for several halogenated long-lived greenhouse gases. See Table 2.6 for the 2016 global mean mole fractions of these gases.

also contribute to radiative forcing. Atmospheric mole fractions of some CFCs, such as CFC-12 and CFC-11, have been decreasing for a decade or more in response to production and consumption restrictions imposed by the Montreal Protocol and its Amendments (Fig. 2.44d). The atmospheric burdens of many CFC-replacement compounds (HCFCs and HFCs) continued to increase in 2016 (Fig. 2.45; Table 2.6).

The NOAA Annual Greenhouse Gas Index (AGGI) summarizes trends in the combined direct radiative forcing by five major LLGHGs $\left(\mathrm{CO}_{2}, \mathrm{CH}_{4}, \mathrm{~N}_{2} \mathrm{O}\right.$, CFC-11, and CFC-12) and 15 minor gases (Hofmann et al. 2006; Fig. 2.46; www.esrl.noaa.gov/gmd /aggi). The AGGI represents the annual cumulative radiative forcing of these gases relative to the Kyoto Protocol baseline year of $1990\left(2.17 \mathrm{~W} \mathrm{~m}^{-2}\right)$. It does not

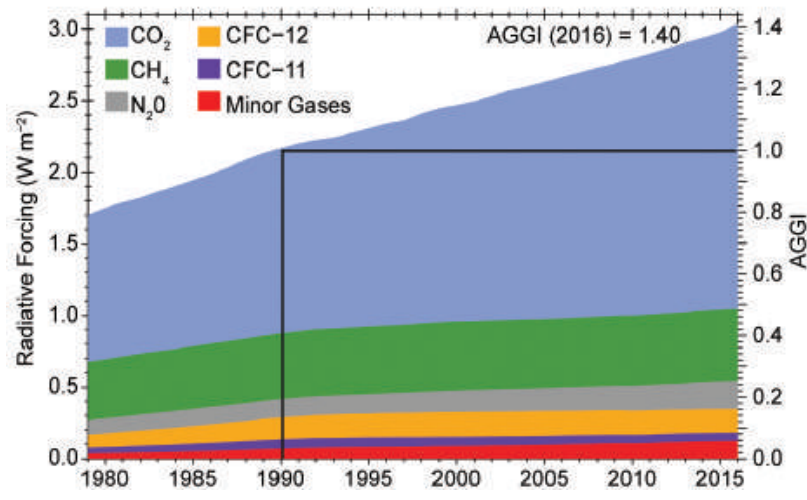

FIG. 2.46. Direct radiative forcing $\left(\mathrm{W} \mathrm{m}^{-2}\right)$ due to 5 major LLGHG and 15 minor gases (left axis) and the associated values of the AGGI (right axis). Direct radiative forcing due to LLGHG and 15 minor gases, 3.03 W m ${ }^{-2}$ in 2016, has increased $40 \%$ since 1990 (AGGI $=1.4$ for 2016). include indirect radiative forcings (e.g., influences on ozone and water vapor). In 2016, $\mathrm{CO}_{2}$ contributed 1.99 $\mathrm{W} \mathrm{m}{ }^{-2}$ direct radiative forcing, $66 \%$ of the combined forcing of $3.03 \mathrm{~W} \mathrm{~m}^{-2}$ by the 5 major LLGHGs and 15 minor gases (Table 2.6). The combined forcing in 2016 represents a nearly 40\% increase since 1990 (2016 AGGI $=1.399 \pm 0.002)$ and a $1.82 \%$ increase over the 2015 AGGI of $1.374 \pm 0.002$. The current combined forcing is equivalent to a global average $\mathrm{CO}_{2}$ mole fraction of $\sim 490 \mathrm{ppm}$. Even without further increases in radiative forcing, current levels of long-lived greenhouse gases portend significant further warming, sea level rise, and financial cost to future generations (Hansen et al. 2016).

2) Ozone depleting gases-B. D. Hall, S. A. Montzka, G. Dutton, and J. W. Elkins

In 2016 the combined radiative forcing by CFCs, HCFCs, and other halogenated ozone-depleting gases was $0.32 \mathrm{~W} \mathrm{~m}^{-2}, 10 \%$ of the total radiative forcing by LLGHG (Table 2.6; Fig. 2.46). In addition, these chlorine- and bromine-containing gases contribute indirectly to radiative forcing by destroying stratospheric ozone. The emissions and atmospheric burdens of many of the most potent ozone-depleting gases have been declining (Figs. 2.44d, 2.45) in response to production and consumption restrictions imposed by the Montreal Protocol on Substances that Deplete the Ozone Layer and its Amendments and Adjustments. The combined direct radiative forcing of CFC-11 and CFC-12 has declined 7\% since 2000, from $0.238 \pm$ $0.001 \mathrm{~W} \mathrm{~m}^{-2}$ in 2000 to $0.222 \pm 0.001 \mathrm{~W} \mathrm{~m}^{-2}$ in 2016, contributing to the "climate benefit" of the Montreal Protocol (Velders et al. 2007).

Equivalent effective stratospheric chlorine (EESC) is a measure of the ozone-depleting potential of the stratospheric halogen loading at a given time and place. As EESC declines, stratospheric ozone is showing some signs of recovery (Bourassa et al. 2014; Pawson et al. 2014; see Section 2g4). EESC is calculated from global average surface mole fractions of halogenated, ozone-depleting gases and weighting factors that include surface- to-stratosphere transport times, mixing during transit, photolytic reactivity, and ozone-destruction efficiency (Schauffler et al. 2003; Newman et al. 2007). Progress toward reducing the stratospheric halogen load is evaluated by the NOAA Ozone-Depleting Gas Index (ODGI; Hofmann and Montzka 2009; www.esrl.noaa.gov/gmd/odgi). The ODGI relates EESC in a given year to the maximum EESC value $(O D G I=100)$ and the 1980 EESC value $(\mathrm{ODGI}=0)$, a benchmark often used to assess prog- 


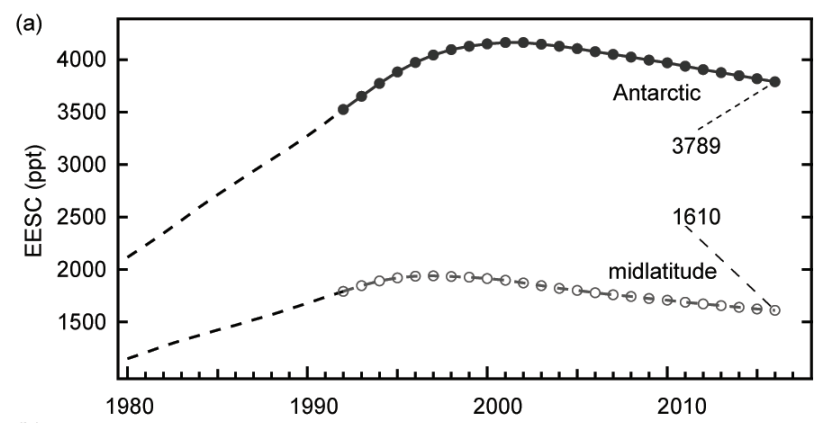

(b)

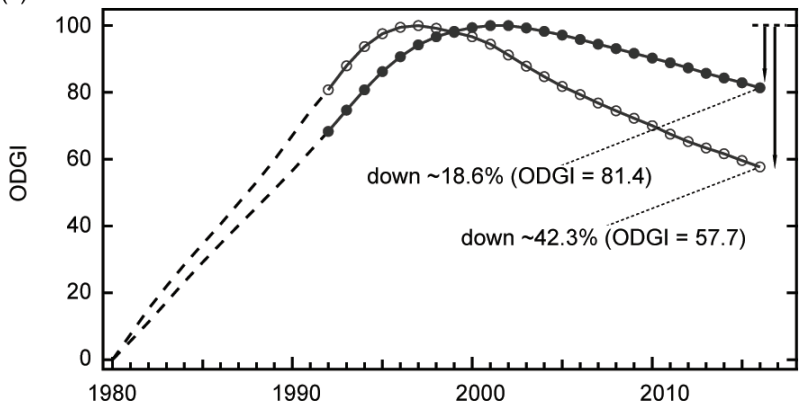

FIG. 2.47. (a) EESC (ppt) and (b) NOAA ODGI. The ODGI represents the relative mole fractions of reactive halogen in in the midlatitude (open circles) and Antarctic (closed circles) stratospheres scaled such that ODGI = 100 at maximum EESC and zero in 1980. ODGI values in these two regions have dropped $42.3 \%$ and $18.6 \%$, respectively, from their peak values. Both EESC and ODGI are derived from NOAA surface measurements of ozone-depleting gases (circles) or, for earlier years, WMO scenarios (dashed lines; Harris et al. 2014). The EESC and ODGI values from 1992 forward are for Jan of each year.

ress towards reducing stratospheric halogen loadings to pre-ozone hole levels (Fig. 2.47).

The EESC and ODGI are calculated for two representative stratospheric regions-Antarctica and the midlatitudes - that differ in total available reactive halogen (Fig. 2.47a). EESC is larger in the Antarctic stratosphere than in the midlatitudes because more ozone-reactive halogen is released during the longer transit time to the Antarctic. At the beginning of 2016, ODGI values in the Antarctic and midlatitude stratospheres were 81.4 and 57.7, respectively, compared to 82.9 and 59.5 at the same time in 2015 . The 2016 values represent $18.6 \%$ and $42.3 \%$ reductions from the peak values in EESC over Antarctica and the midlatitudes, respectively, toward the 1980 benchmarks.

3) Aerosols - S. Rémy, A. Benedetti, and 0. Boucher

Atmospheric aerosol particles affect Earth's climate and can present a serious public health issue during surface pollution events (WHO 2013). Aerosols impact climate directly by scattering and absorbing short- and long-wave radiation, and indirectly by affecting the concentrations, sizes, and chemical composition of cloud condensation nuclei that influence clouds' life cycles, optical properties, and precipitation activity. More information about the radiative forcing by aerosols is provided by Boucher et al. (2013).

Data in this section are based on the Copernicus Atmosphere Monitoring Service (CAMS) interim reanalysis of global aerosols (Flemming et al. 2017) that is constrained by Collection 5 MODIS retrievals of aerosol optical depth (AOD) at $550 \mathrm{~nm}$ (Remer et al. 2005). CAMS couples all relevant physical aerosol processes, such as emissions, wet/dry deposition, and sedimentation, with meteorology. Five aerosol types are considered: sea salt, desert dust, black carbon, organic matter, and sulfate aerosols. Biomass burning aerosol emissions equal the sum of black carbon and organic matter emitted by open fires and biofuel combustion. Open fire emission estimates were provided by the Global Fire Assimilation System (GFAS) inventory (Kaiser et al. 2012) based on MODIS observations of fire radiative power. CAMS interim reanalysis of total AOD has a $-2.5 \%$ bias relative to independent, ground-based AERONET (Aerosol Robotic Network) observations, but the AERONET stations may not be representative of global field values at the model resolution.

The 2016 average anomalies of AOD at $550 \mathrm{~nm}$ due to total aerosols, dust, and biomass burning (Plates $2.1 \mathrm{x}, \mathrm{y}, \mathrm{z}$, respectively) depict strong regional influences. These were calculated against 2003-16 mean values. Dust anomalies were positive in most of the source regions (southern Sahara, Arabian Peninsula, and the Taklamakan desert in northwestern China) and several areas downwind of the sources. The strong positive anomalies extending from western Africa to South America indicate more active transAtlantic dust transport than in previous years. More dust than usual was also transported to the Mediterranean region from central and eastern Sahara, and from the Taklamakan to Mongolia and northern China. Negative dust anomalies were found over Iran and the Caspian Sea.

Overall, the 2016 anomalies of biomass burning aerosols (Plate 2.1z) are consistent with those of tropospheric ozone (Section 2g6), carbon monoxide (Section 2g7), and fires (Section 2h3). Seasonal biomass burning in 2016 was more severe than usual in many regions. Biomass burning and total AOD anomaly maps show the large fire events of 2016 in and around equatorial Africa, in Siberia northwest of Lake Baikal (May-August), and in western Canada 
(May-August), including the Fort McMurray fire (May) in northeastern Alberta (see Sidebar 7.1). Biomass burning aerosols in the Amazon basin in 2016 were below the long-term average, continuing the downward trend from 2003. Interestingly, there was much lower fire activity than usual in Indonesia in 2016, following a year (2015) of extreme Indonesian fire activity caused by a powerful El Niño event (Benedetti et al. 2016).

Positive sea salt aerosol anomalies (not shown) over the North Atlantic Ocean were caused by a more active storm season there in January-February and again in December 2016. Sea salt anomalies were also positive over the northeast Pacific region.

Time series of globally averaged total AOD during 2003-16 (Fig. 2.48) show strong seasonality, with semiannual maxima typically in March-April and August-September driven mainly by dust episodes and biomass burning in Africa and South America.

Figure 2.49 presents global maps of the 2003-16 average total AOD, linear trends in total AOD from 2003 through 2016, and the number of days with extremely high AOD values. The highly polluted areas of eastern Asia and India are prominent features in the total AOD map (Fig. 2.49a), as are the dust-producing regions of the Sahara, Arabia, the Middle East, and the Taklamakan and Gobi deserts. Seasonal biomass burning drives the large total AOD values over equatorial Africa and Indonesia. The map of linear trends in total AOD (Fig. 2.49b) highlights long-term decreases in anthropogenic aerosols over the eastern United States, Europe, Japan, and parts of southern China, while increases in anthropogenic aerosols occurred over most of the Indian subcontinent. Decreasing trends in the southern Amazon basin are associated with reduced deforestation (Chen et al. 2013) while those over the northern Sahara and

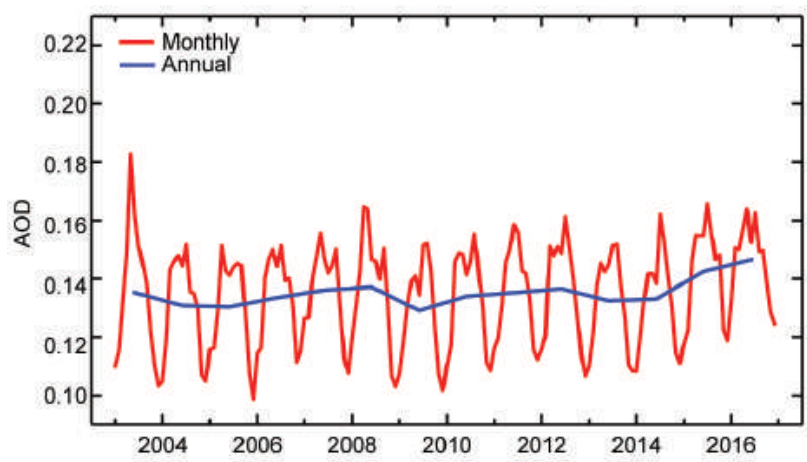

FIG. 2.48. Global averages of total AOD at $550 \mathrm{~nm}$ averaged over monthly (red) and annual (blue) periods for 2003-16. A linear regression fit to the monthly averages suggests a long-term increase, but the trend is not statistically significant ( $95 \%$ confidence). western Mediterranean indicate fewer and/or weaker dust episodes in these regions. Although there are many Southern Hemisphere oceanic regions with positive trends, these may be an artifact of the MODIS Collection 5 observations used in the reanalysis which, over these areas, are typically greater than MODIS Collection 6 (Levy et al. 2013) observations. The number of days with extremely high AOD values (Fig. 2.49c) shows that most extreme events are associated with large fires in Siberia, Central and South
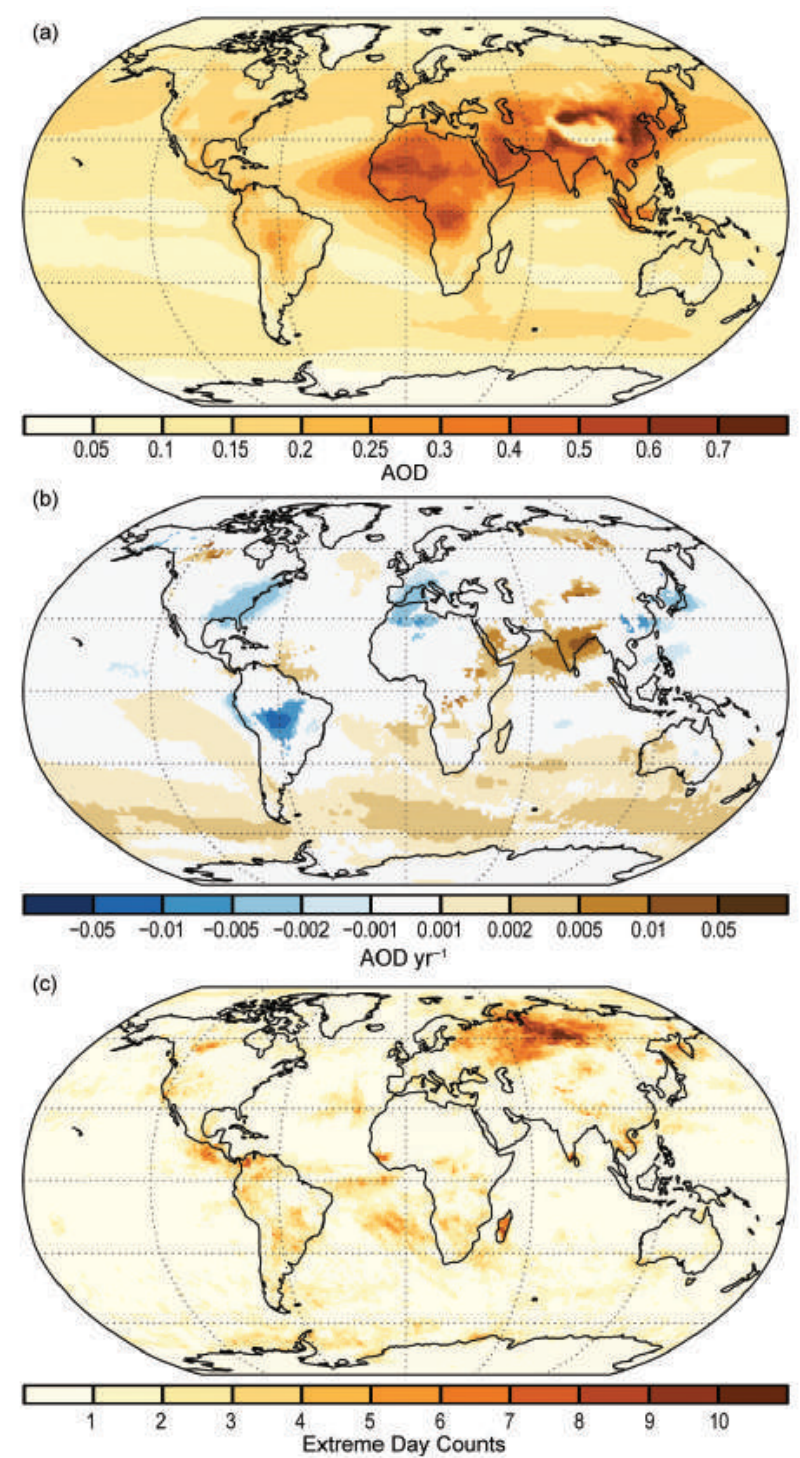

FIG. 2.49. (a) Total $550 \mathrm{~nm}$ AOD averages for 2003- 16. Note the regional differences, with much greater total AOD values over parts of northern Africa, the Arabian Peninsula, southern Asia, and eastern China. (b) Linear trends of total AOD (AOD unit $\mathrm{yr}^{-1}$ ) for 2003-16. Only trends that are statistically significant ( $95 \%$ confidence) are shown. (c) Number of days in 2016 with extremely high AOD (defined as greater than the 2003-16 average plus 5 std. dev.). 
America, northwestern Canada, Southeast Asia, and Africa. Other contributors to extreme AOD values include dust events in the Mediterranean and North Atlantic, and sea salt events near the Antarctic coast.

4) Stratospheric ozone-M. Weber, W. Steinbrecht, S. M. Frith, 0. Tweedy, M. Coldewey-Egbers, S. Davis, D. Degenstein, Y. E. Fioletov, L. Froidevaux, J. de Laat, C. S. Long, D. Loyola, C. Roth, and J. D. Wild

Total ozone columns in 2016 from GOME-2 were within a few Dobson units (DU) of the long-term (1998-2008) average for most of the globe (Plate 2.1s). At middle to high Northern Hemisphere (NH) latitudes total ozone was below the long-term average. The strong NH polar vortex observed during December 2015-February 2016, with record low temperatures and correspondingly large chlorine activation throughout, led to very low ozone values in the Arctic lower stratosphere during this period (not shown; Manney and Lawrence 2016). Very low stratospheric temperatures are needed to form polar stratospheric clouds (PSCs) that activate halogens (chlorine and bromine) for fast catalytic ozone depletion. Large ozone losses are regularly observed over Antarctica in the Southern Hemisphere (SH) spring (see Chapter 6h) but only sporadically over the Arctic. The observed Arctic ozone loss in early 2016 was comparable to or even stronger than the previous record loss during the Arctic winter 2010/11. Both winters showed Arctic ozone losses at levels typically only observed in the Antarctic ozone hole (Fig. 4 in WMO-GNR 2017; Manney et al. 2011).

In contrast, 2016 total ozone at middle to high SH latitudes was above average (Plate 2.1s) because of the below-average size of the Antarctic ozone hole in 2016 (see Chapter 6h). Both the size and intensity of ozone loss within the Antarctic vortex are variable and depend on the meteorology and atmospheric dynamics (transport) of any given winter.

At the equator there was a narrow band of slightly above-average total ozone (Plate 2.1s). Year-to-year variability of tropical total ozone is mainly governed by the phase of the quasi-biennial oscillation (QBO). The QBO is a periodic change of stratospheric winds in the lower to middle tropical stratosphere that affects the meridional (Brewer-Dobson) circulation and modulates high latitude ozone and the strength of the polar vortices (e.g., Strahan et al. 2015). In the 2015/16 boreal winter, radiosonde temperature observations revealed an unprecedented disruption in the downward propagation of the QBO westerly phase (Newman et al. 2016) that modified circulation and substantially impacted tropical and extra- tropical ozone (Tweedy et al. 2017). In Fig. 2.50, a "climatological" ozone QBO anomaly derived from deseasonalized SBUV Merged Ozone Data (MOD) V8.6 for 1982-2014 (14 QBO cycles) is compared to the ozone QBO evolution during late 2014-16. Each cycle is defined as starting when the vertical wind shear at $40 \mathrm{hPa}$ shifts from negative (zonal wind decreasing with height) to positive. The long-term average evolution shows the typical increase in equatorial ozone associated with positive shear followed by a decrease associated with negative shear. The atypical cycle evolution in 2015/16 shows the anomalous equatorial ozone increase starting in June 2016.

The anomalous positive $40-\mathrm{hPa}$ wind shear during April-November 2016 caused decreased tropical upwelling which led to a positive perturbation in tropical total ozone. This reduced upwelling was balanced by weaker extratropical downwelling, which decreased extratropical total ozone from April to September 2016. Total ozone shows markedly perturbed behavior in 2016 compared to the past, but the response of ozone and a variety of dynamical
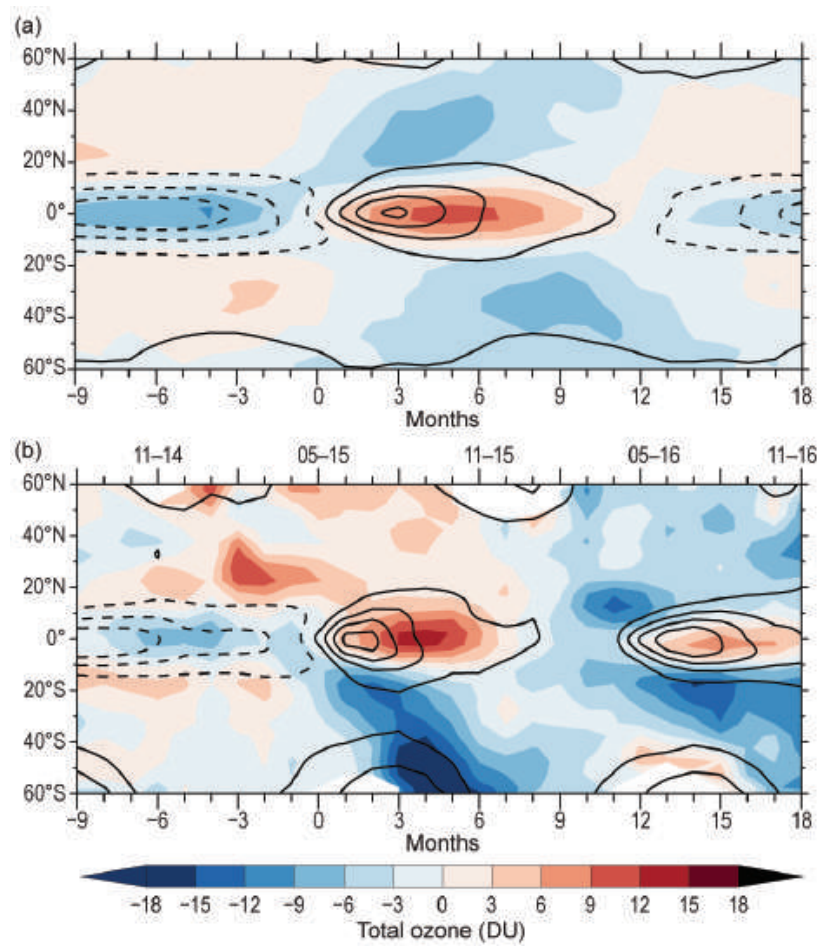

FIG. 2.50. Latitude-time evolution of the deseasonalized SBUV MOD V8.6 total ozone (color scale) for (a) the climatology of I4 QBO cycles (1982-2014) and (b) late 2014-16 (month-year indicated at the top). Solid and dashed black contours (interval is $2 \mathrm{~m} \mathrm{~s}^{-1} \mathbf{k m}^{-1}$ ) show positive and negative vertical wind shear, respectively, for the composite and late 2014-16. Bottom axes show months before and after vertical wind shear changes from easterly to westerly at $40 \mathrm{hPa}$. Adapted from Tweedy et al. (2017). 


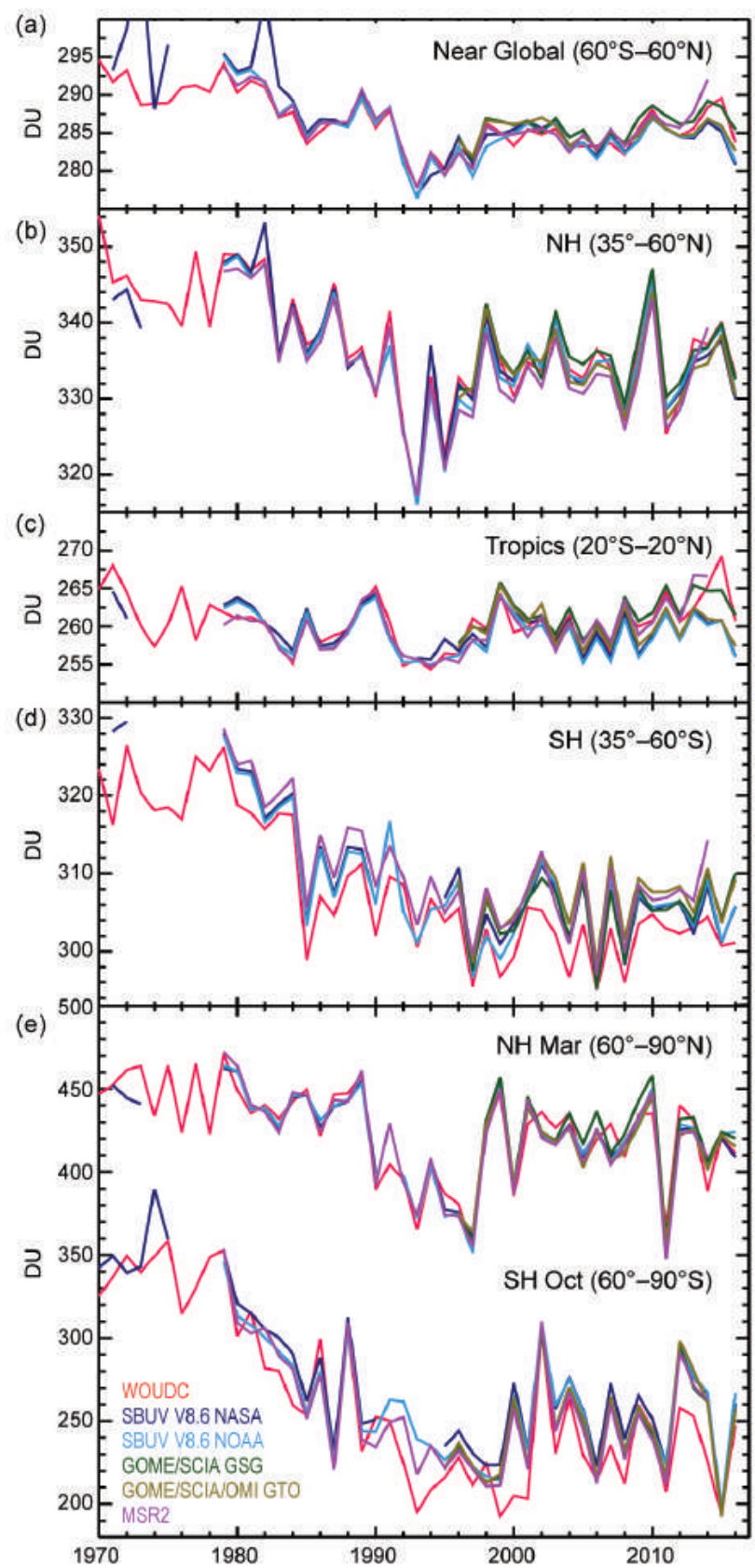

Fig. 2.5I. Time series of annual mean total ozone in (a)-(d) four zonal bands and (e) polar $\left(60^{\circ}-90^{\circ}\right)$ total ozone in Mar (NH) and Oct (SH). Data are from WOUDC ground-based measurements combining Brewer, Dobson, SAOZ, and filter spectrometer data (red; Fioletov et al. 2002, 2008); the BUV/SBUV/SBUV2 V8.6 merged products from NASA (MOD V8.6; dark blue; Chiou et al. 2014; Frith et al. 2014) and NOAA (light blue; Wild et al. 2016); the GOME/SCIAMACHYI GOME-2 products GSG from University of Bremen (dark green; Weber et al. 20II) and GTO from ESA/ DLR (light green; Coldewey-Egbers et al. 2015); and the MSR V2 assimilated dataset extended with GOME-2 data (magenta; van der A et al. 2015). WOUDC values for $\mathbf{2 0 1 6}$ are preliminary because not all ground station data were available at the time of writing this report. and tracer fields is consistent with our understanding of the QBO-induced transport (Tweedy et al. 2017).

Time series of total column ozone annual means from different data sources are shown for 1970-2016 in various zonal bands (Fig. 2.51): near-global $\left(60^{\circ} \mathrm{N}-\right.$ $60^{\circ} \mathrm{S}$ ), middle latitudes in both hemispheres $\left(35^{\circ}-60^{\circ}\right)$, and the inner tropics $\left(20^{\circ} \mathrm{N}-20^{\circ} \mathrm{S}\right)$. Also shown are the polar time series in March $\left(60^{\circ}-90^{\circ} \mathrm{N}\right)$ and October $\left(60^{\circ}-90^{\circ} \mathrm{S}\right)$, the months when polar ozone losses are largest in the $\mathrm{NH}$ and $\mathrm{SH}$, respectively (Fig. 2.51e). As a result of the early final warming in the Arctic (Manney and Lawrence 2016) and the breakup of the $\mathrm{NH}$ polar vortex, the $60^{\circ}-90^{\circ} \mathrm{N}$ ozone levels in March 2016 quickly recovered to values close to the long-term mean despite the previously mentioned large chemical losses in early 2016.

Figure 2.51a shows that the continuous ozone decline due to the increase of ozone depleting substances (ODS) until the mid-1990s has ended. Since 2000 total ozone has leveled off in the extratropics of both hemispheres (Figs. 2.51b,d). Because the decline of ODS is slow (Section $2 \mathrm{~g} 2$ ), ozone recovery is still difficult to separate from the considerable year-toyear variability. In the $\mathrm{NH}$, tropical, and near-global averages, the annual mean ozone columns in 2016 were a few DU lower than those in the last couple of years, an expected result due to the declining phase of the 11-year solar cycle. Overall, the 2016 ozone columns are in agreement with expectations from

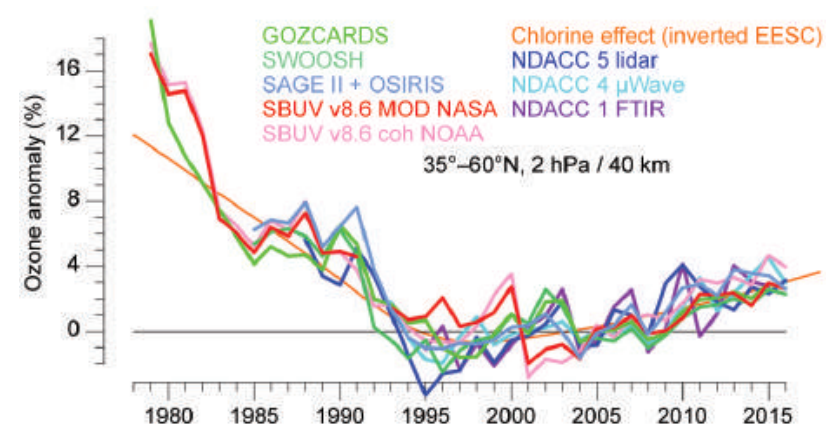

Fig. 2.52. Annual mean upper stratospheric ozone anomalies at $2 \mathrm{hPa}(\sim 40 \mathrm{~km})$ in the zonal band $35^{\circ}-$ $60^{\circ} \mathrm{N}$. Data are from the merged SAGE II/OSIRIS (Bourassa et al. 20I4), GOZCARDS (Froidevaux et al. 20I5), SWOOSH (Davis et al. 20I6b), the BUVISBUVI SBUV2 v8.6 merged products from NASA (Frith et al. 2014) and NOAA (Wild et al. 2016) as well as averages from five lidars, four microwave radiometers, and one FTIR measuring from the ground (Steinbrecht et al. 2009; Vigouroux et al. 20I5). The anomaly basis for all time series is the 1998-2008 average of annual means. The thin orange curve represents EESC, inverted and scaled to reflect the expected ozone variations due to changes in stratospheric halogens. Data points for 2016 are still preliminary as of early 2017. 
the last WMO Scientific Assessment of Stratospheric Ozone Depletion (WMO 2014).

The clearest signs of significant ozone recovery have occurred in the upper stratosphere at $\sim 2$ $\mathrm{hPa} / 40 \mathrm{~km}$ (WMO 2014; Fig. 2.52). Both ground- and satellite-based measurements show recent increases of $2 \%-4 \%$ decade $^{-1}$ in upper stratospheric ozone. At least in the upper stratosphere, adherence to the Montreal Protocol has successfully stopped the decline of stratospheric ozone and turned the previous downward trend into an upward trend since the late 1990s. Ensembles of chemistry-climate models indicate that the decline in stratospheric halogens and increases in greenhouse gases have contributed nearly equally to the positive ozone trend (WMO 2014).

5) Stratospheric water vapor-S. M. Davis, K. H. Rosenlof, D. F. Hurst, H. B. Selkirk, and H. Vömel

Stratospheric water vapor (SWV) levels varied dramatically during 2016. At the start of the year, water vapor mixing ratios in the tropical $\left(15^{\circ} \mathrm{N}-15^{\circ} \mathrm{S}\right)$ lowermost stratosphere (at $82 \mathrm{hPa}$ ) were about $15 \%$ (0.5 ppm, parts per million mole fraction, equivalent

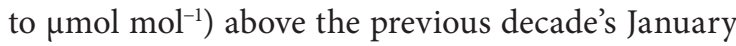
average (Fig. 2.53). These positive anomalies followed the extremely high levels of SWV in November and December 2015 (Davis et al. 2016a; Fig. 2.54a) and the associated warm anomaly in cold point temperatures (CPTs) in the tropical tropopause layer (TTL) that began in mid-2015 and continued through the first two months of 2016 (Fig. 2.54b). The tropical SWV anomaly at $82 \mathrm{hPa}$ in December $2015(\sim 0.9 \mathrm{ppm})$ is the highest observed in the now 13-year Aura Microwave Limb Sounder (MLS) record.

Between March and July 2016 the tropical SWV anomaly at $82 \mathrm{hPa}$ dropped to $\sim 0.2 \mathrm{ppm}$, then in August started to drop further, reaching $-1.0 \mathrm{ppm}$ in November 2016, the driest monthly anomaly observed in the Aura MLS record (Fig. 2.53b). Thus, from December 2015 to November 2016, the anomaly dropped by nearly $1.9 \mathrm{ppm}$, which is $40 \%$ of the longterm November mean tropical SWV mixing ratio at $82 \mathrm{hPa}$ and $80 \%$ of the average seasonal cycle amplitude at $82 \mathrm{hPa}$ in the tropics. In agreement with the MLS measurements, the steep water vapor decrease in the tropical lower stratosphere during 2016 was also observed by balloon-borne frost point hygrometer soundings at the tropical sites Hilo, Hawaii $\left(20^{\circ} \mathrm{N}\right)$, and San José, Costa Rica $\left(10^{\circ} \mathrm{N}\right)$ (Figs. $\left.2.55 \mathrm{~b}, \mathrm{c}\right)$.

The annual cycle of tropical lower SWV is predominantly controlled by the annual cycle of CPTs in the TTL. These minimum temperatures are a major factor in determining the water vapor content of the

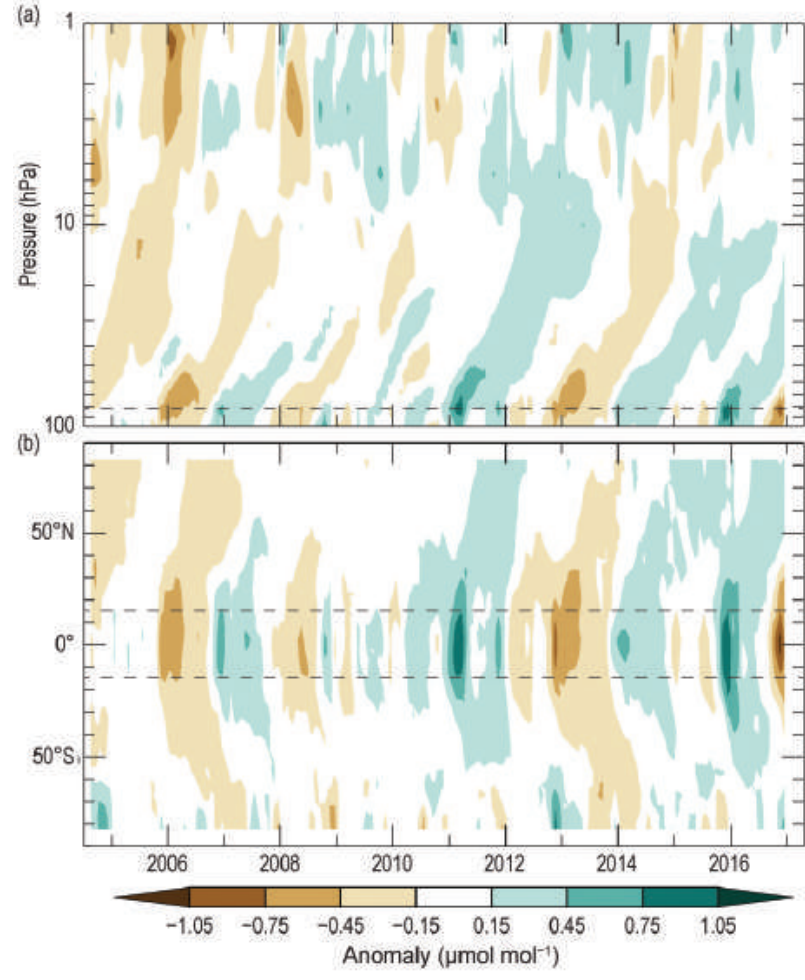

FIG. 2.53. (a) Time series of vertical profiles of tropical $\left(15^{\circ} \mathrm{N}-15^{\circ} \mathrm{S}\right)$ stratospheric water vapor anomalies ( $\mu \mathrm{mol} \mathrm{mol}^{-1}$ ) and (b) latitudinal distributions of SWV anomalies $\left(\mu \mathrm{mol} \mathrm{mol}^{-1}\right)$ at $82 \mathrm{hPa}$. Both are based on Aura MLS data. Anomalies are differences from the mean 2004-2016 water vapor mixing ratios for each month. (b) Propagation of tropical lower SWV anomalies to higher latitudes in both hemispheres as well as the influences of dehydrated air masses from the Antarctic polar vortex as they are transported towards the SH midlatitudes at the end of each year. Dashed horizontal lines in the panels indicate (a) the 82-hPa pressure level and (b) the tropics $15^{\circ} \mathrm{N}-15^{\circ} \mathrm{S}$.

lower stratosphere, because they impact the freezedrying of moist tropospheric air during its slow ascent through the TTL. Seasonal to interannual variability in tropical SWV around $82 \mathrm{hPa}$ is highly correlated with CPT variations. The dramatic decrease in tropical lower SWV during 2016 is consistent with the substantial $\sim 1.5^{\circ} \mathrm{C}$ decrease in tropical CPTs over the same period (Fig. 2.55c).

Interannual variations in CPTs are partially related to interannual variability in the phases of ENSO and QBO in tropical stratospheric winds. At the beginning of 2016, the QBO was in a westerly (warm) phase at $70 \mathrm{hPa}$ in the lowermost stratosphere, but an anomalous set of events brought descending easterlies to the tropical lower stratosphere during June-November 2016 (Newman et al. 2016; Osprey et al. 2016; Dunkerton 2016; Section 2e3). The colder TTL and drier tropical lower stratosphere at the end of 2016 is 

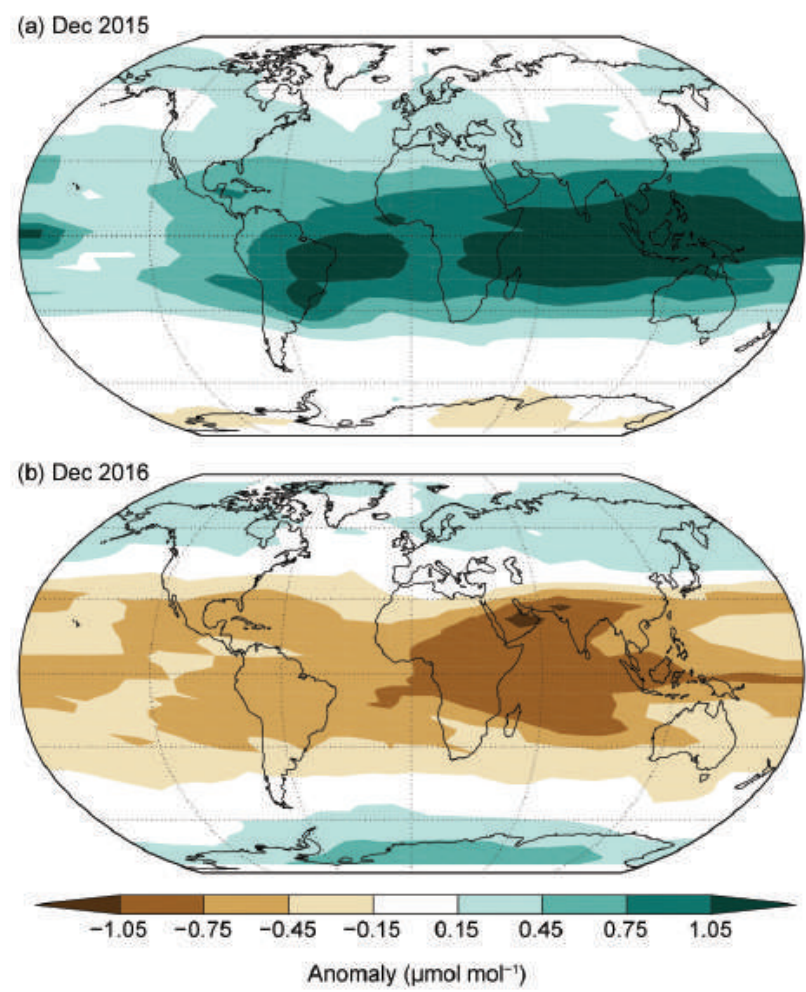

FIG. 2.54. Global stratospheric water vapor anomalies $\left(\mu \mathrm{mol} \mathrm{mol}{ }^{-1}\right.$ ) centered on $82 \mathrm{hPa}$ in (a) Dec 2015 and (b) Dec 2016 from the Aura MLS. In Dec 2016 very strong negative (dry) anomalies were observed in the tropics and subtropics, in stark contrast to the strong positive (wet) anomalies of Dec 2015.

consistent with descending easterlies in this region. The decrease in SWV over the tropical warm pool and the entire tropical Indian Ocean regions during the latter half of 2016 is consistent with an adiabatic response of the TTL to enhanced convection driven by the La Niña conditions present.

Water vapor anomalies in the tropical lowermost stratosphere propagate from the tropics to the middle latitudes of both hemispheres, as is demonstrated by the " $\mathrm{C}$ "-shaped contours in Fig. 2.53b. The early 2016 wet anomaly and the late 2016 dry anomaly in tropical lower SWV can be seen a few months later in the middle latitudes of each hemisphere. These midlatitude anomalies are also observed by balloon measurements at Boulder, Colorado $\left(40^{\circ} \mathrm{N}\right)$, and Lauder, New Zealand $\left(45^{\circ} \mathrm{S}\right)$ (Figs. 2.55a,d). SWV anomalies over Lauder were near zero during most of 2016 but dropped at the end of the year (Fig. 2.55d). The timing of this decrease is consistent with the poleward transport of the strong dry tropical anomalies that emerged in August 2016. The timing of the poleward transport is a function of season. There is less mixing of tropical air into the midlatitudes of the winter hemisphere because of the stronger winter jet, thus
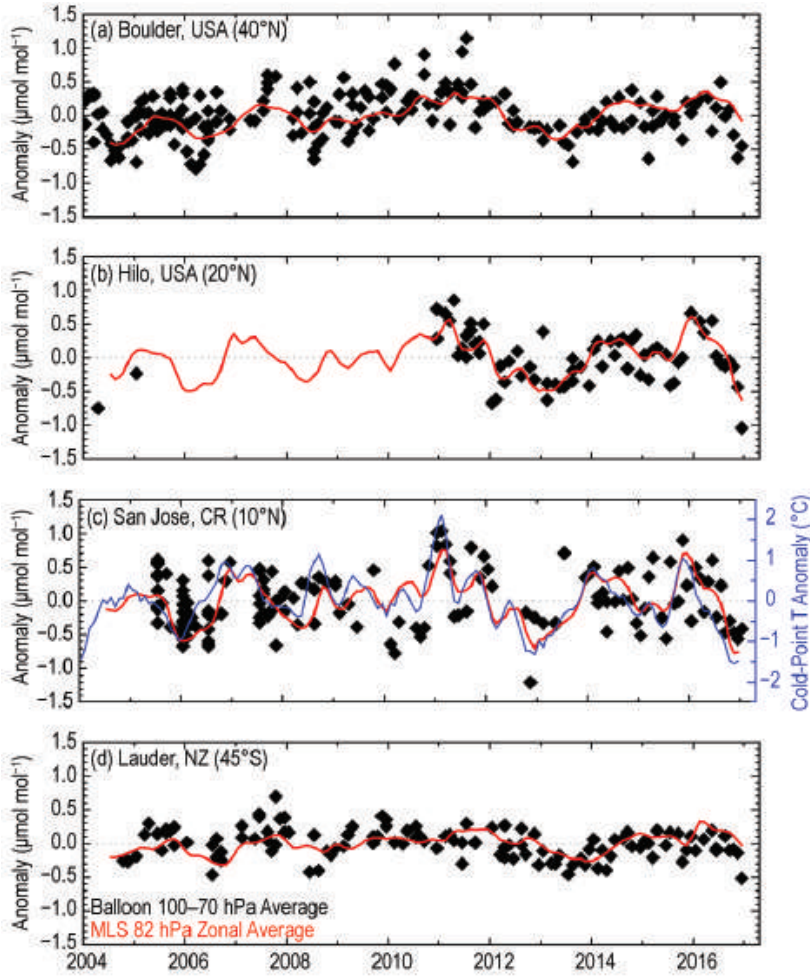

FIG. 2.55. Lower stratospheric water vapor anomalies ( $\mu \mathrm{mol} \mathrm{mol}^{-1}$ ) over four balloon-borne frost point (FP) hygrometer stations. Each panel shows the lower stratospheric anomalies of individual FP soundings (black) and of monthly zonal averages of MLS retrievals at $82 \mathrm{hPa}$ in the $5^{\circ}$ latitude band containing the FP station (red). High-resolution FP vertical profile data were averaged between 70 and $100 \mathrm{hPa}$ to emulate the MLS averaging kernel for $82 \mathrm{hPa}$. Each MLS monthly zonal mean was determined from 2000-3000 profiles. Tropical CPT anomalies based on the MERRA-2 reanalysis [blue curve in (c)], generally well correlated with the tropical lower SWV anomalies, are the driving force behind the sharp decline in tropical SWV during 2016.

the dry tropical anomaly signal is seen at Boulder before Lauder (Figs. 2.55a,d). It should also be noted that SWV in the SH midlatitudes can be influenced during austral springtime (October-November) by the northward transport of air masses dehydrated within the Antarctic vortex. The lack of dry anomalies at high southern latitudes in December 2016 (Fig. $2.54 \mathrm{~b}$ ) indicates that the Antarctic dehydration in 2016 was not unusually strong. Therefore, the strong negative anomalies observed at Lauder in late 2016 are primarily attributed to the southward transport of the strong tropical dry anomalies.

6) Tropospheric Ozone-J. R. Ziemke and 0. R. Cooper

Tropospheric ozone is a greenhouse gas, a surface pollutant, and the primary source of the hydroxyl 
radical $(\mathrm{OH})$, the main oxidizing agent in the troposphere. Sources include transport from the stratosphere and photochemical production from a variety of precursor gases such as lightning $\mathrm{NO}_{x}$, methane, biogenic hydrocarbons, and emissions from the combustion of fossil fuels and biomass (e.g., Sauvage et al. 2007; Martin et al. 2007; Leung et al. 2007; Murray et al. 2013; Young et al. 2013; Neu et al. 2014; Monks et al. 2015). Tropospheric ozone is variable at small (urban) to large (hemispheric) scales because of variations in its photochemical production (i.e., precursor gases and sunlight) and in atmospheric transport. Transport phenomena that drive large-scale variability include the El Niño-Southern Oscillation (e.g., Chandra et al. 1998, 2009; Sudo and Takahashi 2001; Doherty et al. 2006; Koumoutsaris et al. 2008; Voulgarakis et al.2011) and the Madden-Julian oscillation (Sun et al. 2014; Ziemke et al. 2015). Variability at daily to annual timescales (e.g., Ziemke et al. 2015, and references therein) adds challenges to the quantification of decadal trends at hemispheric and global scales (e.g., Neu et al. 2014; Cooper et al. 2014; M. Lin et al. 2014; Parrish et al. 2014).

In 2012 the tropospheric ozone summary was based on measurements by ground- and satellitebased instruments (Cooper and Ziemke 2013). Since then the tropospheric ozone reports have utilized only OMI/MLS satellite measurements (Ziemke et al. 2006) because of delays in obtaining final qualityassured data from the ground-based sites (Cooper and Ziemke 2014, 2015; Ziemke and Cooper 2016). The 2016 analysis again relies mainly on the OMI/MLS satellite data after conducting an in-depth analysis of drift in the 12-year OMI/MLS tropospheric ozone record by comparing with global ozonesondes and OMI convective cloud differential measurements (Ziemke et al. 1998). A small drift of about +0.5 DU decade $^{-1}$ was found, attributed to an OMI error in total ozone, and an appropriate correction has been applied to the OMI/MLS data.

Plate 2.1w shows broad regions of positive anomalies of up to $1.2 \mathrm{DU}(4 \%)$ in $\mathrm{NH}$ tropospheric ozone columns for 2016 and mostly near-zero anomalies elsewhere. Hemispheric and global average tropospheric ozone burdens and their 95\% confidence level uncertainties for 2016 were 151 $\pm 12 \mathrm{Tg}$ for $0^{\circ}-60^{\circ} \mathrm{N}, 136 \pm 9 \mathrm{Tg}$ for $0^{\circ}-60^{\circ} \mathrm{S}$, and $287 \pm 21 \mathrm{Tg}$ for $60^{\circ} \mathrm{N}-60^{\circ} \mathrm{S}$ (Fig. 2.56). Each of these 2016 averages represents an increase from previous years, continuing the long-term upward trends in tropospheric ozone. Linear trends in hemispheric and

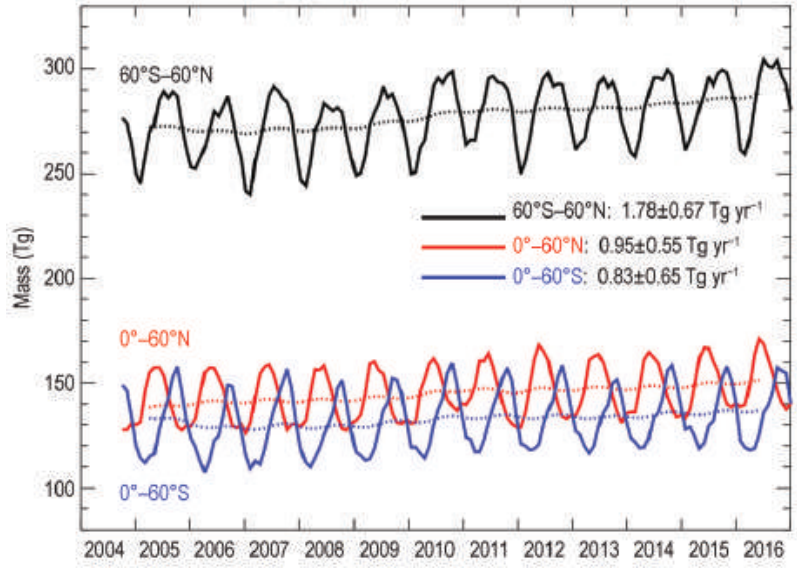

FIG. 2.56. Monthly averages of OMI/MLS tropospheric ozone burdens (Tg) for Oct 2004-Dec 2016. The top curve (black) shows $60^{\circ} \mathrm{N}-60^{\circ} \mathrm{S}$ monthly averages with I2-month running means. The bottom two curves show monthly averages and running means for the NH (red) and SH (blue). Slopes of linear fits to the data are presented with their 2-sigma uncertainties. All three trends are statistically significant at the $\mathbf{9 5 \%}$ confidence level.

global burdens from October 2004 through December 2016 (Fig. 2.56) all depict increases of nearly $0.7 \%$ $\mathrm{yr}^{-1}$ that are statistically significant.

The spatial distribution of linear tropospheric ozone trends is shown on a $5^{\circ} \times 5^{\circ}$ grid in Fig. 2.57. All the trends with statistical significance depict increases, the strongest of which $\left[\sim 3.5 \mathrm{DU}_{\text {decade }}^{-1}\right.$ $\left.\left(1.1 \% \mathrm{yr}^{-1}\right)\right]$ are located in India, Southeast Asia, and the western Pacific. These upward trends are consistent with model estimates based on strengthening emissions of ozone precursors from Southeast, East, and South Asia primarily due to fossil fuel combustion (Yu. Zhang et al. 2016; Lin et al. 2017). The ozone produced in these densely populated areas is clearly transported eastward into the western Pacific region (Fig. 2.57).

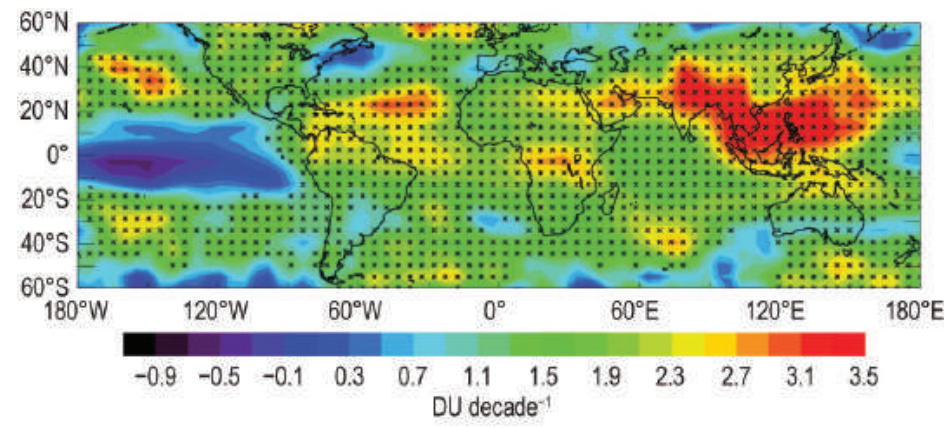

FIG. 2.57. Linear trends in OMI/MLS tropospheric column ozone (DU decade ${ }^{-1}$ ) on a $5^{\circ} \times 5^{\circ}$ grid for Oct 2004-Dec 2016. Asterisks denote statistically significant trends at the $95 \%$ confidence level. Note that all trends with statistical significance depict increases in tropospheric ozone. 
As mentioned, it is difficult to annually update the global ozone distribution using surface observations because most measurement stations do not produce quality-assured final data rapidly enough for the timing of this report. One site with rapidly updated data is the high-elevation Mauna Loa Observatory (MLO) in Hawaii $\left(19.5^{\circ} \mathrm{N}, 155.6^{\circ} \mathrm{W}, 3397 \mathrm{~m}\right.$ asl). Nighttime ozone observations from MLO are representative of a broad region of the lower free troposphere. Figure 2.58 shows that ozone has increased at MLO since 1974, but the large interannual and seasonal variability make it difficult to determine statistically significant trends over the shorter time span of 2000-16. A new technique that can help reduce trend uncertainties and provide additional information is to examine ozone trends separately for the dry and moist air masses that reach the site. Drier air masses tend to originate at higher altitudes and latitudes to the west and northwest of MLO, while moist air masses tend to come from the east at lower latitudes and altitudes (Harris and Kahl 1990; Oltmans et al. 2006). Ozone observations at MLO were divided into dry ( $<40$ th percentile) and moist $(>60$ th percentile) air
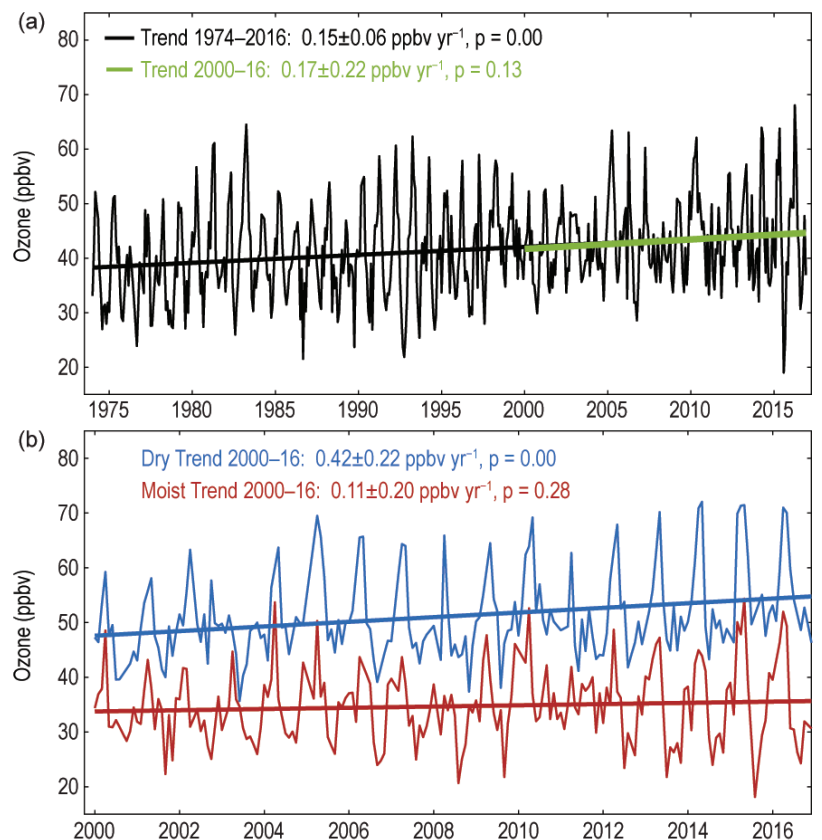

FIG. 2.58. (a) Monthly median nighttime ozone values at MLO for 1974-2016. Linear trends are reported for the full record and for 2000-16. (b) 2000-16 ozone trends at MLO for dry and moist air masses. Ozone in the dry air masses increased at $0.42 \pm 0.22 \mathrm{ppbv} \mathrm{yr}^{-1}$ during 2000-16, a rise of 6.7 ppbv (14\%) in 16 years. There was no statistically significant ozone increase in the moist air masses. The dry air masses reaching MLO tend to come from the northwest so the ozone increase is attributed to the positive ozone trends in southeast Asia (Fig. 2.57). masses using observed dew point temperatures and a long-term climatology. Since 2000, ozone in dry air masses has increased at the rate of $0.42 \pm 0.22 \mathrm{ppb} \mathrm{yr}^{-1}$ while the trend in moist air masses is not significantly different from zero. The robust increase of ozone in dry air masses at MLO since 2000 suggests that the site is being influenced by ozone increases in upwind regions to the west and northwest, most likely Asia where limited in situ observations have shown general ozone increases over the past two decades at the surface (Cooper et al. 2014; Ma et al. 2016; Sun et al. 2016; W. Xu et al. 2016; Wang et al. 2017) and in the free troposphere (Yu. Zhang et al. 2016).

\section{7) Carbon monoxide-J. Flemming and A. Inness}

Carbon monoxide (CO) plays a significant role in determining the abundance of climate forcing gases like methane $\left(\mathrm{CH}_{4}\right)$, through hydroxyl radical chemistry, and tropospheric ozone, as a chemical precursor (Hartmann et al. 2013). CO is therefore regarded as an indirect climate forcing agent. Sources of $\mathrm{CO}$ include the incomplete combustion of fossil fuels and biomass and the oxidation of atmospheric $\mathrm{CH}_{4}$ and other organic trace gases. The combustion and chemical oxidation sources typically produce similar amounts of $\mathrm{CO}$ each year.

The Copernicus Atmosphere Monitoring Service (CAMS) produced a retrospective analysis of CO, aerosols, and ozone for the period 2003-15 by assimilating satellite retrievals of these species (and others) with the ECMWF model (Flemming et al. 2017). Total column retrievals of CO from the MOPITT instrument (Version 5; Deeter et al. 2013) were assimilated in the CAMS interim reanalysis. Anthropogenic emission estimates were taken from the MACCity inventory (Granier et al. 2011) that accounts for projected emission trends according to the representative concentration pathways (RCP) v8.5 scenario (Riahi et al. 2011). Biomass burning emissions were taken from the Global Fire Assimilation System (GFAS v1.2; Kaiser et al. 2012). All analyses have now been extended to the end of 2016 and the updated data are used here.

Studies using MOPITT and other CO observations conclude that the global CO burden has decreased by about $1 \% \mathrm{yr}^{-1}$ during the last decade (Worden et al. 2013; Yin et al. 2015; Flemming et al. 2017). A linear fit of the time series of monthly global CO burdens obtained from the CAMS interim reanalysis (Fig. 2.59) shows a decrease from $405 \mathrm{Tg}$ in early 2003 to $365 \mathrm{Tg}$ at the end of 2016, a trend of $-2.9 \pm 0.8 \mathrm{Tg} \mathrm{yr}^{-1}(-0.75 \%$ $\left.\pm 0.20 \% \mathrm{yr}^{-1}\right)$. Seasonal variations in the global burden result from seasonal changes in CO sources (combus- 


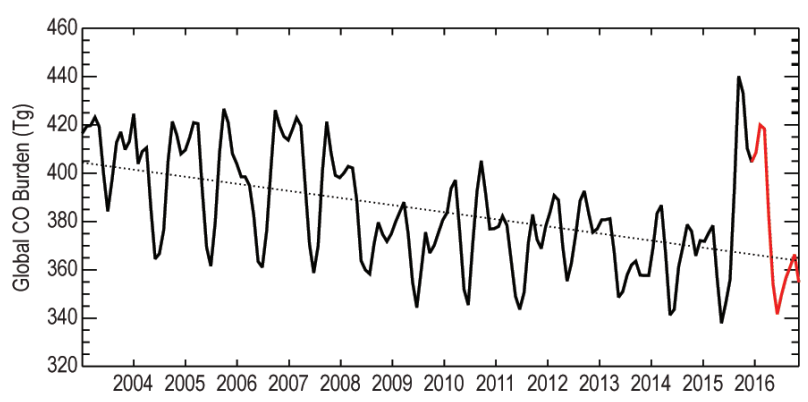

FIG. 2.59. Time series of monthly global total column CO burdens ( $\mathrm{Tg}$ ) from the CAMS interim reanalysis for 2003-I5 (black curve) and 2016 (red curve). The linear fit over 2003-16 (dotted black line) indicates a trend of $-2.9 \pm 0.8 \mathrm{Tg} \mathrm{yr}^{-1}\left(-0.75 \% \pm 0.20 \% \mathrm{yr}^{-1}\right)$.

tion) and sinks $(\mathrm{OH})$. The large upward spike in the CO burden during the latter half of 2015 was due to exceptionally strong biomass burning emissions in Indonesia during September and October. The anomalously high global $\mathrm{CO}$ burden persisted into early 2016, but by mid-2016 had decreased to levels conforming to the decadal trend.

Annual average CO anomalies for 2016 were small $(<5 \%)$ with much of the tropics and SH slightly above the long-term median, with the exception of a strong negative anomaly over the maritime continent, and most of the $\mathrm{NH}$ middle and high latitudes slightly below the median (Plate 2.1ae). However, these annual
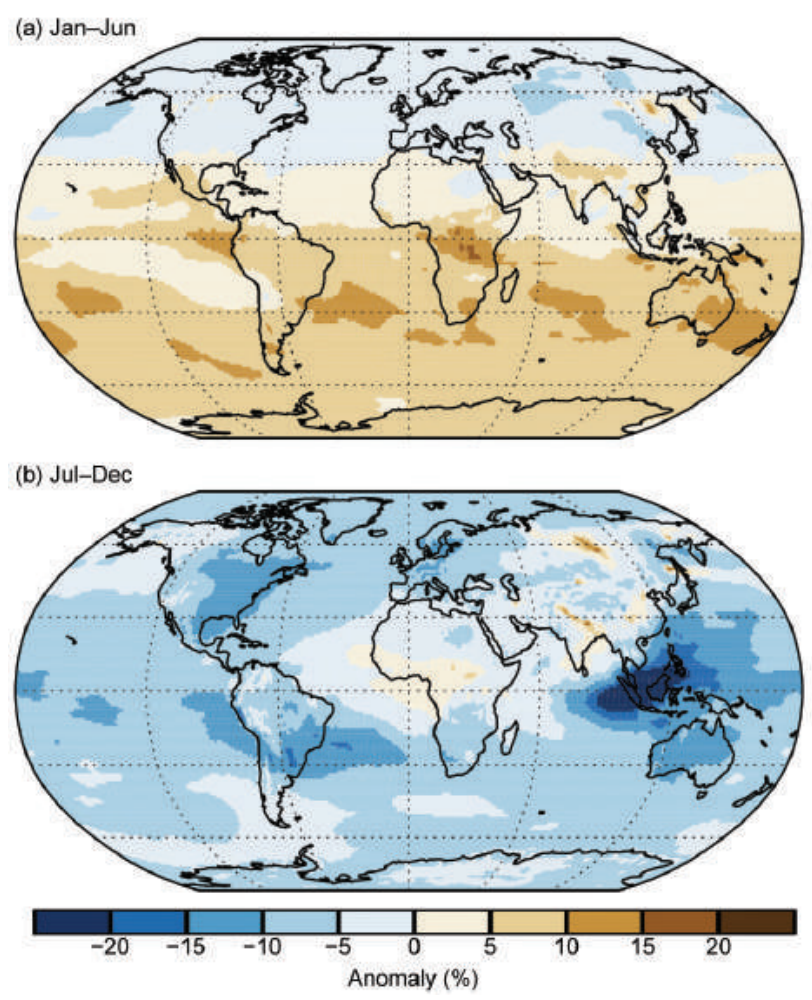

FIG. 2.60. Total column CO anomalies (\%) for (a) Jan-Jun 2016 and (b) Jul-Dec 2016 with respect to the 2003-16 median from the CAMS interim reanalysis. averages don't clearly show that predominantly strong positive anomalies in the first six months (Fig. 2.60a) changed to pronounced negative anomalies in the second six months (Fig. 2.60b). During January-June 2016 the tropical and SH anomalies were still positive due to the Indonesian fires in September-October 2015 and intense fire emissions during JanuaryMarch 2016 in tropical Africa and South America. During July-December 2016 most of the globe showed strong (5\%-10\%) negative CO anomalies, in particular over the eastern half of North America, the outflow region from South America toward southern Africa, and a pronounced $-30 \%$ anomaly over maritime Southeast Asia. The latter anomaly, which also appeared as a $-15 \%$ annual average anomaly (Plate 2.1ae), was caused by a strong reduction in fire emissions from Indonesia and northern Australia. Intense fires in central Siberia during July produced a localized positive anomaly for the last six months of 2016. The May 2016 Fort McMurray fire in Canada is visible as a small positive anomaly in the January-June map (see Sidebar 7.1).

\section{h. Land surface properties}

I) Land surface albedo dynamics-B. Pinty and N. Gobron

The land surface albedo represents the fraction of solar radiation scattered backward by land surfaces. In the presence of vegetation, surface albedo results from complex nonlinear radiation transfer processes determining the amount of radiation that is scattered by the vegetation and its background, transmitted through the vegetation layer, or absorbed by the vegetation layer and its background (Pinty 2012).

The geographical distributions of normalized anomalies in visible and near-infrared surface albedo (V005) for 2016 calculated for a 2003-16 base period (for which two MODIS sensors are available; Schaaf et al. 2002) are shown in Plates 2.1ab,ac, respectively. Mid- and high latitude regions of the Northern Hemisphere are characterized by both positive (blue) and negative (orange) anomalies mainly as a consequence of interannual variations in snow cover (Section 2c2), amount, and duration in winter and spring seasons. The large negative anomalies especially in the visible range over central and eastern Europe, Kazakhstan, western and far east Russia, northeastern China, and across parts of the Tibetan Plateau are probably associated with a below-average snow cover in late winter and early spring seasons, due to the occurrence of anomalous warmth in most of these regions, especially from February onwards. Similarly, negative anomalies over Alaska, central Canada, and north- 
eastern United States can be associated with the fast decline of the snow cover extent and duration as early as February due to unusually warm conditions. These negative anomalies would have been even stronger except for an above-average snow extent in January for the United States and much of Canada, and also in eastern and north central Europe and much of Asia. Nevertheless they reached (or locally exceeded) $-30 \%$ and were larger in the visible than in the near-infrared domain although with the same sign.

A few snow-free regions show slight positive anomalies, especially in the visible domain, in equatorial regions, northeast Brazil, southern Africa, and northeast of the Black Sea. These are generally associated with less favorable vegetation growing conditions in comparison with previous years (see Section $2 \mathrm{~h} 2$ ) although contamination of the albedo retrievals by clouds and aerosol load (especially in intertropical regions) may also induce artifacts. A large fraction of snow-free regions exhibit spatially consistent noticeable negative anomalies, in particular in the visible domain, across Mexico and southern United States, and over the southern regions of South America (including La Pampa and Rio Negro provinces in Argentina), Australia, Indonesia, and southern and central China. Consistent warmer-than-usual conditions persisted over most of these regions, sometimes associated with above-average precipitation. A significant fraction of these variations are attributable to vegetation dynamics (Pinty et al. 2011a,b) over these regions particularly sensitive to water availability. Although weaker in the near-infrared domain, these negative anomalies are, in some instances, spectrally correlated. The amplitude of these positive and negative anomalies often changes with seasons.

Analysis of the zonally averaged albedo anomalies in the visible (Fig. 2.61a) and near-infrared (Fig. 2.61b) spectral domains indicates considerable interannual variations related to the occurrence of snow events in winter and spring at mid- and high northern latitudes, as well as to vegetation conditions during the spring and summer periods. Strong negative anomalies are noticeable between $20^{\circ}$ and $45^{\circ} \mathrm{S}$ in 2016 , featuring a deviation from average conditions mainly over South America and Australia. Consistent negative anomalies in the visible domain are discernible across midlatitude regions in the Northern Hemisphere in 2016.

The amplitude of the globally averaged normalized anomalies resulting from a 12 -month running mean (Figs. 2.62a,b) is within $\pm 5 \%$ (3\%) of the mean in the visible (near-infrared) domain. The anomalies are not estimated over Antarctica due to missing data. The year 2016 is characterized by negative anomalies in

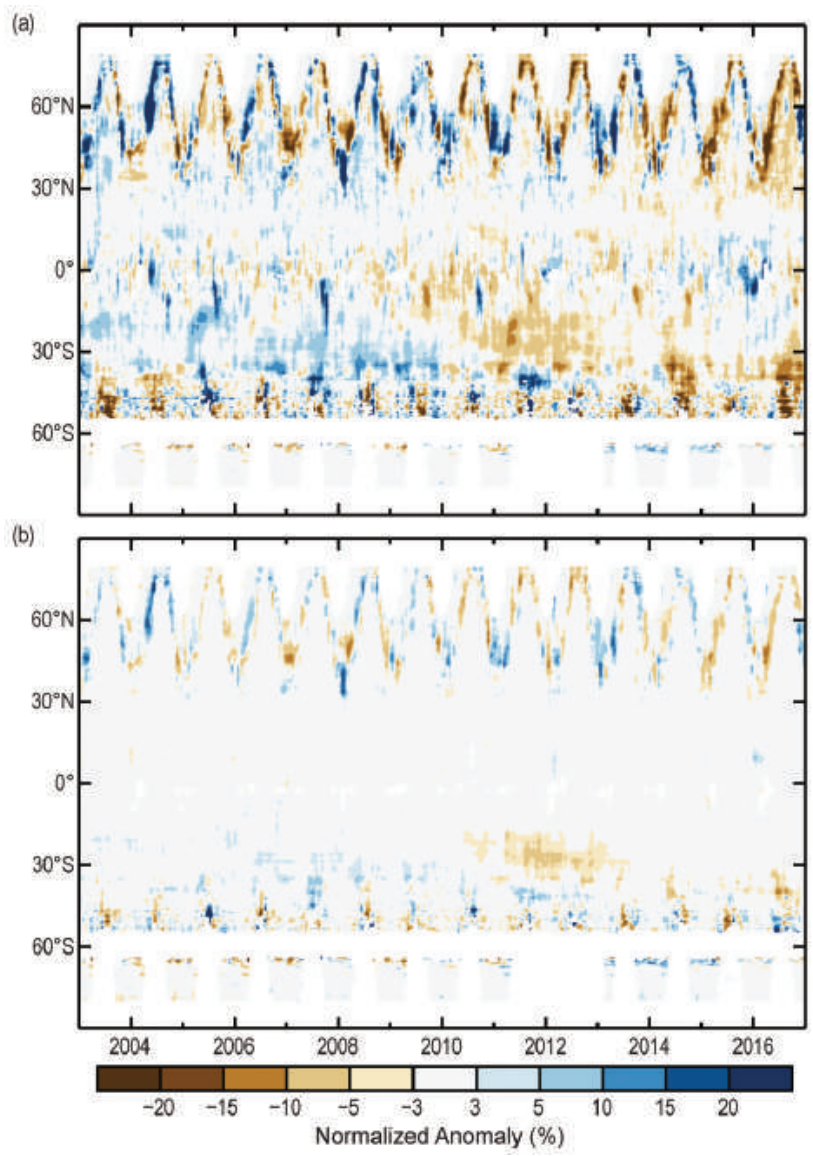

FIG. 2.6I. Zonal means of the MODIS white-sky broadband surface albedo normalized anomalies (\%) in the (a) visible and (b) near-infrared domains relative to the 2003-16 base period.

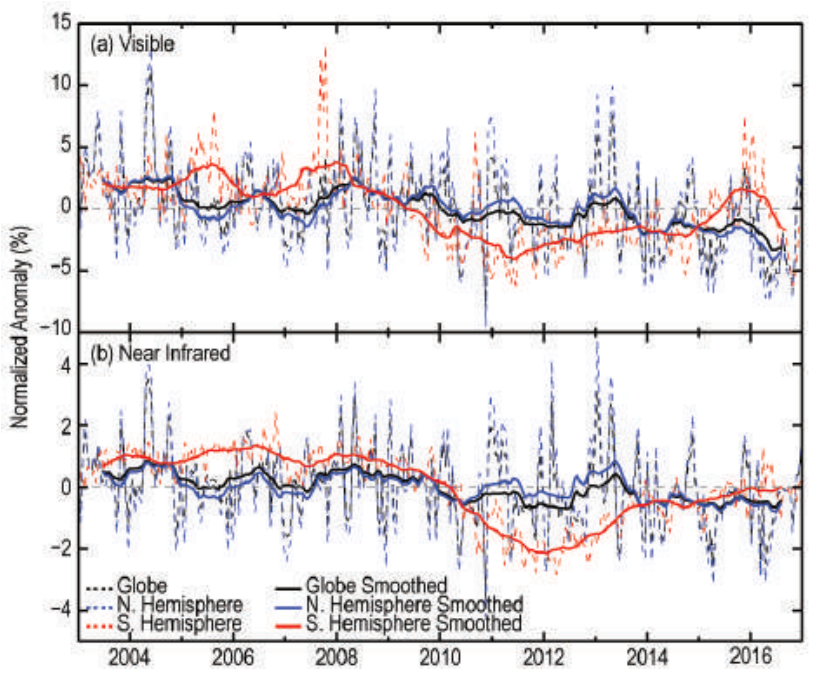

FIG. 2.62. Globally averaged MODIS white-sky broadband surface albedo normalized anomalies with a 12-month running mean in the (a) visible and (b) nearinfrared domain relative to the 2003-16 base period at global scale (black) and over SH and NH in red and blue, respectively. 
the visible domain driven by the dominant contributions from Northern Hemisphere regions. Figure 2.62 also indicates the presence of spectrally correlated multiannual variations during the 2003-16 base period with positively biased values at the beginning of this period.

\section{2) Terrestrial vegetation dynamics-N. Gobron}

Analysis of the 19-year record shows that large spatiotemporal deviations in vegetation dynamics occurred at regional and continental scales during 2016 (Plate 2.1aa). The state of vegetation is examined by merging 1998-2016 estimates of the Fraction of Absorbed Photosynthetically Active Radiation (FAPAR) from three different sensors: SeaWiFS (NASA), MERIS (ESA) and MODIS (NASA) (Gobron et. al. 2010; Pinty et al. 2011b; Gobron and Robustelli 2013). A large number of regions experienced much higher-than-average annual temperatures during 2016 along with a few extreme precipitation and regional drought events. This translates into a large geographical variation in vegetated surface conditions at the global scale.

The largest annual negative FAPAR anomalies (not favorable for vegetation) occurred over Alaska, the central Siberian plateau, and the northeast region of Brazil. Over most of the southern half of the African continent vegetation was stressed, especially over the equatorial regions with evergreen forest, the coastal zones of Kenya and Tanzania, and the Kwazulu-Natal region of South Africa. To a lesser extent, India and the Black and Caspian Seas regions were also affected.

The largest positive annual anomalies are detected over the Saskatchewan-Montana region (CanadaU.S.), West and East Kazakhstan, the southern regions of Ukraine, the eastern part of China, and Indonesia. In the Southern Hemisphere, La Pampa and Rio Negro provinces in Argentina, the wheat belt of western Australia, and northern parts of Victoria (eastern Australia) also show positive anomalies. Smaller positive anomalies occurred over a large fraction of the North American continent, eastern Europe, and central Russia.

The poor rainy season over Africa together with higher temperatures and drought events in South Africa impact the annual anomalies over this continent. The anomalies over Alaska were mainly due to a warmer-than-normal year. Precipitation belowthe seasonal average over the northeast regions of Brazil may be the main cause for the occurrence of strong annual negative anomalies there. Higher-thannormal-precipitation over the second half of the year over La Pampa and Rio Negro provinces in Argentina

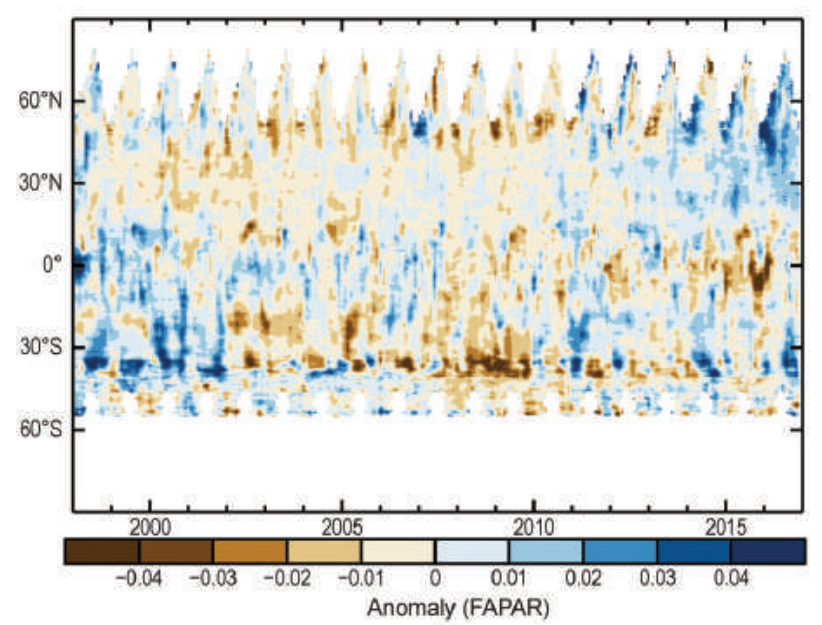

FIG. 2.63. Time series of monthly zonal anomalies (base period: 1998-2016) of FAPAR from SeaWiFS, MERIS, and MODIS sensors. Gray areas indicate missing data.

contributed to favorable conditions for vegetation health and growth.

Zonally averaged monthly mean anomalies (Fig. 2.63) illustrate the differences between the two hemispheres, with persistent negative anomalies over the Southern Hemisphere during all seasons between 2002 and 2009. Large positive anomalies over the Northern Hemisphere exist in 2016 as well as over regions located around $20^{\circ}-30^{\circ} \mathrm{S}$ during the second half of the year.

The monthly mean averaged anomalies for 2016, smoothed using a 12-month running average (Fig. $2.64)$, indicate a relatively healthy state of the vegetation at the global scale and over the Northern Hemisphere, compared with a slightly less healthy state over the Southern Hemisphere.

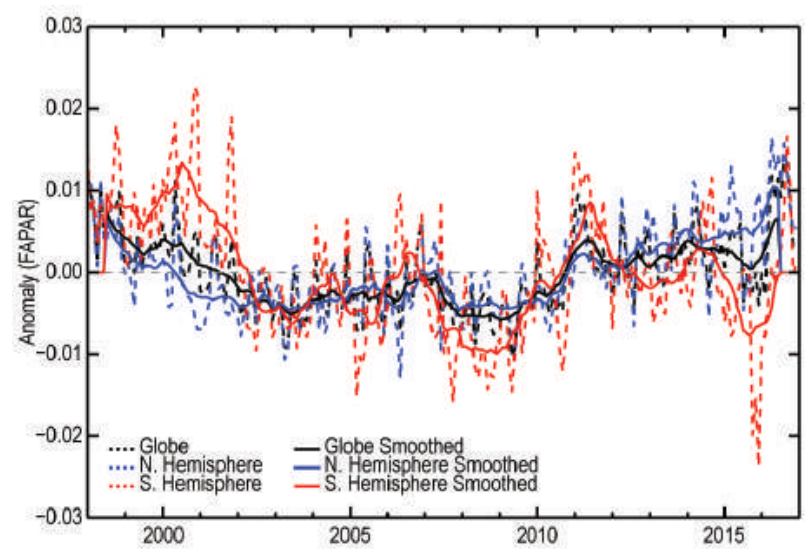

FIg. 2.64. Average monthly FAPAR anomalies with a 12-month running mean (base period: 1998-2016) at the global scale (black) and for the NH (blue) and SH (red). 
3) BIOMASS BURNING-J. W. Kaiser and G. R. van der Werf

Fire has been increasingly recognized as a major source of aerosols and (greenhouse) gases. Especially in the tropics, humans start most fires, but climate governs the temporal and spatial fire patterns leading to relatively large fluctuations in fire strength. On average, fires burn about 500 million hectares, the size of the European Union, each year with the majority of burned areas occurring in tropical savannas.

Since the late 1990s fire occurrence and the associated burned areas have been routinely detected by satellites. The Global Fire Assimilation System (GFAS) builds on active fire detections and their associated fire radiative power to estimate emissions in near-real time (Kaiser et al. 2012). GFAS is calibrated to partly match the Global Fire Emissions Database (GFED) which estimates emissions based on burned area and fuel consumption with a much longer latency (van der Werf et al. 2010). The combined use of GFAS (2001-16) and GFED (1997-2014) indicates that fire emissions were on average 2.1 ${\mathrm{Pg} \mathrm{C} \mathrm{yr}^{-1}}^{-1} \mathrm{Pg}=10^{15} \mathrm{~g}$; $\mathrm{C}$ is carbon) with substantial interannual variability mostly stemming from tropical deforestation zones and the boreal regions where fire activity varies more from year to year than in most savanna areas.

In 2016, negative regional anomalies of around $-75 \mathrm{Tg} \mathrm{C}\left(1 \mathrm{Tg}=10^{12} \mathrm{~g}\right)$ in each of tropical Asia, Australia, and Southern Hemisphere America led to total global fire emissions below average ( $-6 \%$; see Table 2.7, and Plate 2.1ad). Tropical Asia stands out with an $85 \%$ drop in fire activity from 2015 to 2016 (Fig. 2.65); these two years represent the highest and second lowest value in the GFAS record, respectively. Furthermore, North America experienced a negative anomaly of $-30 \mathrm{Tg} \mathrm{C}$ (Table 2.7), and its monthly peak fire activity was the lowest in the GFAS record (Fig. 2.65).

Stronger-than-usual fire activity occurred in particular in northern and southeastern Asia, with anomalies of $+51 \mathrm{Tg} \mathrm{C}$ and $+44 \mathrm{Tg} \mathrm{C}$, respectively. Emissions from northern Asia are dominated by boreal fires in Siberia. These are known to have a strong interannual variability, and the 2016 emissions were within the previously recorded range. However, fires in Southeast Asia were not more active earlier in the GFAS period. Their strong positive anomaly came from the Indochinese peninsula, where fires are dominated by human activity (see Plate 2.1ad). Further positive anomalies were recorded in Central America and Africa north of the equator. The latter is noteworthy because the general trend over the past decade has been one of decreasing emissions there, linked to the expansion of cropland at the cost of frequently burning savannas (Andela and van der Werf 2014).

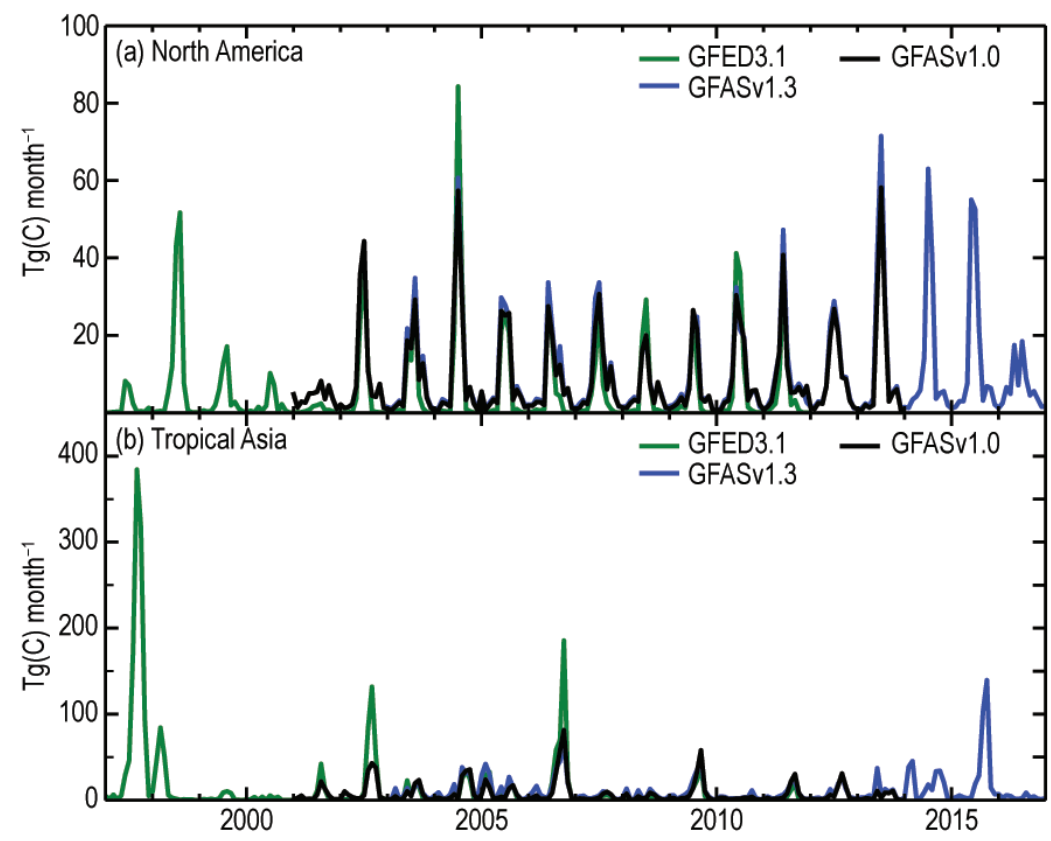

Fig. 2.65. Time series of fire activity during 1997-2016 in terms of carbon consumption for (a) North America and (b) tropical Asia. 
TABLE 2.7. Annual continental-scale biomass burning budgets in terms of carbon emission ( $\left(\mathrm{g} C \mathrm{yr}^{-1}\right)$ : 200I-02 from GFASvI.0 (Remy and Kaiser 2014), 2003-16 from GFASvI.3.

\begin{tabular}{|c|c|c|c|c|}
\hline Time Period & & $2001-15$ & \multicolumn{2}{|c|}{2016} \\
\hline $\begin{array}{l}\text { Quantity in } \\
\operatorname{Tg}_{\mathrm{C} \mathrm{yr}^{-1}}\end{array}$ & & $\begin{array}{c}\text { Mean Value } \\
\text { (Range) }\end{array}$ & Value & $\begin{array}{c}\text { Anomaly } \\
\text { (\%) }\end{array}$ \\
\hline Global & & $\begin{array}{c}2052 \\
(1652-2339)\end{array}$ & 1918 & $\begin{array}{l}-133 \\
(-6 \%)\end{array}$ \\
\hline North America & $\begin{array}{c}30^{\circ}-57^{\circ} \mathrm{N} \\
170^{\circ} \mathrm{W}-30^{\circ} \mathrm{W}\end{array}$ & $\begin{array}{c}112 \\
(50-167)\end{array}$ & 82 & $\begin{array}{c}-30 \\
(-27 \%)\end{array}$ \\
\hline Central America & $\begin{array}{c}0^{\circ}-30^{\circ} \mathrm{N} \\
170^{\circ} \mathrm{W}-30^{\circ} \mathrm{W}\end{array}$ & $\begin{array}{c}68 \\
(49-101)\end{array}$ & 86 & $\begin{array}{c}+18 \\
(+27 \%)\end{array}$ \\
\hline SH America & $\begin{array}{c}0^{\circ}-60^{\circ} \mathrm{S} \\
170^{\circ} \mathrm{W}-30^{\circ} \mathrm{W}\end{array}$ & $\begin{array}{c}310 \\
(153-474)\end{array}$ & 231 & $\begin{array}{c}-79 \\
(-25 \%)\end{array}$ \\
\hline Europe and Mediterranean & $\begin{array}{c}30^{\circ}-75^{\circ} \mathrm{N} \\
30^{\circ} \mathrm{W}-60^{\circ} \mathrm{E}\end{array}$ & $\begin{array}{c}35 \\
(19-62)\end{array}$ & 29 & $\begin{array}{c}-7 \\
(-17 \%)\end{array}$ \\
\hline NH Africa & $\begin{array}{c}0^{\circ}-30^{\circ} \mathrm{N} \\
30^{\circ} \mathrm{W}-60^{\circ} \mathrm{E}\end{array}$ & $\begin{array}{c}402 \\
(33 I-506)\end{array}$ & 427 & $\begin{array}{c}+26 \\
(+6 \%)\end{array}$ \\
\hline SH Africa & $\begin{array}{c}0^{\circ}-35^{\circ} \mathrm{S} \\
30^{\circ} \mathrm{W}-60^{\circ} \mathrm{E}\end{array}$ & $\begin{array}{c}519 \\
(473-591)\end{array}$ & 506 & $\begin{array}{l}-13 \\
(-3 \%)\end{array}$ \\
\hline Northern Asia & $\begin{array}{c}30^{\circ}-75^{\circ} \mathrm{N} \\
60^{\circ} \mathrm{E}-170^{\circ} \mathrm{W}\end{array}$ & $\begin{array}{c}205 \\
(105-470)\end{array}$ & 256 & $\begin{array}{c}+51 \\
(+25 \%)\end{array}$ \\
\hline Southeast Asia & $\begin{array}{c}10^{\circ}-30^{\circ} \mathrm{N} \\
60^{\circ} \mathrm{E}-170^{\circ} \mathrm{W}\end{array}$ & $\begin{array}{c}128 \\
(83-|7|)\end{array}$ & $|7|$ & $\begin{array}{c}+44 \\
(+62 \%)\end{array}$ \\
\hline Tropical Asia & $\begin{array}{c}10^{\circ} \mathrm{N}-10^{\circ} \mathrm{S} \\
60^{\circ} \mathrm{E}-170^{\circ} \mathrm{W}\end{array}$ & $\begin{array}{c}114 \\
(22-329)\end{array}$ & 43 & $\begin{array}{c}-71 \\
(-62 \%)\end{array}$ \\
\hline Australia & $\begin{array}{c}10^{\circ}-50^{\circ} \mathrm{S} \\
60^{\circ} \mathrm{E}-170^{\circ} \mathrm{W}\end{array}$ & $\begin{array}{c}159 \\
(52-296)\end{array}$ & 86 & $\begin{array}{c}-73 \\
(-46 \%)\end{array}$ \\
\hline
\end{tabular}




\section{The Martian Atmosphere}

In terms of its atmosphere and climate, Mars is the planet in the solar system most similar to Earth (e.g., Read and Lewis 2004; Read et al. 2015). With roughly half the radius of Earth (3396 km compared to $637 \mathrm{l} \mathrm{km}$ ), Mars has around the same land surface area as Earth. Its tenuous atmosphere is composed mostly of $\mathrm{CO}_{2}$ ( $95 \%$ by mass) plus much smaller amounts of $\mathrm{N}_{2}(1.9 \%), \operatorname{Ar}(1.9 \%), \mathrm{O}_{2}(0.15 \%), \mathrm{CO}, \mathrm{H}_{2} \mathrm{O}$, and other trace gases (Mahaffy et al. 2013) with a mean surface pressure of $6.1 \mathrm{hPa}$. It orbits at a distance of I.4-I.6 AU' from the sun, receiving around half the solar irradiance of Earth (with significant annual variations) and with an orbital period of 687 Earth days. Mars rotates about its axis with a period scarcely different from Earth $\left(24^{\mathrm{h}} 40^{\mathrm{m}}\right)$ and with an obliquity of $25^{\circ}$, resulting in a seasonal pattern of solar forcing that is remarkably Earth-like (although the seasons are longer in duration). It also sustains massive, permanent caps of water ice which are comparable in mass to Earth's Greenland ice sheet. Winter temperatures fall so low $\left(-128^{\circ} \mathrm{C}\right.$, at the surface) that $\mathrm{CO}_{2}$ also freezes, falling from clouds as snow or condensing directly onto the surface as frost, with up to one third of the total atmospheric mass deposited on the winter pole.

Despite the low atmospheric density, Mars is meteorologically active with intense midlatitude/circumpolar baroclinic storms during autumn, winter, and spring, and frequent dust storms, especially during southern summer (when the planet is closest to the Sun at perihelion). Without surface oceans, this is essentially a desert planet with landscapes variously resembling arid sand and boulder fields or rugged mountain ranges found on Earth, although with numerous ancient impact craters and volcanic peaks. Hence seasonal variations in temperature in response to solar forcing are typically much larger than on Earth, and even the diurnal cycle leads to a strong atmospheric thermal tide that dominates the weather in the tropics.

Even though the present climate is cold, dry, and inhospitable, geological evidence indicates that Mars was more hospitable in the distant past (more than $3 \mathrm{Gyr}$ ago), with

${ }^{1}$ Where $1 \mathrm{AU}$ is the mean Earth-Sun distance of $1.496 \times$ $10^{8} \mathrm{~km}$; see http://nssdc.gsfc.nasa.gov/planetary/factsheet /marsfact.html.

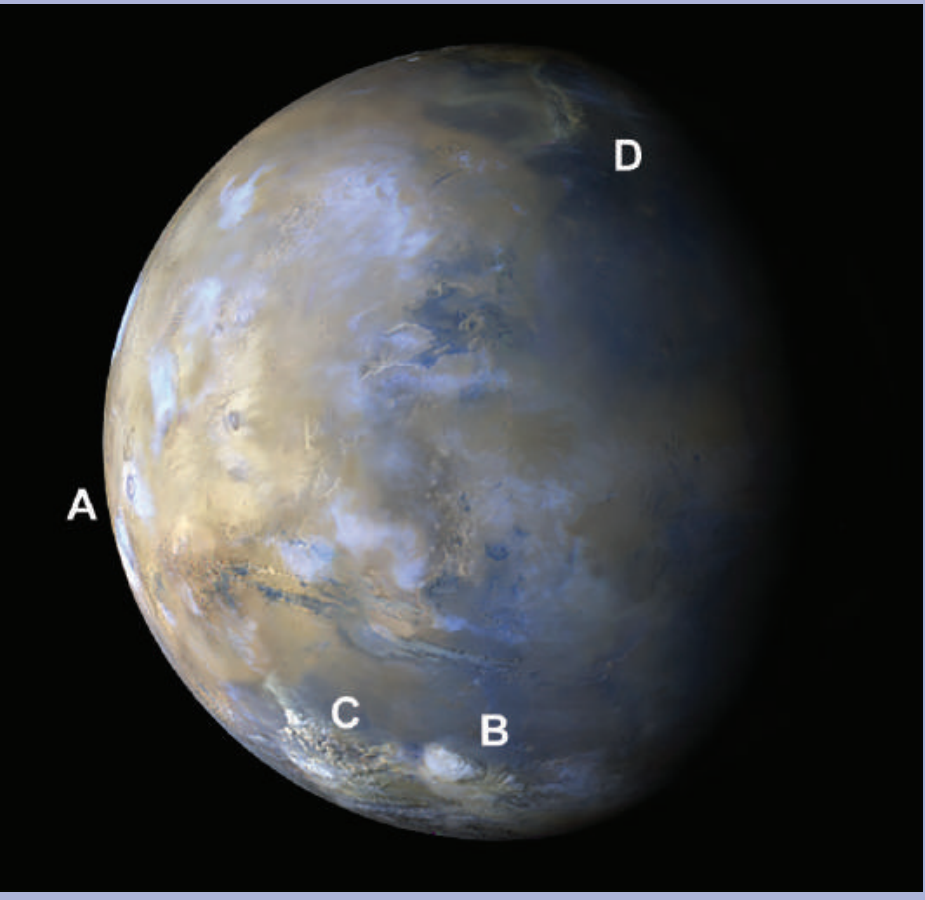

FIG. SB2.I. Mars as seen in May 2016 by the MARCI instrument on board the Mars Reconnaissance Orbiter spacecraft. Blueishwhite features at low and midlatitudes are afternoon water ice clouds, typically tied to high topography, for example, the Tharsis Ridge volcanoes (A). White patches at high southern latitudes show surface frosts and fogs (e.g., B). Regional dust storms appear yellow, for example, lower left of center close to the southern cap (C), and the arc right of center at the top of the disc (D). (Image credit: NASA/JPL-Caltech/Malin Space cience Systems.)

features suggesting erosion by large volumes of flowing water, persistent lakes, or active glaciers, although the precise conditions are still controversial. But the existence of liquid water at the surface raises the possibility that Mars previously sustained life, so it has long been targeted for detailed exploration of its surface and climate, using both observations and model simulations.

\section{Measuring and modeling the Martian atmosphere}

In recent years a succession of sophisticated space missions have visited the planet, aimed at surveying and analyzing the Martian surface and atmosphere, both from orbit and using in situ surface landers. Since the late 1990s, starting with NASA's Mars Global Surveyor (MGS) spacecraft, Mars has been observed from circular polar orbit at relatively low altitude $(350-450 \mathrm{~km})$, enabling remote sensing of the thermal structure of the atmosphere via infrared spectrometry and the detection of clouds and 
aerosols of mineral dust, water, and $\mathrm{CO}_{2}$ ice. The mapping configuration of MGS provided 12 sun-synchronous orbits per Martian day, sampling the full range of latitude and longitude across the planet every day (albeit fairly sparse in longitude), allowing the Thermal Emission Spectrometer (TES) instrument to recover profiles of temperature from the surface to altitudes of $40-50 \mathrm{~km}$, together with column densities of dust and ice. This measurement density and consistency lends itself well to data assimilation approaches, given the availability of a suitable numerical models (e.g., Lewis et al. 2007; Hoffman et al. 2010). Such models borrow heavily from the techniques used for Earth and have now reached a level of sophistication that is beginning to rival Earth climate models, with complex radiative transfer parameterizations (including dust and ice clouds), hydrological cycles for both water and $\mathrm{CO}_{2}$, dust transport cycles, dust storm evolution, and a range of surface processes (Forget et al. 1999; Newman et al. 2002; Steele et al. 2014).

Since the end of the MGS mission in 2004, a number of other spacecraft have continued to remotely sense the surface and atmosphere with increas-

ing coverage and resolution, including NASA's Mars Odyssey and Mars Reconnaissance Orbiter (MRO), and ESA's Mars Express orbiter. The MRO in particular is equipped with the infrared limb-sounding instrument Mars Climate Sounder (McCleese et al. 2007), which can obtain vertical profiles of atmospheric temperature, dust, and ice opacity (Kleinböhl et al. 2009, 201I, 2017). This combination of instruments has thus extended the MGS record, so that the complete observational record stretches from 1999 to the present and consists of more than eight Mars years. Such a consistent record is transforming our view of the Martian climate, allowing detailed studies of dynamical processes across the planet and a clearer perspective on the interannual variability of Martian meteorology.

\section{The Martian climate in 2016-17}

Figure SB2.I shows a composite image of Mars, taken on 8 May 2016 (when Mars was farthest from the Sun; aphelion). The season is mid-late northern hemisphere summer on Mars $\left[L s=149^{\circ}\right.$, where areocentric longitude ${ }^{2}$ is an angle that measures the seasonal date such that $L_{s}=0^{\circ}$ and $180^{\circ}$ represent northern spring and autumn equinoxes while $90^{\circ}$ and $270^{\circ}$ represent summer and winter solstices]. Solar heating is significantly reduced near aphelion due to being farther from the Sun, and the atmosphere is typically colder and clearer than at other times of year. The regional dust storm, indicated by the arc-like feature (D in Fig. SB2.I), is dust revealing frontallike behavior in a northern hemisphere weather system. Baroclinic cyclone waves, of similar horizontal scale to

${ }^{2}$ The year on Mars starts at $L_{s}=0^{\circ}$, northern hemisphere vernal equinox (as the civil year once did on Earth). 
terrestrial weather (on the order of $1000 \mathrm{~km}$ ), circulate around the northern mid-high latitudes (around $60^{\circ} \mathrm{N}$ ) throughout autumn, winter, and spring (Lewis et al. 2016).

Figure SB2. 2 shows how the zonal mean temperature retrieved on the 50-Pa pressure surface from the Mars Climate Sounder instrument aboard NASA MRO varied during the last two Mars years (MY) and during the first year of the mission, which featured a stronger, global dust event in northern winter. Following Clancy et al. (2000), MY are commonly numbered following a scheme where MYI began on II April 1955; northern hemisphere winter of MY33 on Mars started 28 November 2016. Data from the day side of the MRO sun-synchronous orbit have been binned into $5^{\circ}$ latitude and $2^{\circ} L_{s}$ bins and averaged over all longitudes. The 50-Pa surface lies about $25 \mathrm{~km}$ above the reference datum on Mars, except during global dust events (e.g., MY28, Ls $=265^{\circ}-300^{\circ}$ ), when it rises to about $30 \mathrm{~km}$ as the lower atmosphere warms and expands.
The most obvious features of the annual temperature cycle are the cold winter poles in both hemispheres. The first half of the year, northern hemisphere spring and summer, is typically cooler than the second half, as explained in connection with Fig. SB2.I. The notable warm patches at mid- to high southern latitudes from $L_{s}=220^{\circ}-240^{\circ}$ and $L s=250^{\circ}-290^{\circ}$ are large dust events, denoted storms $A$ and $B$ following Kass et al. (2016). Neither approach global scales or are particularly strong in MY33; the warming at similar times at northern midlatitudes is the dynamical consequence of these dust storms, which enhance the strength of the single cross-equatorial Hadley cell, resulting in stronger adiabatic heating in the descending branch. So far, the Martian atmosphere in MY33 has appeared remarkably similar to the previous year on Mars (MY32; Fig. SB2.2b) with, if anything, even weaker dust storm activity. This is in direct contrast to some previous years, e.g., MY25 and MY28 (Fig. SB2.2c), which exhibited global dust events that warmed the atmosphere significantly (by up to $40 \mathrm{~K}$ ) at these altitudes over a large range of latitudes and for intervals of at least 50 days. 


\section{GLOBAL OCEANS}

a. Overview-G. C. Johnson

The transition from a strong El Niño in late 2015 to a weak La Niña by late 2016 included strengthening westward zonal surface current anomalies along the equator, which in turn contributed to sea level and upper ocean heat content rising in the western tropical Pacific north of the equator, and falling in the eastern equatorial Pacific. With resumed upwelling in the eastern equatorial Pacific, sea surface temperatures (SSTs) there cooled, outgassing of $\mathrm{CO}_{2}$ increased, chlorophyll-a levels were high, and local heat flux from atmosphere to ocean increased. Surface salinity freshened in the western equatorial Pacific, under increased precipitation.

El Niño events modulate the rise in global mean SST and ocean heat content (OHC), with warming rates increasing as El Niños wax, and decreasing as they wane. Hence, global SST in 2016 barely broke its 2015 record high, and global OHC from 0-2000 m fell somewhat in 2016 from its 2015 record high. As a result, sea level also rose more slowly in 2016 than in 2015. To summarize in haiku form:

\section{Large El Niño wanes, east Pacific tropics cool, seas shed heat, slow rise.}

SST, OHC, and sea level were all anomalously low around the centers of the extratropical North and South Pacific, and generally high elsewhere, consistent with the continued warm phase of the Pacific decadal oscillation that has held since 2014. Strong winds with anomalously high heat and $\mathrm{CO}_{2}$ loss from the ocean were observed around the eastern sides of these extratropical cold anomalies in both hemispheres in 2016.

North Atlantic SSTs southeast of Greenland rose from 2015 to 2016, but remained below average, as they have for three years now, again with anomalously low OHC and sea level, low sea surface salinity (SSS), low chlorophyll-a, and anomalous heat flux into the ocean. (Arctic Ocean SST and sea ice are discussed in detail in Chapter 5.) Western North Atlantic subtropical SSTs remained anomalously high in 2016, again with high $\mathrm{OHC}$ and sea level along the east coast of North America. In climate models this North Atlantic SST pattern is associated with a reduction in the Atlantic meridional overturning circulation. The coastal warming also impacts ecosystems, which have shifted north or deeper in response.

In the Indian Ocean, SSTs fell in 2016 from recordhigh 2015 levels, although still high compared to the long-term average. OHC and sea level rose north of about $10^{\circ} \mathrm{S}$ and fell south of there, resulting in anomalous eastward zonal surface currents near $10^{\circ} \mathrm{S}$. Surface salinities in 2016 were generally anomalously low in the eastern Indian Ocean and high in the western Indian Ocean, a pattern that has held since the 2010/11 La Niña, also consistent with the tendency of precipitation minus evaporation from 2015 to 2016.

The rate of ocean uptake of carbon from the atmosphere has continued to generally risen along with atmospheric $\mathrm{CO}_{2}$ concentrations, hence the ocean has acidify. The 1993-2016 trends in OHC reflect statistically significant warming in the Southern Hemisphere, mostly north of the Antarctic Circumpolar Current. (Southern Ocean conditions and sea ice are discussed in detail in Chapter 6.)

\section{b. Sea surface temperatures-B. Huang, J. Kennedy, Y. Xue, and H.-M. Zhang}

Sea surface temperature is a key variable in climate assessment and monitoring and is a major source of climate predictability at seasonal to interannual time scales. In 2016, SST in the tropical Pacific evolved from strong El Niño conditions in late 2015/early 2016 toward neutral or slightly-colder-than-average conditions (with the reference to the 1981-2010 climatology) by fall 2016. The 2015/16 El Niño event is one of the strongest three such events since at least 1950 (Huang et al. 2016a; Xue and Kumar 2016). Despite the weakening 2015/16 El Niño event in 2016, the global-average SST in 2016 broke the record set in 2015 by a narrow margin.

The Extended Reconstruction SST version 4 (ERSSTv4; Huang et al. 2015) is used in this report to assess SST and its change in the global oceans. ERSSTv 4 is a monthly $2^{\circ} \times 2^{\circ}$ SST product from 1854 to present based on in situ observations. ERSSTv4 is compared with the Daily Optimum Interpolation SST (DOISST; Reynolds et al. 2007) and U.K. Met Office Hadley Centre SST version 3 (HadSST.3.1.0.0; Kennedy et al. 2011a,b). DOISST is a daily $0.25^{\circ} \times 0.25^{\circ}$ SST product for the modern satellite era from September 1981 to present using both in situ and satellite observations. HadSST.3.1.0.0 is a monthly $5^{\circ} \times 5^{\circ} \mathrm{SST}$ product from 1850 to present using in situ observations. All datasets are averaged to monthly $2^{\circ} \times 2^{\circ}$ grids for comparison purposes.

Annually averaged SST anomaly (SSTA; relative to $1981-2010$ climatology) in 2016 exceeded $+0.5^{\circ} \mathrm{C}$ over much of the tropical oceans and exceeded $+1^{\circ} \mathrm{C}$ near the Gulf of Alaska and the Gulf Stream (Fig. 3.1a). Higher SSTAs were partly associated with the 2015/16 El Niño event (Xue et al. 2016; L'Heureux 


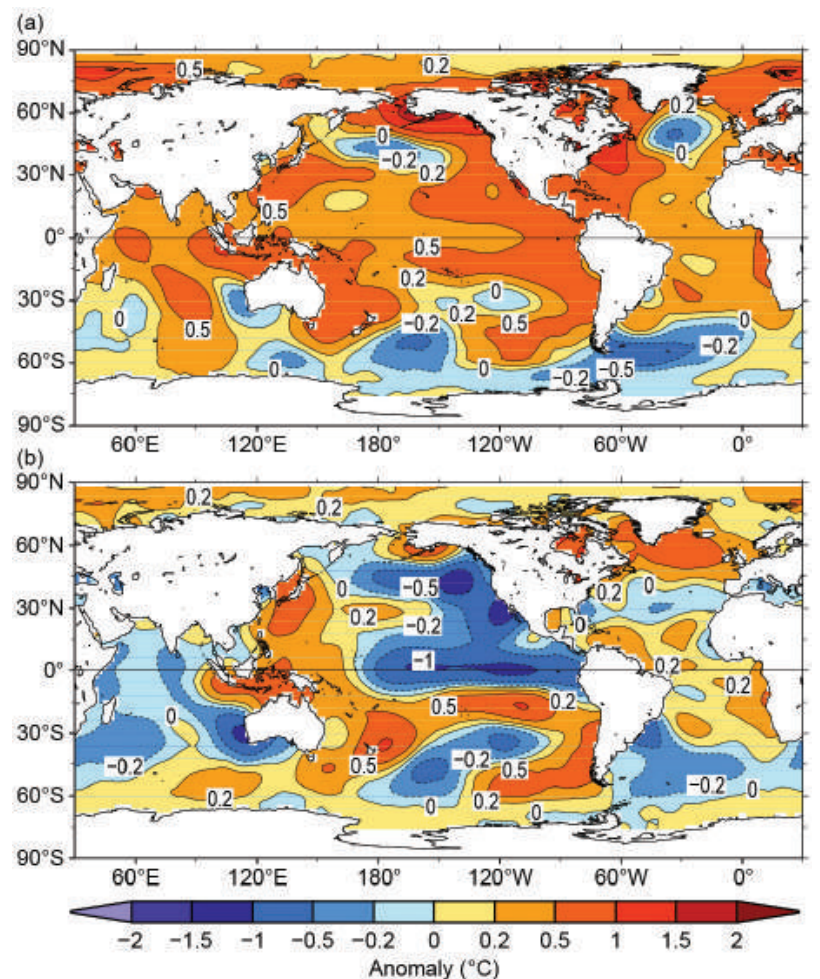

FIG. 3.I. (a) Annually averaged SSTA of ERSSTv4 in 2016 and (b) difference of annually averaged SSTAs between 2016 and 2015 . SSTAs $\left({ }^{\circ} \mathrm{C}\right)$ are relative to 1981-2010 climatology.

et al. 2017), which peaked in November 2015, weakened, and became neutral after June 2016. In contrast, SSTA was slightly lower than average in the Southern Ocean south of $40^{\circ} \mathrm{S}$ between $120^{\circ} \mathrm{E}$ and $0^{\circ}$, the northern North Atlantic south of Greenland near $50^{\circ} \mathrm{N}$, and the central North Pacific near $40^{\circ} \mathrm{N}$. Globally averaged SSTA in 2016 was $0.378( \pm 0.055)^{\circ} \mathrm{C}$, marginally higher $\left(0.013^{\circ} \mathrm{C}\right)$ than the record of $0.365( \pm 0.055)^{\circ} \mathrm{C}$ set in 2015.

In comparison with 2015, SST in 2016 was $0.2^{\circ}-0.5^{\circ} \mathrm{C}$ higher in the western North Pacific, Indo-Pacific maritime region, western South Pacific, subtropical South Pacific along latitudes of $10^{\circ}-30^{\circ} \mathrm{N}$, eastern South Pacific, Atlantic between $30^{\circ} \mathrm{S}$ and $30^{\circ} \mathrm{N}$, northern North Atlantic north of $40^{\circ} \mathrm{N}$, and the Arctic (Fig. 3.1b). However, SST in 2016 was $0.5^{\circ}-1.0^{\circ} \mathrm{C}$ lower in the central to eastern tropical Pacific and eastern subtropical North Pacific, and was approximately $0.2^{\circ} \mathrm{C}$ lower in the central South Pacific/Southern Ocean, South Atlantic south of $30^{\circ} \mathrm{S}$, and most of the Indian Ocean.

Cooling in the tropical Pacific in 2016 relative to 2015 was clearly associated with the weakening 2015/16 El Niño event (Figs. 3.2a-d). SSTAs in the tropical Pacific were more than two standard deviations $(2 \sigma$; derived from ERSSTv4 in 1981-2010) above average in DJF 2015/16 (hereafter DJF), weakened in MAM, and became negative in JJA and SON.

In the North Pacific north of $30^{\circ} \mathrm{N}$, SSTA was both 1-2 $\sigma$ higher than average in the east and 1-2 $\sigma$ lower in the central-west in both DJF and MAM. The low SSTA in the central-west diminished in JJA and reemerged in SON. The high SSTA is consistent with the positive phase of the Pacific decadal oscillation (PDO) in DJF and MAM, and is also consistent with El Niño conditions in the tropical Pacific.

In the western South Pacific east of Australia, SSTA was approximately $1 \sigma$ higher in DJF, strengthened to 1-2 $\sigma$ in MAM and JJA, and weakened to 1 $\sigma$ in SON. In the central-eastern subtropical South Pacific, SSTA was 1-2 $\sigma$ higher in DJF and MAM, which shifted eastward in JJA, and weakened to approximately $1 \sigma$ in $\mathrm{SON}$.

In the Indian Ocean, SSTA was $1-2 \sigma$ higher in DJF and MAM, weakened to approximately $1 \sigma$ in JJA, and dropped to less than $1 \sigma$ in SON. SSTA values in the tropical Indian Ocean in DJF and MAM are consistent with the influence of El Niño events in the region. A transition to neutral-to-low anomalies in $\mathrm{SON}$ seems to be associated with a transition to $\mathrm{La}$ Niña conditions then.

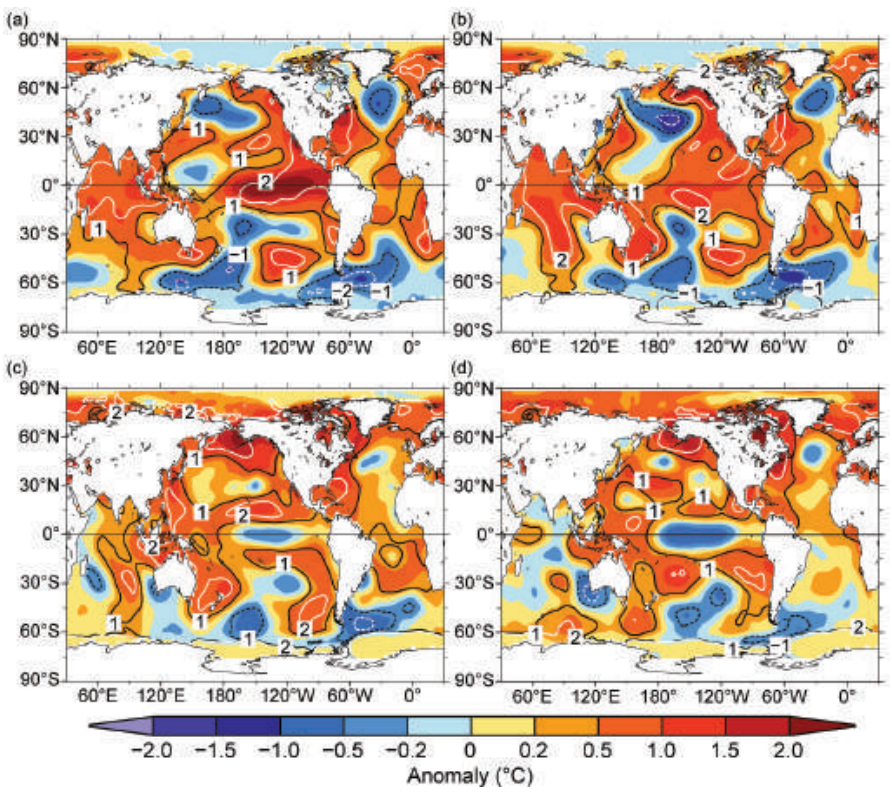

Fig. 3.2. Seasonal averaged SSTAs of ERSSTv4 $\left({ }^{\circ} \mathrm{C}\right.$; shading) for (a) Dec 2015-Feb 2016, (b) Mar-May 2016, (c) Jun-Aug 2016, and (d) Sep-Nov 2016. Normalized seasonal mean SSTA based on seasonal mean std. dev. over 198I-2010 indicated by contours of 2 (dashed white), -I (dashed black), I (solid black), and 2 (solid white). 
SSTA persisted 1-2 $\sigma$ higher in the Gulf of Alaska and subtropical North Pacific in all seasons and was approximately $1 \sigma$ higher in the tropical and South Atlantic in DJF, MAM, and JJA but weakened to less than $1 \sigma$ higher in SON. In the northern North Atlantic, the cold blob south of Greenland (de Jong and de Steur 2016) weakened in the latter half of 2016. Cold anomalies in the high-latitude Southern Ocean persisted largely through 2016.

The record high SST in 2015 and 2016 indicated a continued warming of the global oceans since 1950 (Fig. 3.3a; solid white line) or earlier (Fig. 3.3b; solid white line). The global ocean SST trend for 2000-16 of $+1.62( \pm 0.76)^{\circ} \mathrm{C}$ century ${ }^{-1}$ is higher than the longer term 1950-2016 warming trend of $1.00( \pm 0.11)^{\circ} \mathrm{C}$ century ${ }^{-1}$, although trends for the two time periods do overlap within uncertainties. Further analysis indicates that SST increase for the period 2000-16 was fastest in the North Pacific (Fig. $3.3 \mathrm{~d} ; 2.84^{\circ} \mathrm{C}$ century $^{-1}$ ) and tropical Indian Ocean (Fig. $3.3 \mathrm{e} ; 2.48^{\circ} \mathrm{C}$ century ${ }^{-1}$ ), with lower rates in the tropical Pacific (Fig. 3.3c; $1.61^{\circ} \mathrm{C}$ century ${ }^{-1}$ ), tropical Atlantic (Fig. 3.3g; $1.35^{\circ} \mathrm{C}_{\text {century }}{ }^{-1}$ ), Southern (Fig. $3.3 \mathrm{~h} ; 1.15^{\circ} \mathrm{C}$ century ${ }^{-1}$ ), and North Atlantic (Fig. $3.3 \mathrm{f} ; 1.00^{\circ} \mathrm{C}_{\text {century }}{ }^{-1}$ ) oceans. The SST increase for the period 1950-2016 was fastest in the tropical Indian $\left(1.47^{\circ} \mathrm{C}\right.$ century $\left.{ }^{-1}\right)$, tropical Atlantic $\left(1.12^{\circ} \mathrm{C}\right.$ century $\left.{ }^{-1}\right)$, and Southern $\left(1.02^{\circ} \mathrm{C}\right.$ century ${ }^{-1}$ ) oceans; and slower in the tropical Pacific $\left(1.00^{\circ} \mathrm{C}\right.$ century $\left.{ }^{-1}\right)$, North Atlantic $\left(1.00^{\circ} \mathrm{C}\right.$ century $\left.{ }^{-1}\right)$, and North Pacific $\left(0.65^{\circ} \mathrm{C}\right.$ century $\left.y^{-1}\right)$ oceans. The recent increase of the global mean SST (to the end of 2015) as seen in ERSSTv4 is consistent with the report by Karl et al. (2015) and corroborated by comparisons with independent and homogenous datasets (Hausfather et al. 2017).

In addition to long-term SST trends, internal SST variations can be seen in all global ocean basins, although the amplitude is typically smaller in the Southern Ocean. Variations associated with the Atlantic multidecadal oscillation (AMO) can clearly be identified (Huang et al. 2015) with warm periods from 1950 to 1955 and 1996 to 2016, and a cold period in between.

SSTA deviations of DOISST and HadSST.3.1.0.0 from ERSSTv4 are largely within $2 \sigma$ (gray shading in Fig. 3.3). ERSSTv4 $2 \sigma$ is estimated from a

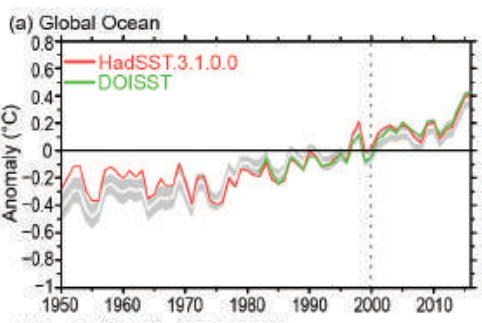

(b) Global Ocean

(c) Tropical Pacific $\left(30^{\circ} \mathrm{S}-30^{\circ} \mathrm{N}\right)$

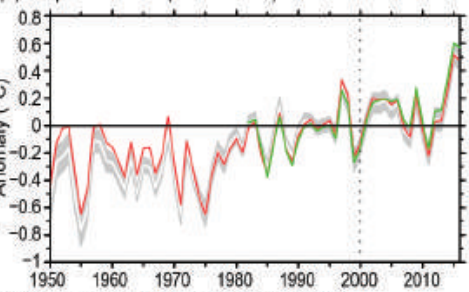

(e) Tropical Indian Ocean $\left(30^{\circ} \mathrm{S}-30^{\circ} \mathrm{N}\right)$

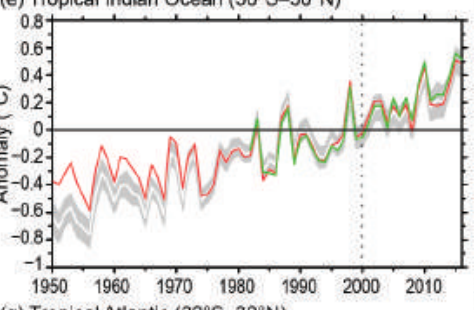

(g) Tropical Atlantic $\left(30^{\circ} \mathrm{S}-30^{\circ} \mathrm{N}\right)$
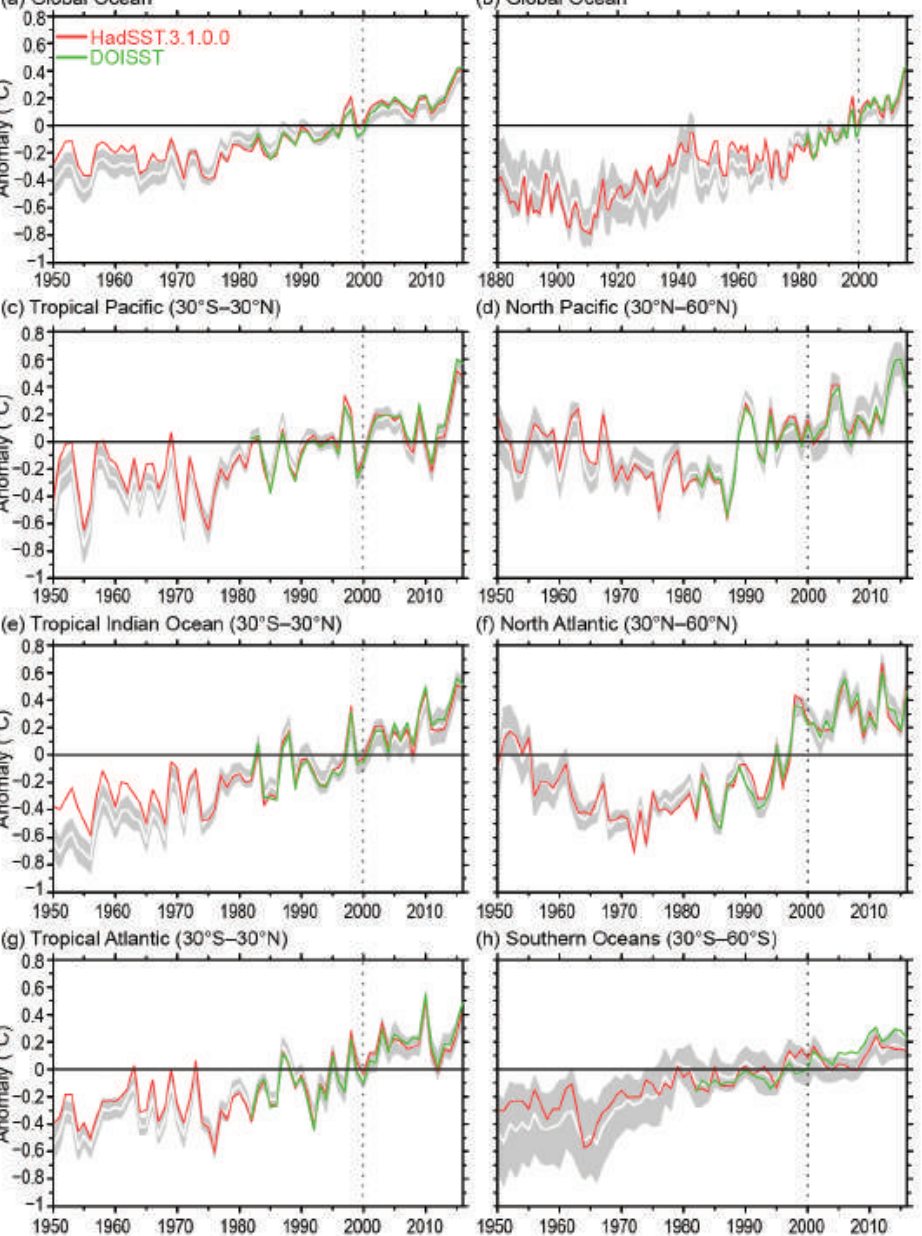

(d) North Pacific $\left(30^{\circ} \mathrm{N}-60^{\circ} \mathrm{N}\right)$

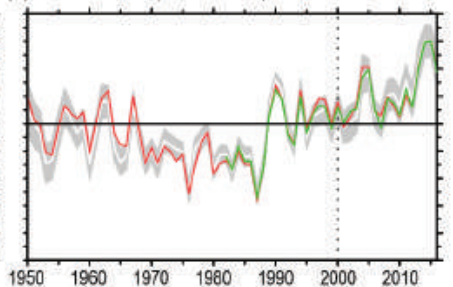

(f) North Atlantic $\left(30^{\circ} \mathrm{N}-60^{\circ} \mathrm{N}\right)$

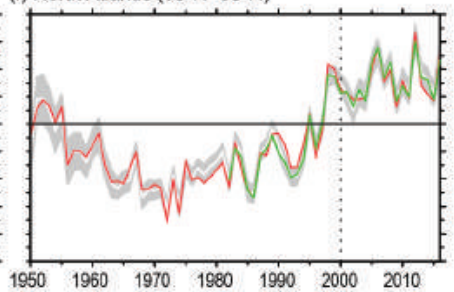

(h) Southern Oceans $\left(30^{\circ} \mathrm{S}-60^{\circ} \mathrm{S}\right)$

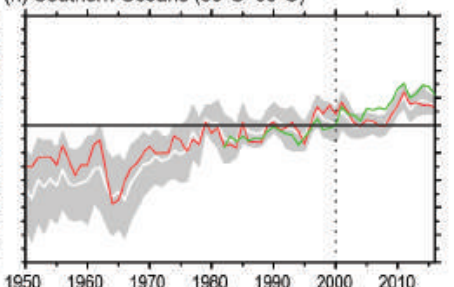

Fig. 3.3. Annually averaged SSTAs (white line) and $2 \sigma$ (gray shading) of ERSSTv4, SSTAs of DOISST (green line), and SSTAs of HadSST.3.1.0.0 (red line). (a) global (1950-2016), (b) global (1880-2016), and (c) tropical Pacific, (d) North Pacific, (e) tropical Indian, (f) North Indian, (g) tropical Atlantic, and (h) Southern Oceans (1950-2016). The year 2000 is indicated by a vertical dotted line.

1000-member ensemble analysis (Huang et al. 2016b) and centered on SSTA of ERSSTv4. However, SSTAs are slightly higher in the 1950s-70s and 1920s-30s in HadSST.3.1.0.0 than in ERSSTv4. SSTAs are also slightly higher in the 2000s-10s in HadSST.3.1.0.0 and DOISST than in ERSSTv4. These SSTA differences have been mostly attributed to the differences in ship bias corrections in different products (Huang et al. 2015). Therefore, SST trends are slightly weaker in HadSST.3.1.0.0 in both 1950-2016 and 2000-16. In contrast, SST trends are slightly higher in DOISST in $2000-16$. For example, the trend of globally averaged SSTA is $1.36( \pm 0.91)^{\circ} \mathrm{C}$ century ${ }^{-1}$ and $1.84( \pm 0.77){ }^{\circ} \mathrm{C}$ century ${ }^{-1}$, respectively, in HadSST.3.1.0.0 and DOISST in $2000-16$, while it is $1.62( \pm 0.76)^{\circ} \mathrm{C}_{\text {century }}{ }^{-1}$ in ERSSTv4; from 1950 to 2016 , it is $0.82( \pm 0.17)^{\circ} \mathrm{C}$ century $^{-1}$ in HadSST.3.1.0.0 and $1.00( \pm 0.11)^{\circ} \mathrm{C}$ 
century ${ }^{-1}$ in ERSSTv4 (Table 3.1). These trends agree within their uncertainty ranges.

C. Ocean heat contentG. C. Johnson, J. M. Lyman, T. Boyer, C. M. Domingues, J. Gilson, M. Ishii, R. Killick, D. Monselesan, and S. E. Wijffels

Storage and transport of heat in the ocean are central to aspects of climate such as ENSO (Johnson and Birnbaum 2017), tropical cyclones (Goni et al. 2009), sea level rise (Leuliette 2015), variations in the global average surface warming rate (Xie et al. 2016), and melting of ice sheet outlet glaciers around Greenland (Castro de la Guardia et al. 2015) and Antarctica (Schmidtko et al. 2014). Ocean warming accounts for about 93\% of the total increase in Earth's energy storage from 1971 to 2010 (Rhein et al. 2013).

Maps of annual (Fig. 3.4) upper (0-700 m) ocean heat content anomaly (OHCA) relative to a 1993-2016 baseline mean are generated from a combination of in situ ocean temperature data and satellite altimetry data following Willis et al. (2004), but using Argo (Riser et al. 2016) data downloaded in January 2017. Near-global average seasonal temperature anomalies (Fig. 3.5) vs. pressure from Argo data (Roemmich and Gilson 2009, updated) since 2004 and in situ global estimates of OHCA (Fig. 3.6) for three pressure layers from six different research groups (including the group responsible for the 2000-6000 m estimate) are also discussed.

The large decrease (Fig. 3.4b) of 0-700-m OHCA in the central and eastern equatorial Pacific from 2015 to 2016 is associated with the waning of the $2015 / 16$ El Niño, as is the OHCA increase in the western and central Pacific just north of the equator (Johnson and Birnbaum 2017). This pattern is consistent with strong westward zonal current anomalies along the equator in 2016 (see Fig. 3.18). Despite this 2015/16 tendency, upper OHCA remains low with respect to the 1993-2016 average in the tropical western Pacific, and high in the eastern tropical Pacific (except for a narrow band along the equator) on both sides of the equator. This pattern has held since 2014 (Johnson et al. 2015a, 2016) and is reflected in sea level (see Fig. 3.16).

Outside the tropics, the eastern North and South Pacific upper OHCA generally rose from 2015 to 2016 (Fig. 3.4b), whereas it fell in regions in the central North and South Pacific. This pattern is consistent with a continued positive (since 2014) Pacific decadal oscillation (PDO; Mantua et al. 1997) and a positive interdecadal Pacific oscillation (IPO). North and
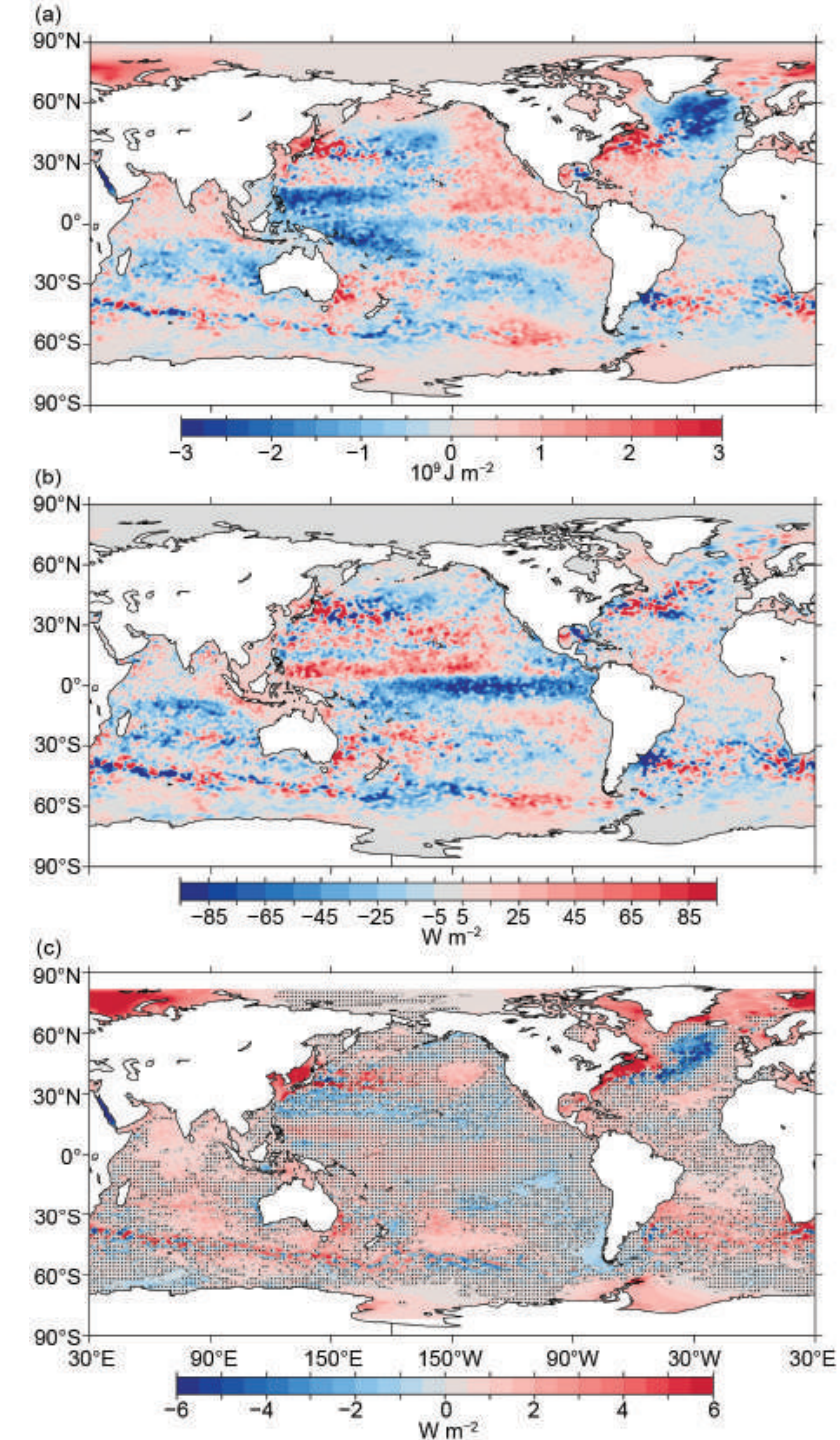

FIG. 3.4. (a) Combined satellite altimeter and in situ ocean temperature data estimate of upper $(0-700 \mathrm{~m})$ OHCA $\left(\times 10^{9} \mathrm{~J} \mathrm{~m}^{-2}\right)$ for 2016 analyzed following Willis et al. (2004), but using an Argo monthly climatology and displayed relative to the 1993-2016 baseline. (b) 2016 minus 2015 combined estimates of OHCA expressed as a local surface heat flux equivalent $\left(\mathrm{W} \mathrm{m}^{-2}\right)$. For (a) and (b) comparisons, note that $95 \mathrm{~W} \mathrm{~m}^{-2}$ applied over one year results in a $3 \times 10^{9} \mathrm{~J} \mathrm{~m}^{-2}$ change of OHCA. (c) Linear trend from 1993-2016 of the combined estimates of upper $(0-700 \mathrm{~m})$ annual OHCA $\left(\mathrm{W} \mathrm{m}^{-2}\right)$. Areas with statistically insignificant trends are stippled. 


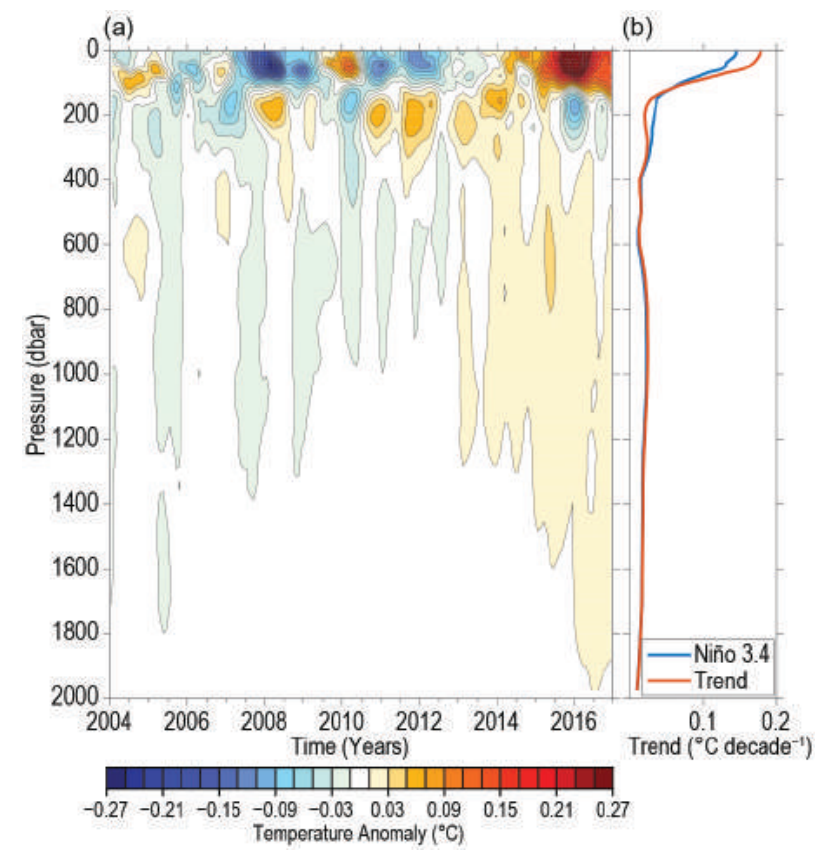

FIG. 3.5. (a) Near-global $\left(60^{\circ} \mathrm{S}-60^{\circ} \mathrm{N}\right.$, excluding marginal seas and continental shelves) integrals of monthly temperature anomalies $\left[{ }^{\circ} \mathrm{C}\right.$; updated from Roemmich and Gilson (2009)] relative to record-length average monthly values, smoothed with a 5-month Hanning filter and contoured at odd $0.02^{\circ} \mathrm{C}$ intervals (see colorbar) vs. pressure and time. (b) Linear trend of temperature anomalies over time for the length of the record in (a) plotted vs. pressure in ${ }^{\circ} \mathrm{C} \mathrm{decade}{ }^{-1}$ (orange line), and trend with a Niño3.4 regression removed (blue line) following Johnson and Birnbaum (2017).

South Pacific 2016 upper OHC (Fig. 3.4a), SST (see Fig. 3.1), and sea level (see Fig. 3.15a) anomalies reflect the positive PDO and IPO. A positive IPO phase may be associated with an increased rate of global average surface warming (Meehl et al. 2013) and also affects regional sea level rise rates (Zhang and Church 2012). Regions around the Kuroshio and the East Australian currents were also anomalously warm in 2016.

In the Indian Ocean there was generally warming from 2015 to 2016 north of about $10^{\circ} \mathrm{S}$ and around the Maritime Continent, and cooling from $10^{\circ} \mathrm{S}$ to $30^{\circ} \mathrm{S}$ (Fig. 3.4b). This pattern is consistent with increased eastward flow near $10^{\circ} \mathrm{S}$ in 2016 relative to 2015 (see Fig. 3.18), similar to the tendency from 2014 to 2015. Upper OHCA in the Indian Ocean remained above average in 2016 (Fig. 3.4a), except for a newly formed low band from about $10^{\circ} \mathrm{S}$ to $30^{\circ} \mathrm{S}$, consistent with a negative phase of the Indian Ocean dipole mode index (Saji et al. 1999). The Agulhas Current remained warm in 2016.

Much of the Atlantic warmed, in both hemispheres, from 2015 to 2016 (Fig. 3.4b). However, the region around the Brazil and Malvinas/Falkland
Currents generally cooled from 2015 to 2016, leaving it cooler than average in 2016 (Fig. 3.4a). The most striking 2015 pattern in the Atlantic OHCA persisted in 2016: anomalously low subpolar North Atlantic OHCA (Fig. 3.4a) coupled with high upper OHCA offshore of much of the east coast of North America. These changes may be related to a reduction in the strength of the Atlantic meridional overturning circulation (AMOC; see Section 3h) in recent years (Saba et al. 2016).

Large-scale statistically significant (Fig. 3.4c) regional patterns in the 1993-2016 local linear trends of upper OHCA reflect a warming trend in much of the Southern Hemisphere, with the only large-scale statis-
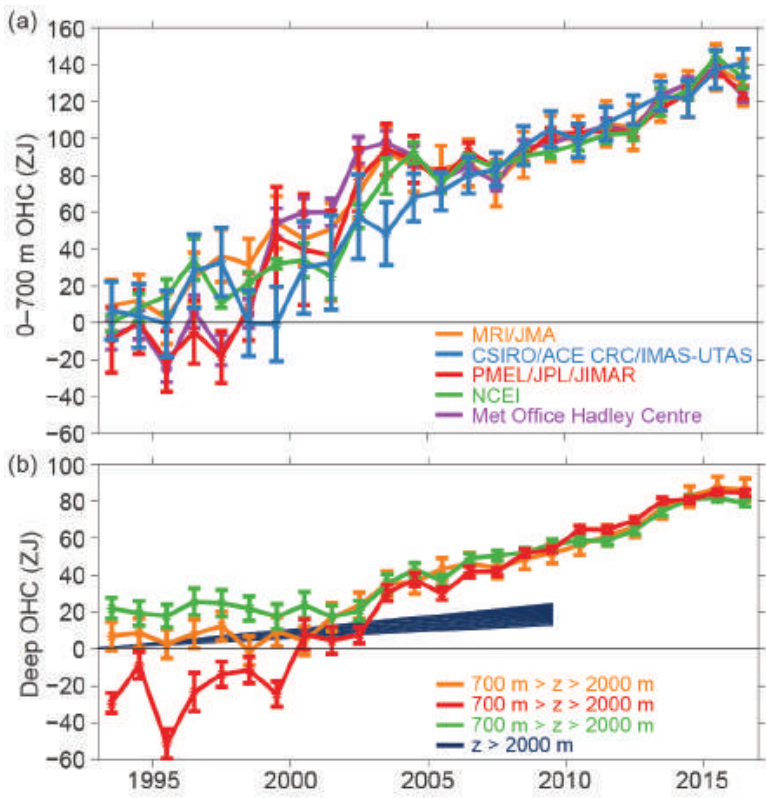

FIG. 3.6. (a) Annual average global integrals of in situ estimates of upper $(0-700 \mathrm{~m})$ OHCA $\left(\mathrm{ZJ}\right.$; I ZJ = $\left.10^{21} \mathrm{~J}\right)$ for 1993-2016 with standard errors of the mean. The MRI/JMA estimate is an update and modification of Ishii and Kimoto (2009). The CSIRO/ACE CRC/IMASUTAS estimate is an update of Domingues et al. (2008). The PMEL/JPL/JIMAR estimate is an update and refinement of Lyman and Johnson (2014). The NCEI estimate follows Levitus et al. (20I2). The Met Office Hadley Centre estimate is computed from gridded monthly temperature anomalies (relative to 1950-2016) following Palmer et al. (2007). See Johnson et al. (2014) for details on uncertainties, methods, and datasets. For comparison, all estimates have been individually offset (vertically on the plot), first to their individual 2005-16 means (the best sampled time period), and then to their collective 1993 mean. (b) Annual average global integrals of in situ estimates of intermediate (700-2000 m) OHCA for 1993-2016 with standard errors of the mean, and a long-term trend with one standard error uncertainty shown from 1992-2009 for deep and abyssal ( $z>2000$ m) OHCA updated (Desbruyères et al. 2016) following Purkey and Johnson (2010). 
tically significant cooling trends there in the southeast tropical Pacific as well as west and south of southern Chile. This prevalence of warming in the Southern Hemisphere is consistent with 0-2000 dbar (1 dbar $\sim 1 \mathrm{~m}$ ) OHCA patterns for 2006-15 (Roemmich et al. 2015; Wijffels et al. 2016). The apparent warming trends adjacent to Antarctica are located in both in situ and altimeter data-sparse regions and are not as robust as suggested by the statistics.

There are also large-scale statistically significant warming trends (Fig. 3.4c) in the North Indian Ocean, the eastern North Pacific (around $40^{\circ} \mathrm{N}$, $150^{\circ} \mathrm{W}$ ), the eastern North Atlantic (around $25^{\circ} \mathrm{N}$, $35^{\circ} \mathrm{W}$ ), and in the Labrador and Nordic Seas, with a zonal band of statistically significant cooling trend around the Tropic of Cancer across the North Pacific. In the North Atlantic, the pattern of a large amplitude and statistically significant warming trend along the North American coast coupled with a large amplitude and statistically significant interior subpolar cooling trend (Fig. 3.4c) again may be linked to reductions in AMOC strength. Statistically significant warming trends are also present near all the subtropical western boundary currents (Lix. Wu et al. 2012).

In previous years, strongest notably in 2013 (Johnson et al. 2014), there was a statistically significant cooling trend in the eastern tropical Pacific and a statistically significant warming trend in the western tropical Pacific. That pattern has been attributed to trade wind intensification (Merrifield et al.2012) and linked to a temporary reduction in the rate of globally averaged surface temperature increase (England et al. 2014), sometimes termed the hiatus. However, weakening of the trade winds starting in 2014, asso- ciated with an end to the hiatus (see Fig. 3.3), as well as a shift in phase of the PDO (and perhaps the IPO) and then El Niño, has resulted in a weak and statistically insignificant warming trend across much of the tropical Pacific for 1993-2016 (Fig. 3.4c).

Near-global average seasonal temperature anomalies from 2004 to 2016 (Fig. 3.5a) largely reflect ENSO redistributing heat (e.g., Roemmich and Gilson 2011) in the upper $400 \mathrm{dbar}$, with lower values in the upper $100 \mathrm{dbar}$ and higher values from 100 to $400 \mathrm{dbar}$ during La Niña (e.g., 2008/09), and vice versa during El Niño (e.g., 2015/16). Since the peak of El Niño near the end of 2015, mean temperatures in the upper $100 \mathrm{dbar}$ have declined, while still remaining quite high relative to time-average values. Negative anomalies from 150 to $400 \mathrm{dbar}$ have also abated somewhat. In addition to the ENSO signature, there is an overall warming trend (Fig. 3.5b, orange line) from 2004 to 2016 that approaches $0.18^{\circ} \mathrm{C}$ decade $^{-1}$ near the surface, declining to around $0.02^{\circ} \mathrm{C} \mathrm{decade}{ }^{-1}$ by $150 \mathrm{dbar}$ and remaining near that rate down to $2000 \mathrm{dbar}$. Removing a linear regression against the Niño3.4 index (e.g., Johnson and Birnbaum 2017) results in a decadal warming trend (Fig. 3.5b, blue line) closer to $0.15^{\circ} \mathrm{C}$ decade ${ }^{-1}$ near the surface, and slightly larger from about 150 to $400 \mathrm{dbar}$.

The analysis is extended back in time from the Argo period to 1993, and deeper, using historical data collected mostly from ships. Five different estimates of globally integrated in situ 0-700-m OHCA (Fig. 3.6a) all reveal a large increase since 1993, and most indicate a slight drop in 2016 from a record high OHCA value in 2015. Global OHCA integrals are modulated by ENSO, increasing faster than the long-term warm-

TABLE 3.2. Trends of ocean heat content increase (in $\mathrm{W} \mathrm{m}^{-2}$ applied over the $5.1 \times 10^{14} \mathrm{~m}^{2}$ surface area of Earth) from six different research groups over three depth ranges (see Fig. 3.6 for details). For the 0-700 and 700-2000 m depth ranges, estimates cover 1993 to 2016 , with $5 \%-95 \%$ uncertainties based on the residuals taking their temporal correlation into account when estimating degrees of freedom (Von Storch and Zwiers 1999). The 2000-6000 m depth range estimate covers 1992-2009, again with $5 \%-95 \%$ uncertainty.

\begin{tabular}{|l|c|c|c|}
\hline & \multicolumn{2}{c|}{ Global Ocean Heat Content Trends $\left(\mathbf{W} \mathbf{~ m}^{-2}\right)$} \\
\hline \multicolumn{1}{|c|}{ Research Group } & $\mathbf{0 - 7 0 0 ~} \mathbf{m}$ & $\mathbf{7 0 0 - 2 0 0 0} \mathbf{~ m}$ & $\mathbf{2 0 0 0 - 6 0 0 0} \mathbf{~ m}$ \\
\hline MRI/JMA & $+0.34 \pm 0.06$ & $+0.28 \pm 0.16$ & - \\
\hline CSIRO/ACE/CRC/IMAS/UTAS & $+0.40 \pm 0.07$ & - & - \\
\hline PMEL/JPL/IIMAR & $+0.42 \pm 0.17$ & $+0.31 \pm 0.03$ & - \\
\hline NCEI & $+0.37 \pm 0.07$ & $+0.24 \pm 0.08$ & - \\
\hline Met Office Hadley Centre & $+0.40 \pm 0.20$ & - & - \\
\hline Desbruyères et al. (2016) & - & - & $+0.07 \pm 0.04$ \\
\hline
\end{tabular}


ing trend as El Niño waxes and slower than that trend when El Niño wanes (Johnson and Birnbaum 2017). The rapid increase in OHCA in 2015 followed by a reduction in 2016 is thus consistent with the transition from a strong El Niño in early 2016 to borderline La Niña conditions in late 2016. Net OHCA appears to plateau in 2016 from 700 to $2000 \mathrm{~m}$ (Fig. 3.6b). Causes of the differences among estimates are discussed in Johnson et al. (2015a). From 2000 to 6000 m (Fig. 3.6b), trends are estimated from differences between decadal surveys (Desbruyères et al. 2016).

The rate of heat gain from linear trends fit to each of the five global integral estimates of 0-700 $\mathrm{m} \mathrm{OHCA}$ from 1993 through 2016 (Fig. 3.6a) range from 0.34 $( \pm 0.06)$ to $0.42( \pm 0.17) \mathrm{W} \mathrm{m}^{-2}$ applied over the surface area of Earth (Table 3.2). Linear trends from 700 to $2000 \mathrm{~m}$ over the same time period range from 0.24
$( \pm 0.08)$ to $0.31( \pm 0.03) \mathrm{W} \mathrm{m}^{-2}$. All trends in the upper two layers agree within uncertainties. For 2000-6000 $\mathrm{m}$, the linear trend is $0.07( \pm 0.04) \mathrm{W} \mathrm{m}^{-2}$ from 1992 to 2009. Summing the three layers (with their slightly different time periods), full-depth ocean heat gain rate ranges from 0.65 to $0.80 \mathrm{~W} \mathrm{~m}^{-2}$.

d. Salinity-G. C. Johnson, J. Reagan, J. M. Lyman, T. Boyer, C. Schmid, and R. Locarnini

I) INTRODUCTION-G. C. Johnson and J. Reagan

Salinity patterns, both means and their variations, reflect ocean storage and transport of freshwater, a key aspect of global climate (e.g., Rhein et al. 2013). Long-term means of sea surface salinity (SSS) are largely determined by patterns of evaporation, precipitation, and river runoff (e.g., Schanze et al. 2010), modified by advection and entrainment (e.g., Yu

\section{SIDEBAR 3.I: CHANGES IN THE NORTHEAST U.S. SHELF ECOSYSTEM AND FISHERIES-J. HARE}

The pace of observed change in the northeast U.S. shelf ecosystem, which extends from Cape Hatteras, North Carolina, through the Gulf of Maine, is faster than in many other continental shelf ecosystems (Pershing et al. 20I5). Future change in the northeast U.S. shelf ecosystem also is projected to be greater than in many other portions of the world's oceans (Saba et al. 2016). Temperatures have risen $\sim 1.5^{\circ} \mathrm{C}$ in this region since 1995 (Fig. SB3.I). Some of this temperature rise is attributable to long-term climate change and some of it is attributable to natural variability related to the Atlantic multidecadal oscillation. The region is also a "hotspot" for sea level rise: increases in the rates of sea level rise are $~ 3-4$ times higher in this region compared to the global average (Sallenger et al. 2012). There are also changes in the Gulf Stream, with increased variability in the Gulf Stream path north of Cape Hatteras (Andres 2016) and recently observed direct interactions with the northeast U.S. shelf (Gawarkiewicz et al. 20I2).

The northeast U.S. shelf ecosystem supports a wide array of living marine resources, from Atlantic sea scallops, one of the most valuable, to the North Atlantic right whale, one of the most endangered. All of these resources-fish, invertebrates, marine mammals, sea turtles, plants, habitats, and other ecosystem components - are being impacted by changing ocean and climate conditions in the region. The productivity of some species has been linked to temperature, with some species exhibiting decreased productivity related to warming (e.g., Atlantic cod, Fogarty et al. 2008; winter flounder, R. Bell et al. 2014) and other species exhibiting increased productivity (e.g., Atlantic croaker, Hare et al. 2010). Still other species have shown no change in productivity during the recent period of

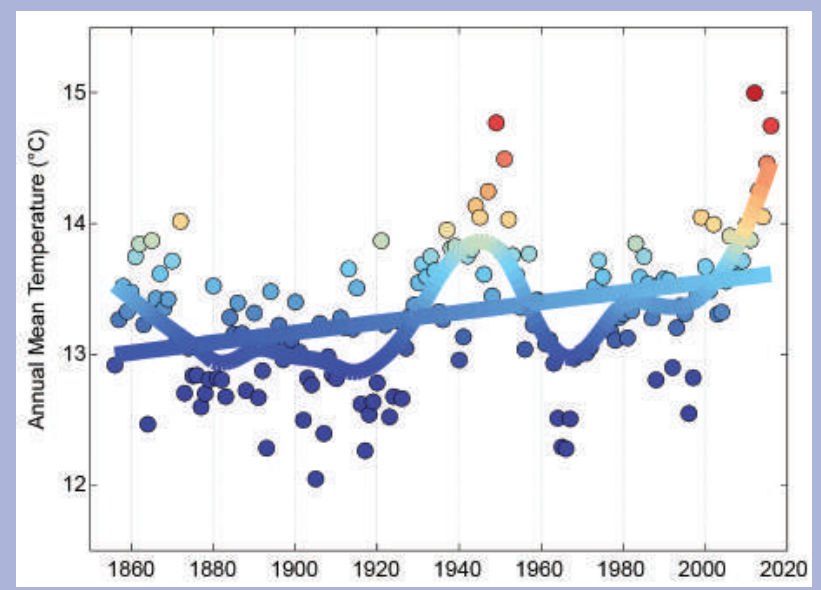

FIG. SB3.I. Mean annual temperature $\left({ }^{\circ} \mathrm{C}\right.$, colors) on the northeast U.S. shelf ecosystem $\left(36-46^{\circ} \mathrm{N}, 76-66^{\circ} \mathrm{W}\right)$ derived from the ERSSTv4 dataset (www.esrl.noaa.gov /psd/data/gridded/data.noaa.ersst.v4.html). Long-term change is estimated with a linear regression (straight line) and multidecadal variability is estimated with a loess smoother. As depicted, the temperatures, as indicated on the $y$-axis, transition from dark blue (lowest) to red (highest).

warming (e.g., summer flounder, R. Bell et al. 2014). This range of responses suggests that some species in the region will be negatively impacted by changes in ocean and climate conditions and other species will be positively impacted.

Changes in marine species distributions have been widely documented in the northeast U.S. shelf ecosystem. Long-term bottom trawl surveys provide an important data source for 


\section{CONT. SIDEBAR 3.I: CHANGES IN THE NORTHEAST U.S. SHELF ECOSYSTEM AND FISHERIES-J. HARE}

documenting changes in distribution. The population center of many species in the southern part of the ecosystem has moved northeastward (Kleisner et al. 2016). In the northern part of the ecosystem, the population center of many species has moved southwestward. These sub-ecosystem differences are related to the complexity of the geology and oceanography in the ecosystem. The southern part of the ecosystem is a typical broad continental shelf; warming waters result in the thermal habitat moving poleward and into deeper water. The northern part of the ecosystem, the Gulf of Maine, is bathymetrically complex with deep basins, banks, and channels. The coolest water is observed in the deeper southwestern basins, and cold-water species appear to be moving into this area. These sub-ecosystem differences in distribution changes indicate the importance of physical characteristics of an ecosystem in influencing the response of species to changing ocean and climate conditions. Similar changes in distribution were observed in the late 1940s during the last warm period (Fig. SB3.I; Taylor et al. 1957; Friedland and Hare 2007).

Fisheries are also changing in the ecosystem. Fishery landings of some species are moving northward as the species themselves move northward (Pinsky and Fogarty 2012). As an example, lobster landings have shifted from Connecticut, New York, and New Jersey to Maine, partly as a result of warming temperatures and decreasing productivity in the south and increasing productivity in the north. This change in landings has greatly diminished the lobster fishery in southern $\mathrm{New}$
England and resulted in a boom in Maine (Steneck and Wahle 2013). New fisheries are also developing in the region, including blueline tilefish and chub mackerel, species that historically occurred south of Cape Hatteras. A number of species are being captured by both commercial and recreational fisheries in new, predominantly more northern areas. There is also concern about the impact of ocean acidification on the region's fisheries. Laboratory and modeling studies have shown the potential for negative impacts on populations and fisheries (Talmage and Gobler 2010; Fay et al. 2017) but effects have yet to be attributed to observed changes in the region's living marine resources.

Changes in population productivity, population distribution, and fishing patterns are challenging some long-held spatial management strategies, including fixed spatial allocation of allowable catch and regional management, with species moving into new regions. These changes are also challenging the collection of fisheries data in the region. In the coming years, developing strategies to provide scientific advice for assessing and managing living marine resources in the face of changing ocean and climate conditions is going to present a major challenge to the stewardship of the nation's ocean resources and their habitat (Morrison and Termini 2016). To meet these challenges, NOAA Fisheries released a Fisheries Climate Science Strategy (Link et al. 2015), and a Regional Action Plan has been developed for the northeast U.S. shelf ecosystem (Hare et al. 2016).
2011). In some high latitude regions, sea ice formation, advection, and melt (e.g., Petty et al. 2014) can also influence SSS. Hence, relatively salty surface waters are observed in the subtropics where evaporation dominates, and fresher waters under the intertropical convergence zones (ITCZs) and in subpolar regions where precipitation dominates. Below the surface, fresher subpolar waters slide along isopycnals to intermediate depths and spread underneath saltier subtropical waters, which are in turn capped at low latitudes by fresher tropical waters (e.g., Skliris et al. 2014). Salinity changes in these layers can quantify the increase of the hydrological cycle associated with global warming over recent decades (Skliris et al. 2014). Below these layers lies salty North Atlantic Deep Water, formed mostly by open ocean convection, with salinity varying over decades (e.g., Yashayaev and Loder 2016). Fresher and colder Antarctic Bottom Waters, formed mostly in proximity to ice shelves, fill the abyss of much of the ocean (Johnson 2008) and have been freshening in recent decades (e.g., Purkey and Johnson 2013). Salinity changes also have an effect on sea level (e.g., Durack et al. 2014) and the thermohaline circulation (e.g., Liu et al. 2017).

To investigate interannual changes of subsurface salinity, all available salinity profile data are quality controlled following Boyer et al. (2013) and then used to derive $1^{\circ}$ monthly mean gridded salinity anomalies relative to a long-term monthly mean for years 1955-2012 (World Ocean Atlas 2013 version 2; WOA13v2; Zweng et al. 2013) at standard depths from the surface to $2000 \mathrm{~m}$ (Boyer et al. 2012). In recent years, the largest source of salinity profiles is the profiling floats of the Argo program (Riser et al. 2016). These data are a mix of real-time (preliminary) and delayed-mode (scientific quality controlled) observations. Hence, the estimates presented here could change after all data have been subjected to scientific 
quality control. The SSS analysis relies on Argo data downloaded in January 2017, with annual maps generated following Johnson and Lyman (2012) as well as monthly maps of bulk (as opposed to skin) SSS data from BASS (Xie et al. 2014). BASS blends in situ SSS data with data from the Aquarius (Le Vine et al. 2014; mission ended in June 2015) and SMOS (Soil Moisture and Ocean Salinity; Font et al. 2013) satellite missions. BASS maps can be biased fresh around land (including islands) and should be compared carefully with in situ data-based maps at high latitudes before trusting features there. Despite the lower accuracies of satellite data relative to Argo data, their higher spatial and temporal sampling allows higher spatial and temporal resolution maps than are possible using in situ data alone. Salinity is measured as a dimensionless quantity and reported on the 1978 Practical Salinity Scale, or PSS-78 (Fofonoff and Lewis 1979).

2) Sea surface Salinity-G. C. Johnson and J. M. Lyman

The 2016 SSS anomalies (Fig. 3.7a, colors) reveal some large-scale patterns that largely held from 2004 to 2015 (e.g., Johnson et al. 2016, and previous State of the Climate reports). Regions around the subtropical salinity maxima are generally salty with respect to WOA13v2. While less clear in 2016 than in previous years, some high-latitude, low-salinity regions are slightly fresher overall than WOA13v2, primarily in portions of the subpolar gyres of the North Pacific and North Atlantic. These multiyear patterns are consistent with an increase in the hydrological cycle (e.g., more evaporation in drier locations and more precipitation in rainy areas) over the ocean, as expected in a warming climate (Rhein et al. 2013). The large, relatively fresh patch in 2016 in the eastern Indian Ocean north of $30^{\circ} \mathrm{S}$ has been present back to 2011 (Johnson and Lyman 2012). It originally resulted from high precipitation owing to the interaction of the strong 2010-12 La Niña with other climate patterns (Fasullo et al. 2013).

Sea surface salinity changes from 2015 to 2016 (Fig. $3.7 \mathrm{~b}$, colors) strongly reflect 2016 anomalies in evaporation minus precipitation (see Fig. 3.12). Advection by anomalous ocean currents (see Fig. 3.18) also plays a role in SSS changes. Prominent large-scale SSS changes from 2015 to 2016 reflect salinification on either side of Central America, east of the Philippines, and in the Labrador Sea (Fig. 3.7b). Freshening during this time period is prominent around the Maritime Continent, in the Bay of Bengal, in the northeast tropical Pacific fresh pool, in portions of the subtropical and subpolar North Pacific, and east of Greenland. The tropical Pacific changes are likely owing to the transition from the strong 2015/16 El Niño to weak La Niña conditions later in 2016.

Seasonal variations of SSS anomalies in 2016 (Fig. 3.8) from BASS (Xie et al. 2014) show that fresh anomalies in the eastern Indian Ocean peak in March-May. Fresh anomalies increased in the center of the subpolar North Pacific over the course of the year, with salty anomalies in the eastern North Pacific peaking in June-August. In the equatorial Pacific
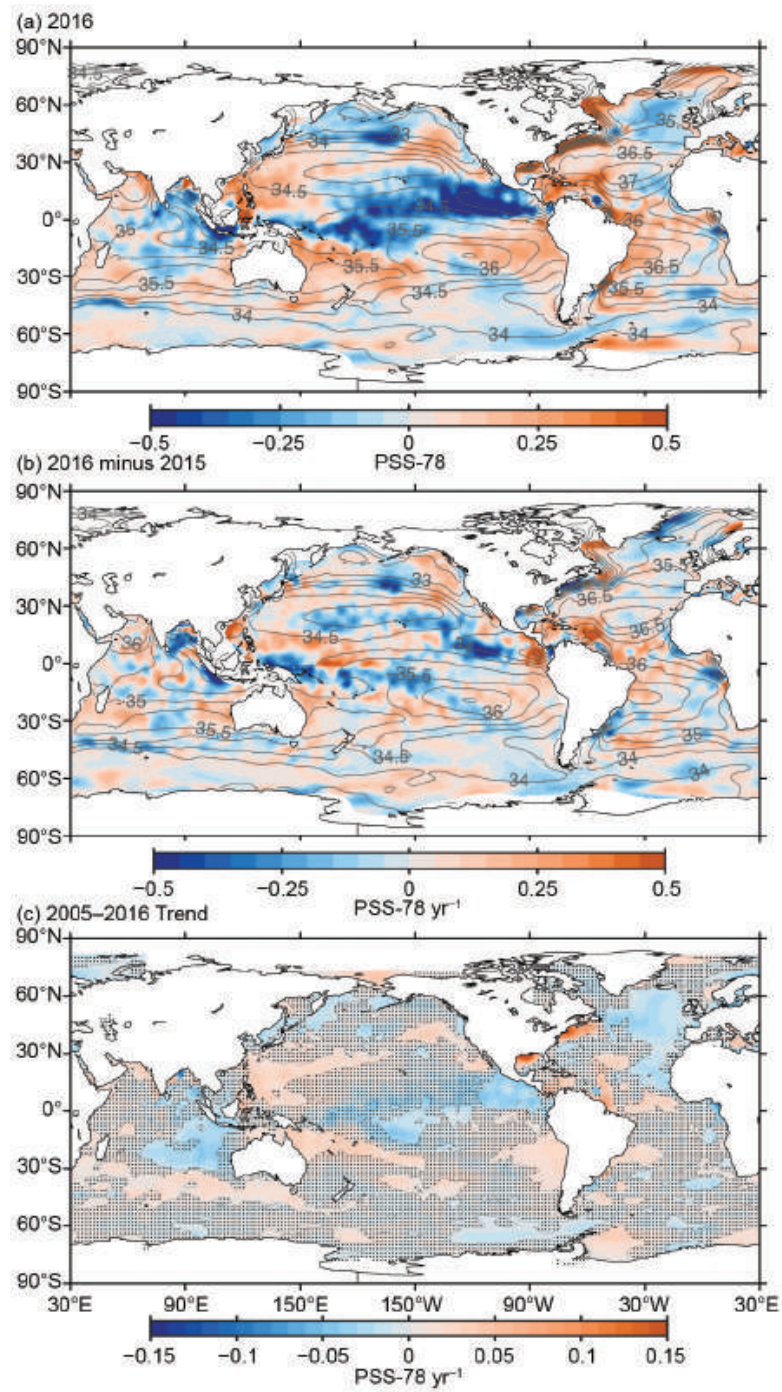

FIG. 3.7. (a) Map of the 2016 annual surface salinity anomaly (colors, PSS-78) with respect to monthly climatological 1955-20I2 salinity fields from WOAI3v2 [yearly average (gray contours at 0.5 intervals), PSS78]. (b) Difference of 2016 and 2015 surface salinity maps (colors, PSS-78 $\mathrm{yr}^{-1}$ ). White ocean areas are too data-poor (retaining $<80 \%$ of a large-scale signal) to map. (c) Map of local linear trends estimated from annual surface salinity anomalies for 2005-16 (colors, PSS-78 $\mathrm{yr}^{-1}$ ). Areas with statistically insignificant trends are stippled. All maps are made using Argo data. 
(a)

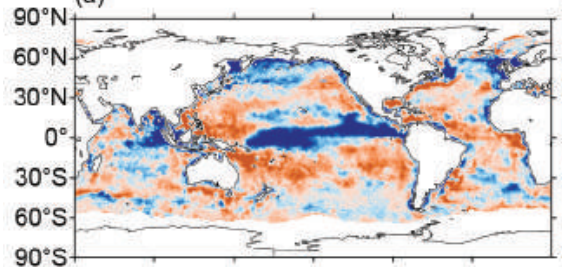

$90^{\circ} \mathrm{N}^{(\mathrm{c})}$

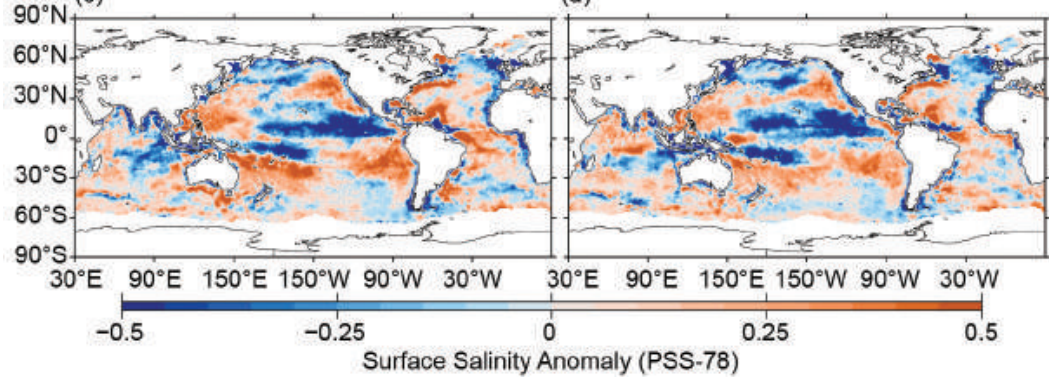

FIG. 3.8. Seasonal maps of SSS anomalies (colors) from monthly blended maps of satellite and in situ salinity data (BASS; Xie et al. 2014) relative to monthly climatological 1955-20I2 salinity fields from WOAI3v2 for (a) Dec-Feb 2015/16, (b) Mar-May 2016, (c) Jun-Aug 2016, and (d) Sep-Nov 2016. Areas with maximum monthly errors exceeding 10 PSS-78 are left white.

region, fresh anomalies moved poleward over the course of the year, likely reflecting both advection of anomalously fresh waters that built up around the equator owing to strong precipitation and the eastward migration of the western Pacific fresh pool during the 2015/16 El Niño, and subsequent upwelling of saltier water along the equator and reductions of precipitation in the eastern equatorial Pacific with the transition to weak La Niña conditions by the end of 2016.

Sea surface salinity trends for 2005-16 exhibit large-scale patterns in all three oceans (Fig. 3.7c). These trends are estimated by local linear fits to annual average SSS maps from Argo data with a starting year of 2005, because that is when Argo coverage became near-global. There are regions of increasing salinity near the subtropical salinity maxima in each basin, except in the eastern subtropical North Atlantic. In the Pacific, this increasing salinity trend is at lower latitudes in the west than in the east. In contrast, there are regions in the Southern Ocean and the subpolar North Atlantic and North Pacific where the trend is toward freshening. Again, these patterns are reminiscent of the multidecadal changes discussed above and suggest a discernible intensification of the hydrological cycle over the ocean over the last dozen years. However, the freshening trend in much of the subpolar North Atlantic is roughly coincident with a trend toward low upper ocean heat content (see Fig. 3.4c), suggesting an eastward expansion of the subpolar gyre that may be linked to reductions in the AMOC over the past decade (Section 3h). In addition, the freshening trend in the eastern Indian Ocean is likely owing to a lingering signature of the strong 2010-12 La Niña, refreshed by anomalously strong precipitation in 2016 (see Fig. 3.12). Freshening trends in the eastern tropical Pacific are likely owing to interannual ENSO variability and not necessarily reflective of a long-term trend. The region to the northwest of the Gulf Stream and in the Gulf of Mexico is trending strongly saltier, as well as warmer (Section 3c).

3) Subsurface Salinity-J. Reagan, T. Boyer, C. Schmid, and R. Locarnini

The 2016 Atlantic Ocean basinaverage monthly salinity anomaly pattern (Fig. 3.9a) is similar to the previous decade, with large $(>0.05)$ salty anomalies in the upper $200 \mathrm{~m}$ decreasing with depth to little/no change near $700 \mathrm{~m}$ and very weak $( \pm 0.005)$ anomalies between 700 and
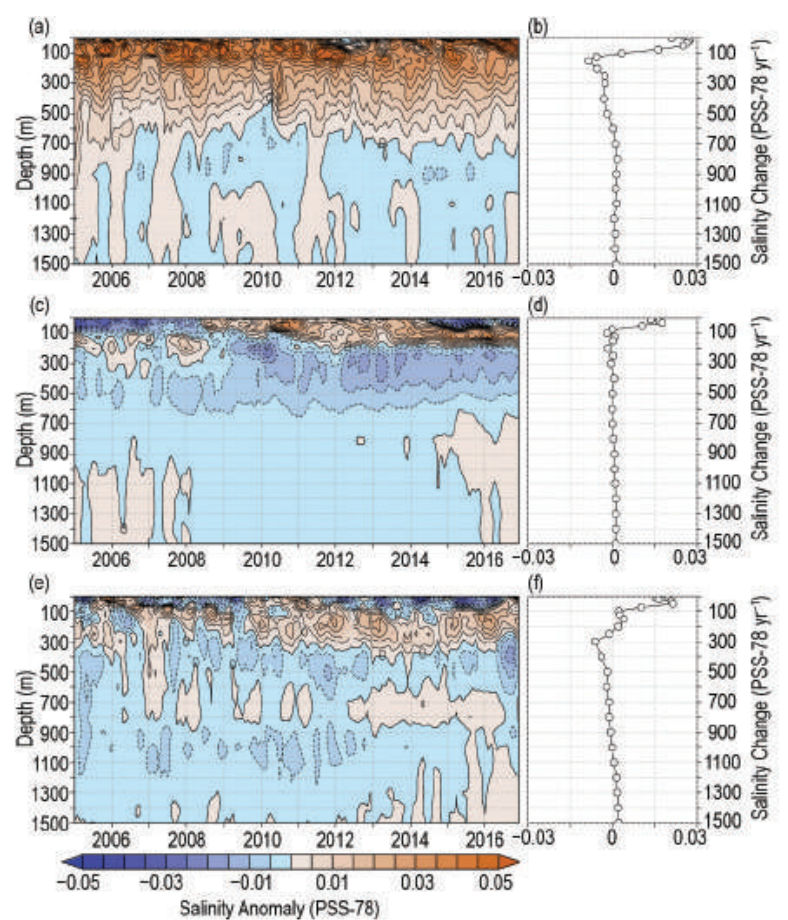

FIG. 3.9. Average monthly ocean salinity anomalies from 0-1500 $\mathrm{m}$ for the (a) Atlantic from 2005-16 and (b) the change from 2015 to 20I6; (c) Pacific from 200516 and (d) the change from 2015 to 2016; and (e) Indian from 2005-2016 and (f) the change from 2015 to 2016. Data were smoothed using a 3-month running mean. Anomalies are relative to the long-term WOAI3v2 monthly salinity climatology (Zweng et al. 20I3). 
$1500 \mathrm{~m}$. From 2015 to 2016, salinity increased in the upper $100 \mathrm{~m}$ with a maximum increase of $\sim 0.03$ near the surface (Fig. 3.9b). From 125 to 600 m, 2016 was slightly fresher than 2015 with a maximum decrease of $\sim-0.01$ at $150 \mathrm{~m}$.

The upper $30 \mathrm{~m}$ of the Pacific Ocean has been fresh since mid-2014, with the exception of weak $( \pm 0.005)$ anomalies in early 2016 (Fig. 3.9c). This pattern con- trasts with positive near-surface salinity anomalies from mid-2008 through mid-2014 (Fig. 3.9c). Salty anomalies from 100 to $200 \mathrm{~m}$ have been persistent since mid-2011, as have fresh anomalies $(<-0.005)$ from 200 to $500 \mathrm{~m}$ since 2009. From 2015 to 2016, salinity increased in the upper $75 \mathrm{~m}$, approaching $\sim 0.02$ at $30 \mathrm{~m}$ (Fig. 3.9d), in stark contrast to the freshening that was seen between 2014 and 2015 (Reagan et al.

\section{SIDEBAR 3.2: DEEP ARGO: SAMPLING THE TOTAL OCEAN}

\section{VOLUME-N. ZILBERMAN}

Full-depth ocean temperature-salinity profiling is essential for closing global and regional budgets of heat, freshwater, and steric sea level; for quantifying the processes causing sea level change; for accurately estimating the meridional overturning circulations; and for assimilating global ocean reanalyses and initializing ocean forecast systems. Deep-ocean temperature and salinity observations have been limited to sparse shipboard hydrographic sections repeated approximately every decade and even sparser deep ocean moorings. The need for more frequent sampling of the full ocean volume has long been recognized by the scientific community but has not, until recently, become practical.

Measuring the variability of temperature and salinity in the deep ocean is technically challenging. Deep-ocean properties show significant large-scale trends on decadal time scales in some deep basins, with the strongest anomalies at high latitudes near water mass formation regions (Purkey and Johnson 2010, 2013; Desbruyères et al. 2016). The Argo Program's international partnership proposes to meet the technical challenge by deploying a new generation of Deep Argo floats globally. At present, Argo operates a total of nearly 4000 floats, homogeneously distributed over the global ocean, measuring temperature and salinity profiles to $2000-\mathrm{m}$ depth. Deep Argo will extend conventional Argo sampling to the ocean bottom.

A Deep Argo workshop held in May 2015 articulated key scientific issues, initiated implementation planning for a global Deep Argo array, and identified broad-scale requirements for Deep Argo float measurement of temperature, salinity, and ocean circulation (Zilberman and Maze 2015). Deep Argo will consist of about 1200 floats distributed globally at $5^{\circ}$ latitude $\times 5^{\circ}$ longitude spacing. Deep Argo floats will sample the water column from the sea surface to 4000 or $6000 \mathrm{~m}$, depending on the float model used, every 15 days. Statistical analysis indicates that such an array will significantly reduce uncertainties in the global decadal trends in ocean heat content and the steric contribution to sea level rise (Johnson et al. 20l5b). The standard error of the trend in global ocean heat content for the 2000-6000 m depth range will decrease to \pm 3 TW $\left(\mathrm{I} \mathrm{TW}=10^{12} \mathrm{~W}\right.$ ) using Deep Argo data, down from $\pm 17 \mathrm{TW}$

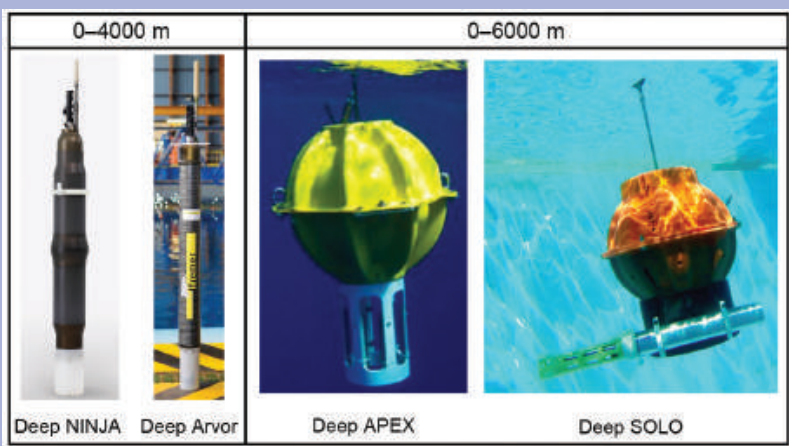

FIG. SB3.2. Deep Argo float models: Deep NINJA, Deep Arvor, Deep APEX, and Deep SOLO.

based on repeat hydrographic transects. With 15-day cycling, the deep Argo array will have a refresh time, based on float battery energy capacity and consumption, of five years, similar to the $0-2000 \mathrm{~m}$ Argo array.

The implementation of a sustainable Deep Argo array will not rely on a single float design. Technology advances have provided pressure housings, pumping systems, and other float components capable of operation at abyssal pressures. Four Deep Argo float models have been developed (Fig. SB3.2), including the 6000-m Deep SOLO (U.S.) and Deep APEX (U.S.) floats, and the 4000-m Deep Arvor (France) and Deep NINJA (Japan) floats. Comparisons of these Deep Argo float models are ongoing to assess their performance, robustness, and cost-effectiveness. Conductivity-temperature-depth (CTD) sensors mounted on Deep Argo floats include an extended-depth version of the SeaBird Electronics SBE-4I on Deep Arvor and Deep NINJA, and the new SBE-6I on Deep SOLO and Deep APEX. Initial results from SBE-6I CTDs in the southwest Pacific indicate that the sensors are stable in abyssal temperature/salinity characteristics, to \pm 0.00 I PSS-78 for more than a year, at constant potential temperature (Fig. SB3.3). These instruments have not yet achieved the absolute accuracy targets set for them $\left(0.001^{\circ} \mathrm{C}, 0.002\right.$ PSS-78, and $\left.3 \mathrm{dbar}\right)$ but are approaching those standards. Additional validation experiments are planned for SBE-4I and SBE-6I CTDs. 


\section{VOLUME-N. ZLLBERMAN}

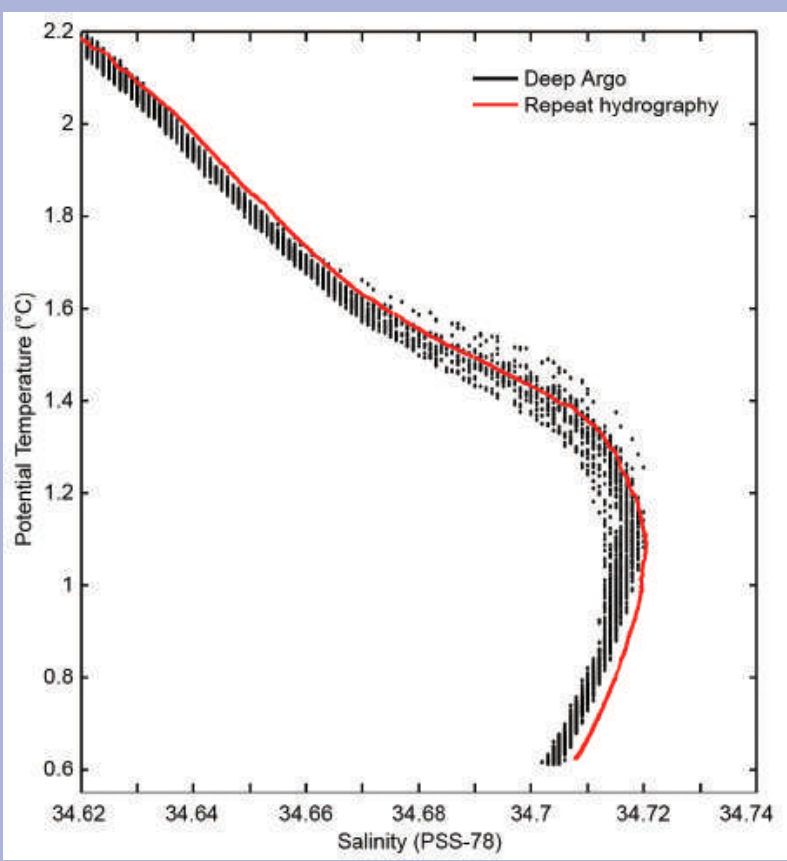

FIG. SB3.3. Temperature/salinity $(\Theta / S)$ relationship in the southwest Pacific basin. Black symbols indicate 75 Deep SOLO float profiles spread over $30.4^{\circ}-35.2^{\circ} \mathrm{S}$ and $172.8^{\circ}-174.5^{\circ} \mathrm{W}$ between Feb 2016 and Jan 2017 (www.usgodae.org/ftp/outgoing/argo/dac laoml/5902447). The red line is a single cast at $35^{\circ} \mathrm{S}$ from the PI5S repeat hydrographic transect of June 2016 (Source: data courtesy of Bernadette Sloyan, CSIRO.)

Several national programs are now deploying regional pilot Deep Argo arrays to demonstrate the feasibility, capabilities, and scientific value of full-depth global ocean observations, and to validate the accuracy of the CTD data against the requirements for abyssal sampling. Results from the pilot arrays are being assessed to revisit the global design of Deep Argo and its objectives. As of February 2017 there were 64 Deep Argo floats either active or registered for deployment in the next few months, including 33 Deep SOLOs, 3 Deep APEXs,
5 Deep NINJAs, and 23 Deep Arvors (Fig. SB3.4). Present Deep Argo pilot arrays are in the North Atlantic, southwest Pacific, Indian, and Southern Oceans. These arrays will be supplemented with additional floats for increasing their areal extent, and an additional pilot array is planned for the Brazil basin in the South Atlantic. The array in the south Australian basin will be extended poleward into the Australian Antarctic basin. Overall, the locations of pilot arrays have been chosen to include regions having stable abyssal temperature-salinity relations and ample hydrographic reference data for CTD validation, regions with previously identified abyssal warming trends, and regions close to water mass formation zones. In the next few years, the expansion of regional pilot arrays will grow toward global implementation of the Deep Argo Program.

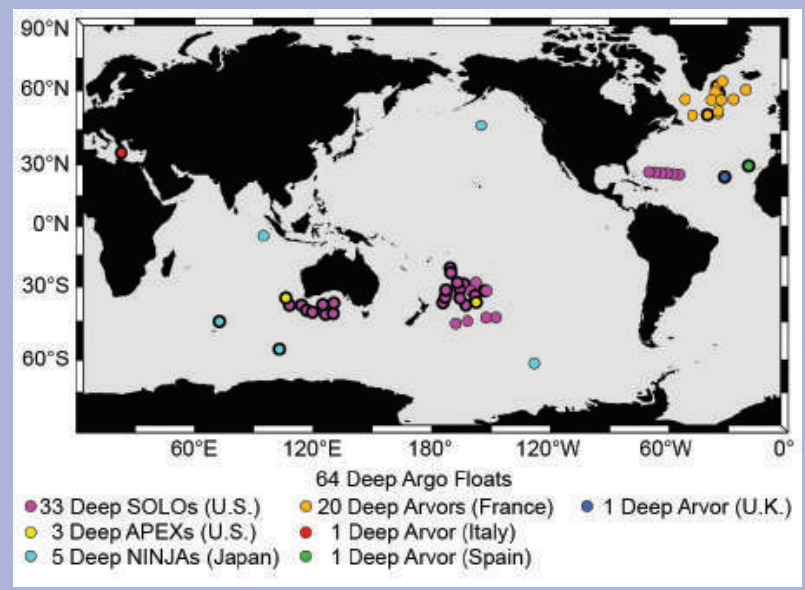

FIG. SB3.4. Location of active Deep Argo floats in Feb 2017 (rounded symbols with thick black contours): 19 Deep SOLOs (U.S.), 3 Deep APEXs (U.S.), 2 Deep NINJAs (Japan), 3 Deep Arvors (France), I Deep Arvor (Italy), I Deep Arvor (Spain), and I Deep Arvor (U.K.). Location of deployments scheduled later in 2017 (rounded symbols with thin black contours) for registered Deep Argo floats: 14 Deep SOLOs (U.S.), 3 Deep NINJAs (Japan), and 17 Deep Arvors (France). (Source: www.jcommops.org.)
2016). This change is likely related to the transition from a strong El Niño in 2015 to a weak La Niña in 2016 and the associated equatorial precipitation (see Fig. 3.12) and wind stress changes (see Fig. 3.13).

Through mid-2016 the Indian Ocean continued to show a similar salinity anomaly structure to that of the previous four years in the upper $300 \mathrm{~m}$, with a fresh surface anomaly from 0 to $75 \mathrm{~m}$ and a salty subsurface anomaly from 100 to $300 \mathrm{~m}$ (Fig. 3.9e). However, from mid-2016 onward, this salty subsurface anomaly extended from the surface down to $\sim 250 \mathrm{~m}$ depth. From 2015 to 2016 salinity increased from 0 to $200 \mathrm{~m}$, with a maximum of about 0.02 at $50 \mathrm{~m}$, while freshening occurred from 250 to $500 \mathrm{~m}$, with a maximum of $\sim-0.008$ at $300 \mathrm{~m}$ (Fig. 3.9f). 
Zonally averaged salinity in the upper $75 \mathrm{~m}$ of the tropical Atlantic $\left(2^{\circ} \mathrm{S}-22^{\circ} \mathrm{N}\right)$ increased by at least 0.06 from 2015 to 2016 (Fig. 3.10a), with a maximum $(\sim 0.12)$ at the surface between $10^{\circ}$ and $16^{\circ} \mathrm{N}$. This band is primarily responsible for the near-surface positive salinity anomaly during 2016 (Fig. 3.9b). There is notable freshening $(<-0.03)$ from 0 to $50 \mathrm{~m}$ centered at $41^{\circ} \mathrm{N}$, but it is shifted south and confined to a smaller region than prior years (e.g., 2015 minus 2014, see Reagan et al. 2016). Additionally, there is strong $(<-0.06)$ subsurface freshening from 100 to $225 \mathrm{~m}$ in the South Atlantic from $22^{\circ}$ to $15^{\circ} \mathrm{S}$ and weaker freshening $(\sim-0.03)$ in the North Atlantic from $21^{\circ}$ to $32^{\circ} \mathrm{N}$ and $55^{\circ}$ to $62^{\circ} \mathrm{N}$ along similar depths, which are the main contributors to the 100$300 \mathrm{~m}$ subsurface freshening (Fig. 3.9b).

Zonally averaged salinity changes in the Pacific from 2015 to 2016 (Fig. 3.10b) show strong $(<-0.06)$ freshening north of $60^{\circ} \mathrm{N}$ from 0 to $110 \mathrm{~m}$ and 160 to $250 \mathrm{~m}$ in the northern portions of the Bering Sea. Additionally, there is freshening from 0 to $200 \mathrm{~m}$ between $39^{\circ}$ and $47^{\circ} \mathrm{N}$, exceeding -0.12 at $125 \mathrm{~m}$. The tropical Pacific experienced salinification $(>0.03)$ in the upper $50 \mathrm{~m}$ between $3^{\circ} \mathrm{S}$ and $17^{\circ} \mathrm{N}$ from 2015 to 2016 and freshening $(<-0.03)$ in both poleward directions from $18^{\circ}$ to $27^{\circ} \mathrm{N}$ (extending and deepening to the south reaching $\sim 250 \mathrm{~m}$ at around $8^{\circ} \mathrm{S}$ ) and $12^{\circ}$ to $4^{\circ} \mathrm{S}$, which is a direct reflection of the transition from a strong 2015/16 El Niño to a weak 2016 La Niña (as discussed in Section 3d2). Farther south, there is a broad region (between $30^{\circ}$ and $13^{\circ} \mathrm{S}$ ) of salinification in the upper $100 \mathrm{~m}$, deepening to $150 \mathrm{~m}$ around $10^{\circ} \mathrm{S}$.

Zonally averaged salinity changes in the Indian Ocean from 2015 to 2016 (Fig. 3.10c) show freshening $(<-0.03)$ between $10^{\circ}$ and $15^{\circ} \mathrm{N}$ in the upper $100 \mathrm{~m}$, with maximum freshening $(<-0.09)$ occurring at the near-surface $(0-30 \mathrm{~m})$. This freshening was primarily located in the Bay of Bengal (see Fig. 3.7b) and may be associated with increased river runoff due to a stronger India monsoon in 2016 than in 2015 (see Fig. 7.47). Salinification occurred in the upper $100 \mathrm{~m}$ from $16^{\circ}$ to $25^{\circ} \mathrm{N}$, with a maximum exceeding 0.18 at $50 \mathrm{~m}$ and a narrow swath extending to $250 \mathrm{~m}$ at $18^{\circ} \mathrm{N}$. Between $0^{\circ}$ and $8^{\circ} \mathrm{N}$ and between $18^{\circ}$ and $2^{\circ} \mathrm{S}$ the salinity increased ( $>0.03$ ), with the former extending down to $\sim 75 \mathrm{~m}$ and the latter to $\sim 100 \mathrm{~m}$. Finally, freshening $(<-0.03)$ occurred between $45^{\circ}$ and $40^{\circ} \mathrm{S}$ in the upper $\sim 125 \mathrm{~m}$. The broad-scale salinification in the upper $200 \mathrm{~m}$ of the southern Indian Ocean in conjunction with the large salinification around $18^{\circ} \mathrm{N}$ were the primary contributors to the near-surface salinification (Fig. 3.9f).
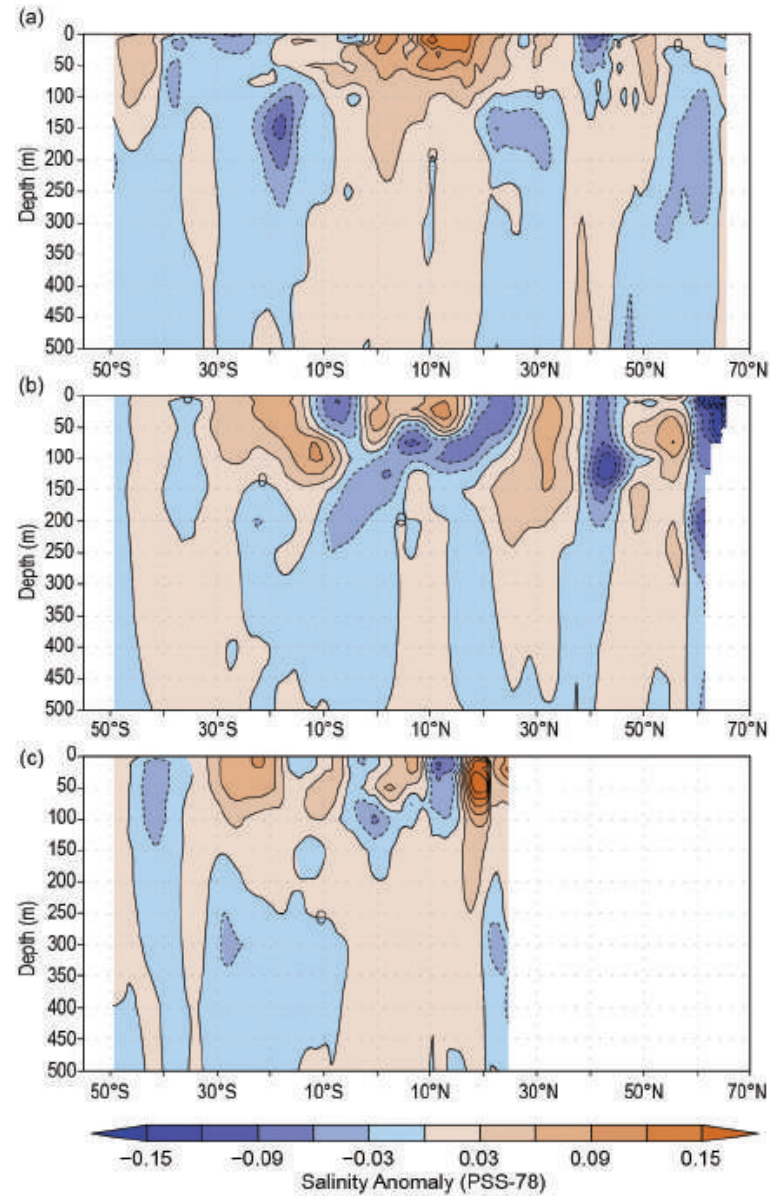

FIG. 3.10. Difference between the 2016 and 2015 zonally averaged monthly salinity anomalies from 0 to $\mathbf{5 0 0} \mathbf{m}$ color contoured at $\mathbf{0 . 0 3}$ intervals (black lines, zero contour bold) for the (a) Atlantic, (b) Pacific, and (c) Indian Oceans. Anomalies are relative to the long-term WOAI3v2 monthly salinity climatology (Zweng et al. 20I3).

e. Global ocean heat, freshwater, and momentum fluxes-L. Yu, X. Jin, S. Kato, N. G. Loeb, P. W. Stackhouse, R. A. Weller, and A. C. Wilber

The ocean and the atmosphere communicate physically via interfacial exchanges of heat, freshwater, and momentum. These air-sea fluxes are the primary mechanisms for keeping the global climate system in balance with the incoming insolation at Earth's surface. Most of the shortwave radiation (SW) absorbed by the ocean's surface is vented into the atmosphere by three processes: longwave radiation (LW), turbulent heat loss by evaporation (latent heat flux, or LH) and by conduction (sensible heat flux, or SH). The residual heat is stored in the ocean and transported by the ocean's surface circulation, forced primarily by the momentum transferred to the ocean by wind stress, as well as diffusive processes. Evaporation connects heat and moisture transfers, 
and the latter, together with precipitation, determines the local surface freshwater flux. Identifying changes in the air-sea fluxes is essential to deciphering observed changes in ocean circulation and its transport of heat and salt from the tropics to the poles.

Air-sea heat flux, freshwater flux, and wind stress in 2016 and their relationships with ocean surface variables are assessed. The net surface heat flux, $\mathrm{Q}_{\text {net }}$, is the sum of four terms: $\mathrm{SW}+\mathrm{LW}+\mathrm{LH}+\mathrm{SH}$. The net surface freshwater flux into the ocean (neglecting riverine and glacial fluxes from land) is simply precipitation $(P)$ minus evaporation $(E)$, or the $P-E$ flux. Wind stress is computed from satellite wind retrievals using the bulk parameterization of Edson et al. (2013). The production of the global maps of $Q_{\text {net }}$ (Fig. 3.11), $P-E$ (Fig. 3.12), and wind stress (Fig. 3.13) in 2016 and the long-term record of surface flux variations (see Fig. 3.14) are made possible through integrating multigroup efforts. Ocean-surface $\mathrm{LH}$, $\mathrm{SH}, E$, and wind stress are from the Objectively Analyzed Air-Sea fluxes (OAFlux; http://oaflux .whoi.edu/) project's satellite-derived, high-resolution (hereafter OAFlux-HR) products (Yu and Jin 2012, 2014; Jin and Yu 2013). Surface SW and LW radiative fluxes are from the Clouds and the Earth's Radiant Energy Systems (CERES) Fast Longwave And Shortwave Radiative Fluxes (FLASHFlux; https://ceres.larc .nasa.gov/products.php?product=FLASHFlux) Ed3A product (Stackhouse et al. 2006). Global $P$ is from the Global Precipitation Climatology Project (GPCP; http://gpcp.umd.edu) version 2.3 products (Adler

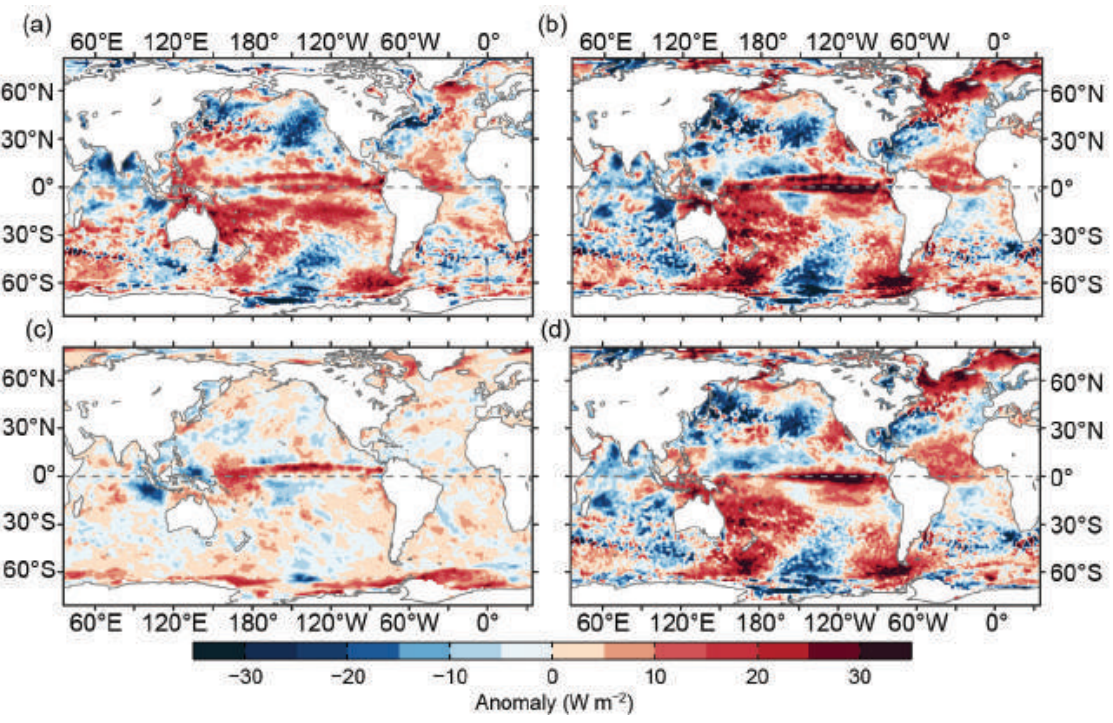

Fig. 3.II. (a) Surface heat flux $\left(Q_{\text {net }}\right)$ anomalies $\left(\mathrm{W} \mathrm{m}^{-2}\right)$ for 2016 relative to a 5 -yr (2010-14) mean. Positive values denote ocean heat gain. (b) 2016 minus 2015 tendencies for $Q_{\text {net }}$, (c) surface radiation (SW+LW), and (d) turbulent heat fluxes ( $\mathrm{LH}+\mathrm{SH})$, respectively. Positive tendencies denote more ocean heat gain in 2016 than in 2015. LH+SH are produced by the OAFlux high-resolution (HR) satellite-based analysis and SW+LW by the NASA FLASHFlux project. et al. 2003). The CERES Energy Balanced and Filled (EBAF) surface SW and LW version 2.8 products (http://ceres.larc.nasa.gov; Kato et al. 2013) are used in the time series analysis.

\section{I) SURface HeAt FLUXES}

The dominant feature in the $2016 \mathrm{Q}_{\text {net }}$ anomalies (Fig. 3.11a) was the broad-scale positive $\mathrm{Q}_{\text {net }}$ region in the equatorial and South Pacific, where the ocean received more than $10 \mathrm{~W} \mathrm{~m}^{-2}$ of anomalous heating from the atmosphere. The anomaly pattern may be associated with the transition from the strong 2015/16 El Niño to a weak La Niña in late 2016 (see Fig. 3.2). Two distinct zonal bands of positive values were present in the equatorial Pacific, both in the $2016 \mathrm{Q}_{\text {net }}$ anomalies (Fig. 3.11a) and in the 2016 minus $2015 \mathrm{Q}_{\text {net }}$ tendencies (Fig. 3.11b). One band was located about 3-5 degrees of latitude north of the equator, and the other centered on the central and eastern equatorial sector. The $\mathrm{Q}_{\text {net }}$ anomaly band off the equator is attributable to the change in surface radiation. The 2016 minus 2015 (SW+LW) tendencies (Fig. 3.11c) in the equatorial region were structured along the ITCZ mean position, with positive values stretching across the entire Pacific and negative values over the far western Pacific and the eastern Indian Ocean. This SW+LW tendency pattern is consistent with the 2016 minus $2015 P$ tendency pattern (Fig. 3.12d), so SW+LW increased in area of reduced ITCZ rainfall and, conversely, SW+LW reduced in area of increased ITCZ rainfall. The close association between the $\mathrm{SW}+\mathrm{LW}$ and $P$ tendencies along the ITCZ reflects the reorganization of the tropical convection in response to the transition from El Niño to La Niña (Rasmusson and Wallace 1983). On the other hand, the 2016 $\mathrm{Q}_{\text {net }}$ anomaly band centered on the equator is associated primarily with $\mathrm{LH}+\mathrm{SH}$ tendencies (Fig. 3.11d). The surface cooling during the development of the 2016 La Niña was at maximum in the central equatorial sector, with SST tendency anomalies at about $1.5^{\circ} \mathrm{C}$ (see Fig. 3.1b). The cooler sea surface produced 
less evaporation, leading to a reduction of turbulent latent and sensible heat loss and hence a warming effect on the ocean. The relation of $\mathrm{LH}+\mathrm{SH}$ tendencies to SST tendencies indicates that the surface fluxes provided a negative feedback, suppressing the development of a La Niña cooling in the central and eastern equatorial Pacific.

In the South Pacific outside of the equatorial band, the 2016 minus 2015 ( $\mathrm{LH}+\mathrm{SH})$ tendencies had a warming effect over the eastern and western portions of the basin, but a cooling effect over the central basin. The SW+LW tendency pattern was similar, albeit with a much smaller $\left(\sim 5 \mathrm{~W} \mathrm{~m}^{-2}\right)$ magnitude. Both $\mathrm{LH}+\mathrm{SH}$ and $\mathrm{SW}+\mathrm{LW}$ tendencies correlate positively with those of SST, which is in stark contrast to their negative correlation in the equatorial region. The positive correlation suggests that the regional SST tendencies were a result of the WES (wind-evaporation-SST) positive feedback associated with anomalous southeast trade winds (Fig. 3.13b). Winds facilitate the rate of evaporation, increasing latent heat loss in stronger winds and reducing it in weaker winds. SST warmed in places where wind speeds weakened and latent heat loss was reduced, and cooled in places where wind speeds strengthened and latent heat loss was increased (Figs. 3.1b, 3.12d, 3.13b). Surface heat fluxes have dual effects on SST: they could be a response to SST anomalies, such as in the equatorial Pacific, and they could also be a forcing of SST anomalies, such as in the South Pacific.

For all three basins in the Northern Hemisphere, surface heat fluxes acted predominantly as a forcing of regional SST anomalies through the WES mechanism. For instance, the band of strong surface cooling (i.e., SST cooling tendency) in the midlatitude North Pacific between $30^{\circ}$ and $50^{\circ} \mathrm{N}$ corresponds to the band of enhanced $\mathrm{LH}+\mathrm{SH}$ loss as a result of strengthened westerly winds. Similar correlations are also displayed in the North Atlantic, where a tripole-like pattern (with extrema broadly in the tropics, subtropics, and subpolar regions) in the $\mathrm{Q}_{\text {net }}$ anomaly field is associated with a tripole pattern of wind speed anomalies of opposite sign, and less clearly with SSTA. In the tropical Indian Ocean, the surface cooling north of $15^{\circ} \mathrm{S}$ is clearly a result of the WES mechanism, as the strengthened monsoonal winds induced stronger $\mathrm{LH}+\mathrm{SH}$ loss that effectively cooled the ocean surface.

\section{2) Surface freshWATER FLUXES}

The $2016 P-E$ anomaly patterns are characterized by significant $P$ anomalies in the tropical Pacific and Indian Oceans (Fig. 3.12). In response to the transition from El Niño to La Niña, the ITCZ rainfall band that was equatorward-strengthened during the 2015/16 El Niño weakened considerably in 2016, leading to a significant reduction in $P$. This is evident in the 2016 minus $2015 P$ tendency pattern, where a zonal band of strong dry tendencies stretched across the entire equatorial Pacific along the ITCZ (Fig. 3.12d). The magnitude of the dry tendencies exceeded one meter over one year and dominated the $P-E$ tendencies in the tropical Pacific (Fig. 3.12b). At the same time, the far western Pacific and the eastern equatorial Indian Ocean received more rainfall (Fig. 3.12), associated with the enhanced regional deep convection during the development of the weak 2016 La Niña. The band of strong dry $P-E$ tendency along the ITCZ, although a striking feature, is not a major climate anomaly in the context of the 27-year (1988-2014) climatological reference. In 2016, the tropical Pacific gained about 
$0.5 \mathrm{~m}$ of freshwater compared to the climatological mean condition.

The western tropical Indian Ocean had a freshwater deficit (Fig 3.12) of about $0.3 \mathrm{~m}$ in 2016, attributed to both enhanced evaporation and weakened precipitation. The pattern of change seems to be ENSOinduced. The enhanced deep convection over the Indo-Pacific region drew the confluence of surface winds, which led to an acceleration of the surface branch of the Walker circulation. The strengthening of the surface winds over the tropical Indian Ocean (Figs. 3.13a,b) enhanced the regional evaporation.

A tripole-like pattern in the North Atlantic (with signs changing broadly among the tropical, subtropical, and subpolar regions) is evident in both $E$ and $P$ tendency (Fig. 3.12), showing that $E$ increased in regions where $P$ decreased, and reduced in regions where $P$ increased. Coherent $E$ and $P$ tendency patterns are also apparent in the South Atlantic and the extratropical Pacific.

\section{3) WIND STRESS}

The 2016 wind stress anomalies were mostly zonally aligned, reflecting the global distribution of the near-surface wind system (Figs. 3.13a,b). The most significant anomalies were the strengthened westerly winds in the midlatitude North Pacific $\left(30^{\circ}-50^{\circ} \mathrm{N}\right)$, where the strengthened winds enhanced $\mathrm{LH}+\mathrm{SH}$ heat loss and caused surface cooling through the

(a)

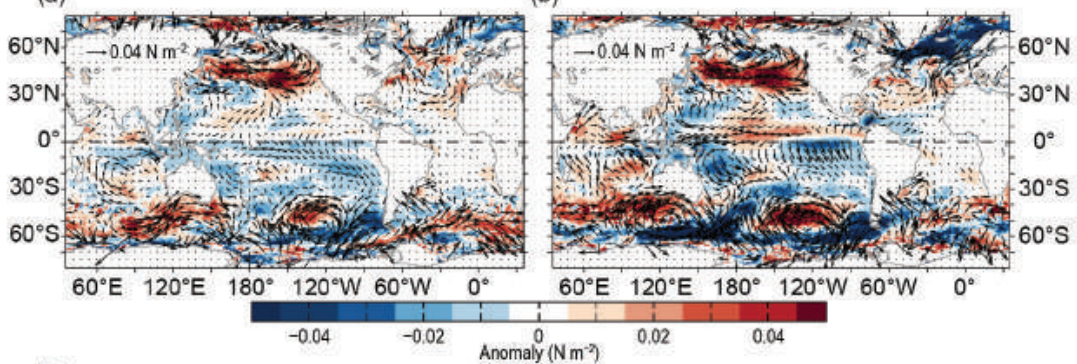

(c)

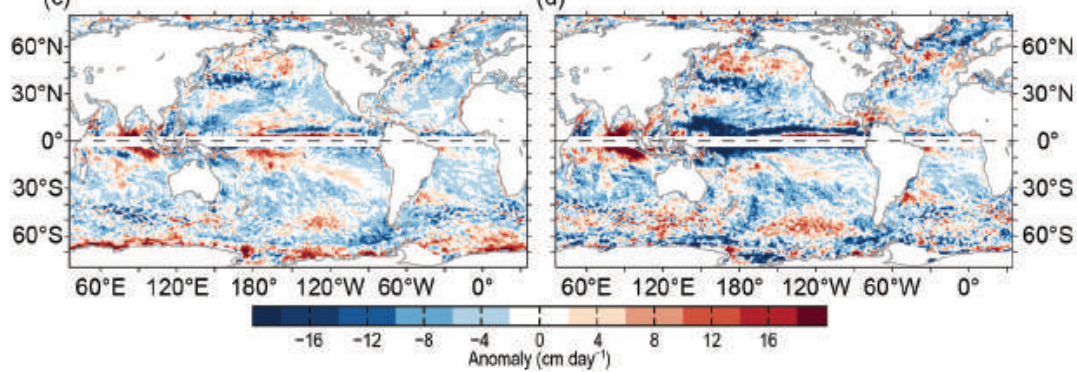

Fig. 3.13. (a) Wind stress magnitude (colors) and vector anomalies $\left(\mathrm{N} \mathrm{m}^{-2}\right)$ for 2016 relative to 1988-2014 climatology, (b) 2016 minus 2015 tendencies in wind stress, (c) Ekman vertical velocity $\left(W_{E K}\right)$ anomalies for 2016 relative to 1988-2014 climatology, and (d) 2016 minus 2015 tendencies in $W_{E K} \cdot \ln (c)$ and (d), positive values denote upwelling tendency, and negative downwelling; units are $\mathrm{cm}$ day $^{-1}$. Winds are computed from the OAFlux-HR satellite-based vector wind analysis.
WES feedback. Significant wind anomalies were also observed along the westerly wind band in the Southern Ocean $\left(30^{\circ}-60^{\circ} \mathrm{S}\right)$, where wind anomalies were structured in a wavelike pattern with alternating positive and negative signs. In the equatorial region, the enhanced deep convection associated with the transition from El Niño to La Niña in the Indo-Pacific region led to an enhanced Walker circulation, and consequently, stronger easterly anomalies in the equatorial Pacific and stronger westerly anomalies in the equatorial Indian Ocean (Rasmusson and Carpenter 1982). In the South Pacific, the southeast trade winds became weaker. It is yet to be examined whether the weakened trades were associated with the decaying El Niño or caused by the warm PDO phase that persisted through 2016 (see Fig. 3.1a).

Spatial variations of winds around the globe cause divergence and convergence of the Ekman transport, leading to a vertical velocity, denoted by Ekman pumping (downward) or suction (upward) velocity $\mathrm{W}_{E K}$, at the base of the Ekman layer. Computation of $\mathrm{W}_{E K}$ follows the equation: $\mathrm{W}_{E K}=1 / \rho \nabla \times(\tau / f)$, where $\rho$ is the density and $f$ the Coriolis force. The 2016 minus $2015 \mathrm{~W}_{E K}$ tendencies (Fig. 3.13d) resulted in strong downwelling (negative) anomalies in the vicinity of the Pacific ITCZ mean position $\left(3^{\circ}-5^{\circ} \mathrm{N}\right)$ and strong upwelling (positive) anomalies in the eastern equatorial Indian Ocean. This pattern corresponds well with the change of trade winds during the transition from El Niño to La Niña. Outside of the tropical region, the strengthened westerly band in the midlatitude North Pacific induced a band of downwelling anomalies (negative) on its southern flank and a band of upwelling anomalies (positive) on its northern flank. In the North Atlantic, $\mathrm{W}_{E K}$ anomalies (Fig. 3.13c) were characterized by a tripole pattern, with positive upwelling anomalies from $40^{\circ}-$ $60^{\circ} \mathrm{N}$ and negative downwelling anomalies both poleward of $60^{\circ} \mathrm{N}$ and from $15^{\circ}-30^{\circ} \mathrm{N}$.

\section{4) LONG-TERM PERSPECTIVE}

Annual-mean time series of $\mathrm{Q}_{\text {net }}, P-E$, and wind stress averaged over the global icefree oceans (Fig. 3.14) provide a decadal perspective on the ocean surface forcing functions in 2016. The $\mathrm{Q}_{\text {net }}$ time series were 
constructed for the period from 2001 onward, using the available period of the CERES EBAF dataset. The time series of $P-E$ and wind stress started from the availability of SSM/I observations in 1988 . The $\mathrm{Q}_{\text {net }}$ time series trended slightly higher in recent years after a major dip in 2008. These $\mathrm{Q}_{\text {net }}$ fluctuations may be related to ENSO, with the ocean gaining more heat as El Niño strengthens and less as La Niña builds (Johnson and Birnbaum 2017). A similar dip is also present in $P-E$ time series and wind time series, except that the dip in wind occurred one year later in 2009 . The $P-E$ time series variations again may be owing to changes in transfers of water between land and sea with ENSO (e.g., Cazenave et al. 2012).

The $P-E$ time series is up slightly in 2016, presumably reflecting El Niño's influence on tropical oceanic precipitation. To first order, the GPCP precipitation dataset shows that changes over land and ocean during El Niño or La Niña years approximately balance, giving a global time series that is more nearly constant than the land-only or ocean-only time series. Over the 29-year period, the $P-E$ time series shows a slight decrease during the 1990s but no obvious trend thereafter. A strengthening of the global winds in the 1990s is also indicated in the global wind stress time series of 29 years. The global average wind stress remains near steady in recent years.

f. Sea level variability and change-P. R. Thompson, M. A. Merrifield, E. Leuliette, W. Sweet, D. P. Chambers, B. D. Hamlington, S. Jevrejeva, J. J. Marra, G. T. Mitchum, and R. S. Nerem

Global mean sea level (GMSL) during 2016 became the highest annual average in the satellite altimetry record (1993-present), rising to $82 \mathrm{~mm}$ above the 1993 average (Fig. 3.15a). This marks the sixth consecutive year (and 21st out of the last 23) that GMSL increased relative to the previous year. The new high reflects the ongoing multidecadal trend in GMSL during the satellite altimetry era, $3.4( \pm 0.4) \mathrm{mm} \mathrm{yr}^{-1}$ (Fig. 3.15a), as well as the continuation of the $2015 / 16$ El Niño into spring 2016 (see Fig. 3.2).

Variations in GMSL (Fig. 3.15a) result from changes in both the mass and density of the global ocean (Leuliette and Willis 2011; Chambers et al. 2017). From 2005 to present, increasing global ocean mass observed by the NASA Gravity Recovery and Climate Experiment (GRACE) contributed approximately two-thirds of the GMSL trend, $2.1( \pm 0.4) \mathrm{mm}$ $\mathrm{yr}^{-1}$. The positive trend in ocean mass primarily resulted from melting of glaciers and ice sheets (see Chapters $5 e, f$ ), but these contributions from land ice were partially offset by increased hydrological storage

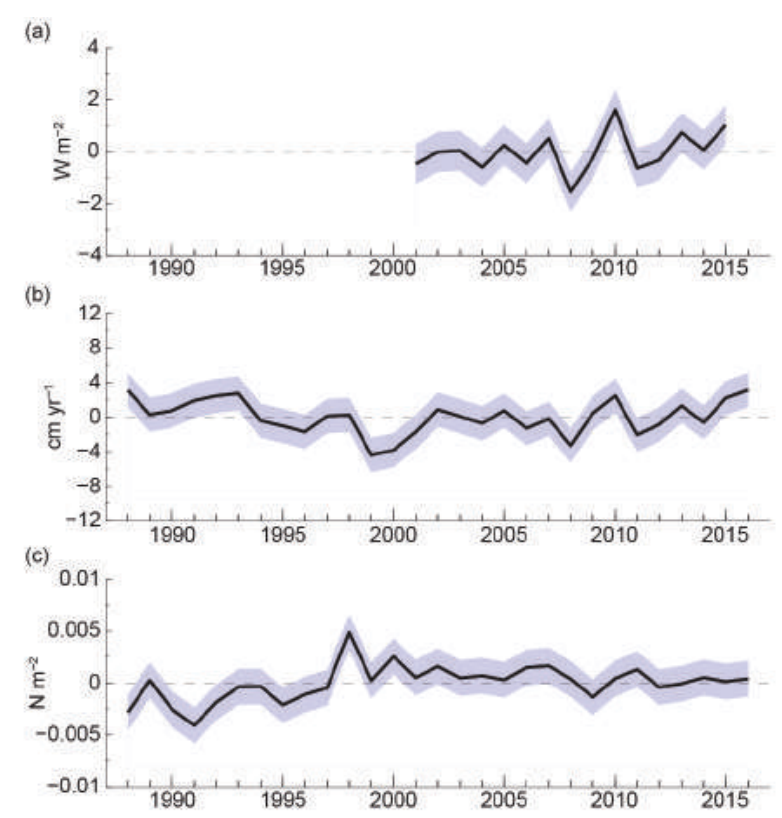

FIG. 3.14. Annual-mean time series of global averages of (a) net surface heat flux $\left(Q_{\text {net}} ; W^{-2}\right)$ from the combination of CERES EBAF SW+LW and OAFlux-HR $\mathrm{LH}+\mathrm{SH}$, (b) net freshwater flux $\left(P-E ; \mathrm{cm} \mathrm{yr}^{-1}\right)$ from the combination of GPCP P and OAFlux-HR E, and (c) wind stress magnitude $\left(\mathrm{N} \mathrm{m}^{-2}\right)$ from OAFlux-HR vector wind analysis. Shaded area denotes one std. dev. of annual-mean variability.

of fresh water on land, $-0.7( \pm 0.2) \mathrm{mm} \mathrm{yr}^{-1}$ (Reager et al. 2016). Mostly owing to ocean warming, steric (i.e., density-related) sea level rise, $1.0( \pm 0.2) \mathrm{mm} \mathrm{yr}^{-1}$, has been observed by the Argo profiling float array and accounts for the balance of the GMSL trend since 2005.

Regional sea level trends differ substantially from the global mean trend (Fig. 3.15b). Since the 1993 advent of satellite altimetry, the Indian Ocean and western Pacific have experienced enhanced sea level rise relative to the global average ( 3 to $7 \mathrm{~mm} \mathrm{yr}^{-1}$ ) while the eastern Pacific and polar regions experienced less sea level rise or even sea level fall ( -1 to 3

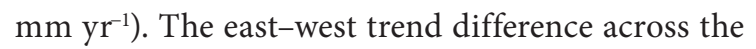
Pacific results from strengthening trade winds and a multidecadal trend toward the negative phase of the PDO during much of the altimetry era (Merrifield 2011; Hamlington et al. 2014). Enhanced trade winds force zonal redistribution of ocean volume across the basin leading to enhanced sea level rise in the west at the expense of regions to the east (Thompson et al. 2014). More recently, beginning with the strong 2010/11 La Niña event and culminating with the recent El Niño, a dramatic reversal occurred in the rates of Pacific sea level change (Hamlington et al. 2016). During 2012-16, much of the eastern Pacific 

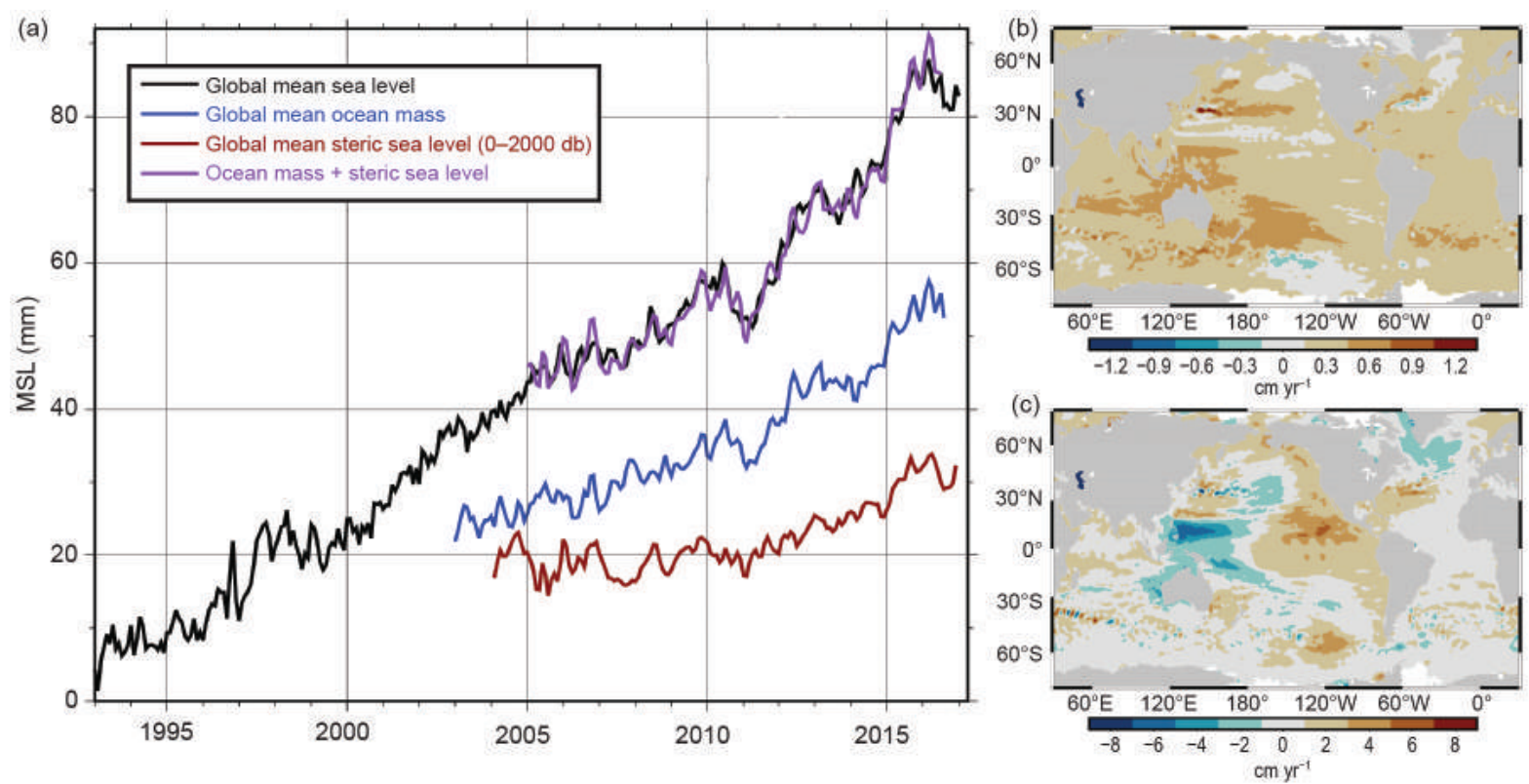

Fig. 3.15. (a) Monthly averaged global mean sea level ( $\mathrm{mm}$; black line) observed by satellite altimeters (19932016) from the gridded, multi-mission product maintained by the CMEMS (product formerly known as Aviso). Monthly averaged global ocean mass (blue; 2003-Aug 2016) from GRACE. Monthly averaged global mean steric sea level (red; 2004-16) from the Argo profiling float array. Mass plus steric (purple). (b) Linear sea level trends

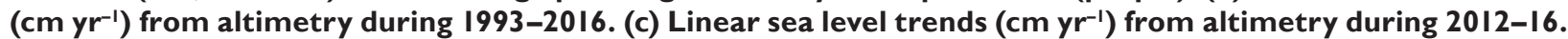

experienced 20 to $40 \mathrm{~mm} \mathrm{yr}^{-1}$ of sea level rise while sea level fell by a similar amount around Southeast Asia and Australia (Fig. 3.15c). Trends in the equatorial and North Indian Ocean did not reverse with the western Pacific, reflecting continued ocean warming since 2004 due to a reduction in wind-forced overturning (Thompson et al. 2016).

In addition to long-term trends, interannual climate variability causes global and regional sea level to deviate from secular trajectories. ENSO is a principal driver of interannual variability in GMSL (Nerem et al. 1999), and the large 2015/16 El Niño caused GMSL to be greater during the past two years than would be expected from the linear trend alone (Fig. 3.15a). During the first half of 2016, a weakened Walker Cell and other ENSO-related teleconnections altered precipitation patterns (particularly at tropical latitudes; see Fig. 2.1i), leading to decreased land-water storage (see Fig. 2.1j) and increased ocean mass (Fig. 3.15a). Similarly, global ocean heat content $(\mathrm{OHC})$ anomalies show a striking warm event in the upper $100 \mathrm{dbar}$ of the global ocean during the course of the El Niño event from late 2015 through early 2016 (see Fig. 3.5). The near-surface OHC anomaly contributes to the positive steric sea level anomaly during the first half of 2016 (Fig. 3.15a). In contrast to $\mathrm{OHC}$, total steric sea level (including thermosteric and halosteric contributions) increased on average during 2016 relative to 2015 due to subsurface fresh- ening in the northeast Atlantic, South Indian, and Southern Oceans (not shown). The freshening at least partially accounts for the year-over-year increase in GMSL despite the relaxation of El Niño conditions and decrease in OHC throughout 2016.

Regionally, positive annual sea level anomalies spanned most the global ocean during 2016 with prominent exceptions in the western Pacific and subpolar North Atlantic (Fig. 3.16a). The structure of annual anomalies in the Pacific weakly resembles the canonical El Niño pattern, which reflects the transition from typical El Niño structure early in the year (Fig. 3.16c) to mostly neutral conditions by the end of 2016 (Fig. 3.16d). The difference between 2016 and 2015 annual sea level anomalies (Fig. 3.16b; similar to OHC, see Fig. 3.4b) clearly shows the interhemispheric seesaw in the tropical Pacific that tends to occur at the termination of strong El Niño events (Widlansky et al. 2014). Near the end of such events, the weak trade winds typical of El Niño tend to shift southward while an anomalous anticyclone develops in the Philippine Sea. Together, these wind patterns prolong negative sea level anomalies south of the equator that subsequently spread eastward along the equatorial waveguide. In the North Atlantic, negative sea level anomalies during 2016 (Fig. 3.16a) continued a multidecadal cooling trend in the region (Fig. 3.15b; see Fig. 3.4c), perhaps related to weakening of the Atlantic overturning circulation and record low 


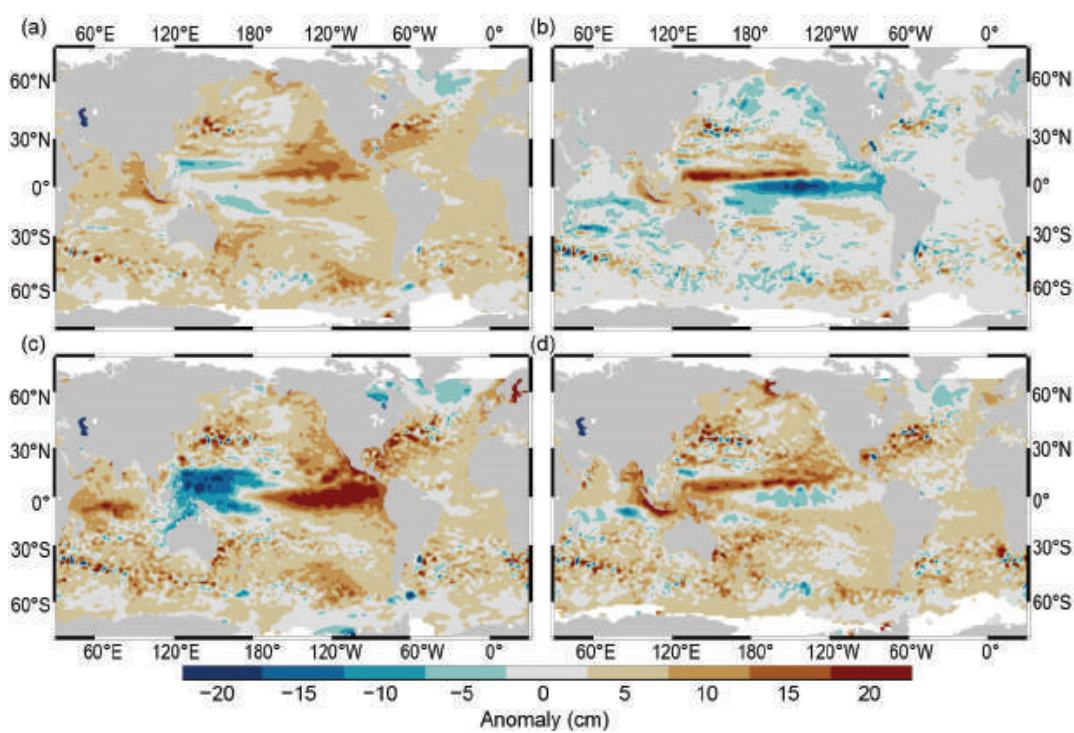

Fig. 3.16. (a) Annual average sea level anomaly during 2016 relative to the average sea level at each location during 1993-2016. (b) Average 2016 sea level anomaly minus 2015. (c) Average sea level anomaly during Dec 2015-Feb 2016 (DJF) relative to the DJF average during 1993-2016. (d) As in (c), but for Sep-Nov 2016. Anomalies are in cm. Altimetry data were obtained from the gridded, multimission product maintained by CMEMS. calculations in Fig. 3.17 reveals the contribution of synoptic timescales (i.e., storminess) to sea level extremes in the tide gauge records (not shown). The filtering exercise suggests that increased storminess mostly accounts for the increased number of 2016 extremes along the U.S. northeast and East Asian coastlines and partially accounts for the increase in southern Australia and the tropical Indian Ocean. This leaves background sea level change as the dominant contribution to elevated numbers of sea level extremes in the southeast U.S., Hawaii, and central South Pacific. Along the southeast U.S. coastline, the increase may be related to the hypothesized slowdown of the Florida Current and Gulf Stream during recent decades (Ezer et al. 2013; Sweet et al. 2016), densities in the deep Labrador Sea (Rahmstorf et al. 2015; Robson et al. 2016).

Global and regional mean sea level change affects coastal communities by changing the frequency of positive sea level extremes that cause flooding and erosion. Infrastructure within coastal communities is currently exposed to "nuisance" (associated with minor impacts) tidal flooding at a median height of about $0.5 \mathrm{~m}$ above mean higher high water (MHHW) tidal datum (Sweet et al. 2014), which is approximated as the long-term average of daily highest water levels. High-frequency measurements by a global set of tide gauges find that the median of the top $1 \%$ of observed daily maximum heights (three to four days per year on average) is also about $0.5 \mathrm{~m}$ above MHHW (Fig. 3.17a). During 2016, multiple regions experienced greaterthan-average numbers of such sea level extremes: the U.S. East Coast, the central South Pacific, southern Australia, and the tropical Indian Ocean (Fig. 3.17b). The U.S. West Coast did not experience a greater number of sea level extremes despite substantially elevated mean sea levels in the region (Fig. 3.16a). Relative to 2015 , spatially coherent increases in sea level extremes occurred over the U.S. northeast coast, Hawaii, portions of East Asia, and southern Australia (Fig. 3.17c).

Two factors can lead to increased numbers of positive sea level extremes: elevated background mean sea level and increased storminess (e.g., Sweet and Park 2014). High-pass filtering the tide gauge observations with a cut-off period of 30 days and then repeating the which would tend to raise coastal sea level in the region. Increased numbers of extremes in the central South Pacific most likely relate to multidecadal regional sea level trends (Fig. 3.15b), because the annual anomaly in the region is generally small (Fig. 3.16a) and the number of extremes decreases relative to 2015 (Fig. 3.17c). The opposite is true for Hawaii, where the multidecadal trend is small (Fig. 3.15b), but the annual anomaly is large (Fig. 3.16a) due to Rossby waves emanating from the eastern boundary during mid- to late 2016 in response to ENSO forcing along the equator.

\section{g. Surface currents-R. Lumpkin, G. Goni, and K. Dohan}

This section describes ocean surface current changes, transports derived from ocean surface currents, and features such as rings inferred from surface currents. Surface currents are obtained from in situ (global array of drogued drifters and moorings) and satellite (altimetry, wind stress, and SST) observations. Transports are derived from a combination of sea height anomaly (from altimetry) and climatological hydrography. See Lumpkin et al. (2012) for details of the datasets used and calculations performed. Anomalies are calculated with respect to the time period 1992-2007. Annually averaged zonal current anomalies and changes in anomalies from the previous year are shown in Fig. 3.18, while seasonal averages are shown in Fig. 3.19. These anomalies are discussed below for individual ocean basins. 
(a)

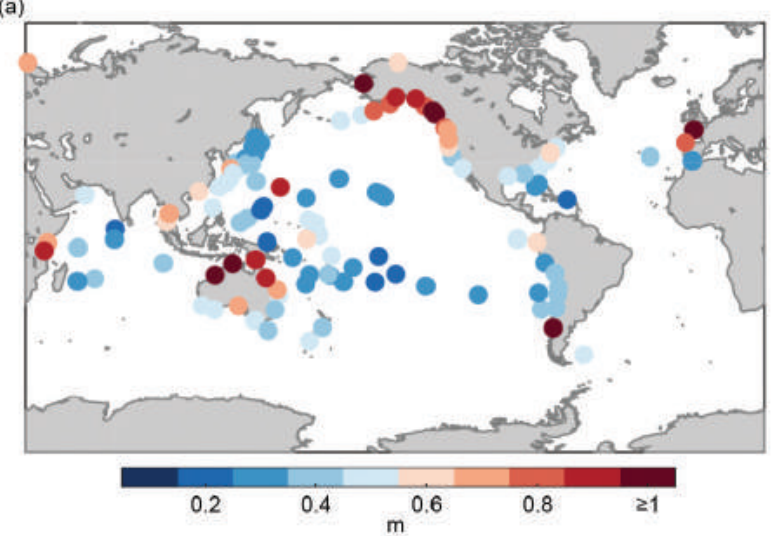

(b)

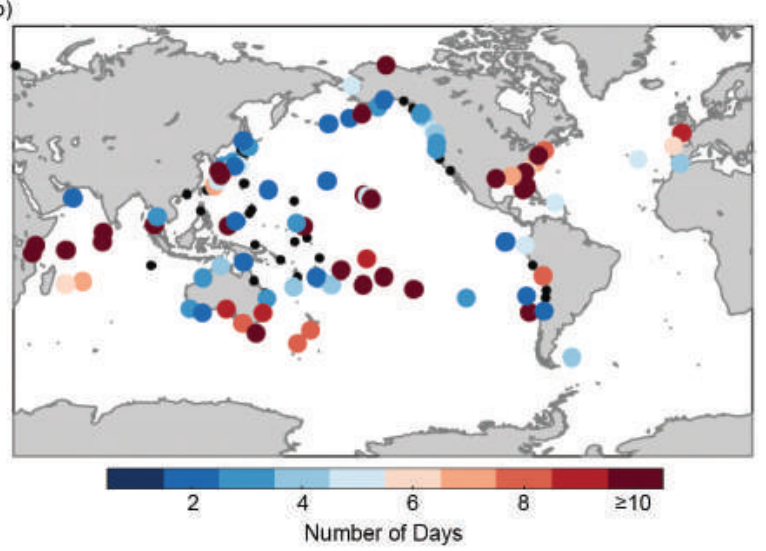

(c)

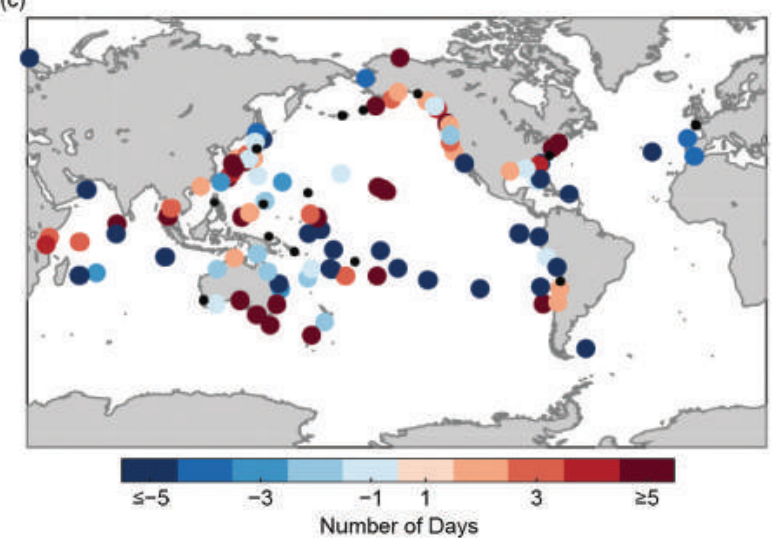

FIG. 3.I7. (a) Thresholds defining an extreme sea level anomaly $(\mathrm{m})$ for each station in the presnt analysis. $1 \%$ of daily maximum water levels at each station reach heights indicated by the colors in the figure. Units are meters above mean higher high water (MHHW) calculated over 1996-2015. (b) Number of daily maximum water levels during 2016 above the thresholds in (a). Small, black circles in (b) and (c) indicate a value of zero. (c) As in (b), but for 2016 minus 2015. Daily maximum water levels were calculated from hourly tide gauge observations obtained from the University of Hawaii Sea Level Center Fast Delivery database. Only records with at least $80 \%$ completeness during 1996-2015 and $80 \%$ completeness during 2016 were analyzed.

\section{I) Pacific Ocean}

Westward anomalies across the equatorial Pacific, associated with the $2016 \mathrm{La}$ Niña, dominated annual mean current anomalies in the Pacific basin (Fig. 3.18a). These anomalies had an annually averaged value of $12-16 \mathrm{~cm} \mathrm{~s}^{-1}$ between $1^{\circ} \mathrm{S}$ and $6^{\circ} \mathrm{N}$. Farther north, a narrow band of eastward anomalies peaked at $15-17 \mathrm{~cm} \mathrm{~s}^{-1}$ between $9^{\circ}$ and $10.5^{\circ} \mathrm{N}$, on the northern flank of the climatological North Equatorial Countercurrent (NECC), associated with a northward displacement of that current. Because 2015 was characterized by a reversal of these patterns, that is, intense eastward equatorial anomalies during the 2015/16 El Niño and westward anomalies in a weakened NECC, the 2016 minus 2015 tendencies (Fig. 3.18b) are a magnified version of the 2016 anomalies.

The year 2016 began (Fig. 3.19) with El Niñorelated eastward anomalies exceeding $20 \mathrm{~cm} \mathrm{~s}^{-1}$ between $2^{\circ} \mathrm{S}$ and $5^{\circ} \mathrm{N}$ in the central basin, with peak anomalies of $40 \mathrm{~cm} \mathrm{~s}^{-1}$ at $3^{\circ} \mathrm{N}$. These anomalies had reversed by February, with westward anomalies of $20-30 \mathrm{~cm} \mathrm{~s}^{-1}$ between the equator and $2^{\circ} \mathrm{N}$. By March, these anomalies were quite dramatic in the eastern half of the basin, with peak values of $50 \mathrm{~cm} \mathrm{~s}^{-1}$ westward between $100^{\circ} \mathrm{W}$ and $155^{\circ} \mathrm{W}$. As a consequence, the westward flow there increased from $75 \mathrm{~cm} \mathrm{~s}^{-1}$ (the climatological March value) to $\sim 130 \mathrm{~cm} \mathrm{~s}^{-1}$. Strong westward anomalies persisted and spread westward (a)

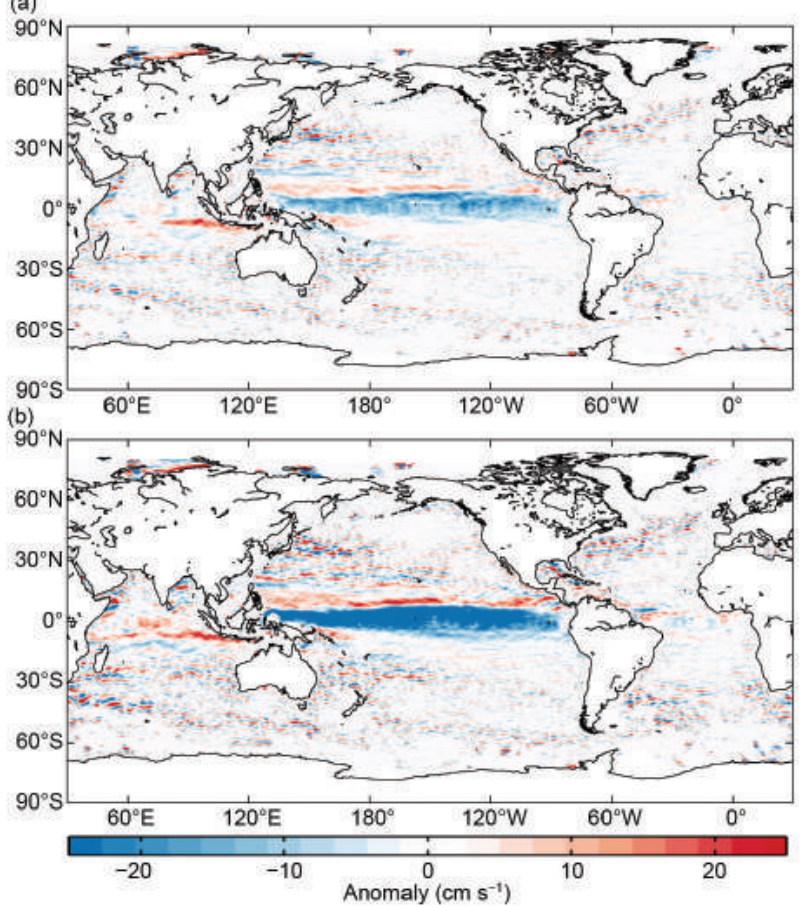

Fig. 3.18. Annually averaged geostrophic zonal current anomalies $\left(\mathrm{cm} \mathrm{s}^{-1}\right)$ for (a) 2016 and (b) 2016 minus 2015 derived from a synthesis of drifters, altimetry, and winds. 
(a)

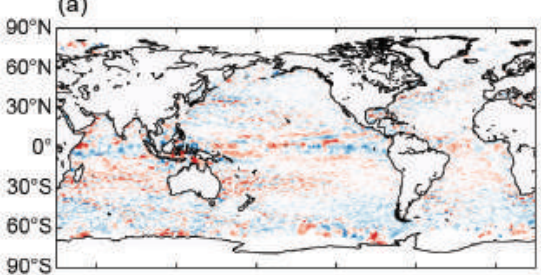

(c)

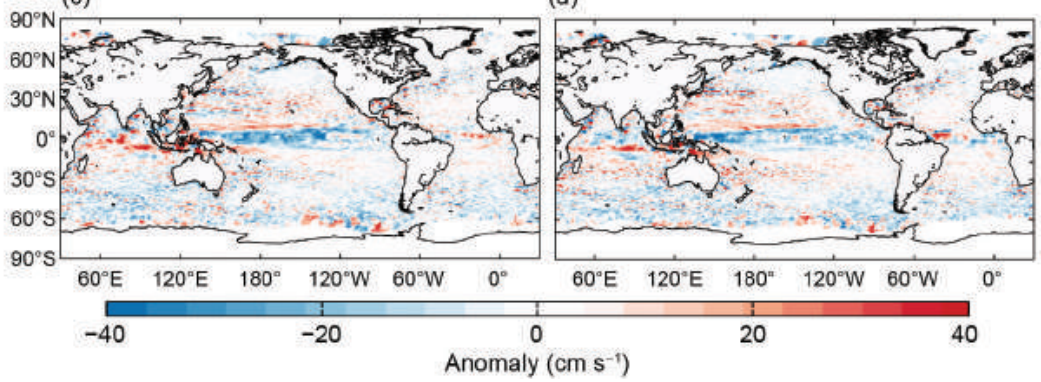

FIG. 3.19. Seasonally averaged zonal geostrophic anomalies $\left(\mathrm{cm} \mathrm{s}^{-1}\right)$ with respect to seasonal climatology, for (a) Dec 2015-Feb 2016, (b) Mar-May 2016, (c) Jun-Aug 2016, and (d) Sep-Nov 2016.

through April and May, by which point they were seen across the entire Pacific basin. These westward anomalies acted to reverse the sea level anomaly pattern across the basin (Figs. 3.16c,d) and erase the $>2^{\circ} \mathrm{C}$ SST anomalies in the eastern tropical Pacific (see Figs. $3.2 \mathrm{a}-\mathrm{c}$ ). In June, these anomalies began to weaken in the eastern half of the basin, and in July, they weakened across the basin when peak anomalies of $\sim 25 \mathrm{~cm} \mathrm{~s}^{-1}$ were at $3^{\circ}-4^{\circ} \mathrm{N}$. These westward anomalies continued to weaken throughout the rest of the year; in December, they averaged $10-15 \mathrm{~cm} \mathrm{~s}^{-1}$ at $4^{\circ}-6^{\circ} \mathrm{N}$.

As noted in earlier State of the Climate reports (e.g., Dohan et al. 2015), the Kuroshio was shifted anomalously northward in 2010-14, although this shift diminished in 2014. During 2015 and 2016, the Kuroshio was close to its climatological latitude.

Equatorial Pacific surface current anomalies advect surface waters across the basin, resulting in SST anomalies. These surface current anomalies typically lead SST anomalies by several months, with a magnitude that scales with the SST anomaly magnitude. SST anomalies typically continue to rise until the currents return to normal conditions. Thus, current anomalies in this region are a valuable predictor of the evolution of SST anomalies and their related climate impacts. This leading nature can be seen in the first principal empirical orthogonal function (EOF) of surface current anomaly (SC) and separately the first EOF of SST anomaly (SST) in the tropical Pacific basin (Fig. 3.20). The maximum lagged correlation between SC and SST is $\mathrm{R}=0.66$ for 1993-2016, with SC leading SST by 81 days. The year began with positive SST and SC anomalies. SC anomalies sharply reversed in January, dropping to a minimum EOF amplitude value of -2.9 standard deviations in April-the smallest value in the record-and remaining negative throughout the year. These westward SC anomalies resulted in a lowering of SST anomalies, although with such strong positive SST anomalies at the start of the year, the SST EOF amplitude remained positive for most of 2016 .

\section{2) INDIAN OCEAN}

The annually averaged nearequatorial current in the Indian Ocean basin is eastward, reflecting the dominance of the Southwest Monsoon Current in the annual average. During 2016, the mean current near the equator was up to $20 \mathrm{~cm} \mathrm{~s}^{-1}$ faster (anomalous eastward current) in the eastern half of the basin, with the largest anomalies at $6^{\circ}-8^{\circ} \mathrm{S}$. Because these anomalies were not seen in 2015, they appear in both the 2016 annual average (Fig. 3.18a) and the 2016 minus 2015 tendencies (Fig. 3.18b). An examination of the month-by-month development of these anomalies reveal that they reflect a much-stronger-than-average Southwest Monsoon Current in the second half of the year. The year 2016 began with $>20 \mathrm{~cm} \mathrm{~s}^{-1}$ westward anomalies from $5^{\circ} \mathrm{S}$ to $1^{\circ} \mathrm{N}$ in the central Indian Ocean, which weakened in February and March and were largely absent by April. In May, very strong $\left(25 \mathrm{~cm} \mathrm{~s}^{-1}\right)$ eastward equatorial anomalies developed across the
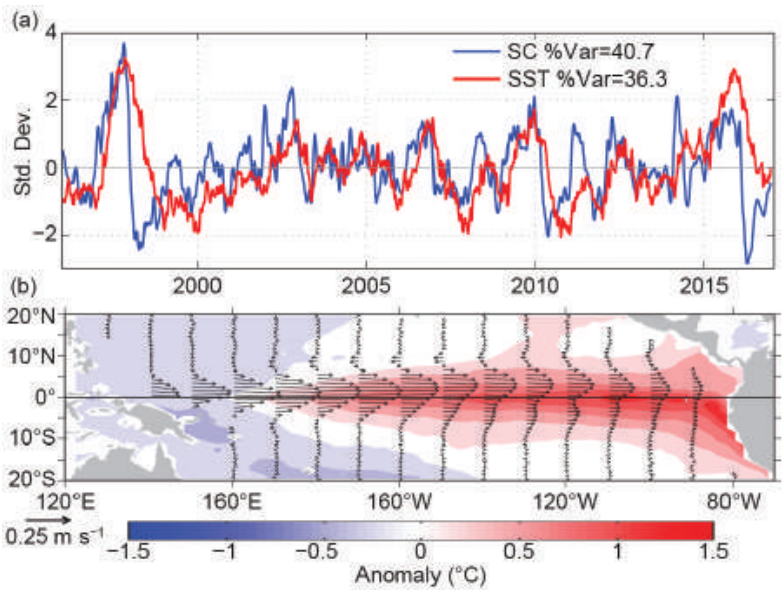

Fig. 3.20. Principal empirical orthogonal functions (EOF) of surface current (SC; $\mathrm{m} \mathrm{s}^{-1}$ ) and of SST anomaly $\left({ }^{\circ} \mathrm{C}\right)$ variations in the tropical Pacific from the OSCAR model (Bonjean and Lagerloef 2002; www .esr.org/enso_index.html). (a) Amplitude time series of the EOFs normalized by their respective standard deviations. (b) Spatial structures of the EOFs. 
basin. Through June and July, these anomalies intensified and propagated east and south, as the current is deflected off the equator by the presence of the Malaysian coast. The anomalies weakened slightly in August, then persisted at approximately the same strength $\left(30-35 \mathrm{~cm} \mathrm{~s}^{-1}\right.$ eastward in the region $6^{\circ}-8^{\circ} \mathrm{S}$, $80^{\circ}-100^{\circ} \mathrm{E}$ ) through the end of 2016 .

The Agulhas Current transport is a key indicator of Indian-Atlantic Ocean interbasin water exchanges. The annual mean transport of the Agulhas Current decreased over the period 2013-15, from 56 Sv (1 Sv $\equiv 10^{6} \mathrm{~m}^{3} \mathrm{~s}^{-1}$ ) in 2013 to $50 \mathrm{~Sv}$ in 2015 (www.aoml .noaa.gov/phod/altimetry/cvar). In 2016, the Agulhas Current had an annual average transport of $54 \mathrm{~Sv}$, exceeding the long-term mean of $50 \mathrm{~Sv}$. These changes are larger than the $\sim 3 \mathrm{~Sv}$ standard deviation of the individual yearly estimates.

\section{3) Atlantic Ocean}

Annual mean anomalies in the Atlantic Ocean (Fig. 3.18a) indicate an $8-10 \mathrm{~cm} \mathrm{~s}^{-1}$ strengthening of the eastward NECC and comparable weakening of the westward northern South Equatorial Current (nSEC) at $2^{\circ}-5^{\circ} \mathrm{N}, 15^{\circ}-40^{\circ} \mathrm{W}$. Elsewhere, conditions were near climatology. Because anomalies were weaker in 2015, the 2016 minus 2015 map (Fig. 3.18b) closely resembles the 2016 map. Looking at the month-to-month development of anomalies, large-scale conditions were close to climatology until May, when eastward anomalies began developing across the equatorial band, indicating a slowing of the westward nSEC. By June, these anomalies exceeded $20 \mathrm{~cm} \mathrm{~s}^{-1}$ at $1^{\circ}-3^{\circ} \mathrm{N}$, $0^{\circ}-30^{\circ} \mathrm{W}$. They then weakened through July and August, when eastward anomalies began developing to the north, in the latitude band of the NECC. These anomalies, which dominated the annual average, intensified through September-November in the western NECC and were still present at the end of the year. Averaged over the last four months of the year, eastward anomalies peaked at $30 \mathrm{~cm} \mathrm{~s}^{-1}$ at $4^{\circ} \mathrm{N}$, $30^{\circ}-45^{\circ} \mathrm{W}$. Weaker westward anomalies centered at $6^{\circ} \mathrm{N}$ in the same longitude band indicate that the NECC was not only stronger, but also shifted somewhat south of its climatological position.

The mean position of the Gulf Stream extension shifted north by approximately $0.5^{\circ}$ latitude in 2016 relative to climatological values (see Sidebar 3.1 for related impacts), while the Loop Current did not extend as fully into the Gulf of Mexico on average in 2016 as it had in the previous two years.

In the southwest Atlantic Ocean, the Brazil Current carries waters from subtropical to subpolar regions mainly in the form of large anticyclonic rings
(Lentini et al. 2006). The separation of the Brazil Current front from the continental shelf break continued to exhibit annual periodicity (www.aoml.noaa .gov/phod/altimetry/cvar), which is mainly driven by wind stress curl variations and the transport of this current. During 1993-2005, the annual mean separation of the front shifted southward in response to a long-term warming in South Atlantic temperatures (cf. Lumpkin and Garzoli 2011; Goni et al. 2011). Since 2005, the location of the front has not exhibited interannual trends. The year 2016 was an anomalous one in which the front was persistently shifted north of its long-term mean position-something not seen since 1994. It remains to be seen if this represents a transient or more sustained reversal of the long-term shift of the confluence to the south.

\section{h. Meridional overturning and oceanic heat transport cir-} culation observations in the North Atlantic OceanM. O. Baringer, D. A. Smeed, J. Willis, M. Lankhorst, W. R. Hobbs, S. Dong, G. McCarthy, D. Rayner, W. E. Johns, G. Goni, and U. Send

This section describes the AMOC and the Atlantic meridional heat transport (AMHT), determined by the large-scale ocean circulation wherein northward moving upper layer waters are transformed into deep waters that return southward, redistributing heat, fresh water, carbon, and nutrients. Large variations in meridional heat transport are associated with strong MOC anomalies (e.g., correlations of 0.94, Johns et al. 2011) and northwesterly wind anomalies while monthly variability is more closely linked to the spatial structure associated with the North Atlantic oscillation (NAO; e.g., Moat et al. 2016). Observed cold North Atlantic sea surface temperatures were consistent with the decadal decrease in MOC transport at $26^{\circ} \mathrm{N}$ (e.g., Baringer et al. 2016). These large-scale ocean anomalies can subsequently impact European weather (e.g., Duchez et al. 2016). Many climate, weather, and ecosystem changes covary with changes in the AMOC (e.g., Srokosz and Bryden 2015; Carton et al. 2014; Srokosz et al. 2012).

The AMOC is computed as the maximum of the vertical accumulation of the horizontally integrated velocity across a zonal-vertical section (i.e., the maximum transport that occurs in either the upper or lower layer before the circulation starts to change direction again). The AMHT involves the covariability of temperature and velocity and is only meaningful as a flux (and hence, independent of the absolute temperature scale used) when the total mass transport can be accounted for (i.e., sums to zero). Observing systems can measure both temperature and velocity, usually with tradeoffs in system design 
that favor the computation of one quantity over the other. Here we describe the AMOC from observing systems at $41^{\circ} \mathrm{N}, 26^{\circ} \mathrm{N}$, and $16^{\circ} \mathrm{N}$ and $\mathrm{AMHT}$ at $41^{\circ} \mathrm{N}$, $26^{\circ} \mathrm{N}$, and $35^{\circ} \mathrm{S}$.

The longest time series of ocean transport to serve as an index of the AMOC's strength in the North Atlantic (e.g., Frajka-Williams 2015; Duchez et al. 2014) is from the Florida Current (FC, as the Gulf Stream is called at $26^{\circ} \mathrm{N}$ ), measured since 1982 (Fig. 3.21). FC and AMOC transport variations at all time scales also are inversely linked to sea level variations along the U.S. East Coast (e.g., McCarthy et al. 2015). The median 1982-2016 transport of the FC is 31.9 $( \pm 0.25) \mathrm{Sv}$, with the uncertainty being one standard error of the mean assuming a 20-day integral time scale. There is a small downward trend in the record of $-0.30( \pm 0.24) \mathrm{Sv}_{\text {decade }}{ }^{-1}$, this time with $95 \%$ significance levels. The 2016 median FC transport was $31.8( \pm 1.9) \mathrm{Sv}$, not statistically significantly below the long-term average. Daily FC transports compared to those of all previous years (Fig. 3.21) indicate that 2016, like previous years, included several unusual transport anomalies (extremes defined as outside the 95\% confidence limits for daily values). During 2016 there were two high transport events during 31 July-3 August and 10-11 September, with transport in excess of $38.8 \mathrm{~Sv}$. Low transport anomalies occurred during 15-21 April, 10-23 October, and 13-15 November 2016. The lowest daily 2016 FC transport was 19.8 $( \pm 1.7) \mathrm{Sv}$ on 18 April, with transports $<23 \mathrm{~Sv}$ for five days around this date. Of note is the coincidence of the low transport events in October and November with king tide events in South Florida, which caused widespread street flooding, and the 14 November 2016 "supermoon" (see www.nasa.gov/feature /goddard/2016/novembers-spectacular-supermoon). The difference between the observed sea level at the Lake Worth tide gauge station was larger than the predicted tidal sea level during these events (Fig. 3.21) and inversely correlated with the FC transport at well over the 99\% significance level (correlation coefficient $-0.62,37 \%$ of variance explained).

In the North Atlantic, the latitudes with currently available AMOC estimates include $41^{\circ} \mathrm{N}$, where a combination of profiling Argo floats (that measure ocean temperature and salinity for the upper $2000 \mathrm{~m}$ on broad spatial scales, as well as velocity at $1000 \mathrm{~m}$ ) and altimetry-derived surface velocity (Willis 2010) are used to estimate the AMOC (Fig. 3.22) and AMHT (Fig. 3.23). This time series has been updated since last year's report (Baringer et al. 2016), extending from January 2002 to April 2016 . At $26^{\circ} \mathrm{N}$, the AMOC (Fig. 3.22) and AMHT (Fig. 3.23) are measured with full-water column moorings that span the full basin and include direct transport measurements in the boundary currents as part of the large RAPID-MOC/ MOCHA/WBTS $26^{\circ} \mathrm{N}$ mooring array (Smeed et al. 2015). The data from this array are collected every 18 months; hence the MOC data shown here extend from April 2004 to October 2015 (MHT data available to April 2014). At $16^{\circ} \mathrm{N}$, a mooring array of inverted echo sounders, current meters, and dynamic height moorings (Send et al. 2011) measures the flow below $1000 \mathrm{~m}$ (the southward flowing part of the AMOC "conveyor belt") that sends North Atlantic Deep Water toward the equator; hence, the AMOC estimate at this latitude (Fig. 3.22) is a negative number (southward deep flow) to distinguish these observations from the full water column systems. Since this array only measures the deep circulation, an estimate of the AMHT is

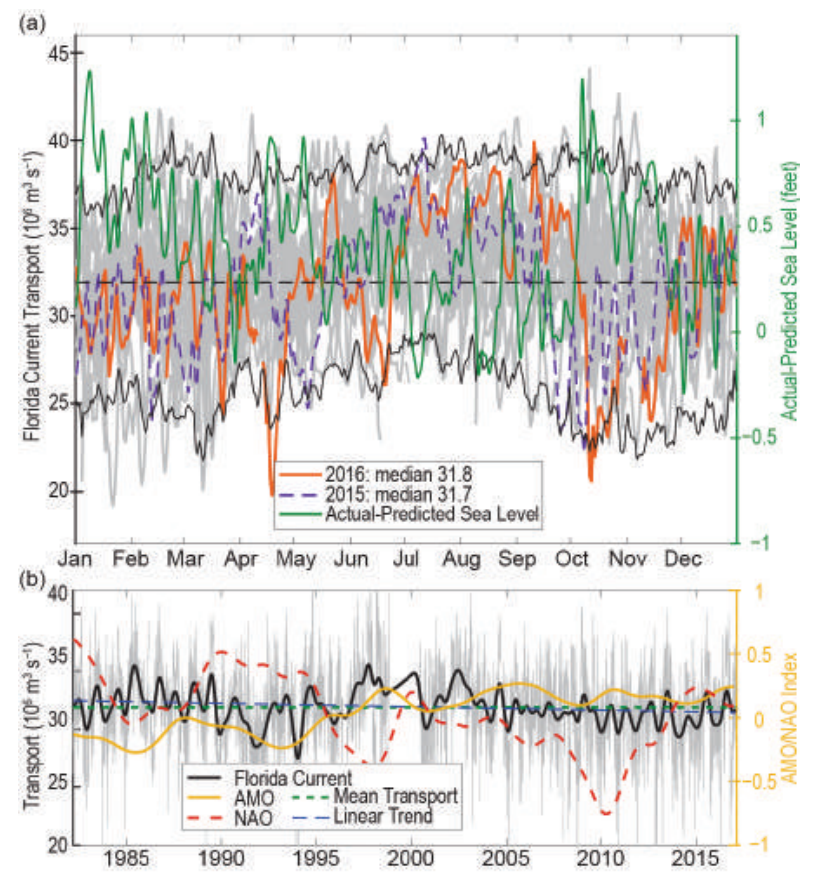

Fig. 3.2I. (a) Daily estimates of Florida Current transport $\left(10^{6} \mathrm{~m}^{3} \mathrm{~s}^{-1}\right)$ during 2016 (orange solid line), 2015 (dashed purple line), and 1982-2016 (light gray lines) with $95 \%$ confidence interval of daily transport values computed from all years (black solid line), the longterm mean (dashed black line), and actual observed sea level at the Lake Worth Pier tide gauge station minus predictions (green line) based on NOAA harmonic tide constituents (https://tidesandcurrents.noaa.gov Istationhome.html?id=8722670). (b) Daily estimates of Florida Current transport $\left(10^{6} \mathrm{~m}^{3} \mathrm{~s}^{-1}\right)$ for the full record (light gray), smoothed using a I2-month second-order Butterworth filter (heavy black line), mean transport for the full record (dashed green line), and linear trend for 1982-2016 (dashed blue line). Two-year low-passed AMO (yellow line) and NAO (red dashed line) indices are also shown. 


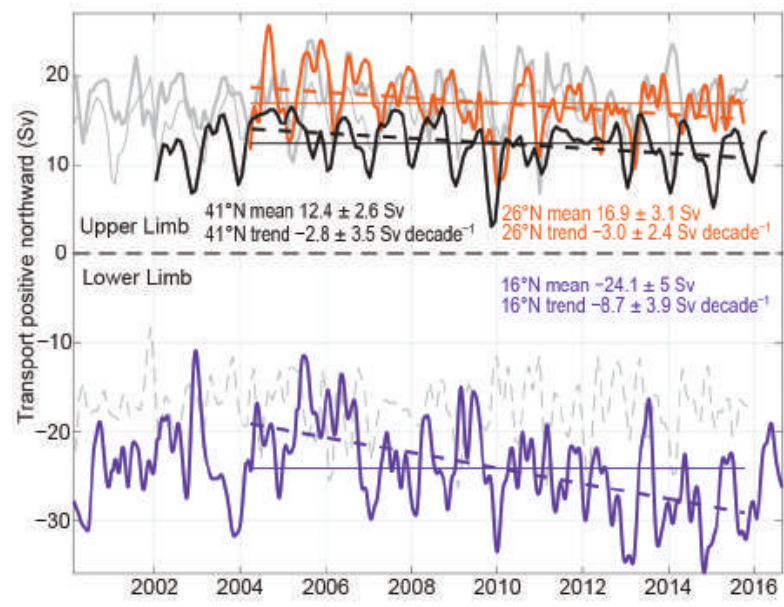

FIG. 3.22. Estimates of 2000-16 AMOC (Sv) from the Argo/Altimetry estimate at $41^{\circ} \mathrm{N}$ (black; Willis 2010), the RAPID-MOC/MOCHA/WBTS $26^{\circ} \mathrm{N}$ array (red; McCarthy et al. 2015), and the German/NOAA MOVE array at $16^{\circ} \mathrm{N}$ (blue; Send et al. 20II); a 3-month second-order Butterworth low-pass filter is also applied. Horizontal lines are mean transports during similar time periods as listed in the corresponding text. Dashed lines are trends for each series. For MOVE data, the net zonal and vertical integral of the deep circulation represents the lower limb of the AMOC (with a negative sign indicating southward flow), and hence a stronger negative (southward) flow represents an increase in the AMOC amplitude. Light gray lines show EC-derived transports (Menemenlis et al. 2008): (top) thin gray is the $41^{\circ} \mathrm{N}$ transport, thick gray is the $26^{\circ} \mathrm{N}$ transport, (bottom) shows the negative meridional overturning circulation in the model for ease of comparison with the $16^{\circ} \mathrm{N}$ data.

impossible at $16^{\circ} \mathrm{N}$ because of the missed large signals and high correlations in the surface waters. These data have been updated since last year's report and now extend from February 2000 to September 2016. At $35^{\circ} \mathrm{S}$ in the South Atlantic, the AMHT is estimated using a combination of high-density (closely spaced) expendable bathythermograph (XBT) and broaderscale Argo profiling float data (Dong et al. 2014). While the AMOC has also been estimated at $35^{\circ} \mathrm{S}$, those estimates (not shown) are rough because the $\mathrm{XBTs}$ only extend to $750 \mathrm{~m}$. These data are collected and analyzed in near-real time, with values spanning July 2002 to August 2016.

In the far North Atlantic the MOC time series continue the relatively low trend in MOC transport: the trend of the MOC at $26^{\circ} \mathrm{N}$ is $-3.0( \pm 2.4) \mathrm{Sv} \mathrm{decade}^{-1}$ (Fig. 3.22) and the MHT trend is $-0.23( \pm 0.19)$ PW decade ${ }^{-1}\left(1 \mathrm{PW}=10^{15} \mathrm{~W}\right.$; Fig. 3.23). At $41^{\circ} \mathrm{N}$ these trends are $-1.2( \pm 3.0) \mathrm{Sv}$ decade $^{-1}$ and $-0.09( \pm 0.21) \mathrm{PW}$ decade $^{-1}$. These values are for the full length of each time series, while Fig. 3.22 lists the trends for the overlapping time periods of each time series (denoted by the dashed line in each panel). These trends are not statistically significantly less than those in last year's report $\left(-4.1( \pm 3.2) \mathrm{Sv}_{\mathrm{decade}}{ }^{-1}\right.$ and $-0.23( \pm 0.19) \mathrm{PW}$ decade ${ }^{-1}$ at $26^{\circ} \mathrm{N}$ and $-1.3( \pm 4.9) \mathrm{Sv}_{\text {decade }}{ }^{-1}$ and $-0.15( \pm 0.27) \mathrm{PW}$ decade $^{-1}$ at $\left.41^{\circ} \mathrm{N}\right)$, despite slightly larger MOC and MHT transports reported this year (e.g., at $26^{\circ} \mathrm{N}$, the mean MOC increased from $16.0 \mathrm{~Sv}$ in 2014 to $16.3 \mathrm{~Sv}$ in 2015, and at $41^{\circ} \mathrm{N}$, the mean MOC increased from $10.7 \mathrm{~Sv}$ in 2015 to $12.5 \mathrm{~Sv}$ in 2016). As more data become available, the $26^{\circ} \mathrm{N}$ data show flow compensation between the FC and upper flows in the center of the ocean, resulting in recirculation that is not associated with a change in the MOC (Frajka-Williams et al. 2016).

Farther south, the MOC and MHT trends are positive but decreasing in the past three years as the annual means at $16^{\circ} \mathrm{N}$ reduced in magnitude from $-29.2 \mathrm{~Sv}$ in 2014 , to $-27.8 \mathrm{~Sv}$ in 2015 , and then to -23.8 in 2016. The trend of the AMOC from February 2000 to September 2016 at $16^{\circ} \mathrm{N}$ is $+3.4( \pm 2.4) \mathrm{Sv}$ decade $^{-1}$

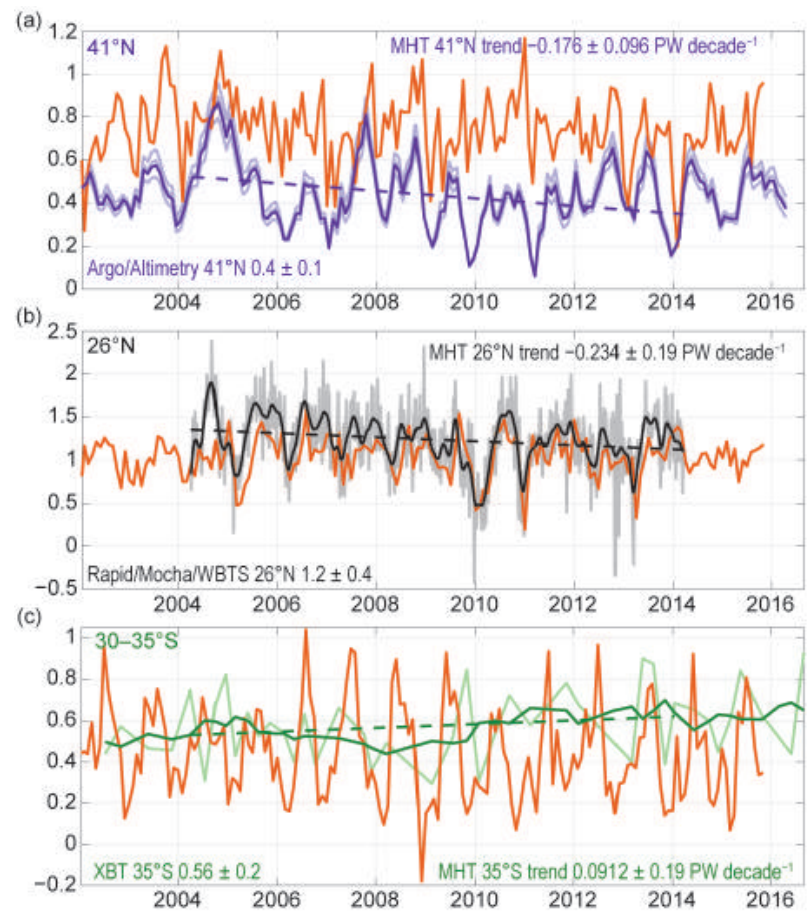

FIG. 3.23. AMHT; (PW) at (a) $4 I^{\circ} \mathrm{N}$ (from profiling floats following Hobbs and Willis 2012; blue lines), with uncertainties (light blue lines) and the trend (dashed blue line); at (b) $26^{\circ} \mathrm{N}$ (from mooring/hydrography data) 12-hourly values (gray line), filtered with a 3 -month low-pass filter (black line), and the trend (black dashed line); and at (c) $30^{\circ}-35^{\circ} \mathrm{S}$ (from XBTs) quarterly values (light green), filtered with yearly boxcar (dark green line), and the trend (dashed green line). Heat transports simulated by EC (orange lines; Menemenlis et al. 2008) are shown at all latitudes. 
(statistically indistinguishable from the trend of $+3.6( \pm 2.5) \mathrm{Sv}_{\text {decade }}{ }^{-1}$ reported last year). Similarly, the $35^{\circ} \mathrm{S}$ AMHT transport estimate has remained fairly constant for the last three years (mean northward values of $0.60 \mathrm{PW}$ in 2014, $0.69 \mathrm{PW}$ in 2015, and $0.63 \mathrm{PW}$ in 2016). These estimates imply a virtually steady AMOC as well (the AMOC and AMHT being highly correlated). The AMHT trend at $35^{\circ} \mathrm{S}$ from July 2002 to August 2016 is $+0.09( \pm 0.10) \mathrm{PW}$ decade $^{-1}$ (again statistically indistinguishable from the trend of $+0.11( \pm 0.10)$ PW decade ${ }^{-1}$ reported last year). Variability at all latitudes in the Atlantic is not well correlated, and therefore, data from more than one latitude are needed to describe the state of the ocean. Interannual and higher frequencies dominate the variability in the MOC and MHT time series, and therefore long records will be needed to determine decadal and longer variability.

i. Global ocean phytoplankton-B. A. Franz, M. J. Behrenfeld, D. A. Siegel, and S. R. Signorini

Marine phytoplankton contribute roughly half the net primary production (NPP) on Earth, fixing atmospheric $\mathrm{CO}_{2}$ into food that fuels global ocean ecosystems and drives biogeochemical cycles (e.g., Field et al. 1998; Falkowski et al. 1998). Satellite ocean color sensors, such as SeaWiFS (McClain 2009), MODIS (Esaias et al. 1998), and VIIRS (Oudrari et al. 2015), provide observations of sufficient frequency and geographic coverage to globally monitor changes in the near-surface concentrations of the phytoplankton pigment chlorophyll-a (Chla; $\left.\mathrm{mg} \mathrm{m}^{-3}\right)$ that serve as a proxy for phytoplankton abundance. Here, global Chl $a$ distributions for 2016 are evaluated within the context of the 19-year continuous record provided through the combined observations of SeaWiFS (1997-2010), MODIS on Aqua (MODISA, 2002-present), and VIIRS on Suomi-NPP (2011-present). All Chla data used in this analysis correspond to version R2014.0 (https://oceancolor.gsfc.nasa.gov /reprocessing), which utilized common algorithms and calibration methods to maximize consistency in the multi-mission satellite record.

The spatial distribution of VIIRS annual mean Chla for 2016 (Fig. 3.24) is consistent with the wellestablished, physically driven distribution of nutrients (Siegel et al. 2013) and surface mixed-layer light conditions (Behrenfeld et al. 2016). To assess changes in this distribution during 2016, mean values for VIIRS Chl $a$ in each month of the year were subtracted from monthly climatological means for MODISA (2003-11). These monthly fields were then averaged to produce the global chlorophyll anomaly map for 2016

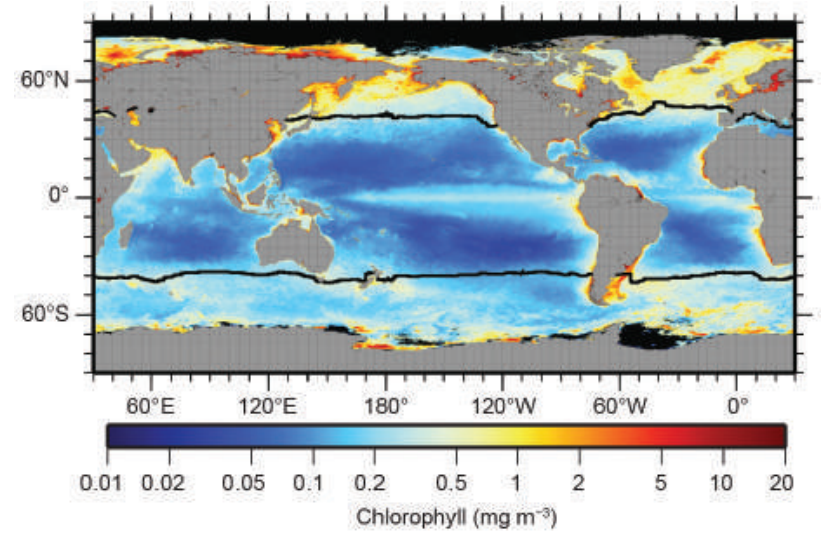

FIG. 3.24. Annual mean Chla distribution ( $\mathrm{mg} \mathrm{m}^{-3}$ ) derived from VIIRS for year 2016. Also shown is the location of the mean $15^{\circ} \mathrm{C} \mathrm{SST} \mathrm{isotherm} \mathrm{(black} \mathrm{lines)}$ delineating the boundary of the PSO. Chla data are from NASA Reprocessing version 2014.0. Data are averaged into geo-referenced equal area bins of approximately $4.6 \times 4.6 \mathrm{~km}^{2}$ and mapped to an equirectangular projection centered at $150^{\circ} \mathrm{W}$.

(Fig. 3.25a). Identical calculations were performed on MODISA sea surface temperature $\left(\mathrm{SST} ;{ }^{\circ} \mathrm{C}\right)$ data to produce an equivalent SST annual mean anomaly (Fig. 3.25b). The relationship between resultant annual anomalies in Chla and SST are shown in Fig. 3.25c.

The dominant driver of phytoplankton Chla change during 2016 was a climatic shift from El Niño to La Niña conditions. Accordingly, Chla concentrations along the equatorial Pacific were elevated by $10 \%-20 \%$ over the climatological mean (red band in eastern equatorial Pacific in Fig. 3.25a). To the north and south of this band, Chla concentrations were diminished relative to climatological values and inversely related with SST anomalies (dark blue areas above and below the equator in Fig. 3.25c). Within the boundaries of the permanently stratified ocean (PSO), delineated by the black lines in Figs. 3.24 and 3.25 at approximately $40^{\circ} \mathrm{N}$ and $40^{\circ} \mathrm{S}$ and defined as the region where annual average surface temperatures are $>15^{\circ} \mathrm{C}$ (Behrenfeld et al. 2006), an inverse relationship was generally observed between Chla and SST anomalies in the South Pacific (dark blue and dark red colors in Fig. 3.25c). By contrast, Pacific regions of the PSO north of the equator exhibited roughly an equal mix of positive and inverse relationships between Chl $a$ and SST anomalies. Similarly, a mixture of Chla-SST relationships was observed throughout the Atlantic and Indian sectors of the PSO. These findings for 2016 contrast with some previous findings (e.g., Behrenfeld et al. 2006, 2008, 2009; O’Malley et al. 2010; Siegel et al. 2012; Franz et al. 2013) and are further discussed below. In regions outside the PSO, 


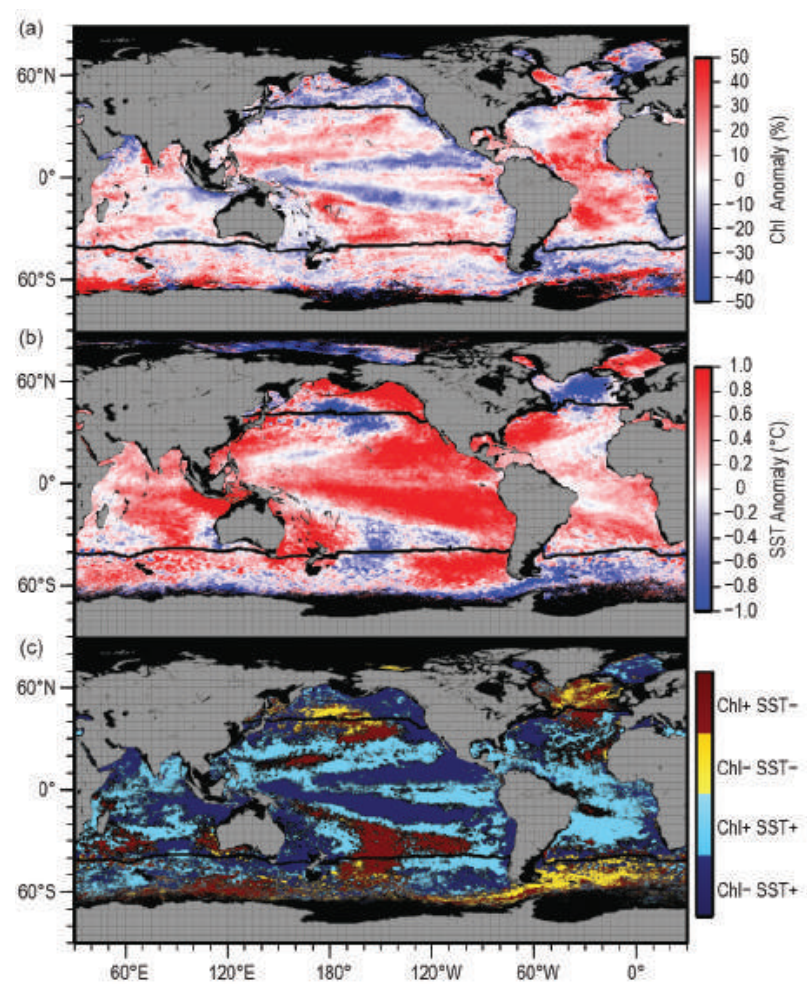

FIG. 3.25. Spatial distribution of averaged monthly 2016 (a) VIIRS Chla anomalies and (b) MODISA SST anomalies, where monthly differences were derived relative to the MODISA 2003-II climatological record. Chla anomaly is expressed as \% difference from climatology, while SST anomaly is shown as an absolute difference ( $\left.{ }^{\circ} \mathrm{C}\right)$. (c) identifies relationships between the sign of SST and Chla anomalies from (a) and (b), with colors differentiating sign pairs and absolute changes of less than $3 \%$ in Chla or $0.1^{\circ} \mathrm{C}$ in SST masked in black. Also shown is the location of the mean $15^{\circ} \mathrm{C} \mathrm{SST}$ isotherm (black lines) delineating the PSO.

no clear relationship was observed between Chla and SST anomalies (Fig. 3.25c), consistent with the previous studies cited above.

Over the 19-year time series of spatially integrated monthly mean Chla values for the PSO (Fig. 3.26a), mean concentrations vary by $\sim 20 \%$ $\left( \pm 0.03 \mathrm{mg} \mathrm{m}^{-3}\right)$ around a long-term average of $\sim 0.15 \mathrm{mg} \mathrm{m}^{-3}$ (Fig. 3.26a). This variability includes significant seasonal cycles in Chla distributions and responses to climatic events. The time series also demonstrates the high level of consistency between the overlapping periods of the SeaWiFS and MODISA missions and between the MODISA and VIIRS missions, thereby lending confidence in our extension of the long-term record using measurements from VIIRS alone.

Chla monthly anomalies within the PSO (Fig. 3.26b) show variations of $\pm 15 \%$ over the multimission time series. Notable for 2016, monthly anomalies in Chla concentrations for the PSO trended consistently upward from an historical low at the start of the year (Franz et al. 2016), rising more than $20 \%$ to reach a $5 \%$ elevated state relative to the climatological reference by the end of the year. The link between these Chla changes and a switch from El Niño to La Niña conditions is demonstrated as a corresponding decline in the multivariate ENSO index (MEI; Wolter and Timlin 1998; Fig. 3.26b, green diamonds, presented in the inverse to illustrate the covariation). Thus, 2016 was a transition year, which likely contributed to the weaker relationship between annual average Chla and SST anomalies, as compared with similar analyses for previous years. However, monthly anomalies in PSO Chla concentrations for 2016 remained consistent with the long-term ocean color record with respect to large-scale climate oscillations (Fig. 3.26b). This consistency is further evidenced in the spatial domain by comparing results shown in Fig. 3.25a with those reported by Franz et al. (2013), wherein a strikingly similar geographic distribution in Chla anomalies was observed, but of opposite sign, for calendar year 2012 when the MEI was continuously trending upward.

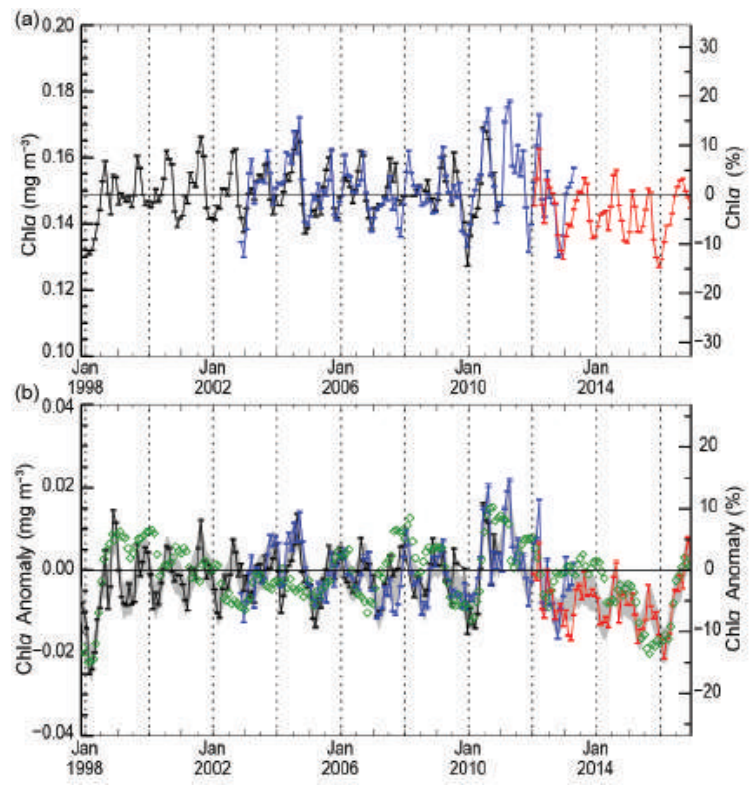

FIG. 3.26. 1998-2016, multimission record of Chla averaged over the PSO for SeaWiFS (black), MODISA (blue), and VIIRS (red). (a) Independent record from each mission, with horizontal black line indicating the multimission mean Chla concentration for the region $\left(\mathrm{mg} \mathrm{m}^{-3}\right)$. (b) Monthly anomaly (\%) for SeaWiFS, MODISA, and VIIRS after subtraction of the 9-year MODISA monthly climatological mean (2003-II). The gray region in (b) shows the averaged difference between SeaWiFS and MODISA over the common mission lifetime. Green diamonds show the MEI, inverted and scaled to match the range of the Chla anomalies. 
Surface layer Chla concentrations, as derived from ocean color remote sensing, have long functioned as a central property for monitoring global changes in marine phytoplankton. Variability and trends in Chla reflect both adjustments in phytoplankton biomass and physiology (or health). Both of these properties are mechanistically linked to physical properties of the upper ocean, as well as ecological relationships between phytoplankton and their zooplankton predators. Unraveling this diversity and often covariation of factors that influence Chla concentrations is essential for correctly interpreting the implications of Chl $a$ anomalies for ocean biogeochemistry and food webs. For example, inverse relationships between Chl $a$ and SST can emerge from changes in either mixed-layer light levels or vertical nutrient flux, but these two mechanisms have opposite implications for phytoplankton NPP (Behrenfeld et al. 2016). An additional complication is that measured changes in ocean color often reflect, at least in part, changes in colored dissolved organic matter signals (Siegel et al. 2005) that are mistakenly attributed to Chla changes (Siegel et al. 2013). Thus, while the satellite record of ocean color continues to provide critical insights on global processes, new insights and approaches are needed to fully understand the story these data are telling regarding relationships between climate and marine ecosystems.

j. Global ocean carbon cycle-R. A. Feely, R. Wanninkhof, P. Landschützer, B. R. Carter, and J. A. Triñanes

The global ocean is a major sink for anthropogenic carbon dioxide $\left(\mathrm{CO}_{2}\right)$ that is released into the atmosphere from fossil fuel combustion, cement production, and land use changes. Over the last decade the global ocean has continued to take up a substantial fraction of the anthropogenic carbon $\left(\mathrm{C}_{\text {anth }}\right)$ emissions and is therefore a major mediator of global climate change. Of the $10.2( \pm 0.7) \mathrm{Pg} \mathrm{C} \mathrm{yr}^{-1} \mathrm{C}_{\text {anth }}$ released during the period 2006-15, about $2.6( \pm 0.5) \mathrm{Pg} \mathrm{C} \mathrm{yr}^{-1}$ (26\%) accumulated in the ocean, $3.1( \pm 0.8) \mathrm{Pg} \mathrm{C} \mathrm{yr}^{-1}$ (30\%) accumulated on land, and $4.5( \pm 0.1) \mathrm{Pg} \mathrm{C} \mathrm{yr}^{-1}$ (43\%) remained in the atmosphere (Global Carbon Project 2016). This decadal ocean carbon uptake estimate is a consensus view based on a combination of measured decadal inventory changes, models, and global air-sea $\mathrm{CO}_{2}$ flux estimates based on surface ocean partial pressure of $\mathrm{CO}_{2}\left(p \mathrm{CO}_{2}\right)$ measurements. Using ocean general circulation models that include biogeochemical parameterizations (OBGCMs) and inverse models that are validated with observationsbased air-sea exchange fluxes and basin-scale ocean inventories, Le Quéré et al. (2016) have demonstrated that the oceanic anthropogenic carbon sink has grown from $1.2( \pm 0.5) \mathrm{Pg} \mathrm{C} \mathrm{yr}^{-1}$ in the decade of the 1960s to $2.6( \pm 0.5) \mathrm{Pg} \mathrm{C} \mathrm{yr}^{-1}$ in the decade from 2006 to 2015. Air-sea flux studies reported here indicate an

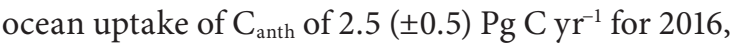
with the uncertainty being the standard deviation of monthly values.

\section{I) AiR-Sea CARbon dioxide fluXes}

Ocean uptake of $\mathrm{C}_{\text {anth }}$ can be estimated from the net air-sea $\mathrm{CO}_{2}$ flux derived from the bulk flux formula with air-sea differences in $\mathrm{CO}_{2}$ partial pressure $\left(\Delta p \mathrm{CO}_{2}\right)$ and gas transfer coefficients as input (Wanninkhof 2014). A steady contribution of carbon from continental runoff estimated at $0.45 \mathrm{Pg} \mathrm{C} \mathrm{yr}^{-1}$ (Jacobson et al. 2007) is included to obtain the $\mathrm{C}_{\text {anth }}$. The data source for $p \mathrm{CO}_{2}$ are annual updates of surface water $p \mathrm{CO}_{2}$ observations from the Surface Ocean $\mathrm{CO}_{2}$ Atlas (SOCAT) composed of mooring and shipbased observations (Bakker et al. 2016). The $\Delta p \mathrm{CO}_{2}$ and a parameterization of the gas transfer with wind described in Wanninkhof (2014) are used to calculate the air-sea $\mathrm{CO}_{2}$ fluxes. Increased observations and improved mapping techniques (e.g., Rödenbeck et al. 2015) now afford global $\mathrm{pCO}_{2}$ fields at a $1^{\circ}$ grid on monthly time scales with a lag of less than three months. This progress allows investigation of variability on subannual to decadal time scales.

The monthly $2016 \Delta p \mathrm{CO}_{2}$ maps are based on an observation-based neural network approach (Landschützer et al. 2013, 2014) applied to biogeographical provinces. Surface temperature, sea surface salinity, climatological mixed-layer depth, satellite chlorophyll-a, and atmospheric $\mathrm{CO}_{2}$ are used to establish relationships with surface ocean $p \mathrm{CO}_{2}$ measurements and are applied where no observations exist. The 2016 air-sea estimate uses wind speeds from 2015 as consistent global wind products for 2016 have not been processed. Changes in winds over time have a small effect on gas transfer (Wanninkhof and Triñanes 2017) so this approximation should not have a determining impact on the interpretation of the air-sea $\mathrm{CO}_{2}$ fluxes calculated for 2016.

The $\mathrm{C}_{\text {anth }}$ fluxes from 1982 to 2016 (Fig. 3.27) suggest a decreasing ocean sink in the first part of the record and a strong increase from 2001 onward. The amplitude of seasonal variability is $\sim 1 \mathrm{Pg} \mathrm{C}$ with minimum uptake in June-September. The $\mathrm{C}_{\mathrm{anth}}$ airsea flux of $2.5( \pm 0.5) \mathrm{Pg} \mathrm{C} \mathrm{yr}^{-1}$ in 2016 is $32 \%$ above the 2005-14 average of $1.9( \pm 0.5) \mathrm{Pg} \mathrm{C} \mathrm{yr}^{-1}$.

The average fluxes in 2016 (Fig. 3.28a) show the characteristic pattern of effluxes in the tropical regions, with the largest effluxes in the equatorial $\mathrm{Pa}-$ 


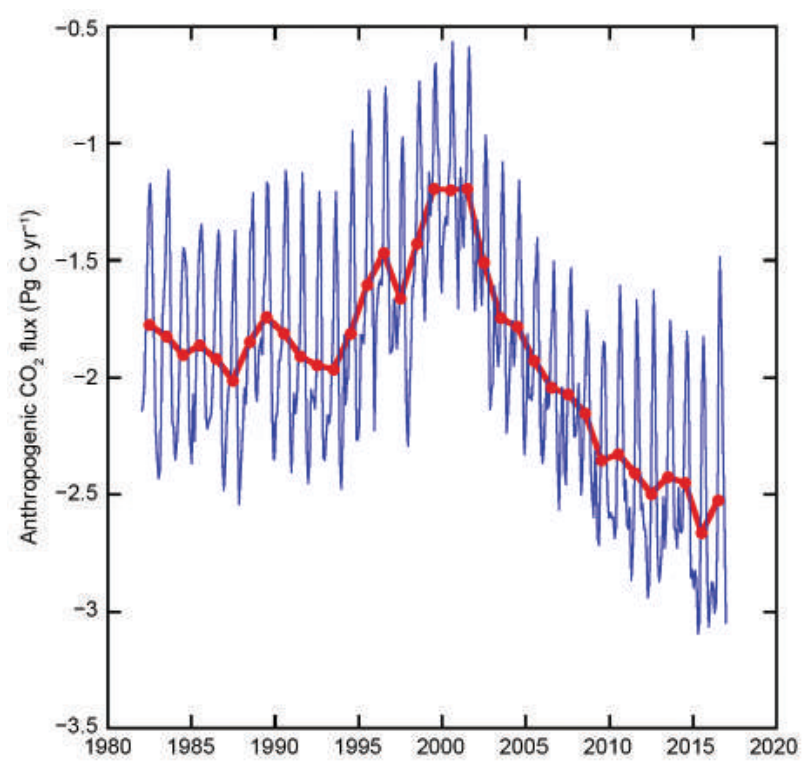

FIG. 3.27. Annual (red line) and monthly (blue line) $\mathrm{C}_{\text {anth }}$ fluxes (Pg C yr ${ }^{-1}$ ) from 1982-20 I6. Negative values indicate uptake by the ocean.

cific and Arabian Sea upwelling regions. Large sinks are observed poleward of the subtropical fronts. The Southern Ocean is a strong sink but net annual effluxes are apparent in the Polar Front regions $\left(55^{\circ}-60^{\circ} \mathrm{S}\right)$ in the Indian and Pacific sectors of the Southern Ocean.

Ocean uptake anomalies (Fig. 3.28b) in 2016 relative to the 1995-2015 average are attributed to the increasing ocean $\mathrm{CO}_{2}$ uptake with time and to several climate reorganizations. The air-sea flux trend since 2000 is $-0.7( \pm 0.08) \mathrm{Pg} \mathrm{C}$ decade $^{-1}$, which leads to predominantly negative flux anomalies (greater uptake). Despite this strong trend there are several regions showing positive anomalies for 2016, notably the eastern equatorial, western, and North Pacific. The subtropical gyres in the North Atlantic and southern Indian Oceans show positive anomalies as well. The positive anomalies are attributed to changes in ocean circulation patterns; however, they are often difficult to attribute to a single cause. The increased effluxes in the eastern equatorial Pacific are possibly caused by the changes in ENSO patterns, with the largest impacts of the recent El Niños being farther west in the central rather than eastern equatorial Pacific (Ashok and Yamagata 2009). Stronger effluxes in the western and North Pacific are related to strongly positive PDO values in 2015-16 as well as the residual of the 2013-15 warm anomaly in the northern North Pacific (Bond et al. 2015) that persisted into the first half of 2016 (Fig. 3.28c).

The differences between the air-sea $\mathrm{CO}_{2}$ fluxes in 2016 compared to 2015 (Fig. 3.28c) are easier to place in context of changes in temperature, circulation, and climate reorganizations as the longer-term trends do not obfuscate the changes. The anomalously high $\mathrm{CO}_{2}$ effluxes in the northeast Pacific associated with the anomalously warm temperatures of the 2013-15 warm anomaly have shifted northward in this region. The equatorial Pacific shows an increase in $\mathrm{CO}_{2}$ fluxes near the equator associated with increasing upwelling after the termination of the 2015/16 El Niño. This shift is also reflected by cooler SST in the region (see Fig. 3.1). The strong increase in uptake in the Atlantic subpolar gyre in 2016 is associated with warmer SST, suggesting that less cold deep waters with high $p \mathrm{CO}_{2}$ were entrained into the surface mixed layer. The strong positive flux anomaly near the polar front in the southeastern sector of the South Pacific Ocean is likely associated with regionally enhanced upwelling of cold deep water with high $\mathrm{CO}_{2}$. This
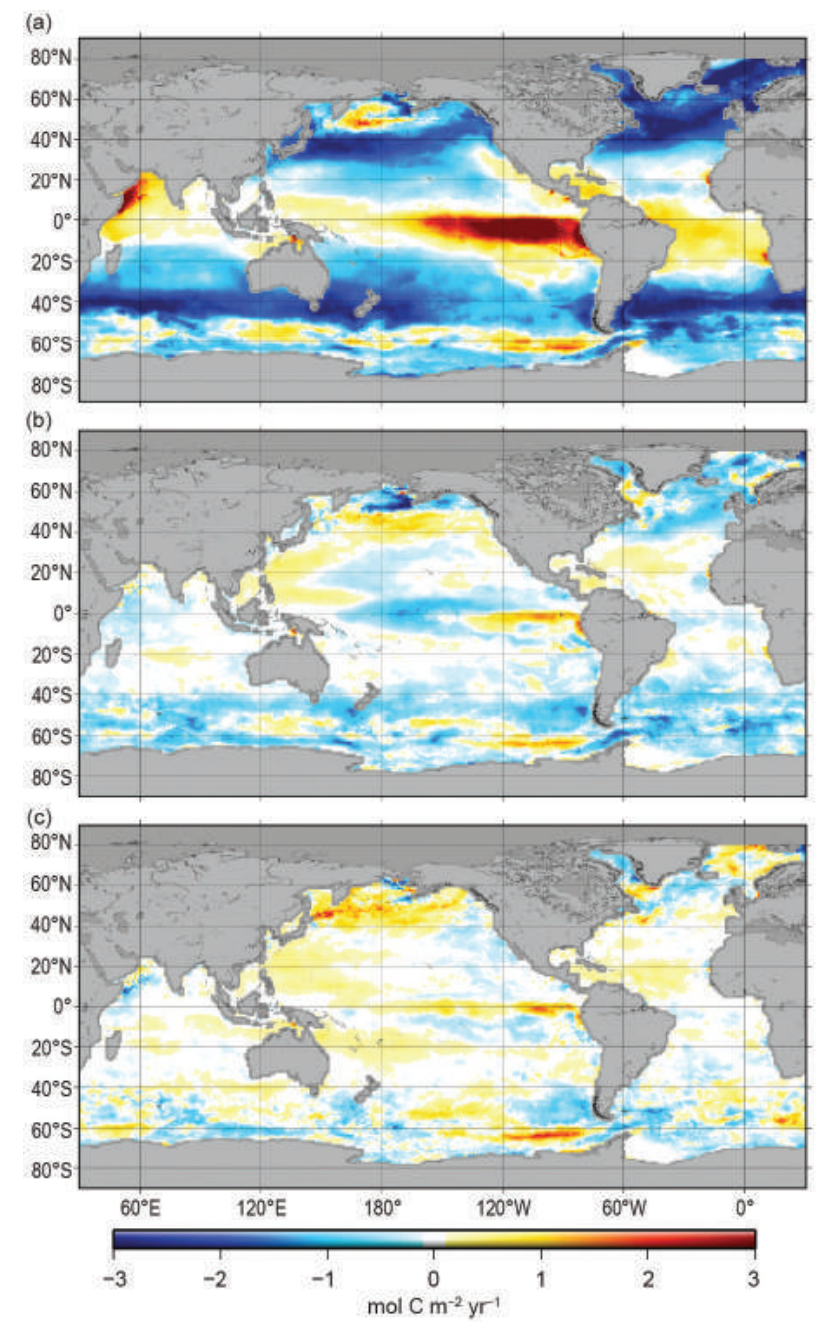

FIG. 3.28. (a) Net air-sea fluxes for 2016; (b) net air-sea flux anomalies for $\mathbf{2 0 1 6}$ compared to the average for 1995-20I5; and (c) net air-sea flux anomalies for 2016 compared to the 2015 values following the method of Landschützer et al. (20l3). Anomalies are in mol C $\mathrm{m}^{-2} \mathrm{yr}^{-1}$. 
feature has the expected small negative SST anomaly associated with it. However, the SST anomaly appears greater in the Atlantic sector and has a strong negative, rather than a positive, flux anomaly associated with it. This relation shows that, while many of the flux $/ p \mathrm{CO}_{2}$ anomalies can be attributed to climate reorganizations and associated physical anomalies, notably temperature, the causality is often complex. For example, the behavior of $p \mathrm{CO}_{2}$ with respect to temperature includes competing processes: thermodynamics dictate decreasing $p \mathrm{CO}_{2}$ with decreasing SST but waters originating from the deep with a cold temperature signal will have a high $p \mathrm{CO}_{2}$.

The strong trend of increasing uptake since 2002 reached its largest uptake value in 2015 and in 2016 has decreased slightly, largely to decreased uptake in June-September (Fig. 3.27). This small decrease in global uptake is well within the envelope of interannual variability and should not be inferred as a longerterm saturation of the ocean $\mathrm{CO}_{2}$ sink.
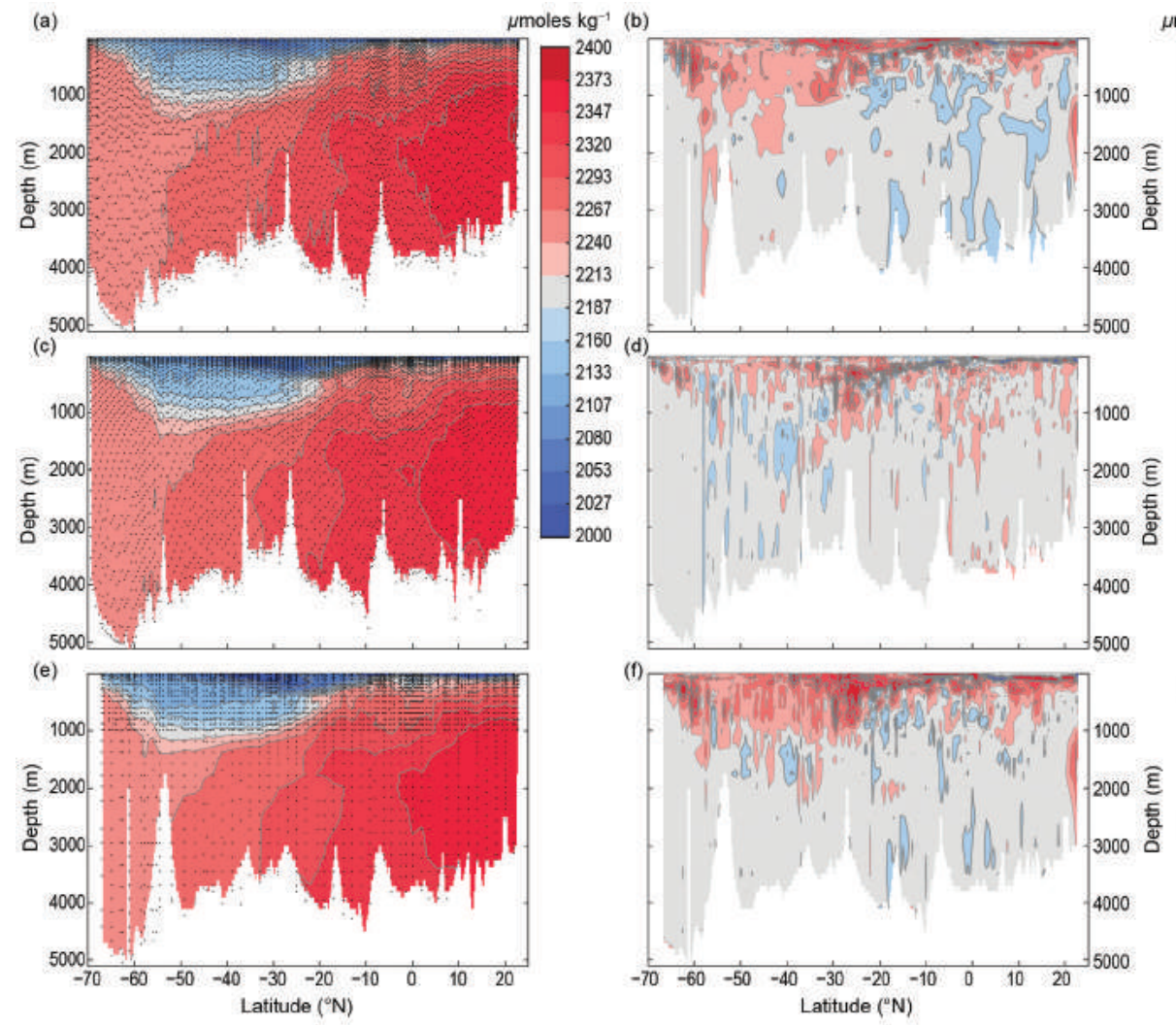

2) CaRbon InVentories

The U.S. Global Ocean Ship-based Hydrographic Investigations Program (GO-SHIP) is providing new information about the uptake and storage of carbon within the ocean interior by determining the change in measured dissolved inorganic carbon (DIC) concentrations and calculations of estimated $\mathrm{C}_{\text {anth }}$ concentration changes between decadal cruise reoccupations. A recent example is the DIC concentrations (Figs. 3.29a,c,e) and the DIC differences (Figs. 3.29b,d,f) for the three P18 cruises that occurred in 2016/17, 2007/08, and 1994. The high decadal DIC differences among the P18 cruises in the Pacific show the buildup of DIC of up to $50 \mu \mathrm{mol} \mathrm{kg}^{-1}$ resulting from gas exchange, mixing, and transport of the water masses in the surface and intermediate waters to depths down to approximately 1500-2000 m. On these approximately decadal time scales, increases are expected in the lighter density thermocline waters found shallower than $2000 \mathrm{~m}$. These increases are owing to continued surface ocean uptake of $\mathrm{CO}_{2}$, which are in turn owing to atmospheric increases caused by human activities, primarily burning of fossil fuels. Apparent noise in this increase is due to large

FIG. 3.29. Vertical-meridional sections of total DIC measured along the GO-SHIP PI8 section in (a) 2016/17, (c) 2007/08, and (e) 1994. DIC change sections (red indicates increases) between (b) 2007/08 and 1994 cruises, (d) $2016 / 17$ and $2007 / 08$ cruises, and (f) 2016/17 and 1994 cruises. For this comparison, measured property values were interpolated vertically using a cubic Hermite piece-wise polynomial method and interpolated linearly against latitude onto a fixed grid. 
DIC variability from changes in ocean circulation on decadal and shorter time scales. Planned future work will quantify the fraction of the observed changes that are directly attributable to increases of $\mathrm{CO}_{2}$ from human activities. These increases are expected to propagate into deeper waters on longer time scales.

Using a modified version of the extended multiple linear regression (eMLR) method with Pacific cruise data, Carter et al. (2017) determined that the Pacific Ocean (from $60^{\circ} \mathrm{N}$ to $60^{\circ} \mathrm{S}$ ) accumulated an average of $6.1( \pm 1.6) \mathrm{Pg} \mathrm{C}_{\text {decade }}{ }^{-1}$ in the decade of 1994-2004 as compared with $8.9( \pm 2.2) \mathrm{PgC}$ decade $^{-1}$ during the decade of 2004-14 (Table 3.3). The eMLR approach uses linear regressions to determine the empirical relationships between properties of interest and other hydrographic properties (salinity, potential temperature, nitrate, and silicic acid) that are also affected by water mass movements but not affected by increases in $\mathrm{C}_{\text {anth }}$. The difference between the regression constants from the earlier and later datasets are then used to estimate the changes in ocean carbon independent of any changes in the water mass distributions. Using a similar approach for the Atlantic, Woosley et al. (2016) showed that $C_{\text {anth }}$ storage increased from 5.1 to $8.1 \mathrm{Pg} \mathrm{C}$ decade $^{-1}$ over the same time intervals. These results suggest that both increases in air-sea exchange of $\mathrm{CO}_{2}$ at the surface as well as changes in ventilation within the ocean interior contribute to increased rates of uptake in the later decade. Because of the vast area of the subtropical gyres, the majority of the $\mathrm{C}_{\text {anth }}$ inventory is stored in the subtropics. By contrast, upwelling regions near the equator, in the North Pacific, and in the Southern Ocean south of the Antarctic Circumpolar Current have low storage rates (Table 3.3). In these regions, upwelling of deep waters that have been isolated from the atmosphere since the preindustrial era displace the better-ventilated, higher $\mathrm{C}_{\text {anth }}$ intermediate depth waters. Anthropogenic carbon inventories inferred from these different approaches are consistent with each other. (Available online at www.nodc.noaa.gov/OC5/woa13.)
TABle 3.3. Pacific decadal $\mathbf{C}_{\text {anth }}$ storage for the latitude bands in Pg C decade ${ }^{-1}$. The "total" values include estimates for data-poor latitude bands from $60^{\circ}$ to $67^{\circ} \mathrm{N}$ and $70^{\circ}$ to $80^{\circ} \mathrm{S}$, and therefore do not exactly equal the sum of all rows (after Carter et al. 2017).

\begin{tabular}{|c|c|c|}
\hline Latitude Band & $\begin{array}{c}\text { WOCE } \\
\text { to CLIVAR }\end{array}$ & $\begin{array}{l}\text { CLIVAR to } \\
\text { GOSHIP }\end{array}$ \\
\hline $70^{\circ}-60^{\circ} \mathrm{S}$ & $\dagger$ & 0.65 \\
\hline $60^{\circ}-50^{\circ} \mathrm{S}$ & 0.56 & 0.84 \\
\hline $50^{\circ}-40^{\circ} \mathrm{S}$ & 0.90 & 0.97 \\
\hline $40^{\circ}-30^{\circ} \mathrm{S}$ & 0.96 & 1.07 \\
\hline $30^{\circ}-20^{\circ} \mathrm{S}$ & 0.65 & I.31 \\
\hline $20^{\circ}-10^{\circ} \mathrm{S}$ & 0.35 & 1.20 \\
\hline $10^{\circ}-0^{\circ} \mathrm{S}$ & 0.29 & 0.72 \\
\hline $0^{\circ}-10^{\circ} \mathrm{N}$ & 0.46 & 0.56 \\
\hline $10^{\circ}-20^{\circ} \mathrm{N}$ & 0.79 & 0.52 \\
\hline $20^{\circ}-30^{\circ} \mathrm{N}$ & 0.60 & 0.64 \\
\hline $30^{\circ}-40^{\circ} \mathrm{N}$ & 0.35 & 0.53 \\
\hline $40^{\circ}-50^{\circ} \mathrm{N}$ & 0.13 & 0.35 \\
\hline $50^{\circ}-60^{\circ} \mathrm{N}$ & 0.07 & 0.21 \\
\hline $\begin{array}{l}\text { Southern } \\
\text { Hemisphere }\end{array}$ & $3.8 \pm 1.0$ & $6.8 \pm 1.7$ \\
\hline $\begin{array}{l}\text { Northern } \\
\text { Hemisphere }\end{array}$ & $2.4 \pm 0.6$ & $2.8 \pm 0.7$ \\
\hline Total $\left(60^{\circ} \mathrm{S}-60^{\circ} \mathrm{N}\right)$ & $6.1 \pm 1.6$ & $8.9 \pm 2.2$ \\
\hline
\end{tabular}


4. THE TROPICS - H. J. Diamond and C. J. Schreck, Eds. a. Overview - H. J. Diamond and C. J. Schreck

In 2016 the Tropics were dominated by a transition from El Niño to La Niña. The year started with an ongoing El Niño that proved to be one of the strongest in the 1950-2016 record. After its peak in late 2015/early 2016, this El Niño weakened until it was officially declared to have ended in May. El Niño-Southern Oscillation conditions were briefly neutral during the transition period before a weak La Niña developed in October. A negative Indian Ocean dipole is commonly associated with the transition from El Niño to La Niña, and 2016 was one of the most strongly negative on record. The transition was also reflected in the dichotomy of precipitation patterns between the first and second halves of the year. Rainfall was well below average across the maritime continent in early 2016 and above normal during the latter months.

Globally, 93 named tropical storms were observed during 2016, as documented in the International Best Tracks Archive for Climate Stewardship (IBTrACS; Knapp et al. 2010). This overall tropical cyclone (TC) activity is above the 1981-2010 global average of 82 storms, but $8 \%$ lower than the 101 TCs recorded in 2015 (Diamond and Schreck 2016). Three basinsthe North Atlantic, and eastern and western North Pacific-experienced above-normal activity in 2016. The Australian basin had significantly below-normal activity and recorded its least active season since the beginning of the satellite era in 1970. It should be noted that for the Southern Hemisphere, the cyclone season covers the period July 2015-June 2016.

Four TCs reached the Saffir-Simpson scale Category 5 intensity level-one each in the North Atlantic, South Indian, western North Pacific, and Southwest Pacific basins. This number was half the number of category 5 storms recorded in 2015 (Diamond and Schreck 2016). The United States experienced a sharp increase in the number of landfalling storms compared to the last three seasons. Five named storms made landfall, including two hurricanes-the largest number of US landfalling storms since 2008 (when six storms struck). Regarding accumulated cyclone energy (ACE; Bell et al. 2000), the North Atlantic basin recorded its first above-normal season since 2012, producing more than 2.5 times the average ACE value of the last three seasons from 2013-15. However, category-5 Hurricane Matthew alone produced 35\% of the season's ACE. The western North Pacific's activity was similarly dominated by two typhoons (Lionrock and Meranti) accounting for about 25\% of the total seasonal ACE in that basin. b. ENSO and the Tropical Pacific-G. Bell, M. L'Heureux, and M. S. Halpert

The El Niño-Southern Oscillation (ENSO) is a coupled ocean-atmosphere climate phenomenon over the tropical Pacific Ocean, with opposing phases called El Niño and La Niña. For historical purposes, NOAA's Climate Prediction Center (CPC) classifies and assesses the strength and duration of El Niño and La Niña using the Oceanic Niño index (ONI; shown for 2015 and 2016 in Fig. 4.1). The ONI is the 3-month average of sea surface temperature (SST) anomalies in the Niño-3.4 region $\left(5^{\circ} \mathrm{N}-5^{\circ} \mathrm{S}, 170^{\circ}-120^{\circ} \mathrm{W}\right.$; black box in Fig. 4.3e) calculated as the departure from the 1981-2010 base period. El Niño is classified when the $\mathrm{ONI}$ is at or warmer than $0.5^{\circ} \mathrm{C}$ for at least five consecutive 3 -month running periods. La Niña is classified when the ONI is at or cooler than $-0.5^{\circ} \mathrm{C}$ for at least five consecutive 3-month running periods.

The time series of the ONI shows that 2016 featured both El Niño and La Niña episodes. The year started with one of the strongest El Niños of the 1950-2015 record already underway (Bell et al. 2016; L'Heureux et al. 2016). This El Niño began during February-April (FMA) 2015 and ended during April-June (AMJ) 2016. Strong El Niño conditions were present from late 2015 through early 2016 . The largest $\mathrm{ONI}$ values ranged from $2.2^{\circ} \mathrm{C}$ to $2.3^{\circ} \mathrm{C}$, and were observed for the three consecutive seasons of October-December (OND) 2015, November 2015January (NDJ) 2016, and December 2015-February (DJF) 2016.

NOAA CPC officially declared that El Niño ended in May. The ONI indicates that ENSO-neutral conditions were then present for the May-July (MJJ) and June-August (JJA) periods, before dropping below $-0.5^{\circ} \mathrm{C}$ during July-September (JAS). La Niña subsequently developed in October 2016 as the atmospheric wind and convection patterns became coupled to the

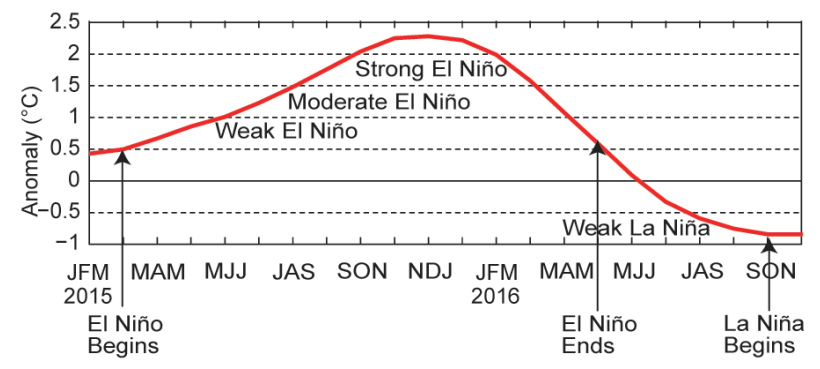

Fig. 4.I. Oceanic Niño index (ONI; $\left.{ }^{\circ} \mathrm{C}\right)$ during 2015 and 2016. Three-month seasons are labeled according to the first initial for each month (Jan-Mar is JFM, MarMay is MAM, etc.). EI Niño and La Niña periods are indicated. Weak, moderate, and strong classifications are shown. ONI values are derived from the ERSST-v4 dataset (Huang et al. 2015). 
negative SST anomalies. This event remained weak (ONI between $-0.5^{\circ}$ and $-1.0^{\circ} \mathrm{C}$ ) during the rest of the year.

\section{I) Oceanic CONDITIONS}

The SST evolution across the tropical Pacific basin during 2016 (Figs. 4.2, 4.3) is shown based on optimum interpolation sea surface temperature (OISST) data (Smith et al. 2008). The strong El Niño conditions during DJF 2015/16 featured an extensive area of SSTs exceeding $30^{\circ} \mathrm{C}$ across the central and eastcentral equatorial Pacific (Fig. 4.2a). Consistent with this anomalous warmth, equatorial SST departures exceeded $2^{\circ} \mathrm{C}$ from just east of the date line to near the west coast of South America (nearly a quarter of the distance around the globe), and the largest departures (exceeding $3^{\circ} \mathrm{C}$ ) extended from near $160^{\circ}$ to $110^{\circ} \mathrm{W}$. As noted in L'Heureux et al. (2016), the far eastern Pacific Ocean was cooler and the western Pacific was warmer in this event relative to the two previous major El Niños of 1997/98 and 1982/83.

Based on area-averaged weekly SST anomalies (Fig. 4.3) calculated for four core regions of the equatorial Pacific (called the Niño regions, shown

(a)
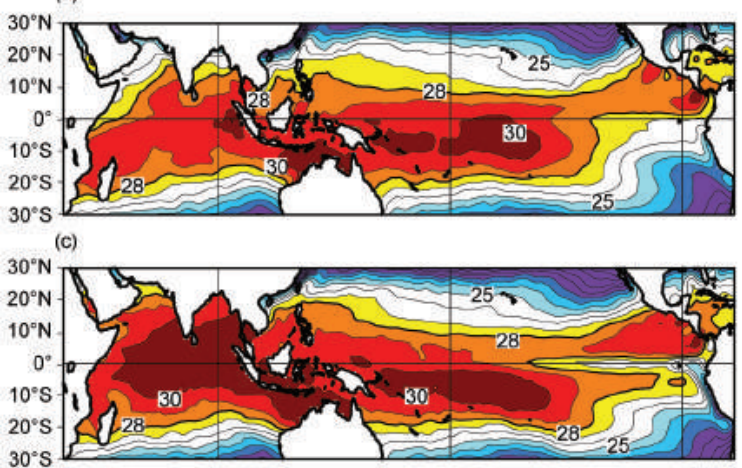

$30^{\circ} \mathrm{S}$
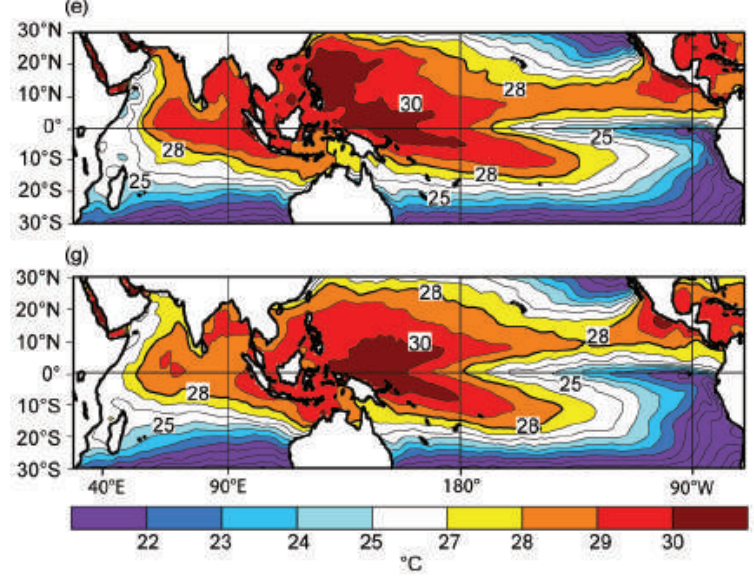

in Fig. 4.3e), the highest anomalies during 2016 occurred early in the year: $1.4^{\circ} \mathrm{C}$ in the Niño- 4 region (Fig. $4.3 \mathrm{a}$ ), $2.6^{\circ} \mathrm{C}$ in the Niño-3.4 region (Fig. $4.3 \mathrm{~b}$ ), $2.8^{\circ} \mathrm{C}$ in the Niño-3 region (Fig. $4.3 \mathrm{c}$ ), and $1.8^{\circ} \mathrm{C}$ in the Niño-1+2 region (Fig. $4.3 \mathrm{~d}$ ).

Seasonal SST anomalies then decreased during March-May (MAM) 2016, with the most rapid decreases observed in the eastern Pacific (Niño-3 and Niño-1+2 regions; Figs. 4.2c,d). This evolution reflected an intensification and westward expansion of the equatorial cold tongue and an increasing confinement of the anomalous warmth to the central and east-central equatorial Pacific. Within this season, SST anomalies in the eastern Pacific returned to nearzero in April (Figs. 4.3c,d), and those in the Niño-3.4 region returned to zero in mid-May (Fig. 4.3b).

During JJA 2016, negative SST anomalies had developed across the eastern half of the equatorial Pacific in association with a further strengthening and westward expansion of the equatorial cold tongue (Figs. 4.2e,f). The anomalies generally ranged between $-0.5^{\circ}$ and $-1.0^{\circ} \mathrm{C}$, with some areas recording departures cooler than $-1.0^{\circ} \mathrm{C}$. This cooling was reflected in all but the Niño-1+2 index (Fig. 4.3).

(b)

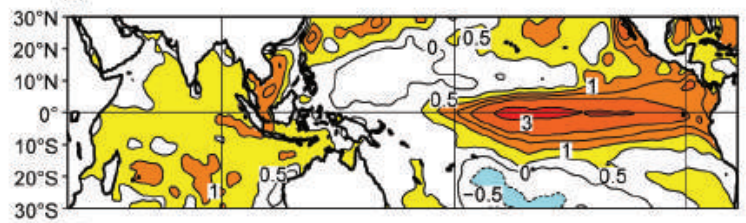

(d)

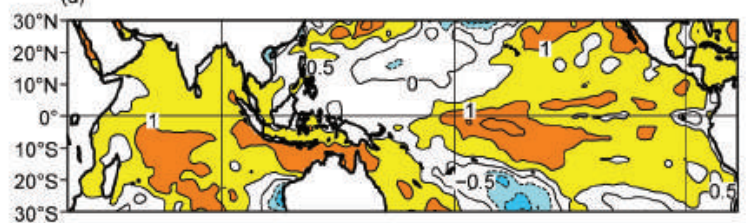

(f)

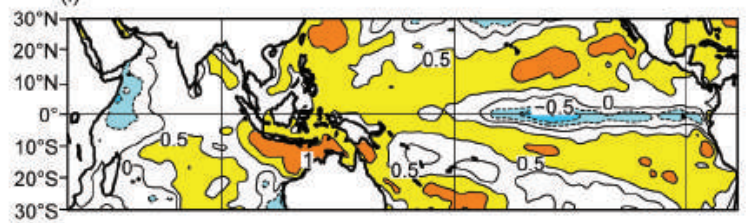

(h)

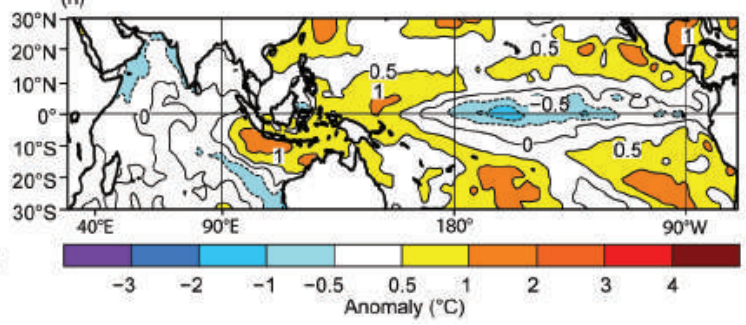

Fig. 4.2. (Left) Seasonal SST $\left({ }^{\circ} \mathrm{C}\right.$ ) and (right) SST anomaly $\left({ }^{\circ} \mathrm{C}\right.$ ) for (a),(b) DJF 2015/16; (c),(d) MAM 2016; (e),(f) JJA 2016; and (g),(h) SON 2016. Contour interval for seasonal SST is $1^{\circ} \mathrm{C}$. For anomalous SST: contour interval is $0.5^{\circ} \mathrm{C}$ for anomalies $\pm 1^{\circ} \mathrm{C}$ and $1^{\circ} \mathrm{C}$ for anomalies $>+1^{\circ} \mathrm{C}$ and $\left\langle-1^{\circ} \mathrm{C}\right.$. Anomalies are departures from 198I-2010 seasonal adjusted Ol climatology (Smith and Reynolds 1998). 


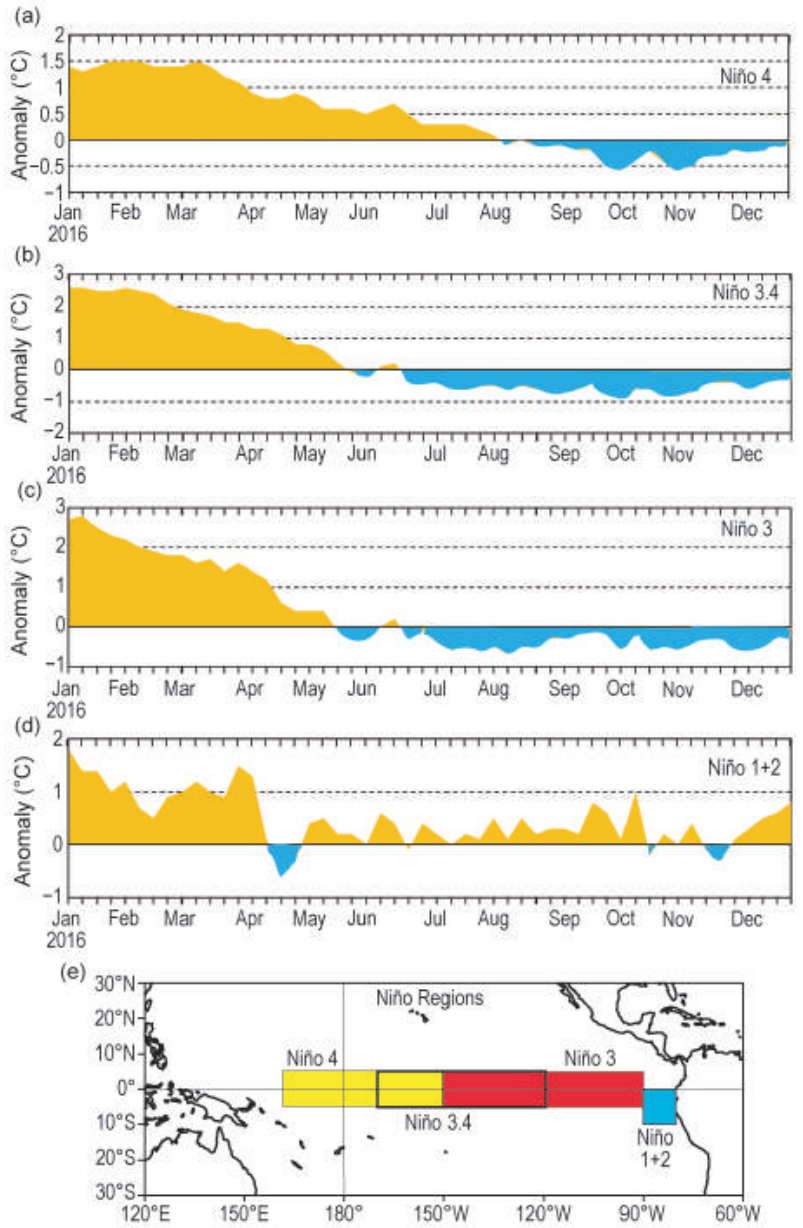

FIG. 4.3. Weekly area-averaged $2016 \mathrm{SST}$ anomalies $\left({ }^{\circ} \mathrm{C}\right)$ in the four Niño regions: (a) Niño-4 region $\left[5^{\circ} \mathrm{N}-5^{\circ} \mathrm{S}\right.$, $160^{\circ} \mathrm{E}-160^{\circ} \mathrm{W}$; yellow box in (e)], (b) Niño-3.4 region $\left[5^{\circ} \mathrm{N}-5^{\circ} \mathrm{S}, 170^{\circ}-120^{\circ} \mathrm{W}\right.$; thick black box in (e)], (c) Niño3 region $\left[5^{\circ} \mathrm{N}-5^{\circ} \mathrm{S}, 150^{\circ}-90^{\circ} \mathrm{W}\right.$; red box in (e)], and (d) Niño- $1+2$ region $\left[0^{\circ}-10^{\circ} \mathrm{S}, 90^{\circ}-80^{\circ} \mathrm{W}\right.$; blue box in (e)]. Values are departures from the $198 \mathrm{I}-2010$ weekly adjusted OI climatology (Smith and Reynolds 1998).

The ONI, which was $-0.3^{\circ} \mathrm{C}$ during JJA, dropped to $-0.8^{\circ} \mathrm{C}$ during SON and OND as the negative SST anomalies expanded westward to the date line (Figs. 4.2e,f). La Niña conditions began in October. However, by late December, La Niña had already begun to weaken, as indicated by a modest warming of all of the weekly Niño indices.

The equatorial subsurface temperature evolution is examined using data from the Global Ocean Data Assimilation System (GODAS), an analysis system that assimilates oceanic observations into an oceanic general circulation model (Behringer et al. 1998). The subsurface temperature structure and evolution during 2016 were consistent with the transition from a strong El Niño early in the year (Fig. 4.4a) to a weak La Niña late in the year (Fig. 4.4d). Subsurface sig- (a)

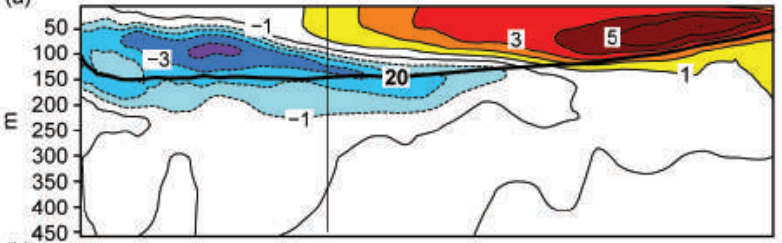

(b)

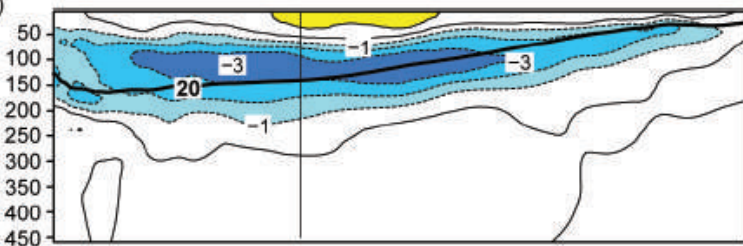

(c) 4

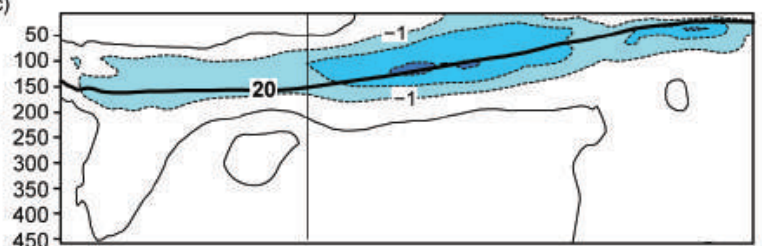

(d)

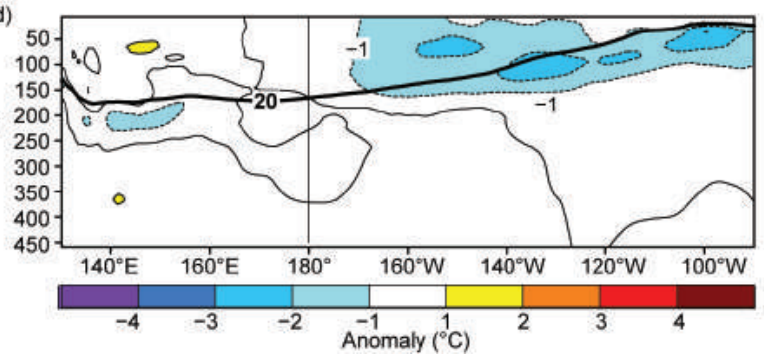

FIG. 4.4. Equatorial depth-longitude section of Pacific Ocean temperature anomalies $\left({ }^{\circ} \mathrm{C}\right)$ averaged between $5^{\circ} \mathrm{N}$ and $5^{\circ} \mathrm{S}$ during (a) DJF 2015/16, (b) MAM 2016, (c) JJA 2016, and (d) SON 2016. The $20^{\circ} \mathrm{C}$ isotherm (thick solid line) approximates the center of the oceanic thermocline. The data are derived from the GODAS analysis system that assimilates oceanic observations into an oceanic general circulation model (Behringer et al. 1998). Anomalies are departures from 198I-2010 monthly means.

nals preceding that transition were already evident during MAM, as indicated by well-below-average temperatures at depth across the entire equatorial Pacific and by a confinement of the anomalously warm waters to the near-surface (Fig. 4.4b). These conditions reflected a progressive shoaling of the oceanic thermocline which often precedes the end of a strong El Niño, such as occurred during the end of the 1997/98 event (Bell et al. 1999). The subsurface cooling during MAM 2016 was reflected by a sharp decrease in the upper-ocean heat content across the equatorial Pacific, with negative heat content anomalies evident by early April (see Fig. 4.8).

The subsurface cooling became increasingly focused east of the date line during JJA (Fig. 4.4c). However, as La Niña developed and strengthened, the negative subsurface temperature anomalies actu- 
ally weakened (Fig. 4.4d), then disappeared from the central and east-central equatorial Pacific during late November and December (not shown).

As expected, ENSO conditions also impacted sea level throughout the year. A full discussion on sea level rise and variability around the globe may be found in Chapter $3 \mathrm{f}$.

2) AtMOSPHERIC CIRCULATION: TROPICS AND SUBTROPICS

Across the tropical Pacific, El Niño signals during DJF 2015/16 included the continuation of an east-west dipole of anomalous convection from last year, with enhanced convection across the central and east-central equatorial Pacific and suppressed convection over the central portion of the Maritime Continent (shading in Figs. 4.5a and 4.6a). This pattern, indicated by the NOAA/NCEP gridded outgoing longwave radiation (OLR) data (Liebmann and Smith 1996), reflected a pronounced eastward extension of the primary area of tropical convection and deep tropospheric heating to well east of the date line.

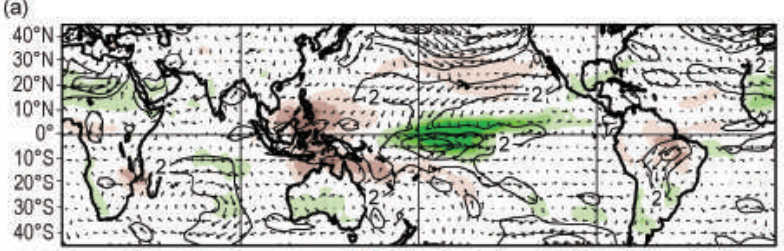

(b)

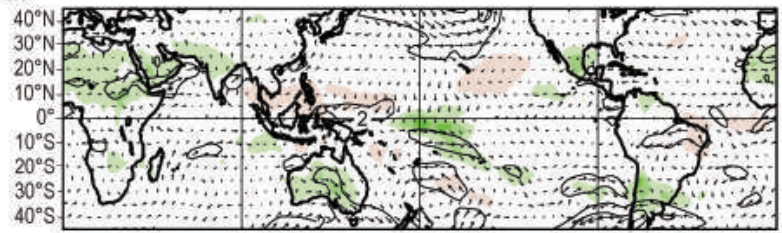

(c)

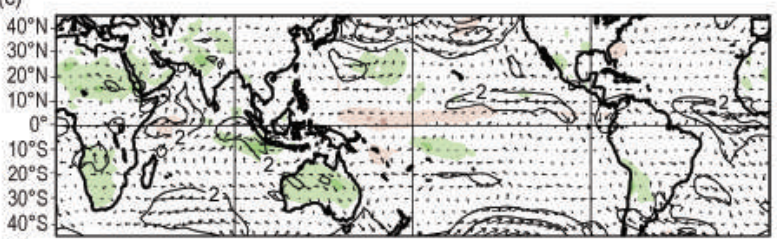

(d)

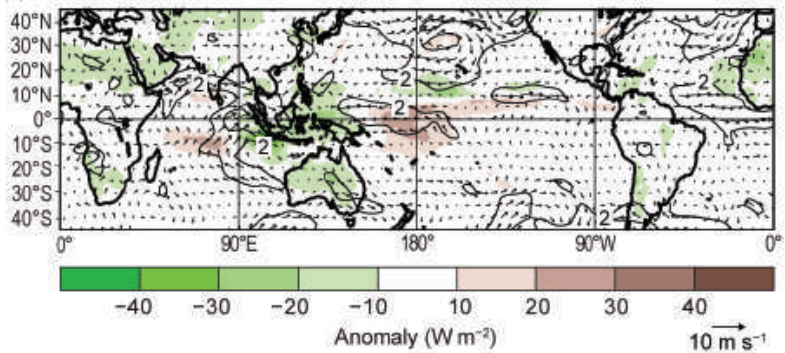

Fig. 4.5. Anomalous $850-\mathrm{hPa}$ wind vectors and speed (contour interval: $2 \mathrm{~m} \mathrm{~s}^{-1}$ ) and anomalous OLR (shaded, W $\mathrm{m}^{-2}$ ) during (a) DJF 2015/16, (b) MAM 2016, (c) JJA 2016, and (d) SON 2016. Reference wind vector is below right of color bar. Anomalies are departures from 1981-2010 monthly means.
The wind patterns as shown by the NCEP-NCAR Climate Data Analysis System (CDAS; Kistler et al. 2001) were strongly coupled to these convection patterns and to the underlying anomalous SST warmth. In the tropics, typical El Niño wind signals at $850 \mathrm{hPa}$ included anomalous westerlies (i.e., weaker easterly trade winds) across the central and east-central $\mathrm{Pa}$ cific (Fig. 4.5a), along with anomalous flow toward the equator near the date line. At $200 \mathrm{hPa}$, the wind anomalies were reversed, with easterly anomalies evident across the eastern half of the equatorial Pacific and anomalous poleward flow extending into the extratropics of both hemispheres (Fig. 4.6a). Collectively, these conditions reflected a weaker equatorial Walker circulation (Bjerknes 1969), a stronger Hadley circulation over the central equatorial Pacific, and a weaker Hadley circulation over the Maritime Continent.

In the subtropics of both hemispheres, the uppertropospheric winds during DJF 2015/16 featured anticyclonic anomalies flanking the area of enhanced equatorial convection. This typical El Niño signal (Arkin 1982) reflected an eastward extension of the

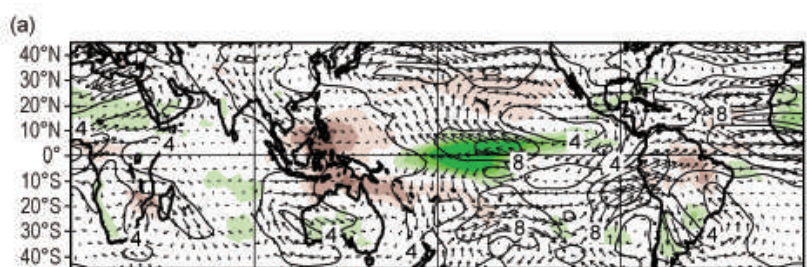

(b)

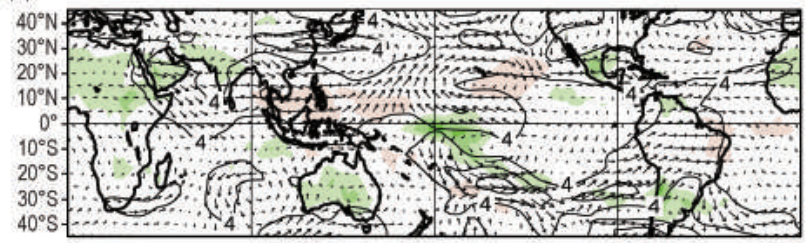

(c)

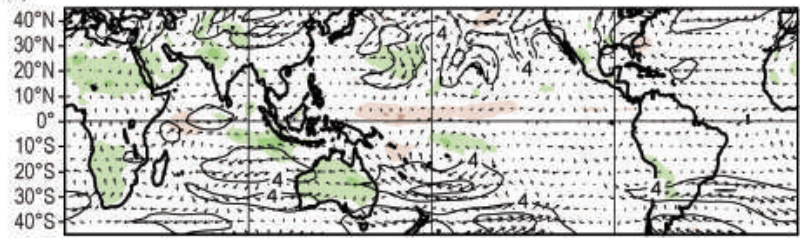

(d)

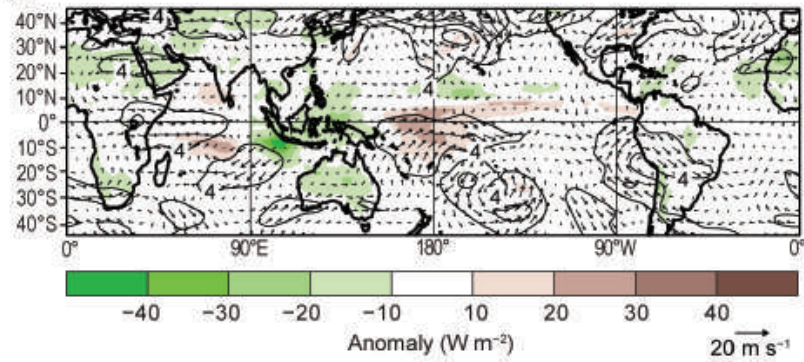

Fig. 4.6. As in Fig. 4.5, but for anomalous $200 \mathrm{hPa}$ wind vectors and speed (contour interval: $4 \mathrm{~m} \mathrm{~s}^{-1}$ ). 
mean subtropical ridges in both hemispheres from Australasia to at least the date line, along with a disappearance of the mid-Pacific troughs normally seen in both hemispheres. In the Northern Hemisphere, the enhanced westerlies reflected both an eastward extension of the East Asian jet stream well east of the date line, and an eastward shift in that jet's exit region to the eastern North Pacific. This wintertime jet stream pattern represents a fundamental manner in which El Niño's circulation impacts are communicated downstream and poleward into the extratropics (Ropelewski and Halpert 1986, 1987, 1989; Harrison and Larkin 1998; Higgins et al. 2002; Chiodi and Harrison 2013).

The El Niño-related conditions were weaker and less extensive in the MAM 2016 averages (Figs. 4.5b, 4.6b) and were no longer present in the JJA 2016 averages (Figs. 4.5c, 4.6c). During SON 2016, the anomaly patterns were reversed from those seen earlier in the year in response to the development of La Niña (Figs. 4.5d, 4.6d). In the tropics, typical La Niña-related signals during SON included: 1) enhanced convection over the Maritime Continent and suppressed convection near the date line, and 2) a Pacific circulation featuring a combination of stronger easterly trade winds at $850 \mathrm{hPa}$ (Fig. 4.5d) and anomalous westerly winds at $200 \mathrm{hPa}$ (Fig. 4.6d). In the subtropics of both hemispheres, typical La Niña impacts included a westward retraction of the mean ridges to the Australasia region, along with enhanced mid-Pacific troughs.

3) EFFECTS ON PRECIPITATION AND TEMPERATURE

Precipitation during January-April (Fig. 4.7a) and October-December (Fig. 4.7b) showed many typical El Niño and La Niña impacts, respectively (Ropelewski and Halpert 1987, 1989). Over the central and east-central equatorial Pacific, El Niño-related rainfall totals were above the 90 th percentile of occurrences during both January and February, and above the 80th percentile of occurrences during March and April (Fig. 4.7c). Overall, the largest precipitation surpluses during January-April were observed near the date line and exceeded $1200 \mathrm{~mm}$ (Fig. 4.7a). Below-normal rainfall then developed across the eastern half of the tropical Pacific by August, and precipitation deficits persisted in association with La Niña during the remainder of the year (Fig. 4.7b). The largest deficits during October-December were centered near the date line and exceeded $400 \mathrm{~mm}$.

The maritime continent (including Indonesia, the Philippines, Papua New Guinea, parts of Malaysia, and Singapore) recorded below-average precipitation during January-April and above-average precipitation during September-December in response to the differing phases of ENSO (Fig. 4.7d). Rainfall deficits
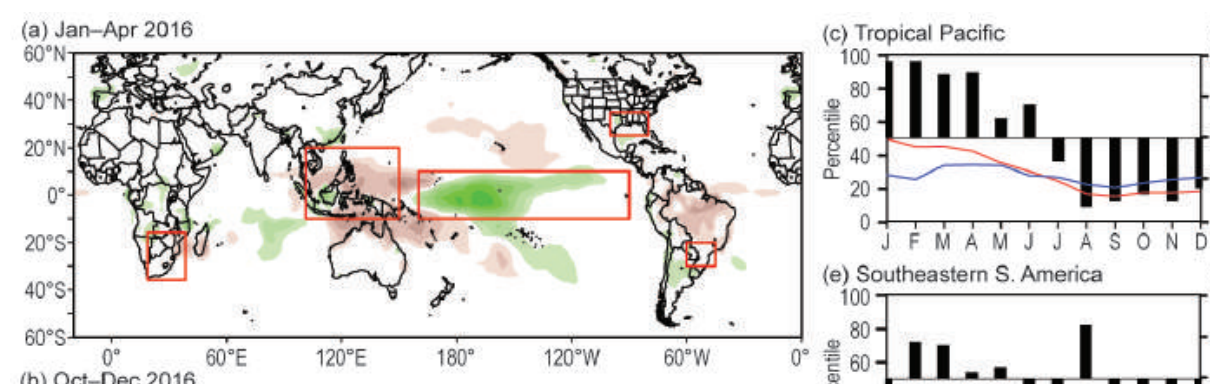

(d) Indonesia

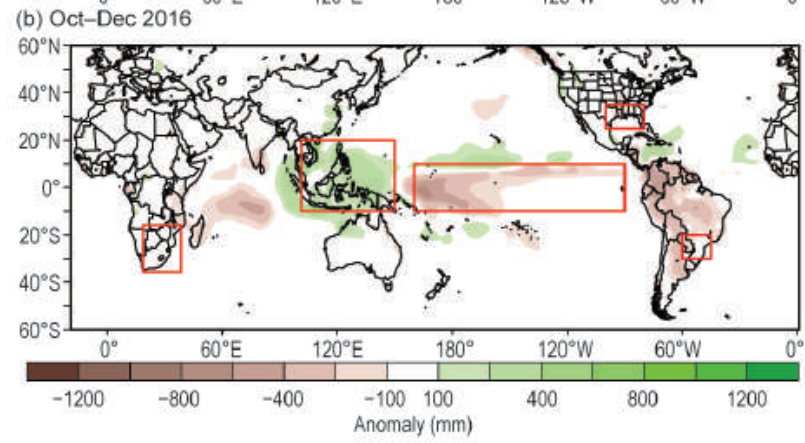

(e) Southeastern S. America
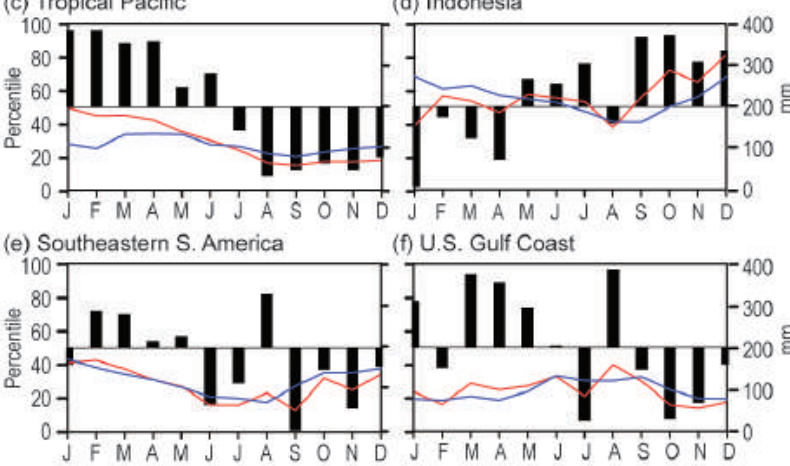

(f) U.S. Gulf Coast

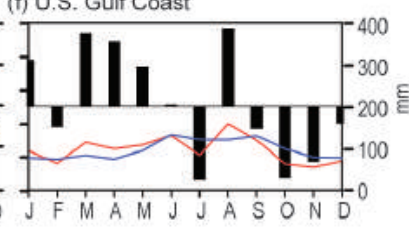

(g) South Africa

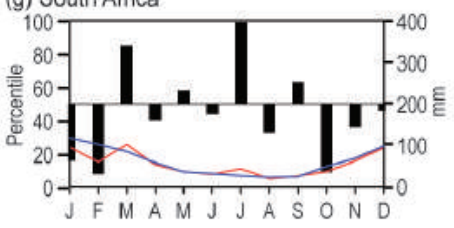

Fig. 4.7. Precipitation anomalies $(\mathrm{mm})$ during 2016: Accumulated precipitation departures during (a) Jan-Apr and (b) Oct-Dec. (c)-(g) Time series of monthly precipitation for each of averaging areas indicated by the red boxes in (a) and (b). Bars show the monthly precipitation percentile percentiles (scale to left of plots), and red and blue lines show monthly observed and climatological mean precipitation (scale to right of plots), respectively. These CAMS-OPI rainfall amounts are obtained by merging rain gauge observations and satellite-derived precipitation estimates (Janowiak and Xie 1999). Precipitation percentiles are based on a gamma distribution fit to the 198I-2010 base period; anomalies are departures from 198I-2010 means. 
during January-April exceeded $200 \mathrm{~mm}$ over much of the region, with many areas recording larger deficits of 400 to $800 \mathrm{~mm}$ (Fig. 4.7a). Conversely, rainfall totals during October-December were more than $200 \mathrm{~mm}$ above average over much of the region (Fig. 4.7b).

Two other regions with consistent ENSO precipitation signals are southeastern South America (Fig. 4.7e) and the Gulf Coast region of the United States (Fig. 4.7f). Both regions during 2016 recorded above-average precipitation during El Niño and below-average precipitation during La Niña. For southeastern South America, large areas recorded totals in the upper 90th percentile of occurrences during DJF 2015/16, followed by totals in the lowest 10th percentile of occurrences during SON 2016. For the US Gulf Coast, totals exceeded the 70th percentile of occurrences in many areas during DJF, and many areas recorded totals in the lowest 10th percentile of occurrences during SON.

The South African monsoon season (OctoberApril) is typically suppressed during El Niño. This region recorded below-average precipitation from October 2015 through February 2016 (Fig. 4.7g; see also Bell et al. 2016).

In the tropical region, the annual temperature for 2016 was the highest on record for the latitude range $24^{\circ} \mathrm{N}-24^{\circ} \mathrm{S}\left(0.96^{\circ} \mathrm{C}\right.$ above the $1951-80$ average, according to the NASA GISS dataset) and for $30^{\circ} \mathrm{N}-30^{\circ} \mathrm{S}$ $\left(0.75^{\circ} \mathrm{C}\right.$ above the $1961-90$ average, according to the HadCRUT4 dataset). Outside of the tropics, typical El Niño surface temperature impacts (Halpert and Ropelewski 1992) early in the year included aboveaverage temperatures across Canada and the northern U.S., southern Africa, and eastern Australia. Typical La Niña surface temperature impacts later in the year included above-average temperatures across the southeastern U.S. and below-average temperatures in Australia.

For more detailed information about region-specific physical and societal impacts caused by ENSO, please refer to Chapter 7 .

\section{c. Tropical intraseasonal activity-S. Baxter, C. Schreck, and} G. D. Bell

Within the Pacific Ocean, the intraseasonal variability during 2016 was dominated by the springtime demise of a strong El Niño, and by three distinct periods of equatorial oceanic Kelvin wave activity (Fig. 4.8). The first period featured an early-year strengthening of El Niño in response to a strong downwelling equatorial oceanic Kelvin wave in January. The second period occurred during July-October as the ocean-atmosphere system was transitioning

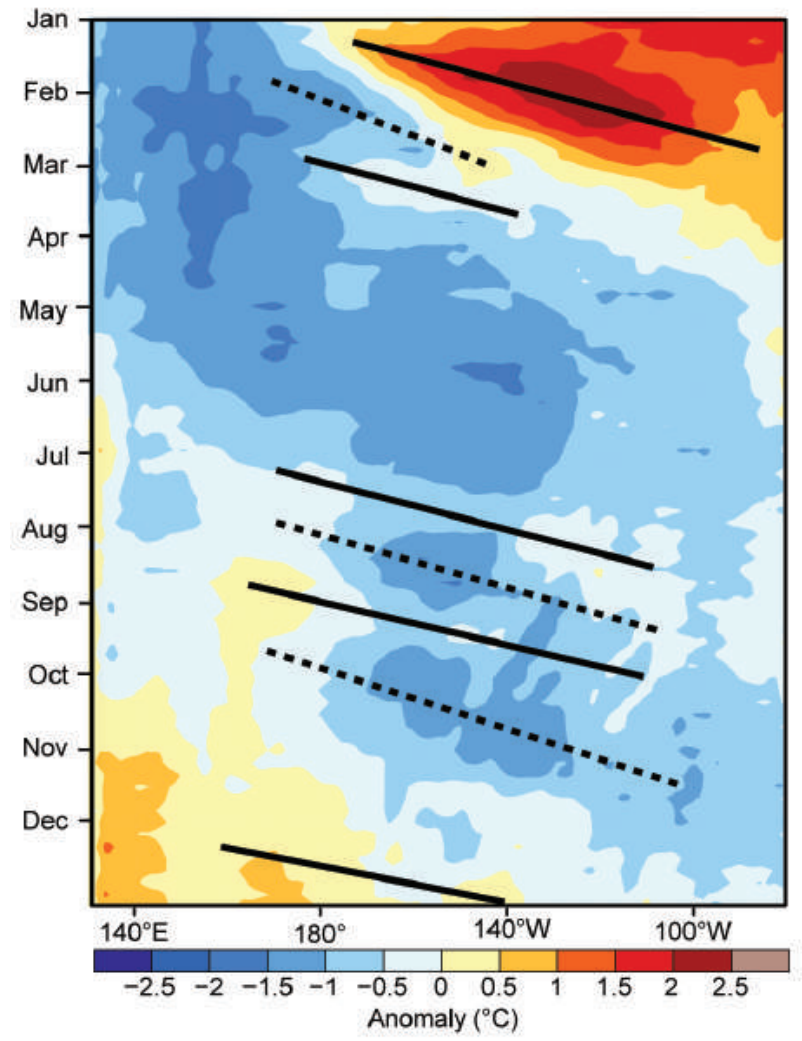

FIG. 4.8. GODAS (Behringer et al. 1998) Timelongitude section for 2016 of the anomalous equatorial Pacific Ocean heat content, calculated as the mean temperature anomaly between $0-300 \mathrm{~m}$ depth and $5^{\circ} \mathrm{N}-5^{\circ} \mathrm{S}$. Yellow/red (blue) shading indicates above- (below-) average heat content. The relative warming (solid lines) and cooling (dashed lines) due to downwelling and upwelling equatorial oceanic Kelvin waves are indicated. Anomalies are departures from 198I-20I0 pentad means.

into La Niña; fluctuations in the oceanic heat content were directly related to these Kelvin waves depicted in Fig. 4.8. The third period occurred in December, when a downwelling Kelvin wave contributed to a weakening of La Niña. A notable period with no equatorial oceanic Kelvin wave activity occurred during mid-March-June, when the Pacific Ocean thermocline was at its shallowest (see Fig. 4.4b).

In the atmosphere, tropical intraseasonal variability was prominent especially during the first half of the year. Two aspects of this intraseasonal variability were the Madden-Julian oscillation (MJO; Madden and Julian 1971, 1972, 1994; Zhang 2005) and convectively coupled equatorial waves (Wheeler and Kiladis 1999; Kiladis et al. 2009), which include equatorial Rossby waves and atmospheric Kelvin waves. There were three distinct periods of MJO activity spanning a total of seven months (Fig. 4.9), which were interspersed with the convectively coupled waves (Fig. 4.10). 


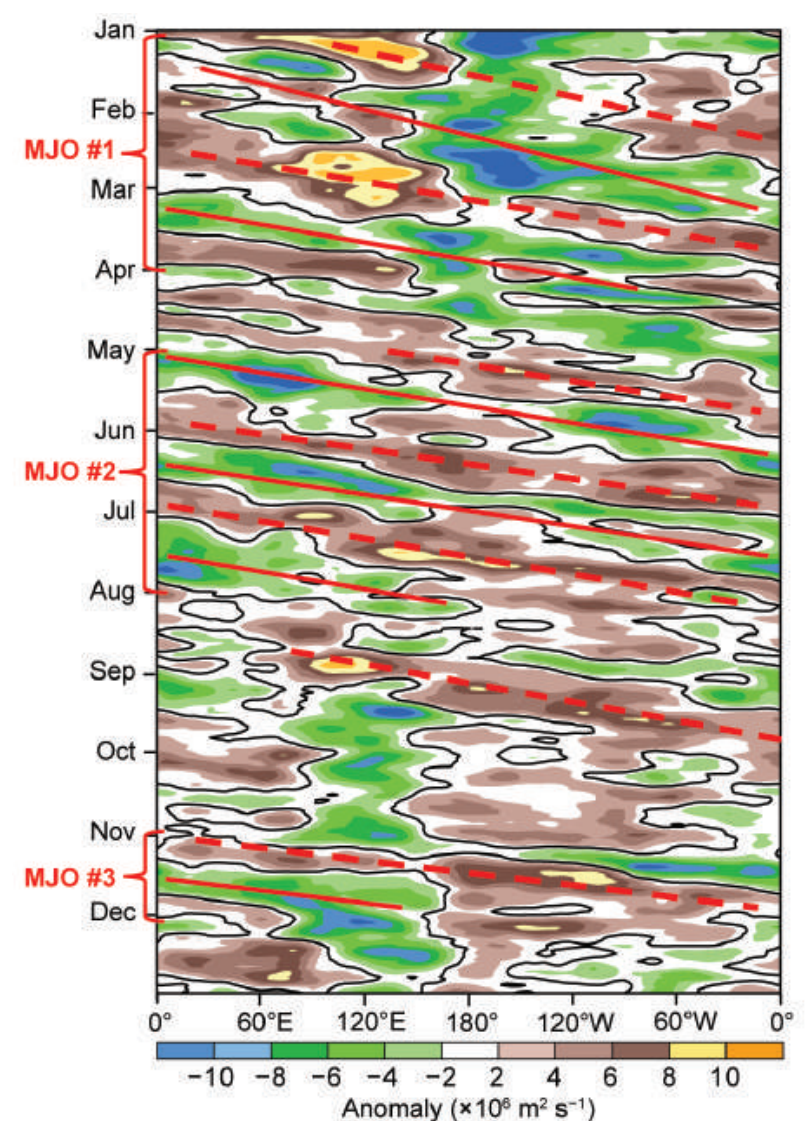

Fig. 4.9. NCEP-NCAR reanlysis (Kalnay et al. 1996) time-longitude section for 2016 of 5-day running anomalous $200-\mathrm{hPa}$ velocity potential $\left(\times 10^{6} \mathrm{~m}^{2} \mathrm{~s}^{-1}\right)$ averaged between $5^{\circ} \mathrm{N}$ and $5^{\circ} \mathrm{S}$. For each day, the period mean is removed prior to plotting. Green (brown) shading highlights likely areas of anomalous divergence and rising motion (convergence and sinking motion). Red lines and labels highlight the main MJO episodes. Anomalies are departures from 198I-2010 daily means.
The MJO is a leading intraseasonal climate mode of tropical convective variability. Its convective anomalies often have the same spatial scale as ENSO but differ in that they exhibit a distinct eastward propagation and generally traverse the globe in 30-60 days. The MJO affects weather patterns around the globe (Zhang 2013), including monsoons (Krishnamurti and Subrahmanyam 1982; Lau and Waliser 2012), tropical cyclones (Mo 2000; Frank and Roundy 2006; Camargo et al. 2009; Schreck et al. 2012), and extratropical circulations (Knutson and Weickmann 1987; Kiladis and Weickmann 1992; Mo and Kousky 1993; Kousky and Kayano 1994; Kayano and Kousky 1999; Cassou 2008; Lin et al. 2009; Riddle et al. 2013; Schreck et al. 2013; Baxter et al. 2014). The MJO is often quite variable in a given year, with periods of moderate-to-strong activity sometimes followed by little or no activity. The MJO tends to be most active during ENSO-neutral and weak El Niño periods and is often absent during strong El Niño events (Hendon et al. 1999; Zhang and Gottschalck 2002; Zhang 2005). Its convection also tends to propagate farther eastward in the Pacific during El Niño events (Picaut et al. 1996).

Common metrics for identifying the MJO include time-longitude plots of anomalous 200 -hPa velocity potential (Fig. 4.9) and outgoing longwave radiation (OLR; Fig. 4.10a), as well as the Wheeler-Hendon (2004) real-time multivariate MJO (RMM) index (Fig. 4.11). In the time-longitude plots, the MJO exhibits eastward propagation. In the RMM, the MJO propagation and intensity are seen as large, counterclockwise circles around the origin. Each of these diagnostics points to three main MJO episodes during 2016. MJO \#1 was a strong episode that began
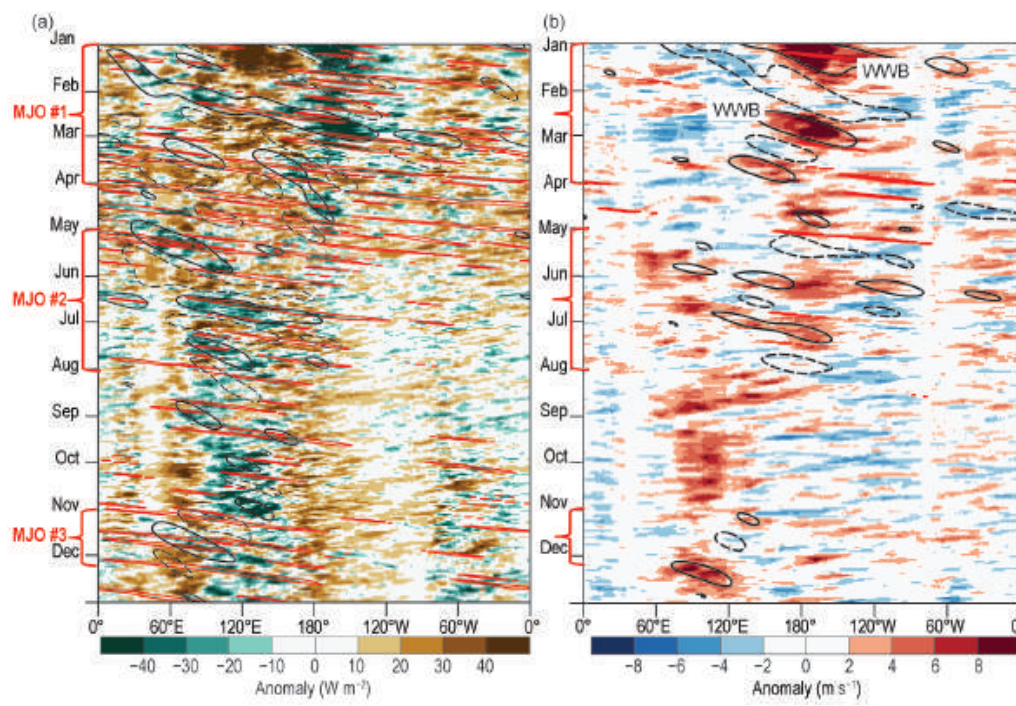

Fig. 4.10. Time-longitude sections for 2016 averaged between $10^{\circ} \mathrm{N}$ and $10^{\circ} \mathrm{S}$ of (a) anomalous OLR (shaded, $\mathrm{W} \mathrm{m}^{-2}$; Lee 2014) with negative anomalies indicating enhanced convection and positive anomalies indicating suppressed convection, and (b) anomalous $850-\mathrm{hPa}$ zonal wind (shaded, $\mathrm{m} \mathrm{s}^{-1}$ ) from CRSR (Saha et al. 2014). In both panels, contours (drawn at $\pm 10 \mathrm{~W} \mathrm{~m}^{-2}$ ) identify anomalies filtered for the MJO (black) and atmospheric Kelvin waves (red) with the enhanced (suppressed) convective phase of these phenomena indicated by solid (dashed) contours. Red labels highlight the main MJO episodes. In (b) significant westerly wind bursts (WWB) that resulted in notable downwelling Kelvin waves are labeled. Anomalies are departures from 198I-2010 daily means. 
(a)

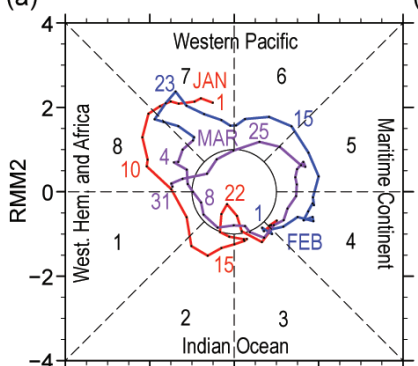

(c)

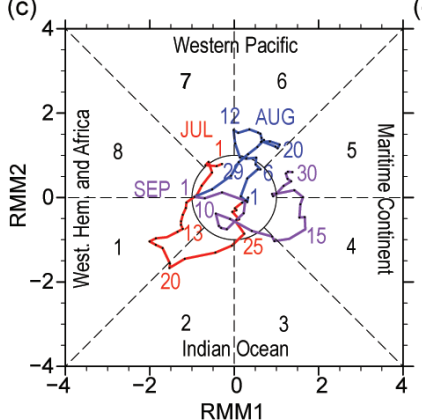

(b)

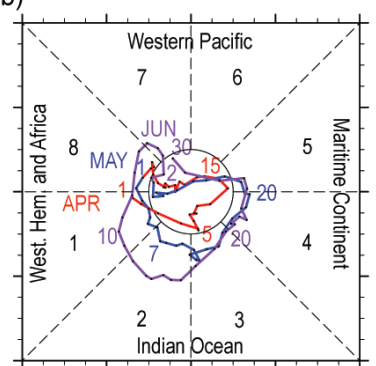

(d)

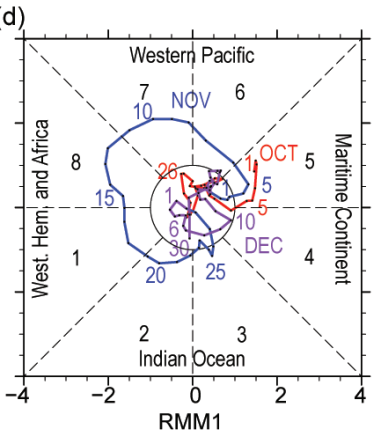

FIG. 4.II. Wheeler-Hendon (2004) RMM index during 2016 for (a) Jan-Mar, (b) Apr-Jun, (c) Jul-Sep, and (d) Oct-Dec. Each point represents the MJO amplitude and location on a given day, and the connecting lines illustrate its propagation. Amplitude is indicated by distance from the origin, with points inside the circle representing weak or no MJO. The eight phases around the origin identify the region experiencing enhanced convection, and counter-clockwise movement reflects eastward propagation. (Source: Australian Bureau of Meteorology.)

in 2015 and continued from January through March 2016. Given that a strong El Niño lasted into early spring 2016, the pronounced MJO activity during this period is notable. MJO \#2 was a weaker but long-lived event that began in May and lasted through July. MJO \#3 was a short-lived event centered on November. The first two MJO events were associated with either westerly wind bursts or trade wind surges over the central Pacific (Fig. 4.10b). These became much less prevalent during the second half of the year, partly due to a strengthening of the easterly trade winds in association with the evolution toward La Niña.

MJO \#1 featured a zonal wave-1 pattern of strong convective anomalies and had a periodicity of approximately 45-50 days (Fig. 4.9). The plot of anomalous velocity potential shows that this event circumnavigated the globe twice, while the RMM index (Fig. 4.11a) indicates that the event was gradually weakening with time. The event ended in April when the convective anomalies became dominated by a series of fast propagating atmospheric Kelvin waves (Fig. 4.10a). This was also when the low-frequency state transitioned out of the El Niño event.

One of the largest impacts from MJO \#1 was its interaction with two high-amplitude equatorial oceanic Kelvin waves (Fig. 4.8). This oceanic Kelvin wave was triggered during January by a westerly wind burst associated with enhanced convection over the central Pacific (Fig. 4.10b). This wave reached the eastern Pacific in late February and March, and it was the last of the strong downwelling Kelvin waves associated with the 2015/16 El Niño. In its wake, MJO \#1's easterly anomalies contributed to the subsequent upwelling Kelvin wave that began the transition toward La Niña.

MJO \#1 also impacted the extratropical circulation, mainly during January, when suppressed convection and anomalous upper-level convergence were present over the eastern Indian Ocean, and enhanced convection and anomalous upper-level divergence were present over the western and central Pacific Ocean (Fig. 4.9). These conditions contributed to a circulation pattern change over North America, wherein the record warmth observed in December 2015 across the southeastern U.S. was replaced with near- to below-normal temperatures for January. MJO \#1 also led to an active period of Southern Hemisphere tropical cyclone activity. Seven storms developed, beginning with Cyclone Corentin in the South Indian Ocean on 21 January and ending with Tropical Storm Yalo in the eastern South Pacific Ocean on 25 February.

MJO \#2 during May-July had its wave-1 signal circumnavigating the globe three times (Figs. 4.9, $4.11 \mathrm{~b}, \mathrm{c}$ ). The phase speed of this event was on the fast side of the MJO envelope, with a period of about 30 days. This event terminated when the anomalous convective pattern became more dominated by lowfrequency variability associated with developing La Niña conditions and a negative phase of the Indian Ocean dipole (Figs. 4.9, 4.10a; Section 4h). This persistent pattern consisted of enhanced convection over the Maritime Continent and suppressed convection over the western and central Pacific.

MJO \#2 played a particularly large role in the tropical cyclone activity over the eastern North Pacific. The convectively suppressed phase of MJO \#2 inhibited tropical cyclone activity during June, while its convectively active phase was associated with a record seven storms during July. Even as MJO \#2 was weakening in August, its remnant convective signal may have played a role in the record-breaking 11 storms that formed over the western North Pacific.

August-October was a period of marked intraseasonal variability in the ocean, if not the atmosphere. A series of alternating upwelling and downwelling oceanic Kelvin waves dominated the oceanic vari- 
ability (Fig. 4.8). The atmospheric variability was less organized in the absence of any significant MJO activity. Nonetheless, periods of sustained westerly anomalies tended to coincide with the downwelling Kelvin waves and easterly anomalies with the upwelling ones (Fig. 4.10b). Finally, November brought the short-lived MJO \#3. The periodicity of this event was also on the shorter end for MJO events at about 30-35 days (Fig. 4.11d). During this period, strong atmospheric Kelvin waves were also present over the eastern Hemisphere (Fig. 4.10a).

\section{d. Intertropical convergence zones}

\section{I) PACIFIC—A. B. Mullan}

Tropical Pacific rainfall patterns are dominated by two convergence zones: the intertropical convergence zone (ITCZ; Schneider et al. 2014) and the South Pacific convergence zone (SPCZ; Vincent 1994). The North Pacific ITCZ lies between $5^{\circ}$ and $10^{\circ} \mathrm{N}$ and is most active from August to December. During this period, it lies at its northernmost position and also displays more of an east-northeastward tilt. The SPCZ extends southeastward from around Solomon Islands $\left(10^{\circ} \mathrm{S}, 160^{\circ} \mathrm{E}\right)$ to near $30^{\circ} \mathrm{S}, 140^{\circ} \mathrm{W}$ and is most active in November-April. The two convergence zones, which merge into the monsoon trough west of $150^{\circ} \mathrm{E}$, are strongly influenced by ENSO; the 2016 transition from strong El Niño to weak La Niña provides a classic example of this influence.

Figure 4.12 summarizes the convergence zone behavior for 2016 and compares the 2016 seasonal variation against the longer-term (1998-2015) climatology. Rainfall transects from $20^{\circ} \mathrm{N}$ to $30^{\circ} \mathrm{S}$ are presented for each quarter of the year, averaged across successive $30^{\circ}$ longitude bands, starting in the western $\mathrm{Pa}$ cific at $150^{\circ} \mathrm{E}-180^{\circ}$. Due to the end of the availability of TRMM satellite in mid-2015, the rainfall data analyzed are from NOAA's CPC morphing technique (CMORPH) global precipitation analysis (Joyce et al. 2004). This dataset, derived from low orbiter satellite microwave observations, is available at the same $0.25^{\circ}$ resolution as the TRMM 3B43 used previously (e.g., Mullan
2014). Although not identical, CMORPH and TRMM 3B43 rainfall are very similar in pattern and magnitude at the broad scale discussed here.

Figures 4.13 and 4.14 extend the comparison for the $180^{\circ}-150^{\circ} \mathrm{W}$ sector, showing smoothed rainfall transects for all years of the CMORPH data from 1998, for January-March and October-December when ENSO influences are largest as documented in Section 4b. Additionally, after an erratic start, La Niña conditions eventually established themselves by the end of October 2016, with the NASA ENSO precipitation index (ESPI; Curtis and Adler 2000) reaching -1.8 at this time.

Figures $4.12,4.13$, and 4.14 show typical ENSO displacement of the convergence zones, well-supported by rainfall observations from Pacific Islands (not shown). In January-March (Figs. 4.12, 4.13), both the ITCZ and SPCZ were located closer to the equator than normal, with substantially higher-than-normal rainfall at the peak latitude; this was especially marked from the date line eastward to $120^{\circ} \mathrm{W}$ in both hemispheres. Conversely, rainfall was reduced on the poleward side of both convergence zones. Figure 4.13 shows that January-March had the steepest rainfall decline with latitude, north of the equator, of any year in the CMORPH dataset. The Northern Hemisphere peak rainfall, between approximately $3^{\circ}-4^{\circ} \mathrm{N}$ in this smoothed representation, was also higher than any
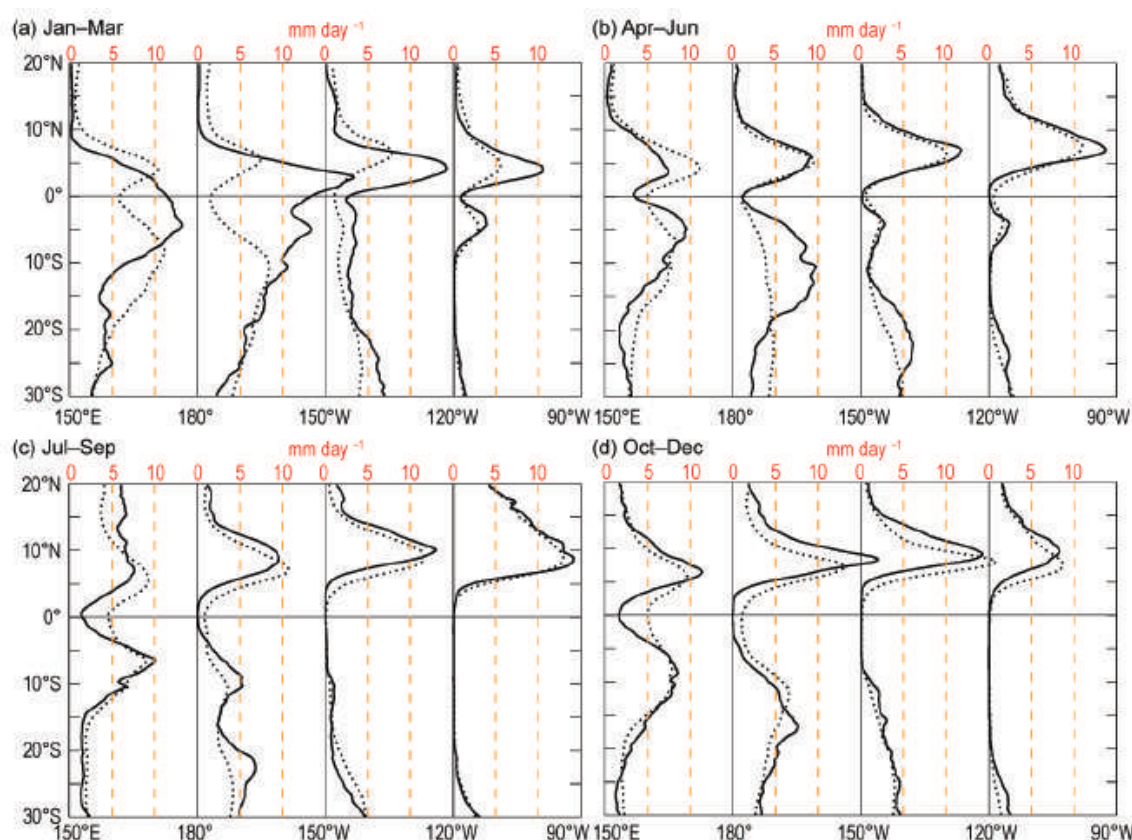

(d) Oct-Dec

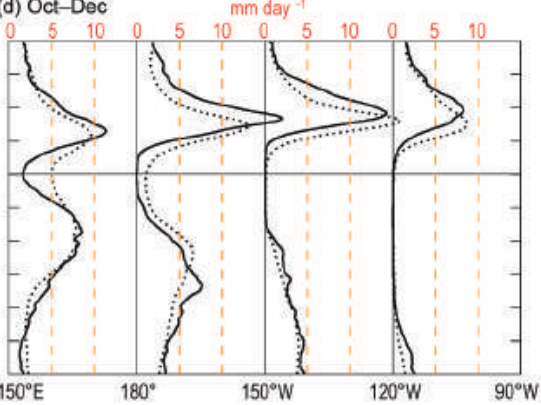

FIG. 4.I2. (a)-(d) Rainfall rate $\left(\mathrm{mm} \mathrm{day}^{-1}\right)$ from CMORPH analysis for the four quarters of 2016. The separate panels for each quarter show the 2016 rainfall cross-section between $20^{\circ} \mathrm{N}$ and $30^{\circ} \mathrm{S}$ (solid line) and the 1998-20I5 climatology (dotted line), separately for four $30^{\circ}$ sectors from $150^{\circ} \mathrm{E}-180^{\circ}$ to $120^{\circ}-90^{\circ} \mathrm{W}$. 


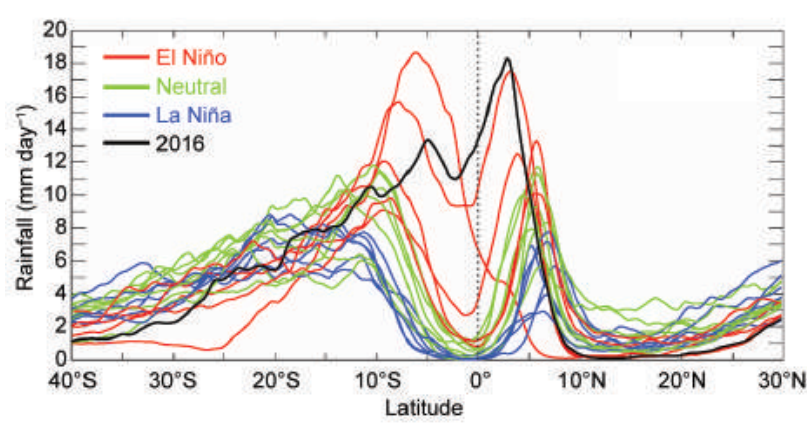

FIG. 4.13. CMORPH rainfall rate ( $\left.\mathrm{mm} \mathrm{day}^{-1}\right)$ for JanMar quarters for each year 1998 to 2016 , averaged over the longitude sector $180^{\circ}-150^{\circ} \mathrm{W}$. The cross-sections are color-coded according to NOAA's ONI, except for 2016 (an El Niño quarter) shown in black.

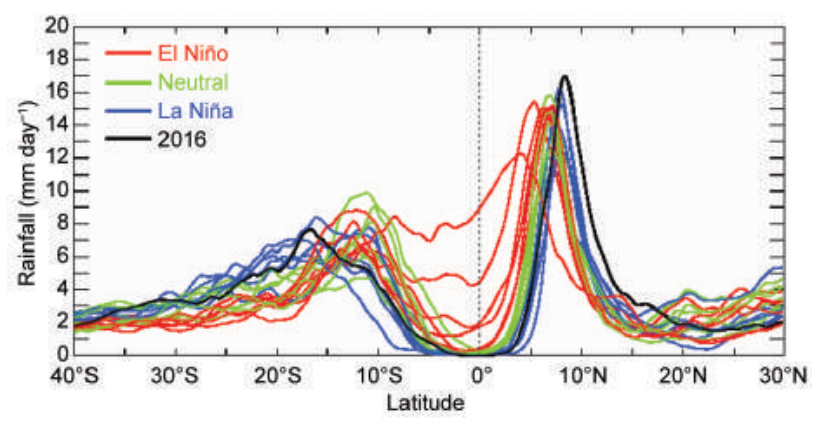

FIG. 4.I4. CMORPH rainfall rate $\left(\mathrm{mm} \mathrm{day}^{-1}\right)$ for OctDec quarters, for each year 1998 to 2016 , averaged over the longitude sector $180^{\circ}-150^{\circ} \mathrm{W}$. The cross-sections are color-coded according to NOAA's ONI, except for 2016 (a La Niña quarter) shown in black.

other year in the dataset (although close to the peak rainfall of January-March 2010, another El Niño season).

Not surprisingly, many off-equator islands in the Pacific experienced drought conditions during the early part of 2016 (Fig. 4.7). In the Northern Hemisphere, very dry conditions were experienced in January through April across much of Micronesia and into Hawaii, which is typical of the post-peak phase of a strong El Niño. The more northern islands fared worse than those closer to the equator. For example, April 2015 to March 2016 was the driest on record in parts of Palau (Koror; $7.3^{\circ} \mathrm{N}, 134.5^{\circ} \mathrm{E}$ ), Yap State (Woleai; $7.4^{\circ} \mathrm{N}, 143.9^{\circ} \mathrm{E}$ ), and the Marshall Islands (Jaluit; $6.0^{\circ} \mathrm{N}, 169.5^{\circ} \mathrm{E}$ ), as reported in the May 2016 Pacific ENSO Update (www.weather.gov/media/peac /PEU/PEU_v22_n2.pdf).

In the Southern Hemisphere, rainfall was much lower than normal in many of the early months of the year as documented in more detail in Chapter 7. With the collapse of El Niño conditions in April-June, the two convergence zones behaved differently. The ITCZ showed a poleward displacement from May onwards (a La Niña signature), whereas the SPCZ remained unusually active for the time of year and maintained its equatorward displacement through the season (Fig. 4.12b). In July-September (Fig. 4.12c), the SPCZ convection had subsided and the ITCZ continued a more pronounced poleward displacement from its climatological position as weak La Niña conditions developed (see Section $4 \mathrm{~b}$ ).

In October-December (Figs. 4.12d, 4.14) the poleward displacement of the ITCZ was quite marked. Despite of the La Nina being categorized as weak, Fig. 4.14 suggests that the peak rainfall $\left(\right.$ near $8^{\circ} \mathrm{N}$ ) in the $180^{\circ}-150^{\circ} \mathrm{W}$ sector was the highest in the CMORPH dataset, with the ITCZ also displaced farther north between $10^{\circ} \mathrm{N}$ and $15^{\circ} \mathrm{N}$ than in any other year. The prolonged El Niño-related dry spell was finally broken in the Marshall Islands during October-December, with well-above-average rainfall in the northern atolls such as Kwajalein $\left(8.7^{\circ} \mathrm{N}\right.$, $\left.167.7^{\circ} \mathrm{E}\right)$.

\section{2) Atrantic-A. B. Pezza and C. A. S. Coelho}

The Atlantic ITCZ is a well-organized convective band that oscillates approximately between $5^{\circ}-12^{\circ} \mathrm{N}$ during July-November and $5^{\circ} \mathrm{N}-5^{\circ} \mathrm{S}$ during JanuaryMay (Waliser and Gautier 1993; Nobre and Shukla 1996). Equatorial atmospheric Kelvin waves can modulate the ITCZ intraseasonal variability (Guo et al. 2014). ENSO and the southern annular mode (SAM) also influence the ITCZ on the interannual time scale (Münnich and Neelin 2005). The SAM is typically negative during El Niño events, but it was generally positive in 2016 despite the strong El Niño in 2015/16. This disconnect helps explain the mixed hemispheric response (L'Heureux et al. 2016).

In South America, extensive dry conditions occurred in southern Brazil in January. Meanwhile, excessive rain fell over the northeastern sector, which typically experiences rainfall deficits during El Niño events. Abnormally dry conditions returned for most of the tropical basin from February onwards as the El Niño dissipated (Figs. 4.15, 4.16). These dry conditions were associated in part with relatively warmerthan-normal waters in the western half of the North Atlantic sector (see Münnich and Neelin 2005). As a result, the Atlantic index, defined in Fig. 4.17 as the north-south sea surface temperature gradient, was moderately positive (Fig. 4.17a). The ITCZ tends to shift toward the warmer side of this gradient, and indeed it was generally north of its climatological position during 2016. The Southern Hemisphere lacked organized deep convection even during the sporadic southerly ITCZ bursts in early April (Fig. 4.17b). However, given the modest magnitude of the Atlantic 

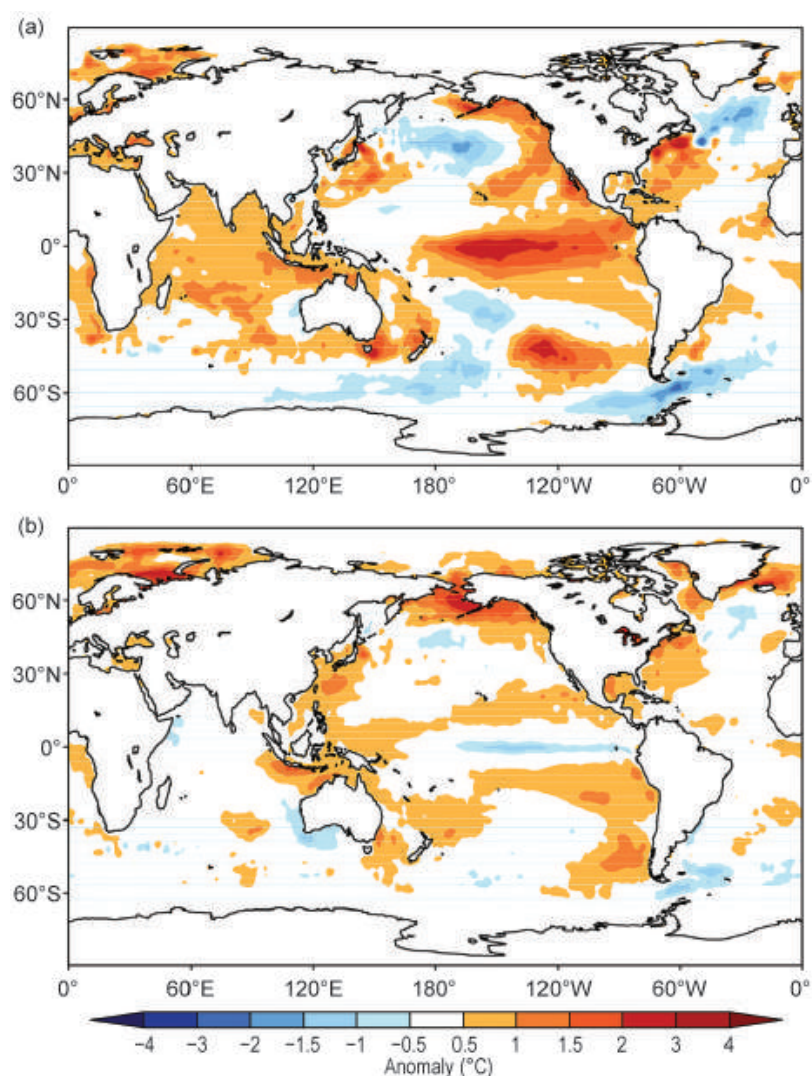

FIG. 4.I5. Spatial distribution of 2016 average global SST anomalies ( ${ }^{\circ} \mathrm{C}$; Reynolds et al. 2002) for (a) JanApr and (b) May-Dec.

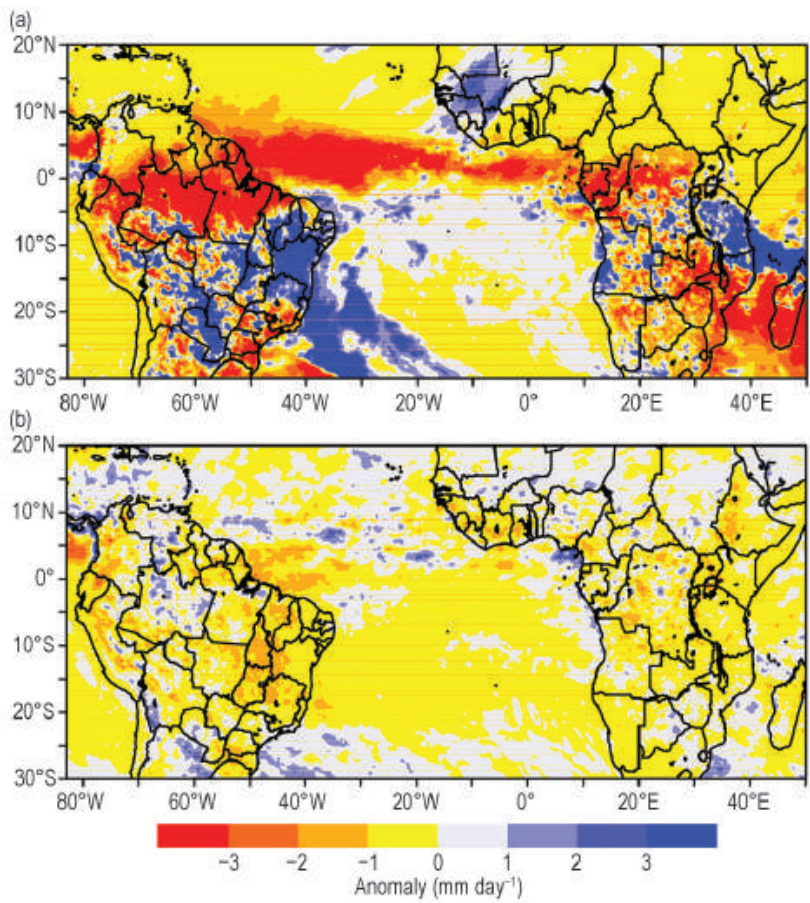

FIG. 4.16. Observed 2016 precipitation anomalies for $\left(\mathrm{mm} \mathrm{day}{ }^{-1}\right)$ tropical and subtropical South America during (a) Jan and (b) Feb-Dec 2016. Anomalies calculated based on a 1998-20I5 climatology derived from CMORPH (Joyce et al. 2004).
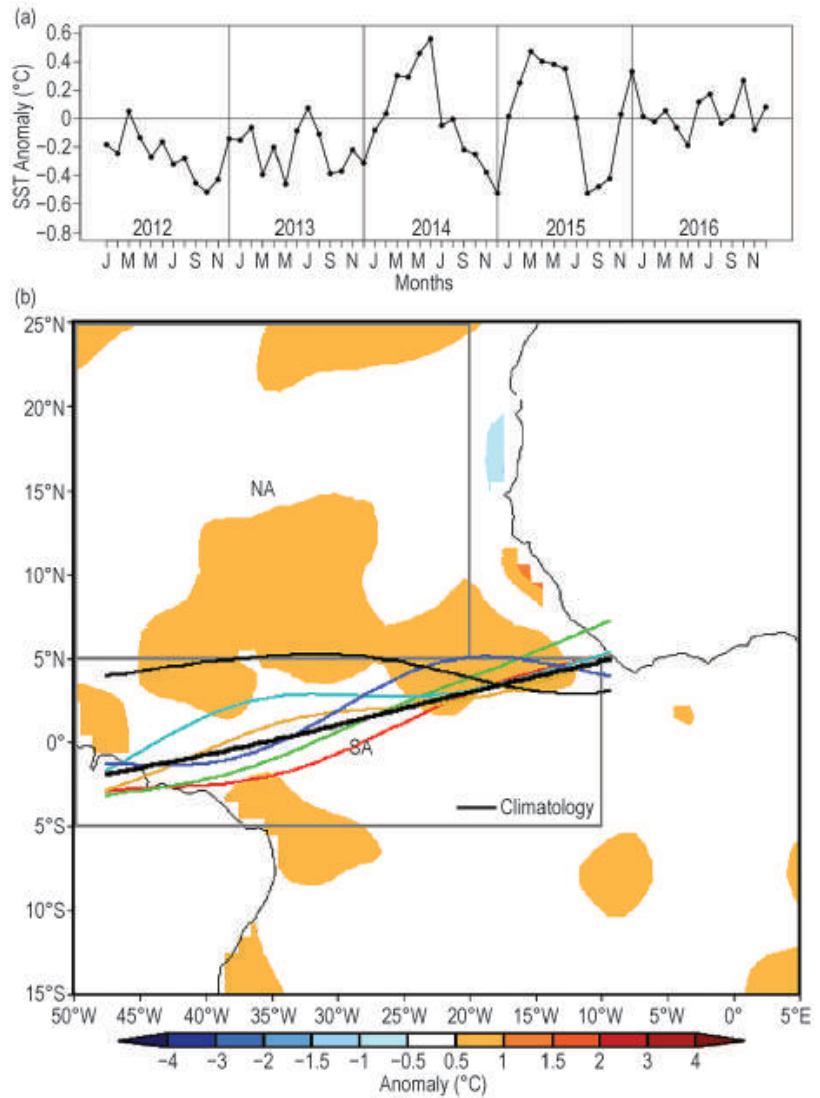

FIG. 4.I7. (a) Monthly OISST (Smith et al. 2008) anomaly time series averaged over the South American sector (SA region, $10^{\circ}-50^{\circ} \mathrm{W}, 5^{\circ} \mathrm{S}-5^{\circ} \mathrm{N}$ ) minus the SST anomaly time series averaged over the North Atlantic sector (NA region, $20^{\circ}-50^{\circ} \mathrm{W}, 5^{\circ}-25^{\circ} \mathrm{N}$ ) for the period 2012-16, forming the Atlantic index. The positive phase of the index indicates favorable conditions for enhanced Atlantic ITCZ activity. (b) Atlantic ITCZ position inferred from OLR (Liebmann and Smith 1996) during Apr 2016. The colored thin lines indicate the approximate position for the six pentads of the month. The black thick line indicates the Atlantic ITCZ climatological position for April. The SST anomalies for Apr 2016 based on the 1982-2015 climatology are shaded $\left({ }^{\circ} \mathrm{C}\right)$. The two boxes indicate the areas used for the calculation of the Atlantic index in (a).

index, other factors likely contributed to the magnitude and extent of the drought.

Precipitation deficits across much of tropical and equatorial South America persisted after widespread drought within most of the Amazon and central Brazil, a feature already noted in Blunden and Arndt (2016) and in preceding editions of this chapter (Fig. 4.7). Persistently low vegetation health indices and reduced soil moisture most likely contributed to lowering the evapotranspiration and relative humidity, facilitating higher temperatures. This large-scale drought pattern extended into southeastern Brazil in recent years (Coelho et al. 2016a,b). Remarkably, this 
dry pattern was already established before the latest El Niño event onset and remained in place after its termination. Recent research has attempted to assess if droughts in different parts of Brazil could be either part of a longer-term natural oscillation or attributed to anthropogenic forcing associated with climate change (Otto et al. 2015).

\section{e. Global monsoon summary-B. Wang}

The global monsoon is the dominant mode of annual variation of tropical-subtropical precipitation and circulation (Wang and Ding 2008) and thus a defining feature of seasonality and a major mode of variability of Earth's climate system. Figure 4.18 summarizes the monsoon rainfall anomalies for November 2015-October 2016-the global monsoon year that includes both the Southern Hemisphere summer monsoon from November 2015 to April 2016, and the Northern Hemisphere summer monsoon from May to October 2016.

TABLE 4.I. (Modified from Yim et al. 2014). Definition of the regional summer monsoon circulation indices and their correlation coefficients (CCs) with the corresponding regional summer monsoon precipitation indices for the period 1979-2015. All circulation indices are defined by meridional shear of zonal winds at $850-\mathrm{hPa}$ which measures the intensity (relative vorticity) of the monsoon toughs at $850 \mathrm{hPa}$ except for the northern African (NAF) and East Asian (EASM). The NAF monsoon circulation index is defined by the westerly monsoon strength: $\mathrm{U} 850\left(0^{\circ}-15^{\circ} \mathrm{N}, 60^{\circ}-10^{\circ} \mathrm{W}\right)$ and the EASM circulation index is defined by the meridional wind strength: $\mathrm{V} 850\left(20^{\circ}-40^{\circ} \mathrm{N}, 120^{\circ}-140^{\circ} \mathrm{E}\right)$ which reflects the east-west thermal contrast between the Asian continent and western North Pacific. The precipitation indices are defined by the areal mean precipitation over the blue box regions shown in Fig. 4.18. The correlation coefficients were computed using monthly time series (I48 summer months) (June to September (JJAS) in NH (1979-2015) and December to March (DJFM) in SH (1979/80-2015/16). The bolded numbers represent significance at $99 \%$ confidence level.

\begin{tabular}{|c|c|c|}
\hline Region & $\begin{array}{c}\text { Definition of the Circulation } \\
\text { Index }\end{array}$ & CC \\
\hline Indian (ISM) & $\begin{array}{l}\text { U850 }\left(5^{\circ}-15^{\circ} \mathrm{N}, 40^{\circ}-80^{\circ} \mathrm{E}\right) \text { minus } \\
\text { U850 }\left(25^{\circ}-35^{\circ} \mathrm{N}, 70^{\circ}-90^{\circ} \mathrm{E}\right)\end{array}$ & 0.73 \\
\hline $\begin{array}{l}\text { Western North } \\
\text { Pacific (WNPSM) }\end{array}$ & $\begin{array}{l}\text { U850 }\left(5^{\circ}-15^{\circ} \mathrm{N}, 100^{\circ}-130^{\circ} \mathrm{E}\right) \text { minus } \\
\quad \mathrm{U} 850\left(20^{\circ}-35^{\circ} \mathrm{N}, 110^{\circ}-140^{\circ} \mathrm{E}\right)\end{array}$ & 0.76 \\
\hline East Asian (EASM) & $\operatorname{V8} 80\left(20^{\circ}-40^{\circ} \mathrm{N}, 120^{\circ}-140^{\circ} \mathrm{E}\right)$ & 0.73 \\
\hline $\begin{array}{l}\text { North American } \\
\text { (NASM) }\end{array}$ & $\begin{array}{l}\text { U850 }\left(5^{\circ}-15^{\circ} \mathrm{N}, 130^{\circ}-100^{\circ} \mathrm{W}\right) \text { minus } \\
\text { U850 }\left(20^{\circ}-30^{\circ} \mathrm{N}, 110^{\circ}-80^{\circ} \mathrm{W}\right)\end{array}$ & 0.85 \\
\hline $\begin{array}{l}\text { Northern African } \\
\text { (NAFSM) }\end{array}$ & $\mathrm{U} 850\left(0^{\circ}-15^{\circ} \mathrm{N}, 60^{\circ}-10^{\circ} \mathrm{W}\right)$ & 0.71 \\
\hline $\begin{array}{l}\text { South American } \\
\text { (SASM) }\end{array}$ & $\begin{array}{l}\text { U850 }\left(5^{\circ}-20^{\circ} \mathrm{S}, 70^{\circ}-40^{\circ} \mathrm{W}\right) \text { minus } \\
\text { U850 }\left(20^{\circ}-35^{\circ} \mathrm{S}, 70^{\circ}-40^{\circ} \mathrm{W}\right)\end{array}$ & 0.80 \\
\hline $\begin{array}{l}\text { Southern African } \\
\text { (SAFSM) }\end{array}$ & $\begin{array}{l}\text { U850 }\left(0^{\circ}-15^{\circ} \mathrm{S}, 10^{\circ}-40^{\circ} \mathrm{E}\right) \text { minus } \\
\text { U850 }\left(10^{\circ}-25^{\circ} \mathrm{S}, 40^{\circ}-70^{\circ} \mathrm{E}\right)\end{array}$ & 0.56 \\
\hline Australian (AUSSM) & $\begin{array}{l}\text { U850 }\left(0^{\circ}-15^{\circ} \mathrm{S}, 90^{\circ}-130^{\circ} \mathrm{E}\right) \text { minus } \\
\text { U850 }\left(20^{\circ}-30^{\circ} \mathrm{S}, 100^{\circ}-140^{\circ} \mathrm{E}\right)\end{array}$ & 0.89 \\
\hline
\end{tabular}
exceeding $55 \%$ of the total annual precipitation amount (Wang and Ding 2008). Here the local summer denotes May-Sep for the NH and Nov-Mar for the SH. The precipitation indices for each regional monsoon are defined by the areal mean precipitation in the corresponding rectangular regions (dashed blue), which are highly correlated with the precipitation averaged over the corresponding real regional monsoon domains (Table 4.I in Yim et al. 2014). The rainfall data were taken from the GPCP analysis from Jan 1979 to Aug 2016 (Huffman et al. 2009) and CMAP from Sep to Oct 2016 (Xie and Arkin 1997).

The global land monsoon precipitation is strongly influenced by ENSO, especially the land areas of Asia, Australia, northern Africa, and Central America (Wang et al. 2012). From November 2015 to October 2016, the equatorial Pacific SSTs evolved from a peak phase of the strong El Niño 2015/16 to the weak La Niña in October 2016.

During Southern Hemisphere summer (November 2015-April 2016), correspond- 
ing to the peak phase of the El Niño, the Southern Hemisphere summer monsoon precipitation was severely suppressed. Deficient rainfall prevailed over the Maritime Continent and Australian monsoon region (except for a narrow band along the equator), the ITCZ in the western and central Pacific, the South Pacific convergence zone, Brazil, and the western Atlantic ITCZ. On the other hand, enhanced precipitation occurred over the equatorial Pacific from $160^{\circ} \mathrm{E}$ to $100^{\circ} \mathrm{W}$, central Indian Ocean, and southeastern China (Fig. 4.18a). The Southern Hemisphere summer monsoon was deficient, mainly due to the drought conditions over the Australian and South American monsoon regions.

During Northern Hemisphere summer (May-October 2016), the precipitation in the equatorial region tended to be reversed. Enhanced rainfall is found over the Maritime Continent, east Asian subtropical region, eastern equatorial Indian Ocean, and the ITCZ in the North Pacific. Meanwhile suppressed rainfall was seen in the equatorial Pacific from $150^{\circ} \mathrm{E}$ to $80^{\circ} \mathrm{W}$, the central-western Indian Ocean, South Pacific convergence zone, and the North and Central American, Venezuelan, and South Asia monsoon regions (Fig. 4.18b).

Figure 4.19 shows the time series of the monsoon precipitation and lower tropospheric circulation indices for each regional monsoon season. Note that the precipitation indices represent the total amount of precipitation over both land and ocean. The definitions of circulation indices for each monsoon region are shown in Table 4.1. The precipitation and circulation indices together represent the strength of each regional monsoon system. As discussed above, from November 2015 to April 2016 during the peak El Niño, all three Southern Hemisphere regional monsoons were weak and rainfall was deficient, especially, for the Australian and South American monsoons (Figs. 4.19f-h). During May (e) NAFSM

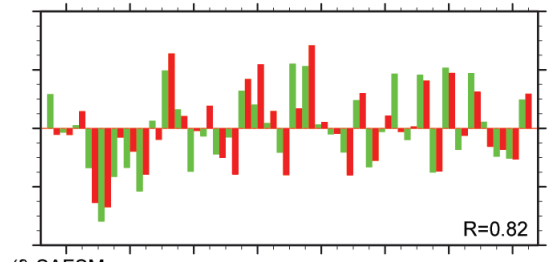

(f) SAFSM

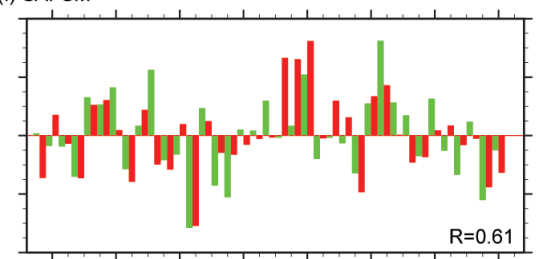

(g) SASM

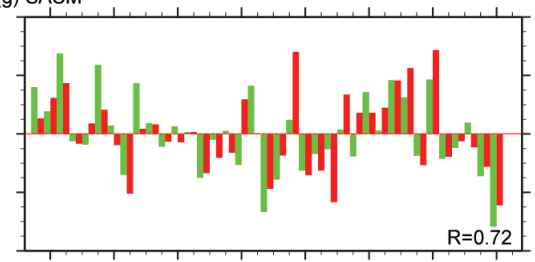

(h) AUSSM

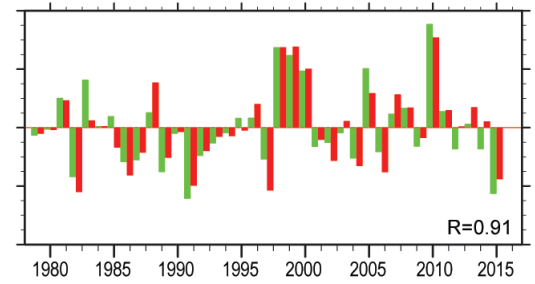

FIG. 4.19. Normalized summer mean precipitation (green) and circulation (red) indices in each of eight regional monsoons defined in Table 4.I. The indices are normalized by their corresponding std. dev. The numbers shown in the corner of each panels denote the correlation coefficient between seasonal mean precipitation and circulation indices. Here the summer denotes May-Oct for the NH and Nov-Apr for the SH. [Source: GPCP (Jan 1979-Aug 2016) and CMAP (Sep-Oct 2016).]

to October, the North American summer monsoon, mainly over Central America and Venezuela, shows moderate negative anomalies (Fig. 4.19d); while the East Asian and northern African summer monsoon are stronger than normal (Figs. $4.19 \mathrm{c}, \mathrm{e}$ ). China experienced heavy flooding from south to north as reflected by the conspicuous positive May-October mean rainfall anomalies (Fig. 4.19c). Over India, the circulation index is high but the rainfall index is normal (Fig. 4.19a). The total strength of the Northern Hemisphere summer monsoon is slightly above normal. Note that these results pertain to the summer mean monsoon strength. Over the Indian and western North Pacific summer monsoon regions, there were large month-to-month fluctuations due to intraseasonal oscillations. 


\section{f. Tropical cyclones}

I) OvervieW-H. J. Diamond and C. J. Schreck

The IBTrACS dataset comprises historical tropical cyclone (TC) best-track data from numerous sources around the globe, including all of the WMO Regional Specialized Meteorological Centers (RSMC; Knapp et al. 2010). IBTrACS represents the most complete compilation of global TC data and offers a unique opportunity to revisit the global climatology of TCs. Using IBTrACS data (Schreck et al. 2014) a 30-year average value for storms (from WMO-based RSMC numbers) is noted for each basin.

The tallying of the global TC numbers is challenging and involves more than simply adding up basin totals, because some storms cross TC basin boundaries, some TC basins overlap, and multiple agencies are involved in tracking and categorizing the TCs.

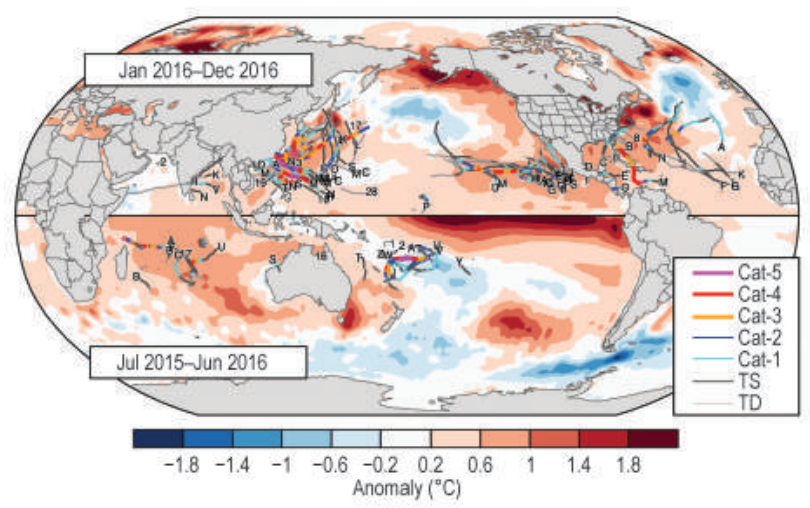

FIG. 4.20. Global summary of TC tracks with respect to SST anomalies ( ${ }^{\circ} \mathrm{C}$ ) for the 2016 TC season.

Compiling the activity using preliminary IBTrACS data over all seven TC basins (Fig. 4.20), the 2016 season (2015/16 in the Southern Hemisphere) had 93

\section{SIDEBAR 4.I: RECORD-SETTING NORTH ATLANTIC HURRICANE MATTHEW-P. J. KLOTZBACH}

The 2016 North Atlantic hurricane season was the first above-average Atlantic hurricane season based on the NOAA definition since 2012. The most notable storm of 2016, in terms of intensity, longevity, damage, and fatalities was Hurricane Matthew. Matthew formed from a tropical wave as it neared the Lesser Antilles, and over the course of the following 12 days, it cut a path of devastation across portions of Hispaniola, Cuba, the Bahamas, and then along the U.S. southeast coast before finally becoming post-tropical. In this sidebar, several of Hurricane Matthew's most notable meteorological records are highlighted. All statistics for Matthew listed are from the operational b-decks, which are utilized to initialize the numerical model guidance on tropical cyclones in real-time every six hours. The b-decks are available at http://ftp.nhc .noaa.gov/atcf/btk. Historical statistics are calculated from the HURDAT2 database, which provides six-hourly estimates of historical Atlantic tropical cyclone wind speeds, pressures, and locations since 185I (Landsea and Franklin 2013).

After being named a tropical storm on 28 September, Matthew steadily intensified. Beginning 30 September, however, Matthew rapidly intensified, reaching category 5 strength with one-minute sustained winds of $140 \mathrm{kt}\left(72 \mathrm{~m} \mathrm{~s}^{-1}\right)$ on I October (Fig. SB4.I). In the 24 hours leading up to reaching category 5 strength, Matthew intensified by $70 \mathrm{kt}\left(36 \mathrm{~m} \mathrm{~s}^{-1}\right)$, the third fastest 24-hour intensification in the Atlantic basin on record, trailing only the 24-hour rapid intensification rates of Hurricane Wilma (2005) and Hurricane Felix (2007). Matthew was also the first category 5 hurricane in the Atlantic basin since Hurricane Felix (2007). In addition, it reached category 5

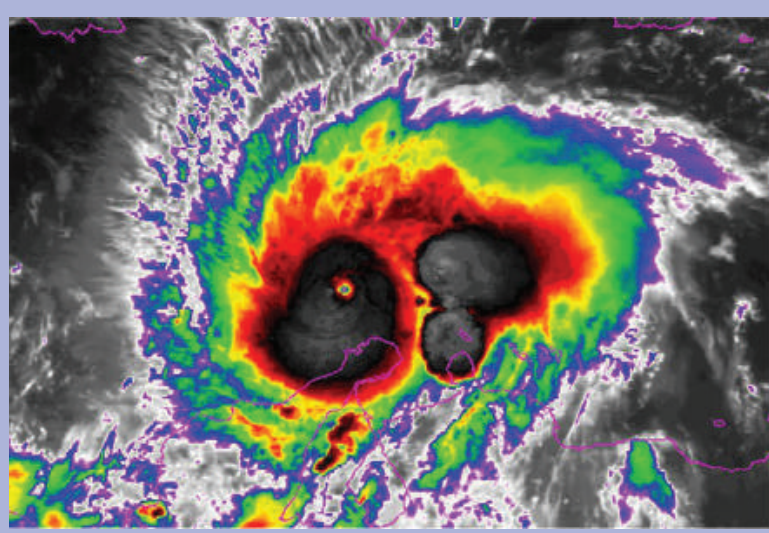

FIG. SB4.I. Infrared satellite image of Hurricane Matthew from GOES-East at near peak intensity at 0800 UTC I Oct 2016.

intensity at an unusually low latitude for an Atlantic hurricane: Matthew became a category 5 at $13.3^{\circ} \mathrm{N}$, the lowest latitude Atlantic category 5 hurricane on record, breaking the old record of $13.7^{\circ} \mathrm{N}$ set by Hurricane Ivan (2004).

While Matthew only maintained category 5 intensity for 12 hours, it was notable for its longevity at category 4-5 strength, especially during the latter part of the Atlantic hurricane season. Matthew was a category 4-5 hurricane for 102 hours in October, the longest an Atlantic hurricane has maintained that intensity on record during October. Due to its intense nature and slow movement, Matthew generated the most ACE (Bell et al. 2000) by any Atlantic tropical cyclone on record in the eastern Caribbean $\left(\leq 20^{\circ} \mathrm{N}, 75^{\circ}-60^{\circ} \mathrm{W}\right)$. Matthew was also a major hurricane for over seven days, the 
named storms (wind speeds $\geq 34 \mathrm{kt}$ or $17 \mathrm{~m} \mathrm{~s}^{-1}$ ), which is above the 1981-2010 average of 82 TCs (Schreck et al. 2014), but eight fewer than the 2015 total of 101 TCs (Diamond and Schreck 2016). The 2016 season also featured 58 hurricanes/typhoons/cyclones (HTC; wind speeds $\geq 64 \mathrm{kt}$ or $33 \mathrm{~m} \mathrm{~s}^{-1}$ ), which is above the 1981-2010 average of 46 HTCs (Schreck et al. 2014). Twenty storms reached major HTC status (wind speeds $\geq 96 \mathrm{kt}$ or $49 \mathrm{~m} \mathrm{~s}^{-1}$ ), which is near the long-term average of 21. In Sections 4f2-4f8, the 2016 seasonal activity is described and compared to the historical record for each of the seven WMO-defined hurricane basins. For simplicity, all counts are broken down by the United States' Saffir-Simpson scale. Figure 4.20 depicts the overall picture of global TCs during 2016. The North Atlantic hurricane season was above normal (Section 4f2), and both the central and east- ern North Pacific hurricane seasons were well above normal (Section 4f3).

Globally, four storms achieved Saffir-Simpson category 5 during the year (four fewer than in 2015, and three fewer than in 2014): (a) Hurricane Matthew in the North Atlantic; (b) Supertyphoon Meranti in the western North Pacific; (c) Cyclone Fantala in the South Indian Ocean; and (d) Tropical Cyclone Winston in the Southwest Pacific. Matthew was the costliest hurricane ( $\$ 10$ billion U.S. dollars in damages) to strike the U.S. since Hurricane Sandy in 2012. Sidebar 4.1 recounts several of the records that Matthew broke. Supertyphoon Meranti, with maximum sustained winds of $165 \mathrm{kt}\left(85 \mathrm{~m} \mathrm{~s}^{-1}\right)$, was the most intense tropical cyclone of the year globally. Sidebar 4.2 describes an unusual situation where Taiwan was impacted by four major typhoons, including

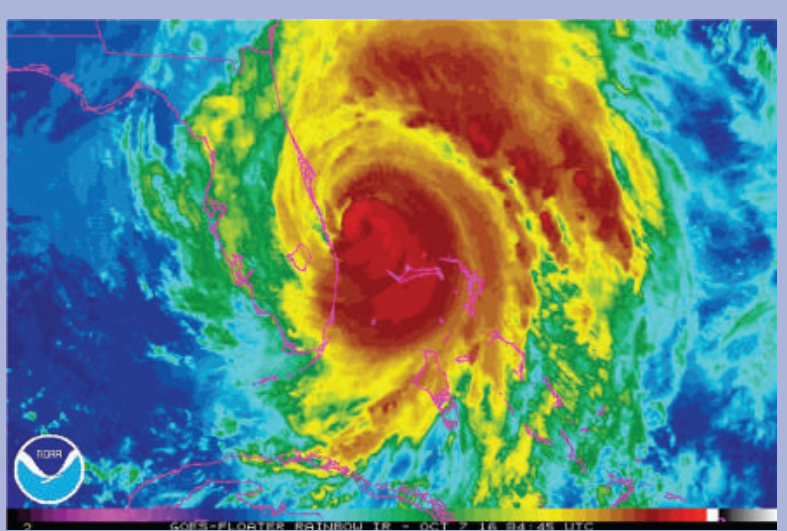

FIG. SB 4.2. Infrared satellite image of Hurricane Matthew from GOES-East near its closest approach to the east coast of Florida at 0445 UTC 7 Oct 2016.

longest-lived major hurricane to form in the Atlantic after 25 September on record.

Matthew made landfall in Haiti as a category 4 hurricane on 4 October, becoming the first category 4 storm to hit Haiti since Cleo in 1964. While the final death toll from Matthew in Haiti may never be fully known, the National Hurricane Center reports (www.nhc.noaa.gov/data/tcr/ALI42016_Matthew.pdf) that Matthew was responsible for 585 direct fatalities across four countries with 546 of those occurring in Haiti. Matthew then made landfall in Cuba as a category 4 hurricane, becoming the first category 4 hurricane to hit Cuba since lke in 2008. Next, Matthew struck the Bahamas, battering the island chain also as a category 4 hurricane. In the process, Matthew became the first hurricane in the historical record (back to
I85I) to make landfall at category 4 intensity in Haiti, Cuba, and the Bahamas.

Matthew tracked within 100 miles of the east coast of Florida (Fig. SB4.2), threatening to break the record-long U.S. landfalling major hurricane drought that has existed since October 2005 when Hurricane Wilma made landfall (Hart et al. 2016). It eventually made landfall along the central South Carolina coast as a weakening category I hurricane. Matthew was the first hurricane to make landfall in South Carolina since Gaston in 2004 and the first to make landfall north of Georgia during October since Hazel in 1954.

While the center of Matthew remained offshore of both Florida and Georgia, storm surge and heavy rainfall caused significant flooding in northeast Florida and along the entire coastline of Georgia. The eastern portions of both South and North Carolina suffered significant damage due to the combination of storm surge and heavy rainfall. Matthew was responsible for nearly 50 deaths in the United States, and total insured and uninsured damage from the storm was estimated at approximately $\$ 10$ billion (U.S. dollars; www.ncdc.noaa .gov/billions).

Matthew was certainly the most notable storm in the Atlantic in 2016, as it was the longest-lived hurricane, the most intense storm, and the most damaging and destructive storm of the season. To put its longevity and intensity into perspective, while Matthew was one of 15 storms that formed in the Atlantic in 2016, it singlehandedly was responsible for $35 \%$ of the total amount of ACE generated by Atlantic tropical cyclones in 2016. 
Meranti-three of which struck during September alone. Several other Saffir-Simpson category 3 and 4 intensity level systems during 2016 had major impacts: (1) Hurricane Nicole in the North Atlantic; (2) Typhoons Chaba, Haima, Malakas, Megi, Lionrock, Nepartik, and Nock-Ten in the western North Pacific; and (3) Typhoon Victor in the Southwest Pacific. Also noteworthy was that $2015 / 16$ was the first year since the onset of the satellite era in 1970 that no major HTCs were observed in the Australian basin.

2) Atlantic basin-G. D. Bell, E. S. Blake, C. W. Landsea, C. Wang, J. Schemm, T. Kimberlain, R. J. Pasch, and S. B. Goldenberg

(i) Seasonal activity

The 2016 Atlantic hurricane season produced 15 named storms, of which 7 became hurricanes and 4 became major hurricanes (Fig. 4.21a). The HURDAT2 30-year (1981-2010) seasonal averages (as embodied in IBTrACS) are 11.8 tropical (named) storms, 6.4 hurricanes, and 2.7 major hurricanes (Landsea and Franklin 2013).

The 2016 seasonal ACE value (Bell et al. 2000) was about $148 \%$ of the $1981-2010$ median $\left(92.4 \times 10^{4} \mathrm{kt}^{2}\right.$;

(a)

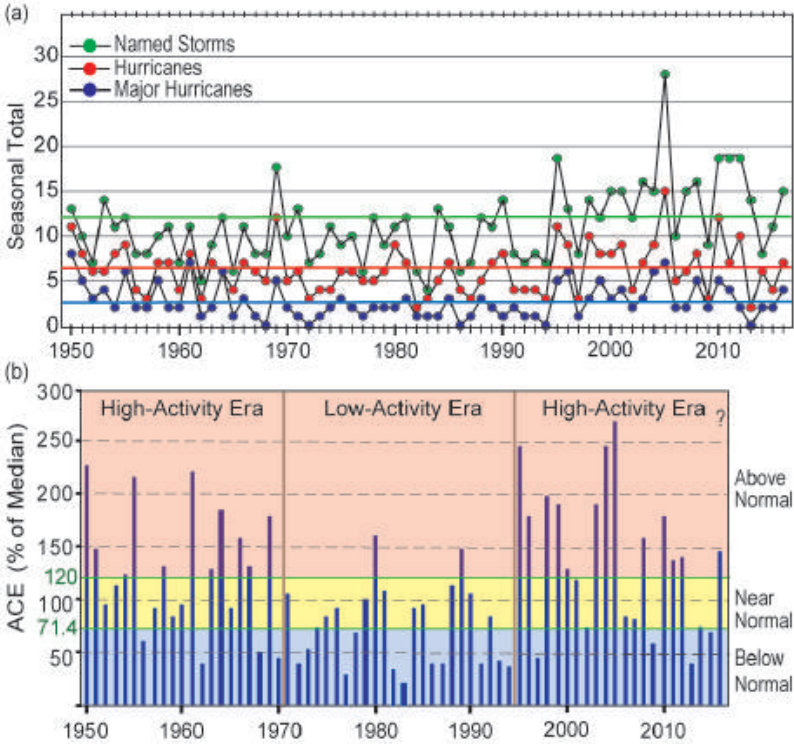

Fig. 4.2I. Seasonal Atlantic hurricane activity during 1950-2016. (a) Numbers of named storms (green), hurricanes (red), and major hurricanes (blue), with I98I-20I0 seasonal means shown by solid colored lines. (b) ACE index expressed as percent of the 1981-2010 median value. ACE is calculated by summing the squares of the 6-hourly maximum sustained surface wind speed (knots) for all periods while the storm is at least tropical storm strength. Red, yellow, and blue shadings correspond to NOAA's classifications for above-, near, and below-normal seasons, respectively. Vertical brown lines separate high- and low-activity eras. High and low activity eras are defined per Goldenberg et al. (200I).
Fig. 4.21b), which is above NOAA's lower threshold (120\% of the median) for an above-normal season (see www.cpc.ncep.noaa.gov/products/outlooks). Based on this ACE value, combined with above-average numbers of named storms, hurricanes, and major hurricanes, NOAA officially classified the 2016 Atlantic hurricane season as above normal. This was the first above-normal season since 2012, producing more than 2.5 times the average ACE value of the last three seasons 2013-15.

\section{(ii) Storm tracks and landfalls}

The Atlantic hurricane main development region (MDR; green boxed region in (Fig. 4.22a) spans the tropical Atlantic Ocean and Caribbean Sea between 9. $5^{\circ}$ and $21.5^{\circ} \mathrm{N}$ (Goldenberg and Shapiro 1996; Goldenberg et al. 2001; Bell and Chelliah 2006). A main delineator between more- and less-active Atlantic hurricane seasons is the number of hurricanes and major hurricanes that first become named storms within the MDR during the peak months (AugustOctober; ASO) of the hurricane season.

During ASO 2016, eight named storms formed in the MDR (Fig. 4.20), with five becoming hurricanes and four of those becoming major hurricanes. Three hurricanes were observed over the Caribbean Sea, a region with only one hurricane during the past three seasons (2013-15). The MDR activity during 2016 is comparable to the above-normal season averages for the MDR of 8.2 named storms, 6.0 hurricanes, and 3.0 major hurricanes. In contrast, the MDR averages for the last three seasons were 5.0 named storms with 2.3 becoming hurricanes and 1.0 becoming a major hurricane. These values are near the MDR averages for seasons that are not classified as above normal: 3.3 named storms, 2.0 hurricanes, and 1.0 major hurricanes.

Another feature of the 2016 season was that two major hurricanes (Matthew and Nicole) formed during October and accounted for more than $50 \%$ of the seasonal ACE value. The October 2016 ACE value was more than $50 \%$ larger than that of any other October since at least 1981 (Schreck et al. 2014).

The 2016 Atlantic hurricane season included a sharp increase in the number of landfalling storms compared to the last three seasons. In the United States, five named storms made landfall, including two hurricanes: Tropical Storm Bonnie and Hurricane Matthew struck South Carolina; Tropical Storms Colin and Julia, and Hurricane Hermine made landfall in Florida. This was the most U.S. landfalling storms since 2008 (six storms). Hermine was not only the first landfalling hurricane in the United 
States since 2014, but also the first hurricane to make landfall in Florida since Hurricane Wilma in 2005.

Several storms during 2016 also made landfall outside of the United States. The most significant of these was major Hurricane Matthew, which reached maximum sustained surface wind speeds of $140 \mathrm{kt}$ $\left(72 \mathrm{~m} \mathrm{~s}^{-1}\right)$ over the Caribbean Sea and remained at major hurricane status for eight days (30 Septem-
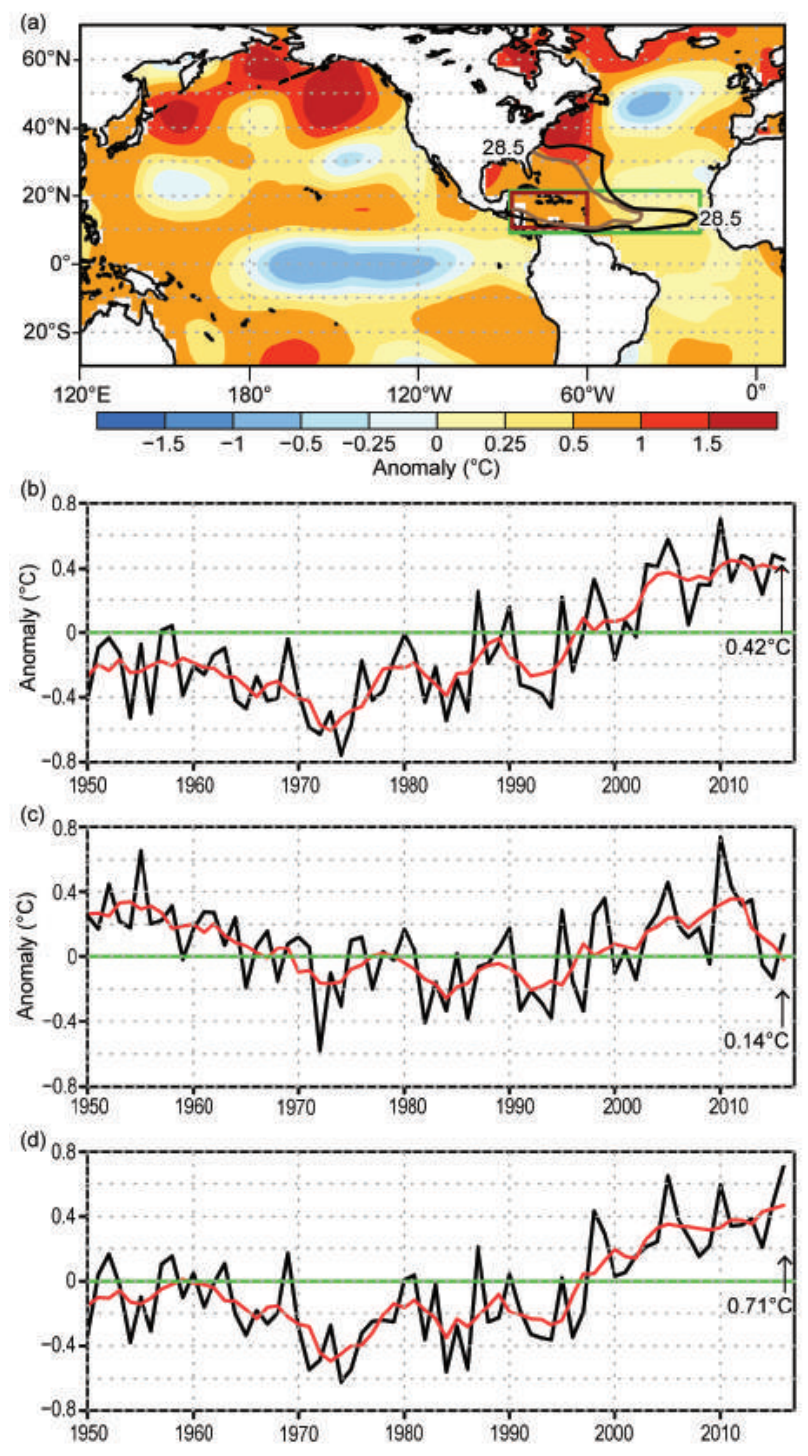

Fig. 4.22. (a) ASO 2016 SST anomalies $\left({ }^{\circ} \mathrm{C}\right)$, with the observed (black contours) and climatological (brown contours) $28.5^{\circ} \mathrm{C} \mathrm{SST}$ isotherms shown. (b) 1950-2016 of ASO area-averaged SST anomalies $\left({ }^{\circ} \mathrm{C}\right)$ in the MDR [green box in (a)]. (c) Difference between ASO areaaveraged SST anomalies ( ${ }^{\circ} \mathrm{C}$ ) in the MDR and those for the entire global tropics $\left(20^{\circ} \mathrm{N}-20^{\circ} \mathrm{S}\right)$. (d) ASO areaaveraged SST anomalies $\left({ }^{\circ} \mathrm{C}\right)$ in the Caribbean Sea [red box in (a) spanning $60^{\circ}-87.5^{\circ} \mathrm{W}$ and $10^{\circ}-21.5^{\circ} \mathrm{N}$ ]. Red lines in (b)-(d) show a 5-pt. running mean of each time series. Anomalies are departures from the ERSST-v4 (Huang et al. 2015) 198I-2010 monthly means. ber-7 October). Matthew made landfall as a category 4 storm in Haiti, Cuba, and the Bahamas, causing extensive damage and loss of life in all three countries, before making landfall in South Carolina as a category 1 hurricane. Matthew is discussed further in Sidebar 4.1. Other landfalling storms included Tropical Storm Danielle in Mexico, Hurricane Earl in Belize, and Hurricane Otto in Nicaragua.

\section{(iii) Atlantic sea surface temperatures}

Within the MDR, SST anomalies during ASO 2016 (Fig. $4.22 \mathrm{a}$ ) were $+0.45^{\circ} \mathrm{C}$ above the $1981-2010$ average (Fig. $4.22 \mathrm{~b})$, and they were also warmer $\left(+0.14^{\circ} \mathrm{C}\right.$ warmer) than the average departure for the global tropics (Fig. 4.22c). Over the Caribbean Sea, SSTs were $+0.71^{\circ} \mathrm{C}$ above average, which is the highest value in the 1950-2016 record (Fig. 4.22d).

The warm phase of the Atlantic multidecadal oscillation (AMO; Enfield and Mestas-Nuñez 1999) and the associated positive phase of the Atlantic meridional mode (Vimont and Kossin 2007; Kossin and Vimont 2007) are the primary climate factors associated with high-activity eras for Atlantic hurricanes (Goldenberg et al. 2001; Bell and Chelliah 2006; Bell et al. 2011, 2012). This warm phase features anomalously high SSTs in the MDR compared to the remainder of the global tropics, as can be seen during the high-activity era of 1950-70 and that which began in 1995 (Fig. 4.22c). NOAA's detrended Kaplan AMO index for ASO 2016 was +0.44 (see report Appendix for link) and has been positive for the ASO season since 1995 (Bell et al. 2016).

The Atlantic warm pool (AWP) reflects the area of SSTs greater than $28.5^{\circ} \mathrm{C}$ (Wang 2015). The AWP during ASO 2016 extended eastward across the entire southern MDR (black contour; Fig. 4.22a), which far exceeds its climatological extension to the central MDR (brown contour). The AWP during ASO 2016 also extended farther north than normal over the western North Atlantic. As a result, the average size

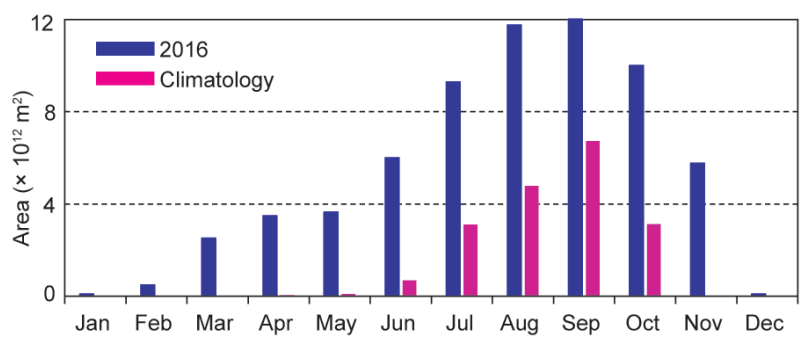

Fig. 4.23. Monthly size of the Atlantic warm pool (AWP) in $2016\left(10^{12} \mathrm{~m}^{2}\right.$; blue) and the climatological AWP area (red). Climatology is the $197 \mid-2000$ ERSST-v4 (Huang et al. 2015) mean area of the $28.5^{\circ} \mathrm{C}$ SST isotherm. 


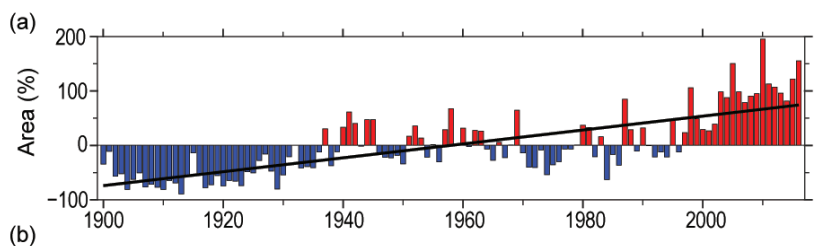

(b)
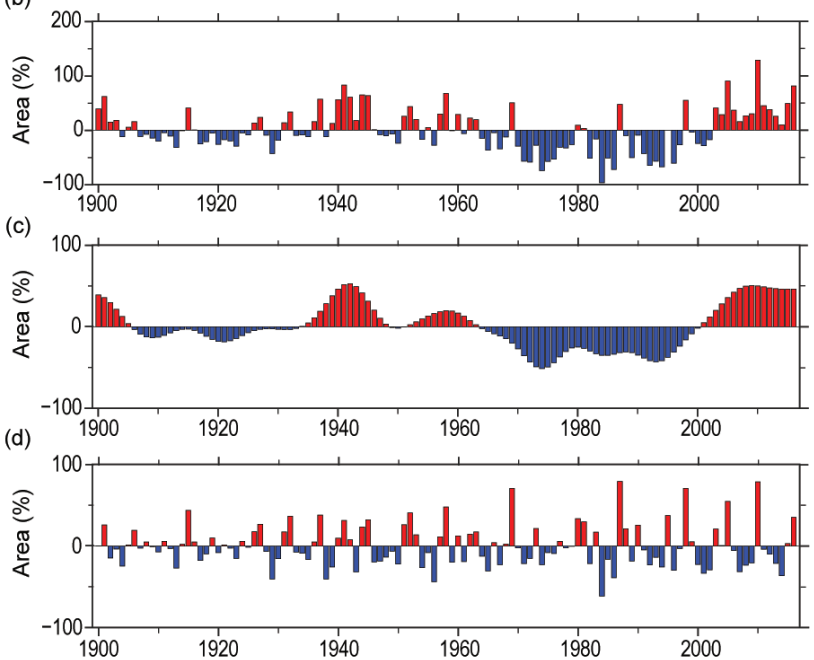

Fig. 4.24. AWP index (\%) for 1900-20I6, calculated as the anomalous area of SST warmer than $28.5^{\circ} \mathrm{C}$ during Jun-Nov divided by the climatological AWP area. Shown are the (a) total, with linear trend indicated (black line), (b) detrended (removing the linear trend), (c) multidecadal, and (d) interannual area anomalies. The multidecadal variability is obtained by performing a seven-year running mean to the detrended AWP index. The interannual variability is calculated by subtracting the multidecadal variability from the detrended AWP index. [Source: ERSST-v4 (Huang et al. 2015) dataset.]

of the AWP during ASO 2016 was more than double its climatological mean (Fig. 4.23).

The 2016 AWP was bigger and lasted longer than the climatological mean throughout nearly the entire year. It persisted for 10 months during 2016 (February through November), while the climatological mean warm pool is present for just five months (JuneOctober). By July, the 2016 warm pool had already exceeded its September climatological peak.

The description and characteristics of the AWP, including its multidecadal variability, have been previously described (Wang 2015). Figure 4.24 shows the extension of the annual AWP time series through 2016, along with its variability on different time scales. Overall, the time series shows an upward trend since 1900 (Fig. 4.24a), along with significant multidecadal and interannual variability (Figs. $4.24 \mathrm{~b}-\mathrm{d}$ ). Its multidecadal fluctuations coincide with those of the AMO (Fig. 4.24c). The transition to an anomalously large size of the AWP in 1995 coincided with a transition to the warm phase of the AMO (e.g., Bell et al. 2016).

\section{(iv) Atmospheric conditions}

The atmospheric circulation during ASO featured an extensive and persistent ridge of high pressure in the middle and upper troposphere over the western half of the subtropical and tropical North Atlantic Ocean and Caribbean Sea (Fig. 4.25a). Within the MDR, the southern flank of this ridge featured anomalous upper-level easterly winds (see Fig. 4.6c) and anomalous lower-level westerly winds (see Figs. $4.5 \mathrm{c}, \mathrm{d})$. The ridge was also associated with a northward shift of the extratropical westerly winds along its northern flank. This wind pattern contributed to an extensive area of weak vertical shear across the western half of the Atlantic basin and the southeastern United States (shading, Fig. 4.25a), with anomalously weak shear spanning the central MDR and the eastern half of the United States (Fig. 4.25b). On monthly time scales, shear values less than $8-10 \mathrm{~m} \mathrm{~s}^{-1}$ are generally considered conducive to hurricane formation (Gray 1968; DeMaria et al. 2005; Tippett et al. 2011).

The anomalous ridge was also associated with enhanced midlevel moisture and anomalous upperlevel divergence over the western subtropical North Atlantic (Fig. 4.26). At $600 \mathrm{hPa}$, area-averaged moisture in that region during ASO was the third largest in the 1970-2016 record (Fig. 4.26a). The area-averaged anomalous divergence during September-October was the largest since the record-breaking Atlantic hurricane season of 2005 (Fig. 4.26b).

All of the above conditions were main contributors to the increased strength of the 2016 Atlantic hurricane season compared to the past three seasons and also to the increased activity over the Caribbean Sea. Those conditions also allowed more storms to track farther westward, increasing the number of landfalls in both the United States and the region around the Caribbean Sea. For example, they were especially prominent during the lifecycle of major Hurricane Matthew, which developed in late September while tracking westward over record-warm waters of the Caribbean Sea (Fig. 4.22d) and then spent its entire life-cycle beneath the upper-level ridge while making landfall in several nations.

The conditions over the western half of the Atlantic basin during ASO 2016 differ notably from the climatological mean. Normally, a tropical upper tropospheric trough (TUTT) is present over the western subtropical North Atlantic and extends southward into the western and central MDR. An enhanced TUTT, along with its associated patterns of strong 

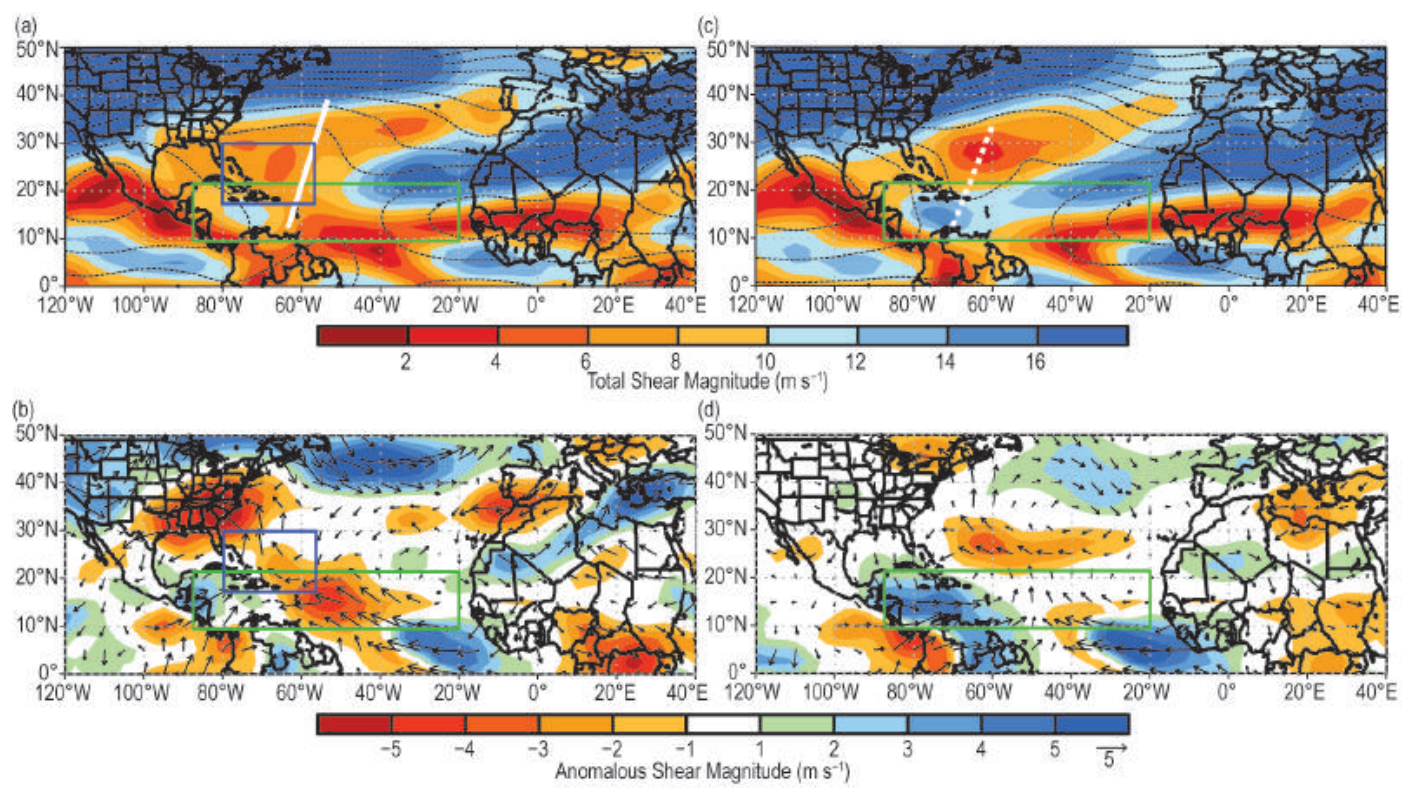

Fig. 4.25. NCEP-NCAR reanalysis (Kistler et al. 200I) 200-850-hPa vertical wind shear (a),(c) magnitude (shaded, $\mathrm{m} \mathrm{s}^{-1}$ ) and (b),(d) anomalous magnitude and vector. (a),(b) ASO 2016 conditions and (c),(d) ASO 2013-15 averages. In (a),(c), the 200-hPa streamfunction field is overlaid (contours; interval: $5 \times 10^{6} \mathrm{~m}^{2} \mathrm{~s}^{-1}$ ), the upper-level ridge and TUTT discussed in the text are labeled, and orange-red shading indicates areas where the vertical wind shear magnitude is $\leq 10 \mathrm{~m} \mathrm{~s}^{-1}$. In (b),(d) anomalous shear vector scale is below right of color bar. Blue box in (a),(b) shows the averaging region for Fig. 4.26. Green boxes denote the MDR. Anomalies are departures from 198I-2010 means.

vertical wind shear (Figs. 4.25c,d), anomalously dry air, and anomalous sinking motion across the Caribbean Sea, was an important contributor to the reduced hurricane activity observed during 2013-15 (Bell et al. 2014, 2015, 2016).
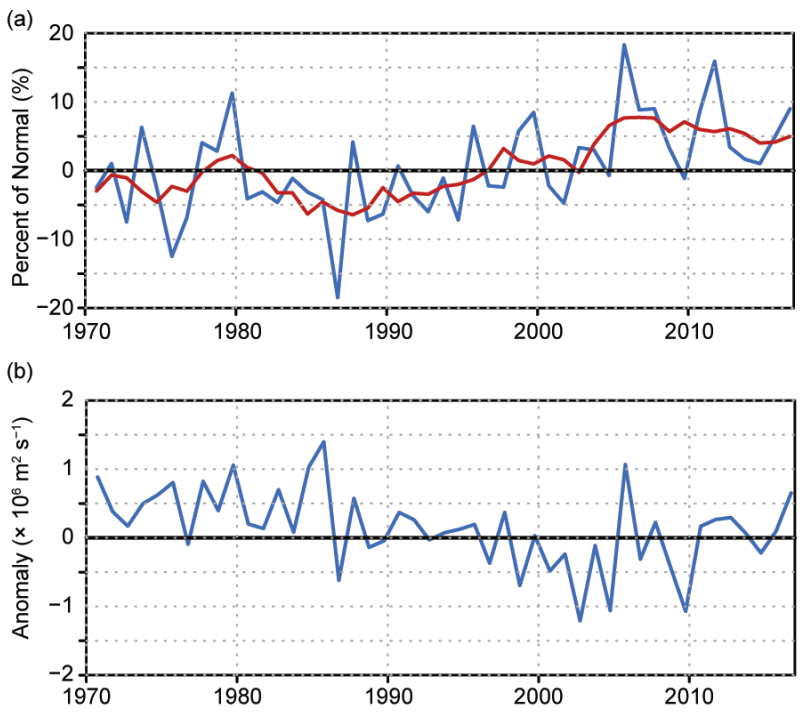

Fig. 4.26. NCEP-NCAR reanalysis (Kistler et al. 200I) time series for 1970-2016 showing (a) ASO percent of normal area-averaged specific humidity and (b) Sep-Oct area-average 200-hPa divergence anomalies $\left(\times 10^{6} \mathrm{~m}^{2} \mathrm{~s}^{-1}\right)$. Area averages are calculated for the blue boxed region $\left(57.5^{\circ}-80^{\circ} \mathrm{W}\right.$ and $\left.17.5^{\circ}-30^{\circ} \mathrm{N}\right)$ in Fig. 4.25a. Anomalies are departures from 198I-2010 means.
During October and November, the upper-level ridge over the western part of the basin was linked to La Niña, whose larger-scale circulation pattern extended across the entire subtropical Pacific Ocean in both hemispheres (Fig. 4.27a). As indicated in

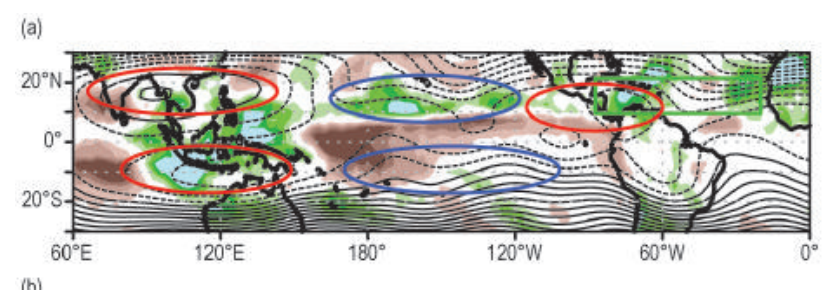

(b)

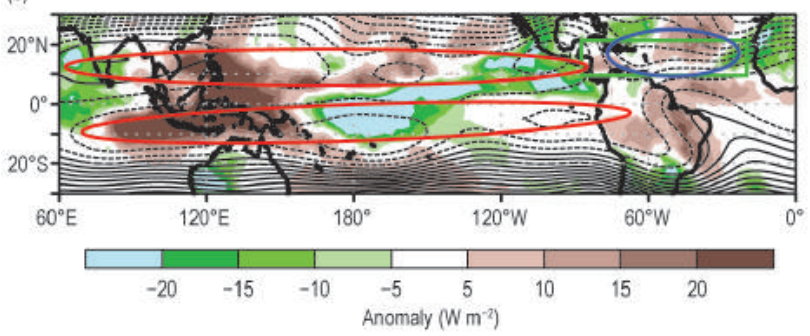

FIG. 4.27. 200-hPa streamfunction (contours; interval: is $5 \times 10^{6} \mathrm{~m}^{2} \mathrm{~s}^{-1}$ ) from the NCEP-NCAR reanalysis (Kistler et al. 200I) and anomalous OLR (shaded, $\mathrm{W} \mathrm{m}^{-2}$; Liebmann and Smith 1996) during (a) Oct-Nov 2016 and (b) Oct-Nov 2015. Ridges (red ovals) and troughs (blue ovals) discussed in the text are indicated. In the tropics, green (brown) shading indicates enhanced (suppressed) convection. Anomalies are based on the 198I-2010 climatology. 
the $200-\mathrm{hPa}$ streamfunction field, that typical La Niña pattern featured a westward retraction of the mean subtropical ridges over the western Pacific (coinciding with enhanced equatorial convection), amplified mid-Pacific troughs in both hemispheres (coinciding with suppressed equatorial convection), and a pronounced downstream ridge extending across the Caribbean Sea. This wave pattern is notably different from the typical El Niño-related pattern observed during October-November 2015 (Fig. 4.27b), which suppressed Atlantic hurricane activity - that pattern featured extended subtropical ridges across nearly the entire Pacific basin in both hemispheres and an extensive downstream trough across the entire MDR.

3) Eastern North Pacific and Central North PACIFIC BASINS-M. C. Kruk and C. J. Schreck

(i) Seasonal activity

The eastern North Pacific (ENP) basin is officially split into two separate regions for the issuance of warnings and advisories by NOAA's National

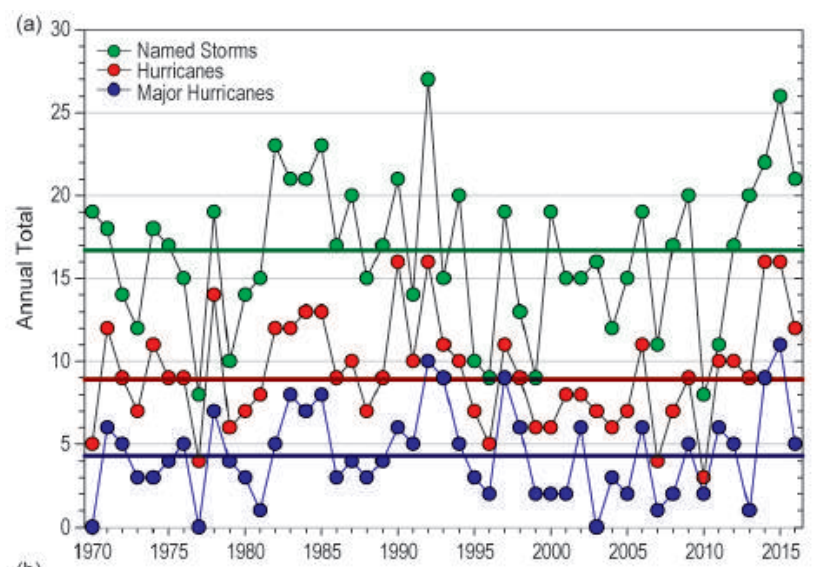

(b)

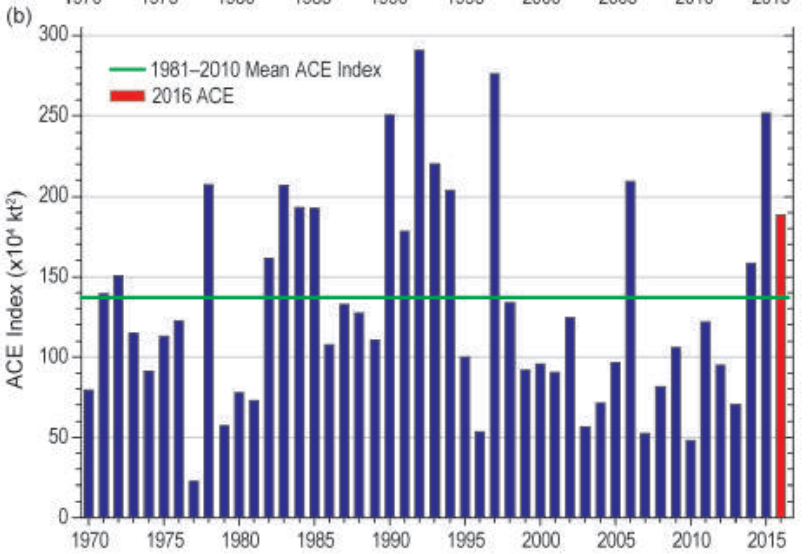

FIG. 4.28. Seasonal TC statistics for the full ENP/ CNP basin over the period 1970-2016: (a) number of named storms, hurricanes, and major hurricanes, and (b) the ACE index $\left(\times 10^{4} \mathrm{kt}^{2}\right)$ with the 2016 seasonal total highlighted in red. Horizontal lines denote the corresponding 1981-2010 means for each parameter.
Weather Service. NOAA's National Hurricane Center in Miami, Florida, is responsible for issuing warnings in the eastern part of the basin (ENP) that extends from the Pacific Coast of North America to $140^{\circ} \mathrm{W}$, while NOAA's Central Pacific Hurricane Center in Honolulu, Hawaii, is responsible for issuing warnings in the central North Pacific (CNP) region between $140^{\circ} \mathrm{W}$ and the date line. This section summarizes the TC activity in both warning areas using combined statistics, along with information specifically addressing the observed activity and impacts in the $\mathrm{CNP}$ region.

The ENP/CNP hurricane season officially spans from 15 May to 30 November. Hurricane and tropical storm activity in the eastern area of the basin typically peaks in September, while in the CNP TC activity normally reaches its seasonal peak in August (Blake et al. 2009). During the 2016 season, a total of 21 named storms formed in the combined ENP/CNP basin (Fig. 4.28a). This total includes 12 hurricanes, 5 of which were major hurricanes. The 1981-2010 IBTrACS seasonal averages for the basin are 16.5 named storms, 8.5 hurricanes, and 4.0 major hurricanes (Schreck et al. 2014).

The 2016 seasonal ACE index was $188.7 \times 10^{4} \mathrm{kt}^{2}$ (Fig. 4.28b), which is above the 1981-2010 mean of $132.0 \times 10^{4} \mathrm{kt}^{2}$ (Bell et al. 2000; Bell and Chelliah 2006; Schreck et al. 2014). By comparison to the 2015 season, which featured a record-shattering 16 tropical cyclones in the CNP basin, the 2016 season featured only 6 storms. Nonetheless, 2016 was still above the long-term 1981-2010 IBTrACS mean of 4.7 storms passing through the CNP per season.

\section{(ii) Environmental influences on the 2016 season}

Figure 4.29 illustrates the background conditions for TC activity in the ENP and CNP during the 2016 season. Consistent with the moderate La Niña conditions later in the season, the equatorial Pacific was dominated by anomalously cool SST anomalies (Fig. 4.29a). As in recent years, however, anomalously warm SSTs prevailed farther north. The ITCZ was also enhanced and shifted somewhat northward (see Section 4d) in association with the SST pattern with most of the TCs forming on the eastern end of that enhanced convection (Fig. 4.29b). Wind direction anomalies were generally westerly, but the vertical wind shear magnitudes were still slightly below their climatological values (Fig. 4.29c). The other years within this recent active period (2012-15) all featured broad areas of 850 -hPa westerly anomalies (Diamond 2013, 2014, 2015; Diamond and Schreck 2016). In this respect, 2016 is an outlier (Fig. 4.29d). 

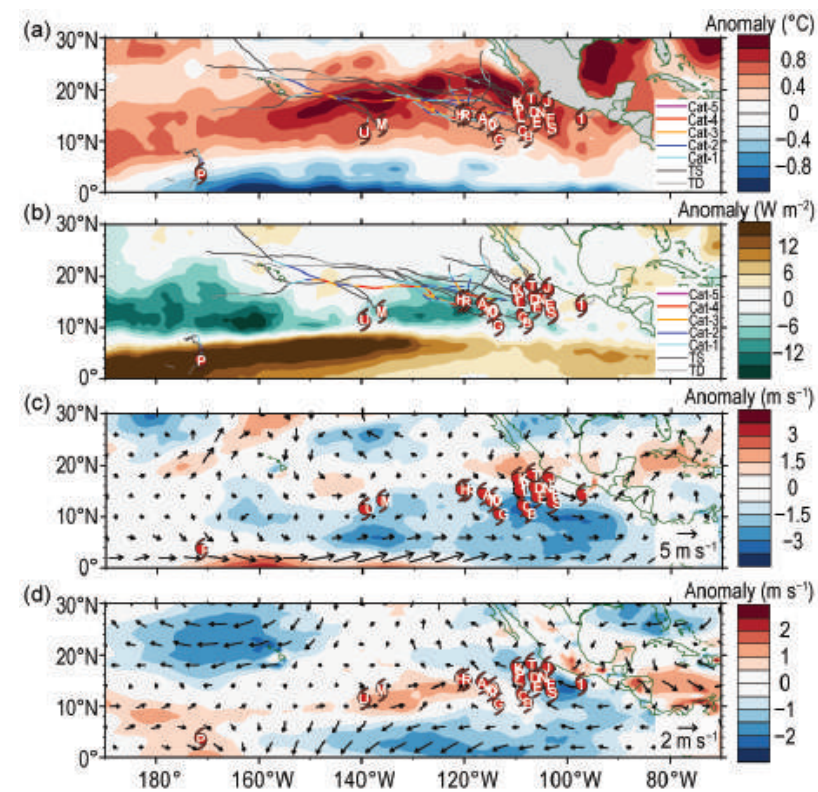

Fig. 4.29. May-Nov 2016 anomaly maps of (a) SST ( $\mathrm{C}$; Banzon and Reynolds 2013), (b) OLR ( $\mathrm{W} \mathrm{m}^{-2}$; Lee 2014), (c) 200-850-hPa vertical wind shear $\left(\mathrm{m} \mathrm{s}^{-1}\right)$ vector (arrows) and scalar (shading) anomalies, and (d) 850-hPa winds ( $\mathrm{m} \mathrm{s}^{-1}$, arrows) and zonal wind (shading) anomalies. Anomalies are relative to the annual cycle from 198I-2010, except for SST which is relative to 1982-2010 due to data availability. Hurricane symbols with letters denote where each ENP TC attained tropical storm intensity. Wind data obtained from CFSR (Saha et al. 2014).

Weak westerly anomalies lie along $10^{\circ} \mathrm{N}$ westward from $120^{\circ} \mathrm{W}$. However, most of the tropical cyclones developed farther east within moderate easterly anomalies. Overall, the broad area of warm SSTs, enhanced convection, and moderate shear in 2016 all contributed to favorable conditions that resulted in above-normal hurricane activity.

ENP TC activity is strongly influenced by the MJO (Maloney and Hartmann 2001; Aiyyer and Molinari 2008; Slade and Maloney 2013), and recent studies have found a greater role for convectively coupled Kelvin waves in modulating tropical cyclogenesis (Schreck and Molinari 2011; Ventrice et al. 2012a,b; Schreck 2015, 2016). Figure 4.30 uses OLR to examine the evolution of convection during the 2016 ENP hurricane season. Following Kiladis et al. (2005; 2009), the black contours identify the MJO-filtered anomalies (1981-2010 base period) and the blue contours identify the Kelvin waves. Easterly waves are also apparent in the unfiltered anomalies (shading) as westward moving features, such as those leading up to Hurricanes Newton and Seymour.

A significant MJO event helped kick off the ENP hurricane season. The convectively suppressed phase of the MJO likely inhibited any development during

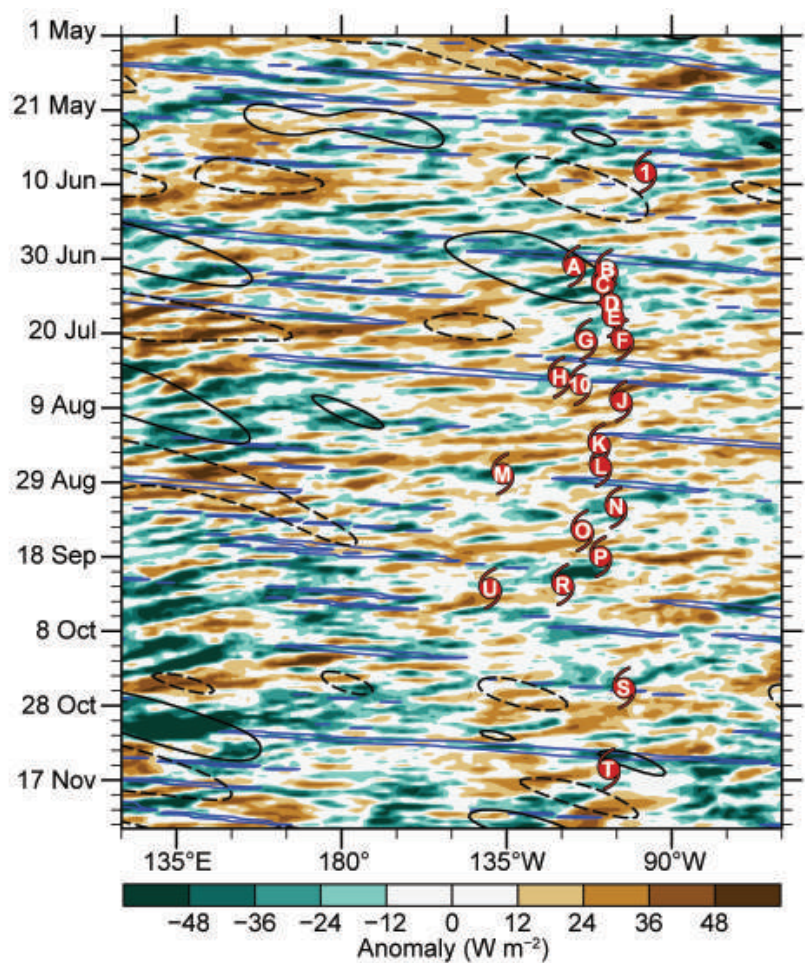

Fig. 4.30. Longitude-time Hovmoller of OLR $\left(\mathrm{W} \mathrm{m}^{-2}\right.$; Lee 2014 ) averaged $5^{\circ}-15^{\circ} \mathrm{N}$. Unfiltered anomalies from a daily climatology are shaded. Negative anomalies (green) indicate enhanced convection. Anomalies filtered for Kelvin waves are contoured in blue at $-10 \mathrm{~W} \mathrm{~m}^{-2}$ and MJO-filtered anomalies in black at $\pm 10 \mathrm{~W} \mathrm{~m}^{-2}$. Hurricane symbols and letters indicate genesis of ENP TCs.

June. However, the subsequent convectively active phase helped produce nine tropical storms within the month of July, the most for any single month since reliable records began in 1981 (Schreck et al. 2014). MJO activity was weaker for the remainder of the season, but two particularly strong Kelvin waves likely favored the development of Tropical Storms Howard and Tina.

\section{(iii) TC impacts}

During the 2016 season, only one of the season's 21 combined ENP/CNP tropical storms made landfall along the western coast of Mexico or Baja California, while no storms in the CNP region made landfall in Hawaii. The long-term annual average number of landfalling storms onto the western coast of Mexico is 1.8 (Raga et al. 2013).

The only storm to make landfall along the Mexican coastline was Hurricane Newton (4-7 September), which had maximum sustained winds of $70 \mathrm{kt}$ $\left(36 \mathrm{~m} \mathrm{~s}^{-1}\right)$ and a minimum central pressure of $979 \mathrm{hPa}$. The hurricane made landfall near Cabo San Lucas, Baja California, on 6 September with maximum sus- 
tained winds of $65 \mathrm{kt}\left(33 \mathrm{~m} \mathrm{~s}^{-1}\right)$. The storm weakened over the Baja, continued its northeastward trajectory, and made a second landfall over mainland Mexico near Bahia Kino, Sonora. Thereafter, the storm encountered increasing vertical wind shear as it moved into southern Arizona in the United States and dissipated completely by 8 September.

Hurricane Newton caused an estimated \$96 million (U.S. dollars) in damages with nine confirmed fatalities. Three fatalities were reported in Chiapas as a result of extreme flooding from Newton's rainbands. An additional five deaths occurred when a shrimp boat in the Gulf of California capsized and all on board were swept out to sea. In Petatlan, one person died in a fast-raging river after being swept downstream. The hurricane forced evacuations in the resort town of Acapulco. While the maximum sustained winds from Newton were not overly strong for a system in the ENP basin, the flooding rains were by far the biggest story. In the town of Mulege, extremely heavy rains cut access to electricity and fresh drinking water and dozens of cars and homes were buried in rocks and debris.

Six storms were recorded in the CNP during the 2016, the strongest of which were Hurricanes Lester (24 August-7 September) and Madeline (26 August-3 September). The earliest storm of the year, and earliest hurricane on record in the CNP basin, was Hurricane Pali, which occurred well south and west of the Hawaiian Islands during 7-14 January. Pali reached category 2 intensity very near the equator on 12 January and globally ranks third all-time as the closest-to-equator tropical cyclone. Later in the season, Hurricane Lester moved westward out of the ENP and came within $210 \mathrm{~km}$ of Honolulu, Hawaii, on 3 September. Due to the storm's asymmetric wind field, the strongest winds remained north of Hawaii and no major impacts were felt across the state. However, while Hurricane Madeline also moved west out of the ENP basin, its trajectory was toward the Big Island of Hawaii. The storm also did not make direct landfall in the state but still produced heavy rains, high surf, and gusty winds in Hilo. The Hilo airport recorded $109 \mathrm{~mm}$ of rain on 31 August, ending the month $>350 \mathrm{~mm}$ above average.

\section{4) Western North Pacific basin—S. J. Camargo (i) Introduction}

The tropical cyclone data used here are from the Joint Typhoon Warning Center (JTWC) western North Pacific (WNP) best-track dataset for the period from 1945-2015 and from the JTWC preliminary operational data for 2016 (also as embodied in
IBTrACS). Climatology is defined using the period from 1981-2010, with the exception of landfall statistics, where 1951-2010 was used. The best-track data from the RSMC-Tokyo, Japan Meteorological Agency (JMA) was also used in Fig. 4.31b. All other figures and statistics were obtained using JTWC best track data.

\section{(ii) Seasonal activity}

The TC season in the WNP was close to normal by most measures of TC activity. According to the JTWC, the 2016 season had a total of 30 TCs, which is above the median of 28.5 (75th percentile is 33 ). Of these, 24 TCs reached tropical storm intensity or higher (median is $25 ; 25$ th percentile is 23 ). There were 6 tropical depressions (median is 3.5 ; 75th percentile is 5), 11 tropical storms (median is 9; 75th percentile is 11), and 13 typhoons (25th percentile is 14 ; median is 16), with 6 reaching supertyphoon status ( $\geq 130 \mathrm{kt}$, or a strong category 4 or category 5 on the Saffir-Simpson scale; median is $3.5,75$ th percentile is 5). In Fig. 4.31a, the number of tropical storms, typhoons, and supertyphoons per year is shown for the period 1945-2016. While the number of typhoons was below normal, the number of supertyphoons was above normal. The percentage of typhoons that reached supertyphoon status in 2016 (46\%) was in the top 5th percentile from 1981-2010, the third consecutive season with a high rate of supertyphoon occurrence (47\% in 2015 and 58\% in 2014). Climatologically, only $24 \%$ of typhoons become supertyphoons (75th percentile is $30 \%$, 95 th percentile is $43 \%$ ). This is remarkably similar to the $1957-59$ period when this ratio was also in the top 5th percentile for three consecutive years, although the data are less reliable from that period (Chu et al. 2002).

The JMA total for 2016 was 26 TCs (median is 25). Tropical Storm Rai was only considered to be a tropical depression by the JTWC and Tropical Storm Malou was not included in the JTWC database. Of those 26,7 were tropical storms, 6 were severe tropical storms (both values equal to the median), and 13 were typhoons (bottom quartile). The number of tropical cyclones (1951-76), tropical storms, severe tropical storms, and typhoons (1977-2015) according to the JMA are shown in Fig. $4.31 b^{1}$.

\footnotetext{
${ }^{1}$ It is well known that there are systematic differences between the JMA and the JTWC datasets, which have been extensively documented in the literature (e.g., Wu et al. 2006; Nakazawa and Hoshino 2009; Song et al. 2010; Ying et al. 2011; Yu et al. 2012; Knapp et al. 2013; Schreck et al. 2014).
} 
The number of named storms, typhoons, and supertyphoons per month in 2016, compared with the climatological distributions, is depicted in Figs. 4.31c-f. The 2016 typhoon season had an extremely quiet start (January-June), with only one tropical depression; this was second only to the 1998 season, with no named storms during that period. (The first named storm of 2016 formed on 3 July, while in 1998 the first named storm formed 8 July.) In contrast, the peak season (July-October) was very active, with 24 tropical cyclones, of which 20 reached tropical storm intensity, both in or close to the top quartiles (medians 19 and 17, 75th percentiles 22.5 and 20.5, respectively). Similarly, the late season (November-December), with 5 tropical cyclones and 4 named storms, was also in the top quartile. The occurrence of a supertyphoon, Nock-ten, in December was unusual (5th percentile). Nock-ten's lifetime maximum intensity (LMI) of $135 \mathrm{kt}\left(69.5 \mathrm{~m} \mathrm{~s}^{-1}\right)$ occurred on 25 December, and it was one of the most

(a)

(b)
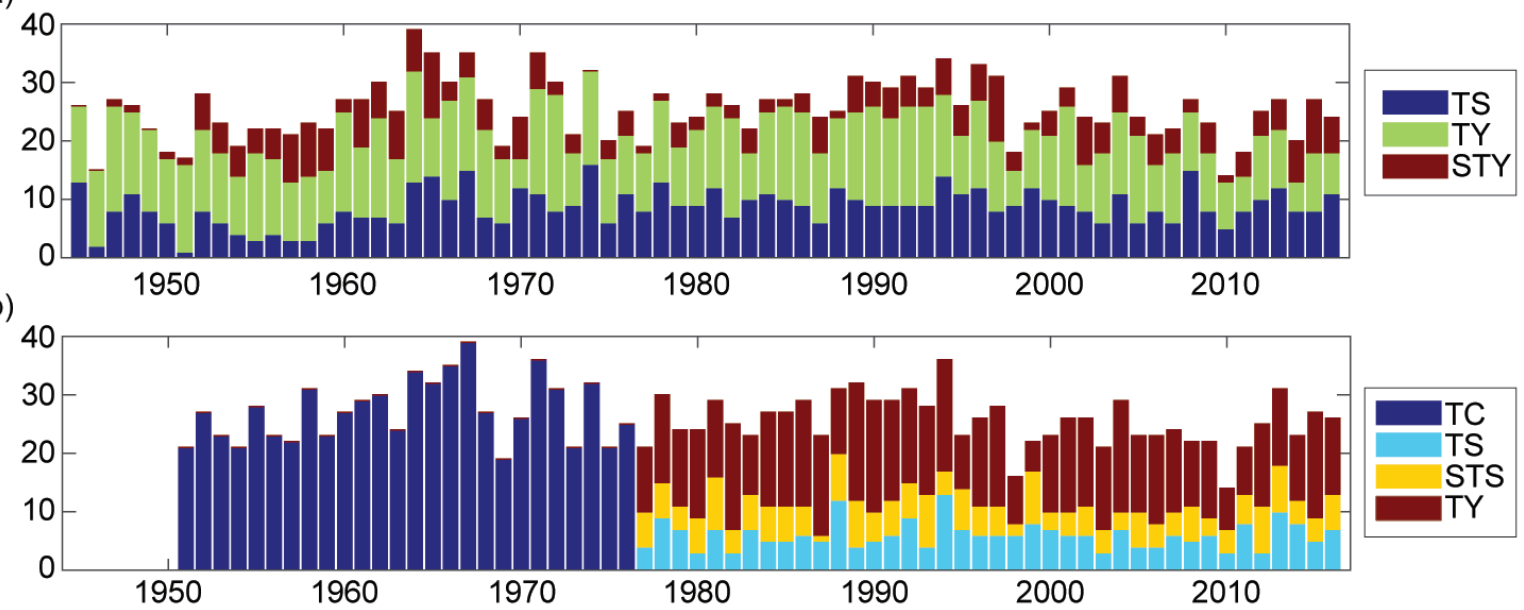

(c)

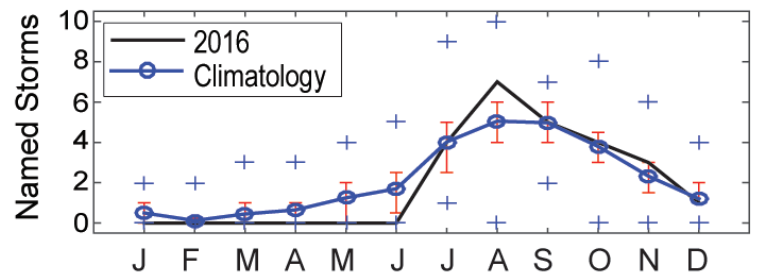

(e)

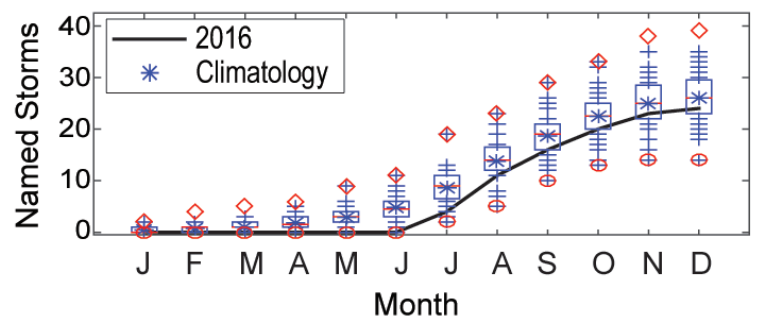

(d)

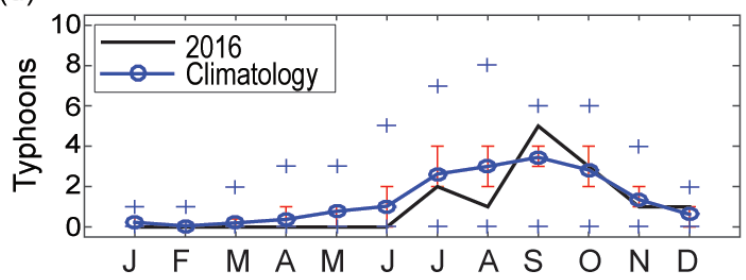

(f)

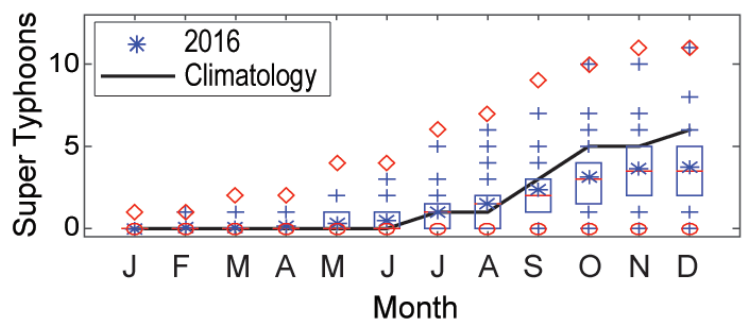

Fig. 4.3I. (a) Number of tropical storms (TSs), typhoons (TYs), and super typhoons (STYs) per year in the western North Pacific (WNP) for 1945-2016. (b) Number of tropical cyclones (TCs) (all storms that reach TS intensity or higher) from 195I to 1976; number of TSs, severe tropical storms (STSs) and TYs from 1977 to 2016. (c) and (d) show the Number of tropical cyclones with TS intensity or higher (named storms) and TYs, respectively, per month in 2016 (black line) and the climatological mean (blue line), the blue + signs denote the maximum and minimum monthly historical records and the red error bars show the climatological interquartile range for each month (in the case of no error bars, the upper and/or lower percentiles coincide with the median. (e) and (f) show the cumulative NSs and number of STYs per month in the WNP in 2016 (black line), and climatology (198I-2010) as box plots [interquartile range: box; median: red line; mean: blue asterisk; values in the top or bottom quartile: blue crosses; high (low) records in the 1945-2015 period: red diamonds (circles)]. [Sources: 1945-2015 JTWC best-track dataset and 2016 JTWC preliminary operational track data for panels (a), (c), (d), (e), and (f). (b) is from the 195I-2016 RSMC-Tokyo, JMA best-track dataset.] 
(a)
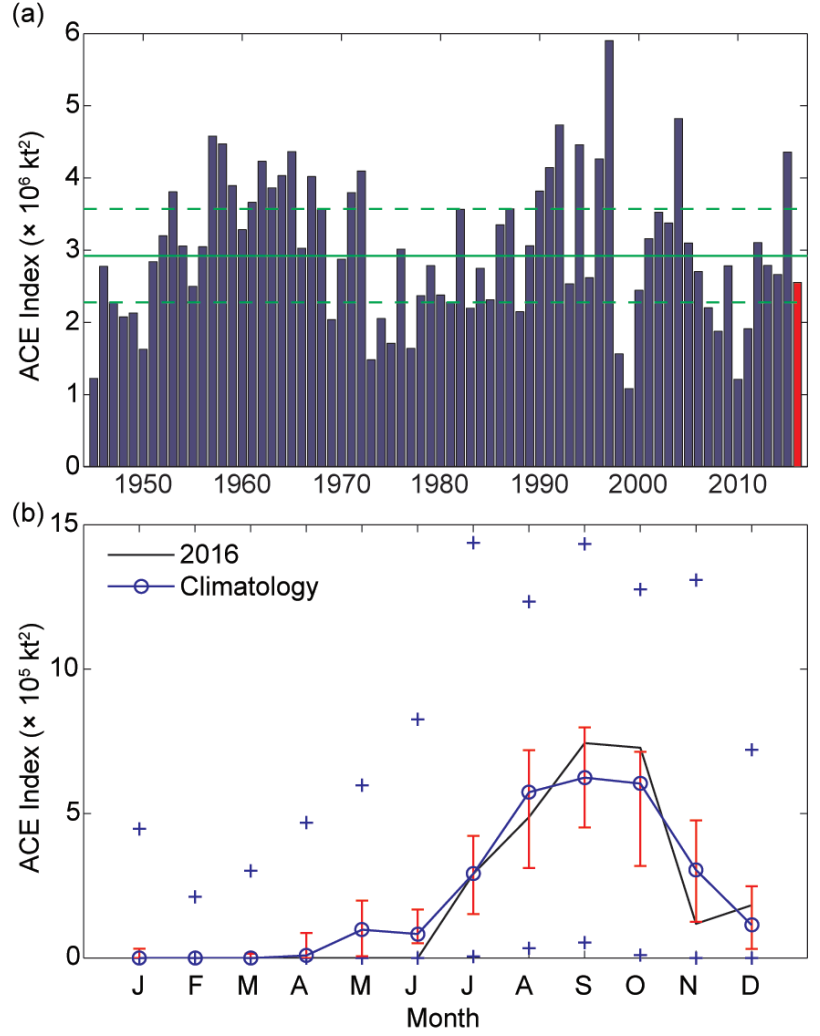

FIG. 4.32. (a) ACE index per year in the western North Pacific for 1945-2016. Solid green line indicates the median for the climatology years 1981-2010, and the dashed lines show the climatological 25 th and 75 th percentiles. (b) ACE index per month in 2016 (black line) and the median during 1981-2010 (blue line), the red error bars indicate the 25 th and 75 th percentiles. In case of no error bars, the upper and/or lower percentiles coincide with the median. The blue "+" signs denote the maximum and minimum values during the period 1945-2015. (Sources: 1945-2015 JTWC besttrack dataset and 2016 JTWC preliminary operational track data.)

intense storms so late in the calendar year in the historical record. Other notable storms in the historical record with an LMI in late December are: Typhoon \#27 in 1952 [LMI of $160 \mathrm{kt}\left(82 \mathrm{~m} \mathrm{~s}^{-1}\right)$ on 31 December], Typhoon \#25 in 1963 [LMI of $135 \mathrm{kt}\left(69.5 \mathrm{~m} \mathrm{~s}^{-1}\right)$ on 26 December], and Typhoon \#33 in 2001 [LMI of $155 \mathrm{kt}$ $\left(79.7 \mathrm{~m} \mathrm{~s}^{-1}\right)$ on 23 December]. The active peak and late season compensated for the early quiet season, so that the total activity in the overall typhoon season was close to normal. In August and September there were days with four storms active simultaneously in the basin-both in the top 10th percentile of the maximum named TCs active per day in each month.

The storms in the months of August and September were highly concentrated close to or south of Japan and included five landfalls in that country. This shift of activity towards the northwest part of the basin is typical of La Niña years (e.g., Chia and Ropelewski 2002; Camargo et al. 2007). During the peak and late 2016 typhoon season, the tropical Pacific SST had weak La Niña conditions (see Fig. 4.1). The mean genesis location in 2016 at $17.0^{\circ} \mathrm{N}, 139.6^{\circ} \mathrm{E}$, shifted northwestward from the climatological mean of WNP storms of $13.2^{\circ} \mathrm{N}, 141.6^{\circ} \mathrm{E}$, with standard deviations of $1.9^{\circ}$ and $5.6^{\circ}$, respectively. The mean track position $\left(21.0^{\circ} \mathrm{N}, 134.4^{\circ} \mathrm{E}\right)$ was also northwestward relative to the WNP climatological mean $\left(17.3^{\circ} \mathrm{N}\right.$, $136.6^{\circ} \mathrm{E}$ ), with standard deviations of $1.4^{\circ}$ and $4.7^{\circ}$, respectively. These shifts are consistent with La Niña conditions, even though the event is considered weak. The total ACE in 2016 was below normal, also consistent with weak La Niña (Camargo and Sobel 2005), as shown in Fig. 4.32a. The bulk of the seasonal ACE occurred in September and October (Fig. 4.32b), with those months contributing to $29 \%$ and $28.5 \%$ of the total ACE, respectively, with October in top quartile for the month. The total ACE in the early season was zero, which had occurred only twice before in the historical record: in 1973 and 1998. The zero value of ACE in the months of May and June was in the bottom quartile and 10th percentile, respectively. The ACE value in November was also in the bottom quartile. Two tropical cyclones in 2016 were in the top decile of the ACE per storm, Lionrock and Meranti, which also had the two top ACE values per storm in the season. Unlike Meranti, Lionrock did not reach supertyphoon status, but it maintained category 3-4 on the Simpson-Saffir scale for a total of four days while tracking in a loop pattern just southeast of Japan. The ACE values of Lionrock and Meranti were similar, and each contributed approximately $11.5 \%$ to the overall seasonal ACE.

The median lifetime of named storms and typhoons in 2016 was 5.5 and 7.25 days, respectively, both in the bottom quartile (25th percentile: 6.25 and 7.75 days). Relatively short-lived storms are typical of La Niña years (Camargo and Sobel 2005) and related to the northwest shift of the season's tropical cyclone activity. The longest living storm was Typhoon Lionrock, which lasted 14 days (17-30 August), in the 90th percentile, followed by Typhoon Malakas, which lasted 9.25 days (11-20 September), above the climatological median of 7.75 days. All other storms in 2016 had lifetimes below the median.

Figure 4.33 shows the environmental conditions associated with the typhoon activity in 2016. The main feature is the weak La Niña with below-normal SST anomalies in the central Pacific for the period from July to October (JASO) as depicted in Fig. 4.33a, and with near-normal SSTs in the WNP. This SST 

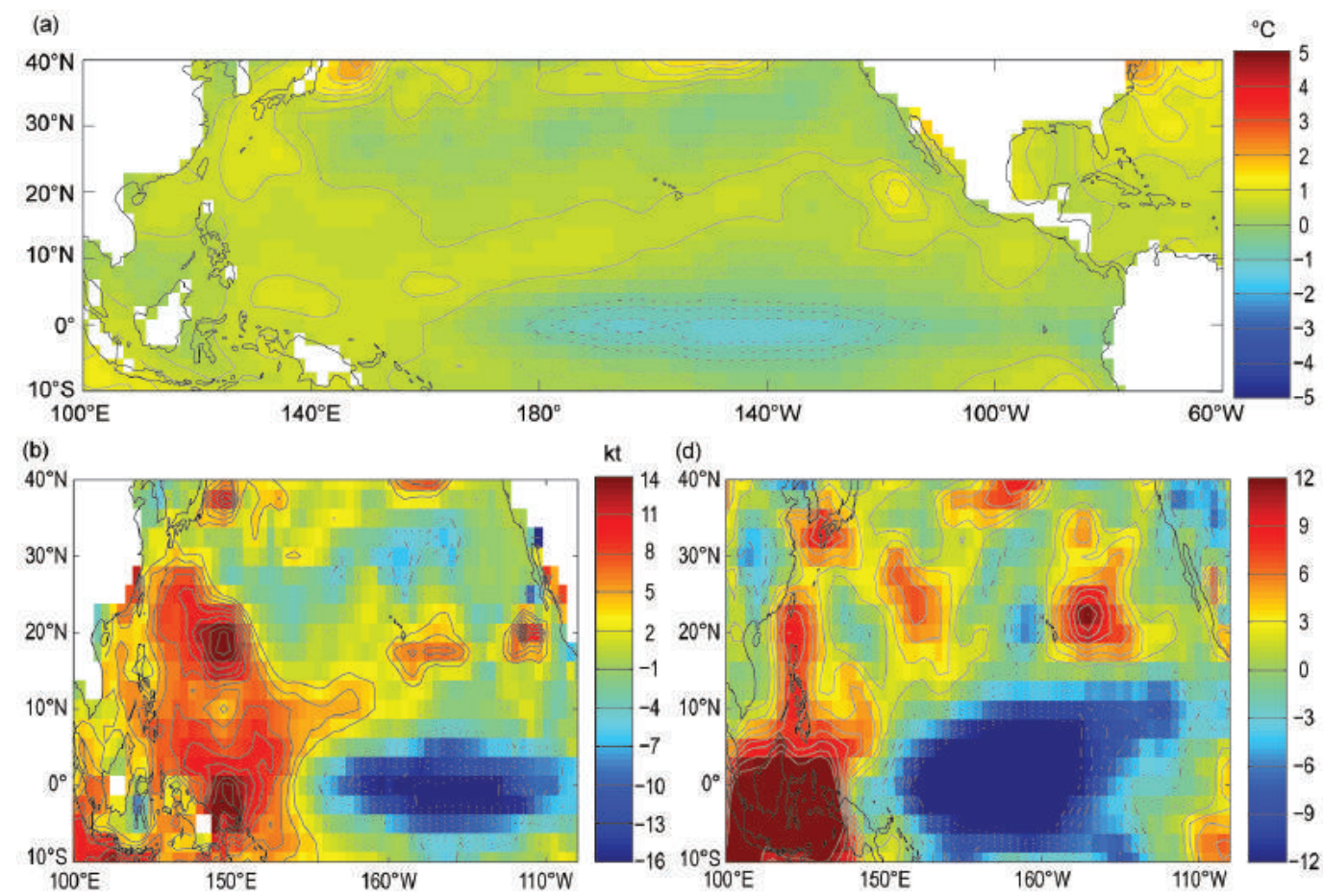

(d)
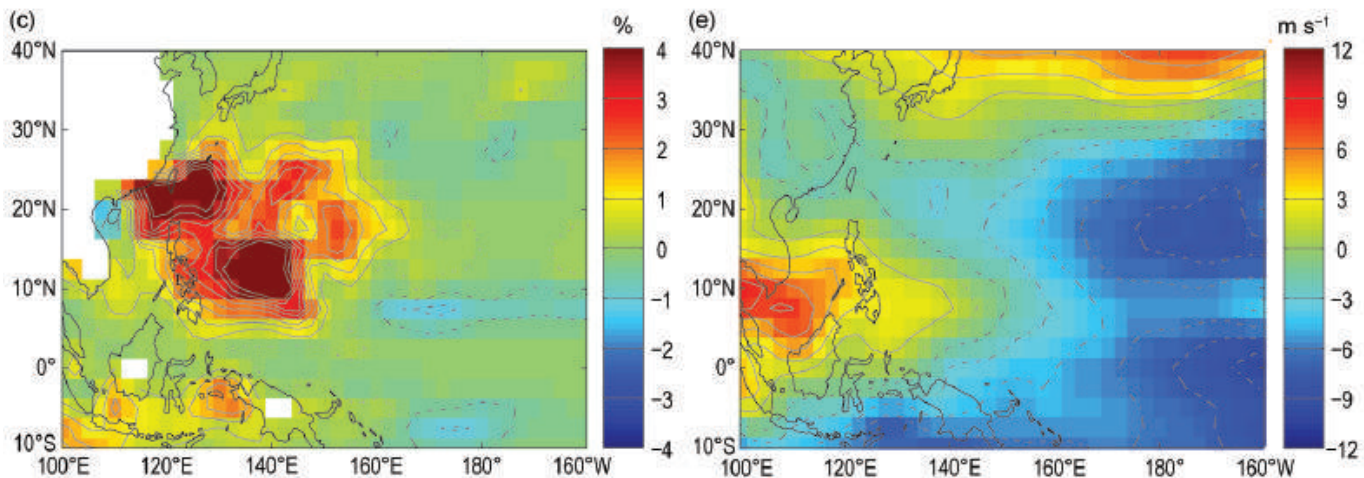

Fig. 4.33. (a) SST anomalies ( ${ }^{\circ} \mathrm{C}$ ) for Jul-Oct (JASO) in 2016. (b) PI anomalies (kt) in JASO 2016. (c) Relative humidity 600-hPa anomalies (\%) in JASO 2016. (d) GPI anomalies in JASO 2016. (e) $850-\mathrm{hPa}$ zonal winds $\left(\mathrm{m} \mathrm{s}^{-1}\right)$ in JASO 2016 (positive contours are shown in solid lines, negative contours in dash dotted lines and the zero contour in a dotted line) [Source: Atmospheric variables: NCEP-NCAR reanalysis data (Kalnay et al. 1996); sea surface temperature (Smith et al. 2008).]

pattern is reflected in other environmental fields, as can be seen in the anomalies for the potential intensity (PI; Emanuel 1988; Fig. 4.33b), 600-hPa relative humidity (Fig. $4.33 \mathrm{c}$ ), and genesis potential index (GPI; Emanuel and Nolan 2004; Camargo et al. 2007; Fig. 4.33d). All of these were positive in the western portion of the basin and negative in the eastern portion, which is typical of La Niña years. The GPI anomalies were at maximum south of Japan, in the region of high occurrence of TCs that affected the Japanese islands. The monsoon trough, the maximum extent of zonal winds (Fig. 4.33e), was confined to the area west of $140^{\circ} \mathrm{E}$ and was consistent with the westward shift of cyclogenesis locations in 2016.

\section{(iii) TC impacts}

Nineteen storms made landfall in $2016^{2}$, slightly above the 1951-2010 climatological median (17). Of these, four systems made landfall as a tropical depression (median is three), seven as tropical storms (median is six), and four as category 1-2 typhoons (median is five). Four Typhoons-Haima, Megi, Nock-Ten, and Sarika-all made landfall as major tropical cyclones (categories 3-5), in the top quartile.

${ }^{2}$ Landfall is defined with the storm track is over land and the previous location was over ocean. In order not to miss landfall over small islands, first the tracks were interpolated from 6-hourly to 15 minutes intervals, before determining if the storm track was over land or ocean using a high-resolution land mask. 
Haima and Sarika made landfall in the Philippines and China, Megi in Taiwan and China, Nock-ten in the Philippines; in all cases, the first landfall was the most intense, and three of these affected the Philippines. The Japanese islands had a large number of landfalls in 2016: Tropical Depression 03W, and Typhoons Chanthu, Kompasu, Lionrock, Malakas, Mindulle, and Namtheun; this was the second largest annual number of typhoon landfalls in Japan since 1951, tied with the 1990 and 1993 seasons, according to the Japan Meteorological Agency.

Many storms resulted in significant socioeconomic impacts in 2016. Supertyphoon Nepartak made landfall in Taiwan and the Fujian province in China in July, killing at least 83 people, mostly in Fujian, as well as causing $\$ 1.5$ billion (U.S. dollars) of direct economic losses. Taiwan and the Fujian province were hit again by Supertyphoon Meranti in September. Sidebar 4.2 provides more details on the storms that struck Taiwan in 2016. Meranti also affected the Philippine island of Itbayat, where a "state of calamity" was declared. Meranti was one of the strongest storms to hit Fujian in the historical record, leading to extensive damage due to flash floods. Typhoon Lionrock made landfall in Japan and Russia, causing fatalities and economic losses in both countries, as well as flooding in both China and North Korea. The North Korea floods were extensive and affected a large area, killing at least 525 .

\section{5) NORTH Indian OCEAN BASIN-M. C. Kruk}

The North Indian Ocean (NIO) TC season typically extends from April to December, with two peaks in activity: during May-June and again in November, when the monsoon trough is positioned over tropical waters in the basin. TCs in the NIO basin normally develop over the Arabian Sea and Bay of Bengal between $8^{\circ}$ and $15^{\circ} \mathrm{N}$. These systems are usually shortlived and relatively weak and often quickly move into the Indian subcontinent (Gray 1968; Schreck et al. 2014).

According to the JTWC, the 2016 TC season produced five tropical storms, one cyclone, and no major cyclones (Fig. 4.34a). The 1981-2010 IBTrACS seasonal averages for the basin are 3.9 tropical storms, 1.4 cyclones, and 0.6 major cyclones (Schreck et al. 2014). The season produced its lowest ACE index since 2012 with a value of $14.0 \times 10^{4} \mathrm{kt}^{2}$ but near the 1981-2010 mean of $12.5 \times 10^{4} \mathrm{kt}^{2}$ (Fig. 4.34b). Typically, there is enhanced TC activity, especially in the Bay of Bengal, during the cool phase of ENSO (Singh et al. 2000). While there was not yet a fully-developed La Niña during the season, four of the five storms developed in the Bay of Bengal and only one (Tropical Storm Two; 27-28 June) developed in the Arabian Sea.

The most intense storm of the season was Very Severe Cyclonic Storm (VSCS; wind speeds of 64-119 kt) Vardah, which formed on 6 December and dissipated on 13 December. Maximum sustained winds reached $74 \mathrm{kt}\left(38 \mathrm{~m} \mathrm{~s}^{-1}\right)$, with a minimum central pressure of $982 \mathrm{hPa}$. Vardah made landfall over the eastern coast of India near Chennai, Tamil Nadu, on 12 December with winds of $56 \mathrm{kt}\left(29 \mathrm{~m} \mathrm{~s}^{-1}\right)$. In Tamil Nadu, the cyclone was blamed for at least 18 fatalities and extensive damage to local road and electrical infrastructure. The storm also brought flooding rains (upwards of $250 \mathrm{~mm}$ ), which further damaged area roadways, restricted access to public transportation, and is believed to have caused the deaths of nearly six dozen cattle, which were found afloat in a lake in the Kancheepurm district.

In contrast to VSCS Vardah, Cyclonic Storm Roanu (17-23 May) was a weak tropical cyclone in the Bay of Bengal but caused extensive flooding in Sri
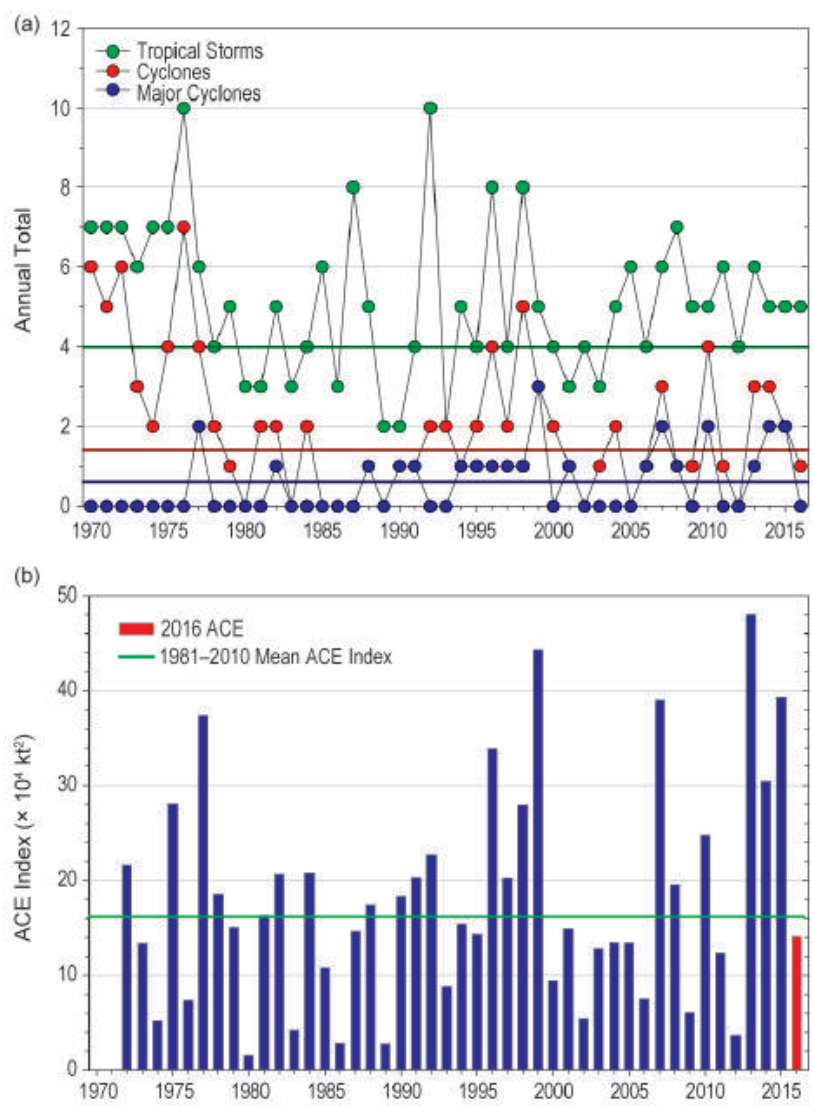

Fig. 4.34. Annual TC statistics for the NIO for 19702016: (a) number of tropical storms, cyclones, and major cyclones and (b) the estimated annual ACE index $\left(10^{4} \mathrm{kt}^{2}\right)$ for all TCs having at least tropical storm strength or greater intensity (Bell et al. 2000). The 1981-2000 means (green lines) are included in both (a) and (b). 
Lanka and Bangladesh. While the storm had weakened to a tropical depression before interacting with land, the system brought torrential rains to Sri Lanka: $373.3 \mathrm{~mm}$ of rain was recorded in Kilinochchi in just 24 hours on 16 May; $145.8 \mathrm{~mm}$ of rain fell on 15 May in Pottuvil; and the highest rainfall total on 17 May was in Mahailukpallama with $267.8 \mathrm{~mm}$. Meanwhile, in Bangladesh, a storm surge of $2 \mathrm{~m}$ above high tide caused 26 deaths as it overtopped area dams. The damage from the storm surge was significant, as it washed away food storage containers, seasonal crops, livestock, and fish and shrimp farms.

6) SOUTH INDIAN OCEAN BASIN-M. C. Kruk and C. Schreck The South Indian Ocean (SIO) basin extends south of the equator from the African coastline to $90^{\circ} \mathrm{E}$, with most cyclones developing south of $10^{\circ} \mathrm{S}$. The SIO TC season extends from July to June encompassing equal portions of two calendar years (the 2016 season includes storms from July to December 2015 and from January to June 2016). Peak activity typically occurs
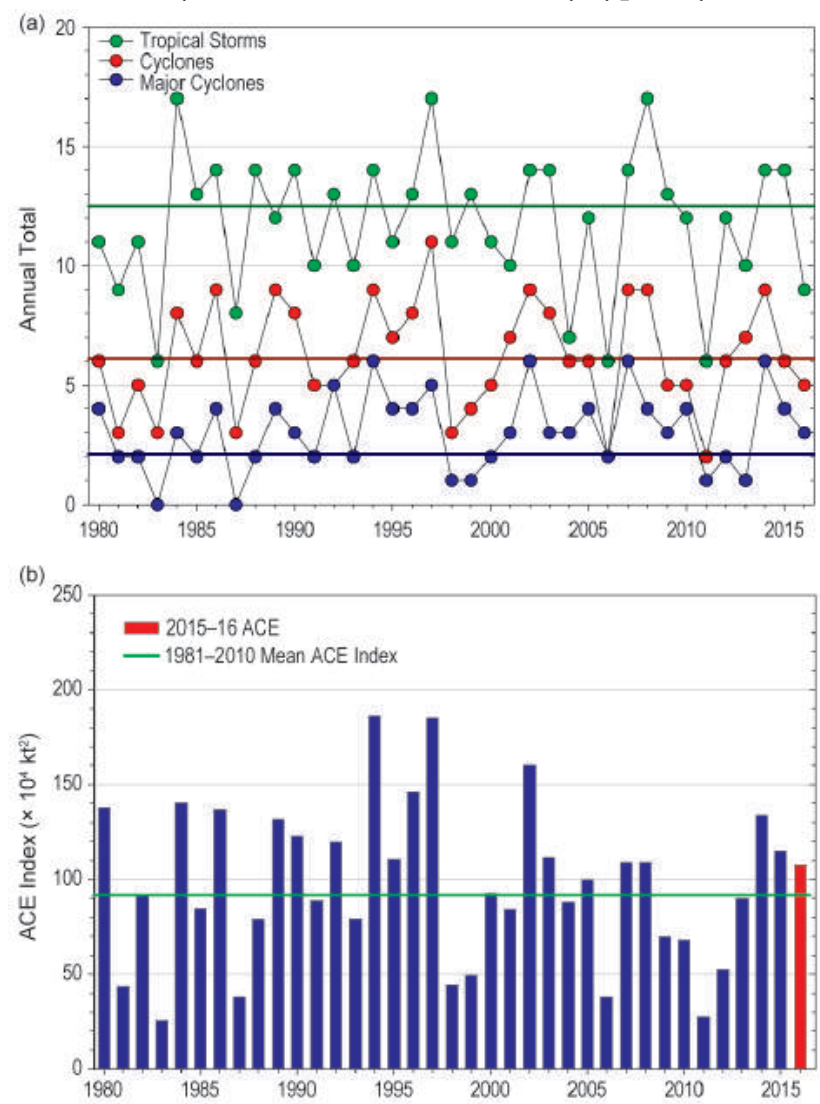

FIG. 4.35. Annual TC statistics for the SIO for 19802016: (a) number of tropical storms, cyclones, and major cyclones and (b) the estimated annual ACE index $\left(10^{4} \mathrm{kt}^{2}\right)$ for all TCs having at least tropical storm strength or greater intensity (Bell et al. 2000). The 198I-2000 means (green lines) are included in both (a) and (b). during December-April when the ITCZ is located in the Southern Hemisphere and migrating toward the equator. Historically, the vast majority of landfalling cyclones in the SIO affect Madagascar, Mozambique, and the Mascarene Islands, including Mauritius and Réunion Island. The Regional Specialized Meteorological Centre on La Réunion serves as the official monitoring agency for TC activity within the basin.

The 2015/16 SIO storm season was near average with eight tropical storms, of which five were cyclones and three were major cyclones (Fig. 4.35a). The 1981-2010 IBTrACS seasonal median averages are eight tropical storms, four cyclones, and one major cyclone (Schreck et al. 2014). The 2015/16 seasonal ACE index was $107.8 \times 10^{4} \mathrm{kt}^{2}$, which was above the 1981-2010 average of $91.5 \times 10^{4} \mathrm{kt}^{2}$ (Fig. 4.35b), and was dominated by Cyclone Fantala which accounted for $48 \%$ of the total seasonal ACE index. This is the third consecutive year with above-average ACE value for the SIO, in part due to continued warmer-than-normal SSTs (Fig. 4.36a). SSTs were above normal throughout the basin, and most of the storms formed near the peak warm anomalies of about $+0.8^{\circ} \mathrm{C}$ centered around $15^{\circ} \mathrm{S}, 70^{\circ} \mathrm{E}$. Convection, as indicated by OLR (Fig. 4.36b), was also slightly elevated in that region, and the equatorial latitudes featured anomalously weak vertical wind shear (Fig. 4.36c). The monsoon trough was also enhanced, as indicated by $850-\mathrm{hPa}$ westerly anomalies (Fig. 4.36d). All these ingredients combined to produce the above-average activity.

During the 2015/16 season, the strongest storm was Cyclone Fantala (11-23 April), which reached category 5 equivalent with peak sustained winds of $150 \mathrm{kt}$ $\left(77 \mathrm{~m} \mathrm{~s}^{-1}\right)$ and an estimated minimum central pressure of $910 \mathrm{hPa}$. The storm formed in the middle of the South Indian Ocean and remained there throughout its lifecycle, generally moving west before weakening due to increased vertical wind shear. While the cyclone never officially made landfall, its outer rainbands did affect a few locations, including the Farquhar Group of the Seychelles (see Chapter 7e5 for more details) and eventually Tanzania. In the Farquhar Group, an estimated 50 structures were severely damaged and many trees were toppled. The island group was declared a disaster area by the Seychelles government and was later visited by the United Nations Secretary-General. In all, an estimated $\$ 4.5$ million (U.S. dollars) in damages were reported in the Farquhar Group archipelago. The cyclone continued westward and its remnant circulation made a close approach to Tanzania, causing tremendous flooding in the Kilimanjaro Region, including the loss of nearly 12000 ha (29 000 acres) of crop fields. 

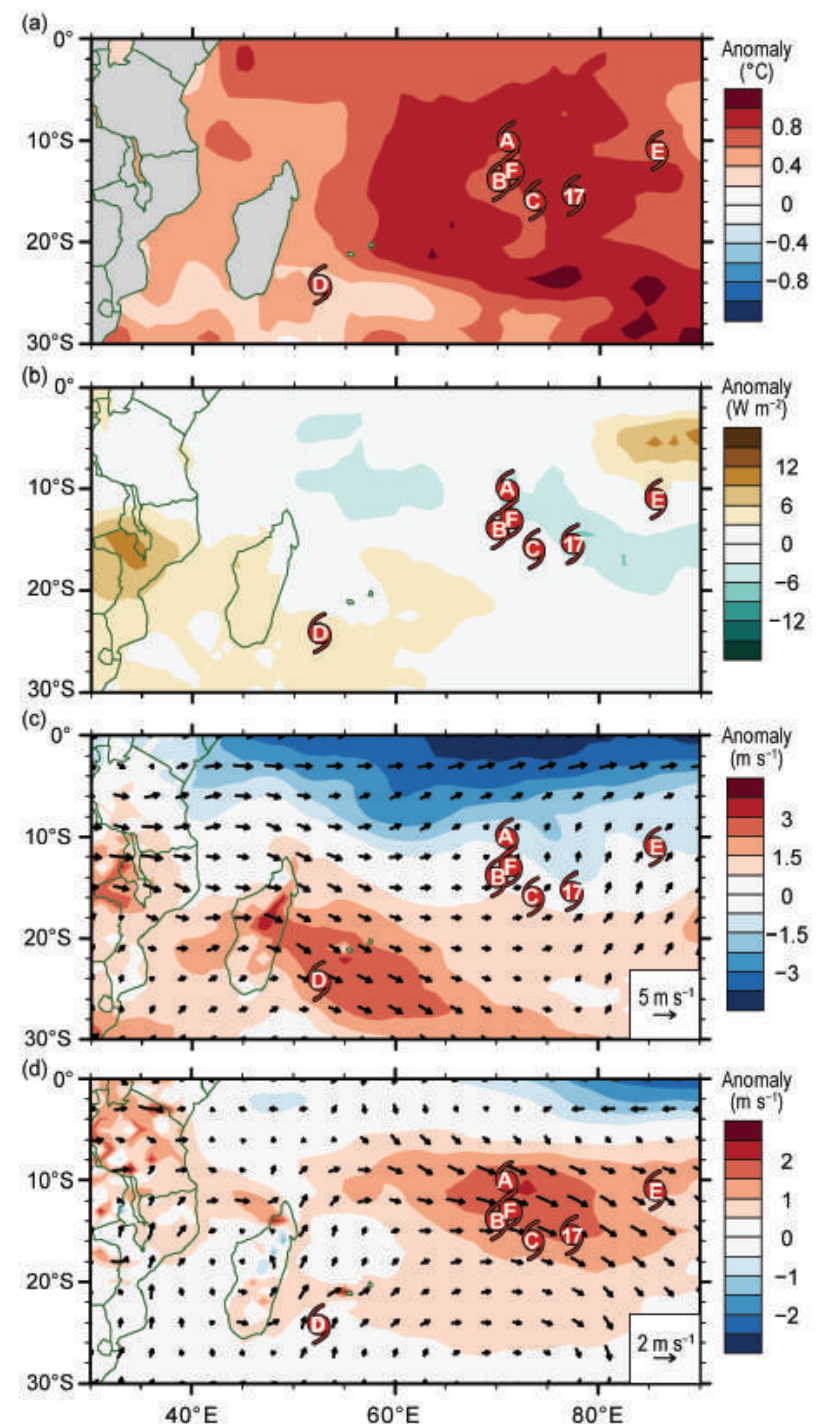

Fig. 4.36. Jul 2015-Jun 2016 anomaly maps of (a) SST ( ${ }^{\circ} \mathrm{C}$; Banzon and Reynolds 2013), (b) OLR (W m ${ }^{-2}$; Lee 2014), (c) 200-850-hPa vertical wind shear $\left(\mathrm{m} \mathrm{s}^{-1}\right)$ vector (arrows) and scalar (shading) anomalies, and (d) $850-\mathrm{hPa}$ winds ( $\mathrm{m} \mathrm{s}^{-1}$ arrows) and zonal wind (shading) anomalies. Anomalies are relative to $198 \mid-2010$, except for SST which is relative to 1982-2010 due to data availability. Letter symbols denote where each SIO TC attained tropical storm intensity. Wind data obtained from CFSR (Saha et al. 2014).

\section{7) Australian basin-B. C. Trewin \\ (i) Seasonal activity}

Typical of a strong El Niño year (Camargo et al. 2007), the 2015/16 TC season saw activity well below normal in the broader Australian basin (areas south of the equator and between $90^{\circ} \mathrm{E}$ and $160^{\circ} \mathrm{E}^{3}$, which

${ }^{3}$ The Australian Bureau of Meteorology's warning area overlaps both the southern Indian Ocean and Southwest Pacific. includes Australian, Papua New Guinean, and Indonesian areas of responsibility). The season produced three TCs, the least active season on record since satellite observations began in 1970 and well below the 1983/84-2010/11 average of 10.8; the previous record low was five, in 1987/88 and 2006/07. (Averages are taken from 1983/84 onwards as that is the start of consistent satellite coverage of the region capable of resolving cyclone intensity.) It was also the first season in the satellite era with no severe tropical cyclones (category 3 or above on the Australian scale; see www.bom.gov.au/cyclone/about/intensity.shtml for the Australian tropical cyclone classification system), with all three cyclones reaching a peak intensity of category 2 while in the Australian region. (Uriah intensified further after leaving the Australian region; see below.) The 1981-2010 IBTrACS seasonal averages for the basin are 9.9 NSs, 7.5 TCs, and 4.0 major TCs (Schreck et al. 2014), which compares with the 2015/16 counts of 3, 1, and 0, respectively (Fig. 4.37).
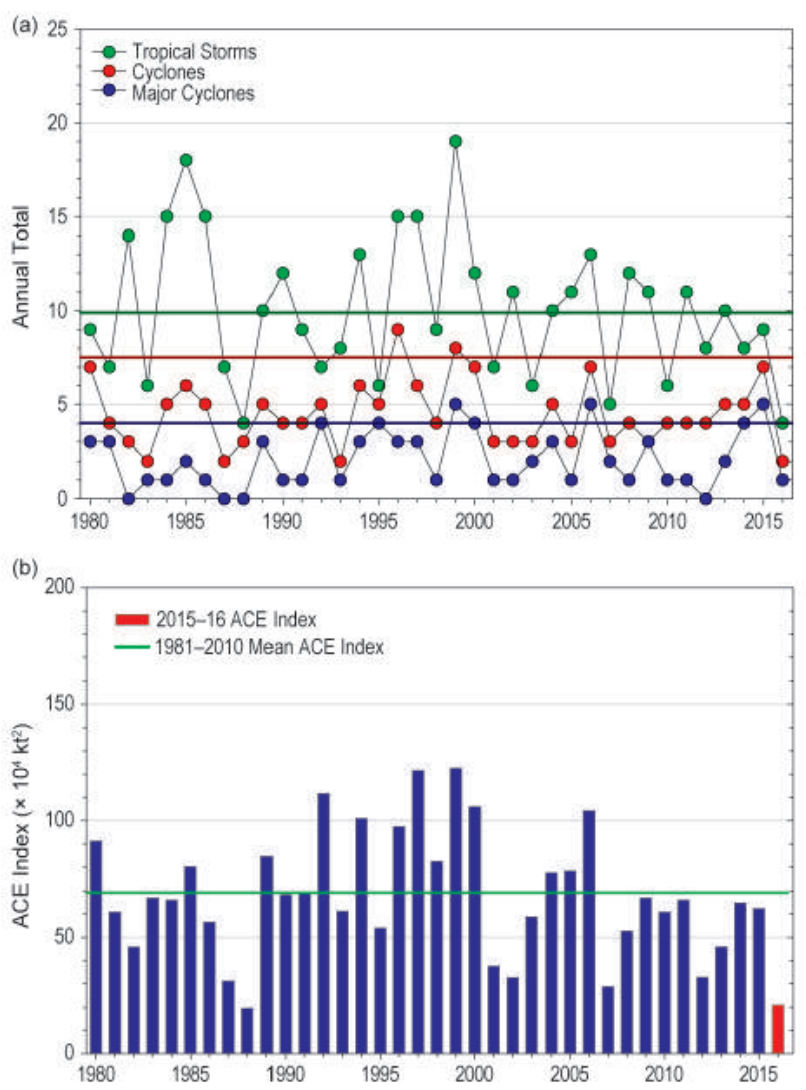

FIg. 4.37. Annual TC statistics for the Australian basin for 1980-2016: (a) number of tropical storms, cyclones, and major cyclones and (b) the estimated annual ACE index $\left(10^{4} \mathrm{kt}^{2}\right)$ for all TCs having at least tropical storm strength or greater intensity (Bell et al. 2000). The 1981-2000 means (green lines) are included in both (a) and (b). 
One TC occurred in the eastern sector ${ }^{4}$ of the Australian region during 2015/16, none in the northern sector, and two in the western sector. Only one cyclone made landfall during the season-equal to the record low in the post-1970 period.

\section{(ii) Landfalling and other significant TCs}

The only landfalling cyclone during the season was Stan. A low formed on 27 January and was named Tropical Cyclone Stan early on 29 January, near $17^{\circ} \mathrm{S}, 118^{\circ} \mathrm{E}$. It moved south-southeast and intensified slightly as it approached the western Australian coast. It made landfall near Pardoo Station, east of Port Hedland, early on 31 January while near its peak intensity, with maximum sustained 10 -minute winds of $55 \mathrm{kt}\left(28 \mathrm{~m} \mathrm{~s}^{-1}\right)$. Stan caused some flooding as it moved inland but only minor wind damage was reported.

Uriah reached tropical cyclone intensity on 13 February while west of the Cocos (Keeling) Islands, having caused some minor wind damage and road erosion on the islands during its formation phase. It continued to intensify as it moved towards the western boundary of the Australian region, with maximum sustained winds of $50 \mathrm{kt}\left(26 \mathrm{~m} \mathrm{~s}^{-1}\right)$ as it moved into La Réunion's area of responsibility on 14 February.

8) Southwest Pacific basin—P. R. Pearce, A. M. Lorrey, and H. J. Diamond

(i) Seasonal activity

The 2015/16 TC season in the Southwest Pacific began in late November. Storm track data for November 2015-April 2016 was gathered by the Fiji Meteorological Service, Australian Bureau of Meteorology, and New Zealand MetService, Ltd. The Southwest Pacific basin as defined by Diamond et al. $\left(2012 ; 135^{\circ} \mathrm{E}-120^{\circ} \mathrm{W}\right)$ had eight tropical cyclones, including five major tropical cyclones (based on the Australian TC intensity scale) which is slightly below the 1981-2010 average. Figure 4.38 shows a TC distribution based on the basin spanning the area from $160^{\circ} \mathrm{E}-120^{\circ} \mathrm{W}$ to avoid overlaps with the Australian basin that could result in double counting of storms. However, it is important to use the above definition of the Southwest Pacific basin as that is how annual TC outlooks are produced and disseminated.

\footnotetext{
${ }^{4}$ The western sector covers areas between $90^{\circ}$ and $125^{\circ} \mathrm{E}$. The eastern sector covers areas east of the eastern Australian coast to $160^{\circ} \mathrm{E}$, as well as the eastern half of the Gulf of Carpentaria. The northern sector covers areas from $125^{\circ} \mathrm{E}$ east to the western half of the Gulf of Carpentaria.
}
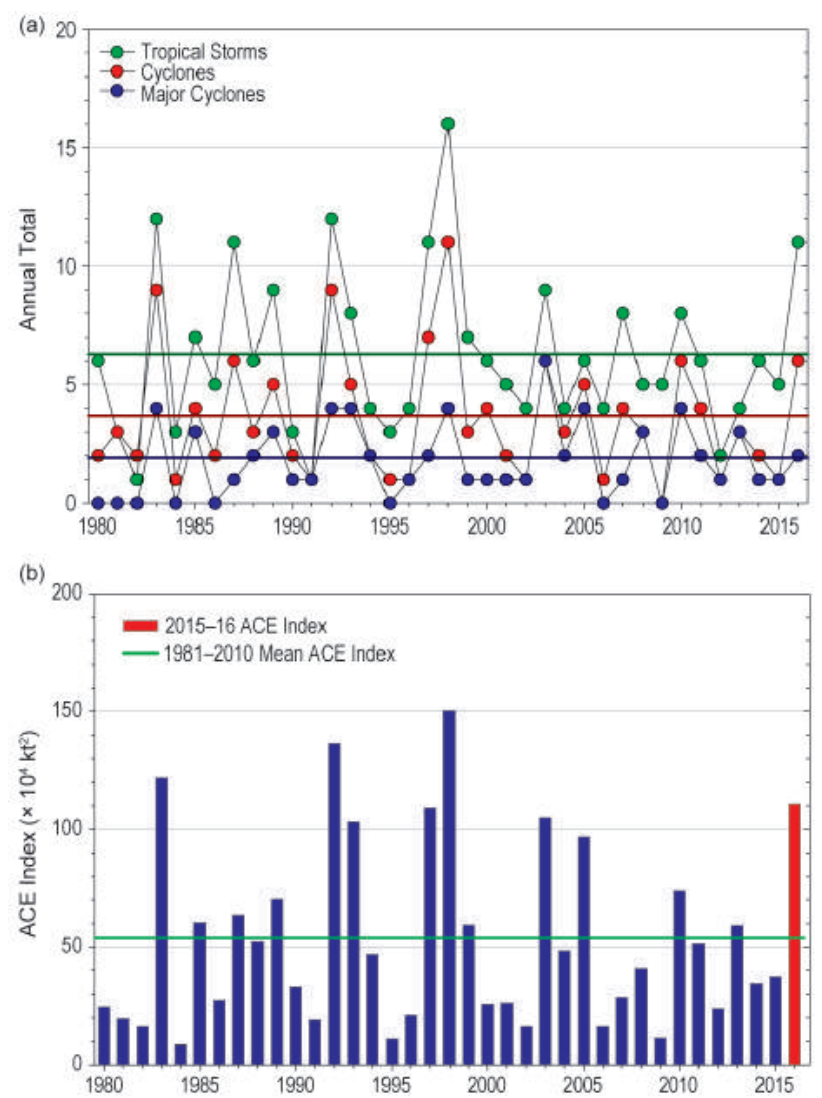

Fig. 4.38. Annual TC statistics for the southwest Pacific for 1980-2016: (a) number of tropical storms, cyclones, and major cyclones and (b) the estimated annual ACE index $\left(10^{4} \mathrm{kt}^{2}\right)$ for all TCs having at least tropical storm strength or greater intensity (Bell et al. 2000). The 1981-2000 means (green lines) are included in both (a) and (b).

The 1981-2010 normals from the Southwest Pacific Enhanced Archive of Tropical Cyclones (SPEArTC; Diamond et al. 2012) indicate a seasonal average of 10.4 named tropical cyclones and 4.3 major tropical cyclones. The first storm (Tropical Cyclone Tuni) developed as a tropical disturbance near Fiji in November, and the season concluded in late April with Major Tropical Cyclone Amos affecting Fiji, Samoa, American Samoa, and Wallis and Futuna. The ratio of major TCs relative to the total number of named TCs in 2015/16 was 63\%, up from 56\% during the previous season.

\section{(ii) Landfalling and other significant TCs}

The first named TC of the 2015/16 season was reported as a tropical disturbance on 23 November to the northeast of the Suva, Fiji. Tropical Cyclone Tuni reached category 1 status, with peak 10-minute sustained wind speeds of $41 \mathrm{kt}\left(21 \mathrm{~m} \mathrm{~s}^{-1}\right)$ and central pressure of $991 \mathrm{hPa}$ at its lowest. Across Samoa and American Samoa, Tuni produced strong winds and 
heavy rain. Some trees were uprooted, and plantations, shacks, and garages in American Samoa sustained damage with total losses amounting to $\$ 5$ million (U.S. dollars). By 30 November, Tuni had completed extratropical transition.

The first major tropical cyclone of the season was Major Tropical Cyclone Ula. Ula formed southeast of the Solomon Islands on 26 December. Over the next few days the system moved eastwards and intensified, achieving category 1 TC status on 30 December when it was located northeast of Samoa. Ula achieved peak intensity as a category 4 Major TC with 10-minute sustained winds of $100 \mathrm{kt}\left(51.3 \mathrm{~m} \mathrm{~s}^{-1}\right)$ and minimum central pressure of $945 \mathrm{hPa}$. Dozens of structures were damaged or destroyed in Tuvalu while buildings and crops in Tonga, Fiji, and Vanuatu were impacted. On 12 January, Ula underwent extratropical transition.

Major Tropical Cyclone Victor was the second major tropical cyclone of the season having formed on 10 January 2016 northwest of the Northern Cook Islands. It eventually reached category 3 status on 18 January; its peak 10 -minute sustained wind speed was $81 \mathrm{kt}\left(41.7 \mathrm{~m} \mathrm{~s}^{-1}\right)$ and central pressure was $960 \mathrm{hPa}$ at its lowest. Major TC Victor traveled southwest over open water between Niue and the Cook Islands and underwent extratropical transition on 24 January.

Major Tropical Cyclone Winston was the strongest tropical cyclone to make landfall in Fiji and the South Pacific Basin in recorded history. It was also the only category 5 TC of the 2015/16 season. Major TC Winston was first noted as a tropical disturbance on 7 February to the northwest of Port Vila, Vanuatu. Over the next few days, the system gradually developed as it moved southeast, acquiring category 1 TC status on 11 February when it was located west-northwest of Fiji. On 12 February, Winston underwent rapid intensification and attained category 4 status that same day due to very favorable conditions. Less favorable environmental conditions prompted weakening thereafter, and Winston moved to the northeast and degraded below major TC status on 15 February. Later that day, Winston reintensified and regained major TC status. On 17 February, Winston stalled to the north of Tonga. Due to a change in higher level steering winds, the storm traveled back towards the west. In the process, TC Winston rapidly intensified, reaching category 5 strength on 19 February. Per the Fiji Meteorological Service's February 2016 Climate Summary report, Winston passed directly over Vanua Balavu in Fiji on 20 February, where a national record wind gust of $165 \mathrm{kt}\left(85 \mathrm{~m} \mathrm{~s}^{-1}\right)$ was observed before the weather station was destroyed. At its peak on 20 February (and now documented in SPEArTC), Major TC Winston had 10-minute sustained winds of $150 \mathrm{kt}\left(77.2 \mathrm{~m} \mathrm{~s}^{-1}\right)$ and a minimum central pressure of $884 \mathrm{hPa}$ at its lowest (as analyzed by the RSMC in Nadi, Fiji), shortly before making landfall on Viti Levu, Fiji. Thereafter, the storm slowly weakened and moved to the southeast. Winston dissipated on 3 March, 26 days after being classified a tropical disturbance.

Major TC Winston inflicted extensive damage on many islands. It killed 44 people in Fiji, with an additional 126 injured. Communications were temporarily lost for at least six islands, and some locations remained isolated for more than two days after the storm passed. Entire communities were destroyed in parts of Fiji, including a total of 40000 homes that were damaged or destroyed. Approximately 350000 people ( $40 \%$ of Fiji's population) were significantly impacted by the storm, and tens of thousands were made homeless. Approximately $80 \%$ of the nation's 900 000 people lost power, including the entirety of Vanua Levu, as extreme winds downed trees and power lines. A national state of emergency was declared in Fiji for 60 days following the storm. The total cost of damage in Fiji from TC Winston amounted to $\$ 1.4$ billion (U.S. dollars), making it the costliest cyclone in Southwest Pacific history.

Major TC Winston also affected Tonga, destroying 10 homes and damaging 200 more. On Vava'u, 85\%$95 \%$ of the banana crop and most of the vanilla crop was lost. Niue experienced damaging heavy swells from the storm. After its extratropical transition, Winston caused abnormally high tides and dangerous surf conditions along the southern Queensland coast in late February, with maximum wave heights of approximately $9 \mathrm{~m}$ off North Stradbroke Island. As a result, beaches on Queensland's Gold Coast and Sunshine Coast were closed from 26-27 February due to dangerous sea conditions, and at least 15 people sustained injuries due to the rough conditions. Winston went on to produce heavy rain in parts of the tropical east coast and ranges of Queensland in early March, with daily totals locally exceeding $200 \mathrm{~mm}$ (see Chapter $7 \mathrm{~h} 2$ for more details).

Tropical Cyclone Tatiana developed within the central Coral Sea on 9 February. Over the next few days the system gradually developed as it moved eastwards, peaking as a category 2 TC on 12 February with 10 -minute sustained winds of $51 \mathrm{kt}\left(26.4 \mathrm{~m} \mathrm{~s}^{-1}\right)$ and central pressure of $983 \mathrm{hPa}$ at its lowest. On 14 February, Tatiana rapidly weakened and degenerated into a subtropical low. It produced powerful, long period swells along southeast Queensland beaches. In late February, TC Yalo formed to the northwest of Tahiti, French Polynesia, and attained category 1 
status before rapidly decaying due to high wind shear. It did not cause any notable damage.

Just six weeks after TC Winston destroyed parts of Fiji, Major Tropical Cyclone Zena passed to the south of the country on April 4. Zena peaked as a category 3 Major TC, with 10-minute sustained winds measuring $70 \mathrm{kt}\left(36.1 \mathrm{~m} \mathrm{~s}^{-1}\right)$ and central pressure $975 \mathrm{hPa}$ at its lowest. Zena caused flooding in parts of Fiji but no significant damage. After passing Fiji, Zena traveled to Tonga where it caused heavy rain.

The last named tropical cyclone of the 2015/16 season was Major Tropical Cyclone Amos. Amos was first noted as a tropical disturbance on 13 April, when it was located to the northwest of Rotuma. The precursor to Major TC Amos caused flooding in Vanua Levu, Fiji, followed by very heavy rain and large waves in Wallis and Futuna after the storm achieved named TC status. The system subsequently moved southeast over Fiji on 16 April. After passing over Fiji, the system developed further as it moved northeast toward Samoa. The depression moved northwest toward Tuvalu and passed between the islands of Wallis and Futuna. Amos was named on 20 April and rapidly intensified as it moved east toward the Samoan Islands. Amos peaked as a category 3 Major TC, with 10-minute sustained wind speeds of $81 \mathrm{kt}$ $\left(41.7 \mathrm{~m} \mathrm{~s}^{-1}\right)$ during 22 April. Amos passed very close to or over Samoa during 23 April and then degraded into a tropical disturbance on 25 April. In Savai'i (Samoa), roads were damaged due to flooding, and approximately $70 \%$ of Samoa's population lost power during TC Amos due to high winds.

g. Tropical cyclone heat potential—G. J. Goni, J. A. Knaff, and $\mathrm{I}-\mathrm{I}$ Lin

This section summarizes the changes in upper ocean thermal conditions within the seven tropical cyclone (TC) basins, using the tropical cyclone heat potential (TCHP; Goni and Trinanes 2003), a measure of the vertically-integrated upper ocean temperature conditions. The TCHP, defined as the excess heat content contained in the water column between the sea surface and the depth of the $26^{\circ} \mathrm{C}$ isotherm, has been linked to TC intensity changes (Shay et al. 2000; Goni and Trinanes 2003; I-I Lin et al. 2014) when favorable atmospheric conditions are also in place. In addition, the magnitude of the TCHP has also been identified as impacting the maximum potential intensity (Emanuel 1986; Bister and Emanuel 1998) through the modulating effect of the SST underlying the TC air-sea coupling (Mainelli et al. 2008; Lin et al. 2013). In general, fields of TCHP show high spatial and temporal variability associated mainly with oceanic mesoscale features and interannual variability (e.g., ENSO), or long-term decadal variability. This variability can be identified using satellite altimetry and in situ observations (Goni et al. 1996; Lin et al. 2008; Goni and Knaff 2009; Pun et al. 2013; Domingues et al. 2015), similar to analyses of meridional heat transport in the Atlantic Ocean (Dong et al. 2015).

To examine the TCHP year-to-year variability, two fields are presented here: 1) the TCHP anomalies (departures from the 1993-2015 mean values) during the months of TC activity in each hemisphere: June-November in the Northern Hemisphere, and November-April in the Southern Hemisphere, which generally show large variability within and among the TC basins (Fig. 4.39); and 2) differences of TCHP between the most recent (2016) and the previous TC season in 2015 (Fig. 4.40).

Most basins exhibited positive TCHP anomalies (Fig. 4.39), except for a small region just east of the date line in the South Pacific basin, providing anomalously favorable ocean conditions for the intensification of tropical cyclones. The western North Pacific basin is characterized by an increase in TCHP of 10\%-20\% over the long-term average, as it recovered from the reduction of TCHP during the 2015 El Niño event (Zheng et al. 2015). Intrusions of the Loop Current in the Gulf of Mexico contribute to the generation of deep warm eddies, characterized by large TCHP values. The TCHP in the western Gulf

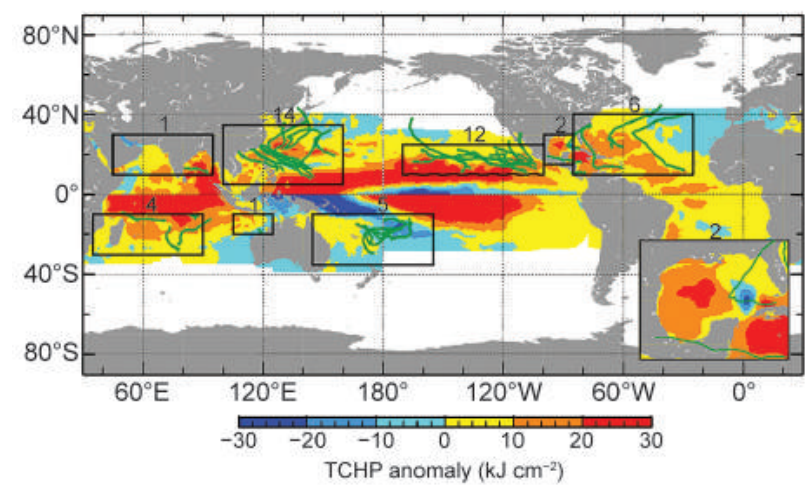

FIG. 4.39. Global anomalies of TCHP $\left(\mathrm{kJ} \mathrm{cm}^{-2}\right)$ for JunNov 2016 in the NH and Nov-Apr 2015/16 in the SH as described in the text. The boxes indicate 7 regions where TCs occur: from left to right, Southwest Indian, North Indian, West Pacific, Southeast Indian, South Pacific, East Pacific, and North Atlantic (shown as Gulf of Mexico and tropical Atlantic separately). Green lines indicate the trajectories of all tropical cyclones reaching at least category $I$ and above during Jun-Nov 2016 in the NH and Nov 2015-Apr 2016 in the SH. Numbers above each box correspond to the number of category $I$ and above cyclones that traveled within each box. Gulf of Mexico conditions during Jun-Nov 2016 are shown in the inset in the lower right corner. 


\section{SIDEBAR 4.2: TAIWAN IN THE BULLSEYE OF SEVERAL MAJOR}

TYPHOONS-II LIN, M.-M. LU, AND M.-D. CHENG

During summer 2016, Taiwan was hit by a series of three major typhoons (Supertyphoons Nepartak and Meranti, and Typhoon Megi), with a fourth typhoon (Malakas) nearly making landfall (Fig. SB4.3). It was one of the most severe seasons for a single region in the global record. Fortunately, with advances in disaster mitigation, prediction of landfall locations, and relatively fast typhoon translation speeds, the damage was not as severe as anticipated. The estimated total death toll in Taiwan from the direct impact of these typhoons was eight, according to the Taiwan government's Central Emergency Operation Center (www.emic.gov.tw), with other socioeconomic impacts (e.g., agricultural loss and power shortages) also reported.

The 2016 typhoon season started very late, with the first named storm, Nepartak, identified in early July. This late start likely resulted from the strong subsidence/weak cyclonic vorticity over the South China Sea and western North Pacific Ocean, possibly caused by the lingering influence of the strong El Niño conditions there (Wang and Chan 2002). On the other hand, oceanic conditions were becoming increasingly favorable with above-normal SSTs and tropical cyclone heat potential (TCHP) conditions (Goni et al. 2016; see also Section 4g) that readily supported Nepartak's intensification. After a few days of development, Nepartak reached category I on 5 July, and within 30 hours it rapidly intensified to its category-5 lifetime peak intensity of $150 \mathrm{kt}\left(77 \mathrm{~m} \mathrm{~s}^{-1}\right)$ on 6 July, making Nepartak one of the world's most intense tropical cyclones on record.

Nepartak maintained a peak intensity of $150 \mathrm{kt}\left(77 \mathrm{~m} \mathrm{~s}^{-1}\right)$ over favorable ocean conditions (with an SST of about $30^{\circ} \mathrm{C}$ and a TCHP value of about $120 \mathrm{KJ} \mathrm{cm}^{-2}$ ) for another day. At around 0000 UTC on 7 July, Nepartak encountered a pre-existing cold eddy at the western Pacific southern eddy zone (Lin et al. 2008), with the TCHP values having dropped to $50-60 \mathrm{KJ} \mathrm{cm}^{-2}$ (Shay et al. 2000; Lin et al. 2008). After passing over this cold ocean feature, it also passed over a small patch of warm water for a short while and soon after made landfall in southern Taiwan. Just prior to landfall, Nepartak's intensity was at $130 \mathrm{kt}\left(67 \mathrm{~m} \mathrm{~s}^{-1}\right)$ at 1800 UTC on 7 July and after landfall, at 0000 UTC on 8 July, it was reduced to $90 \mathrm{kt}\left(46 \mathrm{~m} \mathrm{~s}^{-1}\right.$; Fig. SB4.3). It is worth noting that two deep-ocean buoys from National Taiwan University's Institute of Oceanography were directly in the path of Nepartak as it approached Taiwan, with the storm's center passing close to or directly over the buoys. Post-calibration efforts are ongoing to analyze these rarely-captured data (see http://po.oc.ntu.edu.tw/buoy/typhoons.php).

The 2016 season then went into a rather quiet period with little activity near Taiwan. The lack of typhoon activity around Taiwan, specifically in August, was due to an unusually strong low pressure system over the subtropical western North Pacific which caused more-than-usual northward recurving of typhoon tracks toward Japan. The abnormal low pressure could be an intraseasonal wave excited from high latitudes (Bin Wang and Tim Li, University of Hawaii, personal communications).

At the beginning of September, western North Pacific typhoon activity ramped up considerably with four major typhoons developing (category 3 Typhoons Namtheun and Megi, category 4 Typhoon Malakas, and category 5 Typhoon Meranti). The increase in activity was likely related to the developing La Niña which enhances large-scale convergence over the western north Pacific Ocean east of the Philippines, the South China Sea, and the Maritime Continent (Chan 2000; Chia and Ropelewski 2002; Wang and Chan 2002). For example, reduced vertical wind shear over the western

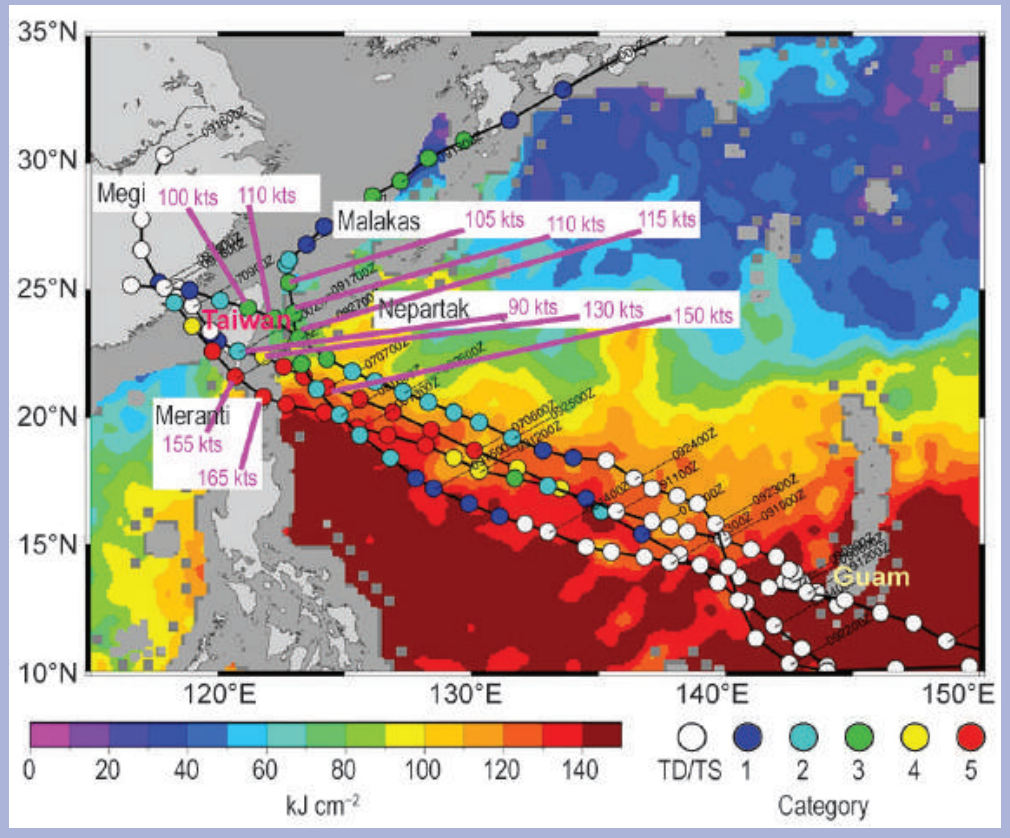

FIG. SB4.3. The tracks of four typhoons (Supertyphoons Nepartak and Meranti, category-4 Typhoon Malakas, and category-3 Typhoon Megi) approaching Taiwan. Typhoon's peak intensity and intensity closest to Taiwan are depicted. The background map is based on daily composite of the four pre-typhoon TCHP (i.e., integrated heat content from SST down to the $26^{\circ} \mathrm{C}$ isotherm depth) maps from 3 Jul, and 9, 12, and 22 Sep. 
Pacific main development region (east of the Philippines), as compared to both August and the long-term climatology, likely favored more TC activity.

With a peak intensity of $165 \mathrm{kt}\left(85 \mathrm{~m} \mathrm{~s}^{-1}\right)$, Supertyphoon Meranti was the most intense tropical cyclone on Earth in 2016. At a peak intensity only $5 \mathrm{kt}\left(3 \mathrm{~m} \mathrm{~s}^{-1}\right)$ below Supertyphoon Haiyan in 2013, Meranti was also the second most intense western North Pacific typhoon on record. It was first identified on 7 September near Guam and developed into a category I typhoon on II September over the Philippine Sea (Fig. SB4.3). Within 30 hours, it rapidly intensified to category 5 intensity of $155 \mathrm{kt}\left(80 \mathrm{~m} \mathrm{~s}^{-1}\right)$ and, in another day, reached an impressive intensity (I-I Lin et al. 2014) of $165 \mathrm{kt}\left(85 \mathrm{~m} \mathrm{~s}^{-1}\right)$. These intensity values were similar to those of Hurricane Patricia in 2015 at $185 \mathrm{kt}\left(95 \mathrm{~m} \mathrm{~s}^{-1}\right.$ ) (Foltz and Balaguru 2016); and Supertyphoon Haiyan in 2013 at $170 \mathrm{kt}\left(87 \mathrm{~m} \mathrm{~s}^{-1}\right)$. The peak intensities of these three storms were far above $\left(30-50 \mathrm{kt} ; 15-26 \mathrm{~m} \mathrm{~s}^{-1}\right)$ the existing category 5 threshold of $135 \mathrm{kt}\left(69 \mathrm{~m} \mathrm{~s}^{-1}\right)$ on the Saffir-Simpson scale.

Due to the strengthening of the subtropical high pressure system in September, Supertyphoon Meranti followed a westward track toward Taiwan (Figs. SB4.3, SB4.4). Throughout its intensification, Meranti was mostly over favorable ocean conditions with SSTs at about $30^{\circ} \mathrm{C}$ and TCHPs of about $130 \mathrm{~kJ} \mathrm{~cm}^{-2}$. After reaching its peak intensity of $165 \mathrm{kt}$ $\left(85 \mathrm{~m} \mathrm{~s}^{-1}\right)$ at 1200 UTC on 13 September, its northern sector encountered a pre-existing cold feature, which may have slightly weakened its intensity to $155 \mathrm{kt}\left(80 \mathrm{~m} \mathrm{~s}^{-1}\right)$. Meranti's center then passed over the waters close to the southern tip of Taiwan (Lu et al. 2013), with the northern half of the storm making landfall (Fig. SB4.4). Due to its large circulation, the entire Taiwan island was impacted by Meranti for another day following landfall.

Three days after Meranti's genesis, Typhoon Malakas formed in association with monsoon trough activity (Lia Wu et al. 2012; Fig. SB4.3). During its intensification phase, Malakas followed a track similar to that of Meranti. However, its intensification was not as drastic as it traveled over the weak cold wake region caused by the previous storm (e.g., Price 198I), with reduced SSTs and TCHP values. At 1800 UTC on 16 September, it reached its category 4 peak of $115 \mathrm{kt}\left(59 \mathrm{~m} \mathrm{~s}^{-1}\right)$ over the waters near eastern Taiwan. Due to the steering effect from a deep, shortwave trough to the west of Taiwan, Malakas traveled northward along the front of the trough. It did not make landfall in Taiwan but did eventually strike southern Japan where it caused substantial damage.
Shortly after the passages of Meranti and Malakas, Typhoon Megi formed on 2I September near Guam (Fig. SB4.3). As noted earlier, the strengthened subtropical high pressure in September guided the track of these typhoons, and all followed a similar westward track towards Taiwan. However, as Megi followed both Meranti and Malakas, ocean conditions along its track were not as favorable for development due to reduced SSTs (e.g., Price 198I). It took Megi three days to intensify from a category I to a category 3 typhoon, and it made landfall in central Taiwan on 27 September (Fig. SB4.3). Megi caused considerable damage, which included three deaths and the loss of electrical power to nearly 4 million households.

In retrospect, the 2016 typhoon season was an eventful and particularly intense one for Taiwan. Given the landfall of three major typhoons, including the most powerful tropical cyclone in 2016 (Meranti), the total number of deaths was fortunately limited to eight. It is interesting to note that while Supertyphoon Nepartak had a smaller outer circulation, it had very tight and intense winds near the center. Supertyphoon Meranti had a broad outer circulation, as well as very intense central winds. Typhoon Megi had a broad outer circulation with weaker winds around its center.

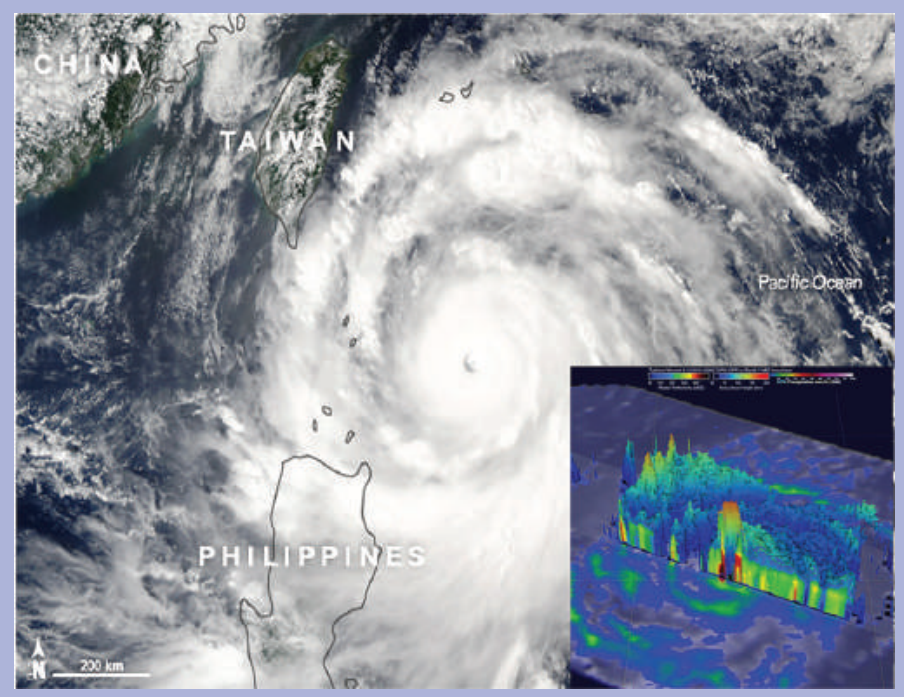

FIG. SB4.4. At an extraordinary intensity of $\sim 155-165 \mathrm{kts}$ (80-85 $\mathrm{m} \mathrm{s}^{-1}$ ), Supertyphoon Meranti approached Taiwan, as observed by NASA's MODIS on 13 Sep. The smaller figure at lower right was observed by NASA's GPM on 12 Sep, showing the extreme rainfall of $\sim 300 \mathrm{~mm} \mathrm{hr}^{-1}$ from Meranti, during its rapid intensification phase before reaching peak intensity. The "hot towers" (deep convective activities) of Meranti were observed to reach $>17 \mathrm{~km}$ in height by GPM's Ku band radar (Image courtesy: NASA Earth Observatory, www.nasa.gov/feature/goddard/2016/meranti-northwestern -pacific-ocean.) 


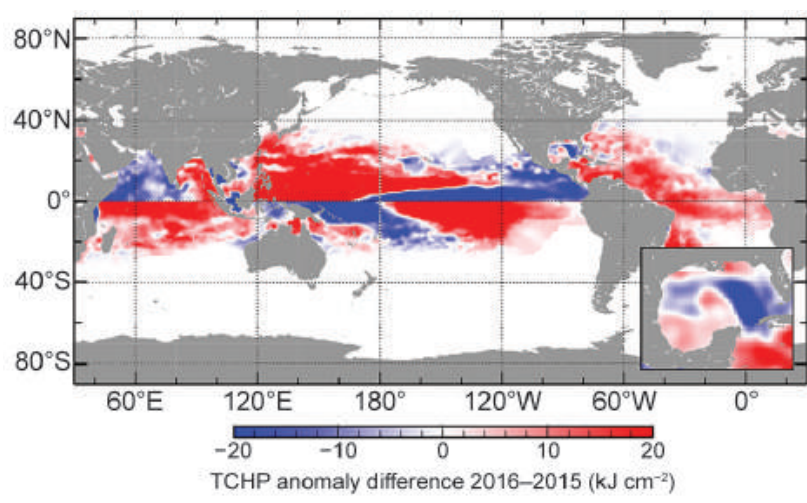

FIG. 4.40. Differences between the TCHP $\left(\mathrm{kJ} \mathrm{cm} \mathrm{cm}^{-2}\right)$ fields in 2016 and 2015 tropical cyclone seasons (JunNov in the NH, and Nov-Apr in the SH).

of Mexico was again dominated by large positive anomalies, probably due to such eddies, while the eastern Gulf of Mexico exhibited lower values of TCHP, mainly due to a smaller-than-usual intrusion of the Loop Current into the Gulf of Mexico. Unlike 2015, when the Gulf of Mexico did not register any hurricanes, this season had two hurricanes traveling in the area. One storm (before it was named Hermine) moved directly over the largest negative anomalies as a tropical depression and later intensified when traveling over positive anomalies of TCHP.

In the ENP basin the positive TCHP anomalies are dominated by the strong El Niño conditions observed during early 2016 and a continued positive phase of the Pacific decadal oscillation (Zhang et al. 1997). The combination of these two phenomena is manifest in positive SST anomalies in that region and extending beyond the date line. Consequently, the TCHP values during the last season were even higher than average (Fig. 4.39). As was the case in 2014 and 2015, positive TCHP and SST anomalies contributed to elevated tropical cyclone activity, with 12 hurricanes in the eastern North Pacific during 2016 (Fig. 4.39).

The western North Pacific basin also usually exhibits anomalies related to ENSO variability (I-I Lin et al. 2014; Zheng et al. 2015). From the 1990s to 2013 it experienced a long-term decadal surface and subsurface warming associated with La Niña-like conditions (Pun et al. 2013; England et al. 2014; Lin and Chan 2015). However, the development of El Niño in late 2014 resulted in a pause in this warming trend. Since 2015, the strongest El Niño year since 1997, the TCHP over the WNP MDR $\left(4^{\circ}-19^{\circ} \mathrm{N}, 122^{\circ} \mathrm{E}-180^{\circ}\right)$ fell considerably, as characterized by evident negative anomalies (Zheng et al. 2015; Goni et al. 2016). With the fading of El Niño in 2016 and the weak development of La Niña in the second half of the year, TCHP has recovered and shows positive anomalies again (Figs. 4.39, 4.40).
Supertyphoon Meranti's intensity reached $165 \mathrm{kt}$ $\left(85 \mathrm{~m} \mathrm{~s}^{-1}\right)$ and was the most intense TC globally in 2016. Meranti was only $5 \mathrm{kt}\left(2.6 \mathrm{~m} \mathrm{~s}^{-1}\right)$ weaker than Supertyphoon Haiyan (2013). Both Meranti and Haiyan (I-I Lin et al. 2014) intensified over very favorable ocean conditions of TCHP $\sim 130 \mathrm{~kJ} \mathrm{~cm}^{-2}$ (Lin et al. 2013; for additional details see Sidebar 4.2). Supertyphoon Nepartak was one of the most intense "first-appearing TC" of the season in recorded history-with its genesis in the month of July, Nepartak rapidly intensified while traveling over very warm water (TCHP $\sim 120 \mathrm{~kJ} \mathrm{~cm}^{-2}$ ) to its peak intensity of $150 \mathrm{kt}\left(77 \mathrm{~m} \mathrm{~s}^{-1}\right)$ on 6 July. It then made landfall in Taiwan. Further details on Meranti and Nepartak can be found in Section $4 \mathrm{f} 4$ and Sidebar 4.2.

The 2016 season was noteworthy for several reasons with respect to intensification of tropical cyclones, including Supertyphoon Meranti in the western North Pacific and Hurricane Matthew in the tropical Atlantic basin, which was the costliest hurricane since Hurricane Sandy in 2012. The exact role that the oceans played in tropical storm intensification, however, requires more in-depth investigation.

\section{h. Indian Ocean dipole-J.J. Luo}

The Indian Ocean dipole (IOD) represents a major mode of year-to-year climate variability in the tropical Indian Ocean (IO). The IOD shows a strong phase-locking with the seasonal cycle of Australian-East Asian monsoonal winds. The IOD usually starts in boreal summer, peaks in NH fall, and decays rapidly in early boreal winter. While IODrelated SST anomalies are generally weak and more localized compared to ENSO, the IOD can also cause large climate anomalies in many regions and play an active role in tropical interbasin interactions (e.g., Luo et al. 2010, 2012). During May-December 2016, a negative IOD (nIOD) occurred, six years after the last nIOD event in 2010 (Luo 2011). Compared to the previous seven negative events over the past 35 years (i.e., 1990, 1992, 1996, 1998, 2001, 2005, and 2010), the 2016 nIOD was fairly strong (Fig. 4.41). The IOD index during September-November 2016 reached $-0.95^{\circ} \mathrm{C}$, only slightly below the strongest nIOD in $1998\left(-0.97^{\circ} \mathrm{C}\right)$. The $2016 \mathrm{nIOD}$ event may have contributed to the flooding during boreal summer-fall in Indonesia and a persistent wet-cool austral spring in southeastern Australia (www.bom.gov.au/climate /iod/\#tabs=Negative-IOD-impacts).

In 2016, as with the previous two strong nIOD events in 1998 and 2010, a strong El Niño occurred in the boreal winter of 2015/16 followed by a La Niña event. (Fig. 4.41). As a result of a delayed response 

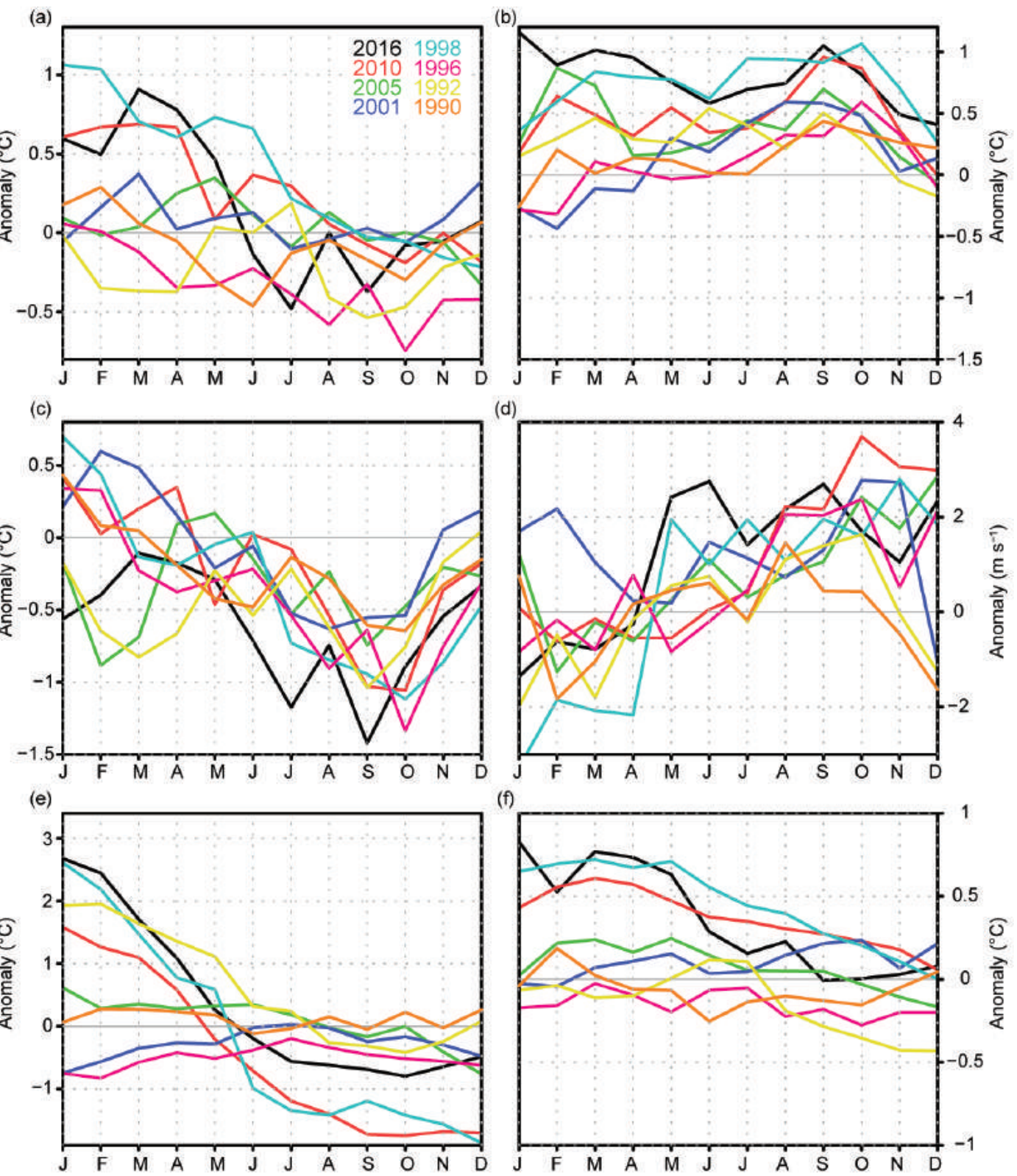

Fig. 4.41. 3-month running mean SST anomalies $\left({ }^{\circ} \mathrm{C}\right)$ in the (a) western $1 O\left(I O D W ; 50^{\circ}-70^{\circ} \mathrm{E}, 10^{\circ} \mathrm{S}-10^{\circ} \mathrm{N}\right),(\mathrm{b})$ eastern IO (IODE; $90^{\circ}-110^{\circ} \mathrm{E}, 10^{\circ} \mathrm{S}-0^{\circ}$ ), and (c) IOD index (measured by the SST anomaly difference between the IODW and the IODE) during eight negative IOD events since 1982. (d) As in (c), but for the surface zonal wind anomaly in the central equatorial $10\left(70^{\circ}-90^{\circ} \mathrm{E}, 5^{\circ} \mathrm{S}-5^{\circ} \mathrm{N}\right)$. (e),(f) As in (a),(b), but for the monthly SST anomalies in the Niño-3.4 region $\left(190^{\circ}-240^{\circ} \mathrm{E}, 5^{\circ} \mathrm{S}-5^{\circ} \mathrm{N}\right)$ and the tropical 10 basin $\left(40^{\circ}-120^{\circ} \mathrm{E}, 20^{\circ} \mathrm{S}-20^{\circ} \mathrm{N}\right)$. The monthly anomalies were calculated relative to the climatology over the period 1982-2015. These are based on the NCEP optimum interpolation SST (Reynolds et al. 2002) and JRA-55 atmospheric reanalysis (Ebita et al. 20II).

to the El Niño, SST anomalies in both the western and eastern IO were above normal in early 2016, and anomalous easterlies blew in the central equatorial IO (Figs. 4.41a-c, 4.42a, 4.43a). The warm SST anomalies persisted across the entire tropical IO up to May 2016 (Figs. 4.41f, 4.42b). In May, the El Niño started to transition to La Niña; this may have caused the rapid decrease of the SST in the western IO as well as the slow decrease of the entire IO basin-mean SST
(Figs. 4.41a,e-f). In contrast, following a small decrease during April-June, SST anomalies in the eastern IO increased in June 2016, in association with the rapid intensification of westerly winds in the central IO and intrinsic air-sea positive feedbacks (Figs. 4.41b,d). As a consequence, the IOD index (i.e., a measure of the SST gradient between the western and eastern IO) dropped quickly during June-September and reached a minimum of about $-1.4^{\circ} \mathrm{C}$ in September (Fig. 4.41c). 

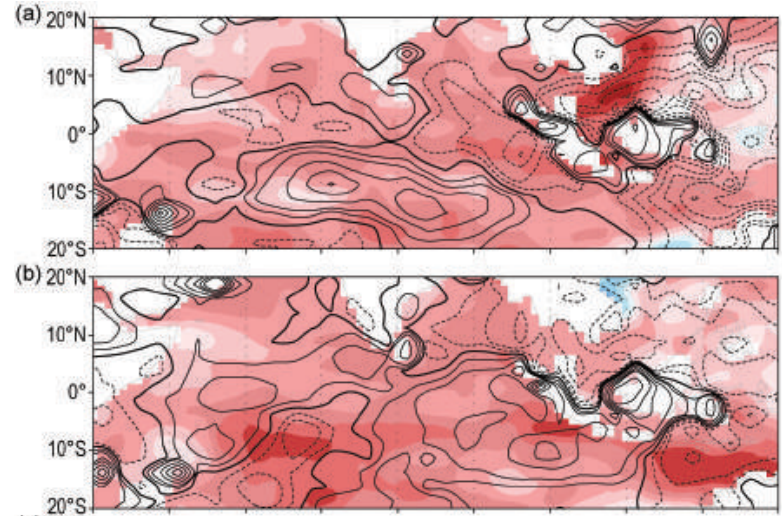

(c) 20
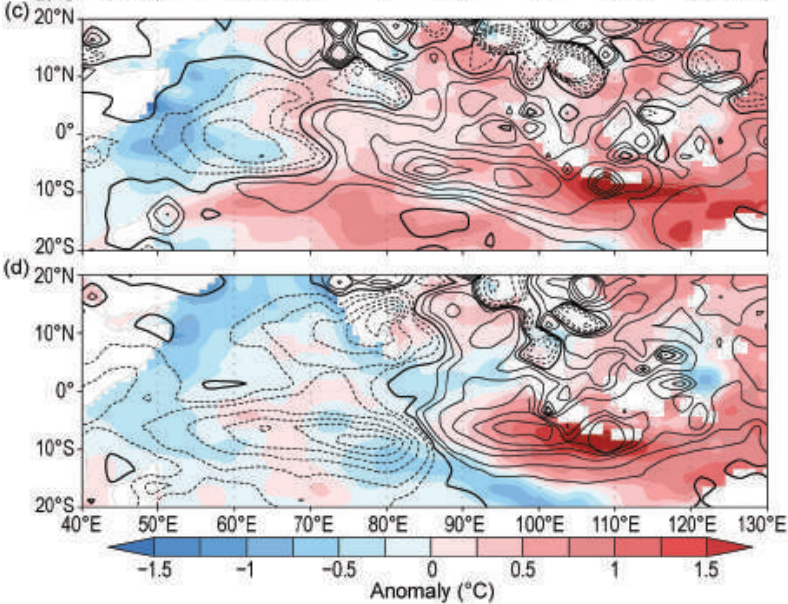

FIG. 4.42. SST ( ${ }^{\circ} \mathrm{C}$, colored scale) and precipitation (contour interval: $0, \pm 0.5, \pm \mathrm{I}, \pm 2, \pm 3, \pm 4$, and $\pm 5 \mathrm{~mm}$ $\mathrm{day}^{-1}$. Solid/dashed lines denote positive/negative values, and thick solid lines indicate zero contour) anomalies during (a) Dec 2015-Feb 2016, (b) Mar-May 2016, (c) Jun-Aug 2016, and (d) Sep-Nov 2016. The anomalies were calculated relative to the climatology over the period 1982-2015. [Source: NCEP optimum interpolation SST (Reynolds et al. 2002) and monthly GPCP precipitation analysis (http://precip.gsfc.nasa .gov).]

Accompanying the development of this strong nIOD event, a clear zonal dipole structure of SST and precipitation anomalies occurred during boreal summer and fall in the tropical IO, with a warm-wet condition in the east and a cool-dry condition in the west (Figs. $4.42 \mathrm{c}, \mathrm{d}$ ). Correspondingly, massive westerly anomalies occurred across the equatorial IO during June-August (Fig. 4.43c). Along the west coast of Sumatra, strong anomalous south-westerlies prevailed during the boreal summer and fall (Figs. $4.43 \mathrm{c}, \mathrm{d}$ ), which likely acted to suppress the coastal oceanic upwelling and generated strong warm SST anomalies along the Indonesia Java coast (Figs. 4.42c,d).

Both the El Niño and the following La Niña may have played an important role in causing the strong
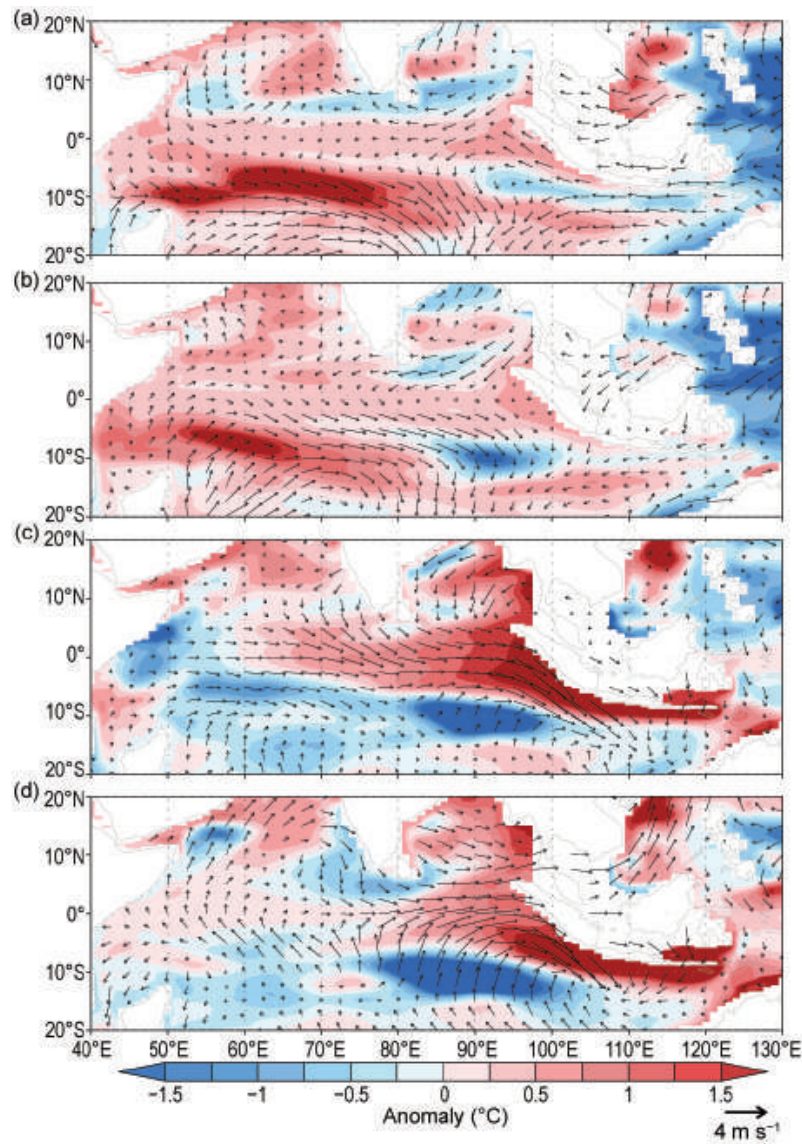

FIG. 4.43. Upper 300-m mean ocean temperature $\left({ }^{\circ} \mathrm{C}\right.$, colored scale) and surface wind $\left(\mathrm{m} \mathrm{s}^{-1}\right)$ anomalies during (a) Dec 20I5-Feb 2016, (b) Mar-May 2016, (c) Jun-Aug 2016, and (d) Sep-Nov 2016. [Source: NCEP ocean reanalysis (www.cpc.ncep.noaa.gov/products /GODAS) and JRA-55 atmospheric reanalysis (Ebita et al. 20II).]

nIOD in 2016. El Niño often forces an anticyclonic wind anomaly in the southern IO during the preceding boreal fall-winter, which can drive a downwelling oceanic Rossby wave that propagates westward at about $10^{\circ}-8^{\circ} \mathrm{S}$ (Luo et al. 2010). A warm Rossby wave reached the western coast of the IO during MarchMay 2016; it was then reflected to be a Kelvin wave that rapidly propagated to the eastern IO along the equator during June-July (not shown; see Fig. 4.43). The arrival of the warm Kelvin wave in the eastern IO may have provided a favorable condition for the development of the 2016 nIOD. In addition, the transition from El Niño to La Niña beginning in May may have contributed to the intensification of the westerly anomalies in the central IO by modifying the atmospheric Walker Circulation (e.g., Klein et al. 1999). The underlying mechanism for the occurrence of the strong nIOD in 2016 appears to be similar to that in 1998 (e.g., Luo et al. 2007). 


\section{THE ARCTIC}

a. Overview-J. Richter-Menge and J. T. Mathis

Arctic air temperatures continue to increase at double the rate of the global temperature increase, and this increase can be linked directly to changes in the Arctic environmental system. In 2016, the average annual surface air temperature (SAT) over land north of $60^{\circ} \mathrm{N}$ was the highest value since reliable records began in 1900 . At $+2.0^{\circ} \mathrm{C}$ relative to the $1981-2010$ baseline, the $2016 \mathrm{SAT}$ represents an increase of $3.5^{\circ} \mathrm{C}$ since the beginning of the 20th century.

Examples of Arctic-specific feedback processes that amplify the rate of environmental change in the Arctic and the impact of large-scale, midlatitude weather systems on the Arctic are clear. For instance, the midlatitude atmospheric circulation enabled the northward advection of warm air into the Arctic and, hence, played a major role in establishing new Arctic monthly above-normal air temperature records during January-April and extreme above-normal temperatures during October-December. Delayed sea ice freeze-up in fall 2016 also helped maintain the above-normal autumn SAT values.

After experiencing the lowest winter maximum sea ice extent in the satellite record (1979-2016), many researchers anticipated a record summer minimum extent. However, relatively cool summer air temperatures over the Arctic Ocean slowed the rate of ice loss. Even with the cool summer, the September 2016 Arctic sea ice minimum extent tied with 2007 for the second lowest value, at 33\% lower than the 1981-2010 average. The sea ice cover continues to be relatively young and thin, making it vulnerable to continued extensive melt.

More widespread sea ice retreat and longer exposure of the ocean surface to solar radiation, along with the increasing SAT and influx of warmer water from the North Atlantic and Pacific Oceans, are associated with increases in sea surface and upper ocean temperatures. In August 2016, sea surface temperatures (SSTs) were up to $5^{\circ} \mathrm{C}$ higher than the 1982-2010 average in regions of the Barents and Chukchi Seas and off the east and west coasts of Greenland. Despite the warming SSTs, the relatively cool Arctic water temperatures (compared to other global oceans) and unique physical processes (i.e., formation and melting of sea ice) make the Arctic Ocean disproportionately sensitive to ocean acidification (OA). Several recent comprehensive data synthesis products clearly show the rapid progression of OA across the Arctic basin, with the potential to impact the marine ecosystem and the people and communities that rely on it.
Under the influence of warming SAT trends, ice on land, including glaciers and ice caps outside Greenland (Arctic Canada, Alaska, Northern Scandinavia, Svalbard, and Iceland) and the Greenland ice sheet (GrIS) itself, continue to lose mass. In 2016, the mass of the GrIS reached a record low value. The onset of surface melt on the GrIS in 2016 ranked second earliest (after 2012) over the 37-year satellite record, with enhanced melt occurring in the southwest and northeast regions.

The spring snow cover extent (SCE) on land has also undergone significant reductions, particularly since 2005. In 2016, new record low April and May snow cover extent was reached for the North American Arctic. In addition to warming air temperatures, there is also evidence of decreasing pre-melt snow mass (reflective of shallower snow) which may further pre-condition the snowpack for earlier and more rapid melt in the springtime.

Regional variability in permafrost temperature records indicates more substantial permafrost warming since 2000 in higher latitudes than in the sub-Arctic, consistent with the pattern of average air temperature anomalies. New record high temperatures were observed at all permafrost observatories on the North Slope of Alaska and at the Canadian observatory on northernmost Ellesmere Island. Thawing permafrost has the potential to release significant amounts of carbon dioxide and methane, which are potent greenhouse gases. As a result, efforts are underway to provide an accurate assessment of the permafrost soil carbon pool, including the pool size and its vulnerability.

Vegetation in the Arctic tundra has also been responding to recent environmental changes. Satellite observations of tundra greenness show long-term trends (beginning in 1982) of increased greening on the North Slope of Alaska, in the southern Canadian tundra, and in much of the central and eastern Siberian tundra. Meanwhile, a decreasing trend in greenness, or "browning", is observed in western Alaska, the more northerly regions of the Canadian Arctic Archipelago, and western Siberian tundra.

Temperatures in the Arctic stratosphere between mid-November 2015 and early March 2016 set new record lows and led to ozone-destroying conditions. The stratosphere warmed rapidly in early March, with ozone concentrations increasing by mid-March. This timing helped maintain the UV index near the historical average in March, when the solar elevation increases significantly at high latitudes. 
The Arctic chapter describes a range of observations of essential climate variables (ECV; Bojinski et al. 2014) and other physical environmental variables, encompassing the atmosphere, ocean, and land in the Arctic and sub-Arctic. When possible, the current standard reference period (defined as 1981-2010 by the World Meteorological Organization and national agencies such as NOAA) is used for calculating climate normals (averages) and anomalies. However, it cannot be used for all the variables described, as some organizations choose not to use 1981-2010 and many Arctic observational records post-date 1981.

While the use of different base periods to describe the state of different elements of the Arctic environment is unavoidable, it does not alter the fact that rapid change is occurring throughout the Arctic environmental system. There are numerous and diverse signals indicating that the Arctic environment continues to be influenced by long-term upward trends in air temperature, modulated by natural variability in regional and seasonal anomalies. The acceleration of many of these signals, the interdependency of the physical and biological elements of the Arctic system, and the growing recognition that the Arctic is an integral part of the larger Earth system are increasing the pressure for more effective and timely communication of these scientific observations to diverse users. A key to meeting this challenging goal is to more directly convey the synthesis of observations across disciplinary boundaries in an effort to better highlight Arctic system change.

b. Surface air temperature-J. Overland, E. Hanna, I. Hanssen-Bauer, S.-J. Kim, J. E. Walsh, M. Wang, U. S. Bhatt, and R. L. Thoman

The average annual surface air temperature (SAT) anomaly for 2016 for land stations north of

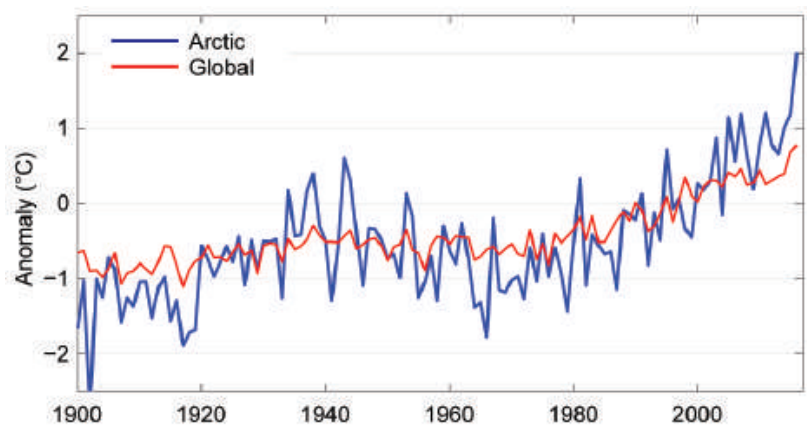

Fig. 5.I. Arctic and global average annual land surface air temperature (SAT) anomalies $\left({ }^{\circ} \mathrm{C}\right)$ for $1900-2016$ relative to the 1981-2010 average. Note that there were few stations in the Arctic, particularly in northern Canada, before 1940. (Source: CRUTEM4 dataset, www.cru.uea.ac.uk/cru/data/temperature.) $60^{\circ} \mathrm{N}$ was $+2.0^{\circ} \mathrm{C}$, relative to the $1981-2010$ average value (Fig. 5.1). This marks a new high for the record starting in 1900, and is a significant increase over the previous highest value of $+1.2^{\circ} \mathrm{C}$, which was observed in 2007, 2011, and 2015. Average global annual temperatures also showed record values in 2015 and 2016. Currently, the Arctic is warming at more than twice the rate of lower latitudes.

Seasonal air temperature extremes for winter (January, February, March), and autumn (October, November, December) of 2016 show extensive positive anomalies across the central Arctic with many regional seasonal anomalies greater than $+4^{\circ} \mathrm{C}$, relative to a 1981-2010 baseline (Fig. 5.2a, d). The Russian subarctic had widespread cold anomalies in autumn (Fig. 5.2d). Spring (April, May, June) showed anomalies of $<+2{ }^{\circ} \mathrm{C}$ in the central Arctic and higher values in the subarctic (Fig. 5.2b). Summer (July, August, September) showed no positive temperature anomalies (Fig. 5.2c). Note, these seasonal definitions are used to coincide with what are typically the coldest (JFM) and warmest (JAS) 3-month periods in the Arctic.

In January, the Arctic-wide average temperature was $2.0^{\circ} \mathrm{C}$ above the previous record of $3.0^{\circ} \mathrm{C}$ above
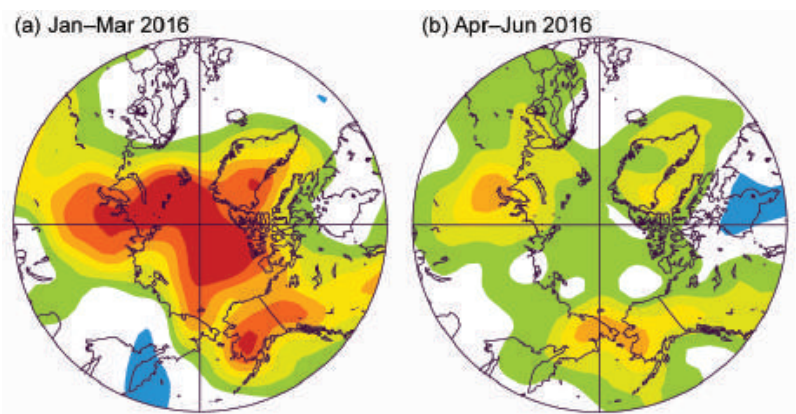

(c) Jul-Sep 2016

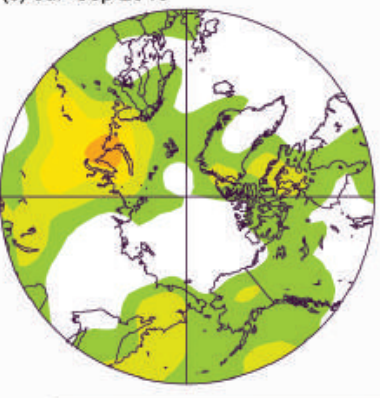

(d) Oct-Dec 2016

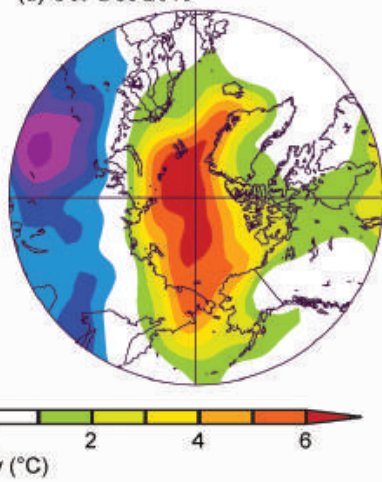

Fig. 5.2. Seasonal anomaly patterns for near-surface air temperatures $\left({ }^{\circ} \mathrm{C}\right)$ in 2016 relative to $1981-2010$ in (a) winter (Jan-Mar), (b) spring (Apr-Jun), (c) summer (Jul-Sep), and (d) autumn (Oct-Dec). Temperatures are from slightly above the surface layer $(925-\mathrm{mb}$ level) to emphasize large spatial patterns rather than local features. (Source: NOAA/ESRL, www.esrl.noaa.gov/psd.) 
the 1981-2010 normal. Some local January observations were in excess of $7^{\circ} \mathrm{C}$ above normal (Overland and Wang 2016). Near-record high temperatures were experienced in some northern Greenland locations. From January through April, Alaska had record high minimum temperatures in all subregions and record high temperature maximums for most subregions (Walsh et al. 2017).

Both winter and autumn illustrate the substantial influence of large-scale weather systems between the Arctic and midlatitudes, specifically the major role of the midlatitude atmospheric circulation (Overland and Wang 2016; Kim et al. 2017; Fig. 5.3). In winter, widespread low geopotential heights at 700 $\mathrm{hPa}$ extended over the Aleutian Islands in the $\mathrm{Pa}$ cific Ocean and across the northern Atlantic Ocean well into the Arctic (Fig. 5.3a). These two regions of low geopotential heights created a major split in the tropospheric polar vortex over the Arctic, which promoted northward transport of heat and moisture. Warm air advection and increased moisture advection north of central Eurasia helped to reinforce the split in the tropospheric polar vortex near the North Pole. A repeat of winter 2016 SAT and 700-hPa wind conditions developed in autumn (Figs. 5.2b, 5.3b). The extremely high Arctic temperatures in winter were related to an unusual subarctic wind pattern, amplified by Arctic feedbacks, implying that the winter extremes were the result of a random, chaotic atmospheric circulation event.

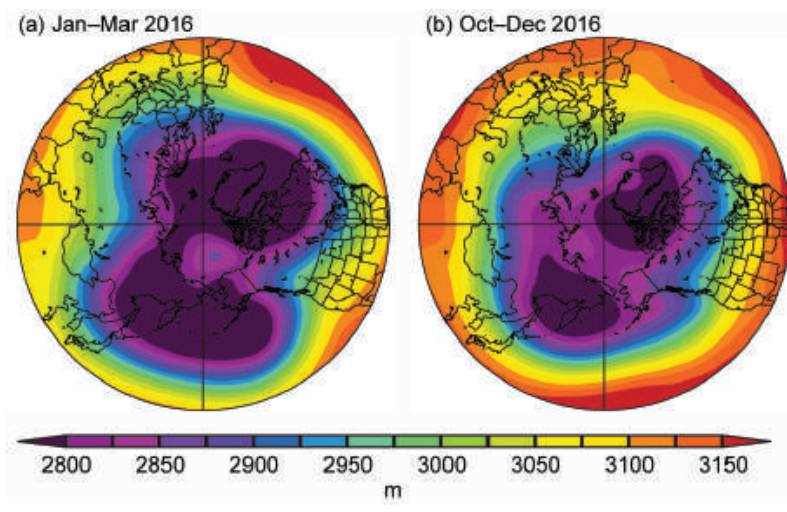

FIG. 5.3. Geopotential heights at $700 \mathrm{hPa}(\mathrm{m})$ for (a) winter (Jan-Mar) and (b) autumn (Oct-Dec) 2016. The geopotential height field generally depicts wind flow in the mid-atmosphere; winds generally follow the direction of the contours and wind magnitudes are greater where the contour spacing is narrow. The normally continuous tropospheric polar vortex of low heights (purple shading) over the central Arctic was split in two in winter 2016 and again during autumn 2016, giving rise to southerly winds and record high temperatures over the central Arctic.
Delayed sea ice freeze up in autumn (see Section 5c) helped to maintain the above-normal autumn surface air temperatures-a clear example of Arcticspecific feedback processes that amplify the rate of environmental change in the Arctic. Warm air delayed autumn sea ice freeze up, and extensive areas of open water allowed warm air and increased moisture to be advected farther into the Arctic, creating a positive feedback (Woods and Caballero 2016).

C. Sea ice cover-D. Perovich, W. Meier, M. Tschudi, S. Farrell, S. Gerland, S. Hendricks, T. Krumpen, and C. Haas

Covering millions of square kilometers, the Arctic sea ice cover is vast in areal extent but is only a thin veneer a few meters thick. This sea ice cover plays many roles. It is a barrier limiting the exchange of heat, moisture, and momentum between the atmosphere and ocean; a home to a rich marine ecosystem, including communities in and under the ice cover; and a stark indicator of climate change.

Sea ice extent has been monitored using passive microwave instruments on satellite platforms since 1979. The months of March and September are of particular interest because they are the months when Arctic sea ice cover typically reaches its maximum and minimum extent, respectively. Maps of monthly average ice extents in March 2016 and September 2016 are shown in Fig. 5.4. The major difference in March 2016 compared to the 1981-2010 average was a large ice-free area north of Svalbard and Novaya Zemlya, which lies between Greenland and Eurasia (Fig. 5.4a).

Based on estimates produced by the National Snow and Ice Data Center (NSIDC) sea ice index (Fetterer
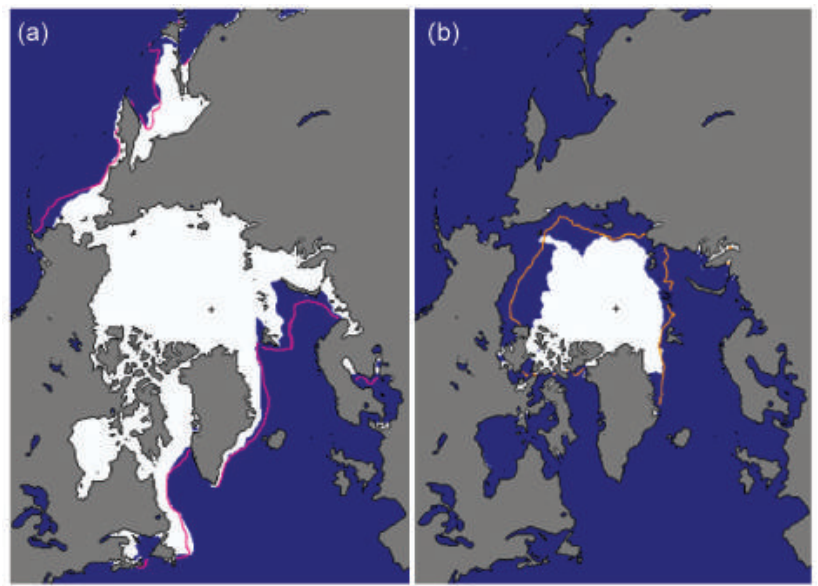

FIG. 5.4. Average 2016 monthly sea ice extents in (a) Mar and (b) Sep, illustrating the respective winter maximum and summer minimum extents. The magenta lines indicate the median ice extents in Mar and Sep, respectively, during the period 198I-2010. [Source: NSIDC, nsidc.org/data/seaice_index (Fetterer et al. 2002).] 


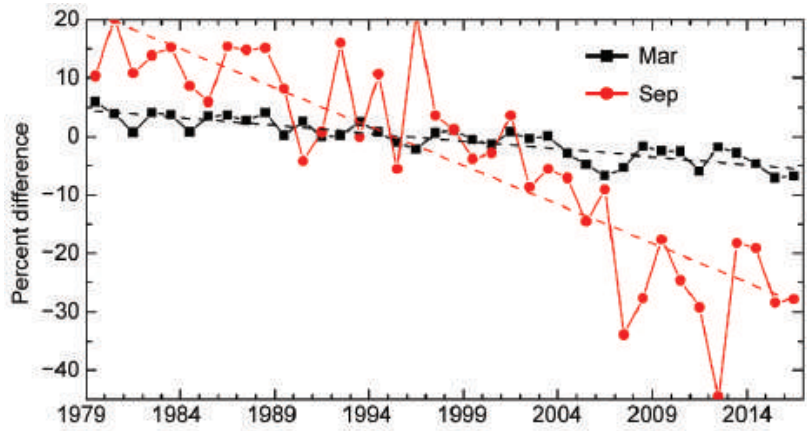

Fig. 5.5. Time series of ice extent anomalies (\% relative to $198 \mathrm{I}-2010$ averages) in Mar (maximum ice extent) and Sep (minimum ice extent). The black and red lines are least squares linear regression lines. The slopes of these lines indicate ice losses of $2.7 \%$ and $13.3 \%$ decade $^{-1}$ in Mar and Sep, respectively. Both trends are significant at the $\mathbf{9 9 \%}$ confidence level.

et al. 2002), the sea ice cover reached a winter maximum value of 14.52 million $\mathrm{km}^{2}$ on 24 March, which was $7.2 \%$ below the 1981-2010 average. This matched 2015 as the lowest maximum value in the satellite record. Also notable, the maximum extent occurred 12 days later than the 1981-2010 average (12 March) and was the fourth latest in the satellite record. The date of the maximum has been trending slightly later (1.7 days decade ${ }^{-1}$ ) over the satellite record, although this trend is not statistically significant. There is considerable year-to-year variability, with a standard deviation in the maximum sea ice extent date of 9.3 days.

On 10 September ice extent reached a minimum annual extent of 4.14 million $\mathrm{km}^{2}$. This matched 2007 as the second lowest minimum extent in the satellite record. The 2016 summer minimum extent is larger by 0.75 million $\mathrm{km}^{2}(22 \%)$ than the record minimum of 3.39 million $\mathrm{km}^{2}$ set in 2012 . It was, however, 1.81 million $\mathrm{km}^{2}(29 \%)$ less than the 1981-2010 average minimum ice extent.

Sea ice extent has decreasing trends in all months and virtually all regions, the exception being the Bering Sea during winter (Meier et al. 2014). The September monthly average trend for the entire Arctic Ocean is now $-13.3 \%$ decade $^{-1}$ relative to the 1981-2010 average (Fig. 5.5). While the 2016 daily minimum ice extent was the second lowest on record, the monthly value shown in Fig. 5.5 was only the fifth lowest due to a brief period of rapid ice formation in late September. Ice extent trends are smaller during March $\left(-2.7 \%\right.$ decade $\left.^{-1}\right)$ but are still decreasing at a statistically significant rate.

In 2016, 10.38 million $\mathrm{km}^{2}$ of ice was lost between the March maximum and September minimum extent. Before 2007, a March to September loss of more than 10 million $\mathrm{km}^{2}$ of ice occurred only once
(1991), but since 2007 such large losses have occurred in seven of the past ten years.

There was a very slow increase in ice extent during fall 2016. From mid-October through December, the ice extent was the lowest observed since the beginning of the satellite record in 1979. The October 2016 ice extent was 2.55 million $\mathrm{km}^{2}$ (27.9\%) less than the 1981-2010 average value for October, with ice extents well below average in the Beaufort, Chukchi, East Siberian, and Kara Seas. This slow increase was likely a consequence of higher-than-average air temperatures (see Section 5b) and above-freezing upper ocean temperatures (see Section 5d).

The age of sea ice is another key descriptor of the state of the sea ice cover. It is an indicator of ice physical properties, including surface roughness, melt pond coverage, and thickness. Older ice tends to be thicker and thus more resilient to changes in atmospheric and oceanic forcing than younger ice. The age of the ice is determined using satellite observations and drifting buoy records to track ice parcels over several years (Tschudi et al. 2010; Maslanik et al. 2011). This method has been used to provide a record of the age of Arctic sea ice since the early 1980s (Tschudi et al. 2015).

The oldest ice ( $>4$ years old) continues to make up a small fraction of the March Arctic ice pack, when sea ice is at its maximum annual extent (Fig. 5.6). In $1985,16 \%$ of the ice pack (relative to the total sea ice areal coverage) was four years old and older, but by March 2016 old ice only constituted $1.2 \%$ of the ice pack. First-year ice now dominates the ice cover, composing about 78\% of the March 2016 ice pack, compared to about $55 \%$ in the 1980 s. Consequently, sea ice cover has transformed from a strong, thick pack in the 1980s to a more fragile, younger, and thinner pack in recent years. The thinner, younger ice is more mobile and vulnerable to melting out in the summer, contributing to lower minimum ice extents.

Observations from multiple sources have revealed the continued decline of the thickness and volume of the Arctic sea ice pack over the last decade (Kwok and Rothrock 2009; Laxon et al. 2013; Kwok and Cunningham 2015; Lindsay and Schweiger 2015). These changes have impacts on the regional Arctic and sub-Arctic climate, environment, and ecosystems. To understand these impacts as the Arctic sea ice cover transitions from a predominantly multiyear ice pack to a seasonal ice cover (Fig. 5.6), continued monitoring of the thickness of the ice pack is required. The European Space Agency CryoSat-2 has been measuring sea ice freeboard (i.e., the distance between the floating ice surface and the open water surface, from 
(a)
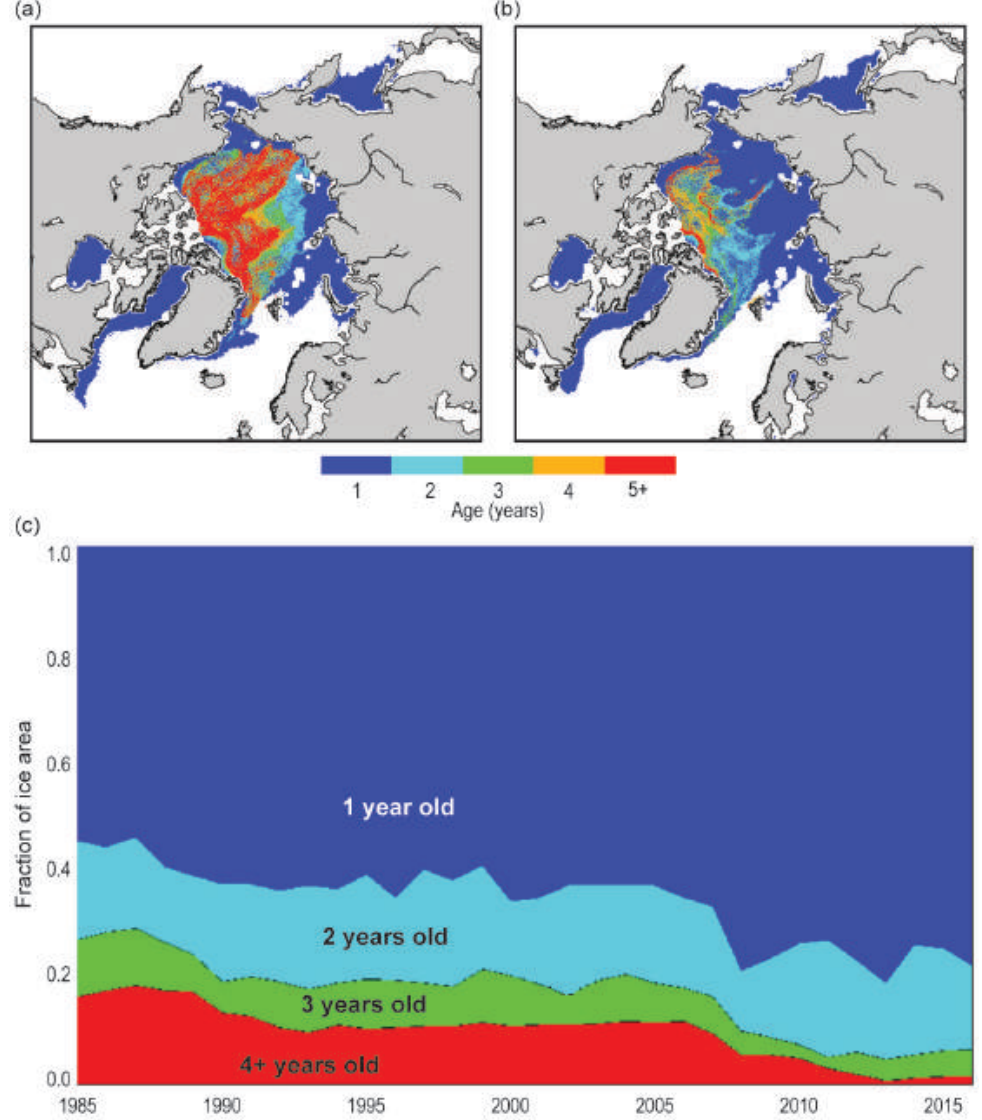

Fig. 5.6. Sea ice age coverage maps for (a) Mar 1985 (Tschudi et al. 2015), (b) Mar 2016 (J. S. Stewart, 2016, personal communication), and (c) 1985-2016 (provided by M. Tschudi). The coverages in (c) are presented as fractions of total sea ice areal coverage. (a)

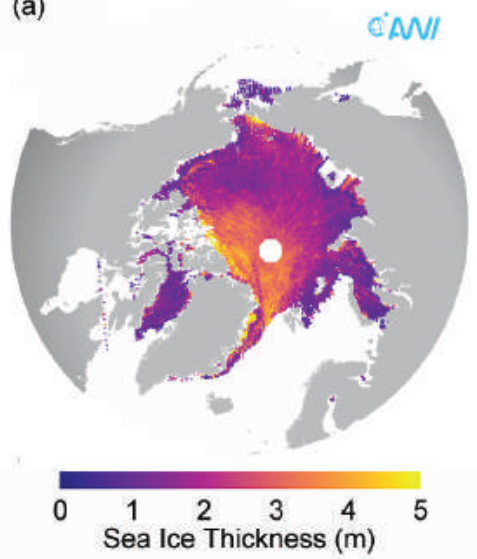

(b)

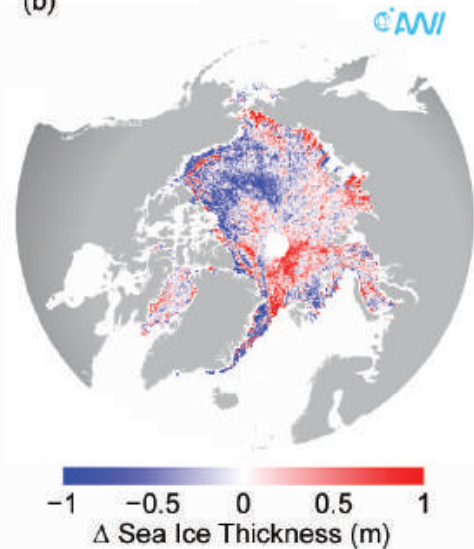

FIG. 5.7. (a) Sea ice thickness derived from ESA Cryosat-2 in Apr 2016. (b) Sea ice thickness anomalies in Apr 2016 compared to the average of all previous years (20II-15) of the CryoSat-2 observational data record. Blue indicates regionally thinner and red indicates thicker sea ice in 2016 than the 5 -year average. which sea ice thickness and volume are derived) since 2010 (Tilling et al. 2015). The uncertainty of sea ice thickness from satellite radar altimetry is mainly controlled by potential ranging biases caused by varying surface roughness, complex snow morphology, and snow and ice densities. In Arctic spring there is no evidence from comparisons with airborne validation data that a significant bias exists in sea ice thickness products. The typical uncertainty in thickness $(0.27 \mathrm{~m})$ is well below the anomalies displayed in Fig. 5.7. Measurements of sea ice plus snow thickness by airborne electromagnetic induction sounding have been made by various organizations in late summer since 2001 (Haas et al. 2010).

Arctic sea ice thickness, derived from CryoSat-2 data, in April 2016 is presented in Fig. 5.7. The ice is near its maximum annual thickness in April, at the end of winter. Also plotted is the 2016 anomaly compared to the average April values from 2011 to 2015. As in previous years, results show a thickness gradient across the central Arctic Ocean between the oldest, thickest ice near Greenland and the Canadian Arctic Archipelago (3-4 m) and younger ice in the Beaufort, East Siberian, and Laptev Seas ( $\leq 2 \mathrm{~m})$ (Fig. 5.7a). In the context of 2011-15 average conditions, the April 2016 results (Fig. 5.7b) show two distinct features. The first is a band of thick multiyear ice in the southern and eastern Beaufort Sea surrounded by thinner ice (up to $1 \mathrm{~m}$ below average) in the western Beaufort Sea and Canada Basin. The second feature is a region with aboveaverage thickness north of Fram Strait in the Eurasian Basin. Airborne electromagnetic induction surveys (conducted by York University; C. Haas, 2016, personal communication) obtained independent measurements of ice thickness north of Fram Strait and confirmed the CryoSat-2 results. Such spatial and temporal variability in ice thickness results from variability in the motion of the ice. Areas of ice divergence typically have thinner ice, while ice convergence causes ridging and thicker ice. 


\section{SIDEBAR 5.I: THE STUDY OF ENVIRONMENTAL ARCTIC CHANGE: PROMOTING SYNTHESIS AND ENGAGEMENT—B. P. KELLY}

In 1979, I learned a few dozen Yupik words for sea ice from Conrad Oozeva, a Native hunter from St. Lawrence Island in the Bering Sea. Some of those terms refer to types of sea ice that are rare or non-existent in 2016 (e.g., tagneghneq for thick, dark, weathered ice). That Yupik terms-probably in use for thousands of years - would become obsolete in just a few decades attests to the rapid pace of change in the Arctic and to the impacts on Indigenous peoples (Berman 2004; Oozeva et al. 2004; Ford and Pearce 2010).

Scientists in many disciplines also recognize the rapid pace of change in the Arctic and the importance of being more timely and effective in conveying what we know (e.g., Post et al. 2013; Francis and Vavrus 2015; Grosse et al. 2016; Tedesco et al. 2016c). Further, our knowledge is most valuable to policy makers and affected communities when we synthesize across disciplines and succinctly communicate the policy-relevant points. Accelerating our science means speeding up syntheses and improving our ability to effectively convey what we know.

The evolution of the Study of Environmental Arctic Change (SEARCH) is one example of Arctic scientists accelerating their science and communication. SEARCH was founded to advance understanding of the Arctic system and its trajectory through synthesis and modeling (www.arcus.org/files /page/documents/19437/search_openletter_1997.pdf). From a scientific perspective, synthesis is an important step in an iterative process.

SEARCH and many in the Arctic research community have become increasingly convinced, however, that additional important syntheses combining scientific research and indigenous knowledge are needed. From a scientific perspective, synthesis may be important for designing the next experiment, but policy makers, local communities, and others look to syntheses to answer specific questions. Syntheses framed in policy-relevant forms are more valuable to these user communities than are framings focused on advancing the state of knowledge. And, in this environment of rapid change, the policy questions are becoming increasingly urgent.

SEARCH now brings together scientists, stakeholders, and government agencies to synthesize knowledge from many disciplines-these syntheses are intended to simultaneously increase the body of knowledge and address stakeholder questions (Fig. SB5.I). Translating science into forms usable by stakeholders calls for translating technical information into language accessible to diverse audiences. SEARCH recognizes that many interested audiences are sophisticated but not facile with technical jargon. To improve communication with all stakeholders, we are developing "knowledge pyramids." Each knowledge pyramid assembles the state of the science concerning a societally important Arctic issue in multiple formats ranging from one-page, jargon-free summaries at the apex of the pyramid (www.arcus.org/search-program/arctic-answers) to original research publications at the base (Fig. SB5.2). Thus, when asked about the state of the science concerning, for example, melting ice sheets and their impact on sea level rise, we would point a geologist to primary literature at the base of the pyramid; a scientist from another discipline to a review article (midpyramid); a science journalist to a more condensed synthesis [e.g., NOAA Arctic Report Card essay (Richter-Menge et al. 2016); www .arctic.noaa.gov/Report-Card/Report-Card-2016]; and a Congressional staffer to a briefing paper in the apex. Naturally, the level at which someone enters the pyramid is not fixed and will vary with their specific background and interests. Especially important in this regard is the potential for the one-page summaries to be useful not only for policy makers but also for efficient communication among scientists of different disciplines. We believe that giving specialists windows into each other's science will facilitate the multidisciplinary collaborations necessary for a fuller understanding of environmental change in the Arctic. We would argue further that translating our research into common language deepens our own understanding of our results and their broader implications.

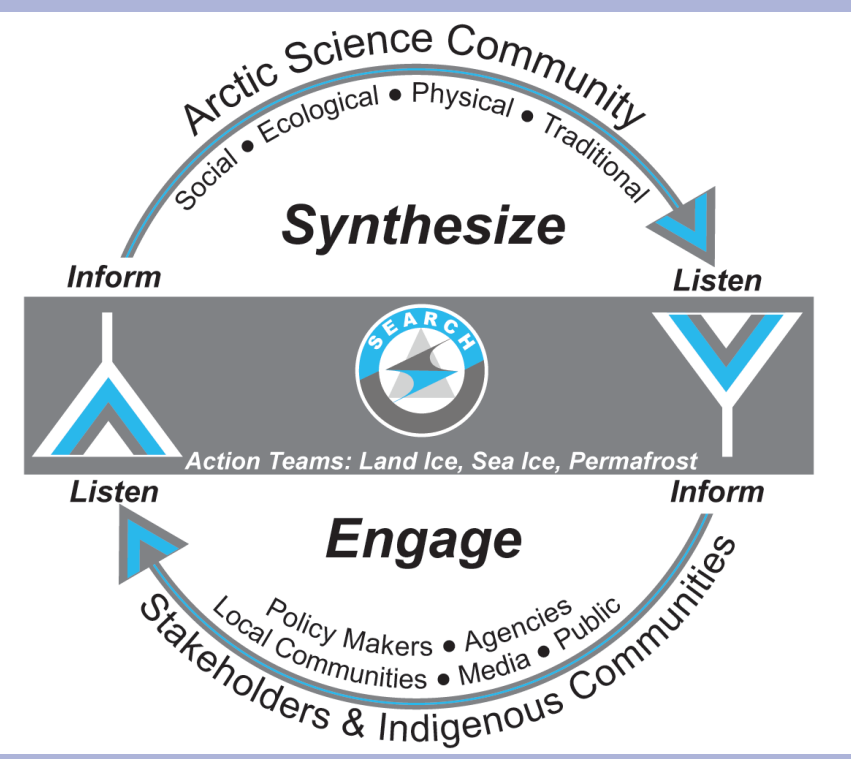

FIG. SB5.I. Graphical representation of SEARCH communication pathways and audiences. SEARCH engages diverse stakeholder and indigenous communities to understand their concerns and questions and to synthesize research to inform those questions. The flow of information is continuous and iterative. 


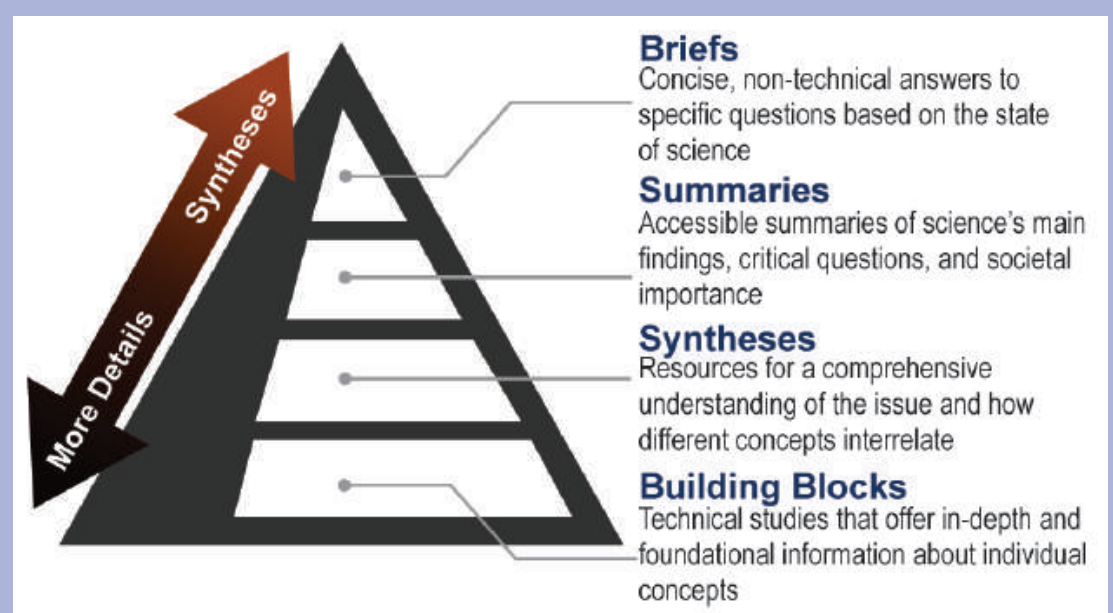

FIG. SB5.2. Knowledge pyramids answer policy-relevant questions about the Arctic environment in a series of web-based products. Briefs are supported by documents of increasing detail in lower tiers of the pyramids. ous Yupik words to describe sea ice, which I would have referred to using a single term, he drew my attention to differences in ice characteristics that I had overlooked.

The communities of St. Lawrence Island, like communities across the Arctic, are facing extremely rapid changes, some of which may make obsolete certain terms in their language. Such cultural losses may challenge those communities, but Conrad advised young people to draw information from various sources-to synthesize-an approach likely to enhance the resilience of their
We also appreciate and honor the valuable information found in the differences between scientific and indigenous perceptions of the Arctic. When Conrad Oozeva used numer- communities. The scientific community can also benefit from Conrad's advice to think across disciplines and his example of translating his knowledge for diverse audiences.

\section{d. Sea surface temperature-M.-L. Timmermans}

Summer sea surface temperatures (SST) in the Arctic Ocean are set mainly by absorption of solar radiation into the surface layer. In the Barents and Chukchi Seas, there is an additional contribution from advection of warm water from the North Atlantic and Pacific Oceans, respectively (for a recent assessment of this in the Chukchi Sea, see Serreze et al. 2016). Solar warming of the ocean surface layer is influenced by the distribution of sea ice (with more solar warming in ice-free regions), cloud cover, water color, and upper-ocean stratification. River influxes influence the latter two. SST data presented here are from the NOAA Optimum Interpolation (OI) SST Version 2 product (OISSTv2), which is a blend of in situ and satellite measurements (Reynolds et al. 2002, 2007). Compared to in situ temperature measurements, the OISSTv2 product shows average correlations of about $80 \%$, with an overall cold SST bias of $-0.02^{\circ} \mathrm{C}$ (Stroh et al. 2015).

August SSTs provide the most appropriate representation of Arctic Ocean summer SSTs, because they are not affected by the cooling and subsequent sea ice growth that typically takes place in the latter half of September. Average SSTs in August 2016 in ice-free regions ranged from $\sim 0^{\circ} \mathrm{C}$ in some regions to around $+7^{\circ}$ to $+8^{\circ} \mathrm{C}$ in the Chukchi Sea and eastern Baffin Bay off the west coast of Greenland, and up to $+11^{\circ} \mathrm{C}$ in the Barents Sea (Fig. 5.8a). Compared to the 1982-2010 August average (note the monthly SST record begins in December 1981), most boundary regions and marginal seas of the Arctic had anomalously warm SSTs
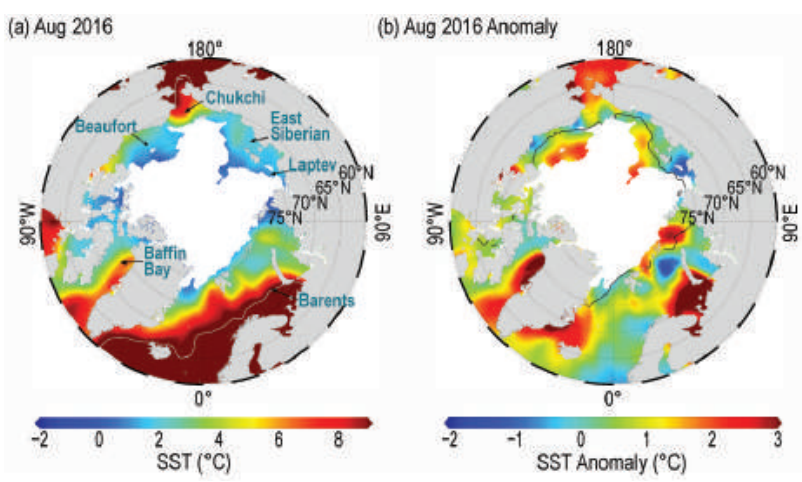

Fig. 5.8. (a) Average SST $\left({ }^{\circ} \mathrm{C}\right)$ in Aug 2016. White shading is the Aug 2016 average sea ice extent, and gray contours indicate the $10^{\circ} \mathrm{C}$ SST isotherm. (b) SST anomalies ( ${ }^{\circ} \mathrm{C}$ ) in Aug 2016 relative to the Aug 1982-2010 average. White shading is the Aug 2016 average ice extent and the black line indicates the median ice edge for Aug 1982-2010 average. 
(Fig. 5.8b). SSTs in these regions, which are mostly ice free in August, are linked to the timing of local sea ice retreat, which facilitates the direct solar heating of the exposed surface waters. August 2016 SSTs were cooler relative to the 1982-2010 average along the southern boundaries of the Beaufort Sea and East Siberian and Laptev Seas (Fig. 5.8b), where summer air temperatures were also below average (see Section 5b). Cooler-than-average SSTs were also notable in the northern Barents Sea. August SST anomalies off the east and west coasts of Greenland and in the southern Barents Sea were up to $5^{\circ} \mathrm{C}$ warmer than the 1982-2010 average, and coincide with regional surface air temperatures that were up to $5^{\circ} \mathrm{C}$ higher in July-August 2016 compared to July-August average temperatures in the 1981-2010 base period.

The Chukchi Sea and eastern Baffin Bay are the only marginal regions to exhibit a statistically significant warming trend over the duration of the record, beginning in 1982 (August SSTs in these regions are warming at a rate of about $+0.5^{\circ} \mathrm{C}$ decade $^{-1}$, based on a linear fit; Fig. 5.9). In the Chukchi Sea, this trend coincides with declining trends in summer sea ice extent. In other marginal seas, for instance the Barents Sea, warm August SST anomalies observed in 2016 are of similar magnitude to warm anomalies observed in past decades (Timmermans and Proshutinsky 2015; 2016).

Given the anomalously warm surface air temperatures in autumn (see Section 5b), it is of interest to examine SST patterns in September and October (Figs. 5.10a,b). These patterns were similar to those in August, although by October average SSTs were generally lower than in August by about $1^{\circ} \mathrm{C}$. In September and October, anomalously warm SSTs (relative to 1982-2010) were largely confined to regions that were previously ice covered in those months,

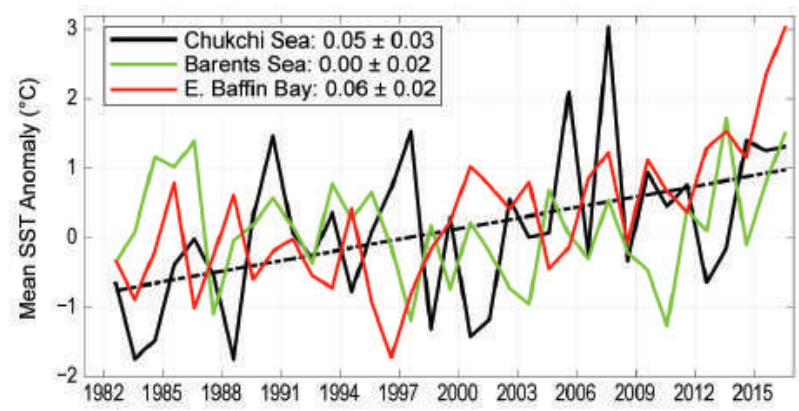

Fig. 5.9. Area-averaged SST anomalies $\left({ }^{\circ} \mathrm{C}\right)$ for Aug of each year relative to the 1982-2010 Aug average for the Chukchi and Barents Seas and eastern Baffin Bay (see Fig. 5.8a). The dashed black line shows the linear SST trend (over the period shown) for the Chukchi Sea. Numbers in the legend correspond to linear trends in ${ }^{\circ} \mathrm{C} \mathrm{yr}^{-1}$ (with $95 \%$ confidence intervals).
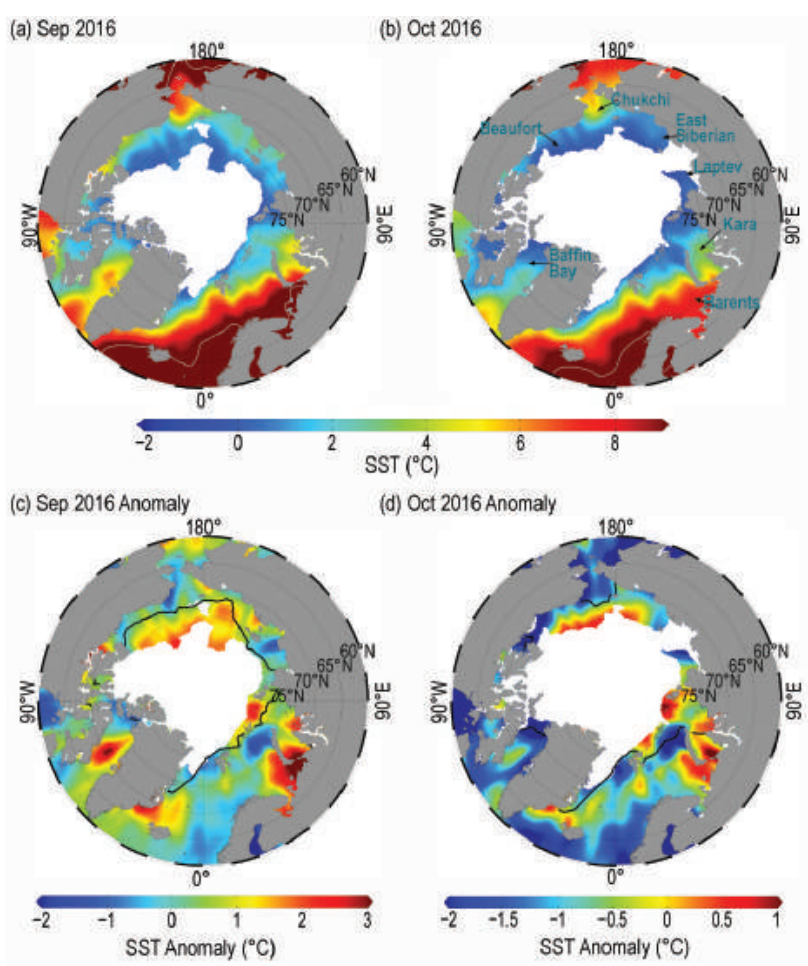

(d) Oct 2016 Anomaly

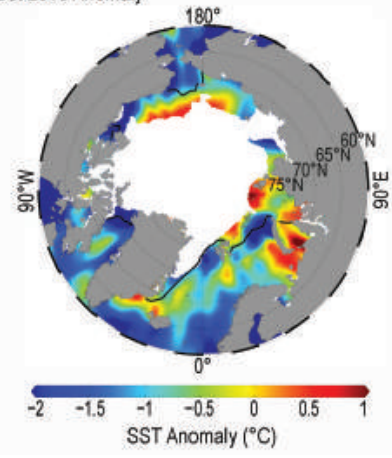

Fig. 5.I0. Average SST $\left({ }^{\circ} \mathrm{C}\right.$ ) in (a) Sep and (b) Oct 2016. White shading is the average sea ice extent for the respective month, and gray contours indicate the $10^{\circ} \mathrm{C}$ SST isotherm. SST anomalies $\left({ }^{\circ} \mathrm{C}\right)$ in (c) Sep 2016 relative to the 1982-2010 Sep average and (d) similar for Oct 2016. White shading is the 2016 average ice extent for the respective month and the black contour indicates the median ice edge in the respective month for the period 1982-2010. Note differences in scale. (Sources: SST data are from the NOAA OISSTv2; sea ice extent and ice-edge data are from NSIDC.)

but which have been ice free more frequently in the past decade (Figs. 5.10c,d). These anomalously warm SSTs likely played a role in the slow rate of fall freezeup in 2016 (see Section 5c). SSTs in the Barents Sea (historically ice free in these months) were up to $+2^{\circ} \mathrm{C}$ warmer compared to the 1982-2010 average; warmer SSTs were also observed in Baffin Bay and off the east coast of Greenland.

e. Greenland ice sheet-M. Tedesco, J. E. Box, J. Cappelen, R. S. Fausto, X. Fettweis, T. Mote, C. J. P. P. Smeets, D. van As, R. S. W. van de Wal, and I. Velicogna

Estimates of the spatial extent of ice surface melt across the Greenland ice (GrIS sheet) during the period 1979-2016 are derived from brightness temperatures measured by the Special Sensor Microwave Imager (SSMI) and the SSMI/Sounder (SSMIS) passive microwave radiometers (e.g., Mote 2007; Tedesco et al. 2013). These observations indicate that 2016 extended the overall increasing melting trend, although it was 
not a record-breaking year in terms of melt extent and duration. The updated trend for melt extent over the entire Greenland ice sheet for the period 1979-2016 is $+15800 \pm 2300 \mathrm{~km}^{2} \mathrm{yr}^{-1}$.

The melting season of 2016 was characterized by an early melt onset (10 April), with melt extent during April reaching values more typical of early June. The melt onset date in 2016 ranked second, by only a few days, to the melt onset day in 2012 (4 April); note that
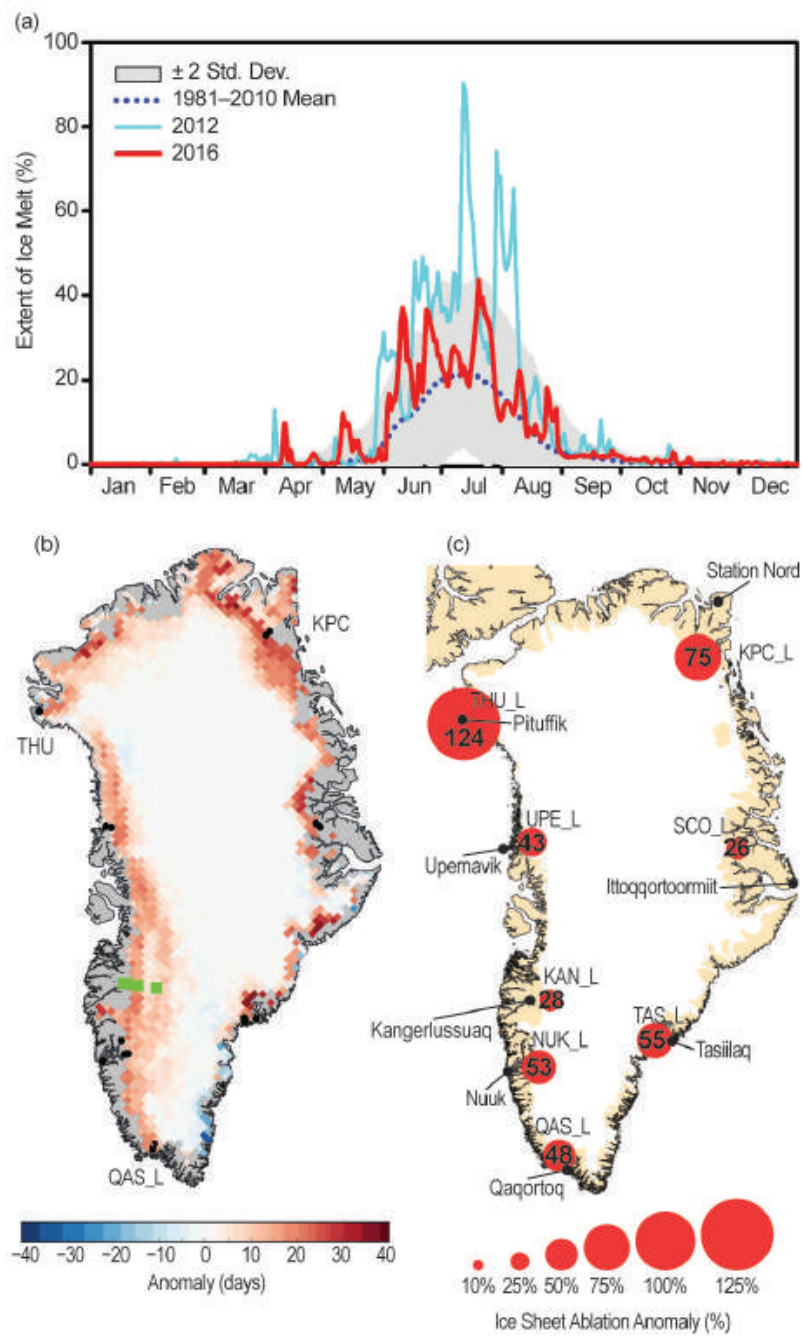

FIG. 5.II. (a) Spatial extent of melt from SSMIS (\%) of the ice sheet area during 2016 (red line) and 2012 (cyan line), the 198I-2010 average spatial extent of melt (dashed blue line), and \pm 2 std. dev. of the average (shaded). (b) Anomalies of melting days for 2016 w.r.t. the $198 \mid-2010$ average. Black dots represent the locations of selected PROMICE stations and green squares show the location of the K-transect stations. Both plots were produced in conjunction with NSIDC. (c) Measured PROMICE ice sheet ablation anomalies (\%) for 2016 near the ice sheet margin at the lower measurement site (baseline period I96I-90). The size of red dots is proportional to the magnitude of the ablation anomaly. summer 2012 was the year of record total maximum melt extent. Periods of extensive melt (exceeding two standard deviations above the average) were also recorded in mid-May and in June (Fig. 5.11a). The melt extent for the period June through August 2016 was above the 1981-2010 average on $66 \%$ of days. The anomaly of the number of days when surface melt occurred with respect to the 1981-2010 period reached its peak in the northeast region (Fig. 5.11b). The number of melt days was also anomalously high along the west and southwest regions, although not as pronounced as in previous years. In contrast to the sea ice cover (see Section 5c), no melting was detected during the anomalous warm events occurring over the Arctic at the end of 2016 (see Section 5b).

Net surface ablation recorded by Programme for Monitoring of the Greenland Ice Sheet (PROMICE) automated weather stations (www.promice.dk) for 2016 were all within 1 standard deviation of the average over the period for which these measurements are available (2008-16). Ablation at lower elevation stations near ice sheet margin elevations was between $26 \%$ and $124 \%$ above the average (Fig. 5.11c; van As et al. 2016). The largest positive ablation anomalies are found in north Greenland (KPC_L and THU_L stations), while the largest absolute ablation was measured in the south at the QAS_L site.

The mass balance year 2015/16 (September 2015August 2016) along the K-transect (van de Wal et al. $2005,2012)$, located in the southwest part of the GrIS near the KAN PROMICE sites, was characterized by a high ablation rate in the upper ablation area (Tedesco et al. 2016a). The 2009/10 mass balance year, when ablation rates at the ice sheet margin were extraordinarily high, was the only period with transect-averaged ablation rates higher than 2016; measurements along the transect began in 1991.

GRACE satellite data (Velicogna et al. 2014, which includes a description of errors for GRACE) are used to estimate monthly changes in the total mass of the Greenland ice sheet, including mass gain due to snow accumulation and summer losses due to meltwater runoff and iceberg calving (Fig. 5.12). Observations from GRACE show that the cumulative mass of the Greenland ice sheet continues to decline, reaching a new record low in September 2016 for the 15-year GRACE record. Between September 2015 and September 2016 GRACE recorded a $310 \pm 45 \mathrm{Gt}$ ( $\mathrm{Gt}=10^{9}$ tons) mass loss; the average September-toSeptember loss for the 2002-16 period is $259 \pm 35 \mathrm{Gt}$. For comparison, the record for 2011/12 September-toSeptember loss was $640 \pm 45 \mathrm{Gt}$, which represented 


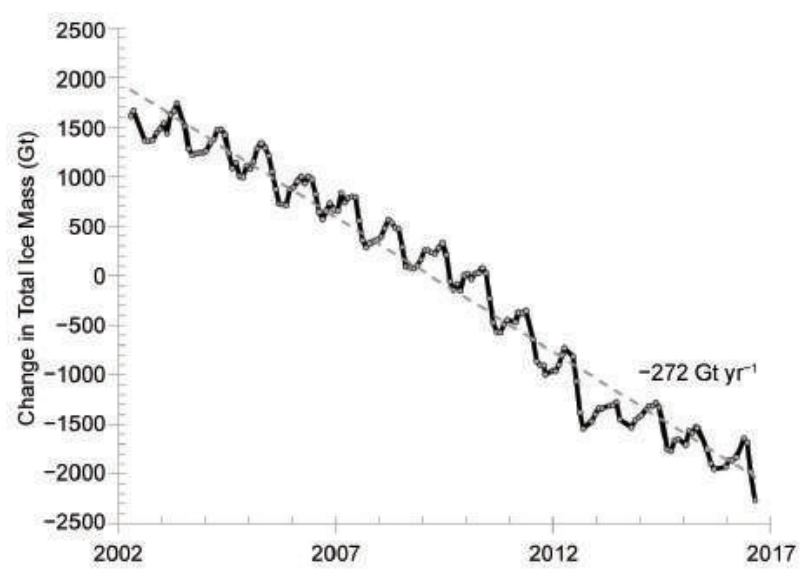

FIG. 5.12. Monthly change in the total mass (Gt) of the Greenland ice sheet between Apr 2002 and Sep 2016, estimated from GRACE measurements. The gray dots represent the GRACE data; the black line is the interpolated values between two successive GRACE points; and the dashed line is the line corresponding to the best linear fit over the entire time period, whose slope is reported in the figure. The uncertainty of the

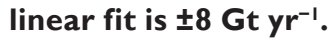

$16 \%$ of the total loss of $~ 3900 \mathrm{Gt}$ since the beginning of the GRACE record in 2002.

The average summer albedo is derived from data collected by the Moderate-resolution Imaging Spectroradiometer (MODIS) Collection 6 (after Box et al. 2017) and spatially averaged over the entire ice sheet (Fig. 5.13a). In 2016, the average summer albedo measured over the entire ice sheet was $78.8 \%$, with low summer albedo anomaly values being widespread. This average is $2.4 \%$ lower than in $2000 / 01$, when MODIS data were first available, and the fourth lowest albedo in the 17 summers of record (Fig. 5.13b). The minimum average summer albedo was recorded in 2012 (76.8\%), the year of record maximum melt extent (Box et al. 2012). The summer and July albedo
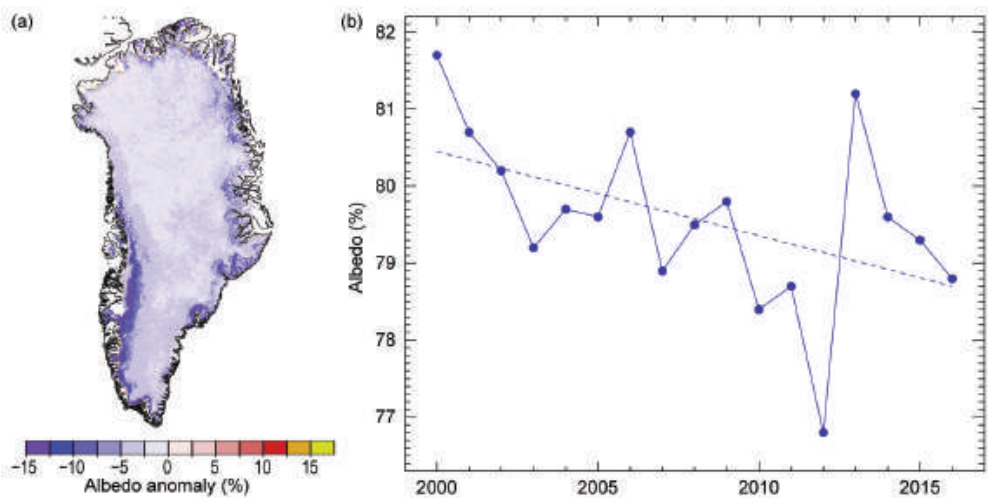

FIG. 5.I3. (a) MODIS (Collection 6) albedo anomaly for summer 2016 (2000-09 reference period). (b) Summer MODIS albedo (\%) averaged over the entire ice sheet having a least-squares regression line with a slope of $-I .1 \% \pm 0.5 \%$ decade $^{-1}$. trends for the period 2000-16 indicate decreases of $-1.1 \% \pm 0.5 \%$ decade $^{-1}$ (Fig. 5.13b) and $-3.1 \% \pm 1.1 \%$ decade $^{-1}$, respectively. Consistent with the spatial distribution of melt anomalies in 2016 (Fig. 5.11b) and as observed in previous recent years (e.g., Tedesco et al. 2016b), the largest area of low albedo anomalies was located along the southwestern ice sheet.

Consistent with the spatio-temporal variability of melt and albedo, air temperature measurements at 20 weather stations of the Danish Meteorological Institute (Cappelen 2017) indicate widespread aboveaverage surface air temperatures in 2016 (relative to 1981-2010). Records were set in 2016 on an annual basis, on a seasonal basis (in spring, summer, and autumn), and in individual months (Table 5.1). The annual average temperature in 2016 was record setting at most coastal observing stations in East Greenland. At Summit (elevation $3216 \mathrm{~m}$ above sea level), 2016 was $+2.2^{\circ} \mathrm{C}$ above average, second only to 2010 . Data collected from the PROMICE network also indicate that the annual temperature in 2016 was above average by $+1.0^{\circ} \pm 1.8^{\circ} \mathrm{C}$, with substantial regional differences.

As highlighted in Table 5.1, new surface temperature records were set during the spring season at Kangerlussuaq, Aasiaat, and Summit. April was particularly warm, with new records set at Summit and eight other sites. Summer temperature anomalies were positive at all stations around the Greenland coastline, with new records set at the southeast coastal sites of Tasiilaq, Aputiteeq, and Illoqqortoormiut, at the northeast site of Danmarkshavn and Daneborg, and at the southern site of Narsarsuaq. July temperatures at Tasiilaq in 2016 were $+2.5^{\circ} \mathrm{C}$ above average, second only to 1929 , and $+1.9^{\circ} \mathrm{C}$ above average at Danmarkshavn, second only to 1958. Autumn was record setting at Kap Morris Jesup and five other sites; in northeast Greenland, records were consecutively broken in each autumn month at several sites. In December 2016, the majority of stations recorded temperatures between 2.5 and 5 standard deviations above the 1981-2010 average. Record high temperatures occurred in December at Kap Morris Jesup $\left(+5.4^{\circ} \mathrm{C}\right.$ anomaly).

In 2016, the average Greenland blocking index (GBI, here defined as the average $500 \mathrm{hPa}$ geopotential height for the region $60^{\circ}-80^{\circ} \mathrm{N}$ and $20^{\circ}-80^{\circ} \mathrm{W}$; e.g., Hanna et al. 2013), calculated from the NCAR/NCEP Reanalysis, was the second highest since 1948, following only the extensive melt year of 2012 (Nghiem et al. 2012). Persistent periods of high 
TABLE 5.I. Seasonal and annual surface air temperature anomalies at 15 of the 20 weather stations in Greenland, where observations have been made for a minimum of 30 years by the Danish Meteorological Institute. The seasons are autumn (SON), winter (DJF), spring (MAM), and summer (JJA). The year that observations began is given, together with the station name and geographic coordinates. Highlighted cells indicate where a new seasonal or annual record was set. The z-score indicates how many std. dev. an element is from the mean.

\begin{tabular}{|c|c|c|c|c|c|c|c|}
\hline \multicolumn{2}{|c|}{$\begin{array}{l}\text { Station Name, Start Year; } \\
\text { Latitude, Longitude }\end{array}$} & \multirow{2}{*}{$\begin{array}{c}\text { SON } \\
2015 \\
0.6\end{array}$} & \multirow{2}{*}{$\begin{array}{c}\begin{array}{c}\text { DJF } \\
2015 / 16\end{array} \\
0.2\end{array}$} & \multirow{2}{*}{$\begin{array}{c}\text { MAM } \\
2016 \\
3.6\end{array}$} & \multirow{2}{*}{$\frac{\text { JJA } 2016}{1.0}$} & \multirow{2}{*}{$\begin{array}{c}\text { SON } \\
2016 \\
0.4\end{array}$} & \multirow{2}{*}{$\begin{array}{c}\begin{array}{c}\text { Jan-Dec } \\
2016\end{array} \\
1.6\end{array}$} \\
\hline \multirow{4}{*}{$\begin{array}{l}\text { Pituffik/Thule AFB } \\
1948 ; \\
76.5^{\circ} \mathrm{N}, 68.8^{\circ} \mathrm{W}\end{array}$} & Anomaly $\left({ }^{\circ} \mathrm{C}\right)$ & & & & & & \\
\hline & z-score & 0.5 & 0.0 & 1.9 & 1.0 & 0.4 & 1.4 \\
\hline & Max Year & 2010 & 1986 & 1953 & 1957 & 2010 & 2010 \\
\hline & Min Year & 1964 & 1949 & 1992 & 1996 & 1964 & 1992 \\
\hline \multirow{4}{*}{$\begin{array}{l}\text { Station Nord } \\
1961 ; \\
81.6^{\circ} \mathrm{N}, 16.7^{\circ} \mathrm{W}\end{array}$} & Anomaly $\left({ }^{\circ} \mathrm{C}\right)$ & 1.3 & 1.9 & -0.2 & 0.8 & 4.4 & 2.0 \\
\hline & z-score & 0.9 & 0.9 & 0.1 & 0.9 & 2.3 & 1.7 \\
\hline & Max Year & 2002 & 2011 & 2006 & 2003 & 2016 & 2016 \\
\hline & Min Year & 1989 & 1967 & 1961 & 1970 & 1989 & 1968 \\
\hline \multirow{4}{*}{$\begin{array}{l}\text { Upernavik } \\
1873 ; \\
72.8^{\circ} \mathrm{N}, 56.1^{\circ} \mathrm{W}\end{array}$} & Anomaly $\left({ }^{\circ} \mathrm{C}\right)$ & -0.2 & 0.2 & 5.4 & 0.9 & 0.7 & 2.1 \\
\hline & z-score & 0.0 & 0.2 & 2.4 & 1.3 & 0.7 & 1.5 \\
\hline & Max Year & 2010 & 1947 & 1932 & 2012 & 2010 & 2010 \\
\hline & Min Year & 1917 & 1983 & 1896 & 1873 & 1917 & 1887 \\
\hline \multirow{4}{*}{$\begin{array}{l}\text { Kangerlussuaq } \\
1949 ; \\
67.0^{\circ} \mathrm{N}, 50.7^{\circ} \mathrm{W}\end{array}$} & Anomaly $\left({ }^{\circ} \mathrm{C}\right)$ & -2.7 & 0.9 & 6.7 & 1.3 & 0.2 & 2.6 \\
\hline & z-score & -1.6 & 0.1 & 2.3 & I.I & 0.1 & 1.4 \\
\hline & Max Year & 2010 & 1986 & 2016 & 1960 & 2010 & 2010 \\
\hline & Min Year & 1982 & 1983 & 1993 & 1983 & 1982 & 1984 \\
\hline \multirow{4}{*}{$\begin{array}{l}\text { Ilulissat } \\
1807 ; \\
69.2^{\circ} \mathrm{N}, 51.1^{\circ} \mathrm{W}\end{array}$} & Anomaly $\left({ }^{\circ} \mathrm{C}\right)$ & -2.0 & 2.5 & 5.7 & 0.5 & -0.2 & 2.2 \\
\hline & z-score & -0.9 & 0.9 & 2.1 & 1.2 & 0.3 & 1.5 \\
\hline & Max Year & 2010 & 1929 & 1847 & 1960 & 2010 & 2010 \\
\hline & Min Year & 1837 & 1863 & 1813 & 1863 & 1837 & 1863 \\
\hline \multirow{4}{*}{$\begin{array}{l}\text { Aasiaat } \\
1958 ; \\
68.7^{\circ} \mathrm{N}, 52.8^{\circ} \mathrm{W}\end{array}$} & Anomaly $\left({ }^{\circ} \mathrm{C}\right)$ & -0.8 & 3.4 & 5.9 & 1.3 & 0.5 & 3.0 \\
\hline & z-score & -0.7 & 0.7 & 2.3 & 1.2 & 0.6 & 1.6 \\
\hline & Max Year & 2010 & 2010 & 2016 & 2012 & 2010 & 2010 \\
\hline & Min Year & 1986 & 1984 & 1993 & 1972 & 1986 & 1983 \\
\hline \multirow{4}{*}{$\begin{array}{l}\text { Nuuk } \\
1784 ; \\
64.2^{\circ} \mathrm{N}, 51.7^{\circ} \mathrm{W}\end{array}$} & Anomaly $\left({ }^{\circ} \mathrm{C}\right)$ & -1.6 & 0.5 & 3.8 & 2.4 & -0.2 & 1.9 \\
\hline & z-score & -0.9 & 0.4 & 2.1 & 2.3 & 0.2 & 1.6 \\
\hline & Max Year & 2010 & 2010 & 1932 & 2012 & 2010 & 2010 \\
\hline & Min Year & 1811 & 1818 & 1802 & 1819 & 1811 & 1818 \\
\hline \multirow{4}{*}{$\begin{array}{l}\text { Paamiut } \\
1958 ; \\
62.0^{\circ} \mathrm{N}, 49.7^{\circ} \mathrm{W}\end{array}$} & Anomaly $\left({ }^{\circ} \mathrm{C}\right)$ & -1.0 & 1.9 & 2.5 & 0.7 & 0.4 & 1.7 \\
\hline & z-score & -0.9 & 0.5 & 1.3 & 0.8 & 0.3 & 1.2 \\
\hline & Max Year & 2010 & 2010 & 2005 & 2010 & 2010 & 2010 \\
\hline & Min Year & 1982 & 1984 & 1993 & 1969 & 1982 & 1984 \\
\hline
\end{tabular}




\begin{tabular}{|c|c|c|c|c|c|c|c|}
\hline \multicolumn{2}{|c|}{$\begin{array}{l}\text { Station Name, Start Year; } \\
\text { Latitude, Longitude }\end{array}$} & $\begin{array}{l}\text { SON } \\
2015\end{array}$ & $\begin{array}{c}\text { DJF } \\
2015 / 16\end{array}$ & $\begin{array}{l}\text { MAM } \\
2016\end{array}$ & JJA 2016 & $\begin{array}{l}\text { SON } \\
2016\end{array}$ & $\begin{array}{c}\text { Jan-Dec } \\
2016\end{array}$ \\
\hline \multirow{2}{*}{$\begin{array}{l}\text { Ivittuut/ } \\
\text { Narsarsuaq }\end{array}$} & Anomaly $\left({ }^{\circ} \mathrm{C}\right)$ & -1.8 & 0.5 & 2.8 & 1.7 & -0.1 & 1.5 \\
\hline & z-score & -1.2 & 0.3 & 1.3 & 2.1 & 0.1 & 1.3 \\
\hline \multirow{2}{*}{$\begin{array}{l}1873 \\
61.2^{\circ} \mathrm{N}, 45.4^{\circ} \mathrm{W}\end{array}$} & Max Year & 2010 & 2010 & 2010 & 2016 & 2010 & 2010 \\
\hline & Min Year & 1874 & 1984 & 1989 & 1873 & 1874 & 1884 \\
\hline \multirow{4}{*}{$\begin{array}{l}\text { Qaqortoq } \\
1807 ; \\
60.7^{\circ} \mathrm{N}, 46.1^{\circ} \mathrm{W}\end{array}$} & Anomaly $\left({ }^{\circ} \mathrm{C}\right)$ & -1.3 & 1.0 & 1.8 & 1.3 & 0.2 & 1.2 \\
\hline & z-score & -0.5 & 0.6 & 0.9 & 1.4 & 0.6 & 1.2 \\
\hline & Max Year & 2010 & 2010 & 1932 & 1929 & 2010 & 2010 \\
\hline & Min Year & 1874 & 1863 & 1811 & 1811 & 1874 & 1884 \\
\hline \multirow{4}{*}{$\begin{array}{l}\text { Danmarkshavn } \\
1949 ; \\
76.8^{\circ} \mathrm{N}, 18.7^{\circ} \mathrm{W}\end{array}$} & Anomaly $\left({ }^{\circ} \mathrm{C}\right)$ & 2.3 & 1.8 & 1.1 & 2.3 & 5.3 & 2.7 \\
\hline & z-score & 1.7 & 1.0 & 1.0 & 3.0 & 3.3 & 3.0 \\
\hline & Max Year & 2002 & 2005 & 1976 & 2016 & 2016 & 2016 \\
\hline & Min Year & 1971 & 1967 & 1966 & 1955 & 197| & 1983 \\
\hline \multirow{4}{*}{$\begin{array}{l}\text { Illoqqortoormiut } \\
1949 ; \\
70.5^{\circ} \mathrm{N}, 22.0^{\circ} \mathrm{W}\end{array}$} & Anomaly $\left({ }^{\circ} \mathrm{C}\right)$ & I.I & 2.0 & 2.6 & 2.2 & 4.2 & 2.9 \\
\hline & z-score & 1.0 & 1.1 & 1.7 & 2.1 & 2.7 & 2.2 \\
\hline & Max Year & 2002 & 2014 & 1996 & 2016 & 2016 & 2016 \\
\hline & Min Year & 1951 & 1966 & 1956 & 1955 & 1951 & 1951 \\
\hline \multirow{4}{*}{$\begin{array}{l}\text { Tasiilaq } \\
\text { 1895; } \\
65.6^{\circ} \mathrm{N}, 37.6^{\circ} \mathrm{W}\end{array}$} & Anomaly $\left({ }^{\circ} \mathrm{C}\right)$ & 0.5 & 2.6 & 2.9 & 2.3 & 2.3 & 2.6 \\
\hline & z-score & 0.7 & 1.6 & 1.8 & 2.9 & 2.2 & 2.7 \\
\hline & Max Year & 1941 & 1929 & 1929 & 2016 & 1941 & 2016 \\
\hline & Min Year & 1917 & 1918 & 1899 & 1983 & 1917 & 1899 \\
\hline \multirow{2}{*}{$\begin{array}{l}\text { Prins Christian } \\
\text { Sund }\end{array}$} & Anomaly $\left({ }^{\circ} \mathrm{C}\right)$ & -0.1 & 0.4 & 1.2 & 0.8 & 1.3 & 0.9 \\
\hline & z-score & 0.0 & 0.3 & 1.3 & 1.1 & 1.5 & 1.3 \\
\hline \multirow{2}{*}{$\begin{array}{l}1958 \\
60.1^{\circ} \mathrm{N}, 42.2^{\circ} \mathrm{W}\end{array}$} & Max Year & 2010 & 2010 & 2005 & 2010 & 2010 & 2010 \\
\hline & Min Year & 1982 & 1993 & 1989 & 1970 & 1982 & 1983 \\
\hline \multirow{4}{*}{$\begin{array}{l}\text { Summit } \\
1991 ; \\
72.6^{\circ} \mathrm{N}, 38.5^{\circ} \mathrm{W}\end{array}$} & Anomaly $\left({ }^{\circ} \mathrm{C}\right)$ & 0.3 & -1.3 & 4.3 & 1.2 & 2.2 & 2.2 \\
\hline & z-score & 0.2 & -0.4 & 2.2 & 0.6 & 1.1 & 1.6 \\
\hline & Max Year & 2002 & 2010 & 2016 & 2012 & 2002 & 2010 \\
\hline & Min Year & 2009 & 1993 & 1992 & 1992 & 2009 & 1992 \\
\hline
\end{tabular}

GBI values have been associated with extensive Greenland surface melt and negative surface mass balance (Hanna et al. 2013; McLeod and Mote 2015). Despite the near-record GBI, the average daily melt during summer of 2016 was much less than the record breaking year of 2012. A major difference between the atmospheric conditions in 2012 and 2016 was the lack of water vapor transport and associated latent heat and downwelling longwave radiative fluxes in 2016, which have recently been shown to have a considerable effect on ice sheet melt (Mattingly et al. 2016). f. Glaciers and ice caps outside Greenland-G. Wolken,

M. Sharp, L. M Andreassen, D. Burgess, L. Copland, J. Kohler, S. O'Neel, M. Pelto, L. Thomson, and B. Wouters

Mountain glaciers and ice caps cover an area of over $400000 \mathrm{~km}^{2}$ in the Arctic, and are a leading contributor to global sea level change despite their relatively small volume compared to ice sheets in Antarctica and Greenland (Gardner et al. 2011, 2013; Jacob et al. 2012). Glaciers gain mass by snow accumulation and lose mass by surface melt and runoff, iceberg calving, and submarine melting where they terminate in water (ocean or lake). The total mass bal- 


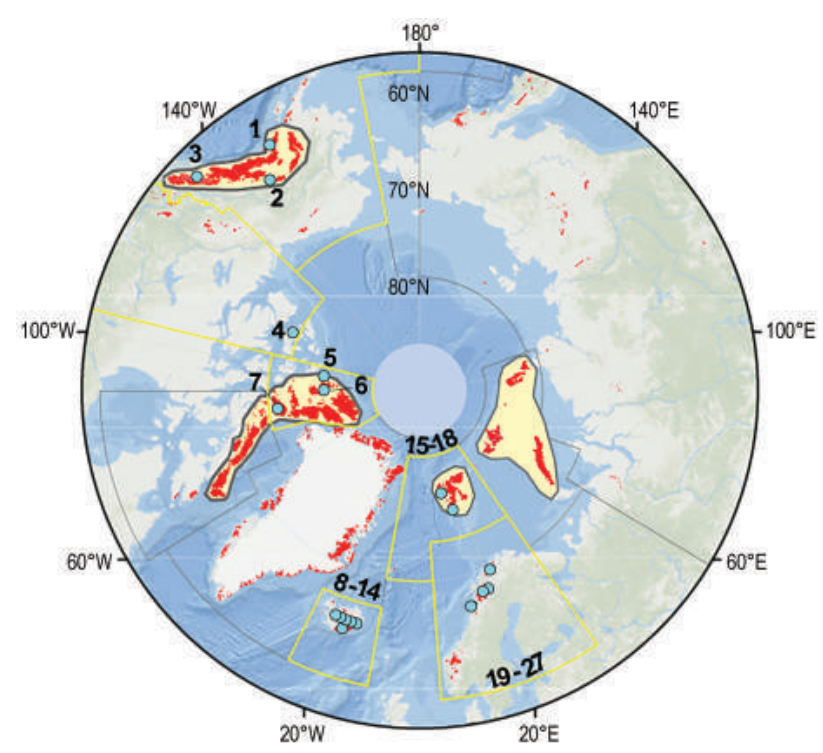

FIG. 5.14. Locations of 27 Arctic glaciers (blue circles) with long-term records of annual $B_{\text {clim. See Table }}$ $\mathbf{5 . 2}$ for glacier names. Regions outlined in yellow are the Randolph Glacier Inventory (RGI) regions of the Arctic (Pfeffer et al. 2014). Individual glaciers located too close together to be identifiable on the map have numbers shown at the edge of the RGI region in which they occur. Red shading indicates glaciers and ice caps, including ice caps in Greenland outside the ice sheet. Yellow shading shows the solution domains for regional mass balance estimates for Alaska, Arctic Canada, Russian Arctic, and Svalbard derived using gravity data from the GRACE satellites (see Fig. 5.16).

ance $(\Delta M)$ is defined as the difference between annual snow accumulation and annual mass losses. Of the 27 glaciers currently monitored, only three (Kongsvegen, Hansbreen, and Devon Ice Cap NW) lose any mass by iceberg calving or melting directly into the ocean. For all glaciers discussed here, climatic mass balance ( $\mathrm{B}_{\text {clim; }}$ the difference between annual snow accumulation and annual runoff), a widely-used index of how glaciers respond to changes in climate, is reported.

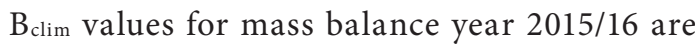
available for only 9 of the 27 glaciers that are monitored across the Arctic (three in Alaska, one in Arctic Canada, two in Svalbard, and three in Norway), and some of these estimates are still provisional. Therefore, the focus is on the 2014/15 Bclim values, which are available for 23 glaciers (WGMS 2017). These glaciers are located in Alaska (three), Arctic Canada (four), Iceland (nine), Svalbard (four), and Norway (three) (Fig. 5.14; Table 5.2). For these glaciers, as a group, the average $B_{\text {clim }}$ in 2014/15 was negative. However, all nine glaciers in Iceland and one in Norway (Engabreen) had positive balances.

For the Arctic as a whole, 2014/15 continues the negative trend of cumulative regional climatic mass

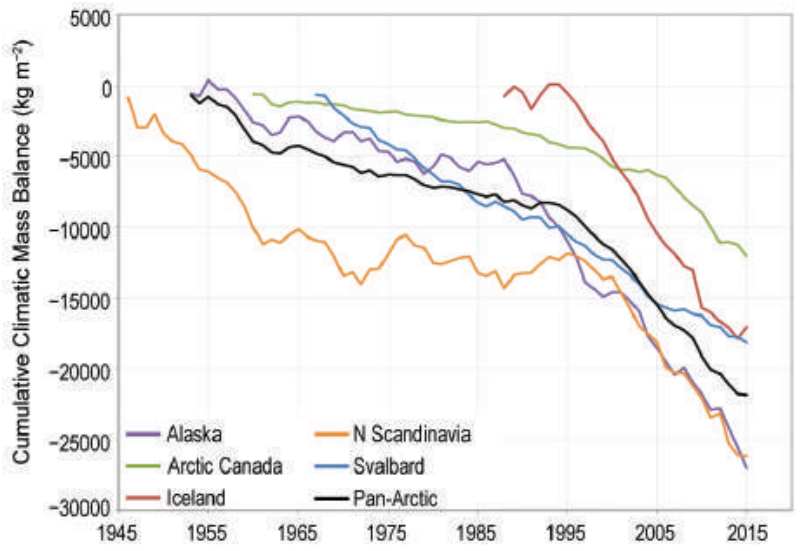

FIG. 5.I5. Cumulative $B_{\text {clim }}\left(\mathrm{kg} \mathrm{m}^{-2}\right)$ for glaciers in five regions of the Arctic, and for the Arctic as a whole (Pan-Arctic). Average balances are calculated for glaciers monitored in each region by summing annual averages for the period of record. Note that monitoring periods vary between regions and that the number and identity of glaciers monitored in a given region may vary between years.

balances, calculated by summing the annual average mass balances for all glaciers in each reporting region of the Arctic (Fig. 5.15). For Alaska and Arctic Canada, 2014/15 was the third most negative mass balance year on record. Climatic balances of Lemon Creek and Gulkana glaciers in Alaska were the most negative and seventh most negative, respectively, since 1966, and, for the four glaciers in Arctic Canada, they were the fourth (Meighen and Melville South ice caps) and sixth (Devon Ice Cap NW and White Glacier) most negative since 1960 . The negative balances of glaciers in Alaska, Arctic Canada, and Svalbard in 2014/15 were most likely linked to melt increases caused by positive air temperature anomalies at the $850-\mathrm{hPa}$ level in July-August (data from NCEP/NCAR Reanalysis; see also Fig. 5.2c). In contrast to the negative anomalies described above, 2014/15 was the second most positive mass balance year on record for Iceland, which was linked to a broad region of negative (cool) 850-hPa air temperature anomalies over the North Atlantic in June-August. These negative $850-\mathrm{hPa}$ air temperature anomalies likely also resulted in melt reduction over northern Scandinavia and the least negative climatic balance for this region since 1946 .

Among the nine glaciers for which 2015/16 $\mathrm{B}_{\text {clim }}$ measurements have been reported, the balances of glaciers in Alaska, Arctic Canada (Devon Ice Cap NW), Svalbard (Midre Lovenbreen and Austre Broggerbreen), and Norway (Engabreen, Langfjordjøkelen, and Rundvassbreen) were all negative. The pattern of negative balances continued into 2015/16 in Arctic Canada and is captured in the time series 
TABLE 5.2. Measured B clim of glaciers in Alaska, the Canadian Arctic, Iceland, Svalbard, and northern Scandinavia for $2014 / 15$ and $2015 / 16$, along with the 1981-2010 average and std. dev. for each glacier (* indicates one or more years of missing data in the climate record). Mass balance data are from the World Glacier Monitoring Service (WGMS 2017), with updates to data provided by S. O'Neel (Alaska), L. Thompson (White Glacier; Thompson et al. 2016), J. Kohler (Svalbard), and the Norwegian Water Resources and Energy Directorate (Norway; Kjøllmoen et al. 2016; Andreassen et al. 2016). Numbers in left most column identify glacier locations in Fig. 5.14. Note that 2015/16 results may be based on data collected before the end of the 2016 melt season and may be subject to revision. Units for all $B_{\text {clim }}$ are $\mathrm{kg} \mathrm{m}^{-2} \mathrm{yr}^{-1}$.

\begin{tabular}{|c|c|c|c|c|c|}
\hline Region & $\begin{array}{c}\text { Glacier } \\
\text { (record length, years) }\end{array}$ & $\begin{array}{c}\text { B clim Average }_{1981-2010} \\
B_{\text {clim }} \text { Std. dev. } \\
1981-2010\end{array}$ & $B_{\text {clim } 2014 / 15}$ & B clim 2015/16 \\
\hline
\end{tabular}

\section{Alaska}

\begin{tabular}{|l|l|c|c|c|c|}
\hline 1 & Wolverine (5I) & -362 & 1157 & -1100 & -500 \\
\hline 3 & Lemon Creek (64) & -594 & 719 & -2270 & -1200 \\
\hline 2 & Gulkana (5I) & -655 & 743 & -1400 & -1300 \\
\hline
\end{tabular}

\section{Arctic Canada}

\begin{tabular}{|l|l|c|c|c|c|}
\hline 7 & Devon Ice Cap (NW) (56) & -157 & 178 & -395 & -301 \\
\hline 5 & Meighen Ice Cap (54) & -176 & 288 & -892 & - \\
\hline 4 & Melville South Ice Cap (53) & -303 & 373 & -1148 & - \\
\hline 6 & White (53) & -267 & 270 & -693 & - \\
\hline
\end{tabular}

\section{Iceland}

\begin{tabular}{|l|l|c|c|c|c|}
\hline 8 & Langjökull S. Dome (19) & $-1448^{*}$ & $817^{*}$ & 413 & - \\
\hline 9 & Hofsjökull E (25) & $-602^{*}$ & $100 *^{*}$ & 850 & - \\
\hline 9 & Hofsjökull N (26) & $-606^{*}$ & $787^{*}$ & 1380 & - \\
\hline 9 & Hofsjökull SW (25) & $-978^{*}$ & $947^{*}$ & 1074 & - \\
\hline 14 & Köldukvislarjökull (23) & $-529^{*}$ & $738^{*}$ & 196 & - \\
\hline 10 & Tungnaarjökull (24) & $-1170^{*}$ & $873^{*}$ & 1469 & - \\
\hline 13 & Dyngjujökull (18) & $-133^{*}$ & $912^{*}$ & - \\
\hline 12 & Brúarjökull (23) & $-368^{*}$ & $660^{*}$ & $813^{*}$ & - \\
\hline 11 & Eyjabakkajökull (24) & $-867^{*}$ & & - \\
\hline
\end{tabular}

\section{Svalbard}

\begin{tabular}{|l|l|c|c|c|c|}
\hline 17 & Midre Lovenbreen (48) & -352 & 303 & -463 & -991 \\
\hline 16 & Austre Broggerbreen (49) & -464 & 333 & -567 & -1244 \\
\hline 15 & Kongsvegen (29) & $-48^{*}$ & $367^{*}$ & -163 & - \\
\hline 18 & Hansbreen (27) & $-431^{*}$ & $512^{*}$ & -436 & - \\
\hline
\end{tabular}

Northern Scandinavia

\begin{tabular}{|l|l|c|c|c|c|}
\hline 20 & Engabreen (46) & -8 & 948 & 610 & -260 \\
\hline 21 & Langfjordjøkelen (25) & $-927^{*}$ & $781^{*}$ & -797 & -1664 \\
\hline 22 & Marmaglaciaren (23) & $-430^{*}$ & $525^{*}$ & - & - \\
\hline 23 & Rabots Glaciar (31) & $-394^{*}$ & $560^{*}$ & - & - \\
\hline 24 & Riukojietna (26) & $-592^{*}$ & $805^{*}$ & - \\
\hline 25 & Storglaciaren (69) & -75 & 678 & - & - \\
\hline 26 & Tarfalaglaciaren (18) & $-211^{*}$ & $-1101^{*}$ & - & - \\
\hline 27 & Rundvassbreen (8) & - & - & -20 & -488 \\
\hline
\end{tabular}




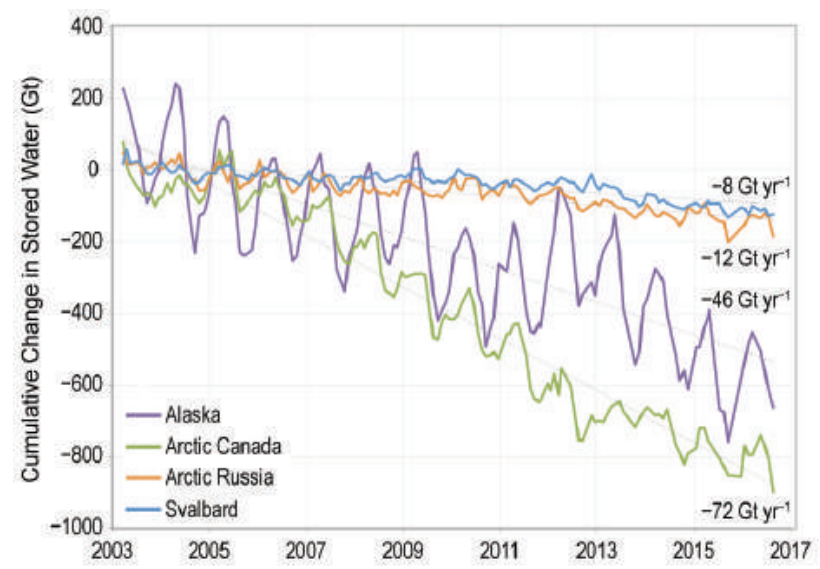

FIG. 5.16. Cumulative changes in regional total stored water for 2003-16 (Gt), derived using GRACE satellite gravimetry. Estimated uncertainty in regional mass

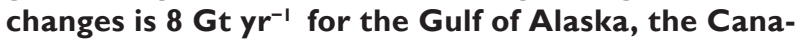
dian Arctic, and the Russian Arctic, and $4 \mathrm{Gt} \mathrm{yr}^{-1}$ for Svalbard. These errors include the formal error of the least squares fit and the uncertainties in the corrections for glacial isostatic adjustment, Little Ice Age, and terrestrial hydrology.

of regional total stored water estimates (Fig. 5.16), derived using GRACE satellite gravimetry available since 2003. Annual storage changes are a proxy for changes in the regional annual glacier mass balance $(\Delta \mathrm{M})$ for the heavily glacierized regions of the Arctic. Measurements of $\Delta \mathrm{M}$ in 2015/16 for all the glaciers and ice caps in Alaska, Svalbard, and the Russian Arctic are inconclusive as the GRACE time series is currently only available through August 2016, and melt in these regions typically continues into September.

g. Terrestrial snow cover-C. Derksen, R. Brown, L. Mudryk, and K. Luojus

Snow cover is a defining characteristic of the Arctic land surface for up to 9 months each year, evolving
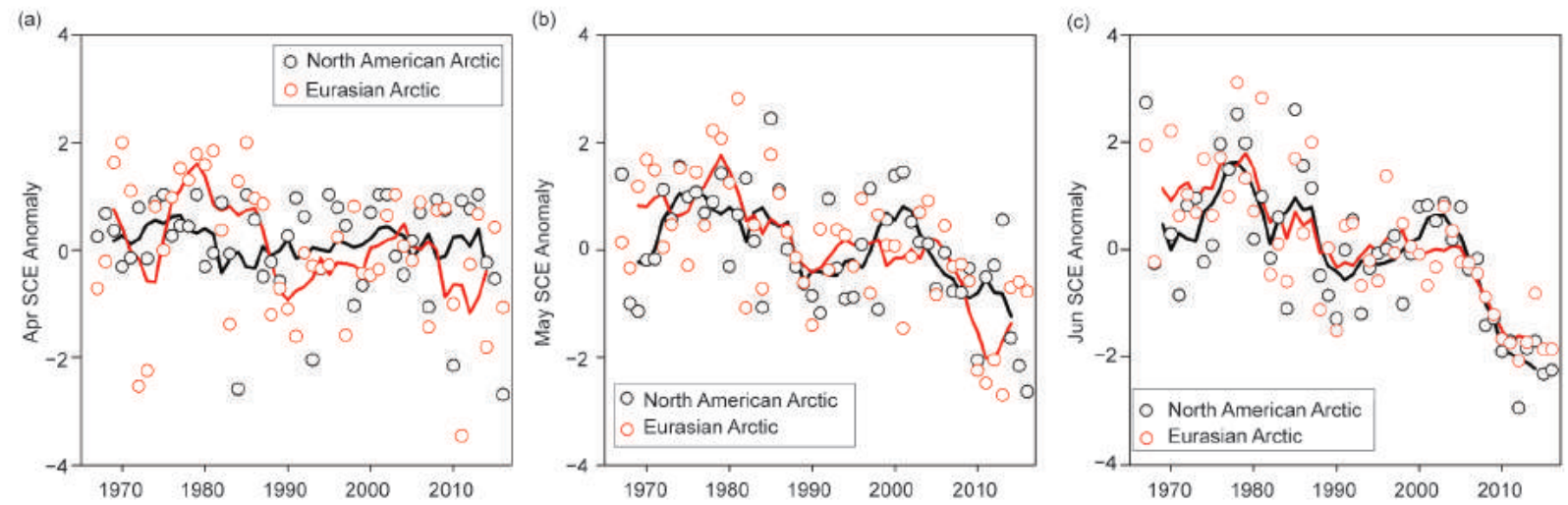

FIG. 5.I7. Monthly snow cover extent (SCE) anomalies (198I-20I0 base period) for Arctic land areas for (a) Apr, (b) May, and (c) Jun, from 1967 to 2016 . Each observation is differenced from the average and divided by the standard deviation and thus unitless. Solid black and red lines depict 5-yr running averages for North America and Eurasia, respectively. (Source: NOAA snow cover extent CDR.) 

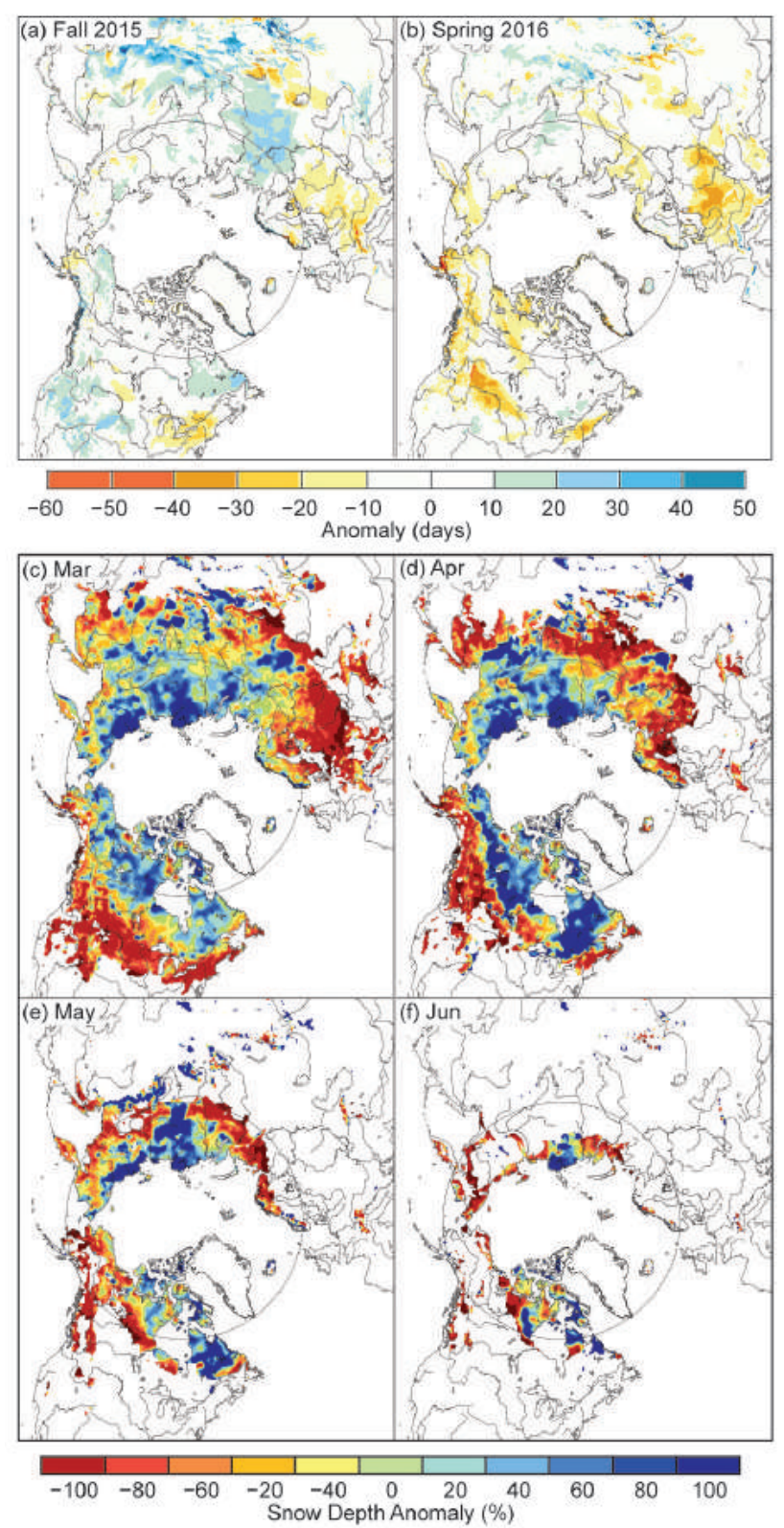

FIG. 5.18. Snow cover duration departures (days; with respect to 1998-2010) from the NOAA IMS data record for the (a) 2015 fall season and (b) 2016 spring season. Snow depth anomaly (\% of 1999-2010 average) from the Canadian Meteorological Centre daily gridded global snow depth analysis (Brasnett 1999) for (c) Mar, (d) Apr, (e) May, and (f) Jun 2016.

significant (95\%). The rate of change in May is dwarfed by the rate of $-17.8 \%$ decade $^{-1}$ in June, which exceeds the pace of summer sea ice reductions in September $\left(-13.3 \%\right.$ decade $\left.^{-1}\right)$. The loss of spring snow cover is a clear indicator of change in the terrestrial cryosphere, much in the same way summer sea ice loss is indicative of changes in the marine cryosphere.

Snow cover duration (SCD) departures (Figs. 5.18a,b) derived from the NOAA daily Inter-

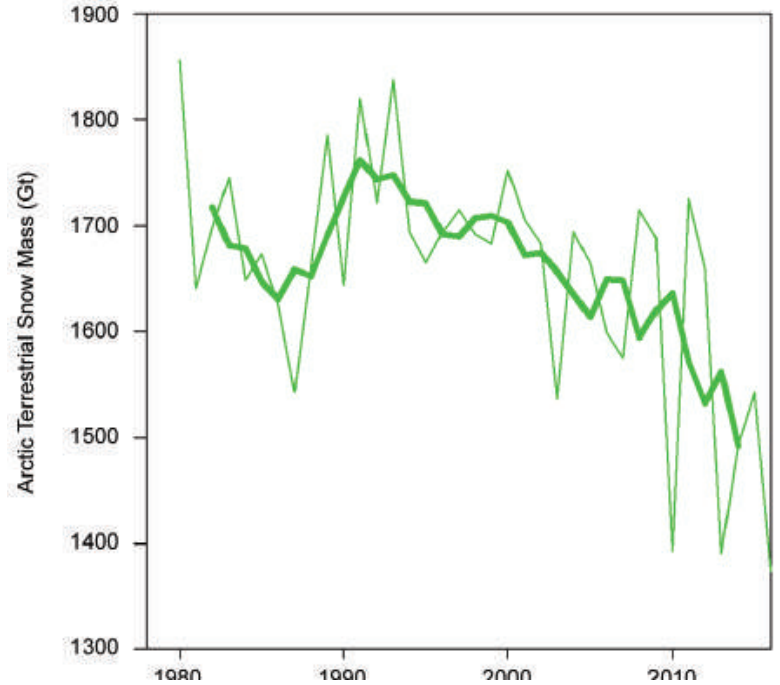

FIG. 5.19. Arctic terrestrial snow mass (Gt) for Apr 1980-2016, from the GlobSnow data record (Takala et al. 20II). The bold line is a 5-year running average.

active Multisensor Snow and Ice Mapping System (IMS) snow cover product (Helfrich et al. 2007) show normal to earlier snow cover onset in the fall 2015 over much of the Arctic. Spring 2016 snow cover duration departures tended toward more negative (earlier snow-off), with the earliest snow-off over Alaska and the western Canadian Arctic. This earlier spring snow-off is consistent with the distribution of spring temperature anomalies which were positive over all Arctic land areas, with the exception of eastern North America (see Fig. 5.2). Snow depth anomalies (Figs. 5.18c-f; show a pattern similar to 2015 in March and April (Derksen et al. 2016) with negative anomalies (i.e., below-normal snow depths) across the sub-Arctic surrounded by mainly positive anomalies over the high latitude regions of Siberia and North America. By May, the North America snow depth anomalies changed to strongly negative (average anomaly of $-10.7 \%$ ) consistent with the record low SCE values reported above. May snow depth anomalies over Eurasia were near normal $(-0.6 \%)$ but plummeted to $-29.2 \%$ in June.

The link between temperature and snow cover extent is straightforward: there is a strong association between trends in surface temperature and snow cover extent in both observational datasets $\left(\mathrm{R}^{2}=0.64\right.$ in Mudryk et al. 2017) and climate model simulations $\left(\mathrm{R}^{2}=0.45\right.$ in Thackeray et al. 2016). There is also evidence of decreasing pre-melt snow mass (reflective of shallower snow depth) in the GlobSnow data record (Takala et al. 2011), which combines surface snow depth observations from weather stations with satellite passive microwave measurements. The trend in 
April snow mass (the month of peak pre-melt Arctic snow mass) is $-4.3 \%$ decade $^{-1}$, with April 2016 having the lowest value in the record (Fig. 5.19). While early snow melt in previous years occurred despite above-average snow mass (e.g., 2011 and 2012), a shallower snowpack combined with above-average temperatures created ideal conditions for early and rapid snow melt, reflected in the new record low SCE values observed in 2016 .

h. Tundra greenness - H. E. Epstein, U. S. Bhatt, M. K. Raynolds, D. A. Walker, B. C. Forbes, M. Macias-Fauria, M. Loranty, G. Phoenix, and J. Bjerke

Vegetation in the Arctic tundra has been responding dynamically to environmental changes, many of which are anthropogenically induced, since at least the early 1980s. These vegetation changes throughout the circumpolar Arctic are not spatially homogenous, nor are they temporally consistent (e.g., Bhatt et al. 2013), suggesting that there are complex interactions among the atmosphere, ground (soils and permafrost), vegetation, and herbivore components of the Arctic system. Changes in Arctic tundra vegetation may have a relatively small impact on the global carbon budget through photosynthetic uptake of $\mathrm{CO}_{2}$ compared to changes in other carbon cycling processes (Abbott et al. 2016). However, tundra vegetation can have important effects on permafrost, hydrology, soil carbon fluxes, and the surface energy balance (e.g., Blok et el. 2010; Myers-Smith and Hik 2013; Parker et al. 2015). Tundra vegetation dynamics also control the diversity of herbivores (birds and

\section{SIDEBAR 5.2: ARCTIC OCEAN ACIDIFICATION-J. N. CROSS AND J. T. MATHIS}

A growing body of recent research has shown that the Arctic Ocean has rapidly acidified over the last several decades, in part due to the oceanic uptake of anthropogenic carbon dioxide $\left(\mathrm{CO}_{2}\right)$ from the atmosphere (e.g., Semiletov et al. 2016; Cross et al. 2017; Qi et al. 2017). While this long-term decrease in ocean $\mathrm{pH}$ does not produce acidic (e.g., $\mathrm{pH}<7$ ) oceans, this gradual ocean acidification (OA) has been shown to compound natural variability in seawater carbonate chemistry. In some areas like the Arctic, the $\mathrm{pH}$ conditions observed today are now corrosive to biologically important carbonate minerals. Some studies indicate that these corrosive conditions can cover up to $40 \%$ of the Chukchi Sea benthos seasonally (Bates et al. 20I3), and persist for $80 \%$ of the year in some hotspots (Cross et al. 2017).

Over the past five years, ocean acidification has emerged as one of the most prominent issues in marine research, especially given newfound public understanding of the potential biological threat to marine calcifiers (e.g., clams, pteropods) and associated fisheries, and the human impacts it poses for communities that directly or indirectly rely on them (e.g., Mathis et al. 2015a; Frisch et al. 2015). Cooler water and unique physical processes (i.e., formation and melting of sea ice) make the waters of the Arctic Ocean disproportionately sensitive to OA when compared to the rest of the global ocean. Even small amounts of human-derive $\left(\mathrm{CO}_{2}\right)$ can cause significant chemical changes in the Arctic that other areas do not experience; these could pose a threat to Arctic populations of calcifying marine organisms and their natural predators.
Recently, several comprehensive data synthesis products (Bates 2015; Cross et al. 2017; Semiletov et al. 2016; Qi et al. 2017) were published using much of the available OA data collected in the Arctic Ocean. Several trends have emerged that clearly elucidate the rapid progression of $\mathrm{OA}$ across the Arctic Basin, including rapid $\mathrm{CO}_{2}$ uptake from the atmosphere and increasing carbonate mineral corrosivity (e.g., Evans et al. 2015). A new analysis released this year suggests that corrosive conditions have been expanding since the late 1990s, spreading northward into the Arctic Basin over a thicker layer (Qi et al. 2017). These Pacific-origin corrosive waters have been observed as far north as the entrances to Amundsen Gulf and M'Clure Strait in the Canadian Arctic Archipelago (Cross et al. 2017).

Though the specifics remain uncertain, it is likely that the consequences of continuing $\mathrm{OA}$ will be detrimental for parts of the Arctic food web (Mathis et al. 20I5a). For example, many large predators (e.g., seals, walrus, and salmon) rely on the small marine calcifiers most likely to be impacted by OA (Cross et al. 2017). Juvenile and larval life stages of some organisms are also particularly vulnerable to OA (e.g., crabs, Punt et al. 2014; shellfish, Ekstrom et al. 20I5). In turn, many subsistence communities rely on seals, walrus, salmon, and other large predators. While biological impacts of OA are not presently visible, it is likely that OA conditions will intensify over the next two to three decades and may produce more prominent food web impacts with economic, ecological, and cultural implications (Mathis et al. 20I5b; Punt et al. 2016). 
mammals) in the Arctic, with species richness being positively related to vegetation productivity (Barrio et al. 2016).

Earth observing satellites with daily return intervals have provided the capacity to monitor Arctic tundra vegetation continuously since 1982 . The data here are from the Global Inventory Modeling and Mapping Studies (GIMMS) version 3g dataset based largely on the AVHRR sensor onboard NOAA satel-

(a)
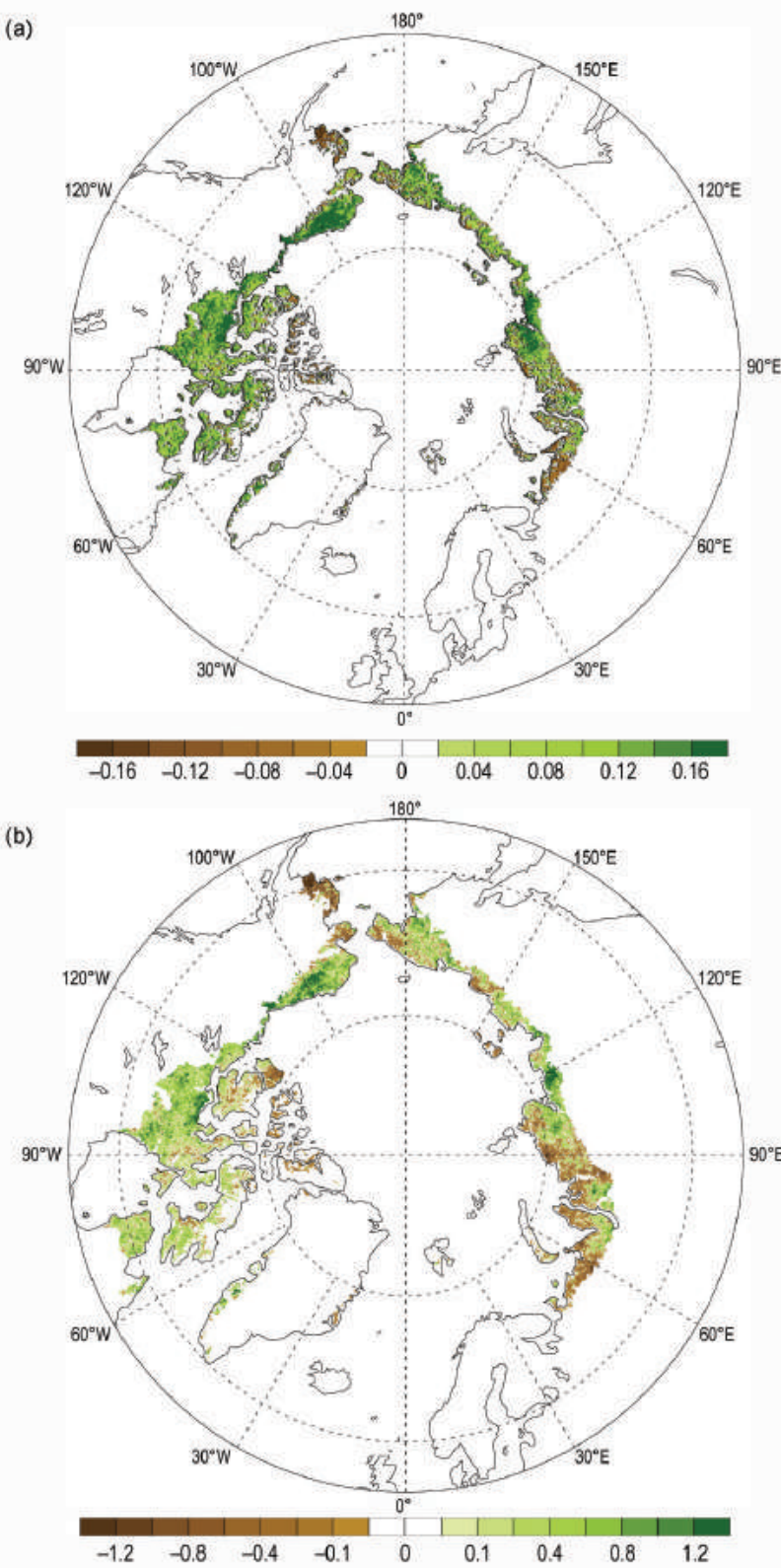

Fig. 5.20. Magnitude of the trend for 1982-2015 in (a) MaxNDVI (peak NDVI for the yearly growing season, related to yearly maximum aboveground vegetation biomass) and (b) TI-NDVI (time-integrated NDVI; sum of the biweekly NDVI values for the growing season, related to the total above ground vegetation productivity). lites (Pinzon and Tucker 2014). The GIMMS product is a biweekly, maximum-value composited dataset of the normalized difference vegetation index (NDVI); NDVI is highly correlated with aboveground vegetation (e.g., Raynolds et al. 2012). Two metrics based on the NDVI are used: MaxNDVI (peak NDVI for the yearly growing season, related to yearly maximum aboveground vegetation biomass) and time-integrated NDVI (TI-NDVI; sum of the biweekly NDVI values for the growing season, related to the total aboveground vegetation productivity). This section reports only through the end of the 2015 growing season (May-September), as a complete 2016 dataset was not available at the time of writing.

Examining the overall trend in tundra greenness for the 34-year record, both MaxNDVI and TI-NDVI are found to have increased on the North Slope of Alaska, in the southern Canadian tundra, and in much of the central and eastern Siberian tundra, whereas tundra greenness has decreased (i.e., "browning") in western Alaska (Yukon-Kuskokwim Delta), the higher Arctic Canadian Archipelago, and western Siberian tundra (Fig. 5.20). Using the same NDVI dataset (albeit with a different vegetation map and a slightly shorter period of 1982-2012), Loranty et al. (2016) found that a much greater fraction of tundra areas overlying continuous permafrost exhibited long-term greening (42\%) compared to browning (5\%); in tundra areas overlying discontinuous permafrost the areal difference was not as great (27\% greening and $10 \%$ browning). Across Arctic vegetation types (from 1982-2014), greening has been most extensive in forest-tall-shrub tundra, moderately extensive in shrub tundra and sedge tundra, and minimal in low-lying shrub tundra. Forest-tallshrub tundra also had the greatest fractional area of browning among the vegetation types, although the area of browning was $<8 \%$ that of the area greening (Park et al. 2016). If the 34-year trends are assessed with more temporal detail, both the North American and Eurasian Arctic have shown substantial increases in tundra greenness up to the early 2010s for MaxNDVI and the early 2000s for TI-NDVI. Since then, declines are visible in these tundra greenness indices (Fig. 5.21).

Following three to four years of successive declines (depending on the index and the continent), the NDVI for Arctic tundra exhibited an upturn during the summer of 2015, with the exception of TI-NDVI for North America, which continued to decrease (Fig. 5.21). Based on land surface temperatures derived from the same sensors as those providing the NDVI values, cumulative summer warmth (sum of 
average monthly temperatures $>0^{\circ} \mathrm{C}$ ) for the Arctic as a whole (and for the two continents separately) was greater in 2015 than in any other year of the satellite record (since 1982). MaxNDVI values in 2015 were greater than the average values for the record (1982-2015), ranking 8, 7, and 9 for the entire Arctic, North American Arctic, and Eurasian Arctic, respectively, over the 34 -year record. TI-NDVI values in 2015 were below the average for the entire record, ranking 28, 28, and 29 for the entire Arctic, North American Arctic, and the Eurasian Arctic, respectively. The relatively high ranking of the MaxNDVI (a measure of the peak quantity of aboveground tundra vegetation) compared to the low ranking of the TI-NDVI (a seasonally integrated measurement of the same) could potentially indicate a shortening of the growing season.

While research on tundra browning is at present relatively sparse, there may be a variety of mechanisms leading to browning, including cooler summer temperatures (Bhatt et al. 2013), deeper winter snow packs and potentially longer snow cover duration ob-
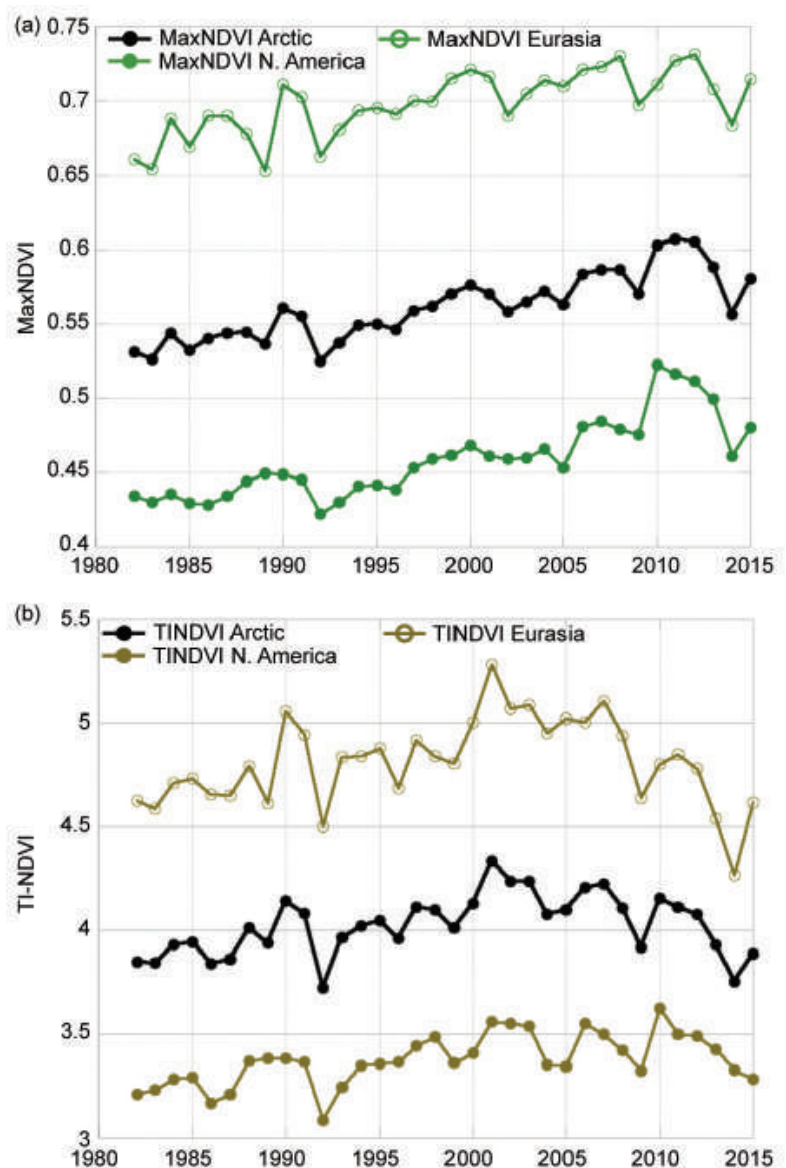

FIG. 5.2I. (a) MaxNDVI and (b) TI-NDVI from 1982 to 2015 for North America, Eurasia, and the Arctic as a whole, as indicated. served specifically in the tundra region (Bieniek et al. 2015), and a shortening of the growing season in the northern high latitudes. Phoenix and Bjerke (2016) propose that tundra browning could be more "event driven" than greening, caused by fire (Bret-Harte et al. 2013), extreme winter warming (Bokhorst et al. 2011), other anomalous weather events (e.g., frost damage), and outbreaks of insect and fungal pests (Graglia et al. 2001; Bjerke et al. 2014). Another potential cause of tundra browning could be increases in herbivore populations (Pederson et al. 2013; Hupp et al. 2015; Barrio et al. 2016).

In a recent remote sensing analysis of global terrestrial ecosystems, Seddon et al. (2016) suggest that the Arctic tundra has been highly sensitive to climate variability over the past 14 years, the length of the satellite-based Moderate Resolution Imaging Spectroradiometer (MODIS) record. They also suggest that this sensitivity is largely correlated with temperature and cloudiness, environmental variables presently being altered by anthropogenic climate change. Further, Seddon et al. (2016) report much greater vegetation sensitivity to climatic variability in the low and midlatitude tundra regions than in the High Arctic, in agreement with other remote sensing results (Epstein et al. 2012) and those of Myers-Smith et al. (2015), based on in situ growth measurements.

i. Terrestrial permafrost-V. E. Romanovsky, S. L. Smith, N. I. Shiklomanov, D. A. Streletskiy, K. Isaksen, A. L. Kholodov, H. H. Christiansen, D. S. Drozdov, G. V. Malkova, and S. S. Marchenko

Permafrost is defined as soil, rock, and any other subsurface earth material that exists at or below $0^{\circ} \mathrm{C}$ continuously for two or more consecutive years. On top of permafrost is the active layer, which thaws during the summer and freezes again the following winter. The average annual temperature of permafrost and the thickness, or depth, of the active layer (ALT) are good indicators of changing climate and are therefore designated as essential climate variables (Smith and Brown 2009; Biskaborn et al. 2015) by the Global Climate Observing System program of the World Meteorological Organization. Changes in permafrost temperatures and ALT at undisturbed locations in Alaska, Canada, Russia, Greenland, and the Nordic region are reported here. Regional variability in permafrost temperature records, described below, indicates more substantial permafrost warming since 2000 in higher latitudes than in the sub-Arctic. The distribution of variability is in general agreement with the pattern of average surface air temperature anomalies, over this same time period. 
In 2016, record high temperatures at 20-m depth were measured at all permafrost observatories on the North Slope of Alaska (Barrow, West Dock, Franklin Bluffs, Happy Valley, and Galbraith Lake) for the period of observation, which ranges from 32 to 39 years (Figs. 5.22a,b). The permafrost temperature increase between 2015 and $2016\left(+0.1^{\circ}\right.$ to $\left.+0.2^{\circ} \mathrm{C}\right)$ was substantial and comparable to the highest rate of warming observed between 1995-2000 (Fig. 5.22b). The largest increase was observed at the two North Slope southern sites, Galbraith Lake and Happy Valley. Since 2000, temperatures at $20-\mathrm{m}$ depth in this region have increased between $0.21^{\circ}$ and $0.66^{\circ} \mathrm{C}$ decade $^{-1}$. Permafrost temperatures in Interior Alaska were higher in 2016 than 2015 at all sites (Coldfoot, Old Man, College Peat, Birch Lake, Gulkana, and Healy), following the slight cooling of 2007-13 (Fig. 5.22c). The recent warming in the Interior was especially strong at Birch Lake, producing a new record high in 2016 for the entire 32 years of measurements. The highest temperature on record was also observed at Gulkana.

In northwestern Canada, temperatures of warm, discontinuous permafrost in the central Mackenzie Valley (Norman Wells, Wrigley) in 2016 were similar to those in 2015 (Fig. 5.23a). Although warming has been observed since the mid-1980s, the rate of temperature increase has generally been lower since (a)

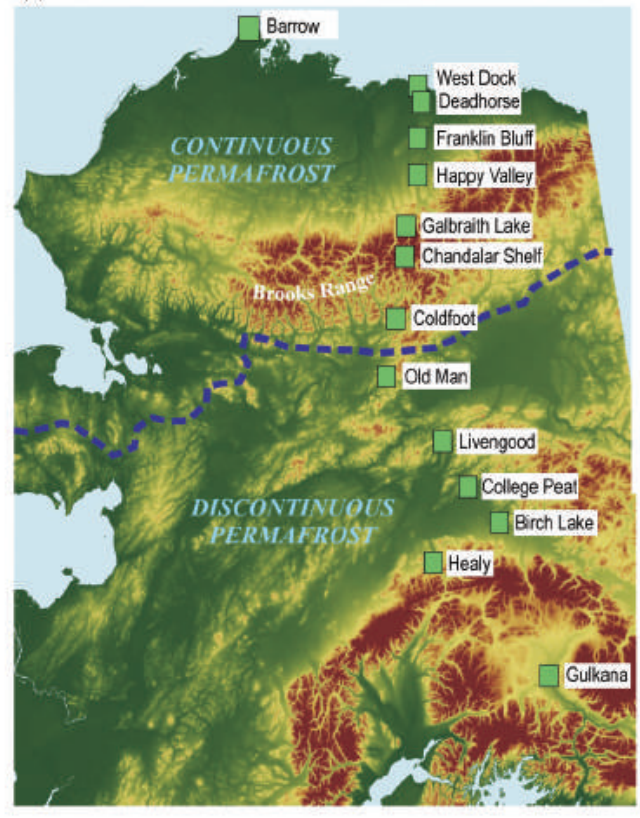

2000 and less than about $+0.2^{\circ} \mathrm{C} \mathrm{decade}{ }^{-1}$. In contrast, recent increases in permafrost temperature have been greater in the northern Mackenzie River region, up to $+0.9^{\circ} \mathrm{C}$ decade $^{-1}$ (Norris Creek, KC-7, as shown in Fig. 5.23a), which is likely associated with greater increases in surface air temperature over the last decade (Smith et al. 2016). In the high Arctic at Alert (northern Ellesmere Island), permafrost temperatures in 2015/16 were the highest on record since 1978 (Fig. 5.23b). Permafrost temperatures at Alert have been increasing at a higher rate since 2000 , ranging between $0.7^{\circ}$ and $1^{\circ} \mathrm{C}$ at $24-\mathrm{m}$ depth and $>1{ }^{\circ} \mathrm{C}$ decade $^{-1}$ at $15-\mathrm{m}$ depth, which is consistent with a greater increase in air temperature over this period since 2000. Although there has been an overall increase in near-surface permafrost temperatures since 2008 at other high Arctic sites located farther south and on Baffin Island, permafrost temperatures at $10-15 \mathrm{~m}$ have decreased since 2012 (Fig. 5.23b). The recent decrease in permafrost temperatures at these sites is consistent with shorter term, regional variations in air temperature; while air temperature in this region has generally increased since 2000 , there was a decrease in air temperature between 2010 and 2015.

Similar to northern Alaska and the Canadian high Arctic, permafrost temperature has increased by $+1^{\circ}$ to $+2^{\circ} \mathrm{C}$ in northern Russia during the last 30 to 35 years. In the Russian European North and in the
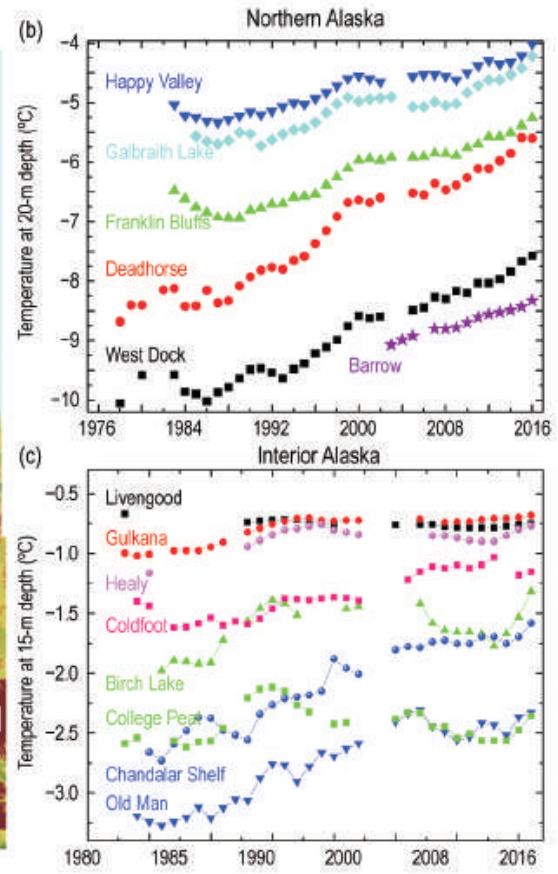

Fig. 5.22. (a) Continuous and discontinuous permafrost zones in Alaska (separated by the broken blue line) and location of a north-south transect of permafrost temperature measurement sites; (b) and (c) average annual temperature at depths of $20 \mathrm{~m}$ and $15 \mathrm{~m}$ below the surface, respectively, at Alaskan measurement sites (updated from Romanovsky et al. 2015). western Siberian Arctic, for example, temperatures at $10-\mathrm{m}$ depth have increased by $\sim+0.4^{\circ}$ to $+0.6^{\circ} \mathrm{C}$ decade $^{-1}$ since the late 1980 s at colder permafrost sites. Less warming has been observed at relatively warm permafrost sites (Drozdov et al. 2015; Malkova et al. 2016).

Since 2000 , permafrost temperature at $20-\mathrm{m}$ depth in the Nordic countries (including Svalbard) has increased between $0.1^{\circ}$ and $0.8^{\circ} \mathrm{C}$ decade $^{-1}$ (Fig. 5.24), with lower rates of increase occurring at sites in the discontinuous permafrost zone (Christiansen et al. 2010; Isaksen et al. 2011; Farbrot et al. 2013). Recently, accelerating thaw and degradation 

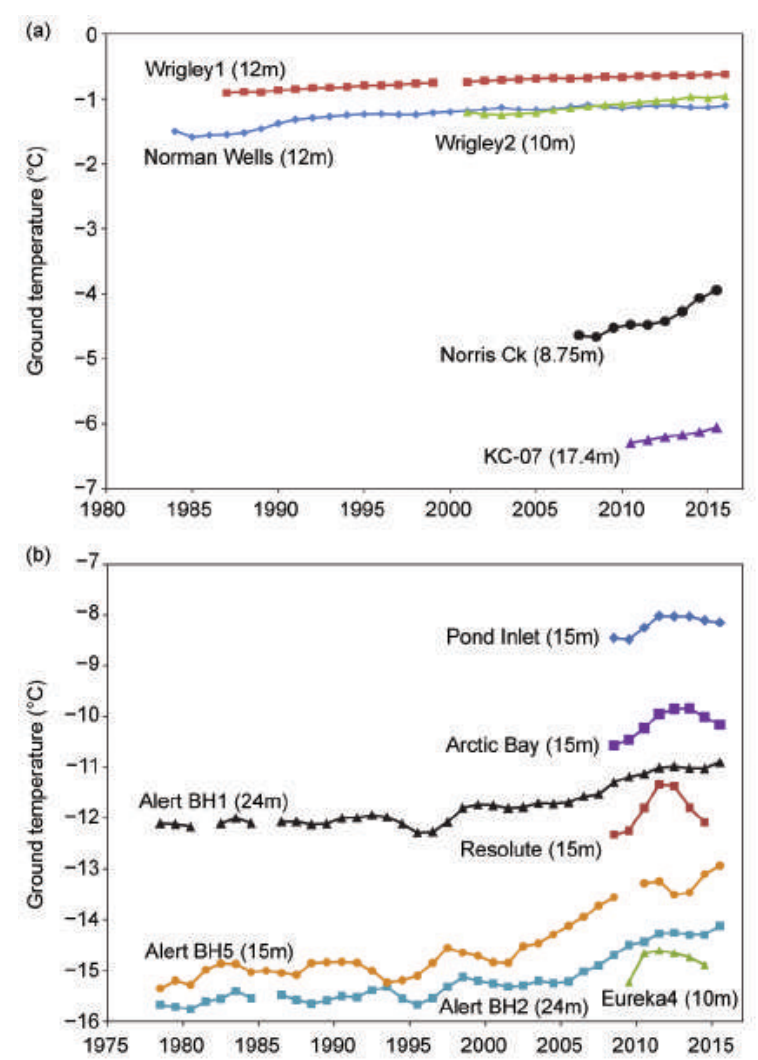

FIG. 5.23. Time series of average annual permafrost temperatures in (a) the discontinuous, warm permafrost of the central Mackenzie River Valley, Northwest Territories, Canada (Norman Wells and Wrigley), and in colder continuous permafrost in the northern Mackenzie Valley near Inuvik (Norris Ck and KC-07); (b) continuous, cold permafrost in the High Canadian Arctic (Alert, Eureka, Resolute, Arctic Bay, and Pond Inlet) (updated from Smith et al. 20I5). The depths of measurement are indicated on the graph.

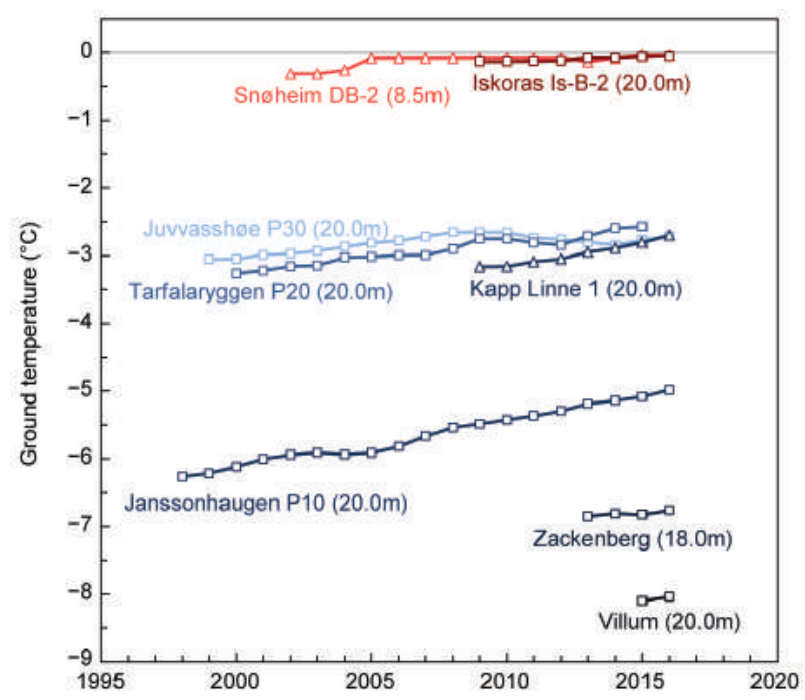

FIG. 5.24. Time series of average annual permafrost temperatures from selected sites in Scandinavia (Iskoras, Tarfalaryggen, Juvvasshøe and Snøheim), Svalbard (Janssonhaugen and Kapp Linne) and Greenland (Zackenberg and Villum). Data updated from Christiansen et al. 2010 and Isaksen et al. 20II. Depths of measurement indicated on graph.

of permafrost have been reported in northern Norway (Borge et al. 2017). On Svalbard, extreme permafrost warming was observed in 2016, where both nearsurface (not shown) and 20-m depth ground temperatures were significantly higher than any previous year since records began in 1998. Permafrost observation sites were recently started in northeastern Greenland (Zackenberg, $74^{\circ} \mathrm{N}$, in 2012) and northern Greenland (Villum Research Station, $81^{\circ} \mathrm{N}$, in 2014). Permafrost at these new sites is continuous and among the coldest observed in the Nordic countries (Fig. 5.24).
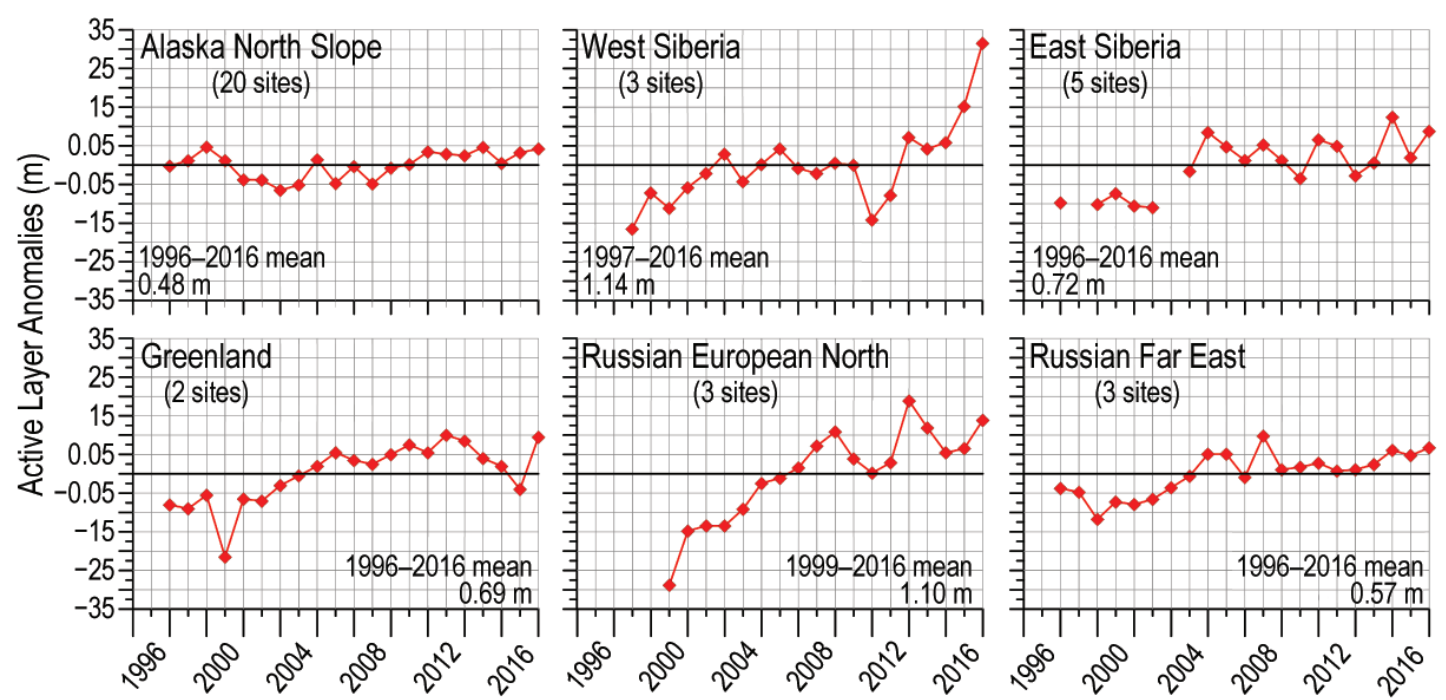

FIG. 5.25. Long-term ALT change (m, relative to average value for period of observations) in six different Arctic regions as observed by the Circumpolar Active Layer Monitoring program. Thaw depth measurements are made at the end of the thawing season. Only sites with at least 15 years of observations are shown. 


\section{SIDEBAR 5.3: PERMAFROST SOIL CARBON POOL: QUANTIFYING A POTENTIALLY SIGNIFICANT SOURCE OF GREENHOUSE GASES-}

T. SCHUUR

Tremendous quantities of organic carbon are stored in Arctic permafrost zone soils, having accumulated over hundreds and thousands of years. To put this into perspective, soils from the rest of Earth's biomes (excluding Arctic and boreal biomes) contain 2050 petagrams (Pg; I Pg = I billion metric tons) of organic carbon in the surface's top 3 meters (Jobbágy and Jackson 2000). Soils from the northern circumpolar permafrost region, that have been quantified, add another $50 \%(1025 \mathrm{Pg})$ to the $0-3 \mathrm{~m}$ inventory, even though they occupy only I5\% of the total global soil area (Schuur et al. 20I5).

When thawed, organic carbons can be released relatively quickly into the atmosphere as greenhouse gases carbon dioxide $\left(\mathrm{CO}_{2}\right)$ and methane $\left(\mathrm{CH}_{4}\right)$ resulting from microbial decomposition. The magnitude and timing of these releases have the potential to accelerate climate change beyond what we project from human activities alone (Field and Raupach 2004; Davidson and Janssens 2006; Zimov et al. 2006; Schuur et al. 2008; Schuur et al. 2013). A key challenge is providing an accurate assessment of the permafrost soil carbon pool and the rate of release. This sidebar highlights recent survey work conducted to refine the estimate of the size of the pool.

The total pool of organic carbon stored in permafrost zone soils is composed of carbon frozen in peatlands $(20 \%$ to $>50 \% \mathrm{C}$ ) and carbon intermixed with mineral soils ( $<1 \%$ to $20 \%$ ), each of which dominates different locations in the Northern Hemisphere (Post et al. 1982; Gorham 1991; Jobbagy and Jackson 2000; Tarnocai et al. 2009; Mishra and Riley 2012). Recent work has shown permafrost soil carbon pools to be much larger at depth than previously recognized due to processes unique to high latitude soils, such as freeze-thaw mixing and accumulation of thick wind- and water-borne sediments (Bockheim and Hinkel 2007; Ping et al. 2008; Schirrmeister et al. 2002; Zimov et al. 2006; Schirrmeister et al. 20II).

The current best estimate of total organic soil carbon (terrestrial) in the northern circumpolar permafrost zone is 1330-1580 Pg (Schuur et al. 2015; Hugelius et al. 2014). All permafrost-zone soils estimated to 3-m depth contain $1035 \pm 150 \mathrm{Pg} \mathrm{C}$ (Fig. SB5.3a). New revisions place between $210 \pm 70$ and $456 \pm 45 \mathrm{Pg} C$ in deep loess (wind-blown sediment) accumulations below three meters in Siberia and Alaska, in the so-called "yedoma" region (Zimov et al. 2006; Strauss et al. 2013; Walter Anthony et al. 2014) (Fig. SB5.3b). The $1.2 \times 10^{6} \mathrm{~km}^{2}$ yedoma region
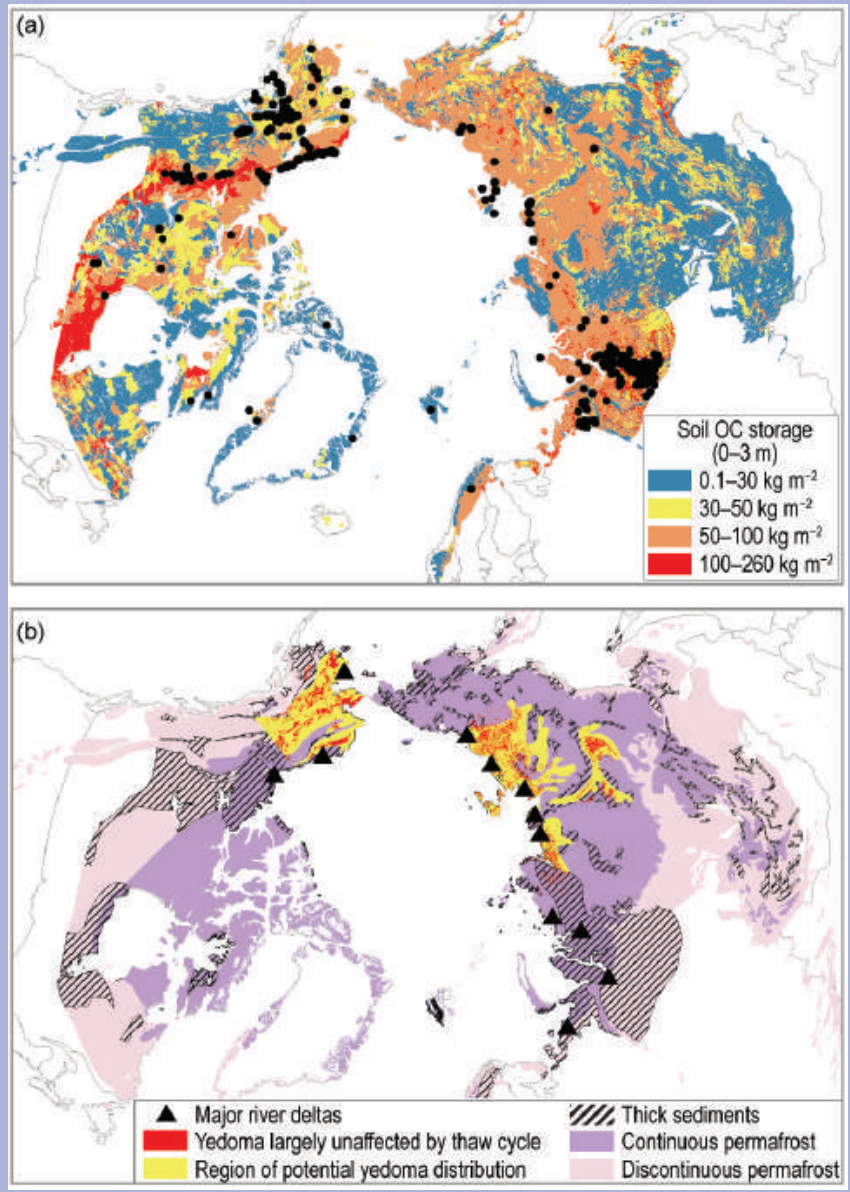

FIG. SB5.3. Soil organic carbon maps for (a) soil organic carbon pool $\left(\mathrm{kg} \mathrm{C} \mathrm{m}^{-2}\right)$ contained in the 0-3-m depth interval of the northern circumpolar permafrost zone. Black dots show field site locations for the $0-3-\mathrm{m}$ carbon inventory measurements. (b) Deep permafrost carbon pools (>3 $\mathrm{m}$ ), including locations of major permafrost-affected river deltas (black triangles), extent of the yedoma region previously used to estimate carbon content of these deposits (yellow), current extent of yedoma region soils largely unaffected by thaw-lake cycles that alter the original carbon content (red), and extent of thick sediments overlying bedrock (black hashed). Yedoma regions are generally also thick sediments. The base map layer shows permafrost distribution with continuous regions to the north having permafrost everywhere ( $>90 \%$, purple shading), and discontinuous regions farther south having permafrost in some, but not all, locations ( $<90 \%$, pink shading). 
remained ice free during the last Ice Age. Even though carbon concentrations of these mineral soils are not remarkably high $(0.2 \%-2 \% \mathrm{C})$ the depths of these sediments give rise to large carbon inventories. Additional deep carbon pools beyond yedoma include river deltas, which are now thought to contain $91 \pm 39 \mathrm{Pg} \mathrm{C}$, much less than was originally estimated for these deep deposits (Hugelius et al 2014; Tarnocai et al. 2009).

Three additional pools of permafrost carbon not yet included in the permafrost carbon pool summarized here are: (I) the permafrost region of the Tibetan plateau and permafrost soils in northern China; (2) other deep terrestrial sediment deposits located over $5 \times 10^{6} \mathrm{~km}^{2}$ outside the yedoma and delta areas; and (3) a reservoir of organic carbon stored in permafrost on the continental shelf under the Arctic Ocean (Rogers and Morack 1980; Brown et al. 1998, revised February 200I). The amount of organic carbon in the Tibetan and North China region is currently estimated at $35.7 \mathrm{Pg}$ (Luo et al. 2000; Wang et al. 2008; Mu et al. 2015; Ding et al. 2016). Simple calculations based on extremely limited data suggest that another $\sim 350-465 \mathrm{Pg} \mathrm{C}$ can be found in additional deep terrestrial deposits, although more sampling and data syn- thesis need to be done to verify or revise these potential deep permafrost carbon deposits (Schuur et al. 2015).

There are no reliable published estimates of total organic carbon inventory for the subsea permafrost pool. Undersea permafrost carbon initially formed on land as the continental shelf was exposed by sea levels that were 120 meters lower during the last glacial period (Walter et al. 2007). Subsequent inundation of this area at the Pleistocene/Holocene transition put this loess permafrost carbon under water and also started thawing the permafrost surface (Rachold et al. 2007). Much of the shallow shelf is thought to have been covered with yedoma deposits when it was exposed during the last glacial period. The shallow shelf area exposed as dry land in the area around Alaska and Siberia during the last Ice Age is about 2.5 times the size of the current terrestrial yedoma region (Strauss et al. 20I3; Brosius et al. 20I2). Submergence over thousands of years helped to thaw the permafrost, exposing organic carbon to decomposition potentially under anaerobic conditions. This would have converted a portion of the carbon pool to $\mathrm{CO}_{2}$ and $\mathrm{CH}_{4}$ in the past, leaving an unknown quantity of organic carbon remaining both in the sediment and in permafrost that persists under the ocean.
In 2016, the active layer thickness (determined by mechanical probing) at all Arctic sites was at or near the long-term maximum for the entire period of observation, which ranges from 18 to 21 years (Fig. 5.25). The all-period record high was observed in 2016 at the West Siberian sites. At the Alaska North Slope and Greenland sites, ALT reached the previously observed maxima, achieved in 1998 and 2013 (North Slope) and 2011 (Greenland). At the rest of the sites the 2016 values were the second highest for the entire period of observation. The largest increase in ALT $(0.31 \mathrm{~m})$ during the last two years was observed at the West Siberia sites, where ALT reached an absolute maximum of $1.45 \mathrm{~m}$ over the 20 -year period of observation, suggesting that at some locations the active layer may not be freezing back completely during the winter. j. Ozone and UV radiation-G. H. Bernhard, V. E. Fioletov, J.-U. GrooB, I. lalongo, B. Johnsen, K. Lakkala, G. L. Manney, and R. Müller

This report emphasizes the period November 2015 to April 2016 because chemically-induced loss of polar ozone mostly occurs during winter and spring (WMO 2014). These chemical processes are initiated by low temperatures in the lower stratosphere (altitude of approximately 15 to $25 \mathrm{~km}$ ) in the presence of chlorine-containing substances (e.g., $\mathrm{HCl}$ and $\mathrm{ClONO}_{2}$ ). Temperatures in the Arctic stratosphere during November and December 2015 were the lowest in the 68-year observational record (Matthias et al. 2016), and temperatures in January 2016 were the lowest since at least 1979 (Manney and Lawrence 2016). Between 16 November 2015 and 10 March 2016 , temperatures below about $195 \mathrm{~K}\left(-78^{\circ} \mathrm{C}\right)$ led to the formation of polar stratospheric clouds (PSCs), which act as a catalyst to transform inactive forms of chlorine to active, ozone-destroying substances. 


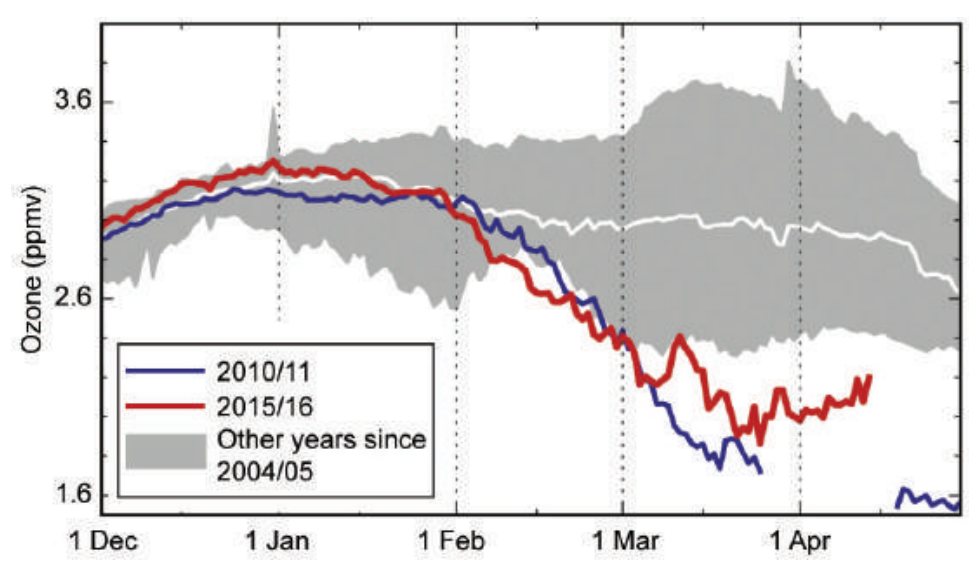

FIG. 5.26. Averaged ozone mixing ratios (ppmv) for the area bounded by the polar vortex at an altitude of approximately $18 \mathrm{~km}$ measured by the Aura MLS. Data from 2015/16 (red) and $2010 / 11$ (blue) are compared with the average (solid white) and minimum/maximum range (gray shading) from 2004/05-2014/15, excluding 2010/II and 2015/16. Gaps in the record for 2010/II are due to missing data. The 2015/16 record ends early because the vortex was not defined after mid-Apr. (Adapted from Manney and Lawrence 2016.)

Destruction of ozone by activated chlorine started in late December 2015, leading to a gradual decrease in ozone (Fig. 5.26). Ozone decreases in 2015/16 initially proceeded more rapidly than those in 2010/11, the winter with the largest Arctic ozone loss on record (e.g., Manney et al. 2011). However, around 5 March 2016 the stratosphere started to warm rapidly, and by mid-March chlorine activation ended and ozone concentrations started to increase by 20 March (Fig. 5.26). This warming occurred one month earlier than in 2011. As a consequence, the cumulative ozone loss observed in 2016 was less than that in 2011.

The temporal evolution of the Arctic total ozone column (TOC; i.e., ozone amounts integrated from the surface to the top of the atmosphere) is assessed with measurements from March because chemically induced ozone loss typically accumulates in this month (WMO 2014). The minimum Arctic daily TOC measured by satellites in March 2016 was 319 Dobson units (DU). This value was 53 DU (14\%) below the average of $373 \mathrm{DU}$ for the period of available measurements (1979-2015) and 49 DU (13\%) below the average of the years 2005-15 (Fig. 5.27), which is the period when data from the Aura Microwave Limb Sounder (MLS) are also available. The record low was 308 DU in 2011. The relatively low value in 2016 can be attributed to the chemical processes in the lower stratosphere discussed above (Manney and Lawrence 2016).

Spatial deviations of monthly average TOCs from historical (2005-15) averages (Figs. 5.28a,b) were estimated with measurements from the Ozone Monitor- ing Instrument (OMI), which is co-located with MLS on the Aura satellite. Average TOCs for 15-28 February 2016 (the period shortly before the stratospheric warming event) were more than $20 \%$ lower than the historical (2005-15) averages over a vast region encompassing northern Greenland, northern Scandinavia, and parts of Siberia and the Arctic Ocean (Fig. 5.28a). This region is encompassed by the Arctic polar vortex, the low-temperature cyclone where the chemical destruction of ozone occurs. In contrast, most of Canada was outside the vortex area, and TOCs were above the 2005-15 average. A similar geographical pattern persisted in March (not shown), with TOCs being 5\%-15\% below the average over Scandinavia and northern Siberia and 5\%-15\% above the average over northern Canada, Greenland, and the Arctic Ocean. Monthly average TOCs for April 2016 (the month of the vortex break-up) departed by less than $\pm 12 \%$ from the historical average with few exceptions (Fig. 5.28b); TOCs were elevated over Scandinavia and depressed over Greenland, Alaska, and the Russian Far East. Ozone anomalies for May through November 2016 were unremarkable.

$U V$ radiation is quantified with the UV index (UVI), a measure of the ability of UV radiation to cause erythema (sunburn) in human skin (WHO

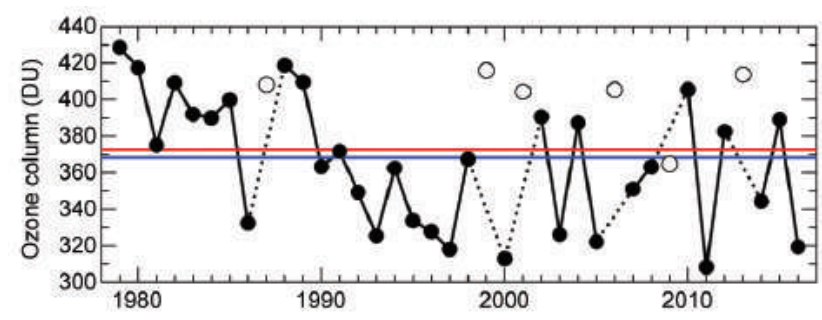

FIG. 5.27. Area-averaged minimum total ozone (DU) for Mar in the Arctic, calculated as the minimum of daily average column ozone poleward of $63^{\circ}$ equivalent latitude (Butchart and Remsberg 1986). Open circles represent years in which the polar vortex broke up before Mar. Ozone in those years was relatively high because of mixing with air from lower latitudes and higher altitudes, and a lack of significant chemical ozone depletion. Red and blue lines indicate the average TOC for 1979-2015 and 2005-15, respectively. [Sources: Data are adapted from Müller et al. (2008) and WMO (2014), updated using ERA-Interim reanalysis data (Dee et al. 20II). Ozone data from I979-20I2 are based on the combined total column ozone database version 2.8 produced by Bodeker Scientific (www .bodekerscientific.com/data/total-column-ozone). Data for 2013-2016 are from OMI.] 
(a) Feb 15-28

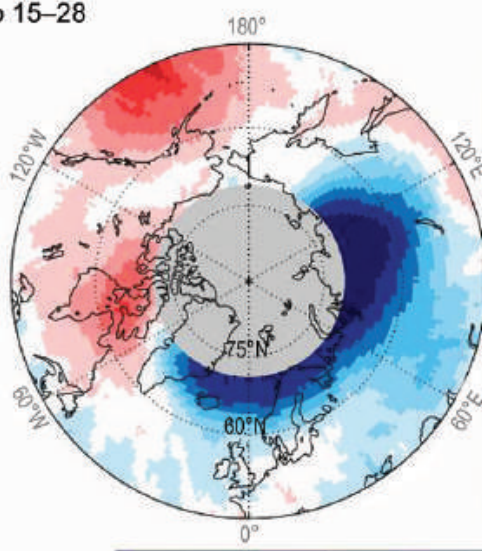

(b) Apr

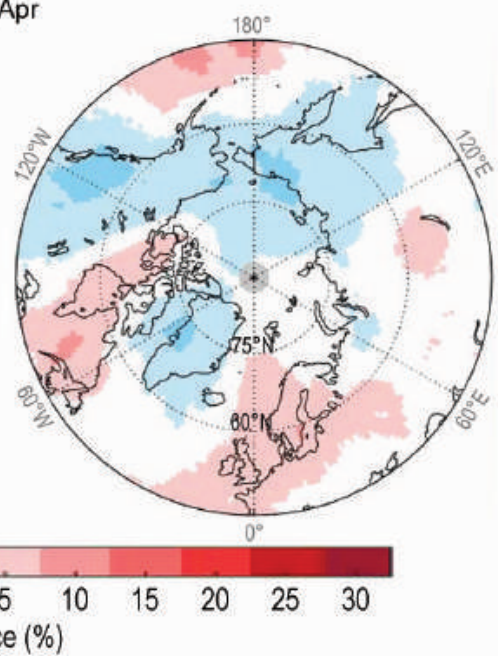

(c) Feb $15-28$

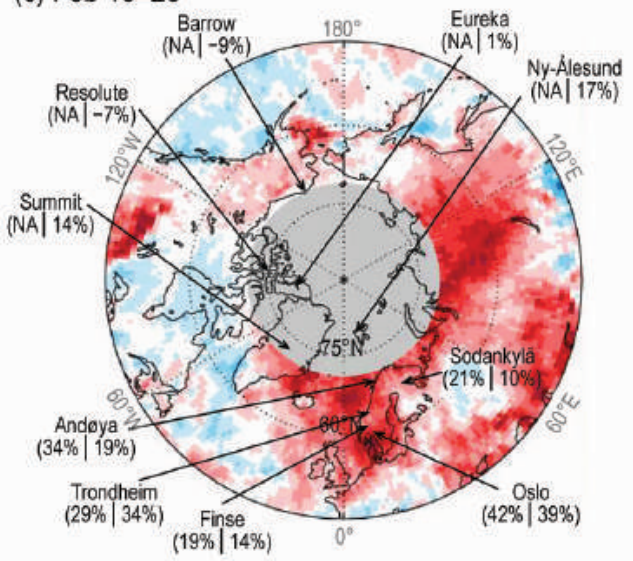

(d) Apr

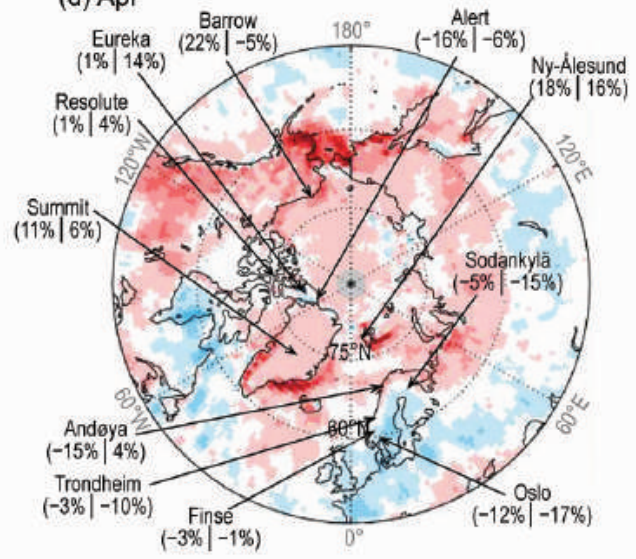

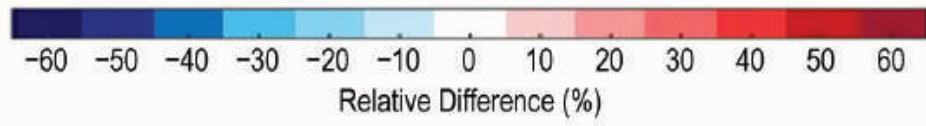

FIG. 5.28. (a) Anomalies of TOC (\%) and (c) noontime UVI (\%) for the second half of Feb 2016. (b),(d) as in (a),(c) but for Apr. Anomalies are relative to 2005-15 averages. Maps are based on OMTO3 Level 3 total ozone product (Bhartia and Wellemeyer 2002). (c) and (d) also compare UVI anomalies from OMI (first value in parenthesis) with ground-based measurements at II locations (second value presented). Gray shading indicates areas where no OMI data are available.

2002). In addition to its dependence on TOC, the UVI depends greatly on the sun angle, cloud cover, and surface albedo (Weatherhead et al. 2005). In the Arctic, the UVI scale ranges from 0 to about 7 , with sites closest to the North Pole having the smallest peak radiation and UVI values $<4$ all year. UVI values $<5$ indicate low to moderate risk of erythema (WHO 2002).

Maps shown in Figs. 5.28c,d quantify differences of monthly average noontime UVIs from historical (2005-15) averages and are based on OMI measurements. The OMI UV algorithm uses a surface albedo climatology (Tanskanen et al. 2003) that does not change from year to year. At places where the actual surface albedo deviates greatly from the OMI albedo climatology (e.g., when snow melt occurred earlier than usual), OMI UVI data may be biased by more than 50\% (Bernhard et al. 2015). Figures 5.28c,d therefore also compare UVI anomalies measured by OMI and ground-based instruments deployed at 11 stations throughout the Arctic and Scandinavia. Anomalies derived from the two datasets agree to within $\pm 15 \%$ at all locations, with the exception of Barrow for April. Surface albedo and cloudiness at this coastal site may not be representative of the satellite pixel, resulting in larger discrepancies. 
Average noontime UVIs for 15-28 February 2016 (Fig. 5.28c) exceeded the 2005-15 averages by up to $60 \%$ over an area roughly matching the region where TOCs were abnormally low in 2016 (Fig. 5.28a). UVI anomalies show a larger spatial variability than TOCs because of their added dependence on cloud cover. While relative increases in the UVI were high, absolute increases remained below 1 UVI unit because solar elevations in February are below $23^{\circ}$ for latitudes higher than $60^{\circ} \mathrm{N}$ (the latitude of Oslo,
Norway). Anomalies for March 2016 differed by less than $\pm 15 \%$ from the historical average (not shown). Monthly average noontime UVIs for April 2016 were $5 \%-15 \%$ above the $2005-15$ averages over most of the Arctic (Fig. 5.27d) with larger anomalies at Svalbard and the Denmark Strait east of Greenland. UVIs in southern Scandinavia were depressed in April. From May through November, UVIs at the ground stations varied within historical bounds. 


\section{ANTARCTICA}

a. Overview-S. Stammerjohn and T. Scambos

Last year we reported on Antarctic climate anomaly patterns in 2015 that produced strong positive southern annular mode (SAM) index values which persisted until austral spring. Climate patterns then distinctly shifted and the anomalies intensified in response to the $2015 \mathrm{El} \mathrm{Niño} \mathrm{(Stammerjohn} \mathrm{2016).} \mathrm{In}$ 2016, Antarctic climate anomalies were again aligned with strong positive SAM index values, particularly for the first third of the year. By austral spring 2016, however, anomaly patterns reversed, leading to strong negative SAM index values. The pressure anomalies (negative SAM index) persisted and strengthened during October to December, such that Antarcticwide climate anomalies stood in stark contrast not only to 2016's beginning, but also to the previous several years. Additional highlights for 2016:

- March and June set new monthly high SAM index values (since 1957) of +4.36 and +3.66 , respectively. Monthly low pressure records for March, June, and September were also broken at many stations. During this time, overall sea ice extent and area were close to the 1981-2010 average.

- With low surface temperatures prevailing during the 2015/16 melt season (generally NovemberFebruary), most of the continent and ice shelves showed negative melt duration anomalies (compared to 1981-2010). However, the Ross Ice Shelf showed an unusual and widespread positive melt season relative to the 1981-2010 mean. Although the Antarctic Peninsula (AP) typically experiences the longest melt seasons relative to the rest of the continent, the AP melt duration anomalies in 2015/16 were mostly negative.

- Climate patterns flipped in October-December, with high surface pressure over the continent, weaker westerly winds, and higher surface temperatures prevailing, leading to negative SAM index values, with a sharp intensification in November. Monthly high pressure records for August and November were set at several stations. During this period, record low daily and monthly sea ice extents were observed.
The November mean sea ice extent was over 5 standard deviations below the 1981-2010 average. These record low sea ice values in austral spring 2016 contrast sharply with the record high values observed during 2012-14.

- Upper ocean positive thermal anomalies in the austral summer-fall of 2016 were tightly coupled to subsequent austral winter sea ice anomalies, suggesting some preconditioning by the ocean. Conversely, austral spring-summer sea ice anomalies in 2015/16 were spatially consistent with upper ocean salinity anomalies in the subsequent austral summer-fall, suggesting that net spring sea ice melt was a strong influence on upper ocean salinity.

- An open-ocean polynya was observed over Maud Rise in winter 2016. Although modest in size compared to its appearances in $1974-76$, the 2016 polynya is significant as it may announce a revival of deep ocean convection in the eastern Weddell Sea.

- Assessments of deep ocean observations support the hypothesis that increased input of freshwater from the ice sheet and changes in sea ice transport continue to contribute to observed Southern Ocean deepwater freshening. A sidebar highlights two new ocean observing programs aimed at improving our understanding of the Southern Ocean's role in capturing anthropogenic carbon and heat.

- Over the last 18 years, the austral spring ozone hole has displayed some indications of diminishing, and 2016 was no exception, with a slightly less severe ozone hole than in earlier decades.

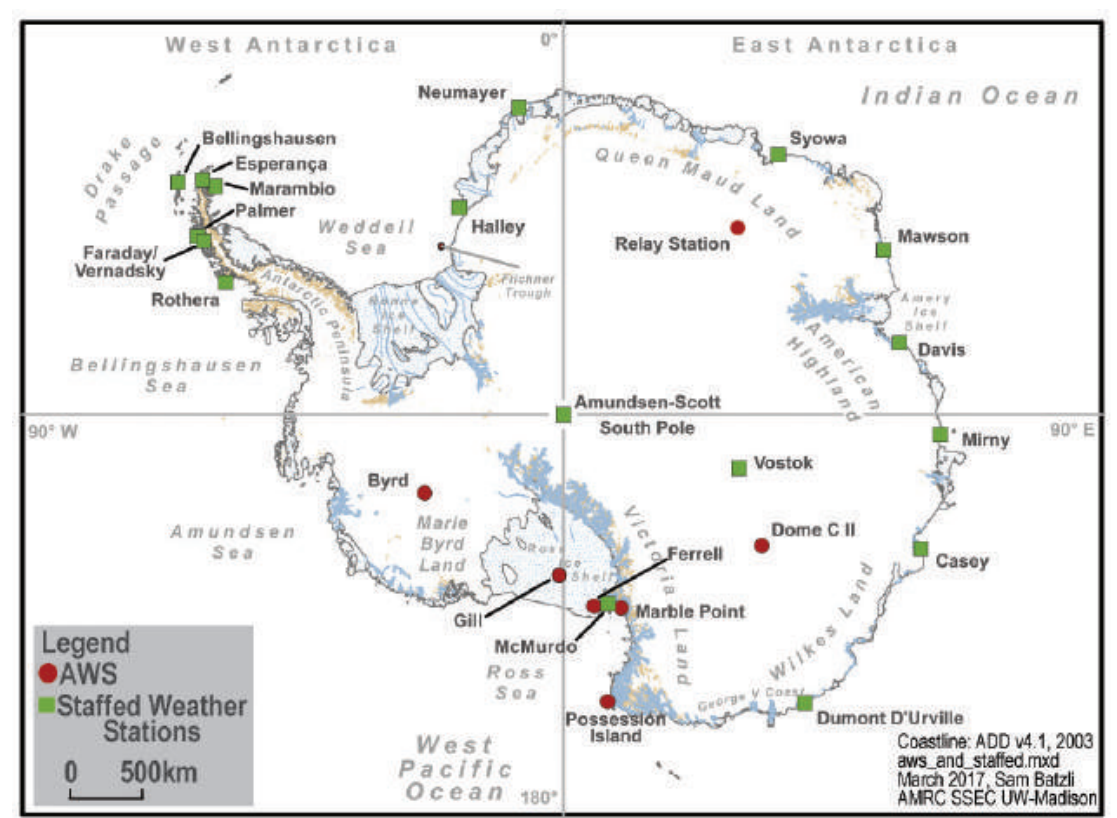

FIG. 6.I. Map of stations and other regions discussed in the chapter. 
Details on the state of Antarctica's climate in 2016 are provided below, beginning with the atmospheric circulation, surface observations, sea ice, and ocean observations, and ending with the Antarctic ozone hole. Place names used throughout this chapter are provided in Fig. 6.1.

\section{b. Atmospheric circulation-K. R. Clem, S. Barreira, and}

\section{R. L. Fogt}

Antarctica experienced persistent below-average pressures and surface temperatures at the beginning of 2016, which led to positive SAM index values through April. Marshall (2003) describes the SAM and the basis for the index. In brief, the SAM index indicates the strength of the annular pressure and wind pattern surrounding the southern continent. It is determined by the difference in the zonally averaged mean sea level pressures at $40^{\circ} \mathrm{S}$ and $65^{\circ} \mathrm{S}$. The 2016 austral winter and spring had record positive SAM indices, but with larger month-to-month variability. Between June and September, the continent had lower-than-average temperatures, except for the month of August, which had warmer-thanaverage conditions. At the end of the year, strong positive pressure and surface temperature anomalies occurred over the continent, producing negative SAM index values for October to December.

A closer look at the Antarctic circulation and temperature anomalies is given in Figs. 6.2 and 6.3. Figure 6.2 shows the geopotential height and temperature anomalies averaged over the polar region (the "polar cap": all areas south of $60^{\circ} \mathrm{S}$; Figs. $6.2 \mathrm{a}$ and $\mathrm{b}$, respectively) and the circumpolar zonal wind anomalies averaged over $50^{\circ}$ to $70^{\circ} \mathrm{S}$ from ERA-Interim reanalysis (Fig. 6.2c). Anomalies are contoured and the standard deviations are shaded. Given the large month-to-month variability in winter, the year is split into six periods of relatively persistent climatic features: January-April, May-June, July, August, September,

(b)

(c) and October-December. The groups are indicated by vertical red bars at the bottom of each panel in Fig. 6.2. Surface anomalies for the six groups are shown in Fig. 6.3, with the standardized surface pressure anomalies contoured and standardized 2-meter temperature anomalies shaded. In all cases, anomalies and standard deviations are with respect to the 1981-2010 climatological mean.
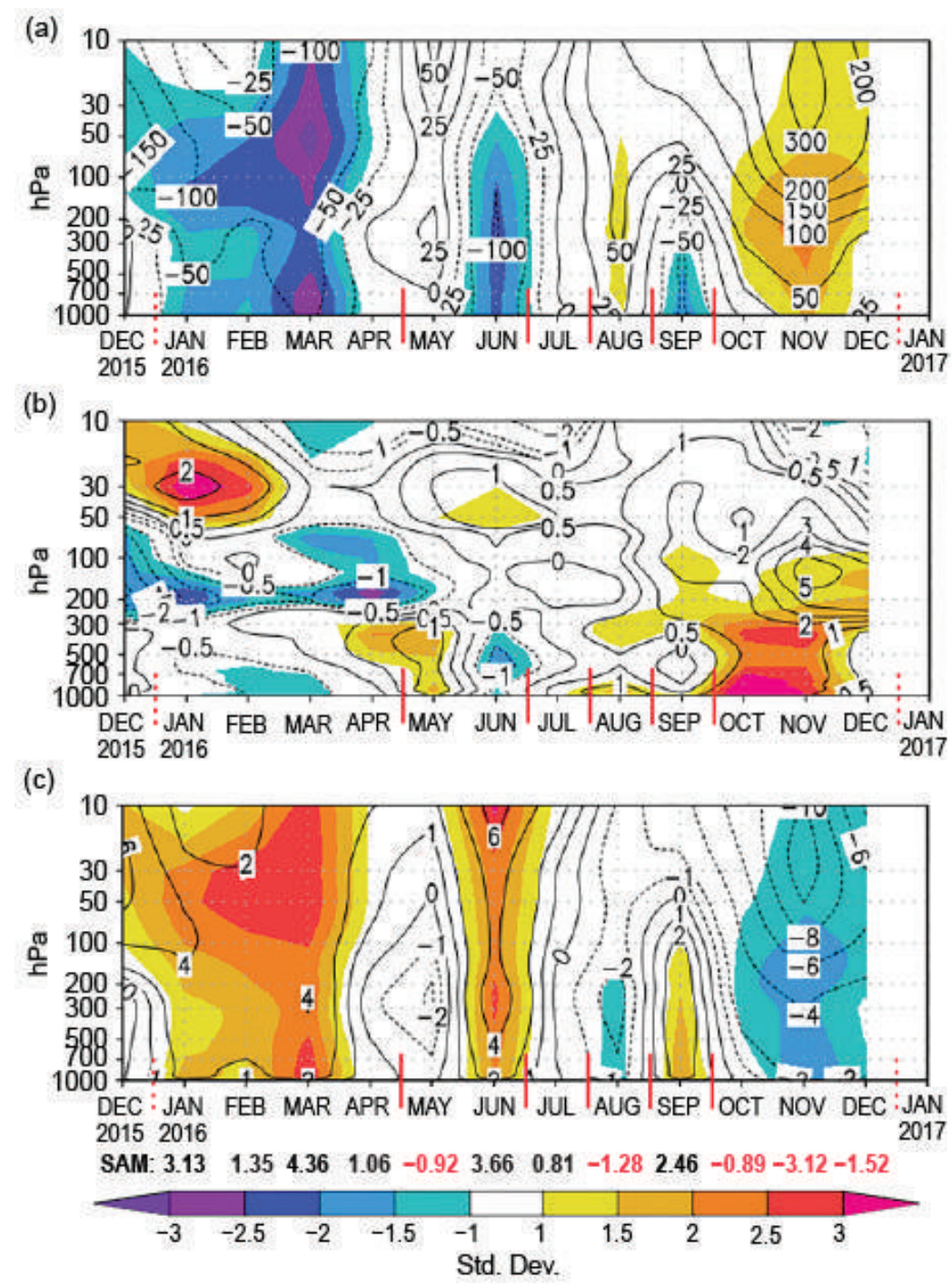

FIG. 6.2. Area-averaged (weighted by cosine of latitude) anomalies over the southern polar region in 2016 relative to 198I-2010: (a) polar cap $\left(60^{\circ}-90^{\circ} \mathrm{S}\right)$ averaged geopotential height anomalies (contour interval is $50 \mathrm{~m}$ up to $\pm 200 \mathrm{~m}$ with additional contour at $\pm 25 \mathrm{~m}$, and $100 \mathrm{~m}$ contour interval after $\pm 200 \mathrm{~m}$ ); (b) polar cap averaged temperature anomalies (contour interval is $1^{\circ} \mathrm{C}$ with additional contour at $\pm 0.5^{\circ} \mathrm{C}$ ); (c) circumpolar $\left(50^{\circ}-70^{\circ} \mathrm{S}\right)$ averaged zonal wind anomalies (contour interval is $2 \mathrm{~m} \mathrm{~s}^{-1}$ with additional contour at $\pm\left(\mathrm{m} \mathrm{s}^{-1}\right)$. Shading represents std. dev. of anomalies. Red vertical bars indicate the six climate periods used for compositing in Fig. 6.3; the dashed lines near Dec 2015 and Dec 2016 indicate circulation anomalies wrapping around the calendar year. Values from the Marshall (2003) SAM index are shown below (c): positive (black) and negative (red). (Source: ERA-Interim reanalysis.) 

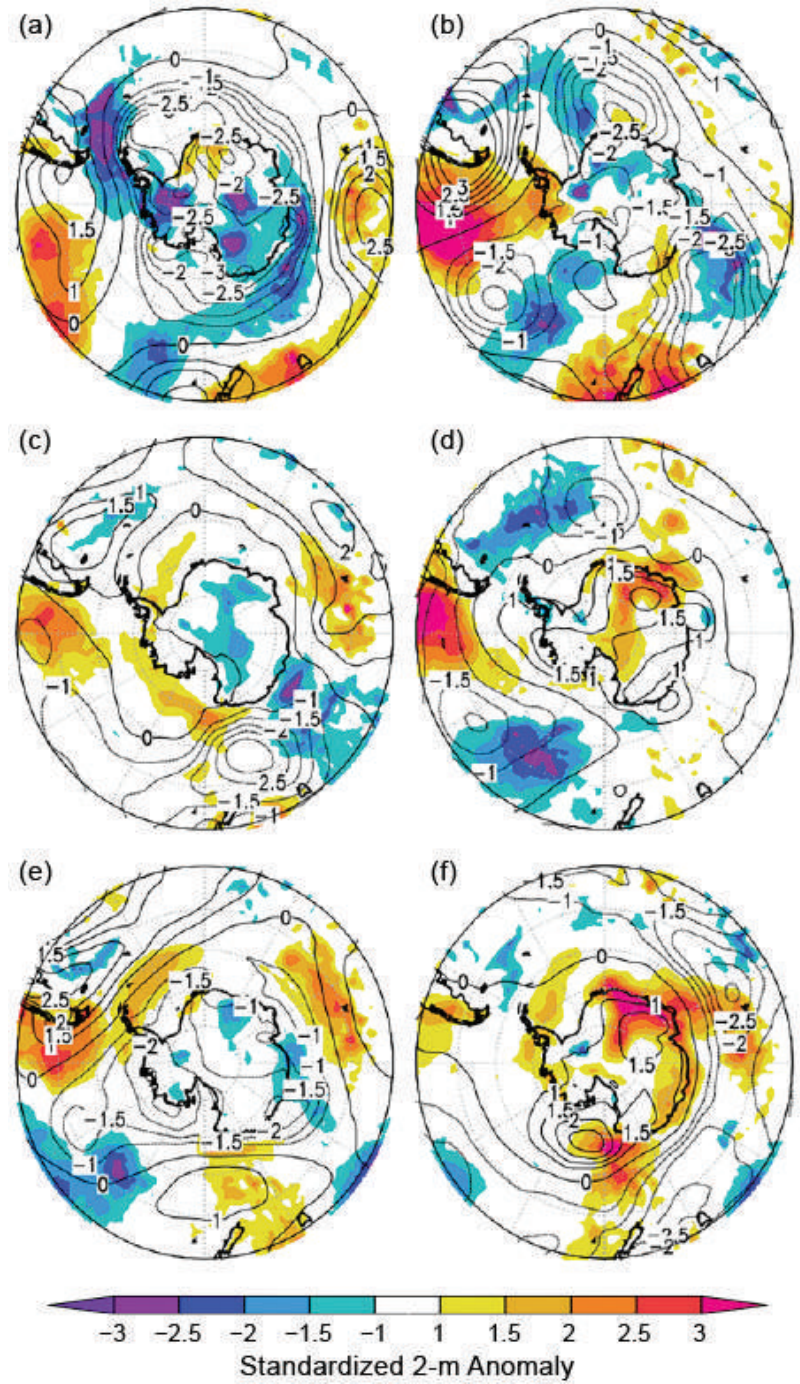

FIG. 6.3. Standardized surface pressure (contours) and 2-m temperature (shaded) anomalies relative to 1981-2010 for (a) Jan-Apr 2016; (b) May-Jun 2016; (c) Jul 2016; (d) Aug 2016; (e) Sep 2016; (f) Oct-Dec 2016. Contour interval is $\mathbf{0 . 5} \mathrm{std}$. dev. of surface pressure anomalies with the \pm 0.5 contour omitted. Shading represents std. dev. of 2-m temperature anomalies. (Source: ERA-Interim reanalysis.)

During January-April, negative geopotential height (Fig. 6.2a) and surface pressure (Fig. 6.3a) anomalies were observed over Antarctica, with negative surface temperature anomalies everywhere across the continent except Queen Maud Land. Strong positive circumpolar zonal wind anomalies of 2-4 m $\mathrm{s}^{-1}$ (>2 standard deviations above the climatological mean) were observed through the troposphere and stratosphere (Fig. 6.2c), and the SAM index set a monthly record-high value (since 1957) of +4.36 in March and reaching its third highest monthly value on record for January ( +3.13 ; based on the Marshall index and archive). The circulation pattern weakened during May, characterized by weak positive height and temperature anomalies over the polar cap but transitioned back to a strong positive SAM index during June, setting another monthly record-high SAM value of +3.66 . Despite the strong positive SAM index value during June, the May-June average circulation consisted of a zonal wave three pattern with three anomalous troughs located along $\sim 55^{\circ} \mathrm{S}$ near $0^{\circ}$, $135^{\circ} \mathrm{E}$, and $135^{\circ} \mathrm{W}$ (Fig. 6.3b). The wave three pattern was associated with above-average sea ice concentration in the eastern Weddell Sea, Davis Sea, and western Amundsen Sea during May-June (see Section 6f). Above-average surface temperature anomalies occurred across the Antarctic Peninsula during May-June while the remainder of the continent was near-average to slightly colder than average. Aloft, strong negative geopotential height and temperature anomalies occurred through the troposphere over the polar cap during June, and positive circumpolar zonal wind anomalies were seen through the troposphere and stratosphere. These exceeded 2 standard deviations above the climatological average, reflecting the strong positive SAM index in June.

The circulation edged closer to its climatological mean over the continent during July (Fig. 6.3c), with near-average temperatures and pressure/heights across the polar cap (except for weak positive surface temperature anomalies over the West Antarctic coast and weak negative surface temperature anomalies over portions of interior East Antarctica) and an average strength of the circumpolar westerlies. During August (Fig. 6.3d), positive surface pressure and temperature anomalies were seen across most of the continent, except for some weak surface cooling along the Antarctic Peninsula. The surface warming during August was strongest over eastern East Antarctica across Queen Maud Land and Enderby Land where positive temperature anomalies of $3^{\circ}-6^{\circ} \mathrm{C}$ (not shown) were observed, exceeding 2.5 standard deviations above the climatological mean. The circulation switched back to a zonal wave three and positive SAM index pattern for September, with three anomalous ridges ( $>1$ standard deviation) located along $\sim 55^{\circ} \mathrm{S}$ at $75^{\circ} \mathrm{E}, 180^{\circ}$, and $60^{\circ} \mathrm{W}$ (orange-red shaded areas in Fig. 6.3e). Much of Antarctica saw near-average to slightly-below-average surface temperatures during September except for the Antarctic Peninsula, which was $3^{\circ}-5^{\circ} \mathrm{C}$ warmer than average (not shown) and exceeded 1.5 standard deviations above the climatological mean (orange-red shading in Fig. 6.3e). The positive SAM index value of +2.46 for September tied 1959 as the fourth highest value on record for the month. 
Strong positive pressure anomalies developed over Antarctica from October to November as positive geopotential height anomalies propagated downward from the stratosphere into the lower troposphere, maximizing in November (Fig. 6.2a). The anomalous high pressure over the polar cap resulted in a strong weakening of the circumpolar westerlies (Fig. 6.2c) and widespread surface warming along coastal Antarctica and over portions of interior Antarctica (Fig. 6.3f), leading to rapid sea ice retreat in many regions (see Section 6f). The surface warming was again strongest across western Queen Maud Land and Enderby Land, where October-December surface temperatures were $2^{\circ}-3^{\circ} \mathrm{C}$ above average (not shown) and 3 standard deviations above the climatological mean (orange-red shading in Fig. 6.3f). Strong surface warming was also found across the Antarctic Peninsula and Marie Byrd Land, both of which were warmer than average and 1-1.5 standard deviations above the climatological mean. The SAM index was negative for all three months to close 2016, reaching a maximum negative value of -3.12 during November, which was the fifth lowest SAM index value on record for that month; this corresponded to a period of rapid sea ice loss after the maximum extent in September 2016 (see Section 6f).

\section{c. Surface observations - L. M. Keller, S. Colwell, M. A. Lazzara, and R. L. Fogt}

Monthly mean temperatures on the Antarctic Peninsula were generally above the long-term (1981-2010) means for the entire year. Late May experienced some very warm conditions (Fig. 6.3b) with Rothera Station recording a daily maximum temperature of $7.5^{\circ} \mathrm{C}$ on $26 \mathrm{May}$, and $11.2^{\circ} \mathrm{C}$ on 30 May at Marambio Station.

In the Weddell Sea and Queen Maud Land regions, monthly mean temperatures at Halley Station were close to the long-term average, with the exception of June (Fig. 6.4b). The average June monthly temperature was $-34.2^{\circ} \mathrm{C}, 2.2^{\circ} \mathrm{C}$ below the previous coldest value. At Neumayer Station, a record high monthly mean temperature for May of $-15.5^{\circ} \mathrm{C}$ was followed by a record low monthly mean temperature of $-28.7^{\circ} \mathrm{C}$ in June. The monthly temperature then remained above the long-term mean at Neumayer for the rest of the year. Very low pressures (8-11 hPa below normal) were recorded in March and May at Neumayer, and March and June at Halley, reflecting the strongly positive SAM index conditions.

Around the coast of East Antarctica, all of the Australian stations and Syowa Station reported new record high monthly mean temperatures in November (Casey: $-3.7^{\circ} \mathrm{C}$; Davis: $-2.2^{\circ} \mathrm{C}$; Mawson: $-2.8^{\circ} \mathrm{C}$;
Syowa: $-4.7^{\circ} \mathrm{C}$; Figs. 6.3f, 6.4c), and Syowa Station also had record high monthly mean temperatures in August and October $\left(-13.9^{\circ} \mathrm{C}\right.$ and $-9.3^{\circ} \mathrm{C}$, respectively; Figs. 6.3d, 6.3f). Pressures at Syowa, Mawson, and Davis stations were below average for most of the year with above-average values recorded in August, November, and December. Farther around the East Antarctic coast, record-breaking low monthly mean pressures were recorded at Casey (Fig. 6.4c) and Dumont D'Urville stations for March $(966.8 \mathrm{hPa}$ and $972.4 \mathrm{hPa}$ ), June (972.2 hPa, $975.9 \mathrm{hPa}$ ), and September $(964.4 \mathrm{hPa}, 969.5 \mathrm{hPa})$, respectively.

At Amundsen-Scott Station (Fig. 6.4a) and Vostok Station, the monthly mean temperatures were close to the long-term means with the exception of July (lower) and August (higher) at Amundsen-Scott and June (lower), July (lower) and August (higher) at Vostok Station. Record-breaking low monthly mean surface pressures were recorded at both Amundsen-Scott and Vostok in June (672.1 and $613.0 \mathrm{hPa}$, respectively), and a record-breaking high monthly mean pressure was recorded at Vostok Station in November $(635.0 \mathrm{hPa})$.

From the automatic weather stations (AWS), the western side of Antarctica reported lower-thannormal mean monthly temperatures for the first half of the year. Ferrell AWS had lower-than-normal mean temperatures for April, June, and July (approximately $3^{\circ}-4^{\circ} \mathrm{C}$ below average), while Byrd AWS (Fig. 6.4e) observed below-normal mean temperatures for February, March, June, and September $\left(2^{\circ}-4^{\circ} \mathrm{C}\right.$ below average). Above-average mean temperatures were reported at Byrd for July, August, and October (by $+2^{\circ}-3^{\circ} \mathrm{C}$ ). Gill AWS (Fig. 6.4f), in the middle of the Ross Ice Shelf (see Fig. 6.1), had lower-than-normal mean temperatures for June and July $\left(-3^{\circ}\right.$ to $\left.-5^{\circ} \mathrm{C}\right)$, but a record high monthly mean temperature was set in January $\left(-5.5^{\circ} \mathrm{C}\right)$, and a higher-than-normal temperature was reported in August. In East Antarctica, Marble Point AWS reported conditions similar to Ferrell; Dome C II reported lower-than-average mean temperatures for March and April (about $2^{\circ}-3^{\circ} \mathrm{C}$ lower) and a record high monthly mean temperature in November $\left(-34.2^{\circ} \mathrm{C}\right)$. Relay AWS (Fig. 6.4d) observed lower-than-average mean temperatures for June and July $\left(-5.3^{\circ}\right.$ and $-2.3^{\circ} \mathrm{C}$, respectively) and higher-than-average temperatures for October and November (about $5^{\circ} \mathrm{C}$ above normal). Record high monthly mean temperatures were set in March $\left(-5.8^{\circ} \mathrm{C}\right)$ and August $\left(-5.6^{\circ} \mathrm{C}\right)$.

Along with lower temperatures for the first part of the year in West Antarctica, most of the AWSs reported lower-than-average mean monthly station pressures generally through June with many low pres- 

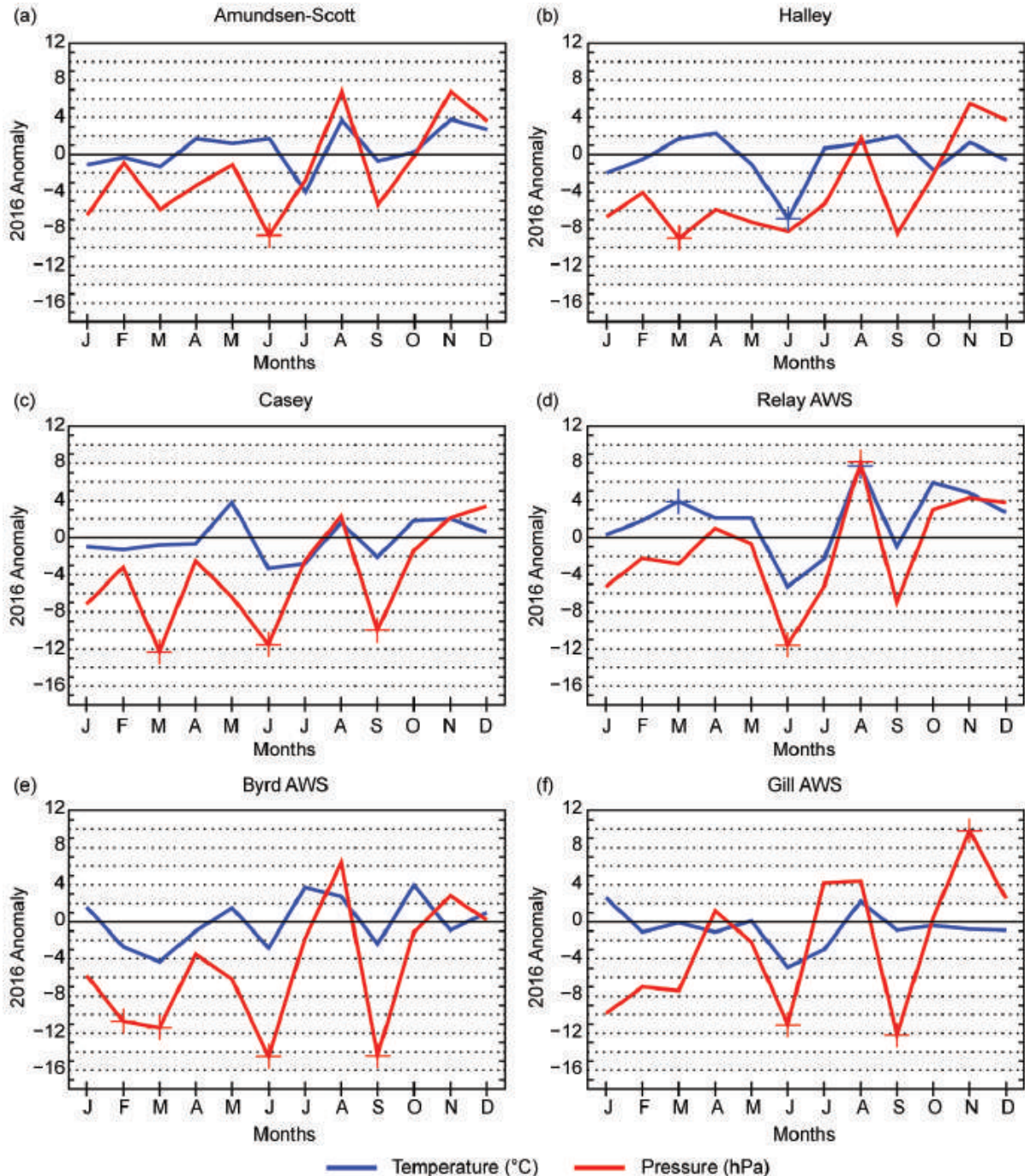

FIG. 6.4. 2016 Antarctic climate anomalies at six representative stations [three staffed (a)-(c), and three automatic (d)-(f)]. Monthly mean anomalies for temperature $\left({ }^{\circ} \mathrm{C}\right)$ in blue and $\mathrm{MSLP} /$ surface pressure $(\mathrm{hPa})$ in red are shown, with + denoting record anomalies for a given month at each station in 2016 . All anomalies are based on differences from 1981-2010 averages, except for Gill, which is based on averages during 1985-2015. Observational data start in 1957 for AmundsenScott and Halley, 1959 for Casey, 1995 for Relay AWS, 198I for Byrd AWS, and 1985 for Gill AWS. See Turner et al. (2004) and Lazzara et al. (2012) for details on the station and AWS data.

sure records set for September, due to an anomalously deep trough extending over the northern Amundsen Sea (Fig. 6.3e). Ferrell, Marble Point, Byrd, and Gill all set record monthly mean low pressures for September (971.8, 965.1, 787.4, and 966.0 hPa, respectively). In addition, Gill AWS recorded a record low monthly mean station pressure in June $(972.5 \mathrm{hPa})$, and Byrd set record lows for monthly mean station pressure in February $(803.8 \mathrm{hPa})$, March $(799.1 \mathrm{hPa})$, June $(795.0 \mathrm{hPa})$, and September (787.4 hPa). Possession Island also had a record low monthly mean station pressure in January $(969.7 \mathrm{hPa})$. While not record setting, plateau station Dome C II also reported lower than normal pressures (by 6-10 hPa) for the early part of the year. Relay AWS (Fig. 6.4d) had a record low monthly mean station pressure in June $(625.0 \mathrm{hPa})$ and lowerthan-normal pressures for January, July, and September (by 5-7 hPa). By austral spring, the situation had reversed with record high monthly mean station pressure in November now located at Ferrell $(990.7 \mathrm{hPa})$, Marble Point $(982.8 \mathrm{hPa})$, Gill (987.5 hPa; Fig. 6.4f), and Possession Island $(985.2 \mathrm{hPa})$. These records were all $10-11 \mathrm{hPa}$ above the mean. Byrd AWS, Dome C II AWS, and Relay AWS had higher-than-normal pressure for November, and Relay Station set a high monthly mean pressure record in August (638.6 hPa).

On the Ross Ice Shelf, monthly mean wind speeds (not shown) were generally lower than normal except for January and February. Gill had record low monthly mean wind speeds in April $\left(0.5 \mathrm{~m} \mathrm{~s}^{-1}\right)$, June $\left(1.7 \mathrm{~m} \mathrm{~s}^{-1}\right)$, and July $\left(2.1 \mathrm{~m} \mathrm{~s}^{-1}\right)$. Marble Point tied the record low for August $\left(2.3 \mathrm{~m} \mathrm{~s}^{-1}\right)$. Ferrell had a record high monthly mean wind speed for January $\left(7.0 \mathrm{~m} \mathrm{~s}^{-1}\right)$, and Gill tied its record high monthly mean for February $\left(4.8 \mathrm{~m} \mathrm{~s}^{-1}\right)$. Gill also reported a record high monthly mean wind speed in September $\left(5.2 \mathrm{~m} \mathrm{~s}^{-1}\right)$. For the plateau stations, Dome C II had record high monthly mean wind speeds in January and February (4.0 and $3.9 \mathrm{~m} \mathrm{~s}^{-1}$, respectively), while Relay AWS had a record low monthly mean wind speed in January $\left(5.3 \mathrm{~m} \mathrm{~s}^{-1}\right)$. Wind speeds at Relay AWS were generally higher than normal for austral spring. 
(a) $45^{\circ} \mathrm{W} \quad 30^{\circ} \mathrm{W} \quad 15^{\circ} \mathrm{W} 0^{\circ} \quad 15^{\circ} \mathrm{W} \quad 30^{\circ} \mathrm{E} \quad 45^{\circ} \mathrm{E}$
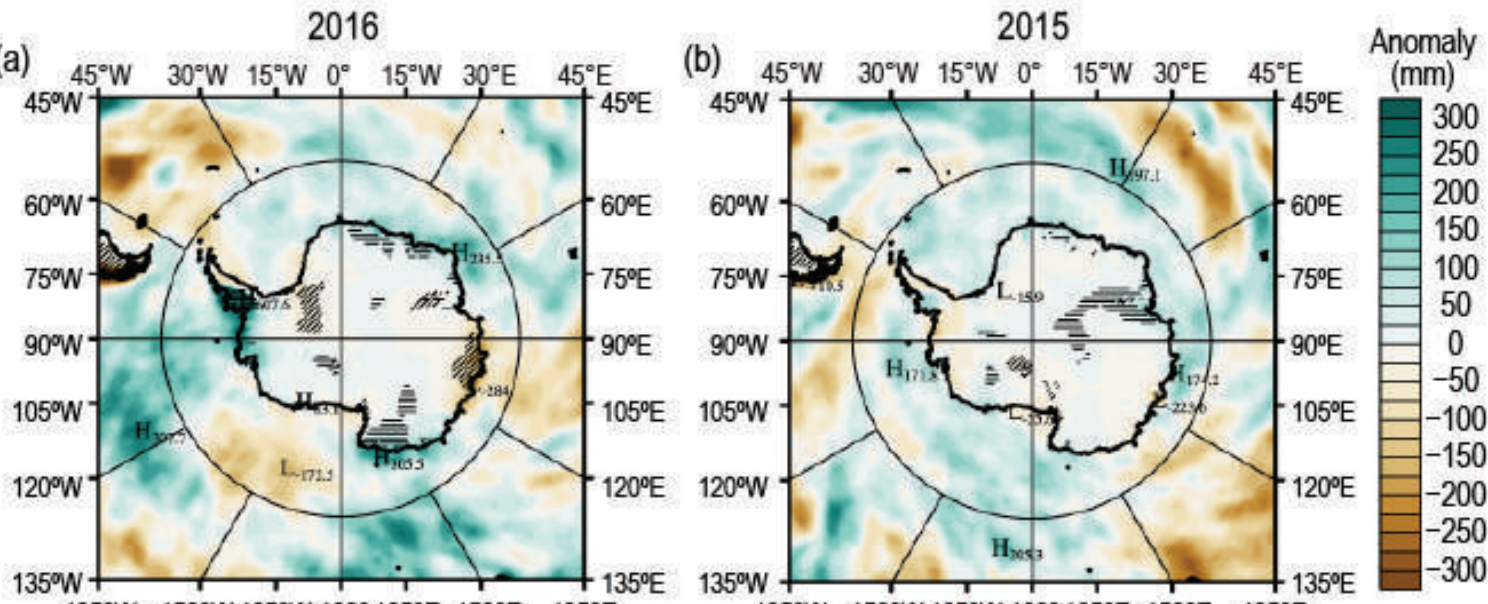

$135^{\circ} \mathrm{W} 150^{\circ} \mathrm{W} 165^{\circ} \mathrm{W} 180^{\circ} 165^{\circ} \mathrm{E} 150^{\circ} \mathrm{E} \quad 135^{\circ} \mathrm{E}$

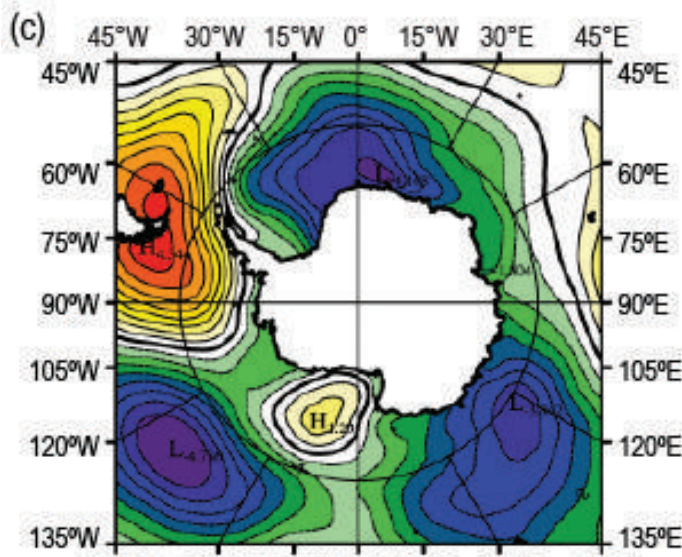

$135^{\circ} \mathrm{W} 150^{\circ} \mathrm{W} 165^{\circ} \mathrm{W} 180^{\circ} 165^{\circ} \mathrm{E} 150^{\circ} \mathrm{E} \quad 135^{\circ} \mathrm{E}$

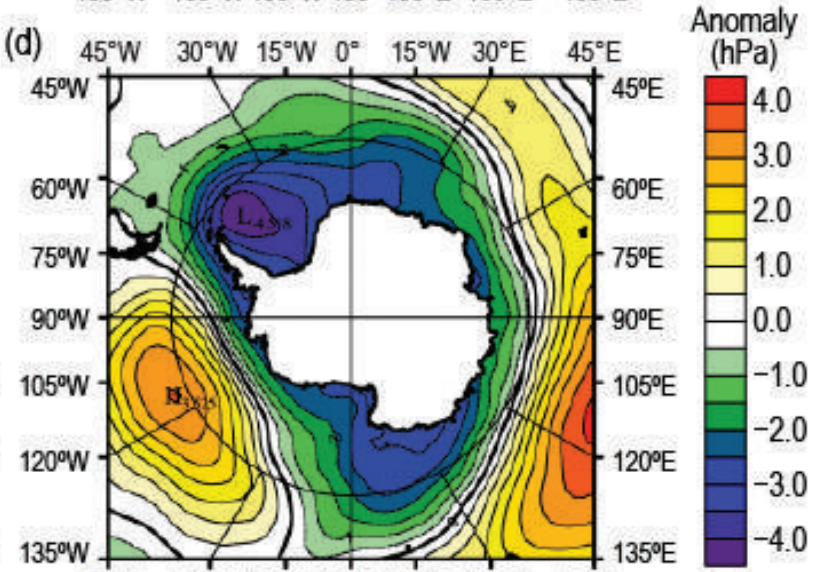

$135^{\circ} \mathrm{W} 150^{\circ} \mathrm{W} 165^{\circ} \mathrm{W} 180^{\circ} 165^{\circ} \mathrm{E} 150^{\circ} \mathrm{E} 135^{\circ} \mathrm{E}$

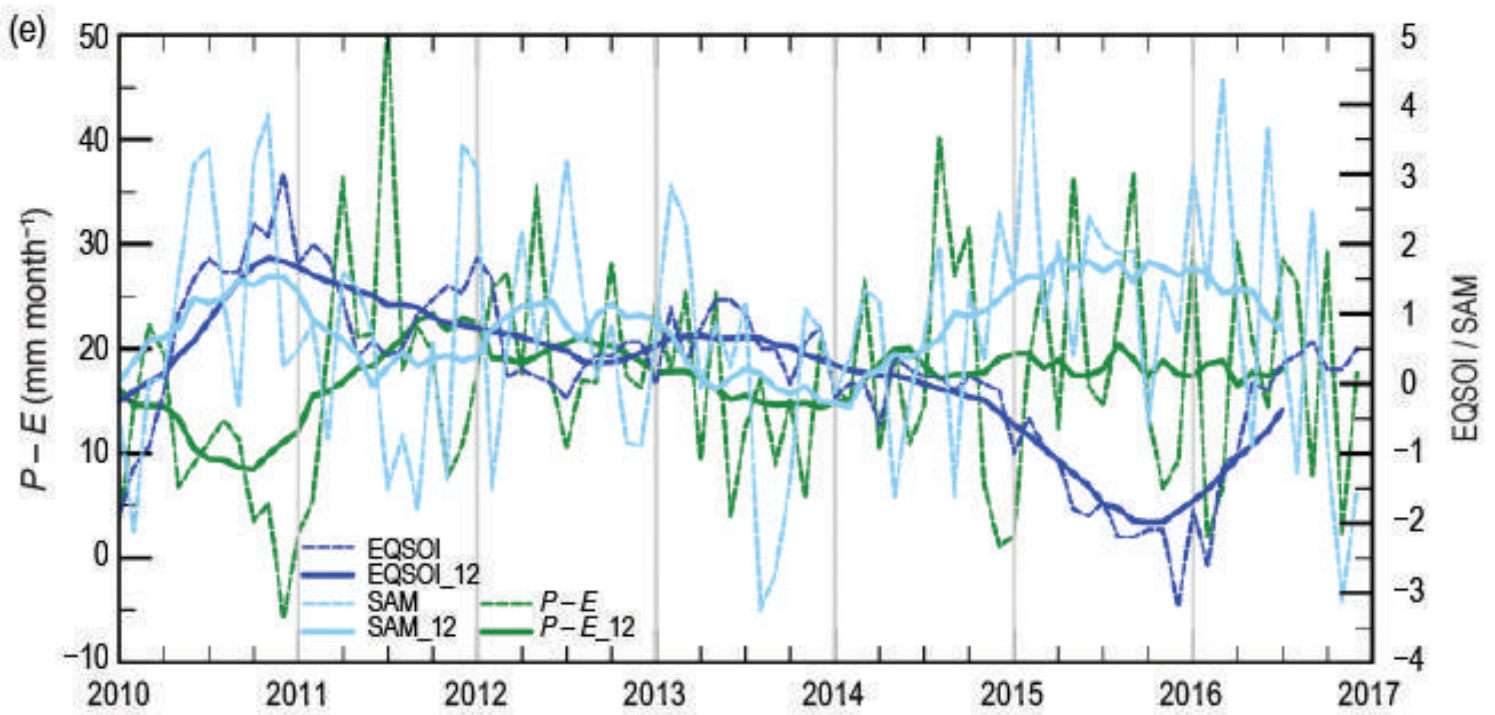

Fig. 6.5. (a) $2016 P-E$ anomaly $(\mathrm{mm})$; (b) $2015 P-E$ anomaly $(\mathrm{mm})$. Antarctic regions with $> \pm 30 \%$ departure from the reference mean are hatched; sloping denotes negative anomaly and horizontal is positive. (c) $2016 \mathrm{MSLP}$ anomaly (hPa); and (d) $2015 \mathrm{MSLP}$ anomaly (hPa). All anomalies are calculated from the 198I-2010 means. (e) Monthly total P-E (mm; dashed green) for the West Antarctic sector bounded by $75^{\circ}-90^{\circ} \mathrm{S}, 120^{\circ} \mathrm{W}-180^{\circ}$, along with index trends for EQ-SOI (dashed dark blue, from NOAA CPC) and SAM [dashed light blue, from Marshall (2003)]. Centered annual running means are plotted as solid lines. 
d. Net precipitation $(P-E)-D$. H. Bromwich and S.-H. Wang Precipitation minus evaporation/sublimation $(P-E)$ closely approximates the surface mass balance over Antarctica, except for the steep coastal slopes (e.g., Bromwich et al. 2011; Lenaerts and van den Broeke 2012) where wind-driven transport and melt runoff to the ocean can become significant factors. Precipitation variability is the dominant term for $P-E$ changes at regional and larger scales over the Antarctic continent. Precipitation and evaporation fields from the Japanese 55-year reanalysis (JRA-55; Kobayashi et al. 2015) were examined to assess Antarctic net precipitation $(P-E)$ for 2016. JRA-55, the second generation of JRA, has incorporated many improvements relative to its predecessor JRA-25 (Onogi et al. 2007; Bromwich et al. 2007). The JRA55 result is used here because of these improvements, rather than ERA-Interim used elsewhere, because the JRA-55 result is available with low latency (a few weeks), and so it is available at the time of writing for this annual summary.

Figure 6.5 shows the JRA-55 2016 and 2015 annual anomalies of $P-E$ (Figs. 6.5a,b) and mean sea level pressure (MSLP; Figs. 6.5c,d) departures from the 1981-2010 average. In general, annual $P-E$ anomalies over the high interior of the continent were small (within $\pm 50 \mathrm{~mm} \mathrm{yr}^{-1}$ ), while larger anomalies were observed along the coast, consistent with the low and high snow accumulation in these respective regions. From JRA-55 $P-E$, higher-than-average net accumulation for 2016 occurred in the southwestern Antarctic Peninsula, eastern Enderby Land and the adjacent Queen Maud Land areas, and Wilkes Land; lower-than-average anomalies were present in the American Highlands, eastern Ross Ice Shelf area, and the northern tip of the Antarctic Peninsula.

These annual $P-E$ anomaly features are generally consistent with the mean annual atmospheric circulation implied by the MSLP anomalies, shown for both 2016 and 2015 (Figs. 6.5c,d; see also Fig. 6.2). In 2016 (Fig. 6.5c), the MSLP anomalies surrounding Antarctica were more regionalized than in 2015 (Fig. 6.5d). The ring of high-pressure anomalies at midlatitudes has diminished. Instead, localized negative anomalies were observed in three Southern Ocean sectors: Atlantic Ocean (between $40^{\circ} \mathrm{W}$ and $35^{\circ} \mathrm{E}$ ), Indian Ocean (between $105^{\circ} \mathrm{E}$ and $165^{\circ} \mathrm{E}$ ), and Pacific Ocean (between $160^{\circ} \mathrm{W}$ and $110^{\circ} \mathrm{W}$ ). The Atlantic Ocean and Indian Ocean negative anomalies had a significant effect on regional net precipitation changes in the coastal areas southeast of those anomaly centers (Fig. 6.5a). Combined with the cyclonic flow associated with the negative anomaly over the South Pacific (centered on $\sim 135^{\circ} \mathrm{W}$; Fig. $6.5 \mathrm{c}$ ), the strong northerly flow produced high precipitation anomalies over the Bellingshausen Sea and along the west coast of the Antarctic Peninsula in 2016 (Fig. 6.5a). A secondary positive anomaly center located over the Ross Sea (between $170^{\circ} \mathrm{E}$ and $130^{\circ} \mathrm{W}$; Fig. $6.5 \mathrm{c}$ ) produced stronger offshore flow and less precipitation over the eastern Ross Sea and eastward along the Ross Ice Shelf (Fig. 6.5a).

Earlier studies show that almost half of the moisture transport into interior Antarctica occurs in the West Antarctic sector. Moisture transport has large inter-annual variability associated with variations in ENSO (e.g., Bromwich et al. 2004) and SAM variability (e.g., Fogt et al. 2011). Figure 6.5e shows the time series, with 12-month running means, of monthly total $P-E$ over Marie Byrd Land-Ross Ice Shelf $\left(75^{\circ}-90^{\circ} \mathrm{S}, 120^{\circ} \mathrm{W}-180^{\circ}\right)$ and the monthly equatorial Southern Oscillation (EQ-SOI) and SAM indices. NOAA Climate Prediction Center EQ-SOI, used here to represent ENSO events, is a standardized sea level pressure difference between the east Pacific $\left(5^{\circ} \mathrm{N}-5^{\circ} \mathrm{S}, 80^{\circ}-130^{\circ} \mathrm{W}\right)$ and the west Pacific-east Indian $\left(5^{\circ} \mathrm{N}-5^{\circ} \mathrm{S}, 90^{\circ}-140^{\circ} \mathrm{E}\right)$ Oceans, and is calculated based on comparatively extensive longitudinal regions centered on the equator. In comparison to the conventional station-based SOI, EQ-SOI is less susceptible to weather noise, and better captures the equatorial trade wind events (see www.climate.gov /news-features/blogs/enso/why-are-there-so-many -enso-indexes-instead-just-one).

It is clear that EQ-SOI and SAM were in phase but had opposite behavior to $P-E$ in most months from 2010 to mid-2011 (Fig. 6.5e). From then on, EQ-SOI and SAM were out of phase through early 2016, especially after mid-2014. Both EQ-SOI and SAM were offsetting factors modulating precipitation, resulting in little overall change of $P-E$. A positive MSLP anomaly can often be located over the South Pacific (Fig. 6.5c) when SAM is positive and EQ-SOI is negative (Fogt et al. 2011). The weak positive MSLP anomaly in the Ross Sea, with both onshore and offshore flows, has a small net impact on precipitation in this sector. As the seasons progressed from 2015 to 2016, the negative MSLP anomalies over the Ross Sea (Fig. 6.3a) became positive and peaked in 2016 austral spring (Fig. 6.3f). In combination with a weaker ENSO signal, the SAM dominated the behavior of $P-E$ in this region in late 2016. 


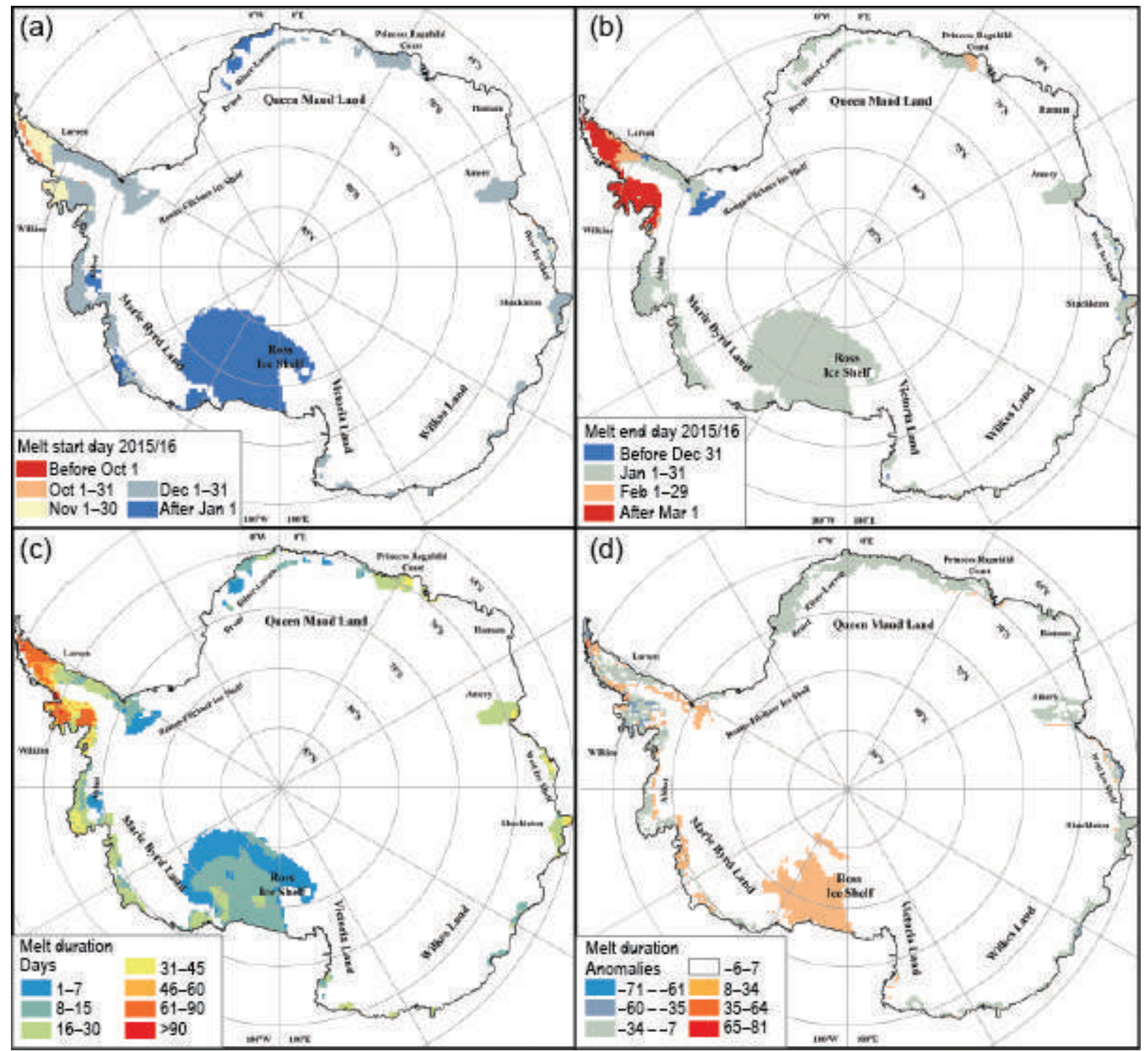

FIG. 6.6. Estimated surface melt for the 2015/16 austral summer: (a) melt start day, (b) melt end day, (c) melt duration (in days), and (d) melt duration anomalies (in days).

e. Seasonal melt extent and duration - L. Wang and H. Liu Surface melt on the Antarctic continent during the 2015/16 austral summer season was estimated from daily passive microwave brightness temperature measurements acquired by the Special Sensor Microwave Imager/Sounder on the Defense Meteorological Satellite Program F17 satellite. The level-3 EqualArea Scalable Earth-Grid brightness temperature data were provided by the U.S. National Snow and Ice Data Center (Armstrong et al. 1994). A wavelet transform edge detection method (Liu et al. 2005) was used to delineate each melt event in the time series by tracking its onset and end dates, with the onset day of the first melt event being the start day of the melt season (Fig. 6.6a) and the end day of the last melt event being the end day of the melt season (Fig. 6.6b). The melt duration for each pixel is the total number of melting days during the defined melt season (excluding any refreezing periods that may have occurred between the first and last melt events; Fig. 6.6c). The melt duration anomaly map (Fig. 6.6d) was created by referencing to the mean melt duration computed over the 1981-2010 period (see Fig. 3 in Liu et al. 2006). The melt extent and melt index (Fig. 6.7) are metrics for quantifying the spatiotemporal variability of surface melting (Zwally and Fiegles 1994; Liu et al. 2006). Melt extent $\left(\mathrm{km}^{2}\right)$ is the total area that experienced surface melt for at least one day, while the melt index $\left(\right.$ day. $\left.\mathrm{km}^{2}\right)$ is the product of duration and melt extent and describes the total accumulated amount of surface melting.

Figure $6.6 \mathrm{c}$ shows the spatial pattern of the melt duration in austral summer 2015/16. The Larsen and Wilkins ice shelves experienced intensive melt sea- 


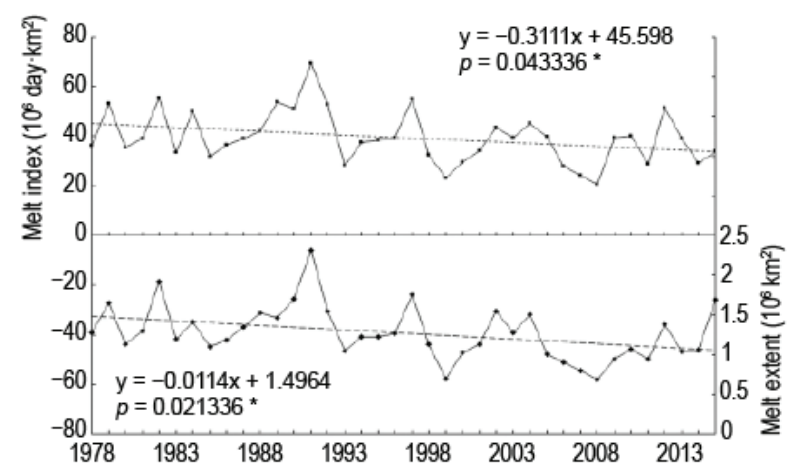

FIG. 6.7. Upper panel: Melt index $\left(10^{6} \mathrm{day} \cdot \mathrm{km}^{2}\right)$ from $1978 / 79$ to $2015 / 16$, showing a negative trend (3I I 100 day $\cdot \mathrm{km}^{2} \mathrm{yr}^{-1}, p<0.05 \%$ ). Lower panel: Melt extent $\left(10^{6} \mathrm{~km}^{2}\right)$ from $1978 / 79$ to $2015 / 16$, showing a negative trend ( $\left.11400 \mathrm{~km}^{2} \mathrm{yr}^{-1}, p<0.05 \%\right)$. Year on the $\mathrm{x}$-axis corresponds to the start of the austral summer melt season, e.g., 2008 corresponds to summer 2008/09.

sons of $>45$ days duration. Areas with moderate melt intensity of 16-45 days duration included the Abbot Ice Shelf, eastern coastal area of Queen Maud Land, and the Amery, West, and Shackleton ice shelves; short-term melt seasons of $<16$ days duration occurred on the Ross Ice Shelf, the western coastal area of Queen Maud Land, and the Filchner Ice Shelf. The entire eastern Ross Ice Shelf experienced a melt duration ranging from 1 to just over 16 days in the summer of 2015/16, an unusually extensive and long melt season for this region.

Due to the extensive melt occurrence on the Ross Ice Shelf, the overall melt index in 2015/16 showed a slight increase compared to the previous year (Fig. 6.7a), but was still the third lowest in the past seven years. An overall negative trend for the melt index (311 100 day.km $\mathrm{yr}^{-1}$ ) since 1978/79 is observed, a statistically significant trend at the $95 \%$ confidence level. Nonetheless, melt extent in 2015/16 was the highest since 1998/99 (Fig. 6.7b). Melt extent still exhibits a negative overall trend $\left(-11400 \mathrm{~km}^{2} \mathrm{yr}^{-1}\right)$ since $1978 / 79$, also significant at the $95 \%$ confidence level. Negative trends in both melt extent and melt index are indicated by previous studies as well (Liu et al. 2006; Tedesco 2009; [Tedesco and Monaghan 2009]). The melt anomaly map in Fig. 6.6d shows that the melt season duration in 2015/16 was generally shorter than the historical average, except for the Ross Ice Shelf.

f. Sea ice extent, concentration, and seasonalityP. Reid, S. Stammerjohn, R. A. Massom, J. L. Lieser, S. Barreira, and T. Scambos

Both net sea ice extent (SIE) and area (SIA) were close to the 1981-2010 average for January through August 2016, after which there was a dramatic departure from the mean through to the end of the year (Fig. 6.8a). Maximum net SIE peaked on 31 August $\left(18.44 \times 10^{6} \mathrm{~km}^{2}\right)$; this was close to the long-term mean daily maximum $\left(18.8 \times 10^{6} \mathrm{~km}^{2}\right)$ but was the earliest annual daily maximum SIE on record since consistent satellite records began in 1979. (Prior to 2016, the earliest annual daily maximum SIE was 3 September 1994.) Thereafter, record low monthly mean SIA was recorded from September through December along with record low monthly SIE from October through December. The monthly anomalies
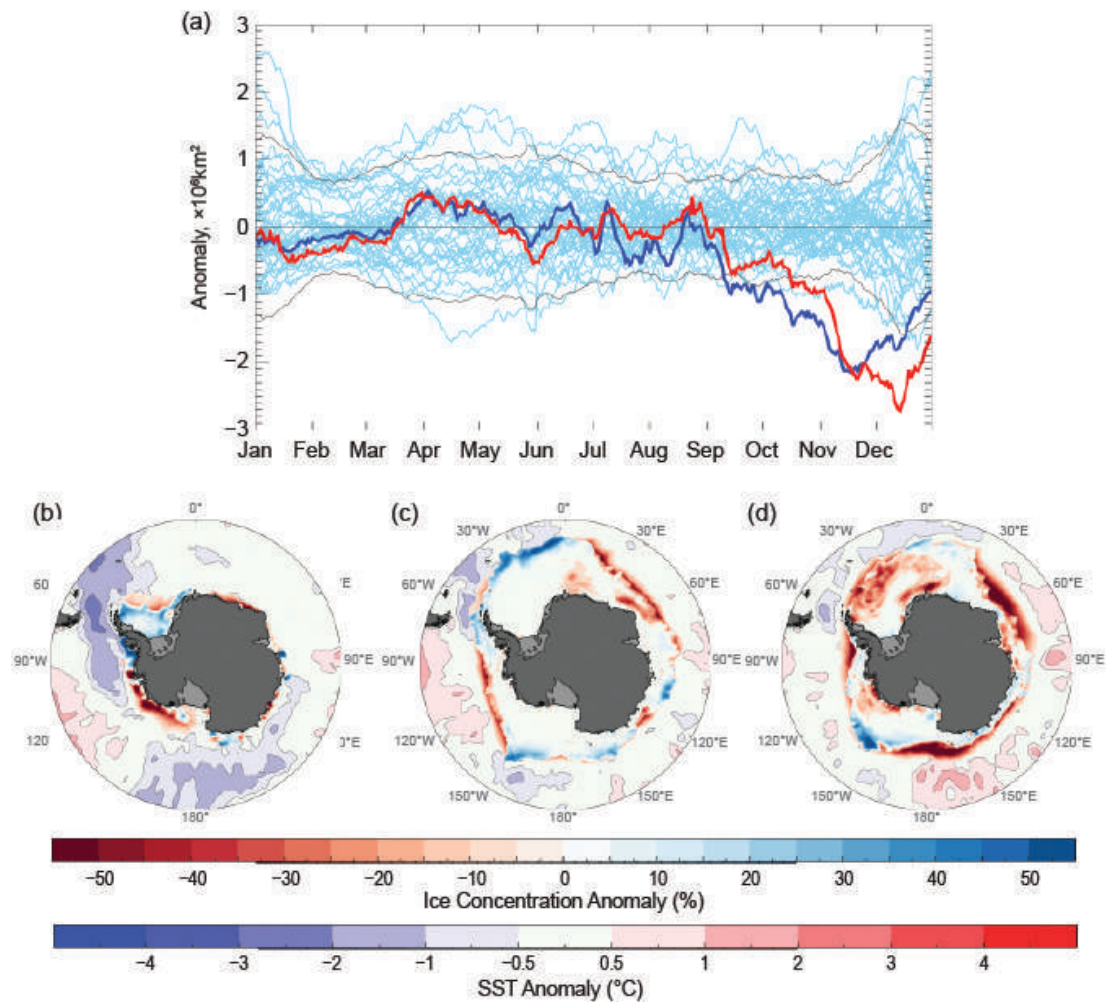

FIG. 6.8. (a) 2016 daily anomaly $\left(10^{6} \mathrm{~km}^{2}\right)$ of $\mathrm{SH}$ sea ice extent (red line) and area (dark blue line), from the 198I-2010 mean. Thin blue lines represent the historical daily values of extent for 1979-20I5, while the thin black lines represents \pm 2 std. dev. of extent. Sea ice concentration anomaly (\%) for (b) Feb (c) Aug 2016 (d) Nov, (relative to 1981-2010 monthly means), along with monthly mean SST anomalies ( ${ }^{\circ} \mathrm{C}$; Reynolds et al. 2002; Smith et al. 2008). Bell is Bellingshausen Sea. 
of net SIE and SIA in November 2016 are over 5 standard deviations below the 1981-2010 average. Many individual daily record lows were broken, with 111 (74) days of record low SIA (SIE) between September and December (Fig. 6.8a). These record low values are a considerable departure both from the record high values observed during 2012-14 (Reid and Massom 2015), and also from the small but statistically significant increase in net SIE observed in satellite data since 1979 (Simmonds 2015; Comiso et al. 2017).

Following on from late 2015 (Reid et al. 2016), the first few months of 2016 saw quite distinct largescale regional variability in the pattern of SIE (Figs. 6.8b, 6.9a). For January-March, very low extent was observed in the Ross and Amundsen Seas $\left(\sim 150^{\circ} \mathrm{E}-\right.$ $\left.110^{\circ} \mathrm{W}\right)$ and eastern Weddell Sea-Indian Ocean sector $\left(\sim 0^{\circ}-60^{\circ} \mathrm{E}\right)$, the latter region being nearly ice free along the Antarctic coast from mid-January through early April. In contrast, SIE was particularly high over this period in the Bellingshausen and western Weddell Seas $\left(\sim 110 \mathrm{~W}^{\circ}-0^{\circ}\right)$, most likely associated with northward Ekman drift due to the contemporary strong westerly winds (Fig. 6.2c) and belowaverage sea surface temperatures (SSTs; Figs. 6.8b, $6.10 \mathrm{~b})$. The contrasting SIE anomaly pattern in the western Weddell-Bellingshausen Seas and western Amundsen/eastern Ross Seas follows on from the anomaly pattern in late 2015, which was influenced by the 2015 El Niño (Reid et al. 2016). In East Antarctica $\left(\sim 60^{\circ}-150^{\circ} \mathrm{E}\right)$, there were locally mixed sea ice anomalies, with higher-than-average SIE being typically coincident with below-average SSTs immediately north of the ice edge (Figs. 6.8b, 6.10b). By the end of March, net SIA and SIE were slightly above the 1981-2010 average (Fig. 6.8a).

The negative SIE anomaly, evident in early April in the Ross Sea, translated over the following few months to a negative SIE anomaly farther to the east, in the Bellingshausen and Amundsen Seas (Fig. 6.9a). Similarly, the positive/negative SIE anomaly in the far western/eastern Weddell Sea migrated eastward over the subsequent several months. This is consistent with the climatological pattern of eastward zonal transport of sea ice anomalies from the strong gyres within the Ross and Weddell Seas and within the Antarctic Circumpolar Current, as shown in Kimura and Wakatsuch (2011), which usually happens from April/May through to about October. From late March-early April, SIE in the eastern Indian Ocean and much of the western Pacific Ocean sectors $\left(\sim 60^{\circ}-120^{\circ} \mathrm{E}\right)$ was anomalously high, partially coinciding with below-average SSTs to the north of the ice edge east of $90^{\circ} \mathrm{E}$. The area of anomalously high
SIE in the eastern Indian Ocean migrated eastward into the southwestern Pacific Ocean region over the following months, positioning itself in the vicinity of $\sim 100^{\circ}-110^{\circ} \mathrm{E}$, where it persisted until to about November. By the end of July, net SIE and SIA were both slightly below average (Fig. 6.8a).

During late July and early August, several cyclones passed eastward across the Weddell Sea and into the

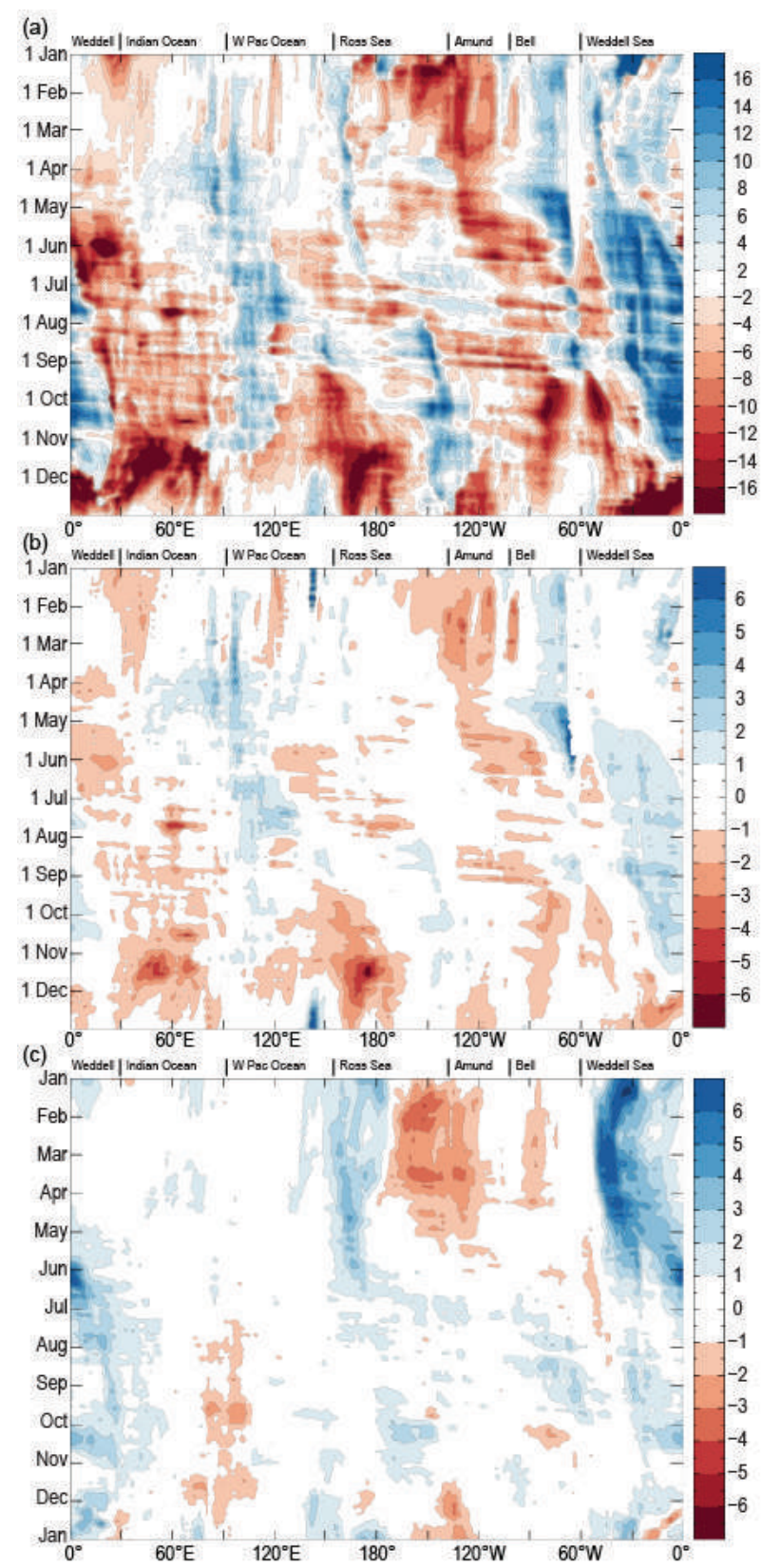

Fıg. 6.9. Hovmöller plots of (a) daily SH sea ice extent anomalies for $2016\left(\times 10^{3} \mathrm{~km}^{2}\right.$ per degree of longitude; from the 198I-2010 mean); (b) standardized sea ice extent; and (c) 1979-2016 trend of sea ice extent $\left(\times 10^{3} \mathrm{~km}^{2}\right.$ decade $\left.^{-1}\right)$. Based on satellite passive-microwave ice concentration data (Cavalieri et al. 1996, updated yearly). 

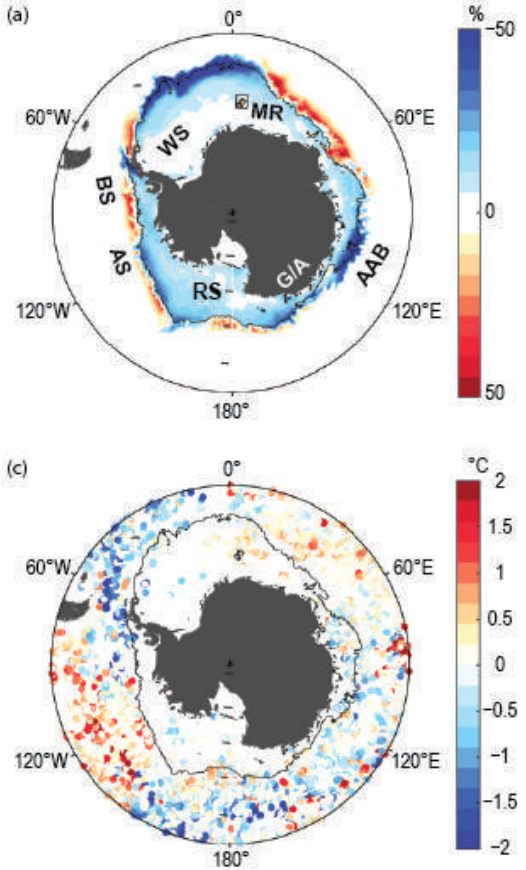

(e)
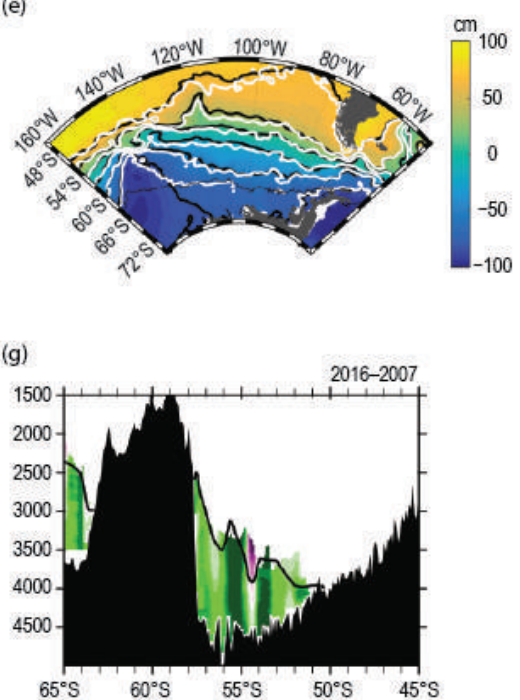
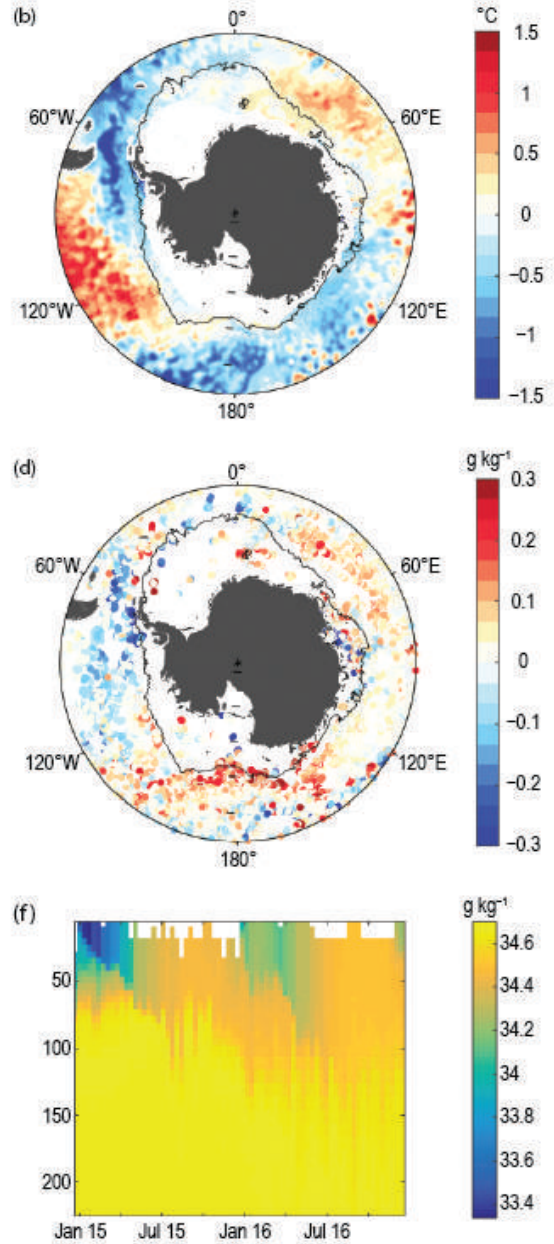

(h)

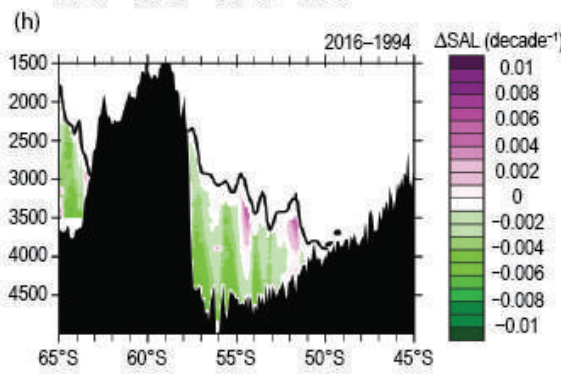

FIG. 6.10. (a) Sea ice concentration anomaly (\%) in Aug 2016 from AMSR-E (Spreen et al. 2008). The gray line in this and subsequent panels is the Aug $2016 \mathbf{8 0} \%$ sea ice concentration contour. Locations discussed in text are denoted: Weddell Sea (WS), Maud Rise (MR), Australian-Antarctic Basin (AAB), George VIAdélie Land Coast (GA), Ross Sea (RS), Amundsen Sea (AS), and Bellinghausen Sea (BS). (b) SST anomaly $\left({ }^{\circ} \mathrm{C}\right.$ ) for Feb-Jun 2016 (OISST from www.remss.com). (c) Anomaly $\left({ }^{\circ} \mathrm{C}\right)$ from climatological seasonal cycle of mixed layer conservative temperature in Feb-Jun 2016. (d) Same as (c), except for absolute salinity. [For information on the method used for (c) and (d) see Pellichero et al. (20I7).] (e) Color and black contours show mean SSH (cm). White contours show mean $2016 \mathrm{SSH}$ after removing SSH linear trend, showing the ACC was displaced poleward in 2016 in this sector. SSH product from Ssalto/Duacs and distributed by Aviso, with support from CNES (www .aviso.altimetry.fr/duacs). (f) Salinity profiles $\left(\mathrm{g} \mathrm{kg}^{-1}\right)$ over Maud Rise from SOCCOM float 9094. (g) Rates of change in PSU of AABW for 2016-2007 for the 108S occupation. (h) Same as (g) but for the change for 2016-1994. The green curve indicates $\beta=28.27 \mathrm{~kg} \mathrm{~m}^{-3}$ in 2016 (g) and 1994 (h).
Indian Ocean sector, bringing with them periods of relatively warmer northerly winds to the Queen Maud Land coast. Subsequently, several central-pack polynyas opened up within the eastern Weddell Sea, the first occurring around $5 \mathrm{Au}$ gust $\left(\sim 1800 \mathrm{~km}^{2}\right)$ over Maud Rise $\left(\sim 3^{\circ} \mathrm{E}, 66^{\circ} \mathrm{S}\right)$ and lasting for two days. This was followed, from 11 to 29 August, by a larger polynya in the Cosmonaut Sea $\left(40^{\circ}-50^{\circ} \mathrm{E}\right.$, $\left.66^{\circ} \mathrm{S}\right)$. Polynyas are thought to recur in these areas due to a combination of oceanic and atmospheric forcing (e.g., Holland 2000; Beckmann et al. 2001; Arbetter et al. 2004). Analysis within the Southern Ocean section of this chapter $(6 \mathrm{~g})$ suggests that the Maud Rise polynya in 2016 was probably related to increased deep convection due to the higher-thanaverage salinity in that region. Above-average SSTs (from the Indian Ocean) may also have contributed by preconditioning the pack ice for polynya formation. Although modest in size compared to the giant polynyas of 1974-76 (Carsey 1980; de Lavergne et al. 2014), the 2016 polynya is significant as it may announce a revival of deep ocean convection in the Weddell Sea. The reemergence implies underlying conditions that may have hastened sea ice retreat (Figs. 6.8c, 6.9a). Over the subsequent two months, sea ice concentration within the Weddell Sea and Indian Ocean sector was predominantly below average. 
Similarly, during these few months (AugustOctober), lower-than-average SIC and sea ice coverage was evident within the Ross, Amundsen, and Bellingshausen Seas, apart from a slightly greater extent between $\sim 140^{\circ}-150^{\circ} \mathrm{W}$ (Figs. 6.8c, 6.9a). These regions were possibly affected by above-average atmospheric temperatures, as a result of low pressure systems in the East Antarctic and BellingshausenAmundsen Seas (e.g., Fig. 6.3e), and SSTs advecting southward within the western and eastern Pacific Ocean (e.g., Fig. 6.8c). SIE in the western Pacific Ocean sector $\left(\sim 100^{\circ}-120^{\circ} \mathrm{E}\right)$ remained slightly higher than average during these months.

By the end of October, large regions showed lower-than-average sea ice concentration, area, and/or extent (Fig. 6.9a), and net SIE and SIA were at record low levels (Fig. 6.8a). From late October through the end of the year, there was a decrease in westerly wind strength around the continent (coincident with the strongly negative SAM index; see Fig. 6.2c) and an influx of warmer water from the north, particularly in the western Pacific Ocean. The reduced westerlies decreased the strength of northward Ekman drift; the influx of warmer water reduced thermodynamic ice growth, respectively. With a thinner sea ice pack at the ice edge, melting occurred earlier in the outer sea ice pack and led to a further reduction in sea ice coverage in the western Ross Sea $\left(\sim 150^{\circ} \mathrm{E}-160^{\circ} \mathrm{W}\right)$ and Indian Ocean $\left(\sim 30^{\circ}-90^{\circ} \mathrm{E}\right)$ while compacting the sea ice (increasing its concentration) in the far eastern Weddell $\left(\sim 0^{\circ}-20^{\circ} \mathrm{E}\right)$ and eastern Ross Seas $\left(\sim 170^{\circ}-130^{\circ} \mathrm{W}\right)$. Elsewhere, in the western Pacific Ocean $\left(\sim 90^{\circ}-150^{\circ} \mathrm{E}\right)$ and the Bellingshausen Sea regions $\left(\sim 130^{\circ}-50^{\circ} \mathrm{W}\right)$, SIE was close to average during this period (Fig. 6.9a).

When the daily SIE anomalies are mapped out in space and time, as shown in the Hovmöller plot in Fig. 6.9a, and normalized by their standard deviation (Fig. $6.9 \mathrm{~b})$, a few additional outstanding features become clear. Most regions experienced anomalously low SIE for most of the year, with the distinct exception of the Bellingshausen Sea (during the first third of the year), the western Weddell (until December) and the western West Pacific. Notably, the rapid switch from strong positive to strong negative anomalies in the western Weddell Sea in December resulted in 20 daily low records for that area. Similarly, the emergence of strong negative SIE anomalies in the Indian Ocean and western Ross Sea (between $150^{\circ} \mathrm{E}$ and $180^{\circ}$ ) sectors from October to December led to 49 and 60 daily record lows, respectively. Another outstanding feature in the standardized figure (Fig. 6.9b) is the positive SIE evident in the summer months in the Mertz
Glacier region $\left(\sim 140^{\circ} \mathrm{E}\right)$. This may have resulted from the enhanced westward advection of sea ice across that region within the Antarctic Coastal Current after the breakup of the Mertz Glacier Tongue in 2010 and is also reflected in the trend panel of Fig. 6.9c. In summary, the 2016 regional anomalies stand in distinct contrast to the long-term trends (Fig. 6.9c), with the exception of the negative SIE anomalies in the Amundsen Sea during January-March.

g. Southern Ocean-M. R. Mazloff, J.B. Sallée, V. V. Menezes, A. M. Macdonald, M. P. Meredith, L. Newman, V. Pellichero, F. Roquet, S. Swart, and A. Wăhlin

By connecting the deep ocean reservoir of carbon and heat to the atmosphere, the Southern Ocean is a primary climate regulator. A readily observed component of regulation is the sea ice cover, which provides insulation and affects albedo. As noted in Section 6f, 2016 showed a spectacular decline late in the year, with the lowest ever recorded spring sea ice cover (see Fig. 6.8a). The upper ocean experienced large temperature anomalies consistent with the sea ice patterns discussed in Section $6 f$ (Figs. 6.10b,c). In addition, the open-ocean polynya observed over Maud Rise in August (e.g., see Fig. 6.8c) was likely driven by unusually weak haline stratification (Fig. 6.10f). Observed salinity changes suggest cryospheric influences on multiyear time scales.

\section{I) UPPER OCEAN}

From February to June 2016, surface and mixed layer temperatures have a quadrupole structure (Figs. 6.10b,c), similar to sea ice extent anomalies (Fig. 6.10a). A strong positive ENSO event occurred from 2015 into mid-2016. It has been shown that the SST quadrupole pattern is consistent with anomalous heat fluxes associated with strong ENSO events (e.g., Vivier et al. 2010). Indeed, a predicted SST anomaly, derived using a Niño-3.4 SST Index (Rayner et al. 2003) and Southern Ocean SST regression between 2002 and 2015, and the Niño-3.4 index for February to June 2016, explains 27\% of the SST anomaly variance between $68^{\circ}$ and $60^{\circ} \mathrm{S}$, and $13 \%$ between $60^{\circ}$ and $50^{\circ} \mathrm{S}$ (not shown).

Sea surface height (SSH) reveals the surface geostrophic circulation and is strongly correlated with SST. In 2016, the Antarctic Circumpolar Current (ACC) appears to have meandered significantly poleward in the Amundsen Sea region (Fig. 6.10e). This may explain the warm SST anomaly and reduced sea ice extent in this region, and it also may imply that relatively warm Circumpolar Deep Water (CDW) was more abundant on the continental shelf and thus more accessible to 
the ice shelves at the coast. The 1993-2016 SSH linear trend was removed prior to estimating the 2016 anomaly in an attempt to remove steric trends, but further work is necessary to better partition diabatic warming from adiabatic meandering in interpreting this SSH anomaly.

Mixed layer salinity between February and June 2016 has a clear anomaly pattern (Fig. 6.10d), yet its structure differs from the temperature anomalies (Fig. 6.10c). However, the signal is consistent with sea ice anomalies in late 2015 (Reid et al. 2016) and early 2016 (see Figs. 6.8b, 6.9a), where anomalously low sea ice was observed almost everywhere except in the western Weddell and eastern Bellingshausen Seas $\left(\sim 30^{\circ}-90^{\circ} \mathrm{W}\right.$; Reid et al. 2016$)$. The positive spring-summer sea ice anomaly translates into more freshwater input, in accord with the observed negative salinity anomaly observed that summer-fall in 2016 (Fig. 6.10d). Meanwhile, the largest negative sea ice anomaly in late 2015/early 2016 (e.g., see Figs. 6.8b, 6.9a) was in the western Amundsen and Ross Seas $\left(\sim 90^{\circ} \mathrm{W}-180^{\circ}\right)$, where the largest positive anomaly of salinity was observed in summer-fall 2016.

\section{2) The Maud Rise polynya}

As noted in Section 6f, an open-ocean polynya was observed over Maud Rise in winter 2016 (see Fig. 6.8c; Fig. 6.10a), likely related to weaker ocean stratification and deeper convection in the region than in previous years. Indeed, floats in the region reveal an anomalously weak halocline in 2016 with respect to earlier observations (Fig. 6.10f). Most austral fall and winter 2016 profiles have weaker stratification than the climatological average, with some profiles showing almost zero stratification in winter (not shown).

It is unclear what caused the weaker haline stratification. The Weddell Sea had anomalously high sea ice extent in austral spring 2015 (Reid et al. 2016). A hypothesis is that increased spring sea ice extent implies more ice being exported from Maud Rise. Increased export leads to either more production and thus more brine rejection in autumn-winter or less ice remaining to provide melt water in spring-summer. Both processes would result in weaker stratification and are also consistent with the apparent deeper mixing beginning in spring 2015 (Fig. 6.10f).

\section{3) Deep ocean}

Observations of most of the deep Southern Ocean are not made annually. The 2015 report (Sallée et al. 2016) assessed $140^{\circ} \mathrm{E}$ between 1969 and 2015, revealing a significant long-term freshening trend of approximately $-0.01 \mathrm{PSU}$ decade $^{-1}$. This section crosses the eastern side of the Australian-Antarctic Basin (AAB), and Antarctic Bottom Water (AABW) found in the $\mathrm{AAB}$ is sourced from the George V/Adélie Land coast $\left(\mathrm{GA} ; 136^{\circ}-154^{\circ} \mathrm{E}\right)$ and the Ross Sea. In 2016 , the I08S $\left(95^{\circ} \mathrm{E}\right.$ ) line was occupied. (IO8S is a World Ocean Circulation Experiment Hydrographic Program indicator.) This line, which was also occupied in 1994 and 2007 (e.g., Figs. 6.10g,h), crosses the western side of the $A A B$ and is also influenced by the GA and Ross Sea AABW source regions. As reported in Menezes et al. (2017), the I08S data showed AABW was warmer and less dense, with changes of $0.06 \pm 0.01^{\circ} \mathrm{C} \mathrm{decade}{ }^{-1}$ and $0.011 \pm 0.002 \mathrm{~kg} \mathrm{~m}^{-3}$ decade $^{-1}$ (e.g., Fig. 6.10h), respectively. A freshening was observed, with mean rates of $-0.002 \pm 0.001 \mathrm{~g} \mathrm{~kg}^{-1} \mathrm{decade}^{-1}$ for the period 1994 to 2007 and $-0.006 \pm 0.002 \mathrm{~g} \mathrm{~kg}^{-1}$ decade $^{-1}$ for $2007-16$ (e.g., Fig. 6.10g). The results at $95^{\circ} \mathrm{E}$ (Figs. $6.10 \mathrm{~g}$,h) and $140^{\circ} \mathrm{E}$ (Sallée et al. 2016) support the hypothesis that increased freshwater input from the ice sheet, either through runoff, basal melting, or iceberg contribution, is contributing to a deep Southern Ocean freshening trend. Changes to sea ice transport and spatial changes in high-salinity shelf water input may also be factors in this trend.

\section{4) Observational gaps and future outlook}

Significant gaps exist in the observations needed to assess the state of the Southern Ocean climate. As in previous years, this report focuses on physical rather than biogeochemical observations, due to a paucity of the latter. However, coverage is improving. Two new projects aim to increase knowledge of the Southern Ocean carbon cycle, giving promise that future reports will address this fundamental component of the climate system. See Sidebar 6.1 on the ORCHESTRA and SOCCOM programs for more information on these efforts. ORCHESTRA and SOCCOM, along with other efforts such as the consortium that is instrumenting marine mammals (www.meop.net/), are also contributing much-needed observations within the seasonally sea ice covered areas. However, other significant gaps remain, including the ocean below perennial sea ice covered areas and ice shelves, the relatively shallow continental shelf seas, and the ocean deeper than 2000 $\mathrm{m}$ (Schofield et al. 2016). 


\section{SIDEBAR 6.I: ADVANCES IN UNDERSTANDING THE SOUTHERN OCEAN'S ROLE IN GLOBAL CLIMATE: THE ORCHESTRA AND SOCCOM PROGRAMS - M. P. MEREDITH, J. L. SARMIENTO, K. S. JOHNSON, E. L. MCDONAGH,}

AND THE ORCHESTRA AND SOCCOM TEAMS

Climate change is one of the most pressing issues facing humanity and life on Earth. The role of the oceans in governing the rate of climatic change is now clear, with more than $90 \%$ of the extra heat and approximately one-third of the extra carbon emitted since the Industrial Revolution having been absorbed by the ocean (Khatiwala et al. 20I3; Rhein et al. 2013). However, not all oceans contribute equally - the Southern Ocean is disproportionately influential due to its unique pattern of circulation and the physical and biogeochemical processes that it hosts (e.g., Marinov et al. 2006; Marshall and Speer 2012).

Unfortunately, the Southern Ocean is also one of the most poorly measured regions of our planet. Its remoteness and inhospitable nature-especially in winter, when much of the surface is covered by sea ice-has led to it being the world's largest data desert. This has slowed progress in understanding the key processes that give it such strong climatic importance, with the consequence that their representation in ocean and climate models remains inadequate.

Two new programs have been initiated with the aim of improving our knowledge of the Southern Ocean. ORCHESTRA-Ocean Regulation of Climate via Heat and Carbon Sequestration and Transports (www .orchestra.ac.uk; Fig. SB6.I) - is a collaboration of seven UK research institutes. Over the next five years, it will conduct a sequence of hydrographic/tracer/carbon research cruises that will quantify the storage and transports of heat and carbon into and through the Atlantic sector of the Southern Ocean, and that will contribute to the international GO-SHIP program. Autonomous systems for air-sea carbon fluxes will also be developed and deployed, and innovative technology (including the tagging of marine mammals with oceanographic instruments) will be used to gather data year-round. Dedicated flights with the British Antarctic Survey's meteorological aircraft (MASIN) will be coordinated with the in situ ocean data collection, including missions over different sea states and sea ice conditions.

Contemporaneously, the Southern Ocean Carbon and Climate Observations and Modeling (SOCCOM; soccom .princeton.edu; Fig. SB6.2) program will deploy 200 automated profiling floats throughout the Southern Ocean, with biogeochemical sensors measuring nitrate, oxygen, and $\mathrm{pH}$ as well as chlorophyll fluorescence and particle backscatter. The SOCCOM consortium includes eight academic and private research institutions and close collaborations with NOAA laboratories. More than 60 SOCCOM profiling floats

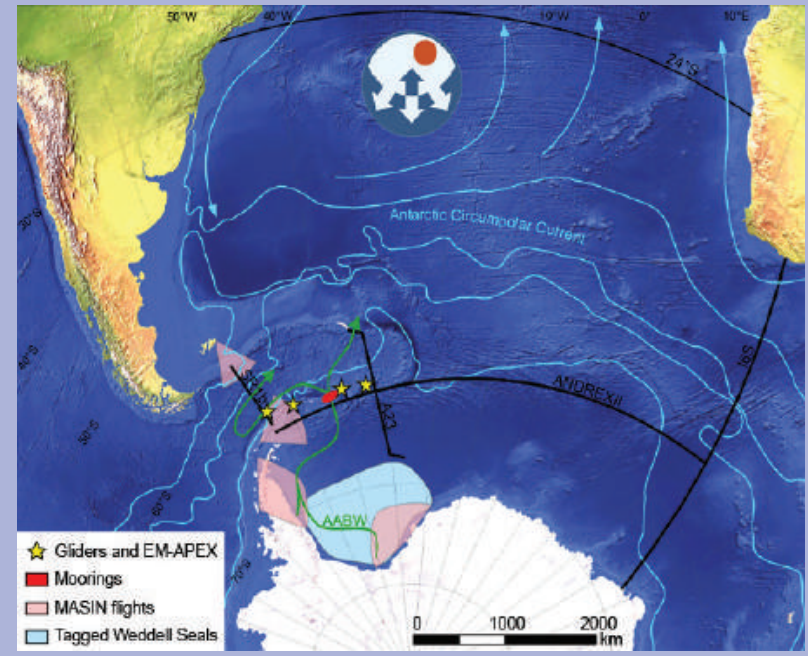

FIG. SB6.I. Schematic of ORCHESTRA fieldwork in the Atlantic region of the Southern Ocean. Black lines denote major hydrographic/carbon sections undertaken by ship. Pink sectors denote missions with the BAS MASIN meteorological aircraft. The light blue denotes the region of ocean data recovery from tagged Weddell seals. The ORCHESTRA deep mooring cluster is marked in red, and nominal deployment positions for ocean gliders and autonomous profiling explorer (EM-APEX) floats are marked in yellow. Profiling float data from the Argo and SOCCOM networks are available throughout the region.

are already in the ocean reporting data every 10 days from all regions of the Southern Ocean, including under sea ice, with some records now approaching three years in length (Fig. SB6.2). These floats will be used to constrain regional and annual estimates of Southern Ocean acidification and uptake of carbon dioxide, as well as the cycling of nutrients and oxygen including the biological pump strength, phytoplankton ecology and productivity, the position of major biogeochemical fronts, and the transport across fronts. SOCCOM will operate through the year 2020, and all float data are being made publicly available in near-real time.

Both programs will use the in situ data collected to improve the high-resolution models used to simulate the Southern Ocean. ORCHESTRA will develop new schemes within the NEMO model (www.nemo-ocean.eu) including a hybrid coordinate system to better simulate the descent of dense water into the ocean depths. The data from the SOCCOM floats will be used to constrain a biogeochemical version of the Southern 
Ocean state estimate model (SOSE; Mazloff et al. 2010) to provide a comprehensive assessment of the contemporaneous carbon cycle. The SOSE output will then be used to improve projections of future carbon cycle using a coupled Earth system model. These improvements will be taken up by the climate modeling centers in both countries, with output made available to the Southern Ocean Model Intercomparison Project and IPCC.

This combination of programs will leave a lasting legacy that will guide the future of research on this globally important topic. The datasets gathered will constitute benchmarks for the Southern Ocean's role in capturing anthropogenic carbon and heat from the atmosphere and will have value in perpetuity. The improved mechanistic understanding of key processes will be incorporated into the coupled models used for climate predictions, upon which advice to policy makers is ultimately based.

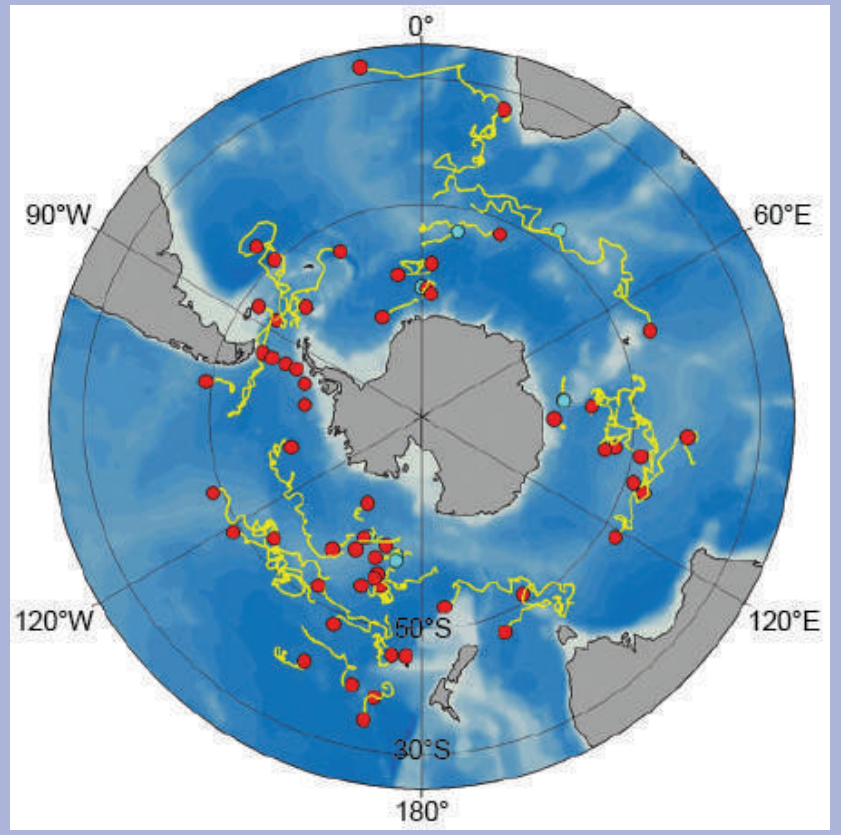

FIG. SB6.2. Locations of the 64 current SOCCOM floats as of 31 Dec 2016. Red dots indicate operating floats while blue dots are inoperative floats. Yellow lines indicate trajectories of floats since deployment. Approximately 200 SOCCOM floats will be deployed in the Southern Ocean by 2020 . h. 2016 Antarctic ozone hole-P. A. Newman, E. R. Nash, S. E. Strahan, N. Kramarova, C. S. Long, M. C. Pitts, B. Johnson, M. L. Santee, I. Petroparlovskikh, and G. 0. Braathen

The Antarctic ozone hole is a severe ozone depletion that regularly appears in austral spring. In 2016, Antarctic stratospheric ozone depletion was less severe compared to the 1991-2006 average (a period of peak chlorine and bromine over Antarctica), but ozone levels were still low compared to pre-1990 levels. Figure 6.11a displays the ozone column between 12 and $20 \mathrm{~km}$ derived from NOAA South Pole balloon profiles averaged over 21 September to 16 October (the period with the largest ozone depletion). The 2016 South Pole ozone column was $\sim 6$ Dobson units (DU) higher than the 1991-2006 average (horizontal dashed line in the figure), and all ozone column means through the ozone minimum seasons since 2009 have been higher than this 1991-2006 average.

Satellite column observations over Antarctica (Aura OMI sensor) also suggest relatively weakerthan-average ozone depletion. Figure 6.11b shows the average of daily minimum total column ozone values over the 21 September to 16 October period. The 2016 total column (Fig. 6.11b) of $124 \mathrm{DU}$ is $\sim 13 \mathrm{DU}$ higher than the 1991-2006 average (horizontal dashed line), consistent with the South Pole partial column (Fig. 6.11a). Since 1991, there have been only five ozone holes with larger minimum values than those in 2016. The 2016 ozone hole area was 20.9 million $\mathrm{km}^{2}$ (averaged from the 7 September-13 October daily estimates); only five ozone holes have had a smaller area.

Both the temperature and chlorine levels of the Antarctic lower stratosphere control the ozone hole's severity. Figure 6.11c displays the time series of $50-\mathrm{hPa}$ September mean temperatures $(\mathrm{K})$ in the $60^{\circ}-90^{\circ} \mathrm{S}$ region from the NASA MERRA-2 (black points) and from the ECMWF ERA-Interim (red points) reanalyses. Note that the ERA-Interim values are biased low with respect to the MERRA-2 data for the period up to 1998, but the two datasets are in excellent agreement from 1999 to the present. The figure 
(a)

(b)

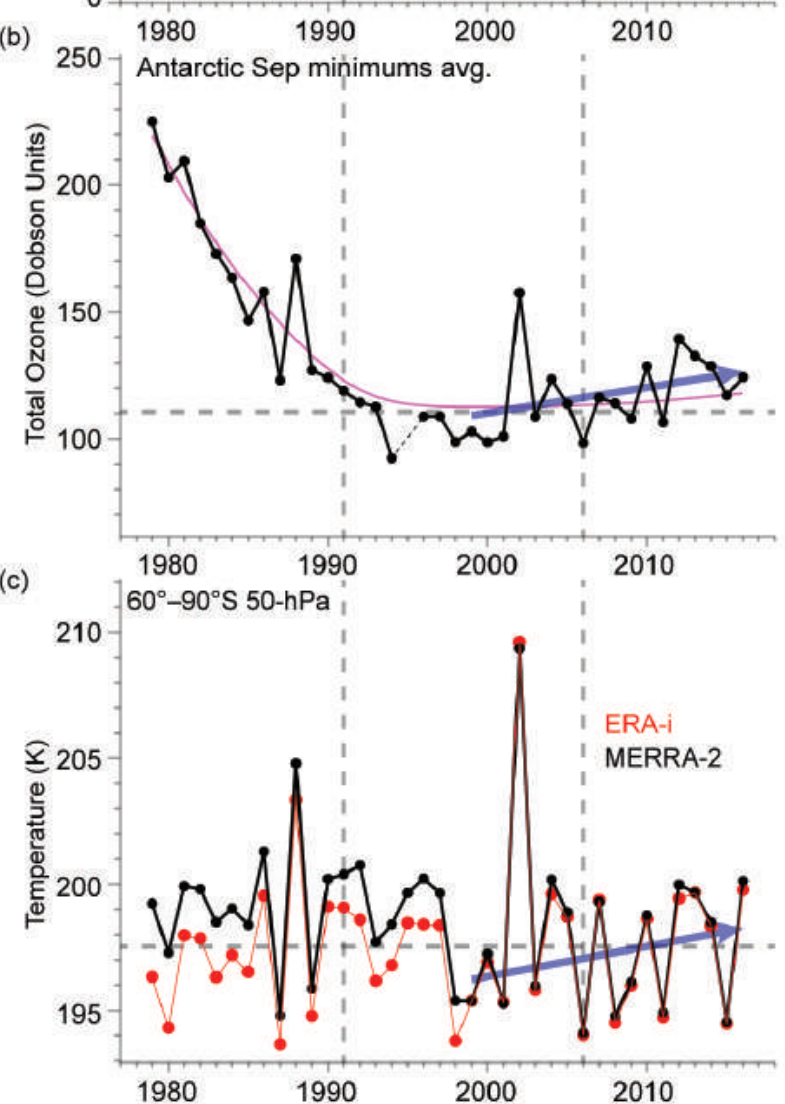

FIG. 6.II. (a) Column ozone (DU) measured within the primary depletion layer $(12-20 \mathrm{~km})$ by NOAA South Pole ozonesondes 21 Sep-16 Oct 2016. (b) Satellite daily total ozone minimum values (DU) averaged over 2I Sep-16 Oct. (c) 50-hPa Sep temperature (K) averaged over $60^{\circ}-90^{\circ} \mathrm{S}$ for MERRA-2 (black points) and ERA-Interim (red points). Blue lines indicate 1999-2016 trend; dashed lines indicate 1991-2006 average values. The magenta curve in (b) is the quadratic fit of total ozone to EESC. shows that the 2016 average temperature was a couple of degrees higher than the average over 1991-2006, the peak ozone hole period.

The 2016 stratospheric dynamical conditions were slightly more active than the 1980-2015 average. The 100-hPa eddy heat flux is a metric of both wave propagation into the stratosphere and the strength of the downward motion over Antarctica. In 2016 the magnitude of the $100-\mathrm{hPa}$ eddy heat flux was above average for the August-September period (not shown). Consequently, the Antarctic stratospheric vortex was warmer than average (Fig. 6.11c) and its jet flow was slightly weaker than average (not shown).

The 2016 ozone hole broke up around 24 November (fifth earliest since 1980), approximately two weeks earlier than the average break-up date for the last 20 years (2015 break-up was 21 December). The "break-up" is estimated when total ozone values less than 220 DU disappear. The ozone hole break-up is tightly correlated with the lower stratospheric polar vortex break-up, which is driven by late spring wave events propagating upward into the stratosphere. The earlier break-up date in 2016 was due to stronger wave activity in October and November that enabled the mixing of ozone-rich midlatitude air into the polar midstratosphere.

The slightly higher 2016 Antarctic lower stratospheric temperature likely lessened the severity of the 2016 ozone hole. Figure 6.12 displays the ozone anomalies associated with the lower stratospheric temperatures from ERA-Interim (Fig. 6.11c).

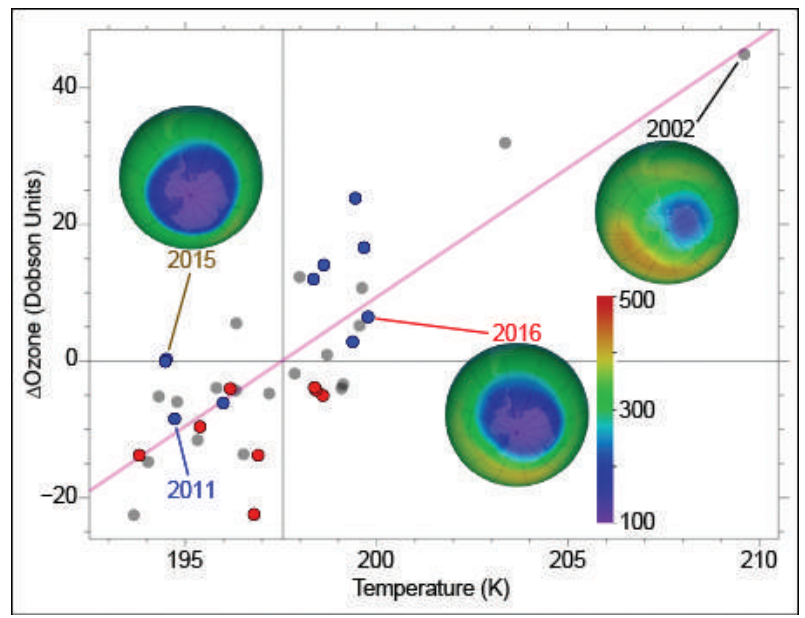

FIG. 6.I2. Column ozone anomalies (DU) versus ERAInterim 50-hPa Sep mean temperatures $(K)$ in the $60^{\circ}-90^{\circ} \mathrm{S}$ region (see Fig. $6.1 \mathrm{lc}$ ). The inset images are total column ozone averages over 21 Sep- 16 Oct periods. Red points indicate years 1992-2000 (large ozone holes); blue points represent the last decade, 2007-16. The vertical line is the temperature average for the entire period. The magenta line shows the linear fit. 
These ozone anomalies are calculated by fitting effective equivalent stratospheric chlorine (EESC, an estimator of human-produced chlorine and bromine loading of the stratosphere) with a 5.2-year mean age to the total ozone (fit is shown as the magenta line in Fig. 6.11b). The ozone anomalies from this EESC fit are well correlated with temperature anomalies. The above-average column ozone in 2016 was likely the result of above-average temperatures, with a small contribution from decreasing EESC.

Satellite observations of chlorine and ozone in the 2016 Antarctic lower stratosphere were not exceptionally different from those in the last 10 years. Aura satellite Microwave Limb Sounder (MLS) observations of hydrogen chloride (HCl: Fig. 6.13a), chlorine monoxide (ClO: Fig. 6.13b), and ozone (Fig. 6.13c) are shown for the Antarctic polar vortex. The reaction of $\mathrm{HCl}$ with chlorine nitrate $\left(\mathrm{ClONO}_{2}\right)$ on the surfaces of polar stratospheric cloud (PSC) particles forms chlorine gas $\left(\mathrm{Cl}_{2}\right)$ and causes $\mathrm{HCl}$ to decline during the June-July period (Fig. 6.13a). $\mathrm{Cl}_{2}$ is easily photolyzed by visible light, and the ozone-reactive $\mathrm{ClO}$ steadily increases as the sun returns to Antarctica (Fig. 6.13b). Chlorine (Figs. 6.13a,b) and ozone (Fig. 6.13c) in the 2016 Antarctic stratosphere (red) were within the 2004-15 climatology (gray).

PSCs provide particle surfaces that enable heterogeneous chemical reactions to release chlorine for catalytic ozone loss. Temperatures provide a useful proxy for PSCs, but the Cloud-Aerosol Lidar and Infrared Pathfinder Satellite Observation (CALIPSO) satellite provides direct observations. Figure 6.13d displays the 2016 PSC volume (red line). High levels of PSCs started later than usual in 2016 and reached very large volumes in midwinter. However, these midwinter values had minimal impact on ozone because depletion requires sunlight. The 2016 PSC volumes during the key depletion month of September were some of the lowest in the record.

The 2016 observations continue to add to our confidence that Antarctic ozone levels are increasing, as noted in Newman et al. (2015), Nash et al. (2016), and Solomon et al. (2016). The South Pole 1999-2016 stratospheric ozone trend of 0.94 DU yr ${ }^{-1}$ (Fig. 6.11a, blue line) is statistically significant (99\% confidence) if 2002, a year of sudden major warming in the stratosphere, is excluded from the trend, and not significant, at $0.44 \mathrm{DU} \mathrm{yr}^{-1}$, if 2002 is included. Similarly, the satellite daily total ozone minimum values trend (Fig. 6.11b, blue line) is $1.6 \mathrm{DU} \mathrm{yr}^{-1}(99 \%$ confidence without 2002), and $1.0 \mathrm{DU} \mathrm{yr}^{-1}$ if 2002 is included (not significant). The EESC fit to ozone is shown in Fig. 6.11b as the magenta line. Because of (a)

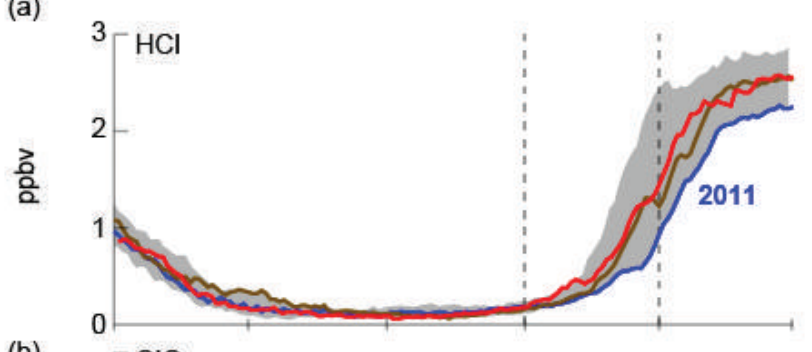

(b)

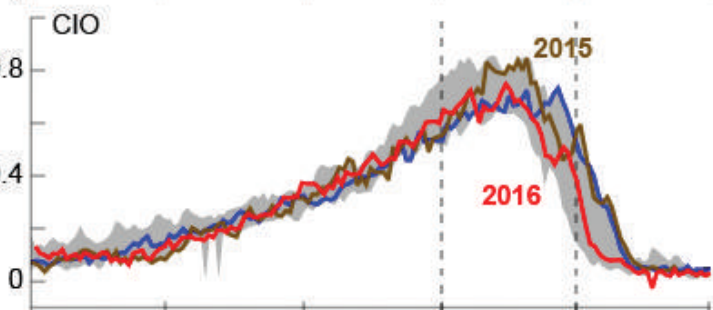

(c)

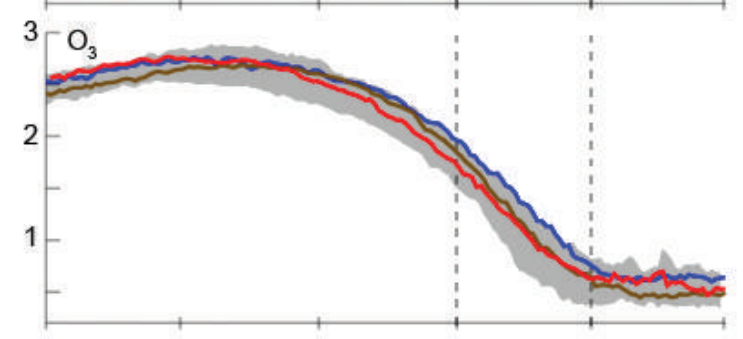

(d)

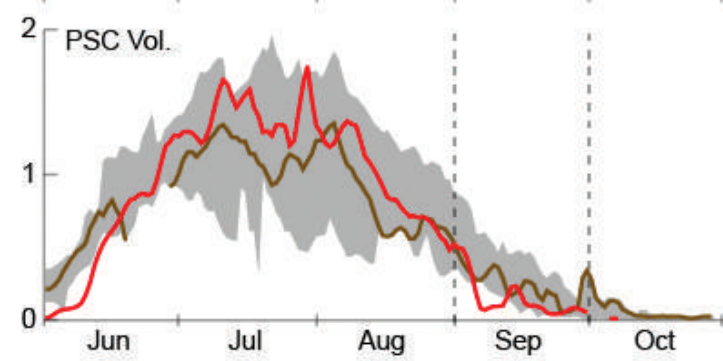

FIG. 6.13. Antarctic 2016 vortex-averaged concentrations (red lines) of: (a) $\mathrm{HCl}$ (ppbv), (b) ClO (ppbv), and (c) ozone (ppmv) from Aura MLS (updated from Manney et al. 20II). The MLS averages are made inside the polar vortex on the $440-\mathrm{K}$ potential temperature surface $(\sim 19 \mathrm{~km}$ or $60 \mathrm{hPa})$. Gray shading shows the range of daily Antarctic values for 2004-15, and $201 \mathrm{I}$ is blue line while 2015 is brown. (d) CALIPSO PSC volume $\left(\times 10^{8} \mathrm{~km}^{-3}\right.$; updated from Pitts et al. 2009). Gray shading in (d) is for 2006-15.

the slow decline of chlorine and bromine in the atmosphere, the Antarctic ozone upward trend expected from EESC is relatively small (5-6 DU between 1999 and 2016) and considerably less than the one-sigma interannual residual variability of $14 \mathrm{DU}$.

The Antarctic lower stratospheric temperature trend is weakly positive during the key September period for ozone depletion. From Fig. 6.11c, the trend is $0.12 \mathrm{~K} \mathrm{yr}^{-1}$ (90\% confidence without 2002), and $-0.025 \mathrm{~K} \mathrm{yr}^{-1}$ if 2002 is included (not significant). While ozone anomalies are highly correlated with temperature $(r=0.82$ in Fig. 6.12 , statistically 
significant at $>99.9 \%$ confidence level), the $2007-16$ ozone anomalies are higher than expected (Fig. 6.12, blue points), while the 1992-2000 ozone anomalies are lower than expected (Fig. 6.12, red points). This is consistent with EESC levels declining since 2000; however, the fact that the ozone trends are larger than the temperature trends suggests that additional processes (e.g., long-term transport, spring initial conditions for ozone) are also playing a role in the ozone trend.

Attribution of ozone hole improvement to declining EESC levels is still difficult. A mean age of 5.2 years is used to estimate EESC (Strahan et al. 2014). Since the 2000-02 peak of 3.79 ppb, EESC has decreased to an estimated $3.43 \mathrm{ppb}$ (a drop of $10 \%)$. This is a $22 \%$ drop towards the 1980 level of
$2.05 \mathrm{ppb}$, a year in the "pre-ozone hole" period. Aura MLS nitrous oxide $\left(\mathrm{N}_{2} \mathrm{O}\right)$ measurements have been used to estimate Antarctic stratospheric inorganic chlorine $\left(\mathrm{Cl}_{\mathrm{y}}\right)$ levels (Strahan et al. 2014) and quantify their transport-driven interannual variability. This transport variability, driven by the direction of the tropical zonal wind (i.e., the quasi-biennial oscillation), has resulted in Antarctic stratospheric $\mathrm{Cl}_{\mathrm{y}}$ levels in 2014, 2015, and 2016 that were higher than in previous years (e.g., 2011-13) and similar to levels found prior to 2010 .

Further information on the ozone hole with data from satellites and ground and balloon instruments, can be found in the WMO Antarctic Ozone Bulletins (www.wmo.int/pages/prog/arep/gaw/ozone/index .html). 
7. REGIONAL CLIMATES — A. Mekonnen, J. A. Renwick, and A. Sánchez-Lugo, Eds.

\section{a. Overview}

This chapter provides summaries of the 2016 temperature and precipitation conditions across seven broad regions: North America, Central America and the Caribbean, South America, Africa, Europe, Asia, and Oceania. In most cases, summaries of notable weather events are also included. Local scientists provided the annual summary for their respective regions and, unless otherwise noted, the source of the data used is typically the agency affiliated with the authors. Please note that different nations, even within the same section, may use unique periods to define their normals. Section introductions will typically define the prevailing practices for that section, and exceptions will be noted within the text. In a similar way, many contributing authors use languages other than English as their primary professional language. To minimize additional loss of fidelity through reinterpretation after translation, editors have been conservative and careful to preserve the voice of the author. In some cases, this may result in abrupt transitions in style from section to section.

\section{b. North America}

This section is divided into three subsections: Canada, the United States, and Mexico. Information for each country has been provided by local scientists, and the source of the data is from the agency affiliated with the authors. Due to the different sources of data, anomalies can be reported using different base periods.

Warmer-than-average conditions engulfed much of North America during 2016, with all three countries experiencing warmth that ranked in the top four in their respective records. Precipitation varied greatly from region to region, but overall Alaska, Canada, and the contiguous U.S. had wetter-thanaverage conditions during 2016, while Mexico experienced drier-than-average conditions.

\section{I) Canada-R. Whitewood, L. A. Vincent, and D. Phillips}

In Canada, 2016 was characterized by warmerthan-average temperatures stretching from the northwest to the central regions. This pattern was also evident during winter (December-February) 2015/16 when drier-than-average conditions were recorded over the same regions.

\section{(i) Temperature}

The annual average temperature in 2016 for Canada was $2.1^{\circ} \mathrm{C}$ above the $1961-90$ average, resulting in the fourth warmest year since nationwide records began in 1948 (Fig. 7.1). Four of the ten warmest years have occurred during the last decade, with 2010 experiencing record warmth $\left(+3.0^{\circ} \mathrm{C}\right)$. The national annual average temperature has increased by $1.7^{\circ} \mathrm{C}$ over the past 69 years. Spatially, annual departures above $+2^{\circ} \mathrm{C}$ were recorded from the northwest to the central regions (Fig. 7.2a), which resulted in six provinces/territories having annual average temperatures among their four highest: Yukon (warmest year), British Columbia, Alberta, and Saskatchewan (second warmest), and Northwest Territories and Nunavut (third and fourth warmest, respectively).

Seasonally, winter was $4.0^{\circ} \mathrm{C}$ above average-the second warmest winter on record, behind the winter of $2009 / 10$. The national winter average temperature has increased by $3.3^{\circ} \mathrm{C}$ over the past 69 years. Winter anomalies above $+4^{\circ} \mathrm{C}$ were recorded from the northwest to the Atlantic coast, and most provinces/ territories had winter average temperatures among their four warmest: Yukon and Atlantic provinces (warmest), Northwest Territories (second warmest), Ontario (third warmest), and Alberta, Saskatchewan, and Manitoba (fourth warmest). During the spring (March-May), the pattern of warmer-than-average conditions continued in the western and central regions, but colder-than-average temperatures were recorded in Quebec and Atlantic provinces. The nationally averaged temperature for spring 2016 was $1.6^{\circ} \mathrm{C}$ above the $1961-90$ average and the 10 th warmest on record. The Yukon, British Columbia, and Alberta each had their warmest spring on record.

Summer (June-August) was $1.2^{\circ} \mathrm{C}$ above average and was the fourth warmest since 1948. Most of the Yukon, Northwest Territories, and Nunavut experienced summer anomalies above $+2^{\circ} \mathrm{C}$; Nunavut

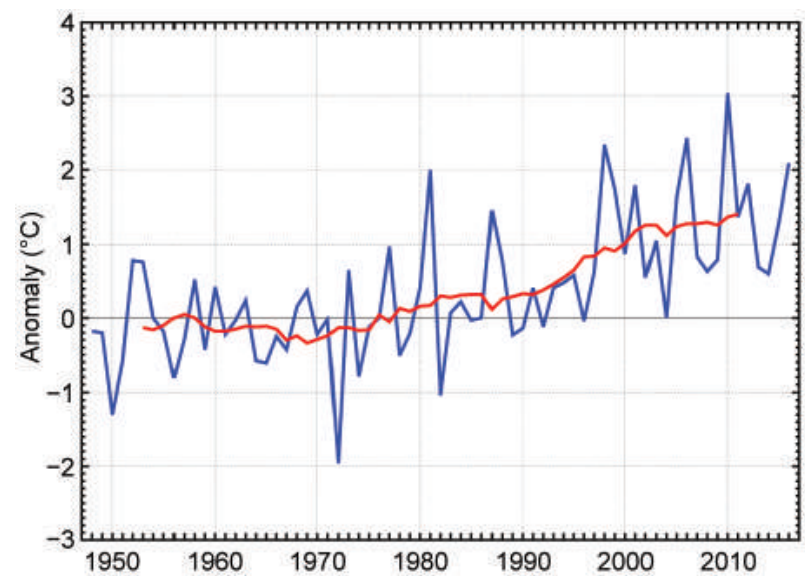

Fig. 7.I. Annual average temperature anomalies $\left({ }^{\circ} \mathrm{C}\right.$; 1961-90 base period) for Canada for 1948-2016. Red line is the II-year running mean. (Source: Environment and Climate Change Canada.) 
(a)

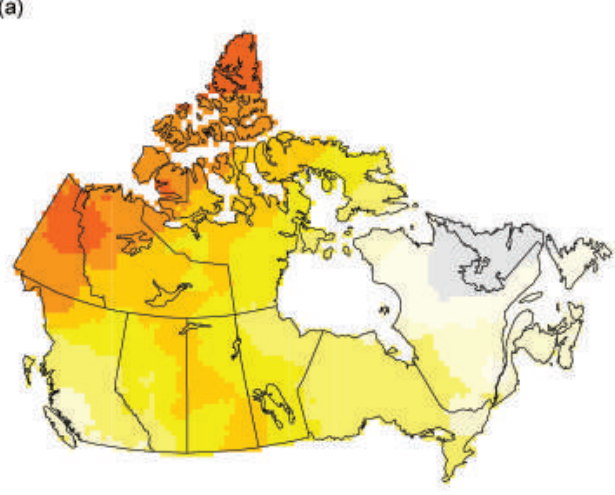

(b)

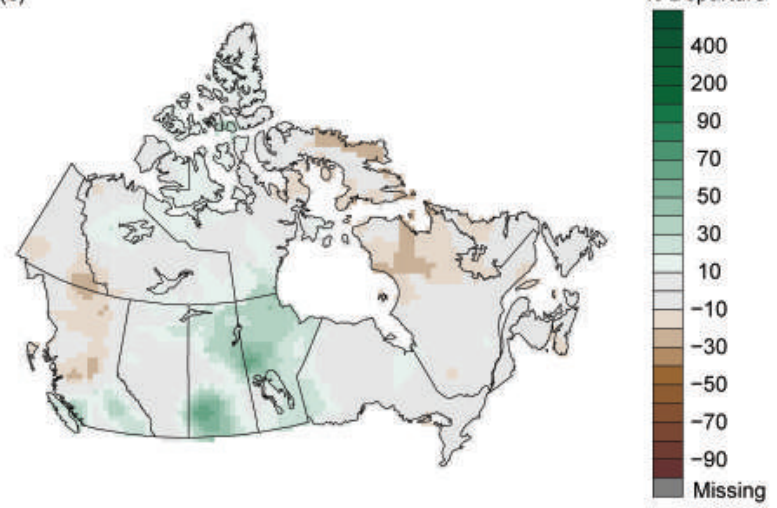

Fig. 7.2. Annual (a) average temperature anomalies ( ${ }^{\circ} \mathrm{C}$; 196I-90 base period) and (b) total precipitation anomalies in Canada (\% departure). (Source: Environment and Climate Change Canada.)

had its fourth warmest summer on record. Summer temperatures for the remainder of the country were slightly above or near average. During autumn (September-November), the central regions of the country, from Saskatchewan to western Quebec and the north, from western Northwest Territories to Nunavut, experienced temperature anomalies above $+3^{\circ} \mathrm{C}$, while the remainder of the country was slightly above or near average. The nationally averaged temperature was $2.4^{\circ} \mathrm{C}$ above the 1961-90 average, marking the second warmest autumn on record, behind only 1998. Four provinces/territories had autumn average temperatures among their four highest: Manitoba and Ontario (warmest) and Saskatchewan and Nunavut (fourth warmest).

\section{(ii) Precipitation}

Canada as a whole experienced slightly wetterthan-average annual precipitation conditions in 2016. Based on preliminary data, it was the 16 th wettest year since nationwide records began in 1948, with nationally averaged precipitation $105 \%$ of the 1961-90 average. The nationally averaged annual precipitation amounts have increased by $17.6 \mathrm{~mm}$ since 1948 .
Wetter-than-average conditions were observed in Saskatchewan and Manitoba, whereas only small areas in northern British Columbia, southern Yukon, northwestern Quebec, and Baffin Island recorded drier-than-average conditions (Fig. 7.2b). Two provinces had annual average precipitation totals among their three highest: Saskatchewan (wettest year) and Manitoba (third wettest).

Seasonally, winter 2015/16 was the 18th driest since 1948, with the national average precipitation 95\% of the 1961-90 average. Drier-than-average conditions were recorded from the northwest to the central regions and, in the north, from eastern Nunavut to northern Quebec, Newfoundland, and Labrador; it was the fifth driest winter in the Yukon. Wetter-than-average conditions were observed over southern British Columbia, western Nunavut, eastern Ontario, and western Quebec. Spring 2016 was the 13th wettest in the 69-year record with nationally averaged precipitation 109\% of average. Wetter-thanaverage conditions were recorded in northern Yukon, northern Northwest Territories, and in the Canadian Prairies, while small regions in central Nunavut, northern Ontario, and eastern Quebec observed drier-than-average conditions.

Summer 2016 was the wettest since 1948 (based on preliminary data), with the national average precipitation $117 \%$ of the $1961-90$ average. Wetter-than-average conditions were recorded in most regions across the country, notably in Saskatchewan (wettest summer) and Manitoba (second wettest). Autumn was the 25 th wettest since 1948 , with nationally averaged precipitation $105 \%$ of average. Wetter-than-average conditions were mainly experienced in southern British Columbia, Saskatchewan, Manitoba (wettest autumn), central Nunavut, and Newfoundland. Drier-than-average conditions were observed in the Yukon (second driest autumn), northern British Columbia, eastern Ontario, Quebec, and Baffin Island.

\section{(iii) Notable events and impacts}

A wildfire wreaked havoc southwest of Fort McMurray in northeastern Alberta, and neighboring communities in early May. At the start of the fire, an unusual hot and dry air mass was in place over northern Alberta, which brought record-high temperatures to Fort McMurray. On 3 May, the temperature reached $32.8^{\circ} \mathrm{C}$ and was accompanied by relative humidity as low as $12 \%$. On 4 May, the temperature climbed to $31.9^{\circ} \mathrm{C}$ with wind gusting to $72 \mathrm{~km} \mathrm{~h}^{-1}$. In addition, the winter and spring preceding the fire were unusually warm and dry in northern Alberta (fourth warmest winter and warmest spring 
in Alberta; seventh driest winter). These climate conditions contributed to the fire's rapid growth. This wildfire became the most costly disaster in Canadian history with total damages reaching $\$ 3$ billion (U.S. dollars) in insured losses and billions more in lost business and infrastructure (A more detailed analysis is provided in Sidebar 7.1.).

During summer 2016, the Canadian Prairies experienced one of its longest and most active storm season since statistics were first kept in 1991. Clusters of intense thunderstorms were more frequent. There were numerous reports of large hail, heavy rain, high winds, frequent lightning, and many localized events that included tornadoes, brief non-destructive landspouts, and microbursts. Tornadoes were more frequent- 46 vortices compared to the 30 -year average of 34 . Altogether, there were 564 reported severe weather events including strong winds, heavy rain, tornadoes, and hail. Nearly two-thirds of these severe events were hailstorms, which caused damage and resulted in payouts for crop hail insurance claims 50\% higher than the previous year's costs and well above the average of the past five years.

2) United States-J. Crouch, A. Smith, C. Fenimore, and R. R. HEIM JR.

The annual average temperature in 2016 for the contiguous United States (CONUS) was $12.7^{\circ} \mathrm{C}$ or $1.2^{\circ} \mathrm{C}$ above the $1981-2010$ average-its second warmest year since records began in $1895,0.2^{\circ} \mathrm{C}$ cooler than 2012 (Fig. 7.3). The annual CONUS temperature over the 122-year period of record is increasing at an average rate of $0.1^{\circ} \mathrm{C}$ decade ${ }^{-1}$, with the trend increasing since 1970 to $0.3^{\circ} \mathrm{C}$ decade $^{-1}$. The nationally averaged precipitation total during 2016 was $102 \%$ of average (or 21.8 $\mathrm{mm}$ above the 1981-2010 average of $787 \mathrm{~mm}$ ), the 24 th wettest year in the historical record. The annual CONUS precipitation total is increasing at an average rate of $4.1 \mathrm{~mm} \mathrm{decade}^{-1}$. Outside the CONUS, Alaska had its warmest year $\left(+2.6^{\circ} \mathrm{C}\right)$ since statewide records began in 1925, and near-median precipitation (99\% of average). Complete U.S. temperature and precipitation maps are available at www.ncdc .noaa.gov/cag.

\section{(i) Temperature}

For the CONUS, ten months in 2016 were warmer than the 1981-2010 average, and each season ranked among its six warmest on record. Every state across the CONUS had an annual temperature that ranked in its high 10th percentile, although Georgia was the only record warm state (Fig. 7.4a). The national warmth in 2016 was driven by a record high annual

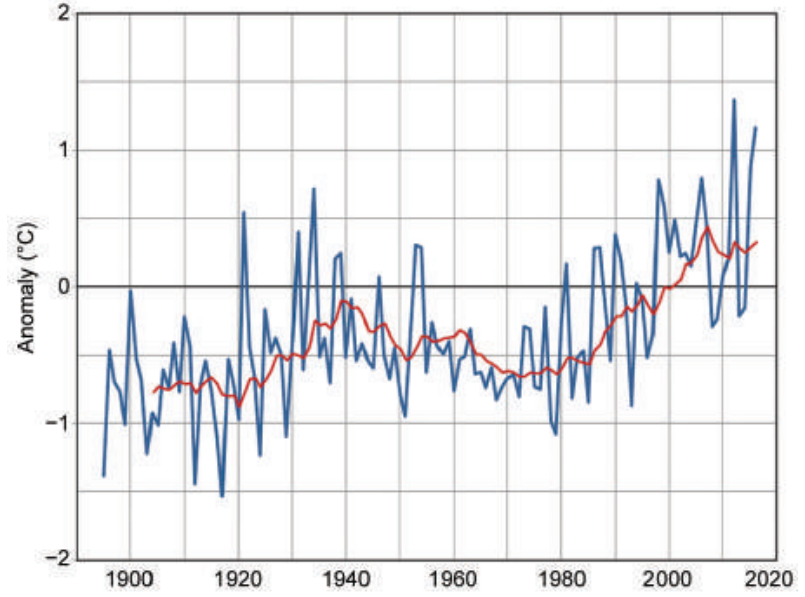

Fig. 7.3. Annual mean temperature anomalies $\left({ }^{\circ} \mathrm{C}\right.$; base period: $1981-2010)$ for the contiguous United States for 1895-2016. Red line is the 10-year running mean. (Source: NOAA/NCEI.)

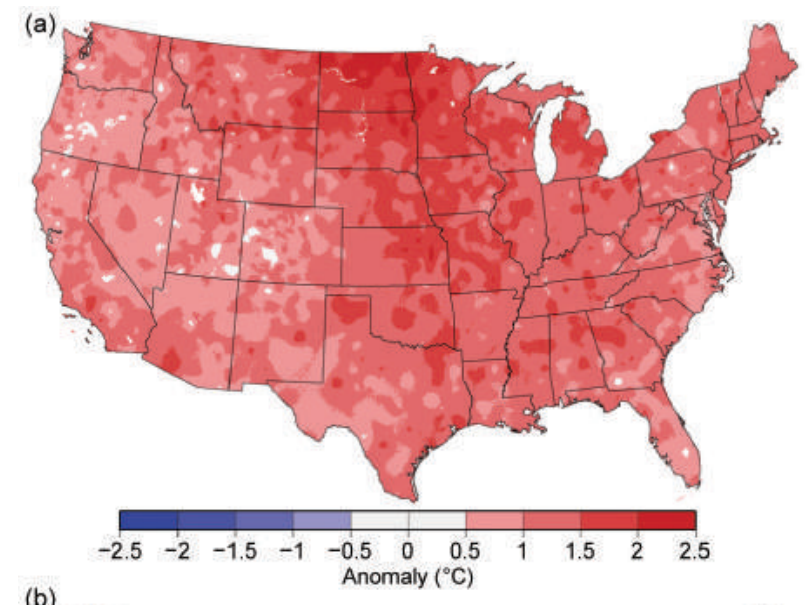

(b)

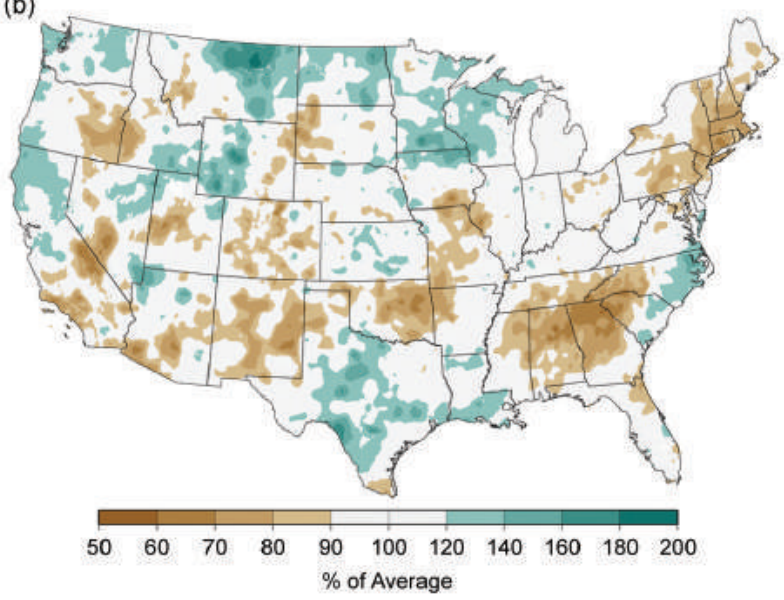

Fig. 7.4. (a) Annual average temperature anomalies ( ${ }^{\circ} \mathrm{C}$; $198 \mathrm{I}-2010$ base period) and (b) \% of average annual total precipitation in the contiguous United States for 2016. (Source: NOAA/NCEI.)

average minimum temperature and third highest annual average maximum temperature. 


\section{SIDEBAR 7.I: THE EXTREME 2016 WILDFIRE IN FORT MCMURRAY,}

ALBERTA, CANADA—B. KOCHTUBAJDA, J. BRIMELOW, M. FLANNIGAN, B. MORROW, AND M. D. GREENHOUGH

In Canada's boreal forest, fire shapes landscape diversity, maintains biological diversity, and controls insects and diseases. However, fire also represents a threat to human life, property, and valuable commercial resources. Three factors influence fire activity: fuels (i.e., type and amount of vegetation available for burning), an ignition source, and weather conditions (Flannigan and Wotton 2001). These factors came together in May 2016 to create the costliest insured claims natural disaster in Canada's history.

The Fort McMurray wildfire, which occurred in northeastern Alberta, was a human-caused wildfire that started on I May 2016 about $7 \mathrm{~km}$ west of Fort McMurray. The intense wildfire spread rapidly, developing into a raging crown fire. On 3 May, nearly 90000 residents of the city and surrounding area were evacuated when the fire grew out of control, jumped several rivers, and headed toward downtown. This wildfire was the third largest fire event in Alberta, consuming nearly 590000 hectares (approximately the size of the state of Delaware). It took until 4 July before the fire was finally declared under control. In Fort McMurray, almost 2600 residential homes and other buildings were destroyed. Total insurable losses are estimated at about $\$ 3$ billion (U.S. dollars), making this the costliest insured claims disaster in Canadian history. Furthermore, the Bank of Canada attributed a slight reduction in Canada's Gross Domestic Product in the second quarter to the shutdown of oil sands production facilities in the area.

The sequence of events leading up to the Fort McMurray wildfire began long before the fire ignited. In 2015, a near-record strength El Niño event developed in sync with a strong positive phase of the Pacific decadal oscillation (PDO). These sea surface temperature oscillations are known to modulate the hydroclimate (Gan et al. 2007; Zhao et al. 2013; Newton et al. 2014a,b) and fire activity over western Canada (e.g., Macias Fauria and Johnson 2006). In this case, the atmospheric response to the EI Niño and PDO manifested as a strong, persistent ridge over

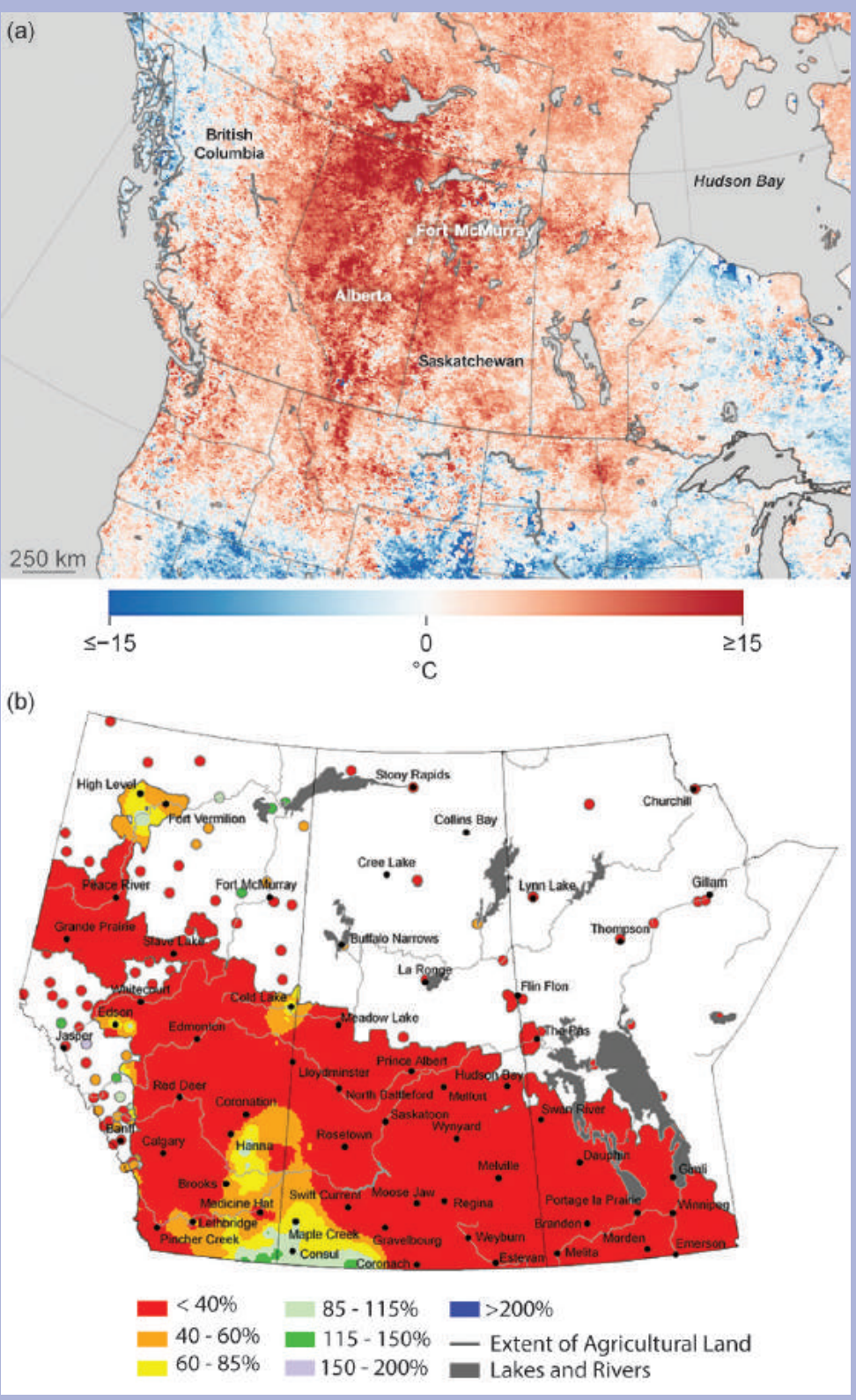

FIG. SB7.I. Antecedent temperature and precipitation conditions associated with the Fort McMurray fire. (a) Satellite-derived land surface temperature departures $\left({ }^{\circ} \mathrm{C}\right.$ ) based on MODIS data (from the TERRA satellite) for 26 Apr-3 May 2016 (compared to the 200I-10 average for the same period). (Source: NASA's Earth Observatory.) (b) Percent of normal precipitation (\%) for $26 \mathrm{Apr}-$ 2 May 2016. (Source: Map based on surface station data and generated by Agriculture and Agri-Food Canada.) the west coast of North America. This persistent ridging is reflected in the positive 12-month Pacific-North American (PNA) index for June 2015 through April 2016 
(not shown), with January and February 2016 recording their second and third highest PNA values (since 1950), respectively. Consequently, abnormally dry and warm conditions prevailed over western Canada, with the 12-month mean standardized precipitation evapotranspiration index (Vicente-Serrano et al. 2010) for June 2015 through April 2016 being the third lowest since 1950 (not shown). Consequently, by the beginning of May 2016 conditions were ripe for extreme wildfires (Figs. SB7.Ia,b). To exacerbate an already serious situation, the ignition of the fire on I May coincided with exceptionally warm and dry conditions, which deteriorated further in the following days. Specifically, record high temperatures on 3 and 4 May (maximum temperatures between $32^{\circ} \mathrm{C}$ and $33^{\circ} \mathrm{C}$ ) were accompanied by exceptionally low hourly relative humidities near 10\% at Fort McMurray. Additionally, persistently strong winds (with gusts to near $72 \mathrm{~km} \mathrm{~h}^{-1}$ ), mixed down to the surface by daytime heating and the passage of an upper front, were another key feature of this event. Collectively, these conditions caused the fire to undergo a dramatic increase in size and intensity as it approached Fort McMurray on 3 May.

The Fort McMurray wildfire was located in a region of the boreal forest that is characterized by large swaths of upland and lowland forests comprised of aspen, spruce, and pine. At the time of the fire, the green-up of vegetation, ground, shrubs, and trees had not begun, and this resulted in plenty of dry fuel being available on the forest floor. This, together with the hot and dry weather leading up to the fire, led to an extreme fire danger rating. The moisture content of the fine fuels on the forest floor was only $5 \%-6 \%$, which is the driest level since records began in 1953 for this area. These extreme weather and fuel conditions meant that any fire would be extremely difficult to manage.

The wildfire generated high concentrations of pollutants that produced a significant health risk to the residents of Fort McMurray through most of May. Observations of fine particulate matter ( $\mathrm{PM}_{2.5}$; smaller than $2.5 \mu \mathrm{m}$ in diameter) by air quality monitoring sites in Fort McMurray exceeded provincial hourly air quality guidelines of $80 \mu \mathrm{m} \mathrm{m}^{-3} \mathrm{~h}^{-1}$, reaching as high as $1000 \mu \mathrm{g} \mathrm{m}^{-3} \mathrm{~h}^{-1}$, and carbon monoxide and ozone levels also exceeded provincial air quality guidelines. By the evening of I May Alberta Health Services had issued an Air Quality Advisory, and Environment and Climate Change Canada had issued a Special Air Quality Statement for the Fort McMurray region warning about the health impacts of smoke from the wildfire.
Pulses of pyrocumulonimbus (pyroCb) clouds associated with the fire were observed on several occasions during 3-18 May, and a significant pyroCb on 4 May (Fig. SB7.2) produced significant lightning activity. The passage of a weak cold front on 4 May destabilized the atmosphere at midlevels, which combined with abundant heat and moisture from the burning vegetation, created conditions favorable for the development of the pyroCb. Later in the day on 4 May, a $54 \mathrm{~km} \mathrm{~h}^{-1}$ low-level jet at $850 \mathrm{hPa}$ permitted the supply of abundant oxygen-rich air to fuel the fire, and this, in combination with unstable atmospheric conditions, helped sustain the pyroCb. An initial radar-detectable echo formed about $20 \mathrm{~km}$ east of Fort McMurray at 2150 UTC 4 May, and reached a maximum vertical extent near $12 \mathrm{~km}$ at 2230 UTC 4 May before dissipating several hours later. Lightning activity associated with this pyro $\mathrm{Cb}$ was sporadic until 0010 UTC 5 May, but in the following hour 26 cloud-to-ground lightning flashes were detected by the Canadian Lightning Detection Network. Provincial fire officials subsequently identified four new fire ignitions in the vicinity of a cluster of flashes. PyroCbs have been observed to produce lightning over many wildfires around the world (Rosenfeld et al. 2007; Cruz et al. 2012; Peterson et al. 2015), but to our knowledge, this is the first reported case of a pyroCb igniting more fires.

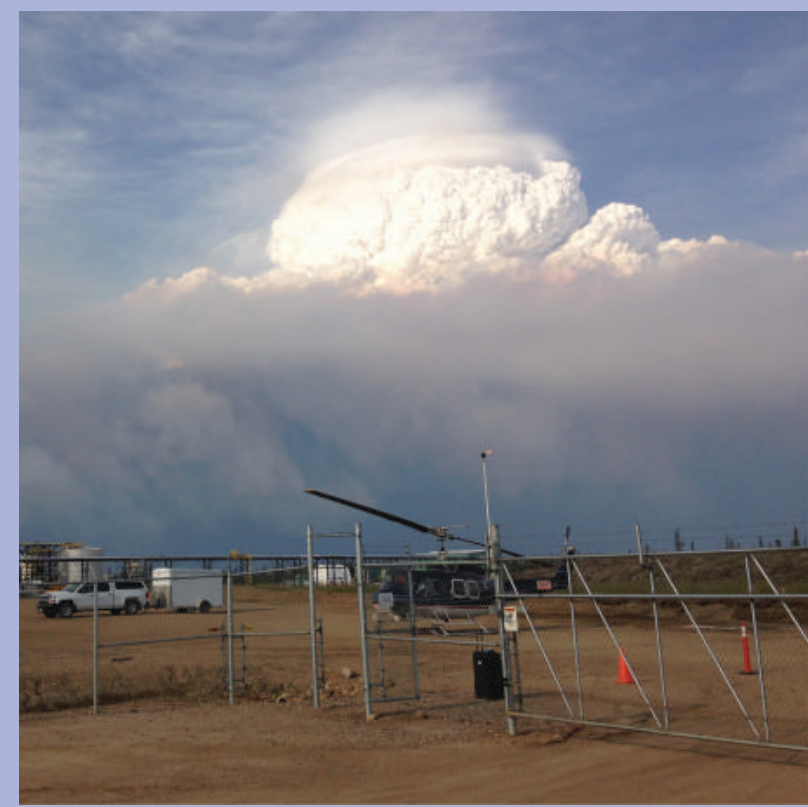

FIG. SB7.2. Photograph of pyro Cb taken (looking north) about $30 \mathrm{~km}$ south of Fort McMurray on the evening of 4 May 2016. (Photograph courtesy of Alberta Agriculture and Forestry.) 
occurred in December. Above-average temperatures spanned the nation with record warmth observed in the Northeast. The CONUS spring (March-May) temperature was $1.0^{\circ} \mathrm{C}$ above average, its sixth warmest spring on record, with April experiencing record warmth. Every state had an above-average (top 33rd percentile) spring temperature, with much-aboveaverage (top 10th percentile) temperatures along the U.S.-Canadian border and the East Coast. The summer (June-August) CONUS temperature was $0.9^{\circ} \mathrm{C}$ above average, its sixth warmest summer on record, with June record warm. Every state had an aboveaverage summer temperature with much-above average temperatures in the Southwest and along the East Coast. California and Connecticut experienced record warmth for the season. The autumn (September-November) temperature was $2.0^{\circ} \mathrm{C}$ above average, the warmest autumn on record for the CONUS. Every state had an above-average autumn temperature, with record and near-record warmth from the Rockies to the East Coast. Six states in the central CONUS had record high temperatures. December was relatively cool compared to the rest of 2016 with a CONUS temperature $0.2^{\circ} \mathrm{C}$ below average. Below-average December temperatures were observed across the Northwest and Central-to-Northern Plains with above-average temperatures in the South and East.

\section{(ii) Precipitation}

Locations across the West, Great Plains, Midwest, and coastal Mid-Atlantic were wetter than average in 2016, while areas of the Southeast and Northeast were drier than average (Fig. 7.4b). Five states had annual precipitation totals that ranked above the 90th percentile while four states ranked below the 10th percentile. California, which had been plagued by drought for several years, had its first wetter-thanaverage year since 2012 with the percent area of the state experiencing drought shrinking nearly $30 \%$. Other areas of the West also experienced significant drought relief during 2016. Drought conditions developed across the Southeast and Northeast in late spring and peaked in late autumn. At the beginning of 2016, the CONUS moderate-to-exceptional drought footprint was $18.4 \%$; it reached its maximum in November at $31.5 \%$ and ended the year with $22.5 \%$ of the CONUS in drought.

The CONUS winter precipitation was $119 \%$ of average, its wettest winter since 1997/98 and 11th wettest on record. El Niño-fueled storms, particularly early in the season, boosted mountain snowpack and improved drought across the West after several years of precipitation-starved wet seasons. Above-average winter precipitation was also observed in the Midwest and East with Iowa having record high precipitation. Spring 2016 was the 17th wettest for the CONUS, with $112 \%$ of average precipitation. Above-average precipitation was observed across the Great Plains and West, helping to further improve drought conditions. Parts of the Southeast and Northeast were drier than average with drought conditions developing. Summer precipitation for the CONUS was $105 \%$ of average, its 24th wettest on record. Above-average precipitation fell across the Midwest and Lower Mississippi Valley where significant flooding events were observed. Below-average precipitation fell across the West, Southeast, and Northeast. For autumn, the CONUS precipitation total was $92 \%$ of average, ranking near the median value. Above-average precipitation was observed across the Northern Plains and West, where Washington State had record high precipitation. Above-average precipitation was also observed along the Southeast coast where Hurricane Matthew dropped torrential rainfall in early October. Below-average autumn precipitation was observed across parts of the Southwest and most of the interior Southeast. December was slightly wetter than average for the CONUS with above-average precipitation across the Rockies and Northern Plains.

\section{(iii) Notable events and impacts}

There were 15 weather and climate events with losses (insured and uninsured) exceeding $\$ 1$ billion (U.S. dollars) each across the United States (Fig. 7.5) in 2016, including drought, wildfire, four inland flood events, eight severe storm events, and a tropical cyclone event (Hurricane Matthew). The 2016 total was the second highest annual number of U.S. billiondollar disasters (adjusted for inflation) since records began in 1980, behind the 16 events that occurred in 2011. Cumulatively, these 15 events led to 138 fatalities and caused $\$ 46.0$ billion (U.S. dollars) in total, direct costs. The four billion-dollar non-tropical inland flood events during 2016 doubled the previous record, as no more than two such costly inland flood events have occurred in a single year since at least 1980.

Tornado activity during 2016 was below average for the fifth consecutive year with 971 tornadoes confirmed, compared to the 1991-2010 annual average of approximately 1250 . There were 17 tornado-related fatalities, far below the 30 -year average of 110 , marking the lowest number of tornado-related fatalities since 1986 when there were 15 .

Wildfires burned over 2.2 million hectares across the United States during 2016, which is below the 2000-10 average of 2.7 million hectares. Despite the 


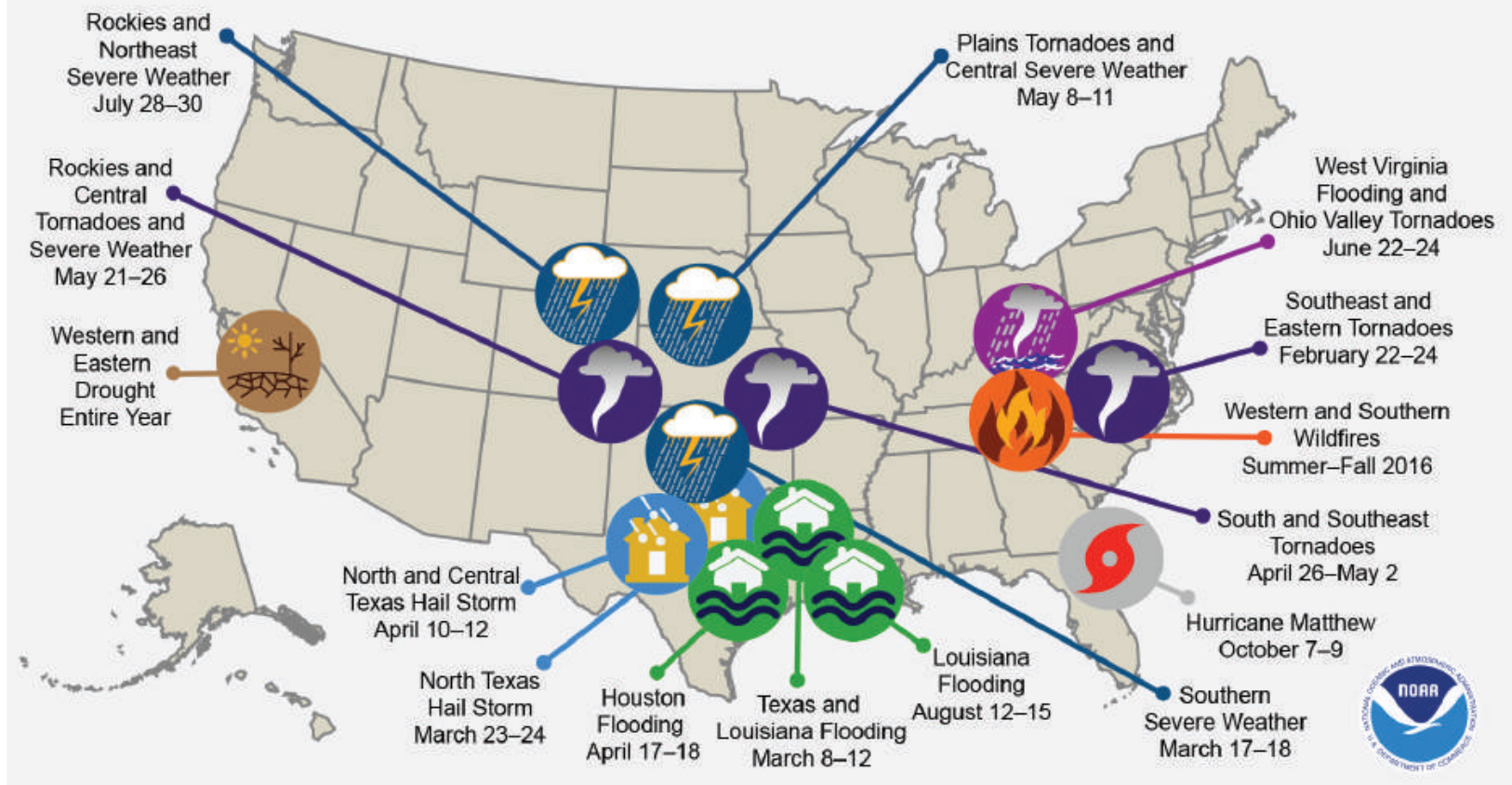

FIG. 7.5. Map depicting date, approximate location, and type of the 15 weather and climate disasters in the United States in 2016 with losses exceeding \$I billion U.S. dollars. (Source: NOAA/NCEI; www.ncdc.noaa .gov/billions/mapping.)

below-average wildfire activity nationally, several devastating wildfires impacted the nation, including fires in California and Tennessee. In December, a firestorm (wildfire with high winds) impacted Gatlinburg, Tennessee, destroying 2500 structures and causing 14 fatalities, raising the national wildfirefatality total to 21 for the year.

\section{3) Mexico-R. Pascual Ramírez}

For most of 2016, monthly temperatures were among their six warmest since records began in 1971, with July, October, and December setting new monthly records. Drier-than-average conditions dominated throughout much of the year. February and October were the driest months, with each receiving $50 \%$ of their monthly average precipitation. Overall, it was the warmest and 15th driest year since records began in 1971.

\section{(i) Temperature}

The 2016 mean temperature for Mexico was $22.4^{\circ} \mathrm{C}$, which is $1.5^{\circ} \mathrm{C}$ above the $1981-2010$ average, marking the warmest year in the 46 -year record and the 13th consecutive year with an above-average annual temperature. The 2016 temperature exceeded the previous record of 2014 and 2015 by $+0.4^{\circ} \mathrm{C}$ (Fig. 7.6). The country experienced above-average temperatures throughout most of the year, with the exception of January when the national average temperature was $0.7^{\circ} \mathrm{C}$ below average (sixth coldest January on record). The highest 2016 monthly anomaly was observed in July when the national temperature was $3.2^{\circ} \mathrm{C}$ above average-the warmest July since 1971. The July 2016 national temperature was also the highest all-time monthly temperature $\left(26.8^{\circ} \mathrm{C}\right)$ on record for Mexico. The national daily maximum, minimum, and mean temperatures were each close to two standard deviations above average during the month (Fig. 7.7). The large positive temperature departure contributed

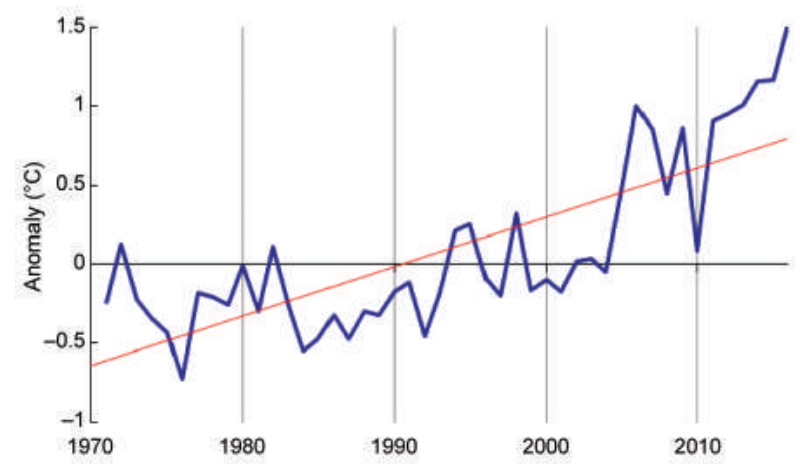

FIG. 7.6. Annual mean temperature anomalies $\left({ }^{\circ} \mathrm{C}\right.$, blue line; 1981-2010 base period) for Mexico. Red line represents the linear trend over this period. (Source: Meteorological Service of México.) 
to the warmest summer (June-August) on record, surpassing the previous record set in 2013 by $+0.1^{\circ} \mathrm{C}$.

Regionally, temperatures in 2016 were above average across most of the country (Fig. 7.8a), although some areas in the north and central regions expe-

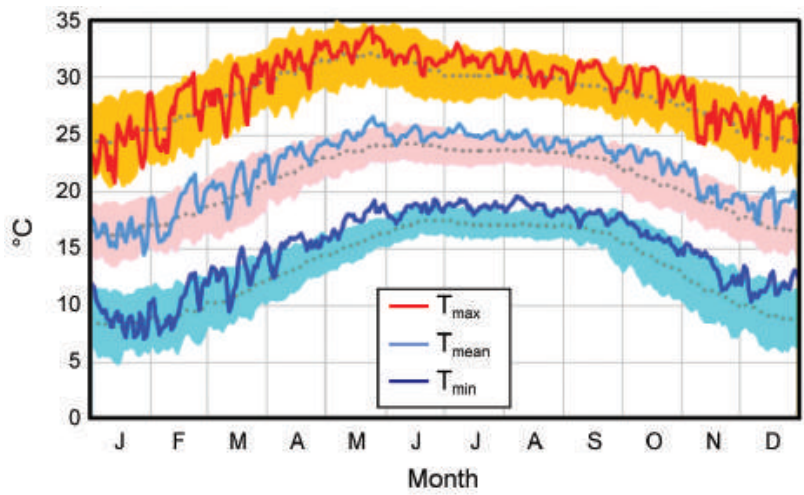

Fig. 7.7. Nationwide daily temperatures $\left({ }^{\circ} \mathrm{C} ; 198 \mathrm{I}-2010\right.$ base period) for Mexico in 2016. Shaded areas represents the \pm 2 std. dev. Solid lines represents daily values for the three temperature parameters and dotted lines are the climatology. (Source: National Meteorological Service of México.)

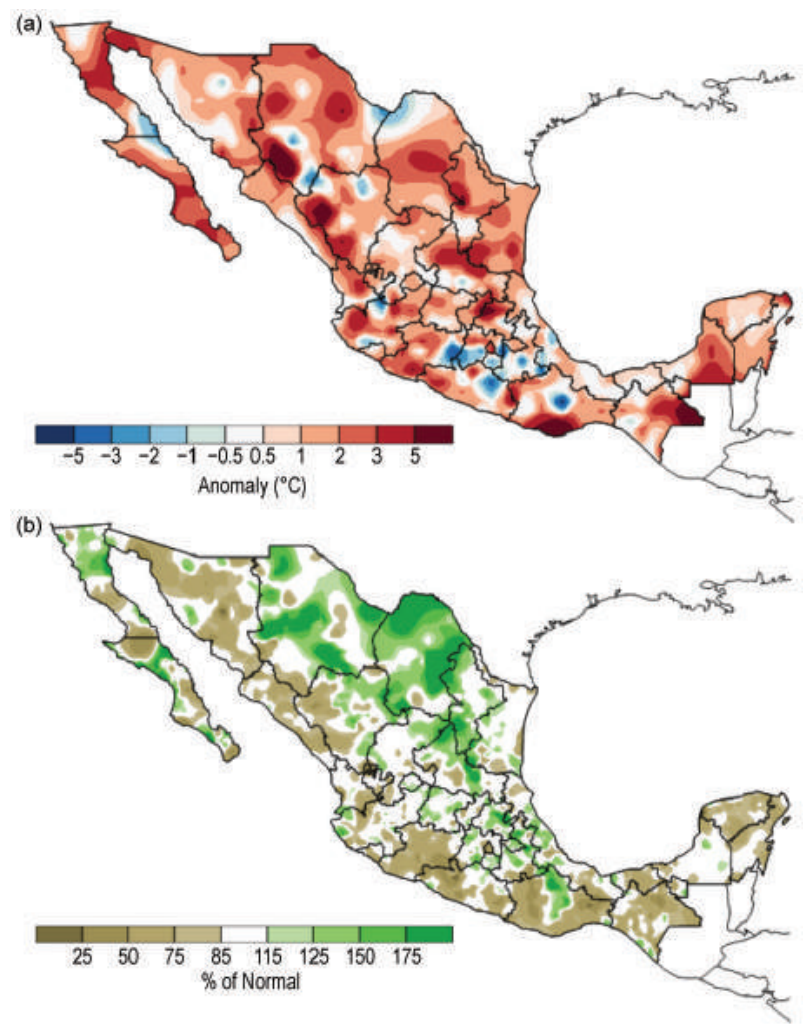

Fig. 7.8. (a) 2016 mean temperature anomalies $\left({ }^{\circ} \mathrm{C}\right.$; 1981-2010 base period) over Mexico and (b) 2016 precipitation anomalies (\% of normal). (Source: National Meteorological Service of México.) rienced cooler-than-average conditions. Twelve of 31 states had their warmest year on record: Sinaloa, Durango, Nuevo Leon, and Tamaulipas (northern Mexico); Aguascalientes, Colima, Hidalgo, Jalisco, Queretaro, and Tlaxcala (central Mexico); and Campeche and Chiapas (southern Mexico).

\section{(ii) Precipitation}

Above-average rainfall was observed in northern, northeastern, and central regions in 2016, while below-average precipitation was evident across the Pacific coast, the south, and southeast (Fig. 7.8b). The 2016 average rainfall total of $744.1 \mathrm{~mm} \mathrm{(94.7 \%}$ of normal) was the 15th driest since records began in 1971. Regionally, states in the south and southeast had exceptionally low precipitation totals, with Oaxaca and Tabasco (both in southern Mexico) each experiencing their third driest year on record. In contrast, Coahuila (northern Mexico) had its third wettest year, behind 2004 and 2010.

August was the wettest month of the year. Hurricane Earl and Tropical Storm Javier brought significant precipitation to the country in early August. Mexico's precipitation total in August 2016 ranked as the sixth wettest in the national records since 1971.

\section{(iii) Notable events and impacts}

Eleven tropical cyclones affected Mexico in 2016, which is four less than the 1971-2012 average of 15. Three tropical cyclones were near land or made landfall from the Caribbean or Atlantic basin (average for this basin is five tropical cyclones). Tropical Storm Danielle and Hurricane Earl made landfall on 5-7 June and 2-6 August, respectively. Tropical Storm Colin formed north of the Yucatan Peninsula and tracked toward the southeast United States in early August. Eight cyclones were near land or made landfall from the Eastern North Pacific basin (average for this basin is 10). This value is lower than the number of storms that impacted the nation from the same basin during 2014 and 2015, when there were 14 and 9 systems, respectively. The low number of Eastern North Pacific storms contributed to the below-average precipitation on the Pacific side of the country in 2016.

\section{c. Central America and the Caribbean}

I) Central America-J. A. Amador, H. G. Hidalgo, E. J. Alfaro, A. M. Durán-Quesada, B. Calderón, N. Mora, and D. Arce

For this region, nine stations from five countries were analyzed (Fig. 7.9). Stations on the Caribbean slope are: Philip Goldson International Airport, 


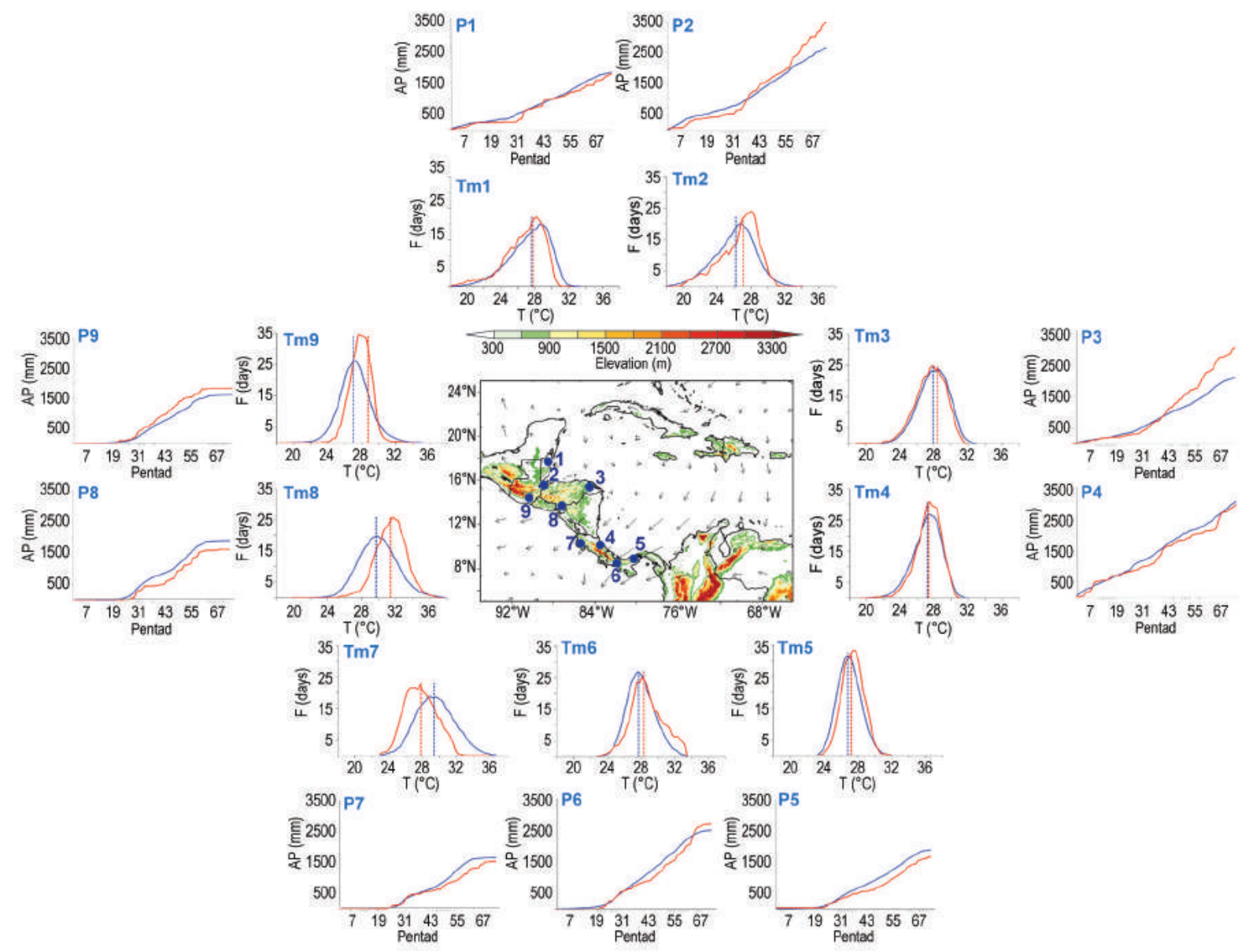

Fig. 7.9. Mean surface temperature $\left(\mathrm{Tm} ;{ }^{\circ} \mathrm{C}\right)$ frequency (F; days) and accumulated pentad precipitation (AP; $\mathrm{mm}$ ) time series are shown for nine stations (blue dots) in Central America: (I) Philip Goldson International Airport, Belize; (2) Puerto Barrios, Guatemala; (3) Puerto Lempira, Honduras; (4) Puerto Limón, Costa Rica; (5) Tocumen International Airport, Panama; (6) David, Panama; (7) Liberia, Costa Rica; (8) Choluteca, Honduras; and (9) Puerto San José, Guatemala. The blue solid line represents the $198 \mathrm{I}-2010$ average values and the red solid line shows 2016 values. Vertical dashed lines show the mean temperature for 2016 (red) and the 198I-2010 period (blue). Vectors indicate July wind anomalies at $925 \mathrm{hPa}$ (198I-2010 base period). Shading depicts regional elevation (m). (Data sources: NOAA/NCEI and Central American NWS.)

Belize; Puerto Barrios, Guatemala; Puerto Lempira, Honduras; and Puerto Limón, Costa Rica. Stations located on the Pacific slope are: Tocumen International Airport and David, Panama; Liberia, Costa Rica; Choluteca, Honduras; and Puerto San José, Guatemala. Precipitation and temperature records for the stations analyzed were provided by Central American National Weather Services (NWS). Anomalies are reported using a 1981-2010 base period and were calculated using NWS data. The methodologies used for all variables can be found in Amador et al. (2011).

\section{(i) Temperature}

With the exception of Belize, the mean temperature (Tm) frequency distributions (Fig. 7.9) for the climatology and for 2016 are significantly different from each other at the 95\% confidence level, accord- ing to a two-sample Kolmogorov-Smirnov goodnessof-fit hypothesis test (Wilks 2011). Anomalously high mean temperatures were observed for most of the stations analyzed, with the largest positive anomalies in Puerto Barrios (Tm2), Choluteca (Tm8), and San José (Tm9). For most stations, the 2016 higherthan-average means were the result of more frequent warm (but not extreme) days.

\section{(ii) Precipitation}

The accumulated pentad precipitation $(\mathrm{P} ; \mathrm{mm})$ time series are shown for the nine stations in Central America in Fig. 7.9. David (P6) and San José (P9) on the Pacific slope, and Puerto Barrios (P2) and Puerto Lempira (P3) on the Caribbean slope recorded above-average precipitation accumulations for 2016. Puerto Lempira had extremely high accumulations 
(at the 95\% confidence level) at the end of the year that were due to large rainfall contributions after pentad 40 (approximately late September). Frequent rains after pentad 40 helped Puerto Barrios end the year with a large positive anomaly. Conversely, Tocumen (P5), Liberia (P7), and Choluteca (P8) in the Pacific, and Belize (P1) and Limón (P4) in the Caribbean experienced below-average accumulations. The year 2016 marked the fourth consecutive year of drought conditions in Liberia. Of all stations analyzed, Tocumen experienced the most severe drought conditions in 2016.

Low-level moisture transport (computed based on ERA-Interim reanalysis data) followed climatology as the 2016 ENSO signal decreased its intensity, with dry conditions until the transition to the first part of the rainy season (May-June). Moisture flux divergence showed a mild second part of the rainy season (September-November), which started about three weeks late. Low-level circulations in the region showed a stronger-than-average Caribbean low-level jet (Amador 1998) 925-hPa winds during July (vectors in Fig. 7.9), consistent with positive multivariate ENSO index values during that period (Amador et al. 2006).

\section{(iii) Notable events and impacts}

Three tropical cyclones affected Central America in 2016, all from the Caribbean Basin. Hurricane Earl made landfall in Belize on 4 August and crossed the isthmus through Guatemala the same day. More than
9000 people were affected by heavy rain and floods in these two countries. Hurricane Matthew was present in the Caribbean Sea from 28 September to 6 October, reaching category 5 intensity by 1 October, but its main impacts were in the Greater Antilles. Hurricane Otto made landfall between Costa Rica and Nicaragua on 24 November and passed over the isthmus during 24-25 November. In Costa Rica, Hurricane Otto directly impacted the northern cities and indirectly impacted the southern Pacific slope communities. For Panama, Costa Rica, and Nicaragua, the impacts of Otto were severe, affecting nearly 25000 people, with 18 fatalities and more than 2400 damaged homes. For additional information on the impacts from these storms and other hydrometeorological events, please refer to Online Table S7.1.

Hurricane Otto was a remarkable meteorological event, breaking several historical records. Otto was the strongest hurricane on record so late in the year, the latest hurricane on record to be located in the Caribbean Sea, and the only known hurricane to move over Costa Rica (Brown 2017). Also, this was the first time that a significant amount of lightning activity (a known proxy for convection) from a hurricane has been documented in this region. Convection associated with Otto produced abundant lightning activity and precipitation in Nicaragua and Costa Rica with large socioeconomic impacts (Online Table S7.1). The World Wide Lightning Location Network (WWLLN), a real-time network with global coverage, was used to depict Hurricane Otto's lightning activity develop-

\begin{tabular}{|l|l|c|c|c|c|}
\hline \multicolumn{7}{|c|}{ TABLE 7.I. Record annual temperatures $\left({ }^{\circ} \mathrm{C}\right)$ for some Caribbean locations. } \\
\hline Country & \multicolumn{1}{|c|}{$\begin{array}{c}\text { Station } \\
\text { Namel } \\
\text { Location }\end{array}$} & $\begin{array}{c}\text { Year } \\
\text { records } \\
\text { began }\end{array}$ & $\begin{array}{c}\text { Min temp } \\
\left({ }^{\circ} \text { C) }\right.\end{array}$ & $\begin{array}{c}\text { Max temp } \\
\left({ }^{\circ} \text { C) }\right.\end{array}$ & $\begin{array}{c}\text { Mean } \\
\text { temp }\left({ }^{\circ} \text { C) }\right.\end{array}$ \\
\hline Barbados & CIMH & 1971 & 24.2 & - & 27.3 \\
\hline Cayman & METEO & 1976 & 25.3 & - & - \\
\hline Dominica & Canefield & 1982 & - & 31.8 & - \\
\hline Dominica & Douglas & 1982 & - & - & 27.6 \\
\hline Jamaica & Sangstes & 1973 & 24.5 & - & - \\
\hline Jamaica & Worthy Park & 1973 & - & - & 24.9 \\
\hline Puerto Rico & Lajas & 1971 & 20.6 & - & 26.4 \\
\hline Puerto Rico & Aibonito & 1971 & 19 & - & - \\
\hline St. Kitts & Golden Rock & 1998 & - & - & 28 \\
\hline St. Lucia & Hewanorra & 1979 & 25.6 & - & - \\
\hline Trinidad & Piarco & 1946 & - & - & 27.8 \\
\hline Tobago & Crown Point & 1969 & 25.4 & - & 27.9 \\
\hline USVI & St. Thomas & 1953 & 25.5 & - & - \\
\hline
\end{tabular}


ment some hours before the storm made landfall near Costa Rica and Nicaragua. Figure 7.10 reveals a highly asymmetric structure of the lightning distribution along the northern highly convective rainbands. Otto seemed to intensify its lightning activity not only after strengthening to a category 3 hurricane (not shown) but also as it approached land, as has been found in previous studies (e.g., Solorzano et al. 2008). The period shown in Fig. 7.10 corresponds to Hurricane Otto some hours after its intensification phase from a tropical storm to a hurricane on 23 November near 1800 UTC (Brown 2017). Figure 7.10 also shows the western movement of the convective rainbands with respect to Otto's center (yellow triangles) for three different hourly periods. Otto's track was estimated from the National Hurricane Center best track information.

2) Caribbean-T. S. Stephenson, M. A. Taylor, A. R. Trotman, C. J. Van Meerbeeck, A. O. Porter, S. Etienne-LeBlanc, M. Hernández, I. T. Gonzalez, V. Cutié, D. Boudet, C. Fonseca, S. Willie, J. M. Spence, K. Kerr, A. Aaron-Morrison, G. Tamar, R. Stennett-Brown, and J. D. Campbell

\section{(i) Temperature}

Warmer-than-average conditions persisted throughout the Caribbean during 2016 (Fig. 7.11a). This was likely related to the El Niño conditions that lasted through May 2016 and year-long above-average Caribbean sea surface temperatures. A number of station temperature records were observed (Table 7.1). Additionally, the annual mean temperature for Cuba $\left(26.2^{\circ} \mathrm{C}\right)$ was the fourth highest since 1951 . Trinidad's Piarco Airport recorded its second-warmest year $\left(28.4^{\circ} \mathrm{C}\right)$, with its second highest annual mean maxi-

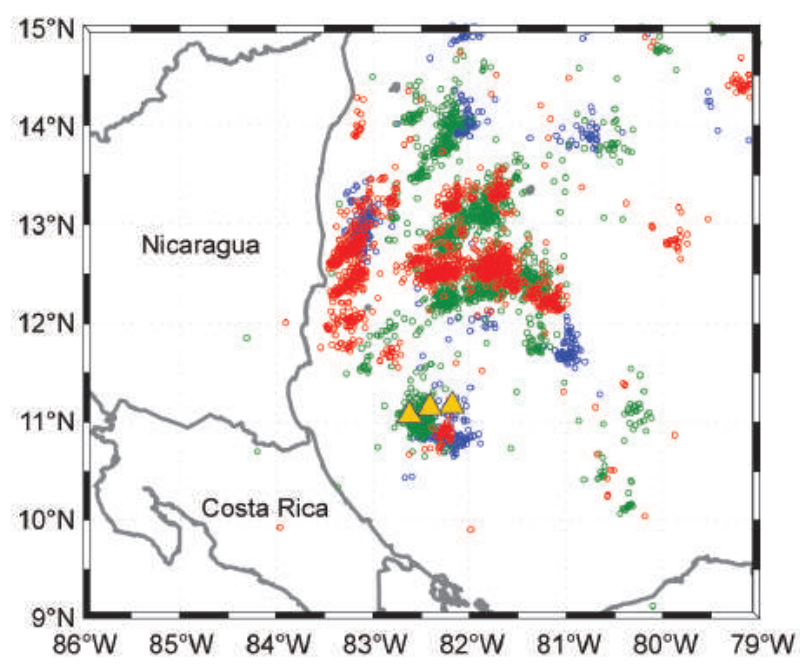

FIG. 7.I0. Lightning activity associated with Hurricane Otto showing the northern rainbands moving westward from 0400 to 0459 UTC (blue open circles), from 0600 to 0659 UTC (green open circles) and from 0800 to 0859 UTC (red open circles). Yellow triangles represent the approximate westward track of Otto at 0400,0600 , and 0800 UTC estimated from the National Hurricane Center best track information. Data is from the WWLLN global data base (http:// webflash.ess.washington.edu/).

mum temperature $\left(31.7^{\circ} \mathrm{C}\right)$ and third highest annual mean minimum temperature $\left(23.1^{\circ} \mathrm{C}\right)$ since records began in 1946 . Monthly mean maximum temperatures were record high for July $\left(33.4^{\circ} \mathrm{C}\right)$ and October $\left(34.3^{\circ} \mathrm{C}\right)$. Similarly, daily extreme temperature records included the highest daily maximum temperature for April $\left(36.3^{\circ} \mathrm{C}\right)$ and October $\left(36.2^{\circ} \mathrm{C}\right)$. Other notable Trinidadian records include March's second highest daily maximum temperature $\left(35.5^{\circ} \mathrm{C}\right)$ on 12 March, behind 1 March $2010\left(35.7^{\circ} \mathrm{C}\right)$, and July's second
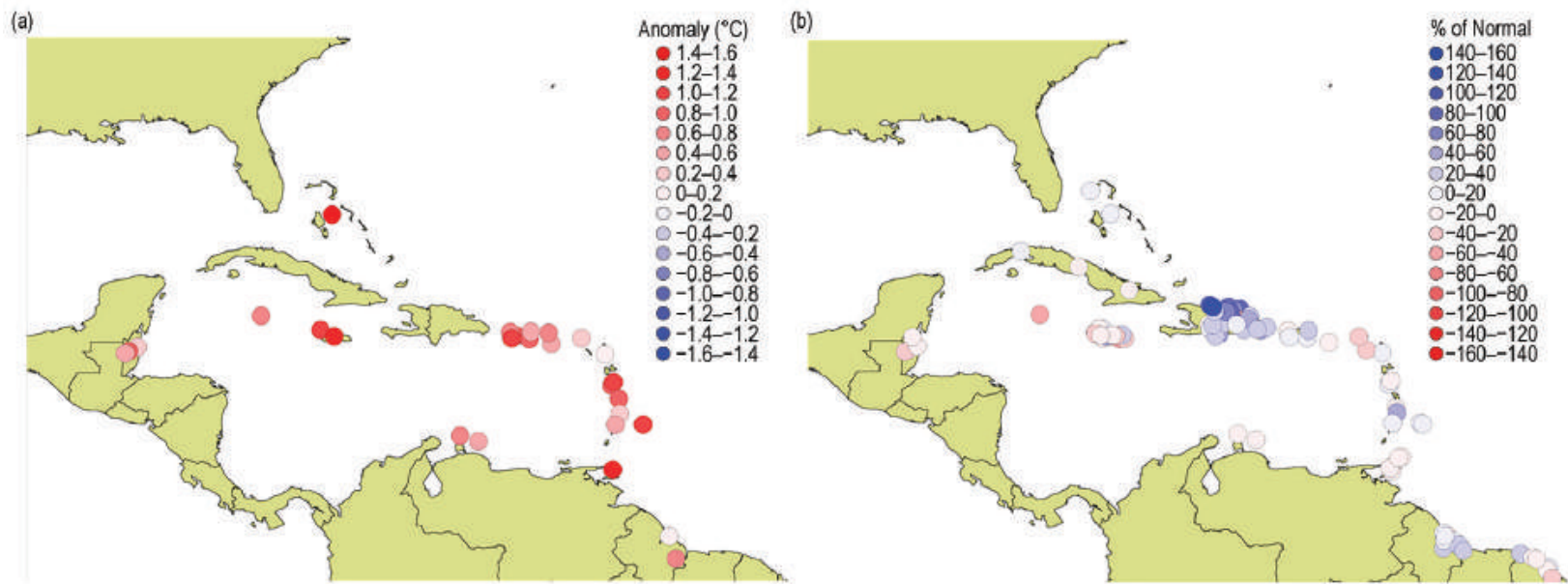

Fig. 7.II. (a) Temperature anomalies $\left({ }^{\circ} \mathrm{C}\right)$ and (b) precipitation anomalies (\%) rainfall for 2016 across the Caribbean basin with respect to the 198I-2010 annual mean. (Source: Caribbean Institute for Meteorology and Hydrology.) 
highest daily maximum temperature $\left(35.0^{\circ} \mathrm{C}\right)$ on 30 July, behind 29 July $1999\left(35.1^{\circ} \mathrm{C}\right)$. A September record daily maximum temperature of $33.5^{\circ} \mathrm{C}$ was observed for Hewanorra Airport, Saint Lucia, on 23 September. A summary of select seasonal temperature records observed for a number of Caribbean stations is shown in Online Table S7.2.

\section{(ii) Precipitation}

In 2016 the Caribbean experienced a mix of wet and dry conditions (Fig. 7.11b). Trinidad had predominantly normal precipitation totals, but with slight to moderately dry conditions ${ }^{1}$ in the west. Dry conditions were also observed for Tobago (moderately to extremely), St. Kitts (moderately), St. Maarten (very), and Grand Cayman (exceptionally). In contrast, Grenada, Antigua, Anguilla, Aruba, and Curacao had near-normal precipitation. Barbados, Dominica, and St. Vincent were normal to moderately wet. St. Lucia and the Dominican Republic were normal to exceptionally wet. Jamaica had near-normal conditions, but with slight to moderately dry conditions in

${ }^{1}$ The wet and dry categories are based on categories of the Standardized Precipitation Index used by the Caribbean Drought and Precipitation Monitoring Network at the CIMH, http://rcc.cimh.edu.bb/climate-monitoring /spi-monitor/. western and eastern extremities. Cuba experienced below-normal rainfall, particularly in central areas.

The 2016 rainfall totals were the second highest annual totals for Hewanorra Airport (2222.5 mm) and 13th highest for GFL Charles $(2129.0 \mathrm{~mm})$ in St. Lucia since records began in 1967. Record-high annual rainfall was also observed for some stations in Dominican Republic, including Carbrera (2832.4 mm), La Union (3008.9 mm), Monte Cristi (1483.8 mm), Salcedo $(2902.1 \mathrm{~mm})$, and Villa Vaquez $(1777.9 \mathrm{~mm})$.

For January-March, normal to below-normal rainfall was observed in the eastern Caribbean. Trinidad, Aruba, Curacao, and Grenada were extremely or severely dry, while St. Vincent and Antigua were moderately dry. Tobago, St. Lucia, St. Kitts, Anguilla, and St. Maarten experienced normal conditions. Barbados and St. Croix were slightly dry and Dominica moderately wet. Normal to above-normal rainfall was apparent in northern territories. Although some southern parts of Puerto Rico were slightly wet, rainfall on the island was predominantly normal. Conditions in the Dominican Republic ranged from very wet in western areas to normal in the south, east, and north. Jamaica and Grand Cayman were normal, while western Cuba was exceptionally wet with the rest of the country experiencing normal conditions.

TABLE 7.2. Record seasonal rainfall $(\mathrm{mm})$ records in the Caribbean in 2016.

\begin{tabular}{|c|c|c|c|c|c|c|}
\hline Country & Stations/ & Year records & \multicolumn{4}{|c|}{ Rainfall } \\
\hline & & & JFM & AMJ & JJA & OND \\
\hline Barbados & $\mathrm{CIMH}$ & 1971 & - & - & - & - \\
\hline Barbados & GAIA & 1979 & - & - & - & $687.3(\mathrm{H})$ \\
\hline Cuba & West & 1971 & - & - & - & $119(\mathrm{~L})$ \\
\hline Dominican Republic & Byagna & 1971 & - & - & - & $656.4(\mathrm{H})$ \\
\hline Dominican Republic & Cabrera & 197| & - & - & - & I444.6(H) \\
\hline Dominican Republic & Gasparh & 197| & - & - & - & I834.I (H) \\
\hline Dominican Republic & La Union & 1971 & - & - & - & $1703.5(\mathrm{H})$ \\
\hline Dominican Republic & Lvega & 1971 & - & - & - & $906.4(\mathrm{H})$ \\
\hline Dominican Republic & Moca & 197| & - & - & - & $1102.6(\mathrm{H})$ \\
\hline Dominican Republic & Monte Cristi & 1971 & - & - & - & $836.6(\mathrm{H})$ \\
\hline Dominican Republic & Salcedo & 1971 & 一 & 一 & 一 & $1410.2(\mathrm{H})$ \\
\hline Dominican Republic & Santiago & $197 \mid$ & 一 & - & - & $917.5(\mathrm{H})$ \\
\hline Dominican Republic & SBLMAR & 197| & - & - & - & I538.3 (H) \\
\hline Dominican Republic & VIVASQ & 1971 & - & $445.6(\mathrm{H})$ & $640.0(\mathrm{H})$ & - \\
\hline French Guiana & Regina & 1971 & 一 & 一 & $674.6(\mathrm{H})$ & 一 \\
\hline Jamaica & Sutton & 197| & - & $1435.5(\mathrm{H})$ & - & - \\
\hline Trinidad & Hillsborough & 197| & - & - & $352.3(\mathrm{~L})$ & - \\
\hline
\end{tabular}


During the second quarter (April-June), the Windward Islands experienced normal to abovenormal conditions, while mixed conditions were observed for the Leeward Islands. Specifically, Trinidad, Tobago, Barbados, St. Vincent, Dominica, Antigua, Anguilla, and St. Croix were normal. Wet conditions characterized Grenada (slightly) and St. Lucia (moderately), while St. Kitts and St. Maarten were moderately dry. Aruba and Curacao were extremely to severely dry. Puerto Rico ranged from normal conditions in the west to moderately wet in the northeast. The Dominican Republic had normal precipitation. Conditions in Jamaica ranged from normal in the south to moderately dry in the north; but Grand Cayman was severely dry. Cuba was normal to moderately wet while the central region was dry.

For July-September, mixed conditions continued. Although Trinidad was slight to moderately dry, Tobago was extremely dry, and St. Lucia, Dominica, and St. Maarten were slightly dry; Grenada, Barbados, St. Vincent, and St. Croix experienced normal rainfall amounts. Although slightly dry for the quarter, it was the second wettest September ( $423.0 \mathrm{~mm}$ ) at St. Lucia's Hewanorra Airport. Martinique and Antigua were moderately wet with St. Kitts and St. Thomas slightly wet. Normal rainfall was observed for Puerto Rico, but the Dominican Republic experienced severely dry conditions in the west to slightly wet in the east. Jamaica was predominantly normal, but Grand Cayman was severely dry. Above-normal rainfall was experienced in western Cuba, but below normal for the rest of the country.

For the last three months of the year, conditions in Trinidad were moderately dry in the southwest to moderately wet in the northeast. While Tobago, Grenada, Antigua, and St. Maarten experienced normal rainfall, Barbados was very wet; St. Vincent was extremely to exceptionally wet; St. Kitts moderately dry; and Anguilla slightly wet. Aruba was normal, but Curacao slightly wet. Conditions in the Dominican Republic ranged from very to exceptionally wet. Jamaica had predominantly normal conditions, with the exception of the extreme south that was slightly to moderately wet, and the extreme west that was slightly to moderately dry. Grand Cayman was extremely dry. Cuba was predominantly normal to below normal. It was the third wettest November $(445.1 \mathrm{~mm})$ at St. Lucia's Hewanorra Airport. Puerto Rico's San Juan International Airport had its wettest November on record $(448.3 \mathrm{~mm})$. Table 7.2 shows selected record quarterly rainfall totals for the Caribbean.

\section{(iii) Notable events and impacts}

Very hot conditions, with a considerable number of consecutive dry days, during the January-May dry season enhanced bushfire potential in Trinidad. The most costly bushfires claimed three lives and destroyed three residential dwellings and other structures.

The wettest day in any July on record was observed at Piarco (Trinidad) on the 14th, with $100.7 \mathrm{~mm}$ (4 inches) of rain in 24 hours, causing significant flooding in eastern Trinidad. This was also the second highest 24 -hour precipitation total in 14 years for all months.

During late September into early October, Hurricane Matthew affected parts of the Caribbean, including Barbados, St. Lucia, Cuba, the Dominican Republic, and Haiti. Matthew brought large rainfall accumulations to parts of the Dominican Republic, with more than $260 \mathrm{~mm}$ in some locations and triggering floods across much of the nation. The storm caused Haiti's largest humanitarian emergency since the 2010 earthquake, triggering severe floods and mudslides, damaging roads and buildings, and causing power and water shortages. Over two million people were affected and more than 540 fatalities were reported for the country. In eastern Cuba approximately $\$ 2.5$ billion U.S. dollars in damages were incurred.

\section{d. South America}

During the first half of 2016, sea surface temperatures (SSTs) along the equatorial Pacific Ocean were higher than usual, as the strong El Niño weakened and dissipated. From June the equatorial Pacific Ocean temperature showed a slight cooling, with the exception of an area near the western coast of South America, where SSTs remained slightly above normal during the second half of 2016 (Fig. 7.12).

The 2016 annual temperature was predominantly above normal in most of South America, with anomalies as high as $+1^{\circ} \mathrm{C}$. However, cooler-than-average conditions were observed across southeastern Bolivia, Paraguay, southeastern Brazil, Uruguay, and central and northern Argentina (Fig. 7.13a).

During 2016, wetter-than-normal conditions predominated over northern and central Venezuela, northern Peru, northern Chile, southwestern Brazil, Paraguay, Uruguay, and Argentina. The largest positive anomalies were observed in central Argentina, where annual precipitation totals were $200 \%$ of average. Drier-than-normal conditions were persistent in Colombia, Amazonia, northeastern Brazil, along the coast of Peru, and Bolivia. Southern Argentina and 


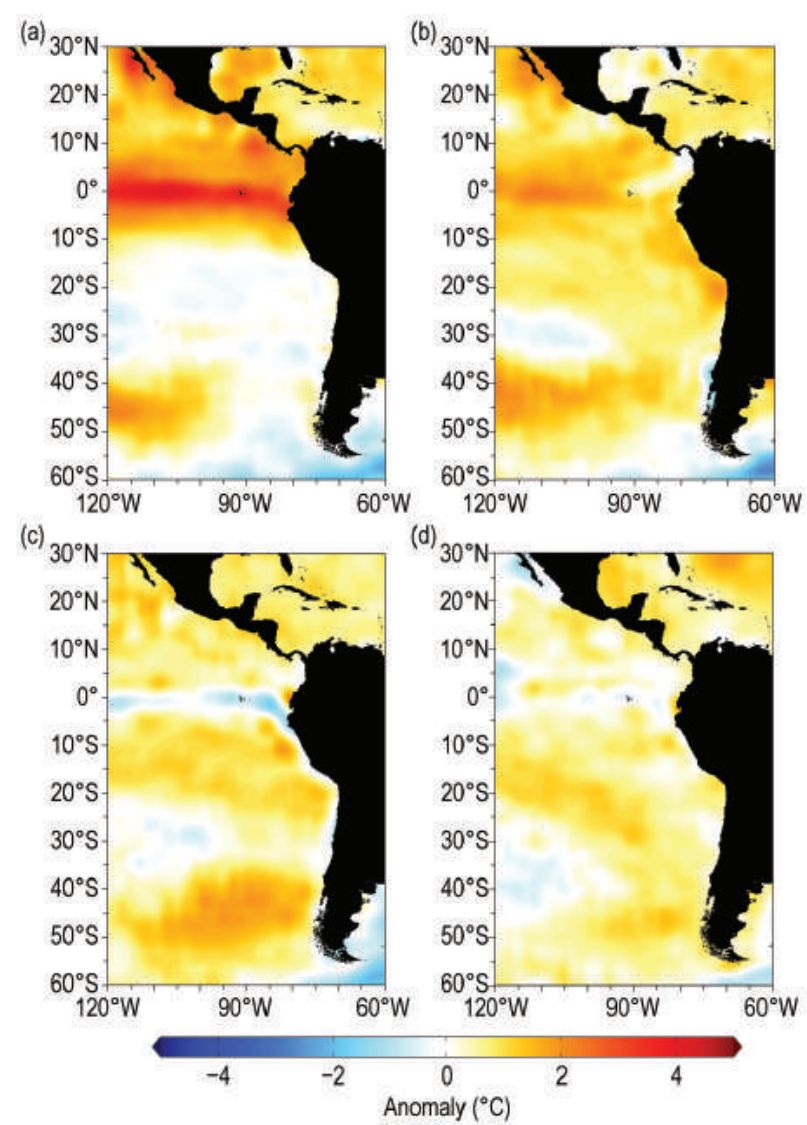

FIG. 7.I2. Sea surface temperature anomalies $\left({ }^{\circ} \mathrm{C}\right)$ for (a) DJF 2015/16, and (b) MAM, (c) JJA, and (d) SON 2016 (base period: 197I-2000). (Source: NOAA/NCEPI EMC/CMB/GLOBAL Reyn_Smith Olv2; processed by CIIFEN.)

southern and extreme northern Chile had the largest deficits, with precipitation totals as low as $60 \%$ of average (Fig. 7.13b).

All anomalies in this section are with respect to the 1981-2010 average, unless otherwise noted.

I) Northern South America-R. Martínez, S. Mitro, A. Alvarez, A. R. Hernández, J. Nieto, and E. Zambrano

The northern South America region includes Ecuador, Colombia, Venezuela, Guyana, Suriname, and French Guiana.

\section{(i) Temperature}

During January-March, Colombia set new maximum temperature records in several locations: Mitú (Amazonia) recorded a mean maximum temperature of $38.6^{\circ} \mathrm{C}$, exceeding the previous January-March record by $4.4^{\circ} \mathrm{C}$; Armero (Andean region) set a mean maximum temperature of $40.8^{\circ} \mathrm{C}$, surpassing the previous record set in 1997 by $1.9^{\circ} \mathrm{C}$; and Valledupar (Caribbean region) had a mean maximum temperature of $40.6^{\circ} \mathrm{C}$, besting the previous record of $38.8^{\circ} \mathrm{C}$
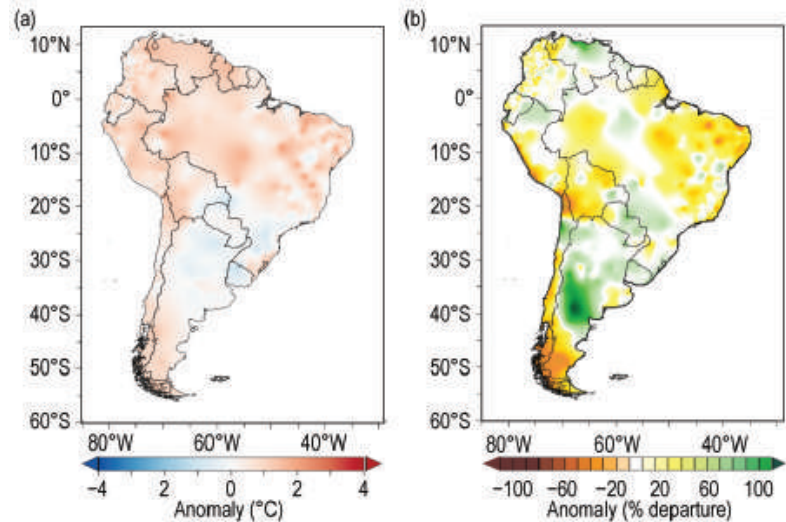

Fig. 7.13. Annual 2016 (a) temperature anomalies $\left({ }^{\circ} \mathrm{C}\right)$ and (b) precipitation anomalies (\%) for South America (base period: 198I-2010). (Sources: Data from II 22 stations provided by National Meteorological Services of Argentina, Brazil, Bolivia, Chile, Colombia, Guyana, Ecuador, Paraguay, Peru, Suriname, Uruguay, and Venezuela. The data were compiled and processed by CIIFEN.)

set in 1997. From May through the end of the year, temperatures were predominantly below normal, with anomalies as low as $-1^{\circ} \mathrm{C}$.

Throughout the year, most of Venezuela experienced above-average temperatures, with the largest monthly positive anomalies observed from January through May (as high as $+3^{\circ} \mathrm{C}$ ). In Ecuador, aboveaverage temperatures persisted throughout the year, with the highest positive temperature anomalies along the Amazonian border with Peru, where seasonal anomalies were as high as $+5^{\circ} \mathrm{C}$ during January-March and October-December. Suriname also had above-average temperatures (anomalies of $+1.0^{\circ}$ to $+2.3^{\circ} \mathrm{C}$ ) during January-March.

\section{(ii) Precipitation}

During January-March, the presence of the strong El Niño in the equatorial Pacific Ocean influenced weather conditions in northern South America. Dry conditions were observed over Guyana, Suriname, and French Guiana. Of note, the river levels in the Caribbean coast of northern South America were the lowest in the last 25 years. In contrast, wetter-than-average conditions were reported over the coastal region of Ecuador, with anomalies for the January-March period ranging between $140 \%$ and $180 \%$ of average.

Precipitation was above normal in April and May across most of northern South America, with anomalies ranging between $150 \%$ and $200 \%$ of average over Ecuador, Venezuela, Guyana, and Suriname. Wetterthan-average conditions persisted over Ecuador and northern Venezuela during June-July. Drier-thanaverage conditions prevailed from August through 
December over northern South America, with the exception of Venezuela. During the last quarter of 2016, Venezuela had significant positive precipitation anomalies in the central region $(173 \%-216 \%$ of average), central Llanos (up to $234 \%$ of average), western Llanos (166\%-186\% of average), and the eastern region (162\%-225\% of average).

\section{2) Central South America一J. A. Marengo, J. C. Espinoza,} L. M. Alves, J. Ronchail, and J. Baez

The central South America region includes Brazil, Peru, Paraguay, and Bolivia. The 2016 climate conditions were characterized by extreme high temperatures and below-average precipitation in the Amazon and Andean regions, while above-average precipitation was observed in northern Peru and northeastern Paraguay.

\section{(i) Temperature}

Temperatures across most of central South America were between $2^{\circ} \mathrm{C}$ and $3^{\circ} \mathrm{C}$ above normal during 2016, with the exception of May and June when cooler-than-average temperatures were observed at the beginning of May and in mid-June. During January-April and July-December, temperatures were $1.5^{\circ}-3^{\circ} \mathrm{C}$ above average in Amazonia and eastern Brazil.

\section{(ii) Precipitation}

With the exception of January 2016, the dry conditions observed in 2015 persisted in eastern Brazil and in Bolivia (see Sidebar 7.2). The Amazon experienced drought conditions that were likely influenced by the strong El Niño episode. Between January and July, the dry conditions contributed to an increase in the number of wildfires, which were more than $740 \%$ of the 1999-2016 average in the state of Amazonas. The drought conditions that started in 2010 in northeastern Brazil persisted in 2016. Figure 7.14 shows the evolution of the water deficit across the semiarid region of northeastern
Brazil from the beginning of the drought though 2016 (Marengo et al. 2017). Southern Bahia and the northern parts of the state of Minas Gerais, over the San Francisco River basin, were the most affected.

In 2016, above-normal precipitation was observed in northeastern Paraguay, particularly notable during December, with rainfall totals $200 \%$ of average. The heavy precipitation raised Paraguay's Asunción River discharge to $4500 \mathrm{~m}^{3} \mathrm{~s}^{-1}$ on 21 December. The mean discharge for December is $2000 \mathrm{~m}^{3} \mathrm{~s}^{-1}$.

\section{(iii) Notable events and impacts}

Several cold air outbreaks impacted the region in 2016. During 27-30 April, most of Paraguay was affected by its most intense cold wave in 57 years, with minimum temperatures dropping to $4.5^{\circ} \mathrm{C}$ in Pedro Juan Caballero and Mariscal Estigarribia, where average temperatures are $17.4^{\circ} \mathrm{C}$ and $18.5^{\circ} \mathrm{C}$, respectively. The same cold front affected Urupema, Brazil, on 28 April, where minimum temperatures were as low as $-3.2^{\circ} \mathrm{C}$. Due to a cold air intrusion on 2 May, São Paulo recorded a minimum temperature of $10.0^{\circ} \mathrm{C}$, the lowest temperature observed during May in 45 years (May average: $13.8^{\circ} \mathrm{C}$ ). During the first half of
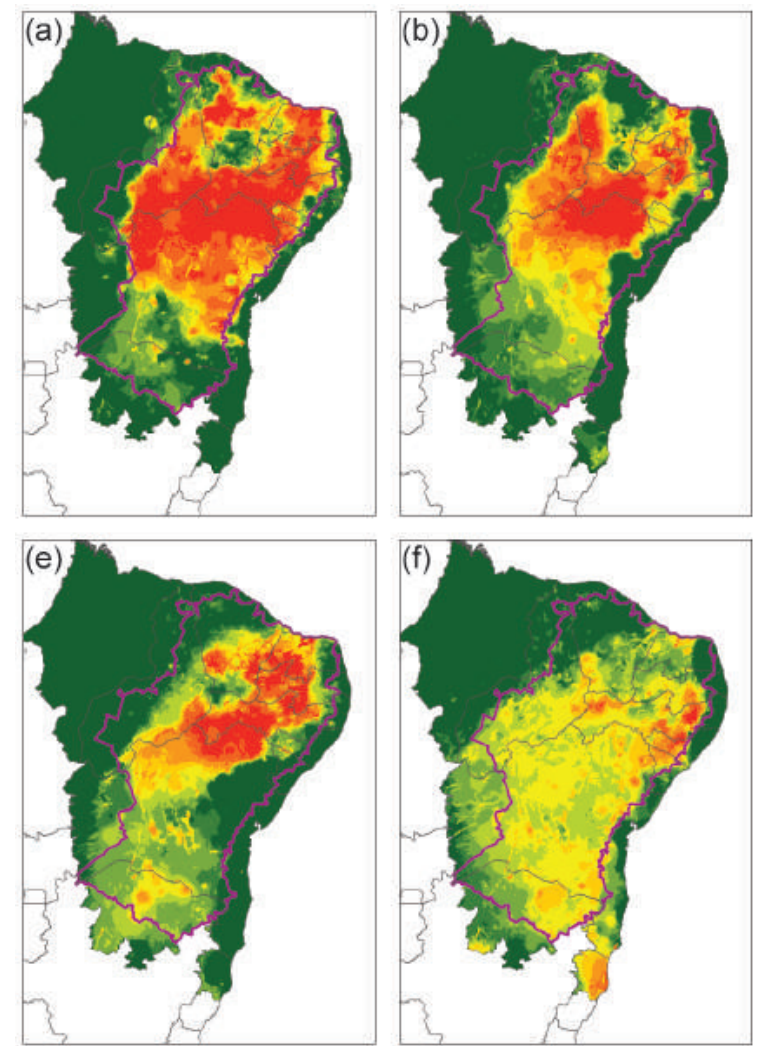

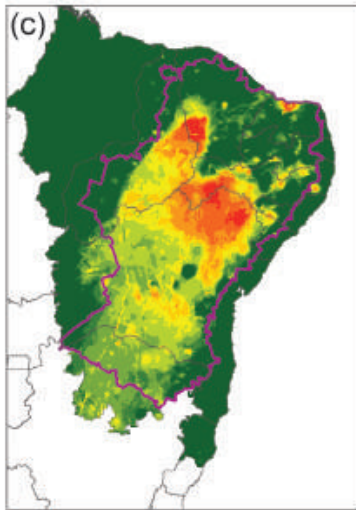

Days with Water Deficit 0-10
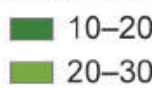

$\square 30-40$

$\square$ 40-50

$\square 50-60$

60-70

- 70-80

- 80-90

Boundary of the Semiarid region

FIG. 7. I4. Maps depicting water deficiency (in days) for Northeast Brazil during its hydrologic year (Oct-Sep): (a) 20II/I2, (b) 2012/13, (c) 2013/14, (d) 2014/15, and (e) 2015/16. Thin purple line represents the boundary of the semiarid region. [Source: Marengo et al. (2017).] 
June, a cold wave brought cooler-than-average conditions (Fig. 7.15) from southern Brazil to western Amazonia. Four people died in the city of São Paulo due to the cold on 13 June, where minimum temperatures were as low as $3.5^{\circ} \mathrm{C}$ (average is $12.4^{\circ} \mathrm{C}$ ). On that same day, minimum temperatures were as low as $-8.5 \mathrm{C}$ at Urupema, while Rio de Janeiro's minimum temperature was $8.6^{\circ} \mathrm{C}$ (average is $18.7^{\circ} \mathrm{C}$ ) - the lowest daily June minimum temperature in the last 14 years.

Severe weather, including heavy rains, floods, flash floods, and landslides, severely affected central South America for most of the year (with the exception of December). In central Brazil, heavy rain in January affected more than 67000 people throughout the state of Mato Grosso do Sul, with 28 municipalities declaring a state of emergency and nearly 1000 people isolated in the Taquarussu district. Recife recorded

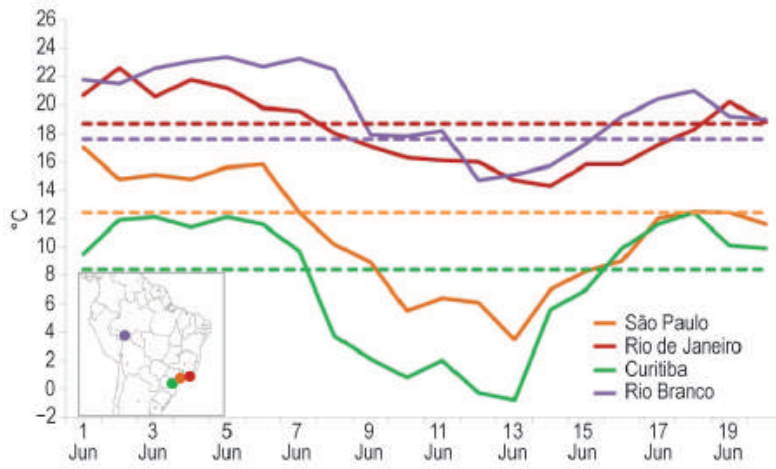

Fig. 7.I5. Solid lines represent the mean temperatures $\left({ }^{\circ} \mathrm{C}\right)$ in São Paulo, Rio de Janeiro, Curitiba, and Rio Branco during I-20 Jun 2016. Dashed lines represent the respective 198I-2010 average (Source: INMET.) Colored dots in the inset map show the locations of the meteorological stations.

\section{SIDEBAR 7.2: DROUGHT IN BOLIVIA: THE WORST IN THE LAST 25 YEARS - J. A. MARENGO, J. C. ESPINOZA, L. M. ALVES and J. RONCHAIL}

Rainfall in the central Andes was deficient in 2016. During the January-April growing season (Fig. SB7.3a), rainfall totals were below average in the central and southern Andes of Bolivia and in the southern Chaco region. Oruro received $66.7 \%$ of its average precipitation (average: $240 \mathrm{~mm}$ ) and Cochabamba just 62.1\% of its average precipitation (average: 290 mm; Fig. SB7.4). These were the lowest values since the strong 1982/83 El Niño event. Scarce rainfall was also observed in the lowlands, where totals were $20 \%$ below average in Trinidad (Beni).

Drought persisted after the dry austral winter season (June-August) and at the end of the year rainfall totals for November-December were about $150 \mathrm{~mm}$ month $^{-1}$ below normal. Total precipitation in $\mathrm{La} \mathrm{Paz}$ and the Altiplano region (Fig. SB7.3b) during September-December 2016 was $25 \%$ below normal. Intense drought conditions affected the center and southern parts of the country and the region of Santa Cruz, in the southern lowlands, with deficits surpassing $30 \%$ in the Andean regions, which were already affected during the first part of the year (Fig. SB7.3a). The hydrology of the Peruvian side of Lake Titicaca showed low river discharge from October 2016, with the Ramis and llave Rivers recording discharge levels of just $3.85 \mathrm{~m}^{3} \mathrm{~s}^{-1}$ and $11.6 \mathrm{~m}^{3} \mathrm{~s}^{-1}$ compared to their respective climatologies of $17.9 \mathrm{~m}^{3} \mathrm{~s}^{-1}$ and $51 \mathrm{~m}^{3} \mathrm{~s}^{-1}$. The water level of Lake Titicaca at Huatajata station dropped to $3807.78 \mathrm{~m}$ in December 2016, just shy of tying its lowest level set in September 1996 (3807.39 m). The Desaguadero River (the main outlet of the Lake Titicaca) discharge dropped as well. In the lowlands, a much longer-than-usual flood recession period was observed, especially in the Mamoré River, located downstream from the
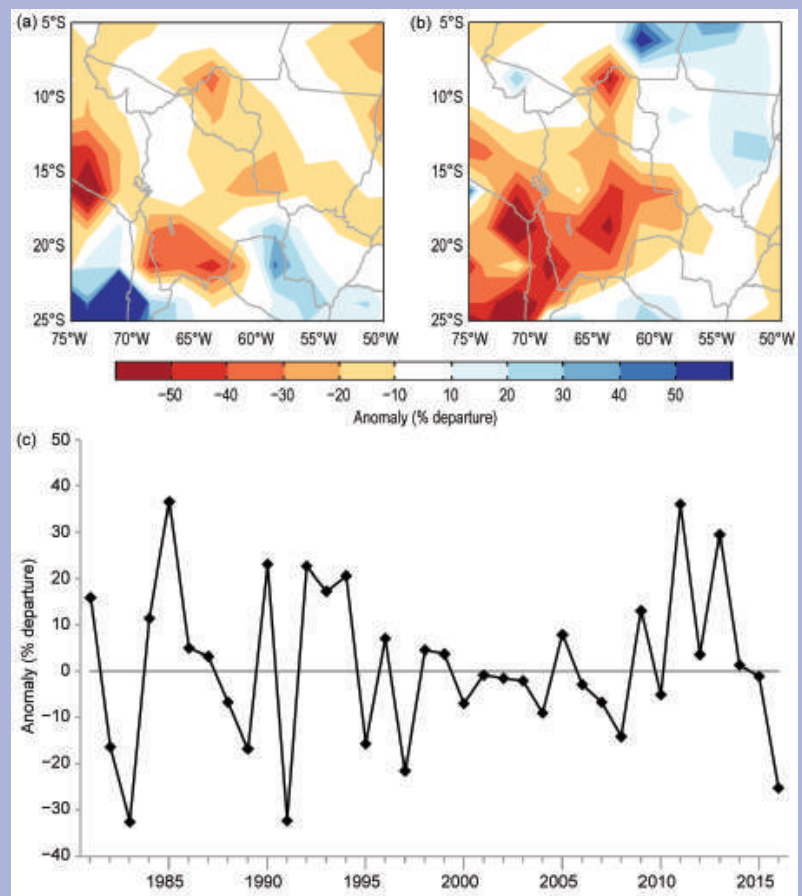

FIG. SB7.3. Precipitation anomaly (\%; 198I-2010 base period) maps for Bolivia, derived from the CMAP dataset for 2016: (a) Jan-Apr, and (b) Sep-Dec. (c) Sep-Dec precipitation anomalies (\%) near La Paz, Bolivia, during 1982-2016. (Source: Rainfall data is from CMAP, produced by NCEP.) 
$188 \mathrm{~mm}$ of rain in just 6 hours on 30 April-57\% of the mean climatology for the month $(328 \mathrm{~mm})$. The copious rain prompted flash floods and landslides in several locations across the city.

Due to a South Atlantic convergence zone episode on 16 January, above-average rain $(+150 \mathrm{~mm})$ was observed in states across northeastern, central, and southeastern Brazil and eastern Bolivia, as well as in western Paraguay and northwestern Peru, causing floods and river overflow. In seven municipalities in the Bolivian department of La Paz, a state of emergency was declared due to intense rainfall that led to overflowing rivers during the first half of the year.

Torrential rainfall, which began in November 2015, continued during January, triggering the overflow of Paraguay's Asunción and Alberdi River levels (7.88 $\mathrm{m}$ in Asunción on 1 January and $9.81 \mathrm{~m}$. in Al- berdi on 6 January) and displacing more than 65000 people in Asunción and leading the government to recommend evacuation of the Alberdi city. This was the fourth largest extreme flooding event since 1905, and according to the Meteorological Service of Paraguay, it was related to the 2015/16 El Niño event. This was also an out-of-season event since river levels typically reach their maximum at the end of May or in June-July.

In the Andean region, extreme drought was reported during 2016, leading the Peruvian government Ministry of Agriculture to declare a state of emergency for 17 regions during November and December.

The extreme dry conditions observed in northeastern Brazil contributed to a water crisis where the reservoirs of the San Francisco River were at less than $10 \%$ of capacity, leaving small farmers and the driest regions discussed above. At the Guayaramerin station very low levels, $\sim 2 \mathrm{~m}$, were observed from July to November compared to the usual September-October period. The severe dry conditions caused water supply issues for people, cattle, and agriculture in the region.

In November, Bolivia declared a national emergency, with drought affecting five of its nine departments. It was also declared due to the impact of dry conditions stemming from El Niño. Previous droughts were observed during past El Niño years in 1983, 1991, and 1997 (Fig. SB7.3c).

Bolivia's Civil Defense estimated that the drought conditions affected 162000 families and threatened 607000 hectares of agricultural land in the Andes and in the Amazonian region of Santa Cruz. About 360000 head of cattle were lost due to the lack of water and fodder. The association of producers of oleaginous seeds and wheat estimated that in 2016 the production of soy in the lowlands of Bolivia decreased by $20 \%$. The UN Food and Agriculture Organization estimated that the losses in Bolivia were as high as $\$ 485$ million U.S. dollars (14\% of the agricultural gross domestic product in 2015). Drought prompted protests in major cities and conflicts between miners and farmers about the use of aquifers. Water rationing was established for the first time ever in La Paz, affecting one-third of the population and probably more in fast-growing El Alto, the poorest city of Bolivia. The three main reservoirs that provide the city's water were almost dry by the end of 2016. The semiarid highlands surrounding the capital rely mostly on replenishment by rainfall and, secondarily on glacial meltwater (20\%-28\%), especially during the winter season. But glaciers such as Chacaltaya, which hosted the highest ski resort in the world (I7785 feet) and provided water to La Paz and El Alto, melted completely. In 2005, only a few patches of snow/ice were left, and in 2009 it dissapeared completely (Soruco et al. 20I5; Escurra et al. 2014).

Others glaciers have lost a great part of their mass and continue melting. Although the average water use in El Alto is low (52 liters person ${ }^{-1}$ day $^{-1}$ ), the critical situation of water supply may worsen as the population migrating to the city increases, especially during drought episodes when food security is no longer guaranteed in the countryside and with the growing demand of water for irrigation for agriculture in the surrounding areas.

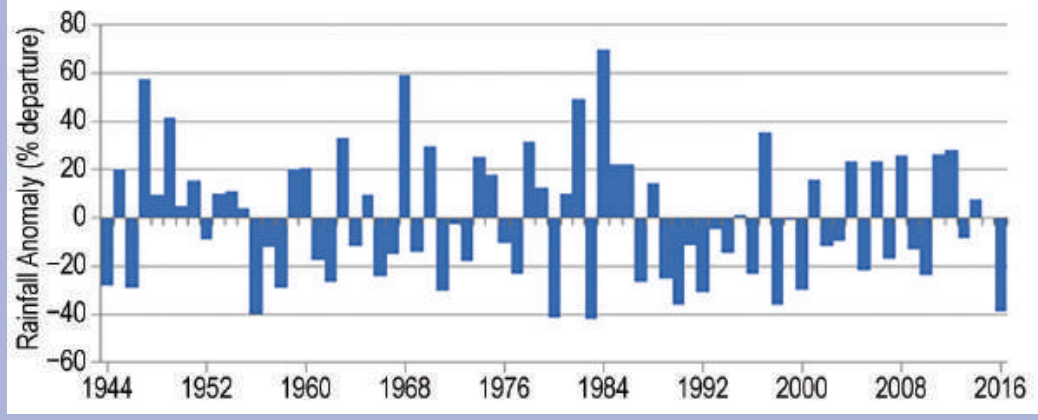

FIG. SB7.4. Jan-Apr precipitation anomalies (\%; 198I-2010 base period) for Cochabamba, Bolivia, during 1944-2016 (Source: SENAMHI-Bolivia.) 
general population with water and electricity shortages, and dependent on water being transported to them. During most of 2016, western Amazonia was dominated by drier conditions, and in the state of Acre rainfall was about $85 \%$ of the 1961-90 average annual rainfall of $1947.5 \mathrm{~mm}$. The Rio Acre levels were $1.41 \mathrm{~m}$ on 4 August, the lowest level since 1970. The Rio Madeira, at Porto Velho, was just $2.98 \mathrm{~m}$ high on 5 August, its lowest level in 48 years; the level dropped even more-to $1.9 \mathrm{~m}$ at Porto Velho on 30 September, the lowest value in 2016. The Ucayali River in the Peruvian Amazon reached $85 \mathrm{~m}$ on 22 September, its lowest level in 23 years. This was due

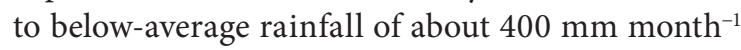
in western Amazonia during the first half of 2016.

Problems related to rainfall deficits and subsequent low water supplies were particularly intense in the central Andes, and this situation is considered the worst drought Bolivia has seen for 25 years (see Sidebar 7.2).

3) Southern South America-M. Bidegain, J. L. Stella, M. L. Bettolli, and J. Quintana

This region includes Argentina, Chile, and Uruguay.

\section{(i) Temperature}

Near or below-normal temperatures were observed over most of southern South America during 2016, with mean temperature anomalies between $-0.5^{\circ}$ and $+0.5^{\circ} \mathrm{C}$ (see Fig. 7.13a). The 2016 mean temperature anomalies for Argentina and Uruguay were $+0.1^{\circ} \mathrm{C}$ and $-0.4^{\circ} \mathrm{C}$, respectively. Argentina's 2016 mean temperature anomaly was its coolest since 2011, breaking the streak of four consecutive years (2012-15) with record or near-record high temperatures. Chile had the largest positive anomaly at $+0.7^{\circ} \mathrm{C}$.

Summer (December-February) 2015/16 was warmer than normal across northern and central Argentina, Chile, and Uruguay, with temperature anomalies $0.5^{\circ}-1.0^{\circ} \mathrm{C}$ above average.

Mean temperatures for autumn (March-May) were $0.5^{\circ}-1.0^{\circ} \mathrm{C}$ below average in northern and central Argentina, central Chile, and Uruguay. Conversely, northwestern Patagonia experienced warmer-than-average anomalies of greater than $+1^{\circ} \mathrm{C}$. For Argentina, its autumn mean temperature was the sixth lowest since national records began in 1961, with average maximum temperatures that were record low. Of note, the average mean temperature for April was much above average for northeastern Argentina $\left(+1^{\circ} \mathrm{C}\right)$, Uruguay $\left(+0.8^{\circ} \mathrm{C}\right)$, and northern Chile $\left(+0.7^{\circ} \mathrm{C}\right)$, while much-below-average anomalies $\left(-2.0^{\circ} \mathrm{C}\right)$ were observed across southern Argentina and Chile. Cooler-than-average conditions occurred across much of Argentina and Uruguay during May, with several locations setting new monthly low average maximum temperature records. Meanwhile, central Chile had above-average temperatures.

Winter (June-August) was characterized by cooler-than-average conditions across northeastern Argentina and Uruguay, with above-average conditions across central and southern Chile and western and southern Patagonia $\left(+1 \cdot 3^{\circ} \mathrm{C}\right)$.

Below-average conditions continued during spring (September-November) for northeastern Argentina and northern Uruguay $\left(-0.2^{\circ} \mathrm{C}\right.$ to $-0.5^{\circ} \mathrm{C}$ anomalies). Above-average temperatures returned to the region in December for the first time since February, particularly notable over central Chile, Argentina, and Uruguay.

\section{(ii) Precipitation}

The 2016 annual rainfall anomaly in Argentina and Uruguay was $+14.3 \%$ and $+9 \%$, respectively (see Fig. 7.13b). Although the annual rainfall was above average, drier-than-average conditions were observed across central and northeastern Argentina, northern Uruguay, and central Chile during the second half of the year, following the influence of the cold phase of ENSO.

Several events in April brought abundant rainfall to northeastern Argentina and Uruguay, with several stations setting new monthly precipitation records. In central Chile, Santiago had its wettest April since 1878 , accumulating $109 \mathrm{~mm}$, which is nearly seven times the monthly average. The extreme precipitation was associated with the strong El Niño that developed in 2015 and dissipated in May 2016, and impacted the Rio de la Plata basin with above-average rainfall during summer and fall.

During autumn, there were two zones with excess precipitation: central-western Argentina, where precipitation totals for April-May were the most significant for the year; and central-eastern Argentina and western Uruguay, with April rainfall totals contributing the largest portion of the annual precipitation total. The much-above-average precipitation during April resulted in devastating floods.

During spring, much of southern South America observed below-normal precipitation, with the exception of areas in northern Patagonia and central and northern Argentina which had above-average precipitation in October. Accumulated rainfall anomalies during October were as high as $+200 \mathrm{~mm}$ in an extensive area that included central-western 
and northeastern Argentina. Central Chile also had above-average precipitation, with anomalies as high as $235 \%$ of average in Curicó.

\section{(iii) Notable events and impacts}

A heat wave impacted a large area in central Argentina during 20-25 January, leading to a great demand for electricity that resulted in power outages. New high records for monthly mean minimum temperatures were set in northeastern and centralwestern Argentina [Resistencia $\left(23.3^{\circ} \mathrm{C}\right)$, Formosa $\left(24.3^{\circ} \mathrm{C}\right)$, Posadas $\left(23.5^{\circ} \mathrm{C}\right)$, Oberá $\left(22.0^{\circ} \mathrm{C}\right)$, Ceres $\left(21.0^{\circ} \mathrm{C}\right)$, Rosario $\left(20.7^{\circ} \mathrm{C}\right)$, Bernardo de Irigoyen $\left(20.2^{\circ} \mathrm{C}\right)$, Laboulaye $\left(19.2^{\circ} \mathrm{C}\right)$, and Malargüe $\left(13.3^{\circ} \mathrm{C}\right)$ ].

Extreme precipitation events in April over central-eastern Argentina and Uruguay resulted in new records for the number of rainy days (days with precipitation $>0.1 \mathrm{~mm}$ ) for the following locations: Concordia and Gualeguaychú (21 days), Buenos Aires (20 days), Monte Caseros (19 days), Sauce Viejo and Rosario (18 days), Ceres and Paraná (17 days). On 15 April, an intense tornado was observed across southwestern Uruguay, affecting the city of Dolores (Soriano Department). Five people were reported dead and more than 500 people were injured. Heavy rainfall in mid-April caused floods in southern Uruguay (departments of Rocha, Maldonado, Canelones, and San Jose), displacing nearly 4000 people and claiming three lives. A maximum daily rainfall total of $250 \mathrm{~mm}$ was reported in Nueva Palmira station (Colonia Department) on 15 April.

An extratropical depression affected the centraleastern region of Argentina and Uruguay during 1214 September. Winds up to $110 \mathrm{~km} \mathrm{~h}^{-1}$ caused severe damage, including toppled trees, power outages, and evacuations. Along the coastal area of Buenos Aires, the strong winds also caused serious problems to ship navigation, caused erosion, and damaged beaches; the city of Mar del Plata was the most affected.

Storms on 12 October affected a large extent of Argentina, including northern Patagonia, La Pampa province, southern Cordoba, and northwestern Buenos Aires. The intense rainfall, strong winds, and hail led to severe flash floods and power outages in several locations.

On 27 October, an extratropical cyclone impacted Uruguay's Atlantic coast, causing estimated losses of $\$ 2$ million U.S. dollars; it was the second extratropical cyclone to affect the area in fewer than 40 days.

During December the city of Mar del Plata (Buenos Aires province) recorded 14 days with maximum temperatures above $30^{\circ} \mathrm{C}$, with three of those days reaching $35^{\circ} \mathrm{C}$. This was the second highest number of days in a single month with maximum temperatures above $30^{\circ} \mathrm{C}$ on record, behind December 2013. A large area in Argentina, including La Pampa province and southern and western Buenos Aires province, was affected by dry conditions, extreme high temperatures, and winds, which triggered severe bushfires, burning more than 500000 hectares.

Santiago, Chile, recorded a new December maximum temperature on 14 December, when temperatures climbed to $37.3^{\circ} \mathrm{C}$, surpassing the century-old record of $37.2^{\circ} \mathrm{C}$ set on 19 December 1915 .

\section{e. Africa}

In 2016, most of Africa experienced above-average surface air temperatures (Fig. 7.16). Rainfall over the region $7.5^{\circ}-15^{\circ} \mathrm{N}$ was above average whereas rainfall over most of equatorial Africa and the region south of the equator was below average (Fig. 7.17). Several extreme weather conditions were reported, including heat waves, droughts, and floods associated with convective storms in Morocco and Egypt and in several countries in West Africa. Unusually low temperatures (around $-6^{\circ} \mathrm{C}$ ) were also reported in Ethiopia.

The reference period for this annual climate assessment is 1981-2010. Both observed and reanalysis data-

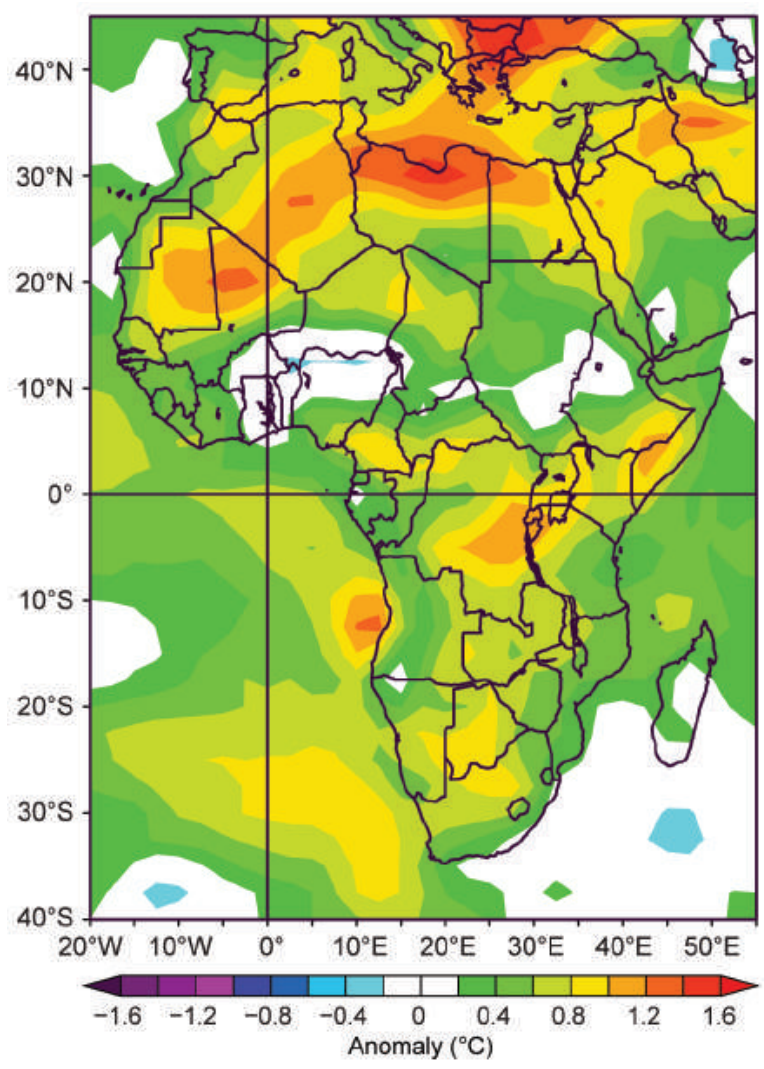

Fig. 7.16. Annual 2016 surface air temperature anomalies ( ${ }^{\circ} \mathrm{C}$; 198I-2010 base period) over Africa. (Source: NOAA/NCEP.) 


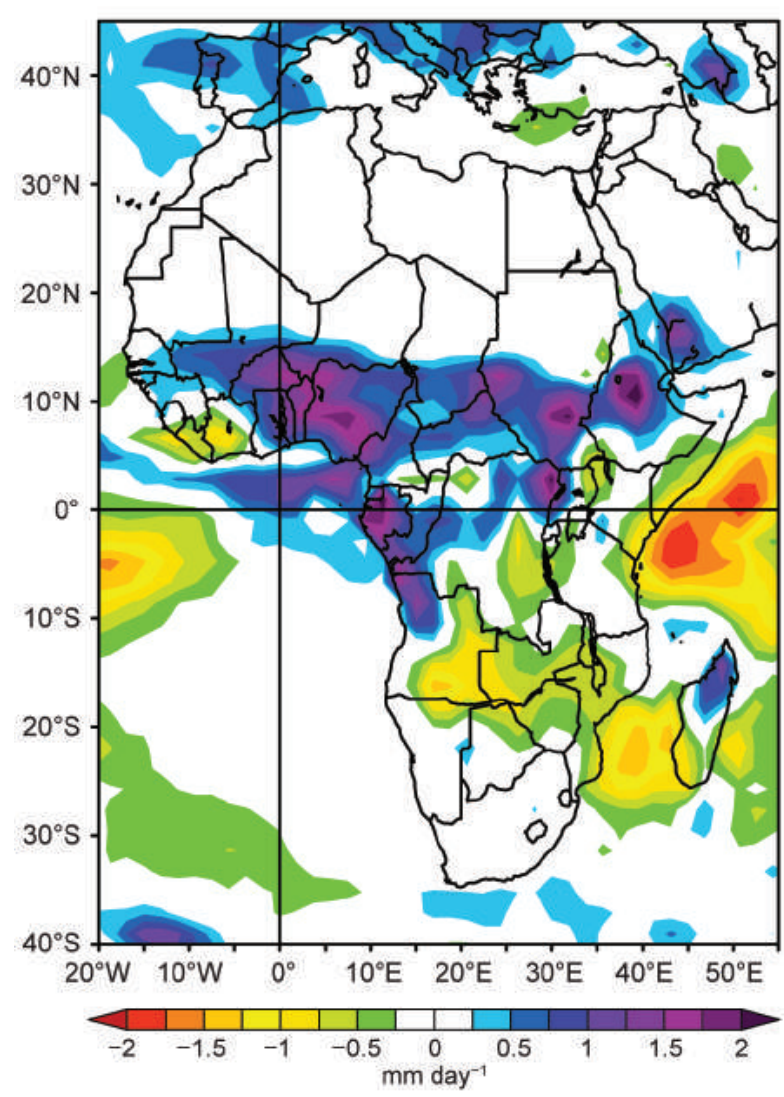

FIG. 7.I7. Annual 2016 rainfall anomalies (mm day ${ }^{-1}$; |98|-2010 base period) over Africa. (Source: NOAA/ NCEP.)

sets were used for the analysis. Observed data sources include meteorological and hydrological services across the continent and the African Centre for Meteorological Application and Development (ACMAD) in Niamey, Niger. Reanalysis sources include the NCEP/NCAR and the ECMWF/ERA-Interim.

I) Northern Africa—K. Kabidi, A. Sayouri, M. ElKharrim, and E. M. Awatif

Countries considered in this report are Morocco, Algeria, Tunisia, and Egypt.

\section{(i) Temperature}

Overall, in 2016, above-average mean temperatures were observed across North Africa. Temperatures over northern Libya were about $1.6^{\circ} \mathrm{C}$ above average (Fig. 7.16). Meteorological data from several stations show that temperatures in Morocco were among the highest since records began in 1960 . Both annual maximum and minimum temperatures were $0.6^{\circ} \mathrm{C}$ above average. However, there was high variability across months. Seasonally, in Morocco, winter and spring temperatures were $0.4^{\circ} \mathrm{C}$ and $0.7^{\circ} \mathrm{C}$ above average, respectively. As shown in Fig. 7.18a, station reports indicate January was exceptionally warm over the region, with the average maximum and average minimum temperatures $3.4^{\circ} \mathrm{C}$ and $2.2^{\circ} \mathrm{C}$ above normal, respectively. In March, temperatures were $1.5^{\circ} \mathrm{C}$ below average over Morocco and Algeria (Fig. 7.18b). The annual mean temperature in Egypt exceeded its average by $0.52^{\circ} \mathrm{C}$, with well-above average temperatures observed during both winter and summer. Maximum temperatures reached $48^{\circ} \mathrm{C}$ on 27 and 28 May at Luxor in Egypt.

Summer was abnormally warm across most of the region due to persistent heat waves during July and August (Fig. 7.18c). Temperatures above $40^{\circ} \mathrm{C}$ were recorded over most of Morocco, especially in the south and the east. During July, central Morocco recorded more than 21 days of temperature exceeding
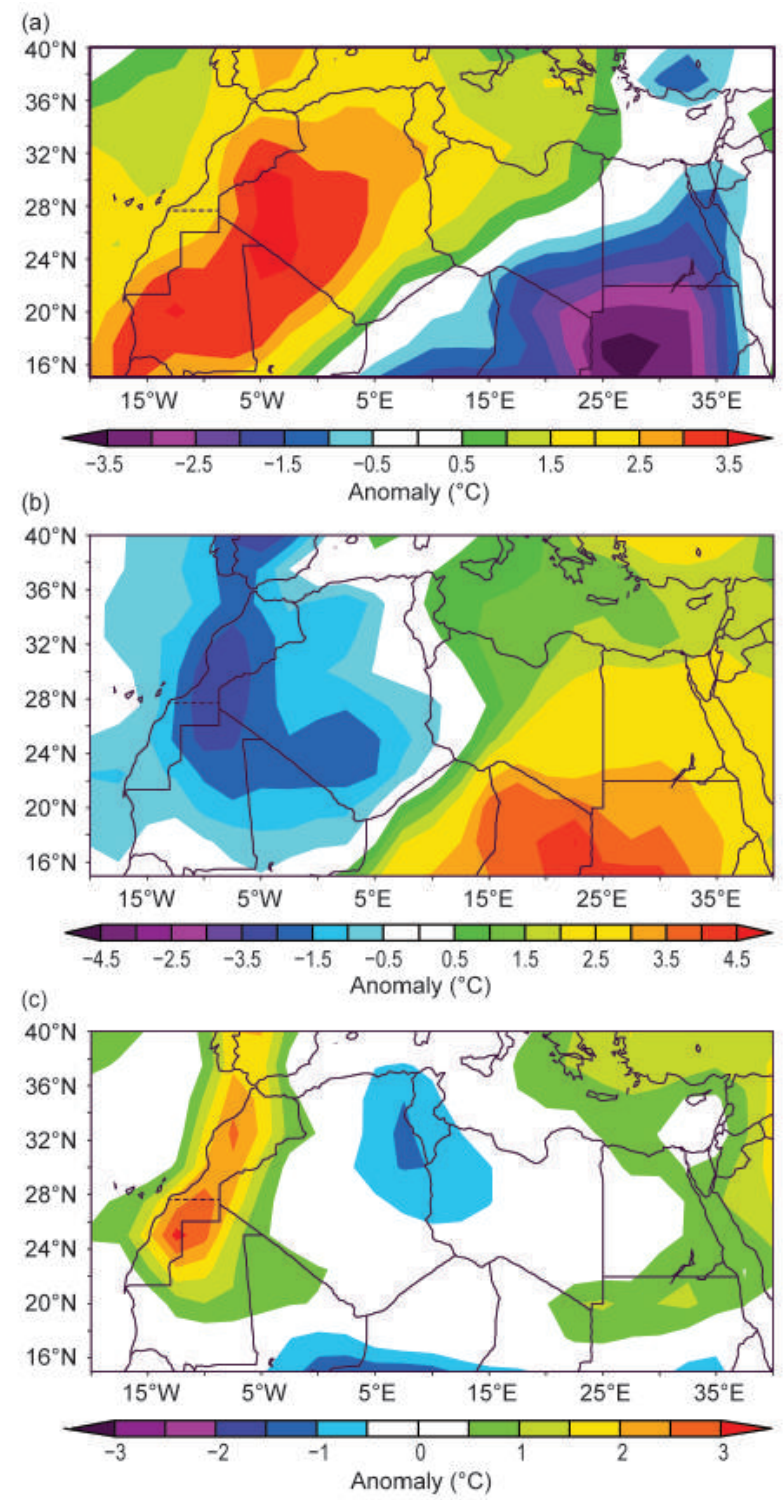

FIG. 7.18. Northern Africa 2016 surface air temperature anomalies ( ${ }^{\circ} \mathrm{C}$; $198 \mathrm{I}-2010$ base period) for (a) Jan, (b) Mar, and (c) Jul-Aug. (Source: NOAA/NCEP.) 


\section{(ii) Precipitation}

Annual precipitation over northern Africa was near normal in 2016 (see Fig. 7.17). Total annual precipitation in Morocco was $43 \%$ higher than in 2015 but still 3\% below the 1981-2010 average, with strong geographical and temporal variability-ranging from $127 \%$ of normal at Smara in the south to $19 \%$ of normal at Tangier in the north. Also, 36\% of the total annual precipitation fell during the months of May and November. In Egypt, dry conditions in the south and wetter-than-normal conditions in the north were observed.

Observational records show that Morocco experienced below-average rainfall during winter mainly due to persistent anticyclonic conditions over the Atlantic coast and western Europe. Although winter precipitation was generally below average in Egypt, extremely heavy rainfall was observed in Cairo (39\% above normal) in January, and a record rainfall of $39 \mathrm{~mm}$ on 13 December was observed at Dabaa.

Spring rainfall was also generally below normal over most of Morocco, with rainfall just $42 \%$ of normal in April. However, in May (Fig. 7.19b), several storms brought exceptionally high rainfall [e.g., $90 \mathrm{~mm}$ in Safi (normal is $10 \mathrm{~mm}$ ); $115.3 \mathrm{~mm}$ in Essaouira (normal: $4.4 \mathrm{~mm}$ ); and $112.6 \mathrm{~mm}$ in Chefchaouen (normal: $45.3 \mathrm{~mm}$ )]. Precipitation during March was above normal over northern Tunisia
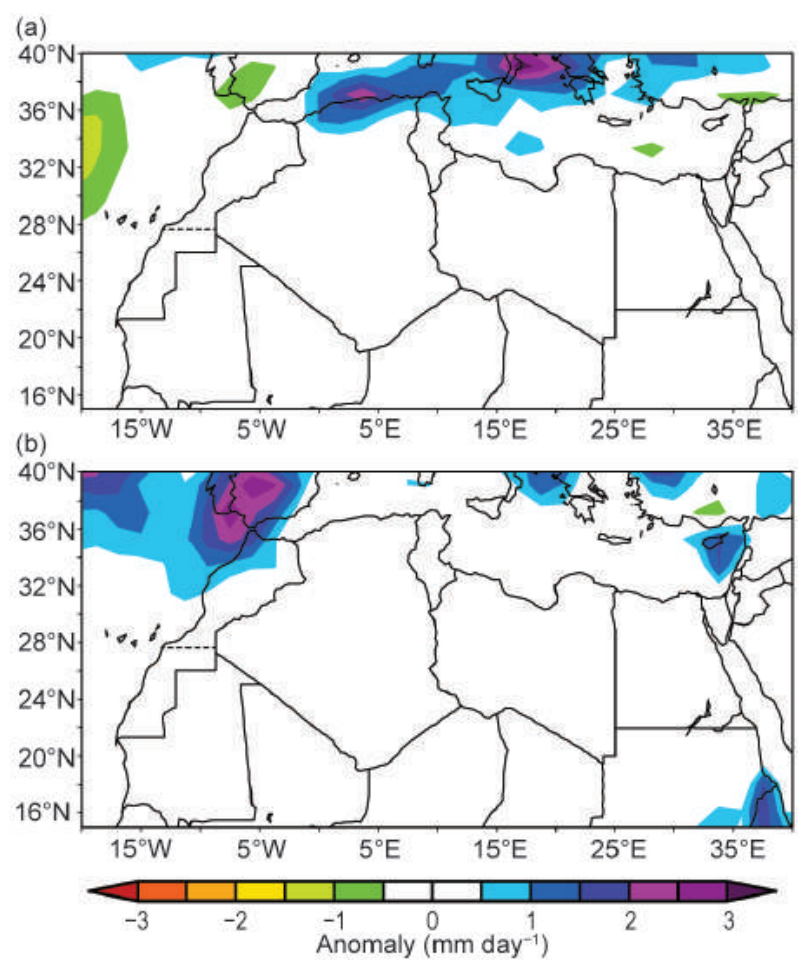

FIG. 7.19. Northern Africa 2016 rainfall rate anomalies (mm day ${ }^{-1}$; 198I-2000 base period) for (a) Mar and (b) May. (Source: NOAA/NCEP.) and Algeria (Fig. 7.19a), with $255 \mathrm{~mm}$ recorded in Meliana, $214 \mathrm{~mm}$ in Jijel-achouat and $194 \mathrm{~mm}$ in Bejaia compared to their respective averages of $73.9 \mathrm{~mm}, 77.2 \mathrm{~mm}$ and $67.3 \mathrm{~mm}$. Reports from the national meteorological services and ACMAD indicate that precipitation in May was above normal in the south of Algeria and near normal in Tunisia.

Rainfall $104 \%$ and $81 \%$ of normal was recorded in Morocco during July and August, respectively. This was associated with local storms that occurred during summer, particularly in the mountainous regions. Observations from the national meteorological services show that precipitation during autumn was generally below normal over the region, especially in October. However, September was rainy for the south of Morocco, Tunisia, and central Algeria. Exceptionally heavy rainfall was observed in the northwest and northern Morocco in November. A record rainfall of about $77 \mathrm{~mm}$ in 24 hours was observed in Tangier.

\section{(iii) Notable events and impacts}

Several extreme events occurred during 2016 resulting in loss of human life and material damages. Extended heat waves occurred over the region during July and August with maximum temperatures exceeding $40^{\circ} \mathrm{C}$. Heat waves originated from heat sources farther east in the Sahara desert and contributed to significant forest fires, especially in Morocco where 235 fires were recorded, causing the destruction of about 1584 hectares of vegetation. Flooding associated with convective storms also caused loss of life and damage in eastern Egypt along the Sinai and Red Sea coastal areas between 27 and 29 October.

2) West Africa-S. Hagos, I. A. ljampy, F. Sima, S. D. Francis, and $Z$. Feng

West Africa refers to the region between $17.5 \leftarrow \mathrm{W}$ (eastern Atlantic coast) and $\sim 15 \leftarrow$ (along the western border of Chad) and north of the equator (near Guinean coast) to about $20 \ll \mathrm{N}$. It is divided into two climatically distinct subregions; the semiarid Sahel region (north of about $12 \ll \mathrm{N}$ ) and the relatively wet Coast of Guinea region to the south.

\section{(i) Temperature}

The annual mean temperature over most of west Africa was slightly above average, with much of the Coast of Guinea region about $1 \ll €$ above its 1981-2010 average (Fig. 7.20). In June, much warmer-thanaverage conditions were reported over the region; record warm conditions were observed over Ghana, Ivory Coast, and the Gambia. In particular, the annual mean maximum temperature in the Gambia 


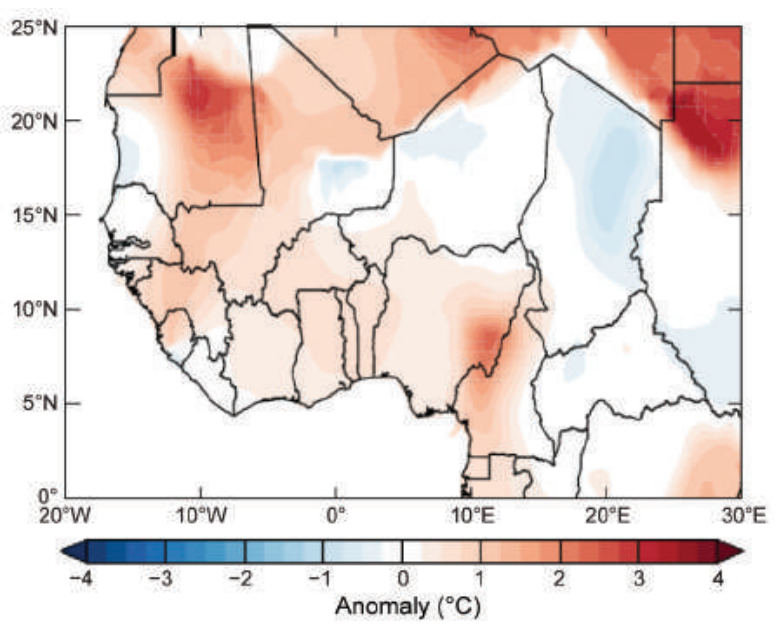

Fig. 7.20. Temperature anomalies ( ${ }^{\circ} \mathrm{C}$; $198 \mathrm{I}-2010$ base period) for west Africa in Jul 2016. (Source NOAA/ NCEP.)

was above average by about $0.6 \leftarrow €$. Record high temperatures were observed over Guinea, southern Mali, and Sierra Leone in August, while Ghana, Togo, and Benin experienced near-record high temperatures in September.

\section{(ii) Precipitation}

The rainy period over the region is associated with the latitudinal movement of the West African monsoon and typically occurs during June-September. Wetter-than-average conditions persisted during this period over most of the Sahel region as the intertropical front was north of its climatological latitudes. The rainy season started with early onset in June, especially over the central Sahel as the monsoon progressed. Rainfall totals and anomalies with respect to the reference period for June-September are shown in Fig. 7.21. Relatively dry conditions prevailed over most of the Coast of Guinea region, from Liberia to the Niger Delta, and wetter-thannormal conditions were observed over Burkina Faso and southern Mali during the period. According to the Nigerian Meteorological Services, wetter-thannormal conditions occurred over the southwest and southeast, including regions of western Nigeria. In contrast, drier-than-normal conditions continued over Katsina, Plateau, and Yobe (Nigeria). The Gambia experienced both late onset and late cessation with near- to below-normal rainfall. While there were significant rainfall amounts during this period, with September recording the highest amount $(305.9 \mathrm{~mm})$, the season also had prolonged dry spells and uneven rainfall distribution, leading to crop failure.

\section{(iii) Notable events and impacts}

In southern Nigeria, a storm lasting several hours brought heavy rain and flooding to Abakaliki, Ebonyi state, on 12 June. Local media reported that the IyiUdele River flooded parts of the city of Abakaliki, with 5000 people left homeless after hundreds of homes were inundated. In Ghana, floods affected Accra and parts of Central Region in June, leaving at least six people dead.

The UN Office for the Coordination of Humanitarian Affairs (UNOCHA) in Niger reported that 11 people died and 1693 homes were destroyed by heavy rains and subsequent flooding in the country during June and July. About 30000 people were affected. Significant material damage and loss of about 20000 head of cattle were also reported by the Humanitarian Coordination Unit. In Mali, UNOCHA also reported that flooding caused 13 deaths and affected more than 9500 people.

In the Gambia, heavy rainfall hit Basse, Sandu, and Wulli districts at the Upper River region on 29 August, resulting in one fatality. The next day, a windstorm destroyed several compounds and homes in
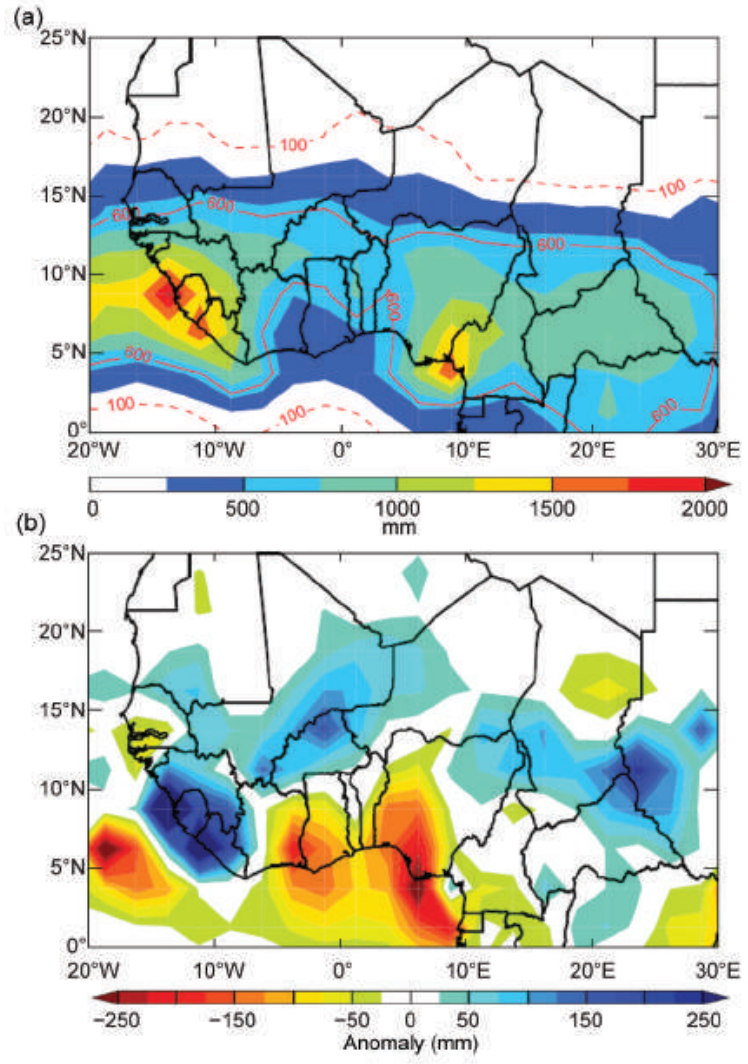

Fig. 7.2I. In west Africa, Jun-Sep 2016 (a) total accumulated precipitation ( $\mathrm{mm}$; red dashed and solid lines mark $100-\mathrm{mm}$ and $600-\mathrm{mm}$ isohyets, respectively) and (b) anomalies (mm; 198I-2010 base period). (Source NOAA/NCEP.) 
the villages of Kafuta and Faraba in Kombo East district of the West Coast Region, leaving some residents stranded in the villages. The powerful wind, followed by heavy rain lasting for several hours, led to the destruction of two compounds in Kafuta and other compounds in the neighboring village of Faraba. On 7 September, the communities of Kafuta and Faraba in the Kombo East district of the West Coast Region again suffered from heavy windstorms, stranding villagers a second time.

\section{3) Eastern Africa一G. Mengistu} Tsidu, and G. Kelem

Eastern Africa, alternatively referred to as the Greater Horn of Africa (GHA), is comprised of regions that either receive mono or bimodal rainfall during JuneSeptember (JJAS), March-May (MAM), December-February (DJF), and September-December (SOND) seasons. Regions that lie across the equator receive bimodal rainfalls while those farther north and south from equator receive rainfall during JJAS and DJF seasons, respectively.

The assessment of the state of climate in 2016 over GHA is based on rainfall from the latest version-2 Climate Hazards Group Infrared Precipitation with Stations (CHIRPS) data, temperatures from the ERA-Interim reanalysis, and daily minimum temperatures from selected synoptic stations over Ethiopia.

\section{(i) Temperature}

Above-normal mean temperatures that prevailed over most of GHA through much of 2016 began to decrease near the end of the year. The DJF 2015/16 mean temperature was below normal over Sudan; southwestern Ethiopia and adjoining Kenya, South Sudan, and Uganda; southern Kenya; and most parts of northern Tanzania (Fig. 7.22a). Normal to abovenormal anomalies of up to $+2^{\circ} \mathrm{C}$ were observed over the rest of Ethiopia and Uganda, Rwanda, Burundi, and northwestern Tanzania. GHA remained warmer

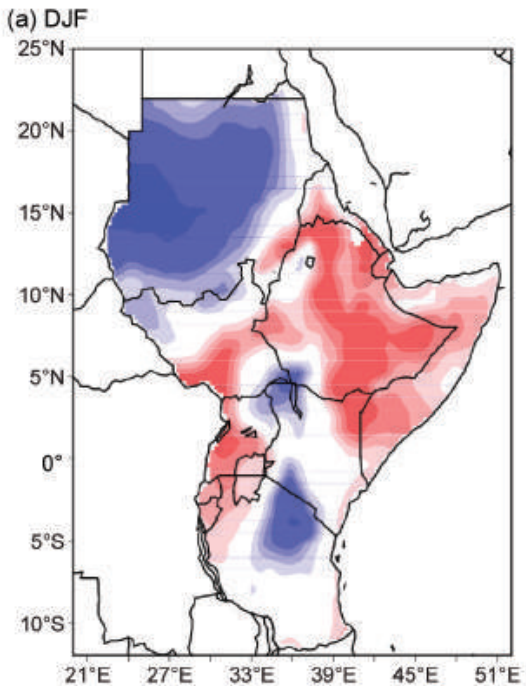

(b) MAM

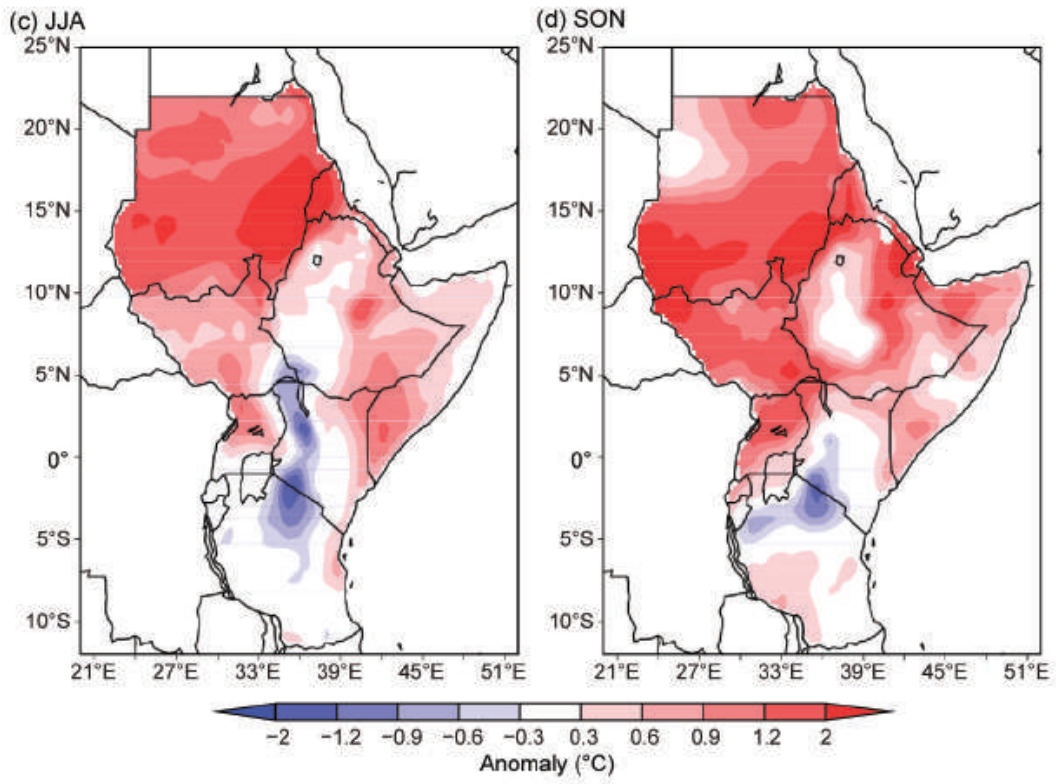

FIg. 7.22. Eastern Africa seasonally averaged mean temperature anomalies ( ${ }^{\circ} \mathrm{C}$; $198 \mathrm{I}-2010$ base period) for (a) DJF 2015/16 and (b) MAM, (c) JJA, and (d) SON 2016. (Source: ERA-Interim.)

than normal during MAM, with the exception of most of Tanzania, central and southern Kenya, and along Ethiopian mountain ranges, which experienced normal to below-normal temperatures (Fig. 7.22b). During June-August (JJA), the warm anomalies subsided over large parts of GHA. The Republic of Sudan remained warmer than normal in JJA (Fig. 7.22c). The mean temperature was above normal during September-November (SON) over Sudan, eastern Ethiopia, Uganda, Rwanda, and southern Tanzania while below-normal temperatures prevailed over the rest of the region (Fig. 7.22d). In November, the western half of Ethiopia, Republic of Sudan, and South Sudan experienced normal to below-normal temperatures. 


\section{(ii) Precipitation}

Eastern Uganda, Burundi, Tanzania, and western Kenya and adjacent southwestern Somalia received substantially higher-than-average precipitation whereas western Uganda, most of Kenya, and Rwanda received about $50 \%-90 \%$ of their mean (Fig. 7.23a). Rainfall during MAM was normal to above normal over southern Ethiopia and adjacent northeastern Somalia, South Sudan, western Kenya, Uganda, Rwanda, Burundi, and Tanzania (Fig. 7.23b). Most parts of Ethiopia (with the exception of the southeastern lowlands), South Sudan, and southern Sudan receive their main rainfall during JJAS; however, below-average rainfall dominated the region in 2016 (as in 2015) with the exception of most of the Republic
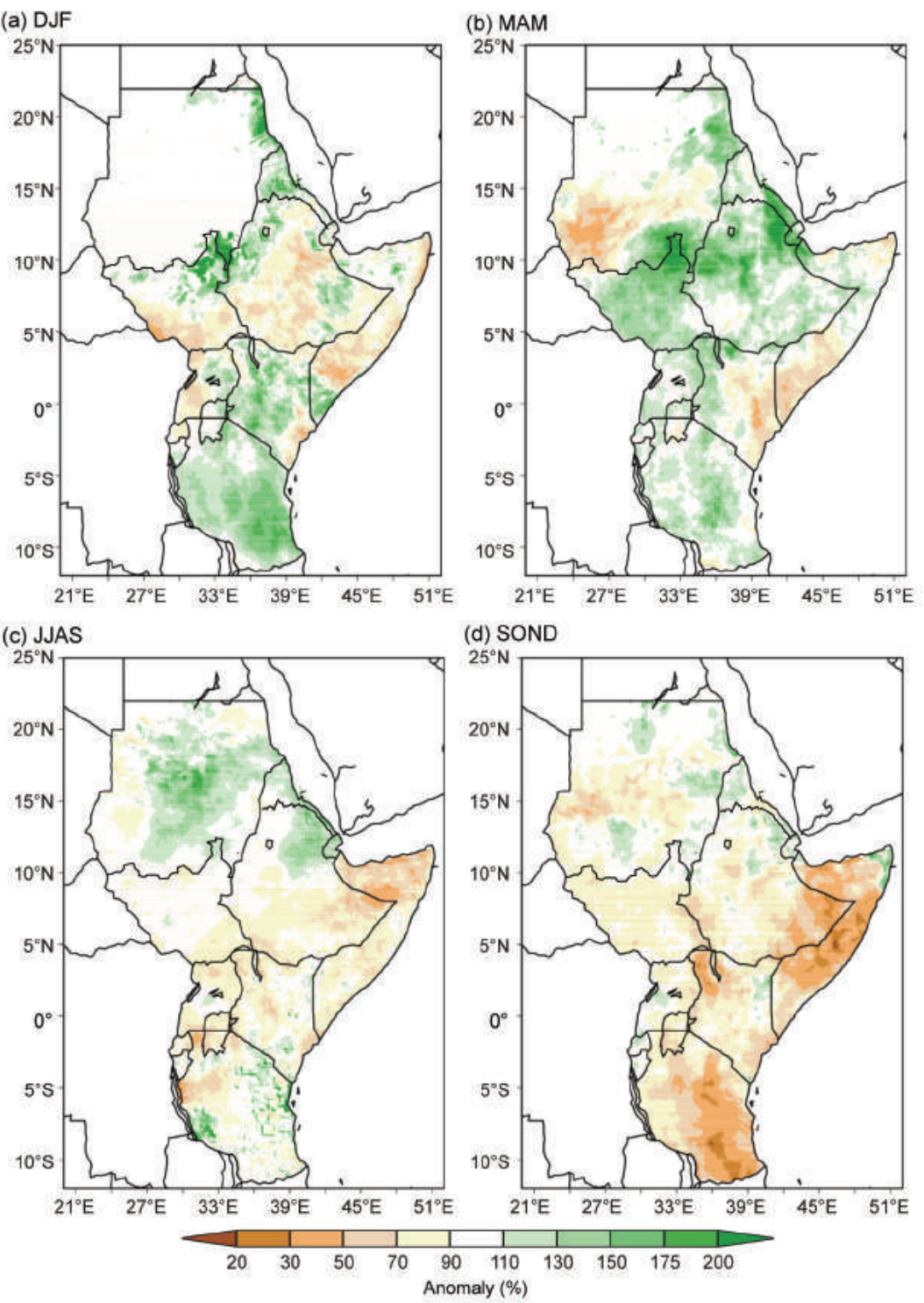

Fig. 7.23. Eastern Africa seasonal total rainfall anomalies (\% of normal; 198I-2010 base period) for (a) DJF 2015/16 and (b) MAM, (c) JJAS, and (d) SOND 2016. (Source: CHIRPS.) of Sudan, Eritrea, Djibouti, and the adjacent Ethiopian Rift Valley, which received $110 \%-200 \%$ of its seasonal mean rainfall (Fig. 7.23c). The dry conditions intensified and covered most parts of GHA that receive rainfall during SOND (Fig. 7.23d).

\section{(iii) Notable events and impacts}

In December, the western half of the Republic of Sudan and much of Ethiopia were under a surge of cold air from Siberia highs (Fig. 7.24b). As a result, a number of places in Ethiopia experienced freezing conditions, with temperatures dropping to as low as $-6^{\circ} \mathrm{C}$. Figure $7.24 \mathrm{c}$ shows daily minimum temperature anomalies for four selected synoptic stations (green dots in Figs. 7.24a,b) that were significantly colder than the monthly average. Daily minimum temperature anomalies of more than $-8^{\circ} \mathrm{C}$ were recorded at Addis Ababa and Debre Birhan (Fig. 7.24c).

4) Southern Africa一G. Mengistu Tsidu, A. C. Kruger, and C. McBride

Southern Africa is comprised of the Republic of South Africa, Angola, Botswana, Zimbabwe, Namibia, Malawi, Zambia, and Mozambique. The region is located between two semipermanent high pressure systems (Saint Helena and Mascarene highs) over the Atlantic and Indian Oceans. This assessment presents state of the climate during the austral seasons: summer [December 2015-February 2016 (DJF)], autumn [March-May (MAM)] and winter [June -August (JJA)], spring [September-November (SON)] of 2016. The assessment over southern Africa is based on rainfall from the latest version-2 Climate Hazards Group Infrared Precipitation with Stations (CHIRPS) data, temperatures from the ERA-Interim reanalysis, and in situ observational data over the Republic of South Africa.

\section{(i) Temperature}

Above-normal temperatures in 2015 continued into 2016. As a result, most of southern Africa 


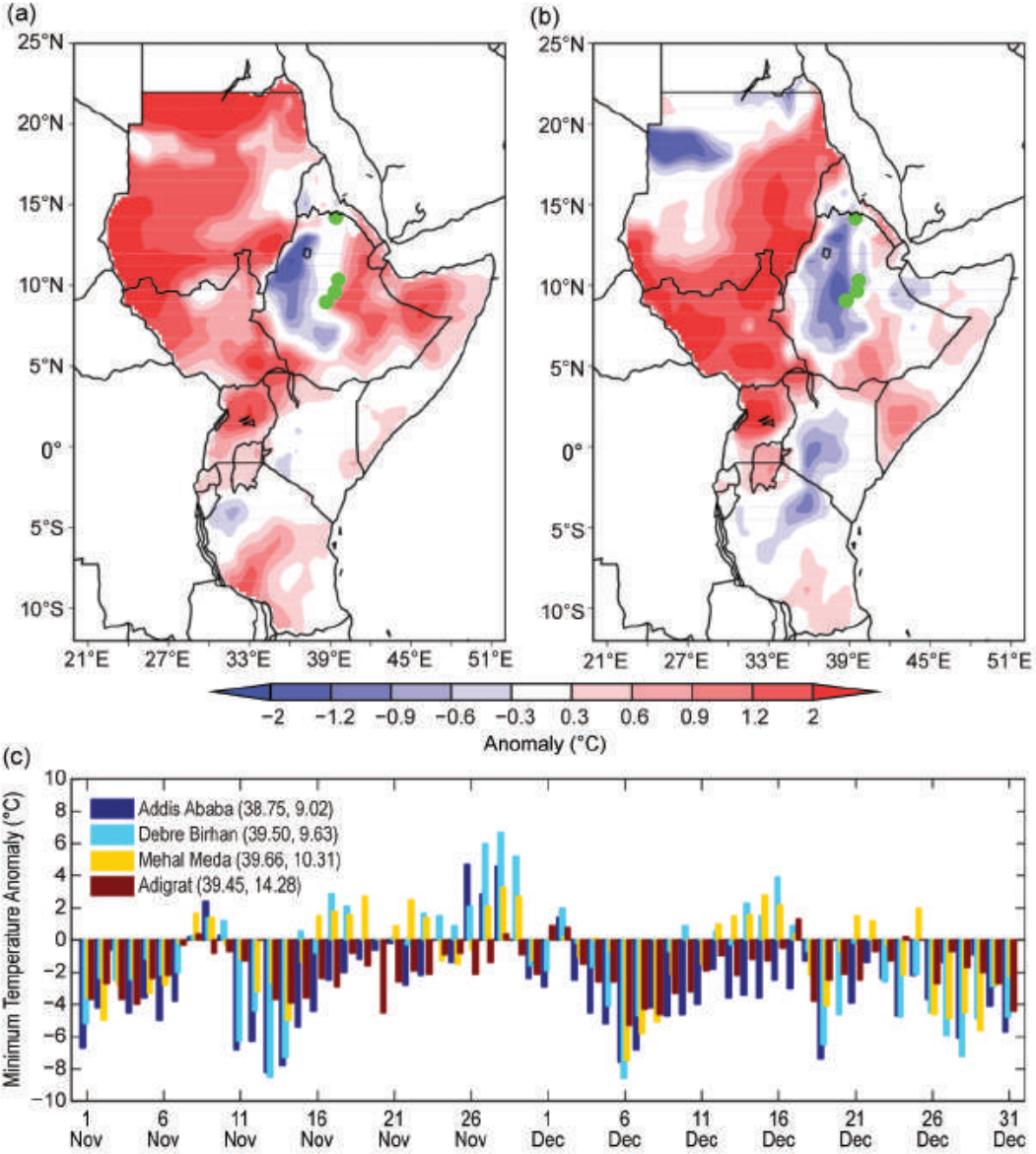

FIG. 7.24. Eastern Africa 2016 minimum temperature anomalies $\left({ }^{\circ} \mathrm{C}\right.$ 1981-2010 base period) during (a) Nov and (b) Dec. (c) Nov-Dec 2016 daily minimum temperature anomalies $\left({ }^{\circ} \mathrm{C}\right)$ at four synoptic stations in Ethiopia, as indicated by the green dots in (a) and (b). (Source: ERA-Interim.) data of these particular climate stations, statistically significant at the $5 \%$ level.

\section{(ii) Precipitation}

Southern Africa received below-normal rainfall $(<70 \%)$ across the region, with the exception of coastal areas of Angola and Namibia and isolated places over northern Cape and Mpumalanga regions of South Africa in DJF (Fig. 7.27a). The region was generally wetter than normal in MAM (Fig. 7.27b). However, the west coast and large parts of South Africa received below-average precipitation. Observations also show normal to wetter-than-normal rainfall during March, while April-May rainfall was mostly below normal over most areas of South Africa.

During JJA, southern and southwestern parts of southern Africa received above-normal rainfall (Fig. 7.27c) whereas the rest of the region remained under relatively dry weather conditions. The whole of southern Africa was extremely dry in SON except in isolated areas in the Western Cape

was warmer than normal in DJF 2015/16, with some exceptions along the coasts and over northern Angola, northern Zambia, and Mozambique, which had near-normal mean temperatures (Fig. 7.25a). While the rest of the region remained warmer than normal in MAM, northern Mozambique and all of Zambia experienced normal to below-normal temperatures (Fig. 7.25b). South Africa, Namibia, and Botswana (including southern Angola) experienced normal to above-normal mean temperatures in JJA (Fig. 7.25c). By SON most of the region experienced warm anomalies exceeding $+2^{\circ} \mathrm{C}$, particularly notable over Botswana, Namibia, and southern Angola (Fig. 7.25d). These results, from ERA-Interim temperature analyses, are consistent with in situ observations over South Africa. As shown in Fig. 7.26, the annual mean temperature anomaly for 2016 from the data of 26 South African climate stations was $0.84^{\circ} \mathrm{C}$ above the $1981-2010$ average, making 2016 the second warmest year in the 66-year record, behind only $2015\left(+0.86^{\circ} \mathrm{C}\right)$. A warming trend of $0.16^{\circ} \mathrm{C} \mathrm{decade}{ }^{-1}$ is indicated by the province in South Africa (Fig. 7.27d).

The annual total rainfall based on 26 stations from South Africa shows near-normal conditions (70\%-125\% of normal) over most parts of the country in 2016 (Fig. 7.28), consistent with CHIRPS estimates shown in Fig. 7.27. This brought some relief from the drought conditions that occurred over most of the country during previous years. However, the drought situation remained serious in many areas due to multiple years of below-normal rainfall. Some central and extreme northeastern areas received wellbelow-normal rainfall, with particularly dry conditions observed in the northern parts of the Kruger National Park.

\section{(iii) Notable events and impacts}

In South Africa, large amounts of rain fell during short time periods during June and July over isolated areas in the Western Cape, Eastern Cape, and KwaZulu-Natal provinces, leading to several localized flooding events. During November, flood- 
(a) DJF
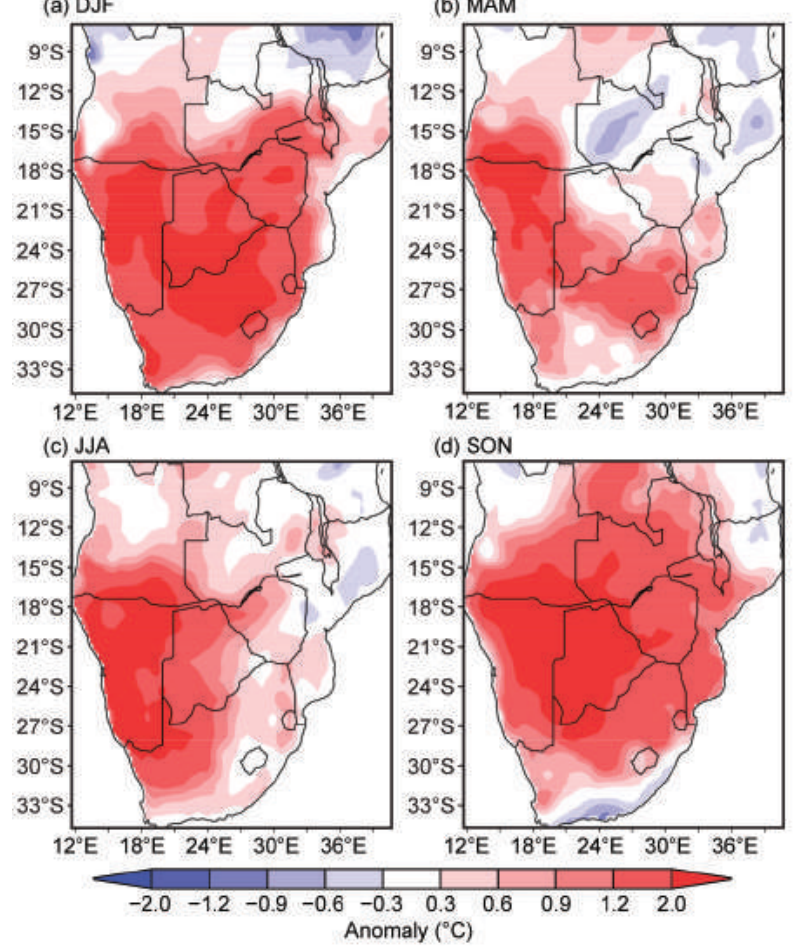

Fig. 7.25. Southern Africa seasonally averaged mean temperature anomalies $\left({ }^{\circ} \mathrm{C}, 198 \mathrm{I}-2010\right.$ base period) for (a) DJF 2015/16 and (b) MAM, (c) JJA, and (d) SON 2016. (Source: ERA-Interim.)

(a) DJF

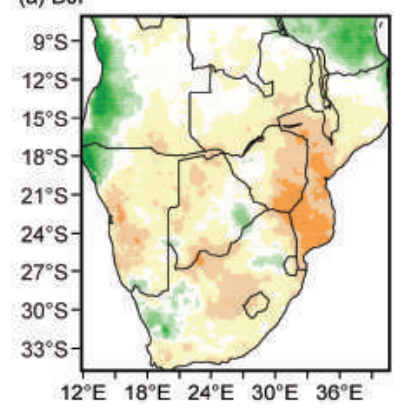

(c) JJA

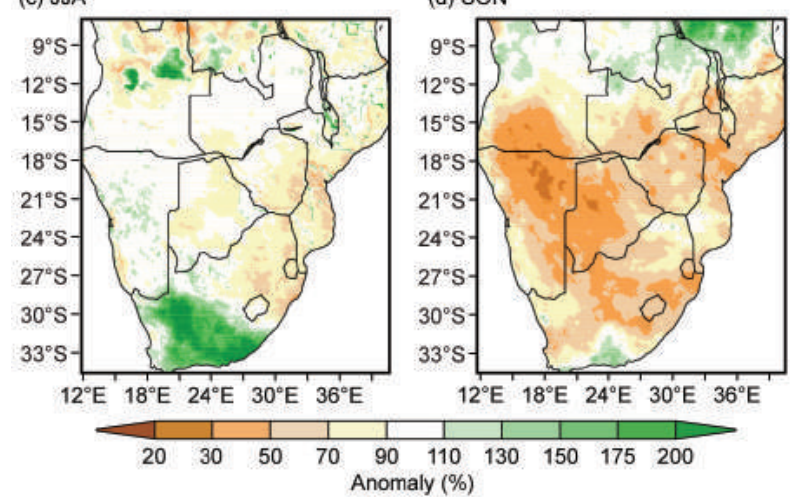

FIg. 7.27. Southern Africa seasonal total rainfall anomalies (\% of normal ; 1981-2010 base period) for (a) DJF 20I5/16 and (b) MAM, (c) JJA, and (d) SON 2016. (Source: CHIRPS.)

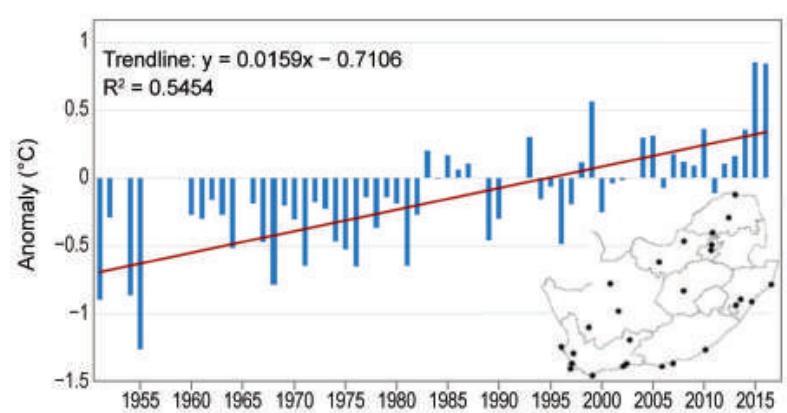

Fig. 7.26. Annual mean temperature anomalies $\left({ }^{\circ} \mathrm{C}\right.$; 198I-2010 base period) of 26 climate stations in South Africa, as indicated on inset map, for the period 1951-2016. The red line represents the linear trend. (Source: South African Weather Service.)

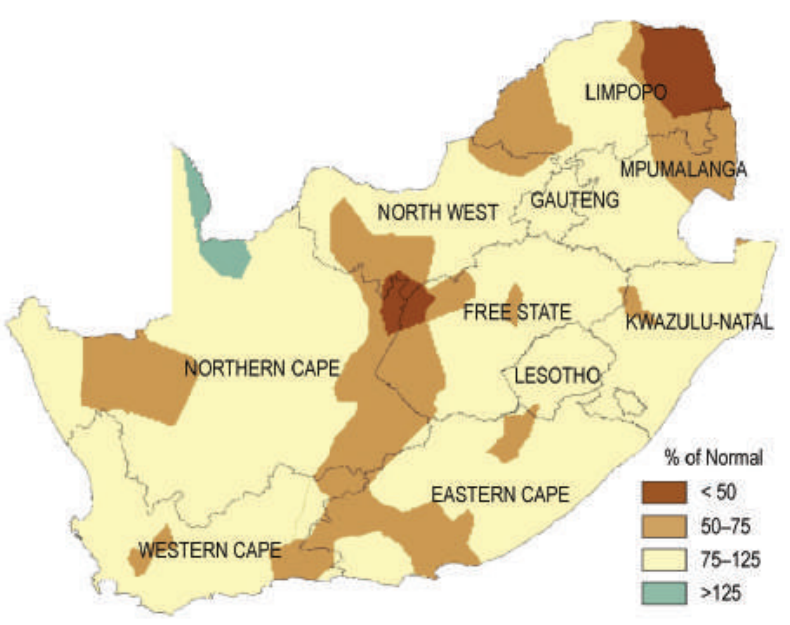

Fıg. 7.28. Rainfall anomalies (\% of normal; $|98|-2010$ base period) for South Africa during 2016. (Source: South African Weather Service.)

ing occurred in the Johannesburg and Ekurhuleni area, with hourly rainfall data indicating a possible 1-in-200 year event.

5) Western Indian Ocean island countriesG. Jumaux, M. Belmont, A. Abdallah, S. Dindyal, and P. Caroff

This region consists of several island countries: Seychelles, Comoros, Mayotte (France), La Réunion (France), Mauritius, and Rodrigues (Mauritius).

Overall, the 2016 mean temperature was well above normal while precipitation was mixed across the region. Figure 7.29 shows temperature and rainfall anomalies for several selected areas.

\section{(i) Temperature}

The annual mean temperature at Seychelles International Airport was $0.5^{\circ} \mathrm{C}$ above the long-term mean, making 2016 its fourth warmest year since records began in 1972. As indicated in Fig. 7.30, only July had a negative anomaly, $-0.1^{\circ} \mathrm{C}$. The highest anomaly was in March with a value of $+1.1^{\circ} \mathrm{C}$. 
For Comoros Islands, 2016 was the second warmest year since records began in 1981, with an annual mean temperature anomaly (based on three stations) of $+0.7^{\circ} \mathrm{C}$. Positive anomalies were recorded during the warmer months of the year (January-April and November-December). Temperatures were close to average during winter, ranging from $24.8^{\circ}$ to $27.0^{\circ} \mathrm{C}$.

For Mayotte Island (Pamandzi Airport station), 2016 was the second warmest year since records began in 1961, with an annual mean temperature anomaly of $+0.7^{\circ} \mathrm{C}$, behind only 2015 . It was the second warmest January-March period, after 1998. Temperatures were slightly above average during winter.

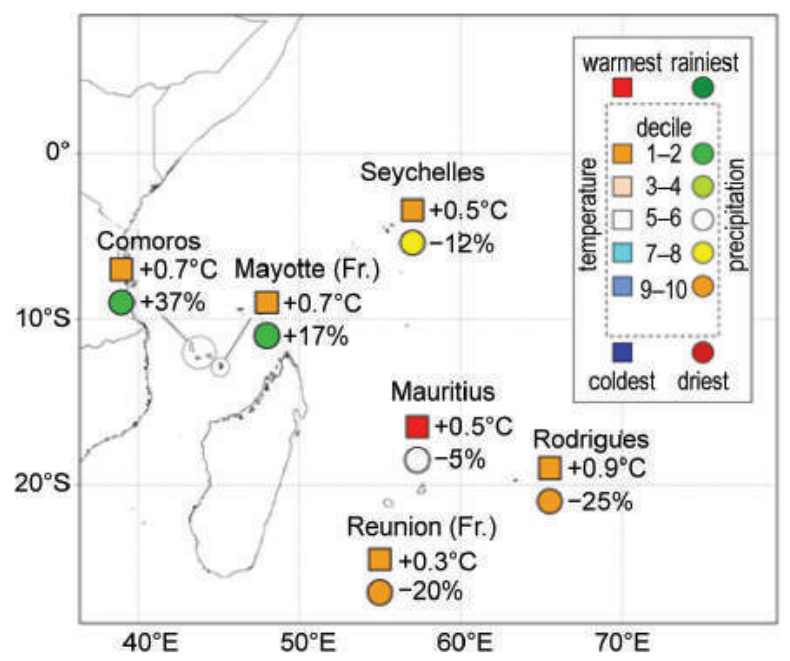

FıG. 7.29. Mean annual temperature anomalies $\left({ }^{\circ} \mathrm{C}\right)$, annual rainfall anomalies (\% of average), and their respective deciles for the Indian Ocean islands. Anomalies with respect to 198I-2010. (Sources: Météo France; and Meteorological Services of Seychelles, Comoros, and Mauritius.)

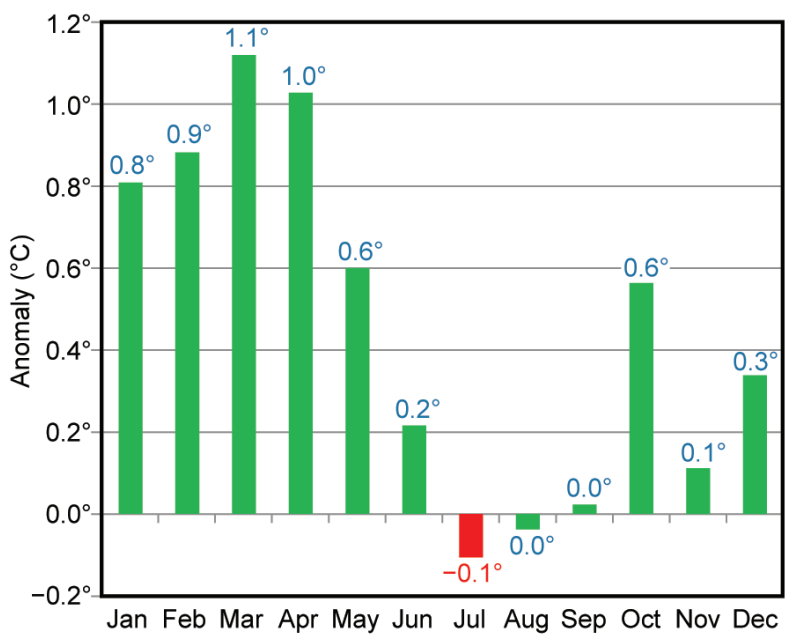

FIG. 7.30. Mean monthly temperature anomalies $\left({ }^{\circ} \mathrm{C}\right.$; 198I-2010 base period) at Seychelles International Airport. (Source: Seychelles Meteorological Services.)
On Réunion Island, the annual mean temperature in 2016 (based on three stations) was $0.3^{\circ} \mathrm{C}$ above average, ranking eighth highest since records began in 1968. Temperatures during January-April and October and November were considerably above the reference base period, but temperatures were below normal during May and June.

In Mauritius, the annual mean temperature was $23.2^{\circ} \mathrm{C}, 0.5^{\circ} \mathrm{C}$ above the long-term mean (based on two stations), making 2016 the warmest year since records began in 1958. The summer months, at the beginning of the year, had temperature departures of $+0.9^{\circ}$ to $+1.2^{\circ} \mathrm{C}$ compared to average. The winter months were near normal, except for August, which was slightly above. The highest maximum temperature of $35.6^{\circ} \mathrm{C}$ for the year was observed in Port-Louis in January.

For Rodrigues (Pointe Canon station), the departure of the annual mean temperature from the longterm average was $+0.9^{\circ} \mathrm{C}$, its ninth highest since 1958 .

\section{(ii) Precipitation}

For Seychelles, the 2016 annual rainfall (2080 mm) was $88 \%$ of its annual average of $2367 \mathrm{~mm}$. This ranks as 15th driest among the 45 years of record. As indicated in Fig. 7.31, July to October were particularly dry months.

For Comoros Islands, annual total rainfall (based on three stations) was $137 \%$ of average. It was the 10 th wettest year since records began in 1961. The rainy season was the wettest on record (163\% of JanuaryMarch average).

For Mayotte Island, the annual rainfall amount in 2016 was $117 \%$ of average at Pamandzi Airport, ranking 11th wettest since 1961. The rainy season (January-March) was its wettest on record (162\% of

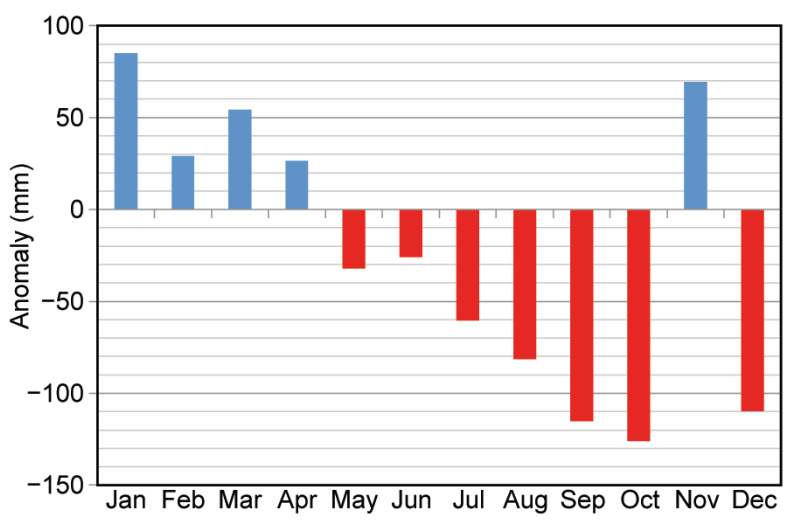

FIG. 7.3I. Mean monthly total precipitation anomalies (mm; 198I-2010 base period) at Seychelles International Airport. (Source: Seychelles Meteorological Services.) 
average). In contrast, the July-December period was the driest on record (39\% of average), leading to severe drought and water use restrictions.

For Réunion Island, the 2016 annual rainfall amount was $80 \%$ of average, ranking as ninth driest since 1969. February was the wettest month of the year (more than $1100 \mathrm{~mm}$ observed in the highlands), but total rainfall during the rainy season (JanuaryApril) was only $73 \%$ of average, ranking sixth driest. During the dry season (May-November), rainfall was slightly below normal.

The annual total rainfall over Mauritius was 1895 mm which was $95 \%$ of average and the 24 th wettest year since 1960. As shown in Fig. 7.32, the highest rainfall amount was recorded in February, associated with active clouds from Tropical Storm Daya. There were variations in summer rainfall, with some months recording above-normal values while others had below-normal values. The winter rain was normal.

For Rodrigues (Pointe Canon) annual rainfall was $75 \%$ of normal accumulation, which is the sixth driest since 1954.

\section{(iii) Notable events and impacts}

Tropical Cyclone Fantala developed $200 \mathrm{~km}$ south of Agalega (Mauritius dependency, located $1070 \mathrm{~km}$ north of Mauritius) on the morning of 16 April. As a precautionary measure, all the inhabitants of the South Island were moved to the North Island. The cyclone effects on the island were minimal. It did however, cause extensive damage on Seychelles islands. On the evening of 17 April the Atoll of Farquhar (Seychelles) was devastated by Fantala, which was about to reach its maximum intensity at the time. The eye passed directly over this main island of the Farquhar group, which was swept by $8^{\circ} \mathrm{S}$ very strong winds, with peak gusts that exceeded $330 \mathrm{~km} \mathrm{~h}^{-1}$. The other small islets of the remote archipelago belonging to Seychelles were also affected in the ensuing hours, although to a lesser extent.

The impact on Farquhar Atoll was $12^{\circ} \mathrm{S}$ great as Fantala was an exceptional storm, one of the five most intense cyclones observed in the southwest Indian Ocean basin since the begin- $14^{\circ} \mathrm{S}$ ning of the satellite era (1976) and virtually tied for the second place with some memorable cyclones of the basin (Geralda, Litanne, Gafilo).

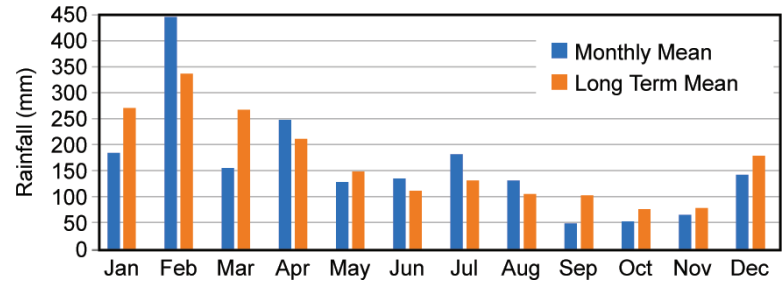

FIG. 7.32. 2016 monthly precipitation totals $(\mathrm{mm}$; 198I-2010 base period) in Mauritius. (Source: Mauritius Meteorological Services.)

Farquhar Atoll became only the second land in the basin to suffer a direct hit from a very intense tropical cyclone. (Madagascar was hard hit by "super cyclone" Gafilo in March 2004.) Fantala was only the second cyclone since the beginning of the satellite era to affect the Farquhar group, which is unaccustomed to preparing for this type of event. (The only other cyclone to hit the group was the passage of cyclone Bondo over the archipelago on 21 December 2006.) Fantala decimated the vegetation, and it will likely take years to reconstitute the coconut groves.

The path of Fantala is shown in Fig. 7.33. After the initial passage, Fantala reversed course and tracked back across the Farquhar group two days later-with much less intensity-as a weaker tropical cyclone. The track of the storm was unique, going back and forth and retracing almost the same trajectory twice for over more than $1000 \mathrm{~km}$. Fantala passed over the Farquhar Archipelago for a third and final time as it finally decayed. While the impacts of this third passage were harmless, it was certainly unique in the history of the basin.

Fantala also became the northernmost very intense tropical cyclone recorded over the southwest

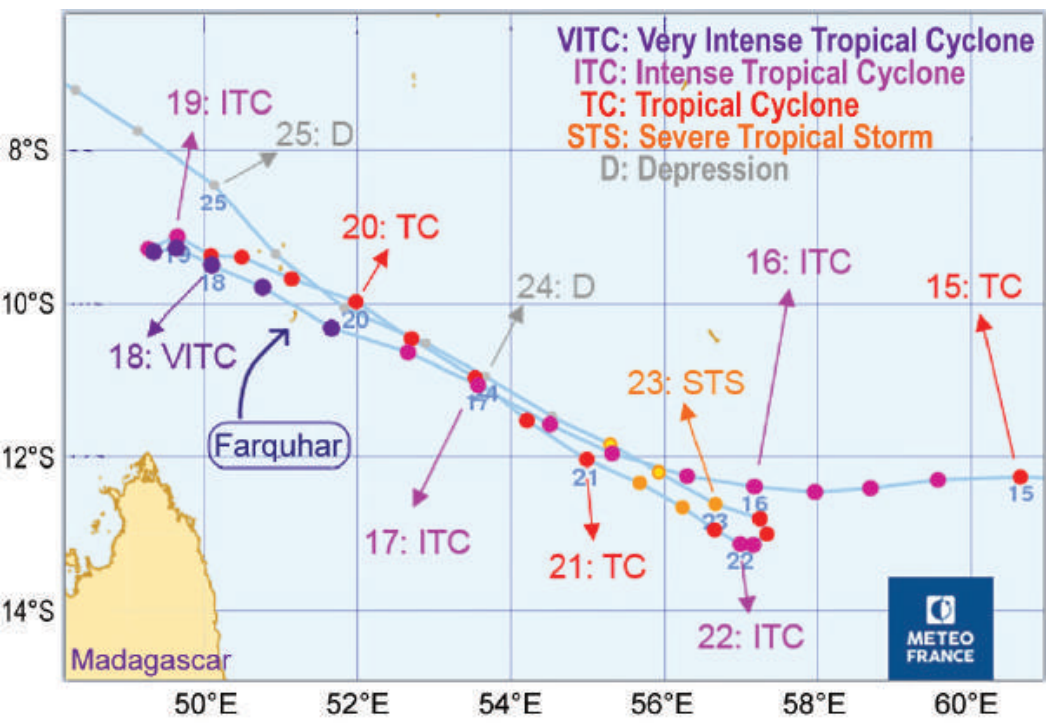

Fig. 7.33. Tropical Cyclone Fantala's unique trajectory over the Farquhar group (15-25 Apr 2016). (Source: Météo France.) 
Indian Ocean basin (and closest to the equator), and had the strongest intensity of any storm north of latitude $10^{\circ} \mathrm{S}$.

f. Europe and the Middle East-P. Bissolli, M. Demircan, J. M. Gutiérrez, M. Kendon, J. Kennedy, M. Lakatos, M. McCarthy, C. Morice, M. R. Pons, R. Rollenbeck, S. Sensoy, K. Trachte, and $\mathrm{G}$. van der Schrier

This section covers western Europe, from Scandinavia to the Mediterranean, and extends from Ireland and the United Kingdom to eastern Europe, European Russia, and parts of the Middle East.

Throughout this section, normal is defined as the 1961-90 average for temperature and 1981-2010 for precipitation, unless otherwise specified. European countries conform to different standard base periods applied by their national weather services. All seasons mentioned in this section refer to the Northern Hemisphere (with winter defined as DJF 2015/16). Significance implies an exceedance of 5 th or 95th percentiles.

More detailed information, including monthly statistics, can be found in the Monthly and Annual Bulletin on the Climate in RA VI - European and the Middle East, provided by WMO RA VI Regional Climate Centre Node on Climate Monitoring (RCC Node-CM; www.dwd.de/rcc-cm). All statistics reported here are for three-month seasons, unless otherwise noted.

\section{I) OVERVIEW}

The annual mean land surface temperature in Europe for 2016 was the third highest in the CRUTEM4 record dating back to 1851 (Fig. 7.34; Jones et al. 2012) with an anomaly of $+1.41^{\circ} \mathrm{C}$ compared to the 1961-90 normal, although the annual temperature declined relative to the two previous years. The spatial dis-

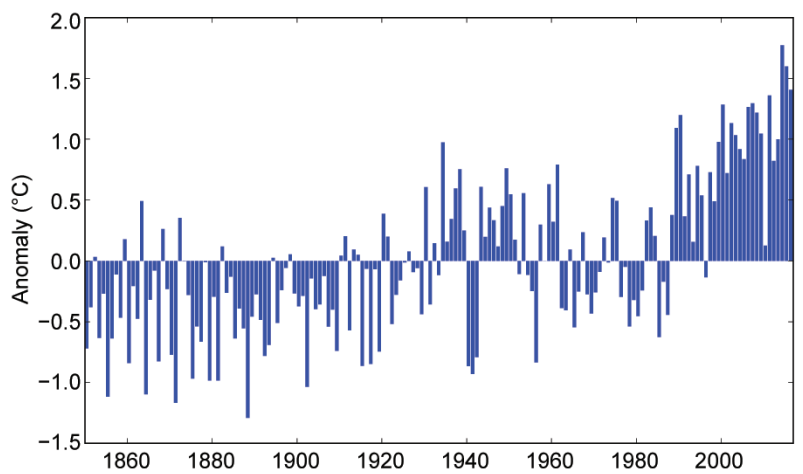

Fig. 7.34. Annual average land surface air temperature anomalies for $185 \mathrm{I}-2016\left({ }^{\circ} \mathrm{C}\right)$ across Europe $\left(35^{\circ}-75^{\circ} \mathrm{N}\right.$, $\left.10^{\circ} \mathrm{W}-30^{\circ} \mathrm{E}\right)$, relative to the $1961-90$ base period. The value for 2016 is represented by the green bar. Data are from the CRUTEM4 dataset (Jones et al. 2012.) tribution of annual anomalies ranged from slightly above average in places primarily in western and southern Europe to above $+6^{\circ} \mathrm{C}$ at the southern edge of the Arctic region. Most of Europe had anomalies between $+1^{\circ}$ and $+2^{\circ} \mathrm{C}$ (Fig. 7.35).

Precipitation totals (Fig. 7.36) showed several large positive deviations from the 1981-2010 average, especially in western parts of Russia, northern Scandinavia, and parts of the Balkans. Drier-than-

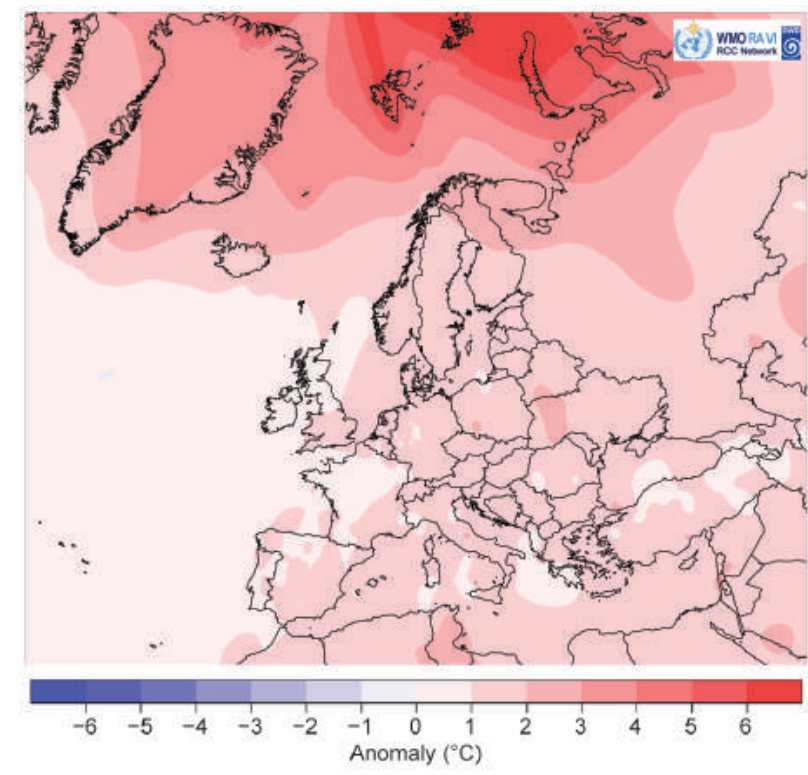

Fig. 7.35. European 2016 annual mean air temperature anomalies ( ${ }^{\circ} \mathrm{C}$; 1961-90 base period), based on CLIMAT station data. Anomalies were computed at stations and values interpolated across the region. [Source: DWD (Hogewind and Bissolli 20II).]

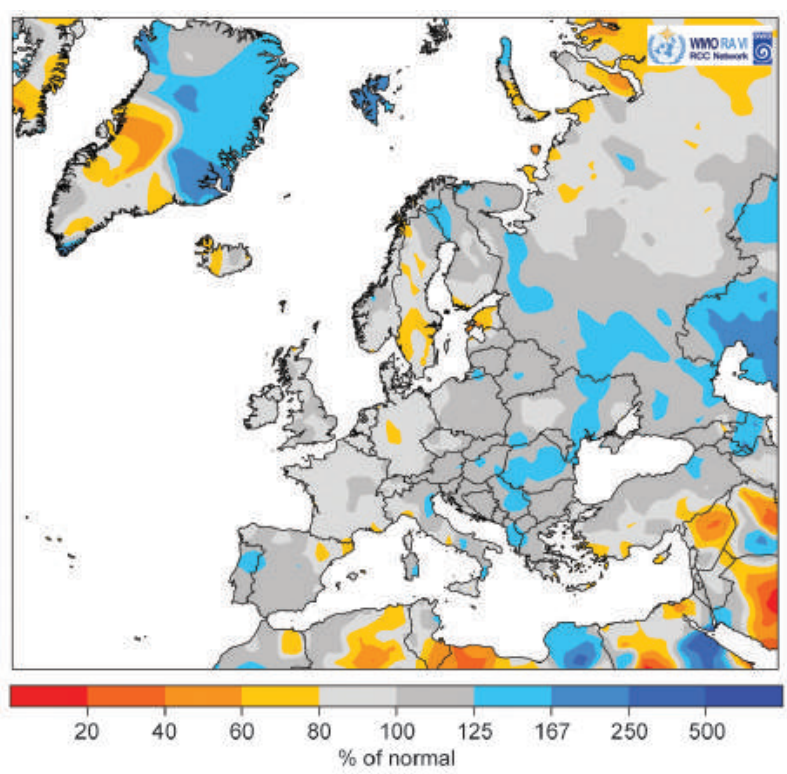

FIG. 7.36. European 2016 precipitation totals (\% of |98|-2010 normal). (Source: DWD.) 
average conditions occurred particularly in small areas at the Mediterranean coast of Spain, France, Greece, and Turkey. Large negative anomalies were observed in the Middle East and in parts of northern urope. For the rest of Europe, precipitation totals were near normal.

Winter 2015/16 was much warmer than normal (Fig. 7.37), with large positive anomalies in Russia (up to $+6^{\circ} \mathrm{C}$ ) and the Arctic and reaching $+4^{\circ} \mathrm{C}$ in a band from Ukraine to England. This anomaly was associated with a well-developed Icelandic low and higher pressure above the Mediterranean Sea (Fig. 7.38), also expressed by a NAO index of +1.31 [North Atlantic Oscillation Index, normalized pressure difference between the Azores high (Ponta Delgada, Azores) and the Icelandic low (Reykjavík, Iceland)]. This synoptic situation caused warmer Atlantic air masses to enter far into central and eastern Europe, where they were advected on the western flank of the Siberian high and displaced far to the north of Russia, causing unusual warmth there and a widespread precipitation surplus for the whole of western Russia.

Spring temperatures were generally above average, especially from Germany eastward, continuing the warm spell in northern Russia with positive anomalies of up to $+4^{\circ} \mathrm{C}$. In spring, low pressures system took a more southerly position and brought a surplus of precipitation to several regions, notably western France, Spain, Portugal, and southern Russia (Fig. 7.38).

Summer saw a reversal of climate conditions in western Europe: high pressure developed west of the Iberian Peninsula and steered low pressure centers farther north. Consequently, temperatures were above normal with anomalies of up to $+4^{\circ} \mathrm{C}$ in Spain, $+1^{\circ} \mathrm{C}$ to $+2^{\circ} \mathrm{C}$ in central Europe, and $+3^{\circ} \mathrm{C}$ to $+4^{\circ} \mathrm{C}$ in eastern parts of the region. Also, the large positive anomaly $\left(+6^{\circ} \mathrm{C}\right)$ in northern Russia remained. The Iberian Peninsula and parts of France suffered a drought with precipitation below $20 \%$ of the long-term average. Dry conditions also occurred in Ukraine, Belarus, and, notably, in parts of southern central European Russia. Scandinavia, the Baltic Countries, and northwestern of Russia, on the other hand, had above-average precipitation amounts of up to $170 \%$ of the normal. Similar positive precipitation anomalies
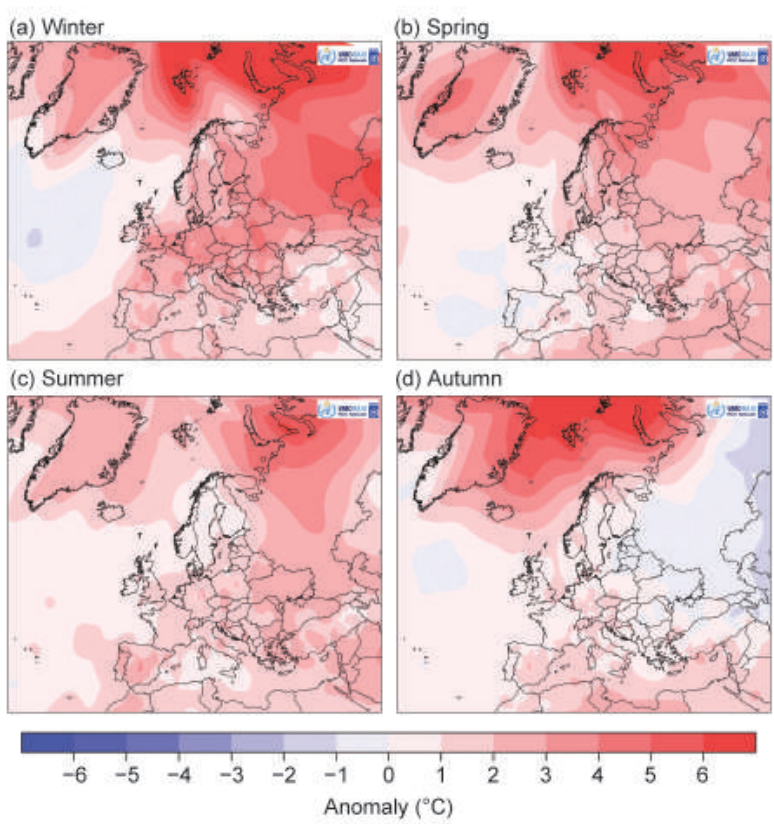

FIG. 7.37. Near-surface air temperature anomalies ( $\left.{ }^{\circ} \mathrm{C}\right)$ using interpolated CLIMAT data from DWD (196I-90 base period) for (a) DJF, (b) MAM), (c) JJA, and (d) SON.
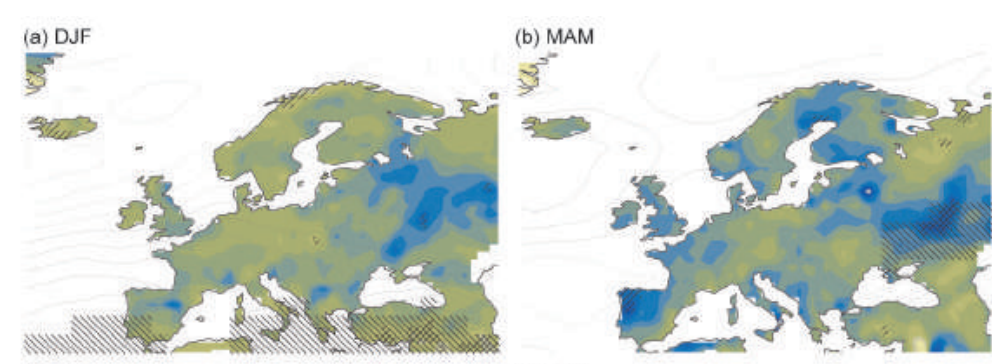

(c) JJA

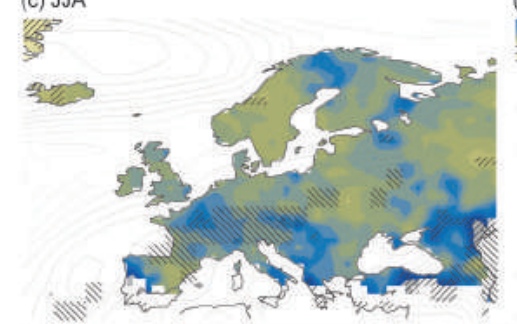

(d) SON
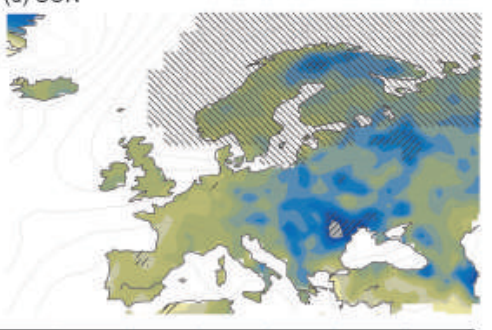

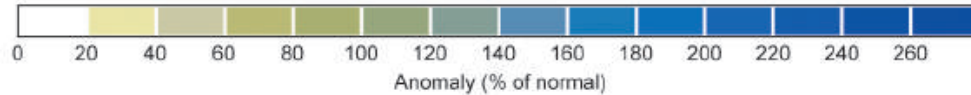

Fig. 7.38. Seasonal anomalies for 2016 (198I-2010 base period) of sea level pressure ( $\mathrm{hPa}$, contours) and seasonal precipitation anomalies (\%, shading) from NCAR-NCEP reanalysis for (a) DJF, (b) MAM, (c) JJA, and (d) SON. Left hatches indicate where the anomaly at sea level pressure is significant at the 5 th or 95 th percentile. Right hatches show the same conditions for seasonal precipitation. White areas have received either less than $20 \%$ of normal or below $15 \mathrm{~mm}$ seasonal precipitation. Negative sea level pressure anomalies are indicated by dashed contours. Black areas indicate regions where data have been inadvertently omitted from the figure. Please note the base period used here is different from that used in Fig. 7.37. (Source: NOAA/ ESRL Physical Sciences Division, www.esrl.noaa.gov/psd.) 
occurred in Sicily, Greece, and, to a lesser extent, in Hungary and Romania (Fig. 7.38).

In autumn, the unusually warm period ended for eastern Europe, and temperatures were slightly below average for all of the region, except the far north, which saw anomalies of $+5^{\circ} \mathrm{C}$ at the coast of the Barents Sea and $+3^{\circ} \mathrm{C}$ in northern Norway. That pattern was associated with a strongly negative NAO period that affected much of Eurasia. Western Europe saw only slight deviations from normal, around $+1^{\circ} \mathrm{C}$ in the Mediterranean. Dry conditions were observed $(60 \%-80 \%$ of normal precipitation, locally even less) in a wide stretch from the Atlantic coast across western Europe and Scandinavia up to northern Russia. Dry conditions also affected parts of the Middle East (down to 20\% of normal in places) and Turkey. Wetter conditions were seen in places from southern Italy and Greece to Romania, Moldova, and Ukraine, with the latter three receiving up to $250 \%$ of their average precipitation. The northern region of positive temperature anomalies across Russia and Scandinavia was associated with elevated 500-hPa heights, whereas a zonal decrease of heights towards the Mediterranean could be seen. As in spring 2016, moist cyclonic systems were displaced to the south in contrast to a strong high pressure system over Scandinavia and Russia.

In December 2016, the warm pool in the north shifted westward, and average temperatures in northern Russia dropped sharply to $6^{\circ} \mathrm{C}$ below normal. Scandinavia remained extremely warm, with anomalies of $+6^{\circ} \mathrm{C}$ in the north of Sweden. The Russian cold air extended far to the south, affecting the eastern Mediterranean with deviations down to $-4^{\circ} \mathrm{C}$ in Turkey. Colder conditions also occurred in France $\left(2^{\circ} \mathrm{C}\right.$ below average in the east). At the same time, December was a rather dry month in several countries. Switzerland reported some places with no precipitation at all, and totals of only $20 \%$ of normal or less were observed in France, Spain, Italy, the Balkan countries, Greece, and western Turkey. The Middle East, however, reported large positive precipitation anomalies of up to $250 \%$ and more. This situation is typical of an "Omega" blocking pattern: constant high pressure above $1030 \mathrm{hPa}$ centered over central Europe effectively blocked all cyclonic systems, leading warm air to the north of Europe and cold arctic air masses to the eastern parts of the region. Due to the frequent formation of ground fog, average surface air temperatures remained low at the core of the high pressure cell.

\section{2) Central and Western Europe}

This region includes Ireland, the United Kingdom, the Netherlands, Belgium, Luxembourg, France, Ger- many, Switzerland, Austria, Poland, Czech Republic, Slovakia, and Hungary.

\section{(i) Temperature}

The year started with another very mild winter, especially in central Europe, and maintained positive anomalies of up to $+2.5^{\circ} \mathrm{C}$ throughout the year. The overall gradient of European temperature anomalies for 2016 was also visible in western and central Europe: slight positive anomalies in the western countries such as Ireland, France, and Portugal (up to $+0.5^{\circ} \mathrm{C}$ ) and higher anomalies in Poland, Hungary, Austria, and Slovakia $\left(+2^{\circ}\right.$ to $\left.+4^{\circ} \mathrm{C}\right)$. In most of the countries, 2016 ranked between sixth and tenth warmest on record. The length of record varies by country, but each has at least 50 years of continuous observation.

Winter 2015/16 was characterized by a warm pool over northeastern central Europe. Average monthly temperature anomalies in Poland, Hungary, Czech Republic, Slovakia, and Austria were up to $+6^{\circ} \mathrm{C}$ in February. Austria registered its second warmest February since its records began in 1858 , with peak temperatures reaching $23.2^{\circ} \mathrm{C}$ on 22 February, a new national record for that date. Warm air also extended into Switzerland but did not break records there.

The circulation pattern in spring turned more meridional, leading to a near-normal season in central Europe, with France slightly below its 1961-90 average. Eastern countries were slightly warmer than average, due to southwesterly flows caused by a Mediterranean low, transporting subtropical air masses to the northeast.

Summer started with near-average temperatures, but positive anomalies developed in July and August as the Azores high strengthened. Temperature anomalies were around $+2^{\circ} \mathrm{C}$ in Poland. By mid-August France, Switzerland, and England reached similar anomalies, with Paris experiencing a new record temperature for late August of $36.6^{\circ} \mathrm{C}$ on the 24th. In Hungary and Austria, however, summer temperature anomalies were as low as $-2^{\circ} \mathrm{C}$.

Conditions in summer led to the onset of a very warm September, with several places in central Europe setting new records for early autumn. Switzerland had its warmest September since its records began in 1864, Germany reported 95 sites with new monthly records, and France saw anomalies of up to $+7^{\circ} \mathrm{C}$. In the maritime southern United Kingdom, Gravesend (Kent) recorded $34.4^{\circ} \mathrm{C}$ in mid-September, an unusually late date to record Britain's highest temperature for the year. September average anomalies of $+3^{\circ} \mathrm{C}$ were observed in Hungary, Slovakia, and the Czech Republic. October and November cooled down 
to average conditions in most of central Europe, leveling the seasonal average to more moderate conditions, even though September was extreme.

In December a persistent high pressure system again settled over central Europe, and the frequent formation of ground fog in Hungary, Slovakia, Austria, and Germany led to low surface air temperatures with negative anomalies as much as $-3^{\circ} \mathrm{C}$. Elevated regions like Switzerland and the French Alps, on the other hand, received a considerable surplus of sunshine and warmer conditions.

\section{(ii) Precipitation}

Total annual precipitation amounts (see Fig. 7.36) in western and central Europe were near-average, but there were notable seasonal differences. Specifically, there was a considerable difference between the first and the second half of the year.

Winter 2015/16 featured a below-average snow cover due to the mild temperatures, but there was abundant rainfall, especially in February, reaching 400\% (Austria and Hungary), 375\% (Slovakia) and 160\% (Czech Republic) of normal. For Austria, February 2016 was one of the wettest on record for the country. Ireland had a considerable precipitation surplus, reported its wettest winter on record. March offset the high precipitation totals, with a dry belt from the French Mediterranean coast across the Alps reaching into Hungary. The northern coasts of Germany and Poland also saw dry conditions.

Spring brought strong and persistent rainfalls for France, Belgium, and the Netherlands. The southeast of the United Kingdom was also affected by this recurring inflow of humid Atlantic air masses supported by an extended low pressure cell above Scandinavia and a secondary cyclonic system above the Mediterranean Sea (the Genoa low) which creates a high potential for torrential rains. Germany, Poland, and Czech Republic had below-average spring precipitation of around $60 \%$ to $80 \%$ of normal.

In June, moist flows into western central Europe persisted, but this time also reached into Germany and Switzerland. Several severe weather events with flooding were reported from Ireland, France, and Germany. Belgium registered its highest June precipitation since 1981. In July, and more pronounced in August, high pressure became dominant in central Europe, steering moisture-bearing systems to the north. In France, dry conditions set in with July and August precipitation amounts only $20 \%$ to $40 \%$ of normal.

This situation persisted into September, with dry conditions extending into Benelux, Germany, and notably in Poland, with totals only $20 \%$ of normal. October and November balanced the deficits in eastern central Europe, but France and Germany maintained a deficit for autumn down to $60 \%$ of the normal. December brought very dry conditions for many central European countries. Several stations in France, Switzerland, Germany, Austria, and Hungary received no rain at all during the month.

\section{(iii) Notable events and impacts}

From 28 April to 1 May, a late snow storm hit central Europe from Scandinavia to the Mediterranean region and brought heavy snow and rain to the Austrian Alps with unusual frost and widespread damage to agriculture, including vineyards, broadleaf/fruit trees, and various crops.

From 26 May to 4 June, southeastern/central France, Belgium, the southern part of the Netherlands, and southern Germany were crossed by a slow moving low pressure system. In several places, twice the monthly total of precipitation was exceeded in a few days, and heavy floods followed, with fatalities and damage to infrastructure, including houses, gardens, and roads (see Sidebar 7.3).

On 23 June, the Netherlands reported an extreme hail event with hailstones up to $10 \mathrm{~cm}$ in its province of Brabant, causing damage of approximately 500 million euros (\$530 million U.S. dollars).

\section{3) The Nordic and the Baltic countries}

This region includes Iceland, Norway, Denmark, Sweden, Finland, Estonia, Latvia, and Lithuania.

\section{(i) Temperature}

Even with widespread cold conditions in January, Scandinavia and the Baltic countries had a warm 2016. All countries in the region had positive anomalies of $+1^{\circ}$ to $+2^{\circ} \mathrm{C}$ for the year. For the northwestern part of Iceland it was the warmest year $\left(+2.1^{\circ} \mathrm{C}\right)$ recorded since records began in 1871 . Norway, Sweden, and Finland had large positive anomalies around $+3^{\circ}$ to $+7^{\circ} \mathrm{C}$, especially in their northern territories. The main source of warmth for the Nordic countries was the unusual warming of the Arctic Ocean and northern Russia, supported by a northward shift of the polar front.

Winter 2015/16 started with a mild December but turned into a cold January with negative anomalies in all countries, down to $-6^{\circ} \mathrm{C}$ in the north of Finland. February and March balanced the seasonal anomaly with very mild temperatures bringing anomalies of up to $+5^{\circ} \mathrm{C}$ or more in Norway, Sweden, Finland, and the Baltic countries (Fig. 7.39). 


\section{SIDEBAR 7.3: THE NAKED SHEEP-RAINSTORMS, FLOODS, AND COLD WEATHER CAUSED BY EXTRAORDINARY CYCLONIC ACTIVITY IN MAY/JUNE 2016 IN CENTRAL EUROPE-R. ROLLENBECK, P. BISSOLLI, AND G. VAN DER SCHRIER}

In Germany sheep are traditionally sheared with the first warming in May; hence a cold wave that follows in early June is termed Schafskälte ("sheep's cold"). The event is caused by advection of cool and moist air, mostly from the North Sea, after a rapid warming of land surfaces with high sun angles, while sea surface temperatures lag behind. This increases the frequency and intensity of convection and resulting cyclonic activity in central Europe. In 2016, the cold wave started early and brought large amounts of precipitation. At the end of May, precipitation totals usually accumulated in one month were obtained in only a few days at many stations particularly in France, Belgium, the Netherlands, and Germany. The situation was especially severe from 26 May to 4 June in the southern part of this region.

The situation developed with a circulation pattern known as a "low over central Europe". A well-developed high pressure ridge from Iceland to across Scandinavia blocked the zonal flow and directed a chain of low pressure systems towards central Europe (Fig. SB7.5). On 26 May a large cut-off low in the eastern Atlantic triggered the development of several slow moving low pressure systems. In France heavy rainfall was widespread, due to large-scale advection of warm and humid air from the south. Germany was more affected by intense local thunderstorms on the leading edge of the cyclonic systems. Similarly, in Austria and Romania moist and unstable air was transported from eastern and southeastern Europe westward, mixing with colder air from the Atlantic.

The first heavy rainfalls of this event started in France on 22 May, with areas stretching from the Pyrenees to northern France receiving daily totals of 15 to $30 \mathrm{~mm}$. This saturated soils and produced the conditions for severe flooding. During the following two days, precipitation cells moved eastwards, orographically enhanced in Switzerland and Austria (>50 $\mathrm{mm} \mathrm{day}^{-1}$ ) and fueled by warm air in Romania and Moldova (up to $50 \mathrm{~mm} \mathrm{day}^{-1}$ ). The almost stagnant low pressure systems over France formed new frontal systems on 28 May, and the southeastern mountain chains in France again received up to $50 \mathrm{~mm}$ of precipitation.

The next day (29 May), the thunderstorm activity shifted northwards with its center in western France and in southern Germany, where the small village of Braunsbach was hit by a thunderstorm of extreme intensity-accumu- lating $>50 \mathrm{~mm}$ of precipitation in one hour and an event total of $90 \mathrm{~mm}$ in a few hours. The resulting flash flood damaged houses and infrastructure. Across southern Germany, four associated fatalities occurred on this day. On 30 May, a precipitation cell developed which covered all of Belgium, almost a quarter of France, and the south of the Netherlands with spatial average rainfall totals of well above $40 \mathrm{~mm}^{-1} \mathrm{day}^{-1}$ and peak event totals of $65 \mathrm{~mm}$ and more recorded at the French stations Trappes and Orléans (Fig. SB7.6). This rainstorm was sufficient to cause widespread flooding, and the River Seine quickly rose to record levels last seen in 1982 and surpassed only by the big flood of 1910.

On I June, the blocking situation weakened and cyclonic activity started to slowly move eastward. Extreme rainfall amounts were again registered in the Limburg Province the of Netherlands and on 2 June at the border of Romania and Moldova. The monthly total for station Ysselstein (Limburg, NL) reached $277 \mathrm{~mm}$, almost four times the June normal value for this station. The station Paris Montsouris, with continuous measurements from 1873, surpassed its former monthly precipitation record for June by $37 \%$ (137\% of normal), with a total of $178.6 \mathrm{~mm}$.

The floods, landslides, and infrastructure damage of this rainy week caused 18 fatalities, II of them in Germany. Economic damage was estimated above I billion euros (>\$I.07 billion U.S. dollars).

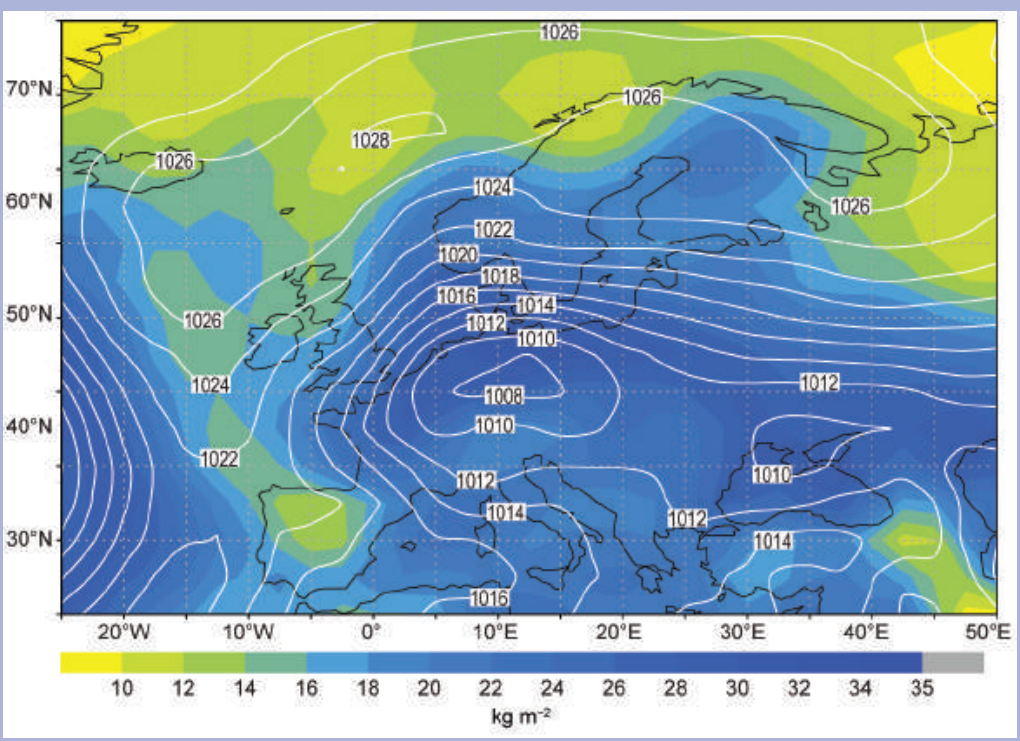

FIG. SB7.5. Four-day average mean sea level pressure (hPa; contours) and precipitable water ( $\mathrm{kg} \mathrm{m}^{-2}$; shading) from 29 May to I Jun 2016. [Source: NOAA/ESRL Physical Sciences Division, www.esrl.noaa.gov Ipsd (Kalnay et al. 1996).] 
CONT. SIDEBAR 7.3: THE NAKED SHEEP-RAINSTORMS, FLOODS, AND COLD WEATHER CAUSED BY EXTRAORDINARY CYCLONIC ACTIVITY IN MAY/JUNE 2016 IN CENTRAL EUROPE-R. ROLLENBECK, P. BISSOLLI, AND G. VAN DER SCHRIER

Additional local events of heavy precipitation occurred during the next weeks in the Netherlands, where a local thunderstorm produced hailstones of $5-10 \mathrm{~cm}$ in the

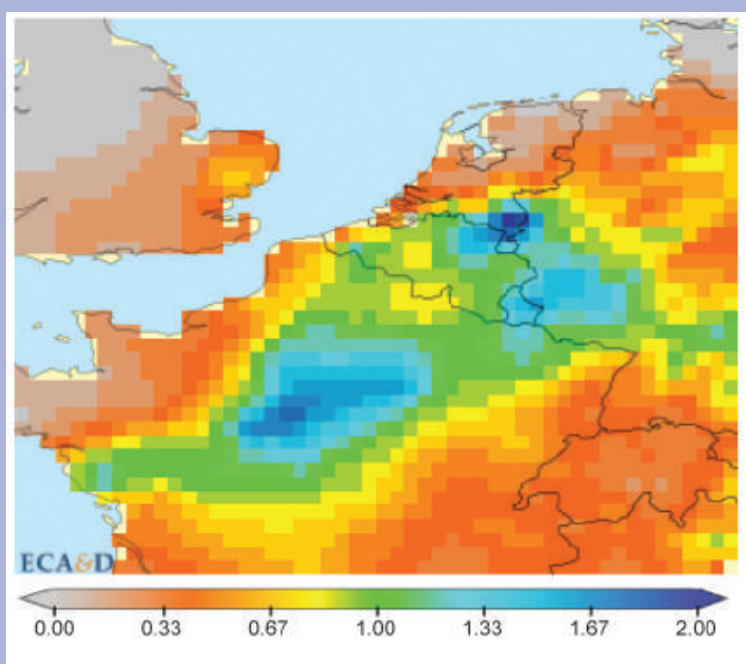

FIG. SB7.6. Total precipitation for 29 May-4 Jun 2016 as a fraction of the May long-term average monthly precipitation. [Source: E-OBS dataset (Haylock et al. 2008; www.ecad.eu).] province of Brabant, causing damage of an estimated 500 million euros (\$533 million U.S. dollars). In Austria, three periods of heavy precipitation occurred: the first on 4 and 5 June, with widespread flooding; a second in mid-June with landslides and hail damage in the Bodensee (Lake Constance) region; and a third event on 25 and 26 June, causing a landslide in the province of Carinthia that completely isolated the village of Pöllatal. With the advance of the Azores high towards central Europe by midJuly, the rainy period ended and gave way to a warm and dry remainder of the summer.

The circulation pattern of stagnant low pressure systems in central Europe is not uncommon, but only rarely are there such intense rainfalls. Although long-term analyses of high-intensity rainfalls in central Europe do not show a significant trend, a steeper zonal gradient of temperature is likely to support higher intensity heavy rainfall events. Authorities and administrations are trying to improve their preparedness for heavy precipitation by using the growing information from meteorology and climate science.
Spring continued with warm conditions with anomalies of $+3^{\circ}$ to $+5^{\circ} \mathrm{C}$ in Norway, Sweden, Finland, and the Baltic countries. Denmark reported its third warmest May since its records began in 1874, and the Baltic countries showed positive anomalies up to $+3.5^{\circ} \mathrm{C}$ in May. In Latvia, the temperature reached $31^{\circ} \mathrm{C}$ at the end of the month, the highest May temperature in the 20-year national record.

June to August was near normal in Scandinavia and around the Baltic coast, while Iceland experienced positive anomalies of around $+2^{\circ} \mathrm{C}$. Autumn started with a very warm September. For Denmark and Sweden, it was the warmest September on record, and the Baltic countries had positive anomalies of $+1^{\circ}$ to $+2^{\circ} \mathrm{C}$. October and November were generally cooler than average, away from the influence of the very warm Arctic Ocean surface.

December 2016 was mild all over the Nordic countries, with temperatures around $+3^{\circ}$ to $+4^{\circ} \mathrm{C}$ above the long-term mean.

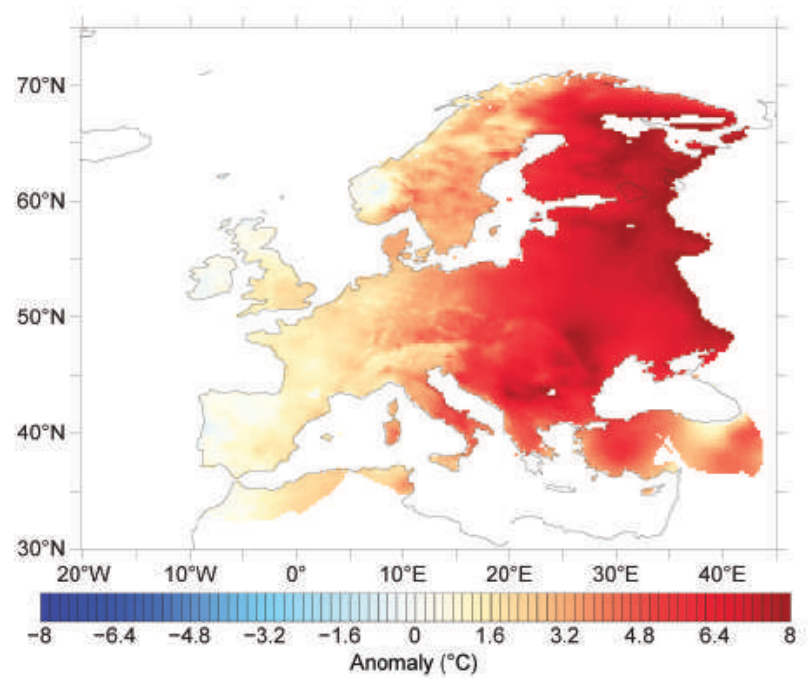

FIG. 7.39. Monthly mean air temperature anomalies for Feb 2016 ( ${ }^{\circ} \mathrm{C}$; 196I-90 base period), based on E-OBS data (van der Schrier et al. 20I3b; Chrysanthou et al. 20I4). (Source: KNMI.) 


\section{(ii) Precipitation}

Annual total precipitation was mostly near-normal across the region, with considerable short-term variability.

Winter 2015/16 saw persistent snow cover in Iceland, and the Baltic countries saw more than double their normal total precipitation. A strong cyclonic system developed in February over northern Scandinavia and entrained humid warm air masses from the Atlantic on its eastern edge.

Spring brought a deficit of rainfall for most of the Nordic countries, with the exception of Sweden and the southern Norwegian mountain ranges, where totals of up to $200 \%$ of normal were registered. Estonia experienced very dry conditions, with May rainfall being only $25 \%$ of normal. Iceland was also affected by a dry period in spring, with about half of its normal precipitation.

The positive precipitation anomalies continued into summer for northern Finland and Sweden, with anomalies up to $50 \%$ above normal. Iceland again showed a deficit in the western half of the island. Lower-than-average pressure remained centered over the north of Scandinavia which pushed rain storms farther to the north.

At the beginning of autumn, high pressure predominated across much of central and eastern $\mathrm{Eu}-$ rope, extending the rather dry conditions far into the Nordic countries through autumn. Drier conditions were noted in Sweden, Estonia, Latvia, Lithuania, and the southern tip of Finland. Some stations reported totals of $20 \%-30 \%$ of normal. The dry conditions continued into December in many places.

\section{(iii) Notable events and impacts}

Norway was hit by several storms in January, and a new record wind speed of $48.9 \mathrm{~m} \mathrm{~s}^{-1}$ was measured on 29 January at Krakenes, north of Bergen. The city of Bergen itself, already known for its frequent rainfall, reported new monthly record totals in July and August with 263 (180\%) and $365 \mathrm{~mm}$ (192\%), respectively.

On 9 November, the Swedish capital, Stockholm, broke its all-time snowfall record for any November day since measurements began in 1905, with $30-$ $40 \mathrm{~cm}$ of snow accumulating in different parts of the city over 24 hours.

A winter storm hit Norway, Sweden, and Denmark on 26 December with gale-force winds causing blackouts and road blockages, but also a significant surplus in harvested wind energy.

\section{4) Iberian Peninsula}

This region includes Spain and Portugal.

\section{(i) Temperature}

Despite a cold spring, the Iberian Peninsula was warmer than average in 2016 (see Fig. 7.35). Positive anomalies up to $+2^{\circ} \mathrm{C}$ were recorded in central parts of Spain, along the Mediterranean coast, and the northwestern tip of the country, while Portugal was not quite as warm, with a spatial mean anomaly of about $+1.2^{\circ} \mathrm{C}$. The main contribution of warmth came during the summer months of July and August.

Winter 2015/16 continued December's warmth into the new year, supported by a strong zonal flow across central Europe. The seasonal mean anomaly for the whole Peninsula was around $+1.3^{\circ} \mathrm{C}$ (see Fig. 7.37).

Spring turned into a colder season $\left(-0.5^{\circ} \mathrm{C}\right.$ below normal), at least for the western half of the Peninsula; the Mediterranean coast maintained elevated anomalies up to $+1^{\circ} \mathrm{C}$ in maritime locations like the Iberian islands. The season was one of the coldest of the 21st century for Spain, behind 2004 and 2013.

With the beginning of summer, the Azores high started to extend to the northeast, and sunny weather created a rapid warming across the central plain of Spain, where temperatures rose to $3^{\circ} \mathrm{C}$ higher than normal. Peak daily high temperatures well above $40^{\circ} \mathrm{C}$ were reported from several stations (e.g., Seville: $42.3^{\circ} \mathrm{C}$ ). Portugal also experienced extreme anomalies, especially in July and August, where most of the country was up to $+3.5^{\circ} \mathrm{C}$ warmer than normal. Summer 2016 takes second place among the warmest years in the country since 1931. June set new station records for maximum air temperature in Portugal and also for highest minimum temperature in at least five different locations. Many stations registered new records for maximum and minimum air temperatures, with Lisbon reaching its record highest daily minimum temperature of $27.9^{\circ} \mathrm{C}$ on 7 August (tied with 2 August 2003). The spatial mean anomaly for the season was lower but still positive at about $+1.5^{\circ} \mathrm{C}$ above normal.

Warm conditions continued into autumn. The first half of September was unusually hot, with a new European record for September maximum temperature of $45.7^{\circ} \mathrm{C}$ registered in Montoro in southern Spain (a neighboring unofficial station registered $46.6^{\circ} \mathrm{C}$ ). Due to the late occurrence of this heat wave, it affected daily maxima more than daily average temperatures; hence the anomaly for September was not that high, but still between $+1^{\circ}$ and $+2^{\circ} \mathrm{C}$ for Spain and around $+1.3^{\circ} \mathrm{C}$ in Portugal. The seasonal mean 
was reduced by a cool November, which saw the return of a cyclonic influence on the Iberian Peninsula and resulted in slightly cooler temperatures. Overall, autumn ended with temperature anomalies of $+1.8^{\circ} \mathrm{C}$ in Spain and around $+0.9^{\circ} \mathrm{C}$ in Portugal.

December showed some influence of colder continental air masses in the north of Spain, with anomalies locally down to $-2^{\circ} \mathrm{C}$, but in general, the Iberian Peninsula maintained the warmth of the previous season by up to $+2^{\circ} \mathrm{C}$ in central Spain and $+1^{\circ} \mathrm{C}$ in Portugal.

\section{(ii) Precipitation}

Annual precipitation totals in Portugal and Spain were close to normal, with a small deficit in the Barcelona region and an isolated patch of surplus in north central Portugal (see Fig 7.36). The main rainfalls occurred in spring, while the rest of the year was below normal and summer was extremely dry.

January and February brought abundant rainfall but mainly in the northwest of the Peninsula where the seasonal mean was around $125 \%$ of normal, while the central and southeastern parts still had deficits of $40 \%$ to $60 \%$ of normal.

Spring saw frequent cyclonic activity for the Peninsula, bringing cold and showery weather. The seasonal precipitation total was $160 \%$ of normal for Portugal and $130 \%$ for Spain. Mountain regions in Portugal also received considerable snowfall.

Summer set in with a strong deficit in precipitation for both countries, again below the extreme value of $20 \%$ totals in many regions in June. The southern half of the Peninsula maintained this deficit throughout summer, making it one of the five driest summers in Portugal since 1931. Nevertheless, some torrential rainfalls occurred, as is usual in the Iberian summer. Southern Portugal and central and southern Spain were all in the range of $20 \%$ to $40 \%$ with regard to the seasonal total, while overall the Iberian Peninsula recorded around $50 \%$ of normal precipitation. Dry conditions persisted well into September although autumn total precipitation was near normal in most places.

In December, northern Spain saw only around $30 \%$ of normal precipitation, while the southeastern coast experienced strong winter storms and wet conditions.

\section{(iii) Notable events and impacts}

In February, Portugal saw unusual snowfall in its southern mountains down to an elevation of $300 \mathrm{~m}$ above sea level. Such an event occurs approximately once every 10 years.
The island of Mallorca received unusually high amounts of precipitation from 5 to 9 May, exceeding $120 \mathrm{~mm}$ in several places.

Portugal reported the largest burned area in summer wildfires since 2006. A fire on Madeira in early August coincided with the hottest day since 1976 at Funchal Airport $\left(38.2^{\circ} \mathrm{C}\right)$, resulting in three deaths and estimated damage of $\$ 67$ million U.S. dollars (WMO 2017).

\section{5) Eastern Europe}

This region includes the European part of Russia, Belarus, Ukraine, Moldova, and Romania.

\section{(i) Temperature}

Winter 2015/16 began with elevated temperatures in Russia, Belarus, and western Ukraine-up $+4^{\circ} \mathrm{C}$ above normal-but in January cold winter conditions prevailed in western Russia, eastern Ukraine, and southern Romania. February saw a vast extension of warm air from the Arctic Ocean with temperature anomalies of $+6^{\circ} \mathrm{C}$ and higher for all countries (see Fig. 7.39). Belarus reported its warmest winter (2015/16) since records began in 1891.

Eastern Europe was dominated by a strong warm anomaly which persisted from February through September. Its core was centered above the Barents and Kara Seas. Record high (since 1891) spring-like temperatures of $13^{\circ} \mathrm{C}$ to $17^{\circ} \mathrm{C}$ were observed during winter in this normally very cold region close to Novaya Zemlya and the Barents Sea. The highest anomaly reached $+12^{\circ} \mathrm{C}$ in the most extreme month of February. Due to colder autumn conditions, the annual anomaly was reduced to $+2^{\circ}$ to $+8^{\circ} \mathrm{C}$ for the region, but 2016 still stands out as the warmest year observed in European Russia since records began in 1891. Kim et al. (2017) attribute this warming to the advection of warm air masses by extratropical Cyclone Frank, which developed in late December 2015 and raised surface air temperatures to anomalies of $+30^{\circ} \mathrm{C}$ in the Eurasian sector of the Arctic. This drastically reduced the ice cover of the Barents and Kara Seas, and the normal cold air and typical winter blocking high over Russia were weaker than normal. The strong zonal flow from central Europe also contributed with humid warm Atlantic air masses. Together with the lower ice cover, the more humid air masses increased downward longwave radiation and further intensified surface heating.

In spring, the temperature distribution was broadly maintained: Belarus reported the onset of vegetation growth two weeks earlier than normal, and Russia maintained positive anomalies especially 
in the north of up to $+5^{\circ} \mathrm{C}\left(+6^{\circ} \mathrm{C}\right.$ for the northern half of Novaya Zemlya). Some Arctic islands in the Barents Sea still reported seasonal anomalies of $+11^{\circ}$ to $+12^{\circ} \mathrm{C}$. Belarus was $+2^{\circ} \mathrm{C}$ warmer than normal. The persistence of warm anomalies from February to May appears to be related to a reduction in snow cover following the anomalously high February temperatures (R. Cornes et al. 2016, unpublished manuscript).

Summer was also warm for eastern Europe. All countries saw positive anomalies of $+1^{\circ}$ to $+2^{\circ} \mathrm{C}$, but it was much warmer in northern Russia $\left(+5^{\circ} \mathrm{C}\right.$ anomaly). In autumn the first cooler-than-average period began, but negative anomalies were limited to northwestern Russia and the east of Ukraine. Romania, Moldova, and Belarus were between $1^{\circ}$ and $3^{\circ} \mathrm{C}$ warmer than normal. Only in December 2016 did the strong and persistent positive anomalies in the north of Russia fade.

\section{(ii) Precipitation}

Annual precipitation totals in eastern Europe were mostly above normal for 2016, especially in the Romanian mountains, Moldova, eastern Ukraine, and the west of Russia. In these regions totals reached about $150 \%$ of normal, due to the frequent advection of humid Atlantic air masses. The north coast of Russia was drier than normal, with strongest anomalies occurring near the center of the warmest ocean water, in Novaya Zemlya (60\%).

Winter 2015/16 brought above-normal snow and rainfalls for Russia and Belarus, except the far north of Russia. Southern and central parts of Russia registered more than $200 \%$ of normal precipitation. Moscow received $183 \%$ and $178 \%$ of normal in January and February, respectively, but the high temperatures prevented persistent snow cover. In Romania, Moldova, and Ukraine the very dry December 2015 caused a slight winter deficit, although January and February were above normal, with an extreme total of $300 \%$ of normal at the Romanian Black Sea coast in January. The far north of Russia was very dry during winter, and snow falls in the Barents Sea region were down to $20 \%$ of normal.

The spring season was mostly dry to normal. Dry and warm weather persisted around the Barents Sea. At the same time the south of Russia, eastern Ukraine, and Romania received a surplus of precipitation, with around $130 \%$ of normal.

Summer saw the end of the extremely dry conditions along the north coast of Russia. A total of $170 \%$ of normal was recorded for the west of northern Russia near the Finnish border and south to the border with Ukraine and Belarus. Elsewhere, drier conditions prevailed, with precipitation totals down to $60 \%$ of normal in parts of Moldova and Romania.

Autumn saw a return of the dry conditions in northern Russia. Ukraine, Belarus, and Moldova experienced a very dry September with total precipitation less than $20 \%$ of normal. The seasonal mean in eastern Romania exceeded $300 \%$ of normal, and Ukraine and Belarus still recorded $130 \%$ to $170 \%$ for the season. Central Russia received heavy snowfalls by mid-October. Unusual amounts of rain fell in the south of Russia, with Krasnodar exceeding $100 \mathrm{~mm}$ in one day at the end of September (daily totals rarely exceed $40 \mathrm{~mm}$ in this area). December brought an early onset of winter, caused by an outbreak of dry continental air from the Siberian high pressure cell which established early in the year. Drier conditions prevailed in Romania, Moldova, and Ukraine, with the strongest deficit in southern Romania of only $20 \%$ of normal. The northwest of Russia saw a positive anomaly with totals up to $150 \%$ of normal in Karelia.

\section{(iii) Notable events and impacts}

The most striking event for eastern Europe was certainly the extreme and persistent warmth of the northern seas, namely the Barents and the Kara. Temperature anomalies of $+12^{\circ}$ to $+14^{\circ} \mathrm{C}$ and locally up to $+23^{\circ} \mathrm{C}$ lasting for several months are truly unprecedented in the history of climate observations (Kim et al. 2017). Russia reported a long list of new record temperatures, including the warmest winter in Russia since records began in 1891.

On the Black Sea coast, snowfall-not seen in 50 years-was recorded in December 2016, reaching $10 \mathrm{~cm}$ in Simferopol at $44^{\circ} \mathrm{N}$ latitude.

\section{6) Mediterranean and Balkan countries}

This region includes Italy, Malta, Slovenia, Croatia, Serbia, Montenegro, Bosnia and Herzegovina, Albania, Macedonia, Greece, Bulgaria, and Turkey.

\section{(i) Temperature}

Similar to central Europe, annual temperature means in the Mediterranean region and Balkan countries were $+1^{\circ} \mathrm{C}$ above normal. Parts of the Balkans, the Greek Peloponnese, and eastern Turkey showed stronger positive anomalies. With national records each at least 50 years in length, 2016 was seventh warmest in Italy, Slovenia, Croatia, and Serbia.

Winter season in the Mediterranean was $+1^{\circ}$ to $+2^{\circ} \mathrm{C}$ warmer than normal, after a cold spell in December 2015. In February, a tongue of the huge positive temperature anomaly extended from Russia into the Balkan countries and increased monthly 
anomalies to $+7^{\circ}$ to $+8^{\circ} \mathrm{C}$ (see Fig. 7.39). Greece had its warmest February in 50 years, with some parts of the Balkans breaking longer records, for example, 80 years for Belgrade (Serbia). In March, temperature anomalies declined again, thus in Greece and Turkey the seasonal mean was close to normal.

Spring continued with positive anomalies of around $+1^{\circ} \mathrm{C}$ in all countries in the region. Parts of Bulgaria, Greece, and Turkey had anomalies of $+2^{\circ} \mathrm{C}$. During summer, the entire area from Bulgaria across to Montenegro experienced temperature anomalies of more than $+2^{\circ} \mathrm{C}$. In August, unusually warm air from the interior of Russia contributed to warm Mediterranean weather, raising peak anomalies in Turkey to $+4^{\circ} \mathrm{C}$. Autumn saw temperature anomalies near normal or slightly below normal over most of the region.

In December most of the Balkan countries, as well as Turkey and Greece, suffered from a strong outbreak of continental polar air masses from Russia. Deviations of $-4^{\circ} \mathrm{C}$ were seen in Turkey, and $-3^{\circ} \mathrm{C}$ in Bulgaria, Greece, and Albania. Serbia, Macedonia, and Montenegro were about $1^{\circ} \mathrm{C}$ colder than normal. Italy on the other hand, remained under the influence of the strong central European high with sunny weather and elevated temperature anomalies of up to $+2^{\circ} \mathrm{C}$.

\section{(ii) Precipitation}

The annual precipitation totals for 2016 were close to normal or slightly above normal for the Mediterranean and Balkan countries. Dry anomalies were observed around the Aegean Sea and the Turkish southern coast, where values were $60 \%$ of normal. Serbia and the southern tip of Italy had elevated precipitation of around $120 \%$ of normal, which is mainly attributed to intense convective events, occurring most frequently in May and October.

In winter 2015/16 only the north of Italy, Slovenia, and Croatia had a small surplus of precipitation, due to a wet February (with locally up to $375 \%$ of normal precipitation). The remaining countries were dry to very dry in winter, with the most extreme anomalies in southern Italy, the Peloponnese of Greece, and the south of Turkey, where totals were as low as $40 \%$ of normal.

Spring brought increased cyclonic activity centered over the Black Sea, with above-normal precipitation from southern Italy and Malta, across Greece, Bulgaria, and the north coast of Turkey. Those regions registered increased rainfall, especially in May with many thunderstorms exceeding $100 \mathrm{~mm}$ in 24 hours and local flooding events. The highest seasonal anomaly was in Serbia, with local spots receiving $250 \%$ of normal in May. Drier spring conditions were found farther east, on the island of Crete, and in southeastern Turkey with around $80 \%$ of the seasonal average precipitation.

June and July continued with mostly convective weather in the Mediterranean. Strong positive anomalies were observed in Sicily, southern Greece, and locally in Albania. Seasonal summer rainfall was around $150 \%$, with up to $300 \%$ in some locations, again associated with heavy thunderstorms in Macedonia, Greece, and Turkey, which caused floods and severe damage. Italy, the region around the Aegean Sea, and Crete were exceptionally dry, with only $40 \%$ to $50 \%$ of normal precipitation. Those regions were most strongly affected by hot and dry continental air masses flowing out of the ridge over central Europe.

During autumn, most of the countries in the region received higher-than-normal precipitation, most of which fell in October and November. Up to 230\% of normal was reported in Serbia. Turkey's southern coast and central parts remained drier with seasonal means of $40 \%$ to $60 \%$ of normal.

December reestablished high pressure for southeastern Europe; hence, very dry conditions (20\% to $40 \%$ of normal) occurred in Italy, Slovenia, Croatia, Bosnia and Herzegovina, Albania, Macedonia, and Greece. Malta, Crete, and central Turkey experienced cyclonic activity and had precipitation totals of $120 \%$ to $200 \%$ of normal.

\section{(iii) Notable events and impacts}

Damaging hail storms were reported in June in Greece (5 cm hailstones) and in August in Slovenia $(10 \mathrm{~cm})$. These same countries reported no rainfall at all for many sites in those months.

A subtropical hurricane (called a "medicane" in the Mediterranean region) crossed Italy at the end of October, with torrential rains and wind speeds up to $34 \mathrm{~m} \mathrm{~s}^{-1}$. Flooding and landslides followed. On 6 November a tornado, estimated to be category EF2, hit a suburb of Rome. A tornado of this intensity is rare for Italy.

\section{7) Middle East}

This region includes Israel, Cyprus, Jordan, Lebanon, Syria, West Kazakhstan, Armenia, Georgia, and Azerbaijan.

\section{(i) Temperature}

The Middle East had a warm 2016 with anomalies between $+1^{\circ}$ and $+2^{\circ} \mathrm{C}$ in almost all countries. Only Armenia and Georgia were slightly less warm with $+0.5^{\circ}$ to $+0.7^{\circ} \mathrm{C}$, respectively. The countries in the vicinity of the Mediterranean Sea had 10 out of 12 
months with positive anomalies (February to November). Around the Caspian Sea, warm conditions were concentrated in the first half of the year, while autumn was cooler than normal.

In winter 2015/16 (especially February) West Kazakhstan was around $+5^{\circ} \mathrm{C}$ warmer than normal under the influence of the huge warm anomaly in Russia. Georgia, Armenia, Azerbaijan, and Syria saw weaker seasonal anomalies of $+1.5^{\circ}$ to $+2^{\circ} \mathrm{C}$, while Cyprus, Israel, Lebanon, and Jordan were in the range of around $+1^{\circ} \mathrm{C}$.

In spring anomalies up to $+3^{\circ} \mathrm{C}$ persisted in West Kazakhstan, where March was extraordinarily warm with deviations up to $+4.5^{\circ} \mathrm{C}$. The warm air also affected Azerbaijan, Armenia, and Georgia to a lesser extent. The eastern Mediterranean countries came under the influence of warm air with southeasterly flows, causing positive anomalies of around $+2^{\circ} \mathrm{C}$ in those countries.

In summer 2016, new June records were set in Israel with daily maximum temperatures over $44^{\circ} \mathrm{C}$, more than $+1^{\circ} \mathrm{C}$ higher than previous records (since 1950). The monthly average for the country was $26.6^{\circ} \mathrm{C},+1.1^{\circ} \mathrm{C}$ higher than the previous maximum recorded since records began in 1950. Extreme temperaturevalues above $42^{\circ} \mathrm{C}$ were also recorded in Cyprus. The monthly anomaly reached $+2.8^{\circ} \mathrm{C}$ in this already hot climate, and the border region between Lebanon, Syria, and Jordan was similarly warm, resulting in seasonal anomalies more than $+2^{\circ} \mathrm{C}$ for those countries. Temperatures were extremely warm in August, with West Kazakhstan reaching $+4.8^{\circ}$ above average and Armenia, Georgia, and Azerbaijan $+3^{\circ} \mathrm{C}$.

The seasonal mean anomaly for autumn in the region of the Caspian Sea (West Kazakhstan, Armenia, Georgia, and Azerbaijan) was around $-1.5^{\circ} \mathrm{C}$. In December all Middle Eastern countries were well below normal, with mildest conditions in Israel, Lebanon, and Jordan with $-0.5^{\circ} \mathrm{C}$, Syria with $-1.4^{\circ} \mathrm{C}$ anomaly, and the countries around the Caspian Sea reaching very cold temperatures. Anomalies in Kazakhstan and Armenia were $-2.8^{\circ} \mathrm{C}$ and Georgia and Azerbaijan around $-1.5^{\circ}$ to $-2^{\circ} \mathrm{C}$.

\section{(ii) Precipitation}

Rainfall in 2016 was unevenly distributed, with the arid countries in the south being even drier than average, while the colder climate of Kazakhstan received a surplus of precipitation during nine months of the year. The Caucasus countries received between 90\% and $110 \%$ of normal (see Fig. 7.36). Cyprus, Syria, and Jordan were drier than average reaching about $80 \%$ of normal rainfall, while Israel and Lebanon were close to normal.

Winter 2015/16 was very dry in Syria with rainfall $20 \%$ to $30 \%$ of normal. The deficit extended into Jordan, and Cyprus was also below average. Several stations in those three countries recorded no rainfall at all in February. Israel and Lebanon received torrential rains at the end of winter and thus were near $100 \%$ for the season. Similarly, Georgia had average precipitation with strong snowfalls in the Caucasus reaching depths of $1 \mathrm{~m}$. The coastal regions around the Caspian Sea received a large surplus, which in Azerbaijan was around $150 \%$ of normal and in West Kazakhstan reached $170 \%$ to $>250 \%$ at the northern coast of the Caspian Sea.

This pattern of strong positive anomalies in West Kazakhstan continued into spring, when a widespread surplus of $170 \%$ to $300 \%$ was reached. Dry conditions again were seen in Syria with around 20\% of normal, rising to $70 \%$ of normal precipitation in Jordan, Israel, and Cyprus.

In summer, extremely dry conditions prevailed in Jordan and Syria. The Negev Desert (in Israel) and Cyprus were also affected by this drought. In the border region between Jordan and Syria, however, some local rain fell in summer. In West Kazakhstan positive anomalies, up to $250 \%$, were registered in June and July, but in August the area received almost no rain. Azerbaijan recorded only little rain on the western coast of the Caspian Sea.

In early autumn a surplus was observed at the coast in West Kazakhstan and Azerbaijan, which was partly compensated by dry conditions in November, resulting in seasonal totals around $150 \%$ of normal. A striking feature of 2016 in this region was the combined positive anomaly of elevated temperatures and precipitation in West Kazakhstan, a normally arid continental steppe region. In the south (Syria, Jordan, Israel, Lebanon, and Cyprus) the drought situation persisted, with only a little rain in places (according to sparse data in war-affected parts of Syria).

December brought snowfall to many places, including the desert regions of Syria, and Israel experienced a series of torrential storms with heavy snowfalls. Anomalies for December were positive in the entire region for the first time in the year with West Kazakhstan leading with 200\%, Syria with around $140 \%$, and Azerbaijan only slightly above normal.

\section{(iii) Notable events and impacts}

The drought situation in the Levant region (eastern Mediterranean), which began in 1998 (Cook et al. 2016) apparently continued in 2016, with Syria again 
being the most affected country. Ten of 12 months were drier than normal, and eight of those were below $50 \%$ of average precipitation.

Georgia was hit by strong hailstorms in April and Cyprus in May, where hailstones were up to $5 \mathrm{~cm}$ in diameter.

In December, continental arctic air broke out of Russia, ending a long and intensely warm period for the countries of the east Mediterranean, and it brought unusually cold conditions and long-lasting snowfall in Israel, Lebanon, Jordan, and Syria.

\section{g. Asia}

Throughout this section the base periods used vary by region. The current standard is the 1981-2010 average for both temperature and precipitation, but earlier base periods are still in use in several countries. All seasons mentioned in this section refer to the Northern Hemisphere, with winter referring to DJF 2015/16 unless otherwise noted.

\section{I) OVERVIEW}

Annual mean surface air temperatures during 2016 were above normal across most of Asia and Siberia (Fig. 7.40), especially north of $60^{\circ} \mathrm{N}$. Annual precipitation amounts were above normal in central Siberia, from southern Mongolia to northern China, in eastern China, from western China to central Asia, in northern Pakistan, in northern India, and in Myanmar, and were below normal in western Siberia, in southern Pakistan, and from southern India to Sri Lanka (Fig. 7.41).

Seasonal mean temperatures were mostly above normal across Southeast and South Asia, and across Siberia (Fig. 7.42). In winter, seasonal mean temperatures were below normal from Mongolia to China. Autumn was marked by a strong zonal contrast with positive temperature anomalies north of $60^{\circ} \mathrm{N}$ and negative anomalies in a broad region between $40^{\circ} \mathrm{N}$ and $60^{\circ} \mathrm{N}$, associated with a strong negative phase of the NAO (see Fig. 7.44). Seasonal precipitation amounts were variable across the region generally but were persistently above normal in central Asia (Mongolia and Kazakhstan and adjacent regions) through the year.

Convective activity was suppressed over the Indonesian region and the western tropical Pacific in winter in association with El Niño conditions (Fig. 7.43a). In spring, anticyclonic circulation anomalies in the lower troposphere were seen from the Indochina Peninsula to the western North Pacific (Fig. 7.43b), and above-normal temperatures were observed over and around Japan (Fig. 7.44b). In

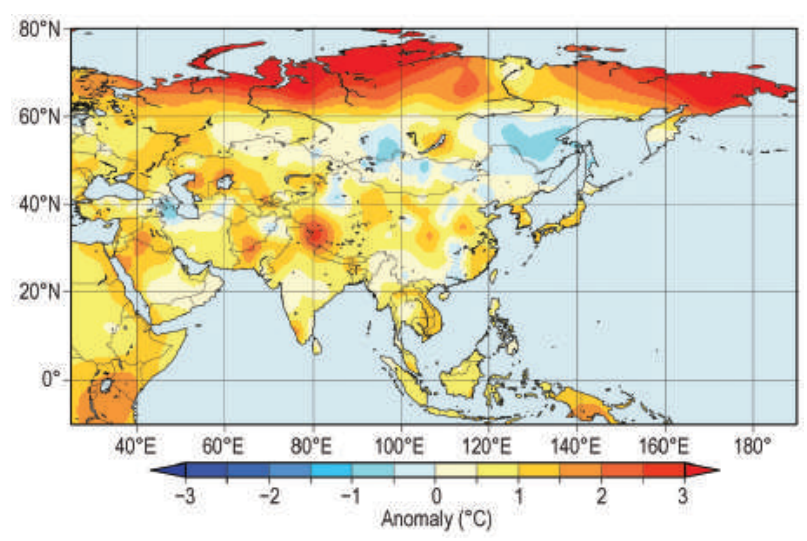

Fig. 7.40. Annual mean temperature anomalies $\left({ }^{\circ} \mathrm{C}\right.$; 198I-2010 base period) over Asia in 2016. (Source: Japan Meteorological Agency.)

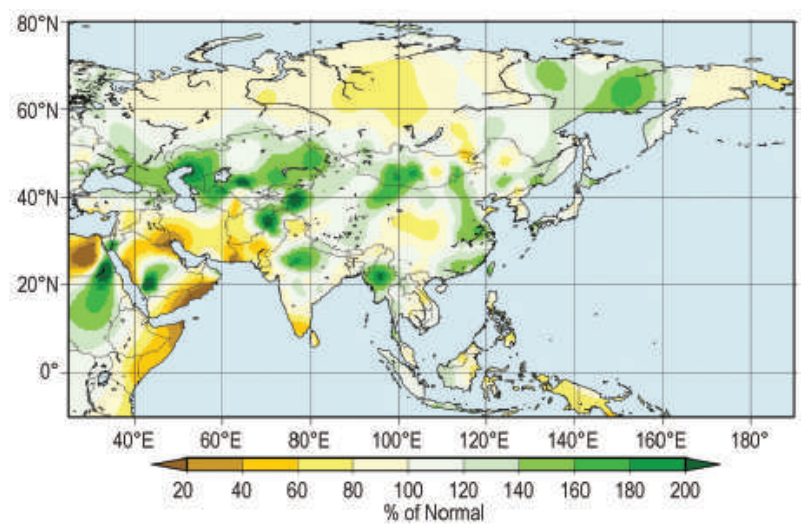

Fig. 7.4I. Annual precipitation (\% of normal; $198 \mid-2010$ base period) over Asia in 2016. (Source: Japan Meteorological Agency.)

summer, the monsoon circulation over the Indian Ocean was stronger than normal, and cyclonic circulation anomalies were seen from the Indian Ocean to the Indonesian region. Convective activity was strongly enhanced over the subtropical North Pacific in association with low-level cyclonic anomalies to the southeast of Japan (Fig. 7.43c). In autumn, negative anomalies of $500-\mathrm{hPa}$ geopotential height and of $850-\mathrm{hPa}$ temperature were observed over the midlatitudes from central Asia to the Kamchatka Peninsula (Fig. 7.44d), associated with a strongly negative $\mathrm{NAO} / \mathrm{AO}$ period.

2) RussIA-0. N. Bulygina, N. N. Korshunova, and N. M. Arzhanova Observational information was obtained from the Roshydromet Observation Network. Official datasets are available from the RIHMI-WDC site: http:// meteo.ru/english/climate/cl_data.php. 


\section{(i) Temperature}

The mean annual Russia-averaged air temperature for 2016 was $0.83^{\circ} \mathrm{C}$ above the $1981-2010$ normal (Fig. 7.45; see also Fig. 7.40), the fifth highest such value in the period 1936-2016. Winter was abnormally warm, especially in western and central regions (Fig. 7.42a), with the seasonal average $2.1^{\circ} \mathrm{C}$ above normal, the second warmest since 1936. Spring also proved to be warm across the whole country, with a Russia-averaged seasonal mean air temperature anomaly of $+1.9^{\circ} \mathrm{C}$ (third warmest since 1936). April and May were especially warm.

Summer was the warmest on record, with an average anomaly of $+1.2^{\circ} \mathrm{C}$. In July a heat wave was recorded in European Russia, particularly along the Arctic coast. In the Lower Volga region and republics of northern Caucasia, daily maximum temperatures exceeded $40^{\circ} \mathrm{C}$. August was the warmest on record for Russia, associated mostly with large positive temperature anomalies over eastern European Russia and the Urals (Fig. 7.46). Monthly average temperatures in Yekaterinburg, Biser, and $\mathrm{Bu}-$ guruslan were the highest on record.

For Russia as a whole, the autumn mean air temperature was $0.75^{\circ} \mathrm{C}$ below normal, with a warm September transitioning through to a cold November. Temperatures were well below normal over southern parts of Russia (Fig. 7.42g), associated with a strong negative $\mathrm{NAO} / \mathrm{AO}$ period.

\section{(ii) Precipitation}

In 2016, Russia as a whole received above-normal precipitation, $107 \%$ of the 1981-2010 normal, tying with 1961, 1966, and 2004 for the second wettest year since records began in 1936 (Fig. 7.47).

Nearly all of European Russia received above-normal precipitation in January and to a lesser extent in February. In the spring Russia received above-normal precipitation (117\%) on average. In the summer, Russia also received above-normal precipitation. Autumn saw above-normal precipitation in eastern Siberia and somewhat below-normal conditions elsewhere in Russia.
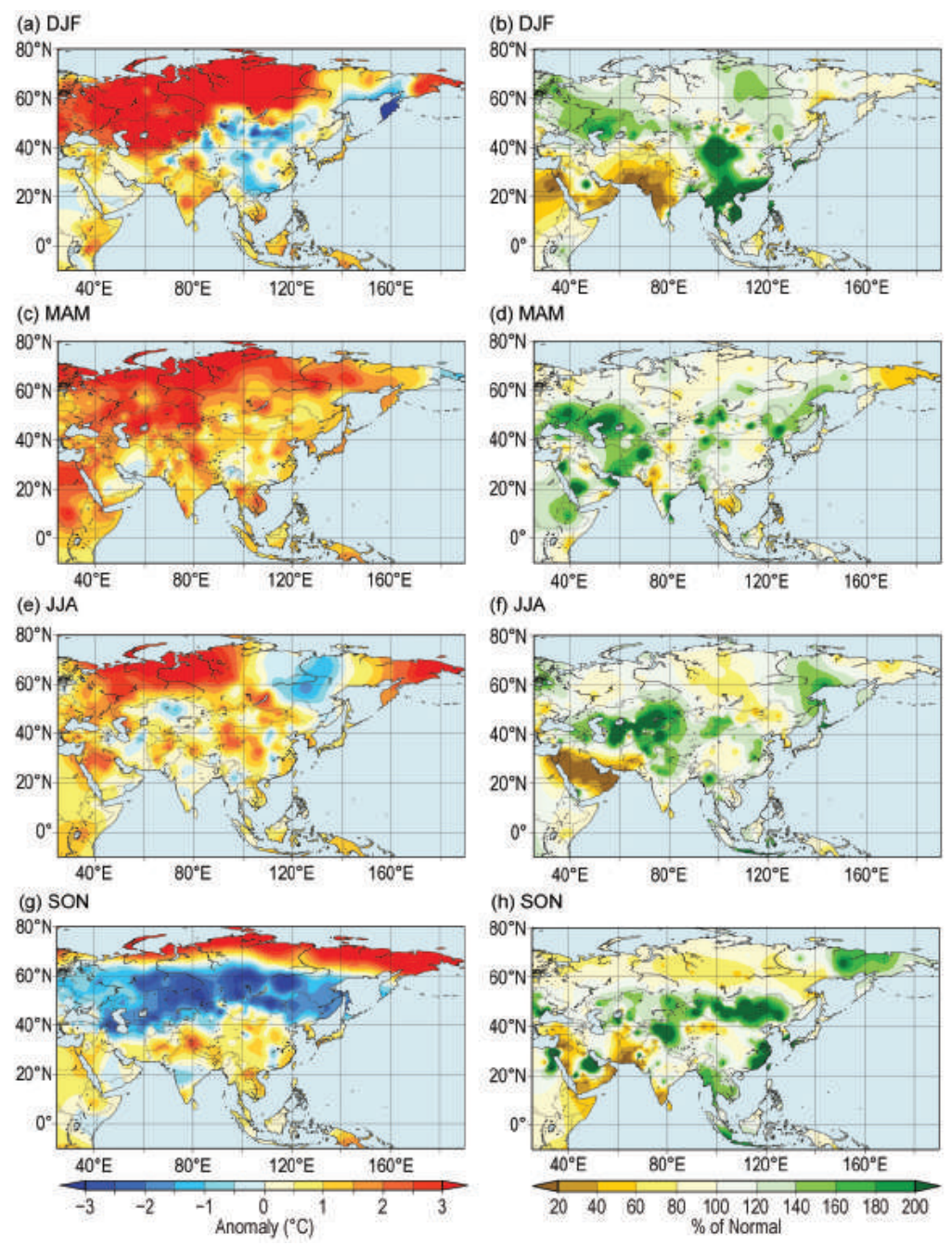

(d) MAM

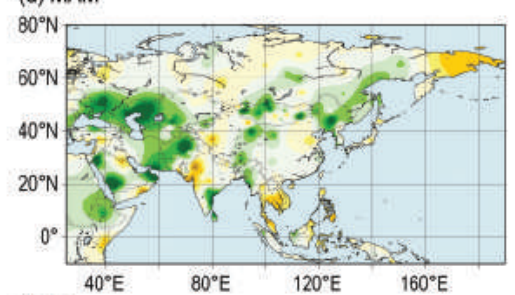

(f) JJA

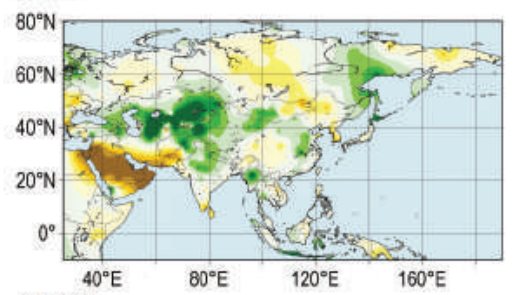

(h) SON

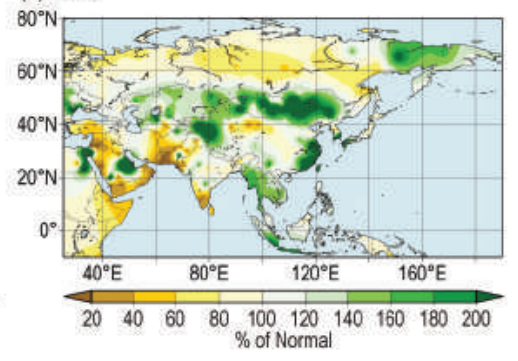

FIG. 7.42. Seasonal temperature anomalies $\left({ }^{\circ} \mathrm{C}\right.$, left column) and precipitation (\% of normal, right column) over Asia in 2016 for (a),(b) winter; (c),(d) spring; (e),(f) summer; and (g),(h) autumn. All relative to 198I-2010. (Source: Japan Meteorological Agency.)

\section{(iii) Notable events and impacts}

On 2 March, Moscow received $25.3 \mathrm{~mm}$ of precipitation, more than $70 \%$ of its monthly precipitation normal of $35 \mathrm{~mm}$, breaking the single-day March record rainfall set in 1966 .

On 15-16 March, a severe wind storm affected Kamchatka. Wind speeds reached $45-53 \mathrm{~m} \mathrm{~s}^{-1}$. Flights and schools were canceled, and many homes lost electricity.

On 15-20 April, an ice jam caused flooding along the Sukhona River in the Vologda Region (European Russia). The water level in the Sukhona rose to almost $10 \mathrm{~m}$ above normal. The city of Velikyi Ustyug and another 24 settlements (with a total population of about 40000 ) were in the flood zone; total flood-related damage was estimated at more than 300 million rubles ( $>\$ 5$ million U.S. dollars). 
On 5 June, $50.5 \mathrm{~mm}$ of precipitation fell in 20 minutes in Vladikavkaz (North Caucasus); it was accompanied by large hail ( $3 \mathrm{~cm}$ in diameter) and
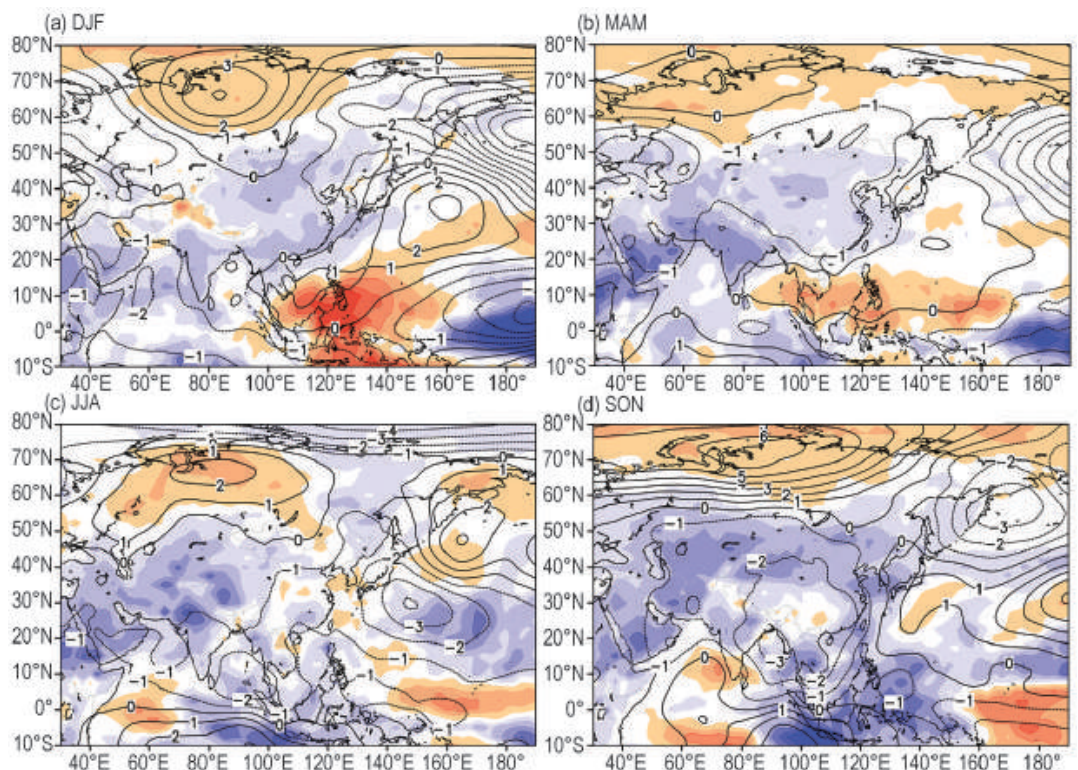
$10^{\circ} \mathrm{N}$ ) $\mathrm{SON}$

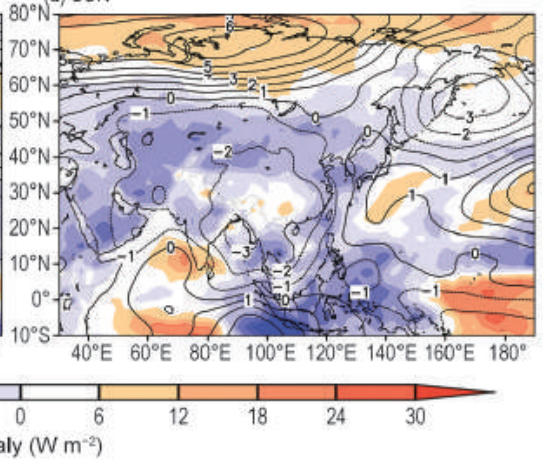

Fig. 7.43. Seasonal mean anomalies of $850-\mathrm{hPa}$ stream function (contour, $1 \times 10^{6} \mathrm{~m}^{2} \mathrm{~s}^{-1}$ ) using data from the JRA-55 reanalysis and OLR (shading, W $\mathrm{m}^{-2}$ ) using data originally provided by NOAA for (a) winter, (b) spring, (c) summer, and (d) autumn. The base period is 1981-2010. (Source: Japan Meteorological Agency.)
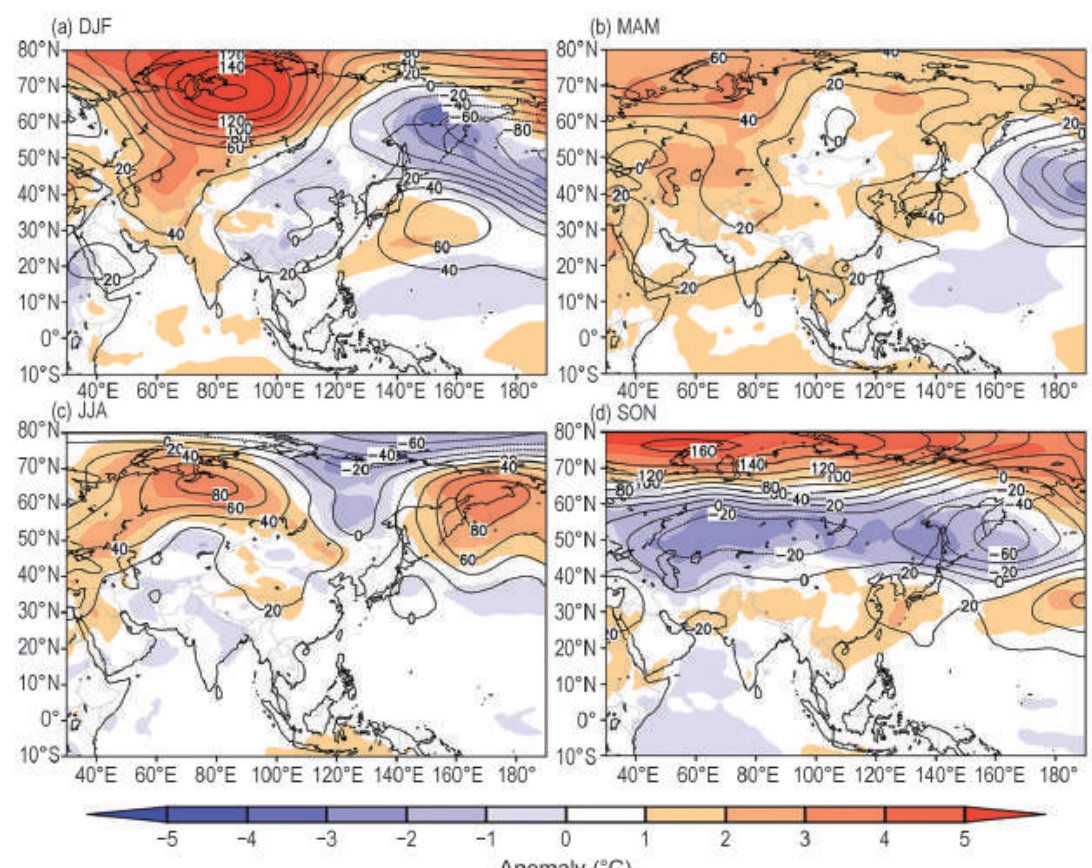

$40^{\circ} \mathrm{E} 60^{\circ} \mathrm{E} \quad 80^{\circ} \mathrm{E} 100^{\circ} \mathrm{E} 120^{\circ} \mathrm{E} 140^{\circ} \mathrm{E} 160^{\circ} \mathrm{E} 180^{\circ}$

Anomaly $\left({ }^{\circ} \mathrm{C}\right)$

Fig. 7.44. Seasonal mean anomalies of $500-\mathrm{hPa}$ geopotential height (contour, gpm) and $850-\mathrm{hPa}$ temperature (shading, ${ }^{\circ} \mathrm{C}$ ) for (a) winter, (b) spring, (c) summer, and (d) autumn, using data from the JRA-55 reanalysis. The base period is 198I-2010. (Source: Japan Meteorological Agency.) and more than 2500 trees were toppled. Two people were injured.

During 6-16 July, 534 forest fires covering an area of more than 230000 ha were recorded in the Transbaikalian Territory (south of eastern Siberia).

On 26 August, large hail (1.5$2.9 \mathrm{~cm})$ and strong winds $(25-$ $28 \mathrm{~m} \mathrm{~s}^{-1}$ ) in Karachay-Cherkessia (North Caucasus) damaged 452 houses and 3 schools, as well as more than 2000 ha of agricultural crops.

On 30-31 August, heavy rainfalls associated with a typhoon affecting the Maritime Territory (Far East) caused flooding with a preliminary damage estimate of 1.2 billion rubles $(>\$ 20$ million U.S. dollars).

3) East and Southeast AsiaP. Zhang, T. C. Lee, A. Goto, S.-Y. YiM, L. Orunargal, and Bertrand Timbal

Countries considered in this section include: China (including Hong Kong), Japan, Korea, Mongolia, and Singapore. Anomalies refer to a base period of 1981-2010.

\section{(i) Temperature}

The annual mean air temperature in 2016 for China was $0.8^{\circ} \mathrm{C}$ above normal (see Fig. 7.40), the third warmest year since records began in 1951, after 2015 and 2007. Apart from January, all months were warmer than normal. December was especially warm compared to average, with the highest anomaly $\left(+2.6^{\circ} \mathrm{C}\right)$ of any month in the historic record. Hong Kong was slightly warmer than normal for the year, with an annual mean temperature anomaly of $+0.3^{\circ} \mathrm{C}$, its seventh highest since records began in 1884 . 

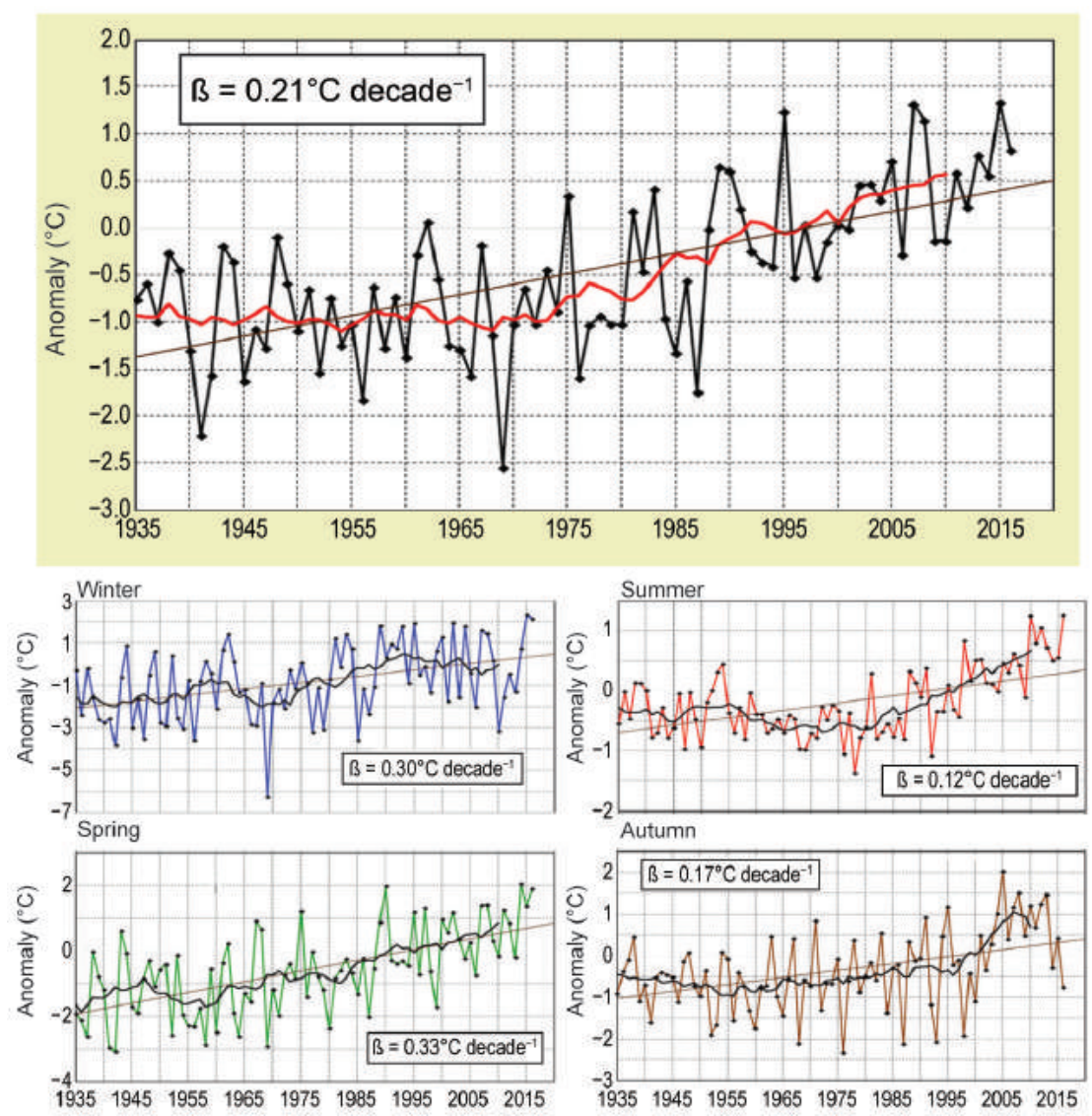

FIG. 7.45. Anomalies of mean (top) annual and (bottom) seasonal air temperatures $\left({ }^{\circ} \mathrm{C}\right)$ averaged over available surface station observations in the Russian territory for the period 1936-2016 (base period: 1981-2010). The II-year running mean is shown as a continuous line (the time series was "mirrored" before 1936 prior to filtering, but no estimate was made for future years after 2016$)$.

Annual mean temperatures were significantly above normal in eastern and western Japan (see Fig. 7.40) and Okinawa/Amami, especially in eastern Japan where average temperatures were the highest since records began in 1946.

The 2016 annual average temperature over the Republic of Korea was $1.1^{\circ} \mathrm{C}$ above normal, making 2016 the country's warmest year since national records began in 1973. Conversely, the annual mean temperature over Mongolia for 2016 was $0.2^{\circ} \mathrm{C}$ below normal. The coldest month there was January, when the mean temperature anomaly was $3.2^{\circ} \mathrm{C}$ below average. A minimum temperature of $-55.0^{\circ} \mathrm{C}$ was observed at Otgon station (western Mongolia), the second-lowest absolute minimum temperature for the country since records began in 1961.

The mean annual temperature for 2016 in Singapore was $28.4^{\circ} \mathrm{C}$, its warmest year on record (since 1929 ) and $0.1^{\circ} \mathrm{C}$ warmer than the previous record tied by 1997, 1998, and 2015. All months in 2016 were above their respective 1981-2010 normals, with record warm months observed in January, April, and August.

\section{(ii) Precipitation}

The annual mean precipitation in China was $730.0 \mathrm{~mm}$, $116 \%$ of normal, the highest since national records began in 1951. Seasonal total precipitation amounts were $153 \%, 122 \%$, $106 \%$, and $137 \%$ of normal for winter, spring, summer, and autumn, respectively. Precipitation in major river catchments was generally above normal. The annual mean precipitation in the Yangtze River basin was $119 \%$ of normal, just below the 1954 record. Hong Kong received well-aboveaverage rainfall in $2016(126 \%$ of normal), with a record wet autumn. Annual precipitation amounts were considerably above normal in western Japan, Okinawa/Amami, and on the Pacific side of northern Japan.

In the Republic of Korea, 2016 saw $97 \%$ of $1981-2010$ normal precipitation. Belowaverage rainfall was observed over the central part of the country, while above-average conditions occurred in the south. In Mongolia, annual precipitation was $242 \mathrm{~mm}, 118 \%$ of normal, with a wet spring favorable for agriculture. March was the wettest month (222\% of normal) while August was the driest month (72\%) in the year.

For Singapore, the decaying strong El Niño gave rise to below-normal rainfall in the first part of the year (71\% of normal for January-May). Rainfall during the southwest monsoon season was mostly near average.

\section{(iii) Notable events and impacts}

In mid-January, minimum temperature records were broken in many cities across the southern part of the Republic of Korea, associated with a negative phase of the Arctic Oscillation. This, combined with a strong Siberian high, brought strong, cold northerly winds into the country. 


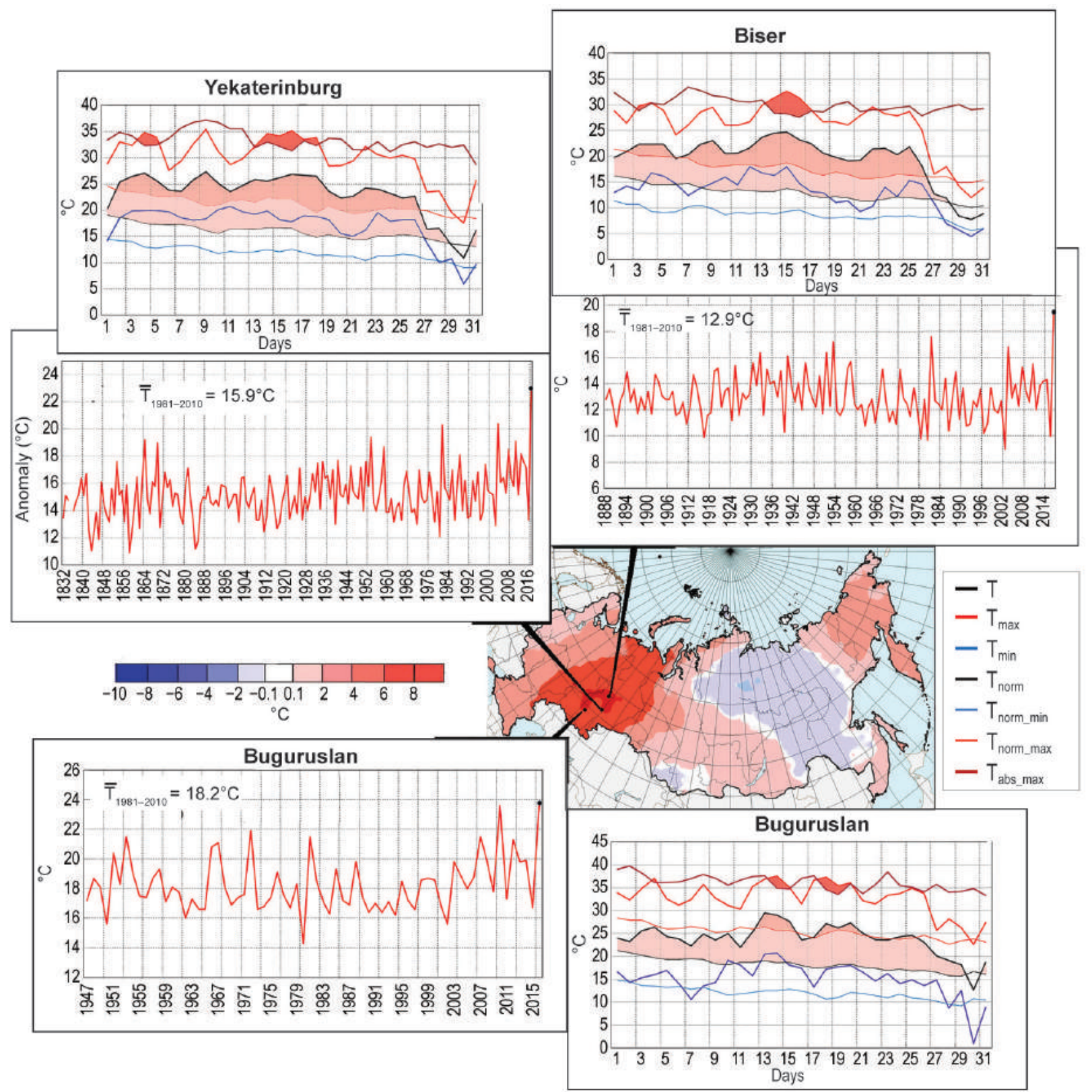

FIG. 7.46. Air temperature anomalies ( ${ }^{\circ} \mathrm{C}$, shaded) in Aug 20I6. Insets show the series of mean monthly and mean daily air temperatures $\left({ }^{\circ} \mathrm{C}\right)$ in Aug 2016 at meteorological stations Yekaterinburg, Buguruslan, and Biser.

Hong Kong reported four consecutive days with maximum temperatures above $35^{\circ} \mathrm{C}$ in June, compared with an average monthly high of $23^{\circ} \mathrm{C}$, and had its warmest July and October on record.

In August, northern Japan experienced several record-breaking heavy rainfall events, associated with Typhoons Conson, Chanthu, Mindulle, Lionrock, and Kompasu. On the Pacific coast of northern Japan, August precipitation was $231 \%$ of normal, a new August record (since 1946). From 16 to 31 August, $858.0 \mathrm{~mm}$ was recorded at Nukabira-gensenkyo in Hokkaido. Heavy rain there caused serious damage, including landslides and river overflows.
In the Republic of Korea, August 2016 was the driest August on record, influenced by a long-lasting anomalous anticyclone over northeastern China and a heat wave early in the month. A temperature of $42^{\circ} \mathrm{C}$ was observed at both Choibalsan and Khalkhin Gol stations, the highest temperature recorded in eastern Korea in the past 50 years.

On 5 October, Typhoon Chaba hit the southern and southeastern coasts of the Republic of Korea with strong winds and heavy rain. Chaba was the strongest October typhoon recorded in the Republic of Korea and caused flooding, damaged several homes, and blocked streets in southeastern cities. 
4) South Asia—A. K. Srivastava, J. V. Revadekar, and M. Rajevyan Countries in this section include: Bangladesh, India, Pakistan, and Sri Lanka. Climate anomalies are relative to the 1981-2010 normal. Monsoon precipitation is defined relative to a 50 -year base period (1951-2000), since there is strong interdecadal variability in Indian monsoon precipitation (Guhathakurta et al. 2015).

\section{(i) Temperature}

South Asia generally witnessed significantly warm conditions in 2016 (Fig. 7.48; see also Fig. 7.40). The annual average mean land surface air temperature over India was $0.7^{\circ} \mathrm{C}$ above average, making 2016 the warmest year on record since national records commenced in 1901. The country-averaged seasonal mean temperatures during the winter months of early 2016 (January-February, anomaly $+1.2^{\circ} \mathrm{C}$, warmest since 1901) and the pre-monsoon season (MarchMay, anomaly $+1.0^{\circ} \mathrm{C}$, second warmest since 1901) contributed most strongly to the record warm year (see Figs. 7.42a,c). Eight of the ten warmest years on record have occurred since 2000 .

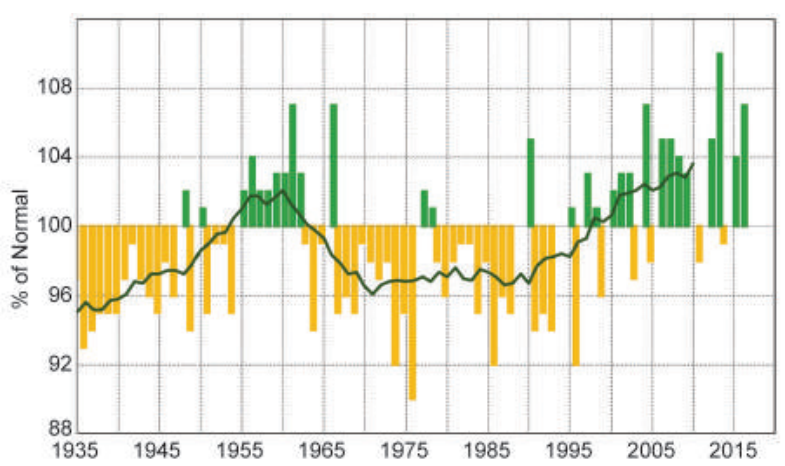

Fıg. 7.47. Annual precipitation (\% of normal; $198 \mid-2010$ base period) averaged over the Russian territory for the period 1936-20I6. The II-year running mean is shown as a continuous line (the time series was "mirrored" before 1936 prior to filtering, but no estimate was made for future years after 2016).

\section{(ii) Precipitation}

The summer monsoon season (June to September) typically contributes about $75 \%$ of the annual precipitation over South Asia. The summer monsoon set in over Kerala (southern parts of peninsular India) on

\section{SIDEBAR 7.4: ANOMALOUS TYPHOON ACTIVITY IN THE NORTHWESTERN PACIFIC AND EXTREME PRECIPITATION IN NORTHERN JAPAN IN AUGUST 2016—P. ZHANG, T. C. LEE, A. GOTO,}

S.-Y. YIM, L. OYUNJARGAL, AND B. TIMBAL

In stark contrast to the first half of the year when tropical cyclone activity was suppressed, seven typhoons (tropical storm intensity or higher) formed in the northwestern Pacific basin in August 2016. Four of those-Chanthu, Mindulle, Lionrock, and Kompasu-made landfall in rapid succession on the Japanese mainland (Fig. SB7.7). This ties with August 1962 and September 1954 as the largest number of typhoon landfalls over the country in a single month since records began in 1951. The pattern of typhoon activity is peculiar given that all four typhoons headed north (instead of west or northwest) and eventually hit the Pacific coast of northern Japan, where it is rare, though not unprecedented, to experience even a single typhoon landfall. Primarily due to rainfall from these typhoons, the regional average monthly precipitation total in the Pacific side of northern Japan for August was the highest on record since 1946 at $231 \%$ of normal. More than 20 fatalities and substantial damage to houses, infrastructure, and agriculture were reported due to river overflows and flooding.

The period of active genesis of typhoons in August was associated with large cyclonic circulation anomalies in the lower troposphere, encompassing much of the northwestern tropical

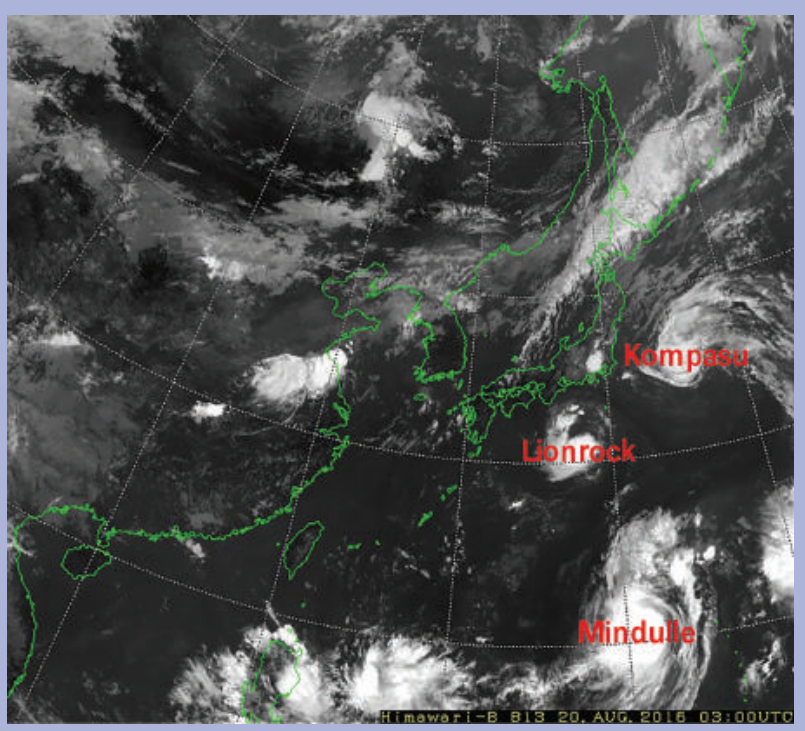

FIG. SB7.7. An infrared satellite image from Himawari-8 taken at 0300 UTC on 20 Aug 2016. Mindulle, Lionrock, and Kompasu would eventually make landfall on northern Japan in late Aug. 
Pacific (Fig. SB7.8). The pronounced cyclonic circulation, which persisted through the month, may be linked to significantly enhanced convective activity to the southeast. The intensified convection, in turn, was ignited and sustained in relation to repeated intrusions of high potential vorticity air associated with the persistent trough over the midlatitude Pacific (Fig. SB7.9).

Meanwhile the northwestern Pacific subtropical high (NWPSH), which, during a more typical summer, would prevail over the Pacific westward into East Asia and hamper typhoons

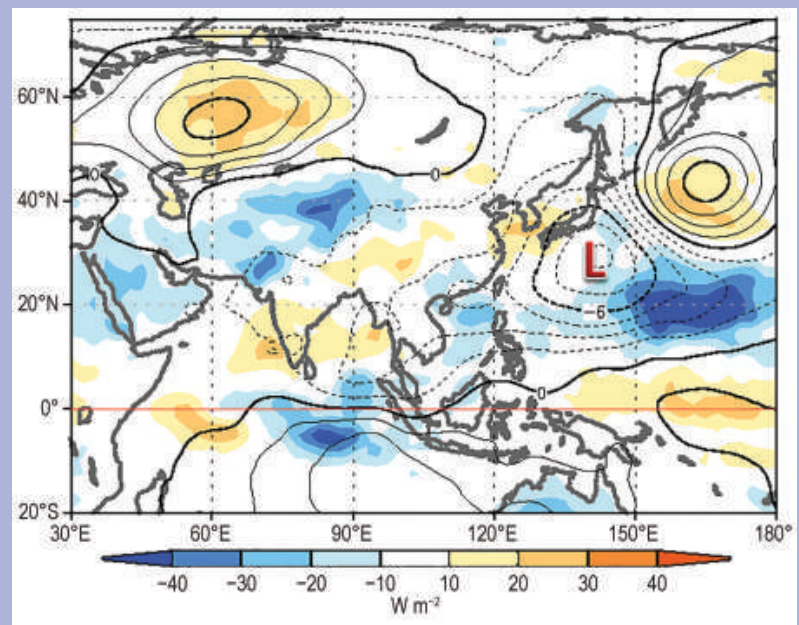

FIG. SB7.8. Stream function anomalies at $850-\mathrm{hPa}$ (contours) and OLR anomalies (color, $\mathrm{W} \mathrm{m}^{-2}$ ) for Aug 2016. Thick and thin contours are drawn at intervals of $10 \times 10^{6} \mathrm{~m}^{2} \mathrm{~s}^{-1}$ and $2.5 \times 10^{6} \mathrm{~m}^{2} \mathrm{~s}^{-1}$, respectively. For the $\mathbf{N H}$, solid and dashed lines indicate anticyclonic and cyclonic circulation anomalies, respectively. For the SH, vice versa. "L" denotes the center of cyclonic circulation anomalies south of Japan associated with significantly enhanced convective activity (negative OLR anomalies to the southeast of "L"). heading north toward Japan, was displaced in August. Far eastward of its normal position in association with a persistent wave train pattern in the upper troposphere extending from Eurasia to the mid-Pacific (Fig. SB7.8). The conspicuous absence of the NWPSH over and to the immediate east of Japan made it possible for the typhoons to find their way on an exceptional track due northward over the seas east of Japan to wreak havoc in the northern part of the country.

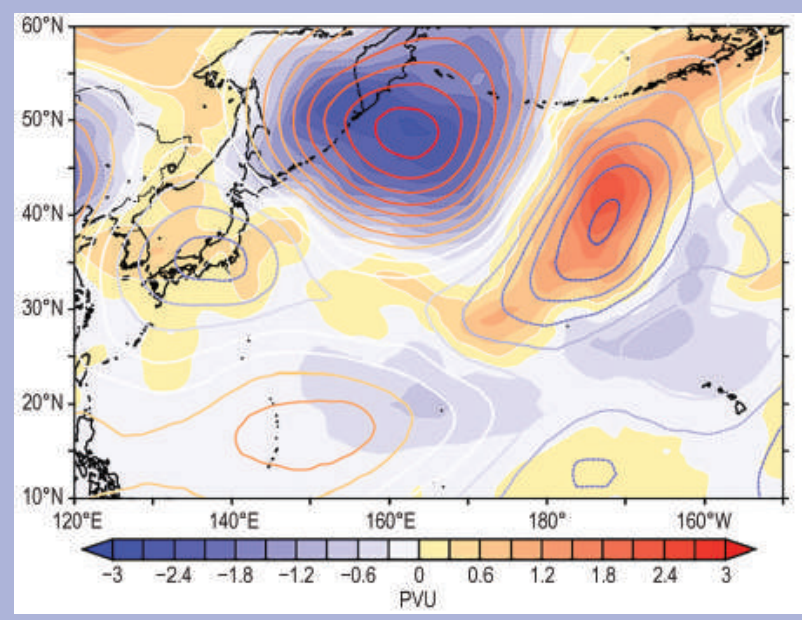

FIG. SB7.9. Stream function anomalies at 200-hPa (contours) and potential vorticity anomalies at $350 \mathrm{~K}$ (color, PVU) for Aug 2016. Contours are drawn at intervals of $2 \times 10^{6} \mathrm{~m}^{2} \mathrm{~s}^{-1}$, with warm (cool) color indicating anticyclonic (cyclonic) circulation anomalies. Note the intrusion into the tropics of high potential vorticity air associated with the trough centered over the midlatitude Pacific.
8 June, seven days later than its climatological normal date (1 June) and covered the entire country on 13 July (two days earlier than normal).

For India, the long-term average value of the summer monsoon rainfall, calculated using all data from 1951 to 2000 , is $890 \mathrm{~mm}$. During 2016, the summer monsoon seasonal rainfall averaged over the country was $97 \%$ of its long-term average and was characterized by significant spatial and temporal variability. The homogeneous region of central India received slightly above normal rainfall (106\% of average), while eastern and northeastern India received only $89 \%$ of monsoon season long-term average (Fig. 7.49). During the season, of 36 meteorological subdivisions, 4 (West and East Rajasthan, Konkan \& Goa, and Marathwada) received excess rainfall, 23 received normal rainfall, and the remaining 9 subdivisions received deficient rainfall. Nationally averaged rainfall varied through the season, but with a predominance of normal to above-normal conditions (Fig. 7.50). 


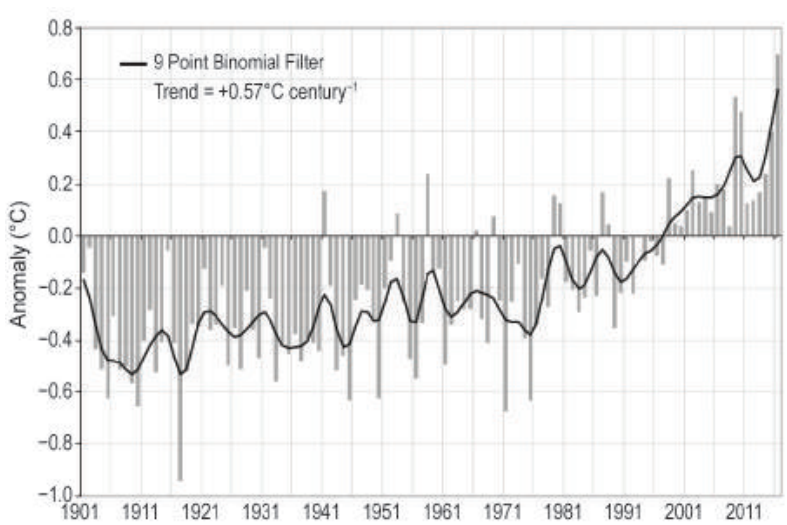

FIG. 7.48. Annual mean temperature anomalies $\left({ }^{\circ} \mathrm{C}\right.$; 1981-2010 base period) averaged over India for the period 190I-2016. The 9-year running mean is shown as a continuous line (the time series was mirrored at both ends prior to smoothing).

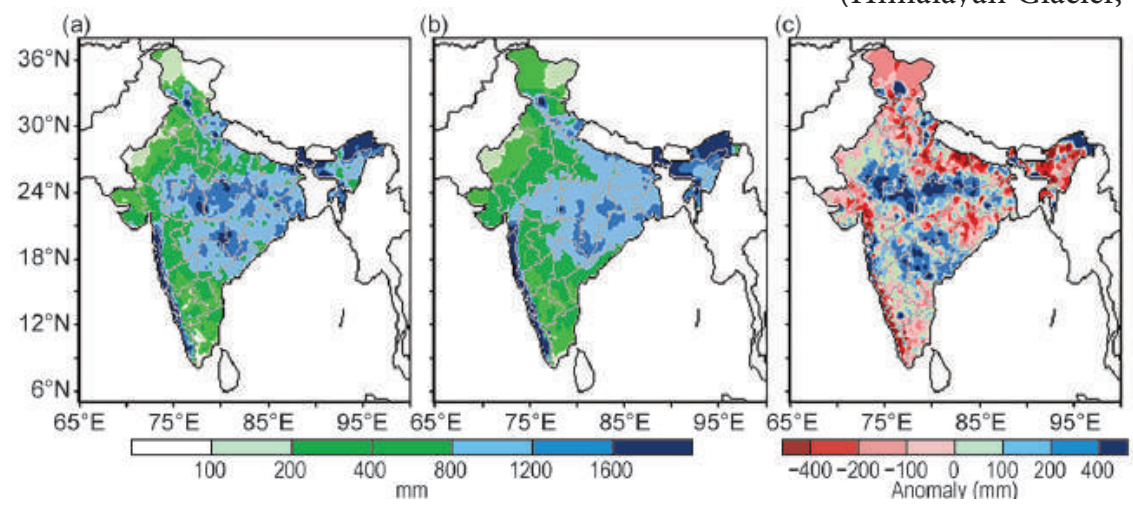

FIG. 7.49. Spatial distribution of monsoon seasonal (Jun-Sep) rainfall over India in 2016. Actual, normal and anomalies are in $\mathbf{~ m m}$.

During winter (January-February), rainfall over India was substantially below normal (44\% of average, clearly visible in Fig. 7.42b). Precipitation was normal during the pre-monsoon season (March-May) but well below normal (44\% of average) during the post-monsoon season (October-December). The northeasterly monsoon sets in over southern peninsular India during October and over Sri Lanka in late November. It contributes $30 \%-50 \%$ of the annual rainfall over southern peninsular India and Sri Lanka as a whole. The 2016 northeasterly monsoon seasonal rainfall over south peninsular India was substantially below normal (65\% of average), the lowest in the 116-year record.

Pakistan, at the western edge of the pluvial region of the south Asian monsoon, receives $60 \%-70 \%$ of its annual rainfall during its summer monsoon season (July-Sep- tember). In 2016, summer monsoon rainfall over Pakistan was below normal ( $84 \%$ of average) and was marked by spatial and temporal variability. Pakistan witnessed well-below-normal rains during July and September (75\% and 51\% of average, respectively). Bangladesh generally received above-normal rainfall during its 2016 summer monsoon season.

Sri Lanka received below-normal rainfall during its summer monsoon season (May-September). Northeasterly monsoon rainfall activity over the island nation during October to December was subdued, similar to southern parts of India.

\section{(iii) Notable events and impacts}

Ten soldiers were buried under snow after their camp in the northern part of the Siachen glacier (Himalayan Glacier, India) was hit by a major snow avalanche on 3 February 2016

A week of heavy rain during the third week of April resulted in floods and deadly landslides in parts of northeastern India. Eighteen people were killed in Arunachal Pradesh after heavy rain triggered two major landslides on 22 and 23 April. The heavy rain also resulted in "premonsoon" floods in Assam and Nagaland, affecting over 40000 people.

A week-long heat wave at the end of April over the northern Indian peninsula (Andhra and Telangana) and Orissa, coupled with already dry conditions from two consecutive deficient monsoons in 2014 and 2015, created an acute water crisis for 330 million people due to a lack of rain and soaring temperatures. Nearly 300 people died of heat-related problems, including 110 in the state of Orissa, 137 in Telengana, and 45 in Andhra Pradesh, as temperatures from the beginning of April reached $44^{\circ} \mathrm{C}$ or more in many areas.

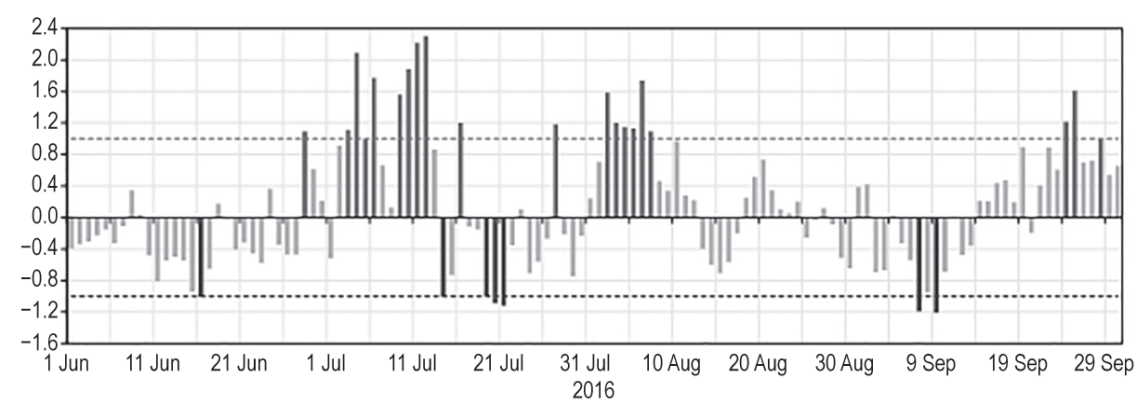

FIG. 7.50. Daily standardized rainfall time series averaged over the core monsoon period (I Jun-30 Sep 2016) over India. 
Lightning from a chain of thunderstorms caused 93 deaths during 19-21 June over different parts of eastern India (Bihar, Uttar Pradesh, and Jharkhand).

Heavy rains and resultant flooding-related incidents in different parts of India during the monsoon season claimed the lives of about 550 people, with the worst-affected state being Bihar where 146 people died during 25 July-3 September.

Many parts of 19 districts in Bangladesh were impacted by their most severe floods on record from mid-July to early August. These events affected 3.7 million people and caused about 110 fatalities. More than 250000 houses were reported damaged, including nearly 17000 houses that were washed away completely and over 65000 partially lost to riverbank erosion.

In 2016 more than 250 people died from lightning in Bangladesh during the warm months of March to July, including the three-day period of 12-14 May, when 67 people were killed.

An area of low pressure over Sri Lanka formed on 14 May and caused unprecedented heavy rainfall across the country. Many stations in Sri Lanka received unusually high rainfall amounts during a 24-hour period during 15-16 May: Deraniyagala (355.5 mm, all-time record), Colombo (256 mm), Katunayake (262 mm), Ratmalana (190 mm), Mannar $(186 \mathrm{~mm})$ and Trincomalee $(182 \mathrm{~mm})$. Floods affected 22 of 25 districts, with more than 100 fatalities (mainly due to landslides) and 3.5 million people affected.

5) SOUTHWESt AsIA—F. Rahimzadeh, M. Khoshkam, S. Fateh, and A. Kazemi

This subsection covers only Iran. Turkey is incorporated in the Europe Section 7f. Climate anomalies are relative to the $1996-2015$ base period.

\section{(i) Temperature}

The year 2016 was warmer than average for Iran; the mean annual air temperature was $0.5^{\circ}-1.0^{\circ} \mathrm{C}$ above average. Autumn (September-November) saw above-average temperatures across almost the entire country (Fig. 7.51b), while all other seasons experienced mixed patterns.

\section{(ii) Precipitation}

Iran experienced drier-than-normal conditions during 2016. During winter, 28 of its 31 provinces experienced critical drought conditions (Fig. 7.52a), as did 23 provinces during summer and most parts of the country in the fall. MODIS snow data show that snow coverage was at $16 \%$ of the country in the first half of January and down to $0.7 \%$ in the first half

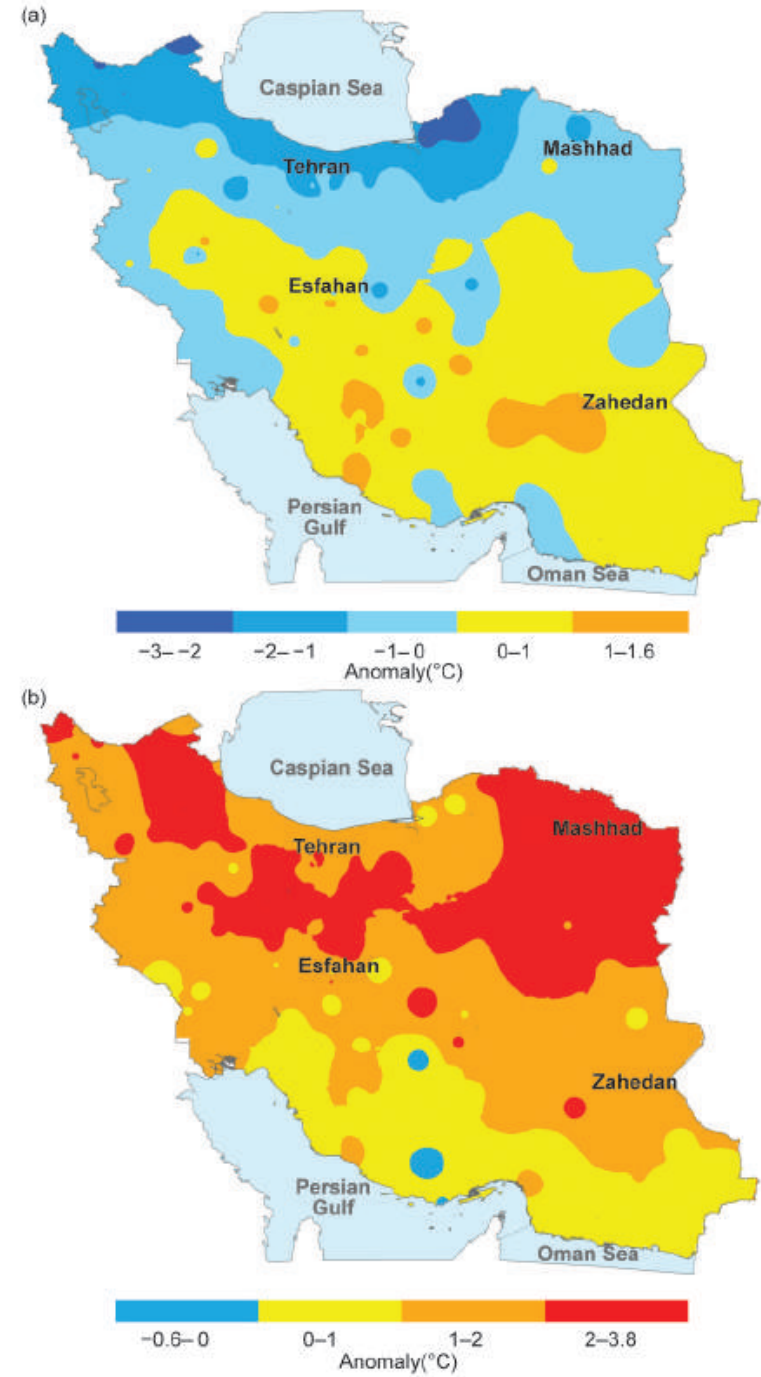

Fig. 7.5I. Seasonal 2016 mean surface temperature anomalies ( ${ }^{\circ} \mathrm{C}$; 1996-20I5 base period) for winter (a) and autumn (b). (Source: I. R. of Iran Meteorological Organization.)

of March. Snow amount and snow cover have both decreased significantly in recent decades.

The only relatively wet season overall was spring; however, several provinces, especially in the southeast, still received below-normal precipitation (Fig. 7.52b). This season was generally wet in the west, north, and northeast, with above-normal precipitation in many regions (more than $200 \%$ of normal in Lorestan, Khoseztan, and Ilam ). Hence, the effects of a dry winter were somewhat offset by the wet spring.

(iii) Notable events and impacts

On 18 May, a massive sand influx and persistent sand storms completely buried 16 villages and endangered another 80, according to the Rigan governor. Agricultural production in this area was ruined, at an 
(a)

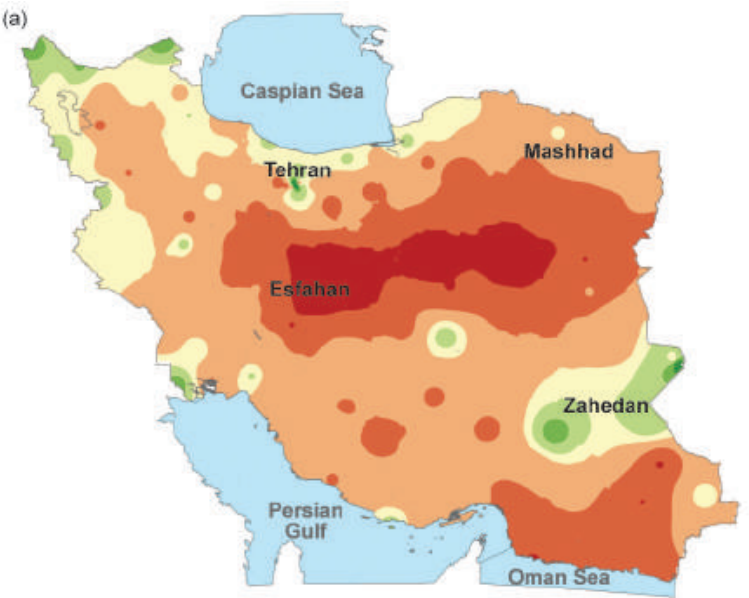

(b)

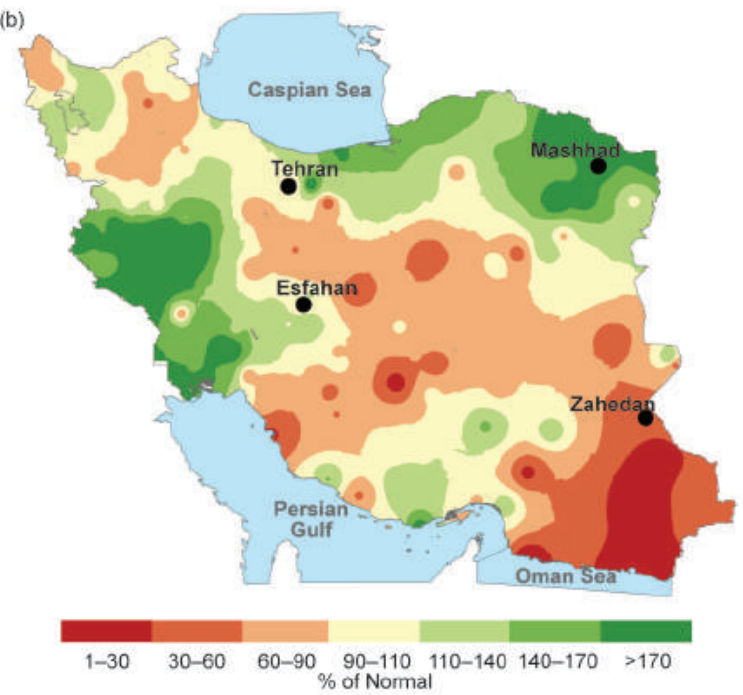

FIG. 7.52. Observed 2016 precipitation (\% of mean; 1996-20I5 base period) for Iran for (a) winter and (b) spring. (Source: I. R. of Iran Meteorological Organization.)

estimated cost of 320 billion rials (nearly $\$ 9$ million U.S. dollars).

\section{h. Oceania}

I) OVERVIEW-J. A. Renwick

The climate of the southwest Pacific in 2016 was affected by a strong El Niño that began in late 2014 and continued until late May 2016 when the equatorial Pacific transitioned to neutral. A neutral ENSO state, bordering on weak La Niña conditions, continued for the remainder of the year. From May, a strong negative Indian Ocean dipole event developed, contributing to Australia's wettest May-October (see Sidebar 7.5). After very strongly positive southern annular mode (SAM) conditions early in 2016, a period of negative SAM conditions set in during late October with unusually windy and unsettled conditions over New Zealand through the last months of the year.

2) Northwest Pacific and Micronesia-M. A. Lander and C. P. Guard

This assessment covers the area from the international date line west to $130^{\circ} \mathrm{E}$, between the equator and $20^{\circ} \mathrm{N}$. It includes the U.S.-Affiliated Islands of Micronesia but excludes the western islands of Kiribati and nearby northeastern islands of Indonesia. See Fig. 7.53 for a map of locations mentioned in the text.

\section{(i) Temperature}

Temperatures across Micronesia in 2016 were mostly well above the 1981-2010 average. The extreme warmth was expected in the dry, sunny, and light tradewind conditions that dominate the post-peak phase of El Niño. Warm anomalies were substantial at some islands, such as Saipan, where some of the temperature anomalies exceeded $+2^{\circ} \mathrm{C}$ (Table 7.3).

\section{(ii) Precipitation}

Annual totals of rainfall during 2016 were mostly below average across all of Micronesia, with some new all-time dry records set, especially in the period October 2015-March 2016. The regional progression of monthly rainfall anomalies throughout the year is illustrated well by the time series at Chuuk (Fig. 7.54). The wet weather of 2015 was followed by prolonged ryness through the first nine months of 2016, with a recovery of rainfall noted in the final months of the year. The 6-month and annual rainfall values for selected locations across Micronesia (along with the temperature) are summarized in Table 7.3.

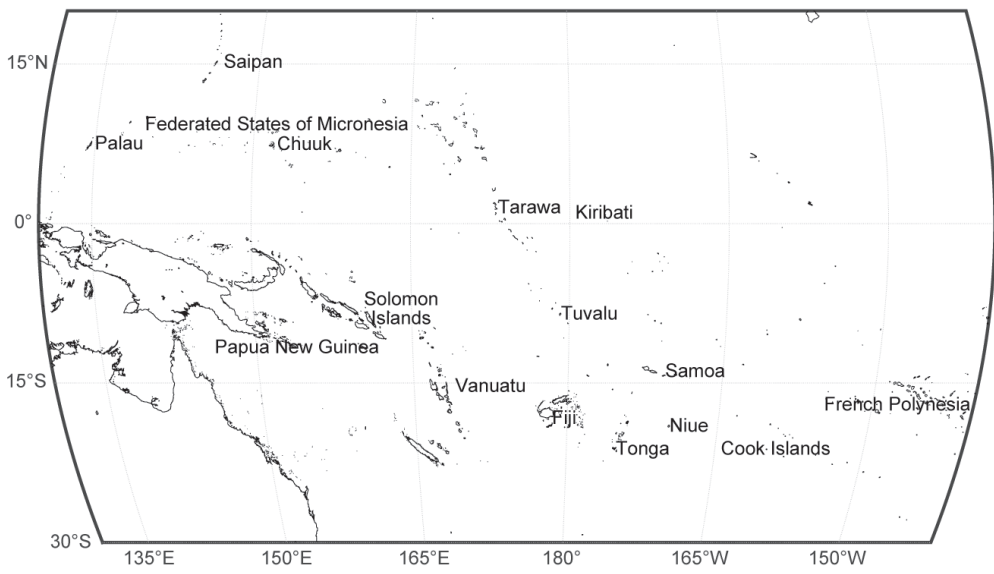

FIG. 7.53. Map showing location of many of the islands and island groups mentioned in Section $7 \mathrm{~h}$. 
(iii) Notable events and impacts

Palau's Jellyfish Lake suffered a catastrophic loss of nearly the entire population of 7 million mature jellyfish. The cause is thought to be the high temperatures that occur during the drought phase of El Niño. By April 2016, Jellyfish Lake was found to be devoid of all mature golden jellyfish that typically have populations of several million. In July 2016, visiting tourists reported that there were still no jellyfish in the lake. Based on prior jellyfish population decimations, it may take over a year before the population begins to recover. The last major die-off of jellyfish occurred during the strong 1997/98 El Niño event.

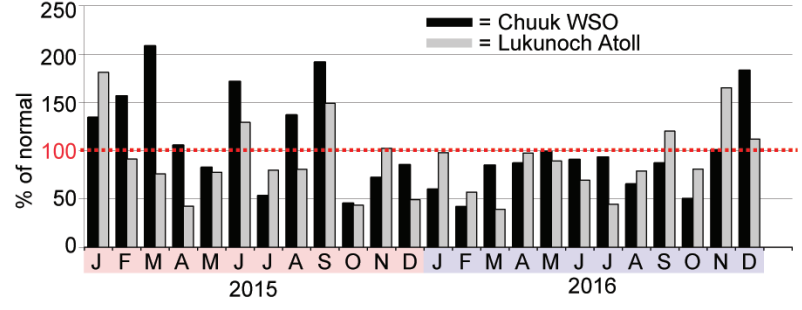

FIG. 7.54. Monthly rainfall $(\mathrm{mm})$ for $2015 / 16$ at the Weather Service Office (WSO) Chuuk Lagoon (black bars) and at Lukunoch Atoll, Mortlock Island group, Chuuk State (gray bars).

\begin{tabular}{|c|c|c|c|c|c|c|c|c|c|c|}
\hline \multirow[t]{2}{*}{ Location } & \multicolumn{2}{|c|}{$\begin{array}{l}\text { Max Temp } \\
\text { Min Temp }\end{array}$} & \multicolumn{8}{|c|}{ Rainfall (mm) } \\
\hline & $\begin{array}{l}\text { Jan- } \\
\text { Jun }\end{array}$ & $\begin{array}{l}\text { Jul- } \\
\text { Dec }\end{array}$ & $\begin{array}{l}\text { Jan- } \\
\text { Jun }\end{array}$ & $\begin{array}{l}\text { Jan- } \\
\text { Jun }\end{array}$ & $\begin{array}{l}\text { Jan- } \\
\text { Jun }\end{array}$ & $\begin{array}{l}\text { Jul- } \\
\text { Dec }\end{array}$ & $\begin{array}{l}\text { Jul- } \\
\text { Dec }\end{array}$ & $\begin{array}{l}\text { Jul- } \\
\text { Dec }\end{array}$ & $\begin{array}{l}\text { Jan- } \\
\text { Dec }\end{array}$ & $\begin{array}{l}\text { Jan- } \\
\text { Dec }\end{array}$ \\
\hline & ${ }^{\circ} \mathrm{C}$ & ${ }^{\circ} \mathrm{C}$ & AVG & 2016 & $\%$ & AVG & 2016 & $\%$ & 2016 & $\%$ \\
\hline $\begin{array}{l}\text { Saipan, } \\
15^{\circ} \mathrm{N}, \\
146^{\circ} \mathrm{E}\end{array}$ & $\begin{array}{l}+2.59 \\
+0.82\end{array}$ & $\begin{array}{l}+2.47 \\
+2.08\end{array}$ & 449.1 & 359.2 & 80.0 & 1322.8 & 1588.8 & 120.1 & 1947.9 & 109.9 \\
\hline $\begin{array}{l}\text { Guam, } \\
13^{\circ} \mathrm{N}, \\
145^{\circ} \mathrm{E}\end{array}$ & $\begin{array}{l}+1.82 \\
+0.79\end{array}$ & $\begin{array}{l}+1.15 \\
+1.00\end{array}$ & 691.6 & 475.5 & 68.8 & 1788.4 & 1910.6 & 107.1 & 2386.1 & 96.4 \\
\hline $\begin{array}{c}\text { Yap, } \\
9^{\circ} \mathrm{N}, 138^{\circ} \mathrm{E}\end{array}$ & $\begin{array}{l}+1.31 \\
+0.34\end{array}$ & $\begin{array}{l}+0.28 \\
+0.17\end{array}$ & 1169.7 & 597.7 & 51.1 & 1902.0 & 1888.5 & 99.3 & 2487.2 & 81.0 \\
\hline $\begin{array}{l}\text { Palau, } \\
7^{\circ} \mathrm{N}, 134^{\circ} \mathrm{E}\end{array}$ & $\begin{array}{l}+1.96 \\
+0.03\end{array}$ & $\begin{array}{l}+0.91 \\
+0.19\end{array}$ & 1717.6 & 1208.3 & 70.3 & 2032.5 & 1814.3 & 89.3 & 3022.6 & 80.6 \\
\hline $\begin{array}{l}\text { Chuuk, } \\
7^{\circ} \mathrm{N}, 152^{\circ} \mathrm{E}\end{array}$ & $\begin{array}{l}+0.69 \\
+0.83\end{array}$ & $\begin{array}{l}+1.01 \\
+0.62\end{array}$ & 1584.2 & 1257.4 & 79.4 & 1833.1 & 1712.5 & 93.4 & 2969.9 & 86.9 \\
\hline \multirow{2}{*}{$\begin{array}{l}\text { Pohnpel, } \\
7^{\circ} \mathrm{N}, 158^{\circ} \mathrm{E}\end{array}$} & +0.28 & -0.42 & \multirow{2}{*}{2266.4} & \multirow{2}{*}{1832.4} & \multirow{2}{*}{80.8} & \multirow{2}{*}{2336.5} & \multirow{2}{*}{2651.0} & \multirow{2}{*}{113.5} & \multirow{2}{*}{4483.4} & \multirow{2}{*}{97.4} \\
\hline & +1.32 & +1.67 & & & & & & & & \\
\hline $\begin{array}{l}\text { Kapinga, } \\
I^{\circ} \mathrm{N}, 155^{\circ} \mathrm{E}\end{array}$ & $N / A$ & N/A & 1750.8 & 1158.5 & 66.2 & 1510.5 & 1124.2 & 74.4 & 2282.7 & 70.0 \\
\hline $\begin{array}{c}\text { Kosrae, } \\
5^{\circ} \mathrm{N}, 163^{\circ} \mathrm{E}\end{array}$ & $\begin{array}{l}+0.42 \\
+1.59\end{array}$ & $\begin{array}{l}+0.35 \\
+1.86\end{array}$ & 2567.9 & 1659.6 & 64.6 & 2342.9 & 2142.0 & 91.4 & 3801.6 & 77.4 \\
\hline $\begin{array}{c}\text { Majuro, } \\
7^{\circ} \mathrm{N}, 17 I^{\circ} \mathrm{E}\end{array}$ & $\begin{array}{l}+0.35 \\
+1.38\end{array}$ & $\begin{array}{l}+0.35 \\
+1.37\end{array}$ & 1368.3 & 678.4 & 49.6 & 1868.2 & 1956.1 & 104.7 & 2634.5 & 81.4 \\
\hline $\begin{array}{l}\text { Kwajalein, } \\
9^{\circ} \mathrm{N}, 168^{\circ} \mathrm{E}\end{array}$ & $\begin{array}{l}+0.83 \\
+0.24\end{array}$ & $\begin{array}{l}+0.63 \\
+0.39\end{array}$ & 801.4 & 464.1 & 57.9 & I579.1 & 1733.0 & 109.7 & 2197.1 & 92.3 \\
\hline \multicolumn{10}{|c|}{ Legend for Table Colors } & \\
\hline & \multicolumn{2}{|c|}{$\begin{array}{c}\text { Orange Above } \\
\text { Avg Temp }\end{array}$} & & \multicolumn{2}{|l|}{$\begin{array}{l}\text { Blue Below } \\
\text { Avg Temp }\end{array}$} & \multicolumn{2}{|c|}{$\begin{array}{l}\text { Yellow Below } \\
\text { Avg Precip }\end{array}$} & \multicolumn{2}{|c|}{$\begin{array}{l}\text { Green Above } \\
\text { Avg Precip }\end{array}$} & \\
\hline
\end{tabular}


3) Southwest Pacific-E. Chander and S. MCGReE

Countries considered in this section include: American Samoa, Cook Islands, Fiji, French Polynesia, Kiribati, New Caledonia, Niue, Papua New Guinea, Samoa, the Solomon Islands, Tonga, Tuvalu, and Vanuatu. Air temperature and rainfall anomalies are relative to the 1981-2010 period. See Fig. 7.53 for a map of locations mentioned in the text.

\section{(i) Temperature}

Mean air temperatures over the southwest Pacific were strongly influenced by El Niño at the beginning of 2016, with temperature anomalies along the equator east of the date line
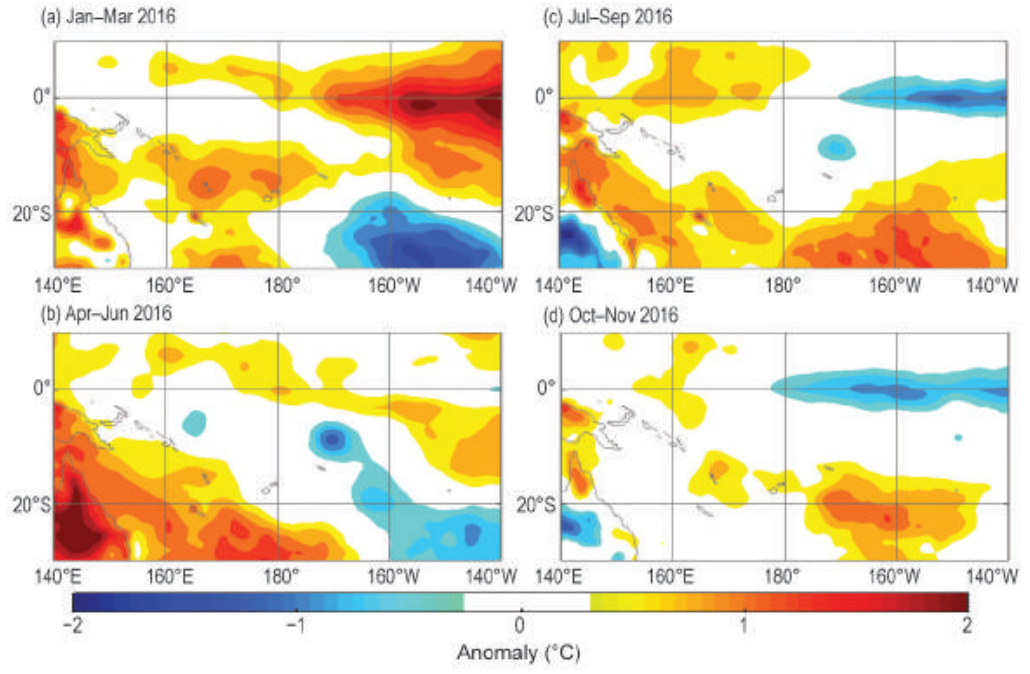

Fig. 7.55. Southwest Pacific 2-m air temperature anomalies $\left({ }^{\circ} \mathrm{C}\right.$; base period 198I-2010) for (a) Jan-Mar, (b) Apr-Jun, (c) Jul-Sep, and (d) Oct-Dec 2016. (Source: ECMWF ERA-Interim reanalysis.)

falling dramatically during the second quarter of the year as the Pacific transitioned towards a neutral ENSO state. Equatorial eastern Pacific temperatures during the second half of the year were below normal, reflecting the borderline La Niña state.

Mean air temperature anomalies were positive in many areas across the southwest Pacific during January-March (Fig. 7.55a). Anomalies exceeded $+1.5^{\circ} \mathrm{C}$ along the equator east of the date line. Negative anomalies of up to $-1.5^{\circ} \mathrm{C}$ occurred to the south of French Polynesia. During April-June, positive anomalies centered on the equator weakened substantially (Fig. 7.55b) and negative anomalies south of French Polynesia also weakened. Positive anomalies

over Queensland, Australia, and the Coral Sea region increased, especially over the Australian landmass.

Negative anomalies (below $-0.25^{\circ} \mathrm{C}$ ) occurred near the equator over the eastern Pacific during the second half of the year, while temperatures were generally near- or above normal in the far west of the region, and south of $20^{\circ} \mathrm{S}$ (Figs. $7.55 \mathrm{c}, \mathrm{d}$ ).

\section{(ii) Precipitation}

Rainfall patterns and the positions of the major convergence zones during January-March were similar to those observed during previous strong El Niño events. The intertropical convergence zone (ITCZ) was displaced southward and the South Pacific convergence zone (SPCZ) displaced to the

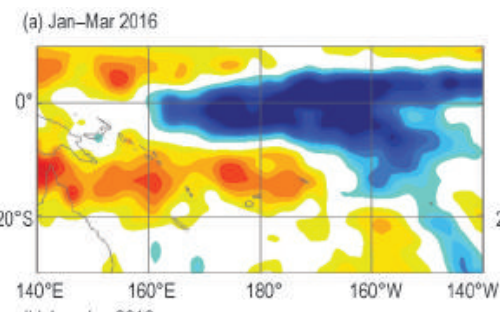

(b) Apr-Jun 2016

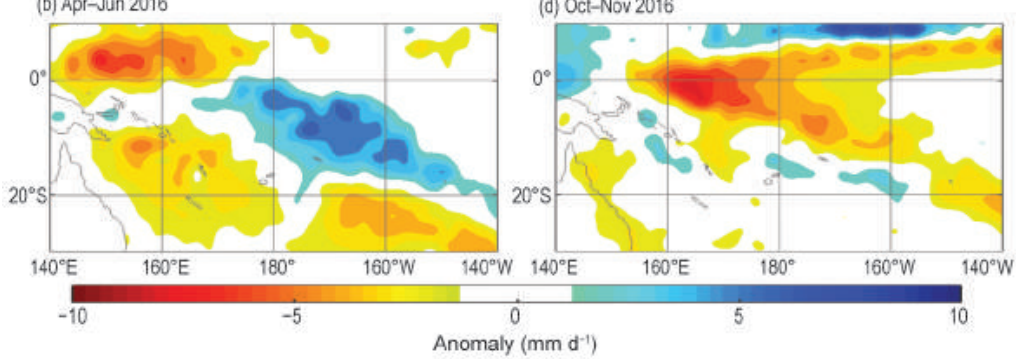

Fig. 7.56. Estimated precipitation anomalies $\left(\mathrm{mm} \mathrm{d}^{-1}\right.$; base period 198I-2010) from the NOAA CMAP dataset, for (a) Jan-Mar, (b) Apr-Jun, (c) Jul-Sep, and (d) Oct-Dec 2016. (Source: NOAA, www.esrl.noaa.gov/psd/data/gridded/data.cmap.html.) northeast (Fig. 7.56a). This resulted in above-normal rainfall across Kiribati, northern Tuvalu, the northern Cook Islands, and in parts of Papua New Guinea (Highlands and New Guinea Islands). Below-normal rainfall was observed across southern Papua New Guinea, most of the Solomon Islands and Fiji, central and southern Tuvalu, northern Tonga, Samoa, and the southern Cook Islands. January-March rainfall was the lowest on record at Taro (northern Solomon Islands, $420.0 \mathrm{~mm}$, since 1975), Sola (569.7 mm, northern Vanuatu, since 1971), Lamap (210.7 mm, northern Vanuatu, since 1961), and Port Vila (197.4 mm, southern Vanuatu, since 1953). Record high 
rainfall was observed at Tarawa $(1880.8 \mathrm{~mm}$, western Kiribati, since 1950).

Rainfall during April-June exhibited aspects of an El Niño-like pattern (Fig. 7.56b) with the SPCZ continuing to be displaced towards the northeast. The central Solomon Islands, western Fiji, Tonga, and Samoa were wetter than normal, which in the case of the countries closer to the date line, was due to a very wet April. Record high rainfall was observed at Apia (1121.4 mm, Samoa, since 1890), Fua'amotu Airport (1078.6 mm, southern Tonga, since 1979) and Nanumea (1139.9 mm, northern Tuvalu, since 1941). April-June rainfall was the lowest on record at Sola (532.5 mm, northern Vanuatu, since 1971).

The transition from an El Niño to a neutral state resulted in a muted rainfall pattern across the South Pacific from July to September (Fig. 7.56c). The ITCZ was displaced north of its normal position. The SPCZ showed month-to-month variability during this period, and rainfalls were mostly near normal south of the equator. During October-December, the ITCZ continued to be displaced north of its mean position and the SPCZ was variable. Rainfall was below normal in Kiribati, northern and central Tuvalu, and in the northern Cook Islands. Rainfall was normal to above normal from Papua New Guinea southeast to the southern Cook Islands. In Fiji, October-December rainfall was the highest on record at Yasawa-iRara (671 mm, since 1950), Suva (762 mm, since 1942), and Navua (928 mm, since 1945).

The impact of the El Niño in the southwest Pacific in 2016 is likely to have been greatest in Vanuatu. Annual rainfall was the lowest on record at Lamap (1197 mm, since 1961) and Port Vila (956.0 mm, since 1953) and in the lowest $10 \%$ of observations at the other five observation stations on the island.

\section{(iii) Notable events and impacts}

Severe Tropical Cyclone Winston was one of the strongest tropical cyclones to make landfall in the southwest Pacific in recorded history. Early on 15 February, while located to the far south of Fiji, Winston took a northeast turn towards southeast Fiji and Tonga. On 17 February, while east of Tonga, the cyclone made a clockwise loop then tracked westward back toward central Tonga. In the process, Winston rapidly intensified once again, reaching category 5 intensity on both the Australian tropical cyclone scale and the Saffir-Simpson hurricane wind scale on 19 February. The storm passed directly over the eastern Fijian island of Vanua Balavu, where a recently installed automatic weather station recorded a wind gust of $306 \mathrm{~km} \mathrm{~h}^{-1}$. The cyclone reached its peak on

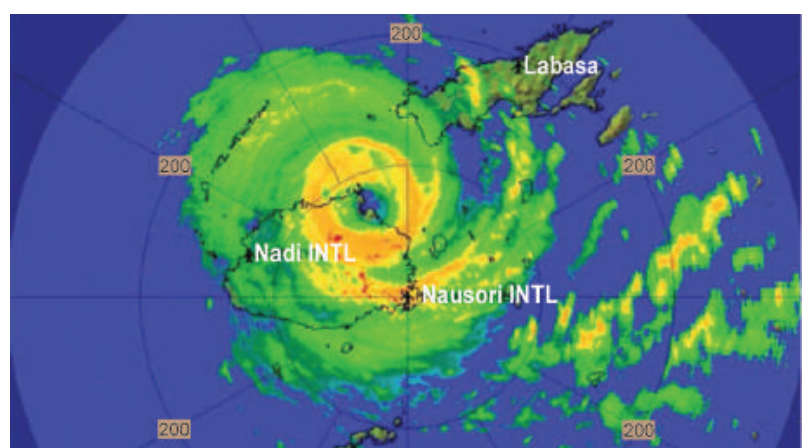

FIg. 7.57. Radar image showing Tropical Cyclone Winston making landfall over Viti Levu, Fiji, on 20 Feb 2016 (Source: Fiji Meteorological Service.)

20 February, shortly before making landfall on Viti Levu, Fiji (Fig. 7.57). While over Fiji on 20 February, Winston inflicted extensive damage and killed 44 people. About 40000 homes were damaged or destroyed, and approximately $40 \%$ of Fiji's population were significantly impacted by the storm. Damage in Fiji alone was estimated to be on the order of FJ\$3 billion ( $\$ 1.4$ billion U.S. dollars). See Chapter $4 \mathrm{f} 8$ for more details about Winston.

\section{4) Australia - C. Ganter and S. Tobin \\ (i) Temperature}

Australia's annual mean temperature for 2016 was $0.56^{\circ} \mathrm{C}$ above the $1981-2010$ average, making it the fourth warmest year on record since national observations commenced in 1910. The decade ending 2016 was $0.27^{\circ} \mathrm{C}$ above average, marking the warmest ten-year period in Australian records. Sea surface temperatures (SSTs) around Australia were the highest on record annually, based on ERSSTv4 data. SSTs around Australia have been persistently high in recent years, as they were throughout 2016, with a range of negative impacts on fisheries and coral reefs.

Land temperatures were persistently above average over Australia throughout 2016, with national average maxima lower than average only for January, August, September, and October, and the national minima lower than average only for October and November. Mean temperatures from February to July were among the nine highest on record for their respective months. Following a warm summer, there were frequent warm spells during autumn, contributing to Australia's warmest March and warmest autumn on record (see Notable events and impacts below). Winter was also warmer than average, and while spring remained warm for the northern tropics, it was cooler than average for parts of southern Australia in September and October. December brought a warm finish to the year for the eastern states and South Australia. 
Australian mean maximum temperatures (Fig. 7.58) were $0.40^{\circ} \mathrm{C}$ above average and mean minimum temperatures (Fig. 7.59) were $0.72^{\circ} \mathrm{C}$ above average. Minimum temperatures were second highest on record, behind 1998. Annual mean temperatures were record high for the tropics and parts of the east coast and southern Tasmania, and above average for almost all of Australia.

Maxima were in the highest $10 \%$ of observations for northern Australia, the eastern seaboard, and Tasmania, and above average for most of the remainder of the eastern states and eastern South Australia. Annual mean maxima were the highest on record for large areas of the far tropical north.

Minima were in the highest $10 \%$ of observations over nearly all of Australia, and the highest on record for Tasmania, most of Victoria, southern to southeastern New South Wales, western Queensland, and areas of northern Australia. Only southwest Western Australia and parts of southern South Australia experienced annual minima close to the long-term average.

\section{(ii) Precipitation}

Rainfall averaged across Australia for 2016 was $545 \mathrm{~mm}$, or $113 \%$ of the $1981-2010$ average, ranking 15 th wettest in the 117-year national record. Most of the country had a wetter-than-average year, but scattered pockets in tropical northern Australia and parts of the east and west coasts experienced an average to drier-than-average year. Large parts of central and southeast Australia had annual rainfall in their highest $10 \%$ of records (Fig. 7.60).

All states had above-average annual rainfall for 2016. Tasmania experienced its second wettest year since 1900, and South Australia its fourth. Victoria and New South Wales were the only other two states in the top 20, ranking 14th and 15th wettest, respectively. This was a dramatic change for Victoria and Tasmania, both of which had low annual rainfall during 2014 and 2015, and began 2016 with large areas of long-term rainfall deficiencies.

Additionally, parts of southwest Australia, southeast South Australia, and inland Queensland began 2016 with rainfall deficiencies on a range of one to four-year timescales. Deficiencies persisted until April, after which good rainfall brought relief across these regions as the year progressed.

El Niño was a strong driver of Australia's rainfall at the start of 2016, with the first four months of the year relatively dry for northern Australia. The northern Australian wet season (October 2015 to April 2016) had a very wet December (largely as a

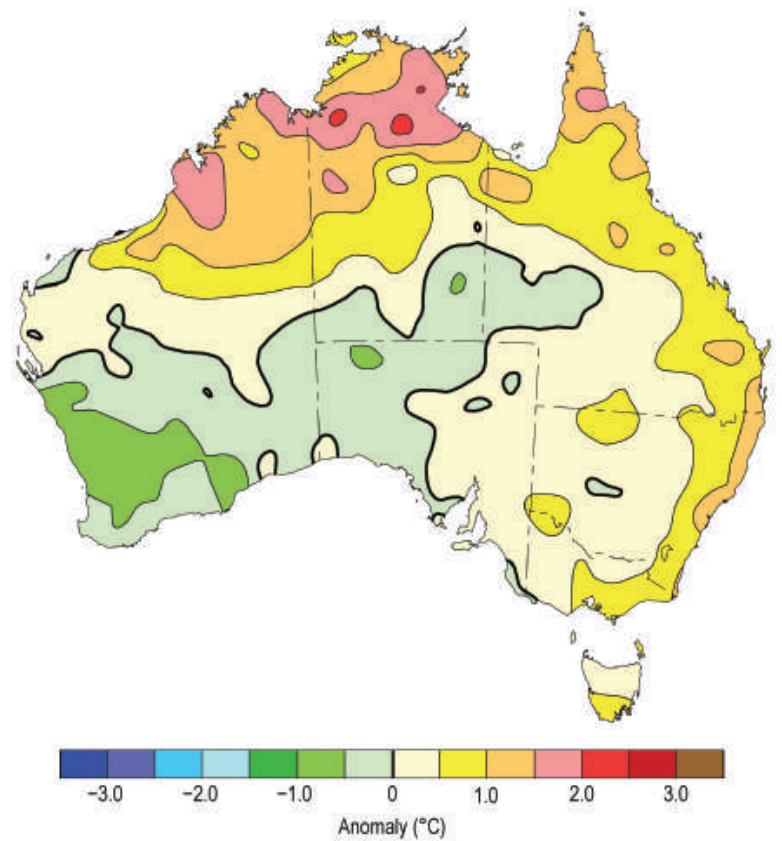

FIG. 7.58. Maximum temperature anomalies $\left({ }^{\circ} \mathrm{C}\right)$ for Australia, averaged over 2016, relative to I98I-2010. (Source: Australia Bureau of Meteorology.)

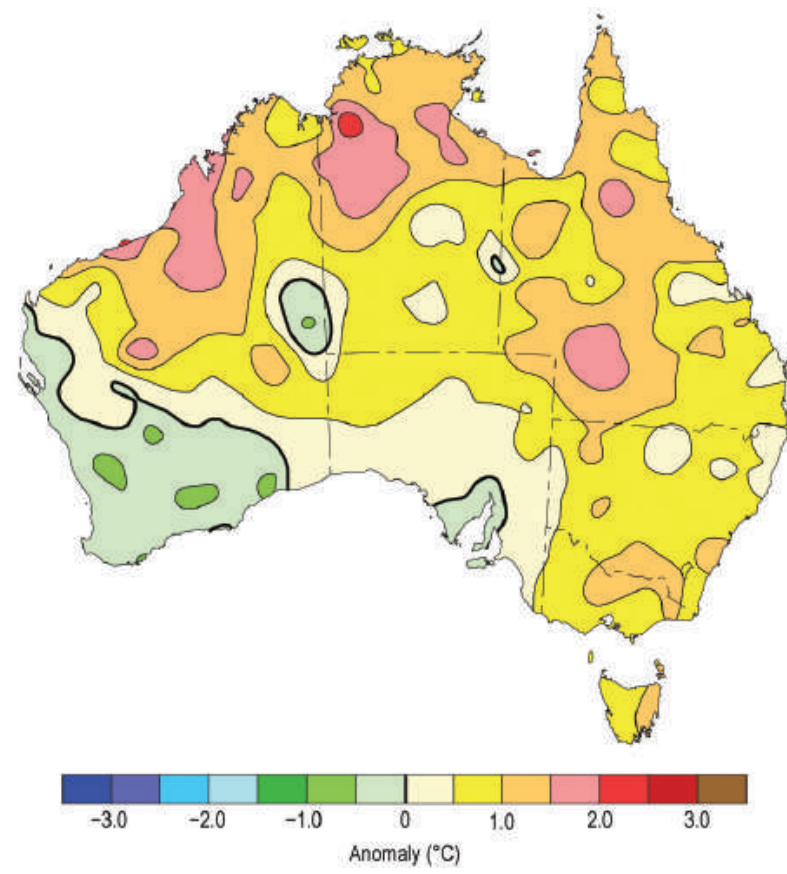

FIG. 7.59. Minimum temperature anomalies $\left({ }^{\circ} \mathrm{C}\right)$ for Australia, averaged over 2016, relative to 1981-2010. (Source: Australia Bureau of Meteorology.)

result of a single low pressure system), but the season overall was the driest wet season in more than 20 years. January in particular was dry for the far north of Australia, with small areas experiencing their driest January on record. It was a quiet season for tropical cyclones (November 2015-April 2016), with 


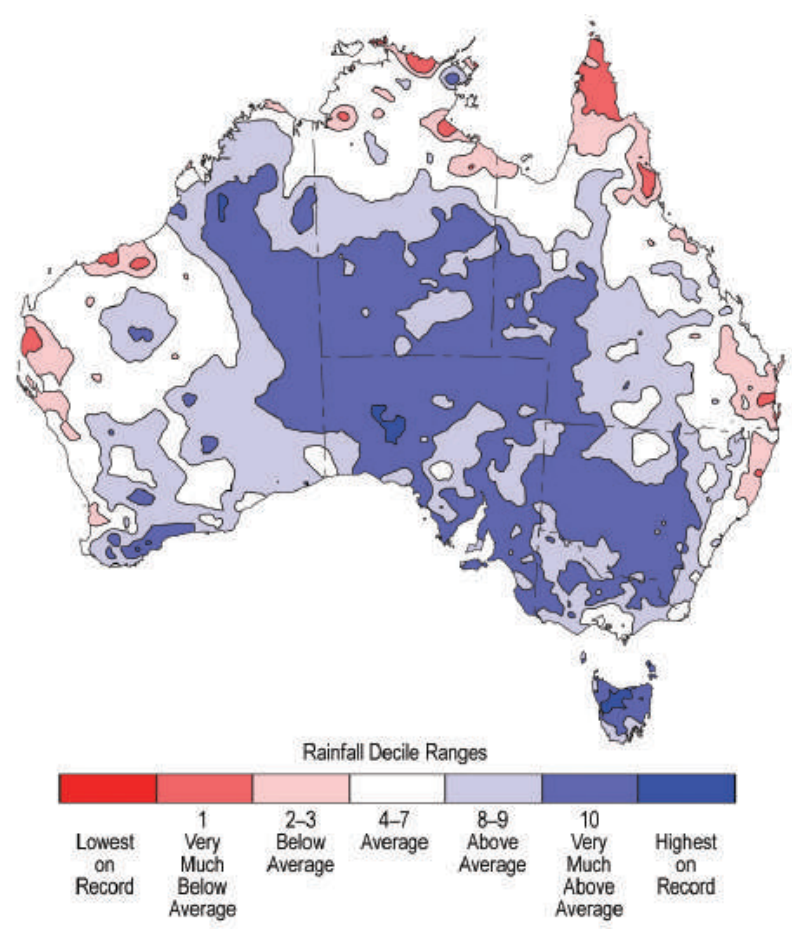

FIG. 7.60. Rainfall deciles for Australia for 2016, based on the 1900-2016 distribution. (Source: Australia Bureau of Meteorology.)

only three storms recorded in the Australian region (compared to a long-term average of 11) - the lowest number since satellite records began in the 1970s. From May through the rest of the year, only southwest Australia, a region that has seen a long-term drying trend, experienced below-average rainfall.

With the decline of the negative Indian Ocean dipole, November to December rainfall continued to be above average across most of the northwest and central Australia, while much of eastern Australia experienced below-average rainfall. December saw a tropical low track across northwest Australia and into the interior, which brought very heavy rain to affected regions (see Notable events and impacts).

\section{(iii) Notable events and impacts}

El Niño, in combination with background global warming, led to record high SSTs around Australia during the first half of 2016 (using ERSSTv4 records back to 1900). Coral bleaching in the northern Great Barrier Reef was the worst in the 32-year monitoring record, affecting a region of some $1000 \mathrm{~km}$, while in the reefs to Australia's northwest it was only the third time a major bleaching event has ever been recorded. SSTs were also record high around Tasmania and across parts of the Tasman Sea, in part driven by a southward extension of the East Australian Current. This was associated with the longest and most intense marine heatwave on record for the southeast Australian region, with outbreaks of disease in aquaculture and the loss of cold-water kelp forests along the Tasmanian coast. The dry and warm conditions with low cloudiness during the northern Australian wet season contributed to widespread mangrove deaths along the northern coastline.

Excessive heat was not restricted to the oceansduring late February and the first half of March a prolonged heatwave affected much of Australia, especially the southeast. This was attributed to weak monsoonal rainfall over northern Australia leading to a build-up of heat, which by the first week of March had extended to cover almost all of Australia, with numerous daily records set.

In northwest Tasmania bushfires occurred over a large area occurred during January and February following an extended dry period; about 123800 ha burned mostly in remote areas, with smoke reaching Hobart and southern Victoria on occasion. At the start of 2016 there were also significant fires near Lorne in Victoria and in southwest Western Australia affecting Yarloop and Waroona. These events led to the loss of many houses with a number of deaths.

By May, El Niño broke down and the dry start to the year was followed by a record-wet May to September period as a negative Indian Ocean dipole developed and took over as Australia's primary climate driver (see Sidebar 7.5).

An East Coast low caused major coastal flooding and erosion in New South Wales in early June, with flooding also affecting Victoria and large areas of Tasmania.

There were also significant storm and wind events that affected the southeast during the wet period. In the Murray-Darling Basin, already wet soils and high river levels meant excessive rain caused flooding in many areas of inland New South Wales and the north and west of Victoria throughout September and October.

Flooding occurred from June to September in western, central, and southern Queensland following the state's second wettest winter on record. Waters in this inland drainage basin can take many months to progress through the system. Significant flooding also occurred in Tasmania during January and in each month of spring.

Spring saw a number of damaging severe storms. In late September severe thunderstorms and multiple tornados caused widespread damage in South Australia. On 21 November widespread thunderstorms affected Victoria, igniting grassfires in the north and 


\section{SIDEBAR 7.5: STRONG NEGATIVE INDIAN OCEAN DIPOLE ASSISTS IN AUSTRALIA'S WETTEST MAY-OCTOBER-C. GANTER AND S. TOBIN}

The combination of the decay of the 2015//6 El Niño and a strong negative Indian Ocean dipole (IOD) from mid-May to mid-November helped bring Australia its wettest May to October on record (Fig. SB7.I0). All six months had aboveaverage rainfall for the country, with the second wettest June and September on record for Australia, sixth wettest May, and tenth wettest August. Despite challenges involving flooding and water-logging for the southern cropping regions in Australia, wheat forecasts at the end of 2016 indicated a record high wheat crop for 2016/17.

Flooding affected many areas during this wet period and was most widespread during September. Regions most significantly affected were central New South Wales, northern and western Victoria, southwestern Queensland, eastern Tasmania, and southeast South Australia. In Queensland, while the flood levels were substantially lower than those that have occurred during summer and autumn on numerous occasions in the past, they were unusual for winter-spring, which is typically a drier period in the annual cycle.

The heavy rainfall in September was more than double the long-term average over large parts of the country (Fig. SB7.II)

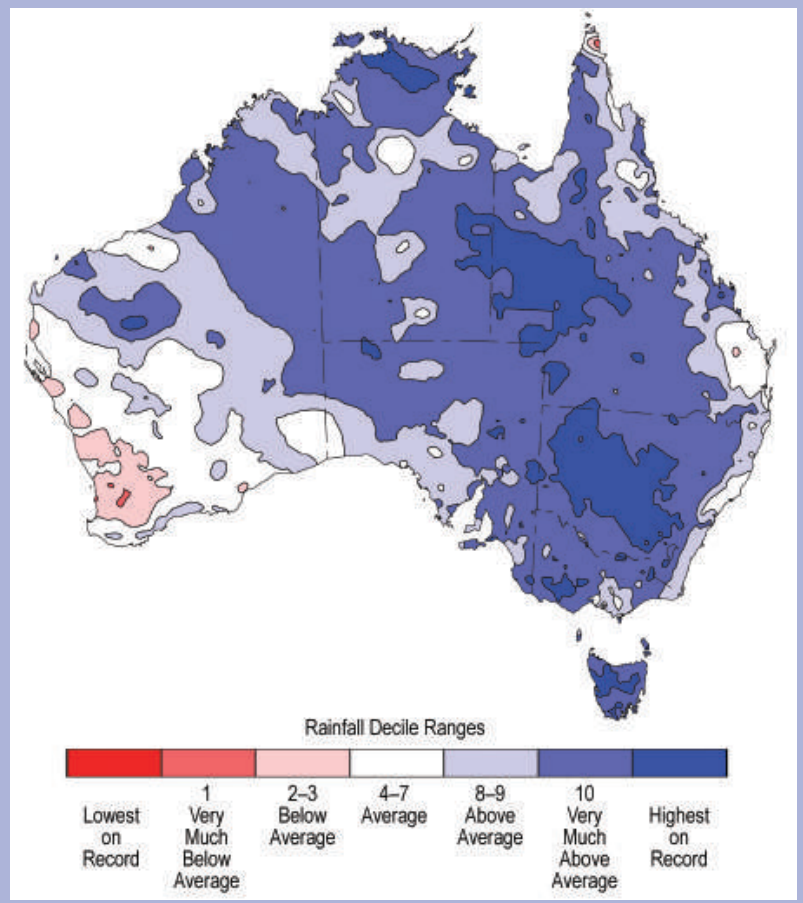

FIG. SB7.10. Rainfall deciles for Australia for I May-3I Oct 2016, based on the II7-year record for 1900-2016 record. (Source: Australia Bureau of Meteorology.)

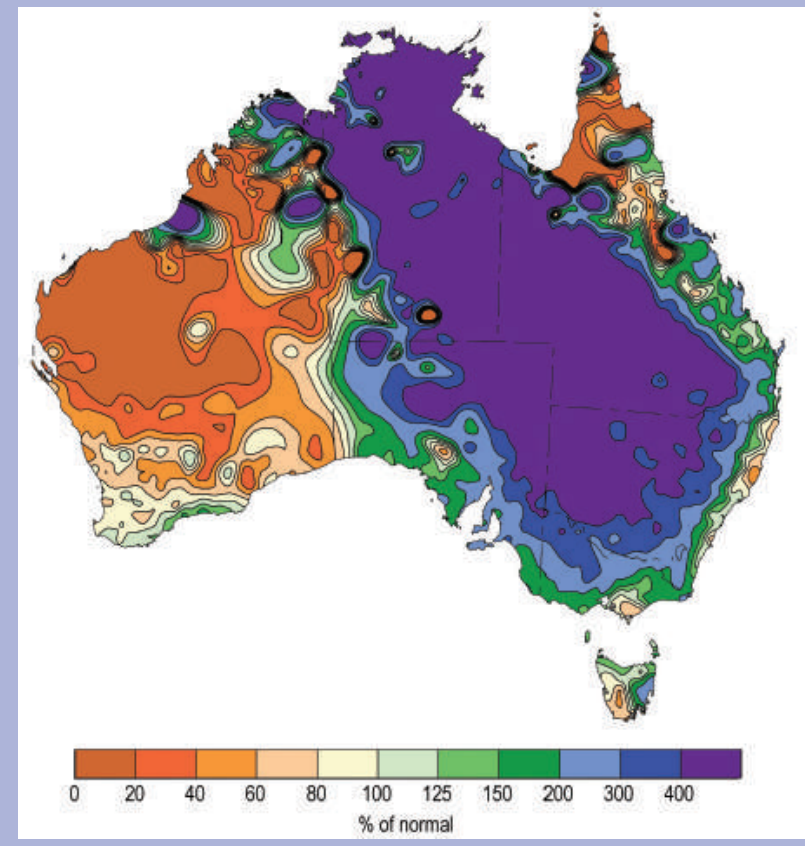

FIG. SB7.II. Percent of normal rainfall for Australia for Sep 2016, based on the 1981-2010 distribution. (Source: Australia Bureau of Meteorology.)

and was especially noteworthy for the number of rainfall events rather than the extreme nature of any one particular event. Across the eastern states of Queensland, New South Wales, and Victoria, 168 stations (with at least 50 years of record) had their wettest September on record, but only 38 had their wettest September day on record.

However, the Northern Territory and an area near Adelaide in South Australia both had extreme rainfall at daily timescales. Prior to 2016, there were only six instances of September daily rainfall totals exceeding $100 \mathrm{~mm}$ in the Northern Territory. On 19 September alone, six stations achieved this feat. The highest total that day, $168.2 \mathrm{~mm}$ at Mainoru, was the third wettest September day on record for a Northern Territory site (close behind the record of $177.4 \mathrm{~mm}$ set on 24 September 1998). In the Adelaide region, $101.4 \mathrm{~mm}$ fell at Uraidla on 15 September, and $100.2 \mathrm{~mm}$ at Ashton, with the former's total the highest daily September rainfall on record for the Adelaide region and sixth highest for South Australia.

For further details on the May-September period, see Special Climate Statement 58 (www.bom.gov.au/climate/current /statements/scs58.pdf). 
triggering thousands of incidents of thunderstorm asthma-the worst such event recorded in Australia.

A tropical low at the end of the year brought exceptional rainfall to a number of regions between the northwest and the southeast of Australia. This 1-in-50 year rainfall event caused flooding in the Kimberley and flash flooding around Uluru in central Australia and around Adelaide, Melbourne, and Hobart. Southeast Australia also experienced exceptional humidity during the event.

For further detail on these and other significant events please see Monthly Weather Reviews, Special Climate Statements, and the Annual Climate Statement-all available from (Australian) Bureau of Meteorology, www.bom.gov.au/climate/current/.

\section{5) New Zealand-G. R. Macara}

In the following discussion, the base period is 1981-2010 for all variables, unless otherwise noted. The nationwide average temperature is based upon NIWA's seven-station temperature series that begins in 1909 (www.niwa.co.nz/our-science/climate /information-and-resources/nz-temp-record/seven -station-series-temperature-data). All statistics are based on data available as of 9 January 2017.

\section{(i) Temperature}

According to NIWA's seven-station temperature series, 2016 was New Zealand's warmest year in the 108 -year period of record. The nationwide average temperature was $13.4^{\circ} \mathrm{C}\left(0.8^{\circ} \mathrm{C}\right.$ above the annual average). Annual mean temperatures were above average (at least $+0.5^{\circ} \mathrm{C}$ ) across much of the country (Fig. 7.61a). The three warmest months in 2016, in terms of the nationwide temperature anomaly, were February $\left(+2.2^{\circ} \mathrm{C}\right)$, May $\left(+2.1^{\circ} \mathrm{C}\right)$, and June $\left(+1.6^{\circ} \mathrm{C}\right)$. Notably, these months were New Zealand's warmest May, second warmest February, and third warmest June on record. August $\left(0.5^{\circ} \mathrm{C}\right.$ below average) and December $\left(0.3^{\circ} \mathrm{C}\right.$ below average $)$ were the only two months in 2016 when the nationwide average temperature was below average. The monthly sequence of temperature anomalies was broadly consistent with strongly positive southern annular mode (SAM) conditions for the first half of the year, and a transition to neutral or negative SAM conditions toward the end of the year.

The highest recorded air temperature for 2016 was $35.5^{\circ} \mathrm{C}$, recorded at Clyde and Alexandra (Central Otago) on 3 February. The lowest recorded air temperature for 2016 (excluding high altitude alpine sites) was $-14.1^{\circ} \mathrm{C}$, observed at Mt. Cook Airport (Canterbury) on 8 August.

\section{(ii) Precipitation}

Annual rainfall totals for 2016 were near normal $(80 \%-120 \%$ of the annual normal) for much of the country (Fig. 7.61b). However, annual rainfall was above normal (120\%-149\%) in the west and north of the South Island and isolated southwestern parts of the North Island. It was an especially wet year in Milford Sound (Fiordland) which observed its wettest year on record (since 1929; $9259 \mathrm{~mm}, 138 \%$ of normal). In contrast, no locations observed record or near-record low annual rainfall totals. Annual rainfall was below normal (50\%-79\%) in parts of the eastern North Island south of Napier and parts of the eastern South Island north of Christchurch. December was a particularly dry month for New Zealand with locations from as far north as Kaitaia (Northland) to as far south as Nugget Point (south Otago) recording $<50 \%$ of normal December rainfall.

Of the regularly reporting rainfall gauges, the wettest location in 2016 was Cropp River, in the Hokitika River catchment (West Coast, South Island), with an annual rainfall total of $11921 \mathrm{~mm}$. The driest of the regularly reporting rainfall sites in 2016 was Cromwell (Central Otago), which recorded $338 \mathrm{~mm}$ of rainfall. North Egmont (Taranaki) experienced the highest 1-day rainfall total for all of New Zealand in 2016 of $350 \mathrm{~mm}$ on 17 February. 
Large-scale influences on New Zealand were mixed in 2016. El Niño conditions, present during the first few months of the year, are normally associated with strong westerly flow over the country and above-average precipitation in western regions. However, strongly positive SAM conditions present at the same time are associated with the opposite pattern of weaker westerlies and reduced precipitation in the west. Toward the end of the year, a strongly negative SAM was associated with increased precipitation in the west of the country.

\section{(iii) Notable events and impacts}

See Fig. 7.62 for a schematic of notable events. In June 2016, the Ministry for Primary Industries extended the drought classification for the east coast of the South Island through the end of December 2016. This South Island drought was classified as a medium-scale adverse event, and regions included were Marlborough, Canterbury, and parts of Otago (Central Otago, Dunedin, and Waitaki). These regions were initially classified as in drought on 12 February 2015, making this the longest period of this type of drought classification in New Zealand. Some wells in Canterbury showed groundwater at record low levels during the event.

During 5-8 August, a significant snow event impacted the central and eastern North Island. The heavy snowfall was rare for the area, with approximately $50-70 \mathrm{~cm}$ of snow reported down to $700 \mathrm{~m}$ a.s.l., and snowfall reported as low as $200 \mathrm{~m}$ a.s.l. A number of major highways were forced to close, and many trucks were stranded by the heavy snow. More than 10000 people were without power in Hawke's Bay and rural areas around Taupo after snow overloaded transmission lines. The snow event brought down approximately 200 power poles across the region.

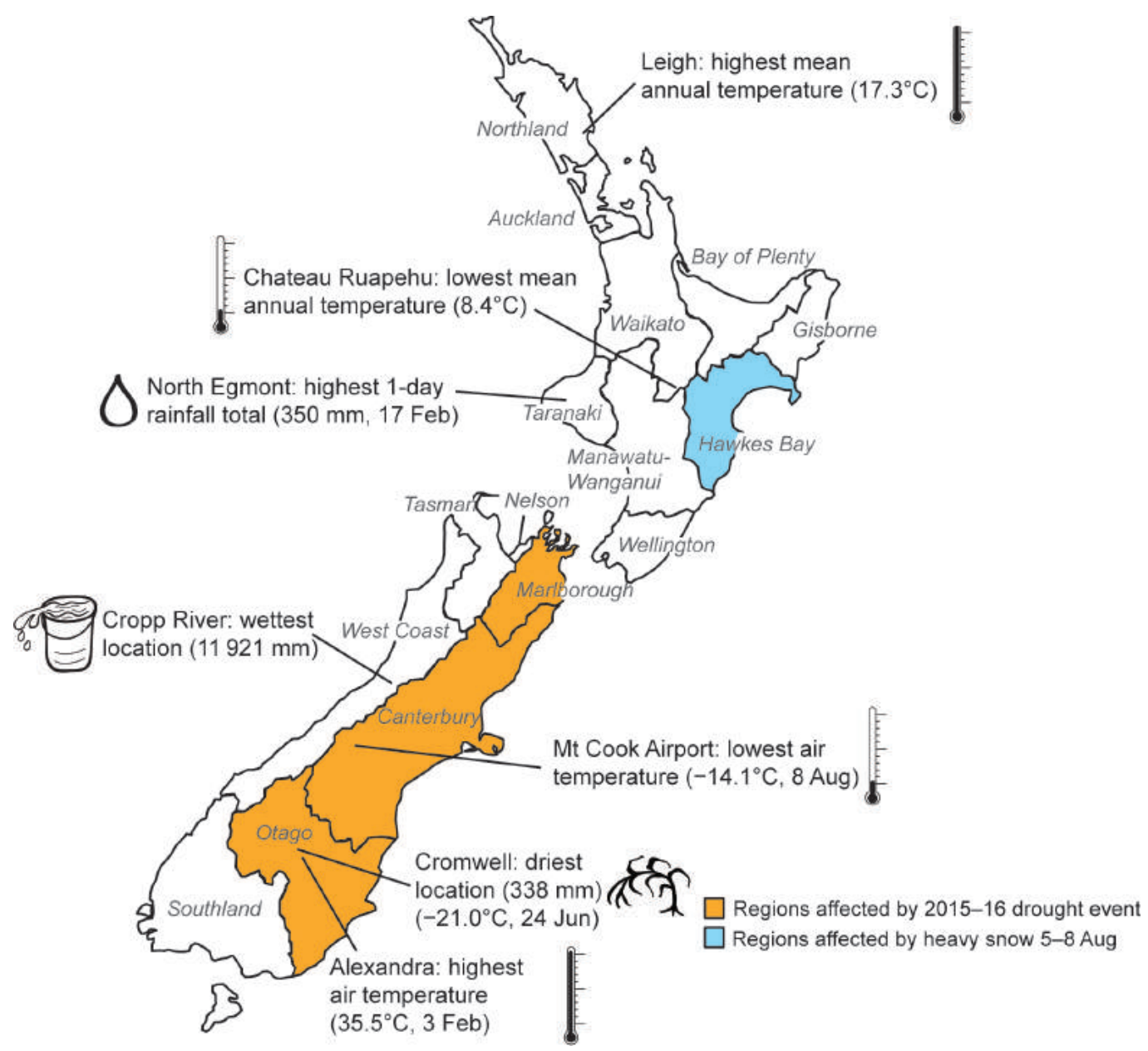

Fig. 7.62. Notable weather events and climate extremes for New Zealand in 2016. (Source: NIWA.) 
APPENDIX I: RELEVANT DATASETS AND SOURCES

\begin{tabular}{|c|c|c|c|}
\hline $\begin{array}{c}\text { General Variable or } \\
\text { Phenomenon }\end{array}$ & $\begin{array}{c}\text { Specific Dataset or } \\
\text { Variable }\end{array}$ & Source & Section \\
\hline Aerosols & CAMS Reanalysis & http://macc.copernicus-atmosphere.eu/catalogue & $2 g 3$ \\
\hline \multirow{3}{*}{ Air-sea Fluxes } & $\begin{array}{l}\text { CERES Energy Balanced and } \\
\text { Filled }\end{array}$ & https://ceres.larc.nasa.gov & $3 e l, 3 e 4$ \\
\hline & CERES FLASHflux & $\begin{array}{l}\text { https://eosweb.larc.nasa.gov/project/ceres/ebaf } \\
\text { _surface_table }\end{array}$ & $3 e l$ \\
\hline & $\begin{array}{l}\text { Woods Hole Oceanographic } \\
\text { Institute OAFlux }\end{array}$ & http://oaflux.whoi.edu & $\begin{array}{l}3 e l, 3 e 3 \\
3 e 4\end{array}$ \\
\hline Albedo & MODIS & http://ladsweb.nascom.nasa.gov & $2 \mathrm{hl}, 5 \mathrm{e}$ \\
\hline \multirow{3}{*}{$\begin{array}{l}\text { Biomass, Greenness, } \\
\text { Burning }\end{array}$} & GFAS & $\begin{array}{l}\text { www.gmes-atmosphere.eu/about/project } \\
\text { _structure/global/g_idas/g_idas_2 }\end{array}$ & $2 \mathrm{~h} 3$ \\
\hline & GFEDv4 & $\begin{array}{l}\text { https://daac.ornl.gov/VEGETATION/guides } \\
\text { /fire_emissions_v4.html }\end{array}$ & $2 \mathrm{~h} 3$ \\
\hline & MODIS NDVI & $\begin{array}{l}\text { https://modis.gsfc.nasa.gov/data/dataprod } \\
\text { /dataproducts.php?MOD_NUMBER=13 }\end{array}$ & $5 \mathrm{~h}$ \\
\hline \multirow{8}{*}{ Clouds, Cloudiness } & CALIPSO & $\begin{array}{l}\text { http://eosweb.larc.nasa.gov/PRODOCS } \\
\text { /calipso/table_calipso.html }\end{array}$ & $2 \mathrm{~d} 5$ \\
\hline & CERES MODIS & $\begin{array}{l}\text { https://ceres.larc.nasa.gov/science_information } \\
\text {.php?page=ModisCloudRetr }\end{array}$ & $2 \mathrm{~d} 5$ \\
\hline & CLARA-A2 & $\begin{array}{l}\text { https://climatedataguide.ucar.edu/climate-data } \\
\text { /clara-al-cloud-properties-surface-albedo-and } \\
\text {-surface-radiation-products-based-avhrr }\end{array}$ & $2 \mathrm{~d} 5$ \\
\hline & HIRS & www.ssec.wisc.edu/ donw/PAGE/CLIMATE.HTM & $2 \mathrm{~d} 5$ \\
\hline & MISR & $\begin{array}{l}\text { http://eosweb.larc.nasa.gov/PRODOCS/misr } \\
\text { /level3/overview.html }\end{array}$ & $2 \mathrm{~d} 5$ \\
\hline & PATMOS-x/AVHRR & $\begin{array}{l}\text { www.ncdc.noaa.gov/cdr/atmospheric/avhrr-cloud } \\
\text {-properties-patmos-x }\end{array}$ & $2 \mathrm{~d} 5$ \\
\hline & PATMOS-x/MODIS C6 & http://ladsweb.nascom.nasa.gov & $2 \mathrm{~d} 5$ \\
\hline & SatCORPS & No public archive & $2 \mathrm{~d} 5$ \\
\hline \multirow{2}{*}{ Drought } & scPSDI & https://crudata.uea.ac.uk/cru/data/drought & $2 \mathrm{~d} 9$ \\
\hline & CRU TS 3.25 & https://crudata.uea.ac.uk/cru/data/hrg & $2 \mathrm{~d} 9$ \\
\hline $\begin{array}{l}\text { Evaporation, } \\
\text { Evapotranspiration, } \\
\text { Sublimation }\end{array}$ & GLEAM & www.gleam.eu & $2 \mathrm{dIO}$ \\
\hline \multirow{3}{*}{ FAPAR } & MERIS & $\begin{array}{l}\text { https://earth.esa.int/web/guest/missions/esa } \\
\text {-operational-eo-missions/envisat/instruments/meris }\end{array}$ & $2 \mathrm{~h} 2$ \\
\hline & MODIS-TIP & http://modis.gsfc.nasa.gov/about & $2 \mathrm{~h} 2$ \\
\hline & SeaWiFS v 2010.0 & http://oceancolor.gsfc.nasa.gov/cms/reprocessing & $2 \mathrm{~h} 2$ \\
\hline \multirow{2}{*}{ Geopotential Height } & ERA-Interim & $\begin{array}{l}\text { www.ecmwf.int/en/research/climate-reanalysis } \\
\text { lera-interim }\end{array}$ & $6 \mathrm{~b}$ \\
\hline & $\begin{array}{l}\text { NCEP/NCAR Reanalysis I: } \\
\text { Pressure }\end{array}$ & $\begin{array}{l}\text { www.esrl.noaa.gov/psd/data/gridded/data.ncep } \\
\text {.reanalysis.pressure.html }\end{array}$ & $5 b$ \\
\hline \multirow{2}{*}{$\begin{array}{l}\text { Glacier Mass or } \\
\text { Volume }\end{array}$} & $\begin{array}{l}\text { World Glacier Monitoring } \\
\text { Service }\end{array}$ & www.wgms.ch/mbb/suml2.html & $2 c 3,5 f$ \\
\hline & $\begin{array}{l}\text { Randolph Glacier Inventory } \\
\text { v3.2 }\end{array}$ & www.glims.org/RGI & $5 f$ \\
\hline \multirow{3}{*}{$\begin{array}{c}\text { Humidity, (near) } \\
\text { Surface }\end{array}$} & Dai & by email to adai@ucar.edu & $2 \mathrm{dl}$ \\
\hline & ERA-Interim & www.ecmwf.int/research/era & $2 \mathrm{dl}$ \\
\hline & HadCRUH & www.metoffice.gov.uk/hadobs/hadcruh & $2 d \mathrm{~d}$ \\
\hline
\end{tabular}




\begin{tabular}{|c|c|c|c|}
\hline $\begin{array}{c}\text { General Variable or } \\
\text { Phenomenon }\end{array}$ & $\begin{array}{c}\text { Specific Dataset or } \\
\text { Variable }\end{array}$ & Source & Section \\
\hline \multirow{5}{*}{$\begin{array}{l}\text { Humidity, (near) } \\
\text { Surface (cont) }\end{array}$} & HadISDH & www.metoffice.gov.uk/hadobs/hadisdh & $2 \mathrm{dl}$ \\
\hline & HOAPS & $\begin{array}{l}\text { http://wui.cmsaf.eu/safira/action } \\
\text { /viewDoiDetails?acronym=HOAPS_V00I }\end{array}$ & $2 \mathrm{dl}$ \\
\hline & $\begin{array}{l}\text { JRA-55 Atmospheric } \\
\text { Reanalysis }\end{array}$ & http://jra.kishou.go.jp/JRA-55/index_en.html & $2 \mathrm{dl}$ \\
\hline & MERRA-2 & http://gmao.gsfc.nasa.gov/reanalysis/MERRA-2 & $2 \mathrm{dl}$ \\
\hline & NOCS 2.0 & www.noc.soton.ac.uk/noc_flux/noc2.php & $2 \mathrm{dl}$ \\
\hline \multirow{3}{*}{$\begin{array}{l}\text { Humidity, Upper } \\
\text { Atmosphere }\end{array}$} & HIRS & $\begin{array}{l}\text { www.ncdc.noaa.gov/cdr/fundamental/hirs-chl2 } \\
\text {-brightness-temperature }\end{array}$ & $2 \mathrm{~d} 3$ \\
\hline & NCEP/NCAR Reanalysis & $\begin{array}{l}\text { www.esrl.noaa.gov/psd/data/gridded/data.ncep } \\
\text {.reanalysis.html }\end{array}$ & $4 \mathrm{e} 2$ \\
\hline & UTH & by email to Viju.John@eumetsat.int & $2 \mathrm{~d} 3$ \\
\hline \multirow{3}{*}{$\begin{array}{l}\text { Ice Sheet } \\
\text { Characteristics }\end{array}$} & DMSP-SSMIS & http://nsidc.org/data/nsidc-0032 & $5 e, 6 e$ \\
\hline & GRACE & $\begin{array}{l}\text { http://podaac.jpl.nasa.gov/datasetlist?ids=Platform } \\
\text { \&values=GRACE }\end{array}$ & $5 e, 5 f$ \\
\hline & PROMICE (Greenland) & www.promice.dk/home.html & $5 e$ \\
\hline \multirow{7}{*}{ Lake Temperature } & Globolakes & www.globolakes.ac.uk & $2 \mathrm{~b} 2$ \\
\hline & Lake Vättern (Sweden) & Vättern Water Protection Association & $2 \mathrm{~b} 2$ \\
\hline & Lake Zurich (Switzerland) & $\begin{array}{l}\text { City of Zurich Water Supply and Amt für Abfall, } \\
\text { Wasser, Energie und Luft of the Canton of Zurich }\end{array}$ & $2 \mathrm{~b} 2$ \\
\hline & Mondsee (Austria) & http://hydro.ooe.gv.at/\#Startseite & $2 \mathrm{~b} 2$ \\
\hline & Neusiedler See (Austria) & $\begin{array}{l}\text { http://wasser.bgld.gv.at/hydrographie/online } \\
\text {-daten.html }\end{array}$ & $2 \mathrm{~b} 2$ \\
\hline & Polish Lakes & www.imgw.pl & $2 \mathrm{~b} 2$ \\
\hline & Wörther See (Austria) & $\begin{array}{l}\text { https://info.ktn.gv.at/asp/hydro/daten/hydroportal } \\
\text { /see_wt.asp }\end{array}$ & $2 \mathrm{~b} 2$ \\
\hline \multirow[t]{2}{*}{ Martian Climate } & MARCI/MRO & $\begin{array}{l}\text { https://mars.nasa.gov/mro/mission/instruments } \\
\text { /marci/ }\end{array}$ & SB2.I \\
\hline & MCS/MRO & https://mars.nasa.gov/mro/mission/instruments/mcs & SB2.I \\
\hline \multirow{10}{*}{ Modes of Variability } & Arctic Oscillation (AO) & $\begin{array}{l}\text { www.cpc.ncep.noaa.gov/products/precip/CWlink } \\
\text { /daily_ao_index/teleconnections.shtml }\end{array}$ & $2 \mathrm{el}$ \\
\hline & $\begin{array}{l}\text { Atlantic Multidecadal } \\
\text { Oscillation (AMO) }\end{array}$ & www.esrl.noaa.gov/psd/data/timeseries/AMO & $3 \mathrm{~h}$ \\
\hline & $\begin{array}{l}\text { Madden-Julian Oscillation } \\
\text { (MJO) - Real-time } \\
\text { Multivariate MJO }\end{array}$ & http://monitor.cicsnc.org/mjo/current/rmm & $4 c$ \\
\hline & $\begin{array}{l}\text { Madden-Julian Oscillation } \\
\text { (MJO) - Real-time } \\
\text { Multivariate MJO }\end{array}$ & $\begin{array}{l}\text { www.bom.gov.au/climate/mjo/graphics } \\
\text { /rmm.74toRealtime.txt }\end{array}$ & $4 c$ \\
\hline & $\begin{array}{l}\text { North Atlantic Oscillation } \\
\text { (NAO) }\end{array}$ & $\begin{array}{l}\text { ftp://ftp.cpc.ncep.noaa.gov/wd52dg/data/indices } \\
\text { /tele_index.nh }\end{array}$ & $2 \mathrm{el}$ \\
\hline & Oceanic Nino Index (ONI) & $\begin{array}{l}\text { www.cpc.ncep.noaa.gov/products/analysis } \\
\text { _monitoring/ensostuff/ensoyears.shtml }\end{array}$ & $2 \mathrm{~d} 6,4 \mathrm{~b}$ \\
\hline & $\begin{array}{l}\text { Pacific Decadal Oscillation } \\
\text { (PDO) }\end{array}$ & www.cpc.ncep.noaa.gov/products/GODAS & $2 \mathrm{~d} 6$ \\
\hline & $\begin{array}{l}\text { Southern Annular Mode } \\
\text { (SAM) }\end{array}$ & www.antarctica.ac.uk/met/gjma/sam.html & $6 \mathrm{~b}$ \\
\hline & $\begin{array}{l}\text { Southern Annular Mode } \\
\text { (SAM, AAO) }\end{array}$ & $\begin{array}{l}\text { www.cpc.ncep.noaa.gov/products/precip/CWlink } \\
\text { /daily_ao_index/aao/aao.shtml }\end{array}$ & $2 \mathrm{el}$ \\
\hline & $\begin{array}{l}\text { Southern Oscillation Index } \\
\text { (SOI) }\end{array}$ & $\begin{array}{l}\text { ftp://ftp.bom.gov.au/anon/home/ncc/www/sco/soi } \\
\text { /soiplaintext.html }\end{array}$ & $2 \mathrm{dI} 0,2 \mathrm{el}$ \\
\hline
\end{tabular}




\begin{tabular}{|c|c|c|c|}
\hline $\begin{array}{l}\text { General Variable or } \\
\text { Phenomenon }\end{array}$ & $\begin{array}{c}\text { Specific Dataset or } \\
\text { Variable }\end{array}$ & Source & Section \\
\hline $\begin{array}{l}\text { Modes of Variability } \\
\text { (cont) }\end{array}$ & $\begin{array}{l}\text { Southern Oscillation Index } \\
\text { (EQ-SOI) }\end{array}$ & www.cpc.ncep.noaa.gov/data/indices & $6 d$ \\
\hline \multirow{3}{*}{ Ocean Carbon } & $\mathrm{PCO}_{2}$ & www.socat.info & $3 \mathrm{j}$ \\
\hline & $\begin{array}{l}\text { Global Ocean Ship-Based } \\
\text { Hydrographic Investigations } \\
\text { Program }\end{array}$ & www.go-ship.org & $3 \mathrm{j}, 6 \mathrm{~g}$ \\
\hline & SOCCOM & https://soccom.princeton.edu/content/float-data & SB6.I \\
\hline Ocean Circulation & $\begin{array}{l}\text { Atlantic Meridional } \\
\text { Overturning Circulation } \\
\text { (AMOC) }\end{array}$ & www.noc.soton.ac.uk/rapidmoc & $3 \mathrm{~h}$ \\
\hline \multirow{6}{*}{ Ocean Heat Content } & $\begin{array}{l}\text { CSIRO/ACE CRC/IMAS- } \\
\text { UTAS estimate }\end{array}$ & $\begin{array}{l}\text { www.cmar.csiro.au/sealevel/thermal_expansion } \\
\text { _ocean_heat_timeseries.html }\end{array}$ & $3 c$ \\
\hline & PMEL/JPL/JIMAR & http://oceans.pmel.noaa.gov & $3 c$ \\
\hline & $\mathrm{MRI} / \mathrm{MA}$ & $\begin{array}{l}\text { www.data.jma.go.jp/gmd/kaiyou/english/ohc/ohc } \\
\text { _global_en.html }\end{array}$ & $3 c$ \\
\hline & NCEP Ocean Reanalysis & www.cpc.ncep.noaa.gov/products/GODAS & $4 \mathrm{~h}$ \\
\hline & NCEI & www.nodc.noaa.gov/OC5/indprod.html & $3 c$ \\
\hline & UK Met Office EN4.0.2 & $\begin{array}{l}\text { www.metoffice.gov.uk/hadobs/en4/download-en4 } \\
-0-2-109 . \mathrm{html}\end{array}$ & $3 c$ \\
\hline Ocean Mass & $\begin{array}{l}\text { NASA Gravity Recovery and } \\
\text { Climate Experiment }\end{array}$ & $\begin{array}{l}\text { https://grace.jpl.nasa.gov/data/get-data/monthly } \\
\text {-mass-grids-ocean }\end{array}$ & $3 f$ \\
\hline \multirow{4}{*}{ Ocean Salinity } & Aquarius V3.0 & http://podaac.jpl.nasa.gov/aquarius & $3 d$ \\
\hline & Argo & http://doi.org//0.17882/42/82 & $\begin{array}{l}3 c, 3 d \\
\text { SB3.2 }\end{array}$ \\
\hline & $\begin{array}{l}\text { Blended Analysis for Surface } \\
\text { Salinity }\end{array}$ & ftp://ftp.cpc.ncep.noaa.gov/precip/BASS & $3 \mathrm{~d} 2$ \\
\hline & World Ocean Atlas 2013 & www.nodc.noaa.gov/OC5/woal3 & $3 \mathrm{~d} 2,3 \mathrm{~d} 3$ \\
\hline \multirow[b]{2}{*}{$\begin{array}{l}\text { Outgoing Longwave } \\
\text { Radiation }\end{array}$} & CERES FLASHFlux Project & http://flashflux.larc.nasa.gov & $3 e$ \\
\hline & Daily OLR & $\begin{array}{l}\text { www.ncdc.noaa.gov/cdr/atmospheric/outgoing } \\
\text {-longwave-radiation-daily }\end{array}$ & $4 \mathrm{~b} 2$ \\
\hline \multirow{10}{*}{$\begin{array}{l}\text { Ozone, Total Column } \\
\text { and Stratospheric }\end{array}$} & Bodeker Scientific & $\begin{array}{l}\text { www.bodekerscientific.com/data/total-column } \\
\text {-ozone }\end{array}$ & $5 j$ \\
\hline & $\begin{array}{l}\text { Calipso } \\
\text { (Polar Stratospheric Clouds) }\end{array}$ & $\begin{array}{l}\text { http://eosweb.larc.nasa.gov/PRODOCS/calipso } \\
\text { /table_calipso.html }\end{array}$ & $6 \mathrm{~h}$ \\
\hline & $\begin{array}{l}\text { GOME/SCIAMACHY/ } \\
\text { GOME2 (GSG) Merged } \\
\text { Total Ozone }\end{array}$ & www.iup.uni-bremen.de/gome/wfdoas & $2 g 4,6 h$ \\
\hline & $\begin{array}{l}\text { GOME/SCIAMACHYI } \\
\text { GOME2 (GTO) Merged } \\
\text { Total Ozone }\end{array}$ & $\begin{array}{l}\text { http://atmos.eoc.dlr.de/gome/gto-ecv.html } \\
\text { www.esa-ozone-cci.org }\end{array}$ & $2 g 4$ \\
\hline & GOZCARDS ozone profiles & $\begin{array}{l}\text { https://gozcards.jpl.nasa.gov } \\
\text { http://mirador.gsfc.nasa.gov }\end{array}$ & $2 g 4$ \\
\hline & KNMI OMI & http://ozoneaq.gsfc.nasa.gov & $6 \mathrm{~h}$ \\
\hline & $\begin{array}{l}\text { Multi Sensor Reanalysis } \\
\text { (MSR) of total ozone }\end{array}$ & www.temis.nl & $2 g 4$ \\
\hline & $\begin{array}{l}\text { NASA Aura Microwave Limb } \\
\text { Sounder }\end{array}$ & http://aura.gsfc.nasa.gov/instruments/mls.html & $5 \mathrm{j}, 6 \mathrm{~h}$ \\
\hline & $\begin{array}{l}\text { NASA BUV/SBUV v8.6 } \\
\text { (MOD v8.6) Merged Ozone }\end{array}$ & http://acdb-ext.gsfc.nasa.gov/Data_services/merged & $2 g 4$ \\
\hline & $\begin{array}{l}\text { NOAA BUV/SBUV v8.6 } \\
\text { (MOD v8.6) Merged Ozone }\end{array}$ & ftp://ftp.cpc.ncep.noaa.gov/SBUV_CDR & $2 g 4$ \\
\hline
\end{tabular}




\begin{tabular}{|c|c|c|c|}
\hline $\begin{array}{l}\text { General Variable or } \\
\text { Phenomenon }\end{array}$ & $\begin{array}{c}\text { Specific Dataset or } \\
\text { Variable }\end{array}$ & Source & Section \\
\hline \multirow{4}{*}{$\begin{array}{l}\text { Ozone, Total Column } \\
\text { and Stratospheric } \\
\text { (cont) }\end{array}$} & Ozonesonde & www.esrl.noaa.gov/gmd/dv/spo_oz & $6 \mathrm{~h}$ \\
\hline & SAGE II/OSIRIS & dataset linked to Bourassa et al. (2014) & $2 g 4$ \\
\hline & SWOOSH & www.esrl.noaa.gov/csd/groups/csd8/swoosh & $2 g 4$ \\
\hline & $\begin{array}{l}\text { WOUDC Ground-based } \\
\text { Ozone }\end{array}$ & $\begin{array}{l}\text { ftp://ftp.tor.ec.gc.ca/pub/woudc/Project-Campaigns } \\
\text { /ZonalMeans }\end{array}$ & $2 \mathrm{~g} 4$ \\
\hline \multirow{2}{*}{ Ozone, Tropospheric } & Aura OMI/MLS & $\begin{array}{l}\text { http://acd-ext.gsfc.nasa.gov/Data_services/cloud } \\
\text { slice/new_data.html }\end{array}$ & $2 g 6$ \\
\hline & MLO Observatory & $\begin{array}{l}\text { www.esrl.noaa.gov/gmd/dv/iadv/graph.php?code } \\
=\text { MLO\&program=ozwv\&type=ts }\end{array}$ & $2 g 6$ \\
\hline \multirow{6}{*}{ Permafrost } & Active Layer Thickness & http://nsidc.org/data/docs/fgdc/ggd3l3_calm & $5 i$ \\
\hline & $\begin{array}{l}\text { Global Terrestrial Network } \\
\text { for Permafrost (GTN-P) }\end{array}$ & http://gtnp.arcticportal.org & $2 \mathrm{cl}$ \\
\hline & Permafrost Temperature & http://permafrost.gi.alaska.edu/sites_map & $5 i$ \\
\hline & $\begin{array}{l}\text { Permafrost Temperature at } \\
\text { French sites }\end{array}$ & permafrance.osug.fr & $2 \mathrm{cl}$ \\
\hline & $\begin{array}{l}\text { Permafrost Temperature at } \\
\text { Norwegian sites }\end{array}$ & $\begin{array}{l}\text { www.tspnorway.com } \\
\text { www.met.no }\end{array}$ & $2 \mathrm{cl}$ \\
\hline & $\begin{array}{l}\text { Permafrost Temperature at } \\
\text { Swiss sites }\end{array}$ & www.permos.ch & $2 \mathrm{cl}$ \\
\hline \multirow{3}{*}{$\begin{array}{l}\text { Phytoplankton, } \\
\text { Ocean Color }\end{array}$} & $\begin{array}{l}\text { MODIS-Aqua Reprocessing } \\
2013.1\end{array}$ & http://oceancolor.gsfc.nasa.gov/cms/reprocessing & $3 i$ \\
\hline & SeaWiFS v 2010.0 & http://oceancolor.gsfc.nasa.gov/cms/reprocessing & $3 \mathrm{i}$ \\
\hline & VIIRS $\vee 2014.0$ & http://oceancolor.gsfc.nasa.gov/cms/reprocessing & $3 i$ \\
\hline \multirow{6}{*}{ Precipitation } & CAMS-OPI & $\begin{array}{l}\text { ftp://ftp.cpc.ncep.noaa.gov/precip/data-req/cams } \\
\text { _opi_v0208 }\end{array}$ & $4 \mathrm{~b} 3$ \\
\hline & CMAP & ftp://ftp.cpc.ncep.noaa.gov/precip/cmap & $4 \mathrm{e}$ \\
\hline & CMORPH & $\begin{array}{l}\text { www.cpc.ncep.noaa.gov/products/janowiak } \\
\text { /cmorph_description.html }\end{array}$ & $4 \mathrm{dl}, 4 \mathrm{~d} 2$ \\
\hline & GHCN & $\begin{array}{l}\text { www.ncdc.noaa.gov/temp-and-precip/ghcn-gridded } \\
\text {-products.php }\end{array}$ & $2 \mathrm{~d} 4$ \\
\hline & GPCPv23 & http://precip.gsfc.nasa.gov & $2 \mathrm{~d} 4,4 \mathrm{e}, 4 \mathrm{~h}$ \\
\hline & GPCC & www.gpcc.dwd.de & $2 \mathrm{~d} 4$ \\
\hline \multirow{2}{*}{$\begin{array}{l}\text { Precipitation (net), } \\
\text { Freshwater Flux }\end{array}$} & $\begin{array}{l}\text { JRA-55 Atmospheric } \\
\text { Reanalysis }\end{array}$ & http://jra.kishou.go.jp/JRA-55/index_en.html & $6 d$ \\
\hline & GPCPv23, OAFlux & http://precip.gsfc.nasa.gov, http://oaflux.whoi.edu & $3 e$ \\
\hline \multirow{5}{*}{$\begin{array}{l}\text { Pressure, Sea Level } \\
\text { or Near-Surface }\end{array}$} & $\begin{array}{l}\text { Antarctic Meteorological } \\
\text { Research Center (AMRC) } \\
\text { AWS }\end{array}$ & http://amrc.ssec.wisc.edu/data & $6 c$ \\
\hline & ERA-Interim & $\begin{array}{l}\text { www.ecmwf.int/en/research/climate-reanalysis } \\
\text { /era-interim }\end{array}$ & $6 \mathrm{~b}$ \\
\hline & HadSLP2r & www.metoffice.gov.uk/hadobs & $2 \mathrm{el}$ \\
\hline & $\begin{array}{l}\text { JRA-55 Atmospheric } \\
\text { Reanalysis }\end{array}$ & http://jra.kishou.go.jp/JRA-55/index_en.html & $6 d$ \\
\hline & READER & https://legacy.bas.ac.uk/met/READER & $6 c$ \\
\hline River Discharge & ELSE & No public archive & $2 \mathrm{~d} 6$ \\
\hline $\begin{array}{c}\text { Sea Ice } \\
\text { Concentration } \\
\end{array}$ & AMSR2 Daily & https://seaice.uni-bremen.de & $6 g$ \\
\hline Sea Ice Duration & $\begin{array}{l}\text { Near-Real-Time DMSP } \\
\text { SSM/I-SSMIS Daily Polar } \\
\text { Gridded }\end{array}$ & http://nsidc.org/data/nsidc-008I.html & $6 e$ \\
\hline
\end{tabular}




\begin{tabular}{|c|c|c|c|}
\hline $\begin{array}{c}\text { General Variable or } \\
\text { Phenomenon }\end{array}$ & $\begin{array}{c}\text { Specific Dataset or } \\
\text { Variable } \\
\end{array}$ & Source & Section \\
\hline $\begin{array}{l}\text { Sea Ice Duration } \\
\text { (cont) }\end{array}$ & $\begin{array}{l}\text { Nimbus-7 SMMR and DMSP } \\
\text { SSM/I (Bootstrap) }\end{array}$ & http://nsidc.org/data/nsidc-0079.html & $6 e$ \\
\hline Sea Ice Extent & $\begin{array}{l}\text { Nimbus-7 SMMR and DMSP } \\
\text { SSM/I (Bootstrap) }\end{array}$ & $\begin{array}{l}\text { http://nsidc.org/data/docs/daac/nsidc0079 } \\
\text { _bootstrap_seaice.gd.html }\end{array}$ & $5 c, 6 f$ \\
\hline $\begin{array}{l}\text { Sea Ice Freeboard/ } \\
\text { Thickness }\end{array}$ & CryoSat-2 & $\begin{array}{l}\text { https://earth.esa.int/web/guest/-/how-to-access } \\
\text {-cryosat-data- } 6842\end{array}$ & $5 c$ \\
\hline \multirow{4}{*}{$\begin{array}{l}\text { Sea Level/Sea } \\
\text { Surface Height }\end{array}$} & $\begin{array}{l}\text { Ssalto/Duacs Multimission } \\
\text { Altimeter Products }\end{array}$ & $\begin{array}{l}\text { http://marine.copernicus.eu/services } \\
\text {-portfolio/access-to-products/?option=com } \\
\text { _csw\&view=details\&product_id=SEALEVEL_GLO } \\
\text { _PHY_L4_NRT_OBSERVATIONS_008_046 }\end{array}$ & $3 f, 6 \mathrm{~g}$ \\
\hline & Tide Gauge & http://uhslc.soest.hawaii.edu & $3 f$ \\
\hline & Tide Gauge & $\begin{array}{l}\text { https://tidesandcurrents.noaa.gov } \\
\text { /noaatidepredictions/NOAATidesFacade } \\
\text {.jsp?Stationid }=8722670\end{array}$ & $3 \mathrm{~h}$ \\
\hline & TOPEX/Jason & http://sealevel.colorado.edu & $3 f$ \\
\hline \multirow{4}{*}{$\begin{array}{l}\text { Sea Surface } \\
\text { Temperature }\end{array}$} & ERSST v4 & http://doi.org//0.7289/V5KDIVVF & $\begin{array}{l}\text { 3b, SB3.I, } \\
4 \mathrm{e} 2\end{array}$ \\
\hline & HadSST3 & www.metoffice.gov.uk/hadobs/hadsst3 & $2 \mathrm{bl}, 3 \mathrm{~b}$ \\
\hline & $\begin{array}{l}\text { NOAA Optimum } \\
\text { Interpolation SST (OISST) } \\
\mathrm{v} 2\end{array}$ & $\begin{array}{l}\text { www.esrl.noaa.gov/psd/data/gridded/data.ncep.oisst } \\
\text {.v2.html }\end{array}$ & $\begin{array}{l}3 \mathrm{~b}, 4 \mathrm{bl}, \\
4 \mathrm{~d} 2,4 \mathrm{~h}, \\
5 \mathrm{~d}, 6 \mathrm{f} \\
\end{array}$ \\
\hline & OI SST (RSS) & www.remss.com & $6 g$ \\
\hline \multirow{2}{*}{$\begin{array}{l}\text { Sea Subsurface } \\
\text { Temperature }\end{array}$} & Argo & http://doi.org//0.17882/42/82 & SB3.2 \\
\hline & NCEP Ocean Reanalysis & www.cpc.ncep.noaa.gov/products/GODAS & $4 \mathrm{bl}, 4 \mathrm{~h}$ \\
\hline \multirow{3}{*}{ Snow Cover } & GlobSnow & http://nsidc.org/data/NSIDC-0595 & $5 g$ \\
\hline & $\begin{array}{l}\text { NOAA daily Interactive } \\
\text { Multi-sensor Snow and Ice } \\
\text { Mapping System }\end{array}$ & http://nsidc.org/data/g02156 & $5 g$ \\
\hline & $\begin{array}{l}\text { Snow Cover Extent and } \\
\text { Duration }\end{array}$ & www.snowcover.org & $2 c 2,5 g$ \\
\hline Soil Moisture & ESA CCI SM & www.esa-soilmoisture-cci.org/node?page=3 & $2 \mathrm{~d} 8$ \\
\hline Solar Transmission & $\begin{array}{l}\text { NOAA/ESRL Mauna Loa } \\
\text { Solar Transmission }\end{array}$ & www.esrl.noaa.gov/gmd/grad/mloapt.html & $2 \mathrm{f} 2$ \\
\hline \multirow{3}{*}{$\begin{array}{l}\text { Stratospheric Water } \\
\text { Vapor }\end{array}$} & $\begin{array}{l}\text { Frost Point Hygrometer } \\
\text { Data (Boulder, Hilo, Lauder) }\end{array}$ & ftp://aftp.cmdl.noaa.gov/data/ozwv/WaterVapor & $2 g 5$ \\
\hline & $\begin{array}{l}\text { Frost Point Hygrometer } \\
\text { Data (San Jose) }\end{array}$ & http://physics.valpo.edu/ozone/ticosonde.html & $2 g 5$ \\
\hline & $\begin{array}{l}\text { NASA Aura Microwave Limb } \\
\text { Sounder }\end{array}$ & http://aura.gsfc.nasa.gov/instruments/mls.html & $2 g 5$ \\
\hline \multirow{5}{*}{ Surface Current } & $\begin{array}{l}\text { Brazil-Malvina Region } \\
\text { Confluence Region }\end{array}$ & $\begin{array}{l}\text { www.aoml.noaa.gov/phod/altimetry/cvar/mal } \\
\text { /BM_anm.php }\end{array}$ & $3 g$ \\
\hline & $\begin{array}{l}\text { Long Term Time Series of } \\
\text { Surface Currents: Agulhas } \\
\text { Current }\end{array}$ & www.aoml.noaa.gov/phod/altimetry/cvar/agu & $3 g$ \\
\hline & $\begin{array}{l}\text { Long Term Time Series of } \\
\text { Surface Currents: North } \\
\text { Brazil Current }\end{array}$ & www.aoml.noaa.gov/phod/altimetry/cvar/nbc & $3 g$ \\
\hline & $\begin{array}{l}\text { Ocean Surface Current } \\
\text { Analysis - Real time } \\
\text { (OSCAR) }\end{array}$ & www.oscar.noaa.gov & $3 g$ \\
\hline & Yucatan Current & $\begin{array}{l}\text { www.aoml.noaa.gov/phod/altimetry/cvar/yuc } \\
\text { /transport.php }\end{array}$ & $3 g$ \\
\hline
\end{tabular}




\begin{tabular}{|c|c|c|c|}
\hline $\begin{array}{l}\text { General Variable or } \\
\text { Phenomenon }\end{array}$ & $\begin{array}{l}\text { Specific Dataset or } \\
\text { Variable }\end{array}$ & Source & Section \\
\hline \multirow{13}{*}{$\begin{array}{l}\text { Temperature, (near) } \\
\text { Surface }\end{array}$} & $\begin{array}{l}\text { Antarctic Meteorological } \\
\text { Research Center (AMRC) } \\
\text { AWS }\end{array}$ & http://amrc.ssec.wisc.edu/data & $6 c$ \\
\hline & $\begin{array}{l}\text { Berkeley Earth Surface } \\
\text { Temperature }\end{array}$ & www.berkeleyearth.org & $2 \mathrm{bl}$ \\
\hline & CRUTEM4 & $\begin{array}{l}\text { www.metoffice.gov.uk/hadobs/crutem4 } \\
\text { http://ww.cru.uea.ac.uk/cru/data/temperature }\end{array}$ & $2 b l, 5 b$ \\
\hline & ERA-Interim & $\begin{array}{l}\text { www.ecmwf.int/en/research/climate-reanalysis } \\
\text { /era-interim }\end{array}$ & $2 \mathrm{bl}, 6 \mathrm{~b}$ \\
\hline & GHCNDEX & www.climdex.org/datasets.html & $2 \mathrm{~b} 3$ \\
\hline & $\begin{array}{l}\text { HadCRUT4 Global } \\
\text { Temperature }\end{array}$ & www.metoffice.gov.uk/hadobs/hadcrut4 & $2 \mathrm{bl}$ \\
\hline & JMA Global Temperature & $\begin{array}{l}\text { http://ds.data.jma.go.jp/tcc/tcc/products/gwp/temp } \\
\text { /map/download.html }\end{array}$ & $2 \mathrm{bl}$ \\
\hline & $\begin{array}{l}\text { JRA-55 Atmospheric } \\
\text { Reanalysis }\end{array}$ & http://jra.kishou.go.jp/JRA-55/index_en.html & $2 \mathrm{bl}$ \\
\hline & MERRA-2 & http://gmao.gsfc.nasa.gov/reanalysis/MERRA-2 & $2 \mathrm{bl}$ \\
\hline & $\begin{array}{l}\text { NASA/GISS Global } \\
\text { Temperature }\end{array}$ & http://data.giss.nasa.gov/gistemp & $2 \mathrm{bl}$ \\
\hline & NCEP/NCAR Reanalysis & $\begin{array}{l}\text { www.esrl.noaa.gov/psd/data/gridded/data.ncep } \\
\text {.reanalysis.html }\end{array}$ & $5 b$ \\
\hline & NOAAGlobalTemp & $\begin{array}{l}\text { www.ncdc.noaa.gov/monitoring-references/faq } \\
\text { /anomalies.php }\end{array}$ & $2 \mathrm{bl}$ \\
\hline & READER & https://legacy.bas.ac.uk/met/READER & $6 c$ \\
\hline \multirow{10}{*}{$\begin{array}{l}\text { Temperature, Upper } \\
\text { Atmosphere }\end{array}$} & ERA-Interim & $\begin{array}{l}\text { www.ecmwf.int/en/research/climate-reanalysis/era } \\
\text {-interim }\end{array}$ & $\begin{array}{l}2 \mathrm{~b} 4,2 \mathrm{~b} 5, \\
6 \mathrm{~b}, 6 \mathrm{~h}\end{array}$ \\
\hline & $\begin{array}{l}\text { JRA-55 Atmospheric } \\
\text { Reanalysis }\end{array}$ & http://jra.kishou.go.jp/JRA-55/index_en.html & $2 \mathrm{~b} 4,2 \mathrm{~b} 5$ \\
\hline & MERRA-2 & http://gmao.gsfc.nasa.gov/reanalysis/MERRA-2 & $\begin{array}{l}2 \mathrm{~b} 4,2 \mathrm{~b} 5 \\
2 \mathrm{~g} 5,6 \mathrm{~h}\end{array}$ \\
\hline & NCEP CFSR & http://cfs.ncep.noaa.gov/cfsr & $2 \mathrm{~b} 5$ \\
\hline & RAOBCORE, RICH & www.univie.ac.at/theoret-met/research/raobcore & $2 \mathrm{~b} 4,2 \mathrm{~b} 5$ \\
\hline & RATPAC A2 & www.ncdc.noaa.gov/oa/climate/ratpac & $2 \mathrm{~b} 4,2 \mathrm{~b} 5$ \\
\hline & RSS & www.remss.com & $2 \mathrm{~b} 4,2 \mathrm{~b} 5$ \\
\hline & NOAA/NESDIS/STAR & www.star.nesdis.noaa.gov/smcd/emb/mscat & $2 \mathrm{~b} 5$ \\
\hline & UAH MSU & http://vortex.nsstc.uah.edu/public/msu & $2 \mathrm{~b} 4,2 \mathrm{~b} 5$ \\
\hline & $\begin{array}{l}\text { University of New South } \\
\text { Wales }\end{array}$ & $\begin{array}{l}\text { http://web.science.unsw.edu.au/ stevensherwood } \\
\text { /radproj/index.html }\end{array}$ & $2 \mathrm{~b} 4,2 \mathrm{~b} 5$ \\
\hline $\begin{array}{c}\text { Terrestrial } \\
\text { Groundwater Storage }\end{array}$ & GRACE & http://podaac.jpl.nasa.gov/star/index.php & $2 \mathrm{~d} 7$ \\
\hline \multirow{2}{*}{$\begin{array}{c}\text { TOA Earth Radiation } \\
\text { Budget }\end{array}$} & CERES FLASHFlux & $\begin{array}{l}\text { https://eosweb.larc.nasa.gov/project/ceres/ebaf_toa } \\
\text { _table }\end{array}$ & $2 \mathrm{fl}$ \\
\hline & CERES EBAF Ed2.8 & $\begin{array}{l}\text { http://ceres.larc.nasa.gov/products } \\
\text {.php?product=EBAF-TOA }\end{array}$ & $2 \mathrm{fl}$ \\
\hline \multirow{3}{*}{$\begin{array}{l}\text { Total Column Water } \\
\text { Vapor }\end{array}$} & COSMIC GPS-RO & $\begin{array}{l}\text { http://cdaac-www.cosmic.ucar.edu/cdaac/products } \\
\text {.html }\end{array}$ & $2 \mathrm{~d} 2$ \\
\hline & ERA-Interim & $\begin{array}{l}\text { www.ecmwf.int/en/research/climate-reanalysis/era } \\
\text {-interim }\end{array}$ & $2 \mathrm{~d} 2$ \\
\hline & $\begin{array}{l}\text { GNSS Ground-Based Total } \\
\text { Column Water Vapor }\end{array}$ & http://dss.ucar.edu/datasets/ds72I.I & $2 \mathrm{~d} 2$ \\
\hline
\end{tabular}




\begin{tabular}{|c|c|c|c|}
\hline $\begin{array}{l}\text { General Variable or } \\
\text { Phenomenon }\end{array}$ & $\begin{array}{l}\text { Specific Dataset or } \\
\text { Variable }\end{array}$ & Source & Section \\
\hline \multirow{3}{*}{$\begin{array}{l}\text { Total Column Water } \\
\text { Vapor (cont) }\end{array}$} & $\begin{array}{l}\text { JRA-55 Atmospheric } \\
\text { Reanalysis }\end{array}$ & http://jra.kishou.go.jp/JRA-55/index_en.html & $2 \mathrm{~d} 2$ \\
\hline & MERRA-2 & http://gmao.gsfc.nasa.gov/reanalysis/MERRA-2 & $2 \mathrm{~d} 2$ \\
\hline & $\begin{array}{l}\text { RSS SSM/I -AMSR-E Ocean } \\
\text { Total Column Water Vapor }\end{array}$ & www.remss.com & $2 \mathrm{~d} 2$ \\
\hline Total Solar Irradiance & SORCE/TIM & http://science.nasa.gov/missions/sorce & $2 \mathrm{fl}$ \\
\hline \multirow{11}{*}{ Trace Gases } & $\begin{array}{l}\text { Atmospheric Greenhouse } \\
\text { Gas Index (AGGI) }\end{array}$ & www.esrl.noaa.gov/gmd/aggi & $2 g l$ \\
\hline & Carbon Dioxide & www.esrl.noaa.gov/gmd/dv/iadv & $2 g l$ \\
\hline & Carbon Monoxide & $\begin{array}{l}\text { http://macc.copernicus-atmosphere.eu/catalogue } \\
\text { www2.acom.ucar.edu/mopitt }\end{array}$ & $2 g 7$ \\
\hline & $\begin{array}{l}\text { Chlorine Monoxide - Aura } \\
\text { MLS }\end{array}$ & http://mls.jpl.nasa.gov/products/clo_product.php & $6 \mathrm{~h}$ \\
\hline & $\begin{array}{l}\text { Halocarbons (CFCs, HFCs, } \\
\text { HCFCs) }\end{array}$ & www.esrl.noaa.gov/gmd/hats/data.html & $2 g l$ \\
\hline & $\begin{array}{l}\text { Hydrogen Chloride - Aura } \\
\text { MLS }\end{array}$ & $\begin{array}{l}\text { http://disc.sci.gsfc.nasa.gov/datacollection/ML2HCL } \\
\text { _V004.html }\end{array}$ & $6 \mathrm{~h}$ \\
\hline & Methane & www.esrl.noaa.gov/gmd/dv/iadv & $2 g l$ \\
\hline & Nitrous Oxide & www.esrl.noaa.gov/gmd/hats/combined/N2O.html & $2 \mathrm{gl}$ \\
\hline & $\begin{array}{l}\text { Ozone-Depleting Gas Index } \\
\text { (ODGI) }\end{array}$ & www.esrl.noaa.gov/gmd/odgi & $2 g 2$ \\
\hline & Perfluorocarbons & http://agage.eas.gatech.edu & $2 g l$ \\
\hline & Sulfur Hexafluoride & www.esrl.noaa.gov/gmd/hats/combined/SF6.html & $2 g I$ \\
\hline \multirow{4}{*}{$\begin{array}{l}\text { Tropical Cyclone } \\
\text { Data }\end{array}$} & $\begin{array}{l}\text { International Best Track } \\
\text { Archive for Climate } \\
\text { Stewardship (IBTrACS) } \\
\end{array}$ & www.ncdc.noaa.gov/oa/ibtracs & $4 f$ \\
\hline & $\begin{array}{l}\text { JTWC Best-track Dataset } \\
\text { (20II preliminary) }\end{array}$ & $\begin{array}{l}\text { www.usno.navy.mil/NOOC/nmfc-ph/RSS/jtwc } \\
\text { /best_tracks }\end{array}$ & $\begin{array}{l}4 \mathrm{e} 4,4 \mathrm{e} 5 \\
4 \mathrm{e} 6,4 \mathrm{e} 7\end{array}$ \\
\hline & $\begin{array}{l}\text { RSMC-Tokyo, JMA best- } \\
\text { track data }\end{array}$ & $\begin{array}{l}\text { www.jma.go.jp/jma/jma-eng/jma-center/rsmc-hp } \\
\text {-pub-eg/besttrack.html }\end{array}$ & $4 \mathrm{e} 4$ \\
\hline & $\begin{array}{l}\text { Southwest Pacific Enhanced } \\
\text { Archive of Tropical Cyclones } \\
\text { (SPEArTC) }\end{array}$ & http://apdrc.soest.hawaii.edu/projects/speartc & $4 \mathrm{e} 8$ \\
\hline \multirow{9}{*}{ Wind, (near) Surface } & Australian (McVicar) & http://doi.org//0.4225/08/56A8549IDDED2 & $2 \mathrm{e} 2$ \\
\hline & ERA-Interim & $\begin{array}{l}\text { www.ecmwf.int/en/research/climate-reanalysis/era } \\
\text {-interim }\end{array}$ & $2 \mathrm{e} 2,2 \mathrm{e} 3$ \\
\hline & ERApreSAT & & $2 \mathrm{e} 3$ \\
\hline & GRASP & https://doi.pangaea.de/I0.I594/PANGAEA.8236I7 & $2 \mathrm{e} 3$ \\
\hline & HadISD2 & www.metoffice.gov.uk/hadobs/hadisd & $2 \mathrm{e} 2$ \\
\hline & $\begin{array}{l}\text { JRA-55 Atmospheric } \\
\text { Reanalysis }\end{array}$ & http://jra.kishou.go.jp/JRA-55/index_en.html & $\begin{array}{l}2 \mathrm{e} 2,2 \mathrm{e} 3 \\
4 \mathrm{~h}\end{array}$ \\
\hline & MERRA-2 & http://gmao.gsfc.nasa.gov/reanalysis/MERRA-2 & $2 \mathrm{e} 2,2 \mathrm{e} 3$ \\
\hline & RSS SSM/I Ocean Winds & www.remss.com/measurements/wind & $2 \mathrm{e} 2$ \\
\hline & WASWind & www.dpac.dpri.kyoto-u.ac.jp/tokinaga/waswind.html & $2 \mathrm{e} 2$ \\
\hline \multirow{3}{*}{$\begin{array}{l}\text { Wind, Upper } \\
\text { Atmosphere }\end{array}$} & $\begin{array}{l}\text { Climate Forecast System } \\
\text { Reanalysis }\end{array}$ & $\begin{array}{l}\text { www.ncdc.noaa.gov/data-access/model-data/model } \\
\text {-datasets/climate-forecast-system-version2-cfsv2 }\end{array}$ & $4 \mathrm{e} 3$ \\
\hline & ERA-Interim & $\begin{array}{l}\text { www.ecmwf.int/en/research/climate-reanalysis/era } \\
\text {-interim }\end{array}$ & $6 b$ \\
\hline & NCEP/NCAR Reanalysis & $\begin{array}{l}\text { www.esrl.noaa.gov/psd/data/gridded/data.ncep } \\
\text {.reanalysis.html }\end{array}$ & $\begin{array}{l}4 c, 4 e 2 \\
4 e 4\end{array}$ \\
\hline
\end{tabular}


The report's editors wish to thank the AMS Journals editorial staff, in particular Melissa Fernau, for facilitating the document, and to the NCEI graphics team for laying the document out and executing the countless number of technical edits needed. We also wish to express our sincere and deep gratitude to Dr. Rick Rosen, who served as the AMS special editor for this report. Dr. Rosen's handling of the reviews was at the same time rigorous and responsive, and greatly improved the document.

Chapter 2:

- The chapter editors thank David Parker, Mark McCarthy, and John Kennedy for providing detailed and comprehensive internal reviews of this chapter.

- The chapter authors also thank Paul Berrisford (ECMWF), Mike Bosilovich (NASA) and Shinya Kobayashi (JMA) for timely provision of reanalysis data.

- Robert Dunn, Rob Allan, Chris Folland, Colin Morice, and Kate Willett were supported by the Joint UK BEIS/Defra Met Office Hadley Centre Climate Programme (GA01101).

- R. Iestyn Woolway was funded by EUSTACE (EU Surface Temperature for All Corners of Earth) which received funding from the European Union's Horizon 2020 Programme for Research and Innovation, under Grant Agreement 640171.

- Laura Carrea was funded by Natural Environment Research Council Globolakes project. Lake location data used for the satellite data processing were derived from the European Space Agency Climate Change Initiative Land Cover Project.

- Svetlana Shimaraeva, Eugene Silow, and Maxim Timofeev were supported by a Russian Ministry of education and science project 6.1387.2017 and by a private grant from "Lake Baikal" foundation (https://baikalfoundation.ru).

- David Robinson acknowledges Thomas Estilow and the NOAA National Centers for Environmental Information Climate Data Record Program for support.

- Hyungjun Kim was supported by the Japan Society for the Promotion of Science KAKENHI (16H06291) for this contribution.

- Research in section 2d7 was supported by grants from NASA's GRACE and GRACE-FO Science Team.

- The ESA CCI SM datasets and the authors were supported by ESA's Climate Change Initiative for
Soil Moisture (Contract No. 4000104814/11/I$\mathrm{NB}$ and 4000112226/14/I-NB) and the European Union's FP7 EartH2Observe "Global Earth Observation for Integrated Water Resource Assessment” project (grant agreement number 331 603608). Wouter Dorigo is supported by the "TU Wien Science Award 2015", awarded by the Vienna University of Technology.

- Tim Osborn received funding from UK NERC (NE/P006809/1).

- Jonathan Barichivich received funding from $(\mathrm{CR})^{2}$ Chile (CONICYT/FONDAP/15110009).

- Ian Harris received funding from UK National Centre for Atmospheric Science (NCAS).

- Diego G. Miralles acknowledges support from the European Research Council (ERC) under grant agreement 715254 (DRY-2-DRY).

- The GFASv1.3 dataset was provided the by GFASCLIM project, funded by the German Bundesministerium für Wirtschaft und Energie (BMWi FKZ 50EE1543).

- David Kass's contribution was performed at the Jet Propulsion Laboratory, California Institute of Technology, under contract with the National Aeronautics and Space Administration. Government sponsorship acknowledged.

Chapter 3:

- The editor thanks NOAA/PMEL's Sandra Bigley for her very helpful work in assembling and copy editing Chapter 3. I couldn't do it without her help.

section 3h:

- The GPCP SG combined precipitation data were developed and computed at the NASA/Goddard Space Flight Center's Mesoscale Atmospheric Processes Laboratory - Atmospheres as a contribution to the GEWEX Global Precipitation Climatology Project.

- Data from the RAPID-WATCH MOC monitoring project are funded by the Natural Environment Research Council and are freely available from www.rapid.ac.uk/rapidmoc.

- JRA-55 Data Japan Meteorological Agency/Japan. 2013. JRA-55: Japanese 55-year Reanalysis, Daily 3-Hourly and 6-Hourly Data. Research Data Archive at the National Center for Atmospheric Research, Computational and Information Systems Laboratory. See more at: https://climatedataguide. ucar.edu/climate-data/jra-55\#sthash.zj1XmMQq .dpuf. 
- MOVE contributions were made under award NA15OAR4320071 from the Climate Observations Division, National Oceanic and Atmospheric Administration, U.S. Department of Commerce. Previously, MOVE was funded by the German Bundesministerium für Bildung und Forschung (Grants 03F0246A and 03F0377B). MOVE data are freely available via the international OceanSITES program (http://www.oceansites.org/data/).

\section{Chapter 4:}

The editors extend their thanks to the following individuals for assisting with the initial internal reviews of the Chapter. Their comments, insights, and careful editing eyes were instrumental in producing a very good chapter.

- Andrew Hagen, NOAA/National Weather Service, Miami, FL

- Ben Schenkel, Princeton University and NOAA/ GFDL, Princeton, NJ

- Bill Ward, NOAA/National Weather Service, Honolulu, HI

\section{Chapter 5:}

- V. Romanovsky and coauthors of the permafrost essay (section 5i) acknowledge the support of the State of Alaska, the National Science Foundation (grants PLR-0856864 and PLR-1304271 to the University of Alaska Fairbanks; PLR-1002119 and PLR-1304555 to the George Washington University), and by Geological Survey of Canada and Natural Resources Canada. Support was also provided by the Russian Science Foundation (projects RNF 16-17-00102, 13-05-41509 RGO, 13-05-00811, 13-08-91001, 14-05-00956, 14-17-00037, and 15-55-71004) and by the government of the Russian Federation.

- The chapter editors thank the authors for their contributions and the reviewers for their thoughtful and constructive comments.

- This publication (specifically support to J. Richter-Menge for coordination and editing) is the result in part of research sponsored by the Cooperative Institute for Alaska Research with funds from the National Oceanic and Atmospheric Administration under cooperative agreement NA13OAR4320056 with the University of Alaska.

- J. Overland, lead author of the surface air temperature section (section 5b), was supported by the Arctic Research Project of the NOAA Climate Program Office.

- M. Tedesco, lead author of the Greenland section (section 5e), acknowledges support from the NASA Cryosphere Program, the NASA IDS program (NNX14AD98G), and the Office of Polar Programs at the National Science Foundation (OPP 1643187).

- H. Epstein and coauthors of the tundra greenness section (section 5h) acknowledge support from the NASA Land Cover Land Use Change synthesis program (NNX14AD906).

- G. Bernhard and coauthors of section 5j acknowledge the U.S. National Science Foundation for supporting UV measurements at Barrow and Summit, a Research Council of Norway Centres of Excellence award (Project 223268/F50) to the Norwegian Radiation Protection Authority, the Academy of Finland for supporting UV measurements through the FARPOCC, SAARA, and ILMA pilot projects, and the ESA Living Planet program for funding the ILMA project (Contract No.: 4000112796/15/I-SBo).

- SEARCH, highlighted in sidebar 5.1, is funded by the National Science Foundation. B. P. Kelly, author of the sidebar, thanks SEARCH's Scientific Steering Committee, and Action Teams. Allen Pope and Matthew Druckenmiller provided graphics and many good ideas.

\section{Chapter 6:}

- The editors acknowledge and thank the authors for their timely contributions, with additional special thanks to the internal and external reviewers and document editors for their thoughtful and constructive comments. The editors also wish to thank Dr. Sam Batzli of the University of Wisconsin-Madison's Space Science and Engineering Center for generating Figure 6.1.

- Sharon Stammerjohn was supported under NSF PLR 1440435; she also thanks the Institute of Arctic and Alpine Research and the National Snow and Ice Data Center, both at the University of Colorado Boulder, for institutional and data support.

- Ted Scambos was supported under NASA grant NNX14AM54G and NSF ANT 0944763, the Antarctic Glaciological Data Center.

- Linda Keller and Matthew Lazzara were supported by the Automatic Weather Station Program, National Science Foundation, ANT-1245663 and PLR-1543305.

- The work of Rob Massom, Phil Reid, Jan Lieser, and Steve Rintoul was supported by the Australian Government's Cooperative Research Centre program through the Antarctic Climate \& Ecosystems CRC, and contributes to AAS Project 4116. 
Phil Reid was also supported through the Bureau of Meteorology. Jan Lieser was upported under Australian Research Council's Special Research Initiative for Antarctic Gateway Partnership (Project ID SR140300001).

- Jean-Baptiste Sallée was supported by the European Research Council (ERC) under the European Union's Horizon 2020 research and innovation program (Grant Agreement no 637770); Mike Meredith received funding from the Natural Environment Research Council via award NE/N018095/1.

- SOCCOM is supported by the National Science Foundation under NSF Award PLR-1425989. ORCHESTRA is funded by the Natural Environment Research Council, and is a joint program of the British Antarctic Survey, National Oceanography Centre, Plymouth Marine Laboratory, British Geological Survey, Sea Mammal Research Unit, Centre for Polar Observation and Modelling, and the UK Met Office. The authors thank the teams of scientists from these centres that are contributing to the programs.

Chapter 7:

North America / Canada:

- The authors express their thanks to Neil Taylor, Curtis Mooney with Environment and Climate Change Canada; Renee Beaulac with the Western Partnership for Wildland Fire Science at the University of Alberta; and Nyree Sharp for their helpful comments and suggestions.

Europe:

- Valuable climate information was provided by National Meteorological and Hydrological Services of the WMO RA VI Region, either by direct submission to the authors or via the web.

- The authors of Sidebar 7.3 acknowledge the data providers in the ECA\&D project: http://www .ecad.eu.

Oceania:

- The Australian authors thank their tolerant, wonderful, and supportive colleagues. We love you. 


\begin{tabular}{|c|c|c|c|}
\hline BASS: & $\begin{array}{l}\text { Blended Analysis of Surface Salinity } \\
\text { (NOAA) }\end{array}$ & KNMI: & $\begin{array}{l}\text { Royal Netherlands Meteorological } \\
\text { Institute }\end{array}$ \\
\hline BOM: & Bureau of Meteorology (Australia) & MLO: & Mauna Loa Observatory (Hawaii, \\
\hline \multirow{2}{*}{$\begin{array}{l}\text { CCI: } \\
\text { CDAS: }\end{array}$} & Climate Change Initiative & & US) \\
\hline & $\begin{array}{l}\text { Climate Data Analysis System } \\
\text { (NCAR) }\end{array}$ & MRI/JMA: & $\begin{array}{l}\text { Meteorological Research Institute/ } \\
\text { Japan Meteorological Agency }\end{array}$ \\
\hline CEMADEN: & $\begin{array}{l}\text { Centro Nacional de Monitoramento e } \\
\text { Alerta de Desastres Naturais (Brazil) }\end{array}$ & NASA: & $\begin{array}{l}\text { National Aeronautics and Space } \\
\text { Administration (US) }\end{array}$ \\
\hline CERES: & $\begin{array}{l}\text { Clouds and the Earth's Radiant } \\
\text { Energy Systems }\end{array}$ & NCAR: & $\begin{array}{l}\text { National Center for Atmospheric } \\
\text { Research (US) }\end{array}$ \\
\hline CFSR: & $\begin{array}{l}\text { Climate Forecast System Reanalysis } \\
\text { (NCEP) }\end{array}$ & NCEI: & $\begin{array}{l}\text { National Centers for Environmental } \\
\text { Information (NOAA) }\end{array}$ \\
\hline \multirow[t]{2}{*}{ CIIFEN: } & $\begin{array}{l}\text { Centro Internacional para la } \\
\text { Investigación del Fenómeno El Niño }\end{array}$ & NCEP: & $\begin{array}{l}\text { National Centers for Environmental } \\
\text { Prediction (NOAA) }\end{array}$ \\
\hline & (Ecuador) & NOAA: & National Oceanic and Atmospheric \\
\hline \multirow[t]{2}{*}{ CLIVAR: } & Climate Variability and & & Administration (US) \\
\hline & Predictability & NSIDC: & National Snow and Ice Data Center \\
\hline \multirow[t]{2}{*}{ CMAP: } & CPC Merged Analysis of & & (US) \\
\hline & Precipitation & OLR: & outgoing longwave radiation \\
\hline \multirow[t]{2}{*}{ CMEMS: } & Copernicus Marine and & PMEL/JPL/JIMAR & (US) \\
\hline & Environment Monitoring Service & & Pacific Marine Environmental \\
\hline \multirow{9}{*}{$\begin{array}{l}\text { CPC: } \\
\text { CSIRO/ACl }\end{array}$} & Climate Prediction Center (NOAA) & & Laboratory/Jet Propulsion \\
\hline & IMAS-UTAS: & & Laboratory/ \\
\hline & (Australia) Commonwealth & & Joint Institute for Marine and \\
\hline & Scientific and Industrial Research & & Atmospheric Research \\
\hline & Organisation & RAPID-MOC/MO & CHA/WBTS: (International, \\
\hline & Antarctic Climate \& Ecosystems & & UK-led) \\
\hline & Cooperative Research Centre & & RAPID Climate Change Programme- \\
\hline & Institute for Marine and Antarctic & & Meridional Overturning Circulation \\
\hline & Studies - University of Tasmania & & Meridional Overturning Circulation \\
\hline DWD: & Deutscher Wetterdienst & & and Heatflux Array \\
\hline ECV: & Essential Climate Variable & & Western Boundary Time Series \\
\hline ESA: & European Space Agency & RSW: & reflected shortwave \\
\hline \multirow[t]{2}{*}{ ESRL: } & Earth System Research Laboratory & SENAMHI-Bolivi & \\
\hline & $(\mathrm{NOAA})$ & & Servicio Nacional de Meteorologia e \\
\hline \multirow[t]{2}{*}{ FLASHFlux: } & Fast Longwave And Shortwave & & Hidrologia (La Paz) \\
\hline & Radiative Fluxes & SENAMHI-Peru: & Servicio Nacional de Meteorologia e \\
\hline \multirow[t]{2}{*}{ GUIB: } & Geographisches Institut der & & Hidrologia (Lima) \\
\hline & Universität Bern (Switzerland) & TOA: & top of atmosphere \\
\hline \multirow[t]{3}{*}{ GO-SHIP: } & Global Ocean Ship-based & TRMM: & Tropical Rainfall Measuring Mission \\
\hline & Hydrographic Investigations & TSI: & total solar irradiance \\
\hline & Program & WOA: & World Ocean Atlas \\
\hline \multirow[t]{2}{*}{ GODAS: } & Global Ocean Data Assimilation & WOCE: & World Ocean Circulation \\
\hline & System & & Experiment \\
\hline
\end{tabular}

KNMI: $\quad$ Royal Netherlands Meteorological Mauna Loa Observatory (Hawaii, Meteorological Research Institute/ Japan Meteorological Agency National Aeronautics and Space dministration (US)

nal Center for Atmospheric National Centers for Environmental nformation (NOAA) Prediction (NOAA) Administration (US) (US)

OLR: outgoing longwave radiation Pacific Marine Environmental Laboratory/Jet Propulsion Laboratory/ Joint Institute for Marine and

RAPID Climate Change ProgrammeMeridional Overturning Circulation Meridional Overturning Circulation and Heatflux Array Western Boundary Time Series

RSW: $\quad$ reflected shortwave

SENAMHI-Bolivia:

Additional acronyms and abbreviations can be found at this AMS website: https://www.ametsoc.org/ams/index.cfm/publications/authors/journal-and-bams-authors/authorresources/list-of-acronyms-and-abbreviations/ Institute 


\section{REFERENCES}

Abbott, B. W., and Coauthors, 2016: Biomass offsets little or none of permafrost carbon release from soils, streams, and wildfire: An expert assessment. Environ. Res. Lett., 11, 034014, doi:10.1088/1748-9326/11/3/034014.

Ackerman, S. A., R. E. Holz, R. Frey, E. W. Eloranta, B. C. Maddux, and M. McGill, 2008: Cloud detection with MODIS. Part II: Validation. J. Atmos. Oceanic Technol., 25, 1073-1086, doi:10.1175/2007jtecha1053.1.

Adler, R. F., and Coauthors, 2003: The version-2 Global Precipitation Climatology Project (GPCP) monthly precipitation analysis (1979-present). J. Hydrometeor., 4, 1147-1167, doi:10.1175/1525-7541(2003)004<1147:tvgpcp >2.0.co;2.

Aiyyer, A., and J. Molinari, 2008: MJO and tropical cyclogenesis in the Gulf of Mexico and eastern Pacific: Case study and idealized numerical modeling. J. Atmos. Sci., 65, 2691-2704, doi:10.1175/2007jas2348.1.

Albergel, C., and Coauthors, 2013: Skill and global trend analysis of soil moisture from reanalyses and microwave remote sensing. J. Hydrometeor., 14, 1259-1277, doi:10.1175/jhm-d-12-0161.1.

Allan, R. J., and R. D. D'Arrigo, 1999: 'Persistent' ENSO sequences: How unusual was the 1990-1995 El Niño? Holocene, 9, 101-118, doi:10.1191/095968399669125102.

—, and T. Ansell, 2006: A new globally complete monthly historical gridded mean sea level pressure dataset (HadSLP2): 1850-2004. J. Climate, 19, 5816-5842, doi:10.1175 /jcli3937.1.

— J. A. Lindesay, and D. E. Parker, 1996: El Niño Southern Oscillation and Climatic Variability. CSIRO Publications, $405 \mathrm{pp}$.

— C. J. C. Reason, J. A. Lindesay, and T. J. Ansell, 2003: 'Protracted' ENSO episodes and their impacts in the Indian Ocean region. Deep-Sea Res. II, 50, 2331-2347, doi:10.1016/S0967-0645(03)00059-6.

Amador, J. A., 1998: A climatic feature of the tropical Americas: The trade wind easterly jet. Top. Meteor. Oceanogr., 5, 91-102.

— E. J. Alfaro, O. G. Lizano, and V. O. Magaña, 2006: Atmospheric forcing of the eastern tropical Pacific: A review. Prog. Oceanogr., 69, 101-142, doi:10.1016/j .pocean.2006.03.007.

—, - H. G. Hidalgo, and B. Calderón, 2011: Central America [in "State of the Climate in 2010"]. Bull. Amer. Meteor. Soc., 92 (6), S182-S183, doi:10.1175/1520-0477 -92.6.s1.

Andela, N., and G. R. van der Werf, 2014: Recent trends in African fires driven by cropland expansion and El Nino to La Nina transition. Nat. Climate Change, 4, 791-795, doi:10.1038/nclimate2313.
Anderson, M. C., and Coauthors, 2011: Mapping daily evapotranspiration at field to continental scales using geostationary and polar orbiting satellite imagery. Hydrol. Earth Syst. Sci., 15, 223-239, doi:10.5194/hess-15-223-2011.

Anderson, R. G., and Coauthors, 2015: Using satellite-based estimates of evapotranspiration and groundwater changes to determine anthropogenic water fluxes in land surface models. Geosci. Model Dev., 8, 3021-3031, doi:10.5194 /gmd-8-3021-2015.

Andersson, S. M., and Coauthors, 2015: Significant radiative impact of volcanic aerosol in the lowermost stratosphere. Nat. Comm., 6, 7692, doi:10.1038/ncomms8692.

Andreassen, L. M., H. Elvehøy, B. Kjøllmoen, and R. V. Engeset, 2016: Reanalysis of long-term series of glaciological and geodetic mass balance for 10 Norwegian glaciers. Cryosphere, 10, 535-552, doi:10.5194/tc-10-535-2016.

Andres, M., 2016: On the recent destabilization of the Gulf Stream path downstream of Cape Hatteras. Geophys. Res. Lett., 43, 9836-9842, doi:10.1002/2016GL069966.

Aquila, V., W. H. Swartz, D. W. Waugh, P. R. Colarco, S. Pawson, L. M. Polvani, and R. S. Stolarski, 2016: Isolating the roles of different forcing agents in global stratospheric temperature changes using model integrations with incrementally added single forcings. J. Geophys. Res. Atmos., 121, 8067-8082, doi:10.1002/2015JD023841.

Arbetter, T. E., A. H. Lynch, and D. A. Bailey, 2004: Relationship between synoptic forcing and polynya formation in the Cosmonaut Sea: 1. Polynya climatology. J. Geophys. Res., 109, C04022, doi:10.1029/2003JC001837.

Argüez, A., T. R. Karl, M. F. Squires, and R. S. Vose, 2013: Uncertainty in annual rankings from NOAA's global temperature time series. Geophys. Res. Lett., 40, 5965-5969, doi:10.1002/2013GL057999.

Arkin, P. A., 1982: The relationship between interannual variability in the $200 \mathrm{mb}$ tropical wind field and the southern oscillation. Mon. Wea. Rev., 110, 1393-1404, doi:10.1175/1520-0493(1982)110<1393:trbivi>2.0.co;2.

Armstrong, R., K. Knowles, M. J. Brodzik, and M. A. Hardman, 1994, updated 2016: DMSP SSM/I-SSMIS Pathfinder Daily EASE-Grid Brightness Temperatures. 2 ed., National Snow and Ice Data Center, doi:10.5067/3EX2U1DV3434.

Ashok, K., and T. Yamagata, 2009: Climate change: The El Niño with a difference. Nature, 461, 481-484, doi:10.1038/461481a.

Azorin-Molina, C., and Coauthors, 2014: Homogenization and assessment of observed near-surface wind speed trends over Spain and Portugal, 1961-2011. J. Climate, 27, 3692-3712, doi:10.1175/jcli-d-13-00652.1.

- - J.-A. Guijarro, T. R. McVicar, S. M. Vicente-Serrano, D. Chen, S. Jerez, and F. Espírito-Santo, 2016: Trends of daily peak wind gusts in Spain and Portugal, 1961-2014. J. Geophys. Res. Atmos., 121, 1059-1078, doi:10.1002/2015JD024485. 
_, S. M. Vicente-Serrano, T. R. McVicar, J. Revuelto, S. Jerez, and J.-I. López-Moreno, 2017: Assessing the impact of measurement time interval when calculating wind speed means and trends under the stilling phenomenon. Int. J. Climatol., 37, 480-492, doi:10.1002/joc.4720.

Bakker, D. C. E., and Coauthors, 2016: A multi-decade record of high-quality fCO2 data in version 3 of the Surface Ocean CO2 Atlas (SOCAT). Earth Syst. Sci. Data, 8, 383-413, doi:10.5194/essd-8-383-2016.

Banzon, V. F., and R. W. Reynolds, 2013: Use of WindSat to extend a microwave-based daily optimum interpolation sea surface temperature time series. J. Climate, 26, 2557-2562, doi:10.1175/jcli-d-12-00628.1.

Baringer, M. O., M. Lankhorst, D. Volkov, S. Garzoli, S. Dong, U. Send, and C. Meinen, 2016: Meridional oceanic overturning circulation and heat transport in the Atlantic Ocean [in "State of the Climate in 2015"]. Bull. Amer. Meteor. Soc., 97 (8), S84-S87, doi:10.1175 /2015BAMSStateoftheClimate.1.

Barrio, I. C., and Coauthors, 2016: Biotic interactions mediate patterns of herbivore diversity in the Arctic. Global Ecol. Biogeogr., 25, 1108-1118, doi:10.1111/geb.12470.

Bastos, A., S. W. Running, C. Gouveia, and R. M. Trigo, 2013: The global NPP dependence on ENSO: La Niña and the extraordinary year of 2011. J. Geophys. Res. Biogeosci., 118, 1247-1255, doi:10.1002/jgrg.20100.

Bates, N. R., 2015: Assessing ocean acidification variability in the Pacific-Arctic region as part of the Russian-American long-term census of the Arctic. Oceanography, 28 (3), 36-45, doi:10.5670/oceanog.2015.56.

—, M. I. Orchowska, R. Garley, and J. T. Mathis, 2013: Summertime calcium carbonate undersaturation in shelf waters of the western Arctic Ocean - how biological processes exacerbate the impact of ocean acidification. Biogeosciences, 10, 5281-5309, doi:10.5194/bg-10-5281-2013.

Bauer-Marschallinger, B., W. A. Dorigo, W. Wagner, and A. I. J. M. van Dijk, 2013: How oceanic oscillation drives soil moisture variations over mainland Australia: An analysis of 32 years of satellite observations. J. Climate, 26, 10,159-10,173, doi:10.1175/jcli-d-13-00149.1.

Baxter, S., S. Weaver, J. Gottschalck, and Y. Xue, 2014: Pentad evolution of wintertime impacts of the Madden-Julian oscillation over the contiguous United States. J. Climate, 27, 7356-7367, doi:10.1175/jcli-d-14-00105.1.

Becker, A., P. Finger, A. Meyer-Christoffer, B. Rudolf, K. Schamm, U. Schneider, and M. Ziese, 2013: A description of the global land-surface precipitation data products of the Global Precipitation Climatology Centre with sample applications including centennial (trend) analysis from 1901-present. Earth Syst. Sci. Data, 5, 71-99, doi:10.5194 /essd-5-71-2013.
Beckmann, A., R. Timmermann, A. F. Pereira, and C. Mohn, 2001: The effect of flow at Maud Rise on the sea-ice cover - Numerical experiments. Ocean Dyn., 52, 11-25, doi:10.1007/s10236-001-8173-5.

Behrenfeld, M. J., and Coauthors, 2006: Climate-driven trends in contemporary ocean productivity. Nature, 444, 752-755, doi:10.1038/nature05317.

— D. A. Siegel, and R. T. O’Malley, 2008: Global ocean phytoplankton [in "State of the Climate in 2007"]. Bull. Amer. Meteor. Soc., 89 (7), S56-S61, doi:10.1175/BAMS -89-7-StateoftheClimate.

__, —_, —_, and S. Maritorena, 2009: Global ocean phytoplankton [in "State of the Climate in 2008"]. Bull. Amer. Meteor. Soc., 90 (8), S68-S72, doi:10.1175/BAMS -90-8-StateoftheClimate.

— pacts on global phytoplankton. Nat. Climate Change, 6, 323-330, doi:10.1038/nclimate2838.

Behringer, D. W., M. Ji, and A. Leetmaa, 1998: An improved coupled model for ENSO prediction and implications for ocean initialization. Part I: The ocean data assimilation system. Mon. Wea. Rev., 126, 1013-1021, doi:10.1175/1520 -0493(1998)126<1013:aicmfe>2.0.co;2.

Bell, G. D., and M. Chelliah, 2006: Leading tropical modes associated with interannual and multidecadal fluctuations in North Atlantic hurricane activity. J. Climate, 19, 590-612, doi:10.1175/jcli3659.1.

—_, M. S. Halpert, V. E. Kousky, M. E. Gelman, C. F. Ropelewski, A. V. Douglas, and R. C. Schnell, 1999: Climate Assessment for 1998. Bull. Amer. Meteor. Soc., 80 (5), S1-S48, doi:10.1175/1520-0477(1999)080<1040 :caf $>2.0$. co;2.

—_, and Coauthors, 2000: The 1999 North Atlantic and eastern North Pacific hurricane season [in "Climate Assessment for 1999"]. Bull. Amer. Meteor. Soc., 81 (6), S19S22, doi:10.1175/1520-0477(2000)081<1328:caf>2.3.co;2.

, E. S. Blake, T. B. Kimberlain, C. W. Landsea, J. Schemm, R. J. Pasch, and S. B. Goldenberg, 2011: Tropical cyclones: Atlantic basin [in "State of the Climate in 2010"]. Bull. Amer. Meteor. Soc., 92 (6), S115-S121, doi:10.1175/1520 -0477-92.6.s1.

—_, - C, C. W. Landsea, T. B. Kimberlain, S. B. Goldenberg, J. Schemm, and R. J. Pasch, 2012: Tropical cyclones: Atlantic basin [in "State of the Climate in 2011"]. Bull. Amer. Meteor. Soc., 93 (7), S99-S105, doi:10.1175 /2012BAMSStateoftheClimate.1.

_- C. W. Landsea, S. B. Goldenberg, R. J. Pasch, E. S. Blake, J. Schemm, and T. B. Kimberlain, 2014: Tropical cyclones: Atlantic basin [in "State of the Climate in 2013"]. Bull. Amer. Meteor. Soc., 95 (7), S86-S90, doi:10.1175 /2014BAMSStateoftheClimate.1. 
$\longrightarrow,-$ - E. S. Blake, J. Schemm, S. B. Goldenberg, T. B. Kimberlain, and R. J. Pasch, 2015: Tropical cyclones: Atlantic basin [in "State of the Climate in 2014"]. Bull. Amer. Meteor. Soc., 96 (7), S105-S107, doi:10.1175 /2015BAMSStateoftheClimate.1.

—, M. Halpert, and M. L'Heureux, 2016: ENSO and the tropical Pacific: A climate perspective [in "State of the Climate in 2015”]. Bull. Amer. Meteor. Soc., 97 (8), S93-S98, doi:10.1175/2016BAMSStateoftheClimate.1.

Bell, R. J., J. A. Hare, J. P. Manderson, and D. E. Richardson, 2014: Externally driven changes in the abundance of summer and winter flounder. ICES J. Marine Sci., 71, 2416-2428, doi:10.1093/icesjms/fsu069.

Benedetti, A., F. D. Giuseppe, J. Flemming, A. Inness, M. Parrington, S. Rémy, and J. R. Ziemke, 2016: Atmospheric composition changes due to the extreme 2015 Indonesian fire season triggered by El Niño [in "State of the Climate in 2015”]. Bull. Amer. Meteor. Soc., 97 (8), S56-S57, doi :10.1175/2016BAMSStateoftheClimate.1.

Berman, M., C. Nicolson, G. Kofinas, J. Tetlichi, and S. Martin, 2004: Adaptation and sustainability in a small Arctic community: Results of an agent-based simulation model. Arctic, 57, 401-414.

Bernhard, G., and Coauthors, 2015: Comparison of OMI UV observations with ground-based measurements at high northern latitudes. Atmos. Chem. Phys., 15, 7391-7412, doi:10.5194/acp-15-7391-2015.

Berry, D. I., and E. C. Kent, 2009: A new air-sea interaction gridded dataset from ICOADS with uncertainty estimates. Bull. Amer. Meteor. Soc., 90, 645-656, doi:10.1175/2008bams2639.1.

— and 2011: Air-sea fluxes from ICOADS: The construction of a new gridded dataset with uncertainty estimates. Int. J. Climatol., 31, 987-1001, doi:10.1002/joc.2059.

— and _ 2017: Assessing the health of the in situ global surface marine climate observing system. Int. J. Climatol., 37, 2248-2259, doi:10.1002/joc.4914.

Betts, R. A., C. D. Jones, J. R. Knight, R. F. Keeling, and J. J. Kennedy, 2016: El Niño and a record CO2 rise. Nat. Climate Change, 6, 806-810, doi:10.1038/nclimate3063.

Bhartia, P. K., and C. W. Wellemeyer, 2002: TOMS-V8 total $\mathrm{O}_{3}$ algorithm. OMI Algorithm Theoretical Basis Document Vol. II, 15-31 pp.

Bhatt, U., and Coauthors, 2013: Recent declines in warming and vegetation greening trends over pan-Arctic tundra. Remote Sens., 5, 4229, doi:10.3390/rs5094229.

Bichet, A., M. Wild, D. Folini, and C. Schär, 2012: Causes for decadal variations of wind speed over land: Sensitivity studies with a global climate model. Geophys. Res. Lett., 39, L11701, doi:10.1029/2012GL051685.
Bieniek, P., and Coauthors, 2015: Climate drivers linked to changing seasonality of Alaska coastal tundra vegetation productivity. Earth Interact., 19 (19), 1-29, doi:10.1175 lei-d-15-0013.1.

Birkett, C., C. Reynolds, B. Beckley, and B. Doorn, 2011: From research to operations: The USDA global reservoir and lake monitor. Coastal Altimetry, S. Vignudelli, A. G. Kostianoy, P. Cipollini, and J. Benveniste, Eds., Springer, 19-50.

Biskaborn, B. K., J. P. Lanckman, H. Lantuit, K. Elger, D. A. Streletskiy, W. L. Cable, and V. E. Romanovsky, 2015: The new database of the global terrestrial network for permafrost (GTN-P). Earth Syst. Sci. Data, 7, 245-259, doi:10.5194/essd-7-245-2015.

Bister, M., and K. A. Emanuel, 1998: Dissipative heating and hurricane intensity. Meteor. Atmos. Phys., 65, 233-240, doi:10.1007/bf01030791.

Bjerke, J. W., and Coauthors, 2014: Record-low primary productivity and high plant damage in the Nordic Arctic region in 2012 caused by multiple weather events and pest outbreaks. Environ. Res. Lett., 9, 084006, doi:10.1088/1748-9326/9/8/084006.

Bjerknes, J., 1969: Atmospheric teleconnections from the equatorial Pacific. Mon. Wea. Rev., 97, 163-172, doi:10.1175/1520-0493(1969)097<0163:atftep>2.3.co;2.

Blake, E., E. J. Gibney, D. P. Brown, M. Mainelli, J. L. Franklin, and T. B. Kimberlain, 2009: Tropical cyclones of the eastern North Pacific basin, 1949-2006. Historical Climatology Series 6-5, 162 pp.

Bliss, A., R. Hock, and V. Radić, 2014: Global response of glacier runoff to twenty-first century climate change. J. Geophys. Res. Earth Surf., 119, 717-730, doi:10.1002/2013JF002931.

Blok, D., M. M. P. D. Heijmans, G. Schaepman-Strub, A. V. Kononov, T. C. Maximov, and F. Berendse, 2010: Shrub expansion may reduce summer permafrost thaw in Siberian tundra. Global Change Biol., 16, 1296-1305, doi:10.1111/j.1365-2486.2009.02110.x.

Blunden, J., and D. S. Arndt, 2016: State of the Climate in 2015. Bull. Amer. Meteor. Soc., 97 (8), Si-S275, doi:10 $.1175 / 2016$ BAMSStateoftheClimate.1.

Bockheim, J. G., and K. M. Hinkel, 2007: The importance of "Deep" organic carbon in permafrost-affected soils of Arctic Alaska. Soil Sci. Soc. Amer. J., 71, 1889-1892, doi:10.2136/sssaj2007.0070N.

Boden, T. A., G. Marland, and R. J. Andres, 2015: Global, Regional, and National Fossil-Fuel $\mathrm{CO}_{2}$ Emissions. Carbon Dioxide Information Analysis Center, Oak Ridge National Laboratory, doi:10.3334/CDIAC/00001_V2015.

Bodhaine, B. A., B. G. Mendonca, J. M. Harris, and J. M. Miller, 1981: Seasonal variations in aerosols and atmospheric transmission at Mauna Loa observatory. J. Geophys. Res, 86, 7395-7398, doi:10.1029/JC086iC08p07395. 
Boening, C., J. K. Willis, F. W. Landerer, R. S. Nerem, and J. Fasullo, 2012: The 2011 La Niña: So strong, the oceans fell. Geophys. Res. Lett., 39, L19602, doi:10.1029/2012GL053055. Bojinski, S., M. Verstraete, T. C. Peterson, C. Richter, A. Simmons, and M. Zemp, 2014: The concept of essential climate variables in support of climate research, applications, and policy. Bull. Amer. Meteor. Soc., 95, 1431-1443, doi:10.1175/bams-d-13-00047.1.

Bokhorst, S., J. W. Bjerke, L. E. Street, T. V. Callaghan, and G. K. Phoenix, 2011: Impacts of multiple extreme winter warming events on sub-Arctic heathland: phenology, reproduction, growth, and $\mathrm{CO} 2$ flux responses. Global Change Biol., 17, 2817-2830, doi:10.1111/j.1365 -2486.2011.02424.x.

Bond, N. A., M. F. Cronin, H. Freeland, and N. Mantua, 2015: Causes and impacts of the 2014 warm anomaly in the NE Pacific. Geophys. Res. Lett., 42, 3414-3420, doi:10.1002/2015GL063306.

Bonjean, F., and G. S. E. Lagerloef, 2002: Diagnostic model and analysis of the surface currents in the tropical Pacific Ocean. J. Phys. Oceanogr., 32, 2938-2954, doi:10.1175/1520-0485(2002)032<2938:dmaaot>2.0.co;2.

Borge, A. F., S. Westermann, I. Solheim, and B. Etzelmüller, 2017: Strong degradation of palsas and peat plateaus in northern Norway during the last 60 years. Cryosphere, 11, 1-16, doi:10.5194/tc-11-1-2017.

Bosilovich, M. G., and Coauthors, 2015: MERRA-2: Initial evaluation of the climate. NASA/TM-2015-104606, Vol. 43, $136 \mathrm{pp}$. [Available online at http:/gmao.gsfc.nasa.gov /reanalysis/MERRA-2/docs/.]

_, F. R. Robertson, L. Takacs, and A. Molod, 2017: Atmospheric water balance and variability in the MERRA-2 reanalysis. J. Climate, 30, 1177-1196, doi:10.1175/jcli -d-16-0338.1.

Boucher, O., and Coauthors, 2013: Clouds and aerosols. Climate Change 2013: The Physical Science Basis, T. F. Stocker et al., Eds., Cambridge University Press, 571-658.

Bourassa, A. E., and Coauthors, 2014: Trends in stratospheric ozone derived from merged SAGE II and Odin-OSIRIS satellite observations. Atmos. Chem. Phys., 14, 6983-6994, doi:10.5194/acp-14-6983-2014.

Box, J. E., and Coauthors, 2012: Greenland ice sheet. Arctic Report Card 2012, NOAA's Arctic Program, 146-158. [Available online at http://ftp://ftp.oar.noaa.gov/arctic /documents/ArcticReportCard_full_report2012.pdf.]

_, D. van As, K. Steffen, 2017: Greenland, Canadian and Icelandic land ice albedo grids (2000-2016). Geol. Surv. Den. Greenl. Bull., 38, 69-72.

Boyer, T. P., and Coauthors, 2013: World ocean database 2013. NOAA Atlas NESDIS 72, 209 pp. [Available online at http://www.nodc.noaa.gov/OC5/WOD13/.]
—, S. Levitus, J. I. Antonov, J. R. Reagan, C. Schmid, and R. Locarnini, 2012: Subsurface salinity [in "State of the Climate in 2011"]. Bull. Amer. Meteor. Soc., 93 (7), S72-S75, doi:10.1175/2012BAMSStateoftheClimate.1.

Brasnett, B., 1999: A global analysis of snow depth for numerical weather prediction. J. Appl. Meteor., 38, 726-740, doi:10.1175/1520-0450(1999)038<0726:agaosd>2.0.co;2.

Bret-Harte, M. S., and Coauthors, 2013: The response of Arctic vegetation and soils following an unusually severe tundra fire. Philos. Trans. Roy. Soc. London, 368B, 20120490, doi:10.1098/rstb.2012.0490.

Bromwich, D. H., A. J. Monaghan, and Z. Guo, 2004: Modeling the ENSO modulation of Antarctic climate in the late 1990s with the polar MM5. J. Climate, 17, 109-132, doi:10.1175/1520-0442(2004)017<0109:mtemoa>2.0.co;2.

, R. L. Fogt, K. I. Hodges, and J. E. Walsh, 2007: A tropospheric assessment of the ERA-40, NCEP, and JRA-25 global reanalyses in the polar regions. J. Geophys. Res., 112, D10111, doi:10.1029/2006JD007859.

, J. P. Nicolas, and A. J. Monaghan, 2011: An assessment of precipitation changes over Antarctica and the Southern Ocean since 1989 in contemporary global reanalyses. J. Climate, 24, 4189-4209, doi:10.1175/2011jcli4074.1.

Brönnimann, S., J. L. Annis, C. Vogler, and P. D. Jones, 2007: Reconstructing the quasi-biennial oscillation back to the early 1900s. Geophys. Res. Lett., 34, L22805, doi:10.1029/2007GL031354.

Brosius, L. S., K. M. W. Anthony, G. Grosse, J. P. Chanton, L. M. Farquharson, P. P. Overduin, and H. Meyer, 2012: Using the deuterium isotope composition of permafrost meltwater to constrain thermokarst lake contributions to atmospheric $\mathrm{CH} 4$ during the last deglaciation. J. Geophys. Res., 117, G01022, doi:10.1029/2011JG001810.

Brown, D. P., 2017: Hurricane Otto (AL162016, EP22016): 20-26 November 2016. Natl. Hurricane Center, Tropical Cyclone Rep., 28 pp. [Available online at http://www.nhc .noaa.gov/data/tcr/AL162016_Otto.pdf.]

Brown, J., O. J. Ferrians Jr., J. A. Heginbottom, and E. S. Melnikov, 1998, Revised February 2001: Circum-Arctic map of permafrost and ground ice conditions. National Snow and Ice Data Center. [Available online at http://nsidc.org /data/docs/fgdc/ggd318_map_circumarctic/.]

Brutsaert, W., 2016: Global land surface evaporation trend during the past half century: Corroboration by ClausiusClapeyron scaling. Adv. Water Res., Early Online, doi:10.1016/j.advwatres.2016.08.014.

Butchart, N., and E. E. Remsberg, 1986: The area of the stratospheric polar vortex as a diagnostic for tracer transport on an isentropic surface. J. Atmos. Sci., 43, 1319-1339, doi:10.1175/1520-0469(1986)043<1319:taotsp>2.0.co;2. 
Calvo, N., R. R. Garcia, W. J. Randel, and D. R. Marsh, 2010: Dynamical mechanism for the increase in tropical upwelling in the lowermost tropical stratosphere during warm ENSO events. J. Atmos. Sci., 67, 2331-2340, doi:10.1175/2010jas3433.1.

Camargo, S. J., and A. H. Sobel, 2005: Western North Pacific tropical cyclone intensity and ENSO. J. Climate, 18, 2996-3006, doi:10.1175/jcli3457.1.

— K. A. Emanuel, and A. H. Sobel, 2007: Use of a genesis potential index to diagnose ENSO effects on tropical cyclone genesis. J. Climate, 20, 4819-4834, doi:10.1175 /jcli4282.1.

—_, M. C. Wheeler, and A. H. Sobel, 2009: Diagnosis of the MJO modulation of tropical cyclogenesis using an empirical index. J. Atmos. Sci., 66, 3061-3074, doi:10.1175/2009jas3101.1.

Cappelen, J., B. M. Vinther, C. Kern-Hansen, E. V. Laursen, and P. V. Jørgensen, 2017: Greenland - DMI Historical Climate Data Collection 1784-2016. DMI Report 17-04, 108 pp. [Available online at http://www.dmi.dk/fileadmin /user_upload/Rapporter/TR/2017/DMIRep17-04.pdf.]

Carpenter, L. J., and Coauthors, 2014: Update on ozonedepleting substances (ODSs) and other gases of interest to the Montreal Protocol. Scientific Assessment of Ozone Depletion: 2014, World Meteorological Organization, 1.1-1.101.

Carrea, L., O. Embury, and C. J. Merchant, 2015: Datasets related to in-land water for limnology and remote sensing applications: Distance-to-land, distance-to-water, waterbody identifier and lake-centre co-ordinates. Geosci. Data J., 2, 83-97, doi:10.1002/gdj3.32.

Carsey, F. D., 1980: Microwave observation of the Weddell polynya. Mon. Wea. Rev., 108, 2032-2044, doi:10.1175/1520 -0493(1980)108<2032:mootwp >2.0.co;2.

Carter, B. R., and Coauthors, 2017: Two decades of Pacific anthropogenic carbon storage and ocean acidification along Global Ocean Ship-based Hydrographic Investigations Program sections P16 and P02. Global Biogeochem. Cycles, 31, 306-327, doi:10.1002/2016GB005485.

Carton, J. A., S. A. Cunningham, E. Frajka-Williams, Y.-O. Kwon, D. P. Marshall, and R. Msadek, 2014: The Atlantic overturning circulation: More evidence of variability and links to climate. Bull. Amer. Meteor. Soc., 95 (8), ES163ES166, doi:10.1175/bams-d-13-00234.1.

Cassou, C., 2008: Intraseasonal interaction between the Madden-Julian oscillation and the North Atlantic oscillation. Nature, 455, 523-527, doi:10.1038/nature07286.

Castro de la Guardia, L., X. Hu, and P. G. Myers, 2015: Potential positive feedback between Greenland Ice Sheet melt and Baffin Bay heat content on the West Greenland Shelf. Geophys. Res. Lett., 42, 4922-4930, doi:10.1002/2015GL064626.
Cavalieri, D. J., C. L. Parkinson, P. Gloersen, and H. Zwally, 1996, updated yearly: Sea Ice Concentrations From Nimbus-7 SMMR and DMSP SSM/I-SSMIS Passive Microwave Data (1981-2011). National Snow and Ice Data Center, doi:10.5067/8GQ8LZQVL0VL.

Cazenave, A., and Coauthors, 2012: Estimating ENSO influence on the global mean sea level, 1993-2010. Mar. Geod., 35 (Sup1), 82-97, doi:10.1080/01490419.2012.718209.

Chambers, D. P., and Coauthors, 2017: Evaluation of the global mean sea level budget between 1993 and 2014. Surv. Geophys., 38, 309-327, doi:10.1007/s10712-016-9381-3.

Chan, J. C. L., 2000: Tropical cyclone activity over the western North Pacific associated with El Niño and La Niña events. J. Climate, 13, 2960-2972, doi:10.1175/1520 -0442(2000)013<2960:tcaotw>2.0.co;2.

Chandra, S., J. R. Ziemke, W. Min, and W. G. Read, 1998: Effects of 1997-1998 El Niño on tropospheric ozone and water vapor. Geophys. Res. Lett., 25, 3867-3870, doi:10.1029/98GL02695.

$\longrightarrow$ - — B. N. Duncan, T. L. Diehl, N. J. Livesey, and L. Froidevaux, 2009: Effects of the 2006 El Niño on tropospheric ozone and carbon monoxide: Implications for dynamics and biomass burning. Atmos. Chem. Phys., 9, 4239-4249, doi:10.5194/acp-9-4239-2009.

Chen, Y., and Coauthors, 2013: Long-term trends and interannual variability of forest, savanna and agricultural fires in South America. Carbon Management, 4, 617-638, doi:10.4155/cmt.13.61.

Chia, H. H., and C. F. Ropelewski, 2002: The interannual variability in the genesis location of tropical cyclones in the northwest Pacific. J. Climate, 15, 2934-2944, doi:10.1175/1520-0442(2002)015<2934:tivitg>2.0.co;2.

Chiodi, A. M., and D. E. Harrison, 2013: El Niño impacts on seasonal U.S. atmospheric circulation, temperature, and precipitation anomalies: The OLR-event perspective. $J$. Climate, 26, 822-837, doi:10.1175/jcli-d-12-00097.1.

Chiou, E. W., and Coauthors, 2014: Comparison of profile total ozone from SBUV (v8.6) with GOME-type and ground-based total ozone for a 16-year period (1996 to 2011). Atmos. Meas. Tech., 7, 1681-1692, doi:10.5194 lamt-7-1681-2014.

Christiansen, H. H., and Coauthors, 2010: The thermal state of permafrost in the nordic area during the international polar year 2007-2009. Permafr. Periglac. Process., 21, 156-181, doi:10.1002/ppp.687.

Christy, J., 2014: Lower tropospheric temperature [in "State of the Climate in 2013”]. Bull. Amer. Meteor. Soc., 95 (7), S10-S11, doi:10.1175/2014BAMSStateoftheClimate.1.

_ 2016: Lower and midtropospheric temperature [in "State of the Climate in 2015"]. Bull. Amer. Meteor. Soc., 97 (8), S13-S15, doi:10.1175/2016BAMSStateoftheClimate.1. 
_ and R. T. McNider, 1994: Satellite greenhouse signal. Nature, 367, 325-325, doi:10.1038/367325a0.

_- R. W. Spencer, and W. B. Norris, 2011: The role of remote sensing in monitoring global bulk tropospheric temperatures. Int. J. Remote Sens., 32, 671-685, doi:10 $.1080 / 01431161.2010 .517803$.

Chrysanthou, A., G. van der Schrier, E. J. M. van den Besselaar, A. M. G. Klein Tank, and T. Brandsma, 2014: The effects of urbanization on the rise of the European temperature since 1960. Geophys. Res. Lett., 41, 7716-7722, doi:10.1002/2014GL061154.

Chu, J.-H., C. R. Sampson, A. S. Levine, and E. Fukada, 2002: The Joint Typhoon Warning Center tropical cyclone besttracks, 1945-2000. Ref. NRL/MR/7540-02-16, Naval Research Laboratory. [Available online at http://www .usno.navy.mil/NOOC/nmfc-ph/RSS/jtwc/best_tracks /TC_bt_report.html.]

Chung, E.-S., B. J. Soden, and V. O. John, 2013: Intercalibrating microwave satellite observations for monitoring long-term variations in upper- and midtropospheric water vapor. J. Atmos. Oceanic Technol., 30, 2303-2319, doi:10.1175/jtech-d-13-00001.1.

$\longrightarrow,-$ X. Huang, L. Shi, and V. O. John, 2016: An assessment of the consistency between satellite measurements of upper tropospheric water vapor. J. Geophys. Res. Atmos., 121, 2874-2887, doi:10.1002/2015JD024496.

Clancy, R. T., and Coauthors, 2000: An intercomparison of ground-based millimeter, MGS TES, and Viking atmospheric temperature measurements: Seasonal and interannual variability of temperatures and dust loading in the global Mars atmosphere. J. Geophys. Res., 105, 9553-9571, doi:10.1029/1999JE001089.

Coelho, C. A. S., D. H. F. Cardoso, and M. A. F. Firpo, 2016a: Precipitation diagnostics of an exceptionally dry event in São Paulo, Brazil. Theor. Appl. Climatol., 125, 769-784, doi:10.1007/s00704-015-1540-9.

— , and Coauthors, 2016b: The 2014 southeast Brazil austral summer drought: Regional scale mechanisms and teleconnections. Climate Dyn., 46, 3737-3752, doi:10.1007 /s00382-015-2800-1.

Coldewey-Egbers, M., and Coauthors, 2015: The GOME-type total ozone essential climate variable (GTO-ECV) data record from the ESA Climate Change Initiative. Atmos. Meas. Tech., 8, 3923-3940, doi:10.5194/amt-8-3923-2015.

Comiso, J. C., R. A. Gersten, L. V. Stock, J. Turner, G. J. Perez, and K. Cho, 2017: Positive trend in the Antarctic sea ice cover and associated changes in surface temperature. J. Climate, 30, 2251-2267, doi:10.1175/jcli-d-16-0408.1.

Cook, B. I., K. J. Anchukaitis, R. Touchan, D. M. Meko, and E. R. Cook, 2016: Spatiotemporal drought variability in the Mediterranean over the last 900 years. J. Geophys. Res. Atmos., 121, 2060-2074, doi:10.1002/2015JD023929.
Cooper, O. R., and J. R. Ziemke, 2013: Tropospheric ozone [in "State of the Climate in 2012"]. Bull. Amer. Meteor. Soc., 94 (8), S38-S39, doi:10.1175/2013BAMSStateoftheClimate.1. __ and _- 2014: Tropospheric ozone [in "State of the Climate in 2013"]. Bull. Amer. Meteor. Soc., 95 (7), S42, doi:10.1175/2014BAMSStateoftheClimate.1.

— and - 2015: Tropospheric ozone [in "State of the Climate in 2014"]. Bull. Amer. Meteor. Soc., 96 (7), S48-S49, doi:10.1175/2015BAMSStateoftheClimate.1.

—_, and Coauthors, 2014: Global distribution and trends of tropospheric ozone: An observation-based review. Elementa: Sci. Anthropocene, 2, 29, doi:10.12952/journal .elementa.000029.

Cross, J.N., J.T. Mathis, R.S. Pickart, and N.R. Bates, 2017: Formation and transport of corrosive water in the Pacific Arctic region. Deep-Sea Res. II, Special issue: Synthesis of Arctic Research (SOAR), Submitted.

Cruz, M. G., A. L. Sullivan, J. S. Gould, N. C. Sims, A. J. Bannister, J. J. Hollis, and R. J. Hurley, 2012: Anatomy of a catastrophic wildfire: The Black Saturday Kilmore East fire in Victoria, Australia. For. Ecol. Manage., 284, 269-285, doi:10.1016/j.foreco.2012.02.035.

Curtis, S., and R. Adler, 2000: ENSO indices based on patterns of satellite-derived precipitation. J. Climate, 13, 2786-2793, doi:10.1175/1520-0442(2000)013<2786 :eibopo $>2.0 . c 0 ; 2$.

Dai, A., 2006: Recent climatology, variability, and trends in global surface humidity. J. Climate, 19, 3589-3606, doi:10.1175/jcli3816.1.

__, 2013: Increasing drought under global warming in observations and models. Nat. Climate Change, 3, 52-58, doi:10.1038/nclimate1633.

__, T. Qian, K. E. Trenberth, and J. D. Milliman, 2009: Changes in continental freshwater discharge from 1948 to 2004. J. Climate, 22, 2773-2792, doi:10.1175/2008jcli2592.1.

Davidson, E. A., and I. A. Janssens, 2006: Temperature sensitivity of soil carbon decomposition and feedbacks to climate change. Nature, 440, 165-173, doi:10.1038 /nature04514.

Davis, S. M., K. H. Rosenlof, D. F. Hurst, and H. B. Selkirk, 2016a: Stratospheric water vapor [in "State of the Climate in 2015”]. Bull. Amer. Meteor. Soc., 97 (8), S51-S53, doi:10 $.1175 / 2016$ BAMSStateoftheClimate.1.

Davis, S. M., and Coauthors, 2016b: The stratospheric water and ozone satellite homogenized (SWOOSH) database: A long-term database for climate studies. Earth Syst. Sci. Data, 8, 461-490, doi:10.5194/essd-8-461-2016.

Dee, D. P., and Coauthors, 2011: The ERA-Interim reanalysis: Configuration and performance of the data assimilation system. Quart. J. Roy. Meteor. Soc., 137, 553-597, doi:10.1002/qj.828. 
Deeter, M. N., and Coauthors, 2013: Validation of MOPITT Version 5 thermal-infrared, near-infrared, and multispectral carbon monoxide profile retrievals for 2000-2011. J. Geophys. Res. Atmos, 118, 6710-6725, doi:10.1002 /jgrd.50272.

de Jong, M. F., and L. de Steur, 2016: Strong winter cooling over the Irminger Sea in winter 2014-2015, exceptional deep convection, and the emergence of anomalously low SST. Geophys. Res. Lett., 43, 7106-7113, doi:10.1002/2016GL069596.

de Lavergne, C., J. B. Palter, E. D. Galbraith, R. Bernardello, and I. Marinov, 2014: Cessation of deep convection in the open Southern Ocean under anthropogenic climate change. Nat. Climate Change, 4, 278-282, doi:10.1038 /nclimate2132.

DeMaria, M., M. Mainelli, L. K. Shay, J. A. Knaff, and J. Kaplan, 2005: Further improvements to the statistical hurricane intensity prediction scheme (SHIPS). Wea. Forecasting, 20, 531-543, doi:10.1175/waf862.1.

de Pablo, M. A., M. Ramos, and A. Molina, 2017: Snow cover evolution, on 2009-2014, at the Limnopolar Lake CALM-S site on Byers Peninsula, Livingston Island, Antarctica. CATENA, 149 Part 2, 538-547, doi:10.1016 /j.catena.2016.06.002.

Derksen, C., R. Brown, L. Mudryk, and K. Luojus, 2016: Terrestrial snow [in "State of the Climate in 2015"]. Bull. Amer. Meteor. Soc., 97 (8), S145-S147, doi:10.1175 /2016BAMSStateoftheClimate.1.

Desbruyères, D. G., S. G. Purkey, E. L. McDonagh, G. C. Johnson, and B. A. King, 2016: Deep and abyssal ocean warming from 35 years of repeat hydrography. Geophys. Res. Lett., 43, 10,356-10,365, doi:10.1002/2016GL070413.

Dewitte, S., D. Crommelynck, and A. Joukoff, 2004: Total solar irradiance observations from DIARAD/VIRGO. J. Geophys. Res., 109, A02102, doi:10.1029/2002JA009694.

Diamond, H. J., Ed., 2013: The tropics [in "State of the Climate in 2012"]. Bull. Amer. Meteor. Soc., 94 (8), S79-S110, doi:10.1175/2013BAMSStateoftheClimate.1.

—, 2014: The tropics [in "State of the Climate in 2013"]. Bull. Amer. Meteor. Soc., 95 (7), S81-S114, doi:10.1175 /2014BAMSStateoftheClimate.1.

—, 2015: The tropics [in "State of the Climate in 2014"]. Bull. Amer. Meteor. Soc., 96 (7), S91-S126, doi:10.1175 /2015BAMSStateoftheClimate.1.

—, and C. J. Schreck III, Eds., 2016: The tropics [in "State of the Climate in 2015”]. Bull. Amer. Meteor. Soc., 97 (8), S93-S130, doi:10.1175/2016BAMSStateoftheClimate.1.

— A. M. Lorrey, K. R. Knapp, and D. H. Levinson, 2012: Development of an enhanced tropical cyclone tracks database for the southwest Pacific from 1840 to 2010. Int. J. Climatol., 32, 2240-2250, doi:10.1002/joc.2412.
Di Girolamo, L., A. Menzies, G. Zhao, K. Mueller, C. Moroney, and D. J. Diner, 2010: Multi-angle imaging spectroradiometer level 3 cloud fraction by altitude algorithm theoretical basis document. JPL Publ. D-62358, 23 pp.

Ding, J., and Coauthors, 2016: The permafrost carbon inventory on the Tibetan Plateau: A new evaluation using deep sediment cores. Global Change Biol., 22, 2688-2701, doi:10.1111/gcb.13257.

Dlugokencky, E. J., E. G. Nisbet, R. Fisher, and D. Lowry, 2011: Global atmospheric methane: Budget, changes and dangers. Philos. Trans. Roy. Soc. London, 369A, 2058-2072, doi:10.1098/rsta.2010.0341.

Dohan, K., G. Goni, and R. Lumpkin, 2015: Surface currents [in "State of the Climate in 2014"]. Bull. Amer. Meteor. Soc., 96 (7), S76-S78, doi:10.1175 /2015BAMSStateoftheClimate.1.

Doherty, R. M., D. S. Stevenson, C. E. Johnson, W. J. Collins, and M. G. Sanderson, 2006: Tropospheric ozone and El Niño-Southern Oscillation: Influence of atmospheric dynamics, biomass burning emissions, and future climate change. J. Geophys. Res., 111, D19304, doi:10.1029/2005JD006849.

Domingues, C. M., J. A. Church, N. J. White, P. J. Gleckler, S. E. Wijffels, P. M. Barker, and J. R. Dunn, 2008: Improved estimates of upper-ocean warming and multi-decadal sea-level rise. Nature, 453, 1090-1093, doi:10.1038 /nature07080.

Domingues, R., and Coauthors, 2015: Upper ocean response to Hurricane Gonzalo (2014): Salinity effects revealed by targeted and sustained underwater glider observations. Geophys. Res. Lett., 42, 7131-7138, doi:10.1002/2015GL065378.

Donat, M. G., L. V. Alexander, H. Yang, I. Durre, R. Vose, and J. Caesar, 2013: Global land-based datasets for monitoring climatic extremes. Bull. Amer. Meteor. Soc., 94, 997-1006, doi:10.1175/bams-d-12-00109.1.

— R. J. H. Dunn, and S. E. Perkins-Kirkpatrick, 2016: Temperature extreme indices [in "State of the Climate in 2015”]. Bull. Amer. Meteor. Soc., 97 (8), S19-S20, doi:10.1 175/2016BAMSStateoftheClimate.1.

Dong, S., M. O. Baringer, G. J. Goni, C. S. Meinen, and S. L. Garzoli, 2014: Seasonal variations in the South Atlantic meridional overturning circulation from observations and numerical models. Geophys. Res. Lett., 41, 4611-4618, doi:10.1002/2014GL060428.

— G. Goni, and F. Bringas, 2015: Temporal variability of the South Atlantic meridional overturning circulation between $20^{\circ} \mathrm{S}$ and $35^{\circ} \mathrm{S}$. Geophys. Res. Lett., 42, 7655-7662, doi:10.1002/2015GL065603.

Dorigo, W. (A.), and R. de Jeu, 2016: Satellite soil moisture for advancing our understanding of Earth system processes and climate change. Int. J. Appl. Earth Obs. Geoinf., 48, 1-4, doi:10.1016/j.jag.2016.02.007. 
- - - - D. Chung, R. Parinussa, Y. Liu, W. Wagner, and D. Fernández-Prieto, 2012: Evaluating global trends (1988-2010) in harmonized multi-satellite surface soil moisture. Geophys. Res. Lett., 39, L18405, doi:10.1029/2012GL052988.

_ , and Coauthors, 2015a: Soil moisture [in "State of the Climate in 2014"]. Bull. Amer. Meteor. Soc., 96 (7), S28S29, doi:10.1175/2015BAMSStateoftheClimate.1.

_- , and Coauthors, 2015b: Evaluation of the ESA CCI soil moisture product using ground-based observations. Remote Sens. Environ., 162, 380-395, doi:10.1016 /j.rse.2014.07.023.

— mate in 2015”]. Bull. Amer. Meteor. Soc., 97 (8), S31-S32, doi:10.1175/2016BAMSStateoftheClimate.1.

Drozdov, D., and Coauthors, 2015: Monitoring of permafrost in Russia and the international GTN-P project. Proc. 68th Canadian Geotechnical Conf. and Seventh Canadian Conf. on Permafrost (GEOQuébec 2015), Quebec, Canada, GEOQuébec 2015, Paper 617.

Duchez, A., and Coauthors, 2014: A new index for the Atlantic meridional overturning circulation at $26^{\circ}$ N. J. Climate, 27, 6439-6455, doi:10.1175/jcli-d-13-00052.1.

—_, and Coauthors, 2016: Drivers of exceptionally cold North Atlantic Ocean temperatures and their link to the 2015 European heat wave. Environ. Res. Lett., 11, 074004, doi:10.1088/1748-9326/11/7/074004.

Dunkerton, T. J., 2016: The quasi-biennial oscillation of 2015-2016: Hiccup or death spiral? Geophys. Res. Lett., 43, 10,547-10,552, doi:10.1002/2016GL070921.

Dunn, R. J. H., and Coauthors, 2012: HadISD: A qualitycontrolled global synoptic report database for selected variables at long-term stations from 1973-2011. Climate Past, 8, 1649-1679, doi:10.5194/cp-8-1649-2012.

_ C. Azorin-Molina, C. A. Mears, P. Berrisford, and T. R. McVicar, 2016a: Surface winds [in "State of the Climate in 2015”]. Bull. Amer. Meteor. Soc., 97 (8), S38-S40, doi :10.1175/2016BAMSStateoftheClimate.1.

— K. M. Willett, D. E. Parker, and L. Mitchell, 2016b: Expanding HadISD: Quality-controlled, sub-daily station data from 1931. Geosci. Instrum. Method. Data Syst., 5, 473-491, doi:10.5194/gi-5-473-2016.

Durack, P. J., S. E. Wijffels, and P. J. Gleckler, 2014: Long-term sea-level change revisited: The role of salinity. Environ. Res. Lett., 9, 114017, doi:10.1088/1748-9326/9/11/114017.

Dutton, E. G., 1992: A coherence between the QBO and the amplitude of the Mauna Loa atmospheric transmission annual cycle. Int. J. Climatol., 12, 383-396, doi:10.1002 /joc.3370120406.
— caused by clear-sky transmission variations above Mauna Loa: 1958-99. J. Climate, 14, 3255-3262, doi:10.1175/1520 -0442 (2001)014<3255:siacbc >2.0.co;2.

_ J. J. Deluisi, and P. Arne, 1985: Interpretation of Mauna Loa atmospheric transmission relative to aerosols, using photometric precipitable water amouts. J. Atmos. Chem., 3, 53-68, doi:10.1007/bf00049368.

Ebita, A., and Coauthors, 2011: The Japanese 55-year reanalysis "JRA-55": An interim report. SOLA, 7, 149-152, doi:10.2151/sola.2011-038.

Edson, J. B., and Coauthors, 2013: On the exchange of momentum over the open ocean. J. Phys. Oceanogr., 43, 1589-1610, doi:10.1175/jpo-d-12-0173.1.

Ekstrom, J. A., and Coauthors, 2015: Vulnerability and adaptation of US shellfisheries to ocean acidification. Nat. Climate Change, 5, 207-214, doi:10.1038/nclimate2508.

Ellis, H. T., and R. F. Pueschel, 1971: Solar radiation: Absence of air pollution trends at Mauna Loa. Science, 172, 845-846, doi:10.1126/science.172.3985.845.

Emanuel, K. A., 1986: An air-sea interaction theory for tropical cyclones. Part I: Steady-state maintenance. J. Atmos. Sci., 43, 585-605, doi:10.1175/1520 -0469(1986)043<0585:aasitf>2.0.co;2.

- - 1988: The maximum intensity of hurricanes. J. Atmos. Sci., 45, 1143-1155, doi:10.1175/1520 -0469(1988)045<1143:tmioh>2.0.co;2.

— the global climate system. Proc. 26th Conf. on Hurricanes and Tropical Meteor., Miami, FL, Amer. Meteor. Soc., 10A.12. [Available online at http://ams.confex.com /ams/26HURR/techprogram/paper_75463.htm.]

Enfield, D. B., and A. M. Mestas-Nuñez, 1999: Multiscale variabilities in global sea surface temperatures and their relationships with tropospheric climate patterns. J. Climate, 12, 2719-2733, doi:10.1175/1520 -0442(1999)012<2719:mvigss >2.0.co;2.

England, M. H., and Coauthors, 2014: Recent intensification of wind-driven circulation in the Pacific and the ongoing warming hiatus. Nat. Climate Change, 4, 222-227, doi:10.1038/nclimate2106.

Epstein, H. E., M. K. Raynolds, D. A. Walker, U. S. Bhatt, C. J. Tucker, and J. E. Pinzon, 2012: Dynamics of aboveground phytomass of the circumpolar Arctic tundra during the past three decades. Environ. Res. Lett., 7, 015506, doi:10.1088/1748-9326/7/1/015506.

Ershadi, A., M. F. McCabe, J. P. Evans, N. W. Chaney, and E. F. Wood, 2014: Multi-site evaluation of terrestrial evaporation models using FLUXNET data. Agric. Forest Meteor., 187, 46-61, doi:10.1016/j.agrformet.2013.11.008. 
Esaias, W. E., and Coauthors, 1998: An overview of MODIS capabilities for ocean science observations. IEEE Trans. Geosci. Remote Sens., 36, 1250-1265, doi:10.1109/36.701076.

Escurra, J. J., V. Vazquez, R. Cestti, E. De Nys, and R. Srinivasan, 2014: Climate change impact on countrywide water balance in Bolivia. Regional Environ. Change, 14, 727-742, doi:10.1007/s10113-013-0534-3.

Estilow, T. W., A. H. Young, and D. A. Robinson, 2015: A long-term Northern Hemisphere snow cover extent data record for climate studies and monitoring. Earth Syst. Sci. Data, 7, 137-142, doi:10.5194/essd-7-137-2015.

Evans, W., and Coauthors, 2015: Sea-air CO2 exchange in the western Arctic coastal ocean. Global Biogeochem. Cycles, 29, 1190-1209, doi:10.1002/2015GB005153.

Ezer, T., L. P. Atkinson, W. B. Corlett, and J. L. Blanco, 2013: Gulf Stream's induced sea level rise and variability along the U.S. mid-Atlantic coast. J. Geophys. Res. Oceans, 118, 685-697, doi:10.1002/jgrc.20091.

Falkowski, P. G., R. T. Barber, and V. Smetacek, 1998: Biogeochemical controls and feedbacks on ocean primary production. Science, 281, 200-206, doi:10.1126 /science.281.5374.200.

Fang, L., C. R. Hain, X. Zhan, and M. C. Anderson, 2016: An inter-comparison of soil moisture data products from satellite remote sensing and a land surface model. Int. J. Appl. Earth Obs. Geoinf., 48, 37-50, doi:10.1016 /j.jag.2015.10.006.

Farbrot, H., K. Isaksen, B. Etzelmüller, and K. Gisnås, 2013: Ground thermal regime and permafrost distribution under a changing climate in northern Norway. Permafr. Periglac. Process., 24, 20-38, doi:10.1002/ppp.1763.

Fasullo, J. T., C. Boening, F. W. Landerer, and R. S. Nerem, 2013: Australia's unique influence on global sea level in 2010-2011. Geophys. Res. Lett., 40, 4368-4373, doi:10.1002/grl.50834.

Fay, G., J. S. Link, and J. A. Hare, 2017: Assessing the effects of ocean acidification in the Northeast US using an endto-end marine ecosystem model. Ecolog. Modell., 347, 1-10, doi:10.1016/j.ecolmodel.2016.12.016.

Fennig, K., A. Andersson, S. Bakan, C.-P. Klepp, and M. Schröder, 2012: Hamburg Ocean Atmosphere Parameters and Fluxes from Satellite Data - HOAPS 3.2 - Monthly Means / 6-Hourly Composites. Satellite Application Facility on Climate Monitoring (CM SAF), doi:10.5676 /EUM_SAF_CM/HOAPS/V001.

Ferraro, A. J., M. Collins, and F. H. Lambert, 2015: A hiatus in the stratosphere? Nat. Climate Change, 5, 497-498, doi:10.1038/nclimate2624.

Fetterer, F., K. Knowles, W. Meier, and M. Savoie, 2002, updated daily: Sea Ice Index. National Snow and Ice Data Center, doi:10.7265/N5QJ7F7W.
Field, C. B., and M. R. Raupach, Eds., 2004: The Global Carbon Cycle: Integrating Humans, Climate, and the Natural World. Island Press, 568 pp.

—, M. J. Behrenfeld, J. T. Randerson, and P. Falkowski, 1998: Primary production of the biosphere: Integrating terrestrial and oceanic components. Science, 281, 237-240, doi:10.1126/science.281.5374.237.

Fioletov, V. E., G. E. Bodeker, A. J. Miller, R. D. McPeters, and R. Stolarski, 2002: Global and zonal total ozone variations estimated from ground-based and satellite measurements: 1964-2000. J. Geophys. Res., 107, 4647, doi:10.1029/2001JD001350.

—_, and Coauthors, 2008: Performance of the groundbased total ozone network assessed using satellite data. J. Geophys. Res., 113, D14313, doi:10.1029/2008JD009809.

Fisher, J. B., K. P. Tu, and D. D. Baldocchi, 2008: Global estimates of the land-atmosphere water flux based on monthly AVHRR and ISLSCP-II data, validated at 16 FLUXNET sites. Remote Sens. Environ., 112, 901-919, doi:10.1016/j.rse.2007.06.025.

Flannigan, M. D., and B. M. Wotton, 2001: Climate, weather and area burned. Forest Fires: Behaviour and Ecological Effects, E. A. Johnson, and K. Miyanishis, Eds., Academic Press, 335-357.

Flato, G., and Coauthors, 2013: Evaluation of climate models. Climate Change 2013: The Physical Science Basis, T. F. Stocker et al., Eds., Cambridge University Press, 741-866.

Flemming, J., and Coauthors, 2017: The CAMS interim reanalysis of carbon monoxide, ozone and aerosol for 20032015. Atmos. Chem. Phys., 17, 1945-1983, doi:10.5194 /acp-17-1945-2017.

Fofonoff, N. P., and E. L. Lewis, 1979: A practical salinity scale. J. Oceanogr. Soc. Japan, 35, 63-64, doi:10.1007 /bf02108283.

Fogarty, M., L. Incze, K. Hayhoe, D. Mountain, and J. Manning, 2008: Potential climate change impacts on Atlantic cod (Gadus morhua) off the northeastern USA. Mitigation Adapt. Strategies Global Change, 13, 453-466, doi:10.1007 /s11027-007-9131-4.

Fogt, R. L., D. H. Bromwich, and K. M. Hines, 2011: Understanding the SAM influence on the South Pacific ENSO teleconnection. Climate Dyn., 36, 1555-1576, doi:10.1007 /s00382-010-0905-0.

Folland, C. K., J. Knight, H. W. Linderholm, D. Fereday, S. Ineson, and J. W. Hurrell, 2009: The summer North Atlantic oscillation: Past, present, and future. J. Climate, 22, 1082-1103, doi:10.1175/2008jcli2459.1.

Foltz, G. R., and K. Balaguru, 2016: Prolonged El Niño conditions in 2014-2015 and the rapid intensification of Hurricane Patricia in the eastern Pacific. Geophys. Res. Lett., 43, 10,347-10,355, doi:10.1002/2016GL070274. 
Font, J., and Coauthors, 2013: SMOS first data analysis for sea surface salinity determination. Int. J. Remote Sens., 34, 3654-3670, doi:10.1080/01431161.2012.716541.

Ford, J. D., and T. Pearce, 2010: What we know, do not know, and need to know about climate change vulnerability in the western Canadian Arctic: A systematic literature review. Environ. Res. Lett., 5, 014008, doi:10.1088/1748 $-9326 / 5 / 1 / 014008$.

Forget, F., and Coauthors, 1999: Improved general circulation models of the Martian atmosphere from the surface to above $80 \mathrm{~km}$. J. Geophys. Res., 104, 24,155-24,175, doi:10.1029/1999JE001025.

Foster, M. J., and A. Heidinger, 2013: PATMOS-x: Results from a diurnally corrected 30 -yr satellite cloud climatology. J. Climate, 26, 414-425, doi:10.1175/jcli-d-11-00666.1.

Frajka-Williams, E., 2015: Estimating the Atlantic overturning at $26^{\circ} \mathrm{N}$ using satellite altimetry and cable measurements. Geophys. Res. Lett., 42, 3458-3464, doi:10.1002/2015GL063220.

_ , and Coauthors, 2016: Compensation between meridional flow components of the Atlantic MOC at $26^{\circ} \mathrm{N}$. Ocean Sci., 12, 481-493, doi:10.5194/os-12-481-2016.

Francis, J. A., and S. J. Vavrus, 2015: Evidence for a wavier jet stream in response to rapid Arctic warming. Environ. Res. Lett., 10, 014005, doi:10.1088/1748-9326/10/1/014005.

Frank, W. M., and P. E. Roundy, 2006: The role of tropical waves in tropical cyclogenesis. Mon. Wea. Rev., 134, 2397-2417, doi:10.1175/mwr3204.1.

Franz, B. A., M. J. Behrenfeld, D. A. Siegel, and P. J. Werdell, 2013: Global ocean phytoplankton [in "State of the Climate in 2012”]. Bull. Amer. Meteor. Soc., 94 (8), S75-S78, doi:10.1175/2013BAMSStateoftheClimate.1.

__, _- _ _, and S. R. Signorini, 2016: Global ocean phytoplankton [in "State of the Climate in 2015"]. Bull. Amer. Meteor. Soc., 97 (8), S87-S89, doi:10.1175 /2016BAMSStateoftheClimate.1.

Free, M., D. J. Seidel, J. K. Angell, J. Lanzante, I. Durre, and T. C. Peterson, 2005: Radiosonde atmospheric temperature products for assessing climate (RATPAC): A new data set of large-area anomaly time series. J. Geophys. Res., 110 , D22101, doi:10.1029/2005JD006169.

Friedland, K. D., and J. A. Hare, 2007: Long-term trends and regime shifts in sea surface temperature on the continental shelf of the northeast United States. Cont. Shelf Res., 27, 2313-2328, doi:10.1016/j.csr.2007.06.001.

Frisch, L. C., J. T. Mathis, N. P. Kettle, and S. F. Trainor, 2015: Gauging perceptions of ocean acidification in Alaska. $\mathrm{Ma}$ rine Policy, 53, 101-110, doi:10.1016/j.marpol.2014.11.022.

Frith, S. M., N. A. Kramarova, R. S. Stolarski, R. D. McPeters, P. K. Bhartia, and G. J. Labow, 2014: Recent changes in total column ozone based on the SBUV version 8.6 merged ozone data set. J. Geophys. Res. Atmos., 119, 9735-9751, doi:10.1002/2014JD021889.
Froidevaux, L., and Coauthors, 2015: Global ozone chemistry and related trace gas data records for the stratosphere (GOZCARDS): Methodology and sample results with a focus on $\mathrm{HCl}, \mathrm{H}_{2} \mathrm{O}$, and $\mathrm{O}_{3}$. Atmos. Chem. Phys., 15, 10,471-10,507, doi:10.5194/acp-15-10471-2015.

Fung, I., J. John, J. Lerner, E. Matthews, M. Prather, L. P. Steele, and P. J. Fraser, 1991: Three-dimensional model synthesis of the global methane cycle. J. Geophys. Res., 96, 13,033-13,065, doi:10.1029/91JD01247.

Gan, T. Y., A. K. Gobena, and Q. Wang, 2007: Precipitation of southwestern Canada: Wavelet, scaling, multifractal analysis, and teleconnection to climate anomalies. J. Geophys. Res., 112, D10110, doi:10.1029/2006JD007157.

Gardner, A. S., and Coauthors, 2011: Sharply increased mass loss from glaciers and ice caps in the Canadian Arctic archipelago. Nature, 473, 357-360, doi:10.1038/nature10089. _, and Coauthors, 2013: A reconciled estimate of glacier contributions to sea level rise: 2003 to 2009. Science, $\mathbf{3 4 0}$, 852-857, doi:10.1126/science.1234532.

Garreaud, R., and Coauthors, 2017: The 2010-2015 mega drought in central Chile: Impacts on regional hydroclimate and vegetation. Hydrol. Earth Syst. Sci. Discuss., 2017, doi:10.5194/hess-2017-191.

Gawarkiewicz, G. G., R. E. Todd, A. J. Plueddemann, M. Andres, and J. P. Manning, 2012: Direct interaction between the Gulf Stream and the shelfbreak south of New England. Sci. Rep., 2, 553, doi:10.1038/srep00553.

GCOS, 2003: The second report on the adequacy of the global observing systems for climate in support of the UNFCCC. GCOS-82 (WMO/TD-1143). World Meteorological Organization, 74 pp. [Available online at http://www.wmo.int /pages/prog/gcos/Publications/gcos-82_2AR.pdf.]

GCOS, 2010: Implementation plan for the global observing system for climate in support of the UNFCCC (2010 Update). GCOS-138 (GOOS-184, GTOS-76, WMO/ TD-1523). World Meteorological Organization, 180 pp. [Available online at http://www.wmo.int/pages/prog/gcos /Publications/gcos-138.pdf.]

Gelaro, R., and Coauthors, 2017: The Modern-Era Retrospective Analysis for Research and Applications, version 2 (MERRA-2). J. Climate, 30, 5419-5454, doi:10.1175 /JCLI-D-16-0758.1.

Gergis, J. L., and A. M. Fowler, 2009: A history of ENSO events since A.D. 1525: Implications for future climate change. Climatic Change, 92, 343-387, doi:10.1007 /s10584-008-9476-z.

Ghilain, N., A. Arboleda, and F. Gellens-Meulenberghs, 2011: Evapotranspiration modelling at large scale using nearreal time MSG SEVIRI derived data. Hydrol. Earth Syst. Sci., 15, 771-786, doi:10.5194/hess-15-771-2011.

Global Carbon Project, cited 2016: Carbon budget and trends 2016. [Available online at http://www .globalcarbonproject.org/carbonbudget/index.htm.] 
Gobron, N., and M. Robustelli, 2013: Monitoring the state of the global terrestrial surfaces. Proc. 2013 ESA Living Planet Symp., Edinburgh, United Kingdom, European Space Agency, SP-722.

_ A. Belward, B. Pinty, and W. Knorr, 2010: Monitoring biosphere vegetation 1998-2009. Geophys. Res. Lett., 37, L15402, doi:10.1029/2010GL043870.

Goldenberg, S. B., and L. J. Shapiro, 1996: Physical mechanisms for the association of El Niño and West African rainfall with Atlantic major hurricane activity. J. Climate, 9, 1169-1187, doi:10.1175/1520-0442(1996)009<1169 :pmftao $>2.0 . c 0 ; 2$.

_- C. W. Landsea, A. M. Mestas-Nuñez, and W. M. Gray, 2001: The recent increase in Atlantic hurricane activity: Causes and implications. Science, 293, 474-479, doi:10.1126/science.1060040.

Goni, G. J., and J. A. Trinanes, 2003: Ocean thermal structure monitoring could aid in the intensity forecast of tropical cyclones. Eos, Trans. Amer. Geophys. Union, 84, 573-578, doi:10.1029/2003EO510001.

— S. Kamholz, S. Garzoli, and D. Olson, 1996: Dynamics of the Brazil-Malvinas confluence based on inverted echo sounders and altimetry. J. Geophys. Res., 101, 16,273-16,289, doi:10.1029/96JC01146.

_—, and Coauthors, 2009: Applications of satellite-derived ocean measurements to tropical cyclone intensity forecasting. Oceanography, 22 (3), 190-197, doi:10.5670 loceanog.2009.78.

—, G. J., F. Bringas, and P. N. DiNezio, 2011: Observed low frequency variability of the Brazil Current front. J. Geophys. Res., 116, C10037, doi:10.1029/2011JC007198.

__, J. A. Knaff, and I-I Lin, 2016: Tropical cyclone heat potential [in "State of the Climate in 2015"]. Bull. Amer. Meteor. Soc., 97 (8), S120-S123, doi:10.1175 /2016BAMSStateoftheClimate.1.

Goni, J. G., and J. A. Knaff, 2009: Tropical cyclone heat potential [in "State of the Climate in 2008"]. Bull. Amer. Meteor. Soc., 90 (8), S54-S56, doi:10.1175 /BAMS-90-8-StateoftheClimate.

Gorham, E., 1991: Northern peatlands: Role in the carbon cycle and probable responses to climatic warming. Ecol. Appl., 1, 182-195, doi:10.2307/1941811.

Graglia, E., R. Julkunen-Tiitto, G. R. Shaver, I. K. Schmidt, S. Jonasson, and A. Michelsen, 2001: Environmental control and intersite variations of phenolics in Betula nana in tundra ecosystems. New Phytologist, 151, 227-236, doi:10.1046/j.1469-8137.2001.00149.x.

Granier, C., and Coauthors, 2011: Evolution of anthropogenic and biomass burning emissions of air pollutants at global and regional scales during the 1980-2010 period. Climatic Change, 109, 163, doi:10.1007/s10584-011-0154-1.
Gray, W. M., 1968: Global view of the origin of tropical disturbances and storms. Mon. Wea. Rev., 96, 669-700, doi:10.1175/1520-0493(1968)096<0669:gvotoo>2.0.co;2.

Grosse, G., S. Goetz, A. D. McGuire, V. E. Romanovsky, and E. A. G. Schuur, 2016: Changing permafrost in a warming world and feedbacks to the Earth system. Environ. Res. Lett., 11, 040201, doi:10.1088/1748-9326/11/4/04021.

Guglielmin, M., M. R. Balks, and K. Seybold, 2016: Permafrost thermal snapshot: Marble Point and Wright Valley, Ross Sea Region, Antarctica. XI. Int. Conf. Permafrost, Potsdam, Germany, Bibliothek Wissenschaftspark Albert Einstein.

Guhathakurta, P., M. Rajeevan, D. R. Sikka, and A. Tyagi, 2015: Observed changes in southwest monsoon rainfall over India during 1901-2011. Int. J. Climatol., 35, 18811898, doi:10.1002/joc.4095.

Guo, Y., X. Jiang, and D. E. Waliser, 2014: Modulation of the convectively coupled Kelvin waves over South America and the tropical Atlantic Ocean in association with the Madden-Julian oscillation. J. Atmos. Sci., 71, 1371-1388, doi:10.1175/jas-d-13-0215.1.

Haas, C., S. Hendricks, H. Eicken, and A. Herber, 2010: Synoptic airborne thickness surveys reveal state of Arctic sea ice cover. Geophys. Res. Lett., 37, L09501, doi:10.1029/2010GL042652.

Haeberli, W., J. Cihlar, and R. G. Barry, 2000: Glacier monitoring within the Global Climate Observing System. Ann. Glaciol., 31, 241-246, doi:10.3189/172756400781820192.

Haimberger, L., C. Tavolato, and S. Sperka, 2012: Homogenization of the global radiosonde temperature dataset through combined comparison with reanalysis background series and neighboring stations. J. Climate, 25, 8108-8131, doi:10.1175/jcli-d-11-00668.1.

Halpert, M. S., and C. F. Ropelewski, 1992: Surface temperature patterns associated with the southern oscillation. J. Climate, 5, 577-593, doi:10.1175/1520 -0442(1992)005<0577:stpawt>2.0.co;2.

Hamlington, B. D., M. W. Strassburg, R. R. Leben, W. Han, R. S. Nerem, and K. Y. Kim, 2014: Uncovering an anthropogenic sea-level rise signal in the Pacific Ocean. Nat. Climate Change, 4, 782-785, doi:10.1038/nclimate2307.

—, S. H. Cheon, P. R. Thompson, M. A. Merrifield, R. S. Nerem, R. R. Leben, and K. Y. Kim, 2016: An ongoing shift in Pacific Ocean sea level. J. Geophys. Res. Oceans, 121, 5084-5097, doi:10.1002/2016JC011815.

Hanna, E., J. M. Jones, J. Cappelen, S. H. Mernild, L. Wood, K. Steffen, and P. Huybrechts, 2013: The influence of North Atlantic atmospheric and oceanic forcing effects on 1900-2010 Greenland summer climate and ice melt/ runoff. Int. J. Climatol., 33, 862-880, doi:10.1002/joc.3475. 
Hansen, J., R. Ruedy, M. Sato, and K. Lo, 2010: Global surface temperature change. Rev. Geophys., 48, RG4004, doi:10.1029/2010RG000345.

— ment of negative CO2 emissions. Earth Syst. Dyn. Discuss., 2016, 1-40, doi:10.5194/esd-2016-42.

Hare, J. A., M. A. Alexander, M. J. Fogarty, E. H. Williams, and J. D. Scott, 2010: Forecasting the dynamics of a coastal fishery species using a coupled climate-population model. Ecolog. Appl., 20, 452-464, doi:10.1890/08-1863.1.

_ , and Coauthors, 2016: Northeast regional action planNOAA Fisheries climate science strategy. NOAA Tech. Memo. NMFS-NE-239, 94 pp. [Available online at http:// www.nefsc.noaa.gov/publications/tm/tm239/.]

Harris, J. M., and J. D. Kahl, 1990: A descriptive atmospheric transport climatology for the Mauna Loa Observatory, using clustered trajectories. J. Geophys. Res., 95, 13,65113,667, doi:10.1029/JD095iD09p13651.

Harris, N. R. P., and Coauthors, 2014: Scenarios and information for policymakers. Scientific Assessment of Ozone Depletion: 2014, World Meteorological Organization, 5.1-5.58.

Harrison, D. E., and N. K. Larkin, 1998: Seasonal U.S. temperature and precipitation anomalies associated with El Niño: Historical results and comparison with 1997-98. Geophys. Res. Lett., 25, 3959-3962, doi:10.1029/1998GL900061.

Hart, R. E., D. R. Chavas, and M. P. Guishard, 2016: The arbitrary definition of the current Atlantic major hurricane landfall drought. Bull. Amer. Meteor. Soc., 97, 713-722, doi:10.1175/bams-d-15-00185.1.

Hartmann, D. L., and Coauthors, 2013: Observations: Atmosphere and surface. Climate Change 2013: The Physical Science Basis, T. F. Stocker et al., Eds., Cambridge University Press, 159-254.

Hausfather, Z., K. Cowtan, D. C. Clarke, P. Jacobs, M. Richardson, and R. Rohde, 2017: Assessing recent warming using instrumentally homogeneous sea surface temperature records. Sci. Adv., 3, e1601207, doi:10.1126/sciadv.1601207.

Haylock, M. R., N. Hofstra, A. M. G. Klein Tank, E. J. Klok, P. D. Jones, and M. New, 2008: A European daily highresolution gridded data set of surface temperature and precipitation for 1950-2006. J. Geophys. Res., 113, D20119, doi:10.1029/2008JD010201.

Heidinger, A. K., M. J. Foster, A. Walther, and X. Zhao, 2014: The Pathfinder atmospheres-extended AVHRR climate dataset. Bull. Amer. Meteor. Soc., 95, 909-922, doi:10.1175 /bams-d-12-00246.1.

Held, I. M., and B. J. Soden, 2000: Water vapor feedback and global warming. Annu. Rev. Energy Environ., 25, 441-475, doi:10.1146/annurev.energy.25.1.441.
Helfrich, S. R., D. McNamara, B. H. Ramsay, T. Baldwin, and T. Kasheta, 2007: Enhancements to, and forthcoming developments in the Interactive Multisensor Snow and Ice Mapping System (IMS). Hydrol. Proc., 21, 1576-1586, doi:10.1002/hyp.6720.

Hendon, H. H., C. Zhang, and J. D. Glick, 1999: Interannual variation of the Madden-Julian oscillation during austral summer. J. Climate, 12, 2538-2550, doi:10.1175/1520 -0442(1999)012<2538:ivotmj>2.0.co;2.

Hersbach, H., and Coauthors, 2017: The potential value of early (1939-1967) upper-air data in atmospheric climate reanalysis. Quart. J. Roy. Meteor. Soc., 143, 1197-1210, doi:10.1002/qj.3040.

Higgins, R. W., A. Leetmaa, and V. E. Kousky, 2002: Relationships between climate variability and winter temperature extremes in the United States. J. Climate, 15, 1555-1572, doi:10.1175/1520-0442(2002)015<1555:rbcvaw>2.0.co;2.

Ho, S.-P., Y.-H. Kuo, W. Schreiner, and X. Zhou, 2010a: Using SI-traceable global positioning system radio occultation measurements for climate monitoring [in "State of the Climate in 2009"]. Bull. Amer. Meteor. Soc., 91 (7), S36-S37, doi:10.1175/BAMS-91-7-StateoftheClimate.

— X. Zhou, Y.-H. Kuo, D. Hunt, and J.-H. Wang, 2010b: Global evaluation of radiosonde water vapor systematic biases using GPS radio cccultation from COSMIC and ECMWF analysis. Remote Sens. Environ., 2, 1320-1330, doi:10.3390/rs2051320.

Hobbs, W. R., and J. K. Willis, 2012: Midlatitude North Atlantic heat transport: A time series based on satellite and drifter data. J. Geophys. Res., 117, C01008, doi:10.1029/2011JC007039.

Hoffman, M. J., and Coauthors, 2010: An ensemble Kalman filter data assimilation system for the Martian atmosphere: Implementation and simulation experiments. Icarus, 209, 470-481, doi:10.1016/j.icarus.2010.03.034.

Hofmann, D. J., and S. A. Montzka, 2009: Recovery of the ozone layer: The ozone depleting gas index. Eos, Trans. Amer. Geophys. Union, 90, 1-2, doi:10.1029/2009EO010001.

_ J. J. H. Butler, E. J. Dlugokencky, J. W. Elkins, K. Masarie, S. A. Montzka, and P. Tans, 2006: The role of carbon dioxide in climate forcing from 1979 to 2004: Introduction of the annual greenhouse gas index. Tellus, 58B, 614-619, doi:10.1111/j.1600-0889.2006.00201.x.

Hogewind, F., and P. Bissolli, 2011: Operational maps of monthly mean temperature for WMO Region VI (Europe and Middle East). Idöjárás, J. Hungarian Meteor. Soc., 115, 31-49. [Available online at http://www.met.hu /downloads.php?fn=/metadmin/newspaper/2012/06/115 -1-2-3-hogewind.pdf.]

Holland, D. M., 2000: Transient sea-ice polynya forced by oceanic flow variability. Prog. Oceanogr., 48, 403-460, doi:10.1016/S0079-6611(01)00010-6. 
Hook, S. R., R. C. Wilson, S. MacCallum, and C. J. Merchant, 2012: Lake surface temperature [in"State of the Climate in 2011"]. Bull. Amer. Meteor. Soc., 93 (7), S18-S19, doi :10.1175/2012BAMSStateoftheClimate.1.

Hrbáček, F., K. Láska, D. Nývlt, Z. Engel, and M. Oliva, 2016: Active layer thickness variability on James Ross Island, Eastern Antarctic Peninsula. XI. Int. Conf Permafrost, Potsdam, Germany, Bibliothek Wissenschaftspark Albert Einstein.

Huang, B., and Coauthors, 2015: Extended reconstructed sea surface temperature version 4 (ERSST.v4). Part I: Upgrades and intercomparisons. J. Climate, 28, 911-930, doi:10.1175/jcli-d-14-00006.1.

_- M. L'Heureux, Z.-Z. Hu, and H.-M. Zhang, 2016a: Ranking the strongest ENSO events while incorporating SST uncertainty. Geophys. Res. Lett., 43, 9165-9172, doi:10.1002/2016GL070888.

— , and Coauthors, 2016b: Further exploring and quantifying uncertainties for extended reconstructed sea surface temperature (ERSST) version 4 (v4). J. Climate, 29, 3119-3142, doi:10.1175/jcli-d-15-0430.1.

Huang, C.-Y., W.-H. Teng, S.-P. Ho, and Y.-H. Kuo, 2013: Global variation of COSMIC precipitable water over land: Comparisons with ground-based GPS measurements and NCEP reanalyses. Geophys. Res. Lett., 40, 5327-5331, doi:10.1002/grl.50885.

Huffman, G. J., R. F. Adler, D. T. Bolvin, and G. Gu, 2009: Improving the global precipitation record: GPCP Version 2.1. Geophys. Res. Lett., 36, L17808, doi:10.1029/2009GL040000.

Hugelius, G., and Coauthors, 2014: Estimated stocks of circumpolar permafrost carbon with quantified uncertainty ranges and identified data gaps. Biogeosciences, 11, 6573-6593, doi:10.5194/bg-11-6573-2014.

Huisman, J., H. C. P. Matthijs, and P. M. Visser, Eds., 2005: Harmful Cyanobacteria. Springer, 243 pp.

Hupp, J. W., D. H. Ward, M. E. Whalen, and J. M. Pearce, 2015: Changing Arctic ecosystems-What is causing the rapid increase of snow geese in northern Alaska? U.S. Geologic Survey Fact Sheet 2015-3062, 2 pp.

Isaksen, K., and Coauthors, 2011: Degrading mountain permafrost in southern Norway: Spatial and temporal variability of mean ground temperatures, 1999-2009. Permafr. Periglac. Process., 22, 361-377, doi:10.1002/ppp.728.

Ishihara, K., 2006: Calculation of global surface temperature anomalies with COBE-SST. Sokko-jiho [Weather Service Bull.], 73 (Special Issue), S19-S25, (in Japanese).

Ishii, M., and M. Kimoto, 2009: Reevaluation of historical ocean heat content variations with time-varying XBT and MBT depth bias corrections. J. Oceanogr., 65, 287-299, doi:10.1007/s10872-009-0027-7.
Jacob, T., J. Wahr, W. T. Pfeffer, and S. Swenson, 2012: Recent contributions of glaciers and ice caps to sea level rise. Nature, 482, 514-518, doi:10.1038/nature10847.

Jacobson, A. R., S. E. Mikaloff Fletcher, N. Gruber, J. L. Sarmiento, and M. Gloor, 2007: A joint atmosphere-ocean inversion for surface fluxes of carbon dioxide: 1 . Methods and global-scale fluxes. Global Biogeochem. Cycles, 21, GB1019, doi:10.1029/2005GB002556.

Janowiak, J. E., and P. Xie, 1999: CAMS-OPI: A global satellite-rain gauge merged product for real-time precipitation monitoring applications. J. Climate, 12, 3335-3342, doi:10.1175/1520-0442(1999)012<3335:coagsr>2.0.co;2.

Jiménez-Muñoz, J. C., and Coauthors, 2016: Record-breaking warming and extreme drought in the Amazon rainforest during the course of El Niño 2015-2016. Sci. Rep., 6, 33130, doi:10.1038/srep33130.

Jin, X., and L. Yu, 2013: Assessing high-resolution analysis of surface heat fluxes in the Gulf Stream region. J. Geophys. Res. Oceans, 118, 5353-5375, doi:10.1002/jgrc.20386.

Jobbágy, E. G., and R. B. Jackson, 2000: The vertical distribution of soil organic carbon and its relation to climate and vegetation. Ecol. Appl., 10, 423-436, doi:10.1890/1051 -0761(2000)010[0423:TVDOSO]2.0.CO;2.

John, V. O., and B. J. Soden, 2007: Temperature and humidity biases in global climate models and their impact on climate feedbacks. Geophys. Res. Lett., 34, L18704, doi:10.1029/2007GL030429.

—, G. Holl, R. P. Allan, S. A. Buehler, D. E. Parker, and B. J. Soden, 2011: Clear-sky biases in satellite infrared estimates of upper tropospheric humidity and its trends. J. Geophys. Res. , 116, D14108, doi:10.1029/2010JD015355.

_-, L. Shi, and E.-S. Chung, 2016: Upper tropospheric humidity [in "State of the Climate in 2015"]. Bull. Amer. Meteor. Soc., 97 (8), S27, doi:10.1175 /2016BAMSStateoftheClimate.1.

Johns, W. E., and Coauthors, 2011: Continuous, array-based estimates of Atlantic Ocean heat transport at $26.5^{\circ} \mathrm{N}$. J. Climate, 24, 2429-2449, doi:10.1175/2010jcli3997.1.

Johnson, G. C., 2008: Quantifying Antarctic bottom water and North Atlantic Deep Water volumes. J. Geophys. Res., 113, C05027, doi:10.1029/2007JC004477.

_ of the Climate in 2011”]. Bull. Amer. Meteor. Soc., 93 (7), S68-S69, S72, doi:10.1175/2012BAMSStateoftheClimate.1.

—_ and A. N. Birnbaum, 2017: As El Niño builds, Pacific warm pool expands, ocean gains more heat. Geophys. Res. Lett., 44, 438-445, doi:10.1002/2016GL071767.

— the Climate in 2013"]. Bull. Amer. Meteor. Soc., 93 (7), S54-S57, doi:10.1175/2013BAMSStateoftheClimate.1. 
_ and Coauthors, 2015a: Ocean heat content [in "State of the Climate in 2014"]. Bull. Amer. Meteor. Soc., 96 (7), S64-S66, S68, doi:10.1175/2014BAMSStateoftheClimate.1.

_ J. M. Lyman, and S. G. Purkey, 2015b: Informing Deep Argo array design using Argo and full-depth hydrographic section data. J. Atmos. Oceanic Technol., 32, 2187-2198, doi:10.1175/jtech-d-15-0139.1.

_ and Coauthors, 2016: Ocean heat content [in "State of the Climate in 2015"]. Bull. Amer. Meteor. Soc., 96 (7), S66-S70, doi:10.1175/2015BAMSStateoftheClimate.1.

Jones, P. D., D. H. Lister, T. J. Osborn, C. Harpham, M. Salmon, and C. P. Morice, 2012: Hemispheric and largescale land-surface air temperature variations: An extensive revision and an update to 2010. J. Geophys. Res., 117, D05127, doi:10.1029/2011JD017139.

Joyce, R. J., J. E. Janowiak, P. A. Arkin, and P. Xie, 2004: CMORPH: A method that produces global precipitation estimates from passive microwave and infrared data at high spatial and temporal resolution. J. Hydrometeor., 5, 487-503, doi:10.1175/1525-7541(2004)005<0487 :camtpg >2.0.co;2.

Jung, M., and Coauthors, 2010: Recent decline in the global land evapotranspiration trend due to limited moisture supply. Nature, 467, 951-954, doi:10.1038/nature09396.

Kaiser, J. W., and Coauthors, 2012: Biomass burning emissions estimated with a global fire assimilation system based on observed fire radiative power. Biogeosciences, 9, 527-554, doi:10.5194/bg-9-527-2012.

Kalnay, E., and Coauthors, 1996: The NCEP/NCAR 40-year reanalysis project. Bull. Amer. Meteor. Soc., 77, 437-471, doi:10.1175/1520-0477(1996)077<0437:tnyrp>2.0.co;2.

Kaplan, A., 2011: Patterns and indices of climate variability [in"State of the Climate in 2010"]. Bull. Amer. Meteor. Soc., 92 (6), S20-S25, doi:10.1175/1520-0477-92.6.s1.

Karl, T. R., and Coauthors, 2015: Possible artifacts of data biases in the recent global surface warming hiatus. Science, 348, 1469-1472, doi:10.1126/science.aaa5632.

Karlsson, K. G., and Coauthors, 2017: CLARA-A2: The second edition of the CM SAF cloud and radiation data record from 34 years of global AVHRR data. Atmos. Chem. Phys., 17, 5809-5828, doi:10.5194/acp-17-5809-2017.

Kass, D. M., A. Kleinböhl, D. J. McCleese, J. T. Schofield, and M. D. Smith, 2016: Interannual similarity in the Martian atmosphere during the dust storm season. Geophys. Res. Lett., 43, 6111-6118, doi:10.1002/2016GL068978.

Kato, S., and Coauthors, 2013: Surface irradiances consistent with CERES-derived top-of-atmosphere shortwave and longwave irradiances. J. Climate, 26, 2719-2740, doi:10.1175/jcli-d-12-00436.1.

Kayano, M. T., and V. E. Kousky, 1999: Intraseasonal (30-60 day) variability in the global tropics: Principal modes and their evolution. Tellus, 51A, 373-386, doi:10.3402/tellusa .v51i3.13459.
Kennedy, J. J., and Coauthors, 2010: How do we know the world has warmed? [in "State of the Climate in 2009"]. Bull. Amer. Meteor. Soc., 91 (7), S26-S27, doi:10.1175 /BAMS-91-7-StateoftheClimate.

— N. A. Rayner, R. O. Smith, D. E. Parker, and M. Saunby, 2011a: Reassessing biases and other uncertainties in sea surface temperature observations measured in situ since 1850: 1. Measurement and sampling uncertainties. J. Geophys. Res., 116, D14103, doi:10.1029/2010JD015218.

—_, —_, _ _ _, and ——, 2011b: Reassessing biases and other uncertainties in sea surface temperature observations measured in situ since 1850: 2. Biases and homogenization. J. Geophys. Res., 116, D14104, doi:10.1029/2010JD015220.

Kent, E. C., D. I. Berry, J. Prytherch, and J. B. Roberts, 2014: A comparison of global marine surface-specific humidity datasets from in situ observations and atmospheric reanalysis. Int. J. Climatol., 34, 355-376, doi:10.1002 /joc.3691.

Khatiwala, S., and Coauthors, 2013: Global ocean storage of anthropogenic carbon. Biogeosciences, 10, 2169-2191, doi:10.5194/bg-10-2169-2013.

Kiladis, G. N., and K. M. Weickmann, 1992: Circulation anomalies associated with tropical convection during northern winter. Mon. Wea. Rev., 120, 1900-1923, doi:10.1175/1520-0493(1992)120<1900:caawtc >2.0.co;2.

— K. H. Straub, and P. T. Haertel, 2005: Zonal and vertical structure of the Madden-Julian oscillation. J. Atmos. Sci., 62, 2790-2809, doi:10.1175/jas3520.1.

—, M. C. Wheeler, P. T. Haertel, K. H. Straub, and P. E. Roundy, 2009: Convectively coupled equatorial waves. Rev. Geophys., 47, RG2003, doi:10.1029/2008RG000266.

Kim, B.-M., and Coauthors, 2017: Major cause of unprecedented Arctic warming in January 2016: Critical role of an Atlantic windstorm. Sci. Rep., 7, 40051, doi:10.1038 /srep40051.

Kim, H., 2016: River discharge [in "State of the Climate in 2015”]. Bull. Amer. Meteor. Soc., 97 (8), S29-S30, doi:10 .1175/2016BAMSStateoftheClimate.1.

— , P. J. F. Yeh, T. Oki, and S. Kanae, 2009: Role of rivers in the seasonal variations of terrestrial water storage over global basins. Geophys. Res. Lett., 36, L17402, doi:10.1029/2009GL039006.

Kim, J., and K. Paik, 2015: Recent recovery of surface wind speed after decadal decrease: A focus on South Korea. Climate Dyn., 45, 1699-1712, doi:10.1007/s00382-015-2546-9.

Kimura, N., and M. Wakatsuchi, 2011: Large-scale processes governing the seasonal variability of the Antarctic sea ice. Tellus, 63A, 828-840, doi:10.1111/j.1600 $-0870.2011 .00526 . x$ 
Kistler, R., and Coauthors, 2001: The NCEP-NCAR 50-year reanalysis: Monthly means CD-ROM and documentation. Bull. Amer. Meteor. Soc., 82, 247-267, doi:10.1175/1520-0477(2001)082<0247:tnnyrm >2.3.co;2.

Kjøllmoen, B., (Ed.), L. M. Andreassen, H. Elvehøy, M. Jackson, and R. H. Giesen, 2016: Glaciological investigations in Norway (Glasiologiske undersøkelser i Norge). NVE Rapport 88, 171+ pp. [Available online at http:// publikasjoner.nve.no/rapport/2016/rapport2016_88.pdf.]

Klein, S. A., B. J. Soden, and N.-C. Lau, 1999: Remote sea surface temperature variations during ENSO: Evidence for a tropical atmospheric bridge. J. Climate, 12, 917-932, doi:10.1175/1520-0442(1999)012<0917:rsstvd >2.0.co;2.

Kleinböhl, A., and Coauthors, 2009: Mars Climate Sounder limb profile retrieval of atmospheric temperature, pressure, and dust and water ice opacity. J. Geophys. Res., 114, E10006, doi:10.1029/2009JE003358.

— J. T. Schofield, W. A. Abdou, P. G. J. Irwin, and R. J. de Kok, 2011: A single-scattering approximation for infrared radiative transfer in limb geometry in the Martian atmosphere. J. Quant. Spectrosc. Radiat. Transfer, 112, 1568-1580, doi:10.1016/j.jqsrt.2011.03.006.

— A. J. Friedson, and J. T. Schofield, 2017: Two-dimensional radiative transfer for the retrieval of limb emission measurements in the martian atmosphere. J. Quant. Spectrosc. Radiat. Transfer, 187, 511-522, doi:10.1016 /j.jqsrt.2016.07.009.

Kleisner, K. M., and Coauthors, 2016: The effects of subregional climate velocity on the distribution and spatial extent of marine species assemblages. PLoS One, 11, e0149220, doi:10.1371/journal.pone.0149220.

Knapp, K. R., M. C. Kruk, D. H. Levinson, H. J. Diamond, and C. J. Neumann, 2010: The international best track archive for climate stewardship (IBTrACS). Bull. Amer. Meteor. Soc., 91, 363-376, doi:10.1175/2009bams2755.1.

— J. A. Knaff, C. R. Sampson, G. M. Riggio, and A. D. Schnapp, 2013: A pressure-based analysis of the historical western North Pacific tropical cyclone intensity record. Mon. Wea. Rev., 141, 2611-2631, doi:10.1175 /mwr-d-12-00323.1.

Knutson, T. R., and K. M. Weickmann, 1987: 30-60 Day atmospheric oscillations: Composite life cycles of convection and circulation anomalies. Mon. Wea. Rev., 115, 1407-1436, doi:10.1175/1520-0493(1987)115<1407 :daoclc $>2.0 . c 0 ; 2$.

Ko, M. K. W., P. A. Newman, S. Reimann, and S. E. Strahan, 2013: Recommended values for steady-state atmospheric lifetimes and their uncertainties. SPARC Report on the Lifetimes of Stratospheric Ozone-Depleting Substances, Their Replacements, and Related Species, 6.1-6.21.

Kobayashi, S., and Coauthors, 2015: The JRA-55 reanalysis: General specifications and basic characteristics. J. Meteor. Soc. Japan, 93, 5-48, doi:10.2151/jmsj.2015-001.
Kopp, G., and J. L. Lean, 2011: A new, lower value of total solar irradiance: Evidence and climate significance. Geophys. Res. Lett., 38, L01706, doi:10.1029/2010GL045777.

Kossin, J. P., and D. J. Vimont, 2007: A more general framework for understanding Atlantic hurricane variability and trends. Bull. Amer. Meteor. Soc., 88, 1767-1781, doi:10.1175/bams-88-11-1767.

Kosten, S., and Coauthors, 2012: Warmer climates boost cyanobacterial dominance in shallow lakes. Global Change Biol., 18, 118-126, doi:10.1111/j.1365-2486.2011.02488.x.

Koumoutsaris, S., I. Bey, S. Generoso, and V. Thouret, 2008: Influence of El Niño-Southern Oscillation on the interannual variability of tropospheric ozone in the northern midlatitudes. J. Geophys. Res., 113, D19301, doi:10.1029/2007JD009753.

Kousky, V. E., and M. T. Kayano, 1994: Principal modes of outgoing longwave radiation and $250-\mathrm{mb}$ circulation for the South American sector. J. Climate, 7, 1131-1143, doi:10.1175/1520-0442(1994)007<1131:pmoolr>2.0.co;2.

Kratz, D. P., P. W. S. Jr., S. K. Gupta, A. C. Wilber, P. Sawaengphokhai, and G. R. McGarragh, 2014: The fast longwave and shortwave flux (FLASHFlux) data product: Singlescanner footprint fluxes. J. Appl. Meteor Climatol., 53, 1059-1079, doi:10.1175/jamc-d-13-061.1.

Krishnamurti, T. N., and D. Subrahmanyam, 1982: The 30-50 day mode at $850 \mathrm{mb}$ during MONEX. J. Atmos. Sci., 39, 2088-2095, doi:10.1175/1520-0469(1982)039<2088 :TDMAMD $>2.0 . \mathrm{CO} ; 2$.

Kwok, R., and D. A. Rothrock, 2009: Decline in Arctic sea ice thickness from submarine and ICESat records: 1958-2008. Geophys. Res. Lett., 36, L15501, doi:10.1029/2009GL039035.

—_, and G. F. Cunningham, 2015: Variability of Arctic sea ice thickness and volume from CryoSat-2. Philos. Trans. Roy. Soc. London, 373A, 20140157, doi:10.1098 /rsta.2014.0157.

L'Heureux, M. L., and Coauthors, 2016: Observing and predicting the 2015-16 El Niño. Bull. Amer. Meteor. Soc. Early Online Release, doi:10.1175/bams-d-16-0009.1.

Landschützer, P., and Coauthors, 2013: A neural networkbased estimate of the seasonal to inter-annual variability of the Atlantic Ocean carbon sink. Biogeosciences, 10, 7793-7815, doi:10.5194/bg-10-7793-2013.

— N. Gruber, D. C. E. Bakker, and U. Schuster, 2014: Recent variability of the global ocean carbon sink. Global Biogeochem. Cycles, 28, 927-949, doi:10.1002/2014GB004853.

Landsea, C. W., and J. L. Franklin, 2013: Atlantic hurricane database uncertainty and presentation of a new database format. Mon. Wea. Rev., 141, 3576-3592, doi:10.1175 /mwr-d-12-00254.1.

Lau, W. K.-M., and D. E. Waliser, 2012: Intraseasonal Variability in the Atmosphere-Ocean Climate System. Springer, $642 \mathrm{pp}$. 
Laxon, S. W., and Coauthors, 2013: CryoSat-2 estimates of Arctic sea ice thickness and volume. Geophys. Res. Lett., 40, 732-737, doi:10.1002/grl.50193.

Lazzara, M. A., G. A. Weidner, L. M. Keller, J. E. Thom, and J. J. Cassano, 2012: Antarctic automatic weather station program: 30 years of polar observation. Bull. Amer. Meteor. Soc., 93, 1519-1537, doi:10.1175/bams-d-11-00015.1.

Lee, H.-T., 2014: Climate algorithm theoretical basis document (C-ATBD): Outgoing longwave radiation (OLR) - daily. NOAA's Climate Data Record (CDR) Program, CDRP-ATBD-0526, 46 pp. [Available online at http:// www1.ncdc.noaa.gov/pub/data/sds/cdr/CDRs /Outgoing\%20Longwave\%20Radiation\%20-\%20Daily /AlgorithmDescription.pdf.]

— Record (CDR) of Monthly Outgoing Longwave Radiation (OLR), Version 2.2-1. Feb 2000-Dec 2015. NOAA National Centers for Environmental Information, doi:10.7289 /V5222RQP.

Lenaerts, J. T. M., and M. R. van den Broeke, 2012: Modeling drifting snow in Antarctica with a regional climate model: 2. Results. J. Geophys. Res., 117, D05109, doi:10.1029/2010JD015419.

Lentini, C. A. D., G. J. Goni, and D. B. Olson, 2006: Investigation of Brazil Current rings in the confluence region. J. Geophys. Res., 111, C06013, doi:10.1029/2005JC002988.

Le Quéré, C., and Coauthors, 2016: Global carbon budget 2016. Earth Syst. Sci. Data, 8, 605-649, doi:10.5194 lessd-8-605-2016.

Leuliette, E. W., 2015: The balancing of the sea-level budget. Current Climate Change Reports, 1, 185-191, doi:10.1007 /s40641-015-0012-8.

—-, and J. K. Willis, 2011: Balancing the sea level budget. Oceanography, 24 (2), 122-129, doi:10.5670 /oceanog.2011.32.

Leung, F.-Y. T., J. A. Logan, R. Park, E. Hyer, E. Kasischke, D. Streets, and L. Yurganov, 2007: Impacts of enhanced biomass burning in the boreal forests in 1998 on tropospheric chemistry and the sensitivity of model results to the injection height of emissions. J. Geophys. Res., 112 , D10313, doi:10.1029/2006JD008132.

Le Vine, D. M., E. P. Dinnat, G. S. E. Lagerloef, P. de Matthaeis, S. Abraham, C. Utku, and H. Kao, 2014: Aquarius: Status and recent results. Radio Science, 49, 709-720, doi:10.1002/2014RS005505.

Levitus, S., and Coauthors, 2012: World ocean heat content and thermosteric sea level change (0-2000 m), 1955-2010. Geophys. Res. Lett., 39, L10603, doi:10.1029/2012GL051106.

Levy, R. C., S. Mattoo, L. A. Munchak, L. A. Remer, A. M. Sayer, F. Patadia, and N. C. Hsu, 2013: The Collection 6 MODIS aerosol products over land and ocean. Atmos. Meas. Tech., 6, 2989-3034, doi:10.5194/amt-6-2989-2013.
Lewis, S. R., P. L. Read, B. J. Conrath, J. C. Pearl, and M. D. Smith, 2007: Assimilation of thermal emission spectrometer atmospheric data during the Mars Global Surveyor aerobraking period. Icarus, 192, 327-347, doi:10.1016 /j.icarus.2007.08.009.

— D. P. Mulholland, P. L. Read, L. Montabone, R. J. Wilson, and M. D. Smith, 2016: The solsticial pause on Mars: 1. A planetary wave reanalysis. Icarus, 264, 456-464, doi:10.1016/j.icarus.2015.08.039.

Li, B., M. Rodell, and J. S. Famiglietti, 2015: Groundwater variability across temporal and spatial scales in the central and northeastern U.S. J. Hydrol., 525, 769-780, doi:10.1016/j.jhydrol.2015.04.033.

Liebmann, B., and C. A. Smith, 1996: Description of a complete (interpolated) outgoing longwave radiation dataset. Bull. Amer. Meteor. Soc., 77, 1275-1277.

Lin, H., G. Brunet, and J. Derome, 2009: An observed connection between the North Atlantic oscillation and the Madden-Julian oscillation. J. Climate, 22, 364-380, doi:10.1175/2008jcli2515.1. Lin, I-I, and J. C. L. Chan, 2015: Recent decrease in typhoon destructive potential and global warming implications. Nat. Comm., 6, 7182, doi:10.1038/ncomms8182.

_C.-C. Wu, I.-F. Pun, and D.-S. Ko, 2008: Upper-ocean thermal structure and the western North Pacific category 5 Typhoons. Part I: Ocean features and the category 5 typhoons' intensification. Mon. Wea. Rev., 136, 3288-3306, doi:10.1175/2008mwr2277.1.

__, and Coauthors, 2013: An ocean coupling potential intensity index for tropical cyclones. Geophys. Res. Lett., 40, 1878-1882, doi:10.1002/grl.50091.

— I.-F. Pun, and C.-C. Lien, 2014: "Category-6" Supertyphoon Haiyan in global warming hiatus: Contribution from subsurface ocean warming. Geophys. Res. Lett., 41, 8547-8553, doi:10.1002/2014GL061281.

Lin, M., L. W. Horowitz, S. J. Oltmans, A. M. Fiore, and S. Fan, 2014: Tropospheric ozone trends at Mauna Loa Observatory tied to decadal climate variability. Nat. Geosci., 7, 136-143, doi:10.1038/ngeo2066.

$\longrightarrow,-$, R. Payton, A. M. Fiore, and G. Tonnesen, 2017: US surface ozone trends and extremes from 1980 to 2014: Quantifying the roles of rising Asian emissions, domestic controls, wildfires, and climate. Atmos. Chem. Phys., 17, 2943-2970, doi:10.5194/acp-17-2943-2017.

Lindsay, R., and A. Schweiger, 2015: Arctic sea ice thickness loss determined using subsurface, aircraft, and satellite observations. Cryosphere, 9, 269-283, doi:10.5194 /tc-9-269-2015.

Link, J. S., R. Griffis, and S. Busch, 2015: NOAA Fisheries climate science strategy. NOAA Tech. Memo. NMFS-F/ SPO-155, 70 pp. [Available online at http://www.st.nmfs .noaa.gov/ecosystems/climate/national-climate-strategy.] 
Liu, H., L. Wang, and K. C. Jezek, 2005: Wavelet-transform based edge detection approach to derivation of snowmelt onset, end and duration from satellite passive microwave measurements. Int. J. Remote Sens., 26, 4639-4660, doi:10.1080/01431160500213342.

—_, - , and ——, 2006: Spatiotemporal variations of snowmelt in Antarctica derived from satellite scanning multichannel microwave radiometer and special sensor microwave imager data (1978-2004). J. Geophys. Res., 111, F01003, doi:10.1029/2005JF000318.

Liu, W., S.-P. Xie, Z. Liu, and J. Zhu, 2017: Overlooked possibility of a collapsed Atlantic meridional overturning circulation in warming climate. Sci. Adv., 3, e1601666, doi:10.1126/sciadv.1601666.

Liu, Y. Y., and Coauthors, 2012: Trend-preserving blending of passive and active microwave soil moisture retrievals. Remote Sens. Environ., 123, 280-297, doi:10.1016/j .rse.2012.03.014.

Loeb, N. G., and Coauthors, 2009: Toward optimal closure of the Earth's top-of-atmosphere radiation budget. $J$. Climate, 22, 748-766, doi:10.1175/2008jcli2637.1.

- - and Coauthors, 2012: Advances in understanding top-of-atmosphere radiation variability from satellite observations. Surv. Geophys., 33, 359-385, doi:10.1007 /s10712-012-9175-1.

Loew, A., T. Stacke, W. Dorigo, R. de Jeu, and S. Hagemann, 2013: Potential and limitations of multidecadal satellite soil moisture observations for selected climate model evaluation studies. Hydrol. Earth Syst. Sci., 17, 3523-3542, doi:10.5194/hess-17-3523-2013.

Loranty, M. M., W. Lieberman-Cribbin, L. T. Berner, S. M. Natali, S. J. Goetz, H. D. Alexander, and A. L. Kholodov, 2016: Spatial variation in vegetation productivity trends, fire disturbance, and soil carbon across Arctic-boreal permafrost ecosystems. Environ. Res. Lett., 11, 095008, doi:10.1088/1748-9326/11/9/095008.

Lu, M.-M., C.-T. Lee, and B. Wang, 2013: Seasonal prediction of accumulated tropical cyclone kinetic energy around Taiwan and the sources of the predictability. Int. J. Climatol., 33, 2846-2854, doi:10.1002/joc.3634.

Lumpkin, R., and S. Garzoli, 2011: Interannual to decadal changes in the western South Atlantic's surface circulation. J. Geophys. Res., 116, C01014, doi:10.1029/2010JC006285.

— G. Goni, and K. Dohan, 2012: Surface currents [in "State of the Climate in 2011"]. Bull. Amer. Meteor. Soc., 93 (7), S75-S78, doi:10.1175/2012BAMSStateoftheClimate.1.

Luo, G. B., G. L. Zhang, and Z. T. Gong, 2000: Areal evaluation of organic carbon pools in cryic soils of China. Global Climate Change and Cold Regions Ecosystems, R. Lal, J. M. Kimble, and B. A. Stewart, Eds., Lewis Publishers, 211-222.
Luo, J.-J., 2011: Indian Ocean dipole [in "State of the Climate in 2010"]. Bull. Amer. Meteor. Soc., 92 (6), S138-S140, doi:10.1175/1520-0477-92.6.s1.

—- S. Masson, S. Behera, and T. Yamagata, 2007: Experimental forecasts of the Indian Ocean dipole using a coupled OAGCM. J. Climate, 20, 2178-2190, doi:10.1175 /jcli4132.1.

—, R. Zhang, S. K. Behera, Y. Masumoto, F.-F. Jin, R. Lukas, and T. Yamagata, 2010: Interaction between El Niño and extreme Indian Ocean dipole. J. Climate, 23, 726-742, doi:10.1175/2009jcli3104.1.

- , W. Sasaki, and Y. Masumoto, 2012: Indian Ocean warming modulates Pacific climate change. Proc. Natl. Acad. Sci. USA, 109, 18,701-18,706, doi:10.1073 /pnas.1210239109.

Lyman, J. M., and G. C. Johnson, 2014: Estimating global ocean heat content changes in the upper $1800 \mathrm{~m}$ since 1950 and the influence of climatology choice. J. Climate, 27, 1945-1957, doi:10.1175/jcli-d-12-00752.1.

Lynch, C. M., I. D. Barr, D. Mullan, and A. Ruffell, 2016: Rapid glacial retreat on the Kamchatka Peninsula during the early 21st century. Cryosphere, 10, 1809-1821, doi:10.5194/tc-10-1809-2016.

Ma, Z., J. Xu, W. Quan, Z. Zhang, W. Lin, and X. Xu, 2016: Significant increase of surface ozone at a rural site, north of eastern China. Atmos. Chem. Phys., 16, 3969-3977, doi:10.5194/acp-16-3969-2016.

MacCallum, S. N., and C. J. Merchant, 2012: Surface water temperature observations of large lakes by optimal estimation. Canadian J. Remote Sens., 38, 25-45, doi:10.5589 /m12-010.

Macias Fauria, M., and E. A. Johnson, 2006: Large-scale climatic patterns control large lightning fire occurrence in Canada and Alaska forest regions. J. Geophys. Res., 111, G04008, doi:10.1029/2006JG000181.

Madden, R. A., and P. R. Julian, 1971: Detection of a 40-50 day oscillation in the zonal wind in the tropical Pacific. J. Atmos. Sci., 28, 702-708, doi:10.1175/1520 -0469(1971)028<0702:doadoi $>2.0 . c 0 ; 2$.

— and — 1972: Description of global-scale circulation cells in the tropics with a 40-50 day period. J. Atmos. Sci., 29, 1109-1123, doi:10.1175/1520-0469(1972)029<1109 :dogscc $>2.0 . \operatorname{co} ; 2$.

—, and —, 1994: Observations of the 40-50-day tropical oscillation-A review. Mon. Wea. Rev., 122, 814-837, doi:10.1175/1520-0493(1994)122<0814:ootdto>2.0.co;2.

Mahaffy, P. R., and Coauthors, 2013: Abundance and isotopic composition of gases in the Martian atmosphere from the Curiosity rover. Science, 341, 263-266, doi:10.1126 /science.1237966. 
Mainelli, M., M. DeMaria, L. K. Shay, and G. Goni, 2008: Application of oceanic heat content estimation to operational forecasting of recent Atlantic category 5 hurricanes. Wea. Forecasting, 23, 3-16, doi:10.1175/2007waf2006111.1.

Malkova, G. V., M. R. Sadurtdinov, A. G. Skvortsov, and A. M. Tsarev, 2016: Thermal state of permafrost in disturbed and undisterbed cryogenic geosystems in the European North. XI. Int. Conf. Permafrost, Potsdam, Germany, Bibliothek Wissenschaftspark Albert Einstein.

Maloney, E. D., and D. L. Hartmann, 2001: The Madden-Julian oscillation, barotropic dynamics, and North Pacific tropical cyclone formation. Part I: Observations. J. Atmos. Sci., 58, 2545-2558, doi:10.1175/1520 -0469 (2001)058<2545:tmjobd >2.0.co;2.

Manabe, S., and F. Möller, 1961: On the radiative equilibrium and heat balance of the atmosphere. Mon. Wea. Rev., 89, 503-532, doi:10.1175/1520-0493(1961)089<0503 :otreah>2.0.co;2.

Manney, G. L., and Z. D. Lawrence, 2016: The major stratospheric final warming in 2016: Dispersal of vortex air and termination of Arctic chemical ozone loss. Atmos. Chem. Phys., 16, 15,371-15,396, doi:10.5194/acp-16-15371-2016.

_, and Coauthors, 2011: Unprecedented Arctic ozone loss in 2011. Nature, 478, 469-475, doi:10.1038/nature10556.

Mantua, N. J., S. R. Hare, Y. Zhang, J. M. Wallace, and R. C. Francis, 1997: A Pacific interdecadal climate oscillation with impacts on salmon production. Bull. Amer. Meteor. Soc., 78, 1069-1079, doi:10.1175/1520 -0477(1997)078<1069:apicow>2.0.co;2.

Marengo, J.A., L.M. Alves, R.C.S. Alvala, A.P. Cunha, S. Brito, and O.L.L. Moraes, 2017: Climatic characteristics of the 2010-2016 drought in the semiarid Northeast Brazil región. Ann. Brazilian Acad. Sci., accepted.

Marinov, I., A. Gnanadesikan, J. R. Toggweiler, and J. L. Sarmiento, 2006: The Southern Ocean biogeochemical divide. Nature, 441, 964-967, doi:10.1038/nature04883.

Marengo, J.A., L.M. Alves, R.C.S. Alvala, A.P. Cunha, S. Brito, and O.L.L. Moraes, 2017: Climatic characteristics of the 2010-2016 drought in the semiarid Northeast Brazil región. Ann. Brazilian Acad. Sci., accepted.

Marshall, G. J., 2003: Trends in the southern annular mode from observations and reanalyses. J. Climate, 16, 4134-4143, doi:10.1175/1520-0442(2003)016<4134 :titsam $>2.0$. co;2.

Marshall, J., and K. Speer, 2012: Closure of the meridional overturning circulation through Southern Ocean upwelling. Nat. Geosci., 5, 171-180, doi:10.1038/ngeo1391.

Martens, B., and Coauthors, 2017: GLEAM v3: Satellite-based land evaporation and root-zone soil moisture. Geosci. Model Dev., 10, 1903-1925, doi:10.5194/gmd-10-1903 $-2017$.
Martin, R. V., B. Sauvage, I. Folkins, C. E. Sioris, C. Boone, P. Bernath, and J. Ziemke, 2007: Space-based constraints on the production of nitric oxide by lightning. J. Geophys. Res., 112, D09309, doi:10.1029/2006JD007831.

Marzeion, B., J. G. Cogley, K. Richter, and D. Parkes, 2014: Attribution of global glacier mass loss to anthropogenic and natural causes. Science, 345, 919-921, doi:10.1126 /science.1254702.

Maslanik, J., J. Stroeve, C. Fowler, and W. Emery, 2011: Distribution and trends in Arctic sea ice age through spring 2011. Geophys. Res. Lett., 38, L13502, doi:10.1029/2011GL047735.

Mathis, J. T., J. N. Cross, W. Evans, and S. C. Doney, 2015a: Ocean acidification in the surface waters of the PacificArctic boundary regions. Oceanography, 28 (2), 122-135, doi:10.5670/oceanog.2015.36.

— ment for Alaska's fishery sector. Prog. Oceanogr., 136, 71-91, doi:10.1016/j.pocean.2014.07.001.

Matthias, V., A. Dörnbrack, and G. Stober, 2016: The extraordinarily strong and cold polar vortex in the early northern winter 2015/2016. Geophys. Res. Lett., 43, 12,287-12,294, doi:10.1002/2016GL071676.

Mattingly, K. S., C. A. Ramseyer, J. J. Rosen, T. L. Mote, and R. Muthyala, 2016: Increasing water vapor transport to the Greenland Ice Sheet revealed using selforganizing maps. Geophys. Res. Lett., 43, 9250-9258, doi:10.1002/2016GL070424.

Maurer, J. M., S. B. Rupper, and J. M. Schaefer, 2016: Quantifying ice loss in the eastern Himalayas since 1974 using declassified spy satellite imagery. Cryosphere, 10, 2203-2215, doi:10.5194/tc-10-2203-2016.

Mayer, M., K. E. Trenberth, L. Haimberger, and J. T. Fasullo, 2013: The response of tropical atmospheric energy budgets to ENSO. J. Climate, 26, 4710-4724, doi:10.1175 /jcli-d-12-00681.1.

—, L. Haimberger, and M. A. Balmaseda, 2014: On the energy exchange between tropical ocean basins related to ENSO. J. Climate, 27, 6393-6403, doi:10.1175 /jcli-d-14-00123.1.

Mazloff, M. R., P. Heimbach, and C. Wunsch, 2010: An eddy-permitting Southern Ocean state estimate. J. Phys. Oceanogr., 40, 880-899, doi:10.1175/2009jpo4236.1.

McCabe, M. F., A. Ershadi, C. Jimenez, D. G. Miralles, D. Michel, and E. F. Wood, 2016: The GEWEX LandFlux project: Evaluation of model evaporation using towerbased and globally gridded forcing data. Geosci. Model Dev., 9, 283-305, doi:10.5194/gmd-9-283-2016.

McCarthy, G. D., I. D. Haigh, J. J.-M. Hirschi, J. P. Grist, and D. A. Smeed, 2015: Ocean impact on decadal Atlantic climate variability revealed by sea-level observations. Nature, 521, 508-512, doi:10.1038/nature14491. 
McClain, C. R., 2009: A decade of satellite ocean color observations. Ann. Rev. Marine Sci., 1, 19-42, doi:10.1146 /annurev.marine.010908.163650.

McCleese, D. J., and Coauthors, 2007: Mars Climate Sounder: An investigation of thermal and water vapor structure, dust and condensate distributions in the atmosphere, and energy balance of the polar regions. J. Geophys. Res., 112, E05S06, doi:10.1029/2006JE002790.

McLeod, J. T., and T. L. Mote, 2016: Linking interannual variability in extreme Greenland blocking episodes to the recent increase in summer melting across the Greenland ice sheet. Int. J. Climatol., 36, 1484-1499, doi:10.1002 /joc. 4440.

McVicar, T. R., T. G. Van Niel, L. T. Li, M. L. Roderick, D. P. Rayner, L. Ricciardulli, and R. J. Donohue, 2008: Wind speed climatology and trends for Australia, 1975-2006: Capturing the stilling phenomenon and comparison with near-surface reanalysis output. Geophys. Res. Lett., 35, L20403, doi:10.1029/2008GL035627.

_, and Coauthors, 2012: Global review and synthesis of trends in observed terrestrial near-surface wind speeds: Implications for evaporation. J. Hydrol., 416-417, 182205, doi:10.1016/j.jhydrol.2011.10.024.

Mears, C. A., and F. J. Wentz, 2009: Construction of the RSS V3.2 lower-tropospheric temperature dataset from the MSU and AMSU microwave sounders. J. Atmos. Oceanic Technol., 26, 1493-1509, doi:10.1175/2009jtecha1237.1.

Meehl, G. A., A. Hu, J. M. Arblaster, J. Fasullo, and K. E. Trenberth, 2013: Externally forced and internally generated decadal climate variability associated with the interdecadal Pacific oscillation. J. Climate, 26, 7298-7310, doi:10.1175/jcli-d-12-00548.1.

Meier, W. N., and Coauthors, 2014: Arctic sea ice in transformation: A review of recent observed changes and impacts on biology and human activity. Rev. Geophys., 52, 185-217, doi:10.1002/2013RG000431.

Menemenlis, D., P. Heimbach, C. Hill, T. Lee, A. Nguyen, M. Schodlok, and H. Zhang, 2008: ECCO2: High-resolution global ocean and sea ice data synthesis. Mercator Ocean Quarterly Newsletter, No. 31, Mercator-Ocean, Ramonville, Saint-Agne, France, 13-21. [Available online at http://ecco2.org/manuscripts/reports/ECCO2_Mercator. pdf.]

Menezes, V. V., A. M. Macdonald, and C. Schatzman, 2017: Accelerated freshening of Antarctic bottom water over the last decade in the southern Indian Ocean. Sci. Adv., 3, e1601426, doi:10.1126/sciadv.1601426.

Menne, M. J., I. Durre, R. S. Vose, B. E. Gleason, and T. G. Houston, 2012: An overview of the global historical climatology network-daily database. J. Atmos. Oceanic Technol., 29, 897-910, doi:10.1175/jtech-d-11-00103.1.
Menzel, W. P., R. A. Frey, E. E. Borbas, N. Bearson, B. Baum, R. Chen, and C. Cao, 2014: Recalibrating HIRS sensors to produce a 30 year record of radiance measurements. Proc. EUMETSAT Meteorological Satellite Conf., Geneva, Switzerland, EUMETSAT.

Merrifield, M. A., 2011: A shift in western tropical Pacific sea level trends during the 1990s. J. Climate, 24, 4126-4138, doi:10.1175/2011jcli3932.1.

— P. R. Thompson, and M. Lander, 2012: Multidecadal sea level anomalies and trends in the western tropical Pacific. Geophys. Res. Lett., 39, L13602, doi:10.1029/2012GL052032.

Miller, B. R., and Coauthors, 2010: $\mathrm{HFC}-23\left(\mathrm{CHF}_{3}\right)$ emission trend response to $\mathrm{HCFC}-22\left(\mathrm{CHClF}_{2}\right)$ production and recent HFC-23 emission abatement measures. Atmos. Chem. Phys., 10, 7875-7890, doi:10.5194/acp-10-7875-2010.

Minnis, P., and Coauthors, 2008: Cloud detection in nonpolar regions for CERES using TRMM VIRS and Terra and Aqua MODIS data. IEEE Trans. Geosci. Remote Sens., 46, 3857-3884, doi:10.1109/TGRS.2008.2001351.

_ , and Coauthors, 2016: A consistent long-term cloud and clear-sky radiation property dataset from the Advanced Very High Resolution Radiometer (AVHRR). CDRPATBD-0826 Rev 1, 159 pp. [Available online at http:// dx.doi.org/10.789/V5HT2M8T.]

Miralles, D. G., T. R. H. Holmes, R. A. M. De Jeu, J. H. Gash, A. G. C. A. Meesters, and A. J. Dolman, 2011: Global landsurface evaporation estimated from satellite-based observations. Hydrol. Earth Syst. Sci., 15, 453-469, doi:10.5194 /hess-15-453-2011.

_ A. J. Teuling, C. C. van Heerwaarden, and J. Vila-Guerau de Arellano, 2014a: Mega-heatwave temperatures due to combined soil desiccation and atmospheric heat accumulation. Nat. Geosci., 7, 345-349, doi:10.1038/ngeo2141.

—_ and Coauthors, 2014b: El Niño-La Niña cycle and recent trends in continental evaporation. Nat. Climate Change, 4, 122-126, doi:10.1038/nclimate2068.

_- , and Coauthors, 2016: The WACMOS-ET project Part 2: Evaluation of global terrestrial evaporation data sets. Hydrol. Earth Syst. Sci., 20, 823-842, doi:10.5194 /hess-20-823-2016.

Mishra, U., and W. J. Riley, 2012: Alaskan soil carbon stocks: spatial variability and dependence on environmental factors. Biogeosciences, 9, 3637-3645, doi:10.5194/bg-9 -3637-2012.

Mo, K. C., 2000: The association between intraseasonal oscillations and tropical storms in the Atlantic basin. Mon. Wea. Rev., 128, 4097-4107, doi:10.1175/1520 -0493(2000)129<4097:tabioa>2.0.co;2.

—_, and V. E. Kousky, 1993: Further analysis of the relationship between circulation anomaly patterns and tropical convection. J. Geophys. Res., 98, 5103-5113, doi:10.1029/92JD02952. 
Moat, B. I., and Coauthors, 2016: Major variations in subtropical North Atlantic heat transport at short (5 day) timescales and their causes. J. Geophys. Res. Oceans, 121, 3237-3249, doi:10.1002/2016JC011660.

Monks, P. S., and Coauthors, 2015: Tropospheric ozone and its precursors from the urban to the global scale from air quality to short-lived climate forcer. Atmos. Chem. Phys., 15, 8889-8973, doi:10.5194/acp-15-8889-2015.

Morice, C. P., J. J. Kennedy, N. A. Rayner, and P. D. Jones, 2012: Quantifying uncertainties in global and regional temperature change using an ensemble of observational estimates: The HadCRUT4 data set. J. Geophys. Res., 117, D08101, doi:10.1029/2011JD017187.

Morrison, W. E., and V. Termini, 2016: A review of potential approaches for managing marine fisheries in a changing climate. NOAA Tech. Memo. NMFS-OSF-6, 35 pp. [Available online at http://www.nmfs.noaa.gov/sfa /publications/technical-memos/nmfs_osf_tm6.pdf.]

Mote, T. L., 2007: Greenland surface melt trends 1973-2007: Evidence of a large increase in 2007. Geophys. Res. Lett., 34, L22507, doi:10.1029/2007GL031976.

$\mathrm{Mu}, \mathrm{C}$., and Coauthors, 2015: Editorial: Organic carbon pools in permafrost regions on the Qinghai-Xizang (Tibetan) Plateau. Cryosphere, 9, 479-486, doi:10.5194 /tc-9-479-2015.

Mu, Q., M. Zhao, J. S. Kimball, N. G. McDowell, and S. W. Running, 2013: A remotely sensed global terrestrial drought severity index. Bull. Amer. Meteor. Soc., 94, 8398, doi:10.1175/bams-d-11-00213.1.

Mudryk, L. R., P. J. Kushner, C. Derksen, and C. Thackeray, 2017: Snow cover response to temperature in observational and climate model ensembles. Geophys. Res. Lett., 44, 919-926, doi:10.1002/2016GL071789.

Mühle, J., and Coauthors, 2010: Perfluorocarbons in the global atmosphere: Tetrafluoromethane, hexafluoroethane, and octafluoropropane. Atmos. Chem. Phys., 10, 5145-5164, doi:10.5194/acp-10-5145-2010.

Mullan, A. B., 2014: Intertropical convergence zones [in "State of the Climate in 2013"]. Bull. Amer. Meteor. Soc., 95 (7), S103-S104, doi:10.1175 /2014BAMSStateoftheClimate.1.

Müller, R., J. U. Grooß, C. Lemmen, D. Heinze, M. Dameris, and G. Bodeker, 2008: Simple measures of ozone depletion in the polar stratosphere. Atmos. Chem. Phys., 8, 251-264, doi:10.5194/acp-8-251-2008.

Münnich, M., and J. D. Neelin, 2005: Seasonal influence of ENSO on the Atlantic ITCZ and equatorial South America. Geophys. Res. Lett., 32, L21709, doi:10.1029/2005GL023900.

Murphy, B. F., and J. Ribbe, 2004: Variability of southeastern Queensland rainfall and climate indices. Int. J. Climatol., 24, 703-721, doi:10.1002/joc.1018.
Murray, L. T., J. A. Logan, and D. J. Jacob, 2013: Interannual variability in tropical tropospheric ozone and $\mathrm{OH}$ : The role of lightning. J. Geophys. Res. Atmos., 118, 11,46811,480, doi:10.1002/jgrd.50857.

Myers-Smith, I. H., and D. S. Hik, 2013: Shrub canopies influence soil temperatures but not nutrient dynamics: An experimental test of tundra snow-shrub interactions. Ecol. Evol., 3, 3683-3700, doi:10.1002/ece3.710.

_- , and Coauthors, 2015: Climate sensitivity of shrub growth across the tundra biome. Nat. Climate Change, 5, 887-891, doi:10.1038/nclimate2697.

Myhre, G., and Coauthors, 2013: Anthropogenic and natural radiative forcing. Climate Change 2013: The Physical Science Basis, T. F. Stocker et al., Eds., Cambridge University Press, 659-740.

Nakazawa, T., and S. Hoshino, 2009: Intercomparison of Dvorak parameters in the tropical cyclone datasets over the western North Pacific. SOLA, 5, 33-36, doi:10.2151 /sola.2009-009.

Nash, E. R., and Coauthors, 2016: Antarctic ozone hole [in "State of the Climate in 2015"]. Bull. Amer. Meteor. Soc., 97 (8), S168-S172, doi:10.1175 /2016BAMSStateoftheClimate.1.

National Research Council, 2003: Cloud, water vapor, and lapse rate feedbacks. Understanding Climate Change Feedbacks, National Academies Press, 21-40.

Nemani, R. R., and S. W. Running, 1989: Estimation of regional surface resistance to evapotranspiration from NDVI and thermal-IR AVHRR data. J. Appl. Meteor., 28, 276-284, doi:10.1175/1520-0450(1989)028<0276 :eorsrt $>2.0 . \mathrm{co} ; 2$.

Nerem, R. S., D. P. Chambers, E. W. Leuliette, G. T. Mitchum, and B. S. Giese, 1999: Variations in global mean sea level associated with the 1997-1998 ENSO event: Implications for measuring long term sea level change. Geophys. Res. Lett., 26, 3005-3008, doi:10.1029/1999GL002311.

Neu, J. L., T. Flury, G. L. Manney, M. L. Santee, N. J. Livesey, and J. Worden, 2014: Tropospheric ozone variations governed by changes in stratospheric circulation. Nat. Geosci., 7, 340-344, doi:10.1038/ngeo2138.

Newman, C. E., S. R. Lewis, P. L. Read, and F. Forget, 2002: Modeling the Martian dust cycle, 1. Representations of dust transport processes. J. Geophys. Res., 107, 5123, doi:10.1029/2002JE001910.

Newman, P. A., J. S. Daniel, D. W. Waugh, and E. R. Nash, 2007: A new formulation of equivalent effective stratospheric chlorine (EESC). Atmos. Chem. Phys., 7, 4537-4552, doi:10.5194/acp-7-4537-2007.

__, and Coauthors, 2015: Ozone depletion [in "State of the Climate in 2014"]. Bull. Amer. Meteor. Soc., 96 (7), S165-S167, doi:10.1175/2015BAMSStateoftheClimate.1. 
— L. Coy, S. Pawson, and L. R. Lait, 2016: The anomalous change in the QBO in 2015-2016. Geophys. Res. Lett., 43, 8791-8797, doi:10.1002/2016GL070373.

Newton, B. W., T. D. Prowse, and B. R. Bonsal, 2014a: Evaluating the distribution of water resources in western Canada using synoptic climatology and selected teleconnections. Part 1: Winter season. Hydrol. Proc., 28, 4219-4234, doi:10.1002/hyp.10233.

$\longrightarrow,-$ and — 2014b: Evaluating the distribution of water resources in western Canada using synoptic climatology and selected teleconnections. Part 2: Summer season. Hydrol. Proc., 28, 4235-4249, doi:10.1002/hyp.10235.

Nghiem, S. V., and Coauthors, 2012: The extreme melt across the Greenland ice sheet in 2012. Geophys. Res. Lett., 39, L20502, doi:10.1029/2012GL053611.

NOAA, cited 2017: State of the climate: Drought for annual 2016. [Available online at http://www.ncdc.noaa.gov/sotc /drought/201613.]

Nobre, P., and J. Shukla, 1996: Variations of sea surface temperature, wind stress, and rainfall over the tropical Atlantic and South America. J. Climate, 9, 2464-2479, doi:10.1175/1520-0442(1996)009<2464:vosstw>2.0.co;2.

O'Malley, R. T., M. J. Behrenfeld, D. A. Siegel, and S. Maritorena, 2010: Global ocean phytoplankton [in "State of the Climate in 2009"]. Bull. Amer. Meteor. Soc., 91 (7), S75-S78, doi:10.1175/BAMS-91-7-StateoftheClimate.

O’Reilly, C. M., S. R. Alin, P.-D. Plisnier, A. S. Cohen, and B. A. McKee, 2003: Climate change decreases aquatic ecosystem productivity of Lake Tanganyika, Africa. Nature, 424, 766-768, doi:10.1038/nature01833.

— ing of lake surface waters around the globe. Geophys. Res. Lett., 42, 10,773-10,781, doi:10.1002/2015GL066235.

Oliva, M., and Coauthors, 2017: Recent regional climate cooling on the Antarctic Peninsula and associated impacts on the cryosphere. Sci. Total Environ., 580, 210-223, doi:10.1016/j.scitotenv.2016.12.030.

Oltmans, S. J., and Coauthors, 2006: Long-term changes in tropospheric ozone. Atmos. Environ., 40, 3156-3173, doi:10.1016/j.atmosenv.2006.01.029.

Onogi, K., and Coauthors, 2007: The JRA-25 reanalysis. J. Meteor. Soc. Japan, 85, 369-432, doi:10.2151/jmsj.85.369.

Oozeva, C., C. Noongwook, G. Noongwook, C. Alowa, and I. Krupnik, 2004: Watching Ice and Weather Our Way [Sikumengllu Eslamengllu Esghapalleghput]. I. Krupnik, H. Huntington, C. Koonooka, and G. Noongwook, Eds. Arctic Studies Center, Smithsonian Institution, 208 pp.

Osborn, T. J., J. Barichivich, I. Harris, G. van der Schrier, and P. D. Jones, 2016: Monitoring global drought using the self-calibrating Palmer drought severity index [in "State of the Climate in 2015”]. Bull. Amer. Meteor. Soc., 97 (8), S32-S36, doi:10.1175/2016BAMSStateoftheClimate.1.
Osprey, S. M., and Coauthors, 2016: An unexpected disruption of the atmospheric quasi-biennial oscillation. Science, 353, 1424-1427, doi:10.1126/science.aah4156.

Otto, F. E. L., and Coauthors, 2015: Factors other than climate change, main drivers of 2014/15 water shortage in southeast Brazil. Bull. Amer. Meteor. Soc., 96 (12), S35-S40, doi:10.1175/bams-d-15-00120.1.

Oudrari, H., and Coauthors, 2015: Prelaunch radiometric characterization and calibration of the S-NPP VIIRS sensor. IEEE Trans. Geosci. Remote Sens., 53, 2195-2210, doi:10.1109/TGRS.2014.2357678.

Overland, J. E., and M. Wang, 2016: Recent extreme Arctic temperatures are due to a split polar vortex. J. Climate, 29, 5609-5616, doi:10.1175/jcli-d-16-0320.1.

Palmer, M. D., K. Haines, S. F. B. Tett, and T. J. Ansell, 2007: Isolating the signal of ocean global warming. Geophys. Res. Lett., 34, L23610, doi:10.1029/2007GL031712.

Panda, D. K., and J. Wahr, 2016: Spatiotemporal evolution of water storage changes in India from the updated GRACEderived gravity records. Water Resour. Res., 52, 135-149, doi:10.1002/2015WR017797.

Park, S., and Coauthors, 2012: Trends and seasonal cycles in the isotopic composition of nitrous oxide since 1940. Nat. Geosci., 5, 261-265, doi:10.1038/ngeo1421.

Park, T., and Coauthors, 2016: Changes in growing season duration and productivity of northern vegetation inferred from long-term remote sensing data. Environ. Res. Lett., 11, 084001, doi:10.1088/1748-9326/11/8/084001.

Parker, T. C., J.-A. Subke, and P. A. Wookey, 2015: Rapid carbon turnover beneath shrub and tree vegetation is associated with low soil carbon stocks at a subarctic treeline. Global Change Biol., 21, 2070-2081, doi:10.1111/gcb.12793.

Parrish, D. D., and Coauthors, 2014: Long-term changes in lower tropospheric baseline ozone concentrations: Comparing chemistry-climate models and observations at northern midlatitudes. J. Geophys. Res. Atmos., 119, 5719-5736, doi:10.1002/2013JD021435.

Pawson, S., and Coauthors, 2014: Update on global ozone: Past, present, and future. Scientific Assessment of Ozone Depletion: 2014, World Meteorological Organization, 2.1-2.66.

Pedersen, Å. Ø., J. D. M. Speed, and I. M. Tombre, 2013: Prevalence of pink-footed goose grubbing in the Arctic tundra increases with population expansion. Polar Biol., 36, 1569-1575, doi:10.1007/s00300-013-1374-9.

Pellichero, V., J.-B. Sallée, S. Schmidtko, F. Roquet, and J.-B. Charrassin, 2017: The ocean mixed layer under Southern Ocean sea-ice: Seasonal cycle and forcing. J. Geophys. Res. Oceans, 122, 1608-1633, doi:10.1002/2016JC011970.

Pelto, M. S., 2010: Forecasting temperate alpine glacier survival from accumulation zone observations. Cryosphere, 4, 67-75, doi:10.5194/tc-4-67-2010. 
PERMOS, 2016: Permafrost in Switzerland 2010/2011 to 2013/2014. Glaciological Report (Permafrost) No. 12-15 of the Cryospheric Commission of the Swiss Academy of Sciences, 85 pp. [Available online at http://www.permos .ch/downloads/permos10-14.pdf.]

Pershing, A. J., and Coauthors, 2015: Slow adaptation in the face of rapid warming leads to collapse of the Gulf of Maine cod fishery. Science, 350, 809-812, doi:10.1126 /science.aac9819.

Peterson, D. A., E. J. Hyer, J. R. Campbell, M. D. Fromm, J. W. Hair, C. F. Butler, and M. A. Fenn, 2015: The 2013 Rim Fire: Implications for predicting extreme fire spread, pyroconvection, and smoke emissions. Bull. Amer. Meteor. Soc., 96, 229-247, doi:10.1175/bams-d-14-00060.1.

Peterson, T. C., and R. S. Vose, 1997: An overview of the global historical climatology network temperature database. Bull. Amer. Meteor. Soc., 78, 2837-2849, doi:10.1175/1520 -0477(1997)078<2837:aootgh>2.0.co;2.

Petty, A. A., P. R. Holland, and D. L. Feltham, 2014: Sea ice and the ocean mixed layer over the Antarctic shelf seas. Cryosphere, 8, 761-783, doi:10.5194/tc-8-761-2014.

Pfeffer, W. T., and Coauthors, 2014: The Randolph Glacier inventory: A globally complete inventory of glaciers. J. Glaciol., 60, 537-552, doi:10.3189/2014JoG13J176.

Phoenix, G. K., and J. W. Bjerke, 2016: Arctic browning: Extreme events and trends reversing Arctic greening. Global Change Biol., 22, 2960-2962, doi:10.1111/gcb.13261.

Picaut, J., M. Ioualalen, C. Menkes, T. Delcroix, and M. J. McPhaden, 1996: Mechanism of the zonal displacements of the Pacific warm pool: Implications for ENSO. Science, 274, 1486-1489, doi:10.1126/science.274.5292.1486.

Ping, C. L., G. J. Michaelson, J. M. Kimble, V. E. Romanovsky, Y. L. Shur, D. K. Swanson, and D. A. Walker, 2008: Cryogenesis and soil formation along a bioclimate gradient in Arctic North America. J. Geophys. Res., 113, G03S12, doi:10.1029/2008JG000744.

Pinsky, M. L., and M. Fogarty, 2012: Lagged social-ecological responses to climate and range shifts in fisheries. Climatic Change, 115, 883-891, doi:10.1007/s10584-012-0599-x.

Pinty, B., 2012: Land surface albedo [in"State of the Climate in 2011”]. Bull. Amer. Meteor. Soc., 93 (7), S52-S53, doi :10.1175/2012BAMSStateoftheClimate.1.

_, and Coauthors, 2011a: Exploiting the MODIS albedos with the two-stream inversion package (JRC-TIP): 1. Effective leaf area index, vegetation, and soil properties. J. Geophys. Res., 116, D09105, doi:10.1029/2010JD015372.

_- , and Coauthors, 2011b: Exploiting the MODIS albedos with the two-stream inversion package (JRC-TIP): 2. Fractions of transmitted and absorbed fluxes in the vegetation and soil layers. J. Geophys. Res., 116, D09106, doi:10.1029/2010JD015373.
Pinzon, J., and C. Tucker, 2014: A non-stationary 1981-2012 AVHRR NDVI3g time series. Remote Sens., 6, 6929, doi:10.3390/rs6086929.

Pitts, M. C., L. R. Poole, and L. W. Thomason, 2009: CALIPSO polar stratospheric cloud observations: Second-generation detection algorithm and composition discrimination. Atmos. Chem. Phys., 9, 7577-7589, doi:10.5194/acp-9-7577-2009.

Post, E., and Coauthors, 2013: Ecological consequences of sea-ice decline. Science, 341, 519-524, doi:10.1126 /science.1235225.

Post, W. M., W. R. Emanuel, P. J. Zinke, and A. G. Stangenberger, 1982: Soil carbon pools and world life zones. Nature, 298, 156-159, doi:10.1038/298156a0.

Price, J. C., 1982: Estimation of regional scale evapotranspiration through analysis of satellite thermal-infrared data. IEEE Trans. Geosci. Remote Sens., GE-20, 286-292, doi:10.1109/TGRS.1982.350445.

Price, J. F., 1981: Upper ocean response to a hurricane. J. Phys. Oceanogr., 11, 153-175, doi:10.1175/1520 -0485(1981)011<0153:uortah>2.0.co;2.

Pryor, S. C., and Coauthors, 2009: Wind speed trends over the contiguous United States. J. Geophys. Res., 114, D14105, doi:10.1029/2008JD011416.

Pun, I.-F., I-I Lin, and M.-H. Lo, 2013: Recent increase in high tropical cyclone heat potential area in the western North Pacific Ocean. Geophys. Res. Lett., 40, 4680-4684, doi:10.1002/grl.50548.

Punt, A. E., D. Poljak, M. G. Dalton, and R. J. Foy, 2014: Evaluating the impact of ocean acidification on fishery yields and profits: The example of red king crab in Bristol Bay. Ecol. Modell., 285, 39-53, doi:10.1016/j .ecolmodel.2014.04.017.

— R. J. Foy, M. G. Dalton, W. C. Long, and K. M. Swiney, 2016: Effects of long-term exposure to ocean acidification conditions on future southern Tanner crab (Chionoecetes bairdi) fisheries management. ICES J. Marine Sci., 73, 849-864, doi:10.1093/icesjms/fsv205.

Purkey, S. G., and G. C. Johnson, 2010: Warming of global abyssal and deep Southern Ocean waters between the 1990s and 2000s: Contributions to global heat and sea level rise budgets. J. Climate, 23, 6336-6351, doi:10.1175/2010jcli3682.1.

_-, and _-, 2013: Antarctic bottom water warming and freshening: Contributions to sea level rise, ocean freshwater budgets, and global heat gain. J. Climate, 26, 6105-6122, doi:10.1175/jcli-d-12-00834.1.

Qi, D., and Coauthors, 2017: Increase in acidifying water in the western Arctic Ocean. Nat. Climate Change, 7, 195-199, doi:10.1038/nclimate3228.

Rachold, V., and Coauthors, 2007: Nearshore Arctic subsea permafrost in transition. Eos, Trans. Amer. Geophys. Union, 88 (13), 149-150, doi:10.1029/2007EO130001. 
Raga, G. B., B. Bracamontes-Cevallos, L. M. Farfán, and R. Romero-Centeno, 2013: Landfalling tropical cyclones on the Pacific coast of Mexico: 1850-2010. Atmosfera, 26, 209-220, doi:10.1016/S0187-6236(13)71072-5.

Rahmani, A., S. Golian, and L. Brocca, 2016: Multiyear monitoring of soil moisture over Iran through satellite and reanalysis soil moisture products. Int. J. Appl. Earth Obs. Geoinf., 48, 85-95, doi:10.1016/j.jag.2015.06.009.

Rahmstorf, S., J. E. Box, G. Feulner, M. E. Mann, A. Robinson, S. Rutherford, and E. J. Schaffernicht, 2015: Exceptional twentieth-century slowdown in Atlantic Ocean overturning circulation. Nat. Climate Change, 5, 475-480, doi:10.1038/nclimate2554.

Ramella-Pralungo, L., L. Haimberger, A. Stickler, and S. Brönnimann, 2014: A global radiosonde and tracked balloon archive on 16 pressure levels (GRASP) back to 1905 - Part 1: Merging and interpolation to 00:00 and 12:00 GMT. Earth Syst. Sci. Data, 6, 185-200, doi:10.5194 lessd-6-185-2014.

Ramos, M., G. Vieira, M. A. de Pablo, A. Molina, A. Abramov, and G. Goyanes, 2017: Recent shallowing of the thaw depth at Crater Lake, Deception Island, Antarctica (2006-2014). CATENA, 149, Part 2, 519-528, doi:10.1016 /j.catena.2016.07.019.

Randel, W. J., R. R. Garcia, N. Calvo, and D. Marsh, 2009: ENSO influence on zonal mean temperature and ozone in the tropical lower stratosphere. Geophys. Res. Lett., 36, L15822, doi:10.1029/2009GL039343.

Rasmusson, E. M., and T. H. Carpenter, 1982: Variations in tropical sea surface temperature and surface wind fields associated with the Southern Oscillation/El Niño. Mon. Wea. Rev., 110, 354-384, doi:10.1175/1520 -0493(1982)110<0354:vitsst>2.0.co;2.

— El Niño/Southern Oscillation. Science, 222, 1195-1202, doi:10.1126/science.222.4629.1195.

Ravishankara, A. R., S. Solomon, A. A. Turnipseed, and R. F. Warren, 1993: Atmospheric lifetimes of long-lived halogenated species. Science, 259, 194-199, doi:10.1126 /science.259.5092.194.

—, J. S. Daniel, and R. W. Portmann, 2009: Nitrous oxide $\left(\mathrm{N}_{2} \mathrm{O}\right)$ : The dominant ozone-depleting substance emitted in the 21st century. Science, 326, 123-125, doi:10.1126 /science.1176985.

Rayner, N. A., and Coauthors, 2003: Global analyses of sea surface temperature, sea ice, and night marine air temperature since the late nineteenth century. J. Geophys. Res., 108, 4407, doi:10.1029/2002JD002670.

Raynolds, M. K., D. A. Walker, H. E. Epstein, J. E. Pinzon, and C. J. Tucker, 2012: A new estimate of tundra-biome phytomass from trans-Arctic field data and AVHRR NDVI. Remote Sens. Lett., 3, 403-411, doi:10.1080 /01431161.2011.609188.
Read, P. L., and S. R. Lewis, 2004: The Martian Climate Revisited: Atmosphere and Environment of a Desert Planet. Springer, $326 \mathrm{pp}$.

$\longrightarrow,-$, and D. P. Mulholland, 2015: The physics of Martian weather and climate: A review. Rep. Prog. Phys., 78, 125901, doi:10.1088/0034-4885/78/12/125901.

Reagan, J., T. Boyer, C. Schmid, and R. Locarnini, 2016: Subsurface salinity [in "State of the Climate in 2015"]. Bull. Amer. Meteor. Soc., 97 (8), S72-S73, doi:10.1175 /2016BAMSStateoftheClimate.1.

Reager, J. T., A. S. Gardner, J. S. Famiglietti, D. N. Wiese, A. Eicker, and M.-H. Lo, 2016: A decade of sea level rise slowed by climate-driven hydrology. Science, 351, 699-703, doi:10.1126/science.aad8386.

Reid, P. A., and R. A. Masson, 2015: Successive Antarctic sea ice extent records during 2012, 2013, and 2014 [in "State of the Climate in 2014"]. Bull. Amer. Meteor. Soc., 96 (7), S163-S164, doi:10.1175/2015BAMSStateoftheClimate.1.

—_, - - S. Stammerjohn, S. Barreira, J. Lieser, and T. Scambos, 2016: Sea ice extent and concentration [in "State of the Climate in 2015"]. Bull. Amer. Meteor. Soc., 97 (8), S163-S166, doi:10.1175/2016BAMSStateoftheClimate.1.

Remer, L. A., and Coauthors, 2005: The MODIS aerosol algorithm, products, and validation. J. Atmos. Sci., 62, 947-973, doi:10.1175/jas3385.1.

Remy, S., and J. W. Kaiser, 2014: Daily global fire radiative power fields estimation from one or two MODIS instruments. Atmos. Chem. Phys., 14, 13,377-13,390, doi:10.5194/acp-14-13377-2014.

Reynolds, R. W., N. A. Rayner, T. M. Smith, D. C. Stokes, and W. Wang, 2002: An improved in situ and satellite SST analysis for climate. J. Climate, 15, 1609-1625, doi:10.1175/1520-0442(2002)015<1609:aiisas>2.0.co;2.

— T. M. Smith, C. Liu, D. B. Chelton, K. S. Casey, and M. G. Schlax, 2007: Daily high-resolution-blended analyses for sea surface temperature. J. Climate, 20, 5473-5496, doi:10.1175/2007jcli1824.1.

Rhein, M., and Coauthors, 2013: Observations: Ocean. Climate Change 2013: The Physical Science Basis, T. F. Stocker et al., Eds., Cambridge University Press, 255-316.

Riahi, K., and Coauthors, 2011: RCP 8.5-A scenario of comparatively high greenhouse gas emissions. Climatic Change, 109, 33-57, doi:10.1007/s10584-011-0149-y.

Richter-Menge, J., J. E. Overland, and J. T. Mathis, Eds., 2016: Arctic Report Card 2016. NOAA’s Arctic Program, various $\mathrm{pp}$.

Riddle, E. E., M. B. Stoner, N. C. Johnson, M. L. L'Heureux, D. C. Collins, and S. B. Feldstein, 2013: The impact of the MJO on clusters of wintertime circulation anomalies over the North American region. Climate Dyn., 40, 1749-1766, doi:10.1007/s00382-012-1493-y. 
Ridley, D. A., and Coauthors, 2014: Total volcanic stratospheric aerosol optical depths and implications for global climate change. Geophys. Res. Lett., 41, 7763-7769, doi:10.1002/2014GL061541.

Riser, S. C., and Coauthors, 2016: Fifteen years of ocean observations with the global Argo array. Nat. Climate Change, 6, 145-153, doi:10.1038/nclimate2872.

Robson, J., P. Ortega, and R. Sutton, 2016: A reversal of climatic trends in the North Atlantic since 2005. Nat. Geosci., 9, 513-517, doi:10.1038/ngeo2727.

Rodell, M., I. Velicogna, and J. S. Famiglietti, 2009: Satellitebased estimates of groundwater depletion in India. $\mathrm{Na}$ ture, 460, 999-1002, doi:10.1038/nature08238.

Rödenbeck, C., and Coauthors, 2015: Data-based estimates of the ocean carbon sink variability - first results of the Surface Ocean $p \mathrm{CO}_{2}$ Mapping intercomparison (SOCOM). Biogeosciences, 12, 7251-7278, doi:10.5194 /bg-12-7251-2015.

Roderick, M. L., L. D. Rotstayn, G. D. Farquhar, and M. T. Hobbins, 2007: On the attribution of changing pan evaporation. Geophys. Res. Lett., 34, L17403, doi:10.1029/2007GL031166.

Roemmich, D., and J. Gilson, 2009: The 2004-2008 mean and annual cycle of temperature, salinity, and steric height in the global ocean from the Argo Program. Prog. Oceanogr., 82, 81-100, doi:10.1016/j.pocean.2009.03.004.

—, and 2011: The global ocean imprint of ENSO. Geophys. Res. Lett., 38, L13606, doi:10.1029/2011GL047992.

_, J. Church, J. Gilson, D. Monselesan, P. Sutton, and S. Wijffels, 2015: Unabated planetary warming and its ocean structure since 2006. Nat. Climate Change, 5, 240-245, doi:10.1038/nclimate2513.

Rogers, J. C., and J. L. Morack, 1980: Geophysical evidence of shallow nearshore permafrost, Prudhoe Bay, Alaska. J. Geophys. Res., 85, 4845-4853, doi:10.1029 /JB085iB09p04845.

Rohde, R., and Coauthors, 2013: A new estimate of the average Earth surface land temperature spanning 1753 to 2011. Geoinfor. Geostat. Overview, 1 (1), doi:10.4172 /2327-4581.1000101.

Romanovsky, V. E., W. L. Cable, and A. L. Kholodov, 2015: Changes in permafrost and active-layer temperatures along an Alaskan permafrost-ecological transect. Proc. 68th Canadian Geotechnical Conf. and Seventh Canadian Conf. on Permafrost (GEOQuébec 2015), Quebec, Canada, GEOQuébec 2015, Paper 479.

Ropelewski, C. F., and M. S. Halpert, 1986: North American precipitation and temperature patterns associated with the El Niño/Southern Oscillation (ENSO). Mon. Wea. Rev., 114, 2352-2362, doi:10.1175/1520-0493(1986)114<2352:na patp $>2.0 . \mathrm{co} ; 2$.
— patterns associated with the El Niño/Southern Oscillation. Mon. Wea. Rev., 115, 1606-1626, doi:10.1175/15200493(1987)115<1606:garspp>2.0.co;2.

- and _ 1989: Precipitation patterns associated with the high index phase of the southern oscillation. J. Climate, 2, 268-284, doi:10.1175/1520-0442(1989)002<0268 :ppawth $>2.0 . \mathrm{co} ; 2$.

Rosenfeld, D., M. Fromm, J. Trentmann, G. Luderer, M. O. Andreae, and R. Servranckx, 2007: The Chisholm firestorm: Observed microstructure, precipitation and lightning activity of a pyro-cumulonimbus. Atmos. Chem. Phys., 7, 645-659, doi:10.5194/acp-7-645-2007.

Saba, V. S., and Coauthors, 2016: Enhanced warming of the northwest Atlantic Ocean under climate change. J. Geophys. Res. Oceans, 121, 118-132, doi:10.1002/2015JC011346.

Saha, S., and Coauthors, 2010: The NCEP climate forecast system reanalysis. Bull. Amer. Meteor. Soc., 91, 1015-1057, doi:10.1175/2010bams3001.1.

-_, and Coauthors, 2014: The NCEP climate forecast system version 2. J. Climate, 27, 2185-2208, doi:10.1175 /jcli-d-12-00823.1.

Saji, N. H., B. N. Goswami, P. N. Vinayachandran, and T. Yamagata, 1999: A dipole mode in the tropical Indian Ocean. Nature, 401, 360-363.

Sallée, J.-B., and Coauthors, 2016: Southern Ocean [in "State of the Climate in 2015”]. Bull. Amer. Meteor. Soc., 97 (8), S166-S168, doi:10.1175/2016BAMSStateoftheClimate.1.

Sallenger, A. H., K. S. Doran, and P. A. Howd, 2012: Hotspot of accelerated sea-level rise on the Atlantic coast of North America. Nat. Climate Change, 2, 884-888, doi:10.1038 /nclimate1597.

Sauvage, B., R. V. Martin, A. van Donkelaar, and J. R. Ziemke, 2007: Quantification of the factors controlling tropical tropospheric ozone and the South Atlantic maximum. J. Geophys. Res., 112, D11309, doi:10.1029/2006JD008008.

Schaaf, C. B., and Coauthors, 2002: First operational BRDF, albedo nadir reflectance products from MODIS. Remote Sens. Environ., 83, 135-148, doi:10.1016/S0034 -4257(02)00091-3.

Schanze, J. J., R. W. Schmitt, and L. L. Yu, 2010: The global oceanic freshwater cycle: A state-of-the-art quantification. J. Mar. Res., 68, 569-595, doi:10.1357/002224010794657164.

Schauffler, S. M., and Coauthors, 2003: Chlorine budget and partitioning during the stratospheric aerosol and gas experiment (SAGE) III ozone loss and validation experiment (SOLVE). J. Geophys. Res., 108, 4173, doi:10.1029/2001JD002040.

Schirrmeister, L., C. Siegert, V. V. Kunitzky, P. M. Grootes, and H. Erlenkeuser, 2002: Late Quaternary ice-rich permafrost sequences as a paleoenvironmental archive for the Laptev Sea Region in northern Siberia. Int. J. Earth Sci., 91, 154-167, doi:10.1007/s005310100205. 
—, G. Grosse, S. Wetterich, P. P. Overduin, J. Strauss, E. A. G. Schuur, and H.-W. Hubberten, 2011: Fossil organic matter characteristics in permafrost deposits of the northeast Siberian Arctic. J. Geophys. Res, 116, G00M02, doi:10.1029/2011JG001647.

Schmidtko, S., K. J. Heywood, A. F. Thompson, and S. Aoki, 2014: Multidecadal warming of Antarctic waters. Science, 346, 1227-1231, doi:10.1126/science.1256117.

Schneider, P., and S. J. Hook, 2010: Space observations of inland water bodies show rapid surface warming since 1985. Geophys. Res. Lett., 37, L22405, doi:10.1029/2010GL045059.

Schneider, T., T. Bischoff, and G. H. Haug, 2014: Migrations and dynamics of the intertropical convergence zone. Nature, 513, 45-53, doi:10.1038/nature13636.

Schneider, U., A. Becker, P. Finger, A. Meyer-Christoffer, and M. Ziese, 2015: GPCC Monitoring Product: Near Real-Time Monthly Land-Surface Precipitation From Rain-Gauges Based on SYNOP and CLIMAT Data. Global Precipitation Climatology Centre (GPCC), Ed., Deutscher Wetterdienst, doi:10.5676/DWD_GPCC/MP_M_V5_100.

Schofield, O., L. Newman, P. Bricher, A. Constable, S. Swart, and A. Wåhlin, 2016: Moving towards implementation of a Southern Ocean observing system. Mar. Technol. Soc. J., 50 (3), 63-68, doi:10.4031/MTSJ.50.3.8.

Schreck, C. J., 2015: Kelvin waves and tropical cyclogenesis: A global survey. Mon. Wea. Rev., 143, 3996-4011, doi:10.1175/mwr-d-15-0111.1.

_ 2016: Convectively coupled Kelvin waves and tropical cyclogenesis in a semi-Lagrangian framework. Mon. Wea. Rev., 144, 4131-4139, doi:10.1175/mwr-d-16-0237.1.

__, and J. Molinari, 2011: Tropical cyclogenesis associated with Kelvin waves and the Madden-Julian oscillation. Mon. Wea. Rev., 139, 2723-2734, doi:10.1175/mwr -d-10-05060.1.

$\longrightarrow,-$, and A. Aiyyer, 2012: A global view of equatorial waves and tropical cyclogenesis. Mon. Wea. Rev., 140, 774-788, doi:10.1175/mwr-d-11-00110.1.

—, J. M. Cordeira, and D. Margolin, 2013: Which MJO events affect North American temperatures? Mon. Wea. Rev., 141, 3840-3850, doi:10.1175/mwr-d-13-00118.1.

—, K. R. Knapp, and J. P. Kossin, 2014: The impact of best track discrepancies on global tropical cyclone climatologies using IBTrACS. Mon. Wea. Rev., 142, 3881-3899, doi:10.1175/mwr-d-14-00021.1.

Schuur, E. A. G., and Coauthors, 2008: Vulnerability of permafrost carbon to climate change: Implications for the global carbon cycle. BioScience, 58, 701-714, doi:10.1641 /B580807.

— - and Coauthors, 2013: Expert assessment of vulnerability of permafrost carbon to climate change. Climatic Change, 119, 359-374, doi:10.1007/s10584-013-0730-7.
- , and Coauthors, 2015: Climate change and the permafrost carbon feedback. Nature, 520, 171-179, doi:10.1038 /nature14338.

Schwietzke, S., and Coauthors, 2016: Upward revision of global fossil fuel methane emissions based on isotope database. Nature, 538, 88-91, doi:10.1038/nature19797.

Seddon, A. W. R., M. Macias-Fauria, P. R. Long, D. Benz, and K. J. Willis, 2016: Sensitivity of global terrestrial ecosystems to climate variability. Nature, 531, 229-232, doi:10.1038/nature16986.

Semiletov, I., and Coauthors, 2016: Acidification of East Siberian Arctic shelf waters through addition of freshwater and terrestrial carbon. Nat. Geosci., 9, 361-365, doi:10.1038/ngeo2695.

Send, U., M. Lankhorst, and T. Kanzow, 2011: Observation of decadal change in the Atlantic meridional overturning circulation using 10 years of continuous transport data. Geophys. Res. Lett., 38, L24606, doi:10.1029/2011GL049801.

Serreze, M. C., A. D. Crawford, J. C. Stroeve, A. P. Barrett, and R. A. Woodgate, 2016: Variability, trends, and predictability of seasonal sea ice retreat and advance in the Chukchi Sea. J. Geophys. Res. Oceans, 121, 7308-7325, doi:10.1002/2016JC011977.

Shay, L. K., G. J. Goni, and P. G. Black, 2000: Effects of a warm oceanic feature on Hurricane Opal. Mon. Wea. Rev., 128, 1366-1383, doi:10.1175/1520-0493(2000)128<1366 :eoawof $>2.0 . \mathrm{co} ; 2$.

Sherwood, S. C., and N. Nishant, 2015: Atmospheric changes through 2012 as shown by iteratively homogenized radiosonde temperature and wind data (IUKv2). Environ. Res. Lett., 10, 054007, doi:10.1088/1748-9326/10/5/054007. Shi, L., and J. J. Bates, 2011: Three decades of intersatellitecalibrated high-resolution infrared radiation sounder upper tropospheric water vapor. J. Geophys. Res., 116, D04108, doi:10.1029/2010JD014847.

Siegel, D. A., S. Maritorena, N. B. Nelson, M. J. Behrenfeld, and C. R. McClain, 2005: Colored dissolved organic matter and its influence on the satellite-based characterization of the ocean biosphere. Geophys. Res. Lett., 32, L20605, doi:10.1029/2005GL024310.

_ - and Coauthors, 2012: Global ocean phytoplankton [in "State of the Climate in 2011"]. Bull. Amer. Meteor. Soc., 93 (7), S89-S92, doi:10.1175/2012BAMSStateoftheClimate.1. _ of phytoplankton dynamics from the SeaWiFS mission. Remote Sens. Environ., 135, 77-91, doi:10.1016 /j.rse.2013.03.025.

Simmonds, I., 2015: Comparing and contrasting the behaviour of Arctic and Antarctic sea ice over the 35 year period 1979-2013. Ann. Glaciol., 56, 18-28, doi:10.3189/2015AoG69A909. 
Simmons, A. J., and P. Poli, 2015: Arctic warming in ERAInterim and other analyses. Quart. J. Roy. Meteor. Soc., 141, 1147-1162, doi:10.1002/qj.2422.

, K. M. Willett, P. D. Jones, P. W. Thorne, and D. P. Dee, 2010: Low-frequency variations in surface atmospheric humidity, temperature, and precipitation: Inferences from reanalyses and monthly gridded observational data sets. J. Geophys. Res., 115, D01110, doi:10.1029/2009JD012442.

—, P. Berrisford, D. P. Dee, H. Hersbach, S. Hirahara, and J. N. Thépaut, 2017: A reassessment of temperature variations and trends from global reanalyses and monthly surface climatological datasets. Quart. J. Roy. Meteor. Soc., 143, 101-119, doi:10.1002/qj.2949.

Singh, O. P., T. M. Ali Khan, and M. S. Rahman, 2000: Changes in the frequency of tropical cyclones over the north Indian Ocean. Meteor. Atmos. Phys., 75, 11-20, doi:10.1007/s007030070011.

Skliris, N., R. Marsh, S. A. Josey, S. A. Good, C. Liu, and R. P. Allan, 2014: Salinity changes in the World Ocean since 1950 in relation to changing surface freshwater fluxes. Climate Dyn., 43, 709-736, doi:10.1007/s00382-014-2131-7.

Slade, S. A., and E. D. Maloney, 2013: An intraseasonal prediction model of Atlantic and east Pacific tropical cyclone genesis. Mon. Wea. Rev., 141, 1925-1942, doi:10.1175 /mwr-d-12-00268.1.

Smeed, D. A., G. D. McCarthy, D. Rayner, B. I. Moat, W. E. Johns, M. O. Baringer, and C. S. Meinen, 2015: Atlantic Meridional Overturning Circulation Observed by the RAPID-MOCHA-WBTS (RAPID-Meridional Overturning Circulation and Heatflux Array-Western Boundary Time Series) Array at $26^{\circ} \mathrm{N}$ From 2004 to 2014. British Oceanographic Data Centre-Natural Environment Research Council, doi:10/6qb. [Available online at http://www.bodc.ac.uk/data/published_data _library/catalogue/10.5285/1a774e53-7383-2e9a-e053 $-6 c 86 a b c 0 d 8 c 7 /$.

Smith, S. (L.), and J. Brown, 2009: Assessment of the status of the development of the standards for the Terrestrial Essential Climate Variables (T7): Permafrost and seasonally frozen ground. Global Terrestrial Observing System Rep. 62, 24 pp. [Available online at http://www.fao.org /gtos/doc/ecvs/t07/t07.pdf.]

—, A. G. Lewkowicz, C. Duchesne, and M. Ednie, 2015: Variability and change in permafrost thermal state in northern Canada. Proc. 68th Canadian Geotechnical Conf. and Seventh Canadian Conf. on Permafrost (GEOQuébec 2015), Quebec, Canada, GEOQuébec 2015, Paper 237.

—, J. Chartrand, C. Duchesne, and M. Ednie, 2016: Report on 2015 field activities and collection of ground thermal and active layer data in the Mackenzie Corridor, Northwest Territories. Geological Survey of Canada Open File 8125, 133 pp. [Available online at http://dx.doi .org/10.4095/299296.]
Smith, T. M., and R. W. Reynolds, 1998: A high-resolution global sea surface temperature climatology for the 196190 base period. J. Climate, 11, 3320-3323, doi:10.1175/1520 -0442(1998)011<3320:ahrgss >2.0.co;2.

$\longrightarrow,-$ T. C. Peterson, and J. Lawrimore, 2008: Improvements to NOAA's historical merged land-ocean surface temperature analysis (1880-2006). J. Climate, 21, 22832296, doi:10.1175/2007jcli2100.1.

Smol, J. P., and M. S. V. Douglas, 2007: Crossing the final ecological threshold in high Arctic ponds. Proc. Natl. Acad. Sci. USA, 104, 12,395-12,397, doi:10.1073 /pnas.0702777104.

—_, and Coauthors, 2005: Climate-driven regime shifts in the biological communities of Arctic lakes. Proc. Natl. Acad. Sci. USA, 102, 4397-4402, doi:10.1073 /pnas.0500245102.

Solomon, S., J. S. Daniel, R. R. Neely, J.-P. Vernier, E. G. Dutton, and L. W. Thomason, 2011: The persistently variable "background" stratospheric aerosol layer and global climate change. Science, 333, 866-870, doi:10.1126 /science.1206027.

—, D. J. Ivy, D. Kinnison, M. J. Mills, R. R. Neely, and A. Schmidt, 2016: Emergence of healing in the Antarctic ozone layer. Science, 353, 269-274, doi:10.1126/science .aae0061.

Solorzano, N. N., J. N. Thomas, and R. H. Holzworth, 2008: Global studies of tropical cyclones using the world wide lightning location network. Third Conf. Meteorological Applications of Lightning Data, New Orleans, LA, Amer. Meteor. Soc. [Available online at http://ams.confex.com /ams/88Annual/webprogram/Paper134367.html.]

Song, J.-J., Y. Wang, and L. Wu, 2010: Trend discrepancies among three best track data sets of western North Pacific tropical cyclones. J. Geophys. Res., 115, D12128, doi:10.1029/2009JD013058.

Soruco, A., C. Vincent, A. Rabatel, B. Francou, E. Thibert, J. E. Sicart, and T. Condom, 2015: Contribution of glacier runoff to water resources of La Paz city, Bolivia $\left(16^{\circ} \mathrm{S}\right)$. Ann. Glaciol., 56, 147-154, doi:10.3189/2015AoG70A001. SPARC, 2016: SPARC Report on the mystery of carbon tetrachloride. SPARC Report No. 7, WCRP-13/2016, 52 pp. [Available online at http://www.sparc-climate.org /publications/sparc-reports/sparc-report-no7.]

Spencer, R. W., J. R. Christy, and W. D. Braswell, 2017: UAH Version 6 global satellite temperature products: Methodology and results. Asia-Pacific J. Atmos. Sci., 53, 121-130, doi:10.1007/s13143-017-0010-y.

Spreen, G., L. Kaleschke, and G. Heygster, 2008: Sea ice remote sensing using AMSR-E 89-GHz channels. J. Geophys. Res., 113, C02s03, doi:10.1029/2005JC003384. 
Srokosz, M. A., and H. L. Bryden, 2015: Observing the Atlantic meridional overturning circulation yields a decade of inevitable surprises. Science, 348, 1255575, doi:10.1126 /science.1255575.

— in the Atlantic meridional overturning circulation. Bull. Amer. Meteor. Soc., 93, 1663-1676, doi:10.1175/bams -d-11-00151.1.

Stackhouse, P. W., D. P. Kratz, G. R. McGarragh, S. K. Gupta, and E. B. Geier, 2006: Fast longwave and shortwave radiative flux (FLASHFlux) products from CERES and MODIS measurements. Proc. 12th Conf. Atmospheric Radiation, Madison, WI, Amer. Meteor. Soc., P1.10. [Available online at http://ams.confex.com/ams/pdfpapers/113479.pdf.]

— T. Wong, D. P. Kratz, P. Sawaengphokhai, A. C. Wiber, S. K. Gupta, and N. G. Loeb, 2016: Earth radiation budget at top-of-atmosphere [in "State of the Climate in 2015"]. Bull. Amer. Meteor. Soc., 97 (8), S41-S43, doi:10.1175 /2016BAMSStateoftheClimate.1.

Stammerjohn, S. (E.), Ed., 2016: Antarctica [in "State of the Climate in 2015”]. Bull. Amer. Meteor. Soc., 97 (8), S155S172, doi:10.1175/2016BAMSStateoftheClimate.1.

—, D. G. Martinson, R. C. Smith, X. Yuan, and D. Rind, 2008: Trends in Antarctic annual sea ice retreat and advance and their relation to El Niño-Southern Oscillation and southern annular mode variability. J. Geophys. Res., 113, C03S90, doi:10.1029/2007JC004269.

Steele, L. J., S. R. Lewis, M. R. Patel, F. Montmessin, F. Forget, and M. D. Smith, 2014: The seasonal cycle of water vapour on Mars from assimilation of thermal emission spectrometer data. Icarus, 237, 97-115, doi:10.1016 /j.icarus.2014.04.017.

Steinbrecht, W., and Coauthors, 2009: Ozone and temperature trends in the upper stratosphere at five stations of the network for the detection of atmospheric composition change. Int. J. Remote Sens., 30, 3875-3886, doi:10.1080/01431160902821841.

Steneck, R. S., and R. A. Wahle, 2013: American lobster dynamics in a brave new ocean. Canadian J. Fish. Aquatic Sci., 70, 1612-1624, doi:10.1139/cjfas-2013-0094.

Strahan, S. E., A. R. Douglass, P. A. Newman, and S. D. Steenrod, 2014: Inorganic chlorine variability in the Antarctic vortex and implications for ozone recovery. J. Geophys. Res. Atmos., 119, 14,098-14,109, doi:10.1002/2014JD022295.

— L. D. Oman, A. R. Douglass, and L. Coy, 2015: Modulation of Antarctic vortex composition by the quasibiennial oscillation. Geophys. Res. Lett., 42, 4216-4223, doi:10.1002/2015GL063759.
Strauss, J., L. Schirrmeister, G. Grosse, S. Wetterich, M. Ulrich, U. Herzschuh, and H.-W. Hubberten, 2013: The deep permafrost carbon pool of the Yedoma region in Siberia and Alaska. Geophys. Res. Lett., 40, 6165-6170, doi:10.1002/2013GL058088.

Stroh, J. N., G. Panteleev, S. Kirillov, M. Makhotin, and N. Shakhova, 2015: Sea-surface temperature and salinity product comparison against external in situ data in the Arctic Ocean. J. Geophys. Res. Oceans, 120, 7223-7236, doi:10.1002/2015JC011005.

Su, Z., 2002: The surface energy balance system (SEBS) for estimation of turbulent heat fluxes. Hydrol. Earth Syst. Sci., 6, 85-100, doi:10.5194/hess-6-85-2002.

Sudo, K., and M. Takahashi, 2001: Simulation of tropospheric ozone changes during 1997-1998 El Niño: Meteorological impact on tropospheric photochemistry. Geophys. Res. Lett., 28, 4091-4094, doi:10.1029/2001GL013335.

Sun, L., and Coauthors, 2016: Significant increase of summertime ozone at Mount Tai in central eastern China. Atmos. Chem. Phys., 16, 10,637-10,650, doi:10.5194/acp -16-10637-2016.

Sun, W., P. Hess, and B. Tian, 2014: The response of the equatorial tropospheric ozone to the Madden-Julian Oscillation in TES satellite observations and CAM-chem model simulation. Atmos. Chem. Phys., 14, 11,775-11,790, doi:10.5194/acp-14-11775-2014.

Sweet, W. V., and J. Park, 2014: From the extreme to the mean: Acceleration and tipping points of coastal inundation from sea level rise. Earth's Future, 2, 579-600, doi:10.1002/2014EF000272.

_ _ J. J. J. Marra, C. Zervas, and S. Gill, 2014: Sea level rise and nuisance flood frequency changes around the United States. NOAA Tech. Rep. NOS CO-OPS 73, 58 pp. [Available online at http://tidesandcurrents.noaa .gov/publications/NOAA_Technical_Report_NOS _COOPS_073.pdf.]

- M. Menendez, A. Genz, J. Obeysekera, J. Park, and J. J. Marra, 2016: In tide's way: Southeast Florida's September 2015 sunny-day flood [in "Explaining Extreme Events of 2015 From a Climate Perspective"]. Bull. Amer. Meteor. Soc., 97 (12), S25-S30, doi:10.1175/bams-d-16-0117.1.

Takala, M., and Coauthors, 2011: Estimating Northern Hemisphere snow water equivalent for climate research through assimilation of space-borne radiometer data and ground-based measurements. Remote Sens. Environ., 115, 3517-3529, doi:10.1016/j.rse.2011.08.014.

Talmage, S. C., and C. J. Gobler, 2010: Effects of past, present, and future ocean carbon dioxide concentrations on the growth and survival of larval shellfish. Proc. Natl. Acad. Sci. USA, 107, 17,246-17,251, doi:10.1073 /pnas.0913804107. 
Tanskanen, A., A. Arola, and J. Kujanpaa, 2003: Use of the moving time-window technique to determine surface albedo from TOMS reflectivity data. Proc. SPIE, $\mathbf{4 8 9 6}$, 239-250, doi:10.1117/12.483407.

Tapley, B. D., S. Bettadpur, J. C. Ries, P. F. Thompson, and M. M. Watkins, 2004: GRACE measurements of mass variability in the Earth system. Science, 305, 503-505, doi:10.1126/science.1099192.

Tarnocai, C., J. G. Canadell, E. A. G. Schuur, P. Kuhry, G. Mazhitova, and S. Zimov, 2009: Soil organic carbon pools in the northern circumpolar permafrost region. Global Biogeochem. Cycles, 23, GB2023, doi:10.1029/2008GB003327.

Taylor, C. C., H. B. Bigelow, and H. W. Graham, 1957: Climatic trends and the distribution of marine animals in New England. Fisheries Bull., 57 (115), 293-345.

Tedesco, M., 2009: Assessment and development of snowmelt retrieval algorithms over Antarctica from K-band spaceborne brightness temperature (1979-2008). Remote Sens. Environ., 113, 979-997, doi:10.1016/j.rse.2009.01.009.

_ record through 2009 and its linkages to high-latitude and tropical climate variability. Geophys. Res. Lett., 36, L18502, doi:10.1029/2009GL039186.

— X. Fettweis, T. Mote, J. Wahr, P. Alexander, J. E. Box, and B. Wouters, 2013: Evidence and analysis of 2012 Greenland records from spaceborne observations, a regional climate model and reanalysis data. Cryosphere, 7 , 615-630, doi:10.5194/tc-7-615-2013.

—, and Coauthors, 2016a: Greenland ice sheet. Arctic Report Card 2016, NOAA's Arctic Program, various paging. [Available online at http://www.arctic.noaa.gov/Report -Card/Report-Card-2016.]

— , and Coauthors, 2016b: Greenland ice sheet [in "State of the Climate in 2015”]. Bull. Amer. Meteor. Soc., 97 (8), S140-S142, doi:10.1175/2016BAMSStateoftheClimate.1.

- , and Coauthors, 2016c: Arctic cut-off high drives the poleward shift of a new Greenland melting record. Nat. Comm., 7, 11723, doi:10.1038/ncomms11723.

Teng, W.-H., C.-Y. Huang, S.-P. Ho, Y.-H. Kuo, and X.-J. Zhou, 2013: Characteristics of global precipitable water in ENSO events revealed by COSMIC measurements. J. Geophys. Res. Atmos., 118, 8411-8425, doi:10.1002/jgrd.50371.

Thackeray, C., C. Fletcher, L. Mudryk, and C. Derksen, 2016: Quantifying the uncertainty in historical and future simulations of Northern Hemisphere spring snow cover. J. Climate, 29, 8647-8663, doi:10.1175/jcli-d-16-0341.1.

Thompson, P. R., M. A. Merrifield, J. R. Wells, and C. M. Chang, 2014: Wind-driven coastal sea level variability in the northeast Pacific. J. Climate, 27, 4733-4751, doi:10.1175/jcli-d-13-00225.1.
—, C. G. Piecuch, M. A. Merrifield, J. P. McCreary, and E. Firing, 2016: Forcing of recent decadal variability in the equatorial and north Indian Ocean. J. Geophys. Res. Oceans, 121, 6762-6778, doi:10.1002/2016JC012132.

Thomson, L., M. Zemp, L. Copland, J. Cogley, and M. Ecclestone, 2017: Comparison of geodetic and glaciological mass budgets for White Glacier, Axel Heiberg Island, Canada. J. Glaciol., 63, 55-66, doi:10.1017/jog.2016.112.

Tilling, R. L., A. Ridout, A. Shepherd, and D. J. Wingham, 2015: Increased Arctic sea ice volume after anomalously low melting in 2013. Nat. Geosci., 8, 643-646, doi:10.1038 /ngeo2489.

Timmermans, M.-L., and A. Proshutinsky, 2015: Sea surface temperature [in "State of the Climate in 2014"]. Bull. Amer. Meteor. Soc., 96 (7), S147-S148, doi:10.1175 /2015BAMSStateoftheClimate.1.

— the Climate in 2015”]. Bull. Amer. Meteor. Soc., 97 (8), S137-S138, doi:10.1175/2016BAMSStateoftheClimate.1.

Tippett, M. K., S. J. Camargo, and A. H. Sobel, 2011: A Poisson regression index for tropical cyclone genesis and the role of large-scale vorticity in genesis. J. Climate, 24, 2335-2357, doi:10.1175/2010jcli3811.1.

Torbick, N., B. Ziniti, S. Wu, and E. Linder, 2016: Spatiotemporal lake skin summer temperature trends in the northeast United States. Earth Interact., 20 (25), 1-21, doi:10.1175/ei-d-16-0015.1.

Trenberth, K. E., A. Dai, R. M. Rasmussen, and D. B. Parsons, 2003: The changing character of precipitation. Bull. Amer. Meteor. Soc., 84, 1205-1217, doi:10.1175/bams-84-9-1205.

Trepte, Q. Z., P. Minnis, C. R. Trepte, S. Sun-Mack, and R. Brown, 2010: Improved cloud detection in CERES edition 3 algorithm and comparison with the CALIPSO vertical feature mask. Proc. 13th Conf. Atmospheric Radiation and Cloud Physics, Portland, OR, Amer. Meteor. Soc., JP1.32.

Tschudi, M., C. Fowler, J. Maslanik, and J. Stroeve, 2010: Tracking the movement and changing surface characteristics of Arctic sea ice. IEEE J. Sel. Topics Appl. Earth Obs. Remote Sens., 3, 536-540, doi:10.1109 /JSTARS.2010.2048305.

—_ —_, and —_, 2015: EASE-Grid Sea Ice Age, Version 2. National Snow and Ice Data Center, doi:10.5067/1UQJWCYPVX61.

Turner, J., and Coauthors, 2004: The SCAR READER project: Toward a high-quality database of mean Antarctic meteorological observations. J. Climate, 17, 2890-2898, doi:10.1175/1520-0442(2004)017<2890:tsrpta>2.0.co;2.

_ and Coauthors, 2016: Absence of 21st century warming on Antarctic Peninsula consistent with natural variability. Nature, 535, 411-415, doi:10.1038/nature18645. 
Tweedy, O. V., and Coauthors, 2017: Response of trace gases to the disrupted 2015-2016 quasi-biennial oscillation. Atmos. Chem. Phys., 17, 6813-6823, doi:10.5194/acp-17 -6813-2017.

van As, D., R. S. Fausto, J. Cappelen, R. S. W. Van de Wal, R. J. Braithwaite, H. Machguth, and PROMICE project team, 2016: Placing Greenland ice sheet ablation measurements in a multi-decadal context. Geol. Surv. Denmark Greenland Bull. 35, 71-74 pp. [Available online at http://www .geus.dk/DK/publications/geol-survey-dk-gl-bull/35 /Documents/nr35_p71-74.pdf.]

van de Wal, R. S. W., W. Greuell, M. R. van den Broeke, C. H. Reijmer, and J. Oerlemans, 2005: Surface mass-balance observations and automatic weather station data along a transect near Kangerlussuaq, West Greenland. Ann. Glaciol., 42, 311-316, doi:10.3189/172756405781812529.

—, W. Boot, C. J. P. P. Smeets, H. Snellen, M. R. van den Broeke, and J. Oerlemans, 2012: Twenty-one years of mass balance observations along the K-transect, West Greenland. Earth Syst. Sci. Data, 4, 31-35, doi:10.5194 lessd-4-31-2012.

van der A, R. J., M. A. F. Allaart, and H. J. Eskes, 2015: Extended and refined multi sensor reanalysis of total ozone for the period 1970-2012. Atmos. Meas. Tech., 8, 3021-3035, doi:10.5194/amt-8-3021-2015.

van der Schrier, G., J. Barichivich, K. R. Briffa, and P. D. Jones, 2013a: A scPDSI-based global data set of dry and wet spells for 1901-2009. J. Geophys. Res. Atmos., 118, 4025-4048, doi:10.1002/jgrd.50355.

_ E. J. M. van den Besselaar, A. M. G. Klein Tank, and G. Verver, 2013b: Monitoring European average temperature based on the E-OBS gridded data set. J. Geophys. Res. Atmos., 118, 5120-5135, doi:10.1002/jgrd.50444.

— J. Barichivich, I. Harris, P. D. Jones, and T. J. Osborn, 2015: Monitoring global drought using the self-calibrating Palmer Drought Severity Index [in "State of the Climate in 2014”]. Bull. Amer. Meteor. Soc., 96 (7), S30-S31, doi :10.1175/2015BAMSStateoftheClimate.1.

van der Werf, G. R., and Coauthors, 2010: Global fire emissions and the contribution of deforestation, savanna, forest, agricultural, and peat fires (1997-2009). Atmos. Chem. Phys., 10, 11,707-11,735, doi:10.5194/acp-10-11707-2010.

Vautard, R., J. Cattiaux, P. Yiou, J.-N. Thepaut, and P. Ciais, 2010: Northern Hemisphere atmospheric stilling partly attributed to an increase in surface roughness. Nat. Geosci., 3, 756-761, doi:10.1038/ngeo979.

Velders, G. J. M., S. O. Andersen, J. S. Daniel, D. W. Fahey, and M. McFarland, 2007: The importance of the Montreal Protocol in protecting climate. Proc. Natl. Acad. Sci. USA, 104, 4814-4819, doi:10.1073/pnas.0610328104.
Velicogna, I., T. C. Sutterley, and M. R. van den Broeke, 2014: Regional acceleration in ice mass loss from Greenland and Antarctica using GRACE time-variable gravity data. Geophys. Res. Lett., 41, 8130-8137, doi:10.1002/2014GL061052.

Ventrice, M. J., C. D. Thorncroft, and M. A. Janiga, 2012a: Atlantic tropical cyclogenesis: A three-way interaction between an African easterly wave, diurnally varying convection, and a convectively coupled atmospheric Kelvin wave. Mon. Wea. Rev., 140, 1108-1124, doi:10.1175 /mwr-d-11-00122.1.

— — - and C. J. Schreck, III, 2012b: Impacts of convectively coupled Kelvin waves on environmental conditions for Atlantic tropical cyclogenesis. Mon. Wea. Rev., 140, 2198-2214, doi:10.1175/mwr-d-11-00305.1.

Vernier, J. P., and Coauthors, 2011: Major influence of tropical volcanic eruptions on the stratospheric aerosol layer during the last decade. Geophys. Res. Lett., 38, L12807, doi:10.1029/2011GL047563.

Vicente-Serrano, S. M., S. Beguería, and J. I. LópezMoreno, 2010: A multiscalar drought index sensitive to global warming: The standardized precipitation evapotranspiration index. J. Climate, 23, 1696-1718, doi:10.1175/2009jcli2909.1.

Vieira, G., and Coauthors, 2016: Thermal state of permafrost and recent active layer dynamics in the South Shetlands, Antarctica. XI. Int. Conf. Permafrost, Potsdam, Germany, Bibliothek Wissenschaftspark Albert Einstein.

Vigouroux, C., and Coauthors, 2015: Trends of ozone total columns and vertical distribution from FTIR observations at eight NDACC stations around the globe. Atmos. Chem. Phys., 15, 2915-2933, doi:10.5194/acp-15-2915-2015.

Vimont, D. J., and J. P. Kossin, 2007: The Atlantic meridional mode and hurricane activity. Geophys. Res. Lett., 34, L07709, doi:10.1029/2007GL029683.

Vincent, D. G., 1994: The South Pacific convergence zone (SPCZ): A review. Mon. Wea. Rev., 122, 1949-1970, doi:10.1175/1520-0493(1994)122<1949:tspcza>2.0.co;2.

Vinukollu, R. K., R. Meynadier, J. Sheffield, and E. F. Wood, 2011: Multi-model, multi-sensor estimates of global evapotranspiration: Climatology, uncertainties and trends. Hydrol. Proc., 25, 3993-4010, doi:10.1002 /hyp.8393.

Vivier, F., D. Iudicone, F. Busdraghi, and Y.-H. Park, 2010: Dynamics of sea-surface temperature anomalies in the Southern Ocean diagnosed from a 2D mixed-layer model. Climate Dyn., 34, 153-184, doi:10.1007/s00382 -009-0724-3.

Von Storch, H., and F. W. Zwiers, 1999: Statistical Analysis in Climate Research. Cambridge University Press, 484 pp. 
Voulgarakis, A., P. Hadjinicolaou, and J. A. Pyle, 2011: Increases in global tropospheric ozone following an El Niño event: Examining stratospheric ozone variability as a potential driver. Atmos. Sci. Lett., 12, 228-232, doi:10.1002/asl.318.

Wagner, W., W. Dorigo, R. d. Jeu, D. Fernandez-Prieto, J. Benveniste, E. Haas, and M. Ertl, 2012: Fusion of active and passive microwave observations to create an essential climate variable data record on soil moisture. Proc. XXIII SPRS Congress, Melbourne, Australia, Intl. Society for Photogrammetry and Remote Sensing, doi:10.5194 /isprsannals-I-5197-5315-2012.

Waliser, D. E., and C. Gautier, 1993: A satellite-derived climatology of the ITCZ. J. Climate, 6, 2162-2174, doi:10.1175/1520-0442(1993)006<2162:asdcot>2.0.co;2.

Walsh, J. E., P. A. Bieniek, B. Brettschneider, E. S. Euskirchen, R. Lader, and R. L. Thoman, 2017: The exceptionally warm winter of 2015/16 in Alaska. J. Climate, 30, 2069-2088, doi:10.1175/jcli-d-16-0473.1.

Walter Anthony, K. M., and Coauthors, 2014: A shift of thermokarst lakes from carbon sources to sinks during the Holocene epoch. Nature, 511, 452-456, doi:10.1038 /nature13560.

Walter, K. M., M. E. Edwards, G. Grosse, S. A. Zimov, and F. S. Chapin III, 2007: Thermokarst lakes as a source of atmospheric CH4 during the last deglaciation. Science, 318, 633-636, doi:10.1126/science.1142924

Wan, H., X. L. Wang, and V. R. Swail, 2010: Homogenization and trend analysis of Canadian near-surface wind speeds. J. Climate, 23, 1209-1225, doi:10.1175/2009jcli3200.1.

Wang, B., and J. Chan, 2002: How strong ENSO events affect tropical storm activity over the western North Pacific. J. Climate, 15, 1643-1658, doi:10.1175/1520 -0442(2002)015<1643:hseeat $>2.0 . c 0 ; 2$.

— of annual variation in the tropics. Dyn. Atmos. Oceans, 44, 165-183, doi:10.1016/j.dynatmoce.2007.05.002.

_ J. Liu, H.-J. Kim, P. J. Webster, and S.-Y. Yim, 2012: Recent change of the global monsoon precipitation (1979-2008). Climate Dyn., 39, 1123-1135, doi:10.1007 /s00382-011-1266-z.

Wang, C., 2015: Atlantic warm pool [in "State of the Climate in 2014”]. Bull. Amer. Meteor. Soc., 96 (7), S123-S124, doi $: 10.1175 / 2015 B A M S S t a t e o f t h e C l i m a t e .1$.

Wang, G., Y. Li, Y. Wang, and Q. Wu, 2008: Effects of permafrost thawing on vegetation and soil carbon pool losses on the Qinghai-Tibet Plateau, China. Geoderma, 143, 143-152, doi:10.1016/j.geoderma.2007.10.023.

Wang, J., L. Zhang, A. Dai, T. Van Hove, and J. Van Baelen, 2007: A near-global, 2-hourly data set of atmospheric precipitable water from ground-based GPS measurements. J. Geophys. Res., 112, D11107, doi:10.1029/2006JD007529.
—, A. Dai, and C. Mears, 2016: Global water vapor trend from 1988 to 2011 and its diurnal asymmetry based on GPS, radiosonde, and microwave satellite measurements. J. Climate, 29, 5205-5222, doi:10.1175/jcli-d-15-0485.1.

Wang, S., X. Mo, S. Liu, Z. Lin, and S. Hu, 2016: Validation and trend analysis of ECV soil moisture data on cropland in North China Plain during 1981-2010. Int. J. Appl. Earth Obs. Geoinf., 48, 110-121, doi:10.1016/j.jag.2015.10.010.

Wang, T., L. Xue, P. Brimblecombe, Y. F. Lam, L. Li, and L. Zhang, 2017: Ozone pollution in China: A review of concentrations, meteorological influences, chemical precursors, and effects. Sci. Total Environ., 575, 1582-1596, doi:10.1016/j.scitotenv.2016.10.081.

Wanninkhof, R., 2014: Relationship between wind speed and gas exchange over the ocean revisited. Limnol. Oceanogr.: Methods, 12, 351-362, doi:10.4319/lom.2014.12.351.

- , and J. Triñanes, 2017: The impact of changing wind speeds on gas transfer and its effect on global air-sea $\mathrm{CO}_{2}$ fluxes. Global Biogeochem. Cycles, 31, 961-974 doi:10.1002/2016GB005592.

Weatherhead, B., A. Tanskanen, and A. Stevermer, 2005: Ozone and ultraviolet radiation. Arctic Climate Impact Assessment, Cambridge University Press, 151-182.

Weber, M., and Coauthors, 2011: The Brewer-Dobson circulation and total ozone from seasonal to decadal time scales. Atmos. Chem. Phys., 11, 11,221-11,235, doi:10.5194 /acp-11-11221-2011.

Wells, N., S. Goddard, and M. J. Hayes, 2004: A selfcalibrating Palmer drought severity index. J. Climate, 17, 2335-2351, doi:10.1175/1520-0442(2004)017<2335 :aspdsi>2.0.co;2.

Wentz, F. J., 1997: A well-calibrated ocean algorithm for special sensor microwave / imager. J. Geophys. Res., 102, 8703-8718, doi:10.1029/96JC01751.

—, L. Ricciardulli, K. Hilburn, and C. Mears, 2007: How much more rain will global warming bring? Science, 317, 233-235, doi:10.1126/science.1140746.

Wever, N., 2012: Quantifying trends in surface roughness and the effect on surface wind speed observations. J. Geophys. Res., 117, D11104, doi:10.1029/2011JD017118.

WGMS, 2015: Global Glacier Change Bulletin No. 1 (20122013). M. Zemp et al., Eds., World Glacier Monitoring Service, $230 \mathrm{pp}$.

__ cited 2017: Latest glacier mass balance data, World Glacier Monitoring Service. [Available online at http:// wgms.ch/latest-glacier-mass-balance-data/.]

Wheeler, M. C., and G. N. Kiladis, 1999: Convectively coupled equatorial waves: Analysis of clouds and temperature in the wavenumber-frequency domain. J. Atmos. Sci., 56, 374-399, doi:10.1175/1520-0469(1999)056<0374 :ccewao $>2.0 . c 0 ; 2$. 
— tivariate MJO index: Development of an index for monitoring and prediction. Mon. Wea. Rev., 132, 1917-1932, doi:10.1175/1520-0493(2004)132<1917:aarmmi>2.0.co;2.

WHO, 2002: Global solar UV index: A practical guide. WHO/SDE/OEH/02.2, 28 pp. [Available online at http:// www.who.int/uv/publications/en/GlobalUVI.pdf.]

_ 2013: Review of evidence on health aspects of air pollution - REVIHAAP project: Final technical report. 302 pp. [Available online at http://www.euro.who.int/_data /assets/pdf_file/0004/193108/REVIHAAP-Final-technical-report-final-version.pdf?ua=1.]

Widlansky, M. J., A. Timmermann, S. McGregor, M. F. Stuecker, and W. Cai, 2014: An interhemispheric tropical sea level seesaw due to El Niño taimasa. J. Climate, 27, 1070-1081, doi:10.1175/jcli-d-13-00276.1.

Wielicki, B. A., B. R. Barkstrom, E. F. Harrison, R. B. Lee III, G. L. Smith, and J. E. Cooper, 1996: Clouds and the Earth's radiant energy system (CERES): An Earth observing system experiment. Bull. Amer. Meteor. Soc., 77, 853-868, doi:10.1175/1520-0477(1996)077<0853:catere>2.0.co;2.

__, and Coauthors, 1998: Clouds and the Earth's radiant energy system (CERES): Algorithm overview. IEEE Trans. Geosci. Remote Sens., 36, 1127-1141, doi:10.1109/36.701020.

Wijffels, S., D. Roemmich, D. Monselesan, J. Church, and J. Gilson, 2016: Ocean temperatures chronicle the ongoing warming of Earth. Nat. Climate Change, 6, 116-118, doi:10.1038/nclimate2924.

Wild, J. D., S.-K. Yang, and C. S. Long, 2016: Ozone profile trends: An SBUV/2 perspective. Quadrennial Ozone Symp. 2016, Edinburgh, United Kingdom, QOS2016-2133.

Wilks, D., 2011: Statistical Methods in the Atmospheric Sciences. 3rd ed. Vol. 100, International Geophysics, Academic Press, 704 pp.

Willett, K. M., P. D. Jones, N. P. Gillett, and P. W. Thorne, 2008: Recent changes in surface humidity: Development of the HadCRUH dataset. J. Climate, 21, 5364-5383, doi:10.1175/2008jcli2274.1.

— surface specific humidity product for climate monitoring. Climate Past, 9, 657-677, doi:10.5194/cp-9-657-2013.

—_ and Coauthors, 2014: HadISDH land surface multivariable humidity and temperature record for climate monitoring. Climate Past, 10, 1983-2006, doi:10.5194 /cp-10-1983-2014.

Willis, J. K., 2010: Can in situ floats and satellite altimeters detect long-term changes in Atlantic Ocean overturning? Geophys. Res. Lett., 37, L06602, doi:10.1029/2010GL042372.
_- D. Roemmich, and B. Cornuelle, 2004: Interannual variability in upper ocean heat content, temperature, and thermosteric expansion on global scales. J. Geophys. Res., 109, C12036, doi:10.1029/2003JC002260.

Winker, D. M., W. H. Hunt, and M. J. McGill, 2007: Initial performance assessment of CALIOP. Geophys. Res. Lett., 34, L19803, doi:10.1029/2007GL030135.

WMO, 2014: Scientific assessment of ozone depletion, 2014. Global Ozone Research and Monitoring Project-Report No. 55, various pp. [Available online at http://www.wmo .int/pages/prog/arep/gaw/ozone_2014/ozone_asst_report .html.]

WMO, 2017: WMO Statement on the state of the global climate in 2016. WMO 1189, World Meteorological Organization, 24 pp. [Available online at https://library.wmo .int/opac/doc_num.php?explnum_id=3414.]

WMO-GNR, 2017: German national report. 10th meeting of WMO/UNEP Ozone Research Managers, Geneva, Switzerland, DWD Hohenpeissenberg, 23 pp. [Available online at http://conf.montreal-protocol.org/meeting/orm/10orm /presession/SiteAssets/Germany_National_Report_2017 .pdf.]

Wolter, K., and M. S. Timlin, 1993: Monitoring ENSO in COADS with a seasonally adjusted principal component index. Proc. 17th Climate Diagnostics Workshop, Norman, OK, NOAA/NMC/CAC, NSSL, Oklahoma Climate Survey, CIMMS, and the School of Meteor., Univ. of Oklahoma, 52-57.

-_, and —-, 1998: Measuring the strength of ENSO events: How does 1997/98 rank? Weather, 53, 315-324, doi:10.1002/j.1477-8696.1998.tb06408.x.

Woods, C., and R. Caballero, 2016: The role of moist intrusions in winter Arctic warming and sea ice decline. J. Climate, 29, 4473-4485, doi:10.1175/jcli-d-15-0773.1.

Woolway, R. I., and Coauthors, 2016: Lake surface temperatures [in "State of the Climate in 2015"]. Bull. Amer. Meteor. Soc., 97 (8), S17-S18, doi:10.1175 /2016BAMSStateoftheClimate.1.

Woosley, R. J., F. J. Millero, and R. Wanninkhof, 2016: Rapid anthropogenic changes in $\mathrm{CO} 2$ and $\mathrm{pH}$ in the Atlantic Ocean: 2003-2014. Global Biogeochem. Cycles, 30, 70-90, doi:10.1002/2015GB005248.

Worden, H. M., and Coauthors, 2013: Decadal record of satellite carbon monoxide observations. Atmos. Chem. Phys., 13, 837-850, doi:10.5194/acp-13-837-2013.

Wu, J., J. Zha, and D. Zhao, 2016: Estimating the impact of the changes in land use and cover on the surface wind speed over the East China Plain during the period 1980-2011. Climate Dyn., 46, 847-863, doi:10.1007/s00382-015 $-2616-z$. 
Wu, Lia., Z. Wen, R. Huang, and R. Wu, 2012: Possible linkage between the monsoon trough variability and the tropical cyclone activity over the western North Pacific. Mon. Wea. Rev., 140, 140-150, doi:10.1175/mwr-d-11-00078.1.

$\mathrm{Wu}$, Lix., and Coauthors, 2012: Enhanced warming over the global subtropical western boundary currents. Nat. Climate Change, 2, 161-166, doi:10.1038/nclimate1353.

Wu, M.-C., K.-H. Yeung, and W.-L. Chang, 2006: Trends in western North Pacific tropical cyclone intensity. Eos, Trans. Amer. Geophys. Union, 87, 537-538, doi:10.1029/2006EO480001.

Wylie, D., D. L. Jackson, W. P. Menzel, and J. J. Bates, 2005: Trends in global cloud cover in two decades of HIRS observations. J. Climate, 18, 3021-3031, doi:10.1175 /jcli3461.1.

Xie, P., and P. A. Arkin, 1997: Global precipitation: A 17year monthly analysis based on gauge observations, satellite estimates, and numerical model outputs. Bull. Amer. Meteor. Soc., 78, 2539-2558, doi:10.1175/1520 -0477(1997)078<2539:gpayma>2.0.co;2.

_ , and Coauthors, 2014: An in situ-satellite blended analysis of global sea surface salinity. J. Geophys. Res. Oceans, 119, 6140-6160, doi:10.1002/2014JC010046.

Xie, S.-P., Y. Kosaka, and Y. M. Okumura, 2016: Distinct energy budgets for anthropogenic and natural changes during global warming hiatus. Nat. Geosci., 9, 29-33, doi:10.1038/ngeo2581.

Xu, G., T. J. Osborn, A. J. Matthews, and M. M. Joshi, 2016: Different atmospheric moisture divergence responses to extreme and moderate El Niños. Climate Dyn., 47, 393-410, doi:10.1007/s00382-015-2844-2.

$\mathrm{Xu}, \mathrm{H} ., 2006$ : Modification of normalised difference water index (NDWI) to enhance open water features in remotely sensed imagery. Int. J. Remote Sens., 27, 3025-3033, doi:10.1080/01431160600589179.

Xu, M., C.-P. Chang, C. Fu, Y. Qi, A. Robock, D. Robinson, and H.-M. Zhang, 2006: Steady decline of East Asian monsoon winds, 1969-2000: Evidence from direct ground measurements of wind speed. J. Geophys. Res., 111, D24111, doi:10.1029/2006JD007337.

Xu, W., W. Lin, X. Xu, J. Tang, J. Huang, H. Wu, and X. Zhang, 2016: Long-term trends of surface ozone and its influencing factors at the Mt. Waliguan GAW station, China - Part 1: Overall trends and characteristics. Atmos. Chem. Phys., 16, 6191-6205, doi:10.5194/acp-16-6191-2016.

Xue, Y., and A. Kumar, 2016: Evolution of the 2015/16 El Niño and historical perspective since 1979. Sci. China: Earth Sci., First Online, 1-17, doi:10.1007/s11430-016-0106-9.

-, Z.-Z. Hu, A. Kumar, V. Banzon, B. Huang, and J. Kennedy, 2016: Sea surface temperatures [in "State of the Climate in 2015”]. Bull. Amer. Meteor. Soc., 97 (8), S63-S66, doi :10.1175/2016BAMSStateoftheClimate.1.
Yashayaev, I., and J. W. Loder, 2016: Recurrent replenishment of Labrador Sea Water and associated decadal-scale variability. J. Geophys. Res. Oceans, 121, 8095-8114, doi:10.1002/2016JC012046.

Yim, S.-Y., B. Wang, J. Liu, and Z. Wu, 2014: A comparison of regional monsoon variability using monsoon indices. Climate Dyn., 43, 1423-1437, doi:10.1007/s00382-013-1956-9.

Yin, Y., F. Chevallier, P. Ciais, G. Broquet, A. FortemsCheiney, I. Pison, and M. Saunois, 2015: Decadal trends in global CO emissions as seen by MOPITT. Atmos. Chem. Phys., 15, 13,433-13,451, doi:10.5194/acp-15-13433-2015.

Ying, M., E.-J. Cha, and H. J. Kwon, 2011: Comparison of three western North Pacific tropical cyclone best track datasets in a seasonal context. J. Meteor. Soc. Japan, 89, 211-224, doi:10.2151/jmsj.2011-303.

Young, P. J., and Coauthors, 2013: Pre-industrial to end 21st century projections of tropospheric ozone from the atmospheric chemistry and climate model intercomparison project (ACCMIP). Atmos. Chem. Phys., 13, 2063-2090, doi:10.5194/acp-13-2063-2013.

Yu, H., Y. Lu, P.-Y. Chen, and W.-C. Zhou, 2012: Intensity change characteristics of tropical cyclones in the western North Pacific as revealed by three different datasets. J. Trop. Meteor., 18, 119-126, doi:10.3969/j.issn.1006 -8775.2012 .02 .002 .

Yu, L., 2011: A global relationship between the ocean water cycle and near-surface salinity. J. Geophys. Res., 116, C10025, doi:10.1029/2010JC006937.

, and X. Jin, 2012: Buoy perspective of a high-resolution global ocean vector wind analysis constructed from passive radiometers and active scatterometers (1987-present). J. Geophys. Res., 117, C11013, doi:10.1029/2012JC008069.

$\longrightarrow$, and _ 2014: Insights on the OAFlux ocean surface vector wind analysis merged from scatterometers and passive microwave radiometers (1987 onward). J. Geophys. Res. Oceans, 119, 5244-5269, doi:10.1002/2013JC009648.

Zemp, M., and Coauthors, 2015: Historically unprecedented global glacier decline in the early 21st century. J. Glaciol., 61 (228), 745-762. [Available online at https://www.igsoc .org/journal/61/228/j15j017.pdf.].

Zeng, N., 1999: Seasonal cycle and interannual variability in the Amazon hydrologic cycle. J. Geophys. Res., 104, 9097-9106, doi:10.1029/1998JD200088.

Zhang, C., 2005: Madden-Julian oscillation. Rev. Geophys., 43, RG2003, doi:10.1029/2004RG000158.

__, 2013: Madden-Julian oscillation: Bridging weather and climate. Bull. Amer. Meteor. Soc., 94, 1849-1870, doi:10.1175/bams-d-12-00026.1.

__, and J. Gottschalck, 2002: SST anomalies of ENSO and the Madden-Julian oscillation in the equatorial Pacific. J. Climate, 15, 2429-2445, doi:10.1175/1520 -0442 (2002)015<2429:saoeat $>2.0$. co;2. 
Zhang, X., and J. A. Church, 2012: Sea level trends, interannual and decadal variability in the Pacific Ocean. Geophys. Res. Lett., 39, L21701, doi:10.1029/2012GL053240.

— and Coauthors, 2011: Indices for monitoring changes in extremes based on daily temperature and precipitation data. Wiley Interdiscip. Rev.: Climate Change, 2, 851-870, doi:10.1002/wcc.147.

Zhang, Yo., and Coauthors, 2016: Multi-decadal trends in global terrestrial evapotranspiration and its components. Sci. Rep., 6, 19124, doi:10.1038/srep19124.

Zhang, Y., J. M. Wallace, and D. S. Battisti, 1997: ENSO-like interdecadal variability: 1900-93. J. Climate, 10, 10041020, doi:10.1175/1520-0442(1997)010<1004:eliv>2.0.co;2.

Zhang, Yu., O. R. Cooper, A. Gaudel, A. M. Thompson, P. Nedelec, S.-Y. Ogino, and J. J. West, 2016: Tropospheric ozone change from 1980 to 2010 dominated by equatorward redistribution of emissions. Nat. Geosci., 9, 875-879, doi:10.1038/ngeo2827.

Zhao, H., K. Higuchi, J. Waller, H. Auld, and T. Mote, 2013: The impacts of the PNA and NAO on annual maximum snowpack over southern Canada during 1979-2009. Int. J. Climatol., 33, 388-395, doi:10.1002/joc.3431.

Zheng, Z.-W., I. I. Lin, B. Wang, H.-C. Huang, and C.-H. Chen, 2015: A long neglected damper in the El Niñotyphoon relationship: A 'Gaia-like' process. Sci. Rep., 5, 11103, doi:10.1038/srep11103.

Ziemke, J. R., and O. R. Cooper, 2016: Tropospheric ozone [in "State of the Climate in 2015"]. Bull. Amer. Meteor. Soc., 97 (8), S73-S75, doi:10.1175/2016BAMSStateoftheClimate.1.

— S. Chandra, and P. K. Bhartia, 1998: Two new methods for deriving tropospheric column ozone from TOMS measurements: Assimilated UARS MLS/HALOE and convective-cloud differential techniques. J. Geophys. Res., 103, 22,115-22,127, doi:10.1029/98JD01567.

— S. Chandra, B. N. Duncan, L. Froidevaux, P. K. Bhartia, P. F. Levelt, and J. W. Waters, 2006: Tropospheric ozone determined from Aura OMI and MLS: Evaluation of measurements and comparison with the Global Modeling Initiative's Chemical Transport Model. J. Geophys. Res., 111, D19303, doi:10.1029/2006JD007089.

—, A. R. Douglass, L. D. Oman, S. E. Strahan, and B. N. Duncan, 2015: Tropospheric ozone variability in the tropics from ENSO to MJO and shorter timescales. Atmos. Chem. Phys., 15, 8037-8049, doi:10.5194/acp-15 -8037-2015.

Zilberman, N., and G. Maze, 2015: Report on the Deep Argo implementation workshop. Ifremer Doc. LPO-15-04, $36 \mathrm{pp}$. [Available online at http://archimer.ifremer.fr /doc/00281/39238/37799.pdf.]

Zimov, S. A., E. A. G. Schuur, and F. S. Chapin III, 2006: Permafrost and the global carbon budget. Science, 312, 1612-1613, doi:10.1126/science.1128908
Zou, C.-Z., and W. Wang, 2010: Stability of the MSU-derived atmospheric temperature trend. J. Atmos. Oceanic Technol., 27, 1960-1971, doi:10.1175/2009jtecha1333.1.

Zwally, J. H., and S. Fiegles, 1994: Extent and duration of Antarctic surface melting. J. Glaciol., 40, 463-475, doi :10.3198/1994JoG40-136-463-375.

Zweng, M. M., and Coauthors, 2013: Salinity. Vol. 2, World Ocean Atlas 2013, NOAA Atlas NESDIS 74, 40 pp. [Available online at http://www.nodc.noaa.gov/OC5/woa13/.] 


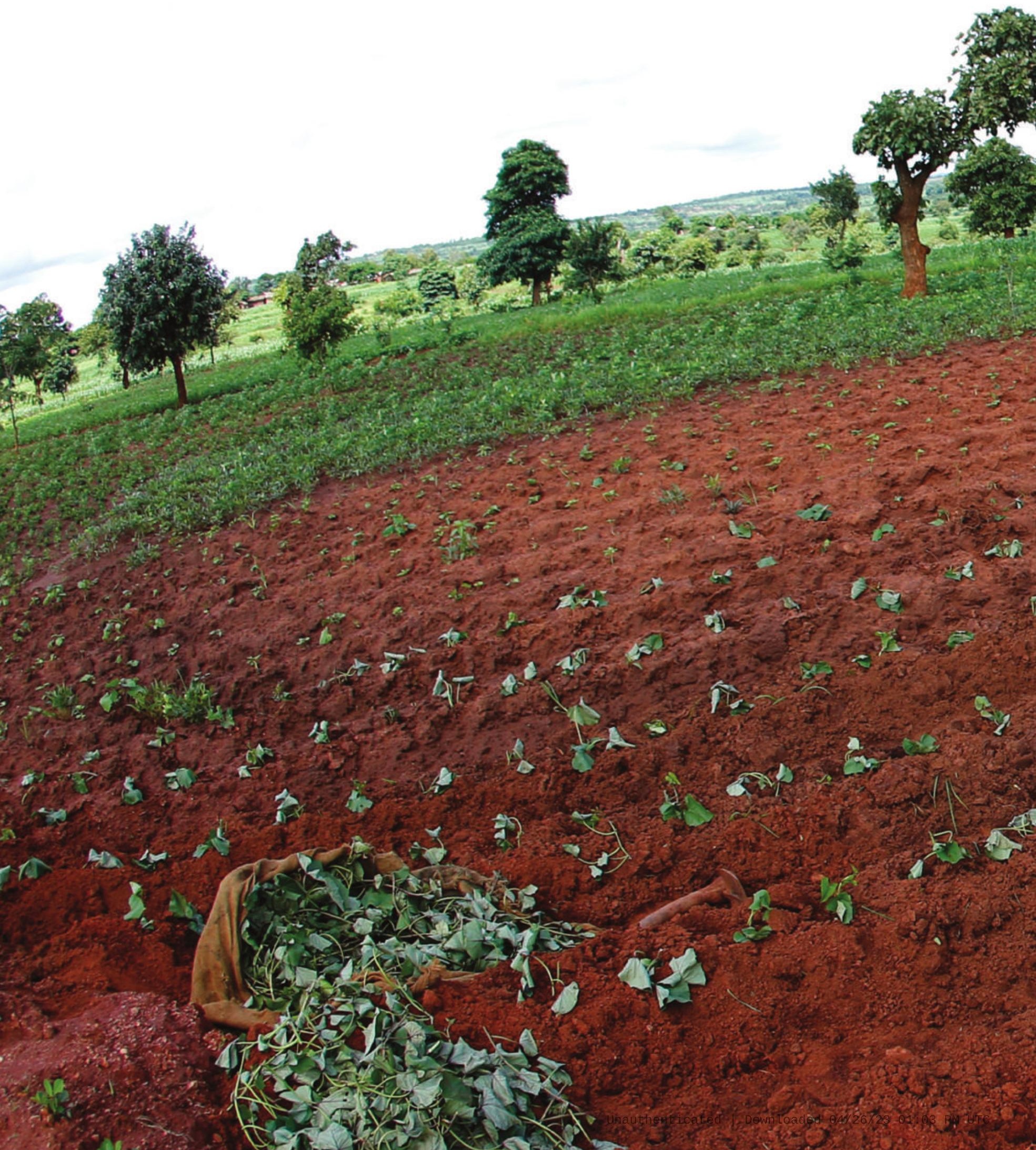

